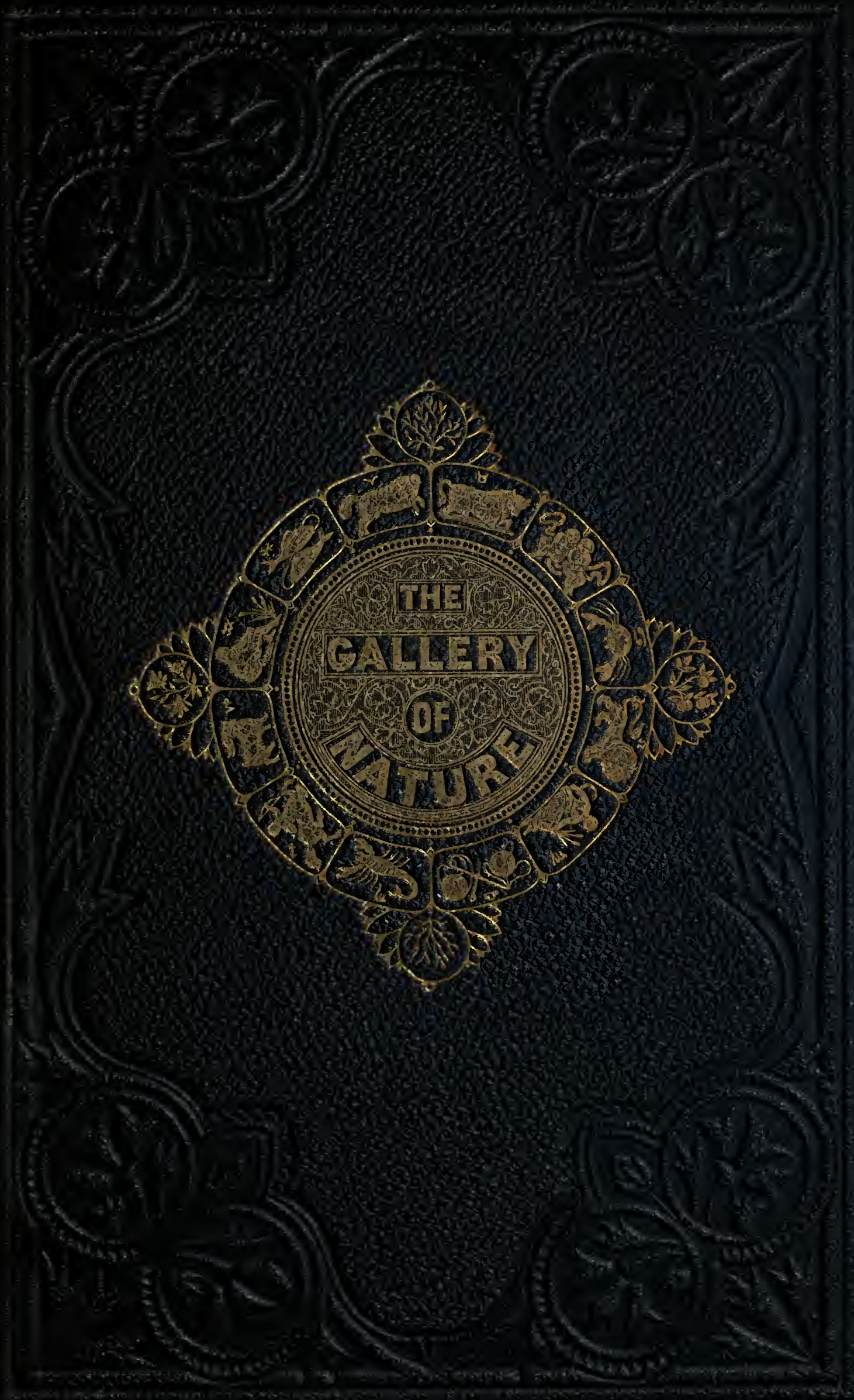



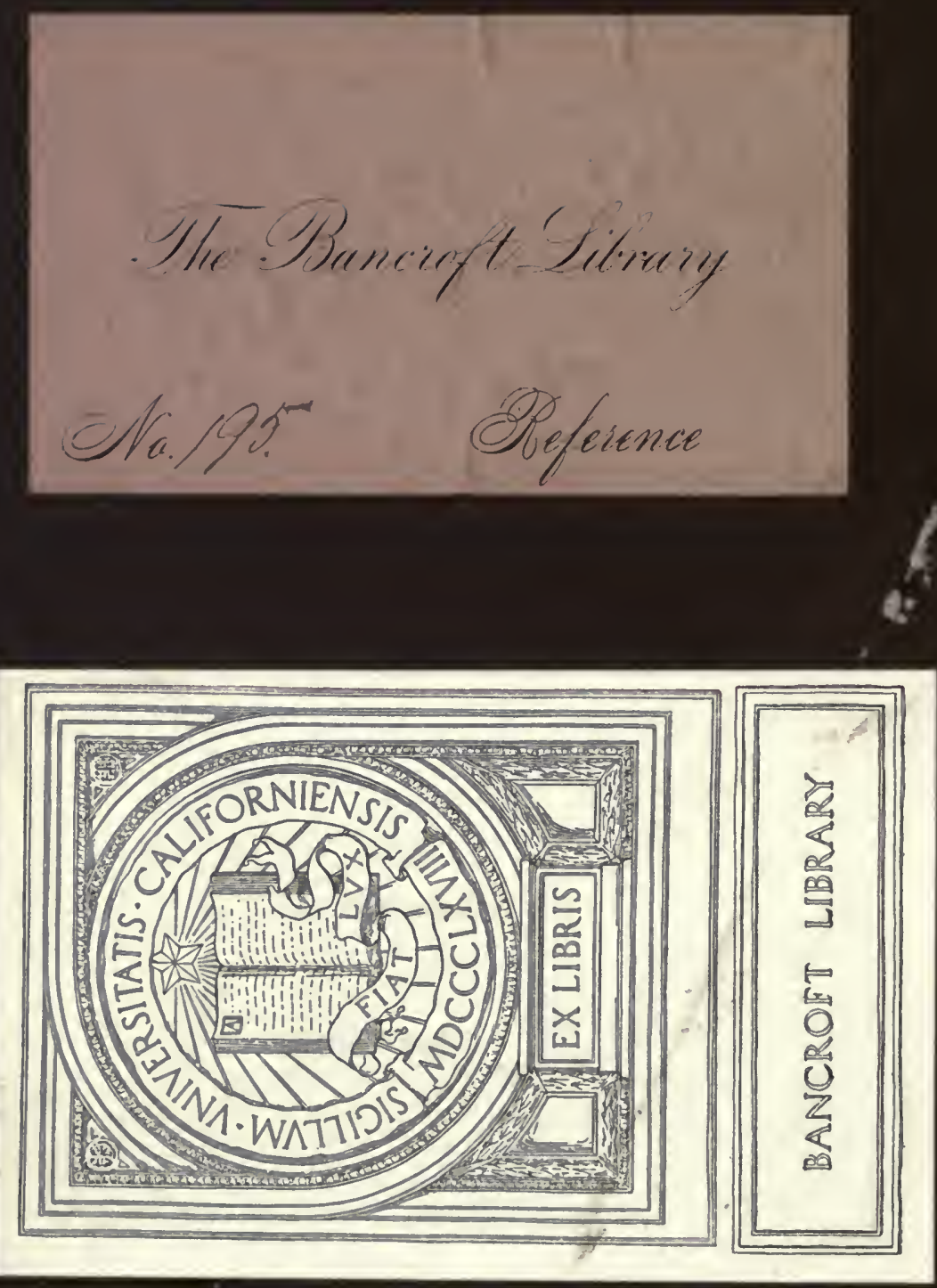


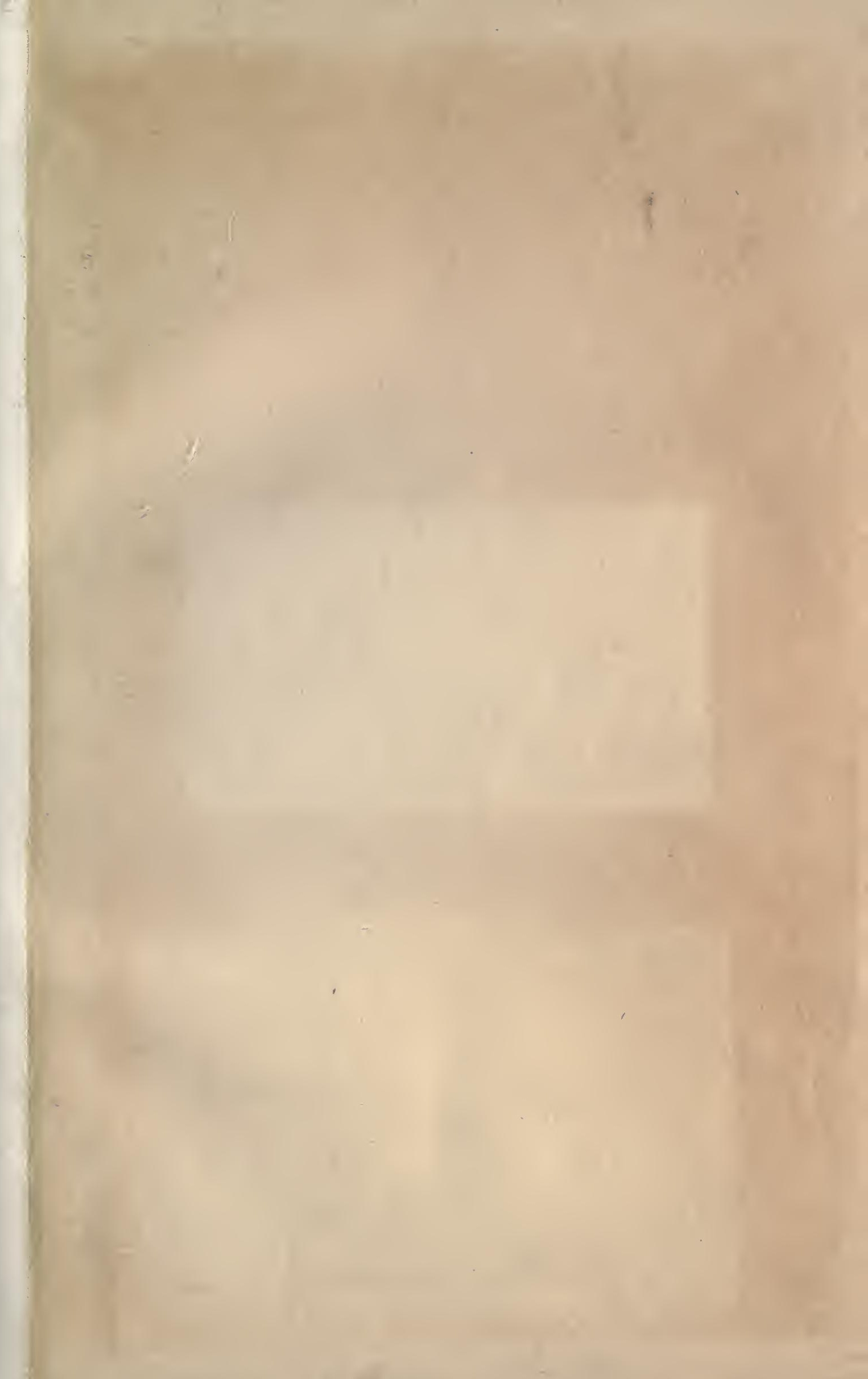



THE

GALLER OF NATURE 


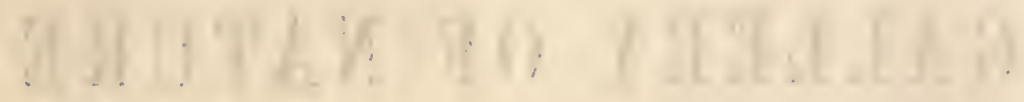
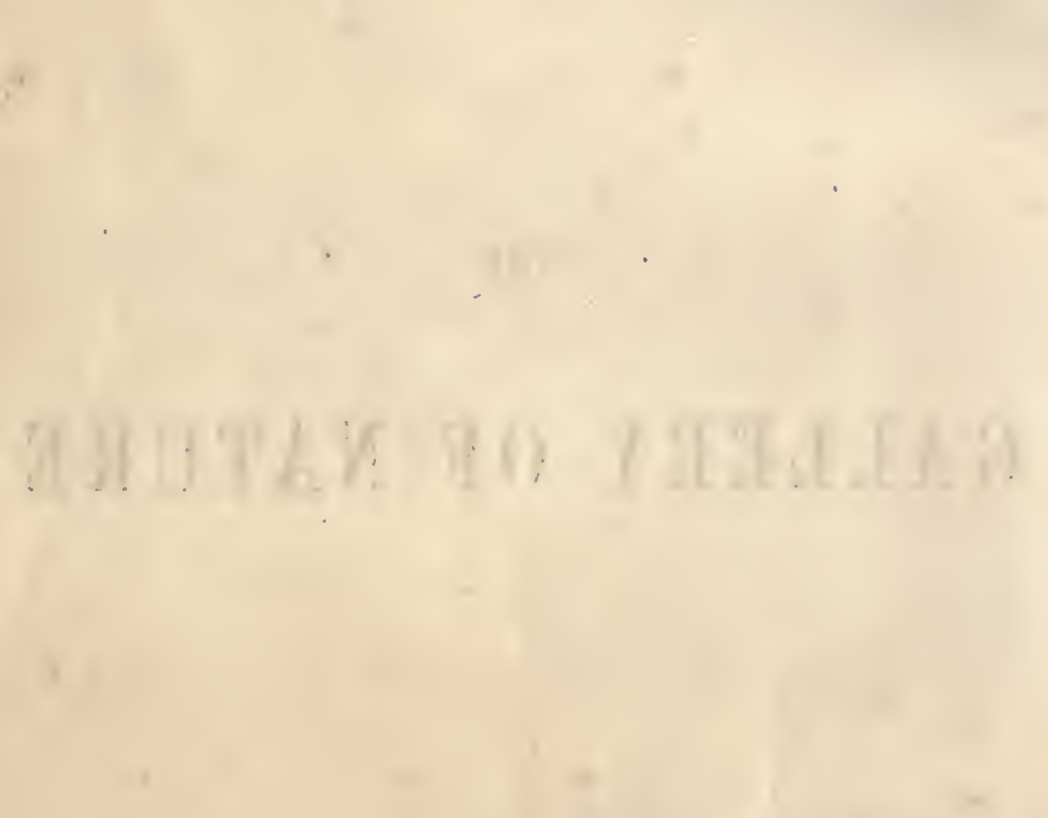



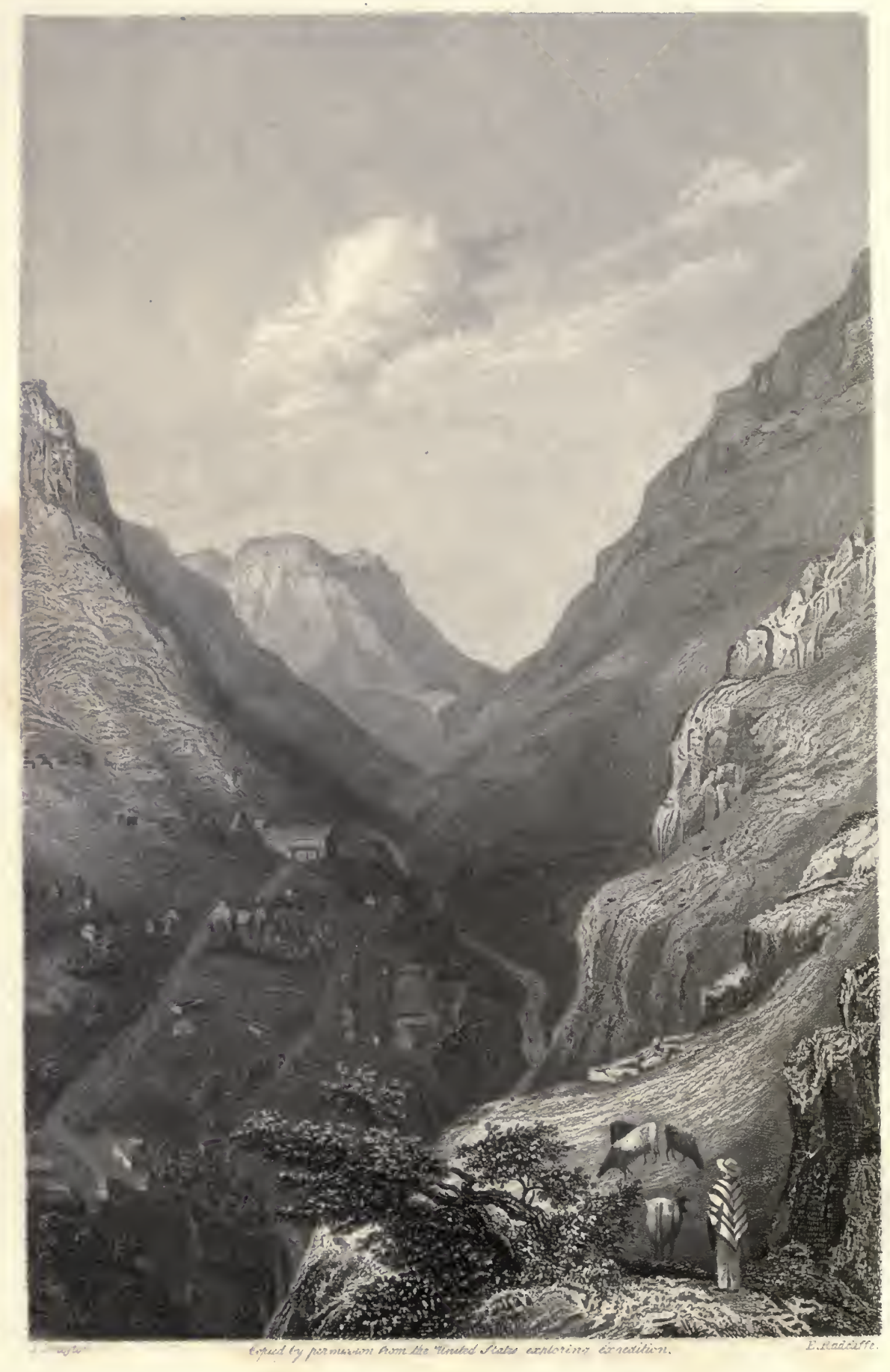

Banos, Peru 


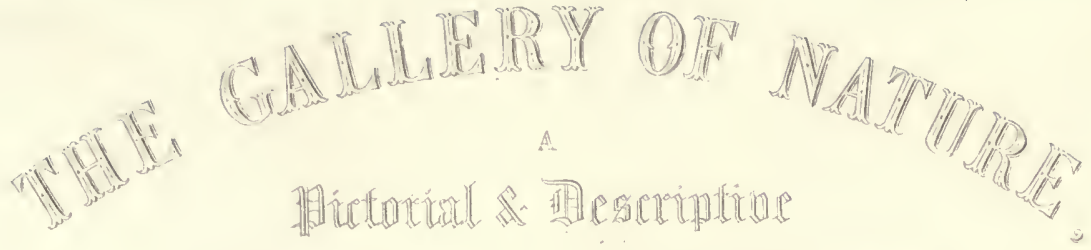

TOURS THROUGH CREATION.

by

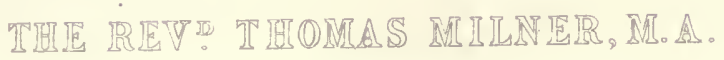

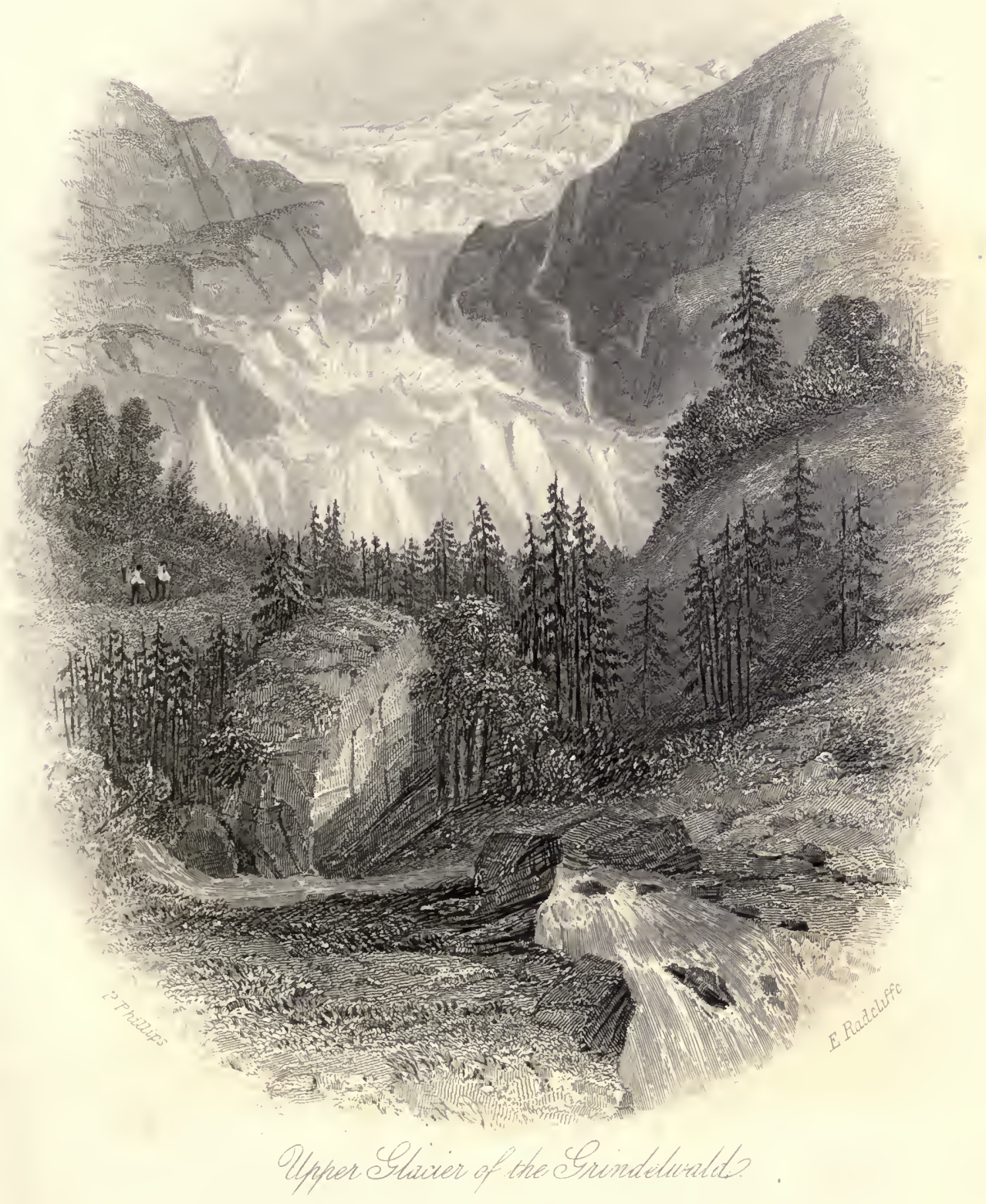

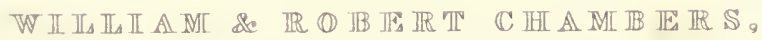




\title{
THE
}

\section{GALLERY OF NATURE}

A

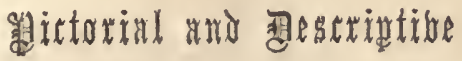

\section{TOUR THROUGH CREATION}

ILLUSTRATIVE OF THE

WONDERS OF ASTRONOMY, PHYSICAL GEOGRAPHY, AND GEOLOGY

BY

THE REV. THOMAS MILNER, M.A., F.R.G.S. d. 1882. AUTHOR OF 'ASTRONOMY AND SCRIPTURE,' ETC, ETC.

g đelo exdition

CAREFULLY REVISED AND CORRECTED BY THE AUTHOR

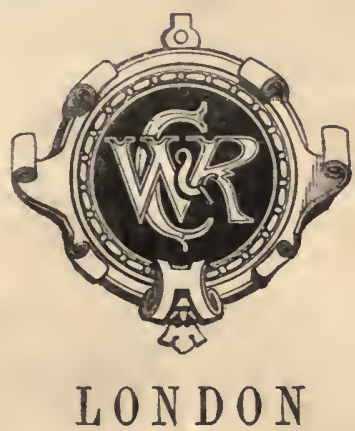

W. AND R. CHAMBERS, 47 PATERNOSTER ROW AND IIGH STREET EDINBURGH

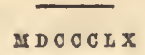




$$
\begin{gathered}
Q 162 \\
. M 4 \\
1860 \\
x
\end{gathered}
$$

Fdinbargh :

Printed by W. and R. Chambers. 

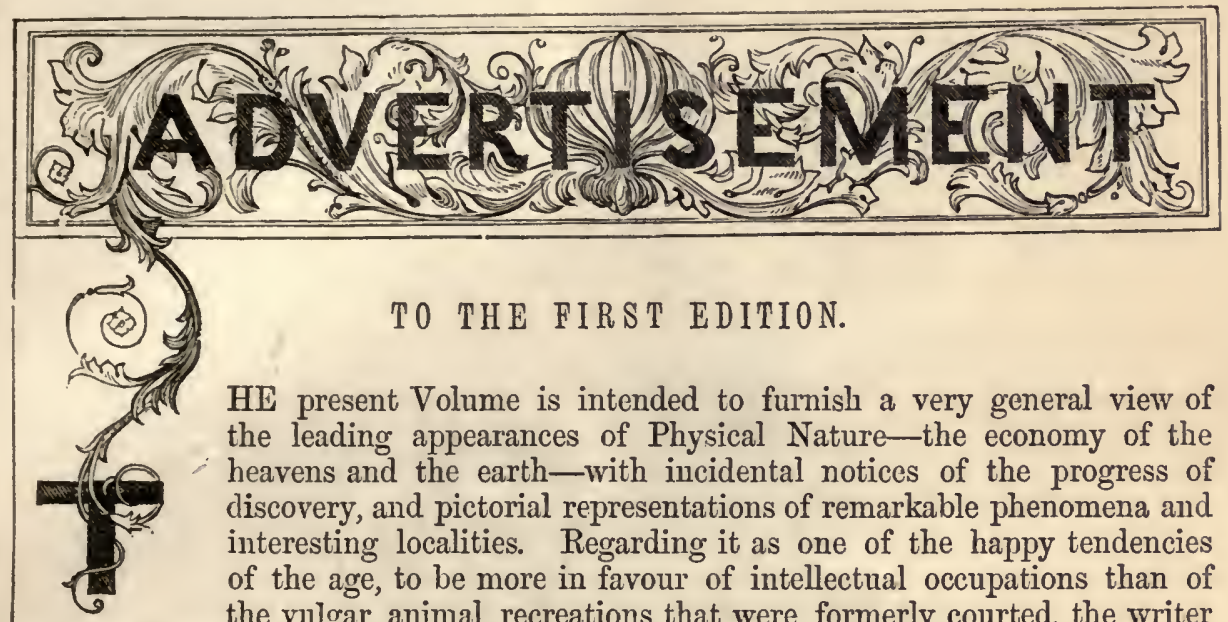

TO THE FIRST EDITION.

HE present Volume is intended to furnish a very general view of the leading appearances of Physical Nature-the economy of the heavens and the earth-with incidental notices of the progress of discovery, and pictorial representations of remarkable phenomena and interesting localities. Regarding it as one of the happy tendencies of the age, to be more in favour of intellectual occupations than of the vulgar animal recreations that were formerly courted, the writer has endeavoured to supply a digest of the knowledge obtained respecting the "wondrous whole," of which we form a part, which the enterprise of the proprietors of the work has profusely illustrated.

In submitting the accomplishment of this design to the judgment of the public, the writer may be allowed to observe, that he was called to the task at a very short notice; that disadvantageous circumstances, which could neither be foreseen nor avoided, have much interfered with its execution; but that he has honestly endeavoured, amid professional engagements, and oft-recurring physical debility, to carry out the design of the projectors.

The AUTHor.

The extensive sale experienced by Milner's GALLERY OF NATURE since its first publication, a few years ago, is the best proof of the happy adaptation of the book to its object; which was to convey to the popular mind-to the young in particular -a general idea of the external Wonders of the Heavens and the Earth. Written in an easy and agreeable style, and profusely illustrated, it may fairly be said to have gained a position above all the similar works of its day. To sustain its place as a favourite Gift-book and useful member of the Village Library, it seems only necessary that it should be kept, in all particulars, in harmony with the present state of Science.

The Work has now accordingly been carefully and thoroughly revised by the Author, with the advantage of all recent additions and corrections supplied by modern investigators, and with the further benefit of a considerable number of new illustrations.

W. \& R. C. 


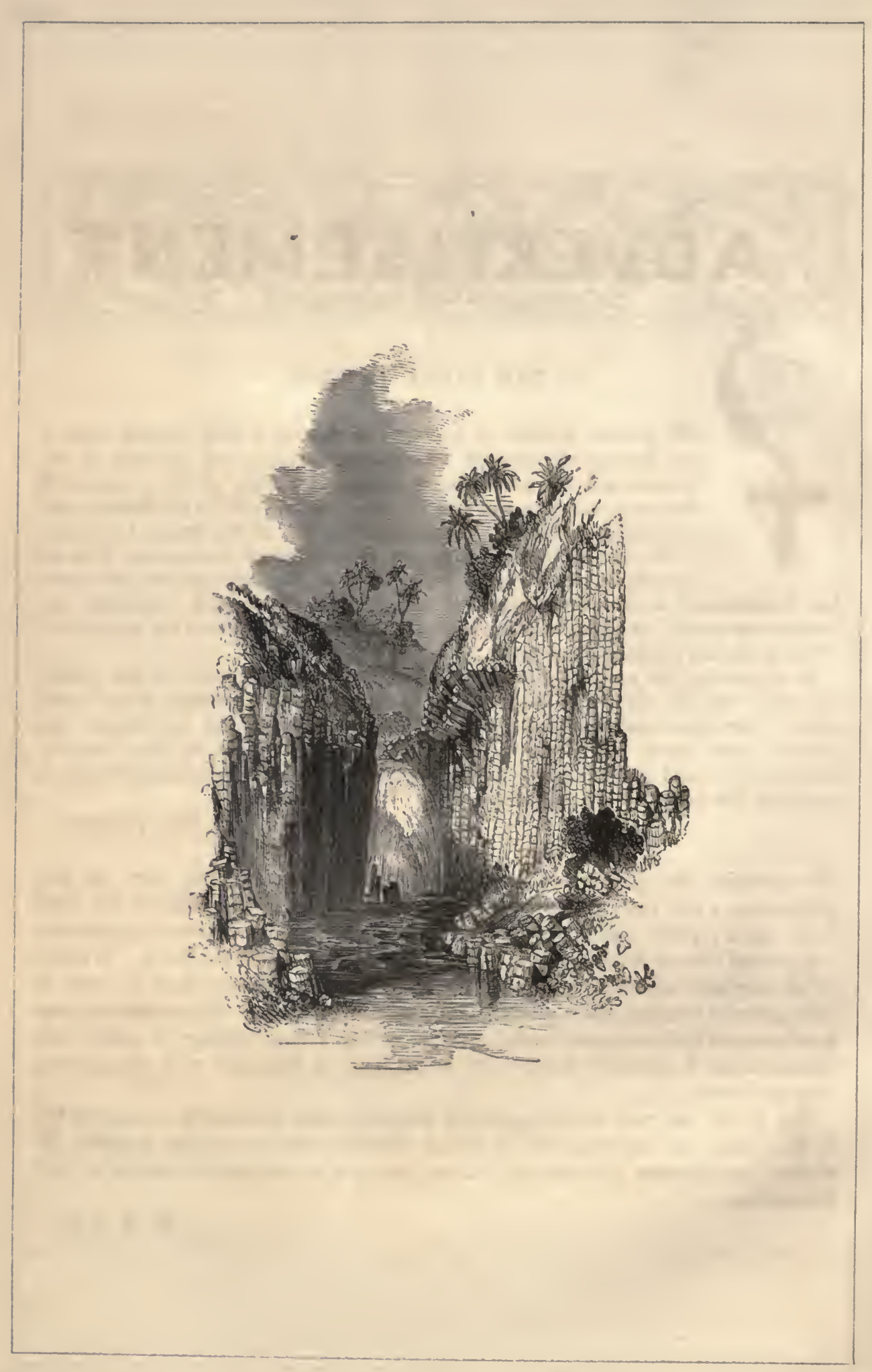




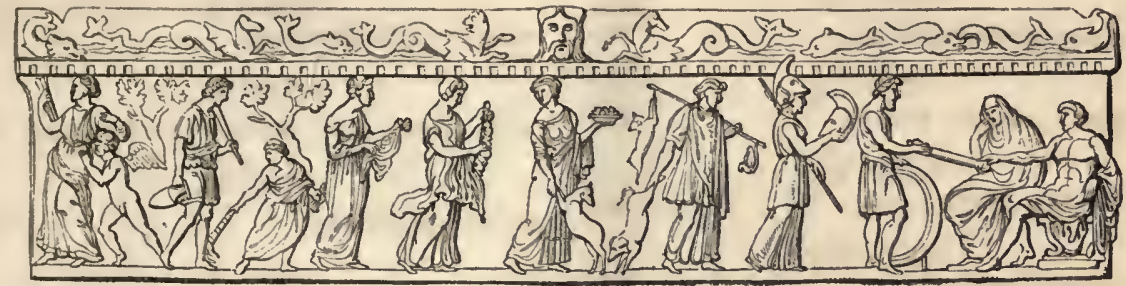

\section{TABLE OF CONTENTS.}

HISTORY OF ASTRONOMICAL DISCOVERY.

CHAP. I.

PAGE

ERA OF THE GREEK AND ALEXANDRIAN SCHOOLS, 1 CHAP. II.

ERA OF COPERAICUS, TYCHO BRAHE', KEPPLER,

AND GALILEO, .

CHAP. III.

ERA OF NEWTON, HALLET, AND HERSCHEL, - 33

SCENERY OF THE HEAVENS.

CHAP. I.

THE SUN AND SOLAR PHENOMENA,

CHAP. II.

MERCURY, VENUS, THE EARTH,

CHAP. III.

THE MLON AND LUNAR PHENOMENA,

CHAP. IV.

MARS, PLANETOIDS, JUPITER, SATURN, URANUS, NEPTUNE, . CHAP. V.

Courers, . . 108

CHAP. VI.

A GLANCE AT THE STARS, .

CHAP. VIII.

NOMBER, DISTANCE, AND MAGMTUDE OF STARS,
CHAP. IX.

NEW, VARIABLE, AND COMPOUND STARS, . 166

CHAP. $\mathrm{X}$.

STAR-SYSTEMS-NEBULER, $\quad . \quad 180$
17

3

E

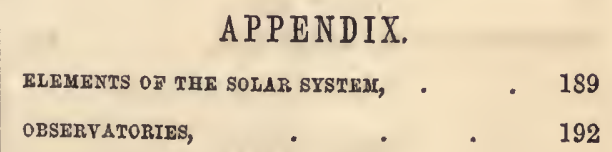

\section{PHYSICAL GEOGRAPHY. CHAP. I.}

GREAT NATURAL DIVISIONS OF THE EARTH, . 193 CHAP. II.

HIGH LANDS OF THE EARTH, . . 200

CHAP. III.

VALLEYS AXD GREAT LEVELS OF THE EARTH, 217

CHAP. IV.

CAVERNS AND SEBTERRANEAN PASSAGES, - 238

CHAP. V.

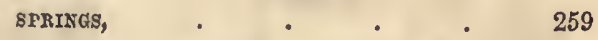

CHAP. VI.

RIVERS, • • . . . 278

CHAP. VII.

LAKES, - • • . $\quad 308$

CHAP. VIII.

THE OCEAT, . . . . 325 


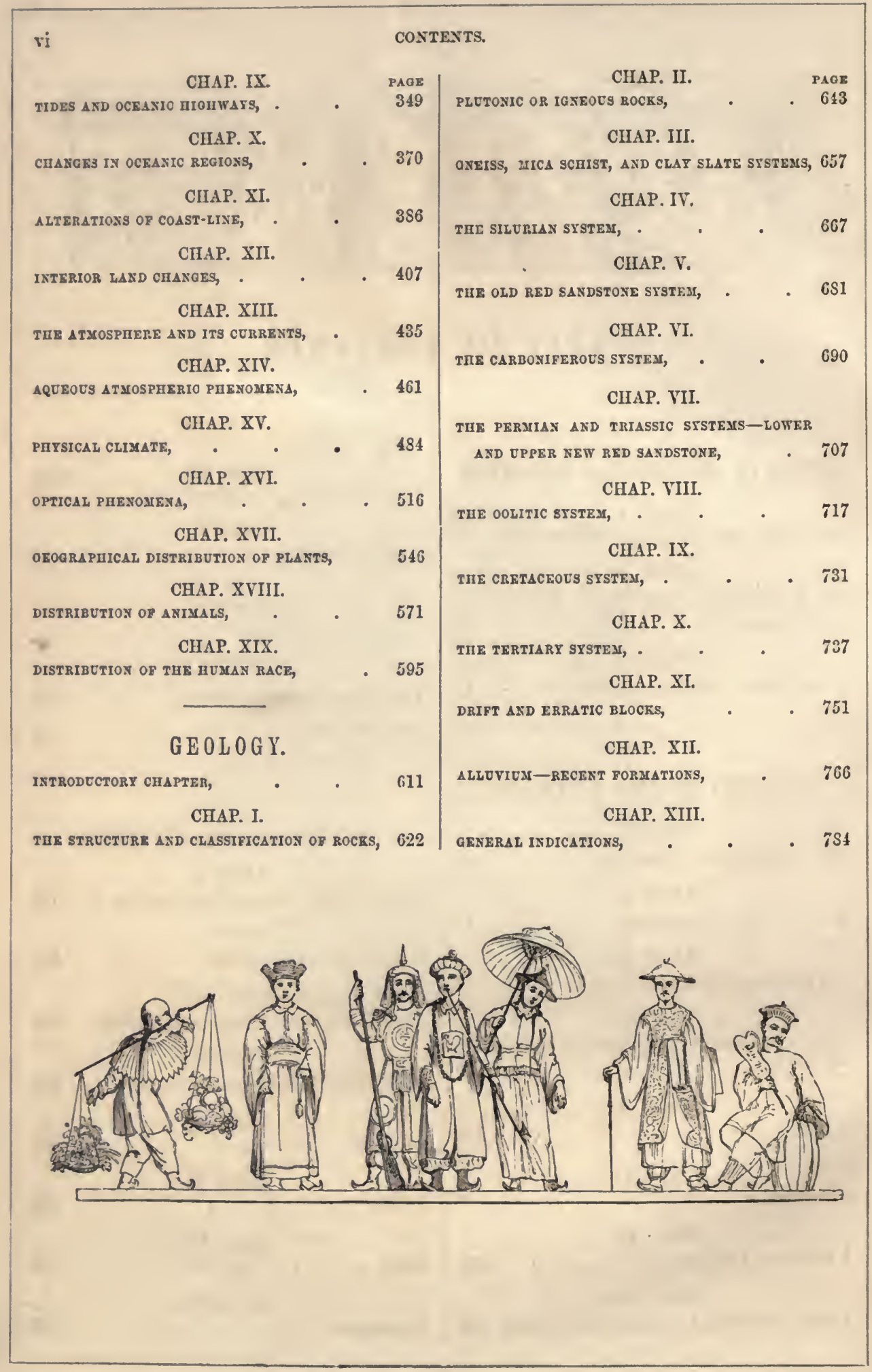




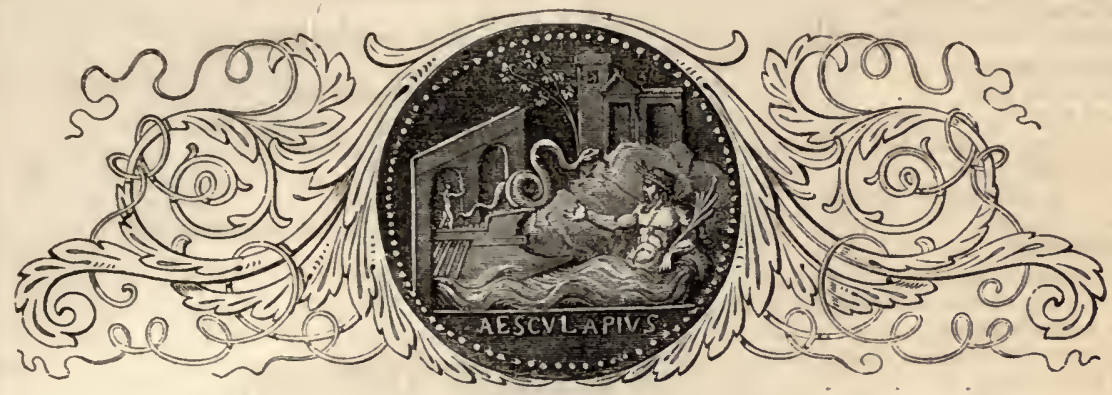

ENGRAVINGS ON STEEL。

\section{E R R A T U M.}

Or page 499 reference is made to a Meteorological Map. This map existed in former editions, but was for various reasons omitted in the present one. The reference has, by an awkward overlook, been allowed to stand.

\section{ENGRAVINGS ON WOOD.}

Birs Nimrood,

Portrait of Thales,

Portrait of Pythagoras,

Aristarchus' a Plan of Earth's distance from the Sun,

Eratosthenes'a Plan of Earth's magnitude,

Portrait of Ptolemy,

System of Ptolemy,

Mars and Jupiter's Circuits,

System of Hipparchus,

Ptolemy's Theory of Epicycles.

Obelisk at Heliopolis,

Tail-piece,

Portraits of Cop

Jotions of the Planets,

Portrait of Tycho Brahe,

\section{System of Tycho,}

Earth's motion on its axis,

Tycho Brahe'a Observatory,

Refraction of the Atmosphere,

raniberg, or Castle of the Heavens, . . . . 20

Unequal velocity of the Planets, . 27

Portraits of Halley, Newton, and Herschel, . . 33

Initial Letter,

Velocity of Light,

Greenwich Observatory, . ${ }^{\circ}+{ }^{-},{ }^{-}$

Newton's Birthplace,

Newton's Theory of Attractions, . . . 39

Newton's Theory of Centrifugal Force, . . 39

Room in which Newton was borm.

Halley's Tomb, . . . . . . 41

Aberration of the Stars, . . . . 42,43 


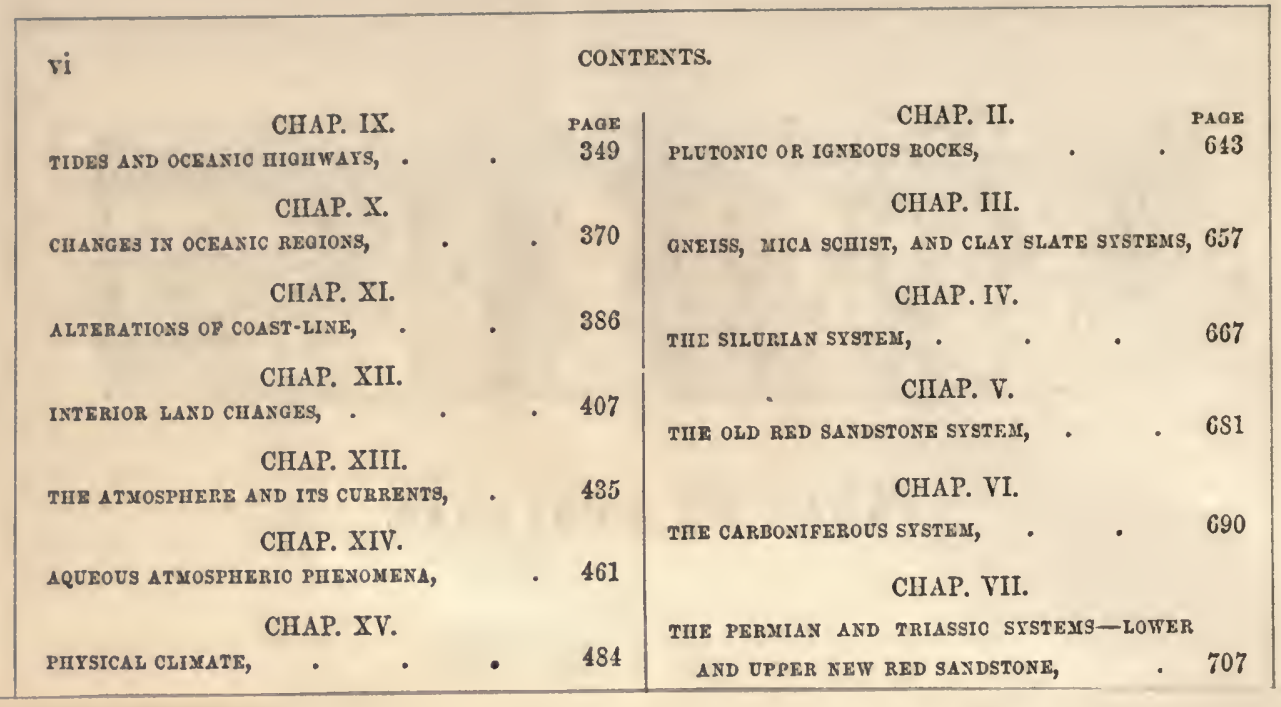

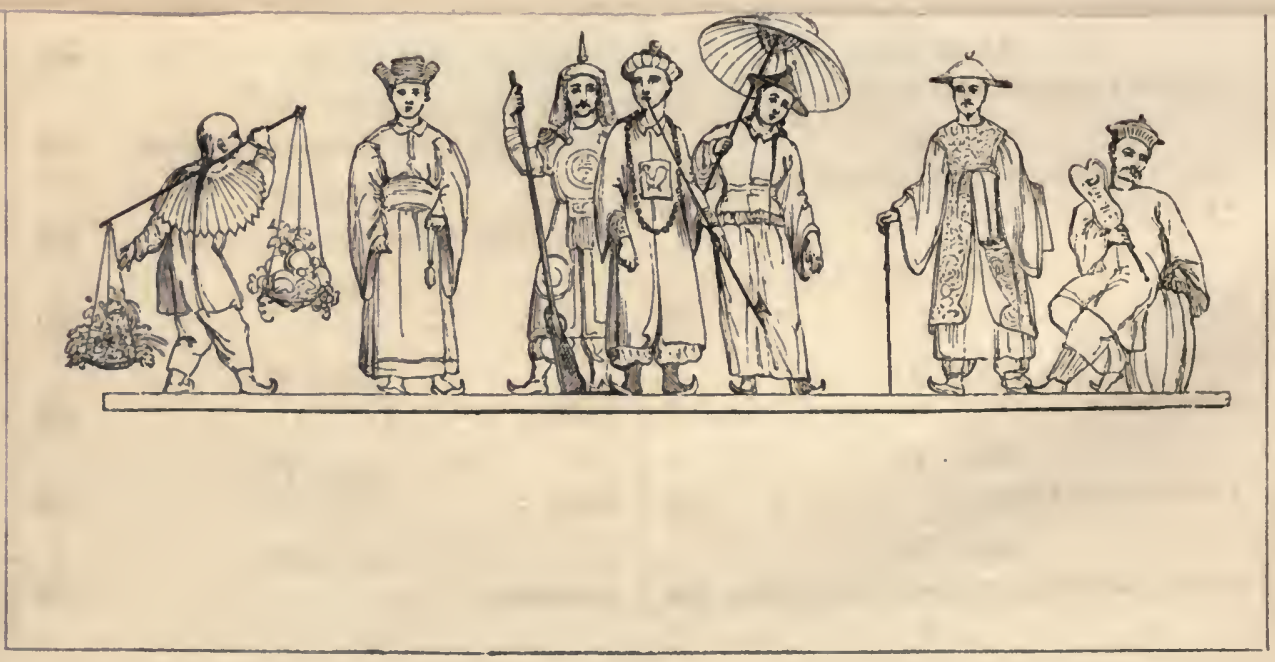




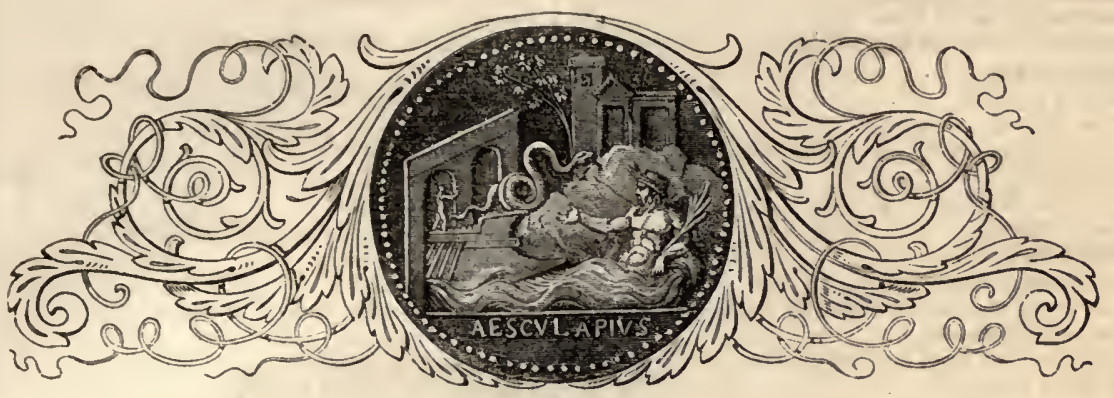

\section{ENGRAVINGS ON STEEL.}

THE BANOS PASS, PERE,

PAGE

UPPER GLACIER OF THE GRINDELTIALD,

Frontispiece.

MAPS OF THE SIDEREAL IRAVETS-

Tignette.

JANUARY TO APRIL,

APRII TO JULY,

AUGUST TO OCTOBER,

NOVEMBER TO JANUART,

\section{ENGRAVINGS ON WOOD.}

Birs Nimrood,

Portrait of Thales,

Portrait of Pythagoras,

Aristarchns's Plan of Earth's distance from the Sun,

Eratosthenes's Plan of Earth's magnitude,

Portrait of Ptolemy,

System of Ptolemy,

Mars and Jupiter's Circuits,

System of Hipparchus, .

Ptolemy's Theory of Epicycles,

Obelisk at Heliopolis,

Tail-piece,

Portraits of Copernicus, Keppler, and Galileo,

Initial Letter,

Motions of the Planetz,

Portrait of Tycho Brahe,
System of Tycho,

Earth's motion on its axis, . . . . 23

Tycho Brahés Observatory, . . . . . 24

Refraction of the Atmosphere, .

Uraniberg, or Castle of the Heavens, . . . . 26

Unequal velocity of the Planets, . $\quad 27$

Portraits of Halley, Newton, and Herschel, . . 33

Initial Letter,

Velocity of Light,

Greenwich Observatory, . . . . 35

Newton's Birthplace,

Newton's Theory of Attractions,

Newton's Theory of Centrifugal Force, . . 39

Room in which Newton was born, . . . 40

Halley's Tomb, . 、 . . . . 41

Aberration of the Stars, . . . . 42,43 
Tail-plece-Halley's Comet,

\section{Illustrated Titlo-Astronomy,}

Sun at Midnight at the North Cape,

Vertical and Horizontal Rays of the Sun,

Spots in the Sun,

Eclipses of the Sun,

Annular Eclipse,

Zodiacal Light,

Orbits of the Planets,

Transit of Mercury,

Orbit of Veans,

Physical constitution of Venus,

Vessels at Sea, shewing the Rotundity of the Earth,

Sycne, near Alexandria,

Translation of the Earth in space,

Orbit of the Earth,

Precession of the Equinoxes,

Atmosphere of the Earth,

Taul-pleco-Sunset,

Initial Letter-AIoonlight,

Phases of the Moon,

Eclipse of the Mron

Uneven Surface of the Moon,

Tail-piece-Moonlight at Sea,

Initial Letter,

Aspect of Mars,

Aspect of the Earth viewed from Mars,

Aspect of Jupiter,

Jupiter and his Satellites,

The Thames by Moonlight,

Saturn and his Rings,

Orbit of Saturn,

Phases of Saturn,

Rings of Saturn,

Comparative size of the Sun as seen from the Planets, 105

Relative bulk of the Planets, . . . . 108

Initial Letter.

Path of the Comet of 1C80,

Tail of a Comet, . . . 111

Comet of 1456, as seen at Constantinople, . . 115

Comet of 1835

Fancied Forms of Comets, copied from a Celestial

Atlas of 1680

Comet of 1744,

Schroeter and Bessel's Drawings of the Comet of 1807 , 119

Comet of 1811, as seen at Winchester, . . 120

Comet of 1s11, 121

Telescopic view of Encke'a Comet, . . . 122

Orbit of the Comet of 1832, . . . 123

Comet of 1848, as aeen on the Essequibo, . . 126

Varions appesrances of Halley's Comet in 1835, . 127

Initial Letter, . $. \quad . \quad . \quad 130$

Meteoric Shower in Greenland, . . 138

Meteoric Shower at the Falls of Niagara, . . 139

Meteoric Shower on Lake Niagara, . . 140

Radiation of Meteors, . . . . 147

Orbit of Meteoric Shower of Nov, 13, 1833, . 142

Initial Letter, . 143

Mouth of the Dardanelles, . . . . 145

Banks of the Enphrates, . . . . 145

Constellations-

Aries, . . . . . . 149

Taurus, Gemini, Cancer, . . . 150

Leo, Virgo, Libra, Scorpio, Sagittarius, . 151

Capricornus, Aquarius, Pisces, . . . 152

The Pointers in Ursa Major, . . . 153

Ursa Major moving round the Pole, . . 153

Orion, .

Southern Cross, . $\quad . \quad$. $\quad$ - 155
Page

Initial Letter,

Herschel's Tclescope, . . . . . 160

Parallax, 161

Earth'a distance from the Stars, . . . 162

Initial Letter, $\quad$. 160

New Star observed in 1572, . . . . 167

Supposed Orbit of a temporary Star, . . 169

Variable Star observed in 1506, . . . 170

Binary Stars, . . . . . 173, 174

Theory of Double Stars, . 17

Positions of Double Stars in different years, . 175

Tail-piece-The Earth,. . . . . 179

Initial Letter, . 180

Architecture of the Stellar Unirerse, . . . 181

Nebuls in Hercules, . . . . 182

Nebuls in Andromeda, . . . 184

Planetary and Double Nebulie, . . . 184

Crab Nebula, • • • . 187

Dumb-bell Nebula, ․ . . . 187

Spiral Nebulæ, . $\quad$. . . . . 188

Tail-piece-Nebulæ, . . 192

Mlustrated Title-Physical Geography, . . 193

Port of Sidon from the Sea, . . . 194

Chart of the World, . . . . 195

Ieuctra and Cape Matapan, . . . 198

Month of the Bosphorus, 199

Initial Letter, . . 200

Mount Egmont in Niew Zealand, . . . 201

Peter Botte Mountain, . . . 202

Cotopaxi, . . . . . 211

Mount Etna, from Syracuse, . . 213

Bolivian Platean, . . . . . 215

Mexican Plateau, . . . . 215

Plateau of Central Asia, . . . . 216

Initial Letter, $\quad$. . . . 217

Defile of the Darial, . . . . . 218

Glacier of the Rhone, . . . . $\$ 20$

222

Great Plain of the Cancasus, . . . 224

Mount Kasibeck, and Steppes of the Caucasus, . 225

Lake of Mandia, . . . . . 220

Sand-storm in the Desert, . . . . 227

Ruins of Palmyra, from the Desert, . . 228

Ianos of Badajoz, . . . 231

The Pyrenees from the Great Plain of Languedoc, 237

Initial Letter-Kirkdale Cave, . . . 238

Jorullo, Mlexico, . . . . . 239

241

Peveril of the Peak's Castle, with the Mouth of the

Cave, .

The Cupola Cavern,

Organ, Blue John Cavern, . • 249

. $\quad 259$

Kent's Cave, near Torquay, _... 253

Gailenrenth, 254

Section of Gailenrenth Care, . . . 255

Grotto del Cane, . . 256

Caverns of Dudley Castle, . . . . 257

Entrance to Odin's Mine,

Initial Letter-Fountain of Arethusa, . $\quad 259$

Castalian Spring on Mount Parnassus, . . 260

St Winifred's Well, . . . 264

Intermittent Spring, . . . . 205

Artesian Well,

Pool of Siloam, . . . . . 267

The Great Geyser, Iceland, . . . . 273

Ebullient Spring, . . 273

Dripping Well, Knaresborough, . . . $\$ 277$

Initial Letter-Falls of Tivoli, . . . 278

The Susquehanna, . . . . . 281 


\section{ILLUSTRATIONS.}

The Rhine at Oberweise],

Kaaterskill Falls,

Falls of Trolhetta,

Falls of Terni,

Natural Bridge, Virginia,

Valley of the Concon, Chili,

The Nile at the Pyramids, .

Source of the Angitas, .

Natural Bridge of Ain el Leban,

Delta of the Ganges,

Initial Letter-Derwentwater,

Loch Katrine,

The Kandal Steig, Switzerland,

Cascade in Mount Taurus,

The Dead Sea,

Lake Saratoga, .

Lake of Joannina,

Cader Idris,

Tnitial Letter-Source of the Jordan, - $\quad 325$

Fiord of Norway, . . . . . 332

Gale in the Pacific, . . . . . 335

Temperature of the Ocean, . . . . 335

Iceflelds, . . . . . . 337

Icebergs, . . . . . . 338

The Egean Sea from Eigina, . . . . 346

The Month of the Bosphorus, . . . 347

Cape Horn,

Initial Letter,

Tidal influence of the Moon, .

Tidal influence of the Sun, . . . . . 354

Lancaster Sands,

Diagram of Atlantic Tides,

Tide-wares around Great Britain

Port of Egina,

Solway Sands,

Cronbure Castle, and Entrance to the

Sinope, on the Black Sea, . . . . 365

Straits of Gibraltar,

Initial Letter-Bass Rock, . • • . • 370

The Valley of Chamouni after a Flood, . . . 372

Barren Island,

Hotham Island,

Island of St Eustatia West Indies,

Blocks of Coral, . . . . . 350

Aurora Island, .

Dean's Island, . . . . . 381

Lanks of the Euphrates, . . . . . 335

Initial Letter-Whitby Abbcy, . . . 380

Undercliff, Isle of Wight, _ . . . . . 391

Hob-Hole, Whitby, . . . 393

The Needles, Isle of Wight, . . . . 39t

Bay of Alexandria, . $\quad$ - . . . 397

Coast of Asia Minor, from the Isle of Samos, . 398

Gulf of Trieste, . $\quad 399$

Map of Coast of Baia, . . . . . 403

Coast of Pozzuoli, . . . . . . 404

Plains of Kosova, . . . . . 400

Initial Letter, . $\quad . \quad$. . $40 \%$

The Righi Pass, . . . . . 409

Valley of the Adige, . . . . 413

Phymer's Hill, . . . . . . 417

White Mountain, in the Alleghanies, . . 419

Plains of Thebes, . . . . 422

Extinct Volcano, Catecucaumene, . . . 430

Fissures at Polistena, . . . . . 432

Circular Hollows at Polistena, . . . 433

Volcano of Orizaba,

Initial Letter-Balloon, . . . . 435

A Calm at Sea, .

Commencement of the Monsoon, . . . Page

Vesuvius from St Elmo, . . . . 445

Hurricane in the Tropics, . . . . 451

Waterspout in the Nediterranean, . . . 457

Tail-piece-Man overboard, . . . 460

Initial Letter-Ignis Fatuus, . . . . 401

Ioch Achray, . . 165

Durrenstein on the Danube, . . . . 466

Thunder-storm, . . . . 469

Various forms of Snow Crystals, . . . 475

Dogs of St Bernard, . . . . 477

Snow-storm, . . . 478

Castle of the Seven Towers, . . . 483

Initial Letter, . . . . . . 484

Plains of Beloochistan, . 485

Line of Perpetual Snow, . . . . 486

Mlount Ararat, . . 488

Gorge of the Tyrolese Alps, . . . . 490

Alleghany Mountsins, . . . . . 494

The Andes,

Cape of Good Hope, . . . . 503

Theodomer marching his Army across the Danube, $\quad 509$

Fair on the River Thames, 1716, . 512

Boiling Mud of Iceland, . . . . 515

Initial Letter-Mirage, . . . . 516

Towrer of St Mark's, Venice, . . . 521

Aurora Borealis, Loch Leven, . . . 524

Aurora Borealis, Hudson's Bay, . . . 526

Halo, - . . . . . . 531

Parhelia, . . . .

Rainbow, Rosamond's Bower, . . . 533

Lunar Rainbow, . . . . . 534

Mirage of the Desert, . . . . . 536

Atmospheric Illusion, . . . . 537

Fata Morgana at Reggio, . . . . 538

Spectre of the Brocken, . . . . 541

Refraction in the Polar Sea, . . . $\quad .543$

Ignis Fatuus,

Initial Letter, - $\quad$. $\quad . \quad$. 546

The Ortler Spitz, . . . . . 547

Pine Forest, . . . . . 553

Banyan Tree, . . . . . 554

Palm Forests, . . . . . . 556

Cedars of Lebanon, .

Initial Letter, .

Shall of the Sea-urchin, . . . . 572

Group of Fish, . . . . . 577

Boa Constrictor and Rattlesnakc, . . . $\quad 579$

Group of Birds, . . . . . 581

Group of Animals, . . . . . . 5 . 55

Tail-piece, 591

Initial Letter, . $\quad . \quad . \quad 695$

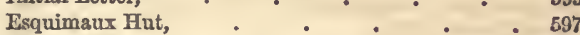

Classical Heads, . 602

Groups of Physiognomical Portraits, . . . $603,604,606$

South-Sea Islanders,

nlustrated Titlo-Geology: Restoration of Ante-

diluvian Animals, . . . . . 611

Iimestone Rocks in the Gulf of Corinth, _ 612

Land-slip, . . . . . . 613

Castalian Spring, . . . . . 614

limestone Mrountains on the Coast of Areadia, . 616

Granite Rocks of Meteora in Albania, . . 621

Cave of Jupiter, Egina, . . . . 622

Lamination of Rocks, 625

Unstratified Rocks, . . . - $625-626$

Basalt Columns, . . . . . 626

Basalt Rocks on the Volant, . . . . 626

Titan's Piazza, . . . . . . 626

Stratifled Rocks, . . . . $627-630$ 
Crich-hill, Derbyshire, $\quad 028$

Section of the Jurs Mountains, _ . . 630 Association of Stratifled and Unstratified Rocks, 631-633

Interior of a Silver Mine,

Classification of Rocks,

Catenlpora escharoides,

Sphænopteris Hæninghausi,

Encrinites moniliformis,

Ammonite Catens,

Tumilites costa

inoton of the Anoplotherium,

Skelcton of the Megatherium,

Lurly on the Phine,

Granite,

Ben Lomond, from the Lake,

Aiguille de Dru,

Disintegrated Granite,

Granite Veins,

Serpentine,

Positions of Trap,

Basalts,

Grotte des Fromages,

Porphyry,

Needle Rocks, Isle of Wight,

Initial Letter,

Gneiss System,

Mlica-schist System,

Monnt Taygetus, from the Plains of Sparta, . 660

Skiddaw Mountains,

Fossils from Snowdon

Nereites Cambrensis,

Initial Letter-The Bone Well, Ludlow,

Hills near Brecon,

Silurian System of Rocks,

Vale of the Towy,

Trilobites,

Eye of the Trilobite

The Stiper Stones,

Terebratulæe,

Old Lincoln Quarry, near Iron Bridge

Euomphala,

Wenlock Limestone,

Indlow Corals,

Wenlock Corals,

Remains of Fishes,

Palmer's Cairns, Lindlow,

Initial Letter-Trap Dyke, Brockbill, Worcester,

Old Red Sandstone, near Bristol Channel,

Vegetable Remains in Old Red Sandstone,

Scales of Fossil Fishes,

Tails of the Shark, Tront, and Trasse,

Scales on head of Cephalaspis,

Coccosteus cuspidatus,

Pterichthys,

Initial Letter-Carboniferous System

Mountain Limestone, . . . 691

Section of the Crich-hill, . . . . 692

Encrinal Limestone, . . . 693

Orthoceras lateralis, and Bellerophon costatus, . 603

Teeth of the Hybodants and Megalichthys, . . 694

Projection of Millstone Grit,

Section of the Bristol Coal-field

Fault in Coal-field,

Imaginary section before disturbance, . . 699

Section after disturbance, . . . . . 699

Seam dipping,
Turnpike Stair in Coal-mine, . . . $\quad 700$

Tropical Fern, 703

Annularia brevifolia, and Sphenophyllum dentatum, 703

Sigillarix,

Section of a Coal-mine near Etienne, . . 704

Fossil Trees on the Bolton and Manchester Railway, 705

Stigmaria and Lepidodendron, . 705

Calamites, . . . . 706

Tree in Craigleith Ouarry, 700

Initial Letter-Caverns under Nottinghan Castle, . 707

Conifera and Cycadea, . . . . . 709

Nottingham Castle,

Labrinthodon pachygnatus, . . . 713

Foot-print and Rain-drops, . . . . 714

Tracks of the Chirotherium, 714

Slab of New Red Sandstone, with Eoot-prints, . 715

Dipterus, . 716

Initial Letter-Limestone Ridges at Leuctra, . . 717

Shells of the Lias group, . . . . 719

Ammonites, . 719

Belemnite, . . . . . 720

Cidaris coronata, and Spatangus, . . . 721

Restoration of Saurians and other Animals of the Lias,

Jaw of the Phascolotherium

Astarte elegans, . . . . . 726

Iguana cornuta, * , . 729

Initial Letter, $. \quad . \quad . \quad 0^{\circ}$

Trigonia, . . . 732

Spherulites and Hippurites, . . . 733

Terebratula, .. . . . . . 733

Spatangus, .

Tail-piece, . $\quad . \quad 736$

Mount Parnassus, . . . . . 737

Marls with Magnesite, . . . . 738

London Basin, . $\quad$. $\quad$. $\quad$. 741

Alum Bay, Isle of Wight, . . . . 742

Cerithium giganterm, . . . . 744

Animals of the Paris Basin, . . . . 745

Extinct Volcanoes of Auvergne, . . . 746

Cama foliacea, Palmacites Lamanonis, Lymnca

longiscala, and Balanus crassus, . . . . 748

Restoration and Lower Jaw of the Dinothcrium, . 743

Murex alveolatus, . . . . . 750

Initial Letter-Erratic Blocks in Massachusetts, . 751

Monument Mountain, . . . . . 752

Tooth of the Mastodon, . . . . 754

Remains of a Salamander, . . . . 759

Drift near Cape Cod, . . . . 761

Rocking-stone, Fall River, . T T

Block in Cornwall, . . . . . 762

Broken Ledges of Slate, . . . . 763

Strata smoothed and striated by Drift, . . 764

Diluvial Formations seen from the Acropolis at Athens, $7 \mathrm{C5}$

Cyclopean Remains, Mycene, . . . . 766

Plains of Mantinea, in Arcadis, . . . 766

Corais, . . . . . . 768

Coast of Northern Greece, from the Gulf of Corinth, 773

Temple of Jupiter Serapis, . . . 774

Section of a Terraced Valley, . . . . 777

Chart and View of the Isle of Falma, . . 779, 780

Crater of Vesuvius in 1829, . . . . 781

Volcano of Jorullo, . . . 78

Descent of the Curral, Madeira, . . . 783

Initial Letter-American Aloe, . . . 784

Barren Island, Gulf of Rengal, . . . . 788

Various Tail-picces, Vignettes, \&c. 


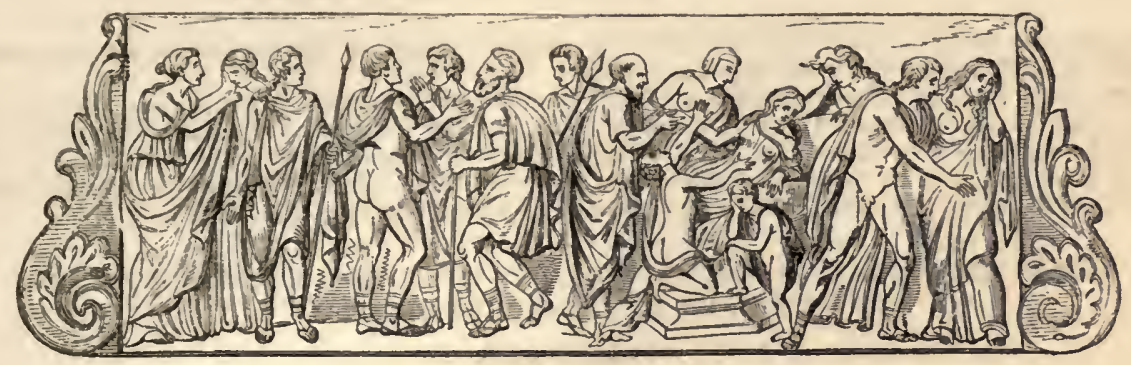

\section{DESCRIPTION AND USE OF THE SIDEREAL MAPS,}

These Maps have been constructed to show the sidereal hemisphere visible on the parallel of Greenwich, and being also adapted to the meridian of Greenwich, they are drawn on the plane of that horizon. To insure the greatest amount of accuracy, the stereographic projection has been made use of, because of all projections that occasions the least possible disarrangement of the relative position of the stars and of the angles they form one with another.

There is a difficulty in reducing a concave surface to a plane without distortion taking place somewhere, and in the projection here adopted a little compression will be found, gradually increasing from the horizon to the centre of the map. The constellations when at or near the zenith, will be found to be somewhat smaller than when at the extremities of the projeetion or near the horizon. Three, four, or five stars may appear in the heavens so as to form a group, and present to the observer the appearance of a triangle, a rhomboid, trapezium, or parallelogram, which figures are more correctly preserved by this projection than by any other which might have been made use of.

The difference between celestial and terrestrial maps should not be lost sight of. When a comparative observation is made between one of these maps and the heavens at any of the times given on the next page, the map should be held up in a vertical position, placing that part of the map downwards towards which the observer is directing his attention. For instance, if the stars in the south are to be examined, the person's face must be turned that way, with the south or bottom of the map downwarks; if for the north, the map must be reversed, with the north or top of the map downwards, when a complete view of the heavens in either of those directions will be obtained. If for the east and west, the sides of the map are to be similarly held, corresponding with the aspect required.

The centre of each map represents the zenith, that part of the heavens which is exactly over the observer's head, and will answer equally well for any other place upon the same parallel of latitude, making the allowance of four minutes for each degree, east or west, sooner or later; which shows that all persons living on the same parallel of latitude have in succession the same view of the starry concave. Another appearance would be presented if the observer were at either of the poles. Supposing there were inhabitants at the North Pole, to them one balf of the firmament would never set, and the other half would never rise. The polar star would be their zenith, and appear quite stationary, with all the other stars in view revolving round it in circles. To sueh inhahitants the equator would be the horizon, and at whatever elevation a star was first seen in their winter, there it would remain, and appear to complete a circle at that elevation once in every twenty-four hours.

If there were inhabitants at the South Pole, they would be similarly situated with regard to stars in the southern hemisphere; they would never see the stars on the north side of the equator or northern hemisphere, nor would those in the southern hemisphere ever set to them.

To the inhabitants of the equator, the whole of the stars from pole to pole, rise and set perpendicularly to their horizon once in every twenty-four hours. As the equator has no parallel of latitude, so has its zenith no declination, because the celestial equator passes immediately over it in a line from east to west. If an observer moves towards either pole from the equator; for every degree of his progress his zenith will have just so many degrees of declination, and as many degrees can he see beyond the pole towards which he is advancing, and he will lose sight of the pole from which he is receding in the same proportion. For example, as the inhabitants of London are situated $511^{\circ}$ from the equator northwards, their zenith is $51 \frac{1}{2}^{\circ}$ elevated above the celestial equator. As $511^{\circ}$ is the distance from the zenith to the equator, it follows that $381^{\circ}$ must be seen by an inhabitant of London below the equator to make up the complement of the quadrant, or $90^{\circ}$. Between the zenith and the pole will be found $381_{2}^{\circ}$, requiring $511^{\circ}$ beyond the pole to complete the other quadrant of $90^{\circ}$, thus together completing the hemisphere of $180^{\circ}$.

With these preliminary explanations a few words will explain the use of the maps.

Each map may be supposed to represent the heavens at the hours named. The dotted circle crossiug 
xii

DESCRIPTION AND USE OF THE SIDEREAL MLAPS.

the graduated meridian line at $41^{\circ}$, is the circle of perpetual apparition, the stars within that circle being visible at all times from the meridian of Greenwich.

The maps may, by a little calculation, be made to represent the aspect of the heavens at other times than is named; for instance, reckoning backwards, and allowing a difference of about twenty minutes for every five days, or four minutes for every twenty-four hours, we find that on the 21 st of January at 40 minutes past 1 o'clock in the morning, the stars will appear as they are represented in the map for March, and so on for every other month, following the same reckoning for every day in the year.

\section{TABLE SHOWING THE HOUR AND DAY WIIEN THE STARS OCCUPY THE} POSITION INDICATED IN THE MAP.

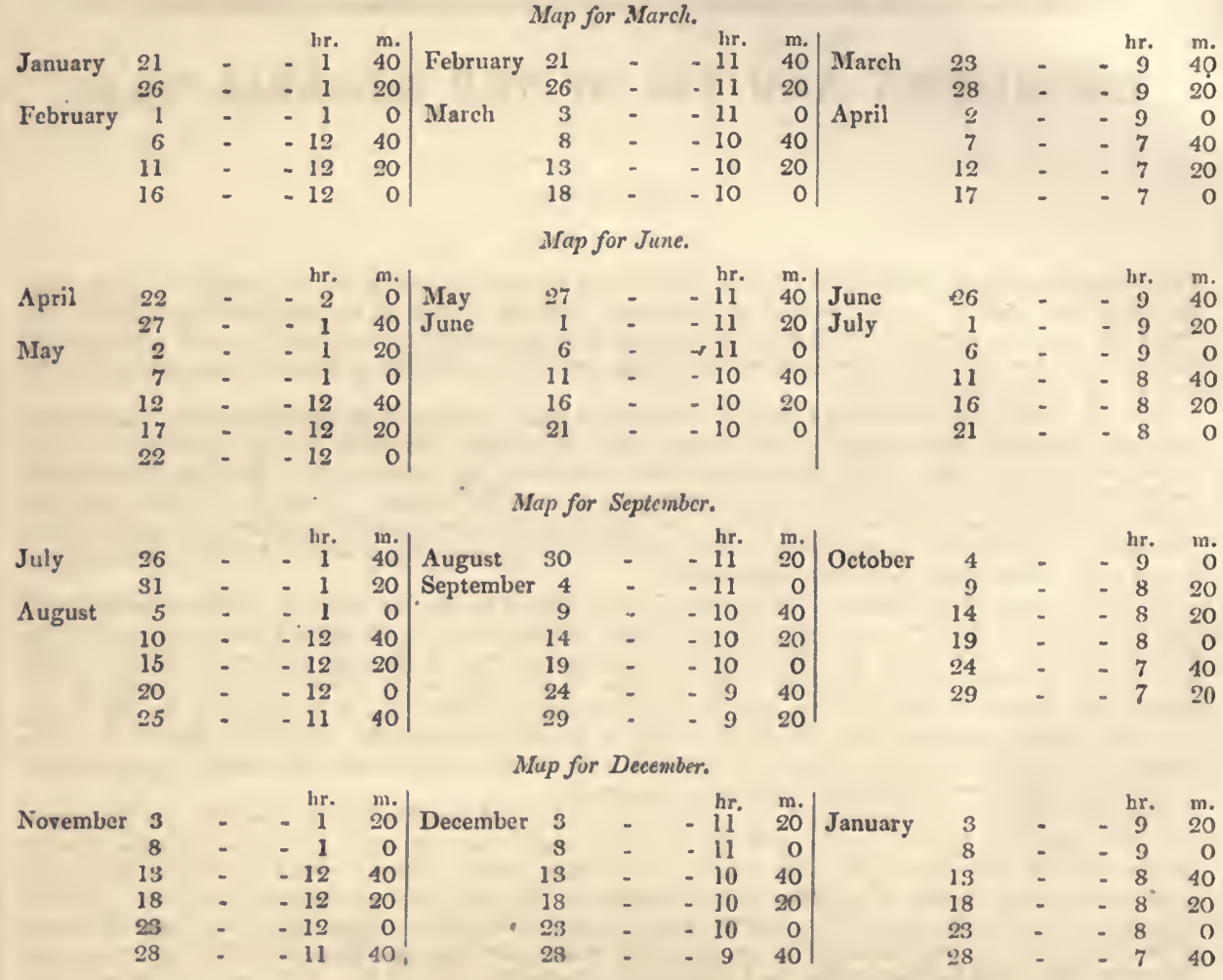

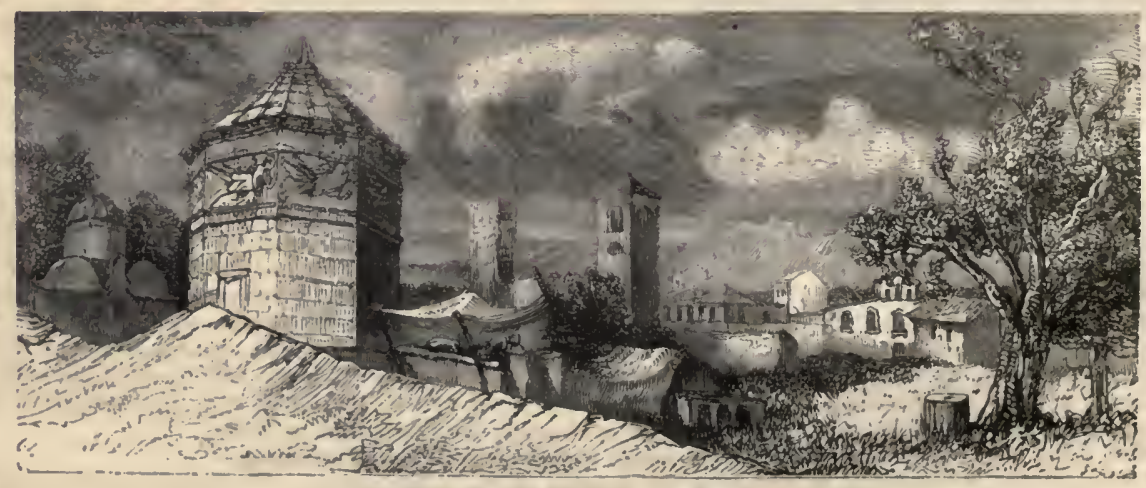

Temple of the Winds, A thens. 
Eeceroft Library 


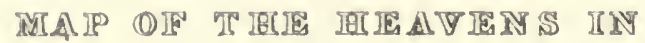

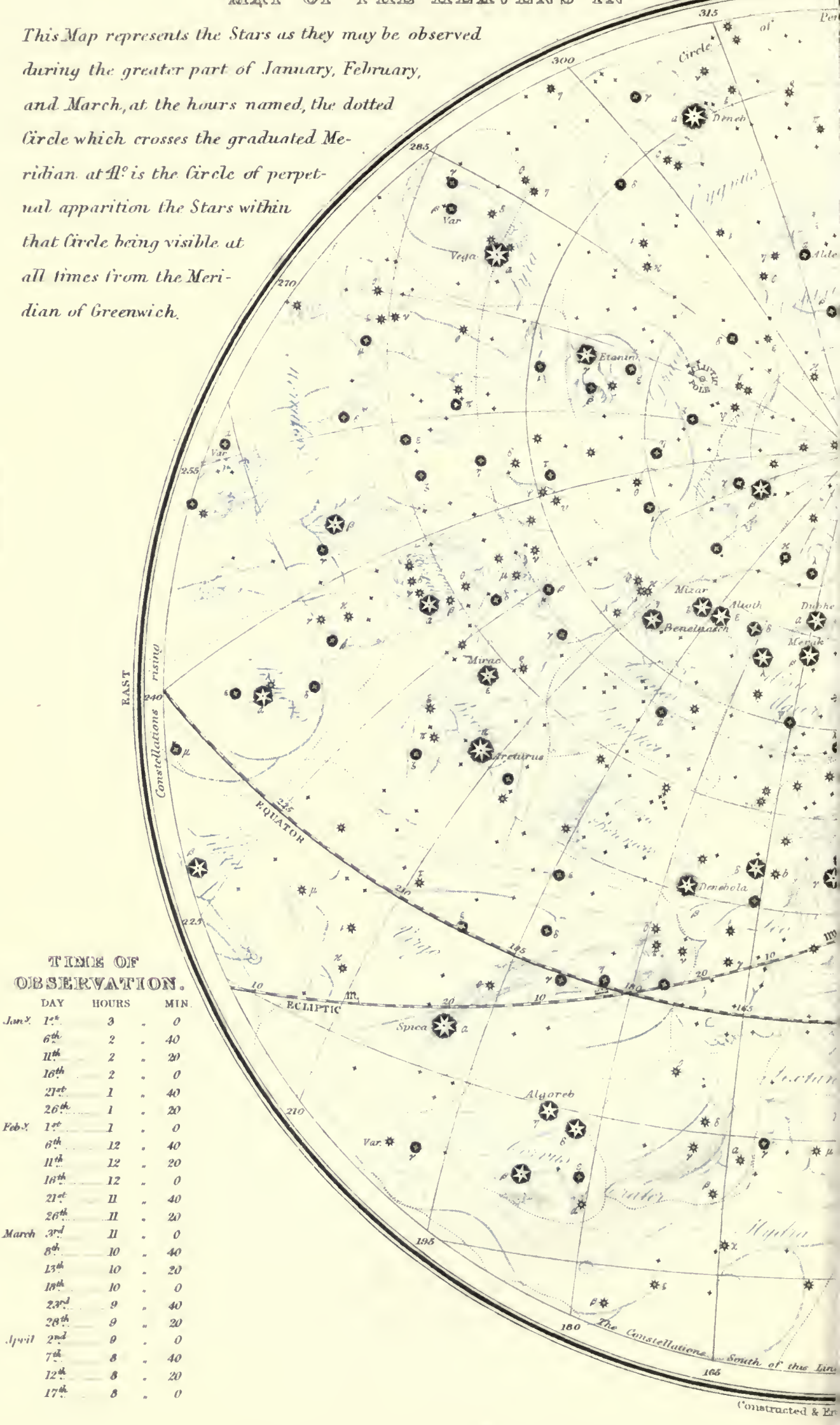




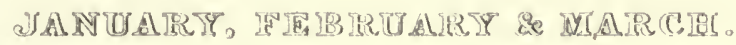

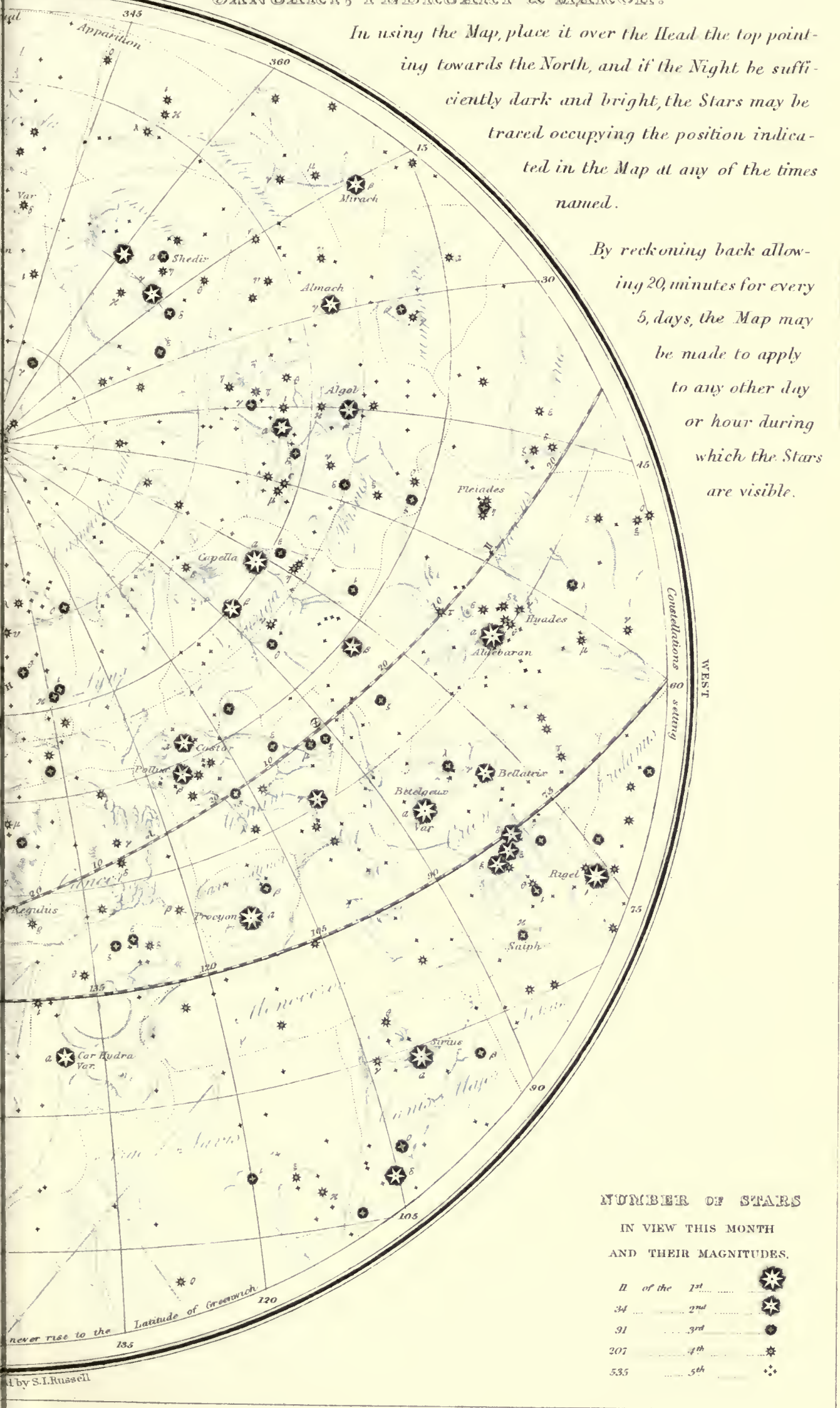



This Map represents the Sturs as they may be abserved during the greater part of April, Mav, and June. at the hours named, the dottel Circle which crosses the yraduated Meridian at $410^{\circ}$ is the lircle of perpetual apparition, the Stars within that Circle being visible at all times from the Heridian of breanich.

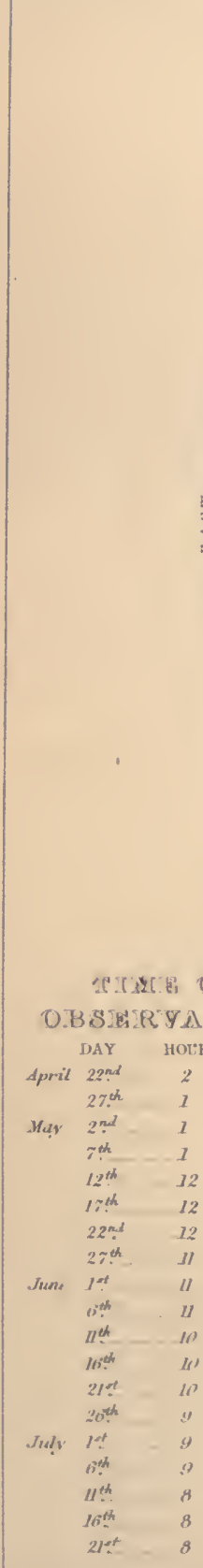

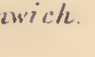




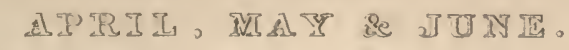
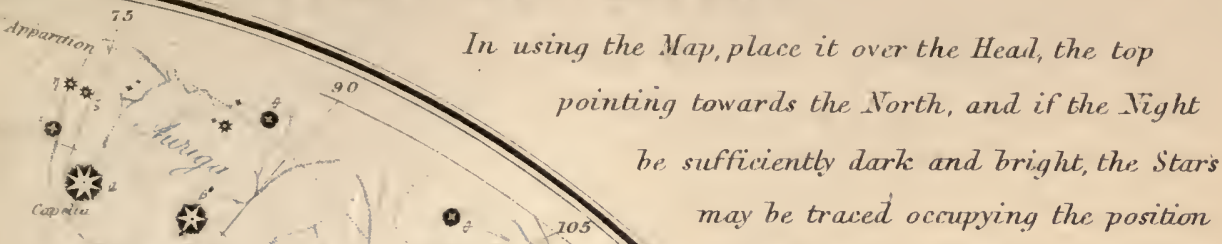

-
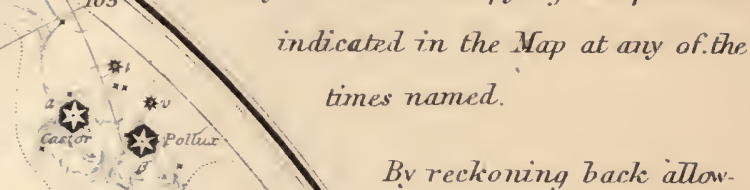

times named.

00 a 11000

3
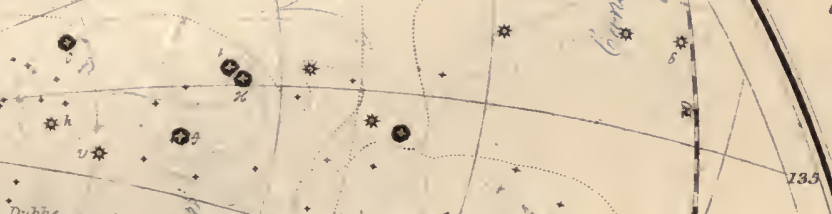

, days, the Map may

be made to apply to any other day or
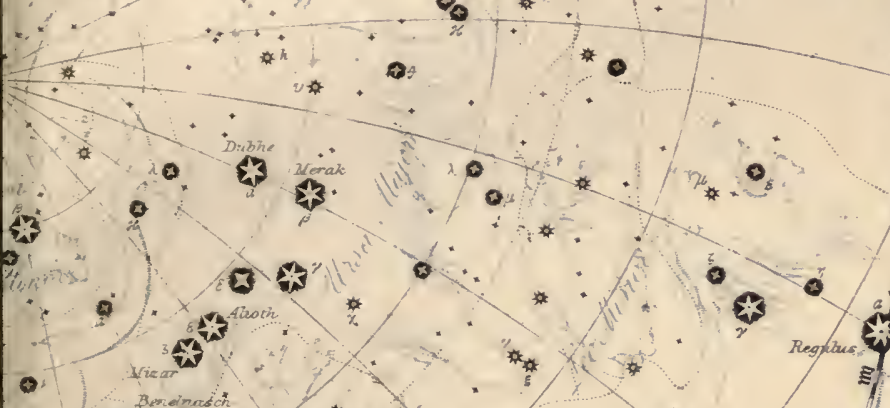

(

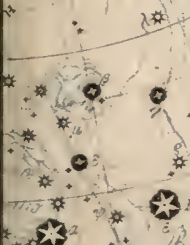



Enactolt Libn 


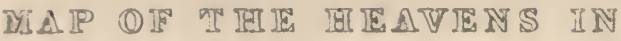

This Map, represents the Stars as thuy may be observed during the greater part of Aujust, September, and October, at the hours named, the dotted Circle which crosses the graduated Meritian at $\mathbb{A}^{\circ}$ is the Circle of perpetual apparition, the stars with. in that Circle being visible at all times from the Meridian of Greenwich.

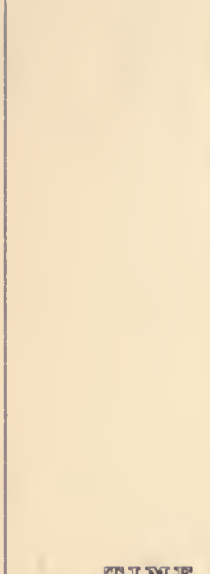

TIMIJ OT
OBSIETRATIDN

DAY HOURS MIX

July $26^{\text {ta }} \cdot 1$. 1 . 40

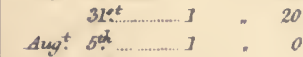

Aug: $5^{2}-12-12=40$

$\begin{array}{rrrr}25^{2} & 12 & 12 & 20 \\ 20^{\text {th }} & 12 & 12 \\ 25^{\text {th }} & \text { II } & 0 \\ 30^{\text {t }} & 11 & 11 & 40\end{array}$

Sept? $4^{\text {th }}$

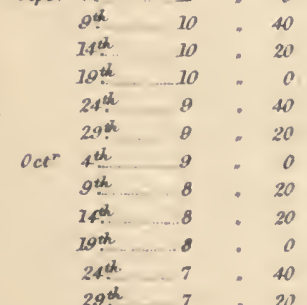

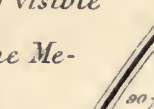



Thascrolt int 
This Map represents the Sturs as tha may be observed during the greater part of November, Desember, and Januarv, at the hours named, the dotted Circle which crosses the yrube ated Meritian at $410^{\circ}$ is the Circk: of perpetual apparition, the Stars within that Circle being visible at all bimes frow the Meridian of Greerwich. 


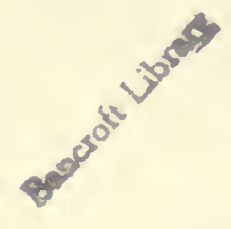




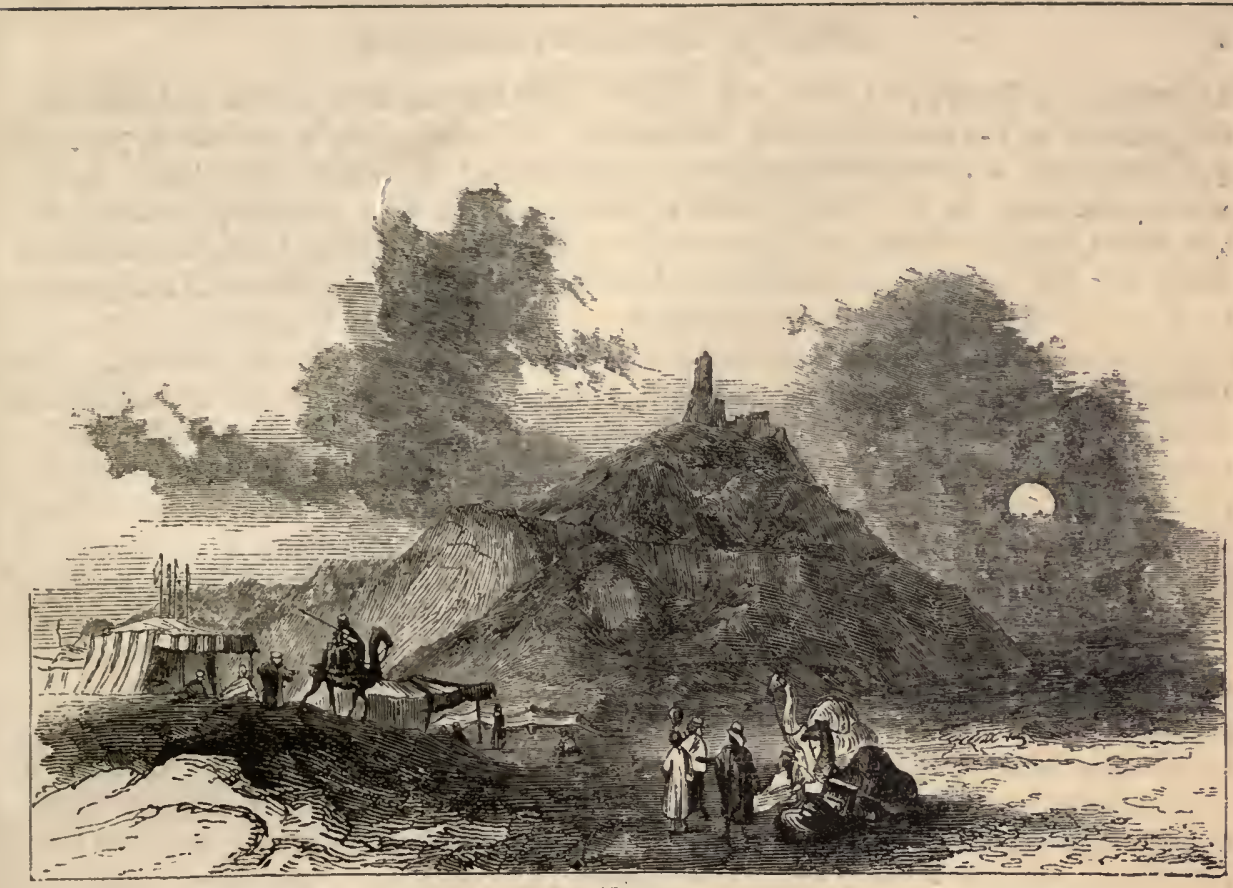

Birs Nimrood.

\section{HISTORY OF ASTRONOMICAL DISCOVERY.}

\section{CHAPTER I. \\ ERA OF THE GREEK AND AIEXANDRIAN SCHOOLS.}

Astrovour, now the most perfect of all the sciences, is also the most sublime and ancient. It separates man in thought from the spot upon which his foot is planted; makes him acquainted with forms and spaces, in comparison with which terrestrial magnitude and distance shrink into insignificance; and unfolds the constitution of the universe, as a scheme involving the intimate connection of the mighty and remote masses that are open to observation, - their incessant activity, unfailing order, and mutual dependence. The idea of extension - a feature of the sublime - is created by the scenes with which we are in immediate contiguity, and enlarged by the knowledge we possess of the superficies of the globe; but it is wonderfully expanded by the science which deals with the objects that are exterior to its surface. By measuring the distances and volume, and weighing the masses, of the planets-by calculating the orbits of the comets, which accomplish their aphelia in the regions of invisibility, and only discover themselves to us during a scanty portion of their course-by contemplating the stellar firmament, which, in the case of its nearest members, has required the highest modern intelligence, aided by the finest instruments, to detect even the slightest amount of parallaxby such investigations as these, we gather some faint conception, improving to our nature, yet humbling to our faculties, of the immensity in which the Creator centres, with whom the vast scheme originated, and to whom alone it is reserved to estimate 
its length and breadth, its depth and height. Man has learnt to distrust and disbelieve the evidence of the most perfect of his senses. He has been taught that the apparently quiescent earth is in perpetual movement; that the real motions of the celestial bodies are, in most cases, in direct antagonism to those which he daily perceives; and that lis own world, instead of being the "greatest in the kingdom of heaven," having subordinates under it in the sun, moon, and stars - the long and fondly cherished dream of antiquity is, in reality, one of the smallest provinees in the great empire of Nature.

Astronomical inquiry goes back to a remote era, and had its origin in the East. The splendour of the celestial phenomena; the fact of periodical changes and of accompanying powerful effects being produced upon the surface of the earth - such as alterations in the temperature of the air, the processes of vegetation, and the habits of animals, - these are circumstances too obvious and striking to have escaped attention, or not to have awakened curiosity. Accordingly, it is only reasonable to consider their thoughtful observation as coeval with the primitive age of man. We may undoubtedly regard the great levels of South-western Asia - the country between the Nile and the Euplirates - the eradle of mankind-as the birth-place of the science, and the scene of its first culture. Though no original memorials liave been preserved of the facts noted, nor of the progress made by the earliest inhabitants of that region, yet the references made by subsequent historians showing their derotion to the study of the heavens, and the reputation assigned to them for such pursuits by the unanimous voice of antiquity, long after the downfal of the Chaldean monarchy, may be accepted as sufficient proof of an inquisitive eye having been cast from that quarter upon the oljects and movements of the firmament. The district possesses many natural advantages for observation; a climate not subject to sudden variations, a serene sky, an open horizon, and a remarkably transparent atmosphere. Upon a winter night in our northern latitude, the spectacle is brilliant that is unfolded over the head of the traveller by the unclonded heavens, as he emerges from the smoke of the eity into the clearer air of the country; but the mild beauty of the moon, the vivid sparkling of the stars, and the intense darkness of unoccupied space, present a far more glorious exhibition, as seen through the purer medium of an eastern clime; and nothing more forcibly arrests the attention of the European than the magnificent canopy which the eventide unveils to him, on first visiting the oriental deserts. Besides the striking garniture of the sky, the occupations of man in the more primitive times - the warfare of the huntsman by night and by day - the custody of flocks and herds, wandering in solitary places, and requiring the shepherd's vigilance to protect them from the beasts of prey, - together with the infinence of the revolving seasons, coincident with celestial changes, upon the flowers of the field, the trees of the forest, and the productions of the vineyard-would combine to stimulate interrogation respecting the vault of heaven, the meaning of its visual glories, and the laws of their movement.

From the book of Job-in all probability the record of some pastoral chief migrating at an early period on the plains near the Euphrates-we gather indications of the heavenly bodies having attracted the watchful observance of mankind. Though it may be doubtful whether our version rightly renders the asterisms named by Arcturus, Orion, and the Pleiades, it is obvious, from the tenor of the passages in which they are introduced, that principal constellations or single stars are intended. The temple of Belus at Babylon, coeval with the foundation of the city, whose ruins are identified with those now extant of Birs Nimrood, is supposed to have been devoted to an astronomical as well as an idolatrous purpose. Its reported construction would seem to intimate this, being of a pyramidal form, with its four faces opposed to the four cardinal points of the horizon. Upon the summit, according to the Greek historian, the Chaldean priests contemplated and exactly noted the risings and settings of the stars. 
At the time of the capture of the city by Alexander, his tutor, the philosopher Aristotle, is said by one of his commentators to have received from Callisthenes a catalogue of eclipses observed there during a previous period of 1903 years. Though there may be considerable exaggeration here, yet there is, no doubt, substantial truth in the statement, since Ptolemy gives six Chaldean eclipses, which seem to have been taken from the catalogue, the earliest of which, however, goes no farther back than the year 720 B. C., answering to about the time of the first captivity of the Jews. A comparison of these ancient with modern observations led Halley to the discovery of the doctrine of the moon's acceleration - that is, that she now moves round the earth with greater velocity than formerly, the cause of which Laplace has satisfactorily explained. Ptolemy distinctly refers to Chaldea as furnishing the best and most numerous astronomical observations; and Cleomedes, speaking of a peculiar eclipse of the moon, states that "no astronomer, whether Chaldean or Egyptian, has cver recorded one of this kind." It is remarkably illustrative of the habit of diligent observation, that the Chaldeans were acquainted with the cycle of $6585 \frac{1}{3}$ days, during which the moon makes about 223 synodical revolutions, and experiences the same number of eclipses, alike too in order and magnitude, comparing cycle with cycle. To them is attributed the invention of the zodiac and the duodecimal division of the day.

Superstition was the mainspring of that observance of celestial phenomena which prevailed at an early period in the regions bordering on the Euphrates. The heavenly bodies were the objects of religious veneration. We can easily understand how, as the light of the primitive revelation respecting the Supreme Ruler faded from the mind, men fell into the error of regarding the glorious realities of the firmament as the governing intelligences of the world. Their uses in the economy of the universe; their resplendence and incomprehensible character, to the untutored observer; their elevation and far removal from man; their regular disappearance and return; their stability and undiminished lustre ;these are circumstances upon which popular ignorance would be likely to fasten, convert into intimations of intelligent existence, and establish thereby the worship of the stellar orbs. Such, in subsequent ages, has been the effect of the impressive appeal, made by the great lights of heaven to the physical eye, in the absence of information. Even in our day many a savage falls prostrate before the rising sun, or honours with religious ceremony the different phases of the moon.

The supposed possibility of dirining future events by the appearance of the heavens, was another inducement by which the ancient mind was powerfully actuated to observe the face of the sky - a hollow but imposing superstition, springing out of the witnessed regularity of the effects produced upon the face of nature by the heavenly bodies. The apparent varying altitude of the sun, at different times of the year, affecting the earth with different degrees of heat as his rays are more or less oblique, producing thereby the phenomena of the seasons, was one of the physical facts open to the notice of the early observers. 'They saw not only the day and night of the world, but the summer and winter of the world's year, through which vegetation quickens, flourishes, and dies, determined by the movements of a mighty luminary in the firmament; and the supposition was not unnatural, in a connection so close and marvellous, that the sun was an intelligent body appearing in certain positious to prognosticate certain events. The office supposed to be performed by one of the heavenly bodies was also assigned to the rest, and the connection observed between them with the changes upon the surface of the earth was likewise extended to every class of circumstances, even the physical and moral qualities of men; and thus, in the observation of effects regularly occurring, their true causes overlooked, but being plainly dependent upon celestial appearances, the art of judicial astrology had its origin. The Chaldean priests marked the position of the stars in their courses, and of the moon 
walking in lier benuty, for astrological purposes; and hence inspired propheey, when denouncing the divine judgments against Babylon, challenges the "astrologers, the stargazers, and the monthly prognosticators," to try their power to avert them. The predominance of this delusion during the middle ages in Europe, transported hither from the East, is well known. The fate of empires, the destiny of monarchs, the consequences of battle, the private fortunes of individuals might, it was supposed, be gathered from the position of the stars at the time of the nativity of the persons on whose behalf they were consulted, compared with their position at the time of the consultation; and without applying to the seer, who was imagined to read in the heavens the character of every event, whether it would prove favourable or adrerse, scarcely any public measure or private enterprise was undertaken.

'The lonour of priority in observing the celestial sphere has, however, been claimed for the aneient Hindús, the Chinese, and the Egyptians ; and to the two former especially, a cultivated knowledge of its mechanism at a far distant era has been assigned. It would involve a tedious and unsatisfactory detail to consider this question at length. It may suffice to remark, that the preponderance of evidence is in favour of the plains of Chaldea being the primal seat of application to observative astronomy - that from thence, as from a general centre, it radiated, at some unknown but remote period, towarls the banks of the Nile on the one side, and to India and China on the other-and that, in the infuncy of national existence in those eountries, the rising and setting of the stars, lunar and solar eclipses, and eonjunctions of the planets, were objects of attention, with an entire reference either to astrology, religion, or policy of state. 'The Hindú tables claim an epoch of 3102 years before Christ, and fix a general eonjunction of the sun, moon, and planets, at that era, the beginning of the Caliyug, or iron age of their mythology; but modern calculation proves the impossibility of such a conjunction then occurring - that Venus, in particular, could not have been near it at the time specified. 'The tables therefore are not established on observation, but have been calculated backwards, either from data supplied by native application in a comparatively recent age, or derived from the Greeks and Arabs. In opposition to this last conjecture, the proud scorn of foreign nations entertained by the Brahmins has been quoted, which seems to lave been special in relation to the Greeks or Yavans, from their proverb that no base creature can be lower than a Yavan; but the following curious passage from one of their earliest astronomers upholds the former opinion:- "The Yavans," says he, "are barbarians, but this science is well establislied among them, and they are revered like holy sages." With reference to the ancient Chinese, we have little in their annals beyond records of solar eclipses, which were regarded as prognostics of importance to the empire. Those which may be depended upon, as having been actually observed, commenee with the year 776 before Christ, and terminate with the year 1433 of our era. But nothing is more dubious than the credit of their native histories; and nothing more certain than the ignorance of the professedly scientific elass, even of the simplest operations of practical astronomy, when intercourse was first opened with the people of the West. In Egypt, no doubt, attention to celestial phenomena commenced with the era of its early inhabitants. The exactness with which some of the pyramids have been made to face the four cardinal points has engendered the suspicion that they were designed for an astronomical use; and authorities may be eited, who state, that they terminated at the top in a platform which the priests occupied as an observatory of the heavens. But if the Greek philosopher taught them how to find the height of the pyramids by the shadow, one of the most simple examples of practical geometry, we can form no high idea of the aceomplishments of the Egyptians. In fact, Ptolemy, who lived in the country, and may be presumed to have been acquainted with its records, derived none of his materials from that source, but only quotes the observations of the Chaldeans. 
The sculptured planisphere of the temple of Denderah, discovered by the scientific men of the French expedition, and supposed to represent the appearance of the heavens at midnight on the summer solstice, about seven centuries prior to the Christian era, is now well known to be a work as recent as the time of the Roman empire. Upon the whole, we have reason to suppose that the astronomy of the ancient oriental nations made no advances beyond that tolerably exact knowledge of the mean motions of the sun and moon which the purposes of agriculture required, - that it chiefly dealt with the simple observation of eclipses, occultations, and the rising and setting of principal stars, which was the work of a priesthood who made it subservient to the consolidation of their superstition, -and that the idea of a cultivated science existing in times of venerable antiquity, the lhypothesis of some plilosophers half a century ago, - is without foundation.

The present divisions of the sun's apparent path in the heavens, upon each of which imagination has stamped an earthly figure; with the arrangement of the extra-zodiacal signs; date their origin from a remote period, but both era and authors are lost in the mists of ancient time. However inconvenient their use, and undesirable, on other grounds, their retention in the present day, there was a moral grandeur in the idea of registering in the skies the wild legends of mythology, and writing upon the imperishable vault of heaven the customs and events of earth - all so surely liable to change and to oblivion. The grouping of the stars into constellations, to which definite names and figures are attached, had an oriental commencement, though subsequently the Greeks and Romans largely altered and amplified the work of their predecessors. It is not an improbable surmise, that the figures of the zodiac have some relation to the rural occupations of the ancients, or to the phenomena presented by the sun. Thus, the figure of a ram is supposed to lave been assigned to the assemblage of stars forming the first constellation, because of the sun being in that part of the heavens at the season when the flocks were taken from the stables to the fields. Thus, also, the lion was chosen to represent the fierceness of the solar heat in summer; the scorpion, to indicate the unhealthiness of autumn; and the balance, to express the equilibrium, or equal length of the days and nights, at the same period. While the Greeks and Romans retained the zodiacal constellations, derived from remoter antiquity, they constituted, as extra-zodiacal, images having a special reference to their own history - the figures of heroes, and the emblems of their deeds, over whose existence hang the clouds of fable, or upon whose reported character rest the blots of shame. It must, however, be acknowledged that the moderns are scarcely in circumstances to blame this proceeding, having contributed themselves to make confusion worse confounded by adding to the motley assemblage of celestial signs. A place in the heavens has been given to the shield of Sobieski, the sceptre of Brandenburg, the crown of Frederick, the heart of Charles the First, and one was proposed for Napoleon in the height of his guilty greatness.

The age of astronomy in Greece commenced in the seventh century previous to our era ; but in the writings of the older poets, Hesiod and Homer, some centuries earlier, allusions occur which show that the appearance of particular stars and groups had been carefully noted. The former mentions the Pleiades remaining invisible for forty days, which has been found to be as accurate as possible for his epoch and latitude. In precepts concerning rural affairs, he advises the sickle to be applied to the ripened corn at the heliacal rising of the cluster, and the ground to be ploughed at its heliacal setting. Now, supposing that he lived about nine centuries before Christ, the era usually given, it is ascertained, by astronomical formulæ, that the heliacal rising of the Pleiades took place at a time of the year corresponding to about our seventh of May, so that the harvest in Greece is now a month later than it was then. It is also found that their heliacal setting would be at a period answering to our twenty-ninth of March. The interval between the two 
periods, about forty days, during which time the cluster would be invisible owing to its proximity to the sun, corresponds with the preceding statement. Hesiod likewise observes, that when the Pleiades rise from the dark seas, sailing is dangerous, and that, on account of violent winds and rain, it is necessary to have large vessels, well provided with ballast, and to work much at the pumps. Here, he evidently alludes to what is called the acronical rising of the stars, which takes place at the setting of the sun. This would happen in his day soon after the autumnal equinox, in the case of the group named; and at that season, we know that storms are common in the Grecian seas. The names of several of the constellations occur in Homer. In the fifth book of the Odyssey, he makes Ulysses, upon leaving the island-goddess for his bark, speak of the "Pleiades and Bootes, the Hyades, and bold Orion, the Bear, which is ealled the Wain, the unwearied sun, and the full moon, and all the stars, by which, like a crown, the heavens are surrounded." He mentions Sirius also, and Hesiod in addition introduces Areturus; but neither of these writers take any notice of the planets. The referenee, in the fine passage descriptive of Tydides in the Iliad, is doubtful :-

\footnotetext{
" High on his helm celestial lightnings play,

His beamy shield emits a living ray;

The unwearied blaze incessant streams supplies,

Like the red star that fires the autumnal skies,

When fresls he rears his radiant orb to sight,

And bath'd in ocean shoots a keener light."
}

Some conjecture Venus to have been intended, others Sirius; and it may here be mentioned, as a singular physical fact, that Sirius, now so brilliantly white, was known as a red star to the ancients - a change of aspect which is not a solitary instance of the phenomenon.

By 'Thales - the founder of the Ionie school - the basis was laid, of whatever profl-

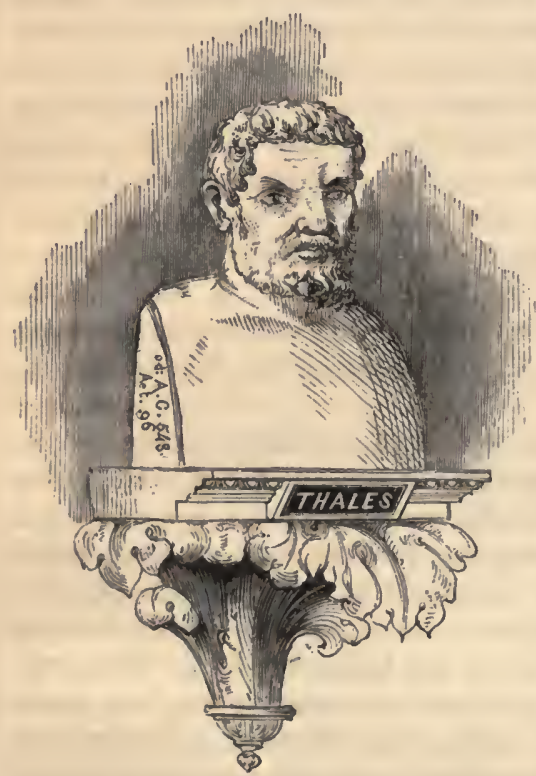
ciency the Greeks attained in astronomical science, for they were never distinguished as a people by the study of physical nature. Of him, the familiar story is related, that when a boy at Miletus, his native eity, he fell into a diteh while contemplating the stars, upon which Thressa, his conductress, exclaimed, "Why, O Thales, do you seek to comprehend the things which are in the heavens when you are not able to see those before your eyes?" The truth of this anecdote has been doubted, but the remark harmonises with what we know to have been the general tone of the Grecian mind. The great men of the country were chiefly poets, warriors, statesmen, orators, and moral rather than natural philosophers. It was not the spirit of scientific enquiry, but a love of speculative and tasteful sentiment, that elevated the soul of Plato into communion with the skies, and inspired the thought, that because the flight of birds, and the movement of every body through space, produced a vibrative sound, that therefore the motion of the celestial objects must oceasion a ravishing harmony, fitly called the music of the spheres - an idea to which Shakspeare gives expression in the address of Lorenzo in the grove to Jessica :- 
"How sweet the moonlight sleeps upon this bank!

Here will we sit, and let the sounds of music

Creep in our ears; - soft stillness and the night

Become the touches of sweet harmony.

Sit, Jessica; look how the floor of heaven

Is thick inlaid with patterns of bright gold:

There's not the smallest orb, which thou behold'st,

But, in his motion, like an angel sings,

Still quiring to the young-eyed cherubim.

Such liarmony is in immortal souls."

It was the tendency in general of the Attic mind to study with ardour, morals, politics, and religion, but to play with physical phenomena : regarding only the graceful and poetic sentiments they suggested. Thales, an Ionian, and his successors, were exceptions to this rule of their countrymen, and arrived at conceptions respecting the constitution of the universe which strongly sympathise with the hypotheses that are now admitted. The most prominent circunstances concerning him are, that while the Greeks were contented with the rough approximation to the north afforded by the Great Bear; he introduced the knowledge of the Little Bear, by which the Phœnician mariners had long been accustomed to steer; that he made a near approach to the diameter of the sun, taken at a mean; taught the sphericity of the earth; and predicted a great solar eclipse, which occurred at the time announced. We may regard this last-mentioned particular as the greatest astronomical achievement, resting upon good authority, that had hitherto transpired. Herodotus, whose relation may be substantially confirmed by other testimonies, observes, that in the midst of an action between the Medes and Lydians, the day was suddenly changed into night. He adds, that Thales the Milesian had predicted the year in which the eclipse would happen, and that the hostile armies, when they saw the darkness, desisted from the battle. According to the calculations of Bailly, the centre of the moon's shadow passed in a right line over the north-eastern part of $\Lambda$ sia Minor, the scene of the war, through Armenia into Persia, on the morning of September 30th, B. c. 610. Want of minuteness in the historian probably led to the statement that the prediction referred only to the year in which the eclipse would take place, for, as it was total, or nearly so, Thales must have been able to come much nearer to the time. It follows, also, that such a prediction could only have been made with certainty by one in possession of a long series of observations derived from some foreign source, as the Greeks themselves had not originated any: in all likelihood from Chaldea, where the requisite materials might be found.

The opinions held by the successors of Thales are in several respects remarkably accordant with modern ideas. Anaximander maintained the tenet of the earth's movement about its axis, and of the moon's light being reflected from the sun. Anaxagoras, who transferred the Ionic school from Miletus to Athens, in addition, offered a conjecture that, like the earth, the moon had habitations, hills, and valleys. These doctrines were taught upon a more extended scale by Pytriagoras, who appears to have reached the sublime conception of the earth's motion round the sun, which Philolaus, his successor in the Crotonian school, is generally believed to have taught openly. According to the Pythagoreans, not only the planets, but the comets themselves, are in motion round the sun, and not floating meteors formed in the atmosphere. But these were the conjectures merely of sagacious minds, not possessed of the evidence requisite to give prevalence and stability to opinions, while they were directly opposed to the testimony of the senses. Hence, instead of obtaining the suffrages of antiquity, they met with little acceptance; and for eighteen centuries, the apparent motions of the heavenly bodies were regarded as unfolding the true constitution of the universe. A blind submission was yielded for ages to the dogmas of the Aristotelians, who held the earth to be the quiescent centre of the universe, the 
celestial bodics its serrants, moving in circular orbits, and with uniform velocities, and

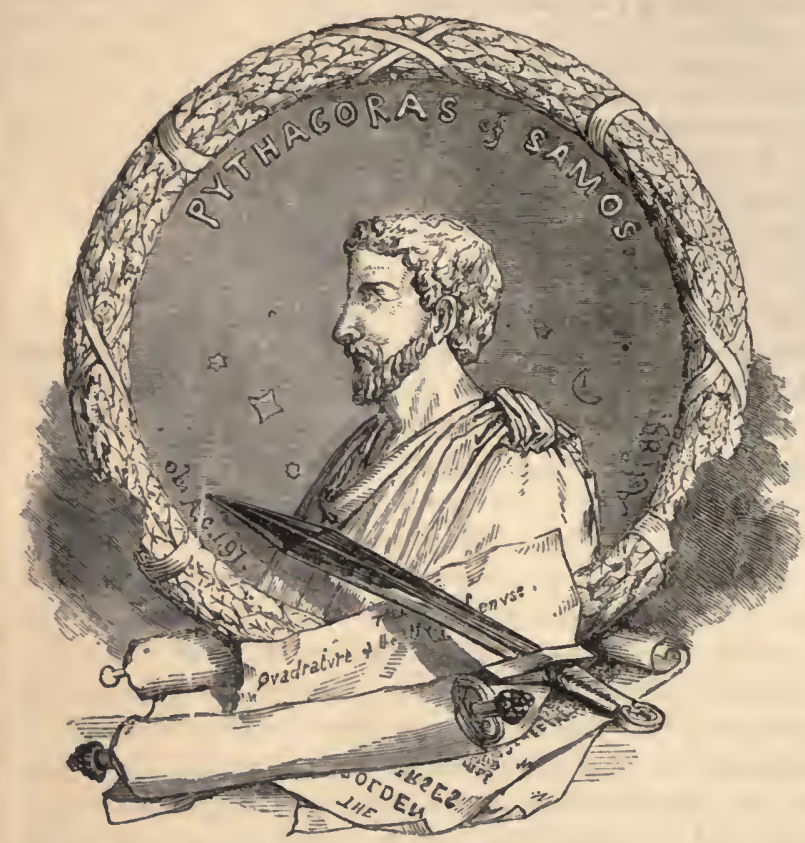
comets simply meteors generated in the terrestrial atmosphere. The "divine" Plato indeed, the master of Aristotle, is said to have renounced his opinion upon one of these points in his old age, and to lave admitted that the centre ought to be appropriated to some more noble object than the earth, or, rather, than terrestrial substance. It is a plausible conjecture, that the elements of his own system were first suggested to the mind of Copernicus by notices of the opinions of the diseiples of Thales and Pythagoras. 'They won few converts, however, among the Greeks, and in some instances exposed their professors to persecution. The Athenians condemned Anaxagoras to death for his philosophical views, a fite from which he was saved by the interest of Pericles, but he was sentenced to perpetual banishment, and died in an obscure town on the Hellespont. Philolaus also suffered persecution on account of his doctrine of the earth's annual revolution, which so shocked the prejudiecs of men as to subject him who maintained it to the suspicion of impiety.

Egypt became the chief seat of astronomical science in the ancient world soon after the age of Aristotle. Alexandria had risen by the delta of the Nile at the command of the conqueror from whom its name is derived, and under the superintendence of the architect who proposed cutting mount Athos into the figure of a man. Upon the death of Alexander it became the capital of one of the kingdoms formed out of the ruins of his empire. The first of the Ptolemies laid the foundation of its celebrated library-perhaps the most extensive collection of books ever brought together before the invention of printing. His successor established in connection with it a college for the cultiration of the pure sciences, invited the most accomplished of the Greeks to repair to it, supplied them with whatever instruments could be furnished necessary to their pursuits, and thus arose the Alexandrian school, which received the flattering epithet of Divine, on account of the acquirements of its professors, and the philosophical character of its investigations. It originated a connected series of observations relative to the constitution of the universe. The positions of the fixed stars were determined, the paths of the planets carefully traced, and the solar and lunar inequalities more accurately ascertained. Angular distances were calculated with instruments suitable to the purpose by trigonometrical methods, and, ultimately, the school of Alexandria presented to the world the first system of theoretical astronomy that had ever comprehended an entire plan of the celestial motions. The system we know to be false, and inferior to the Pythagorean notions ; but it had the merit of being founded upon a long and patient observation of phenomena, a principle which finally brought about its own destruction, while the previous theories were the results of pure hypothesis. 
The most interesting circumstances connected with the early history of the Alexandrian school are the attempts made to determine the distance of the earth from the sun, and the magnitude of the terrestrial globe. Aristarchus of Samos is the author of an ingenious plan to ascertain the former. Suppose the centre of the circle $s$ to represent the centre of the sun, $\mathrm{x}$ that of the moon, $\mathrm{E}$ being the position of an observer on the surface of the earth. It is easy to perceive that, when the moon has half her disc illuminated by the sun, a line drawn from $\mathrm{E}$ to Is will be perpendicular to another line drawn from $\mathrm{S}$ to $\mathrm{sr}$, making with each other a right angle. The plan of Aristarchus was, that the angular distance $\mathrm{S}$ E II should at that time be taken, which is possible, because both the sun and moon may then be seen at once above the horizon, from whence the ratio of $E S$ to $\dot{E} \mathrm{M}$ may be determined. - He obtained the general result, that the distance of the sun from the earth is about nineteen times as great as that of the moon from the earth. We now know that the distance is much greater; but notwithstanding the inaccuracy of the result, the method employed is undoubtedly just, and reflects the highest honour upon the genius of its proposer. He failed in practice, owing to the difficulty of ascertaining the exact time of the bisection of the moon's disc, and the imperfect instruments then in use for the measurement of angular distances. The determination of the sun's distance from the earth, with any thing like precision, is only of recent date, and has been effected by means of which the ancients could have had no conception. Aristarclius held the Pythagorean doctrine of the motion of the earth in space, and gave the right answer to the formidable objection long afterwards made to it, that of the non-existence of an annual parallax. The answer recognised the earth's orbit as being an insensible point in comparison with the vast distance of the fixed stars. The boundaries of the universe were thus extended to his mind far beyond any limits coneeived by his predecessors. There is great obseurity resting upon his life. The era of his birth and death is unknown; but lie was alive B. c. 280 , as an observation of the solstices made by him at that date has been preserved. 'The Greek text of his only surviving work, "On the Magnitudes and Distances of the Sun and Moon," was edited in this eountry by Dr. Wallis in 1688. He estimated the apparent diameter of the sun at $30^{\prime}$, - about $2^{\prime}$ too little.

The attempt to determine the magnitude of the earth was made by Eratosthenes, and we have reason to believe this was the first attempt ever made to solve the problem, as ". certainly it was to do it upon a true prineiple. Syene, in Upper Egypt, then

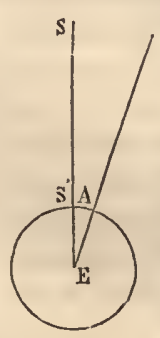
a flourishing city, now Assouan, has acquired an interest from its connection with this experiment. It was supposed to lie exactly under the tropic of Caneer, as it had been observed that, on the day of the summer solstice, at noon, a well there was enlightened to the bottom, while vertical bodies threw no shadow for the space of about three hundred stadia around it. At Alexandria, therefore, which was conceived to lie under the same meridian, on the same day at noon, when the sun was believed to be vertical at Syene, Eratosthenes measured his zenith distance, or the value of an arc of the meridian between the two cities. Let $\mathrm{E}$ be the centre of the earth, $\mathrm{A}$ Alexandria, $s$ the sun, and $s^{\prime}$ Syene. The eelestial arc contained between the zeniths of the two places, Alexandria and Syene, was found to be equal to $\frac{1}{50}$ th of the circumference of a circle, that is, to $7^{\circ} 12^{\prime}$. Now, admitting the earth to be of a spherical form, Eratosthenes would obtain the measure of its circumference, by multiplying fifty times the distance between the cities. This distance was ascertained by order of the government to be 5000 stadia, and consequently the result obtained for the length of the 
whole terrestrial circumference was 250,000 stadia. The great uncertainty that exists, as to the value of the stadium in question, prohibits any appreciation of the measurement: but several important errors were committed in the practical application of a right principle. No allowance was made for the solar parallax, and instead of Syene being under the tropic of Cancer and on the meridian of Alexandria, it is about $50^{\prime}$ north of the former, and nearly $3^{\circ}$ east of the latter. The principle of the method employed is, however, precisely the same as that which has been acted upon in modern times; and our more accurate results in determining the magnitude of the earth are owing to greater nicety in observation, attention to all the elements which the solution of the problem requires, and more perfect instruments for the measurement of linear and angular distances. The inventor of the method was born at Cyrene, in the year 276 B. c. The third Ptolemy invited him to his capital, giving him the charge of its library; but becoming weary of life at the adranced age of eighty, he died by voluntary starvation, and was succeeded in his office of librarian by the author of the Argonautics.

We now come to the greatest astronomical name in antiquity - that of Hipparehus who may be properly regarded, on account of the plans he pursued and the results he obtained, as the father and founder of real astronomy. The invention of spherical trigonometry is supposed to be due to him, and undoubtedly the first application of it is, by which the places of the celestial bodies may be fixed, and the variations of their movements exhibited with precision. He approximated also closely to the true length of the tropical year, which had been previously held to be $365 \frac{1}{4}$ days. This lie discovered to be an error in excess, by comparing one of his own observations of the summer solstice, with another made by Aristarchus of Samos, 145 years before. His own determination of 365 days, 5 hours, 55 minutes, 12 seconds, exhibits a value greater than the truth by $6^{\prime} 13^{\prime \prime}$ only, as according to Laplace, the length of the tropical year at that time must liave been about $4^{\prime \prime} \cdot 2$ shorter than in the present age. The error can occasion no surprise. It must be remembered, in behalf of the ancients generally - to use the words of Delambre, that their astrolabes were nothing but armillary spheres, of no great dianzeter, and with very small subdivisions of a degree; and that they had neither telescope, vernier, nor micrometer. "What should we do," he goes on to remark, "even now if deprired of these helps, and if we knew neither the refraction nor the true altitude of the pole, on which point, even at Alexandria, and with armillæ of every sort, an error of a quarter of a degree was committed?" At this day we dispute about a fraction of a second; they could not then answer for any fraction of a degree, and might be wrong by a whole diameter of the sun and moon. The appearance of a new star in the time of Hipparchus is said to lave induced him to make a catalogue of the fixed stars, in order that posterity might be able to recognise any changes that might take place in the appearance of the heavens. He was well aware of the importance of such a catalogue, especially for observations of the moon and plancts; and in executing the task he rendered essential service to astronomy, and made his most remarkable discovery. Comparing the place of the star Spica Virginis, as determined by himself, with that assigned to it about 170 years previously by two distinguished Alexandrians, he found that this star was six degrees distant from the autumnal equinox, whereas the before-mentioned astronomers had found it eight degrees from the equinox. He saw that there must have been either a movement of the star in longitude during the interval, or a contrary movement of the equinoctial point in the heavens. The same phenomenon was observed in relation to other stars; that while their latitudes had been retained unaltered, they had advanced in longitude; and hence the retrogradation of the equinoctial points along the ecliptic was inferred, the cause of which remained a secret till the age of Newton.

The catalogue formed by Hipparchus contained 1080 stars. The labour it involved, 
and its use, called forth the strong language of Pliny, who describes it as a thing even hard for a god to perform - "Ausus rem etiam Deo improbam." Perhaps, had we an accurate catalogue of the stars, dating back four thousand years, some remarkable variations of position would be discovered, transpiring by slow and imperceptible degrees, which would open views of the universe, which will now require the observations and comparisons of future centuries to develope and confirm. After determining the places of the stars, Hipparchus made a representation of the heavens on the surface of an artificial globe, which appears to have been deposited at Alexandria; and with him also the happy idea originated of marking the positions of towns in the same manner, by circles drawn through the poles perpendicularly to the equator, or by latitudes and longitudes. When his brilliant career commenced and terminated, is unknown; but he was born at Nice, in Bithynia, made many of his observations at Rhodes, and was alive in the interval between 160 and 125 B. C. He amply merited the epithet applied to him by Ptolemy, "the lover

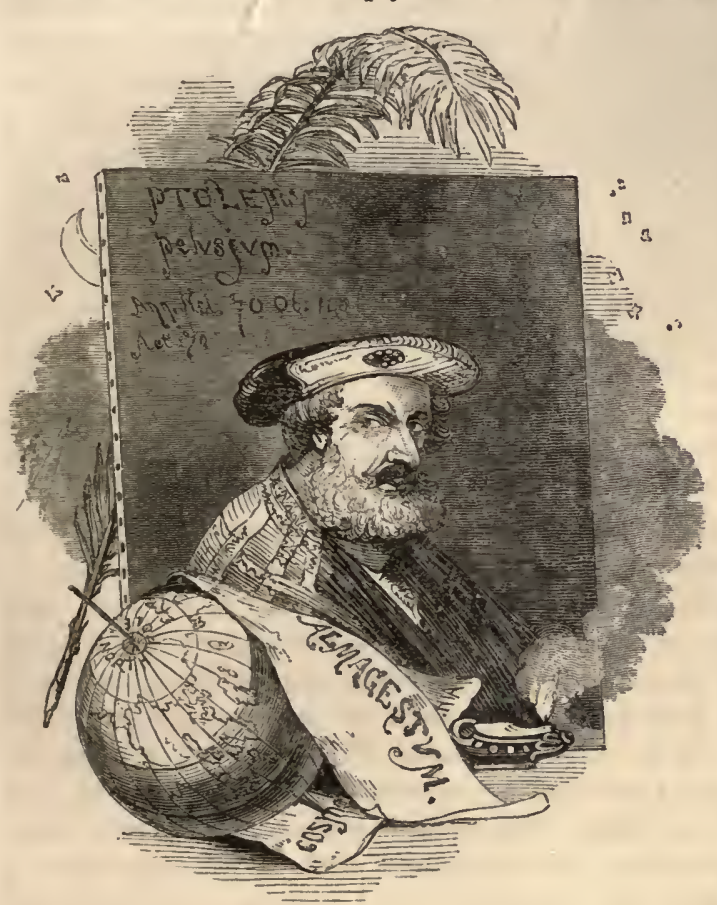

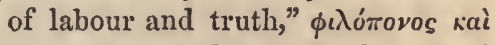
$\phi \iota \lambda \alpha \lambda \hat{j} \theta \eta \eta$; and is properly classed in scientific opinion with the Bradleys and Flamsteads of modern times. After him, there is little to invite attention in the history of astronomy for nearly three centuries, when we come to Ptolemy, the first who formally broached a system of the universe which has been handed down to us.

Apart from his theory, Ptolemy has great merits. He was the best scholar of his age - a practical astronomer, mathematician, and geographer-the author of the important discorery of the evection or libration of the moon. Born in Egypt, and flourishing at Alexandria through the reigns of the emperors Adrian and Antoninus, he there became acquainted with the writings and observations of Hipparchus. The former, with one exception, unfortunately perished at the destruction of the Alexandrian library; but the chief of the latter have been preserved by Ptolemy in his own works, and they have largely contributed to his fame. In a celebrated production which ruled the mind of Europe for fifteen centuries, the Great Collection, or Almagest, as it was called by the Arabic translator, he recorded the advances of past ages in astronomy, the state of the science in his own time, and developed a plan of the celestial movements. It recognised the earth to be a spherical body for reasons similar to those that are now alleged in proof of its convexity - to be the immovable centre of the universe - the sun, moon, planets, and fixed stars, prosecuting a daily revolution around it, in perfect circles, and with uniform velocities. This is in accordance with the appearance presented by the first blush of the universe to the physical eye. The sun is seen daily pursuing a course through the heavens in the segment of a circle from cast to west. The same path is ap- 
parently described by the moon and stars; and on a caln autumnal or winter night, when the winds are lulled, and scarce a twig stirs, or a ripple is seen upon the waters, but the "river wanders at its own sweet will," how perfeet the illusion in which the scene involves the senses - the quiescence of our terrestrial globe, and the ceaseless revolution of the firmament round it as a central point! These were dogmas firmly held by the Platonists and Aristotelians, who stoutly clung also to the idea of circular orbits and uniform velocities in relation to the celestial luminaries; because the circle was deemed the most

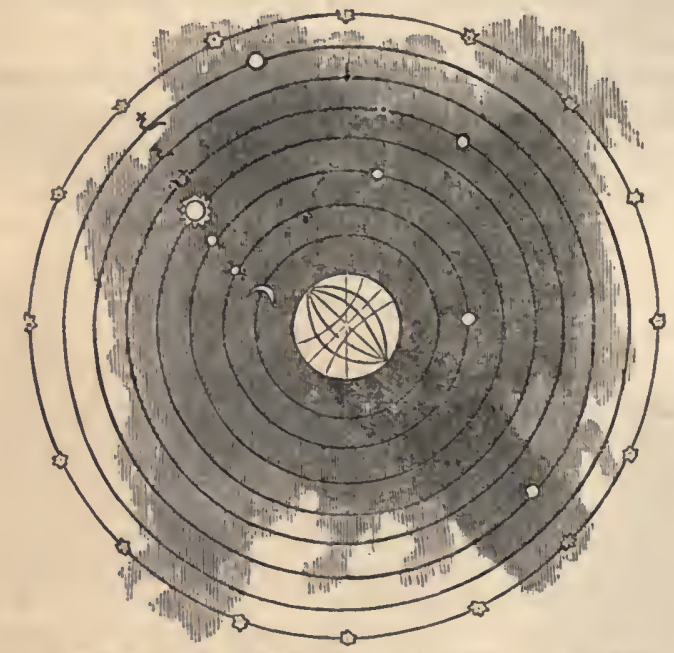

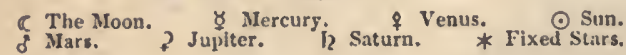
perfect of all geometrieal figures, and on that account alone proper. to represent their motions; and beeause of the faney, that in such divine and eternal bodies no irregularity can exist.

We have seen, however, that the Greeks liad a cultivated acquaintance with other movements besides the apparent diurnal revolution of the sphere, movements in an opposite direction to it. 'They had carefully traced the sun's path in the ecliptic, that of the moon in her orbit, and they had marked likewise the striking peculiarities of planetary motion. To an observer on the eartl, the planets appear to pursue a course of the most irregular and unsystematic kind, which was a perfect puzzle to the ancient theorists. Sometimes they seem to go along with the sphere, but with greater celerity; then, to remain stationary; then, to retrograde, or make an angular movement, or describe a cireuit like a loop in a knot of ribbons. The paths of Mars and Jupiter, as observed from the earth, described the courses roughly represented in the diagram, at the interrals stated. It seems surprising therefore, in

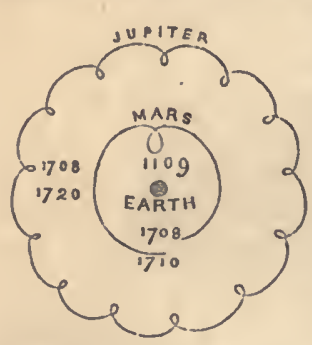
the face of these appearances, that the centrical station of the earth, and all the orbs of heaven moving round it in perfeet circles, should have become so much the grand leading idea of the aneient mind. Hipparchus, indeed, was too well aware of the imperfection of observation, and of the importance of supplying data upon which to found a theory, to be given to theorising himself. But when lie did systematise, he departed from one of the cardinal maxims of his compeers and successors, by supposing the sun to revolve round the earth in a circle, the earth not being at the centre. He had found the interval between the vernal equinox and the summer solstice $94 \frac{1}{2}$ days, and that from the summer solstice to the autumnal equinox only $92 \frac{1}{2}$ days, thus making the length of the summer half year 187 days, and that of the winter half year 178 days. To account for this unequal division of the year, and to reconcile it with the idea of the sun's orbit being a circle and his velocity uniform, Hipparchus dismissed the hypothesis of the centrical position of the earth. He supposed an eccentric circle, according to which, A B C D may represent the solar orbit, $\mathrm{E}$ the place of the earth, not coincident with $\mathrm{F}$ the centre of the orbit. E F will be the eccentricity, $\mathrm{G}$ H the line of the apsides, 1 the position of 
the sun at the summer, and $J$ at the winter solstice, $K$ his place at the vernal and $L$ at the

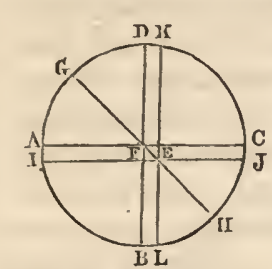
autumnal equinox. This theory provides for the circular orbit and uniform velocity of the sun; for the unequal division of the year, and an apparently unequal rate of motion to a spectator at the eartli ; for the two ares formed between $\mathrm{K}$ and $\mathrm{L}$ are unequal, and it is perfectly obvious that if perceptible to a terrestrial observer the sun would appear to travel fastest at the nearest point of the apsis, $\mathrm{H}$, and slowest at the farthest, G. This scheme is chiefly remarkable for its removal of the earth from the post of honour in relation to the solar orb, which the general voice of antiquity assigned to it with reference to the whole universe, that of being the centre of all the celestial revolutions.

The idea of his great predecessor was not admitted by Ptolemy, who contended for the immobility and centrieal situation of the earth, and attempted to reconcile with these positions, and with the dogmas of perfect circles and uniform velocities, the diverse and complex morements in the heavens. In explaining the irregularities of the planetary courses, he adopted largely the hypothesis of epicyeles; a scheme based upon the general prineiple, that irregularities of movement may be resolved into a combined series of regular movements - a sagacious idea, not however his own, but proposed by some of the earlier Greeks, yet one which he was the first laboriously to apply to the phenomena observed. It is demonstrable that two motions, each uniform in itself, may, in combination, appear rexed and tortuous. In illustration, Dr. Nichol says, suppose that a ship were sailing evenly and uniformly along a coast; it is manifest that a passenger standing on deek would appear to a spectator on shore to move past him also in a regulated and uniform manner, with the same velocity as the ship; but if, instead of standing, the passenger should walk to and fro on the vessel's deck, likewise with a constant pace, his aetual motion along the coast would clearly seem of the most irregular kind. While walking from stern to prow his motion would appear faster than the ship's; and when walking from prow to stern, it would, on the contrary, appear slower; nay, if in this latter ease the passenger walked faster than the ship sailed, he would appear for a certain time to go along the coast the other way; so that if the vessel were invisible, and the observer fixed his attention solely on the passenger, he would see very irregular motions; sometimes accelerated, sometimes retarded, sometimes even retrograde-all, howerer, flowing from

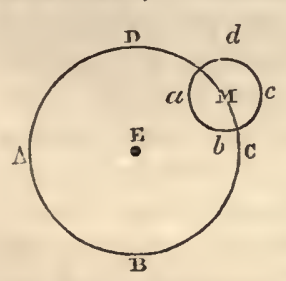
the more combination of two uniform motions, the sailing of the vessel and the walking of the passenger. Now, Ptolemy's theory of epicycles combines two movements in the hearens, that of a centre and a circumference. Thus let $\mathrm{E}$ be the earth, and $\mathrm{s}$ an imaginary centre in the heavens: the planet is supposed to be moving around it in the cireumference $a b c d$ all the while the imaginary centre is accomplishing the orbit A B C D. A little attention will soon discover that upon this hypothesis the planet's motion will appear at times direct, stationary, and retrograde to an observer on the earth. But though the assumption satisfies some of the conditions required by the problem of the planetary movements, it goes a very little way towards answering them all, and Ptolemy was obliged to erowd cycle upon cyele, and combine them with eccentrics, in a manner that would be difficult to make intelligible, and useless if attempted.

It was a blind adhesion to the plysics of Aristotle - an unquestioning adoption of the false principle respecting circular motion being the law of nature and the earth the centre of the universe-that led to this complicated scheme to harmonise its apparent movements. These fundamental errors being admitted, it necessarily followed that the mind must go forth in quest of some plan, to bring into coherenee with the maxims 
adopted the observed facts of planetary motion. The acute intellect of the ancients is illustrated by the theories proposed; but the lesson is strikingly furnished by their laborious and abortive efforts, that it is folly to take for granted that which has not been proved. The later Ptolemaists occupied themselves for centuries in amplifying and mending his system, supplying an epicycle here where it was wanted, and an eccentric there when required, and even converting his imaginary spheres into solid transparent wheels, revolving the one within the other, and each carrying a planet attached to it. 'The profound of space was crammed with a succession of huge globular forms, in which the planets were placed, all of the finest crystal, else the light of the stars had been intercepted; beyond these was the vast sphere of the fixed stars, crystalline likewise; beyond that was the primum mobile, incessantly rolling and giving motion by its friction to the spheres in its concave; while still farther out was the empyrean heaven, or paradise of blessed souls.

The illustrious Alexandrian is not, however, to be identified with those who bore his name in the middle ages. He would have repudiated at once their vain inventions. They were schoolmen chiefly, more.familiar with the dreamy philosophy of the Academy and Stoa than with the experimental science of Hipparchus - more skilled in logic than in the examination of physical nature. 'The Ptolemy of the early Christian era was a practical astronomer, and his merits as such give him a title to fame, which his theory, now exploded and obsolete, ought not to obscurc. He was the first to point out the effect of the atmosphere in changing the direction of the rays of light ; and, though unable to appreciate the amount of its refractive power, he clearly perceived its influence on the altitudes of the stars, was aware of its increase with the distance from the zenith, and assigned this as the cause of the greater apparent magnitudes of the solar and lunar discs at the horizon - an explanation now generally held.

A scheme nearer to the truth than the Ptolemaic, comnonly called the Egyptian, was in vogue when the former was broached, though there is no reason to suppose, with some, that it prevailed at an early period in that country. It regarded the inferior planets as revolving round the sun, and moving, in conjunction with the sun, round the earth. It is obscurely hinted at by Pliny ; but explicitly announced by Vitruvius, who lived a short time prior to Ptolemy. Mercury and Venus, the architect remarks, are the planets nearest to the rays of the sun, and move round the latter as a centre, appearing sometimes progressive, sometimes retrograde, and occasionally stationary among the signs. But this system, the prototype of the Tychonic, never became popular. A valid objection to it was probably found in the fact that the inferior planets were never seen in phase, an appearance which would be exhibited if alternately beyond the sun and between it and the earth; a position strictly true, and had the eye at that period been aided by the telescope, Venus would have been seen in phase as at present. The superior planets were invariably arranged by the ancients in the same order - that which now obtains. They had obviously no guide as to their respective distanecs from the earth, but the indications discernible in their different brightness and velocity. Those which had the slowest apparent movement were concluded to be the most remote. Hence Saturn, a dull and sluggish traveller in space, was placed on the exterior; then Jupiter and Mars followed in succession towards the earth : the sun, moon, and inferior planets were placed within the orbit of Mars, and the moon was considered the nearest celestial object to our globe. Next to eclipses of the sun and moon, occultations of the stars and planets by the moon, or the approach of the moon or of a planet to any star, with the appearance of comets, attracted attentive observation. An occultation of Mars by the moon is mentioned by Aristotle, and one of Saturn is recorded by Ptolemy as having taken place in the year 228 в. с. In fact, we may find some notice, more or less distinct, taken by the ancients, of all the celestial phenomena which the unaided vision has observed in modern 
times, with one exception, that of an annular eclipse of the sun, with reference to which the voice of antiquity is silent.

The instruments of observation known to the ancient world were of a simple and imperfect kind. The earliest of which we read is a vertical pillar employed to determine the sun's altitude by means of its shadow. It was in general use for this purpose among the Oriental nations. The lofty pyramidal stone which Diodorus Siculus describes as hewn out of the mountains of Armenia by order of Semiramis, and set up in a conspicuous part of the city of Babylon, is conjectured to have been erected with this design. A Chinese record of uncertain date, but undoubted antiquity, refers to an observation on the length of the meridional shadows cast at the times of the summer and winter solstices by means of a vertical pillar. It is scarcely to be doubted that such a simple and obvious way of approximating to the length of the year must have suggested itself at a very remote period. The greatest elongation of the shadow cast by the pillar at noon at midwinter, its gradual decrease towards the vernal equinox, its greatest declension at midsummer, and its gradual advance to its maximum elongation again, are points to which we may believe attention was early directed; and a series of observations, taken with

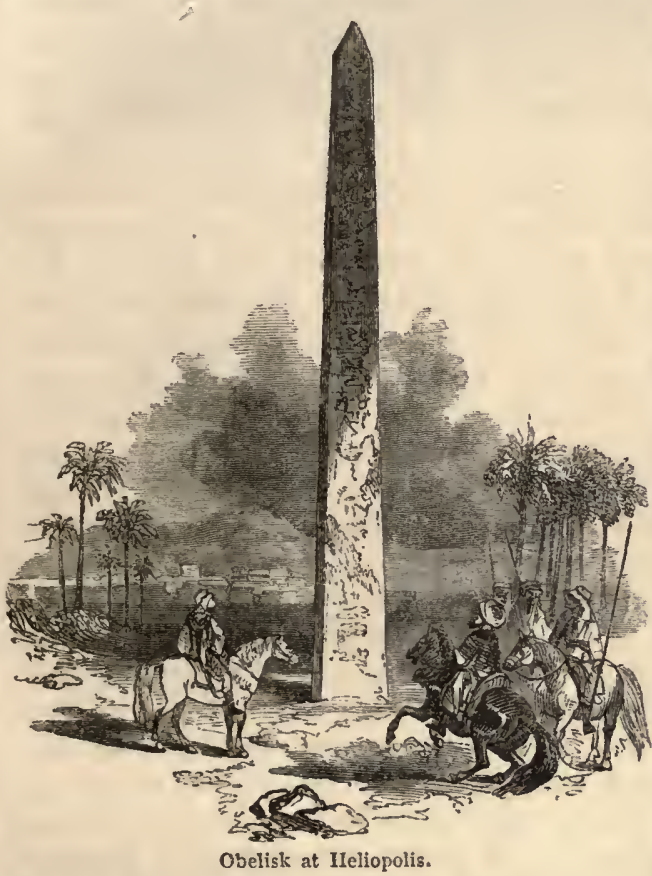
precaution, would lead to some results valuable in a rude state of society, and to an agricultural people. The same instrument was also employed to divide the day into equal parts, by means of lines traced on the pavement, which indicated the hour as the shadow of the column fell upon them. There is strong reason to believe that these instruments originated the obclisks of a subsequent age, erected in open squares in the Asian cities, and near the entrances of the Egyptian temples, and that these were intended primarily to answer one or all of the purposes named. It has been objected to this idea that the form of the summit of the obelisk will not allow of the extremity of the shadow being accurately defined; but there is some foundation for the surmise that a ball crowned the summit, by which the end desired might be gained. Augustus removed two grand obelisks from Egypt to Rome expressly to be used as gnomons, which conveys the impression that they had previously served that office; and Manlius placed a ball upon the obelisk erected by him in the Campus Martius, with a view to facilitate the accurate delineation of its shadow. The great importance in astronomy of precisely ascertaining the hour of any phenomenon occurring, or observation being made, led to various forms of the sundial, and to the construction of instruments for measuring time by night and by day when the sun was obscured. The one in general use was the clepsydra, or waterclock, as its name imports, an hour-glass, water being used prior to sand. The orations of the Greeks and Romans were regulated by this contrivance as to their time of speaking, which was called pleading by the clepsydra. The Tower of the Winds at Athens, otherwise styled the Tower of the Clock, an edifice of the age of Alexander, seems to have 
been erected to contain a sundial with eight faces, mecting the four cardinal and four intermediate points of the horizon, and a clepsydra; and, by an ingenious contrivanec, it would appear that the latter was sometimes made to divide the day into twelve equal parts, the aperture through which the water flowed contracting or enlarging aecording as the length of the natural day increased or diminished.

A great variety of instruments were construeted by the Alexandrians. Astrolabes, or armillary spheres, were used in the observanee of solar and sidereal phenomena. These, in the hands of the Arabs, at a subsequent period were lirgely improved, and made upon a gigantic scale. Whether any knowledge was possessed of the means by which the natural sight is now assisted in the contemplation of distant objects, is a controverted topic. From some obscure intimations found in the ancient writers of bodies circulating in the universe invisible to the naked eye, it has been conceived that the satellites of Jupiter and Saturn are meant, having been diseovered by the aid of instruments analogous to the telescope. Sir W. Drummond assigns a knowledge of that instrument to the Greeks, Chaldeans, and Hindús; but though some strong facts may be quoted in favour of the former, the cridence is not suffieient to warrant the inference. In enabling the eye to bear the brilliancy of the solar light, when direeted towards that luminary, various methods were adopted. Aristotle speaks of mirrors being used in his time, probably meaning thin metallic plates finely polished. Ptolemy mentions vessels of oil being employed in viewing eclipses, and Seneca refers to the medium now common, that of smoked glass.

We now take leave of the ancient world, bewildered by the apparently involved and disorderly movements of the hearens, having hold of no clue by which to arrive at the discovery of their larmony, "puzzled with mazes and perplexed with errors." The economy of the universe was a sealed book to the eye of antiquity-the theory of its best scholar a dream, at utter variance with the truth. The book had been shiut for thousands of years previous, and it remained closed for more than a thousand years afterwards. Yet there were not wanting some lofty minds who elearly perceived the discordance between the interpretation given and the facts observed, after all that ingenuity and application had done towards a reconcilement, and who seem to have indulged the anticipation of the appearance of a person able to open the volume and read the perfect colherence of its contents. Sucl was Sencea the philosopher. "How many things," he remarks, "are beyond the reach of human intelligence! and low small is the part of the universe accessible to our knowledge! even the Deity himself is no better known to us." But, as if inspired with the spirit of prophecy, he observes : - "The time will come when posterity will be surprised that we could be ignorant of things, the knowledge of which might have been so casily acquired, and some one vill at length arise who shall teach men the paths of the comets, their magnitude and number, and why they deviate so far from the routes of the planets." How has the anticipation been realised - the prophecy been fulfilled! It is somewhat remarkable that he who in his Natural Questions thus expressed limself, should, in a similarly happy vein, have treated another topic in the tragedy of Medea as follows:- " Eras shall come in late years, in which ocean may loosen the bonds of things, and a spreading continent expand, and Tethys reveal new regions, nor Thule be the boundary to the lands." If the former passage strongly reminds us of Copernicus and Halley, the latter does so equally of Columbus and Vasco de Gama.

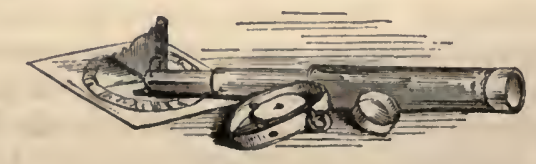



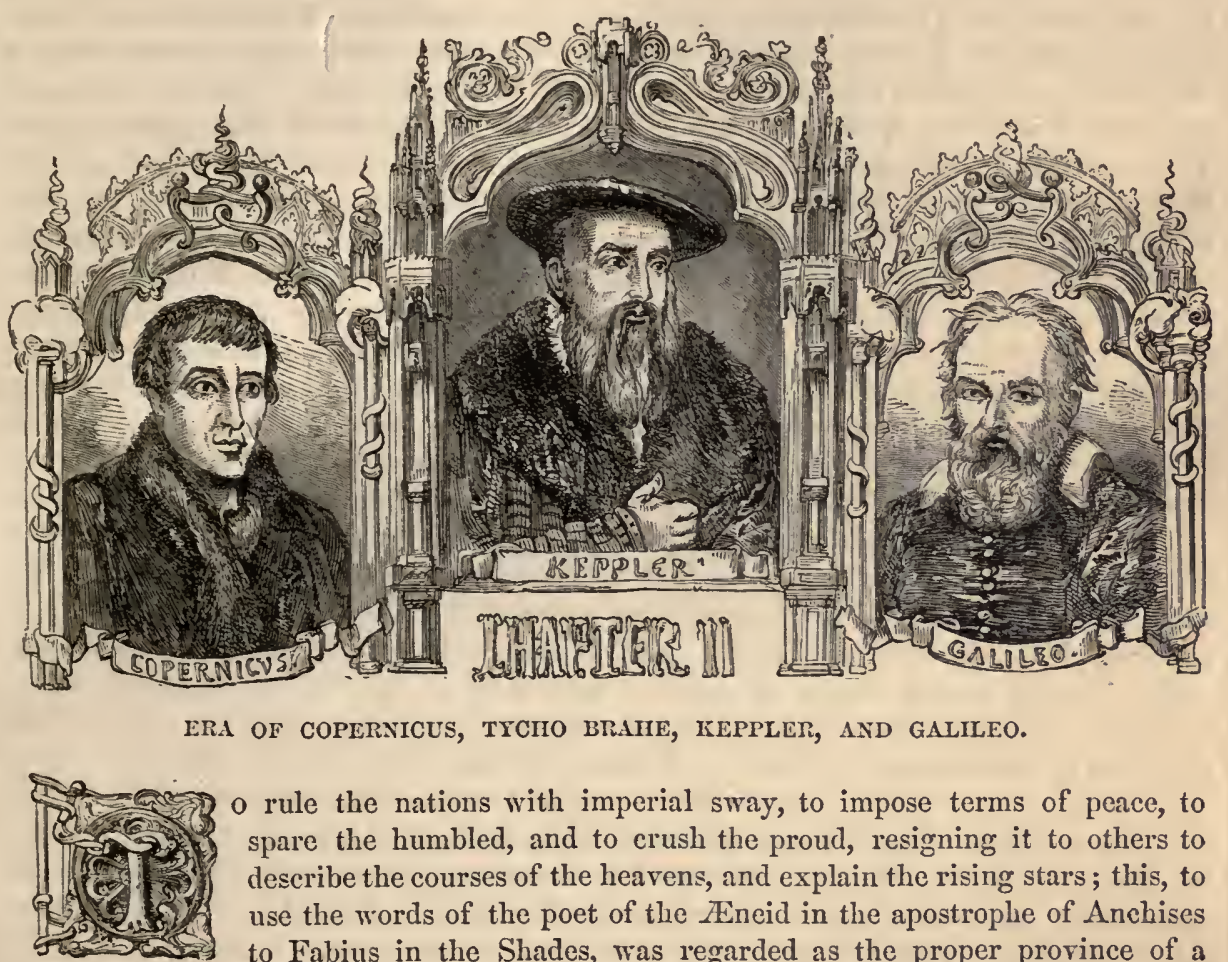

o rule the nations with imperial sway, to impose terms of peace, to spare the humbled, and to crush the proud, resigning it to others to describe the courses of the heavens, and explain the rising stars; this, to use the words of the poet of the Eneid in the apostrophe of Anchises to Fabius in the Shades, was regarded as the proper province of a Roman. The genius of the people was even more adverse to the cultivation of the physical sciences than that of the European Greeks; and we have seen that the latter left experimental philosophy chiefly in the hands of the Asian and African colonists. The elegant literature and metaphysical speculations of Athens, her epics, dramas, histories, and orations, had a numerous host of admirers in Italy, but a feeling of indifference was displayed to the practical science of Alexandria. This repugnance of the Roman mind at home to mathematics and plysics, together with the prevalence of its military despotism abroad, which extended from the Atlantic to the Indian Ocean, from Northern Britain to the cataracts of the Nile, annihilated in a measure the pure sciences in the conquered districts where they had been pursued, and prohibited attention to them in the mother country. Long, indeed, after the age of Ptolemy, the school in connexion with which he flourished, remained in existence; but, receiving no countenance from the imperial representatives, and the iron yoke of arbitrary power prostrating the energies of the people, it gradually waned, and was finally extinguished by the disorders that broke up the Roman empire. The interval between the overthrow of ancient civilisation by the rude and warlike tribes that took possession of its seat, and the revival of learning, exhibits an entire neglect of the liberal arts, with the exception of the Arabs during the era of their power on the banks of the Tigris in the East, and the Guadalquiver in the West.

The brilliant career of these Children of the Desert, soon after their emergence from it, was marked by an act, committed in the ferer of fanaticism-the destruction of the Alexandrian library, which betokened little the literary and scientific ardour of their descendants. The event strikingly contrasts with that which occurred in the reign of Almamon, 
when a long train of camels entered the gates of Bagdad laden with volumes of iniported learning, the fruit of a treaty made with the emperor of the East which imposed upon him the condition of furnishing copies of all the Greek authors. The medicine of Galen, the metaplysics of Aristotle, and the astronomy of Ptolemy, thus came into the hands of the caliph, and speedily appeared in the language of the caliphate. Arabian cultivation commenced with the dynasty of the $\Lambda$ bassides, or the middle of the eighth century. 'Three princes in succession, Almansor, Alrasehid, and Almamon, used every means in their power to promote the growth of learning among their people, and the advantages supplied by their fine elimate were not lost upon the followers of the Prophet, when a taste for astronomical science had been created; for upon the same sites where the old Chaldeans, two thousand years previously, had gazed with wonder upon the heavens, they entered upon a course of observation, with all the ardour common to their impulsive character, guided by the light of the Greek results. The work of Ptolemy was their text-book; his system, theirs : but instruments were constructed upon a larger scale; his determinations were subjected to a rigid examination; and in many instances a more accurate conclusion was obtained. The length of the tropical year was found within a fer seconds of the truth. A degree of the terrestrial meridian was measured in the Desert near Palmyra, to verify the value obtained by Eratosthenes. The obliquity of the ecliptio was determined. The great inequalities also of Jupiter and Saturn are marked in the tables of planetary motions constructed by the Arab astronomers. Their observations, in general, of the celestial bodies have a greater degree of accuracy than those of the Greeks, on account of the necessary correction being made for the phenomena of refraction, which was observed with reference to bodies near the horizon. Bagdad, however, was only the centre of a movement in favour of science. The impulse extended as wide as the language and profession of Islam, to Egypt, Morocco, and Spain ; and it long survived after the political power of the Eastern caliphs, which had gleamed like a meteor, had as suddenly vanished. An observatory was erected in the northern part of Persia, by a descendant of Gengis-Khan ; and Ulugh Beg, a prince of the house of Timour, erected one at Samarcand, where he compiled his now extant catalogue of the stars. The preface to this work states that eight stars marked in the catalogue of Ptolemy could not then be found in the heavens. This may have arisen simply from a mistaken entry in the first instance; but, if a case of real disappearance, it is far from being the only one, though a profound mystery.

Arabian eultivation attained its meridian splendour in Spain at a period when the rest of Europe was plunged in darkness. Through intercourse with the Moors of that country, some gleams of light gradually radiated through the Continent; and undoubtedly they are to be regarded as having transmitted the torch of civilisation from antiquity to modern ages. Among the first fruits of their influence, the construction of the Alphonsine tables may be placed, a work of the king of Castile of that name, chiefly confined to a more accurate determination of the motions of the sun and planets, and the lengtli of the year, the materials for which were derived from his Mahommedan neighbours to the south. There is little to detain us of any interest or importance in relation to astronomy, at this era, in countries where it has now arrived at such marvellous perfection. Observers abounded in the middle ages; but their midnight watehings of the great canopy of heaven liad very generally only an astrological purpose in view. Speculatists were numerous respecting the mechanism of the universe; but blindly adhering to the doctrines of the earth's immobility, and of the uniform and circular motions of the celestial lights, they laboured hard, but in vain, to adjust observed phenomena with preconeeived theory. The Aristotelian notion of the spheres was revived in all its grossness, and huge materialities were conceived to constitute the eternal paths of the bodies composing the solar system, necessary to the end of kecping them in place. To account for all the celestial move- 
ments, several of these solid spheres were required to be in attendance upon the same body, and to be of various structure; and they were multiplied and shaped, until a system was imagined which it fairly baffled the inventors to comprehend. The remark of the Castilian monarch respecting this intricate and cumbrous architecture was not without some justification, though breathing an irreverent spirit: "Had the Deity," said he, "consulted me at the creation of the universe, I could have given him some good advice."

The presumptive evidence against the truth of the Ptolemaic theory is admirably, though not professedly, expressed by Milton, in the representation of Adam reasoning,

How Nature, wise and frugal, could commit

Such disproportions,

as the supposition of the revolution of the firmament round the earth involves. It must then travel, as he argues, "spaces incomprehensible," the "swift return diurnal" implying a swiftness not to be described or imagined; and when the phenomena of the celestial appearances are accounted for, and day and night produced, by the simple rotation of the earth upon its axis, and its trunslation in space, the presumption is strong, that " Nature, wise and frugal," would never "commit such disproportions," as the theory of terrestrial repose and firmamental movement supposes. But it is difficult for the mind to disengage itself from the force of a universal opinion, especially when it is sanctioned by a venerable antiquity; and hence, it was not until some time after the era of Copernicus, and not until after many a battle in bchalf of the faith of past ages, that his system, beautiful for its simplicity, and now demonstratively proved to be correct in its leading features, received the credence of mankind. It was reserved for this great man, born on the banks of the Vistula, to deviate from the path of his predecessors, to renounce allegiance to the speculative physics of Aristotle, and to point the way, though with a cautious footstep, to the true system of the universe; a labour which occupied upwards of thirty years of his life, one of the most glorious achievements that has marked the page of human history. He it was who revolutionised for ever the face of astronomical science, and in the magnificent language of one of his immediate followers, "commanded the sun to stand still, moved the earth from its foundations, stopped the revolution of the firmament, and subverted the whole ancient order of the universe."

Nicholas Copernicus, or Zepernic, was born at Thorn, near the place where the Vistula crosses the Polish frontier, some time in the years 1472 or 1473 . He was educated with an eye to his father's profession, that of medicine, but was happily diverted from it by accidentally hearing a course of lectures, which inspired him with a passion for astronomy. He was at Bologna in Italy in 1497, studying the science under Dominic Maria, and settled for a time at Rome as a teacher of mathematics, where he established a considerable reputation. His uncle, who was a dignified ecclesiastic, bishop of Ermeland, upon a vacancy occurring in the canonry of his cathedral church of Frauenburg, appointed Copernicus to the place in the chapter, who had previously taken orders probably in Italy. Hore he passed the remainder of his days, dividing his time between his ecclesiastical duties, the gratuitous practice of medicine among the poor, and astronomical researches. He went but little into company, seldom conversed except on serious and scientific topics, was mild and gentle in his manners, and steadfast in his friendships. Frauenburg is a small town on the coast, not far from the junction of the Vistula with the sea. There, in a house situated on the brow of a mountain, overlooking the waters of the Gulf of Dantzic, he pursued his enquiries into the economy of the universe in peaceful seclusion, confident that he was doing a great work for posterity to appreciate. His mind was profoundly impressed with the idea that simplicity characterises the arrangements of 
nature; and, struck with the want of this in received hypotheses, he seems to have come to the conclusion that such scenes of complexity could not be true representations of the heavens. It does not appear when his own views became settled; but in the year 1530, the manuscript of his work "On the Revolutions of the Heavenly Bodies" was finished. In this production he disclosed his system: the Earth, a planet revolving round the Sun in an orbit between Venus and Mars; its rotation upon its axis producing the apparent diurnal procession of the heavens; the eomplicated movements of the planets being the consequence of their own motions in space, combined with that of the Earth. It is difficult to appreciate fully the freedom of spirit and independence of thought displayed in thus rising superior to the prejudices of centuries, now that the truth of the system has been long settled; neither is it easy to conceive the delight and awe which must have filled the mind of its author, when, after year's of patient and intense application, he was permitted to gaze upon the mechanism of the heavens unveiled, in its simplieity and grandeur, from his mountain home at Frauenburg.

The prudence of the great discoverer in propounding his views is no less admirable than his sagacity in seizing hold of them. Aware of the obstinacy with which human nature clings to its early imbibed opinions, he was eareful not to rouse hostility by an abrupt dogmatic attack upon the ancient theory. He communicated privately with his friends; Reinhold and Rhetieus, astronomers; Schomberg, a cardinal ; and Gyse, a bishop. With these parties his views found acceptance. They were discussed in their respective eircles, and obtained a number of converts; not, however, without opposition, for Copernicus was satirised upon the stage at Elburg. His work, completed in 1530, was still in manuscript in 1540, notwithstanding repeated efforts to induce him to publish it. An arrangement at length was made, during the latter year, for Rheticus to furnish an aceount of the manuscript volume; and, that being favourably received, Copernicus eonsented to the appearance of his own production. It was committed into the hands of Rheticus; Andrew Osiander of Nurcmberg superintended the printing, and Cardinal Schomberg bore the expense. But the illustrious anthor did not live to read his work in print. A eopy was handed to him as he lay, a paralytic, upon his bed. He saw it, he touched it, and in a few hours afterwards expired, May 23. 1543. The eathedral of Frauenburg received his aslies without pomp or epitaph, exeept that upon his tombstone some spheres were cut in relief. The great square of Warsaw has a statue in honour of his memory; and the eivilised world holds his name in reverence, as one whose genius dissipated the illusions of the senses, and discovered the true astronomy. Copernicus is described as a man of ruddy complexion and light hair. $\Lambda$ portrait, painted by himself, a half-length, came into the hands of Tycho Brahé, who made it the subject of an epigram to the effect that the whole earth would not contain the whole of the man who whirled the carth itself in ether.

The scheme of Copernicus was presented to the world in the form of hypothesis. It could not be broached in any other manner, for not until the discovery of the aberration of the stars by Bradley, and the determination of the diminution of gravity at the equator by Richter, was demonstration given to the doetrine of the carth's rotation and translation in space. "Astronomers," he remarks, in the dedication of his work to Paul III., "being permitted to imagine eircles to explain the motions of the stars, I thought myself equally entitled to examine if the supposition of the motion of the carth would render the theory of these appearanees more exact and simple." But, though the resolving the apparent diurnal revolution of the sphere into the actual diurnal motion of the globe in an opposite direction was a pure hypothesis, yet we have so many examples of a real movement on our part producing an apparent antagonistic motion in other bodies, as when we sail along a river or travel on a railway, while there is something so manifestly absurd in supposing the daily revolution of the firmament, that, even if no demonstration 
conld now be offered in proof of the Copernican doctrine, there is an air of truth about it sufficient to command the assent of a thoughtful mind. Proceeding upon the assumption, which was universally admitted, that the earth is a mere point when compared with the distance of the fixed stars, he very naturally remarked upon the improbability of such a vast circumference revolving in twenty-four hours, instead of the infinitesimal point by which the whole phenomena would be equally as well explained. It had been urged in support of the earth's immobility, that, if it revolved on its axis, objects on its surface would be seattered and dispersed in space by the extreme rapidity of the motion overcoming the force of gravity. He did not see the true reply to this, that such effects would not take place unless the velocity of rotation was greater than the force of gravity, which was an arbitrary assumption, but still he reasonably turned the argument against the objector by observing that the diurnal revolution of the sphere of the universe would be far more likely to derange the situations of the heavenly bodies, and produce their displacement. "Why, then," he exclaims, "do we hesitate to give to the earth the mobility suitable to its form, rather than that the universe, whose bounds we do not and cannot know, should revolve? Why should we not confess that the diurnal revolution is apparent only in the hearens, and real in the earth? Thus Eneas, in Virgil, exclaims,

'Provehimur portu, terræque, urbesque recedunt.'

Since, while the ship glides tranquilly along, all external objects appear to the sailors to move in proportion as their vessel moves, and they alone, and what is with them, seem to be at rest."

'The other conditions of the problem of the celestial motions, the sun's path in the ecliptic, are as exactly answered by the supposition of the earth's orbital motion. The annual revolution of the earth round the sun causes the apparent annual revolution of the sun round the earth; and when we consider the vast magnitude of the solar orb, and the enormous waste of force implied in moving the greater body around the less, when precisely the same effeets are produceable by moving the less about the greater, our common sense is at once enlisted in favour of the latter hypothesis as Nature's "wise and frugal" plan. 'The apparent eceentricities of the planets likewise, their direct and retrograde movements, that mysterious puzzle which called the epicycles of the Ptolemaists into existence, are explained upon their own principle of two combined motions : an observer on the earth in ceaseless translation sees them performing a similar orbital course, and apparent irregularity and involution are the consequences of the combined prosecution of direct and regular paths. Suppose s the sun, A B C D part of the earth's

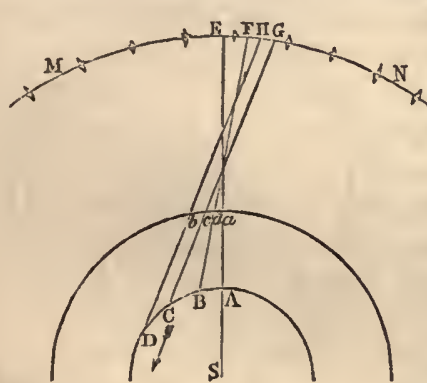
orbit in the direction of the arrow, $a d c b$ part of the orbit of a superior planet, and $\mathrm{s} \mathrm{N}$ an are of the celestial sphere. $\mathcal{W}$ When the earth is at $\Lambda$, and the planet at $a$, a terrestrial spectator will see it projected to a place in the heavens at E. The angular motion of a superior planet being less rapid than that of an inferior, when the earth is at $\mathrm{B}$ the planet may be supposed to be at $d$, and its place will be projected in the heavens at $\mathrm{F}$, thus apparently retrograding in the sphere from $\mathbf{E}$ to $F$, while accomplishing the direct movement from $a$ to $d$. The next movement of the earth, $\mathrm{B} \mathrm{C}$, and of the planet, $d c$, will produce a further retrogradation of the latter in the heavens from $F$ to $G$; but, when the earth has arrived at $\mathrm{D}$, and the planet at $b$, the retrocession of the planet will appear to have ceased, and the direct movement, G II, to have taken place. As both the earth and the planet proceed in their orbits, the planet will appear stationary among the fixed stars, then to 
pursue a direct course, and afterwards to retrograde again. As an hypothesis, therefore, the Copernican theory had strong presumptive evidence in its favour, accounting for the celestial movements, and being in beautiful congruity with Nature's frugal and simple plan of general operation. Still presumptive evidence is not positive proof, nor could the truth of the theory at that time be demonstrated. It detracts not from the glory of its author, that to others the merit belongs of establishing his leading views as a real expression of the phenomena of the universe. He had not the instruments by which alone this could be done. He seems to have entertained a noble confidence that he had conceived the true system, and that future discoveries would remove the mechanical difficulties then in its way, and a more enlarged observation of physical facts place it upon the basis of incontrovertible evidence, - a confidence which has been amply justified.

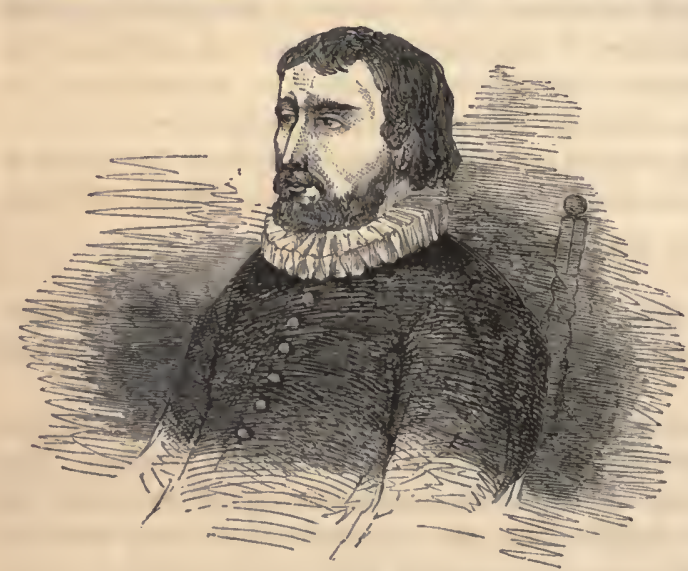

The sixteenth century, rendered memorable at its commencement by the foundation being laid of true views respecting the constitution of the universe, was distinguished at its close by the labours of Trcho Blinné, a Dane, born at Knudsthorp, near the Baltic, three years after Copernicus terminated his carcer. "His attention was called to astronomy by a great eclipse of the sun, August 21. 1560, when quite a child. Upon being sent to the university for his education, he was accustomed to watch the constellations while his tutor slept. Of noble extraction, and strongly influenced himself by prevailing aristocratic prejudices, he at length conquered the pride of his order, devoted himself to public usefulness in the particular department to which his natural genius was inclined, became a student, an author, an astronomical lecturer, and finally completed his offences against the pride of life by marrying a plebeian. This last step, probably, rendered exile desirable, in order to escape from the slights of his relatives. He found a welcome reception at the court of the Landgrave William of Hesse-Cassel, a prince who was himself an ardent student of astronomy, of whom it is related that, while observing the brilliant new star of 1572 , his servants ran to tell him that the house was on fire: but he quietly pursued his task to its completion. The fame of 'Tycho has been obscured by his rejection of the Copernican doctrine, and the construction of a system of his own, combining the elements of the Ptolemaic and Copernican theories. He maintained the earth to be the immoveable centre of the universe, but supposed the planets to revolve round the sun, and to be carried with their centre in revolution round the earth.

The adoption of this hypothesis has been usually deemed discreditable to Tycho; but it will be only fair to recollect

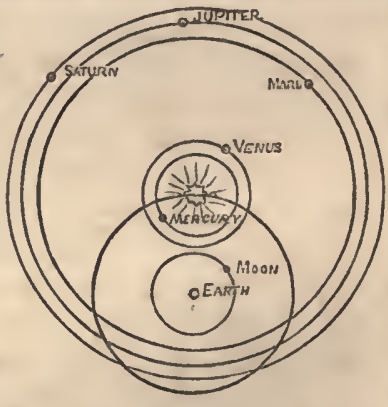
that the Copernican theory was, in his day, quite incapable of proof. He argued, against the diurnal motion of the earth, that, upon that assumption, a stone dropped from the summit of a high tower would not fall at the base, as we see it does, because the velocity of rotation would carry the tower several hundred feet during the descent of the stone, 
which would, therefore, fall at that distance behind it. This argument was employed by Ptolemy, who stated that, if the earth revolved with great rapidity from west to east, it would leave behind it the clouds, birds flying in the air, and, generally, all objects suspended in the atmosphere. The answer to this is, that a falling body will partake of a rectilinear and circular motion; the former tending to the centre of gravity, the latter proceeding in the direction of the circumference described by the point from which it falls. Gassendi tried experiments in the harbour of Marseilles, and proved, what every one now knows, that a stone dropped from the mast of a vessel in full sail will partake of the advance of the mast, and fall at its foot, as though the vessel were at rest. It may also be proved, that a stone falling from a considerable elevation, so far from being left behind during its descent, will fall in advance of the base of the perpendicular, upon the theory of the earth's rotation. Let the circle $\mathrm{E}$ be the equatorial circumference of the earth, the line $\mathrm{T}$ a tower perpendicular to $\mathrm{C}$ the centre, and the circle $\mathrm{x}$ will then be the circumference described by the summit of the tower $\mathrm{s}$, in the course of one rotation of the earth upon its axis. If we suppose the base of the tower, $b$, to pass to $c$, the summit, $s$, will, in the same time, pass to $a$, and, this being the larger arc, it follows that the summit must travel faster than the base. Assuming, then, the earth's rotation eastward, a stone dropped from the summit will leave it with its momentum, and will move faster eastward, through the whole of its deseent, than the base. The result will be, that it will deviate from the plumb-line, and reach the ground a little to the east of $c$,

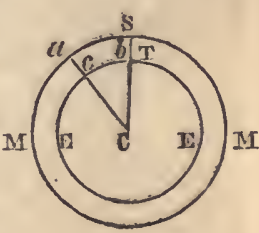
the foot of the perpendicular. Experiment has confirmed the accuracy of this reasoning, though obviously a very difficult matter to test, owing to the comparatively small height of buildings suitable to the purpose. Newton first threw out the idea, and calculated that a ball would deviate about half an inch from the plumb-line, to the east, from the height of three hundred feet. Thirty balls descended from the height of two hundred and thirty-five feet, in St. Michael's tower, Hamburg, and deviated from the perpendicular four lines eastward, swerving also one line and a half southward, owing probably to a current of air in the tower. The experiment was, therefore, repeated in a coal-pit, in the county of Mark, two hundred and sixty feet deep. There the balls fell five lines eastward of the perpendicular, but neither northward nor southward, so that the theory of the earth's motion on its axis may now be said to have received a complete and sensible confirmation.

The reason which led Tycho to reject the doctrine of the carth's orbital motion was of great force in his time. Supposing the earth to revolve round the sun, two points of the orbit will be distant from each other by the whole diameter of the orbit; yet lines drawn from those points to the nearest fixed star discovered no appreciable angle, or annual parallax. It is sufficient to reply now, that the distance of the stars is so great as to render insensible the diameter of the earth's orbit; but, previously to the invention of the telescope, this answer could not be deemed so satisfactory. To the naked eye the stars of the first magnitude present a diameter equal to two minutes of space. The telescope has shown this to be an optical delusion, that no star has an apparent diamcter of a second. But Tycho, knowing that if the earth moved, its change of place from one extremity of the diameter of its orbit to another produced no sensible alteration in the place of the stars, so that they must be at an enormous distance, and yet seeing them present a diameter to the eye varying from a quarter to as much as two minutes, had little option but to assign a magnitude utterly inconceivable to the nearest fixed star, or reject the theory of the earth's motion in space. He chose the latter alternative; and, though undoubtedly it would have been a wiser course to have paused before coming to such a conclusion, 
which the Coperuican system as then developed might well have justified when viewed as a whole, we are not warranted in interpreting his rejection of it much to his disparagement.

The carcer of Tyeho is far more satisfactory as a practieal astronomer than as a

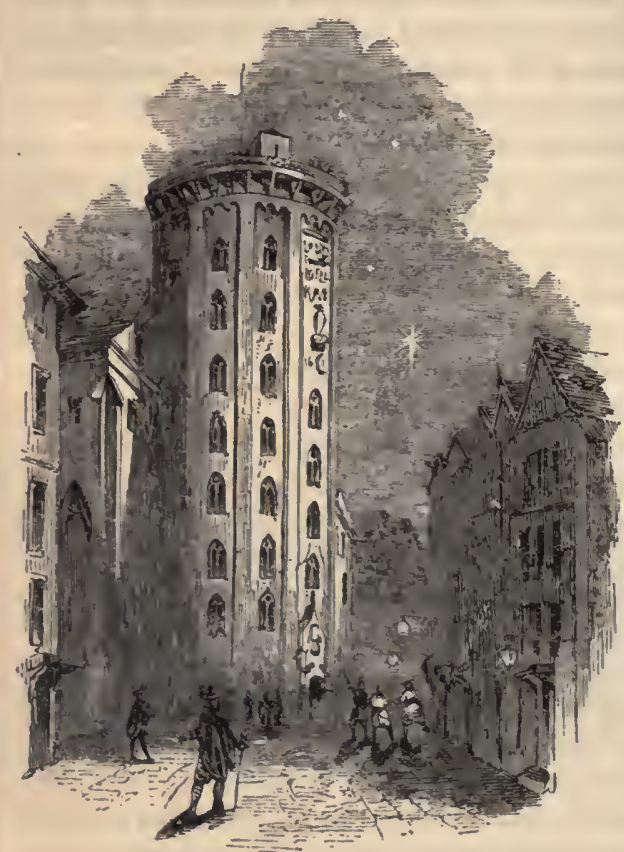
theorist; indeed, few men have done so much for the advance of the scienee, or are more worthy of praise for the amount of toil they hare undergone, and the success of their labours. In the year 1572 , the remarkable event of a stellar apparition attracted the attention of Europe, and excited universal astonishment and speculation. It was early in November, when Tyeho, who then resided at his paternal home, observed a star of great splendour in the constellation Cassiopeia, which he had never seen before, as he was walking across the fields about ten o'clock in the evening. It beamed with a lustre quite unwonted in that part of the heavens. It eould not have eseaped his observation had it previously been there. He suspected at first an optical illusion oceasioned by some defect of his own vision, but found a group of peasants gazing upon it with as much astonishment as himself. Its place he at once fixed by his instruments, and noted the fact with all its circumstances in his journal. Soon afterwards, when at Copenhagen, he found that the seientific men of the university lad not observed the stranger, and exeited some derision at a eonvivial party by mentioning the phenomenon, which, however, he soon turned into surprise by pointing out the star. One of his works is devoted to this object. The same star was observed by Cornelius Gemma, who had particularly examined that part of the heavens two nights previous, and was eonfident of its not being present then. It continued risible for the space of sixteen months, gradually diminishing in lustre, until it finally vanished in Mareh 1574. The brilliance of this star was so great as at first to cause Tyeho's staff to deflect a shadow. Its light changed from white when the brightest to a yellowish hue, and afterwards had a fiery tinge like Mars, becoming livid like Saturn before its disappearance. During the whole time of its visibility, its plaee in the heavens remained unaltered; it had no annual parallax, eonsequently its locality was far beyond the bounds of our system, at a remote distance in the region of the fixed stars. The appearanee of a new star had been observed in Europe about three centuries previous, and such oceurrenees are mentioned by the ancients; but this taking place in a eomparatively enlightened age naturally exeited serious observation and inquiry. The idea of the Danish astronomer, never happy in his philosophieal speculations, was not very fortunate. He supposed that it was produced by a condensation of the matter collected in the Via Lactea, in which it was situated.

The appearance of a eomet in 1577 was industriously watehed by Tyeho, and he was led to some important conclusions. Unable to detect any sensible parallax, it beeame obvious that these bodies move at a remote distanee from the earth, and were not, aceording to the common opinion of the times, sublunary objects; and observing the spheres of 
the planets cut by them in every direction, the inference was clear that the planctary spheres had no material existence. It may seem idle now to notice so absurd a notion as that of the planets moving in solid transparent spheres, but it was not so then; and even Newton deemed it necessary to argue against the monstrous doctrine in the Principia. The labours of 'Tycho were also directed towards forming a catalogue of the stars, and he determined the relative and absolute positions of 777 , a work inferior as to numbers to preceding catalogues, but rastly superior on account of its scrupulous exactness. He amassed, likewise, a regular series of observations on the planets, which afterwards, in the hands of Keppler, materially contributed to the framing of his fumous laws. To him, also, we owe the discovery of that inequality of the moon called the variation, that of the inequalities of the motion of the nodes, and of the inclination of the lunar orbit; and by a comparison of his own observations with previous ones, he was the first to announce the slow diminution of the obliquity of the ecliptic, which the theory of universal gravitation now teaches, while he commenced the systematic application to the observed altitudes of the sun, moon, and stars, of the correction required for the refraction of light. In practical astronomy the refraction of the atmosphere is an important element, for, owing to it, all the heavenly bodies appear to us considerably higher than they really are. Let $a b, a b, a b, a b$, be strata, or layers of the atmosphere, increasing in density towards $m n$, the surface of the earth. A ray of light from the star $\mathrm{s}$, impinging

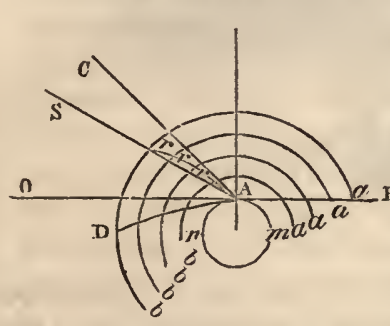
on the atmosphere, will be refracted, or bent, so as to move in the curve $r \boldsymbol{r} \boldsymbol{A}$; and as an object is seen in the direction of the ray that meets the eye, the star which is actually at $\mathrm{s}$, will seem, to a spectator at $\mathrm{A}$, to be in the direction $\mathrm{c}$. This refraction, which always acts in a vertical direction, "elevates objects above their real place, and hence a body at $\mathrm{D}$, below the horizon $\mathrm{I} 0$, will be raised and seen as if at 0 . Ptolemy, as has been already noticed, was acquainted with the refraction of the atmosphere, and mentions it in a treatise on optics, but as it is not alluded to in his astronomical work, it is presumed that he had not then discorered it, and made no practical use of it in observation. The Arab astronomers, likewise, were aware of the fact through him, but to Tycho Brahe the honour belongs of calculating its effects, correcting altitudes by them in a systematic manner, and forming the first table of refractions. He estimated its amount at $34^{\prime}$ with reference to bodies in the horizon, which is nearly correct, but crroneously supposed that it did not exist at elevations greater than forty-five degrees. This was owing to the effects of refraction above that altitude being insensible to his instruments.

The urgent recommendation of Tycho to his own sovereign by the Landgrave William, induced the Kring of Denmark to offer him an asylum in his own country, and an annual provision for the prosecution of his scientific pursuits. Embracing the offer, he received a grant of the small island of Hoëne in the Baltic, opposite Landscrona, and an annual allowance of two thousand dollars, with the proceeds of a fief in Norway, and a canonry in the church. Here he laid the foundation of a house for himself and an observatory, which ultimately grew into a fantastic castle, resembling rather the abode of an eastern magician than the home of a sober astronomer. Uraniberg, or the castle of the heavens, expressed the large views, feudal spirit, and undisciplined mind of its architect and tenant. He was an admirable observer, had high thoughts of the dignity of his possession, never forgot his own nobility, was abundantly superstitious likewise, and unskilful at systematising. 'These are characteristics plainly stamped upon the edifice which he constructed. Its front elevation, shown in the vignette, extended sixty feet in length, and seventy-fice in height. It was surrounded by a wall twenty-two fect high, in the form of a square, each 
side of which was three hundred feet, and had in the middle stately gateways, with residences for servants. The instruments of the observatory were upon a corresponding

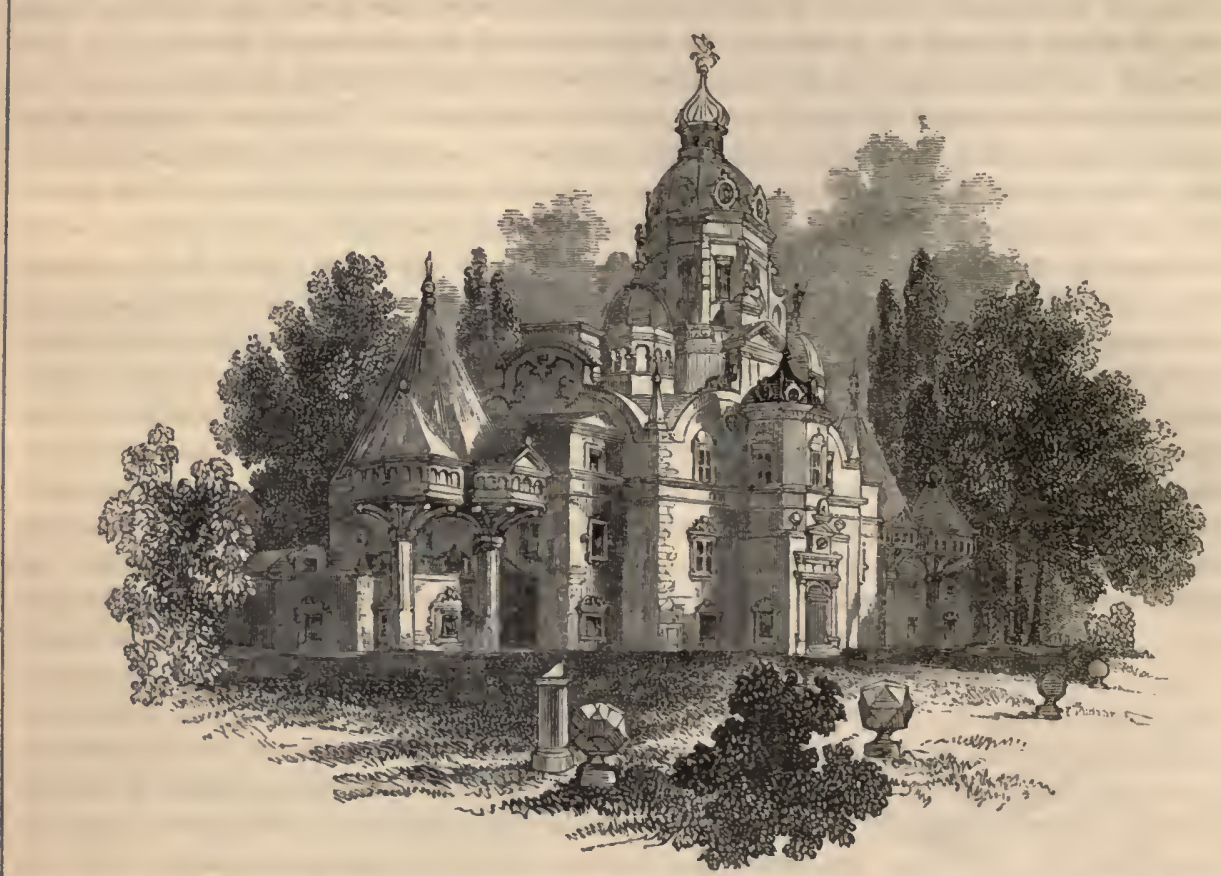

scale. $\Lambda$ celestial globe, upon which Tycho fixed the positions of the stars he catalogued, stood upon a pedestal five feet high, the diameter of the ball being no less than six. His whole apparatus is supposed to have cost upwards of two hundred thousand crowns. IIere, in his castle, in the severe climate of the Baltic, for twenty-one years, he resided, observed and wassailed, a favourite poodle being the constant companion of his studies. Abroad, his fame extended far and wide. Kings visited his sanctuary. Our James I. spent eight days beneath his roof upon going to Denmark to attend his bride. Misfortune, however, came soon after the death of his royal patron, and outward glory departed from Tycho. The envy of the nobles fomented dislike to the celebrated astronomer in the mind of the successor to the throne, and a personal squabble with the minister, who struck his poodle, led to his being deprived of his appointments, and removal from the island. He finally quitted his country, but Uraniberg had obtained a firm hold upon his affections, and separation from it took away the charm from life. After various wanderings, he settled at Prague under the patronage of the emperor Rudolph. There he died in the first year of the seventeenth century, leaving a name second to none in point of pure observation. Hoëne was ceded to the Swedes fifty-seven years after Tycho's deaththe castle of the hearens was totally demolished-its site became a green field, and even that has been blotted from remembrance.

However bitter and disastrous to himself the exile of Tycho from his northern home, it was fortunate for science that it took place, as it threw into his way the enthusiastic and indefatigable Keppler, the very man in his maturity to seize hold of his materials, and draw a philosophical deduction from them. The Danish astronomer, who had previously seen one of his works, invited him to become his assistant at Prague. He appreciated his genius, hospitably supplied the wants of his porerty, taught him the habit of rigid inves- 
tigation, and left him the legacy of his own observations at his decease. JoHn KEPPLER, born at Wiel, in the duchy of Wirtemberg, in 1571, was educated for the ehureh, and entered upon an ecelesiastical office, but withdrew from the science of theology to that of mathematies and astronomy, and oceupied the chair of the latter at Gratz in 1594. His native lively imagination and fiery impetuosity led him to plunge headlong, at first, into the regions of speculation; but 'Tycho's advice, "to lay a solid foundation for his views by actual observation, and then, by ascending from these, to strive to reach the eauses of things," - advice expressing the principle of inductive philosophy, - drew him away from pursuing the vain phantoms of fancy to conform his mind to the results of calculation and experience. His first reward was the discovery of the elliptical orbits of the planets. The Copernican system had respected the ancient reverence for the circle as the only path proper for celestial bodies to describe. An opposition of Mars, whose path is one of the most eccentric in the planetary system, led Keppler to study his motions, and among the papers of 'Tyclo, then deceased, he found a large number of observations upon this and the other planets. He began his researches with his mind fully possessed with the idea of circular motion, but he found it utterly impossible, by any conceivable arrangement of eycle and epicycle, to represent the known motions of Mars. The discovery came at length that the planct's path was an ellipse, the sun occupying one of the foci, the two points around which the oval is former, instead of being in the centre. Cireumstances forbid us estimating aright the labour involved in this discovery, the diffieulties that arose in its progress, and the mental confliet they occasioned; but Keppler describes his battles, defeats, and conquests in the following racy manner:- "While in this way I triumph over the motions of Mars, and form for him, as one completely conquered, the prison of tables, and the chains of the equations of the eccentric, intelligence is brought me from different places that the vietory is all vain, and the war as fierce as ever; for the captive enemy has broken through all the bonds of the equations, and the dungeons of the tables... And the fugitive would have effected his junction with the rebels, and driven me to despair, had I not suddenly brought up a new reserve of physical considerations, the first having been beaten and scattered." Well might he think, as he tells us, of Galatea in the eclogue of Virgil, who, after inviting approach, the nearer she was approached was the more petulant in lier sportive attempts to escape. The demonstration, howerer, of the orbit of Mars being an ellipse was finally complete, and Keppler ultimately established the fact, that all the planets describe ellipses-the FIRST of his great Laws.

His next discovery was no less remarkable. While the scheme of Copernicus retained the ancient idea of the heavenly bodies deseribing cireles, it held also the notion of their velocities being uniform. But the mass of facts accumulated by Tycho proved that the motions of Mars were not uniform - that the planets move with different velocities in different parts of their orbits ; and the inquiring mind of Keppler directed itself to ascertain the rule which regulated their rate of motion - a bold attempt, but crowned with complete success. Let the ellipse represent the orbit of a planet, and s the sun in one of the foci. A straight line drawn from the planet at $a$ to the focus, called the radius vector, and another line drawn from the planet at $b$, bound a certain extent of area, and the

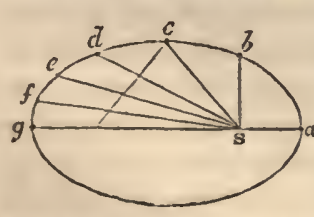
planet periodically passes from $a$ to $b$ in a certain amount of time proportioned to the area. For the sake of illustration, the time may be rated at a month. If we now draw straight lines from the planet at $c, d, e, f$, and $g$, other areas will be bounded, which we may suppose equal to the former, and to each other. The planet will then pass from $a$ to $b$, from $b$ to $c$, from $c$ to $d$, and so on, in equal times or in a month. But, obviously, while the areas described by the radius vector are equal, the actual orbital path of the planet is unequal, and it must 
travel with greater velocity from $a$ to $b$, than through the other parts of its course. This is the SECOND of Kieppler's laws, technieally expressed by saying that equal areas are deseribed in equal times, to accomplish which the velocity of the planet caunot be uniform. Previous observation diseovered the want of uniformity; but Keppler found the rule which governed the phenomena, and thus did his master mind bring into conformity to law a ease of apparent deviation from it. The THIRD of his laws refers to the distances of the planets from the sun. Ilis mathematical mind caught the idea that these bodies must bear some mysterious relation to each other, and after a long and harassing pilgrimage in search of a clue to their affinity - after roaming in the wilds of conjecture, and setting the planets to music in imitation of a Pythagorean phantasy - he groped his way to the perception of a plyysical fact, which unfolded before him the unity of the solar system. This was the discovery, that the squares of the periodic times of any two plancts are to one another as the cubes of their distances from the sun. His joy was unbounded at this discovery, as it transpired in an unexpected manner. He could hardly persuade himself that he had not been dreaming; and it may be ranked anong the most important and glorious pliysical truths ever reached by the intelligence of mankind. Popularly expressed, the fact arrived at is, that the distances of two planets from the sun being known, and the period or year of one of them, the period of the other may be ascertained by the above simple proportion; and clearly does this fact involve the idea of the bodies to which it applies not being thrown at random into their places-not being independent - but members of one great system. As an example, Mars is about four times the distance of Mercury from the sun; lis period of revolution is about eight times that of the latter; and the cube of four, or sixty four, is equal to the square of eight. Such are the laws of Kieppler. They obviously confirm while they correct Copernicus; and their author became a zcalous Copernican. They served afterwards as a foundation already prepared for the splendid superstructure of the Newtonian philosoplyy. 'They were framed out of materials gathered by 'Tyeho. Moëne, in the Baltic, has thus played a conspicuous part in the world's history, looking to the causes of things. The eastle of the heavens was not built in vain!

The phenomenon of a new star was again presented to the gaze of mankind in the ycar 1604, thirty-two years after the former appearance. It suddenly shone forth from the constellation of Serpentarius, continued visible upwards of a year, and gradually waned in its lustre before its final disappearance. When at the brightest it surpassed the fixed stars of the first magnitude and rivalled Venus, changed in colour from a yellow to a purple and fiery hue, and presented no sensible parallax. Keppler was one of its observers, and adopted the hypothesis that it proceeded from some vast combustion. But what these stellar apparitions portend is one of the mysteries of the universe. We may conjecture - we may theorise - but we cannot know. If they are bodies beyond telescopic range, that start into temporary visibility under the action of fervent heat, their diminishing lustre and ultimate disappearance being the decline and termination of mighty conflagrations, "it is impossible," says Mrs. Somerville, "to imagine anything more tremendous than a conflagration that could be visible at such a distance." In 1607 the comet, afterwards known as Halley's, engaged the attention of Keppler, and again in 1618 lie had the opportunity of observing a similar object. It is somewhat remarkable that he did not grasp the analogy between the orbits of these bodies and those of the planets. He attempted to determine the path of Halley's on the supposition of its motion being rectilinear, conceiving comets to be eranescent bodies, appearing and vanishing for ever. But he fulfilled a ministry in the great temple of nature sufficiently glorious as it is, and required not the anticipation of the triumplis of others to give him a hold upon the admiration of posterity. It is melancholy to reflect, that he lived in misery, owing 
to the difficulty of obtaining his pension as mathematician to the emperor, through the rapacity of the subordinate officers of government, while the professional astrologers of the court, who flattered the vanity of the great, were magnificently recompensed. Sir Henry Wotton, the English ambassador, finding him in difficulties, invited him to this country; but Keppler was too strongly attached to his native land to accept the proposal. He thus refers to it in one of his letters:- "The fires of civil war are raging in Germany - they who are opposed to the honour of the empire are getting the upper hand. Shall I then cross the sea, whither Wotton invites me? I, a German - a lover of firm land - who dread the confinement of an island - who presage its dangers, and must drag along with me my little wife and flock of children?" At last the fatigue and vexation of a fruitless journey to procure payment of his arrears terminated his life at Ratisbon, in the year 1630. The spot where he was buried-in the churchyard of St. Peter's - cannot now be identified; but a marble monument, consisting of his bust and the ellipse of Mars, the work of prince Charles of Alberg, has since been erected to lis memory.

The age of Keppler was the era of GaliLEo, born at Pisa in 1564, whose discoveries made a profounder impression upon the public mind, and effected more for the system of Copernicus, than those of his great compeer, because more open to popular compreliension, though not the fruits of so high an order of intellect. The early part of the seventeenth century was distinguished by the construction of an instrument which rendered objects accessible to human vision in the remoter depths of space, and which speedily added important accessions to the knowledge previously acquired of the visible hearens. A journey to Venice on the part of Galileo in the year 1609, the same year in which Keppler published his commentary on Mars - the accidental mention of a fact in a conversation there-led to the construction of the telescope, to the accurate survey of the heavens by it, and to the confirmation of those views of the universe which the retired ecclesiastic of Frauenberg liad the sagacity to conceive and the boldness to alopt. Having heard that a Dutchman had contrived an instrument that magnified distant objects, the circumstance took possession of the mind of Galileo, and its important application in astronomy was immediately perceived. He directed his inventive powers to the construction of such an instrument for himself, and ultimately succeeded in perfecting a telescope which, in lis own words, could "show things almost a thousand times larger, and above thirty times nearer, to the naked eye." On examining the moon, he at once discovered its analogy with the earth, and detected the fallacy of the Aristotelian physics, which regarded all the celestial bodies as perfectly round, self-luminous, and without any terrestrial tarnish. The lunar surface exhibited plains and mountain ranges, highlands and glens, with the diversity of dark shadows and vivid illumination, which the face of our own globe displays as scen from some towering peak, or from the car of the aëronaut. But a richer harvest awaited him on turning his attention to the planets. Gazing at Jupiter on the night of January 7. 1610 - a memorable night-he saw three small bright stars eastward of the planet, and close to its disk. Subsequent observations revealed a fourth, and ultimately disclosed the faet that Jupiter was before him with a retinue of four satellites, which he named the IIedicean stars, from his patrons the Medici. 'Tlis was a death-blow to that dream of pride which the followers of Aristotle had been indulging for ages; and one of the chicf objections advaneed by them to the Copernican doctrine was now demolished. 'The earth, as their vain philosophy had taught, could no longer be regarded as the most dignified body in the universe, having an attendant moon, and, on that ground, entitled to be the centre ; and, equally, she must resign her right to be at rest, for here was a more dignified body in motion. This revelation of the telescope was as gall and wormwood to the disciples of the ancient creed. They denied, for a time, the existence of the Medicean 
stars, but would not take the instrument in hand to look for themselves. "Olh, my beloved Keppler," wrote Galileo, "how I wish that we could have one long laugh together!"

In anagrams, the letters of which, when transposed, make the following sentences, he conveyed the result of the telescopic observation of Saturn and Venus :-

Altissimum Planetam tergeminum observari.

The most distant planet I have observed to be threefold.

Cynthiæ figuras æmulatur mater amorum.

Venus rivals the moon's phases.

The practice was not then obsolete of publishing discoveries in philosophy in an anagram, which could only be deciphered by the author, or by the party to whom he had conveyed the key. This was a relic, now happily extinct, of that pride of science prevalent in remote antiquity which disdained the communication of knowledge to the mass. The peculiar structure of Saturn, the subject of the first anagram, was only imperfectly discernible by the telescope of Galileo. The discovery of the phases of Venus, the subject of the second, was an important observation. It liad been argued that, if the planet revolved round the sun, she ought to exhibit phases like the moon, whereas she always appears to the naked eye in full-orbed brightness. The argument was just and formidable; and Copernicus could only reply to it, as tradition reports, that some time or other this resemblance to the moon would be found out. The prediction was verified seventy years after his death; and, by the telescope discovering Venus exhibiting the various phases of the waxing and the waning moon, the apparent objection to his system was converted into a confirmation of it by it being established beyond a doubt that the planet revolved round the sun. Another fact which the application of the telescope brought to light, illustrating the truth of the Copernican system, was the solar spots, their incessant motion, and the consequent rotation of the great luminary. 'The metaphysics of the schoolmen had taught the quiescence of the earth on account of its ponderous mass, but the position was destroyed at once by the sun, a far mightier body, being discovered to have a revolution upon his axis. Galileo was equally as successful in overthrowing the mechanical objections advanced against the doctrine of the earth's rotation, which supposed that the ground would pass away from beneath stones in the air and birds upon the wing. He showed that the atmosphere of the globe, and all bodies in it, will participate in the common motion of rotation, and illustrated his argument by referring to the clear case of a stone falling from the mast of a vessel participating in the motion of the ship.

Galileo undoubtedly contributed more than any man of his age to weaken the hold which the natural philosophy of Aristotle had long had of the human mind, and establish a conviction in favour of the physical constitution of the universe as now demonstrated, though in early life he regarded the Copernican theory as a "solemn folly." But just in proportion to his success he became an object of malevolence to those whose pride would not submit to abandon opinions once embraced, however false, or whose ignorance could not appreciate the evidence of their falsity. The career of the Tuscan artist, as Milton calls him, turning to the moon his optic glass,

\footnotetext{
At evening from the top of Fesolé,

Or in Valdarno, to descry new lands,

Rivers, or mountains, in her spotty globe,
}

was a splendid one, but its close was overcast with clouds and shadows. The authorities of the papal clurch were roused to treat his scientific demonstrations as heretical - to visit the illustrious observer with an ecclesiastical process on account of his opinions and he had the mental and moral weakness to abjure what he knew to be true. Who 
san think of his mock recantation of the doctrines of the earth's axical and orbital motion without feelings of deep shame and regret? - an old man, at the age of seventy, on his knees, with his right hand resting on the Gospcls, renouncing opinions of the truth of which he had not the slightest doubt, and ecclesiastical authority exacting the sacrifice with the temporal sword. But in judging of the actions of men we should always take into account the circumstances of temptation in which they have been placed, the general current of opinion in their day, and a due sense of human infirmity. Such was the state of public feeling in Italy, that it is more than probable that Galileo regarded the scrvice imposed upon him as a church ceremony, through which, as a son of the church, he was bound to go, without being responsible for its demerits. The sorrows that accompanied his descent to the grave, the indomitable energy which he displayed under them, together with his achievements, may be accepted as a reason for moderating censure upon his one failure in the time of trial. He lost his favourite daughter, Maria, in his old age - the charm and comfort of his life. The sight he had so well employed failed him, and he becanie totally blind. In sickness, his petition to repair to Florence for medical assistance was denied. He afterwards lost his hearing; but his intellectual powers remained strong and active until his death in 1642, wanting a year to the birth of Newton, and to the lapse of a century from the death of Copernicus. Galileo was lax in his morals, like the rest of his countrymen, fond of society, of cheerful spirit, and highly popular manners. He was strongly attached to a country life, attended to agriculture, and spent much of his leisure among his vines. But for years he was a martyr to acute bodily pain. His house is still standing at Arcetri, about a mile from Florence, near St. Matthew's convent. His last surviving pupil, Viviani, became a fellow of our Royal Society, and lived to enter the eighteenth century.

The remains of Galileo were interred in unconsecrated ground in the front of the noble church of Santa Croce in Florence. They have since been removed into the interior of the building, and laid in the centre aisle. His monument stands opposite the tombs of Dante, Alfieri, and Michael $\Lambda$ ngelo, and consists of a bust, said to be a portrait. $\Lambda$ finger stolen from the coffin when the body was removed is now in the Laurentian Libiary, enclosed in a glass case, and placed in considerable state upon a pedestal. Galileo is thus apostrophised by the late American Minister in this country (Mr. Lverett), in some lines written after visiting Santa Croce:-

"And thou, illustrious sage! thine eyc is clos'd, To which their secret patls new stars expos'd. Haply thy spirit in some higher sphere

Soars with the motions which it measur'd here.

Dost thou, whose keen perception pierc'd the cause

Which gives the pendulum its mystic laws,

Now traee each orb with telescopic eyes,

And solve the eternal clock-work of the skies?

While thy worn frame enjoys its long repose,

And Santa Croce heals Arcetri's woes."

There is no reason to doubt the perfect sincerity of the theologians of the church of Rome in their proceedings against Galileo, and strong mitigating circumstances might be cited on their behalf. They believed his scientific conclusions to be contrary to the sense of Scripture, and hence acted under an honest conviction that they could not be true. Nor were they alone in this opinion, having the authority of all the early fathers on their side, and that of many Protestant interpreters. But as a book designed for popular use, the Bible is adapted for popular comprehension; and hence its representations are framed in wise and benign accommodation to the understanding in ordinary life. The appearance presented by physical nature to the eye of the observer is expressed, and not the 
philosophical fact - a style still in vogue, which shows its propriety, for we never speak of the globe rotating in common speech, but of the sun rising and setting; and we are guilty of no false philosophy in popularly assigning fixidity to the earth, and speaking of its repose. Yet, overlooking the plain design and popular style of Scripture-rigidly construing the latter - the theologians of the fifteenth and sixteenth centuries, in great numbers, regarded the sacred record as teaching the sun's daily apparent procession through the heavens, and the earth's stability, as physical facts, and hence denounced the Copernicans as heretics in religion, and deluded in philosophy. The controversy that ensued deserves attention, because, in a precisely similar way in our own times, the Scriptures have been arrayed against geoloxy. The termination of the former contest should lave been a monitory example to some modern exponents of holy writ, not to assume their expositions to be right and the geologists wrong, but to admit the possibility of being fallible interpreters themselves.

Before the death of Galileo the telescope had been adapted to instruments for measuring angular distances. A countryman of our own, of the name of Gascoyne, who became a soldier in the civil war, and was slain while yet a youth in the battle of Marston Moor, is the first person recorded as having applied the telescope to the quadrant. This improvement in the art of observing perished with him, and was not known again in practice until a quarter of a century afterwards, when it appeared in France as a new invention. The same ingenious and unfortunate individual was the first constructor of the micrometer, by which the diameters of celestial objects are taken ; and this likewise remained unknown, to be re-discovered at the commencement of the eighteentl century. Practical astronomy also receired one of its most beautiful and important acquisitions soon after the telescope, in the application of the pendulum to clocks, affording a more exact method of measuring time. This was followed by the invention of the transit instrument, used in determining declination and right ascension, or the distances of the stars and any celestial phenomenon from certain fixed points in the heavens - a problem analogous to that of terrestrial latitude and longitude. The former was the work of Huygens, a Hollander, the latter of Roemer, a Dane - two invaluable contributions to the furniture of the observatory. But the "optic glass" of the "Tuscan artist " is the chief glory of the seventecnth century among mechanical constructions - as the germ of those mighty tubes which, at Greenwich, Dorpat, and Washington, now search the profundities of space - utterly insignificant, indeed, when compared with them, as much so as the seedling to the tree which a thousand years has braved the breeze, yet still the germ! A cylinder of lead, a few inches long, with two spectacle-glasses at its extremities, one convex, and the other concave - the plaything of a child - was the original telescope; yet, even in the day of its feebleness, it was sufficiently strong to break down the barrier which had arrested the knowledge of all antiquity, and manifest to the gaze of man what had successfully defied his glance for ages - the lunar steppes, highlands, and ravines - Venus in plase-Jupiter surrounded with his servitors - and Saturn's strange and then inexplicable structure. 


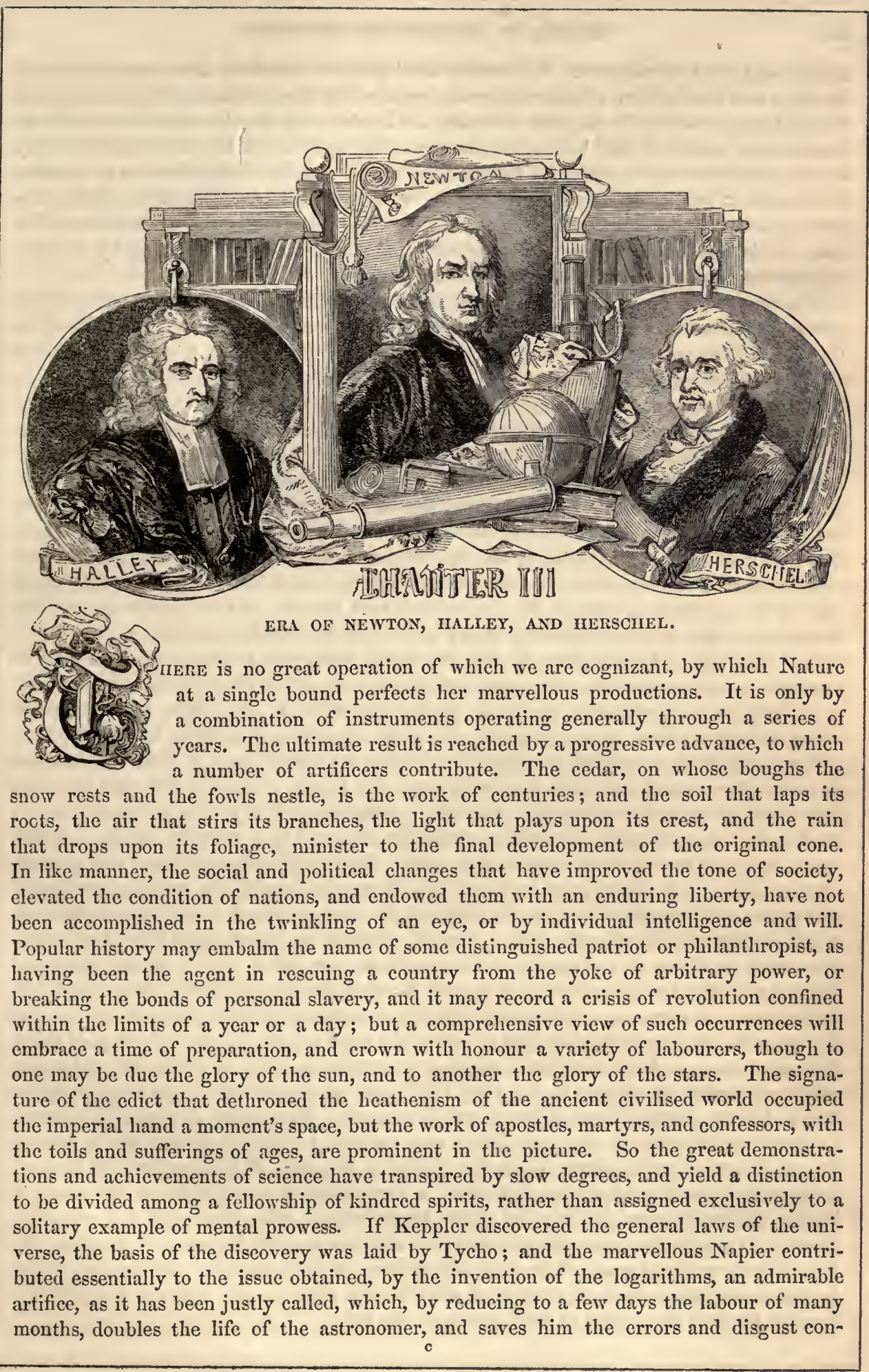


nected with long calculations. If Newton developed the cause of those laws, he started to his grand result from a point expressly prepared by Keppler, and left the solution of the problem imperfect for Laplace to finish. It is obviously in wise accordance with the happiness of mankind, that no nation possesses a monopoly of talent and fame, that many of the most remarkable efforts of human genius owe a debt of obligation to the accomplishments of genius at another era, and in a different clime. The fact proclaims the affinity of the species, between whom the mighty decp may roll, or the mountain rampart rise. It evinees too their mutual dependence, and will bo hailed as a motive by the considerate mind, to the maintenance of universal amity.

We have seen four of the European nations represented in the advance of astronomical science-Poland by Copernicus, Denmark by 'Tycho, Germany by Keppler, and Italy by Galileo. The procession had been joined by Holland, France, and England, before the middle of the seventeenth century; but it will be impracticable to record the labours, or even mention the names, of those who were then employed in the investigation of eelestial phenomena. The selection of a few of the most distinguished is imperative. To Hevelius, one of the merchant princes of Dantzic, an example of the close alliance of commerce with the fine arts and science which runs through the page of history, we owe the first aceurate delineation of the lunar surface; the discovery of a libration in longitudo; by lis observation of the comet of 1664 , he further corroborated the view previously taken, that such bodies are not sublunary, and approximated to the nature of their orbits. His contemporary Huygens, after effecting various improvements in the telescope, discovered one of the satellites of Saturn, the largest and best known, or Titan; and obtained an insight into the singular structure of the planet, an inexplicable appearance to all preceding observers. An anagram, in the year 1656, announced to the world the following sentence by a transposition of letters, annulo cingitur, tenui, plano, nusquam coharente, ad eclipticam inclinato-the planet is surrounded with a ring, thin, plane, nowhere adhering, and inclined to the ecliptic. He justly observes, in a letter to his brother: "If any one shall gravely tell me that I have spent my time idly in a vain and fruitless inquiry, after what I can never become sure of ; the answer is, that at this rate, he would put down all natural philosophy, as far as it concerns itself in searching into the nature of things. In such noble and sublime studies as these, it is a glory to arrive at probability, and the search itself rewards the pains. But besides the nobleness and pleasuro of the studies, may we not be so bold as to say, they are no small help to the advancement of wisdom and morality?" The discovery of the great nebula in Orion was accidentally made by Huygens in the year 1656. Cassini, nurtured in France, soon afterwards added four more satellites to the system of Saturn, those now called Tethys, Dione, Rhea, and Japetus, and he detected the black list, or dark elliptical line bisecting the surface of the ring, and dividing it into two. Astronomy is under immense obligations to a measure adopted by the courts of France and England at nearly the same period, for the patronage of scientific associations, and the founding of national observatorics. The Royal Society of London was incorporated by charter in the year 1662, and numbered among its early members Boyle, Hooke, Wallis, Ward, Newton, and Flamstead. The Royal Academy of Sciences at Paris was founded in the year 1666, and enrolled among its first members Auzout, Picard, Roberval, and Richer. Upon the invitation of Louis XIV. Huygens left Holland to become a royal academician, but being a Protestant, the revocation of the edict of Nantes ultimately compelled him to return to his native soil. The edict did not affect Cassini, a Catholic foreigner similarly invited; and to him, with his son and grandson, the French academy owes much of its early distinction. Besides his before-named discoveries, he determined the periods of rotation of the principal planets, and observed the elliptical form of Jupiter's disc orving to compression at the poles. 
Roëmer, the inventor of the transit instrument with which he made observations from the window of his house, rendered no unimportant service by showing that the instruments need not be fixed on high towers: he also discovered, in the year 1675, the interesting and hitherto unsuspected fact, of the progressive transmission of light through space, and the appreciable velocity with which it travels. This was attained by a series of careful observations of the eclipses of Jupiter's satellites. It was found, by comparing the times of immersion of the satellites in the planet's shadow and emersion from it, with the times

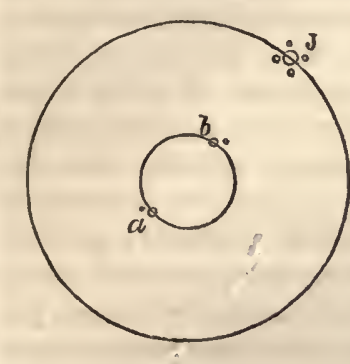
calculated from the laws of their movements, that there was an acceleration or retardation of the phenomena by a few minutes, plainly dependent upon the variations of the earth's distance from Jupiter; for the retardation was observed to be the greatest when the earth was in that part of its orbit most remote from him. The diameter of the orbit of the earth being a hundred and ninety millions of miles, we are more remote from Jupiter, by the whole of that distance, at one time than at another; as, when the earth is in its orbit at $a$, its distance is greater from $J$ than when at $b$ by the interval between the two points. But notwithstanding this immense addition of space, or any conceivable increase, an eclipse would be observed to occur no later at the one than at the other, if light were propagated instantaneously. Roëmer found, however, a difference of eleven minutes to exist, which he afterwards estimated at fourteen, but which the precision of modern astronomy has fixed at sixtcen minutes and a quarter. This determines the progressive motion of light, and the rate of its velocity. It requires time for its transmission; and flying over the diameter of the carth's orbit in sixteen and a quarter minutes gives it a velocity of twelve millions of miles a minute, or upwards of a hundred and ninety thousand miles a second. Thus, in the eighth part of a second, it accomplishes the passage of a space equal to the equatorial circumference of our globe: yet so vast is the system to which we belong, that this swift-winged messenger, which requires no more than two hours to travel from the central sun to the farthest planet, could not dart through the intervening solitudes between us and the nearest of the stars under a period of five years. Notwithstanding the velocity of the rays of light, which travel more than fifteen hundred thousand times faster than a cannon ball, experiment has not yet been able to detect that they have any impulsive power. The surmise has, however, been thrown out - and it is not improbable - that the attrition of the solar beams with the terrestrial surface may have some connexion with the phenomena of heat.

The national observatory of England-the noblest institution in the world for the extent and exactitude of its astronomical tables, and their practical value in the art of navigation - was originated by the spread of foreign commerce. The growth of our colonies across the Atlantic, together with the establishment of our relations with India, rendered it of the first importance to have an easy and accurate method of finding the longitude at sea. A plan was proposed, founded upon the principle now in use, of observing the lunar motions and distances during a voyage, and comparing them with a previous home calculation, thus ascertaining the difference between home time and time at sea, from whence the difference of longitude is readily deduced. A reward being sought by the proposer from the government of Charles II., it was referred to a commission to report upon the merits of the scheme. Flamstead, one of the commissioners, at once decided against its practical utility, on the ground of the inaccuracy both of the lunar tables and of the positions of the stars in existing catalogues, which only a lengthened course of observation could rectify. The king, declaring that his pilots and sailors 
should not want such assistance, immediately instituted the office of astronomer royal, and determined upon founding an observatory. The site - selected by Wren - was a commanding eminence in Greenwich Park, in former times the seat of Duke Humplurey's tower, within view of all vessels passing along the 'Thames; a spot which Piazzi was accustomed to call the "paradise" for an observer; being free from a fluctuating atmospheric refraction which annoyed him in the climate of Sicily. The foundation-stone was laid August 10th, 1675. An original inscription, still existing, states the lesign of the building - the benefit of astronomy and navigation. The observatory has been suceessively under the superintendence of Flamstead, Halley, Bradley, Bliss, Maskelyne, Pond, and Airy, its present head, with assistants for its proper management. It is not a spot devoted to star-gazing, and the general observance of celestial phenomena, but essentially a place of business, earrying on by day and by night, when the weather permits, those observations of the sun, moon, planets, and principal stars, passing the meridian, from which the Nautical $\Lambda$ lnanac derives its information. This has been done with admirable regularity for a long series of years, nor has Europe any data comparable with the Greenwich tables. During the interval in which the office of astronomer royal is necessarily vacant, the

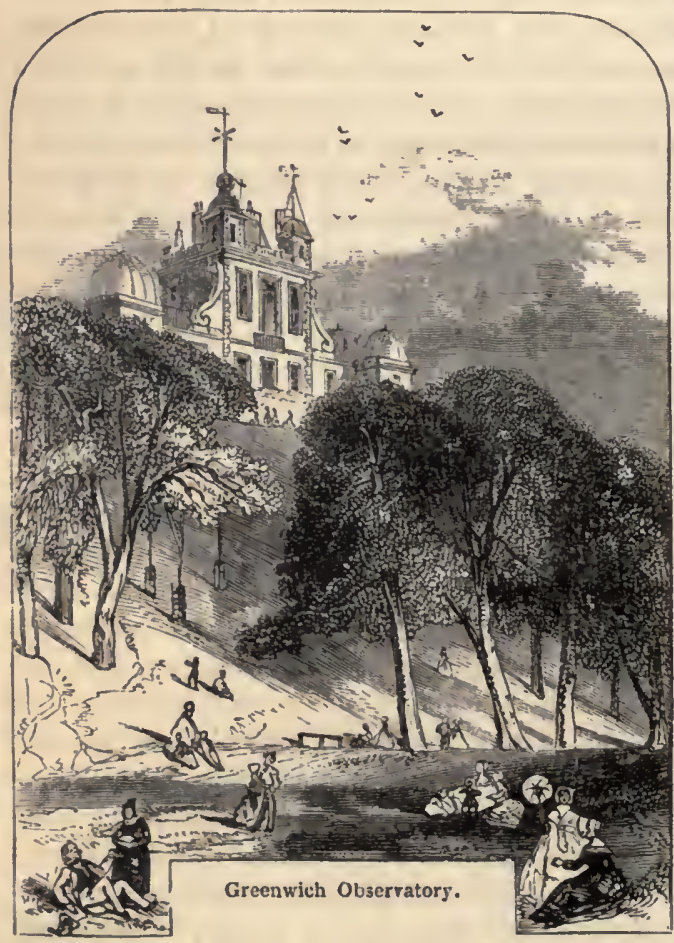
business of the observatory proceeds; and that interval is now less than formerly. Thirty-three days elapsed between Bradley's last observation and Bliss's first; fifty-three between I3liss's last and Maskelyne's first; four between Maskelyne's last and Pond's first; and two between Pond's last and Airy's first. It has been asserted by Baron Zach, that, if the other observatories had never existed, our astronomical tables would be equally perfect; and Delambre, when delivering an éloge on Maskelyne before the Institute of Franee, remarked, that if by some grand revolution in the noral or plysical world, the whole of the monuments of existing science should be swept away, leaving only the Greenwich observations and some methods of computation, it would be possible to reconstruct from these materials the entire edifice of modern astronomy.

A few years ago it was resolved by the Lords of the Admiralty, that the time should be shown at Greenwich once in every day of the year. This is done by means of a large black ball which surmounts the north-western turret of the obecrvatory. The ball, seen down in the vignette, is elevated by machinery to the index, showing the four cardinal points; and, the instant it begins to descend, marks the mean solar time to be noon. Being plainly observable from the Thames, the arrangement affords a convenient opportunity for seamen to regulate their chronometers and clocks.

The fame of FLAMSTEAD, the first astronomer royal, does not rest upon any brilliant discovery, but upon an enlightened view of the importance of accurate observation, and the unwearicd zeal and industry with which he pursued it. A better representation of 
him cannot be given than by supposing Tycho Brahe in possession of a telescope, and the adaptation of it to other instruments. Laplace calls him "one of the greatest observers that has ever appeared," and Delambre remarks, "his name will be eternally cited like those of Hipparchus and Tyeho, both of whom, as an observer, he surpassed." Born in the neighbourhood of Derby, and brought up in limited circumstances in that town, he wrought his way to a station at the head of practical astronomy, and established a continental reputation by dint of strong natural genius and unremitting application, in the face of great discouragements. Bad health was a frequent attendant upon him all his days. The patronage of the Crown did not screcn him from the want of adequate resources, while from scveral of his scientific contemporaries he encountered dishonourable treatment. The salary attached to his office, then a hundred a year, was often in arrears. Instruments were promised him by the government, but he had to find his own, commencing his duties in 1676 with an iron sextant of seven feet radius, two clocks, and a quadrant of three feet radius, with two telescopes, which he brought with him from Derby. With these instruments he could only measure the relative positions of the stars, and it was not until 1689 that he succeeded in constructing at his own expense a mural arc to determine their absolute places. From this period, through an interval of thirty years, his time was spent in valuable labours, the fruit of which appears in the formation of a catalogue of three thousand stars, and a vast collection of lunar and planetary observations, from which Newton derived material assistance in forming his lunar theory. Yet, as if some annoyance must follow him to the grave, upon his death in 1719 , the government of the day attempted to claim liis instruments as public property, because found in the national observatory. The name of Flamstead, lost in a great measure to public recollection, or only dimly recognised as one of those who, with "lamp at midnight hour

$$
\begin{gathered}
\text { in some high lonely tower, } \\
\text { may oft outwatch the Bear, }
\end{gathered}
$$

With thriee great Hermes"-

was revived a few years ago, and acquired notoriety at the expense of Newton and Hallcy's fame. It fell to the lot of Mr. Baily to discover a large number of lis letters in private hands, with others, and a manuscript autobiography, upon the shelves of the library in the observatory; and upon their publication, in 1835, by order of the Lords Commissioners of the Admiralty, some painful and unexpected disclosures were made. It may be admitted that Flamstead exaggerates his own case, that his temper was irascible, that lie did not appreciate the value of Newton's theory, and over-estimated the importance of his own labours; yet, after having allowed these clements of correction full force, the conclusion is sufficiently plain, that he was most injuriously treated, and that much of the moral distinction with which posterity has crowned the head of Newton is altogether misplaced. His deep obligations to Flamstead's lunar observations are acknowledged in the first edition of the Principia, but carefully suppressed in the second, apparently when irritated feeling had begun to operate; and, in fact, nothing is more remarkable than the opinion universally entertained of the meck and placable disposition of the great philosopher, and the want of temper and honour displayed in his dealings with Flamstead. The truth appears to be, that as when we view a country beneath a brilliant sky and a balmy atmosphere, we are apt to frame our impressions of the people in harmony with the beauty of the scene; so, to the early admirers of Newton, his intellectual greatness invested with fictitious lustre his private claracter, and the infirmities of the man were lost sight of in the glory of the sage.

But however much we may take from the moral greatness usually attributed to Newton, and a considerable abatement is unquestionably necessary, his reputation for wonderful sagacity and grasp of mind is incapable of impeachment. The course of events has only 
served to render more conspicuous that sublime intelligence by which he unravelled the mechanism of the heavens ; and establish more indisputably his claim to be regarded as the architect of physical astronomy. To determine the motions of the heavenly bodies was the work of Keppler : to explain and demonstrate the causes of those motions was the achievement of Newton. So far however from gaining universal assent when first proposed, his theory was ill understood, slightly appreciated, or altogether rejected by numbers of scientific men ; and, especially on the continent, it very slowly won its way to notice and confidence. Newton survived the publication of the Principia forty years, and at the time of his death, according to Voltaire, it had not twenty readers out of the country of its production. It was not until the mutual perturbations of the planets began to occupy the attention of the continental philosophers, that his theory was fully admitted abroad, and the work in which it was developed took the rank it has since occupied, pre-eminent, in the words of Laplace, above all the productions of the human mind. It is a common but vulgar error, to suppose the merit of our countryman to lie in conceiving the idea of the attraction of gravitation. That idea liad been suggested to many minds long before his time, and the impression had been created that such a power in nature was the cause of the planetary motions. Thus Keppler surmised an attractive force to reside in the sun, producing these movements, and he even threw out the conjecture, that this force diminishes in proportion to the square of the distance of the body on which it was exerted. Borelli and Hooke also distinctly developed the influence of gravity, and both referred the orbits of the planets to the doctrine of attraction combining with their own proper motions to produce curvilinear movements. What really distinguished Newton, was not the idea of gravity as the principle of attachment between the different members of the solar system, but proving it to be so. He succeeded vague surmise upon the point with mathematical demonstration; explained and applied the laws of the force; an accomplishment which crowns him with honour above all his rivals,

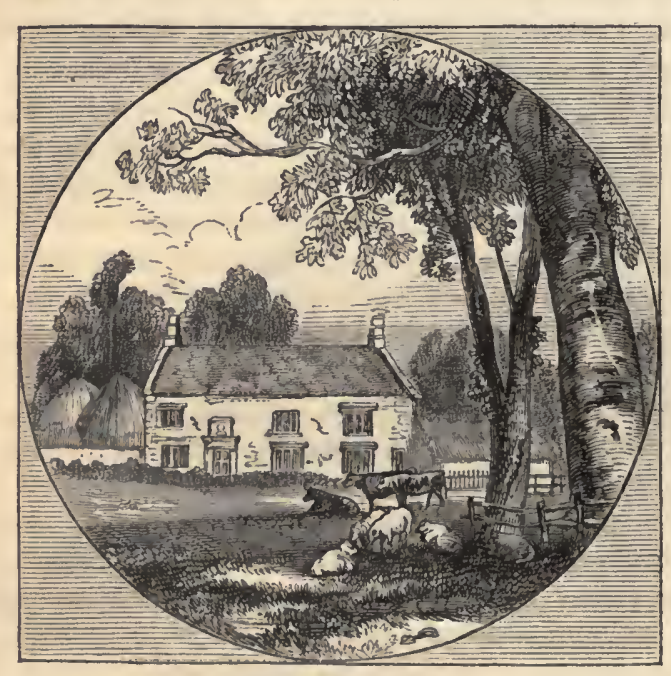

Newton's Birth-place. inasmuch as he who works a mine, and distributes its wealth through society, is incomparably in advance of him who has merely apprehended its existence, but failed in gaining access to its treasures.

The manor-house of Woolsthorpe, a few miles from Grantham, seated in a little valley near the source of the Witham, was the scene of Newton's birtl. Popular tradition reports, that the fall of an apple from a tree in the orchard belonging to this house was the mustard-seed out of which ultimately grew the grand theory of universal gravitation, and the story is not without a leaven of truth. It is certain that, to avoid the plague which ravaged England in 1666, Newton retired from Cambridge; and, when sitting alone in his garden at Woolsthorpe, his thoughts were directed to that remarkable power which causes all bodies to descend towards the centre of the earth. The supposition presented itself, that as this power extends to the highest altitudes of the earth's surface, it probably extends much farther into space; so that even the moon may gravitate towards the earth, and be balanced in her orbit by the combined force of attraction and the centrifugal force implied in her motion. If this 
were true, the planets might be supposed to gravitate towards the sun, and to be restrainel thereby from flying off under the action of the centrifugal force. Sixteen years rolled away before this beautiful hypothesis was verified, and difficulties arose in testing it which seemed to disprove it altogether. It was necessary to caleulate the force of gravity at the surface of the earth; to estimate its diminished energy at an increased distance; and, after having found the law of the diminution, to ascertain whether the phenomena of the lunar motions eorresponded proportionably with those of falling bodies at the terrestrial surface. Assuming the force of gravity to vary inversely as the square of the distance, it followed that, at the distance of the moon, it would be about 3600 times less than at the surface of the earth. The problem, therefore, to be solved was, whether the versed sine of an are described by the moon, which measures the space through which in the same time she would fall to the earth, if abandoned to the action of gravity, would be 3600 times less than the space through which in the same time a heary body falls, at

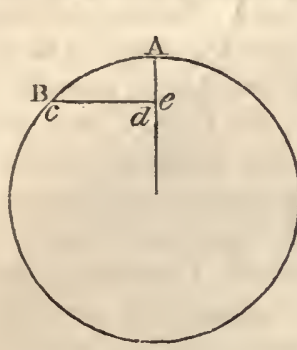
the earth's surface, A B being the arc of the moon's orbit, $c d$ the sine of the are, and $e f$ the versed sine. After a careful study of the lunar observations supplied by Flamstead, and a series of calculations displaying unexampled originality and industry, Newton fully demonstrated that the versed sine of an arc described by the moon in one minute was equal to the spaee traversed in descent by a heavy body at the surface of the earth in one second - the exact proportion that ought to exist, according to the modification to which the intensity of gravity is subject by variation of distance.

The first eertain gleam of this grand conclusion obtained by Newton, is said so to have overpowered him, that he was obliged to suspend his ealculations, and call in the aid of a friend to finish the last few arithmetical computations. He saw the important relations of the demonstration - the planets wheeling round the sun - the satellites round the planets - the far-wandering comets returning to the source of light in obedience to the law of gravitation:- a result sufficient to throw the suecessful discoverer into nervous excitement. It is clear that, if a body be projected into space, it will proceed in the direction of the original impulse and with a uniform velocity for ever, supposing no obstacle to impede its course. But the combination of two antagonistic forces will produce a resulting motion in a diagonal direction.

Suppose the straight lines A i to represent the direction in which the earth would travel

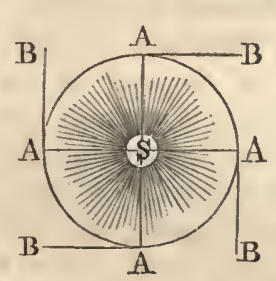
under the influence of the projectile force which launched it into universal space: the straight lines $\mathrm{A}$ s are those it would describe at any point of its orbit if surrendered to the influence of the sun's attraction. The primitive impulse is, however, ehecked by the solar attraction, and the latter by the former ; so that while the eartl, if abandoned to either, would describe $\mathbf{A} \mathrm{B}$ or $\mathrm{A} \mathrm{s}$, the effect of their joint influence incessantly acting is to deflect it from both, and produce a curred path. The eause perpetually operating, the effect is constant; and henee the formation of the terrestrial orbit, and the cause extending to the other bodies in the system, the planetary orbs are deflected from their natural rectilinear paths, and pursue a circuit round the common centre. The force of attraction is, however, proportional to the quantity of matter, and the proximity of the attracting body. Like light, the power of gravitation is weakened by diffusion, and diminishes as the square of the distance inereases. This square is the produet of a number multiplied by itself. A planet, therefore, twice our distance from the sun, will gravitate four times less than we do, the produet of two multiplied by itself being four. Such is the great LAw of 
Grevrrx, subject to the two conditions, that its force is directly as the mass of the bodies, and inversely as the square of the distance. It extends to the confines of the system, and acts as a mighty invisible chain to keep the primary bodies in brotherly relationship to each other, and in mutual subjection to the central luminary. And who can trace its operation without recognising a Supreme Potentate, who appointed to the sum lis place, launched the plinets in the depths, obedient to a law which has preserved the family eompact originally established unbroken through the long series of ages?

It must, however, be borue in mind that the attraction between bodies is mutual, proportioned to their masses and distances. While the sun attracts the planets towards himself, they also attract the sun, though their effect is comparatively small, owing to the vastness of the solar mass. The planets likewise act upon each other; and as their relative distances are perpetually varying, certain perturbations are caused in the system, which, though minute in each particular case, become considerable by accumulation, and yet arc ultimately corrected and repaired by the same cause that produces them. Newton left to posterity the task of thoroughly investigating these inequalities, of showing them to be a result of the law of gravitation, and establishing the permanence of the system, notwithstanding the accumulating influence of its internal disturbances. He limself had no gleam of the latter truth, but seems to have entertained an opinion that the irregularitics occasioned by the mutual action of the planets and comets would probably go on increasing till the system either wrought out its own destruction or received reparation from the direct interrention of its Creator. But Fuler, Clairaut, D'Alembert, Lagrange, and Laplace have demonstrated the problem that the perturbations of the planets are periodic in their nature, that accurate compensation for them is laid up in store, so that the system is not arranged upon a principle of self-destruction. The elements of disorder and decay are removed from it. The very conditions of its existence guarantee its stability till the will of the great Ruler shall be expressed to the contrary. When an end shall come to its present constitution, that will not be the effect of its own faulty architecture, but of the fiat of Oмxirotexce.

The house of Newton at Woolsthorpe, now the homestead of a farmer, has been in the

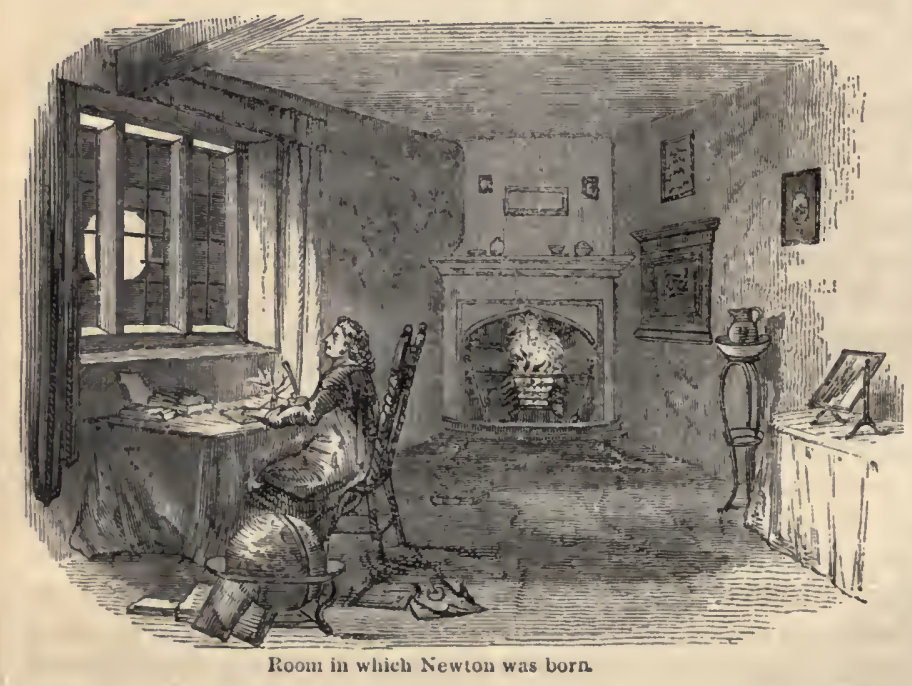
ownership of persons anxious to protect it, and preserve every relic of its former occupant. Stukeley thus deseribed it in 1727 : - "'Tis built of stonc, as is the way of the country hereabouts, and a reasonable good one. 'They led me up-stairs, and showed me Sir Isaac's study, where I suppose he studied when in the country in lis younger days, or perhaps when lie visited his mother from the university. I observed the shelves were of his own making, being pieces of deal boxes which probably he sent his books and 
clothes down in on those occasions." Two sun-dials remain which he made when a boy; but the styles of both are wanting, and one has been recently taken from the wall to be presented to the Royal Society. The room in which he was born has the following inscription upon a tablet of wlite marble:- "Sir Isaac Newton, son of John Newton, Lord of the Manor of Woolsthorpe, was born in this room on the 25th of December 1642." The apple-tree, the fall of one of the apples of which, according to tradition, drew his attention to the sulject of gravity, was blown down by a gale some years ago, and a chair was constructed out of its timber. The Royal Society of London possesses his telescope; the Royal Society of Edinburgh the door of lis book-case; and 'Trinity College, Cambridge, has a lock of his silver white hair.

While the foundations of physical astronomy were laid by Newton, his confidant and friend, the brilliant and active Halley, pursued a remarkably successful career in the

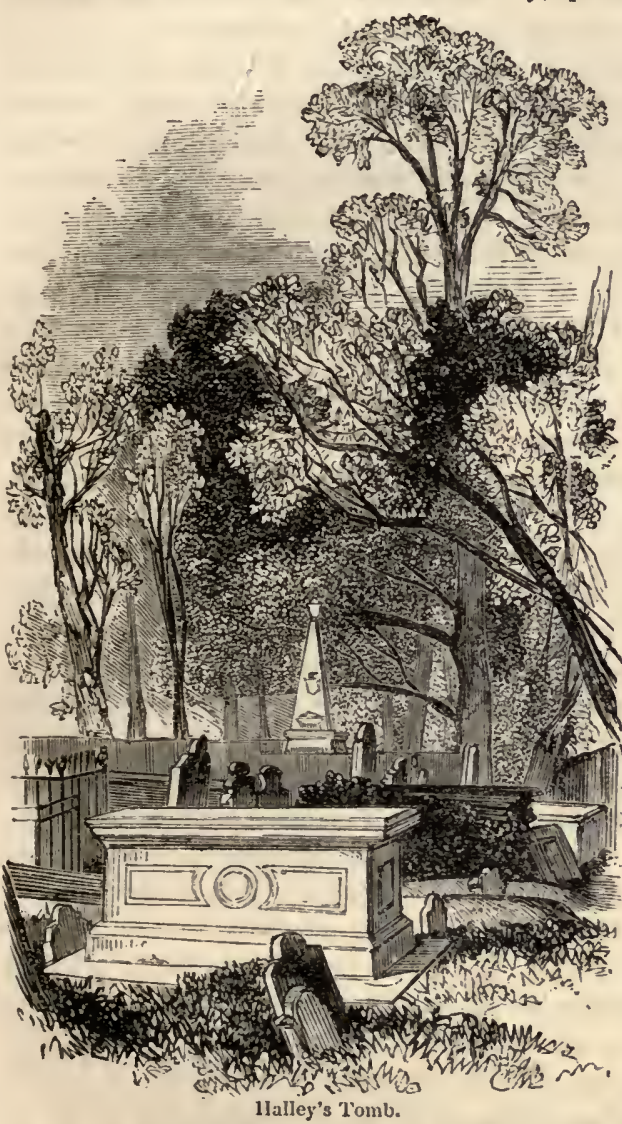
practical departments of the science. Born in mereantile life, yet independent of it through the wealth amassed by his father, he early embarked his means and energies in the advaneement of observation. Leaving Hevelius and Flamstead to keep guard orer the northern hemisphere, he sailed to St. Helena to inspect the southern; and in lionour of the reigning monarch who patronised the expedition, the oak which latd screened him from his pursuers after the battle of Worcester, was raised to a place in the skies, forming the constellation Robur Carolinum. The object of the royage was to determine the absolute and relative positions of the stars invisible to the European cye; but owing to the unpropitious climate of the island, only a catalogue of 360 was made after more than a year's residence. Upon this voyage the oscillations of the pendulum were observed to decrease in number as the instrument approached the equator; a fact noticed a few years previous by Richer, and explained by Newton to result from the greater intensity of centrifugal force there, proportionably diminishing the force of gravity. The life of Halley was remarkable for locomotion, devoted to various scientific objects. He was twice at St. IIelena, twice in the Adriatic, once in the West Indies, now with Newton in lis study at Cambridge, anon with Hevelius in his observatory at Dantzic, and then with Cassini watching a comet at Paris. Upon the death of Flamstead, he succeeded to the office of astronomer royal, and though then in the sixty-fourth year of his age, he commenced the observation of the moon through a complete revolution of her nodes, involving a period of nineteen years, and lived to finish it, registering upwards of two thousand observed lunar places. It was while journeying in France towards the close of 1680, that he observed the great comet of that year, on its return from proximity to the sun; 
and being aware of the conclusion of Newton, that such bodies describe very eccentric ellipses, his active mind began to study intently their phenomena, which resulted in a prophecy that has immortalised his name. After cataloguing and comparing a considerable number of comets, that of 1682 fortunately appeared. This he was led to regard as identical with those of 1456,1531 , and 1607 , between which there is nearly the same interval. Hence he anticipated its return after the lapse of a similar period. "I dare venture," said he, "to foretell that it will return again in 1758 ;" and, sanguine as to the result, he called upon posterity to notice that it was an Englishman who had hazarded the statement. This was a prediction announced in 1705, the accomplishment of which ranks with the greatest achievements of modern astronomy, and will perpetuate the fame of Halley to the remotest generations. He had been gathered to his grave in Lee churehyard seventeen years, when the celestial traveller re-appeared, at the time announced, to verify his words, illustrate his sagacity, and invest him with undying honour.

Bradley, the English Hipparchus, the model of observers, as he is styled by Laplace, became the third astronomer royal upon the death of Halley. He had previously effeeted one of his two great discoveries, the aberration of the stars, an optical illusion, arising from the combined movement of the earth in space, and the progressive transmission of light; a discovery of the highest importance, requiring the greatest precision of observation to detect. Ever since the doctrine of the earth's translation in space had been received, astronomers had been anxious to find some parallax of the fixed stars, as a sensible confirmation of the fact. Although the whole diameter of the earth's orbit is relatively insignificant, it is yct absolutely vast. Hence it was deemed no unreasonable expectation that some small apparent change of place in the heavens would be discerned in the case of the fixed stars, when viewed from the two extremities of the earth's annual orbit, - separated from eacl other by the mighty ehasm of a hundred and ninety millions of miles. To ascertain this,

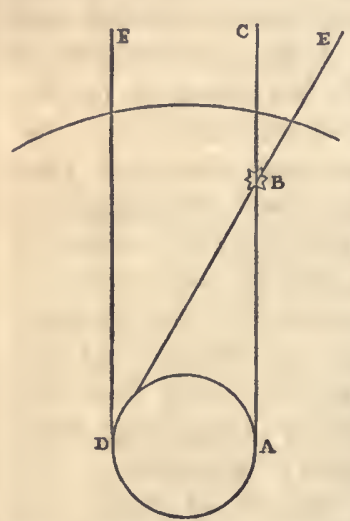
if possible, Bradley commenced observing a particular star, $\gamma$ Draconis, in connection with his friend the Hon. Mr. Nolyneux, in the house of the latter on Kew Green, which was afterwards the residence of George III. The star in question was selected from its passing very near the zenith of their observatory. After a series of laborious observations, which began towards the elose of the year 1725 , this star was found to have a southerly motion, a result which excited profound surprise, as it was in a dircetion opposite to what would liave been produced by an annual parallax. For instance, when the earth is in its orbit at $A$, the place projected in the leavens by the star $\mathrm{B}$ will be at $\mathrm{C}$; but when the earth is in its orbit at $\mathrm{D}$, provided that there be any sensible parallax, the star will be seen in the direction $\mathbf{E}$. Instead of this being the case, the observed appearance was that of the star appearing from $D$ in the direetion F. The observed change of place, then, could not be explained by means of parallax, or the earth's motion simply, because the ehange was in a direction opposite to what would have been caused by the parallactic motion. Suspecting some error, instruments were examined and observation renewed; but the fact was verified, and the star was found to move sontherly from December to $\Lambda$ pril, then to move northerly again, returning to its original place in the December following, after having described a small apparent

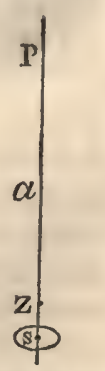
orbit in the heavens. The diagram represents the apparent course annually described by $\gamma$ Draconis, and other stars similarly situated. Imagine the line $a$ bent overhead, $z$ being 
the zenith, and $\mathrm{P}$ the pole. The ellipse represents the apparent movement of the star, the transverse diameter of which is about forty seconds; and sits mean place.

Aberration, or wandering, is the name given to this phenomenon. The term is not strictly accurate, as the apparent movements thus denominated are not irregular, but uniform. To discorer the physical cause became an object of intense interest to Bradley, but it long baffled his researches and reasonings, and was at length developed by an accidental circumstance. He was accompanying a pleasure-party in a sail on the river Thames. The boat in which they were was provided with a mast which had a vane on the top of it ; it blew a moderate wind, and the party sailed up and down the river for a considerable time. Bradley remarked, that every time the boat put about, the vane at the top of the mast slifted a little, as if there had been a slight change in the direction of the wind. He observed this three or four times without speaking; at last he mentioned it to the sailors, and expressed his surprise that the wind should shift so regularly every time they put about. The sailors told him that the wind had not shifted, but that the apparent change was owing to the change in the direction of the boat, and assured him that the same thing invariably happened in all cases. From that moment he conjectured that all the phenomena of aberration he had observed, arose from the progressive motion of light combined with the earth's motion in its orbit. This sagacious conjecture satisfactorily explains

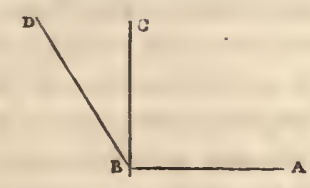
the apparent movement of the stars. Suppose a body to pass from $\triangle$ to $B$ in the same time that a ray of light passes from $C$ to $B$. Owing to the two motions, the impression of the ray of light meeting the eye of a spectator at B will be exactly similar to what it would have been if the eye had been at rest at $\mathrm{B}$, and the molecule of light had come to it in the direction $\mathrm{D}$, B. The star, therefore, whose real place is at $\mathrm{C}$, will appear at $\mathrm{D}$ to the spectator at $\mathrm{B}$. This effect is precisely analagous to what takes place when a person moves or travels rapidly through a shower of rain or snow in a perfectly calm state of the atmosphere. Without locomotion the rain-drops or snow-flakes will fall upon his hat, or upon the head of the carriage that conveys him, and not beat in his face, or against the front windows of the carriage. But if he is passing along swiftly, in any direction, east, west, north, or south, the rain or snow will come in contact with his face, or enter the front windows of the carriage if they are open, as though the drops or flakes fell obliquely, and not from the zenith. Now as an object appears to us in the direction in which the rays of light strike the eye, it is easy to understand that a star in the zenitl will appear at a little distance from it, to a spectator carried along with the earth in its orbit. This discovery established the fame of Bradley, who was exonerated from all future payments to the Royal Society on account of it; and it is of great importance, as the only sensible evidence we have of the eartli's annual motion. Soon after his appointment to the Greenwich observatory, he effected his second great discovery, that of the nutation of the earth's axis, a slight oscillation of the pole of the equator about its mean place, describing an ellipse in the period of eighteen years. He determined likewise its cause, which theory had previously inferred to be the action of the moon upon the equatorial regions of the earth. Some idea of his in. dustry may be formed from the fact, that in conjunction with his nephew, he made no less than eighteen thousand observations in a single year while astronomer royal; and the number from the year 1750 to 1762 amounted to upwards of sixty thousand. The death of Bradley was interpreted as a Divine judgment by the populace. He had taken an active part with the Earl of Macclesfield and others, in urging on and assimilating the British calendar to that of other nations. This rendered it necessary to throw eleven days out of the current year in the month of September 1752 - a measure which the ignorance of great numbers of the people led them to regard as an impious intermeddling with the 
Divine prerogative. Lord Macclesfield's eldest son, at a contested election for Oxfordshire, was greeted with the ery from the mob, "Give us back the eleven days we have been robbed of !" and Bradley's mortal sickness, some year's later, was viewed as a punitive dispensation for having participated in the sacrilegious theft.

'The latter half of the eighteenth century furnishes a large catalogue of distinguished names, men of high scientific ability, and, for the most part, of the finest mathematical minds, by whose labours practical astronomy made vast adrances, and the physical theory of the universe, as previously developed, was amply illustrated and confirmed. During this era lunar tables were constructed of sufficient accuracy to be enployed to solve the great problem of the longitude at sea. This was the work of Mayer, for which his widow received the sum of $3000 \mathrm{l}$. from our government; and since that period, the publication of such tables, showing the places of the sun and nioon, with the distance of the latter from certain fixed stars, for every three lours, threc years in advance, has been a national object, contributing to the safety of navigators upon the trackless deep. The same period is also celebrated for the determination of the figure and magnitude of the earth, and for the great improvements made in instruments of observation. If the century opened with lustre derived from the physical demonstrations of Newton, it closed magnificently with the telescopic discoveries of Herschel, the wonderful resident by the stately battlements of Windsor, by whose mechanical skill and matchless industry new regions were added to our solar system, and views unfolded of the infinity of the firmament, and the character of its architecture, which eye had not seen or the mind conceired.

$\Lambda$ work specially devoted to the life and labours of Herschel is a desideratum. It is not to the credit of the country, that the men who have headed its physieal force upon the field of battle have enjoyed a larger measure of public admiration and gratitude, and found a more speedy chronicle, than those who have enlarged the field of thought, ministered to the intellectual gratification and elevated the mental character of the community. Bradley had lain in his grave 70 years, Newton 104, and Flamstead 116, before their memory received its meed of justice from the hands of Rigaud, Brewster, and Baily; a slackness to be attributed to the want of al dne national estimate of the value of science, rather than to the reluetance of those who were competent to do ample honour to their merits. Herschel still remains without a record of this kind, though the matcrials for it are abundant, and his claims undoubted. Born at Hanover, the son of a musician in comparatively humble life, but early a resident in England, he appeared first as a professor and teacher of music, but rapidly rose by his own unaided efforts to eminence as an optician and astronomer. Anxious to inspect for limself the sublime revelations of the liearens, but destitute of means to purchase a telescope of sufficient power for his purpose, he resolved to employ some previous knowledge of optics and mechanics in the construction of an instrument. The earliest, a five-foot reflector, was completed in 1774 : but altogether he accomplished the construction of upwards of five hundred specula of various sizes, selecting the best of them for his telescopes. After having established his fame by the discovery of a new planet, and fixed his residence at Slough, under the munificent patronage of George the Third, he completed the giant instrument that attracted travellers from all parts to the spot, and rendered it one of the most remarkable sites of the civilised world. The tube was forty fect long, the speculum four feet in diameter, three inches and a lalf thick in every part, and weighing nearly two tons. Its spacc-penetrating power was estimated at 192, that is, it could search into the depths of the firmament 192 times further than the naked eye. We can form no adequate conception of this extent, but only fecbly approximate to it. Sirius, the brightest of the stars, is separated by a scarcely measurable gulf from us. But stars of a far inferior order of brightness are visible to the naked eye. These we may conclude to be bodics 
far more remote, and reasonably suppose the star which presents the faintest pencil of light to the eye to be at least twice or thrice the distance of Sirius. Yet onwards, 192 times further, the space-penetrating power of the telescope at Slough swept the henrcus. It was completed in the year 1789 , but the frame of the instrument becoming decayed through exposure to the weather, it was taken down by Sir John Herschel in 1823.

It will be conrenient here to notice a reflecting telescope of far greater magnitude and power, recently constructed by the Farl of Rosse, and now in use at the seat of that nobleman, Birr Castle, in Ireland. 'The mechanical difficulties involved in this work the patience, perseverance, and talent required to overcome them - and the great expenliture necessarily incurred-render the successful completion of this instrument one of the most extraordinary accomplishments of modern times; and entitle its owner and projector, from first to last, to the admiration of lis conntrymen. When the mechanical skill and profound mathematical knowledge essential to produce such a work are duly considered, together with the years devoted to previous experimenting, and an outlay of upwards of twelve thousand pounds, this telescope must be regarded as one of the most remarkable and splendid offerings ever laid upon the altar of science. 'The speculum has a diameter of six feet, and therefore an area of reflecting surface nearly four times greater than that of the Herschelian, and its weight approaches to four tons. The casting - a work of no ordinary interest and difficulty - took place on the 13th of April, 1842, at nine in the crening; and as the crucibles poured forth their glowing contents - a burning mass of fluid matter, hissing, heaving, and pitching - for the moment almost every one was anxious and fcarful of accident or failure but Lord Rosse, who was observed directing his men as collectedly as on one of the ordinary occurrences of life. The speculum has been formed into a telescope of fifty feet foeal length, and is established between two walls of castellated architecture, against one of which the tube bears when in the meridian. It is no slight triumph of ingenuity, that this enormous instrument may be moved about and regulated by one man's arm with perfect ease and eertainty. What will result from its application to the heavens remains to be ascertained, but an adrancement of sidereal astronomy has already transpired.

'To return tu Herschel. No addition had been made of any new body to the universe since Cassini discovered a fifth satellite in the train of Saturn. Nearly a century had elapsed without any farther progress of that kind. The solar system, including the planets, satellites, and Halley's comet, consisted of eighteen bodies when Herschel turned his attention to astronomy; but, before his carcer of observation terminated, he increased the number to twenty-seven, thus making the system half as large again as he found it, as to the number of its constituents - a brilliant recompense, but not an over-payment, considering the immense expenditure of time, and toil, and care. A primary planet with six moons, and two more satellites about Saturn, composed the reward. It was on the 13th of March, 1781, that, turning a telescope of high magnifying power - though not his gigantic instrument - to the constellation Gemini, he perecived a cluster of stars at the foot of Castor, and one in particular, which sensibly increased in diameter while the rest of the stars remained unaltered. Two nights afterwards its place was changed, which originated the idea of its being a cometary body; an opinion embraeed upon the continent when attention was called to it, but soon dispelled by clear evidence of its planetary nature. The new planet was named after the reigning monarch by the discoverer, but received his own name from astronomers, which was finally exchanged for the Uranus of heathen mythology, the oldest of the gods, the fabled father of Saturn and the grandsire of Jupiter - referring to the position of the planet beyond the orbits of the bodies named after the latter. By this discovery the extent of the system was at once doubled; for the 
path of the stranger lies as far beyond what had been deemed its extreme confine, as that limit is removed from the sun. The first moment of his "attack" upon Saturn, upon completing the forty-feet reflector, he saw a sixth satellite, and a seventh a month later, now called Mimas and Enceladus. But Herschel realised his most surprising results from the observation of the sidereal heavens. The resolution of nebule and the Milky Way into an infinite number of stars - the discovery of new nebula of various forms, from the light luminous cloud to the nebulous star - of double and multiple stars - of the smaller revolving round the greater in the binary systems; - these were some of his revelations to the world, as night after night, from dewy eve till break of dawn, he gauged the firmament. Caroline Herschel was the constant partner of her brother in lis laborious undertakings - submitting to the fatigues of night attendance - braving with him the inclemency of the weather - noting down his observations as they issued from his lips - and taking, as the best of all authoritics reports, the rough manuscript to the cottage at the dawn of day, and producing a fair copy of the night's work on the ensuing morning. He died in 1822 ; but she survived to 1848 , witnessing the heir of lis name recognised as the heir also of his talents and fame. It was one of the conceptions of this remarkable man - as bold an idea as ever entered the human mind - that the whole solar system has a motion in space, and is advancing towards a point in the heavens near the star $\lambda$ Herculis. General opinion is now in favour of the idea, that not only the solar but the entire stellar universe revolves around some mighty centre.

The nineteenth century commenced with a fresh ingatlering of members into the planetary family. It had been deemed a matter of surprise that the immense interval of about 350 millions of miles between Mars and Jupiter should be void, when only spaces varying from 25 to 50 millions divide Mars, the Earth, and the inferior planets. Keppler had therefore started the conjecture that a planet would be discovered in the vast region between the Iwo former bodies; and thus bring it into something like proportion with the spaces between the latter. This idea was confirmed by a curious relation diseorered by Professor Bode between the mean distances of the planets from the sun. It is to the effect, that procceding outwardly from the sun, the interval between the orbits of any two planets is about twice as great as the inferior interval, and only half the superior one, except in the instance of Mars and Jupiter. Uranus had not been discovered when Bode arrived at this remarkable analogy, but the distance of that planet being found to correspond with the law, furnished a striking confirmation of its truth.

\begin{tabular}{llllrrrrr} 
Write the Series, & 0 & 3 & 6 & 12 & 24 & 48 & 96 & 192 \\
Add to each term, & 4 & 4 & 4 & 4 & 4 & 4 & 4 & 4 \\
\cline { 2 - 8 } \\
The sums are, & 4 & 7 & 10 & 16 & 28 & 52 & 100 & 196
\end{tabular}

If the third term 10 be taken to represent the distance of the earth, the third planet, in order from the sun, the remaining terms will represent very nearly the respective distances of the other planets. Thus,

$\begin{array}{cccccccc}\text { Mercury. } & \text { Venus, } & \text { Earth. } & \text { Mars. } & - & \text { Jupiter. } & \text { Saturn. } & \text { Uranus. } \\ 4 & 7 & 10 & 16 & 28 & 52 & 100 & 196\end{array}$

The fifth term in the series is unrepresented, except by the exaggerated leap from Mars and Jupiter. It will be perceived, that while there is a striking approach to duple progression in the succession of distances, the condition is not exactly fulfilled; and as it fails utterly in the case of Neptune, the last discovered planet, Bode's law, as it is called, is purely empirical.

The void in the series between Mars and Jupiter, so convineed the German astronomers of the existence of a planet to oceupy it, that a search for the concealed body was commenced. The anticipation was soon substantially realised by the discovery of 
four planets-Ceres, Pallas, Juno, and Vesta, revolving round the sun at a mean distance of one hundred millions of miles from Mars, so small as only to be telescopic objects. This discovery we owe to Piazzi, Olbers, and Harding. Some singular features, without parallel in the planetary system, such as their close contiguity, the intersection of their orbits, with their diminutive size,-Vesta not being much larger than the Spanish peninsula,-led to the surmise that these bodies are fragments of a planet which once revolved in their mean path with a magnitude proportionate to that of its neighbours. The possibility of such a disruption cannot be denied-the revolution of the fragments round the sun would follow in obedience to the mechanical laws by which the system is governedbut the point is obviously one of those questions which must remain entirely hypothetical.

The career of planetary discovery which began with the century, was resumed in the year 1845 ; and has since been continued with most surprising results. Another miniature orb, Astræa, discovered by M. Hencke, was then added to the family of minute worlds rolling between Mars and Jupitcr; and in one year alone, 1852, no less than eight such bodies were found. The known number at the time of writing these lines (1st of September 1857) is forty-five. Besides this, in the present age, the members of the solar universe have been increased by the detection of the primary planet Neptune, attended with a satellite; and of an eighth satellite of Saturn, called Hyperion, remarkable for its simultaneous discovery by independent observers, in 1848, Mr Lassel of Liverpool, and Mr Bond of Cambridge, in the United States. The addition of a primary planet to our system demands a brief notice.

Observations upon Uranus had shown the motions of that planet to present great irregularities, which could not be explained by the action of Jupiter and Saturn; and after carefully examining the analytical theory of Uranus, Leverrier, a young academician of France, in the summer of 1846, published the elements of an undiscovered planet, the cause of the perturbations. He boldly predicted its existence, calculated its mass, and referred to its place in the heavens; and scarcely a month afterwards, on the 23rd of Scptember, the hitherto concealed object was found by M. Galle of Berlin. But it has only been by accidental circumstances that France has the honour of this remarkable achievement. Upon retiring from the chair of the British Association, a fortnight before the observation of MI. Galle, Sir John Herschel, in remarkable words, referred to the astronomical events of the past year, observing that it had given a new planet (Astrea) to our list, and adding, "it has done more, it has given us the probable prospect of the discovery of another. We see it as Columbus saw America from the shores of Spain. Its movements have been felt trembling along the far-reaching line of our analysis, with a certainty hardly inferior to that of ocular demonstration." This striking paragraph, as subsequently explained, had a twofold reference to the calculations of Leverrier, and to a similar investigation previously completed by Mr. Adams of Cambridge, the independence of the investigations, and their very nearly coincident results, justifying the confidence so strongly expressed by the speaker. Mr. Adams commenced his theoretical researches in January, 1843, recommenced them upon larger data in February, 1844, and obtained results for the heliocentrie longitude, eccentricity of orbit, longitude of perihelion and mass of an assumed exterior planet, deduced entirely from unaccounted-for perturbations of Uranus. These results were communicated to Mr. Challis, the Professor of Astronomy at Cambridge, in September, 1845. In October they were in the hands of Mr. Airy, the Astronomer Royal, whereas Leverrier's labours were not made public till the June of the year following. They were not then so complete as those of Mr. Adams, indicating merely the probable position of the hypothetical planet, while the latter liad given values respecting its mass and the form of its orbit. The correspondence between two independent inquiries as to position inspired confidence, and Mr. Airy recommended 
a systematic search for the object, which Mr. Challis commenced on July 29. It now appears that, on August 4th and 12th, he actually seized the planet, and recorded two positions of it, but did not reeognise it, through not comparing his observations, which a pressure of occupation, and an impression that the discovery required a much more extensive search, prevented. But for this, and the non-publication of the Cambridge mathematician's results at the time they were forwarded to Mr. Airy, the honourable position of M. Leverrier would have been occupied by Mr. $\Lambda$ dams, and that of M. Galle by Mr. Challis.

The progress of astronomical discovery which has now been briefly traced, reminds us of the obligations we owe to those who have gone beiore us. How ineumbent the duty upon us, then, as we have largely benefited by our predeecssors, that, as fitithful stewards of their gifts, we should hand them down to posterity with an inerease of value! How grand, and yet low simple, those riews of the universe, upon the evidence of which we are now invited to gaze! The Sun, a central orb, attended by a stately cortège of planets, forming a system under the empire of law, - a system not unique, but a general type of others as countless as the member's of the stellar host, whose front ranks alone come within the range of telescopic vision;-systems, probably, not pliysically insulated, but bound together by fine relationships, the nature of which, judging from the progress of the past, it is not arrogant to presume, will yet be revealed to the understanding of man! These are not ingenious theories - splendid conjectures-but established facts, and sober anticipations based upon them. To live and learn is the high vocation of humanity, one of the appointed ends which the great $\Lambda \mathrm{r}$ tificer of existence contemplates in its continued series; the generations that are to come improving upon the aequirements of that which now is. Nor ean we fix any limit to the growtl of knowledge in relation to the pliysical universe, clear and insurmountable in the present state as are its bounds with respect to the spiritual world. Who can desery a resting point in the wilderness of space? - diseern a burrier to the range of the creation? Vast as are the regions that have been entered, there are vister ainplitudes unapproached beyond them, towards which the mind may advance in endless progression; often indeed fultering in the pilgrimage beneath the burden of those conceptions of space and magnitude which immensity suggests, but still going onwards.

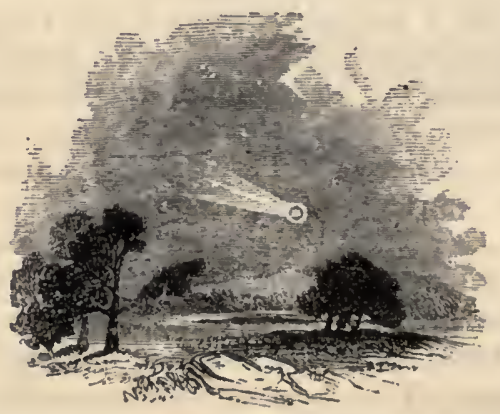




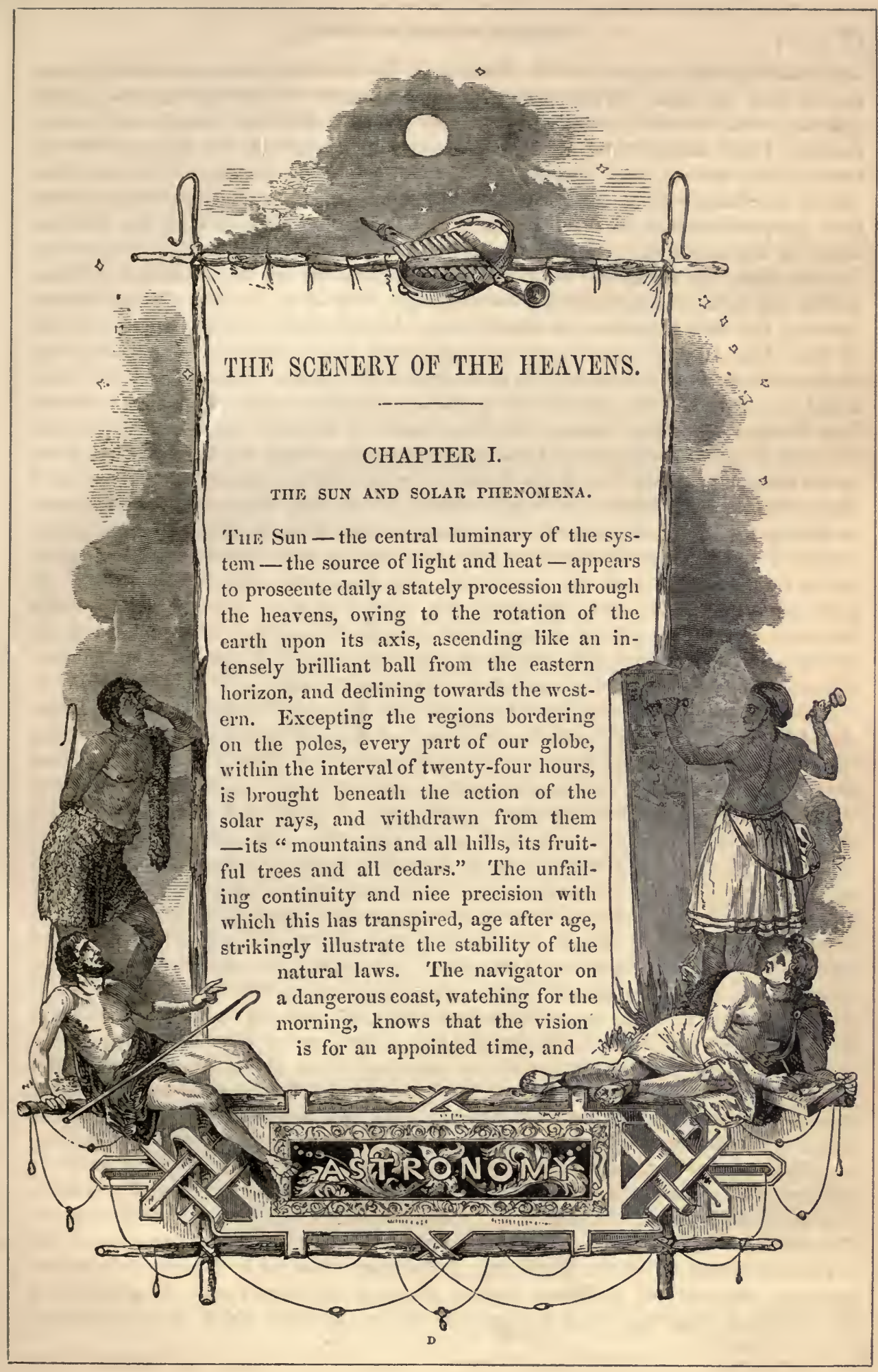


will infallibly keep the appointment. In countries favoured with a more transparent atmosphere than our own, the day-spring, the commencement of terrestrial nature's diurnal audience with the solar presence, is a scene of great combined beauty and magnificence. Faint rosy-coloured streamers are early indications of the point of sunrisc; these rapidly become more distinct, and are followed by resplendent saffron hues, from that of burnished gold at the horizon, to the lighter shades gradually fading upwards into the pure cerulean of the illuminated sky. A recent pilgrim from the Western world to the sacred sites of the East, during his stay at Athens, went to witness the sunrise from the Acropolis, amid the solemn grandeur of its desolations. Seated within the ruins of the Parthenon, commanding a vicw of the horizon through the columns of the eastern portico, he awaited from the grey dawn the appearance of the orb of day. Gradually the sky became so resplendent in the direction of the advancing luminary, as to render it impossible to determine the precise point where his presence would be revealed. The tops of the northern mountains caught lis beams, and some light fleecy clouds seemed changed into liquid gold, as, hovering over mount Hymettus, they met the rays of the sun. At length, the eye encountered the solar glory, lighting up the columns and marbles of the Parthenon with a silvery splendour. It was one of those moments in the life of man, says Robinson, the traveller in question, that can never be forgotten. In our own latitude, the sunrise is a spectacle of surpassing interest and beauty, as viewed from the summit of Snowdon, or from some eminence overlooking the sea, in a propitious state of the atmosphere. The progressive illumination - the varicgated colours deepening and brightening that are peneilled on the sky - the growing distinctness of the superficies, whether field or flood-the retreat of mists and vapours glittering in the sunbeams while vanishing before their action;-combine to form a scene of visual beauty which has few parallels in the realms of nature.

Light is sensibly transmitted to us while the sun is below the horizon. This is oceasioned by the refractive and reflective properties of the atmosphere. By the former, the place of the luminary in the heavens is optically raised; and morning and evening, when the lower limb appears to rest upon the horizon, the entire body is actually below it, and would be invisible but for the refraction of the rays. This effect is only produced while the depression is within 33', which is rather more than the sun's greatest apparent diameter. At a further distance from the horizon, the rays pass over our heads into the upper regions of the atmosphere, and their direct transmission to the cye ceases. But they continue to reach us for an interval by reflection from the illuminated atmosphere, and produce the morning and evening twilight, the gradual transition from darkness to light, and from light to darkness. It is owing to the particles of air possessing the property of successively reflecting and re-reflecting the solar light, scattering it in every variety of direction, that all those objects are visible to us in the daytime, which are indirectly situated with reference to the luminary. Without it, the cloudless sky at noon, now so blue and brilliant, wonld present the blackness of darkness, with the exception of the places occupied by the sun and the stars. The latter would be as visible by day as at midnight, while no object wonld be perceptible, not receiving the direct sunbeams. It is not impossible but that at niidnight, in the hour of the deepest gloom, some of the solar influence may be transmitted to us by an infinite number of reflections, so reduced, however, in its amount and power as to be imperceptible. The period of the sensible reflection of light from the sun, or the twilight, is generally supposed to be confined to his depression eighteen degrees below the horizon. The limit of depression, however, at which the greatest observed darkness commences, varies in different climates. In the torrid zone it has been found to be between sixteen and seventeen degrees; and in France between seventeen and twenty-one. The duration of the twilight is different at every different latitude on the earth, and it varies in the same 
latitude at different seasons of the year; but much depends upon the atmosphere being free from elouds and fogs, or surcharged with them, as to its perceptible length in all places and at all times. Astronomically speaking, in the latitude of Greenwich, there is no night from the $22 \mathrm{~d}$ of May to the 21 st of July, but twilight from sunset to sunrise. It reaches its minimum three weeks after the autumnal equinox, and three weeks before the vernal equinox, having a duration of one hour and fifty minutes. At midwinter it is longer by rather more than a quarter of an hour than at the former periods, though this is not often perceptible, but rather the contrary, owing to the greater prevalence of clouds and mists at the winter solstice, intercepting, absorbing, and reflecting away from the earth the rays of light that otherwise would visit it. The duration is least at the equator and greatest at the poles; but at the former there are two twilights every twenty-four hours, and at the latter only two in the year. At the north pole the sun is below the horizon for six months. But from the autumnal equinox to the 12th of Norember, and from the 29th of January to the vernal equinox, the solar depression is within eighteen degrees. Consequently through the whole of these intervals there is twilight, which reduces the extent of the absolute night to about two months and a half. If this region is thus for a long interval deprived of the solar presence, it is compensated by a lengthened possession of it at an opposite season of the year, for from the 20th of March to the 23d of September, the sun is constantly above the horizon. The annexed view exhibits the sun as seen at midnight at the North Cape of Europe, which is within

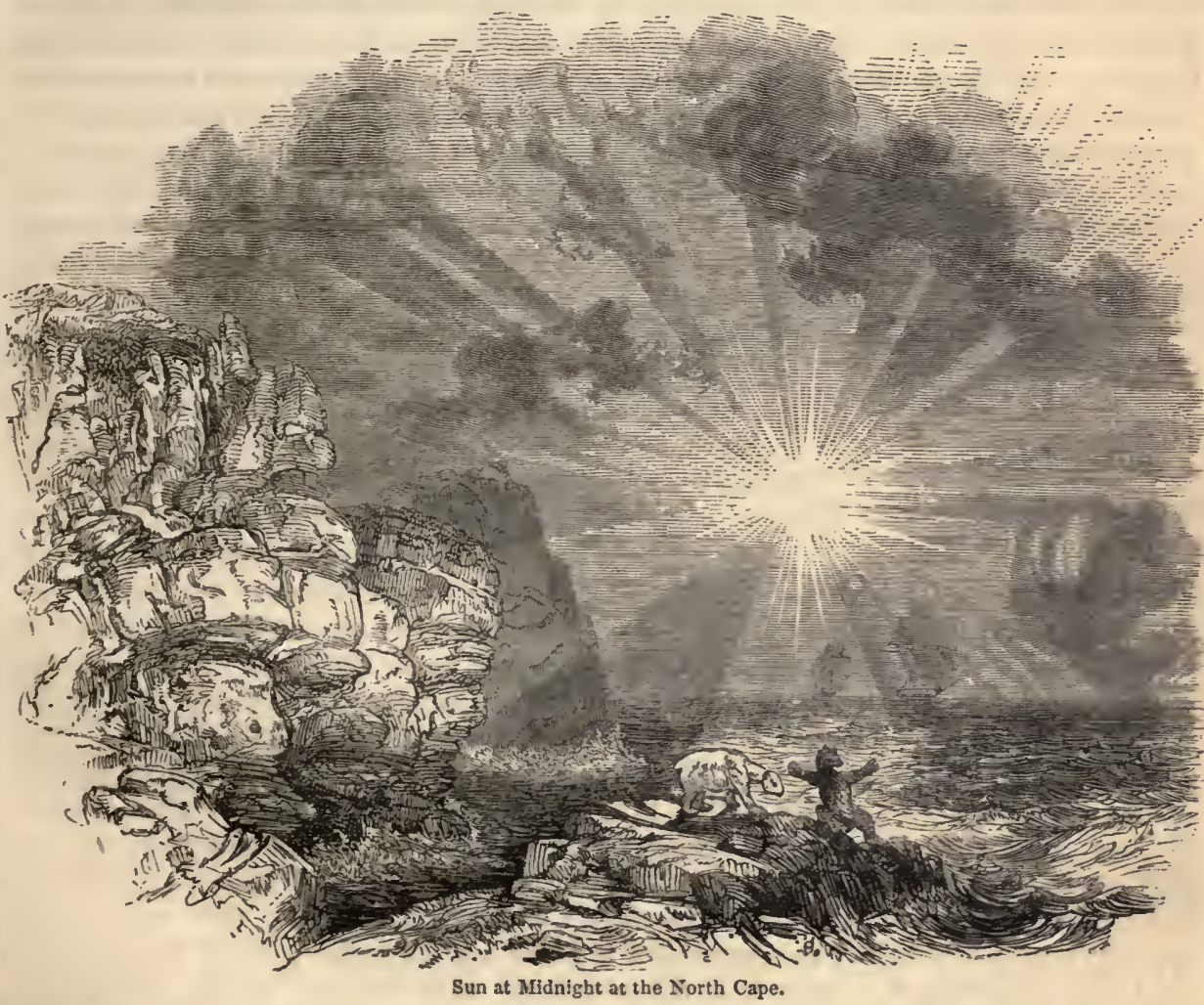

eighteen degrees of the pole - an appearance novel in the extreme to the dwellers in more southern latitudes. In the locality upon the earth's surface in which we are 
situated, the frequent interchange of day and night, with the gradual advance and recession of both, is a benign and beautiful arrangement, the gentle, silent, yet emphatic signal of nature, for man to go forth to his work and to his labour until the evening, when the "ploughman homeward plods his weary way," to give sleep to his eyes and slumber to his eyelids.

Owing to the refractive property of the atmosphere, the disk of the sun when near the lorizon loses its circular form, and assumes an oral appearance. This is particularly observable when sunrise or sunset is viewed from the summit of a mountain, or from an eminence by the sea. The refringent power of the atmosphere being the greatest when nearest to the horizon, it follows that the rays of light proceeding from the lower limb of the sun are raised more than those which proceed from the upper point. 'This diminishes the apparent rertical diameter, while the apparent horizontal diameter is scarcely at all affected, as refraction acts only in a vertical direction. Measured by the micrometer, the vertical height of the solar surface, in the circumstances named, is sometimes found to be four, five, or even six minutes of a degree less than the horizontal width, and hence the term given to the appearance, that of the "horizontal sun." No such effect is perceived in other situations of the solar body, because refraction operates more feebly away from the liorizon, and the difference between the refraction of the rays of light issuing from the upper and lower extremities of the vertical diameter is too small to be observed. We are accustomed to speak of the meridian glory of the sun; and independent of the greater purity of the atmosphere at noon, through the dissipation of mists and vapours, a greater quantity of rays reach the eye from the sun when high in heaven than when near the horizon. The air is an absorbent as well as a refractive and reflective medium: and however transparent the medium may be, the quantity of light absorbed will increase or diminish according to the extent of atmospheric space it has to traverse. This extent is much smaller with reference to an object in the zenith than one near the horizon. By a reference to the diagram, it will at once be seen that a ray of light passing from $z$ the zenith will embrace a much less portion of the atmosphere included

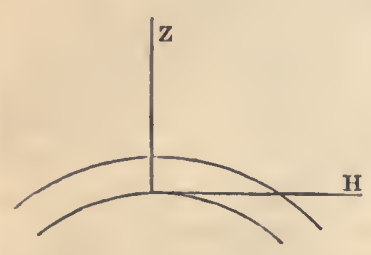
between the two ares than one from II the horizon; consequently a less quantity will be absorbed; and hence a celestial object will appear the brighter as its distance from the horizon increases. The comparatively dim and hazy appearance of objects seen in the direction of the horizon, is not only oceasioned by the rays of light having to traverse a larger space of the atmosphere, but of its lower strata, where it is the most dense and most absorbent. It is estimated that the solar light is diminished thirteen hundred times in passing throngh it, and we are thereby enabled to gaze upon the sun when setting without being dazzled by his beans. The apparent diameter of the grand orb varies slightly at different seasons of the year. This is owing to an actual variation of distance, for the ellipticity of the earth's orbit alternately increases and diminishes our proximity to the luminary. The solar diameter appears the least about the summer solstice, because the sun is then in apogee, or most remote from the earth. It is the greatest about the winter solstice, when the sun is in perigee, or at the nearest point to us. It' seems extraordinary at first sight, that at mid-winter, when the streams are icc-bound, the snow lies upon the fields, and the traveller shivers in the blast, we should be nearer to the sun than when, at an opposite season of the year, the greensward is burnt up, the cattle pant in the shade of the trees, and men seek a covert from the solar heat. But the effect of the sun's rays is increased or modified by two circumstances, more than sufficient to counterbalance that of the varying distance;-the length of time during which they act continuously, and 
their direction being more or less oblique. When he is farthest from us, as in summer, he is daily above the horizon twice as long as when he is nearest, at the winter solstice. This continued action causes a powerful accumulation of heat; and the nights being short, but little of it is radiated, or given off, during his absence. But temperature is affected by the direction of the sun's rays, whether vertical or oblique, their greatest force being experienced when they are perpendicular to the surface; while in proportion as they are oblique, they glance off, and having to pass through a larger portion of the atmosphere, a larger number are absorbed and dispersed by it. Out of ten thousand rays falling upon the earth's atmosphere, 8123 arrive at a given point if they come perpendicularly, 7024 if the angle of direction is fifty degrees, 2831 if it is seven degrees, and only 5 if the direction is horizontal. Now, in summer, the sun, being north of the equator, rises to a greater elevation in the heavens; the rays reach us in a more vertical direction; and the days being longer than the nights, more heat is absorbed than what is radiated. But in winter he traverses those signs of the zodiac that are south of the equator; and, ascending to a less elevation in the heavens, the rays reach us more obliquely, and the days bcing short, the solar action is less continnous. Hence in summer we have the greatest heat though the earth is then farthest from the sun; and in winter the greatest cold when it is at the nearest point.

The mean distance of the sun from the earth, as determined by observation of the transits of Venus, is ninety-five millions of miles. This may be confidently regarded as within $\frac{1}{300}$ th of the true distance, so that no error is involved either way grcater than about three hundred thousand miles. The immense magnitude of the solar body appears from the fact, that it occupies so much space in the heavens, and presents such a stately aspect, with so vast an interval between us. If a locomotive had been started five centuries and a half ago, at the termination of the Crusades, and had been travelling incessantly at the rate of twenty miles an hour, it would only now just have accomplished a space equal to that which lies between the terrestrial and the solar surface. Though light comes to the former from the latter in about eight minutes, a cannon ball would not perform the same feat, retaining its full force, under some twelve ycars. That an object therefore should be so splendidly visible as the sun, so far removed, and should so powerfully influence us with light and heat, argues grand dimensions and wonderful energy. The direct light is supposed to be equal to that of 5570 wax candles placed at the distance of one foot from an object; and so great is the powcr of the rays, that some of the men employed in constructing the Plymouth Brcakwater had their caps burnt in a diving-bell thirty feet under water, owing to their sitting under the focal point of the convex glasses in the upper part of the machine. The sun's diameter of 882,000 miles is equal to $111 \frac{1}{2}$ times that of the earth; and his circumference of 2,764,600 miles describes a bulk nearly a million and a quarter times larger than our own globe, and above five hundred times greater than the united volume of all the planetary bodies that revolve around him. If his mass occupied the place of the earth, it would fill up the entire orbit of the moon, and extend into space as far again as the path of that satellite. The density of the solar substance is, however, far less than that of the matter of our globe. If the two bodies could be weighed in a balance, the weight of the sun would not preponderate in the same proportion as the bulk, but be only 354,936 times heavier. This proportion is about a fourth less than that of the magnitude; so that the same extent of solar substance would be found four times lighter than the same extent of terrestrial substance.

To the naked cye the disk of the sun ordinarily presents a surface incomparably brilliant and uniformly luminous. There is no spot, or wrinkle, or blemish. The perfect purity of its aspect was an article of faith universally received by the ancient world. It 
was not till teleseopic views had been obtained, that the apparently smooth, unchequered, uniformly luminous face of the sun was found to be an illusion. The discovery of the vast and mysterious peculiarities, called the solar spots, is due to Galileo, though it has been elaimed by and for other observers. They were first diseerned by him in April, 1611. In a letter published in the following year, he announced their irregular and rariable figures, the nnequal term of their continuance, their motions across the disk in parallel lines, and their confinement to a narrow zone north and sonth of the sun's equator. Scheiner, a German Jesuit ; and Fabricius, the friend of Keppler, observed them about the same period, but not with the aecuracy of Galileo. Being unaequainted with any method of intercepting a portion of the solar rays to save the eye, Fabricius could only observe the sun at the horizon, when his brilliancy was impaired by the density of the atmosphere, and even then he suffered much from the impression of the solar light. Our own countryman also, Harriot, the companion of Raleigh in his voyage to the New World, must be ranked among the first observers of these phenomena, the discovery and study of which have contributed to correet former opinions respecting the physical constitution of the great orb of day. Though ordinarily to the unassisted sight the sun exhibits a face of uniform and dazzling splendour, yet instanees are recorded of his tarnished surface being pereeptible to the naked eye. Herschel, who intently studied solar phenomena, and lost one of his eyes through the intense glare, mentions a spot appearing in the year 1779 large enough to be thus diseerned. This may explain and justify some statements which have been regarded with incredulity. Thus, we have it upon the authority of Plutarch, that, in the first year of the reign of Augustus, the sun's light was so greatly diminished, that the unprotected eye might steadily contemplate his orb. Abulferagius also relates, that, in the nintl year of Justinian, the sun suffered a diminution of his light, which lasted above a year and two months; and that, in the seventeenth year of the emperor Heraclius, half of his body was obsenred, which continued from the first Tisrin till Haziran; that is, from October to June. Keppler likewise states, that once in his time the solar aspeet was strangely altered, as though a thick haze envcloped his body; and the stars shone out at mid-day. Hakluyt gives the following entry from the log of a ship on the coast of Africa in December, 1590 :- "The 7 th, at sunset, we saw a great black spot on the sun; and on the 8th, both at rising and setting, we saw the like, the spot nppcaring about the size of a shilling."

The spots are all evanescent, but some are sufficiently permanent to be recognised as the same after the lapse of a considerable period. They appear upon the eastern edge of the sun, and move towards the western, vanishing when its edge has been gained, reappearing at the eastern extremity in about thirteen days and a half, to pursue the same route. When first seen upon the eastern limb they scarecly seem in motion, afterwards they appear to travel slowly, their velocity increasing till the eentral regions have been passed, when they apparently relax, and gradually disappear at the western extremity. This is obviously an optical illusion occasioned by the oblique direction in which we view the marginal parts of the sun's body. The fact sensibly demonstrates the solar rotation; but the period included between the appearance of a spot at the eastern edge and its return thither, is greater than the real time of one rotation, owing to the earth advancing all the while in its orbit. The apparent interval of revolution is rather more than twentyseren days; the true time of rotation is somewhat less than twenty-fire days and a half, a much longer period than that taken by our own globe, harmonising with the mightier dimensions of the solar machine. The discovery of the chequered physiognomy and rotation of the sun was so repugnant to ancient ideas respecting the glorious orb, that upon Scheiner reporting the evidence of his senses to his provincial superior, the latter treated it as an illusion. "I have read," said he, "Aristotle's writings from end to cnd many 
times, and I can assure you that I have nowhere found anything in them similar to what you montion. Go, my son, and tranquillise yourself; be assured that what you take for spots in the sun are the faults of your glasses, or of your eyes." Scheiner was not allowed to publish his opinions under his own name; and they appeared anonymously.

Some general results of observation may now be succinctly stated. The spots are not uniformly obscure. They consist of a central portion, characterised by intense blackness,
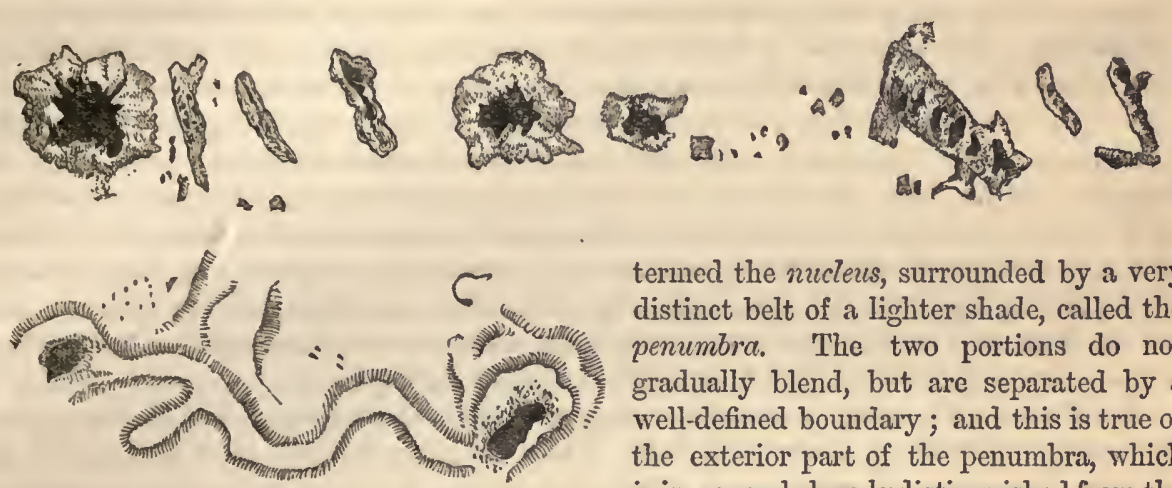

termed the nucleus, surrounded by a very distinct belt of a lighter shade, called the penumbra. The two portions do not gradually blend, but are separated by a well-defined boundary; and this is true of the exterior part of the penumbra, which is in general sharply distinguished from the luminous region around it. By photometrical experiments, Herschel determined that representing the wholly luminous part of the solar surface by 1000 , the relative brightness of the penumbra will be represented by 469 , and that of the nucleus by 7 . On some occasions, though rarely, a large nucleus has appeared without any penumbra ; and on the other hand, a penumbra without a nucleus has been seen.

The spots are of very irregular shape, and varying magnitude. Sometimes they are numerous, but small, while individual spots appear of enormous dimensions. The latter are usually formed by simultaneous enlargement on all sides of the nucleus and penumbra from a comparatively minute speck. On the last day of June 1830, a spot of vast extent was observed. Its diameter was estimated at 23,000 miles ; and being nearly circular, its area included about $443,000,000$ of square miles. But Mayer, in 1754, perceived a spot equal to $\frac{3}{20}$ th of the sun's apparent diameter, which gives it an absolute diameter of more than 45,000 miles. Still greater magnitudes are reported.

Both in form and dimensions, the spots are subject to great changes, which transpire with astonishing rapidity. Two or more, situated very close together, will frequently expand towards each other, and form one large spot. On the contrary, one of great extent has been seen suddenly to crumble into several smaller. Dr Wollaston observed a spot which seemed to burst in pieces, like a lump of ice thrown upon a hard surface. Herschel states, that on the 19 th of February 1800 , he fixed his attention on several spots; but on looking off, even for a moment, they could not be found again. Sir Jobn Lubbock also remarks, that he has observed spots visible to the naked eye, of which, on the following clay, not a trace could be distinguished, even with the aid of a good telescope. These rapid and extraordinary changes indicate that the material subject to them cannot be solid, or liquid, but gaseous.

It is a remarkable circumstance connected with the solar spots, that they invariably appear near the equator, but apart from it. By Galileo they were seen as far as $29^{\circ}$ of latitude, north and south. But Scheiner found them extending to $30^{\circ}$, and called the intermediate region, on this account, the "royal zone." They have, however, been occasionally observed at a greater distance on both sides of the sun's equator, but never at 
the circle itself, or within several degrees of it. They are thus confined to two belts of the solar surface, parallel to its equator, corresponding in some degree to the two temperate zones of the earth.

Intervals of some length have oecurred, during which the disk of the sun has been comparatively pure. This was the case from the year 1650 to 1670 ; and in 1724 the surface appeared unblemished. But from 1611 to 1629 , according to Seheiner, it was never free from tarnish, except for a few days in December 1624. At a more recent date, scarcely a year has passed without spots being seen, many of which have been of great magnitude. It is supposed by Schwabe, whose observations liave been continued without intermission for more than thirty years, that the extent of the solar surface obscured by spots increases and decreases periodically, the length of the period being eleven years and forty days. This remarkable conclusion has attracted great attention; and upon the suggestion of Sir Jolm Herschel, a photo-heliographic apparatus has lately been established at Kew, for the purpose of depieting the actual state of the solar disk from time to time. It has been thought, that spots of vast extent, or unusually numerous, may have the effect of depressing the terrestrial temperature, and thus affect the fertility of the seasons. But so far from such an inference being in harmony with observed facts, some of our warmest scasons have coincided with an aceumulation of spots on the sun.

Besides the dark spots, or maculoe, as they are called, the telescope has disclosed other interesting appearances on the sun's disk. There are parts brighter than the rest of the surface-luminous aggregations-to which the term faculce (little torches) has been applied. They occasionally exhibit a round form, but have generally an extended, ridge-like shape. Though commonly scen in the immediate neighbourhood of spots, they sometimes appear alone, in which case they are almost always the precursors of spots, which become visible on the following day. Messier was frequently enabled by these brilliant indications to predict the appearance of spots twenty-four hours before they actually presented themselves on the disk. While the facula are confined to the "royal zone," or region of the spots, the remainder of the solar surface is diversified with minute luminous specks and streaks, of varying brightness. These are bordered by more obscure jarts, in which a multitude of small pores are observed, as black as the nuclei of the spots. The resulting mottled and corrugated aspect of the sun, Herschel compared to the roughness of an orange.

Conjecture has been busy respecting the nature of these appearances, their cause, and probable indications respecting the physical constitution of the body to which they belong. The early observers, indulging the vagaries of imagination, supposed the spots to be the fuel of the solar furnace, or ashes floating on the surface of an abyss of combustion, or the smoke of volcanic explosions. But the views first broached by Dr Wilson of Glasgow, founded upon a minute examination of their peculiarities, substantially adopted and amplified by Herschel, now generally obtain with astronomers. It secms scarcely to admit of doubt, that the sun is a solid body, surrounded by two envelopes, suspended in a transparent atmosphere; the upper one luminous, forming the visible surface; the lower obseure, a layer of dense clouds, highly reflective, throwing back the light of the upper regions. In these strata, temporary openings or rents are supposed to be made by currents operating from below, analogous to the hurricanes and tornadoes of our tropical districts. The altered appearance of the spots, as they are carried round by the solar rotation, strikingly confirm the fact that they are exeavations; for after passing the centre of the disk, the penumbra is impaired on the side nearest to it, and gradually disappears ; then the nucleus is nipped on the same side, till it vanishes; and then, finally, the penumbra on the opposite side begins to contract, narrows to a line, and is carried out of sight. These variations are exactly those which depressions will present in the course of rotation. Adopting this view, the nucleus of a spot is the exposed dense body or solid substance of 
the sun; the penumbra is the cloudy interior surrounding stratum; and the faculæ, or bright ridges, are accumulations of the exterior luminous matter, heaped up by the violent local agitations. In its interior physical constitution, therefore, that magnificent phantom, or globe of fire, which the ancients conceived the sun to be, is, in all probability, an opaque substance, like the ground we tread upon; and, correspondingly, the atmosphere of our own globe is in a state of constant mutation. It is sometimes charged with clouds, which will completely hide the surface from view at no considerable distance from it. These are often rapidly rent asunder, gathered into distinct masses, and driven again into conjunction, affording transient glimpses of the earth to the adventurous aeronaut ; circumstances which are apparently analogous to the superficial solar changes, though comparatively upon a most puny scale.

If this view of the constitution of the central globe be correct, there are strong resemblances between the sun and the bodies circulating in the system. They exhibit a family-likeness, being opaque masses, having a motion of rotation, and rotating in the same direction. In fact, according to Herschel, the sun appears to be nothing else than a very eminent, large, and lucid planet, evidently the first, or rather the only primary one of our system; and because of this analogy, in regard to solidity, atmosphere, and diversified surface, he was led to infer that it is most probably inhabited by beings whose organs are adapted to the peculiar circumstances of that vast globe. We feel it difficult to embrace this conclusion, from the fact of the solar rays producing, at the distance of so many millions of miles, a heat so considerable, that it must be intense and insufferable on the sun's surface, inferred to be far greater than that of the strongest blast furnace. But heat is only produced by the solar influence when it comes into contact with a substance that combines with it. Various experiments and familiar circumstances prove this to be the case. If the solar radiation collected in the focus of a powerful lens is thrown into the air, and continued there for a considerable time, no sensible heat will afterwards be perceived at the place, though had the most incombustible object been exposed there, such as gold or platina, it would have been fused. The eternal snow rests upon the summits of high mountains, which receive the direct infuence of the sun's rays, while in sheltered parts of valleys below, receiving only their indirect influence, there is overpowering heat. The ligher in the regions of the atmosphere an acronaut ascends, the more intense is the cold, though there is nothing to interrupt the solar influence. Heat, thercfore, is only generated by the sun's rays, when they unite with caloric, or heat in a latent state. We may conceive, then, the temperature of the sun's luminous atmosphere to be greater than that of any artificial heat which chemistry or galvanism can produce; yet the great globe itself may be constituted incapable of any chemical combination with the rays of the brilliant atmosphere without, beyond a certain extent, and if so, a temperature consistent with animal and vegetable life may there exist.

It is not, however, unlikely that the penumbra of the spots, - the stratum of dense clouds below the vividly resplendent visible surface of the sun,-may officiate to moderate the effect of the exterior atmosphere. Sir John Herschel, referring to that inner curtain of the mighty orb, remarks, "That the penumbral clouds are highly reflective, the fact of their visibility in such a situation can leave no doubt." They may thus serve the purpose of effectually defending the sclar body from the insufferable light and heat of the outermost surface, furnishing the solid nucleus of the luminary with a moderate temperature by their friendly interposition.

In the class of solar phenomena, Eclipses of the sun are always interesting, and sometimes imposing events. Few occurrences have given rise to more anxious feelings in the human breast, or have been watched with more unfailing curiosity. We are so familiar with their physical causes, and can predict with such nicety the time of their appearance, 
that it is impossible for us to estimate the impression they would make upon the ignorant mind, transpiring under circumstances favourable to their full effect. To beliold the sun, after shining in all its glory, apparently lose a part of the disk, become more indented, and then entirely invisible, while perhaps not a cloud has appeared upon the sky to account for the elange of aspect; to witness nature in the elear day suddenly invested with an unaccountable gloom, the larger stars becoming distinet, and the brute creation exhibiting symptoms of restlessness and alarm; to feel a chilling cold supplanting the fervent heat of noontide, - these are peculiarities calculated to excite the consternation of uncivilised tribes, as well as of nations unaequainted with their true natural explanation. They have accordingly arrested the tide of battle, and perplexed monarchs with fear of change. In the first year of the Peloponnesian war, on a summer afternoon, there was an eclipse of the sun that was nearly total. Thucydides states, that the sun looked for a time like the crescent of the moon, and some stars appeared, but the full orb shone out afterwards in all its lustre. Pericles, according to Plutarch, was then on board his galley, about to proeeed on a warlike expedition; and it required some address on his part to quiet the apprehensions of his troops, who looked upon the darkness as an unfarourable omen. Not many years afterwards, when the $\Lambda$ thenians were in desperate cireumstances in the harbour of Syracuse, and had resolved on retiring, an eclipse of the moon happening at the hour appointed for the retreat, excited their alarms, caused a delay, and led to the destruction of both fleet and army. Columbus once rescued himself from cireumstances of great difficulty, when in want of provisions which the Jamaicans refused to supply, by means of a lunar eelipse. Knowing that it was nigh at hand, he announced it to them as a token of the anger of the Great Spirit on account of their inhospitality, which lad the desired effect when the beautiful orb began to be impaired. Chronology has derived much valuable assistance from the connection which superstitious fear has recorded between particular events and these phenomena, for eclipses may be calculated thousands of years backwards with the same precision as forwards. Thus the coincidence between a total eclipse of the sun, a rare oceurrence in the same region, and the battle between the Lydians and Persians, establishes the date of the latter; and the very day on which the great battle of Arbela was fought is likewise known from its taking place eleven days after an eclipse.

A solar eclipse is oceasioned by the dark body of the moon interposing between the sun and the eartl, and deflecting a shadow upon the latter. The shadow cast by an object is merely an interception of the light of some illuminating body, and has its shape and extent

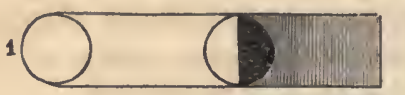
determined by the form and relative magnitudes of the two. If the moon were as large as the sun, her shadow would be cylindrical, like the first figure, and of an unlimited length. If she were of greater magnitude it would resemble a truncated cone, the diameter and length increasing to an indefinite extent, as in the second figure; but being immensely inferior to the sun, she projects a shadow which converges to a point, like that in the third figure. This shadow, at the distance of the earth from the moon, ean never be more than about a hundred and seventy miles broad; and eonsequently the sun ean never be totally eclipsed at the same instant over a greater extent of terrestrial space. But as the earth is continually moring, the shadow is a passing traveller, and sweeps over it; no total obscuration of the sun lasting longer at one spot than about eight minutes. Although the limits within which an eclipse is total are very circumscribed, it will be more or less partial over an area baving a diameter of five thousand miles. In the diagram, lines 
drawn to the earth from the upper and lower limbs of the sun and moon define the conical

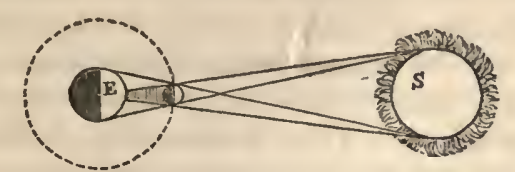
shadow projected by the latter, or the umbra, which, wherever it falls, occasions a total obscuration of the solar orb. Similar lines drawn to the earth along opposite edges of the two bodies define the limits of a fainter shadow, or the penumbra, caused by the moon only hiding parts of the sun's disk; and, within the space it includes, the eclipse is more or less partial, according to the situation of an observer.

As a general rule, it may be stated that an eclipse will diminish in magnitude about one digit for every two hundred and fifty miles from the centre where it is total - a digit being the twelfth part of the solar or lunar surface. The lunar shadow may, however, terminate, when the earth is in a direct line with it, without reaching its surface. When the sun is at the least distance from us, and the moon at the greatest, the shadow will fall short of our globe by about twenty thousand miles, though when these elements are reversed it is sufficiently long to extend nearly the same distance beyond us. In the former case the sun has his greatest apparent diameter, and the moon her least. She is unable, therefore, to cover his entire face, and appears projected upon his disk, with a slender ring of dazzling light around her dark body. This is termed an annular eclipse, from the Latin, annulus, a ring.

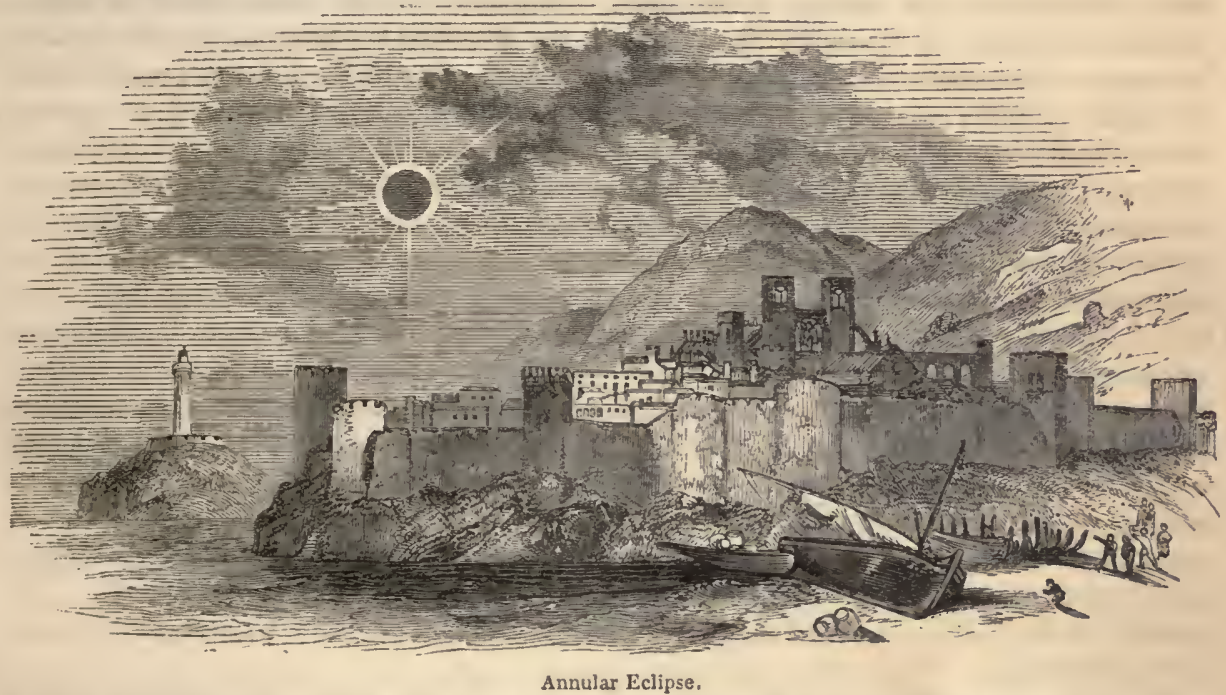

An annular eclipse is a rare occurrence. The last, on the morning of October the 9 th, 1847 , was very imperfeetly observed owing to cloudy weather.

There may be five solar eclipses in a year, and the least number which can take place is two. As the moon passes through that part of her orbit which lies between the sun and the earth once a month, we should obviously have an eclipse every month, every new moon, if she moved in the plane of the earth's orbit. This is, however, not the case-the lunar path is inclined to that of the earth. She is above it during one half of her course, and below it during the other, crossing it twice a month at two opposite points, called leer nodes. It is only when the moon is between the sun and the earth, at or very near her node, that is, when her path cuts the plane of the earth's orbit, that she intercepts to us the solar light, and eclipses occur; at other times, she passes either above or below the 
sun as seen from the earth, and the earth passes above or below her shadow. Owing to the irregularity of the moon's motions, she does not cross the plane of the earth's orbit at the same point in every revolution, but these points shift through a certain interval, after which the same change is repeated, and the same cycle of eclipses occurs. This interval is eighteen years and about eleven days, a period early diseovered by the Claldean astronomers, and used for the purpose of foretelling eelipses. Thus, on the sixth of May 1845, there was a solar eclipse; and if we add to this era the ecliptic period just named, we are carried on to the seventeenth of May 1863, which will be the epoch of another. The complete period is 6585 days, 7 hours, $42 \frac{1}{2}$ minutes nearly. But though the eclipses of each cycle correspond, and may be regarded as identical with respect to the earth in general, they vary in their appearances, and as to the localities in which they are visible. There was an eclipse of the sun visible at the north pole in the month of June 1295, but ever since, it has been proceeding more southerly. It made its first appearance in the north of Europe in August 1367. It was central in London in 1601, which was its nineteenth return; and nearly so again on the 15 th of May 1836, its thirty-second appearance. At its thirty-ninth return, in August 1880, the lunar shadow will fall south of the equator, and continue receding from it, until its seventy-eighth appearance will be at the south pole, on the 30 th September 2665 .

Though solar eclipses are of common occurrence, yet a total one depends upon a conjunetion of so many cireumstances, that the spectacle liappens only on very rare occasions, even anywhere on the surface of the earth. Especially at the same place, or within convenient distance of it are the opportunities for observing the phenomenon few and far between, so that entire astronomical lives have passed away without being gratified with the sight. Halley, in a paper on the total eelipse of the sun which happened at London on the 3d of May 1715-the reign of George I.-remarked, that there had not previously occurred a similar event, visible in that city, since the 20th of March 1140-the reign of Stephen-an interval of five hundred and seventy-five years. "I forbear," he observed, addressing the Royal Society, "to mention the chill and damp which attended the darkness of this eelipse, of which most spectators were sensible and equally judges. Nor shall I trouble you with the coneern that appeared in all sorts of animals, birds, beasts, and fishes, upon the extinction of the sun, since ourselves could not behold it without some sense of horror." One of his correspondents who was stationed on an eminence on Salisbury Plain, wrote to him as follows: "It was the most awful sight that I had ever beheld in my life. We looked in vain for the town of Amesburg, situated below us; scarcely could we sce the ground under our feet. So dcep an impression has this spectacle made on my mind, that I shall long be able to recount all the circumstances of it with as much precision as now." The total obscuration lasted 3 minutes, 22 seconds. The planets, Jupiter, Mercury, and Venus, with the stars, Aldebaran and Capella, were visible to the naked eye.

A partial solar eclipse, however considerable, gives not the faintest idea of what a total one is, as to the obscuration, the chill, and the altered physiognomy of heaven and earth. The "Saxon Chronicle" records of the eclipse in the reign of Stephen:-_"In the Lent the sun and the day darkened about the noontide of the day, when men were eating; and they lighted candles to eat by. Men were very much struck with wonder." Of the same event, William of Malmsbury states, that "while persons were sitting at their meals, the darkness beeame so great, that they feared the ancient chaos was about to return, and upon going out immediately, they perceived several stars about the sun." An eclipse visible in Scotland in 1433, was long remembered by the people of that country as the Black Hour; another in 1598 was similarly commemorated by the inhabitants of the border counties as the Black Saturday; and a third in 1652 gave rise to the expression 
of Mirk Monday. The darkness which attends full solar eclipses appears to vary, owing chiefly to a difference in the condition of the atmosphere, and the time of the day. Though strongly marked on all occasions, it is more peculiar than profound; and altogether confined to the brief period of totality. So long as the smallest portion of the lustrous orb is visible, there is considerable light. Nature simply looks sobered and saddened till the moment of entire obscuration arrives. Then, besides the sensible diminution of light, a strange, spectre-like aspect is stamped upon the appearance of every object-sky, clouds, trees, buildings, mountains, streams, animals, and man-producing an effect which is unexpected, sublime, and cven appalling. Equally startling and remarkable is the change upon the first re-appearance of the solar ray. It rushes out suddenly, and with brilliant effect from the limb of the overshadowed orb, and in an instant the day is restored to nature. An interesting ancedote appeared in the journal of the Lower Alps respecting the eclipse of July 8, 1842. "A poor child of the commune of Sièyes was watching her flock when it commenced. Entirely ignorant of the event which was approaching, she saw with anxiety the sun darken by degrees, for there was no cloud or vapour visible which might account for the phenomenon. When the light disappeared at once, she began to weep; and in the height of her terror, called out for help. Her tears were still flowing when the sun sent forth his first ray. Reassured by the aspect, the child crossed her hands, exclaiming, in the patois of the province, "O beou souleou!" "O beautiful sun!"

The eclipse just referred to excited extraordinary interest, as the lunar shadow travelled over a part of Europe studded with crowded cities, the north of Italy, and the southern provinces of France, Germany, and Russia. It was well observed at various stations by the leading astronomers of the age. M. Arago awaited its occurrence at Perpignan; M. Valz at Marseilles; M. Petit at Montpelier; M. Carlini at Mrilan; MM. Santini and Conti at Padua; MM. Schumacher and Littrow at Vienna; MM. Otto Struve and Schidlowsky at Lipesk; while of our own countrymen, Mr Baily was posted at Pavia, and Mr Airy at the Superga near Turin. The sun was totally hidden $2 \mathrm{~m}$. and $11 \mathrm{~s}$. at Perpignan; and $3 \mathrm{~m} .5 \mathrm{~s}$. at Lipesk. The planet Mars, with Aldebaran, Capella, two stars of the constellation Gemini, and others, shone out. At Venice, the citizens remarked, with reference to a steamer on the Lagunes, that the column of smoke from the funnel ceased to be visible, while the sparks of fire which accompanied it were very distinct and striking. The obscurity had a wan and livid hue-a shade of grayish olive-which scemed to throw over nature an air of appalling sickliness, and imparted to the human countenance an aspect painful to contemplate. The heavens appeared of a grayish violct; horses and other animals employed in the fields halted at once, and obstinately refused to move; but, on the other hand, the fact was well ascertained, that horses in the diligences jogged on without seeming to be at all affected by the phenomenon. At Montpelier, the bats, thinking that night was come, left their retreats; an owl was seen to leave the church tower of St Peter, and fly over part of the town; the swallows disappeared; the fowls went to roost; a herd of cattle, feeding in a ficld, formed themselves into a circle, with their heads directed ontwards, as if to resist an attack; and several plants, which usually shut up their leaves at night, were observed to close. A heavy dew fell at Perpignan, Turin, and Vienna, during the total obscuration; and the red stars Aldebaran and $a$ Orionis appeared quite white. The fidelity with which this eclipse answered to previous calculations respecting the time of its occurrence, made a powerful impression upon the popular mind, with reference to the advanced state of science, and the regularity which marks the great clock-work of the universe. At Milan and Pavia the populace gave vent to their feelings in a general Huzzah! vivent les astronomes!

When totally obscured by the body of the moon, the place of the sun is made apparent by the brightness of that part of the heavens in which it is situated. This brightness appears 
in the form of a corona, or luminous ring, encircling the moon and exhibiting a radiating

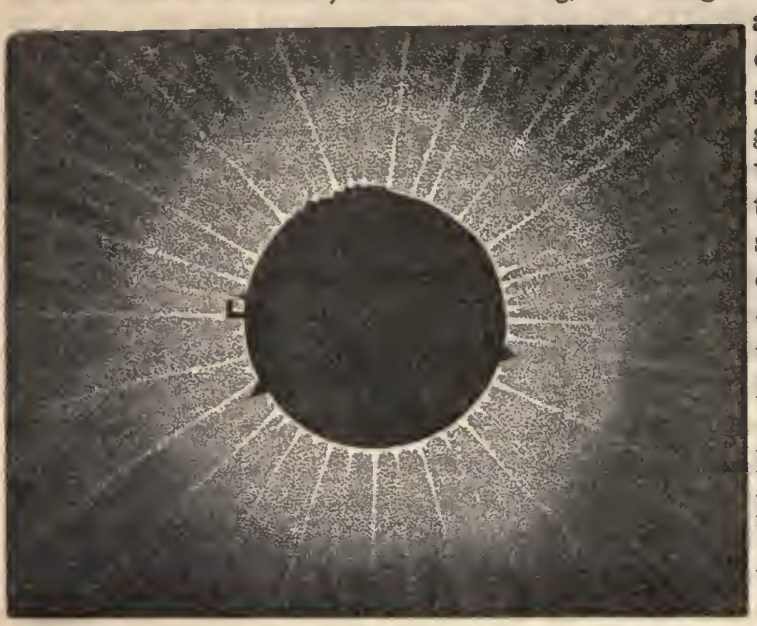
aspect. The most probable conclusion, founded upon its round shape, nebulous structure, and gradually diminishing density outwards, is, that the ring is due to the presence of an extensive atmosphere which encompasses the solar orb. Other striking features of total eclipses are ruddy spots, or protuberances, varying in colour from light pink to deep crimson, which appear upon the margin of the dark lunar disk. They have been compared by different observers to beautiful sheaves of flame, and to the snowy peaks of the Alps, rosecoloured by the morning or evening sun. These appearances are supposed to arise from clouds suspended in the atmosphere of the sun, which absorb nearly all the rays of the spectrum, except the red, as in the case of the terrestrial clouds when illuminated after sunset. It has been often remarked, that when the margin of the moon comes into contact with that of the sun, the appearance presented is that of a broken glimmer of light, which the late Mr Baily compared to a link of bright beads. The curious spectacle of "Baily's beads," as they are called, seems to be caused by the rough mountainous edges of the moon, which touch the margin of the sun, while transiently the sunlight gleams through the chinks or valleys between them.

A delicately luminous cone is sometimes seen accompanying the sun, extending from the horizon obliquely upwards in the direction of the zodiac, and, therefore, called the Zodiacal Light. It appears before sunrise and after sunset, but is never seen by us so well defined as in the equatorial regions, though it may frequently be discerned after the evening

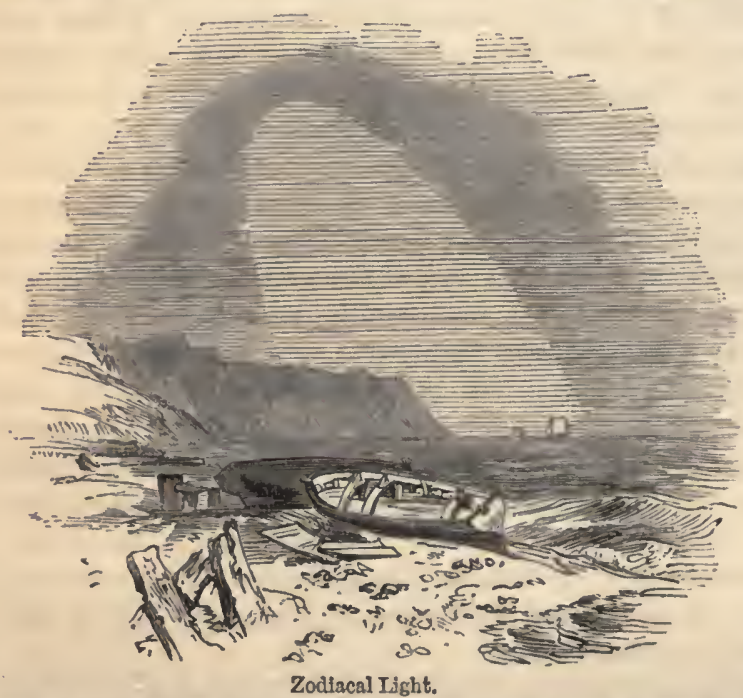
twilight in March and April, and before the morning twilight in September and October. The light resembles in appearance the tail of a comet. The faintest stars shine through it. Its colour varies according to the state of the atmosphere, but it is generally of a pure rose tint. The brightness also varies, and some years it has never been seen at all. Keppler appears to have been the first who noticed this phenomenon. Afterwards Cassini observed it, and when Humboldt was travelling in South Amcrica, he had several distinct views of it at Caraccas. Its extent from the sun, situated at its base to the vertex, varies from $45^{\prime}$ to $50^{\prime}$, and its breadth at the base from $20^{\prime}$ to $30^{\prime}$. It has been conjectured that 
it derives its form,- - that of a long and narrow ellipsis, only the half of which we see, -from its rapid revolution with the sun on its axis; but the nature of the phenomenon itself is one of those points respecting which we are compelled to confess our ignorance.

The decline of the sun to the horizon is as imposing a spectacle as his advance to it, when the atmosphere favours the exhibition of the descent. The most gorgeous sunsets are those of the West Indies, during the rainy season. The sky is then sublimely mantled with gigantic masses of clouds, which are tinged with the glare of the descending luminary, and which seem to be impatiently waiting for his departure in order to discharge their pent-11p wrath on the bosom of the night. In the South Atlantic the sunset has a milder and more sober aspeet. In the Eastern tropies it has generally an overpowering fierceness, as though the last expression of the solar heat should be the greatest. But during the summer, in temperate latitudes, there is often a serenely beautiful horizon, a mellowness of light, together with a rich and varied colouring of the sky, which combine to render the European sunsets far more attractive than those which are intertropical. The milder radiance of the "great light" in parting from us presents a picture to the eye of the sentiment of the All-Merciful, "Again, a little while and ye shall see me." And how open to observation are wise Contrivance and bountiful Design in the unvarying position of the sun in the centre of the system, and the axical rotation of his tributaries, which not only guarantee the regular return of their surfaces to his presence, but the undiminished power and splendour of his beams! If, instead of an instant creation, we suppose the masses of the sun and of the planets to have been gradually formed, under control of the law of attraction, the question still arises, how it came to pass, that the self-luninous matter was collected into one mass at the centre, and not gathered into many masses like the matter of the planets. So striking did this circumstance appear to Newton, that he remarked in his first letter to Bentley: "I do not think it explicable by mere natural causes, but am forced to ascribe it to the counsel and contrivance of a Voluntary Agent."

\section{CHAPTER II.}

\section{MERCUTY - VENUS-THE EARTH.}

To a superficial observer of the heavens at night when the moon is absent, only one class of objects will be apparent - the stars. But a little attentive observation will discover other bodies, which, besides taking part in the apparent revolution of the celestial concave, will be found to have independent movements. They seem stationary at intervals, then in motion from west to cast, and going back again from east to west, their positions constantly changing in regard to the earth, to each other, and to the host of stars. These peculiarities were marked in very early times, and in allusion to them the Greeks applied to such bodies the term planet, which signifies to wander. Their course, capricious and uncertain to the ancient eye, is now discerned to be a direct and regular highway; and hence, if as yet they had received no general title, we should find one for them, expressing the prosecution of orderly rather than erratic travel. The planets are divided into primary and secondary. The former revolve round the common centre of gravity in the system; the latter officiate as satellites to the primaries in their great pilgrimage, and combine with it a revolution round them. The planets are also divided into inferior and superior, referring to their positions being within or without the path of the earth. The expressions are somewhat unfortunate, for the immediate idea conveyed by them refers to 
magnitude rather than to situation, and in that sense is erroneous. Venus, an inferior planet, is far larger than Mars, one of the superior, and more resplendent than any of the rest. The words interior and exterior will exactly express what is intended, prevent confusion, and had better be adopted. The planets are denoted in astronomical writings by their respective symbols, as $\Varangle$ Mercury, $q$ Venus, $\oplus$ the Earth, $\delta$ Mars, $\%$ Jupiter, ${ }_{2}$ Saturn, II Urauus, and

'The paths of the planets are elliptical, as previously described; but the ellipses vary to some extent in their eccentricity, or as to the distance of the sun at $\mathrm{s}$, from the ecntre

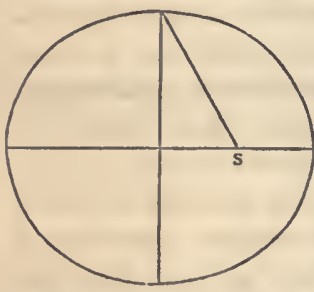
of the oval, which here represents a planetary orbit. 'This distance in the case of Mereury is about seven millious of miles; in that of Venus it is less than half a million; in that of the Earth it is somewhat more than a million and a half; in that of Mars it is upwards of thirteen millions : while in that of Juno and Pallas it is sixty-four millions and a half. The orbits of the plancts are more or less inclined to each other, instead of lying in the same pline. It may be desirable here to explain the meaning of this oft-recurring phrase. Referring to the earth, an imaginary smooth and thin surface, cutting through the centre of the sun, and reaching out to the fixed stars, is the plane in

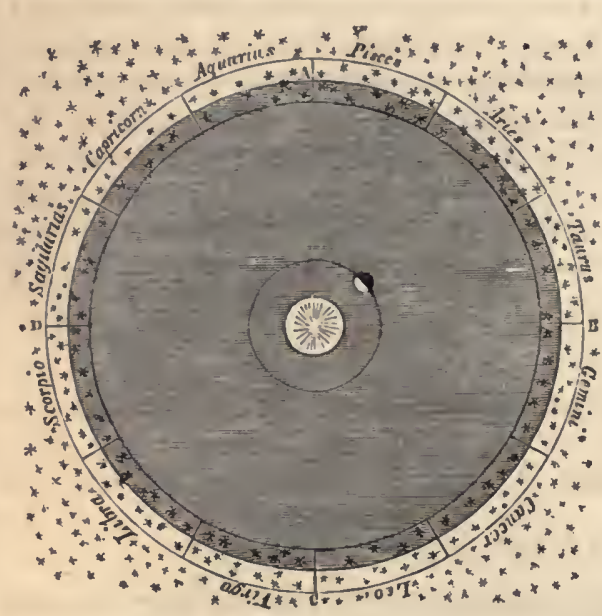
which the earth moves in revolution round the sun. This is represented by the shaded part of the diagram. The stars to which it extends form the constellations of the zodiac, the circle $A, B, C, D$, being the ecliptic, which shows the sun's place in the heavens as seen from the earth, or the earth's as seen from the sun. The orbits of the other planets are in different degrees inclined to this plane, one half being below and the other half above it. If we suppose the shaded part of the diagram to be the surface of a basin of water, a ring held inclined so as to dip into it half way, will describe the relation between the plane of the earth's orbit and that of another planet. The mean velocity of the planets in their orbits exhibits great diversity, those which are nearer to the sun being far more rapid than those which are remote. Saturn prosecutes his circuit at the sober pace of little more than twenty thousand miles an hour, while Mercury rushes on at a rate which is more than five times that speed. The extraordinary swiftness of the interior planets is obviously necessary to counterbalance the powerful attraction of the solar mass, which acts with diminished force upon the bodies that are more distant from him.

Mercerr, the nearest planet to the sun, is the smallest primary in the system, with the exception of the asteroids. It is the fastest traveller also, having a velocity in space ' which is nearly twice the rate of the earth's orbital motion. It is the densest celestial body with which we are acquainted, supposed to be fourteen times that of water. $\Lambda$ globe of lead therefore of the same volume, if weighed in the balances against its mass, would be found wanting. Yet notwithstanding this remarkable density, if loosened from the centrifugal force, it would require more than a fortnight for the planet to accomplish its dash headlong to the sun. The days and nights are about the same length as our own; but a whole cycle of seasons has been four times gone through, before the eartl's 
spring, summer, autumn, and winter have once revolved. Owing to comparatively near neighbourhood, the sun will occupy seven times more space in the Mercurian heavens than in ours, and afford a light and heat which would be intolerable to our organs without some modifying circumstances. We may, however, dismiss the idea of water always boiling at the surface, and an ever-burning heat seven times greater than the fiercest experienced at our equator, distinguishing its material. The sensible heat at the different planets may depend chiefly upon their substance being more or less adapted to combine with the solar influence; there is nothing improbable, therefore, in the supposition that the nearest may be as cool, and the remotest as warm, as the temperate zones of the earth. Besides, it is a proud presumption to imagine the organism of the terrestrials to be the standard and model of finite beings. We are bound to admit that the great Author of existence can as duly attemper to every dwelling-place the physical constitution of its inhabitants, as obtains with reference to our globe and its population.

Mercury is at the mean distance of thirty-seven millions of miles from the sun, and performs an orbital revolution in about 88 days, travelling at the rate of more than a hundred thousand miles an hour. This speed originated the name-that of the swiftwinged messenger of the gods. The planet rotates upon its axis in rather more than twenty-four hours, and has a diameter of 2950 miles. Its volume must therefore be increased upwards of twenty millions of times in order to equal the sun in magnitude; but the mass, if increased only two millions of times with matter of the same density, would be equal in weight. Mereury is an evening star when eastward of the sun, and a morning star when westward of him, but is quite invisible to the naked eye, owing to the vicinity of the solar splendour, except at or near the time of the greatest elongations. The telescope discovers phases like the moon, and atmospherie indications. Some have even professed to discern irregularities of outline, supposed to express superficial elevations; but of this we have no certainty. Not the least departure from the circular form in the shape of the planet was detected till the transit of November 1848, wheu micrometrical measurements, executed by the Rev. Mr Dawes, showed it to be slightly spheroidal.

Astronomers have been sorely plagued in their observation of Mercury - a giddy planet - imperceptible generally, through a close attendance upon the sun - never at such a distance from him as to appear in a dark part of the heavens - and going at a rate through space, which is a perfect gallop when compared with the sober jog-trot of the earth. These circumstances, together with the smallness of the planet's mass, and a

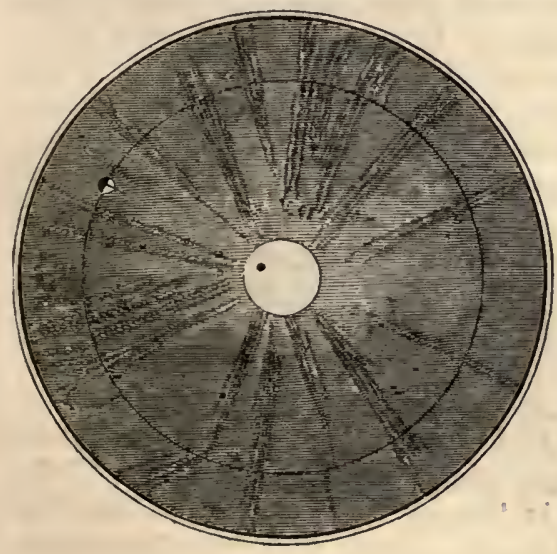
peculiar quick scintillation, render it a very difficult object to examine. Copernicus is said never to have seen Mercury through his whole life, and Delambre was only able to discern him twice with the naked eye. The description of one of the old writers - a "squirting lacquey of the sun, who seldom shows his head in these parts, as if he were in debt"-however odd, is yet characteristic. The planet may be caught for a short time before sunrise in autumn, and after sunset in spring; and appears to sline with a brilliant white light, being alternately a crescent, a semicircle, and gibbous. When between us and the sun, and at the same time in the plane of the earth's orbit, Mercury transits the solar disk, and is seen as a small black speck 
upon the surface, an evident proof of the borrowed radiance of the orb. The first transit ever observed was predicted by Keppler, and witnessed by Gassendi, at Paris, on the 7th of November 1631. The second observed transit, on the 3d November 1651, was watched at Surat, in India, by Shakerley, a young Englishman, who, having found by calculation that it would be visible only in Asia, proceeded thither to witness the occurrence. Tho third recorded transit, on the $3 d$ of May 1661, was observed by Hevelius at Dantzic, and by Huyghens, Street, and Mercator at London, who are said to have made their observations at Long Acre, with a telescope of excellent workmanship. Halley enjoyed the sight of another, 7th November 1677, at St. Helena; and was the first who witnessed both the ingress and egress of the planet. Lalande, in his old age, remarked of tho transit of 8 th November 1802 :- "The passage of Mercury over the sun's disk was observed this morning for the nineteenth time. Astronomers enjoyed in the completest manner the sight of this curious phenemenon. I was the more anxious to have a view of it, as I shall never see it more."

The recent transits of Mercury have been chicfly interesting on account of the accuracy with which they have been predicted. Formerly, owing to difficulties of observation, the tables of the planet's motions were so imperfect, that there was no certainty respecting the exact time of the phenomenon. Gassendi was on the watch three days for the transit he witnessed. Hevelius and his assistants were kept waiting at their telescopes four days. Both Halley's and Lalande's calculations were wrong by three quarters of an hour with reference to the transit of 1786 . At a later date, the errors amounted to minutes. At length, in 1844, Leverrier took the planet in hand, instituted a profound examination into the theory of its motions, and constructed tables which represent them with wonderful precision. Mr. Mitchel, of the newly-established observatory of Cincinnati, in the United States, remarks of the transit of 8th May 1845:- "Five minutes before the computed timo of the contact (Leverrier's), I took my place at the instrument; the beautiful machinery that carries the telescope with the sun was set in motion; and the instrument directed to that part of the sun's disk at which it was anticipated the contact would take place. It scemed as if time had folded his wings, so slowly did the moments crawl on. I watched until I was told that but one minute remained; and within sixteen seconds of the time, I had the almost bewildering gratification of secing the planet break the contact, and slowly move on till it buried itself, round, and deep, and sharp, in the sun."

Venus. The nearest planet to the earth, and the second in point of distance from the sun, Venus is the most beautiful of his satellites, and brilliant of the stars. Like Mercury, she never adorns the midnight sky, nor has she ever been seen rising in the east while the sun was setting in the west, or on the meridian at either sunrise or sunset. This shows her path to be comparatively near the throne of the great luminary, from whom she never departs more than $48^{\circ}$, rather more than half the space from the horizon to tho zenith; and to be interior to that of the earth, while exterior to that of Mereury, whoso greatest elongation, or distance from the sun, is little more than $28^{\circ}$. In addition to this, she has been observed to eclipse Mercury, a clear proof of her position in space being external to him, an instance of which occurred on the 17th of May 1737. Venus is alternately a morning and evening star, visible for about threo hours after sunset, and as long before sunrise. As a morning star she was called Phosphorus and Lucifer by tho ancients, and as an evening star Hesperus and Vesper. This bright herald of the sun's advance to the eastern horizon, and his faithful follower to the western, were once supposed to be distinct bodies. Pythagoras is said to have been the first who proclaimed their identity. Obvious as this conclusion now is, it required experience and reflection to arrive at it. The Greek Phosphorus, or the light-bringer, alludes to the office of the planet, when rising before the sun, she ushers in the day. The Romans adopted the expression: hence, the invocation in Martial, Phosphore, redde diem, "O Phosphorus, 
restore the day." As an image of the anticipated dawn of full mental illumination, the sacred writers introduce the day-star; and it occurs as an emblem of mere human glory in the ode on the overthrow of the King of Babylon :-

"How art thou fallen from heaven, O Lucifer, son of the morning!"

Homer compares the son of Hector to the star that gilds the morn, and the point of the spear of Achilles to the keen light of radiant Hesper. Men of all ages, climes, and ranks, from the shepherd boy to the grave philosopher, have turned with interest and delight to this planet; and whether examined as a telescopic object, or contemplated with the unassisted sight, it is an inexpressibly lovely orb, and one that will always excite admiration.

Venus is situated in the system at a mean distance of sixty-eight millions of miles from the sun, through which she would fall in thirty-nine days and a half, if surrendered solely to the attraction of his mass. Her periodical revolution is accomplished in $224 \frac{2}{3}$ days, involving a velocity of 80,000 miles an hour. The planet is rather smaller than our own globe, having a diameter of 7700 miles. She rotates upon her axis in about $23 \frac{1}{2}$ hours. Venus exhibits alternately a fine thin crescent and a semicircle like the moon, but she can scarcely be seen quite full, because when the whole of her enlightened hemisphere is turned towards us, she is either behind the sun or so near him as to be hid by the splendour of his light. The diagram represents the various appearances of the planet as she moves in her orbit, in the order of the letters.

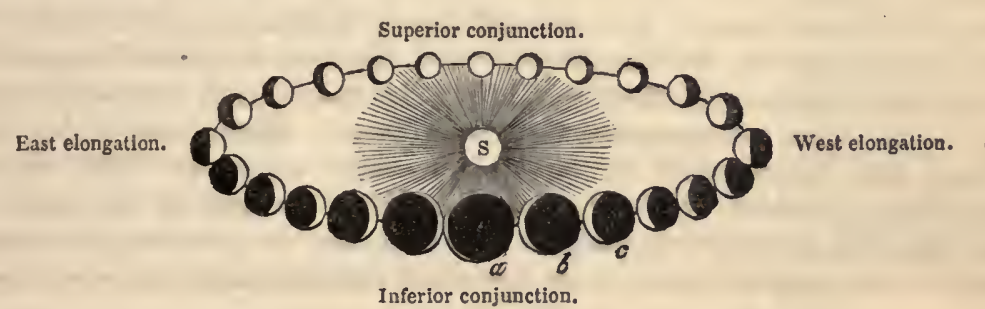

We first behold Venus as a morning star for a short time before sunrise, soon after passing between the earth and the sun at her inferior conjunction, when she appears crescent-shaped as seen through a telescope. She continues gradually to gain upon the sun, rising earlier and earlier, until her greatest angular distance westward has been attained, when she exhibits a semicircle, and shines with great splendour. Then the planet begins to return towards the luminary, making the same daily progress as in separating from him, rising later and later, diminishing also in brilliance, owing to the overpowering solar glory, in which she is lost at the time of her superior conjunction, being then behind the sun in relation to us. A few days afterwards Venus becomes an evening star, and is seen a short time east of the sun after his setting. She soon seems to have fallen considerably behind him, and continues to depart farther and farther, setting later every night, until her greatest elongation eastward has been reached, when she again exhibits a bright semicircle. The course towards the sun is then resumed, until she comes between him and the earth, sets with him, and is invisible, owing to the whole of her enlightened side being turned away from us. In a few days the phenomena of the morning star are repeated. Venus is seen to keep on the same side of the sun for a period of about two hundred and ninety days together. This seems at first sight a singular anomaly, as it is a greater interval than that occupied by an entire circuit round him It is however at once accounted for by considering that the earth is proceeding at 
the same time in the same direction, though at a slower pace. The planet accomplishes an angular motion of $1^{\circ} 36^{\prime}$ per day, while the earth follows at the rate of $59^{\prime}$, and is thus gained upon by only $37^{\prime}$ daily. But the two planets will obviously appear to keep on the same side of the sun, until Venus has gained half her orbit in advance, or $180^{\circ}$. This it will require about two hundred and ninety days to effect, as the difference of their daily rate, $37^{\prime} \times 290=10730^{\prime}=180^{\circ}$ nearly. It will be seen from the diagram, that at the time of the inferior conjunction, the unenlightened half of the orb is turned towards us. Did she present in that position lier illuminated side, we should see the planet as a small brilliant moon, shining with twenty times her ordinary lustre, as she is then a hundred and sixty millions of miles nearer the earth than when at the opposite point. $A s$ it is, however, she is our best friend among the stars, the most radiant of the lost, and has been observed to cast a clearly defined sliadow.

This planct, like Mercury, transits the sun's disk, and then appears shorn of her beauty, under the form of a dull dark spot. The first instance of the phenomenon being seen by any human being occurred on the 24th of November 1639 , under remarkable circumstances. It was observed by two youthful friends; Jeremiah Horrocks, at Hoole, near Liverpool, and William Crabtree, at Broughton, near Manchester. The great credit in the observation is due to the former of these individuals, who anticipated the event, and predicted the time. Upon Keppler completing his tables in 1627, he predicted that Venus would pass over the sun's disk on the 6th of December 1631. He died before the time arrived. The transit was looked for, especially by Gassendi, but it was not seen; and Keppler had distinctly announced that it might not be visible in Europe, as the planet would not be in contact with the sun till towards sunset. It is now well known to lave taken place during the night between the 6 th and 7 th. But Keppler had stated, that after this period Venus would not be seen again upon the solar disk till the year 1761. This was an error. Horrocks suspected it on going over the tables, and comparing them with others. Having repeated his calculations, he found that Venus might be expected to enter upon the solar disk a little before sunset, November 24, 1639. It appears that the time of the transit was nigh at hand when the discovery was made, so that there was no possibility of giving general publicity to the expected event, in an age when communication was very slowly maintained.

Though not doubting his own calculations, Horrocks did not deem it prudent to trust implicitly to them. Accordingly, the day before the event was really expected, he watched the sun at intervals; but only ordinary appearances were noticed. The next day, a Sunday, he attentively obscrved the solar image from sunrise till the hour appointed for going to church-" "higher duties," as he remarks, "which might not be neglected for these pastimes." Upon becoming at leisure, he resumed his observations ; and at a quarter past three o'clock in the afternoon, his sagacity and industry were rewarded. "At this time," he states, "an opening in the clouds, which rendered the sun distinctly visible, scemed as if Divine Providence encouraged my aspirations, when, oh! most gratifying spectacle, the object of so many wishes, I perceived a new spot of unusual magnitude, and of a perfectly round form, that had just wholly entered upon the left limb of the sun, so that the margins of the sun and of the spot coincided with each other, forming the angle of contact." Owing to the near approach of sunset, his time of observation was limited to about half an hour. Meanwhile, in the neighbourhood of Manchester, the day opened inauspiciously, and continued gloomy to a late hour in the afternoon. Crabtree had abandoned all hope of being ablc to test the prediction of his friend, till just before going down below the horizon the sun broke through the clouds. Repairing to the room where he had made his preparations, he saw the round black spot with unspeakable delight; and, according to Horrocks, he was so struck with admiration at the spectacle, as to continuc gazing upon 
it, without attempting to take measurements, till it became impossible to do so, owing to the clouds returning. Both observers received the sun's image through a telescope in a dark room upon a piece of white paper.

The transits of Venus are of special interest from their rarity and great physical importance. They occur at intervals of eight years, a small section of individual life ; but alternating with intervals of more than a century, during which whole generations pass away, thrones crumble, and dynasties change. They are of importance as the very best means of ascertaining the distance and volume of the sun, which supply data for determining the distances and magnitudes of the planets, and serve as a universal standard of astronomical measurement. The second recorded transit, in 1761, was well seen; but the discordance of the results obtained at different stations shonk faith in the accuracy of the observations. For the third and last, in 1769, many of the European governments sent costly expeditions to various parts of the globe ; and among others, Captain Cook was despatched to witness the phenomenon at Tahiti. The next transit will occur December 9, 1874 ; and though not visible in this country, it will be watched elsewhere with an intensity of scientific solicitude which no natural incident has ever yet excited, and with much better instruments than have before been used. Another will follow after an interval of eight years, December 6,1882, which will be seen in England, but only partially, commencing near sunset. Venus will not again be seen upon the sun's disk through the whole of the next century, or till June the 8th, 2004.

But little is known of the physical constitution of Venus, owing to the intense splendour with which she shines. 'The existence of a considerable atmosphere is inferred from the appearance of a penumbral light round the planet during her trausits, as well as from a faint radiance observed to stretch beyond her directly illuminated hemispliere. The line in the annexed uppermost figure marks the boundary of the direct influence of the sun's rays; and the upper and lower projections beyond it show the twilight, which is referred to atnospheric reflection. Variable and fleeting spots lave also been repeatedly noticed, as in the second figure, which naturally leads to the supposition of an atmosphere cliarged with clouls and vapours, with water upon the surface, from which they are formed. The conclusion that she has mountains and valleys rests upon the fact that the edge of her enlightened part appears shaded, that her corners are sometimes obtuse, and present a luminous point apparently detached from the planet. Schroeter regarded this as the summit of a high mountain, illuminated by the sun after he lad ceased to be visible to the rest of that hemisphere. If these conclusions may be depended upon, and they are warranted by strong evidence, Venus presents striking points of analogy to the constitution of the earth. An atmosphere reflecting light, the medium of sound, and a highway for "fire and hail, snow and vapour," - a superficies exlibiting the diversities of land and water, hill and vale - these are some of her probable attributes, features expressing a family likeness to our globe, and indicating the action upon her surface of that mighty upheaving agency, which, in bygone ages, piled the Alps, and reared the ramparts of the Himalaya.

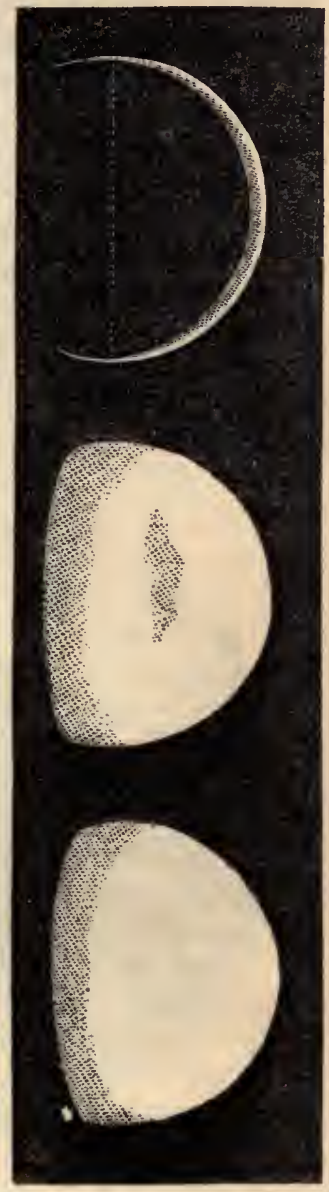


The Eartir. We now come to the abode of Man - the cradle, the home, and the grave of our race for a period of six thousand years - the third planetary body in point of distance from the central sun, and the first in the system of which we have eertain knowledge of its being dignified with the presence of an attendant orb. The introduetion of our globe to a place among celestial objects involves an apparent contradiction; yet such is its real character in the constitution of the universe, and such is its obvious aspect as viewed away from its surface. To rustic ignorance it will seem a statement palpably absurd, that any affinity exists between the earth and the stars in the firmament. They are mere points of light in the sky, and hare no perceptible dimensions, whereas our world appears of immensurable extent, and exhibits no luminosity like theirs to the eye of sense. It seems, too, a perfectly inert mass. There is no movement discernible independent of that of the rivers flowing in their channels, the seas tossing in their bed, and the forests bending to the gale, while the celestial bodies appear in constant procession from place to place in the concave of the heavens. There is nothing, however, more susceptible of demonstration than that the obvious state of our globe is not its actual condition - that the apparently quiescent habitation of mankind is an unceasing trareller in space-that its opaque mass exhibits the same luminous aspect to the nearer planets which they present to us - and that in structure and eeonomy the earth is in fraternal relationship to the celestial host, and may be denominated, with perfect propriety, a star.

Pliysical scierice; in the three departments of astronomy, geograplyy, and geology, deals with the mass of our globe. The former is chicfly concerned with its figure and magnitude, its ntmosphère and motions.

To the eye thè ebrth appears an immense plain stretching out in all directions to an indefinite extenit. This was the current opinion of mankind respecting its form in carly times: But a few simple facts prove the suggestion of the senses liere to be erroneous. The linit of tisibil to the traveller upon an extensive level, or to the mariner at sea, is a well-deffined eirele of which the observer is the eentre; and it may be geometrically

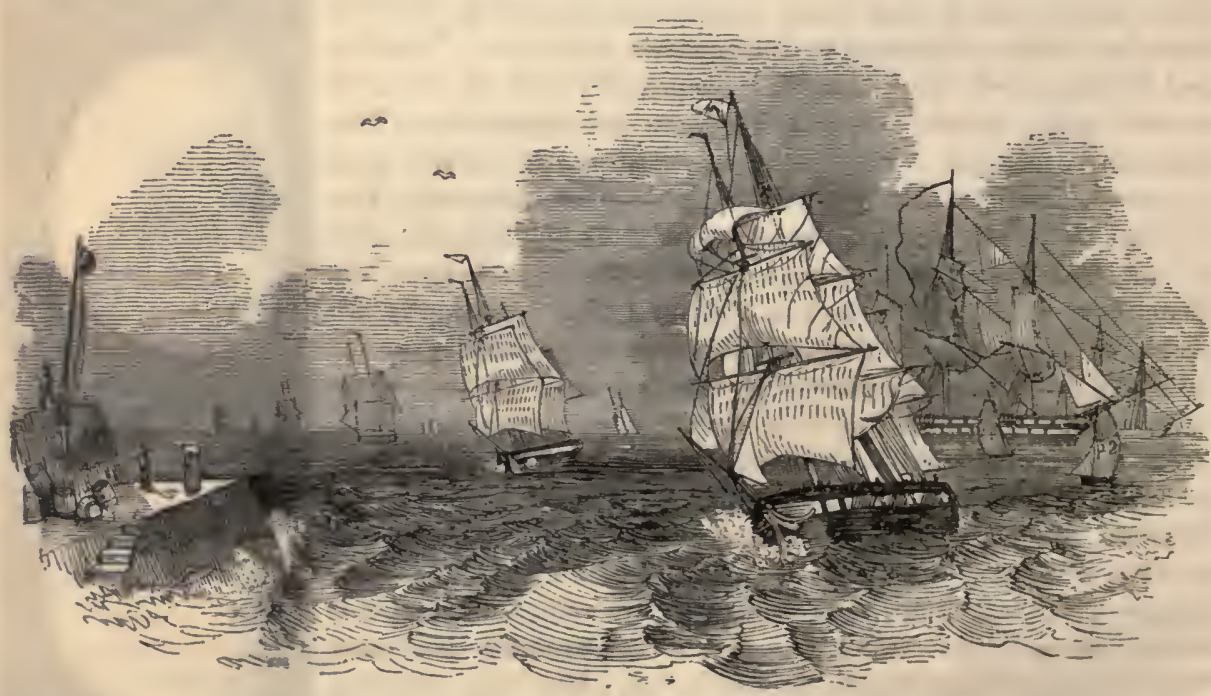

proved, that this circular horizon is a certain indication of the eircular figure of the body to which it relates: In any direction in which a ship leaves shore, or approaches the coast, the ressel is observed as if gradually sinking in the ocean, or rising from it - 
evidence of the convexity of the water between the eye and the object. We also find, that during a lunar eclipse the shadow projected by the earth upon the disk of the moon is always of a circular shape. The common occurrence now of a voyage round the world, proceeding in the same general direction, east or west, and arriving at the same point again, demonstrates the figure of the earth to be either that of a sphere or a cylinder; and the latter is disproved, and the convexity of the surface shown, north and south, by the gradual declination or rise of the north and south circumpolar stars, as the equator is approached or receded from. Our terrestrial mansion, therefore, is a vast mass of matter of a spherical form like the planets whose round disks are the objects of telescopic observation. The spherical figure of the planetary bodies - a result of the law of gravitation - is, on many accounts, the best shape they could have assumed. The same phenomena could not have been offered to their surfaces, with the same machinery, supposing any other form. Had the earth been a rotating cylinder, the solar beams could not have reached its two extremities together, or its general superficies with either extremity. But it is only an approximation to the truth of its actual shape, to speak of our world as having a spherical form. It is not a globe whose circumference is everywhere at an equal distance from the centre, a property essential to a sphere. A process of reasoning led Newton to the conclusion, that the circle of the earth's daily rotation upon its axis being the greatest at the equator, the consequent greater action there of the centrifugal force would produce a bulging out of the surface in the equatorial regions of a yielding mass, and a flattening at the poles; and this deduction from the laws of forces has been proved to be correct by the actual measurement of the lengths of degrees of the meridian, made with care and precision by the commissioners of various nations. The certain conclusion obtained is, that our globe is an oblate spleroid, an orange-shaped ball, compressed at the poles, and elevated at the equator, having the following dimensions : -

$$
\begin{array}{lllll}
\text { Diameter at the equator } & - & - & - & 7925.648 \text { miles } \\
\text { Diameter at the poles } & - & - & - & 7899 \cdot 140 \quad-
\end{array}
$$

The length of the axis of the poles is thus about twenty-six miles and a half less than the diameter of the equator. It is highly improbable that any error of importance exists in this measurement, founded upon the principle first employed by Eratosthenes, when he attempted to determine the value of an arc of the meridian between Alexandria and Syene.

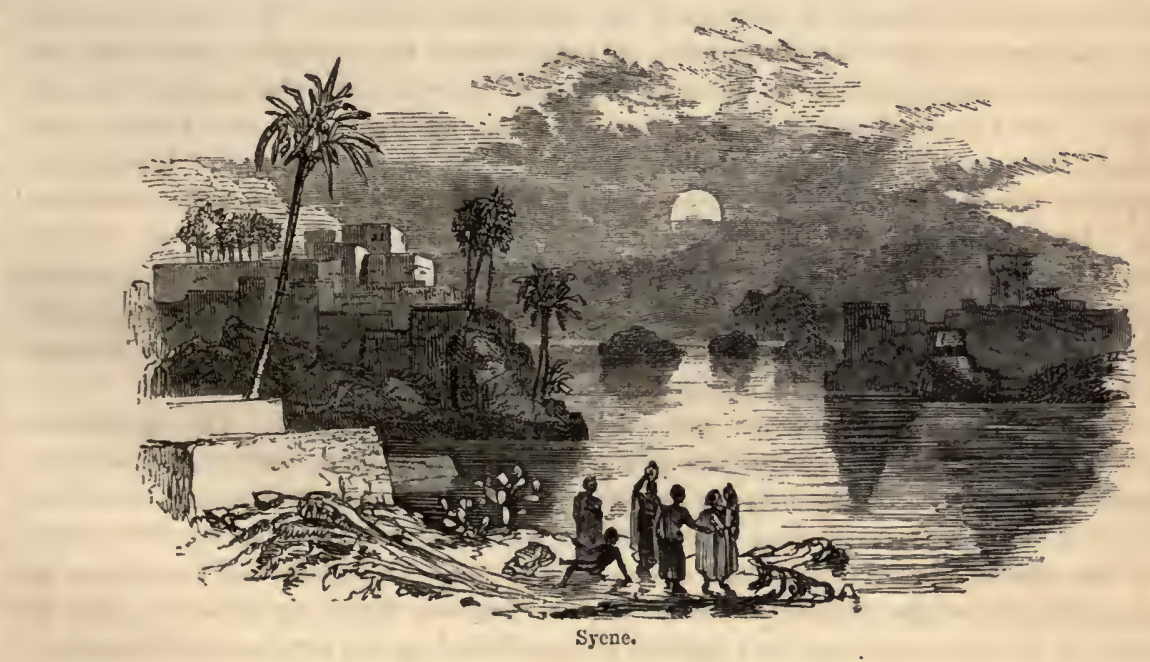


Sir John Herschel considers it unlikely that an error to the extent of five miles can subsist in the diameters; and the equatorial diameter gives an extent of nearly twentyfive thousand miles, accurately 24,899 , as the value of the equatorial circumference.

The earth lias two principal motions, a rotation upon its own axis, and a translation in space. We can obviously have no ocular evidence of the diurnal rotation like that which we obtain in the case of the sun and some of the other planets, by observing the movement of spots upon their surface. But we have ample proof of the fact. There is absurdity upon the face of the ancient doctrine, that the daily apparent procession of the heavenly bodies round the earth is a real progress - that a point utterly insignifieant when compared with the general aggregate of stars is a centre around which they circulate; and when we think of the inconceivalble velocity with which they must travel, in order to compass the immeasurable circles which in that ense they describe, the absurdity heightens. The rotation of our globe is not, however, a doctrine based on probabilities. The experiment of falling bodies descending in advance of the plumb line is direct and positive demonstration of the fact, corroborated by the diminution of the force of gravity at the equator. According to Laplace, the chances are eight thousand to one that the earth so revolves. The rate of the earth's rotation at the equator, where the cirele of the circumference is the greatest, is about sixteen miles a minute. Its velocity, at thirty degrees of latitude, which is below the most southerly point of Europe, is computed at fourteen miles in the same time; and at forty-five degrees, or about the centre of France, it is eleren miles. Laplace has diseussed the point with great eare, whether the rate of the diurnal rotation is liable to be perturbed, and the time of revolution affected by the influence of volcanoes, earthquakes, winds, and currents in the ocean, and has demonstrated their effeets to be altogether insensible. He has also examined the question, whether a variation of the mean temperature of the globe may not have influenced the velocity of rotation, and altered the length of the day. The temperature at the bottom of deep mines indieates a central heat. Geological appearances also intimate a lạrge portion of the erust of the globe to have onee been in a state of fusion, and it is a well-known property of heat to cause the expansion of the substances into which it enters. Allowing therefore a former very high temperature, the contraction of the terrestrial spheroid would be a consequence of its cooling down, the diminution of its volume without altering its mass, through the molecules approximating to the eentre, eausing therely some change of velocity in the superfieial rotation. We have no reason, however, to suppose, that any diminution of temperature lias occurred, since man has existed upon the soil, sufficient to produce a sensible alteration in the length of lis day and night. All history proclaims its uniform duration, age after age; and Laplace, who first started this speculation, eame to the conclusion, that since the time of Hipparehus, the length of the day has not been affected by the two-hundredth part of a centesimal second. How beautiful the arrangement of the diurnal revolution of our terrene mansion! How benign the results! 'The alternation of light and darkness - the gorgeous sunrise - the resplendent noon - the calm glory of the erentide-the absorption and radiation of heat-and the trade winds, upon whose uniform dircetion and constant action the navigator reekons on the breast of the occan.

The other prineipal motion of our globe is its translation in space. This appeals not to our senses like the orbital movements of the surrounding planets, but it is supported by irrefragable evidence. It accounts for the phenomenon of theapparent annual revolution of the sun, as an aetual transit in a vessel on the whter accounts for the apparent movement of the banks of a river, or the shore of the sen. It satisfactorily explains the seeming anomalies of the planetary paths. It has received direct confirmation from the aberration of the stars, and may be regarded as established on the firm basis of demonstra- 



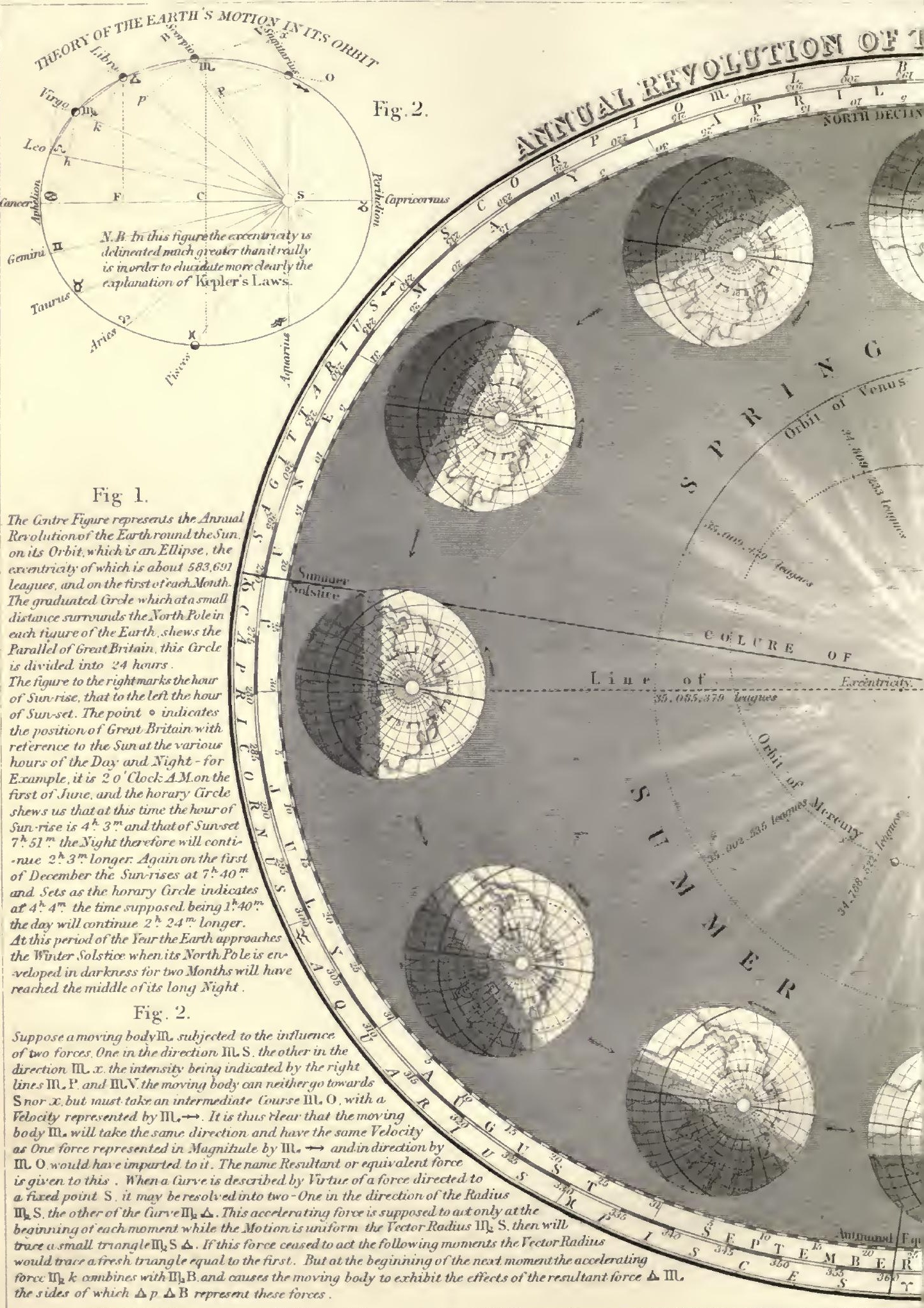




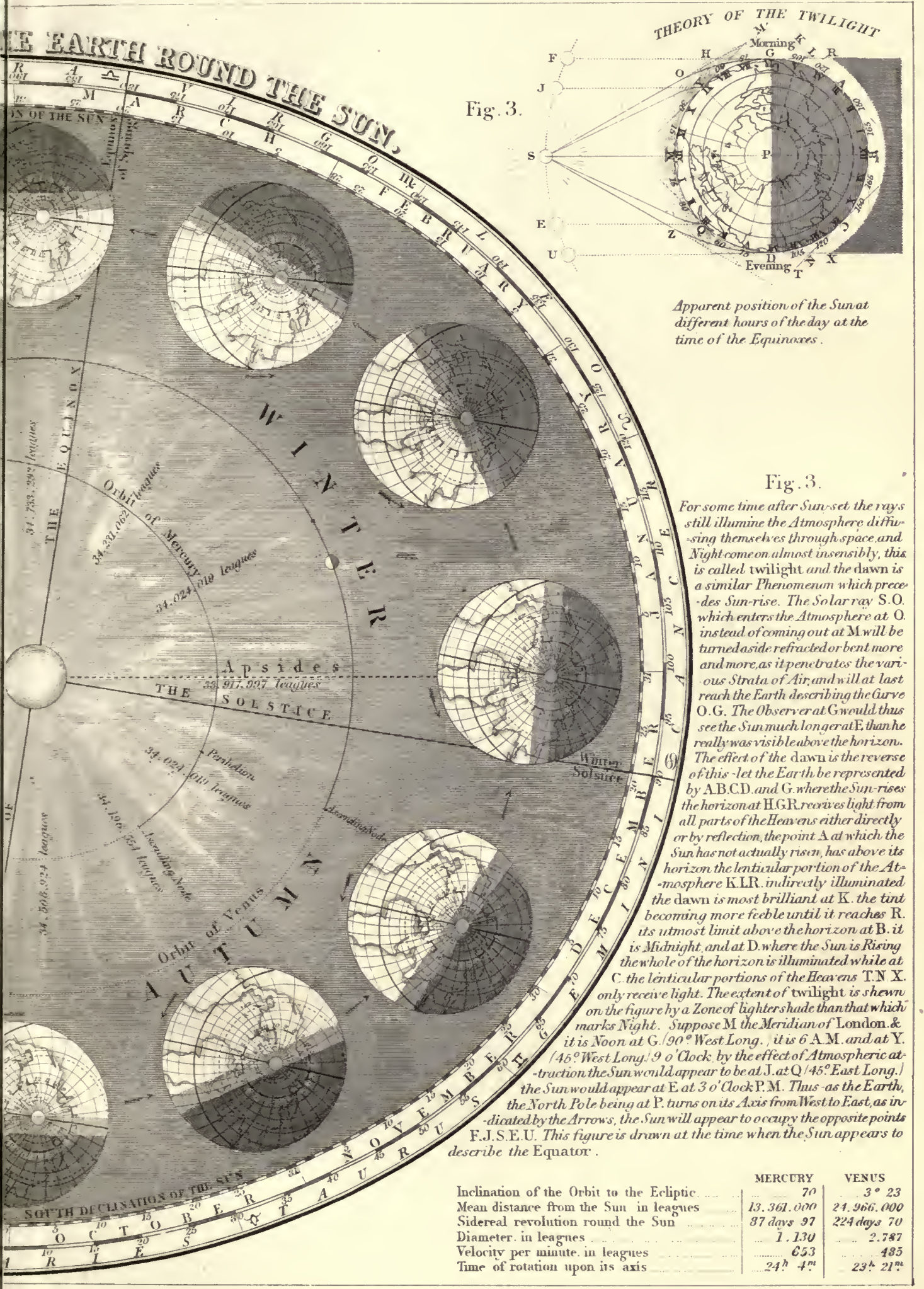


<smiles>[CH][CH]</smiles> 
tion. Placed at the distance of nincty-five millions of miles from the sun, the carth has an orbit of near six hundred millions of miles to travel over. This circuit is performed at the mean rate of sixty-cight thousand miles an hour. Supposing the impulse that appoints this path to be withdrawn, in sixty-four days and a half, the terrestrial would crash with the solar surface, and sink into its mass like a millstone in the sea, owing to its greater density. 'That diversity of seasons which marks the year of our globe is the joint result of its movements, and of the inclination of its axis to the plane of its orbit. Supposing one of the poles to be always pointed towards the sun, as in fig. 1, then, not-

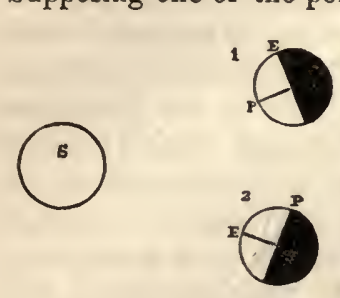
withstanding the daily rotation and the motion in space, the regions fiom the poles to the equator would be one half in constant light and the other half in constant darkness. Or supposing the equator always pointed directly towards the sun, as in fig. 2, light and darkness would alternate for equal times on all parts of the globe; and there would be different seasons at different places, but no change of seasons in cvery place as at present. 'The axis is inclined $23 \frac{1}{2}^{\circ}$ from a line perpendicular to the plane of the orbit, and remains constantly parallel to itself during the annual revolution. This arrangement causes the same part of the globe to experience days and nights of unequal length, and to receive the solar influence in a more or less oblique direction. The annexed view represents the earth in four different parts of its orbit.

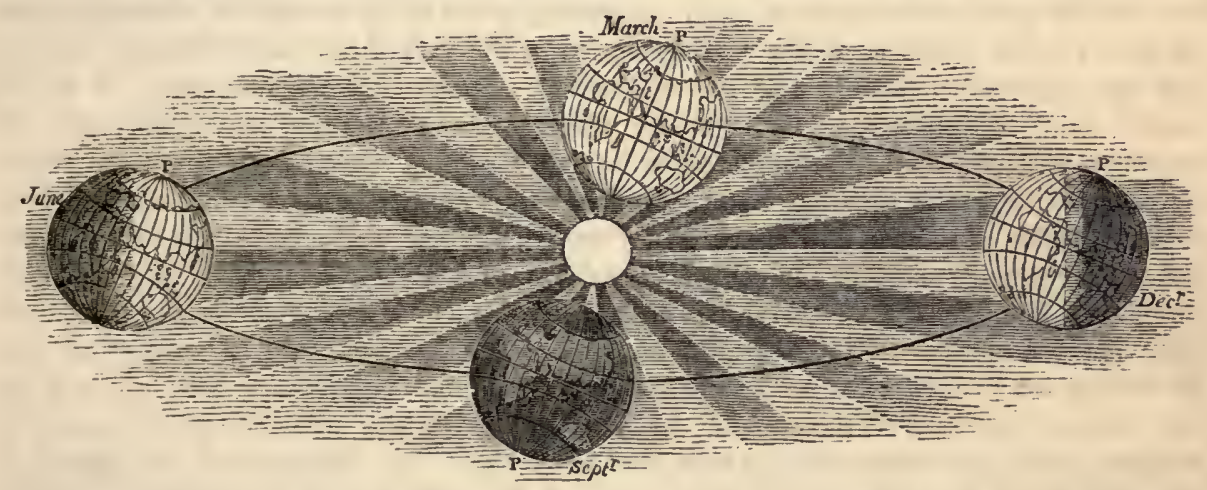

It illustrates the varying direction of the sun's rays to the same regions of the globe, and the varying duration of the diurnal exposure to their action, and withdrawment from it. Thus, at the vernal and autumnal equinoxes, it will be seen, that the sun's light reaclies equally from pole to pole, so that each part of the surface is carried by the daily rotation into light and darkness of the same duration. At the summer solstice, as the earth rotates, the whole arctic circle enjoys continued day, while the north temperate zone has not only long days and short nights, but receives the sun's rays less obliquely than at the former periods, and consequently experiences an increase of temperature. A precisely opposite effect takes place in the same region at the winter solstice. Hence arises scasonal vicissitude with its resulting phenomena, the repose of vegetation in winter, the renewal of the face of nature in spring, the manhood of its productions in summer, and their autumnal ripeness and garnering.

There is a third motion to which the earth is subject, occasioning what is called the precession of the equinoxes. Wherever, in spring and autumn, the sun, in his apparent annual course, crosses the equinoctial, or the circle of the earth's equator extended to the heavens, there are the vernal and autumnal equinoxes. These points are found to 
have a constant motion westward, at a very small yearly rate, but which effects considerable alterations in a series of ages. To give a familiar illustration of the faet, we may suppose three roads to extend round the earth: one, running due east

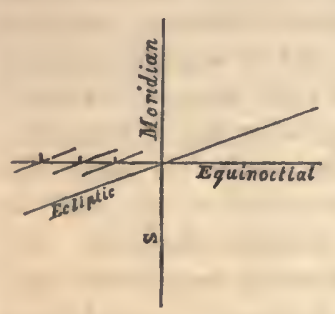
and west, representing the equator or equinoctial; another, proceeding above and below the former, crossing it at two opposite points, representing the ecliptic; a third, erossing the first at right angles, at the points of interseetion with the second, representing the prime meridian, or initial point of longitude. We may now suppose a earriage to be started along the ecliptie from the common point of intersection, returning, after a eomplete eireuit of the earth, not to the place from whenee it started, but passing the equinoctial about a hundred rods to the west of it. The repetition of this at each circuit, the more westerly intersection of the roads, will illustrate the annual retrograde movement of the equinoctial points, termed on account of its effect in accelerating the time of the equinoxes, their preeession, or going forward. This movement, first observed by Hipparehus, eauses a progressive increase of the longitude of the stars, and has been clearly shown to be a necessary consequence of the rotation of the earth, combined with its elliptical figure, and the unequal attraction of the sun and moon on its polar and equatorial regions. The mass of matter about the earth's equator being greater than at the poles, the former is more powerfully aeted on by the law of attraction than the latter, which produces a slow reeling motion of the axis of the earth from east to west, and the retrocession westward of the equinoetial points. The retrogradation is at the rate of about $50_{4}^{1 \prime \prime}$ in a year, or $1^{\circ}$ in $71_{\frac{1}{2}}^{1}$ years, so that in a period of 25,000 years the equinoxes will aecomplish a complete revolution along the eircle of the eeliptic. While the plane of the earth's equator, or the equinoetial, thus experiences a constant displacement from the action of the sun and moon, it is a remarkable and well ascertained fact that the plane of the earth's orbit, or the ecliptic, is subject to a slow annual displacement, which diminishes its obliquity, an effect due to tho baiting which our globe endures from the other planets, chiefly from the attacks of Jupiter and Venus. In consequence of this, the tropics are slowly and steadily approaching the equinoctial, so that the sun does not now come so far north of the equator in summer, nor deeline so far south in winter, by a degree, as he must have done six thousand years ago. The obliquity of the ecliptic, or the angle which the plane of the earth's orbit makes with that of the equator, has been observed with eare in different ages, and the following results obtained.

\begin{tabular}{llccccc} 
& \multicolumn{9}{c}{ Date. } & & Obliquity. \\
Eratosthenes & - & - & 230 B.C. & - & - & $23^{\circ} 51^{\prime} 20^{\prime \prime}$ \\
Ptolemy - & - & - & 140 A.D. & - & - & $23^{\circ} 48^{\prime} 45^{\prime \prime}$ \\
Ulugh Beigh & - & - & 1463 & - & - & $23^{\circ} 30^{\prime} 17^{\prime \prime}$ \\
Cassini - & - & - & 1655 & - & - & $23^{\circ} 29^{\prime} 15^{\prime \prime}$ \\
Flamstead - & - & - & 1690 & - & - & $23^{\circ} 29^{\prime} 00^{\prime \prime}$ \\
Bradley - & - & - & 1750 & - & - & $23^{\circ} 28^{\prime} 18^{\prime \prime}$ \\
Maskelyne & - & - & 1800 & - & - & $23^{\circ} 27^{\prime} 56^{\prime \prime} \cdot 5$ \\
Airy - & - & - & 1840 & - & - & $23^{\circ} 27^{\prime} 36^{\prime \prime} \cdot 5$
\end{tabular}

Thus, in the interval of two thousand years, the obliquity of the ecliptie has deereased by only $23^{\prime} 43^{\prime \prime} \cdot 5$. There is little ground, therefore, for the apprchension of the seasons being annihilated owing to the ecliptic coinciding with the equator, and equalising the length of our days and nights. The event is far away in the womb of the future, even supposing the diminution to go on without eleck. But the theory of gravitation tells us 
that it will at length cease, and an increase of the obliquity set in, to decrease again and increase, oscillating about a mean position within very restricted limits.

One of the most important attributes of our globe as a planet is the gaseous envelope that encloses it on all sides - the atmosphere - essential to the vitality of its organised occupants, man, brute, bird, and plant, but chiefly interesting to the astronomer

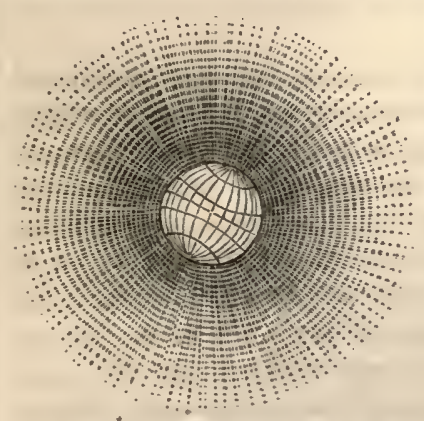
from its influence in displacing celestial phenomena by its refractive power, and diffusing the rays of light so as to surround us on every hand with visible glories. 'The atmosphere rapidly diminishes in density as we recede from the surface. The diagram exhibits various strata of air resting upon the earth, the upper pressing upon the lower, and causing the interior to be more dense than the exterior strata. It is not known how high this elastic medium extends, but

\section{" to breathe}

The difficult air on the ic'd-mountain's top,"

is an experiment which shows the atmosphere to be exceedingly rare at no greater height than what is reached by many of the superficial elevations of the earth. Mr Green the acronaut ascended in a balloon upwards of five miles-the greatest altitude ever renched by man. Visible clouds, however, are supposed to be sometimes twice that height, and atmospheric phenomena have been noticed, conceived to have had an elevation of forty miles. But the chief peculiarity of our planet is the presence of a sccondary body as a satellite, reflecting to its surface the light of the sun in the absence of his direct rays. It has indeed been supposed that Venus is similarly dignified, and we are not in circumstances to say positively that this is not the case, either in relation to her or Mercury, as such an attendant, if small, might exist, and have hitherto escaped notice, owing to the position occupied by those bodies. Cassini and others have imagined they perceived a satellite attending Venus, but the observation has not been verified.

The terrestrial world occupies a favoured place in the system, a position from which nearly all the sister planets are visible to the naked eyc. It will not be seen itself by the inhabitants of Uranus, and be scarcely perceptible to those of Saturn. As an interior planet to Jupiter and Mars, it will appear occasionally as a spot upon the sun's disk, performing similar transits to those of Venus and Mercury. Its great divisions of land and water, the outlines of its continents and seas, with its masses of ice and snow at the poles, will be seen from Mars; and at the time of the inferior conjunction of Venus, when she is not more than twenty-six millions of miles removed from us, our globe will exhibit a full orb, shining with great splendour through the whole of her night.

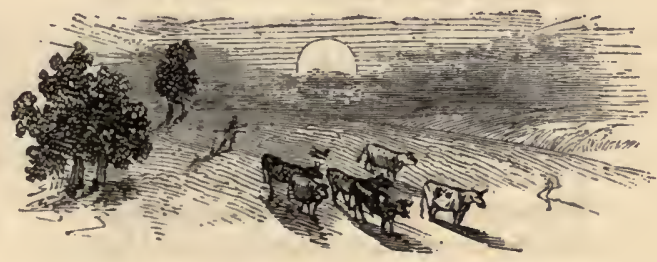




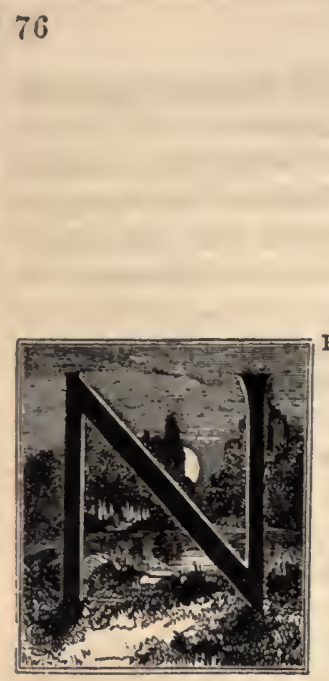

SCENERY OF THE HEAVENS.

CHAPTER III.

THF MIOON AND LUNAR PHENOMENA. raccs. The unfailing performance within a definite period of a synodical revolution, or the cycle included between each conjunction with the sun, when she is invisible, called synodical, from the Greek word signifying a coning together, has rendered the moon a convenient time-keeper to men in rude states of society, and won for her the love and respect of savage tribes. Among the wandering hordes of the western continent, sueh a number of moons measures the duration of a journey, and the lapse of events ; and successive lunar appearances are discriminated by coineident terrestrial occurrences, as the wild-strawberry moon, the wild-rice gathering moon, the ice moon, the deer-rutting moon, and the leaf-falling moon. Some of the sacred ceremonies of the Jews, in the early periods of their listory, were regulated by the sign of the lunar crescent in the heavens, and the rabbins relate, that persons were stationed on the tops of the mountains to watch for the first appearance of the moon, which erent was proclaimed by signal fires throughout the land. In all ages, the eye of man has gazed with delight upon lier face, whether in courtly or in rustic life, from old baronial halls or cottages obscure. The meek splendour, the quietude, the fidelity, of which the luminary is a visible image, bewitch the senses, excite the imagination, and lave originated some of the most captivating strains of poetic description, among which the Trojan bivouac scene in the Iliad still stands peerless.

\footnotetext{
"The troops exulting sat in order round, And beaming fires illumin'd all the ground.

As when the moon, refulgent lainp of night,

O'er heaven's clear azure spreads her sacred light ;

When not a breath disturbs the deep serene,

And not a cloud o'ereasts the solemu scene,

Around her throne the vivid planets roll,

And stars unnumber'd gild the glowing pole;

O'er the dark trees a yellower verdure shed,

And tip with silver every mountain's head;

Then shine the vales, the rocks in prospect rise,

A flood of glory bursts from all the skies;

The corscious swains, rejoicing in the sight,

Eye the blue vault, and bless the useful light."
}

An imaginary soliloquy, put into the mouth of Milton by a living writer, strikingly expresses the emotions of such a mind, upon first perceiving the curtain about to fall 
between him and the resplendence of day and night, through the blindness that attended his declining ycars. "Beautiful light! beautiful lamp of heaven! what marvel that the blinded and benighted leathen should ignorantly worship thee? What marvel, that a thousand altars, in a thousand ages, slould have sent up their fumes of adoration unto thee, the mooned Ashtaroth - unto thee, the Ephesian Diana-unto thee, the nightly visitant of the young-eyed Endymion? What marvel, that to those who knew not, neither had they heard of the One, Uncreate, Invisible, Eternal, thou shouldst have seemed meet Deity to whom to bend the knee, thou first-born offspring of his first-created gift! thou blessed emanation from his own ethereal glory! What wonder, when I, his humble follower, his ardent though unworthy worshipper-when $I$, an honest though an erring Christian, do strive in vain to wean my heart from love of thee; indoctrinating my spirit, that I may kiss the rod, with which I am assured, too well, He soon will ehasten me, in changing the fair light, that glorious essence in which my soul rejoiceth, for one black, everlasting, self-imparted midnight? Yet so it shall bc. A few more revolutions of these puissant planets, a few more mutations of the sweet returning seasons, and to me there slall be no change again on earth for cver! no choice between the fairest and the foulest! no difference of night or day ! no charm in the rich gorgeousness of flowery summer, above the sere and mournful autumn! no cheery aspect in the piled heartll of winter! no sweet communion with the luman eye compassionate! no intercourse with the great intellects of old - dead, but surviving still in their sublime and solid pages!"

Upon first becoming visible in the course of a lunation, the moon is secn soon after sunset as a thin crescent in the west with its convex side towards the sun. Gradually the breadth of the crescent increases, the inner curve is changed into a straight line, and she exhibits a complete laalf circle in the heavens. Afterwards, the line becomes a curvature again, bulging ont in a direction opposite to its former inclination, and the moon is said to be gibbous, that is, bunched or convex. The curve turned from the sun continues to strengthen, and the apparent breadth of the moon to increase, until she is a full or circular orb, when a repetition of the same phases in inverse order commences. At length she appears like a fine thread of light in the morning, a little west of the rising sun, and for a few days she is lost to view, being in conjunetion with him. The lunar phases clearly prove that the material of the moon is in itself as dull and opaque as the rock we gaze upon in our own world, that she slines by virtue of the reflected light of the sun, a fact reeognised in the earliest ages, and apparent from the different appearances presented by those parts of her surface which are turned to and from his beams. The earth appears in the diagram as the central body, with the moon in eight different

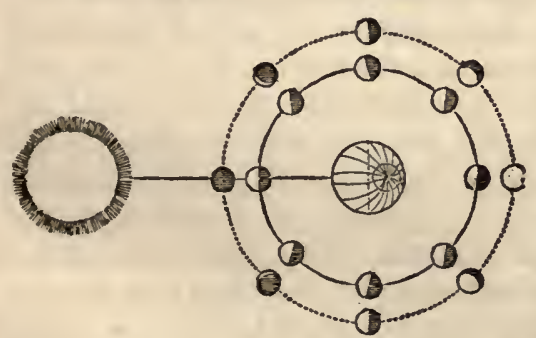
parts of her orbit, receiving the light of the sun. The outermost circle exhibits the appearances presented to a terrestrial spectator in each station of the lunar globe, a crescent, a semicircle, gibbous, and full. It is evident, therefore, that the satellite is not self-luminous, otherwise she would always appear as a round full orb. After solar phenomena, the lunar phases are the most bcautiful celestial objects; and but for their periodical return and frequent observation, they would excite enthusiastic admiration. If for long and indefinite intervals the earth was deserted by its attendant, the renewal of the crescent moon would meet with a marked and general welcome, like that which the inhabitants of polar regions give to the sun, when he appears above their horizon after a five months' absence from it. 
The crescent moon presents a singular appearance in the sky. Under farourable circumstances, the whole lunar circlet may then be seen, the dark part appearing of somewhat smaller dimensions in proportion to the illuminated. The appearance is popularly described as that of the new moon with the old one in her arms. It arises from the light reflected from the earth to the lunar surface, hence called earthshine, and lumière cendrée by the French, or ashy light, on account of its inferiority in quantity and briglitness, to that which is directly received from the sun. It only serves to render the unenlightened portion of the moon very faintly visible; and the dark part of her body appears disproportionate to the size of the crescent, owing to the optical illusion which the presence of a strong light creates, that of apparently augmenting the magnitude of objects. Two causes contribute to render the dark portion of the lunar disk invisible in other stages of her progress : the increase of her directly illuminated part diffusing a stronger light, which proportionably nullifics that which is reflected from the earth; and the actual diminution of the earthshine itself. When the moon is a crescent to us, the carth is about full to her, and, consequently, more light is then transmitted from the earth than in other circumstances, which has the effect of then bringing that portion of her disk, not exposed to the solar rays, into feeble visibility. The effect is not produced when the moon is half full, owing to the cause, for the reasons stated, being less influential.

The moon is situated in external space at a mean distance of 237 thousand miles from the earth. Great as this interval is when compared with terrestrial extent, it is only about $\frac{1}{400}$ th part the earth's distance from the sun, and little more than one fourth the diameter of the solar body. It is owing to this proximity to us, that she occupies solarge a space in the heavens, for the lunar diameter is only 2160 miles. Our own globe is equal in magnitude to forty-nine such bodies, and the sun to near seventy millions. If loosened from the action of other forces, the earth and the moon would fall together by the power of mutual attraction; but the earth being not only the larger body but the most dense, and its attraction being far the most powerful, the moon would descend to it, passing the intervening space in less than five days, our own planet courteously advancing about the distance of its semidiameter to meet the satellite. To the lovers of singular coincidences, the following may be acceptable, respecting the three bodies with which we are principally concerned.

Miameter of the Moon, $2160 \times 110=237,600$, arerage mean distance from the earth.
Diameter of the Sun $870,320 \times 110=95,735,200$, average mean distance from the earth.
Diameter of the Earth, $7912 \times 110=870,320$, estimated diameter of the sun.

There are two proper motions belonging to the moon, besides the annual pilgrimage around the great central orb accomplished in company with the earth. If her place with reference to a neighbouring star on any clear night be ascertained, the next night she will be found to have moved about $13^{\circ}$ further eastward, and each night the distance will luave widened, until from an opposite quarter of the heavens she will appear advaneing towards the same proximity to the star. This proves her motion in an orbit round the eartli; but great irregularities belong to it, which accurately to estimate is one of the most difficult problems and highest achievements of astronomy. The lunar tour through the heavens is accomplished in $27^{\mathrm{d}} 7^{\mathrm{h}} 43^{\mathrm{m}} 11^{\mathrm{s}}$, after which time, she returns to nearly the same position in relation to the stars. But the interval between one conjunction with the sun and another, or her synodical period, the lunar month, is $29^{\mathrm{d}} 12^{\mathrm{h}} 44^{\mathrm{m}} 2^{\mathrm{s}}$, because of her partnership in the orbital motion of the earth. To compare and reconcile the motions of the sun and moon with each other, bringing a certain number of months and years to coincide, was an object to which the ancients applied themselves with great care 
and industry. To Meton, the Athenian, the invention is aseribed, of the eelebrated lunisolar period of 6940 days, supposed to be equal to 19 years, or 235 lunations. This period, called the Metonic cycle, was adopted in the year $432 \mathrm{B.c}$. It was published amid the applause of the Greeks at the Olympic games, who decreed a statue to the inventor, and declared him victor of the first elass. The eoincidenee, however, is not exact, for 6940 days exceed 19 tropieal years by about $9 \frac{1}{2}$ hours, and exceed 235 lunations by $7 \frac{1}{2}$ hours, an error which the Calippic period was designed to rectify, by the leap of a day in four Metonic cycles, or in an interval of seventy-six years. This brought 940 lunations into correspondence with 27,759 days, within $5^{\mathrm{h}} 54^{\mathrm{m}}$, an inaccuracy which became important by accumulation in the civil usage of the period, and eventually entailed the necessity of the Gregorian reform of the calendar.

While, in the course of her monthly circuit, the moon passes between the sun and the earth, and defiects a shadow upon the latter, the compliment is returned in another part of her orbit, by the earth's shadow being cast upon the face of the satellite. A lunar eclipse, as well as a solar one, would occur every month if the moon revolved in the same plane with the earth, but she escapes the terrestrial shadow owing to the inclination of her orbit $5^{\circ}$ to the ecliptic, earrying her above or below it, and only suffers an eclipse, when, besides being in opposition to the sun, she is in or near the plane of the earth's path. The shadow of our globe is computed to extend 800,000 miles into space. It is long enough, therefore, to reach a body three times the distance of the moon. The diagram represents the immersion of the satellite in it. The lunar globe, however, when

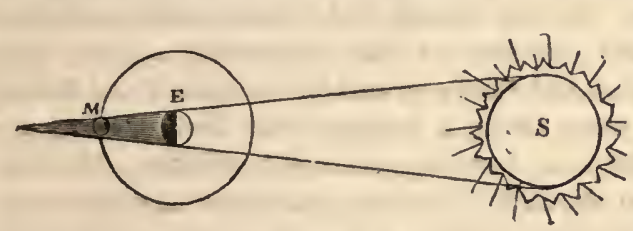
wholly immersed, is rather obscured than hid from view, owing to the inflexion of the rays of light to her orb from the terrestrial atmosphere. She appears frequently of a dark copper colour, because the red rays, which have the greatest momentum, are those which principally reach her. During the eclipse of September 2d, 1830, the moon exhibited a deep blood-red hue, as seen from the metropolis. Upon comparing the ancient observations of eclipses recorded by Ptolemy, with those of Albutegnius in the ninth century, and of modern astronomers, Halley discovered the acceleration of the mean Iunar motion, a phenomenon which Laplace referred to its true eause, that of a diminution of the eecentricity of the earth's orbit, owing to the disturbing forees of the planets. The terrestrial orbit is gradually changing from an ellipse into $a^{\circ}$ circle, its eceentricity decreasing at the rate of about forty-one miles annually, thereby accelerating the mean motion of the moon ; and should the decrease proceed equably, the earth's path will be reduced to a circle in 37,527 years. But, like all the other phenomena depending on gravitation, there is redress laid up in store for this perturbation, through the disturbing forces of the planets beginning to aet in a contrary direction, which will produee a change towards eceentricity in the earth's orbit, and proportionably retard the mean motion of the moon. It may require thousands of ages for one part of this cycle of change to transpire; but the faet itself is not without interest to us, as one of the most sublime and beautiful results which the mind has mastered, and an illustration of the permanence of the system under all its disturbances. While lunar eelipses have thus been watched by the eye of scienee, and knowledge enlarged by their means respecting the condition of the system, they have created no small alarm among barbarian races. The Landers give an interesting account of an eclipse of the moon, Sept. 2. 1830, during their stay at Boossa in Central Africa:- "The earlier part of the evening had been mild, serene, and remarkably pleasant. The moon had arisen with uncommon lustre, 
and being at the full, her appearance was extremely delightful. It was the conclusion of the holidays, and many of the people were enjoying the delicious coolness of a serene night, and resting from the laborious exertions of the day; but when the moon became gradually obscured, fear overcame every one. As the eclipse increased, they became more terrified. All ran in great distress to inform their sovereign of the circumstance, for there was not a single cloud to cause so deep a shadow, and they could not comprehend the nature or meaning of an eclipse. Groups of men were blowing on trumpets, which produced a harsh and discordant sound; some were employed in beating old drums; others again were blowing on bullocks' horns. 'The diminished light, when the eclipse was complete, was just sufficient to enable us to distinguish the various groups of people, and contributed in no small degree to render the scene still more imposing. If an European, a stranger to Africa, had been placed on a sudden in the midst of the terror-struck people, he would have imagined himself among a legion of demons, holding a revel over a fallen spirit."

Besides the orbital motion, there is another lunar movement, not so obvious, but plainly demonstrable. It is a well known fact, that the same portion of the moon's surface, or nearly so, is always turned towards the earth. It necessarily follows, that during each revolution she must rotate upon herself, and accomplish one rotation in the time of one revolution. If we suppose an individual to walk round a tree, and to keep lis face turned towards it, he will see completely round the horizon during his circuit, and will of course turn round upon himself. The alterations are slight as to the face which the moon presents to us in all her revolutions. On the eastern and western sides, and also on the northern and southern edges, small portions of disk alternately appear and disappear, as though the lunar globe oscillated and swung to and fro in space; and hence these appearances are termed librations, from libra, a balance, the former being in latitude, and the latter in longitude. There is, however, no real oscillation, but the orbital motion being irregular, while that on the axis is uniform, the effect is, alternately to extend and diminish the sides of the exlibited surface, as though an actual vibration of the whole body took place. These variations do not affect the correctness of the general statement, that the moon always shows the same face to us; and this is the consequence of the coincidence between the time in which she moves round the earth and rotates upon her axis. Here we have a law to which none of the primary bodies in the system are subject, though it is probable that all the secondary bodies are. There is the same correspondence between the period occupied by the satellites of Jupiter in revolving round that planet and rotating upon their axes. The reasons of the law are at present inscrutable. It is one of those mechanical arrangements, the design of which we have yet to apprehend.

It will be seen from the preceding statements, that though the moon is our near neighbour, and has been for ages a faithful companion orb, the acquaintance is very partial and reserved. Almost one half of the satellite is perpetually turned from the earth, and to those regions that are thus concealed from us the earth is never risible. The lunarians, if such there are, inhabiting the districts beyond and opposite to the exhibited side of the moon, never catch a glimpse of the earth, unless they travel into the hemisphere presented. A parallel case on our globe would be, for the moon never to appear in the nocturnal sky of Europe and Africa, and for an Englishman to know nothing of the luminary, unless he should travel towards the heart of Asia, or land upon the shores of America. To an inhabitant of the moon on the border of her visible disk, the earth will appear in the horizon. One about the centre of the visible disk will have the earth near his zenith, but through the wide extent beyond the border, embracing nearly half the lunar surface, the earth is never seen. The hemispheres of the moon 
Bencrols Library 


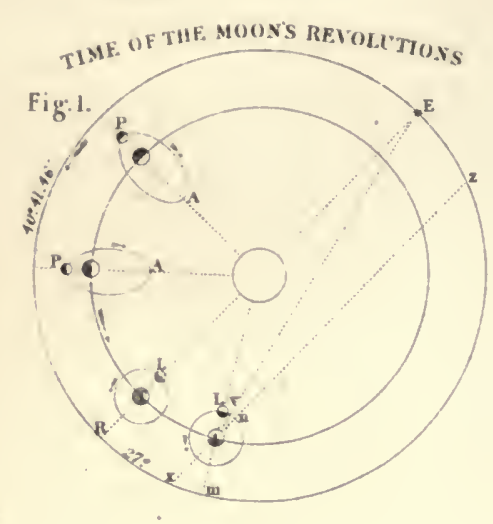

The natral rioure represents the Moons phases anound the Ear pluevd in the antre. the elliptical line A.A.A. indiontes the path of the yoon revolving from west to east, at aght points in her orbit. The Moon is shown of her axad relative size to the Eurth her distance is howare about ton aimes greater in pro portion within the umas. orout the Moons phases are repres ented on ar clarged disk: in onder so show the procipal spots. The loon is the sateitue of the Earth. That is whist the Earth performs its annual revolution round the Sunt the Moon acromyanies the Earth re olsing also anound it. The

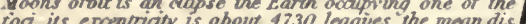

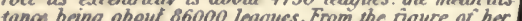
orbit the $1100 \pi$ is sometimes nearer than at other she point at which she is nearest is called-Perigee ( fir l P. that at which she is farchest-Apogee if ig

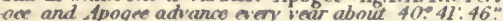
firom west to eust. The plane of the lunar orbit makes an angle of 5.8 .49 . with the adiphe fio 4 !'The planes oi the two proits are ait by a line passing throush the more of tha canh the two poinis where this yne miets the Yaors onbit ars the Nodes one the ascending node when the Moon rises above the daptic towards the north the other. the descriding node. When she sink's below it to

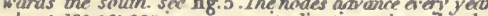
ubout 19: 30. 29. in an opposite diretion to her orbicular motion. Led the Mouns L.fig. 6. be at a point of her orbit Ln. betow the ediptic advanang towands her ascending node. The Suns autracion will. be in the direction L.S. the intensin of this fonce being represented by the line L.a. it mav be decomposed inte wo roras one. L. Th cowas the ediptic the action of these two fornes would guse the 3 (oon

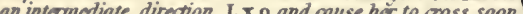
or the plane of the ediptic. The are described above the ho rizon by the Moon in summer appears much smaller thon that des oribed by her in winter. us is thus explained - on the niahe of the winter solstice 27 st or $22^{2}$. Dexember the Earch T. fig. 2. secs the Sun at S. on the tropic of Caprioom \& the Jf con QL L. on the tropic of Cancer. the line of oto horizon H.R. shows that the anc describerd above it by tho sun is very smiall. whilst that described by the Moon is very extended. One complate revol whon of the Hoon round the Earth. that is. from one point of her orbit to the same point again.is called a Periodical revolution and us perrormed in 27 days.7 hours. 43 munutes. 42 soconds: Now suppos ing the Moon L figI. at the beginning of her revolution. to be in oon. jundion i.e. botwen the sun and the Larth.d that these threebodies and a stas E. Are on the same line R.E. at the and of her resolution. the Earth having advanced in uts orbit. she will be at in in the plane x. on he re on the are n. E. a mumber of deciras equal to the anc T.t.or R.M.des. corval trome one conjunction to

t4 munutes 3 seconds.

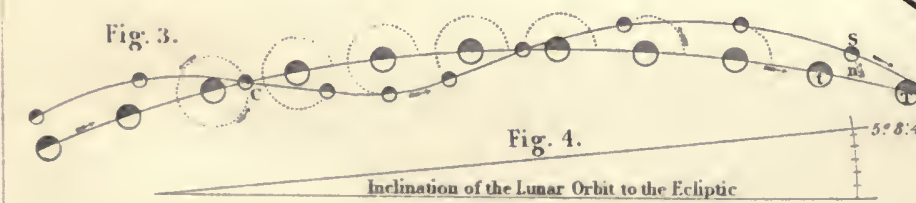

Sibs 


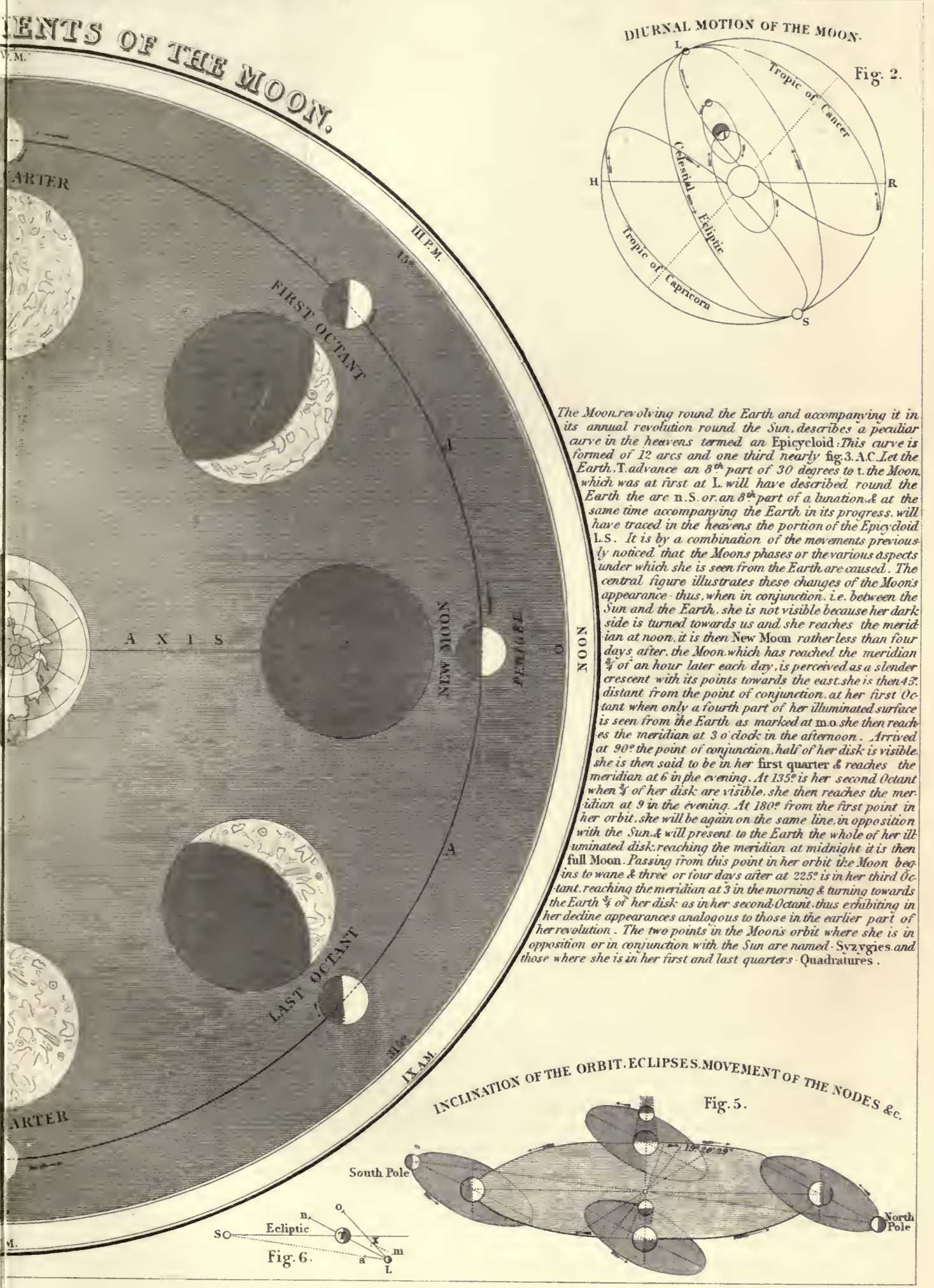




$$
\text { Denem } 150 \text { th }
$$


thus present a singular contrast to each other, inasmuch as the darkness of the night in one is constantly relieved by the presence of our globe reflecting light, while the nocturnal darkness of the other is as constantly left to the illumination of the stars. In another respect also the moon contrasts strikingly with the earth. As slie turns upon her axis but once a month, nearly fifteen days' sunlight will alternate with the same period of darkuess, and thus the lunar day and night be each of that extent. The physical consequences of this arrangement will be-according to the analogy of terrestrial things winter and summer once a month of the fiercest description. During fifteen days' exposure to the sun an intense degree of heat will accumulate, and by fifteen days' deprivation of his beams an equal degree of cold be occasioned; and thus a temperature equal to the most fiery experienced upon the plains of India will alternate with one rivalling in severity that of ice-bound Spitzbergen. But it is a curious speculation, that it lies within the limits of possibility for a lunarian to travel as fast as the moon's motion upon her axis, and thus keep up with the day, living in perpetual sunshine. A ten miles per hour rate of locomotion wouid suffice for this, and a terrestrial dweller might accomplish that distance by a walk in lialf the time if transported to the moon, because of the fceble gravitation of bodies at her surface, for a body weighing six pounds at the earth would weigh only one pound at the moon. Consequently the same muscular force would there perform six times as much as on the eartl.

Linked in the bonds of a close and enduring relationship to the earth, the surmise is natural, that the two bodies dwelling together in unity harmonise in their physical constitution. We are apt to transfer to the lunar mansion the features of our terrestrial residence-its diversities of ebbing ocean and stable continent-hill, dale, and plain wood, brook, and flower - stormy wind and balmy breeze. But a course of observation diligently pursued with reference to the satellite corrects some of these imaginings, and discloses striking points of discordance with those of agreement. Whether the lunar globe has any gaseous covering, like that which supplies us with the breath of life, is a subject upon which there has been considerable conflict of opinion. Those who deny the existence of any atmosphere depend chiefly upon the equable brightness of the moon's disk, which, it is argued, would not be the case if she were surrounded with one like ours, so variable in its density, and so often charged with immense masses of cloud and vapour. It is also pleaded, that when the moon occults a planet or fixed star, there is no perceptible diminution of light and alteration of colour before complete obscuration, which there would be, owing to the influence of the lunar atmosphere, if there were one. An occultation of Jupiter took place on the $2 d$ of January 1857, and was carefully observed with this reference. But there was not the slightest distortion of figure, diminution of light, or change of colour. Hevelius, however, and others, have observed variations in the brightncss of the lunar orb, instances in which the moon and her spots have not appeared equally lucid and conspicuous, when the terrestrial skies have been free from cloud. Some have also thought that both Jupiter and Saturn undergo a perceptible cliange of figure when about to be occulted, and that fixed stars may be discovered in such circumstances to experience an evident diminution of light. Professor Nichol observes of the annular eclipse of May, 1836, that just before the rims of the sun and moon osculated, the light of the sun was mollified into lovely twilight, which he attributed to the effect of the moon's atmosphere. One fact is clear, and is admitted by all parties, that if there be a lunar atmosphere, it is of extreme tenuity and exceedingly small, considered by Laplace to be as attenuated as what is called the vacuum of an airpump, and estimated by Schroeter to be little more than a mile in height: Hence, with such a medium, we cannot conceive of some of the grand phenomena with which we are familiar having any existence in the lunar world - such as the noise of many waters and 
of mighty thunderings - the voice of the passionate storm, or the melancholy wailing of the autumnal gales. No clouds are there, analogous to those which in ten thousand fantastic shapes are present with us, dropping fatness upon the fields, and casting shadows upon the landscape - a covert in the daytime from the heat. No rain, hail, or snow descends upon the lunar soil. It is difficult to imagine water at all, or any liquid, upon the surface; for if the atmospherie pressure were remored in relation to the earth, its liquids would be dissipated by the heat of the sun; and how much more might this result be expected at the surface of the moon, where the heat accumulated by its fifteen days' continuous exposure to the solar rays must be intense? There can be, therefore, no seas or lakes, or else evaporation would take place, and clouds be formed, perceptible through a telescope.

But though apart from the majestic features of the ocean, the tracts of cloud that float in our atmosphere, and the commotions that agitate it, the lunar surface exhibits several points of accordance with the terrestrial superficies. There are mountains answering in their contour to those which diversify our own globe, intermingled with plains, glens, and extensive depressions. To the naked eye, the face of the moon appears chequered, exhibiting dusky patches and bright parts, which, in former times, the fancies of men converted into images of terrestrial things. Thus, Agesianax, as reported by Plutarch, supposed the moon's disk to reflect back to us, as in a mirror, the forms and outlines of our continents, islands, and seas. Nor is the idea so fanciful as not to have occurred to more than one mind. Observers have been impressed with it under widely different circumstances. It has continued to be a popular belief in Western Asia to the present day. Humboldt remarks : "I was once very much astonished to hear a very accomplished Persian of Ispahan, who had certainly never read a Greek book, to whom I was showing, in Paris, the spots on the moon's face through a large telescope, propound the same hypothesis of reflection as that of Agesianax as prevalent in his own country. "It is ourselves we see in the moon,' said the Persian; 'that is the map of our earth.' "With the aid of a telescope, the lunar superficies presents an aspect that is excessively torn, ragged, and disturbed ; and we are able to define peculiar physical features. There is, however, no foundation for some reports respecting the probable discovery of minute lunar objects; and but little reason to suppose that any instrumental power will be obtained sufficient to disclose them. Schroeter conjectured the existence of a great city on the east side of the orb, north of her equator, an extensive canal in another place, and fields of vegetation in another. Fraunhofer also announced the discovery of an edifice, resembling a fortification, together with several lines of road. The hope has likewise been entertained of discerning the dwellings and persons of the lunarians, should there be any ; but these are visions, sanguine and baseless. Assuming, says M. Mädler of Berlin, that a German mile is the utmost limit of distance at which the keenest unassisted eye can distinguish human beings, to bring the moon to that distance, a magnifying power of 51,000 would be necessary; but, up to the present time, 300 is the highest power which has been applied to that object with advantage. Alone therefore, upon this ground, those who indulge the imagination of studying any lunar samples of social and domestic economy, are clinging to a forlorn hope.

The time when the moon's unevenness of surface may be most favourably seen, is when she is horned or gibbous. The boundary of the light and dark parts of the disk would obviously be an unindented line if the disk were perfectly plane, and had no surfaces higher than the rest. But look at the lunar crescent. The bounding line appears notched and broken, which is precisely the aspect which elerations and depressions will produce. Close by the edge of the illuminated portion, yet within the dark part, wholly surrounded with shade, there are small shining points, like islands of light in a sea of darkness. These are gradually joined to the luminous space, and become part and parcel of it, as the moon 

SELENOGRAPHIC MAP

()F THF WIOLF.

YISIBLE HFMTSIPERH

IF THE

iv. 0 O N.

In wider se understund the plenomenn arhihited bu the Joon the unost moriul and acxurnte observation or werv part of the lunar disk is requird at all the various periods or her libru non. The position of remurtiable sputs nust be determined

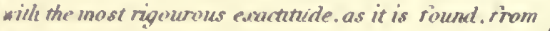
the change of simntion mative to summunding appear unces consequowt upon the Jlemsis phuses. that a spot tevry distinguishable br the nahed gye upon her sur 20 ff ace, when at the rill.will be with ditriauls discrned vin by the ylass towards the last quarter. The uppenviness abstrital on the Komis surrace une caused either bi ditienence of level.or by dirier ene or the intensits if the liaht. The light wer Inded inm the suriace of the Hown is plninly. sen to be of dirierent shautes; althowah the livht er part.s are ocnerally. the muntains, of the dark * ones the low plains. still, cuneriul obscrvaciunt huse shown that this is not alwav's the oast. but that. the streak's of light. which at the tull surpass in brilliancr all the adjacent parts.some vimes surst entirel independent or mounfuins. and extend alike orer heights and valleys with. out being atterted by them. Besides ditiencure in infensitv or" the light, colvers specinually divier ent mav be observed partiularty aren somatimes a colour or a redlish tint.at others a vellowish brown The devations of the Jeen ane in oenervl or " much more precipitous nature than thase of the earth. In the plate. the edoes of the streper onters. more espevinlly these of sull artent are ocmerully shown by a plain line the nurrow derts or muines by paralel lines without a cros tint. The mitille edge or the Mcon. i.e. the onat cincte which in the man librution seperates the heavispher which is visible rimn that which is imisible is neressulv aldineated in provile. Chains of muntrins or mountuinous regions or awn importrucear nantel aiter the montains or the enrth.and the various spots witer distinguishal men.as annered. To avoid onnitsina the objerts in the

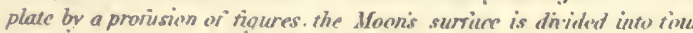
parts. the numbering or the sputs in cach commerting with unif.

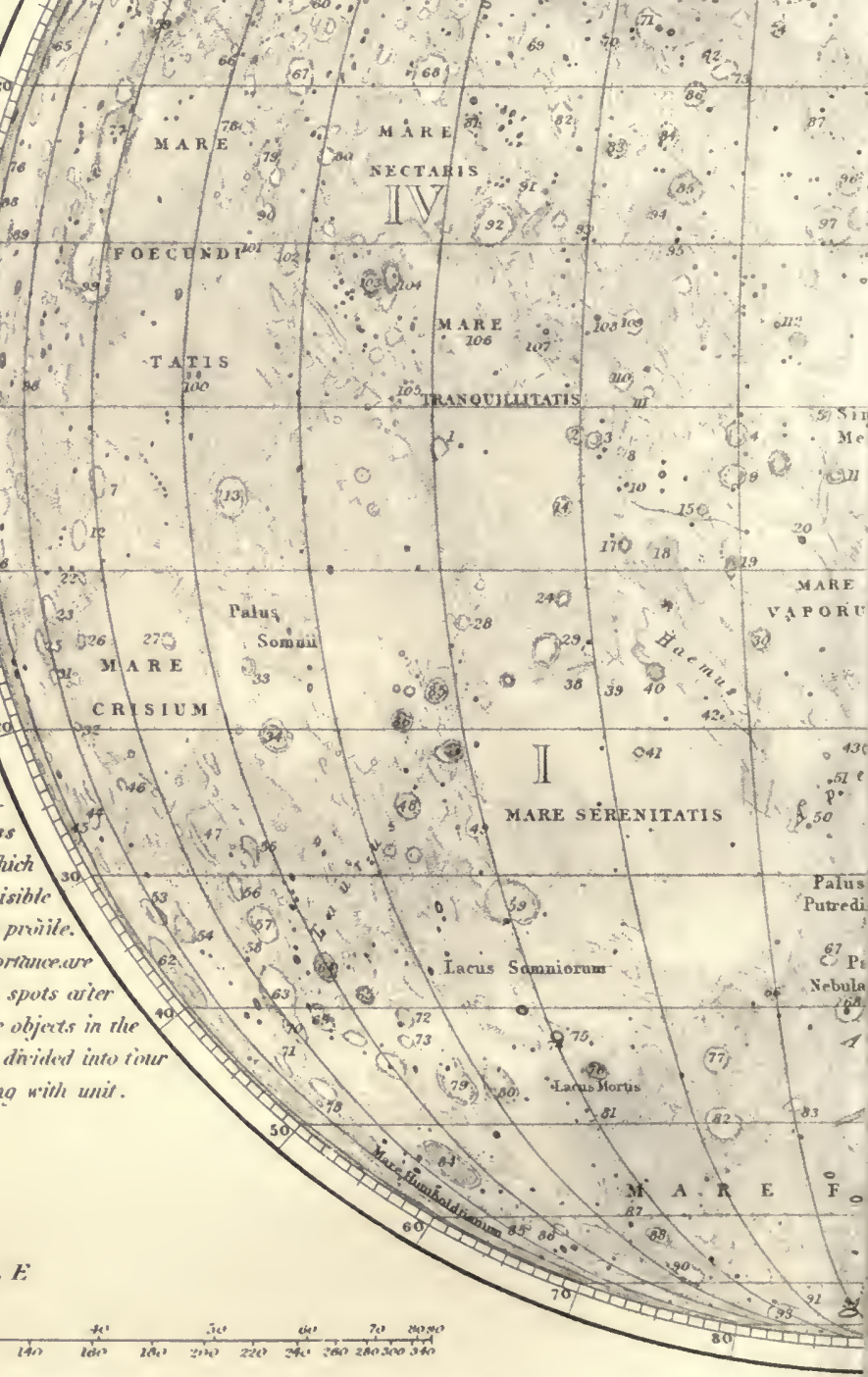




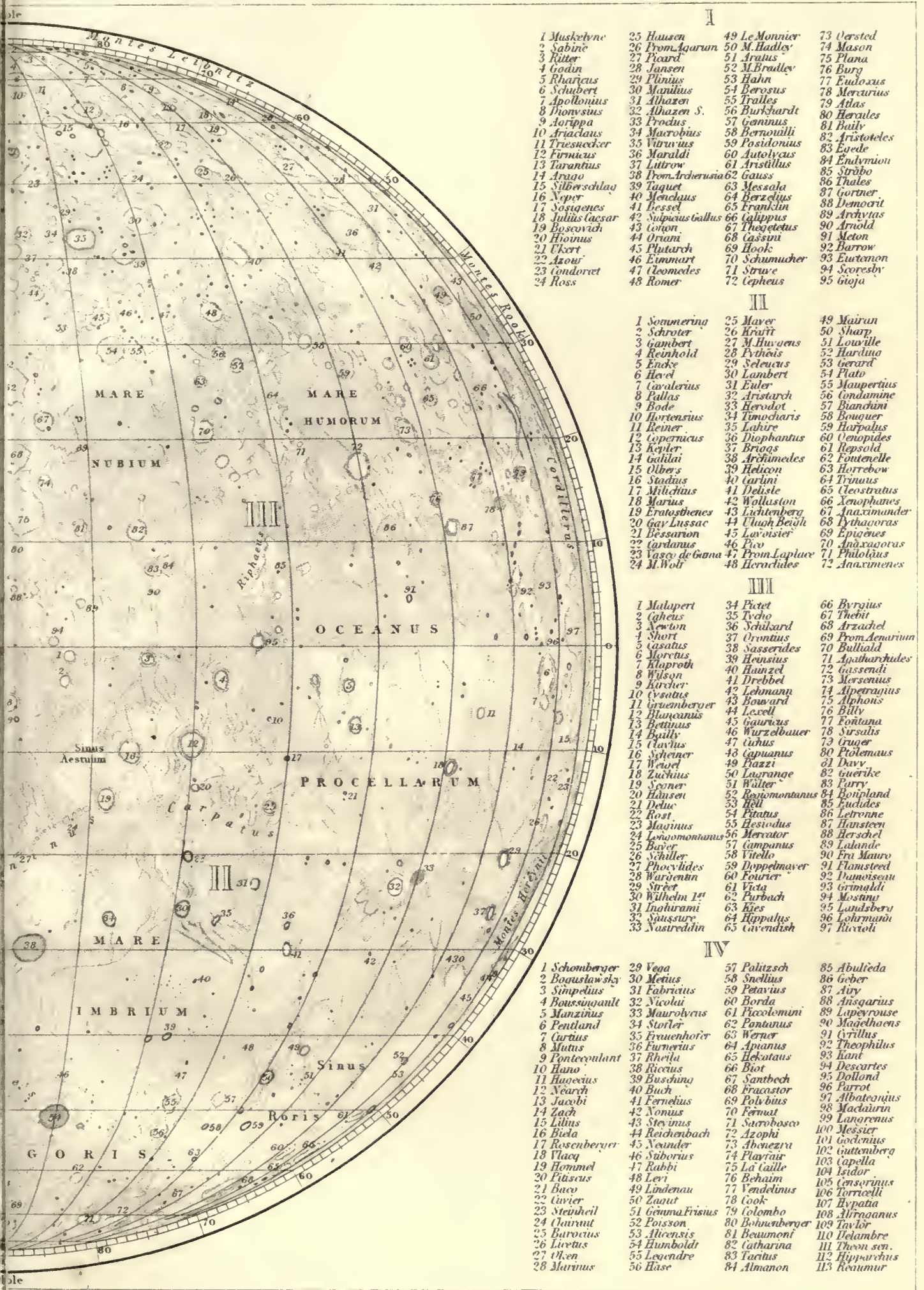



waxes. Here we have a clear indication of elevations. The portions of the dark part of the moon which thus stand out into the light are plainly eminences, their summits catching

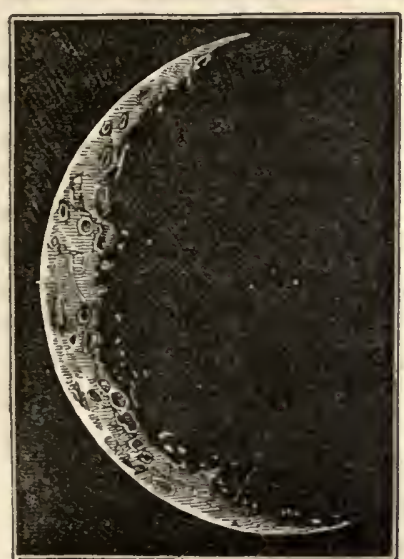
the illumination of the sun's rays before the adjacent plains below, exactly as the summit of Mont Blanc is enlightened whilst the valley of Chamouni at its foot is in darkness. But we have further evidence of the existence of lunar mountains and valleys. It is obtained from the fact that what are considered elevations project shadows in a direction opposite to that of the sun, while the depressions are dark on the side nearest to him, and illuminated on the opposite one. These shadows are observed to shorten as the sun's rays become more direct, and they proportionably lengthen as his beams fall more obliquely. This is so answerable to the phenomena which the action of sunlight upon hills and valleys will yield, and so consistent with what takes place on our own globe, as to place the conclusion of the moon's irregularity of surface beyond all doubt.

A remarkable appearance may perhaps be explained by the inequalities of the lunar superficies. It has repeatedly been observed in the case of an occultation, that a star has advanced actually upon and within the edge of the moon's disk before its disappearance behind the lunar body. Admiral Smyth remarks :- "October 15, 1829. I saw Aldebaran approach the bright limb of the moon very steadily. It kept the same steady line to about $\frac{3}{4}$ of a minute inside the lunar disk, where it remained, as precisely as I could estimate, two seconds and a quarter, when it suddenly vanished. In this there could be no mistake, because I clearly saw the bright line of the moon outside the star, as did Dr. Lee, who was with me." The same accurate observer, on the 18th of December 1831, saw the star 119 Tauri pass over the disk, and disappear between two protuberances on the moon's bright edge; and on the same night Sir James South observed the star 120 Tauri accomplish the same achievement. Sir John Herschel never witnessed this singular phenomenon, but it rests on the best evidence, for several other cases are on record. It is not an optical illusion, as formerly supposed, but the effect of the lunar superficial inequalities. A star may shine on such occasions through deep fissures in the substance of the moon. The rim being jagged and uneven, owing to elevations and depressions, a star, in the process of occultation, may obviously pass into one of the cavities, and be actually within the disk before its complete obscuration by the general body.

We have now large and accurate maps of the lunar superficies. The average aspect of our attendant planet is minutely exhibited in the map of MM. Baer and Mädler of Berlin, which has a diameter of three feet. A reduction of this map appears in connection with the present work. Prominent lunar peculiarities have their respective names, taken from those of places on the earth, or from eminent men, chiefly astronomers, as Plato, Tycho, Keppler, and the Apennines.

The dark and dusky patches apparent upon the moon's face, which remained constantly obscure, were supposed by the early observers to be seas, owing to water reflecting less light than land. Hence the names applied to them, as Mare Tranquillitatis, Mare Imbrium, and Oceanus Procellarum, which are still retained. The supposition, however, of any quantity of fluid at the surface is plainly precluded by the fact of there being little or no atmosphere. These parts have all the appearance of being enormous spaces of lunar depression, their obscurity arising from being below the general level. They are not, however, depressed uniformly. The intermingling of light and dark shades, with the occurrence of districts as luminous as any portion of the lunar disk, 
indicate great superficial inequalities in these regions, apparently similar to what would Le exhibited by the beds of the terrestrial oceans, if the waters were dissipated. Large spaces of depression would then be laid bare, but of very unequal depth, varying from a few fathoms to several miles. Are, then, the vast lunar cavities intended to cradle a fluid element at some approaching epoch, or have they served that office, and by some physical ehange been deprived of it? Have the billows rolled and sported in their depths in by-gone time, or are they to come? These are queries which observed appearances naturally suggest, but we can grasp no certain conclusions. The aspect of the satellite is however thought to favour the idea that the surface has not yet been water-worn - that the present stage of its history is parallel to that of the earth, before the sharp asperities of its upheaved masses had been abraded by aqueous action, and smoothed by the detritus which it deposits. It is a striking peculiarity of these districts that they shine with various hues, from the grey tints of the Oceanus Procellarum to the beautiful green of Mare Tranquillitatis, and the dark tracts of Plato. 'This diversity of colour proceeds, probably, from some difference of substance; and to distant observers of our own world its chalk, red-sandstone, and granite formations may be supposed to present a similar diverse aspect, as well as the golden sands of Africa in contrast with the grey masses of the Alps, the white cliffs of England, and the green prairies of America.

The lunar mountains include several chains, the principal of which bears the name of the Apennines, a range running from north-east to south-west, in a straight line towards the centre of the disk, rising to the height of 20,000 feet. This altitude closely approaches that of the loftiest terrestrial mountains, though the diameter of the moon is little more than one-fourth of that of the earth. The chain may be scen casting long shadows over the Mare Imbrium, of which it forms the northern boundary, and from which the ascent is precipitous, while more gradual on the opposite side. Not only are the mountains higher, in proportion to the size of the moon, than those of the earth, but they are larger, much more numerous, and apparently of harder texture, projecting such sharp outlines, and overhanging in such a tremendous manner, as to lead many to the supposition, that the rocks composing them must be of a more solid nature than wrought iron.

But chains of mountains are exceptions in the lunar world. The prevailing arrangement is circular or crateriform, though without analogy, when closely examined, to the volcanic formations of our globe. The distinguishing circumstance is, that the areas enclosed are in almost every case depressed far below the general surface of the moon. These hollows in the lunar substance are surrounded with lofty ramparts, which often rise up with the steepness of vertical walls, and have of course their exterior height exceeded by that of the interior. They vary in magnitude from a diameter of not many yards to sixty and even more than a hundred miles; and are termed holes, bulwark-plains, and ring-mountains, according to their size. The floors of these enclosed hollows are in some rare cases flat spaces, strewed with blocks; in a few instances they appear to be convex; but very frequently, one or more isolated peaks rise up from them, of a conical or sugar-loaf form, characterised with great abruptness and considerable elevation. When there is a central mountain of this kind in a large enclosure, its shadow is distinctly cast upon the floor, by which its shape can be ascertained, and its height measured trigonometrically. Many of the ring-mountains exhibit conspicuously a radiating aspect, streaks of light issuing from them like the rays of a lamp. The appearance is exactly like that exhibited by a piece of plate-glass struck with a stone. These radiations are comparable to the lava streams of our volcanoes in actual eruption, and were formerly considered to be such, but are most probably the illuminated summits of elevated ridges. No trace of active volcanic agency has hitherto been discovered in the moon; and the immense dimensions of its erateriform constructions have no analogy to anything on the earth. 
The ring-mountain, Eratosthenes, is one of the most remarkable of its class, termed by Mädler "the mighty key-stone of the Apennines," standing at the northern extremity of the range. The interior plain has a diameter of thirty-seven miles. It is depressed 3000 feet below the level of the outer surface; and as the bounding wall rises about the same leight above it, the entire interior descent is 6000 feet. The enclosed plain is not featureless. From the centre a huge mountain shoots up, at least 10,000 feet above the rim of the encircling rampart, so that its summit and sides are brightly lighted by the sunbeams long before its base, or any portion of the surrounding plain, has received a ray. Still morc colossal are the dimensions of Tycho, an object with a radiating aspect, on the southern part of the lunar disk, plainly discernible by the naked eye at full moon. The enclosed area, which is nearly circular, has a diameter of 54 miles; and from its level, the enclosing ridge rises 17,000 feet with the steepness of a wall.

In order to afford an idea of lunar scenery, Mr Crampton has drawn with happy boldness the following inferential picture of a tract marked in the south-eastern portion of our map :"It is the Mare Imbrium, or Sea of Showers, as it is called, though no water is to be found, and no shower ever cools or moistens its barren surface. It is about 700 miles in extent cvery way. Let us cast our eyes around, and what do we see? - a boundless plain or desert, stretching array as far as the eye can reach on every side, save in one or two points where a chain of lofty mountains can be perceived, whose brilliant pointed summits, glittering in the 'sunbeams, just appear upon the distant horizon. The' light that glares upon the plain is intense, and the heat of a tropical fierceness, for no cloud shelters us. By that light we may perceive, scattered over the plain, an infinite number of circular pits, of different sizes and depths, varying from a few yards to some hundreds in diameter, and sunk in the body of the planet: some of them but a few feet, and others to an unknown and immeasirable depth. Above, the sky is black, out of which the sun gleams like a red-hot ball, and the stars sparkle like diamonds-for no atmosphere such as ours exists, to give, by its refractive and reflective powers, the delicious blue to its heavens, and the softened shade to the landscape. The lights and shades are indented upon its features deep and dark, or intensely bright; no softening away in the distance, no gentle and beautiful perspective, no lovely twilight-morning or evening-stealing over or away from the scene. All the shadows are abrupt, sudden-all the ontlines sharp, elear; appearing startlingly near, even when really distant. No sound follows our footfall, or is ever heard in that silent placefor there is no atmosphere to conduct it; no fresh breeze blows on its mountain tops, sighs through its burning deserts, rustles through the brilliant green of forests, or waves over meadows; the silence of death broods over its arid wastes and rocky shores, against which no tides or billows break."

How delusive the conceptions excited by the aspect of our satellite silently prosecuting her nightly walk through the heavens! The silvery splendour cast over the face of terrestrial nature, the moonlight painting the dark bcsom of the waters with radiance, and lustrously streaming into the sombre glades of the forest, together with the resplendent countenance of the planet, satisfying to the imaginative Easterns, as an image of feminine loveliness-these suggest, through the eye to the mind, conceptions of graceful and soothing scenery upon the surface of the lunar world. But the illusion vanishes when we take the telescope. A drear reality is unfolded, at least so it seems to us, from which the bcautiful is absent, and the terrible appears. We must go to the wild and frightful precipices of the Andean mountains, or to the charred and sterile declivities of Hecla, to find analagous examples of stern scenery, and with these specimens we must intermingle the naked and arid wastes of the great African desert. Yet, even from such sites, Life, brute and sentient Life, is not banished in the case of our globe. The Arab scours the wilderness, through a land where no water is. The condor and the eagle scream in the 
solitudes of the earth, and visit some of its proudest heights. Man, his foot-marks, home, and handiwork, are to be met with upon the slopes of the burning Vesuvius. And is there fellowship, in this respect, between our world and its companion? Is the latter with the former the abode of vegetable creations, animal existence, and intelligent natures ? It can only be said in reply, that beyond a certain rarefaction of the atmosphere with us, no life of man, beast, bird, or plant, does or can exist-that we are quite unable to conceive of anything kindred to terrestrial life existing under what appear to be lunar circumstances, though it would be great folly and presumption to suppose that we are acquainted with all the forms of organic being, and familiar with all the modes by which organised beings may be sustained. Yet there is nothing startling in the contemplation of the lunar globe as at present a desolation, a land not inhabited, considering the decisive testimony of geology to the past condition of our now populous world. It may be making ready to sharo a similar destiny, to receive and support at some future epoch the varieties of Living Existence, a consummation towards which, according to terrestrial analogy, progressive formation is the preparatory process.

Occultations, repeatedly referred to in this chapter, are the apparent temporary extinction of planets and fixed stars by the moon in her monthly circuit, and phenomena parallel to eclipses of the sun. The lunar globe, in revolving round the earth, interposes in a direct line between us and the celestial bodies that lie in her path, and for a time appears to expunge them from the vault of heaven. Any. of the planets may thus suffer an occultation by the moon, because they all move in nearly the same plane as the terrestrial and lunar orbit; but, obviously, only those fixed stars can ever be hid by the interposition of the lunar disk, which are situated at no greater distance from the ecliptic than the moon's extreme latitude. When the moon is crescent-shaped, and occults a star with the dark part of her body, it is apparently extinguished without visible cause; and if a bright object, the occurrence is striking and impressive. The rapidity with which our satellite changes her place in the heavens is of vast service to mankind, as it supplies the mariner with one of the best and most available methods for finding his longitude, a problem of vital importance to the safety of navigation. The longitude of any station, or its distance east or west of another station, is at once solved, if the difference of time betwcen the two stations can be ascertained, four minutes of time being equal to one degree of space, an hour to fifteen degrees, and so on-earlier time denoting an eastward, and later time a westward position. Now the distance of the moon from the sun, and from some of the more conspicuous stars or planets, is computed for every three hours through the year, for three years in advance, and registered in the Nautical Almanac, with the corresponding Greenwich timcs. Hence, when out on the broad ocean, if the mariner wishes to know his longitude, or distance from the meridian of Greenwich, he marks when such a lunar distance, tabulated in the Almanac, occurs as seen from his own vessel; and deduces thereby his whereabouts on the watcry waste, as far as the longitude is concerned. The principles of the problem are stated, omitting the details. Thus, to borrow from the representation of an eloquent astronomer, the surface of the celestial vault may be compared to a vast dial-plate; the stars are as fixed marks distributed upon it; the moon is a hand in motion among them; the whole, with the Almanac, answering the purpose of a clock in the heavens, marking Greenwich time to our sailors, and enabling the skilled commander to estimate the position of his ship, though no landmark may have been seen for weeks, and no object have been visible, but the billowy deep, the stormy petrel, and the changeful sky.

Upon the subject of lunar influence, we have no conclusion established by careful observation, beyond that of the moon being the chief agent in the riso and recession of the tides. The old persuasion, still prevalent, that the changes of the moon influcnce the weather is completely groundless. This is the conclusion of Arago, 
from observations made at Munich, Stuttgard, Augsburg, and Vienna, extending through an interval of twenty-eight years. In addition to affecting the terrestrial atmosphere, it has been from time immemorial an almost universal opinion, that lunar influence operates upon organic life, and is unpropitious to it. The Roman poet speaks of "the moon's doubtful and malignant light:" -

" incertam Lunam sub luce maligna."

Throughout the East the opinion is common, that the moonbeams are deleterious, injuring the sight, and defacing the countenances of persons who sleep exposed to them. The light of the moon, Plutarch supposed in his day to be an active agent in putrefying animal substances; and the fishermen of Sicily now cover the fish at night exposed on the sea-shore to dry, alleging that the moonbeams would otherwise putrefy them. It is supposed, also, that tender plants are often cut off in April and May by the moonlight. The facts observed in these cases are no doubt true, but referable to another cause than the one stated. Animal substances putrefy, plants are cut off, and sight is injured, by open-air exposure on a moonlight night, yet not because of that light, but of the removal of the clouds, the fine clear sky, which favours the radiation of heat, by which exposed bodies become colder than the surrounding air, and hence the mischiefs narrated. We cannot attribute to the moonlight any potential effect upon terrestrial substances, when it has been ascertained that chloride of silver, the colour of which suffers the greatest and most rapid change by an exposure to light, is not at all affected by the lunar beams condensed in the focus of a powerful burning-glass. Besides these supposed instances of lunar action, cases of disease, such as epilepsy and insanity, were believed to be largely influenced by the moon by the two great physicians of antiquity-Hippocrates and Galen; and many of the moderns have countenanced the same opinion. Hence the word lunacy is applied to mental distempers. There would be a reasonable basis for the idea in question, if it could be proved that the moon has any deranging effect upon the constituents of the atmosphere. But this remains to be shewn; and to suppose disorders of the brain to be exasperated by lunar changes, as an effect of those changes, may be safely dismissed as a vulgar conceit. Even were it incontestably established that such effects occur at such intervals, a simple coincidence would be proved, and the question of connection left untouched. There is some reason to suppose that exasperations of insanity are coincident with the full moon, owing to the more distinct lights and shadows of the night powerfully affecting the imagination.

With reference to one province of the satellite, that of giving light to the earth, there can be no difference of opinion as to its utility, inferior as is the borrowed lunar to the direct solar illumination. Owing to the unfailing prosecution of her orbital route from west to east about $13^{\circ}$ daily, the moon rises at a mean rate 50 minutes later every day. This is the general rule. But there is a remarkable deviation from it in our latitude, when the moon's path lies in Pisces and Aries. This part of the ecliptic makes but a small angle with the horizon of those places that have considerable latitude, and, taking that of our own country as an example, as much of Pisces and Aries rises in two hours as the moon requires six days to travel through. The consequence is, that she differs but two hours in the time of her rising for six days together, or rises each day about 20 minutes later than the one preceding. This takes place in our autumnal months: September and October; and hence we have the harvest and the hunter's moon. It is true that the phenomenon of the moon's rising for a week together so nearly at the same period must occur every time she is in Pisces and Aries, or once a month. But she only rises as a full moon, with so little variation, about the autumnal equinox; and it is her appearance that arrests attention and renders the erent remarkable. The husbandman prizes it as an important benefaction, lengthening out the day during 
the appointed weeks of harvest, and affording useful aid in gathering in the fruits of tho earth. The comparative proportion which the light of the moon bears to that of the sun is a problem to the solution of which the attention of several philosophers has been directed. The whole heavens covered with full moons would scarcely make daylight. From various experiments that have been made, it is supposed that the lunar light is only equal to the 800,000 th part that of the sun; and, until very recently, its rays were believed to be without heat, as when collected by the aid of the most powerful glasses, no appreciable effect was produced upon the thermometer. But by concentrating them in a lens of three feet diameter, Melloni, the Italian philosopher, is said to have obtained a sensible elevation of temperature; and the same result has been gained by experimenting at a high altitude. In 1856, under the auspices of the British Association, Professor Smyth conveyed a large collection of instruments for scientific purposes to the Peak of Teneriffe, and made observations at two stations, respectively 8840 and 10,700 feet above the sea. At both stations, the heat radiated from the moon, so often sought for in vain in a lower region, was distinctly perceptible. But, vastly inferior as is the lunar to the solar light, its utility has been appreciated in all ages and countries by both rude and cultivated nations. To those, indeed, who are the least advanced in civilisation, or who are locally situated apart from its aids, its value is the greatest. Owing to the rapid progress of the useful arts among the cultivated races, they have been abundantly supplied with the means of artificial light; superseding to some extent their dependence upon the arrangements of Nature, and lowering their estimate of the advantage of her provisions. 'To the inhabitants of London or Paris, whose streets are splendidly illuminated at night, the presence of the moon is more a matter of ornament than of use. But it is otherwise when the day has closed with the mariner at sea; the peasant homeward tracking his way through the drifted snow; the traveller in a strange country; and the barbarous migratory hordes of men. 'To such, when the day has departed, the moon pursues her nightly circuit through the heavens in beauty and brightness, as a friend in need, chasing away the gloom, revealing the features of the scenery, and disclosing the right path. 'To the Lunarians, if such there be, a similar service will be rendered by the earth, which, to those who occupy the presented hemispliere of the moon, will relieve with reflected light their fifteen days of darkness. The terrestrial world will exhibit to the lunar inhabitants all the phases which their dwelling presents to us, but upon a far grander scale, the earth appearing upwards of three times the size of the sun, and thirteen times greater than does the satellite, to ourselves. Its aspect will be perpetually changing by the rapid rotation upon its axis - its tracts of sea and continent being alternately presented; and provided with instrumental aid as powerful as that which we possess, a lunar dweller may discern various terrestrial phenomena - the mighty masses of cloud that are pendent in our atmosphere, the flashing lightning, the fields of ice at the poles, and the occasional outburst of volcanic fires.

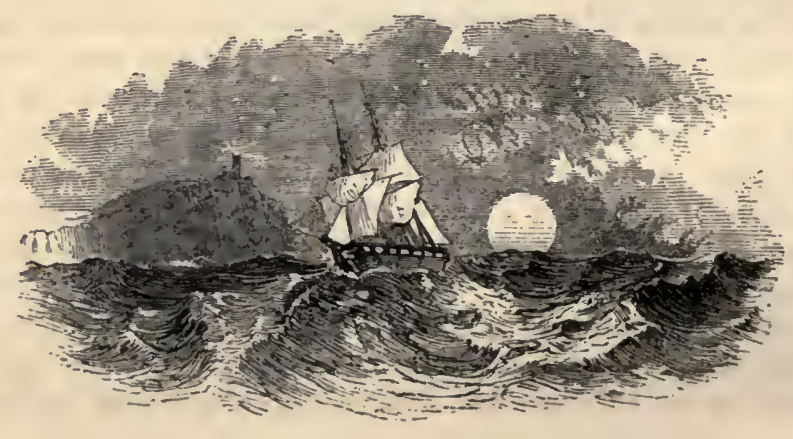




\section{CHAPTER IV.}

\section{MARS - PLANETOIDS - JUPITER - SATURN - URANUS - NEPTUNE}

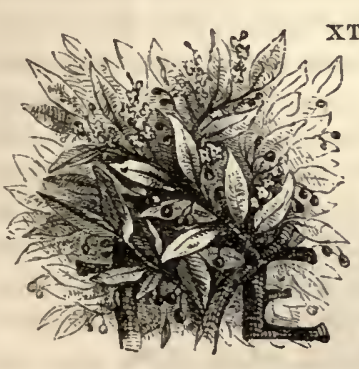

XTERIOR to our terrestrial world in the system, its noblest compeers are to be found, whether we consider the magnitude of their forms, the peculiarities of their structure, or the number of their attendants. The planets technically called superior are known to lie out in space beyond the orbit of the earth. This is shown by several decisive proofs. They never appear crescent-shaped like Mercury and Venus, or exhibit any perceptible phase when viewed through a telescope, but are always seen with a full orb, with the exception of Mars, whose appearance is often gibbous. Jupiter, Saturn, and Uranus always appear round, and the gibbosity of Mars is but a slight deviation from a circle. The inference is; that we see these planets in nearly the same direction in which the sun's rays enlighten them, and consequently the position of the earth must be comparatively proximate to the centre of their orbits. They are also never observed, when in the direction of the sun, to transit his disk, which would occasionally occur, if their path was interior to that of the earth, and carried them between us and the luminary. They are likewise seen at all distances from the sun, even in opposition, or in that quarter of the heavens which is diametrically opposite to the sun's place, rising in the east at sunset in the west, and being visible at midnight, which would plainly be impossible if the earth's orbit circumscribed theirs. These facts prove their position in the system to be exterior to our own. The external planets are chiefly distinguished from the internal by the attendance of secondary bodies, supplying in some degree to their primaries the place of the sun in his absence, and compensating for that diminution of his light when present, which arises from their vast distance from him. Mercury and Venus appear to have no moon, for, in connection with the earth, they answer the purpose of satellites to each other, Venus shining with great splendour in the night of Mereury, and our own globe forming a brilliant object in the night of Venus. At that point of the system in which we are placed, the scheme of satellites seems to commence, and with the exception of Mars and the asteroids it is a feature belonging to the other planets. If a moon should ever be discovered revolving around Mars, the law of secondary bodies attending the outlying planets would be unbroken from the point we occupy in the system to its outskirts, for the case of the asteroids may be cxcluded, their whole character being anomalous. Even as it is, the rule is general exterior to the earth's path; and there may be peculiar circumstances, not yet known, to explain the exceptive case of Mars. The number of secondary bodies appears to be proportioned to the wants of the primaries. While our globe has one, Jupiter, at fire times the distance from the sun, has four; Saturn, at nearly ten times the distance, has eight, besides the enormous rings, which afford an illumination equal to several thousand such attendants; and Uranus, of nearly twice the distance of Saturn, besides his discovered five or six, may have hundreds that escape our notice, owing to the immense interval that separates him from us.

Mars, the nearest to us of the exterior planets, was, in former ages of superstition, the dread of the terrestrials on account of his fiery aspect, and ministered more than any other celestial object to give employment to the astrologers, and to fill their coffers :- 
"But most is Mars amisse of all the rest ; And next to him old Saturnc."

If Spenser were alive now, he must admit his words to involve a libel upon a very harmless body, fit to be commended to the inhabitants of the earth as an example of peacefulness and order, rather than regarded as a patron of belligerent propensities, delighting in " manslaughter and byrnyngs of houses, and in warres," as an old almanac states. The planet is placed in the system at a mean distance from the sun of 142 millions of miles, which is nearly fifty millions of miles farther than the eartls. The space, however, between us and Mars varies prodigiously. When the two bodies are on the same side of the sun, they are five times nearer to each other than when on opposite sides, for then their distance is augmented by the entire diameter of the terrestrial orbit, or 190 millions of miles. On this account, the apparent size of the Earth will vary greatly as seen from Mars, while Mars varies in appearance to us from a diameter of $18^{n}$ to 4". He thus dwindles from a considerable orb in the heavens to an insignificant speck, presenting a faint hazy appearance when most remote from us, and contending with Jupiter for the palm of splendour under a farourable juncture of circumstances. An era of this kind occurred in the month of August 1719, when Mars was not only nearest us, but within $21^{\circ}$ of his perihelion; that is, the two events were almost coincident, of being nearest the earth and nearest the sun, and then his appearance was so brilliant as to fill the minds of the vulgar with alarm, being mistaken for a new luminosity in the skies.

The planet has been closely watched by many accurate observers, and his elements are known with considerable precision. Mars accomplishes his revolution round the sun in $686^{d} 23 \frac{1 h}{2}$, the length of his year, extending to nearly two of ours, travelling at the rate of 54 thousand miles an hour. In traversing the zodiac, he appears to move at the rate of about half a degree each day, passing through a whole sign in somewhat less than sixty days. Hence, if we know what constellation Mars has just entered, we may conclude that two months afterwards he will be in the next, and four months afterwards in the next, and six months after the date in the succeeding one. His period of rotation upon his axis is $24^{\mathrm{h}} 39^{\mathrm{m}} 21^{\mathrm{s}}$, but a slight difference in excess from the length of the terrestrial day. His true diameter is computed to be 4100 miles, rather more than one-half that of our globe, and his volume is about one-fifth. His form is spheroidal, the diameter at the equator being one-sixteenth more than at the poles. From his period of rotation being so nearly equal to that of the earth, while his diameter is very little more than one-half, it might have been concluded that the inferior velocity of his equatorial regions would have produced a much less bulging out there than at the equator of the earth. But while the equatorial diameter of our globe exceeds the polar by twenty-six miles, that of Mars does so by two hundred and fifty, which gives a greater degree of oblateness to his form, and is probably due to his far inferior density. If the orbital career of the planet were suspended, his mass would plunge to the sun in 121 days 10 hours. To Mars, the solar diameter will appear one-third less than to us, and the solar light and heat be proportionably diminished; but his night-sky will be adorned by our globe and its satellite, a beautiful pair of objects, about a quarter of a degree distant from each other.

The physical constitution of Mars is in many respects analogous to that of the earth. Indeed, the agreement between them is greater than between any two bodies in the system, as far as our knowledge extends. An atmosphere surrounds the planet. His ruddy complexion, observed in very ancient times, has been attributed to its density, and regarded as a phenomenon similar to the redness of our morning and evening sky near the horizon, which arises from the sun's rays passing through the densest part of our atmosphere, which reflects or absorbs the other colours; while the red rays are those which 
chiefly make their way through the resisting medium. The idea of Sir John Herschel is however more probable, that the fiery aspect of Mars proceeds from the geology of the

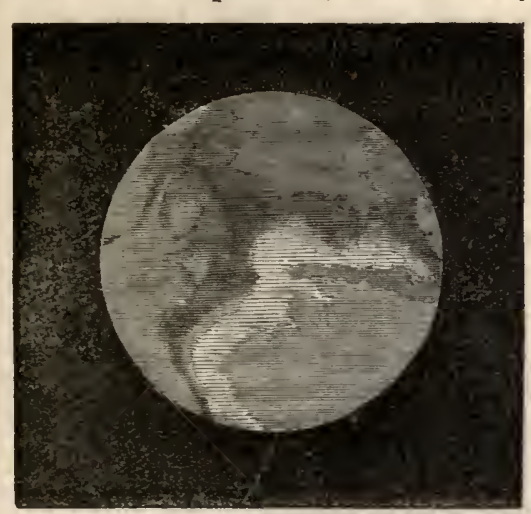
planet, its general soil having this colour, like the red-sandstone districts of the earth, but in a more decided manner. When viewed through a telescope, the surface exhibits a variety of spots, of which, as observed by Cassini, Hook, and Maraldi, we have several drawings. Some of the spots are changing and evanescent, and appear to be clouds and vapours floating in the atmosphere; but others are permanent, and are evidently geographical features of the planet - continents, seas, and regions of polar snow. The annexed view of Mars was taken by Sir John Herschel at Slough, August 16 th, 1830, in the twenty-feet reflector. The darker parts are seas, which appeared of a greenish hue. The zone observable at the polar point is brilliantly white, but of variable brightness, and is conceived to be snow, its luminosity being least after exposure to the sun through the summer season of the planet, and greatest after the darkness of its long wintry night.

There are thus points of striking accordance between the Martial and Terrene worlds.

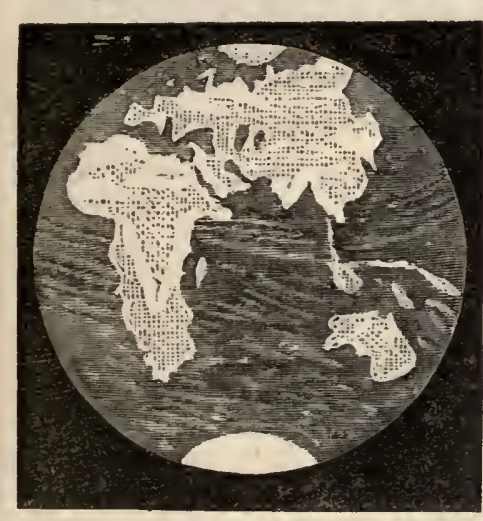
Their periods of light and darkness, night and day, are nearly equal. Both have a succession of seasons, arising from the obliquity of their respective ecliptics, though of different duration. Both have an atmosphere clouds, rain, snow, continents and seas; but without an attendant moon, the oceans of Mars must be nearly tideless, only gently undulating like the waters of the Mediterranean and the Baltic. Each planet has also vast fields of ice and snow at its poles. Should the inhabitants of Mars take a view of our world through any far-seeing instrument like that with which we inspect their dwelling, the terrestrial aspect, viewed from that distance, in one of its phases will not be very remote from the sketch now given.

Proceeding farther on an outward-bound course through the system, we arrive at the cluster of diminutive bodies, whose existence is a modern discovery. They present a variety of anomalies which distinguish them from the older planets; and received from Herschel the distinctive appellation of Asteroids, a Greek compound signifying the appearance of stars, but by others they are more properly called Planetoids, or small planets. Of these bodies, now (August 1858) fifty-three in number, four were discovered early in the century, Ceres, Pallas, Juno, and Vesta, as the result of a search conducted upon the presumption that some unknown orb lurked in the vast space between Mars and Jupiter. The first three are exclusively telescopic objects, and require the best instruments to be caught. But Vesta shines with a very intense light, as a brilliant point in the heavens, and has been observed on a clear evening by the naked eye. Following the order of succession in the system, Vesta is at the mean distance of 225 millions. of miles from the sun, Juno 254, Ceres and Pallas 263. Their periods of revolution range from somewhat more than $3 \frac{1}{2}$ to $4 \frac{2}{3}$ years. The orbit of Juno is remarkable for its eccentricity, being so elliptical that the greatest distance of this minute world from the sun is nearly double the least. Both Ceres and Pallas appear to be surrounded with a nebulous haze. 
There are several peculiarities belonging to these bodies. Though their dimensions are not known with precision, they are very exceptionally minute, even when compared with the least of the secondary bodies in the system. They deviate, also, considerably from the path in the hearens described by the other planets; so much so, that the zodiac must be expanded to nearly five times its breadth, in order to include their orbits. Their mean distances from the sun likewise differ very slightly, while their orbits intersect me another, the most remarkable feature of their condition. The paths of Ceres and Pallas cross each other, while that of Vesta cuts the orbits of the other three. These are peculiarities altogether without parallel in the system. Immense intervals separate the other planets, so that there is no possibility of intersection or collision, without an entire derangement of the constitution of the solar universe. But interlacing periodically happens with reference to the paths of these four bodies; and it is within the limits of possibility for collision to occur by the accumulation of ordinary planetary disturbances.

To this remarkable group, forty-nine members have been added in our own day. The whole are arranged below in the order of discovery.

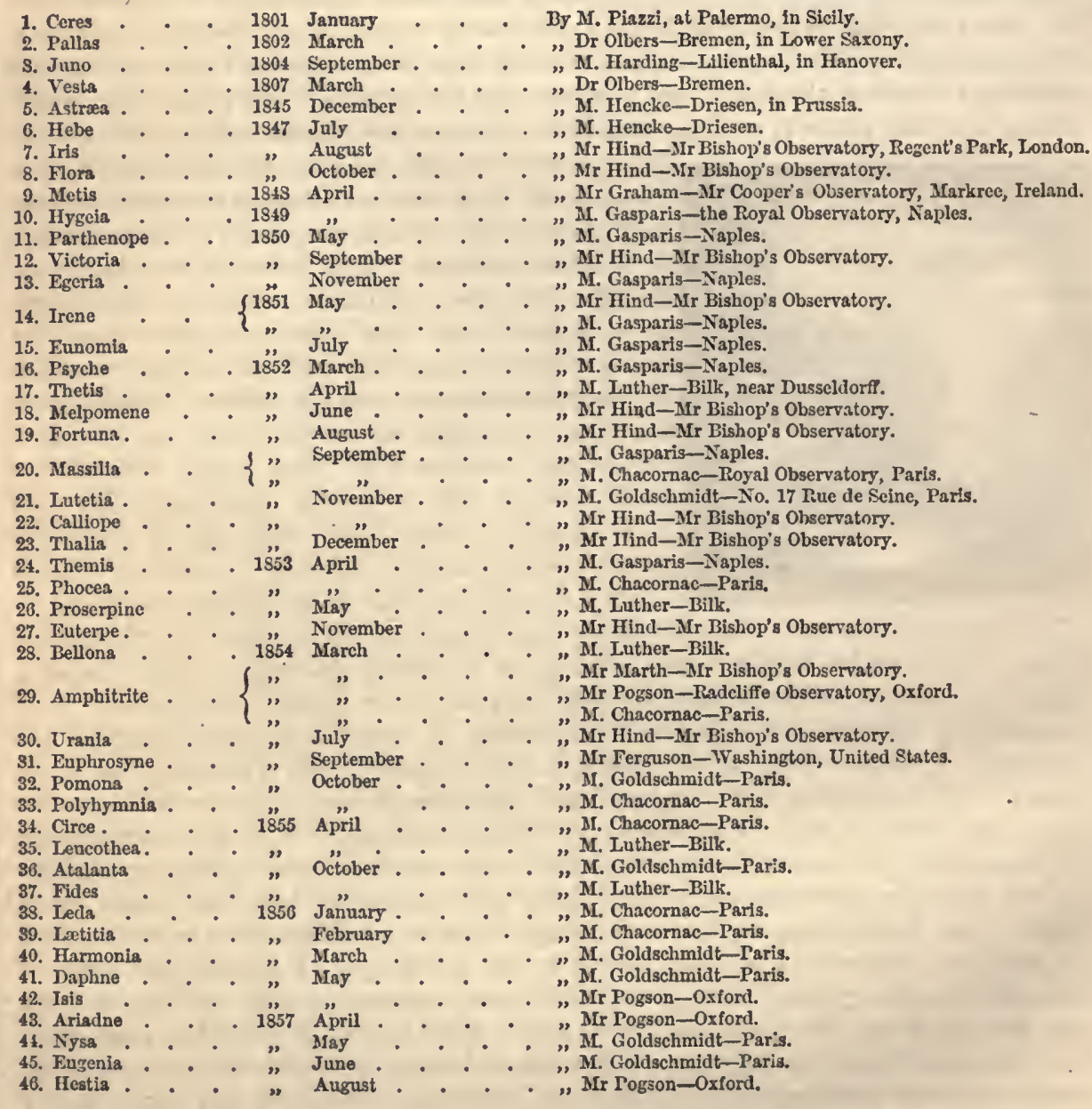




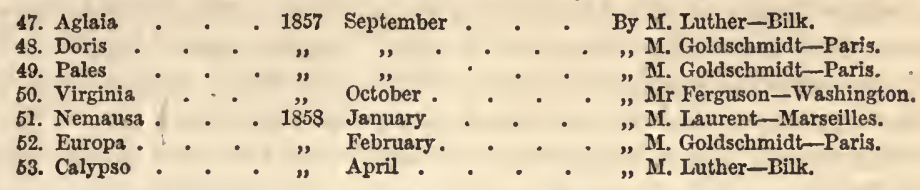

The newly-discovered planetoids correspond to those of older date in minuteness of volume, mean distances from the sun, and the very varying eccentricities and inclinations of their orbits. The superficial area of some of them is not larger than that of many a terrestrial estate. Atalanta has a diameter computed to bo little more than four miles. Vesta, Pallas, Iris, and Flora, are the brightest-perhaps the largest. The orbits of Pallas, Euphrosyne, and Phocen, have the greatest inclination; and those of Massilia and Themis the least, coinciding nearly with the ecliptic. Polyhymnia and Juno are the most eccentric in their paths, or deviate most from the circle; Amphitrite, Ceres, and Egeria, deviate the least. Flora is at the least mean distance from the sun; Euphrosyne, Hygeia, and Themis at the greatest. To illustrate the intimate connection of the entire family of small planets, it has been remarked, that if the orbits are supposed to be represented materially as hoops, they will hang together in such a manner that the whole group may be suspended by any given one. It was the bold hypothesis of Olbers, when only Ceres and Pallas were known, that they were fragments of a single planet, once revolving in the same region, which, by internal explosion from some cause analogous to volcanic action, or by concussion, had been broken up. He suggested, in harmony with the conjecture, that many more similar fragments might possibly be found. Lagrange computed that the explosive force necessary to produce the disruption, and give to the fragments certain orbits, would not be more than twenty times the velocity of a cannon-ball. This theory, it must be admitted, is strongly supported by the extraordinary number of bodies discovered since it was proposed. But it still remains a theory only. On the other hand, Leverrier and others, who have carefully examined the elements of the planetoids, believe them to have been formed originally as they are, in common with the other members of the system.

JUPITER, the next in succession after the telescopic planets, is the noblest member of the solar family in his dimensions, and the brightest in his appearance, with the exception of Venus, whom, however, he rivals in splendour, although more than seven times her distance from the sun. His mean distance from the central body is 495 millions of miles. His entire path in space extends over about 3000 millions of miles, an orbit accomplished in nearly twelve years, at a mean rate of twenty-nine thousand miles an hour. Jupiter travels over $4^{\prime} 59^{\prime \prime}$ of the zodiac in a day, somewhat less than one-twelfth of a degree, or $30^{\circ} 20^{\prime} 32^{\prime \prime}$ in a year, rather more than a sign. His course in the heavens may therefore be very easily traced. In whatever constellation he is seen on a certain night, a year hence he will be seen equally advanced in the next, and two years afterwards in the next. Jupiter occupies but $9^{\mathrm{h}} 55^{\mathrm{m}} 49^{\mathrm{s}}$ in his axical rotation. Thus, in the time in which we have one day and night, he has two, each about five hours long, the sun by day and the stars by night, with his own moons, apparently flying across his heavens more than twice as fast as the celestial bodies appear to traverse ours. By this rapid spinning upon his axis, his equatorial inhabitants will be carried round at the rate of 26,000 miles an hour, which is farther than the equatorial inhabitants of the earth are carried by its diurnal motion in twenty-four times that period. Of the stately dimensions of this fine planet, some idea may be formed from the statement, that a chain extending from the earth to the moon would not compass the equatorial circumference; and that, supposing a sailing 
vessel to accomplish the circumnavigation of our globe in a year, it would require upwards of ten years to perform at the same rate a similar voyage round Jupiter. His diameter is nearly ninety thousand miles, eleven times that of the earth ; and his volume is thirtcen hundred times greater. But as his density is about one-fourth that of the earth, but little exceeding that of water, the quantity of matter in that vast orb is only 331 times greater than what our globe contains. In two years and thirty-five days it would descend upon the sun, if left to the influence of his attraction.

From the immense velocity of the equatorial regions of Jupiter, and the intensity of the centrifugal force, a considerable deviation in his figure from a perfect sphere is to be expected. This is open to observation. The form of the planet, even on a careless view through a good telescope, appears that of an oblate spheroid. According to the observations of Struve and others, while the polar diameter of the earth is only $\frac{1}{305}$ less than the equatorial, that of Jupiter amounts to $\frac{1}{14}$, or, in round numbers, his diameter at his poles is six thousand miles less than that at his equator. This ellipticity exceeds that of any of the other planets except Saturn, owing to his great axical speed. The rapid rotation of the planet is a beneficial physical arrangement. Remored to a distance from the source of light and heat which is $5 \frac{1}{6}$ that of the earth, the sun's apparent size will be $\frac{1}{2} \frac{1}{7}$ what it is to us, supplying to him only $\frac{1}{27}$ of the light and heat that we receive. But before the earth has once rolled round upon its axis, he has accomplished two rotations upon his, and thus his surface is brought under the solar influence after a much shorter interval of suspension than with us, compensating, to some extent, for its diminished power through his distance. That change of seasons which we experience is a diversity unknown to this planet. This arises from the axis being perpendicular, or nearly so, to the plane of the orbit, so that the days and nights are constantly of equal length, and the direction of the sun's rays constantly uniform, oblique towards the poles, and perpendicular at the equator. We have here undoubtedly another instance of wise arrangement, for otherwise the regions towards the poles would have been alternately immersed in the darkness of a six years' wintry night. It is not, however, to be understood that one uniform season prevails over the surface, but that the same parallels of latitude north and south of the equator enjoy uniformly the same season, whatever that season may be. It is perpetual summer in the equatorial regions, and perpetual winter at the poles; but the rapid rotation of the planet is a security against intense heat accumulating in the former through the invariably direct action of the solar rays, and against the intensity of cold that would prevail at the latter, if their influence was absent for any considerable interval.

Jupiter, when viewed through a telescope, exhibits a series of zones, or bands, familiarly called belts, stretching across his surface in a direction parallel to his cquator, and, generally, to each other. They were first observed at Naples by the Jesuits Zappi and Bartoli, abont the year 1633. These belts are variable both in number and breadth. Sometimes eight have been seen, sometimes only one, but more usually three. Instead of being uniformly regular in their shape, they have frequently a lacerated appearance, and, while some continue in the same form for months, others change in a few hours. The aspect of the planet lias been sketched by many observers. The views given by Cassini, Dr. Hook, Sir W. Hersehel, and Dr. Long are here inserted. In Hook's drawing, taken in May, 1664, a spot appears upon one of the dark belts, by which Cassini ascertained the period of Jupiter's rotation in the following year. This ancient spot, as it is called, has repeatedly appeared and vanished. It was not seen between the years 1708 and 1713 , but in the winter of 1834 it was distinctly visible. Other similar spots have been observed, generally situated in the belts. These appearances open a wide field for speculation. The belts have been deemed alterations upon the surface of the planet 
caused by great physical convulsions. A far more probable and generally received opinion is, that the dark bands are the actual body of the planet, and the bright bands compact and undisturbed strata of clouds and vapour. It is also supposed that currents similar

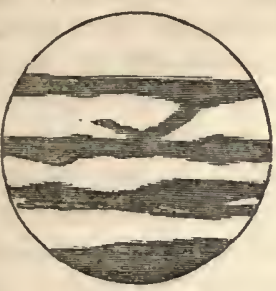

to our trade winds set in from the poles to the equator of Jupiter, which assume a parallel direction as the equator is approached, owing to the prodigious velocity of his equatorial regions, and thereby cause those parallel aggregations of vapour, through the interstices of which the opaque body of the planet is seen. Of course, this explanation is purely hypothetical, but it is the best

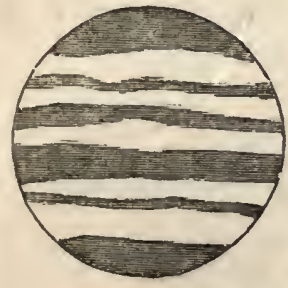
that has been offered. Admitting the explanation, it follows that Jupiter has clouds, rain, wind, water, evaporation, and seems thus fitted up to be the habitation of vegetable productions and animal life.

The discovery of the moons of Jupiter, four in number, was one of the first-fruits gathered from the use of the telescope. An opinion has indeed been current that

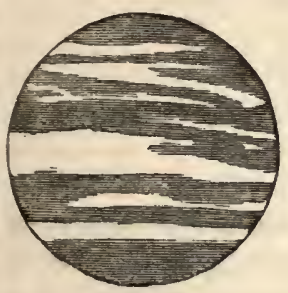
they may be discerned by a strong unassisted eye, but it appears to be erroneous. Sir John Herschel remarks that Dr. Wollaston, who had a keen eye, never succeeded in so observing them, though he cut off the light of the planet by hiding the body behind a distant ob-

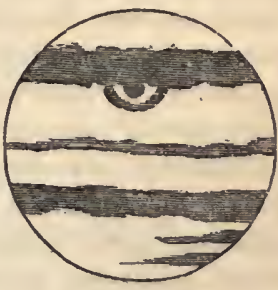
ject. The satellites are named after their
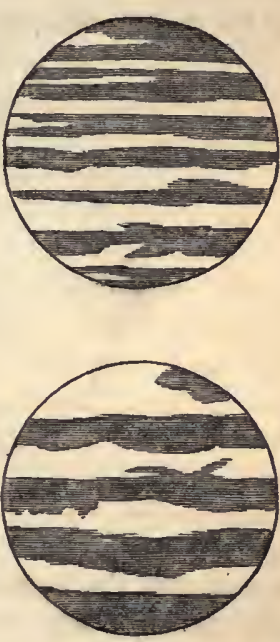

respective position in relation to the primary, the nearest to him being the first. Their comparative distances and magnitudes may be thus expressed:-

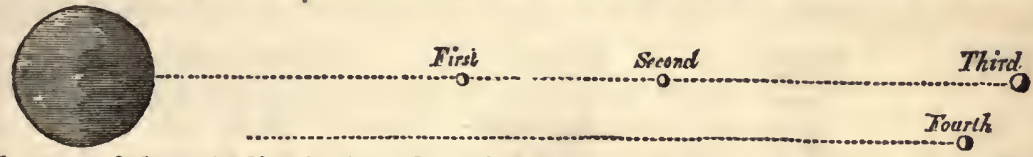

The largest of these bodies is thus the third in point of distance; the next in magnitude is the fourth; the third in magnitude is the first; and the smallest is the second, being rather less than our own moon. It is in striking accordance with the case of our satellite, that the moons of Jupiter always turn the same face towards him, and thus make one rotation upon their axes while accomplishing one orbital revolution. These attendants are obviously designed to give him a splendid night in compensation for a day less lustrous than that which we enjoy; and it deserves notice that their orbital motions are so arranged that they can never be all new moons, and consequently invisible, at the same time. The position of the satellites with respect to each other, and to their primary, as seen from the earth, is very variable. Sometimes they appear ranged in a line on each side of the planet; at other times they are all grouped on the same side; and on Nov. 2, 1681, Jupiter appeared deserted by his guards, three being on his disk, and one behind his body. This rare phenomenon was also noticed September 27, 1843. 
All the satellites are eclipsed once in every revolution by passing through the shadow of the planet, with the exception of the fourth, which sometimes escapes, because of the greater magnitude and inclination of its orbit. But with reference to the first satellite, it is never the case that both the immersion and the emersion can be observed, owing to its being so near the planet, and this is generally true of the second. On the other hand, the satellites pass between Jupiter and the sun in their revolution round him, and then project their shadows upon the enlightened portion of lis disk, causing a solar eclipse to that part of his surface. They pass also between the planet and the earth, and then exhibit the phenomena of transits; and, lastly, they pass direetly behind the body of the planet in opposition, and are then occulted. At A B C D the earth is represented in different parts of its orbit; and at $J$ Jupiter is seen surrounded by his four satellites, whose orbits are marked $1,2,3,4$. The first satellite is shown entering the sliadow of the planet at $a ; b$ is the point of emergence from it; and clearly, the interposing body of the planet will prevent the emersion from being visible to a spectator on the earth at

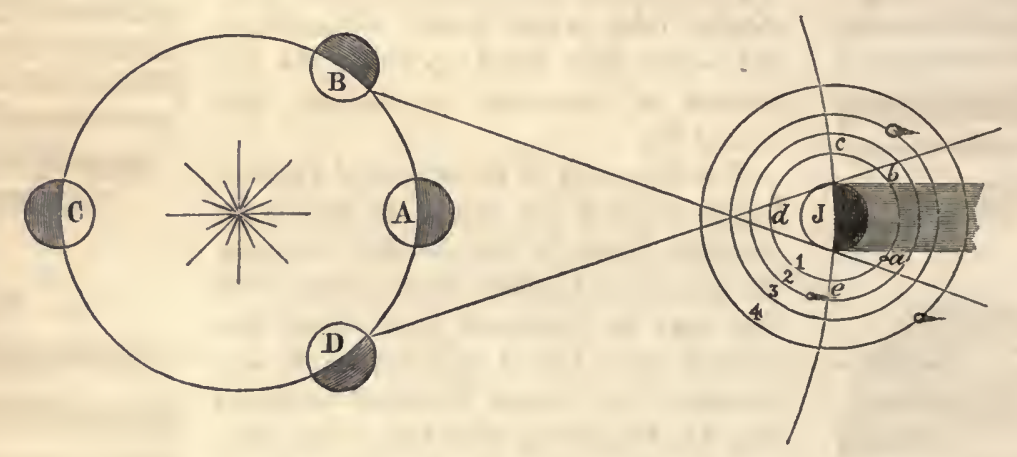

$\mathrm{n}$, who sees the immersion, and that will be invisible from the same cause to a terrestrial olsserver at $\mathrm{B}$, who sees the emergence. The satellite at $c$ and $e$ has its greatest eastern and western elongations to a spectator on the earth at $\mathrm{A}$; and it appears projected as a small dirk spot upon the disk of Jupiter at $d$. The following table expresses the general elements of the satellites, their distances and dimensions, times of revolution, and the duration of their eclipses:

$\begin{array}{ccr}\text { Satellite. } & \begin{array}{c}\text { Diameter } \\ \text { In Mliles. }\end{array} & \text { Distance. } \\ 1 & 2508 & 260,000 \\ 2 & 2068 & 420,000 \\ 3 & 3377 & 670,000 \\ 4 & 2890 & 1,180,000\end{array}$

$\begin{array}{cccc}\text { Time of Rerolution. } & \begin{array}{c}\text { Duration } \\ \text { cf Eclipse. }\end{array} \\ \begin{array}{rrrrr}1 \mathrm{~d} & 18 \mathrm{~h} & 28 \mathrm{~m} & 2 \text { hours. } \\ 3 & 13 & 14 & 3 \\ 7 & 3 & 43 & 3 \frac{1}{2} \\ 16 & 16 & 32 & 5\end{array}\end{array}$

Owing to the eclipses of the satellites taking place so frequently, they are of great use in the determination of terrestrial longitudes, those of the first being of the most importance on account of their more rapid recurrence. For this purpose they are carefully calculated, predicted, and registered in the Nautical Almanack, a book which forms one of the finest examples we have of the power of the human mind. There is nothing more simple than this method of finding the longitude. Let us suppose an individual to observe the immersion of the first satellite to take place where he is situated at ten o'clock at night, and that the Nautical Almanack registers its oecurrence at Greenwich at six, it follows, that, as the sun apparently travels fifteen degrees an hour, the longitude of the observer is $4^{\mathrm{h}}=60^{\circ}$ east of Greenwich; for faster time shows that he is east, and slower that he is west. At sea, great practical difficulty besets this method of finding the longi- 
tude, owing to the unsteadiness of the observer's station on board a vessel; and more convenient and accuratc modes have superseded it in navigation. To the inlabitants of Jupiter, the opportunity will occur of witnessing upwards of four thousand lunar eclipses, and as many solar, in the course of their year. 'To us, the planct with his moons, constituting what is technically called the Jovian system, exhibits a miniature picture of the great solar scheme. The laws which govern the planets in their revolution round the

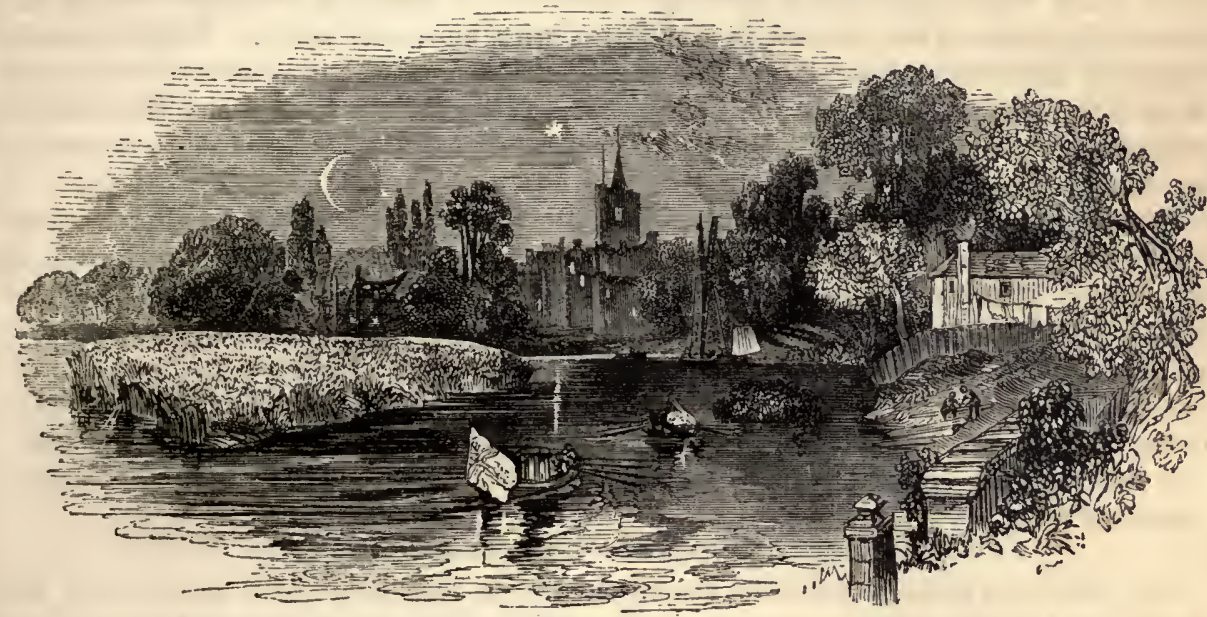

sun, govern the satellites in their revolution round their centre. They move in elliptical orbits, and, like the larger bodies, travel in a direction from west to east. Though insignificant in point of magnitude when compared with their primary, their united bulk is equal to thirteen of our moons. The first satellite will be a conspicuous object in the Jovian firmament, while, to it, the great planet will be exhibited on a scale of inconceivable magnificence, presenting every forty-two hours the varying forms of a crescent, a half and full moon, and a gibbous shape, appearing a thousand times larger than our moon appears to us in her corresponding phases.

SatURN.-From the noblest of the planets in point of magnitude, we pass to the most extraordinary in architecture - an orb which would exhibit the most fascinating appearance to the eye but for its remoteness. An interval of space, nearly twice as great as the vast chasm between Jupiter and the sun, must be crossed to arrive at Saturn, whose mean distance from the solar body is about nine hundred millions of miles, and who never hails the terrestrials from any station nearer than eight hundred millions. He occupies a period of 10,759 solar days in accomplishing his circuit round the sun, having a mean daily motion among the stars of only about $2^{\prime}$, the thirtieth part of a degree. If observed therefore entering a particular constellation of the zodiac, we may conclude that a period of two years and a half will elapse before he will bid it farewell. The year of the planet, extending to nearly thirty of ours, gives an age to his octogenarians, should there be any, parallel to that of a terrestrial born when the Jews were in Babylon, and surviving to be one of our contemporaries. His day is rather longer than that of Jupiter, but shorter by more than one half than our own, as he rotates upon his axis in $10^{\mathrm{h}} 29^{\mathrm{m}}$. While appearing to the naked eye as a pale feeble point in the heavens, the Saturnian orb has an actual equatorial diameter of 79,160 miles, and a volume which is nine hundred times greater than that of the earth. Owing to his far removal from the central source of light and heat, his surface receives only the ninetieth part of these 
elements compared with that we enjoy; but it is computed, that cren the ninetieth part of the solar light exceeds the illuminating power of three thousand of our moons at the full, and would itself be amply sufficient for the purposcs of life. If arrested in his orbital course, and abandoned to the force of the solar attraction, Saturn would drop to the sun in about five years and two months. His true form is a recent determination. Though not so swift upon his axis as Jupiter, the two diameters exhibit a greater difference, the polar being 6700 miles shorter than the equatorial, a degree of oblateness due to tho greater lightness of his material in connection with his axical speed. It was formerly supposed that the diameter is not the greatest at the equator, but at some distance from it, and that the north polar region is much more flattened than the south. This was the conclusion of Sir W. Herschel ; and it still passes current. But the real shape is that of an exact spheroid of considerable ellipticity.

Men had long been upon terms of acquaintance and familiarity with Saturn without suspecting the grandeur of his construction, or the remarkable apparatus with which he is furnished. The shepherd astronomers of Chaldea-the star-gazers of Egypt, Greece, and Rome-the astrologers of the middle ages-Copernicus and Tycho Brahe-saw the planet only as a dull nebulous star slowly moving through the heavens. It was not until the earth had performed its annual circuit round the sun many thousand times, that the stately form and numerous attendants of the remote wanderer-hitherto deemed obscure and dreary-were revealed. At length, in the year 1610, Galileo sent to Keppler the enormous word,

\section{Smaiomrmilmepoetalevmibrnenvgttaviras}

which veiled the Latin sentence to uninstructed eyes, introduced in a former page, and announced the most distant planet to be threefold. This was a glimpse caught of the annular appendage of Saturn, which Huygens, with a more perfect instrument, found to be a ring, at the same time discovering one of the satellites. The planet is now more fully known to us. It occupies an illustrious place in the system, having a train of eight moons, with two conspicuous rings encompassing its body-a peculiarity of structure without another example in the universe, so far as we are acquainted with it. The two

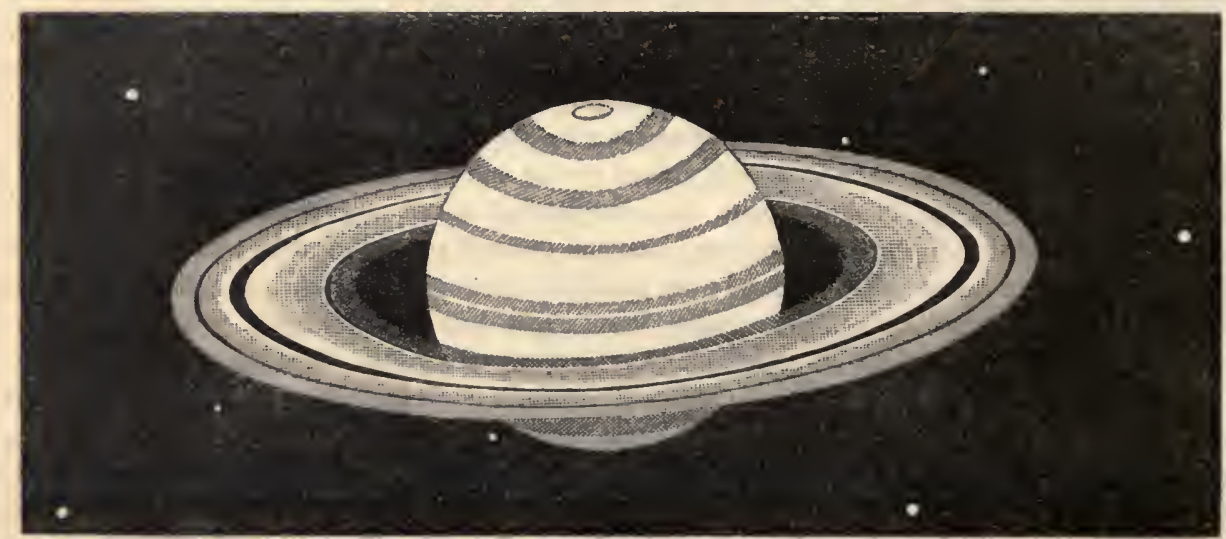

rings are readily seen in good telescopes separated by a dark interval. But recently, using mightier instrumental power, the discovery has been made of a third, inside the other two, which seems to be composed of a substance altogether different. It is of a dusky aspect, and semi-transparent, as the ball of the planet can be seen through it. It has also been ascertained that there is a delicate sub-division of the outer ring, visible only near the extremities. The planet is not exactly central with reference to the annuli, but a 
little to the west, a position which is found to contribute to the stability of the Saturnian system. The surface of the globe exhibits belts, bright and dark, which point to the same cause as similar phenomena in the case of Jupiter, whatever that cause may be. But, unlike his neighbour, the axis of Saturn is inclined $29^{\circ}$ to the plane of his orbit. He has days and nights therefore of unequal length, a diversity of seasons, and alternately for years continued winter and darkness reign at his poles.

The satellites of Saturn have been named by Sir John Herschel, beginning with the innermost, Mimas, Enceladus, Tethys, Dione, Rhea, Titan, Hyperion, and Iapetus, after the Titanian divinities. Their respective distances from their primary vary from about half the distance of our own moon to upwards of two millions of miles. Their periodic revolutions also vary from twenty-two hours to seventy days. Little is known as to their precise magnitude, but the most distant is evidently the largest, and is supposed to be nearly equal to Mars in size. The first discovered, or the sixth as to distance, called in honour of the discoverer the Huygenian satellite, is the brightest. These two may be discerned with ordinary optical aid. The rest are more difficult objects, and it requires the mightiest telescopes to reach those, which just skirt the rings, discovered by Herschel. The dimensions of the two conspicuous rings, as given from the measurements of Struve, made at Dorpat in the year 1828, with Frauenhofer's large refractor, are as follows :-

$\begin{array}{llll}\text { Exterior diameter of exterior ring } & - & - & -176,418 \text { miles } \\ \text { Interior diameter of exterior ring } & - & - & -155,272- \\ \text { Exterior diameter of interior ring } & - & - & -151,690- \\ \text { Interior diameter of interior ring } & - & - & -117,339- \\ \text { Interval between the inner ring and Saturn } & - & - & - \\ \text { Interval between the rings - } & - & - & - \\ \text { Thickness of the rings not more than - } & - & - & 100-\end{array}$

The above measurcments give to the exterior ring a width of 10,573 miles, and to the interior of 17,175 miles, making the entire width of the bright rings, including the interval, 29,539 miles. That these appendages are opaque substances is shown by the fact that they throw shadows on those parts of the planet that are on a line with them and the sun, and on the other hand they receive the shadow of the planet. Both these rings have a motion of rotation, accomplished in $10^{\mathrm{h}} 29^{\mathrm{m}} 17^{\mathrm{s}}$, a condition plainly essential to their stability, the centrifugal force engendered by the rotatory motion balancing the attraction of the planet, and preventing their precipitation to its surface. But notwithstanding the centrifugal force, it may be demonstrated to be a condition necessary to the stable equilibrium of the rings, that they should not be of uniform thickness or density, otherwise the system would be in a state of unstable equilibrium, like that of a needle balanced on its point, and the slightest disturbance, such as must arise from the action of the satellites, would bring on a catastrophe. Accordingly, evidence appears that the rings are not alike in all their parts. The edge is not flat but spheroidal, and according to Messier the surface is diversified with inequalities, an irregularity of form which satisfies the demands of theory, and guarantees the preservation of this remarkable appendage. The system of Saturn, the most complicated with which we are acquainted, is an astonishing instance of artistic skill, of nicely adjusted mechanism-a ball launched in space, surrounded by ponderous zones, each independent of the other, all acted upon by the attraction of the sun and of the planets, and acted upon by one another and by the satellites of the planet - yet no confusion has arisen, but the original order is maintained, after the lapse of ages of constant antagonism!

The planet is here shown in different parts of its vast circuit round the sun, with the 
earth in corresponding orbital positions. As the rings maintain the same inclination to the plane of the orbit, it is obvious at a glance that their aspect to a terrestrial spectator must greatly vary, in the course of revolution. Alternately one side is seen and then

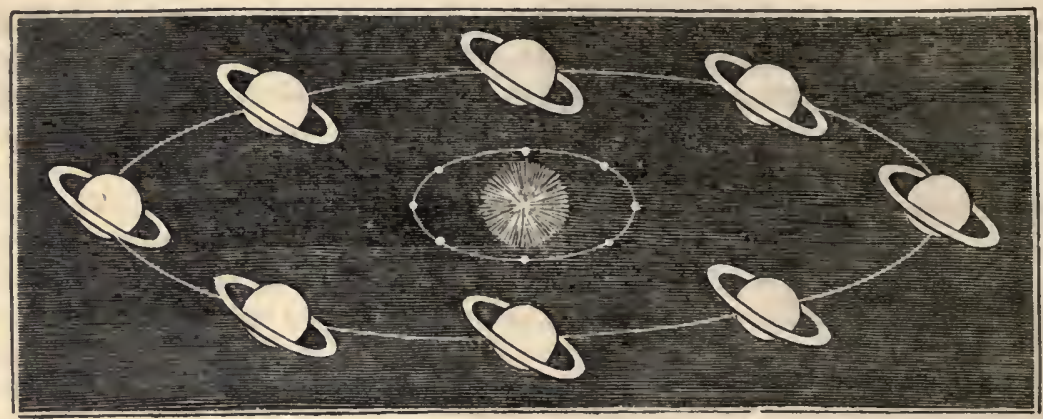

the other, and oval forms of different ellipticity are presented. It also happcns that the earth being in the plane of the rings, or in a direct line between them and the sun, only the edge is turned to us, about a hundred miles thick. They are then invisible, except with the aid of the mightiest telescopic power, when a fine line appears drawn across the disk of the planet, projecting on each side. This occurs twice in each revolution, or once in every fifteen years. These are the phases of Saturn, exhibited in the side views, phenomena which astonished Galileo, and which Huygens was the first to explan. The appearance in the centre represents Saturn and his rings as he would be seen if placed perpendicularly above us.

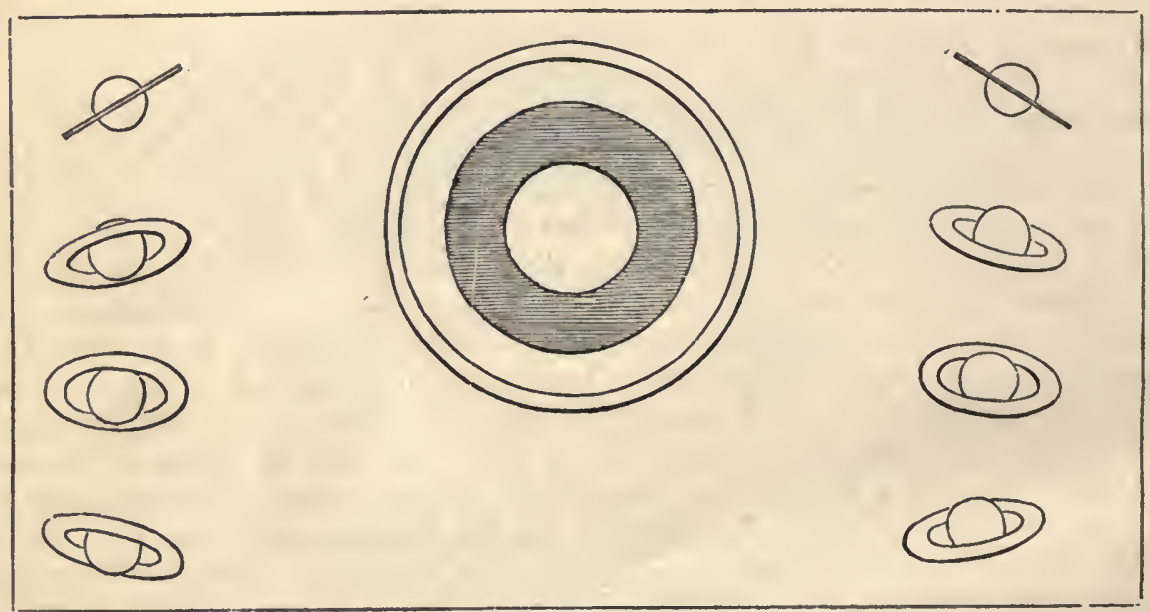

Phases of Saturn.

The annular apparatus of Saturn illustrates the resources of the Creator, and in connection with his moons is no doubt intended to give him compensation for a scanty supply of direct solar light. Three of the satellites are nearer to him than our moon to us, and the other four will be conspicuous objects in the heavens of the planet. The nearest satellite probably presents a disk equal in extent to nine or ten times that of our lunar 
globe ; and flying round its primary every twenty-two hours, a rapid succession of phases will be exhibited. But the rings are doubtless the chief glory of the Saturnian firmament at night, constituting a very noble spectacle, varying in their appearance according

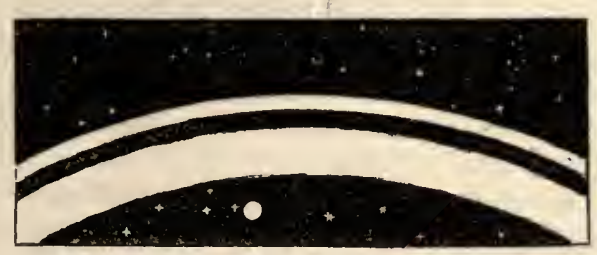
to the position of the place of observation. From the polar regions they will scarcely be perceptible, but at thirty degrees from the poles a segment of them will be seen emerging above the horizon, increasing in altitude as equatorial latitudes are gained. Supposing them appendages of the earth, the sketch may convey no inaccurate idea of their appearance, at about sixty degrees from the equator.

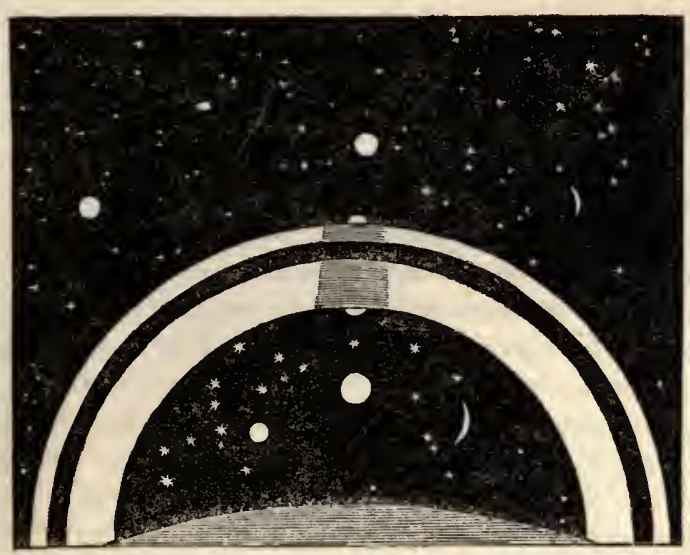

Sir John Ross, when in a high northern latitude, obscrved a striking aurora bestriding the sky, which he describes as answering to his conceptions of the aspect of Saturn's rings as scen from his surface. Advancing to the equator, they will span the heavens like magnificent arches near the zenith, with the shadow of the planet resting upon them, the satellites pursuing their respective courses at different distances, and the stars shining on each side of the luminous zones, and in the interval between them.

URANUS. - This remote and obscure body, removed to about twice the distance of Saturn from the sun, may be seen with the naked eye by a practiscd observer in fine weather when the moon is absent, and appears like a fixed star of the least visible magnitude, shining with a pale blue light. It was observed three times by Flamstead, once by Bradley, once by Mayer, eleven times by Lemonnier, who registered it among the star's; but Herschel discovered its planctary character at Bath in 1781, and thus effected all achievement, no parallel to which history before had chronicled. For some time previous, astronomers had been aware of the motions of Jupiter and Saturn being subject to certain perturbations which could not be explained; and it had been conjectured that some planet might revolve beyond the latter, which would account for them. The verification of this idea illustrates the accuracy of astronomical observations. The planet is situated at a mean distance from the sun of 1800 millions of miles, and has a path of more that 10,000 millions to traverse in revolution round him, accomplished in a period of eighty-four years. One circuit therefore has not been performed since it was discovered to be a member of the solar system. It moves over one degree of its orbit in eighty-five days, and is thus seven years in passing one constellation of the zodiac. Uranus, apparently insignificant in the heavens, is the third of the planets in magnitude, eighty times larger than the earth in volume, having a diameter of 35,000 miles. Six satellites, according to Herschel, attend his course. But this observation has not yet been fully verified. No other astronomer obtained a sight of any of these faint objects until the year 1848, when Sir John Herschel detected two, and so far confirmed his father's views. Two more have since been seen by Mr Lassell and M. Otto Struve. They revolve in orbits, the planes of which are nearly perpendicular to the ecliptic, and in a direction from east to west - singular anomalies-exceptions to the general laws of the system. All the other primary planets 
and the satellites move from west to east, and the satellites move nearly in the same plano with the orbits of their primaries. Why these laws should be departed from in this instance is an inexplicable circumstance. As we know little of Mercury owing to his proximity to the sun, so we know little of Uranus owing to lis remoteness. The proportion of light and heat which reaches him is about $\frac{1}{3} \frac{7}{6}$ that which the earth receives, but this is equal to the illuminating power of several hundreds of our full moons. From lis far distant sphere, the planet would fall if subject alone to the centripetal force, and require an interval of nearly fifteen years to be precipitated upon the sun.

The last discovered and farthest planet is at the enormous distance of 2800 millions of miles from the sun, and marks the present boundary of the planetary system. Neptune has a diameter of 37,500 miles, a period of revolution of 164 ycars, and is certainly attended by at least one satellite, first seen by Mr. Lassell in 1846 .

A cursory view has now been taken of the individual members of the solar system. The vastness of its area and the magnitude of its objects forcibly arrest attention. The more, indeed, we become experimentalists in the scenery of the universe, the more impressed we are with the imperfection of all human thought and language in relation to its range, the dimensions of its structures, and conscious of the inadequacy of our conceptions. In early life we form ideas of magnitude which are notoriously defective. To childhood romping upon the village green the scene of its gambols presents an extensive surface, and the hill-side from which the daisy and cowslip are plucked appears a considerable elevation; - the experience of after years corrects these impressions. When the man returns to the scenes of his youtl, after having becn long separated from them, he is surprised at their altered aspect, and struck with the fallacy of his former views. The green of the village scems but a span, and the eminence a hillock. After having gazed upon the expanse of the Amazon, or the powerful current of the Mississippi, the stream meandering through the meadows which once suggested an idea of amplitude, inspires only a notion of insignificance. It is thus with us when the mind departs from terrestrial regions, and studies the outlying realms of nature. The survey corrects and expands its views. The fallacy of former conceptions of height, length, breadth, and depth is felt, and, penetrating into space, the conviction becomes more distinct, at every step, of the poverty of language to express, and the inadequacy of intelligence to grasp, the real magnitude of the universe. To a Welsh goatherd Snowdon and Cader Idris have gigantic dimensions in comparison with the scale of his own bodily structure; but the sovereigns of his native wilds dwindle into dwarfishness in contrast with Mont Blane, Mont Rosa, or the Ortler-Spitz. Yet these are shorn of their attributes of extension, massiveness, and grandeur, in the vicw of the great Andean chain. All the inequalities, however, of the earth's surface taken together, arc, proportionally to its magnitude, but as a handful of dust sprinkled upon an artificial globc, while the earth itself is but one of the smaller objects of the solar universe.

The superficial extent of the earth includes upwards of a hundred and ninety-seven millions of square miles, and its solid contents amount to two hundred and sixty thousand millions of cubical miles. Huge as this ball is, it is but like Snowdon to Mont Blanc, when contrasted with Jupiter, Saturn, or Uranus. The areas, and solid contents, of these planets are about as follows :-

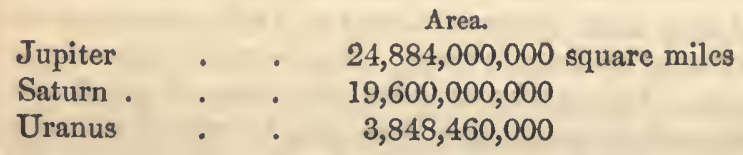

Solid contents. $368,283,200,000,000$ cubic miles $261,326,800,000,000$ $22,437,804,000,000$

Including the other planets and the satellites, their combined surface cannot be estimated 
at less than sixty thousand millions of square miles, which is about three hundred times the surface of the globe. The mind can only imperfectly embrace this vastness of territory; yet it is but as a province to an empire when compared with a single object in the system - the Sun. The solar surface comprises an area of nearly $2 \frac{1}{2}$ billions of square miles, the planetary surface being in proportion to it as $\frac{1}{40}$, and the terrestrial surface as $\frac{1}{12350}$. Situated in a forest containing 12,350 trees, a single tree would be lost in the aggregate; but we must imagine a tree placed by the side of another 12,350 times larger, in order to form a proximate idea of the comparative extent of the terrestrial and solar surfaces. Regarding the earth as a very small pea, a circle would be required of 11 inches diameter to represent the relative size of the sun. In its solid bulk, the solar globe is equal to five hundred times the volume of the planets, and to nearly $1 \frac{1}{4}$ million such worlds as ours.

The extent of space occupied by the orbits of the planets is no less astonishing than the stateliness of some of their dimensions. At the railroad speed of fifty miles an hour, an individual would ascomplish the journey over the longest tract of land in the old world, from the coast of Senegal to that of Kamschatka, in ten days. But it would require a period of 430 years to proceed in a direct line from one extremity of the earth's orbit to another, at the same rate of motion; and this is but a trifling span when compared with the diameters of some of the other planetary orbits. If a vehicle had been set in motion at the commencement of the Christian era, and had incessantly kept up the velocity mentioned, it would not yet have performed half its passage across the orbit of Saturn; or if one had begun a similar pilgrimage at the same rate across the orbit of Uranus when Adam was in paradise, it would yet be far away from its goal. Suppose an inch employed to represent the earth's distance of 95 millions of miles from the centre of the system, 19 inches will be required to express the proportionate distance of Uranus, and 30 inches that of Neptune, its visible boundary. Views of extensiveness thus break in upon us which are perfectly inappreciable and confounding. Of a mile, or ten miles, or a hundred miles, we can form a distinct conception, because these are spaces which we often travel over; and a person who has sailed across the Atlantic will be able to entertain a commensurate idea of one, two, or three thousand miles. But when millions are brought before us, we have an extent to grapple with, which so far transcends that of the scenes of terrestrial locomotion as to defy our mental grasp to embrace the distance. We can only approximate to an adequate notion of the real range of the planetary universe by calculation upon a reduced scale. 'Thus, if the metropolis be taken to represent the site of the sun, and one mile a million, the orbit of Mercury will be a circle passing within the neighbourhood of Rochester and Bedford, while that of Neptune will embrace the whole of Europe, and pass northwards beyond the pole, southward below the equator, westward to North America, and eastward into Asia. The area occupied by the system to which we belong is thus stupendous. To form a conception of its amplitude, worthy of it, is at present beyond the scope of our faculties. Yet our further inquiries will show this area to be but a small department of the creation, as small, when compared with the visible regions of the universe, as a few yards of rock peeping up above the surface of the waves to the broad expanse of the Pacific!

Some general considerations suggested by the aspect of the planetary system will now be appropriate.

It is impossible to contemplate physical nature without perceiving identical features in its home and foreign regions. In the arrangements of our own globe the evidences of uniform plan are emphatic, indicating the presence and operation of one Intelligence and Will in its construction. Passing from the bounds of our own island, we discover in every region through the length and breadth of the earth's surface, similar classes of 
phenomena to those in our immediate neiglibourlood. The agitations of the atmosphere, its masses of clouds, and its refractive and reflective properties - the rise and subsidence of the great waters - the alternations of light and darkness - and a diversity of seasons, are universal over the globe. Columbus opened a new world to the knowledge of the old, but in the new as in the old the general laws of nature were the same-the tides flowing and ebbing along the coasts, eleetricity operating in the atmosphere, the magnetic needle pointing to the pole, day and night, summer and winter interehanging. The general structure and physical properties of its human inhabitants, its plants and animals, are accordant, and their subordinate diversities may in most eases be traced to the action of laws which universally produce the same effects where the circumstances are the same. But leaving the ball upon which we live, and viewing the kindred orbs associated with it in the solar universe, the intimations of uniform plan are equally strong. Let us dwell upon some of the unitics of the system. Omitting for obvious reasons the telescopic planets, though in many respects they harmonize with the rest, the following phenomena are prominent:-1. All the planets have a projectile motion in space in the same direction from west to east. 2. They move in nearly the same plane. Taking the plane of the earth's orbit as a horizontal base, the planes of the other orbits exhibit only a slight divergence from it.

\begin{tabular}{|c|c|c|c|c|c|}
\hline \multicolumn{4}{|c|}{ Inclination. } & \multicolumn{2}{|r|}{ Inclination. } \\
\hline Mercury & - & $\begin{array}{lll}-7^{\circ} & 0^{\prime} & 9^{\prime \prime}\end{array}$ & Jupiter - & - & $-1^{\circ} 18^{\prime} 51^{\prime \prime}$ \\
\hline Venus & - & - $\begin{array}{lll}3 & 23 & 28\end{array}$ & Saturn - & - & - $2 \quad 2935$ \\
\hline Mars & - & - 1516 & Uranus - & - & $\begin{array}{lll}-0 & 46 & 28\end{array}$ \\
\hline
\end{tabular}

3. All the satellites move in the same direction as their primaries, and nearly in the same plane, with the exception of the moons of Uranus. 4. The orbits of the planets and satellites exhibit only slight variations in their amount of eccentricity. 5. These different bodies have a motion of rotation in the same direction with the sun, and their own motions of projection. 6. The planets exhibit traces of atmospheres more or less decided. These are confessedly striking phenomena. They clearly exclude the operation of chance-medley from the system. They are unities which spenk intelligibly of One causing and governing Mind, and significantly proclaim the simultaneous origin of the solar universe under the control of eommon laws. When we consider that the bodies which compose it maintain their present stations, motions, and distanecs, by their mutual action on each other - that neither could be where it is, nor as it is, unless they were all co-existent - the inference is strong, and seems philosophically certain, that they obtained contemporaneously, or nearly so, that arrangement, and those positions in which we now behold them, under the action of the same physical eause. The foree of the solar attraction to Mercury is in some degree counteracted by that of Venus and the Earth, and the orbital motions of the former are the result of the nice adjustment of these complieated forces. This fact, true of all the planets, is a strong indication that their formation was simultaneous.

But if, in relation to the terrestrial world, uniformity characterises the general plan, the detail displays an endless diversity. Its great divisions of land and water, its mountains, plains, and valleys, have each distinguishing peculiarities. Plants of the same genus have no perfect similarity, nor have their stems, flowers, and leaves. The grains of sand and the blades of grass differ. The same fact is true of the human race, and of animals of the same species; and hereby property ean be elaimed in the latter, friendship recognise its objects of affection, and justice its criminals, in the former. In like manner, all the knowledge we have of the creation exterior to our globe assures us of the stamp of variety being impressed upon it. Thus the planets, alike in dependence upon a cen- 
tral orb, in rotation and orbital motion, differ in their distances, magnitudes, densities, velocities, and construction. Some are more gorgeously fitted up than their companion globes. The day of Mercury nestling near the sun, and that of Uranus so distant from him - the moonless night of Mars, and that of Saturn with his rings and satellites - must be widely discordant, while each planet experiences a real day and night. The arrangements of the system do not more strongly declare the one-ness of its authorship, than the boundless resources of that author.

The relative distances of the planets from the central source of light and heat exhibit great discrepancies. Taking that of the earth as 1, the proportionate distance of Mercury is $\frac{4}{10}$, Venus $\frac{7}{10}$, Mars $1 \frac{1}{2}$, Jupiter $5 \frac{1}{4}$, Saturn $9 \frac{1}{2}$, Uranus 19, Neptune 30 . This diversity of position must produce diverse physical effects; but even to the farthest planet the Sun is still a Sun, and will afford an illumination several hundred times surpassing our largest supply of lunar light. 'The apparent diameter of the sun, as seen from the earth, is 32 '. As seen from the other planets, it will be,

$\begin{array}{ccccccc}\text { Mercury } & \text { Venus } & \text { Mars } & \text { Jupiter } & \text { Saturn } & \text { Uranus } & \text { Neptune } \\ 80^{\prime} & 46^{\prime} & 21^{\prime} & 6^{\prime} & 3^{\prime} & 1^{\prime} \cdot 3 & 60^{\prime \prime}\end{array}$

The comparative size of the solar orb from these several stations may be thus pictorially expressed :
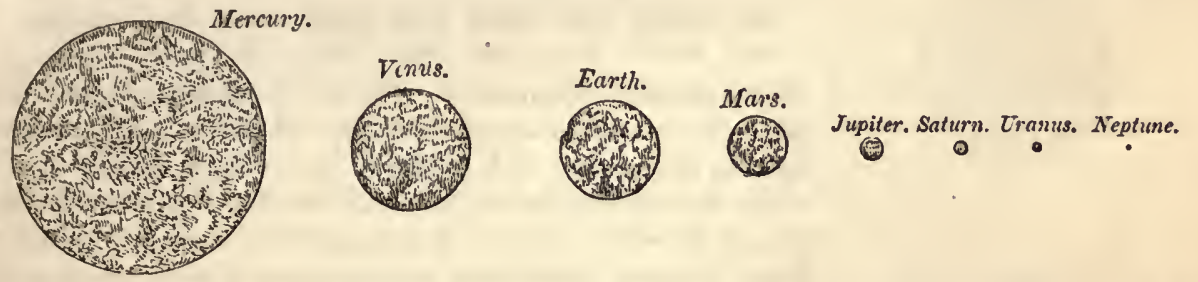

While a motion of translation in an orbit and one of axical rotation belong to all the planets, as far as observation has gone, constituting to each respectively its ycar, and its day and night, the length of these periods widely differs, as the annexed table shows:-

\begin{tabular}{|c|c|c|c|c|c|c|c|c|}
\hline \multirow[b]{2}{*}{ Mercury } & \multirow[b]{2}{*}{ - } & \multicolumn{4}{|c|}{$\begin{array}{l}\text { Length of Day } \\
\text { and Night. }\end{array}$} & \multicolumn{3}{|c|}{ Length of Year. } \\
\hline & & - & - $24 \mathrm{~h}$ & $6 \mathrm{~m}$ & - & -0 & 2 & 28 \\
\hline Venus & - & - & - 23 & 21 & - & -0 & 7 & 15 \\
\hline Earth & - & - & - 23 & 56 & - & 1 & 0 & 0 \\
\hline Mars & - & - & -24 & 30 & - & 1 & 10 & 21 \\
\hline Jupiter & - & - & - 9 & 56 & - & -11 & 10 & 17 \\
\hline Saturn & - & - & -10 & 30 & - & - 29 & 0 & 0 \\
\hline Uranus & - & - & unkr & own & - & - 84 & 0 & 0 \\
\hline Neptune & - & - & unk & own & - & . 164 & 0 & 0 \\
\hline
\end{tabular}

The planets are spheroids more or less oblate, but their magnitudes rary prodigiously. Taking the earth as 1 , the comparative volume of Mercury will be $\frac{1}{25}$, Venus $\frac{4}{5}$, Mars $\frac{1}{5}$, Jupiter 1330, Saturn 857, Uranus 88, Neptune 107. Their apparent diameters, as seen from the sun, will be,

$\begin{array}{ccccccccc}\text { Mercury } & \text { Venus } & \text { Earth } & \text { Moon } & \text { Mars } & \text { Jupiter } & \text { Saturn } & \text { Uranus } & \text { Neptano } \\ 16^{\prime \prime} & 30^{\prime \prime} & 17^{\prime \prime} \cdot 2 & 4^{\prime \prime} \cdot 6 & 10^{\prime \prime} & 37^{\prime \prime} & 16^{\prime \prime} & 4^{\prime \prime} & 2^{\prime \prime}\end{array}$

Their relative bulk may be brought before the eye as they are represented on the next page.

To express the proportionate volume of the sun, a circle with nearly a diameter of one foot would be required. The following illustration of the relations of the sun and his attendants is taken from Sir Joln Herschel and Dr. Nichol. If we conceive the sun to be a globe two feet in diameter, then a grain of mustard seed, at eighty-two feet distance, 
will represent the size and place of Mercury. A pea, at the distance of one hundred and forty-two feet, will be the similitude of Venus; and another, slightly larger, at two hundred

- Mercury.

O Venus.

Earth

- Mars.
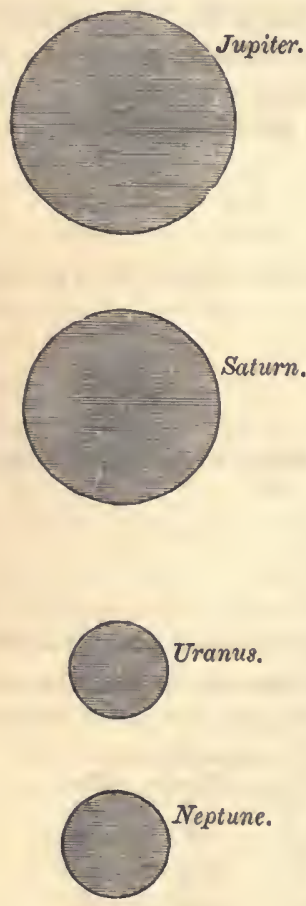
and fifteen feet, will be the appropriate representative of the earth. A good pin's head, removed thrce hundred and twenty-seven feet from the central globe, will stand for Mars; and a few of the smallest grains of sand, placed at the distance of five hundred feet, will denote the Asteroids. An orange of moderate size, distant a quarter of a mile, will indicate Jupiter. Saturn may be shown by a lesser one, at two-fifths of a mile; and Uranus by a cherry, at three quarters of a mile.

There are remarkable differences as to the material of the solar and planetary orbs. Their weight, compared with that of the earth taken as 1, is,

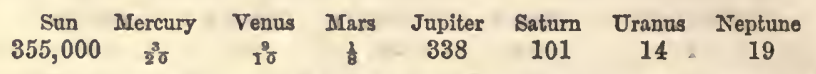

Their weight, compared with that of a globe of water of the same size, is estimated to be

Sun Mercury Venus Earth Mars Jupiter Saturn Uranus Neptune

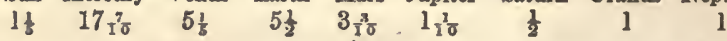

What striking diversities! While our planet, weighed in the balance against an equal volume of water, is five times heavier, the matter of Mercury is three times heavier still, while that of Saturn has only half the density of the fluid. If cast therefore upon an ocean capacious enough to receive them, Mercury would sink with as great a momentum as a globe of lead, while Saturn would be buoyant as a vessel of cork upon the deep. Upon the magnitude and density of the planetary spheroids, the force of gravity or the weight of bodies at their surface depends. Hence, though the solar substance is so much less dense than that of the earth, yet, owing to its vast bulk, a man weighing 140 pounds at the terrestrial equator would weigh more than 3500 at the surface of the sun. Jupiter is still less dense, but on account of his superior magnitude the force of gravity at his surface is eight times as great as at the earth's, so that a terrestrial inhabitant transported thither would be burdened with eight times his present weight, would move with eight times the difficulty, and would fall with eight times the force. But upon the diminutive telescopic planets, owing to their feeble gravity, a race of terrestrials might play such high fantastic tricks as would realise the dreams of fairy legends, bounding across a chasm of no trifling span, with the same muscular effort as here will only enable us to compass a step, and alighting with no greater shock than is felt in one of the paltry leaps of childhood. We may however infer a nice adjustment between the planetary worlds and their respective occupants, from the beautiful adaptation, which meets us here, of the constitution of man, animals, and plants, to the circumstances of their dwelling-place. Supposing that constitution to remain the same, and the earth's volume to be increased to the size of Jupiter; the intensity of the force of gravity would suspend the functions of animal and vegetable existence. The tiger would cease to spring upon his prey from the sheer impossibility of doing it ; the swift gazelle would become a laggard upon the plain; the soaring flight of the eagle would terminate; the sap would fall in the trees to rise 
no more; plants and flowers would be unable to circulate their juices; and man himself would sink down to the level of a slow-moving quadruped like the sloth. There is thus with us an express adaptation of the varieties of living existence to the magnitude and circumstances of our globe; and it is philosophical to accept this fact as a guarantec that a similar adjustment obtains throughout the system with which we are connected. And whence this adjustment? Whence this marvellous proportioning of the power of the humble crocus peeping above the snow, and the magnificent rein-deer bounding across it, to the earth's volume and mass, so that the force of gravity is not too strong in the one case for the development of the flower, nor muscular energy too great in the other for the purposes of the animal? Epicurus, upon reading the well-known lines of Hesiod in his youth -

“ Eldest of beings, Chaos first arose,

Thence Earth wide-stretch'd, the steadfast seat of all

The Immortals, -

is said to have proposed the natural question to his preceptor, "And Chaos whence?" The philosopher originated a theory in his riper years which assigned the creation to a fortuitous concoursé of atoms; but how natural the inquiry, overlooked by the theory, "And atoms whence?" A sober understanding will not stop short of recognising a presiding Providence in adapting the economy of terrestrial life to terrestrial conditions ; and even so are we warranted, from the evidence of what is near, to look upon the remote, as the scene of similar adaptations, the operation of the same First Cause.

In regarding the planetary worlds as the abodes of sentient life and of forms of existence kindred to those which occupy the earth, we are in advance of what is written, or what observation detects, but not beyond what the sobrieties of reason will justify. It may be hard to imagine how life can be sustained under the apparent heat of Mercury, or amid the seeming cold, the tremendous storms, and rapid atmospheric changes of Jupiter. But, ignorant of facts, a parallel difficulty would be a stumbling-block to us, in relation to our own planet, when we consider the high temperature of its equatorial regions and the intense cold of its polar circles. Yet we have great families of men and animals in each extreme. We meet with human life upon the sultry plains of Delhi, and on the ice-bound shores of Greenland; and where the citron, the myrtle, and the palm will not flourish, the pines, the mosses, and the lichens grow. It is impossible to naturalise the elk in England, owing to its warmth; and turn the giraffe adrift, and how long would it survive the chill of the climate? Yet each animal, in circumstances to which it is adapted, is stately and vigorous. All the planets are plainly of one family as to their physical character, their general configuration, their motions of revolution and rotation, and the alternation of day and night; and these are resemblances which may reasonably lead us to suspect other analogies. The fact is also clear, of Mercury, Venus, Mars, Jupiter, and Saturn being surrounded with atmospheres; - a constitution which strongly indicates their occupancy with some varieties of organised being. We know, in the case of our own globe, the important uses of its atmosphere in maintaining animal life, transmitting sound and light, and in advancing the arts which tend to civilise society. Without such a gaseous envelope, bound inseparably around the earth, its partner in all its motions, - yet no emanation from it, but a separate element, - the ear would have no office to perform, the tongue would be speechless, and the service of the eye be greatly abridged. The song of birds, the hymns of religion, the eloquence of senates, and the utterance of relative kindness would perish. The fiercest waves would dash in sullen silence upon the strand; and mankind would have no medium of inter-communication beyond that of sign and gesture. We may well believe, therefore, that our world has been furnished with this elastic and essential apparatus, in order to adapt it for the reception of animal existence 
and intelligent inhabitants ; and the inference is just, that a similar arrangement distinguishing other planets, points to the same destination. It is a possible conception, - but we should smile at the credulity of the man who believed it real, - that a fleet of ships navigating the ocean, with sails unfurled and pennons flying, did so without a cargo in the hold, a crew on board, or an object in vicw.

\section{CHAPTER V.}

\section{COMETS.}

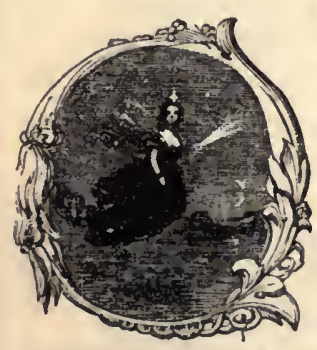

F all the celestial objects which have arrested the attention of mankind, none have excited such general and lively apprehension as those upon the consideration of which we now enter. Undoubtedly their sudden appearance, rapid movements, and occasionally extraordinary aspect, were calculated to awaken terror in ages of ignorance and superstition, and to originate the wild conjectures that are on record respecting their character and office. The Romans regarded a comet which was seen in the year 44 before our era as a celestial chariot conveying the soul of Cxsar, who had been assassinated a short time before its advent, to the skies. Cometary bodies liave been deemed the vehieles in which departed spirits are shipped by their guardian angels for the realms of Paradise; and on the other hand, they have been viewed as the active agents of natural and moral evil upon the surface of the earth, and been formally consigned to ecclesiastics for excommunication and cursing. A volume of no inconsiderable dimensions might be compiled, and not without interest, from the accounts of old ehronicles respecting their appearances, registering the quaintly expressed opinions of the chroniclers coneerning them, the terrestrial events they have tacked to them as effects to a cause, and the deportment to which men have been moved by the apparition of

" the blazing star

Threat'ning the world with famine, plague, and war:

To princes, death; to kingdoms, many crosscs ;

To all estates, inevitable losses;

To herdsmen, rot; to ploughmen, hapless scasons ;

To sailors, storms; to cities, civil treasons."

We have the word comet from the Greek x's $\mu$, or hair, a title which had its origin in the hairy appearance often exhibited, a nebulosity, haze, or kind of luminous vapour, being one of the characteristics of these bodies. Their general features are a definite point or nucleus - a nebulous light surrounding the nucleus, the hair, called by the French chevelure-and a luminous train preceding or following the nucleus. Milton refers to one of these attributes in a passage which countenances the popular superstition :-

\section{"Satan stood}

Unterrified, and like a comet burned,

That fires the length of Ophiucus huge,

In th' arctic sky, and from its horrid hair,

Shakes pestilence and war."

Anciently, when the train preceded the nucleus, as is the case when a comet has passed its perihelion, and recedes from the sun, it was called the beard, being only termed the tail 
when seen following the nucleus as the sun is approached. This distinction has disappeared from all modern astronomical works, and the latter name is given to the appendage, whatever its apparent position. Neither this luminous attendant, the tail, nor the nucleus, are now considered essential cometary elements, but all bodies are classed as comets which hare a motion of their own, and describe orbits of an extremcly clongated form. There are several plain points of difference between comets and planets. The planets move in the same direction from west to east, which is astronomically called direct motion; but the movements of comets are often from east to west, or retrograde. The orbits of all the plancts are confined to a zone of no great breadth on either side of the ecliptic; but the paths of comets cut the ecliptic in erery direction, some being even perpendicular to it, traversing the heavens in all parts. The contrast is striking likewise between the forms of their respective orbits. A hoop will with no great inaccuracy represent the courses of the planets, but cometary paths are of every possible eccentricity, both elongated ellipses and open curves, as parabolas or hyperbolas. Only one end of the ellipse lies within the limits of the system, in the case of the great majority of comets with shut orbits. They only visit our gaze therefore during one part of their course, and that a very small part, travelling during the rest of their journey far beyond the range of the most distant planet, into spaces inaccessible to our sight. Those which describe parabolas and hyperbolas are casual vistors only; and depart to return no more. Planetary configuration is also uniformly globular, but the external appearances of comets exhibit great diversities of form, from that of an irregular wisp of cloud to a simple spherical luminosity, or a strongly-defined scimitar-shaped aspect.

Most of the ancients, following Aristotle, regarded comets simply as meteors born and perishing in the atmosphere of the earth. Seneca, however, clearly classed them with the enduring realities of nature, having a definite path, and not wandering uncertainly through a transient existence: "I cannot believe," he observes, "that a comet is a fire suddenly kindled, but that it ought to be ranked among the eternal works of nature; it has its proper place, and is not easily moved from thence ; it goes its course, and is not extinguished, but runs off from us;" and in a passage already quoted, he anticipates the arrival of a Newton or Halley to determine their orbits, and the laws of their motions. Tycho Brahe took the initial step in the path of true discovery by assigning them a place out of the terrestrial atmosphere. By careful observation of the comet of 1577 he proved its extralunar position in space. It yielded no sensible diurnal parallax, and was therefore beyond the region of the moon. Hevelius next ascertained the concavity of the orbits of comets, which Keppler had supposed to be straight lines. Newton succeeded in demonstrating that comets are guided in their movements by the same principle as that which controls the planets in their orbits, as the law of gravitation admits of revolving bodies describing any one of the conic sections, or the four curves, the circle, ellipse, parabola, and hyperbola. Halley finally, after a laborious comparison of elements, arrived at a measurable ellipse as the orbit of one of these bodies; and predicted the periodic return of the object, which has twice appeared at the time appointed to verify his conclusion. The diagram represents a part of the path of one of the long period comets, that of 1680 , obviously but a very small part, as it was described in little better than two months, and the periodic time is supposed to be not less than five hundred years. The direction of the luminous train or tail is shown, the frequent attendant of cometary bodies. This is nearly always away from the sun, frequently assuming a curved form. It increases in length with its proximity to the solar body, but does not acquire its greatest extent until after the perihelion or the point nearest to the sun is passed. If we regard the train as vaporisation produced by the intense hent to which the body of the comet is exposed upon approaching the sun, this accounts for its increasing length and greatest extent after the perihelion, just as it is after 
the summer solstice that the carth attains its highest temperature, although its daily supply of solar influence is then actually diminishing. The comet appears in the diagram at its perihelion passage merely for the sake of illustration, as in that part of its course it was completely lost in the solar blaze. In the other positions it was observed at the times stated by Cassini, Newton, Halley, and Flamstead.

Cometary statisticians have compiled a record of between six and scren hundred appearances since the commencement of the Christian era. But little dependence can be placed upon this enumeration, as simple meteors and such phenomena as new stars were confounded in former times with true comets, and instances of the re-appearance of the same body are no doubt included in the return. In about 200 instances, the orbits have been ascertained with more or less certainty. Of this number, forty appear to have described ellipses; seven hyperbolas; and a hundred and fifty parabolas. The ellipse is an oval which admits of every possible degrec of eccentricity, or deviation Peritielion. from the circle; the hyperbola is an open curve, the branches of which may be considered straight lines indefinitely divergent; the parabola is an open curve, the branches of which extend in a nearly parallel direction, never converging. Consequently the elliptic comets are regular members of the solar system, with periodic times, some of them never wandering bcyond the planetary orbits, while the hyperbolic and parabolic comets appear within its limits, depart, and return no more, unless thrown by some disturbing force into a new path.

The three features of nebulosity, nucleus, and tail, aro usually assigned to cometary bodies, but many arc destitute of the latter appendage, and also without any clearly defined nucleus. They appear as simple ncbulosities, globular masses of vapour, having no central condensation, through which the feeblest of the stars readily shine. Herschel perceived a star of the sixth magnitude through the centre of the comet without nucleus of the year 1795 ; and a star of the eleventh magnitude was perfectly distinguished by Struve through the middle of one of the short-period comcts. Others present a nucleus strongly defined, with surrounding nebulosity, the "horrid hair" of poetry. The vapoury envelope is dim towards the central point, but suddenly beconies luminous at some distance from it, so as to resemble a ring resting in equilibrium around a star, like the ring of Saturn. The cometary nuclei often shine with a light as vivacious as that of the planets, and exceed them in splendour upon nearing the sun. They vary considerably in their diameters, but are in general very small. The measurement of the diameters of five given by Arago range between thirty-three miles and three thousand two hundred. The external appearance of other comets exhibits the three features combined, and these are remarkablc objects, occasionally presenting a terrific aspect. Immense spaces are sometimes covered by the luminous trains, or tails, as much as ninety or a hundred degrees; so that while the nucleus has been below the horizon, the train has rcached the zenith, stretching through an extent of nearly a hundred and fifty millions of 
miles. The tails appear to stream from that part of the nucleus which is farthest from the sul, but seldom in the direction of a straight line joining the two bodies. They generally exhibit a sensible curvature, bending towards that region of the heavens last quitted by the comet, and cases have been observed in which they have formed a right angle with the nucleus. The figure represents their common form, the arrow showing the direction of the comct's motion, and the dotted line the direction of the sun. There is great enlargement in the breadth of the tail, as its distance from the nucleus increases; and an obscure stripe appears passing down the middle, which has suggested the hypothesis of a hollow luminous cone. It is obvious that whether comets shine by inherent light, or reflect the solar rays, if the train be a hollow cone, a much greater number of nebulous particles will be in the direction of the eye at the sides than at the centre, which will account for the interior dim stripe, and the exterior brightness. Comets, lowever, are by no means confined to one train each, but as many as six have been observed appended to the same nucleus. While these variations of form may be due in a measure to different velocities, it is clearly ascertained that the aspect of the same cometary body undergoes great changes in its period of revolution. In recognising two apparitions as appearances of the same body, after having accomplished its periodic time, astronomers do not depend upon the circumstances of shape, size, or brilliancy being similar, but upon the elements of the path being accordant.

Towards the close of the year 1680, a comet, illustrious on account of its observers, and apparently formidable from its aspect, appeared within the visible limits of our system, and approximated nearer to its centre than any other, except the remarkable comet of 1843. It finally vanished from terrestrial gaze in the month of March 1681, and has not since been seen. The mind of Europe was profoundly impressed with the vast size, velocity, and form of this object, which engaged the accurate observation of Flamstead and Cassini, and the mathematical science of Bernouilli, Newton, and Halley. $\Lambda \mathrm{fter}$ its perihelion passage, its appearance, as seen from Paris and particularly from Constantinople, was most imposing. The train reached to the zenith when the nucleus had set below the horizon, coruscations attending the whole length of the luminosity, giving to the phenomenon the aspect of a wrathful messenger, and not that of a tranquil body pursuing a harmless course. The greatest length of the tail was computed to be 123 nillions of miles, and in two days an cxtent of 60 millions of miles was emitted from the nucleus. Its average velocity was upwards of 800 thousand miles an hour. A traveller through our heavens, covering such a space, and rushing with such speed through the firmament, might well excite the astonishment of mankind. It must not be imagined that this rate of motion is its average orbital velocity. In obedience to the Keplerian law its pace slackens in receding from the sun. According to the computation of Newton, this body approached the sun within the 163rd part of the semidiameter of the earth's orbit, being rather more than half a million of miles from his centre, and not more than 144,000 apart from his surface. If the projectile force had been stopped, in three minutes it would have closed with his mass. In such a situation it must have been exposed to a temperature which in an instant would dissipate any substance with which we are acquainted. Newton calculated the body of the comet to have been heated to a degree two thousand times greater than that of red-hot iron. 'This comet is supposed to be identical with the one that appeared about the time of Crsar's death, with that which was scen in the reign of Justinian in the year 531, and with another in the year 1106 in the reign of Henry II. Comparing these dates, we find, from before Christ 44 to 531 leaves a 
period of 575 years. Again, from 531 to 1106, leaves a second period of 575 years; and from 1106 to 1680 , a period of 574 years, which Newton supposed to be about its periodie time. If this conjecture be eorrect, the comet is now winging its flight from the sun far beyond the orbit of Neptune, and will not return from its long pilgrimage to revisit the fountain of light till the year 2255. How vast the cireuit! How opposite the cireumstances of the two extreme points of the route-the perihelion, in the immediate neighbourhood of the solar glory - the aphelion, at the probable distance of 13 thousand millions of miles from him! At the fur extremity, the sun, if observed by a spectator, would appear simply as a point of light, and at the other extremity the solar orb would be seen nearly filling the whole hemisphere. At the first recorded appearance of this comet, it was seen as a long-haired star in the skies of Rome during the games which the youthful Augustus exhibited in honour of Venus and his uncle, the assassinated Crsar; and while the inhabitants of the capital hailed the olject as the Julium Sidus, conveying aloft the soul of the dictator, his ambitious suceessor secretly regarded it as a presage of his own glory, while apparently falling in with the popular notion. Pliny has preserved to us his published memorial respeeting it, which ran as follows: - "In those days during the solemnity of my games there was seen a blazing star for seven days together, in that region of the sky which is under the north star Septentriones: it arose about the eleventh hour of the day, bright and elear, and was evidently seen in all lands: by that star it was signified that the soul of Cæsar was received among the divine powers of the immortal gods." At its second exhibition, in the fifth year of Justinian, in the month of September, the comet was seen during twenty days in the western heavens with a tail inclining towards the north. The Byzantine writers applied to it the name of Lampadias, because of its resemblance to a burning lamp. Its third visit is mentioned by the chroniclers, who describe it as like the blaze of the sun, having an immense train. At its fourth return, there was a cultivated science able to grapple with its phenomena, and divest them of a supernatural character. Upon its fifth appearanee, after more than three centuries and a half from the present have elapsed, if the estimate of the periodic time be correct, Gibbon has speculated upon its course and phase engaging the astronomers of some future eapital in the Siberian or American wilderness. Calculating backwards the periodic time, Whiston brought a return of this comet into coincidence with the era of the Deluge, of which he conceived it to have been the agent. He broached likewise the presumptuous fancy of lost spirits being incarcerated in this body, and hurried by it to the extremes of perishing cold and devouring fire, as a part of their punishment. Such chimeras deserve no serious notice.

The first comet whose return was predicted and determined made its appearance in our hearens in the year 1682, the year following that in which the preceding had vanished. Though far inferior in magnitude and splendour to its predecessor, it was a considerable object, and has now become in consequence of its associations one of the most interesting bodies of the system. It presented a tail extending through thirty degrees of the hemisphere; and while seience watched its movements, the eye of the populace rested upon its form without alarm, as the former had signally failed in causing any direful catastrophe. The views of Newton who had spoken of the older bodies as planets without tails, and of comets as a species of planets revolving about the sun in very eccentric orbits, had arrested the attention of Halley; and probably his remarkable achievement was suggested by the following passage in the third book of the "Principia," - "I leave the transverse diameters and times of revolution to be determined by the comparison of comets which return after long periods of time in the same orbits." Upon this hint Halley commenced ealeulating the orbits of all the comets upon which definite 
observations had been made, twenty-four in number, for the purpose of comparing their elements - a work of immense labour and difficulty, of which the present Astronomer Royal has remarked, that in all probability he was the only person then in existence who could have performed it. He found the elements of two comets to coincide with tolerable exactness with those of the comet of 1682 , as follows:-

\begin{tabular}{|c|c|c|c|c|c|c|c|}
\hline$a$ & $b$ & c & $d$ & $e$ & $f$ & $g$ & $h$ \\
\hline 1581 & $49^{\circ} 25^{\prime}$ & $17^{\circ} \quad 56^{\prime}$ & $301^{\circ} 99^{\prime}$ & 56,700 & Aug. 24 & $107^{\circ} 46^{\prime}$ & Retrograde \\
\hline 1607 & $50 \quad 21$ & 172 & $302 \quad 16$ & 58,680 & Oct. 16 & 1085 & - \\
\hline 1682 & 16 & 56 & 302 & 58,328 & Sept. 4 & 108 & - \\
\hline
\end{tabular}

$a$. Year of the comet. $b$. Longitude of ascending node. $c$. Inclination of the orbit. $d$. Longitude of the perihelion. e. Perihelion distance from the sun, that of the earth being 100,000. $f$. Time of the comet arriving at its perihelion distance. $g$. Distanca from perihelion to ascending node. $h$. Direction of the comet's motion.

The general elements here are pretty closely analogous. With reference to the periodic time, there is, from

$$
\begin{aligned}
& \text { Aug. 24. 1531, to Oct. 16.1607, - } \quad \text { - } 76 \text { years } 53 \text { days, } \\
& \text { Oct. 16. 1607, to Sept. 4.1682, - } \quad \text { - } 75 \text { years wanting } 42 \text { days, }
\end{aligned}
$$

a difference of about fifteen months. This Halley conjectured might arise from the disturbing action of the planets, a correct idea, and one of great sagacity, as the theory of planetary disturbance was but then in its infancy. Upon these data, therefore, he ventured the conclusion that the three appearances were returns of the same comet, which would reappear after the lapse of a similar interval. His words are:- "Nothing seems to contradict this my opinion, besides the inequality of the periodic revolutions, which inequality is not so great neither, as that it may not be owing to physical causes; for the motion of Saturn is so disturbed by the rest of the planets, especially Jupiter, that the periodic time of that planet is uncertain for some whole days together. How much more, therefore, will a comet be subject to such like errors, which rises almost four times higher than Saturn, and whose velocity, though increased but a very little, would be sufficient to change its orbit from an elliptical to a parabolical one? This, moreover, confirms me in my opinion of its being the same comet, that in the year 1456, in the summer time, was scen passing retrograde, between the earth and the sun, much after the same manner ; which, though nobody made observations upon it, yet, from its period and the manner of its transit, I cannot think different from those $I$ have just now mentioned. Hence $I$ dare venture to foretell that it will return again in the year 1758." Subsequently his tone grew more decided. Historical records supplied some further links to the chain of cometary appearances after nearly the same interval. Thus :-

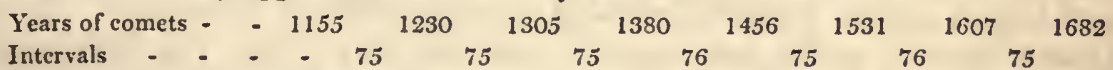

The astronomer was confirmed by this evidence in the accuracy of his prediction, and called upon all posterity to remember that an Englishman had announced it. The prophecy was no random guess. It was not founded merely upon the coincidence of the dates, but a result obtained, in the case of the last three comets, from the close agreement of the elements of their orbits.

Great curiosity was excited as the year 1758 approached, to ascertain whether the prediction would be verified. No doubt existed upon the subject in the scientific world, but some apprehension was felt lest circumstances should be unfarourable to a perception of the plienomenon. "We cannot doubt," observed Lalande, in 1757, " that it will return; and even if astronomers should not see it, they will not be the less persuaded of 
its return. They know that the faintness of its light, and its great distance, perhaps even bad weather, may keep it from our view; but the public will find it difficult to believe us; they will put this discovery, which has done so much honour to modern philosophy, among the number of predictions made at hazard. We shall see dissertations spring up again in the colleges, contempt among the ignorant, terror among the people, and serenty-six years will elapse before there will be another opportunity of removing all doubt." Lalande engaged with Clairaut and Madame Lepaute in calculating the attractive influence of Jupiter and Saturn upon the comet, which might change to some extent its time of perihelion. "During six months," he remarks, "we calculated from morning till niglit, sometimes even at meals; the consequence of which was, that I contracted an illness which changed my constitution for the remainder of my life. The assistance rendered by Madame Lepaute was such, that without it we never could have dared to undertake this enormous labour, where it was necessary to calculate for every degree, and for 150 jears, the distance and force of each of the two planets with respect to the comet." 'They finally announced in November 1758, just as astronomers began to look out for its return, that the comet would employ 618 days more to return to the perihelion than on the preceding revolution; namely, 100 days from the effect of Saturn, and 518 days from the action of Jupiter. The perihelion was placed therefore about the middle of April 1759, but Clairaut distinctly forewarned the world, that being pressed for time, he had neglected small values, which collectively might amount to, more or less, about a month in the seventy-six years. The erent realised the anticipation of Halley, and answered as nearly as possible to the calculations of the French philosophers. The comet was first seen from the neighbourhood of Dresden by George Palitzch, a respectable landowner, but a self-educated astronomer. This was on Christmas-day 1758, with an eight-feet telescope. It was afterwards seen at Paris, Leipsic, Lisbon, and Cadiz. It passed its perihelion on the 12th of March 1759, exactly a month before the time announced, but within the assigned limit of divergence from that date. The elements of its orbit proclaimed it to be the comet of the former periods by their similarity. The following is Lalande's deduction, the letters indicating the particulars connected with the table already given :-

$$
\begin{array}{ccccccc}
a & b & c & d & e & f & h \\
1759 & 53^{\circ} 46^{\prime} & 17^{\circ} 40^{\prime} & 303^{\circ} 8^{\prime} & 58490 & \text { MLarch } 12 & \text { nictrograde. }
\end{array}
$$

Another period of revolution has transpired since the time to which we are referring. Dating seventy-six years forward, we are brought to the year 1835. After estimating the action of the planets, Damoiseau, of the French Board of Longitude, fixed the perihelion passage on Nov. 4th of that year, and Pontécoulant on Nov. 13th, a difference of nine days. Both agreed that the first appearance of the comet would be in the early part of August, and the perihelion certainly about the middle of November. The conet was seen at Rome Aug. 5th, and passed its perilelion Nov. 16th. The fictitiousness of the representation,

$$
\begin{aligned}
& \text { "A pathless conet, and a curse, } \\
& \text { The menace of the universe; } \\
& \text { Still rolling on with innate force, } \\
& \text { Without a sphere, without a course," }
\end{aligned}
$$

has thus been demonstrated, and these bodies proved to be constituent members of our system, obedient to the law of gravitation, which keeps them within prescribed limits and in definite orbits, as with bit and bridle.

We may now glance at some of the appearances of this comet at its successive returns, as far as historical records supply information.

The comet of 1006 is conceived on good grounds to have been identical with that of 
1682. Its first recorded appearance was thus immediately prior to the Danish invasion of England, and during the declining days of the empire of the caliphs. Hali-ben-Rodoan mentions the immense curved tail in the form of a scythe. The head appeared four times as large as Venus. The second visit, which must have been about 1082, in the reign of the Conqueror, is unrecorded: and the third and fourth, in 1155 and 1230, are merely mentioned by the annalists, without any detail. Its fifth return was in the year 1305, when the papal chair was removed to Avignon, the Swiss cantons were effecting their independence, and Edward I. tyrannising over Scotland. At the season of Easter, this "great and fearful star," as it was called, was perceived, but so far from raising the temperature, a supposed cometary effect in later times, a general cold prevailed over Europe, and a severe frost in England at Midsummer destroyed the corn and fruits. History gives no particulars of its next visit in 1380, but in 1456 its appearance filled all Christendom with consternation. It passed very near to the earth, and swept the heavens with a tail extending over sixty degrees, in the form of a sword or sabre. The Turks had just become masters of Constantinople, and threatened an advance into the heart of Europe. The comct variously excited hope or fear, according as it was deemed

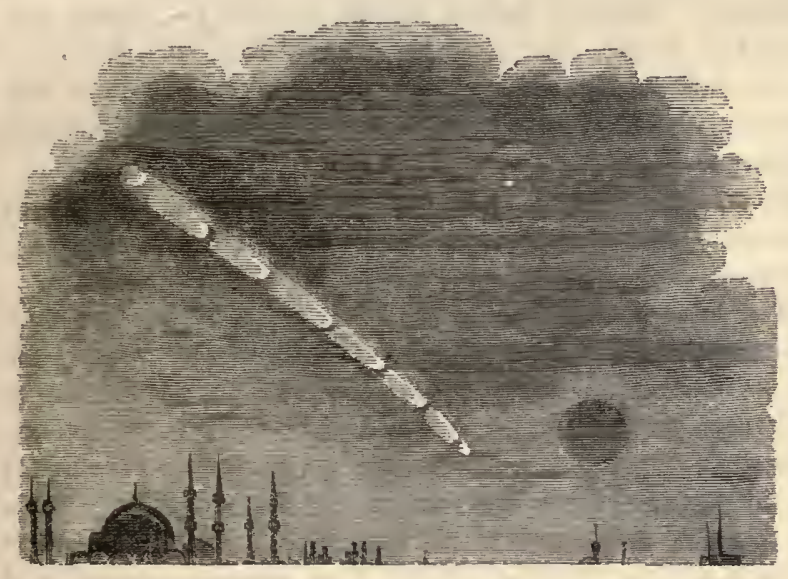
the friend of the crescent or the cross. At Constantinople, the occurrence of a coincident lunar eclipse increased the portentousness of the event. Phranza, grand-chamberlain and principal secretary to the last head of the Greek Roman empire, reports : - "Each night, soon after sunset, a comet was seen like a straight sabre, approaching the moon. The night of the full moon having arrived, and then by chance an eclipse having taken place, according to the regular process and circular orbits of the celestial lights, as is customary - some persons seeing the darkness of the eclipse, and regarding the comet in form of a long sword which arose from the west, and travelled towards the east, approaching the moon, thought that the comet in shape of a long sword thus designated, with regard to the darkness of the moon, that the Christians, inhabitants of the West, had agreed to march against the Turks, and would gain the victory; but the Turks, also considering these things, became not a little fearful, and had great discussions." The pope, however, Calixtus III., regarded the comet as in league with the Moslems, and ordered the Ave MLaria to be repented by the faithful three times a day instead of two. He directed the church bells to toll at noon, a custom which still prevails in Catholic countries. To the Ave Maria the prayer was added, "Lord save us from the Devil, the Turk, and the Comet;" and once each day these three obnoxious personages were regularly excommunicated. There was perhaps as much worldly policy as superstition in sounding this note of alarm, for fees accumulated to the priesthood from the increase of confessions. The comet at length, after patiently enduring some months of daily excommunication and cursing, showed signs of retreat, and Europe breathed freely when it vanished from the skies. At the eighth return in 1531, the New World had been discovered, and by the invention of printing the foundation had been laid for the intellectual and religious 
reform of the Old. The comet as then seen in Cancer was of a bright gold colour. In 1607, the ninth visit, the Copernican system had been broached, and Galileo and Keppler were labouring to establish it. The course of the comet was observed through Ursa Major, Boötes, Serpentis, and Ophiuchus. Its light was pale and watery. The tail is described as long and thick, like a flaming lance or sword. The apparent magnitude of the head was greater than that of any of the fixed stars, or Jupiter; and, say the chronicles of the agre, of its direful effects " the Duke of Lorraine died"- " $a$ great war between the Swedes and the Danes." "The comet does me much honour," was the remark of Cardinal Mazarine on his death-bed, when informed by his servile attendants that one had made its appearance. It is happily said in Shakspearc, in allusion to this sycophancy,

"When beggars die there are no comets seen."

The tenth return brings us to the time of Newton and Halley. Cassini calls it then as

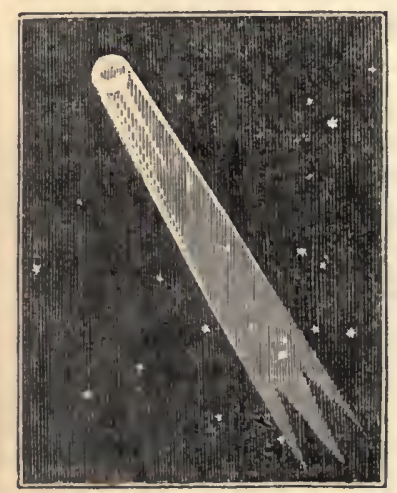
clcar and round as Jupiter, referring to the nucleus. $\Lambda \mathrm{t}$ the eleventh revolution in 1759 , it was a pale and fecble object. Messier was obliged to use a powerful reflecting telescope. Palitzch, indeed, caught it with the naked eye once, but no one else appears to have done so. In 1835, the tavelfth advent, it was much more distinct, and was frequently seen without a telescope presenting the annexed appearance.

Its thirteenth return will occur in 1911 , when the present generation shall have passed away, and the few remaining infants of to-morrow be anticipating the infirmities of age.

The later apparitions of Halley's comet have thus been far less brilliant and conspicuous than its earlier exhibitions. At its four last periodic returns, it bore no resemblance to the comceta horrenda magnitudinis of the year 1305. Arago conjectures that the comets, in describing their immense orbits, disseminate in space at each revolution all the matter which when near the perihelion is detached from the nucleus and forms the tail. It is clearly possible, therefore, that some of them may in process of time completcly waste away, unless by travelling through similar detached trains, they recover a quantity of matter sufficient to compensate for. their own losses. Wre may believe, also, that dissipation occurring, the same body that now presents an insignificant appearance, cxhibited a bolder front in days of yore, thougl the early annalists and artists have undonbtedly borrowed largely from imagination in describing these bodies. In a celestial atlas publislied

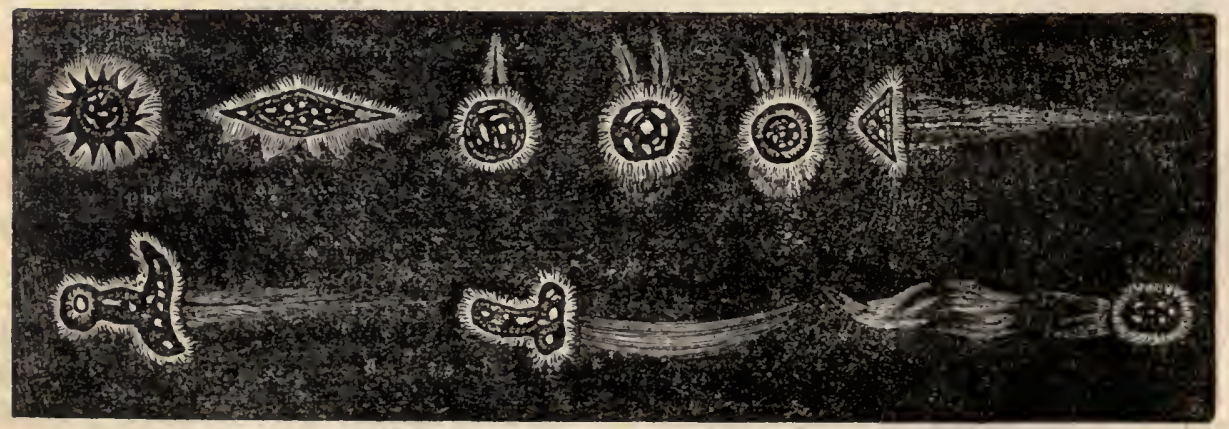

ubout the year 1680 , several drawings of comets occur, from which the annexed are selected. 
It is evident that these artistic efforts are not true to nature, however true to such wild and distorted descriptions as the following, from the "Exempla Cometarum" of Rossenburg, a contemporary of Newton:- "In the year 1527, about four in the morning, not only in the Palatine of the Rhine, but nearly over all Europe, appeared for an hour and a quarter a most horrible comet, in this sort. In its length it was of a bloody colour, inclining to saffron. From the top of its train appeared a bended arm, in the hand whereof was a huge sword in the instant posture of striking. At the point of the sword was a star. From the star proceeded dusky rays, like javelins or lesser swords, as if imbrued in blood, between which appeared human faces of the colour of blackish clouds, with rough hair and beards. All these mored with such terrible sparkling and brightness, that many spectators swooned with fear!"

Before we finally take leave of the eomet of Halley, some notice may be bestowed upon his claim to the distinction of being the first to foretell the precise periodical return of one of these bodies. This has bcen disputed, and assigned to Newton, on evidence recently detailed in one of the leading journals, but which certainly cannot be admitted to invalidate his pretensions. It is affirmed that previously to the appearance of the comet of 1736, Coloncl Guise told Whiston that Sir Isaac Newton had said in his presence, that "though he would not say he was sure of it, nor would publish it, he had some reason to believe that a comet would return about the latter end of 1736." Another witness also, Mr. Howard, is cited, as having heard him make a similar remark; and upon being questioned concerning it, it is stated that " he seemed to draw back, as sorry that he had said so much, but still could not deny that he had such an expectation." Whiston therefore says :- " $\Lambda \mathrm{s}$ far as we yet know, Sir Isaac is the very first man, and this the very first instance, where the coming of a comet has been predicted beforehand, and has actually come according to that prediction, from the beginning of the creation to this day." Thomson seems to fall in with this idea in panegyrising the great philosopher:-

\footnotetext{
"He, first of men, with awful wing pursued

The comet, through the long clliptic curve,

As 'long innumerous worlds he wound his way,

'Till to the forehead of our evening sky

Return'd, the blazing wonder glares anew,

And o'er the trembling nations shakes dismay."
}

This is all the evidence that can be arrayed in favour of Newton; and obviously its hearsay source, with the dubious tone of the testimony reported, cannot weigh a feather in the scale against the claims of Hallcy, whose prediction was the result of careful comparison, and as such boldly published to the world.

The next most remarkable comet of modern times appeared about the middle of December, 1743, and continued visible during the spring of the year following. On the 1st of February, according to Chizeaux, it was more brilliant than Sirius, the brightest star in the heavens. On the 8th it equalled Jupiter, and was visible in the presence of the sun at the beginning of the next month. By selecting a convenient situation many persons saw it at mid-day without glasses. Several instances of similar brilliancy are on record. Justin mentions a comet which appeared at the birth of Mithridates, and overcame the brightness of the sun by its splendour; and, however this may be an exaggeration, there are many well-attested cases of these bodies being seen by broad daylight. The Cxesarian comet, two others in 1402 , with one in 1532, were thus visible. The fine comet of 1577 was seen with the naked eye by Tycho Brahe before sunset. On account of its brightness and peculiar form the comet of 1744 excited great attention and interest. It exhibited $\mathrm{nn}$ train until within the distance of 
the orbit of Mars from the sun ; but, early in March, it appeared with a tail divided into six branches, all diverging, but curved in the same direction. Each of these tails was

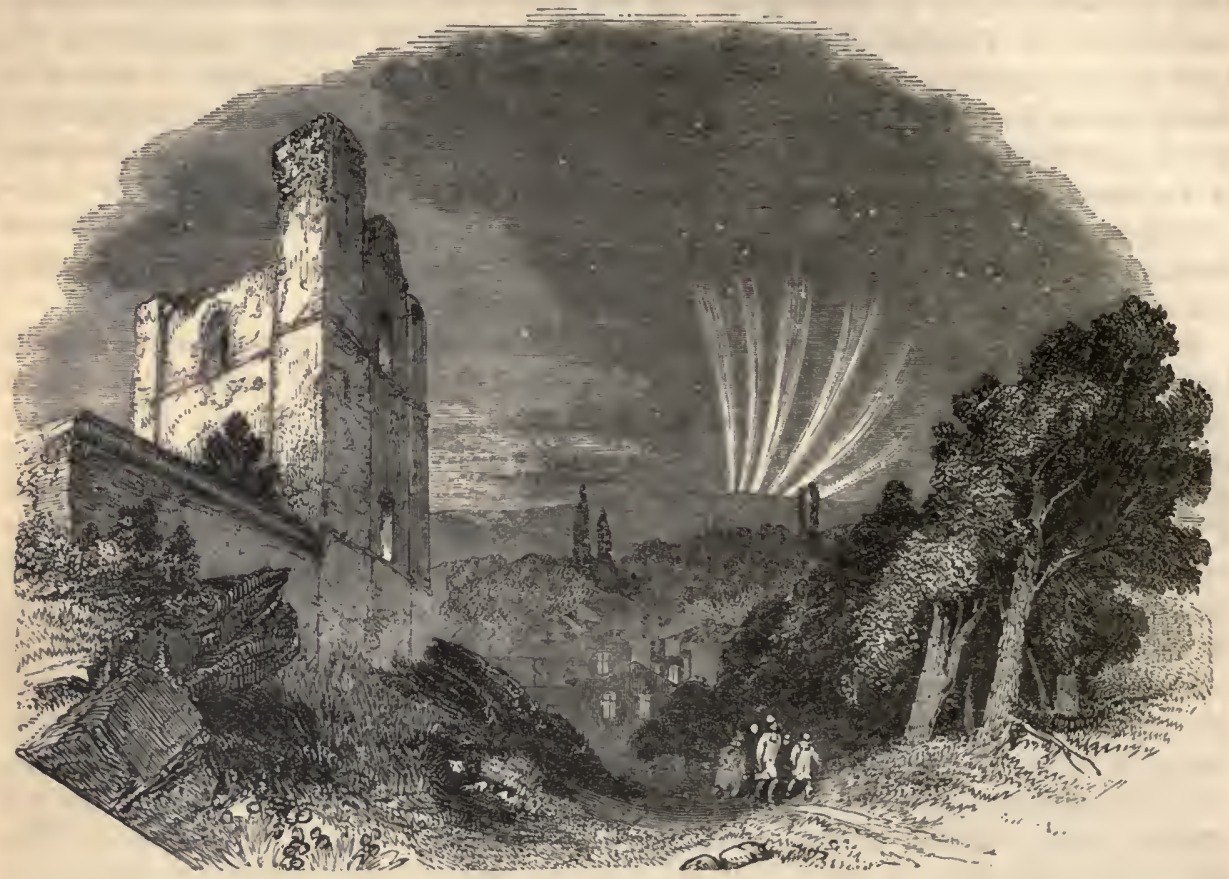

about $4^{\circ}$ in width, and from $30^{\circ}$ to $44^{\circ}$ in length. The edges were brigit and decided, the middle faint, and the intervening spaces as sombre as the rest of the firmament, the stars shining in them. 'This comet was repeatedly seen in Switzerland, with the nucleus below the horizon, and the six tails extending from twenty to thirty degrees above it. The scene presented by this remarkable body in the situation referred to was striking in the extreme when circumstances favoured the display.

In the year 1770 a comet appeared which has acquired considerable notoriety from the alterations which its orbit has undergone. It was first observed by Messier, a man who united great simplicity of character with high scientific attainments. Louis XV. called him le furet des cométes, from his zeal in hunting after them. He had discovered twelve, every one of which, says Delambre, gained him admission to some foreign academy. While attending to his wife during her last moments, Montagne discovered another. This was a cutting stroke to Messier, and he exclaimed, "Alas, I had discovered twelve, and this Montagne has taken away my thirtecnth!" Then remembering that it was his wife he should mourn for, he began to say, "ah! la pauvre femme!" and went on deploring his comet. The elements of the comet of 1770 were calculated by Lexel, who found for its orbit round the sun an ellipse of which the transverse diameter was only equal to three times the diameter of the earth's orbit, which corresponded with a period of revolution of five years and a half. It was deemed a singular circumstance that an object having so short a periodic time, whose greatest distance from the sun was not far beyond the orbit of Jupiter, and which shone with a vivid light, should not have been observed before; and the wits of the day made themselves merry, when, at the expiration of the appointed term, the comet was not observed to return. It has not been seen since; and was popularly called Lexel's lost comet. But this sport was premature. The previous 
invisibility and subsequent disappearance of this body, after once presenting itself, have been sufficiently explained; and a confirmation of the laws of universal attraction has been drawn from circumstances apparently adverse to them. Its previous invisibility is accounted for by its orbit being altogether different prior to the year 1770 , its nearest point to the sun being as distant as the path of Jupiter, corresponding, not to five, but to fifty years of revolution. Its appearance that year arose out of the fact that in 1767 it was in such close contact with the planet, moving in the same direction and in nearly the same plane, that the attraction of the sun upon it was not $\frac{1}{200}$ that of Jupiter. This entirely altered the form of the orbit, and caused the comet to wheel its path towards that of the earth, coming within our view, and executing the ellipse described by Lexel in the periodic time of five and a half years. But why has not the comet since been seen ? Its passage to the point of perihelion in 1776 took place by day; and in 1779 , before another return, it again encountered the vast body of Jupiter, and suffered a fresh orbital derangement, the attraction of the planet deflecting it into more distant regions. The comet therefore, though "lost" to us, is in existence, and in each instance of its change of route has faithfully obeyed the laws of gravitation. Those laws in 1770 introduced it as a bright and beautiful stranger to the notice of the human race, and again in 1779 stopped the fellowship, removing the comet into a remoter path, where it is hid from the gaze of man, and will be so unless some new perturbation directs its course towards the terrestrial orbit.

Another comet, exhibiting some remarkable features, presented itself in the year 1807. It was assiduously observed by Herschel in this country, and by the continental astronomers, Schroeter, Bessel, and Olbers. The drawings of the two former are here given,

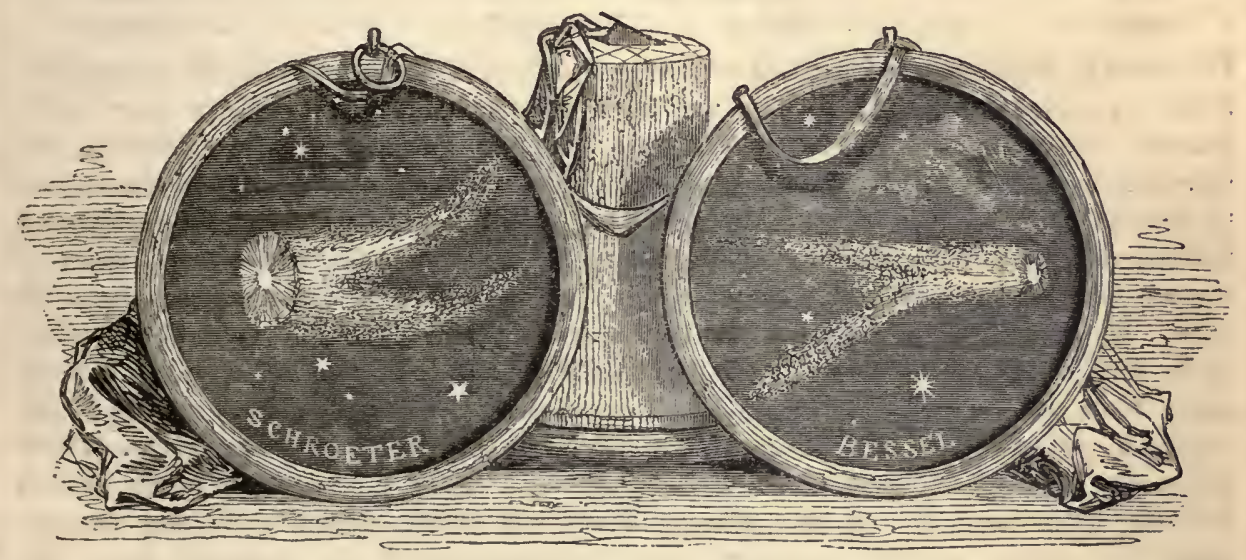

taken on two succeeding evenings, which show a divided tail, the separate branches having varied their aspects. Coruscations, flickering and vanishing like the norther'n lights, appeared to shoot out in an instant from the train to an immense extent.

In the autumn of 1811 , within the memory of many of the present generation, by far the finest comet suddenly appeared to adorn our heavens, that had been seen since the age of Newton. It was first beheld in this country in the beginning of September, and was visible for more than threc months in succession to the naked eye, shining with great splendour, the observed of all observers. This was a comet of the first class in point of magnitude and luminosity. Its brilliant tail, at its greatest elongation, had an extent of 123 millions of miles, by a breadth of 15 millions; and thus, supposing the nucleus of the comet to have been placed on the sun, and the tail in the plane of the orbits of the planets, it would have reached over those of Mercury, Venus, the Farth, 
and have bordered on that of Mars. At its nearest approacli to us, the comet was yet distant 141 millions of miles, so that even had the tail pointed to the earth, its extremity

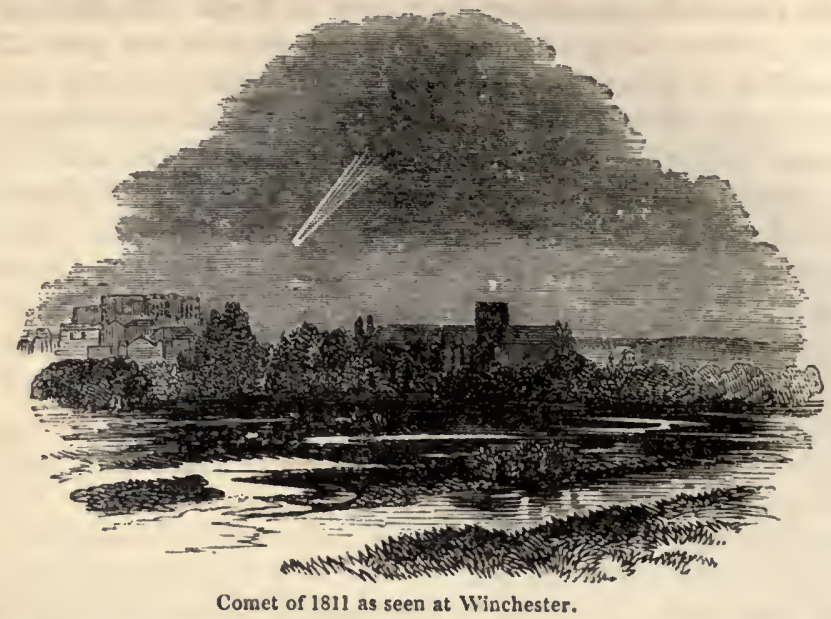

would have been 18 millions of miles away from its surface. The following are the calculations respecting its period of revolution :-

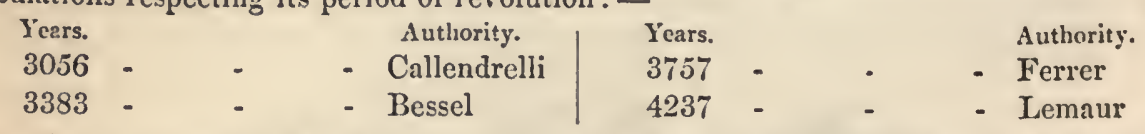

The mind is astounded at a journey requiring the least of these cycles for its accomplishment - a period equal to that extending from the fabulous age of Grecian story to the present; nor is the thought less wonderful, of the ehain of solar influence following the traveller through the whole of its course, and preventing its elopement into the regions of immensity. The laws of the system, indeed, impose upon the long-period comets rast differences of relocity. The same body that rushes round the sun at the nearest point of contact with prodigious speed, will more but sluggishly through the remoter parts of its orbit. In computing the periodic time of the comet of 1811 , Lemaur assigned 775 years to the half of the ellipse nearest the sun, and 3462 to the more distant half. But the space must be immense that las to be traversed by an object whose return is not expected, taking the lowest estimate given, till the year 4867 . The appearance of this comet was strikingly ornamental to the evening sky. Many a reaper late in the harvest field stayed his hand, and many a peasant homeward-bound stopped in the way, to gaze upon the celestial novelty as it grew into distinctness with the declining day. The Ettrick shepherd has left a memorial of his impressions in the well-known lines :-

"Stranger of heaven, I bid thee hail!

Shred from the pall of glory riven,

That flashest in celestial gale -

Broad pennon of the King of Hearen!

"Whate'er portends thy front of fire,

And streaming locks so lovely pale :

Ur peace to man, or julgments dire,

Stranger of heaven, I bid thee hail!"

Those who were alive in 1811 will recollect the high temperature of that year - its bountiful harvest - its abundant vintage. Popular opinion assigned these blessings to the resplendent comet; ; and the wine of the comet was sold afterwards at high prices. No doubt, however, but that precisely different circumstances would have been connected, 
by the public mind, with the same cause; and this has literally been the case, for "a cold winter," and "meteors in Germany," are referred to the comet of 1680 , by a writer in 1829. The following table, given by Arago, is valuable upon this point:-

\begin{tabular}{|c|c|c|c|c|c|c|c|}
\hline \multirow{2}{*}{ Years. } & \multicolumn{2}{|c|}{ Mean Temperature. } & \multirow{2}{*}{$\begin{array}{l}\text { Number } \\
\text { of } \\
\text { Cornets. }\end{array}$} & \multirow{2}{*}{ Years. } & \multicolumn{2}{|c|}{ Mean Temperature. } & \multirow{2}{*}{$\begin{array}{l}\text { Number } \\
\text { of } \\
\text { Comets. }\end{array}$} \\
\hline & Reaumur. & Fahrenheit. & & & Reaumur. & Fahrenheit. & \\
\hline 1803 & $10 \cdot 6^{\circ}$ & $56^{\circ}$ & 0 & 1818 & $11 \cdot 4^{\circ}$ & $58^{\circ}$ & 2 \\
\hline 1804 & $11 \cdot 1$ & 57 & 1 & 1819 & $11 \cdot 1$ & 57 & 3 \\
\hline 1805 & $9 \cdot 7$ & 54 & 2 & 1820 & 98 & 54 & 0 \\
\hline 1806 & $12 \cdot 1$ & 59 & 1 & 1821 & $11 \cdot 1$ & 57 & 1 \\
\hline 1807 & $10 \cdot 8$ & 56 & 1 & 1822 & $12 \cdot 1$ & 59 & 3 \\
\hline 1808 & $10 \cdot 4$ & 55 & 4 & 1823 & $10 \cdot 4$ & 55 & 1 \\
\hline 1809 & $10 \cdot 6$ & 56 & 0 & 1824 & $11 \cdot 2$ & 57 & 2 \\
\hline 1810 & $10 \cdot 6$ & 56 & 1 & 1825 & $11 \cdot 7$ & 58 & 4 \\
\hline 1811 & $12 \cdot 0$ & 59 & 2 & 1826 & 114 & 58 & 5 \\
\hline 1812 & $9 \cdot 9$ & 56 & 1 & 1827 & $10 \cdot 8$ & 56 & 3 \\
\hline 1813 & 102 & 55 & 2 & 1828 & $11 \cdot 5$ & 58 & 0 \\
\hline 1814 & $9 \cdot 8$ & 54 & 0 & 1829 & $9 \cdot 1$ & 53 & 1 \\
\hline 181.5 & $10 \cdot 5$ & 56 & 1 & 1830 & $10 \cdot 1$ & 55 & 2 \\
\hline 1816 & $9 \cdot 4$ & 5.3 & 0 & 1831 & $11 \cdot 7$ & 53 & 0 \\
\hline 1817 & $10 \cdot 4$ & 55 & 0 & & & & \\
\hline
\end{tabular}

From this table, it is clear that no conclusion can be drawn, to the effect that cometary appearances have any influence in raising the temperature. In 1828 and in 1831 no comets presented themselves, and the temperature was nearly at its maximum. In 1808 there were four, and it was nearly at its minimum.

'There was no inconsiderable amount of superstitious fear blended upon this occasion with the natural feelings of wonder and admiration that were excited. As the great comet of 1680 had been deemed a manifest presage of the revocation of the edict of Nantes, the persecution of the French protestants, and the long wars that ensued, so was the beautiful

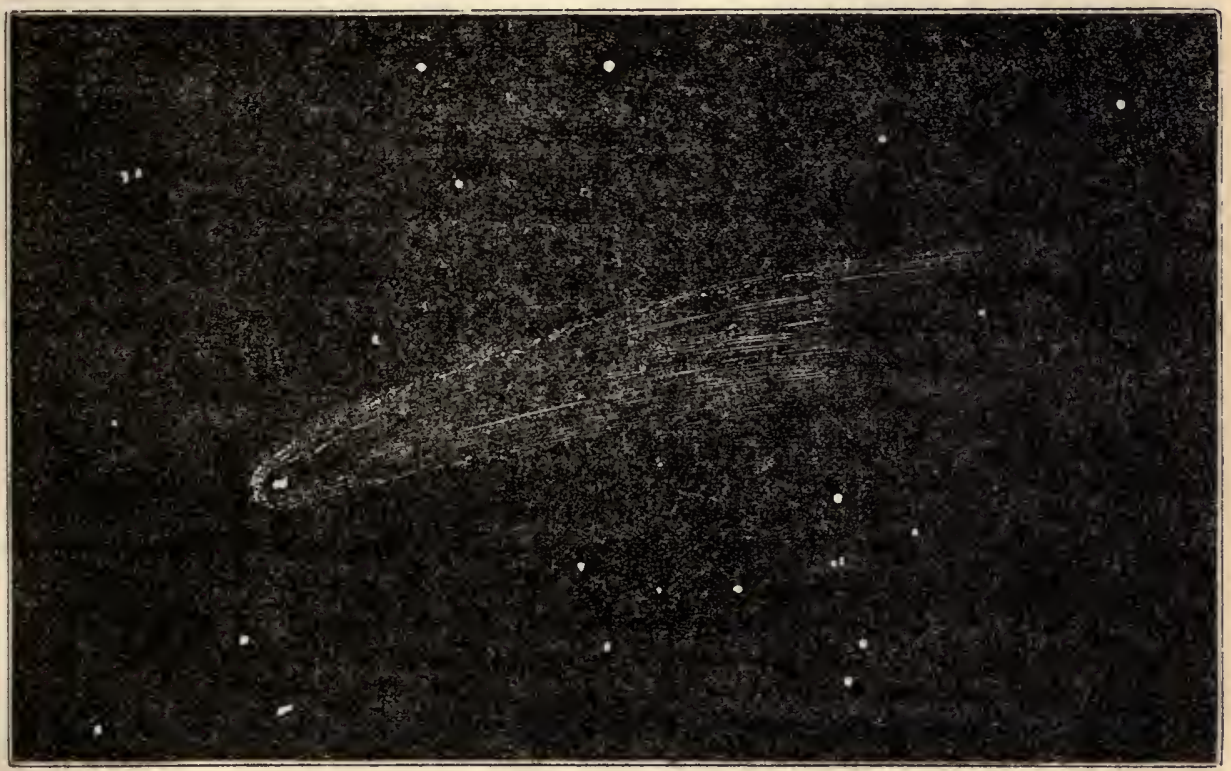

and transient visitor of 1811 abused in a similar manner. It was widely regarded as the herald of some awful terrestrial occurrence, and the particular event intended was not 
doubtful to many minds when Napoleon led his legions from the West to perish amid the snows of Russia, and Moscow was in flames!

Science has been more recently occupied with comets of short periods, insignificant in their external aspect, but deeply interesting on account of the discovery that their orbital course is included within the bounds of our system, and their predicted returns fulfilled with unfailing punctuality. 'The first is known as the comet of Encke. It was observed

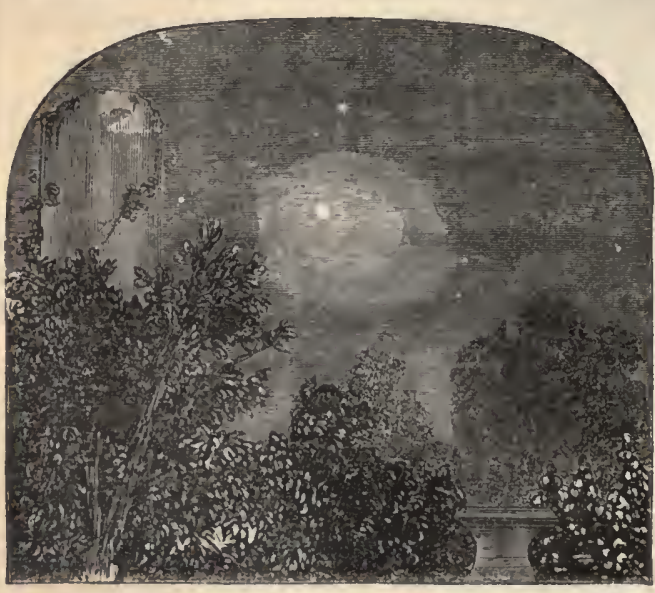

'Telezcopic View. in the year 1786, by Messier, traversing the constellation Aquarius; afterwards seen by Miss Herschel, in 1795, in Cygnus; and by M. Pons, in 1805, in Ursa Major; but no idea was entertained that these were appearances of the same body, till Encke, in 1819, established their identity, in consequence of which the comet has reccived his name. It passes at its perihelion within the orbit of Mercury, and has its aphelion midway between the paths of the telescopic planets and Jupiter, its greatest distance from the sun being twelve times its least distance, and its period of revolution 1203 days or $3 \frac{3}{10}$ years. This object has now frequently answered to the announcements made respecting its course, incontestably establishing its character as a regular member of our system, moving in obedieuce to its laws. The comet appears as a small globular patch of vapour, without any starlike nucleus or tail, scarcely perceptible, and its dimness seems to be inereasing. But this insignificant and shadowy thing exhibits a deeply interesting and important phenomenon, that of the gradual diminution of its periodic time, owing to a decrease in the size of its orbit, the supposed effect of a resisting medium in space, which is urging it nearer the sun, and may ultimately terminate its eareer as a separate body. The same conclusion is entertained with reference to the planets, founded upon this peculiarity of the comet of Encke. If the spaces in which they move is occupied by a resisting medium, that, it is conceived, will, in the long run of ages, diminish their actual velocity, decrease the centrifugal foree, give more power to the solar attraction, draw them towards the centre, and thus end the system. Such a speculation is, to say the least, premature. We may admit the existence of an etherial medium which shall perceptibly affect the movements of a small vapoury globule, yet offer no appreciable opposition to the solid and weighty planetary masses. The proper course is to wait until such a medium is placed beyond all doubt, for it cannot be said yet to be demonstrated; and until we have some evidence of its action in the case of the planets, before we reason upon it as a fact. Besides the comet of Encke there is another whose periodicity has been ascertained, a discovery due to M. Biela, in 1826. This object is also without tail or nucleus, and scarcely visible to the naked eye. Its aphelion place is a little beyond the orbit of Jupiter, its perihelion within that of Venus, its time of revolution 2461 days, or $6 \frac{3}{4}$ years. This was the comet which excited a large amount of apprehension for the safety of our terrestrial mansion, prior to its return in 1832. It was calculated that a little before midnight, on the 29 th of October, it would cross the plane in which the earth revolves, near the point where our globe itself would be on the morning of the 30 th of November following; and, undoubtedly, had the comet been delayed a month by any disturbance, a collision with its nebulosity would have taken place. The alarm was 
principally confined to the Parisians, who seem to be somewhat addicted to such fears. In the year 1773 , in consequence of some rumour getting afloat concerning an expected comet, the public tranquillity was completely disturbed, and Lalande was requested by the civil authorities to interfere to assuage the popular terrors. To prevent their renewal in 1832 the authority of the Academy of Sciences was invoked in relation to the anticipated visitor, and Arago wrote a celebrated treatise to show the groundlessness of all alarm. Accordingly, the earth's progress in its orbit being at the mean rate of two millions of miles daily, and a month intervening between the passage of the comet across it and the

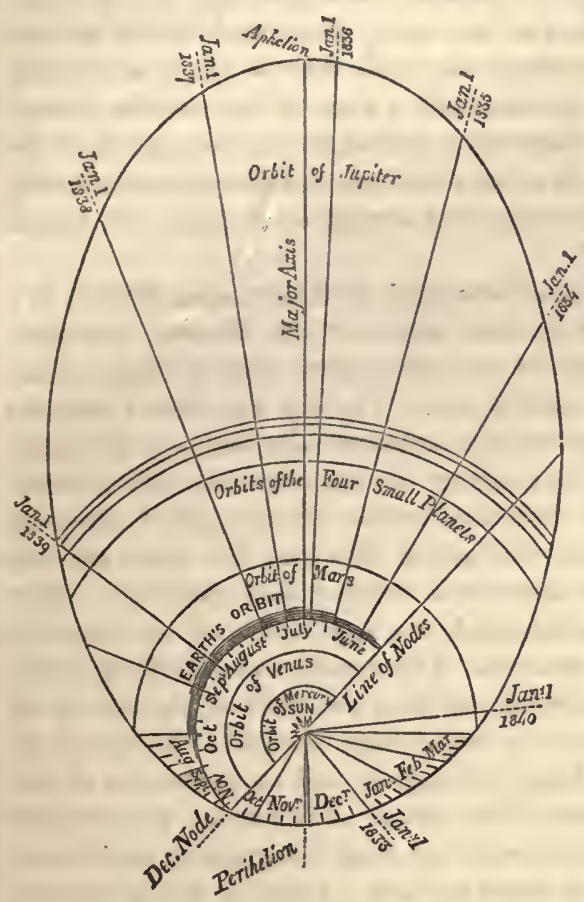
arrival of the earth at the same point, the two bodies were never nearer than sixty millions of miles. The accompanying diagram represents its course as compared with that of the earth. On the ellipse are marked its places for the beginning of each year, from 1833 to 1840 . There are 13 elliptic comets now known revolving within the orbit of Saturn; 7 whose mean distances are nearly equal to that of Uranus; and 21 of long period which pass beyond the limits of the solar system.

In the spring of 1843 the world was suddenly startled by the apparition of an object in the western heavens, soon after sunset, like a streak of aurora, streaming from the region of the sum below the constellation Orion. Its outline was so distinct, and its light so conspicuous, as immediately to arrest the attention of persons abroad upon the roads, and in vessels at sea. By many observers it was mistaken at first for the zodiacal light; but its aspect and movements proved it to be a comet of the very largest class. The nucleus was not seen here, but it was visible in more southern latitudes, where the whole appearance of the comet was far more definite than with us. The phenomenon was observed on board the Tay on her lomeward voyage from the West Indies, upon the 6th of March; at Nice on the 12th, by our countryman, Mr. Cooper; at Oporto on the 14th; and at Paris on the 17th. On Sunday evening, soon after seven o'clock, MIr. Cooper had his attention called by his servant to a white line of light near the western horizon. It was like a narrow thin cloud (cirro-stratus), one end being apparently merged in the remaining solar light, and the other in or near the constellation Lepus. On the 13th, at the same hour, the light re-appeared in a direction parallel to the line joining $\eta$ Leporis with $\gamma$ Eridani. On the 14th, having prepared his comet-seeker, he found the nucleus by sweeping down the line of light, which appeared stellar about the sixth magnitude. The proportion of the tail actually visible here on the nights of the 17 th and 18 th was fully $30^{\circ}$ in length according to Sir John Herschel, and afterward $45^{\circ}$ were measurable by Sir James South. Instead of being luminous at the edges, and more obscure in the middle, a general characteristic of cometary tails, which has induced the belief that they are cones internally empty, the light of the tail, in the present instance, was visibly more intense in the centre than on the sides. 
This was one of the largest comets ever observed, and would have appeared an extraordinary object if eircumstances had been favourable to its exhibition to us. Its train must have extended through eelestial space to the enormous length of a hundred and sixty millions of miles. It was travelling with prodigious velocity away from the sun, having doubled the solar orb upon first becoming visible, and soon vanished from terrestrial gaze in the immensities of the universe. In South Africa its appearance was very distinct. Mr Maclear, at the observatory in the neighbourhood of Cape Town, states:- "Of the casual observatory phenomena, the grand comet of March takes precedence; and few of its kind have been so splendid and imposing. I remember that of 1811 : it was not half so brilliant as the late one. Immersed in the ravines of the Cedar-berg, with high and preeipitous ranges on each side of me, I made strenuous efforts to reach the Snew-berg station, to command a view of the sudden visitor. Those unacquainted with the cliaracter of the Cedar-berg cannot form a coneeption of the difficulties I had to encounter. For seventeen days we toiled on, tantalised every evening by seeing a portion of the tail over the mountain tops, and sometimes a sight of its bright head, as openings in the mountains permitted."

This comet, as observed at Washington, is thus deseribed by Lieutenant Maury, in a communication from the Hydrographical Office in that city:- "On Monday morning, March 6, our attention was called to a paragraph in the newspapers, stating that a comet was visible near the sun at mid-day with the naked eye. The sky was clear; but, not being able to discover any thing with the unassisted eye, recourse was had to a telescope, without any better success. About sunset in the evening the examination was renewed with great diligence, but to no purpose. The last faint streak of day gilded the west, benutiful and delicate fleeces of cloud curtained the bed of the sun, the upper sky was studded with stars, and all hopes of seeing the comet that evening had ranished. Soon after we had retired, the officer of the watch announced the appearance of the comet in the west. The phenomenon was sublime and beautiful. The needle was greatly agitated; and a strongly marked pencil of light was streaming up from the path of the sun in an oblique direction to the southward and eastward; its edges were parallel. It was $1^{\circ} 30^{\prime}$ broad, and $30^{\circ}$ long. Stars could be seen twinkling through it, and no doubt was at first entertained but that this was the tail of the comet. The officer of the watch was directed to search the eastern sky with the telescope in the morning, from early dawn and before, till sunrise. Nothing strange or uncommon was noted by him. Tuesday was a beautiful day. The sun was clear, gilding, as it sunk below the hills, a narrow streak of cloud, seen through the tree-tops beyond the Potomac. The tail had appeared of great length for the first time the evening before; therefore we expected to find its length this evening greatly increased. It was a moment of intense interest when the first stars began to appear. The last rays of the sun still lingered on the horizon, and at this moment a well defined pencil of laairy light was seen pointing towards the sun. At $5 \mathrm{~h} .41 \mathrm{~m}$. sidereal time, the first measurement of length of the tail was taken; it measured $41^{\circ}$ to the horizen. At $6 \mathrm{~h} .19 \mathrm{~m}$. it had become most distinet. It was then $1^{\circ} 45^{\prime}$ broad, and $55^{\circ}$ long, not including the part below the horizon, which, supposing its terminus to be near the sun, could not, owing to the oblique angle which it made with the horizon, be less than $10^{\circ}$ or $15^{\circ}$ more. It now commenced gradually to fade away, and in a short time had entirely disappeared. The morning observations were diligently renewed, but nothing could be seen worthy of note." A letter dated March $22 \mathrm{~d}$ from Constantinople records the advent of the visitor in that region, and the various speculations of its mongrel population coneerning it:- "The attention of the public has been called from terrestrial to celestial matters within the last week, by the appearance of a luminous body in the southern hemisphere, by some declared to be a comet of extraordinary magnitude, by others a 
meteoric or nebulous coruscation. It becomes visible about seven 'o'clock, P. x., and remains in sight for about two hours. Its position is nearly S.S.W., and its magnitude, measured by the sextant, is $1^{\circ}$ in breadtl and $21^{\circ}$ in length, with a dip of $45^{\circ}$. The appearance of this phenomenon has excited general interest among the natives. The mounejimbashy (chief astrologer) declares that it prognosticates great disasters to people residing southwards; it forebodes, in the first place, divers calamities to Greece; and, secondly, a termination of French Razias in Algiers. On the other hand, the Greek priests, with no other instruments than their spectacles, announce that they read in its luminous tail the restoration of the profligate Greek empire, and the downfal of modern rule in Europe. Then, again, the Persian muchats at the Valide Khan all stroke their beards, and swear by the twelve Imans that the meteor represents the flaming death-bladed sword of Ali uplifted to wreak vengeance upon the heretic followers of Omer, for the outrages recently committed upon the sainted tombs of Kerbebah. In the meanwhile, as there are neither astronomers nor instruments at this place, nothing is left for us but to await accounts from Europe, in order to determine the real nature of this extraordinary and splendid phenomenon."

A European, travelling in the wilds of America, the only representative of the civilised world present upon the occasion, has graphically narrated his own impressions, and those of his Indian companions :- "We were ascending the Essequibo, that noble river which, though a small rill among the mountains of the equator, disembogues its accumulated waters through three channels nearly twenty miles wide. The weather was unfavourable; torrents of rain had descended, and the sky had been covered with clouds for weeks. We were approaching the cataract Ouropocari in $4^{\circ} 11^{\prime}$ north latitude, and had encamped, on the 8th of Marcli, three miles below it, when, for the first time since our departure from the coast, the sky, hitherto a uniform mass of greyish clouds, cleared in the evening, and exposed, towards the south-west, the deep tropical blue, spangled with stars. We hailed with pleasure the prediction of better weather; but what was our amazement when we observed, in the W.S.W., a broad, white, nebulous band, inclining towards the horizon, and stretching to an altitude of $45^{\circ}$ ! The zenith was covered witl those beautiful clouds which the meteorologist calls cirro-cumulus; the sky was, however, perfectly clear on both sides of the band which, $64^{\prime}$ (in arc) broad, and of a pure white, almost transparent, formed a strong contrast with the deep azure of the tropical sky. I could not observe whether the band rested apparently on the horizon, as the wall-like forest, near the edge of which we were encamped, prevented me from seeing that portion of the sky. From the point where the band became visible it appeared of a uniform breadth, becoming more transparent, and slightly diverging, near the summit. What can it be? was the first question. My Indian friends stood around, looking now with wonder at the phenomenon, now askance at me. Our doubts were solved next evening, March 9: it was a comet! Our camp was so favourably situated that the south-western horizon was exposed to our view. The sky was partially clouded until seven o'clock, when the clouds to the west cleared away, and there stood the comet in all its grandeur, the nucleus being about $12^{\circ}$ above the horizon, and the tail extending to the star $v$ Eridani, then about $45^{\circ}$ high. The nucleus appeared, to the naked eye, like a star of the second magnitude; its tail, near the base like a narrow band, spread in its broadest part $1^{\circ} 10^{\prime}$, and lost itself in the constellation Eridanus. The whitish light and transparent vapour of its tail, resembling more those clouds compared to

' The beauteous semblance of a flock at rest,'

diverged about $20^{\circ}$ below the foot of Orion, in nebulous stripes. We stood amazed. A bright moon somewhat lessened the effect which this most wonderful of all natural phenomena would have produced had all else been hidden in darkness; but the extent of 
the tail rendered it remarkable; indeed, it was the largest which we, who stood assembled, had ever witnessed in our lifetime. I still recollect the beautiful comet of 1811 , with its diverging beams of fiery hue, but its tail was much less in length than the one now looked upon. It was a scene which has fixed itself firmly upon my memory. There we stood, upon a small island in the middle of the Essequibo, surrounded by foaming waters which, opposed in their course by dykes of granite, went thundering away over the black stony masses, - I the only European among a number of naked savages, the coppery tint of whose bodies shone in strong contrast when the burning embers of the camp fires threw a ray upon their figures; some standing upright, with their arms across their breast, others squatting on the ground, but their fearful eyes all directed towards the strange star with its luminous train. No word was spoken. 'The rush of the foaming waters was the orly interruption of the silence. Tamanua, a young Wapisiana, of more intelligence than is generally met with among his tribe, at last broke silence: "This is the Spirit of the stars, the dreadful Capishi - famine and pestilence await us;' and, as if they laad only wanted the utterance of a syllable to give vent to their feelings, the assembled Indians burst into a torrent of declamation, lamenting the appearance of the dreaded Capishi, as the precursor of pestilenee and famine, and raising, with violent gesticulations, their arms towards the comet. I was surprised to find among my Indian followers the same superstitious dread of a comet which, in all ages, rendered their celestial appearance the

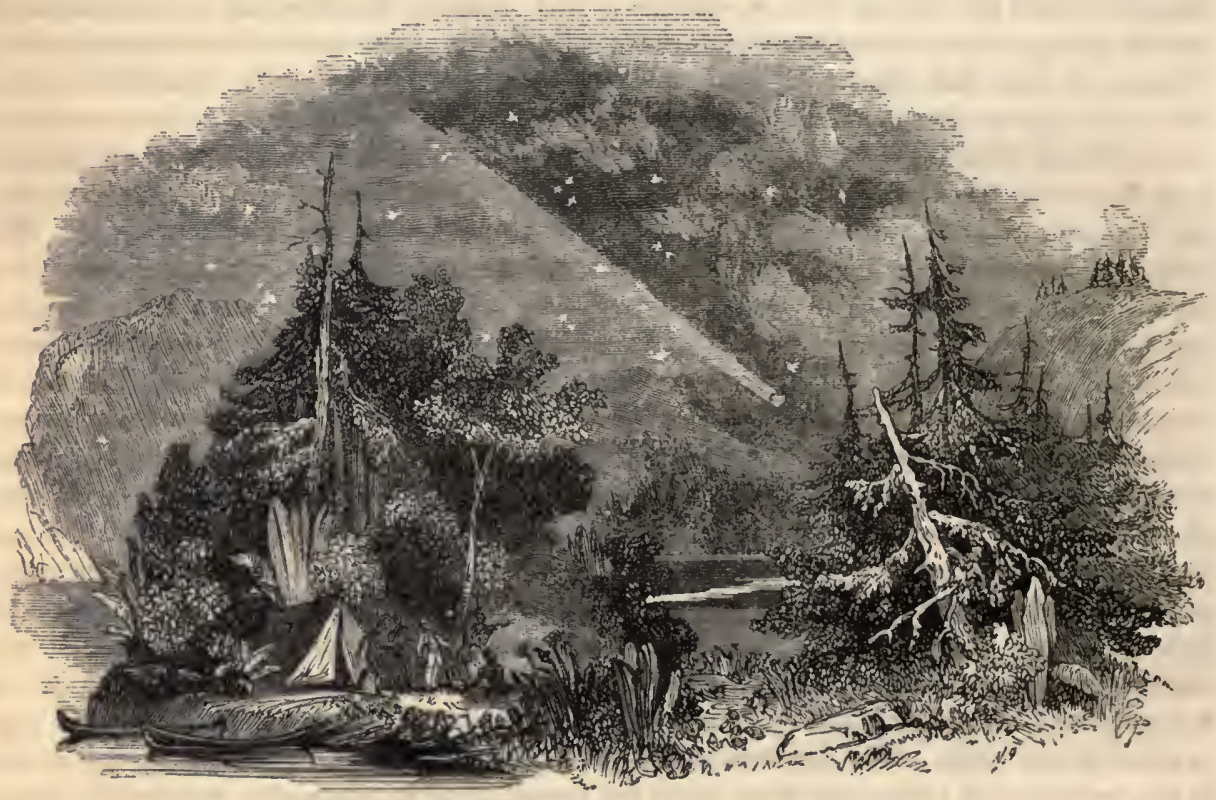

terror of the uninstructed and vulgar. The Indians around me consisted of Arécuna ; Wapisianas, and Macusis. The first called the comet Wátaimá, signifying, like Capishi, the Spirit of the stars. The Macusi Indians named it Cá-poéséimá, 'a fiery cloud,' or Wœ-inopsa, 'a sun casting its light behind.' Must. we not acknowledge that these simple children of Nature have given to this magnificent plienomenon a more expressive name than we civilised nations?"

This comet is remarkable on various accounts. It advanced nearer to the solar surface than any other on record. That of 1680 approached the sun within one-third of his diameter; but that of 1843 came within one-seventh, and was consequently more than 
twice as near, exposed to a heat of proportionate greater intensity. Sir John Herschel computed that the heat received by its surface during the passage of the perihelion was equal to that which would be received by an equal portion of the earth's surface, if it were exposed to the influence of 47,000 suns, placed at the common distance of the actual sun. It is difficult to conceive how a flimsy body could have resisted such a temperature so as not to have been entirely dissipated. This comet is also remarkable as one of the few on record which have been visible in broad daylight.

Comets have been observed to undergo remarkable transformations on their approach to the perihelion, breaking up into two or more separate parts, evidently owing to the action of the sun. Seneca reports an instance of dissolution of this kind; Hevelins witnessed another; and Biela's comet exhibited the strange phenomenon on the occasion of its third re-appearance, in the year 1846 . It then separated into two distinct comets, which moved side by side, in distinct and independent orbits, as long as visible. One of these objects was a little fainter than the other, but both had tails, and exhibited the distinctive features of a comet. The change of constitution seems to have taken place very suddenly. It was first observed in Europe on the 15th of January, by Mr Challis of Cambridge, and M. Wickmann of Konigsberg; but it was afterwards found to have been seen on the 12th by Lieutenant Maury, at the Observatory of Washington, in the United States. The separation has probably been permanent, and become more decided. In 1852 , on the occasion of the fourth re-appearance, Biela's comet was preceded by another, a fainter object, which may have been the companion separated from it, removed to a greater distance. The annexed cut represents some of the various appearances presented by Halley's comet in 1835 in different parts of its orbit- $a, b, c$, in approaching the sun; $d, e$, in retreating.

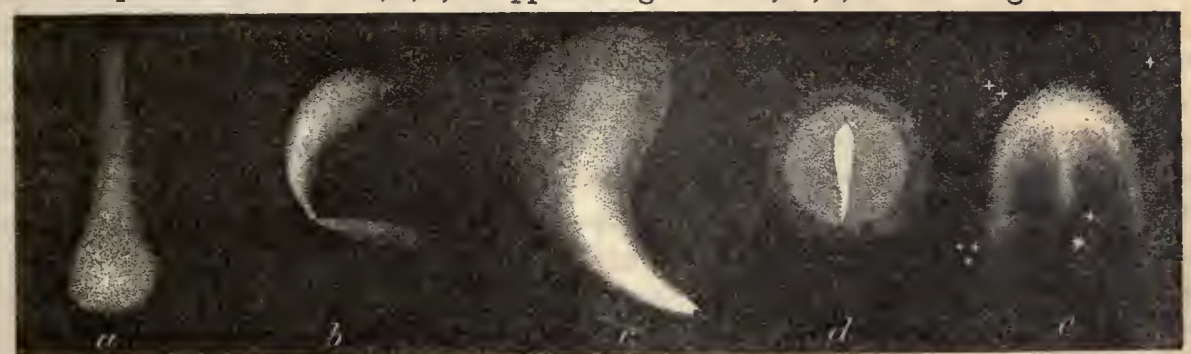

It is probable that a great comet, revolving round the sun in the long period of nearly three centuries, was observed in the years 975,1264 , and 1556. This is the opinion of Gauss of Gottingen, Mr Hind, and other astronomers. Assuming the comets of those years to be three apparitions of the same body, its return to the sun may be anticipated after the lapse of a corresponding interval. The wanderer is now overdue, as full three centuries have elapsed since the last period; but as its time of revolution may be lengthened by planetary perturbations, it will be looked for till the year 1860. In 1264, the comet was visible many months, and very conspicuous. All Europe regarded it as intimating the death of Pope Urban IV. "Its apparition," says Thierri, "boded his illness, and its disappearance his death, as events have proved." Historians relate that it was last seen on the night of the pontiff's decease. In 1556, the comet was also a striking object, and similarly interpreted as signifying terrestrial changes. It was noticed that "the tail was always at first turned towards Spain." The emperor Charles V. was greatly alarmed at its appearance; and looked upon it as a sign of his approaching death. He is said to have been induced by the impression to cede the imperial crown to his son.

The leading features of the chief cometary appearances of modern times have now been sketched. There are various inquiries which naturally suggest themselves with reference to these bodies. What is their physical constitution? What their origin and office in 
the system? Are they inherently luminous, or dependent upon the solar glory, shining like the planets by virtue of his light? Hare they any terrestrial influence? Is there a chance of our globe coming into actual collision with them; and supposing collision, what would be its probable effects? Upon most of these points we have nocertain knowledge. Herschel and Schroeter thought the comet of 1811 a self-luminous body, but in opposition to this opinion Cassini is quoted as having descried the comet of 1744 showing a phase. On the very day, says Arago, that any comet shall appear with a distinct phase, all doubts will have ceased. At present however no satisfactory evidence is possessed of such an appearance being observed. Upon the question of physical constitution, it is pretty certain that the great majority of these bodies, and most probably all of them, are entirely gaseous - simple aggregations of vapour. The eridence to this effect is various. The comet of 1770 passed twice through the system of Jupiter; and calculation shows, that had it been $\frac{1}{30}$ of one of the satellites in mass, it would have sensibly affected that system. Yet there was not the slightest derangement of the planes of motion, or of the periods of revolution, by its intrusion among the satellites. The same body also passed at that time at no very great distance from the earth. In fact it approached us nearer than any other that has visited our terrestrial sky. Had it possessed a quantity of solid matter equal to that of the earth, it would then have shortened the length of our year by one ninth of a day; or had it been $\frac{\text { ' }}{500}$ of the earth in mass, it would have appreciably altered its length to a degree that must long ago have bcen observed. But not the least perturbation was caused by its close proximity. These are sufficient proofs of the smallness of its mass, even allowing it to have had any solid matter at all, which may be reasonably suspected. Through the very centre of Biela's comet in 1832 a group of stars of the sixteenth magnitude was very distinctly seen by Sir Joln Herschel. While admitting that many comets are mere agglomerations of vapour, some hold to the opinion that where there is a nucleus remarkable for its vivacity of light, there is a solid and opaque body. But several facts declare against this supposition. Instances hare occurred of stars being visible through a strongly defined nucleus. In 1618 , the nucleus of the comet of that year is described as having dissolved into several detached parts; that of 1661 observed by Hevelius, clanged also from a globular figure, and entirely disappeared; and the most extraordinary transformations are suddenly effected in the constitution of these objects. It is most probable that a comet is altogether a gaseous body, and has no solid matter whatever. Sir John Herschel remarks, that " whenever powerful telescopes have been turned on them, they have not failed to dispel the illusion which attributes solidity to that more condensed part of the head, which appears to the naked eye as a nucleus; though it is true that in some a very minute stellar point has been seen, indicating the existence of a solid body." Mr. Airy also states, that "on the physical constitution of comets we lave learnt nothing, except that they appear to be wholly gaseous."

These views of the constitution of cometary bodies show the fallacy of apprehending those consequences from a shock with them, of which terrific pictures have been drawn, and the impossibility of those events being produced by collision, which have been assigned to it, such as the deluge of Noah, the depression of the Caspian Sea and its neighbourhood, with the formation of the small telescopic planets out of a comet-stricken orb. "It is easy to represent," says Laplace, "the effect of such a shock upon the earth; the axis and motion of rotation changed; the waters abandoning their ancient position to precipitate themselves towards the new equator; the greater part of men and animals drowned in a universal deluge, or destroyed by the violence of the slock given to the terrestrial globe ; whole species annililated; all the monuments of human industry reversed; such are the disasters which a shock of a comet would produce. We see then," he observes, referring 
to this cause some singular facts in geology, explained, "why the ocean has abandoned the lighcst mountains, on which it has left incontestable marks of its former abode. We see why the animals and plants of the soutl may have existed in the climates of the north, where their relics and impressions are still to be found. Lastly, it explains the short period of the existence of the moral world, whose earliest monuments do not go much further back than three thousand years. The human race, reduced to a small number of individuals, in the most deplorable state, occupied only with the immediate care for their subsistence, must necessarily have lost the remembrance of all sciences and of every art; and when the progress of civilisation has again created new wants, everything was to be done again, as if mankind had been just placed upon the earth." When this was the language of a philosopher of such high repute, the cockneys and belles of Paris might well tremble at the announcement of a comet. "Popular terrors," said a professor there upon a recent occasion, "are productive of serious consequences. Several members of the Academy may still remember the accidents and disorders which followed a similar threat, imprudently communicated to the Academy by M. Delande in May 1773. Persons of weak minds died of fright, and women miscarried. There were not wanting people, who knew too well the art of turning to their advantage the alarm inspired by the apprehended comet, and places in Paradise were sold at very high prices. 'The announcement of the comet of 1832 may produce similar effects, unless the authority of the Academy apply a prompt remedy; and this salutary intervention is at this moment implored by many benevolent persons." The possibility of collision with one of these ragrant cruisers in space may indeed be soberly entertained, as they move in all imaginable directions, penetrate within the interior of the planetary orbits, and often pass between Mercury and the sun. But a calculation of probabilities shows, that of $281,000,000$ of chances, there are $280,999,999$ that are favourable to one unfavourable. The probability, therefore, of such an event happening in the experience of any individual of the human race is no greater than it would be with reference to his drawing one black ball, supposing it in an urn with $280,999,999$ white balls. As to the near approach of a comet producing any great terrestrial change, such as deflecting our globe from its orbit by attraction, and scampering off with it as a satellite, we have plain warrant to treat the assumption as romance. The case of Lexel's lost comet intruding in the system of Jupiter without disturbing it, but being itself twisted into a new path, may lead us to allow of some approach to fellowship with perfect safety. That comet advanced to within six times the distance of the moon from us, yet it neither raised our tides a jot, nor added a single second to our year, though the diameter of its head was estimated to be thirteen times that of our satellite.

We, indeed, were not quite so passive upon that occasion, for the action of the earth upon the comet increased the time of its revolution by two days. Even should an instance of actual contact occur, there seems no more reason to infer physical convulsion from the attack of a gaseous body, than in the case of a squadron of clouds assailing the sides and summit of a mountain. In all probability the only effect would be a change of temperature, with some peculiar atmospheric phenomena, yet compatible with a full security to human life and happiness. That the orbital course and rotation of our planet would be affected ; that the pole and the equator would exchange places; that the ocean would leave its present bed, and the dry land be submerged; that any consequence would follow beyond a temporary alteration of climate, we have not only no authority to suppose, but strong grounds to deny. The surmise has been entertained that, in the year 1837, our globe experienced some cometary entanglement; and nothing more likely than that repeatedly, since the Creation, the terrestrial surface has received a brush. No trifling service has been rendered to mankind by science, that now these bodies are divested of those attributes of 
terror with which they were identified in ages past, when regarded as the heralds of political misfortune, or portending fatal physical events. When tidings came across the seas, brought by merchant and monk, that William the Norman was preparing to contest the possession of his territories with Harold, a comet, flaring in the heavens, raised misgivings in the Saxon mind as to the issue of the event, and unnerved him for the struggle when all his vigour was most required. An after chronicle relates how a star with three long tails appeared in the sky, how the learned declared that such stars appeared only when a kingdom wanted a new king, and how the said star was called a " comette." So, in 1618, a similar object was believed, in France, to foreshow another Bartholomew massacre; in Holland, to predict the death of Barnevcldt; at Vienna its fiery aspect was viewed as symbolic of destruction to the Bohemian heretics; while, in England, it was connected with coming wars, and the death of James's queen. It is no slight advantage to the moderns, that they can gaze upon such objects without anticipating disaster, and regard them as controlled by those laws to which their own world is obedient.

\section{CHAPTER VI.}

\section{AËROLITES.}

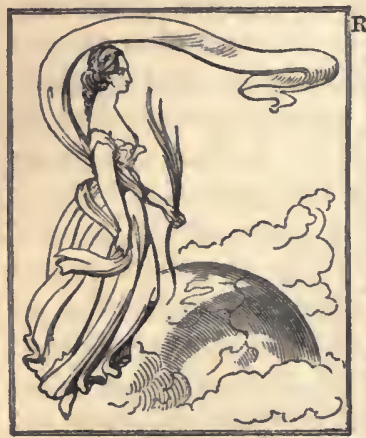

Rour every region of the globe, and in all ages of time within the range of history, exhibitions of apparent instability in the heavens have been observed, when the curtains of the evening have been drawn. Suddenly, a line of light arrests the eye, darting like an arrow through a varying extent of space, and in a moment the firmament is as sombre as before. The appearance is exactly that of a star falling from its sphere, and hence the popular title of shooting star applied to it. The apparent magnitudes of these meteorites are widely different, and also their brilliancy. Occasionally, they are far more resplendent than the brightest of the planets, and throw a very perceptible illumination upon the path of the observer. A second or two commonly suffices for the individual display, but in some instances it has lasted several minutes. In every climate it is witnessed, and at all times of the year, but most frequently in the autumnal months. As far back as records go, we meet with allusions to these swift and evanescent luminous travellers. Minerva's hasty flight from the peaks of Olympus to break the truce between the Greeks and Trojans, is compared by Homer to the emission of a brilliant star. Virgil, in the first book of the Georgics, mentions the shooting stars as prognosticating weather changes:-

" And oft, before tempestuous winds arise,

The seeming stars fall headlong from the skies,

And, shooting through the darkness, gild the night

With sweeping glories and long trains of light."

Various hypotheses have been framed to explain the nature and origin of these remarkable appearances. When electricity began to be understood, this was thought to afford a satisfactory explanation, and the shooting stars were regarded by Beccaria and Vassali as merely electrical sparks. When the inflammable nature of the gases became known, Lavoisier and Volta supposed an accumulation of hydrogen in the higher regions of the atmosphere, because of its inferior density, giving rise by ignition to the meteoric 
exhibitions. While these theories of the older philosophers have been shown to be untenable, there is still great obscurity resting upon the question, though we have reason to refer the phenomena to a cause exterior to the bounds of our atmosphere. Upon this ground, the subject assumes a strictly astronomical aspect, and claims a place in a treatise on the economy of the solar system.

The first attempt accurately to investigate these elegant meteors was made by two university students, afterwards Professors Brandes of Leipsic, and Benzenberg of Dusseldorf, in the year 1798. They selected a base line of 46,200 feet, somewhat less than nine English miles, and placed themselves at its extremities on appointed nights, for the purpose of ascertaining their average altitude and velocity. Out of twenty-two appearances identified as the same, they found

7 under 45 miles

9 between 45 and 90 miles
5 above 90 miles

1 above 140 -

The greatest obserred velocity gave twenty-five miles in a second. $\mathbf{\Lambda}$ more extensive plan was organised by Brandes in the year 1823, and carried into effect in the neighbourhood of Breslau. Out of ninety-eight appearances, the computed heights were,

$$
\begin{aligned}
& 4 \text { under } 15 \text { miles } \\
& 15 \text { from } 15 \text { to } 30 \text { miles } \\
& 22-30 \text { to } 45- \\
& 33-45 \text { to } 70-
\end{aligned}
$$

13 from 70 to 90 miles

6 above 90 miles

5 from 140 to 460 miles.

The velocities were between eighteen and thirty-six miles in a second, an average velo. city far greater than that of the earth in its orbit.

The rush of luminous bodies through the sky of a more extraordinary kind, though a rare occurrence, has repeatedly been observed. They are usually discriminated from shooting stars, and known by the vulgar as fire-balls; but probably both proceed from the same cause, and are identical phenomena. They have sometimes been seen of large volume, giving an intense light, a hissing noise accompanying their progress, and a loud explosion attending their termination. In the year 1676, a meteor passed over Italy about two hours after sunset, upon which Montanari wrote a treatise. It came over the Adriatic Sea as if from Dalmatia, crossed the country in the direction of Rimini and Leghorn, a loud report being heard at the latter place, and disappeared upon the sea towards Corsica. A similar visitor was witnessed all over England in 1718, and forms the subject of one of Halley's papers to the Royal Society. Sir Hans Sloane was one of its spectators. Being abroad at the time of its appearance, at a quarter past eight at night, in the streets of London, his path was suddenly and intensely illuminated. This, he apprehended at first, might arise from a discharge of rockets ; but found a fiery object in the heavens, moving after the manner of a falling star, in a direct line from the Pleiades to below the girdle of Orion. Its brightness was so vivid, that several times he was obliged to turn away his eyes from it. The stars disappeared, and the moon, then nine days old, and high near the meridian, the sky being very clear, was so effaced by the lustre of the meteor as to be scarcely seen. It was computed to have passed over three hundred geographical miles in a minute, at the distance of sixty miles above the surface, and was observed at different extremities of the kingdom. The sound of an explosion was heard through Devon and Cornwall, and along the opposite coast of Bretagne. Halley conjectured this and similar displays to proceed from combustible vapours aggregated on the outskirts of the atmosphere, and suddenly set on fire by some unknown cause. But since his time, the fact has been established, of the actual fall of heavy bodies to the earth from surrounding space, which requires another hypothesis. To these bodies the term aërolites is applied, signifying atmospheric stones, from à $\rho_{\rho}$, the atmosphere, and $\lambda i \theta o s$, a stone. 
While many meteoric appearances may simply arise from electricity, or from the inflammable gases, it is now certain, from the proved descent of aërolites, that such bodies are of extra-terrestrial origin.

Antiquity refers us to several objects as having descended from the skies, the gifts of the immortal gods. Such was the Palladium of Troy, the image of the goddess of Ephesus, and the sacred shield of Numa. The folly of the ancients in believing such narrations has often been the subject of remark; but, however fabulous the particular cases referred to, the moderns have been compelled to renounce their scepticism respecting the fact itself, of the actual transition of substances from celestial space to terrestrial regions; and no doubt the ancient faith upon this subject was founded on observed events. The following table, taken from the work of M. Izarn, Des Pierres tombées du Ciel, exhibits a collection of instances of the fall of aërolites, together with the eras of their descent, and the persons on whose evidence the facts rest; but the list might be largely extended.

\begin{tabular}{|c|c|c|c|}
\hline Substance. & Place. & Period. & A uthority. \\
\hline 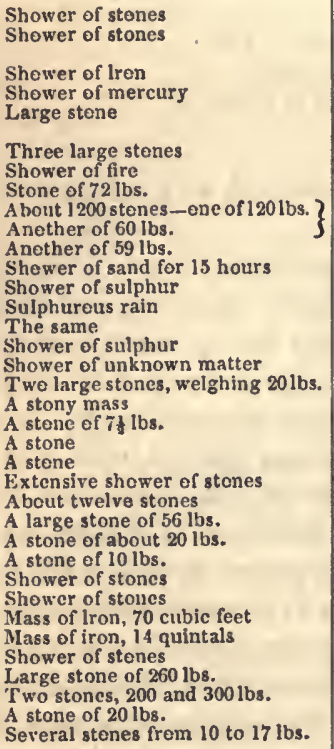 & $\begin{array}{l}\text { At Rome } \\
\text { At Rome } \\
\text { In Lucanila } \\
\text { In ltaly } \\
\text { Near the river Neges, Thrace } \\
\text { In Thrace } \\
\text { At Quesnoy } \\
\text { Near Larissa, Macedonia } \\
\text { Near Padua, in Italy } \\
\text { On Mount Vasier, Provence } \\
\text { In the Atlantic } \\
\text { Sodom and Gemorra } \\
\text { In the Duchy of Mansfield } \\
\text { Copenhagen } \\
\text { Brunswlck } \\
\text { Ireland } \\
\text { Liponas, In Bresse } \\
\text { Niort, Normandy } \\
\text { At Luce, In I.e Maine } \\
\text { At Aire, In Arteis } \\
\text { In Le Cotentin } \\
\text { Environs of Agen } \\
\text { Sienna, Tuscany } \\
\text { Weld Cottage, Yorkshlre } \\
\text { Sale, Department of the Rhone } \\
\text { In Portugal } \\
\text { Benares, East Indies } \\
\text { At Plaun, near Tabor, Bohemia } \\
\text { America } \\
\text { Abakauk, Siberia } \\
\text { Barboutan, near Roquefort } \\
\text { Ensisheim, Upper Rhine } \\
\text { Near Verona } \\
\text { Sules, near Ville Franche } \\
\text { Near L'Aigle, Nermandy }\end{array}$ & $\begin{array}{l}\text { Under Tullus Hostilius } \\
\text { Consuls C. Martius and M. Tor- } \\
\text { quatus } \\
\text { Yearbefore the defeat of Crassus } \\
\text { Secend year of the 78th Olym- } \\
\text { plad } \\
\text { Year before J. C. } 452 \\
\text { January } 4.1717 \\
\text { January, 1706 } \\
\text { In } 1510 \\
\text { November } 27.1627 \\
\text { April } 6.1719 . \\
\text { In } 1658 \\
\text { In } 1646 \\
\text { October, } 1721 \\
\text { In } 1695 \\
\text { September, } 1753 \\
\text { In } 1750 \\
\text { September } 13.1768 \\
\text { In } 1768 \\
\text { In } 1768 \\
\text { July } 24.1790 \\
\text { July, } 1794 \\
\text { December } 13.1795 \\
\text { March } 17,1798 \\
\text { February } 19.1796 \\
\text { December } 19.1798 \\
\text { July } 3.1753 \\
\text { April } 5.1800 \\
\text { Very old } \\
\text { July, 1789 } \\
\text { November } 7.1492 \\
\text { In } 1762 \\
\text { March } 12.1798 \\
\text { A pril } 26.1803\end{array}$ & $\begin{array}{l}\text { Livy. } \\
\text { J. Obsequens. } \\
\text { Pliny. } \\
\text { Dion. } \\
\text { Pllny. } \\
\text { Ch. of Count Marcellin. } \\
\text { Geoffroy le Cadet. } \\
\text { Paul Lucas. } \\
\text { Carden, Varcit. } \\
\text { Gassendi. } \\
\text { Pere la Fuillée. } \\
\text { Moses. } \\
\text { Spangenburgl. } \\
\text { Olaus Wormius. } \\
\text { Siegesbar. } \\
\text { Musclienbroeck. } \\
\text { Lalande. } \\
\text { Lalande. } \\
\text { Baclielay. } \\
\text { Gursonde de Boyaral. } \\
\text { Mlorand. } \\
\text { St. Amand, Baudin, \&.c. } \\
\text { Earl of Bristol. } \\
\text { Captain Topham. } \\
\text { Lelievre and De Drée. } \\
\text { Southey. } \\
\text { J. Lloyd Williams, Esq. } \\
\text { 13. de lBorn. } \\
\text { Philosophical Mag. } \\
\text { Pallas, Chladnl, \&c. } \\
\text { Darcet,Jun., Lomet,\&c. } \\
\text { Butensehoen. } \\
\text { Acad. de Bourd. } \\
\text { De Drée. } \\
\text { Fourcroy. }\end{array}$ \\
\hline
\end{tabular}

Some of the instances in the table are of sufficient interest to deserve a notice.

A singular relation respecting the stone of Ensisheim on the Rhine, at which plilosophy once smiled incredulously, regarding it as one of the romances of the middle ages, may now be admitted to sober attention as a piece of authentic history. A homely narrative of its fall was drawn up at the time by order of the emperor Maximilian, and deposited with the stone in the church. It may thus be rendered :- "In the year of the Lord 1492, on Wednesday, which was Martinmas eve, the 7 th of November, a singular miracle occurred; for, between eleven o'clock and noon, there was a loud clap of thunder, and a prolonged confused noise, which was heard at a great distance; and a stone fell from the air, in the jurisdiction of Ensisheim, which weighed two hundred and sixty pounds, and the confused noise was, besides, much louder than here. Then a child saw it strike on a field in the upper jurisdiction, towards the Rhine and Inn, near the district of Giscano, 
which was sown with wheat, and it did it no harm, except that it made a hole there : and then they conveyed it from that spot; and many pieces were broken from it; which the landvogt forbade. They, therefore, caused it to be placed in the church, with the intention of suspending it as a miracle: and there came here many people to see this stone. So there were remarkable conversations about this stone: but the learned said that they knew not what it was; for it was beyond the ordinary course of nature that such a large stone should smite the earth from the height of the air; but that it was really a miracle of God; for, before that time, never anything was heard like it, nor seen, nor described. When they found that stone, it had entered into the earth to the depth of a man's stature, which everybody explained to be the will of God that it should be found; and the noise of it was heard at Lucerne, at Vitting, and in many other places, so loud that it was believed that houses had been overturned: and as the King Maximilian was here the Monday after St. Catharine's day of the same year, his royal Excellency ordered the stone which had fallen to be brought to the Castle, and, after having conversed a long time about it with the noblemen, he said that the people of Ensisheim should take it, and order it to be hung up in the church, and not to allow anybody to take anything from it. His Excellency, however, took two pieces of it; of which he kept one, and sent the other to the Duke Sigismund of Austria : and they spoke a great deal about this stone, which they suspended in the choir, where it still is ; and a great many people came to see it." Contemporary writers confirm the substance of this narration, and the evidence of the fact exists; the aërolite is precisely identical in its chemical composition with that of other meteoric stones. It remained for three centuries suspended in the church, was carried off to Colmar during the French revolution; but has since becn restored to its former site, and Ensisheim rejoices in the possession of the relic. A piece broken from it is in the museum of the Jardin des Plantes at Paris, and another in the British Museum.

The celebrated Gassendi was an eye-witness of a similar erent. In the year 1627, on the 27 th of. November, the sky being quite clear, he saw a burning stone fall in the neighbourhood of Nice, and examined the mass. While in the air it appeared to be about four feet in diameter, was surrounded by a luminous circle of colours like a rainbow, and its fall was accompanied by a noise like the discharge of artillery. Upon inspecting the substance, he found it weighed 59lbs., was extremely hard, of a dull metallic colour, and of a specific gravity considerably greater than that of common marble. Having only this solitary instance of such an occurrence, Gassendi concluded that the mass came from some of the mountains of Provence, which had been in a transient state of volcanic activity. Instances of the same phenomenon occurred in the ycars 1672, 1756, and 1768; but the facts were generally doubted by naturalists, and considered as electrical appearances magnified by popular ignorance and timidity. A remarkable example took place in France in the year 1790. Between nine and ten o'clock at night, on the 24th of July, a luminous ball was seen traversing the atmosphere with great rapidity, and leaving behind it a train of light; a loud explosion was then heard, accompanied with sparks which flew off in all directions; this was followed by a shower of stones over a considerable extent of ground, at various distances from each other, and of different sizes. A procès verbal was drawn up, attesting the circumstance, signed by the magistrates of the municipality, and by several hundreds of persons inhabiting the district. This curious document is literally as follows:- "In the year one thousand seven hundred and ninety, and the thirtieth day of the month of August, we, the Lieut. Jean Duby, mayor, aud Louis Massillon, proculator of the commune of the municipality of La Grange-de-Juillac, and Jean Darmite, resident in the parish of $\mathrm{La}$ Grange-de-Juillac, certify in truth and verity, that on Saturday, the 24th of July last, between nine and ten o'clock, there passed a great fire, and after it we heard in the air a very loud and extraordinary noise; and about two 
minutes after, there fell stones from heaven; but fortunately there fell only a very few, and they fell about ten paces from one another in some places, and in others nearer, and finally, in some other places farther; and falling, most of them, of the weight of about half a quarter of a pound each, some others of about half a pound, like that found in our parish of La Grange; and on the borders of the parish of Creon, they were found of a pound weight; and in falling, they seemed not to be inflamed, but very hard and black without, and within of the colour of steel : and, thank God, they occasioned no harm to the people, nor to the trees, but only to some tiles which were broken on the houses; and most of them fell gently, and others fell quickly with a hissing noise; and some were found which had entered into the earth, but very few. In witness whereof, we have written and signed these presents. Duby, mayor. Darmite." Though such a document as this, coming from the unlearned of the district where the phenomenon occurred, was not calculated to win acceptance with the savans of the French capital; yet it was corroborated by a host of intelligent witnesses at Bayonne, Thoulouse, and Bordeaux, and by transmitted specimens containing the substances usually found in atmospheric stones, and in nearly the same proportions. A few years afterwards, an undoubted instance of the fall of an aërolite occurred in our own country, which largely excited public curiosity. This was in the neighbourhood of Wold Cottage, the house of Captain Topham, in Yorkshire. Several persons heard the report of an explosion in the air, followed by a hissing sound; and afterwards felt a shock, as if a heavy body had fallen to the ground at $\Omega$ little distance from them. One of these, a ploughman, saw a huge stone falling towards the earth, eight or nine yards from the place where he stood. It threw up the mould on every side, and after penetrating through the soil, lodged some inches deep in solid chalk rock. Upon being raised, the stone was found to weigh fifty-six pounds. It fell in the afternoon of a mild but hazy day, during which there was no thunder or lightning; and the noise of the explosion was heard through a considerable district. It deserves remark, that in most recorded cases of the descent of projectiles, the weather has been settled and the sky clear; a fact which plainly places them apart from the causes which operate to produce the tempest, and shows the popular term thunderbolt to be an entire misnomer.

While this train of circumstances was preparing the philosoplic mind of Europe to admit as a truth what had hitherto been deemed a vulgar error, and acknowledge the appearance of masses of ignited matter in the atmosphere occasionally descending to the earth, an account of a phenomenon of this kind was reccived from India, vouched by an authority calculated to secure it general respect. It came from Mr. Williams, F.R.S., a resident in Bengal. It stated that on December 19th, 1798, at eight o'clock in the evening, a large luminous meteor was seen at Benares and other parts of the country. It was attended with a loud rumbling noise, like an ill-discharged platoon of musketry; and about the same time, the inhabitants of Krakhut, fourtcen miles from Benares, saw the light, heard an explosion, and immediately after the noise of heavy bodies falling in the neighbourhood. The sky had previously been serene, and not the smallest restige of a cloud had appeared for many days. Next morning, the mould in the fields was found to have been turned up in many spots; and unusual stones of various sizes, but of the same substance, were picked out from the moist soil, generally from a depth of six inches. As the occurrence took place in the night, after the people had retired to rest, the explosion and the actual fall of the stones were not observed: but the watchman of an English gentleman, near Krakhut, brought him a stone the next morning which had fallen through the top of his hut, and buried itself in the earthen floor. This event in India was followed in the year 1803 by a convincing demonstration in. France, which compelled the eminent men of the capital to believe, though much against their will. On Tuesday, April 26th, about one in the afternoon, the weather being serene, there was observed, in 
a part of Normandy, including Caen, Falaise, Alençon, and a large number of villages, a fiery globe of great brilliancy moving in the atmosphere with great rapidity. Some moments after, there was heard at L'Aigle and in the environs to the extent of more than thirty leagues in every direction, a violent explosion, which lasted five or six minutes. At first there were three or four reports like those of a cannon, followed by a kind of discharge which resembled the firing of musketry; after which there was heard a rumbling like the beating of a drum. The air was calm and the sky serene, except a few clouds, such as are frequently observed. The noise proceeded from a small cloud which had a rectangular form, and appeared motionless all the time that the phenomenon lasted. The vapour of which it was composed was projected in all directions at the successive explosions. The cloud seemed about half a league to the north-east of the town of L'Aigle, and must have been at a great elevation in the atmosphere, for the inhabitants of two hamlets, a league distant from each other, saw it at the same time above their heads. In the whole canton over which it hovered a hissing noise like that of a stone discharged from a sling was heard: and a multitude of mineral masses were seen to fall to the ground. The largest that fell weighed $17 \frac{1}{2}$ pounds ; and the gross number amounted to nearly three thousand. By the direction of the Academy of Sciences, all the circumstances of this crent were minutely examined by a commission of inquiry with the celebrated M. Biot at its head. They were found in harmony with the preceding relation, and reported to the French minister of the interior. Upon analysing the stones they were found identical with those of Benares.

The following are the principal facts with reference to the aërolites, upon which general dependence may be placed. If examined immediately after their descent, they have always a temperature more or less elevated. They are almost invariably invested with a peculiar thin crust, consisting chiefly of oxide of iron, often of pitchy lustre, very distinctly defined from the interior mass. What is most remarkable, in the great majority of cases, their chemical analysis develops the same substances combined in nearly the same proportions, though one may have reached the earth in India, another in England, and a third in the United States. Not more than twenty primary ingredients at the utmost have been noticed in them. But some of the best known consist almost entirely of one ingredient, iron, with a small proportion of nickel. Others contain cobalt, manganese, chromium, copper, tin, arsenic, associated with a small per-centage of oxygen, sulphur, and chlorine. Others consist principally of silica and metallic oxides. It should be distinctly noted, that the iron and nickel are almost always in the metallic form-a state in which they are not found naturally on the surface of the earth. It is also to be observed, that though a chemical examination of their composition has disclosed no substance with which we were not previously acquainted, yet not only are the majority of terrestrial elements wanting, but while non-metallic ingredients occur in the largest quantities in terrestrial nature, they occur in aërolites in much smaller quantities than the metals. Their ingredients are earthly in their kind; but while many important terrene elements are absent, those that are present are not mingled in earthly proportions. Neither products of our volcanoes, whether active or extinct, nor the stratified or unstratified rocks, exhibit any example of chemical combination similar to that of the meteoric masses. Thus they differ immensely from things terrestrial, as to the number and relative proportion of their constituents. One non-metallic substance alone, oxygen, is computed to form a third of the weight of the crust of the earth; and oxygen appears feebly in these remarkable objects.

During the era that science has admitted the fall of bodies from celestial space scarcely a year has elapsed without a known instance of descent occurring. To Izarn's list, previously given, a great number of examples might be added, which have transpired during the last fifty years. A report relating, to one of the 
most recent, which fell in a valley near the Cape of Good Hope, with the aflidavits of the witnesses, was communicated to the Royal Society by Sir John Herschel in March 1840. Previously to the descent of the aërolite, the usual sound of explosion was heard, and some of the fragments falling upon grass caused it instantly to smoke, and were too hot to admit of being touclied. When, however, we consider the wide range of the ocean, and the vast unoccupied regions of the globe, its mountains, deserts, and forests, we can hardly fail to admit that the observed cases of descent must form but a small proportion of the actual number; and obviously in countries upon which the luman race are thickly planted many may escape notice through descending in the night, and will lie imbedded in the soil till some accidental circumstance exposes their existence. Some too are no doubt completely fused and dissipated in the atmosphere, while others move by us horizontally as brilliant lights, and pass into the depths of space. The volume of some of these passing bodies is very great. One which travelled within twenty-five miles of the surface, and cast down a firagment, was supposed to weigh upwards of half a million of tons. But for its great velocity, the whole mass would have been precipitated to the cartl. Two aërolites fell at Braunau in Bohemia, July 14, 1847.

In addition to aërolites, properly so called, or bodies known to have come to us from outlying space, large metallic masses exist in various parts of the world, lying in insulated situations, far remote from the abodes of civilisation, whose chemical composition is closely analogous to that of the substances the descent of which has been witnessed. These circumstances leave no doubt as to their common origin. Pallas discovered an immense mass of malleable iron, mixed with nickel, at a considerable elevation on a mountain of slate in Siberia, a site plainly irreconcileable with the supposition of art having been there with its forges, even had it possessed the character of the common iron. In one of the rooms of the British Museum there is a specimen of a large mass which was found, and still remains, on the plain of Otumba, in the district of Buenos Ayres. The specimen alone weighs 1400lbs., and the weight of the whole mass, which lies half buried in the ground, is computed to be thirteen tons. In the province of Bahia, in Brazil, another block has been discovered weighing upwards of six tons. Considering the situation of these masses, with the details of their chemical analysis, the presumption is clearly warranted that they owe their origin to the same causes that have formed and projected the aerrolites to the surface. With reference to the Siberian iron a general tradition prevails among the Tartars that it formerly descended from the heavens. A curious extract, translated from the Emperor Tchangire's memoirs of his own reign is given in a paper communicated to the Royal Society, which speaks of the fall of a metallic mass in India. The prince relates, that in the year 1620 (of our era) a violent explosion was heard at a village in the Punjaub, and at the same time a luminous body fell through the air on the earth. The officer of the district immediately repaired to the spot where it was said the body fell, and having found the place to be still hot, he caused it to be dug. He found that the heat kept increasing till they reached a lump of iron violently loot. This was afterwards sent to court, where the Emperor had it weighed in his presence, and ordered it to be forged into a sabre, a knife, and a dagger. After a trial the workmen reported that it was not malleable, but shivered under the hammer'; and it required to be mixed with one third part of common iron, after which the mass was found to make excellent blades. The royal historian adds, that on the incident of this iron of lightning being manufactured, a poet presented hin with a distich that, "during lis reign the earth attained order and regularity; that raw iron fell from lightning, which was, by his world-subduing authority, converted into a dagger, a knifé, and two sabres."

A multitude of theories have been devised to account for the origin of these remarkable 
bodies. The idea is completely inadmissible that they are concretions formed within the limits of the atmosphere. The ingredients that enter into their composition have never been discovered in it, and the air has been analysed at the sea level and on the tops of high mountains. Even supposing that to have been the case, the enormous volume of atmospheric air so charged required to furnish the particles of a mass of several tons, not to say many masses, is, alone, sufficient to refute the notion. They cannot, either, be projectiles from terrestrial volcanoes, because coincident volcanic activity has not been observed, and aërolites descend thousands of miles apart from the nearest volcano, and their substances are discordant with any known volcanic product. Laplace suggested their projection from lunar volcanoes. It has been calculated that a projectile leaving the lunar surface, where there is no atmospleeric resistance, with a velocity of 7771 feet in the first second, would be carried beyond the point where the forces of the earth and moon are equal, would be detached, therefore, from the satellite, and come so far within the sphere of the earth's attraction as necessarily to fall to it. But the enormous number of ignited bodies that have been visible, the shooting stars of all ages, and the periodical meteoric showers that have astonished the moderns, render this hypothesis untenable, for the moon, ere this, must have become sensibly impaired, while no trace of an active voleano has yet been discovered on her surface. Olbers was one of the first to prove the possibility of a projectile reaching us from the moon, but at the same time he deemed the event highly improbable, regarding the satellite as a very peaceable neighbour, not capable now of strong explosions from the want of water and an atmosphere. The theory of Chladni will account generally for all the phenomena, be attended with the fewest difficulties, and, with some modifications to meet circumstances not known in his day, it is now widely embraced. He conceived the system to include an immense number of small bodies, either the scattered fragments of a larger mass, or original accumulations of matter, which, circulating round the sun, encounter the earth in its orbit, and are drawn towards it by attraction, become ignited upon entering the atmosphere, in consequence of their velocity, and constitute the shooting stars, aërolites, and meteoric appearances that are observed. Sir Humphry Davy, in a paper wlich contains his researches on flame, strongly expresses an opinion that the meteorites are solid bodies moving in space, and that the heat produced by the compression of the most rarefied air from the velocity of their motion must be sufficient to ignite their mass so that they are fused on entering the atmosphere. It is estimated that a body moving through our atmosphere with the velocity of one mile in a second, would extricate heat equal to $30,000^{\circ}$ of Falırenheit-a heat more intense than that of the fiercest artificial furnace that ever glowed. The chief modification given to the Chladnian theory has arisen from the observed periodical occurrence of meteoric showers - a brilliant and astonishing exhibition - to some notices of which we proceed.

The writers of the middle ages report the occurrence of the stars falling from lieaven in resplendent showers among the physical appearances of their time. The experience of modern days establishes the substantial truth of such relations, however once rejected as the inventions of men delighting in the marvellous. Conde, in his history of the dominion of the Arabs, states, referring to the month of October in the year 902 of our era, that on the night of the death of King Ibrahim ben Ahmed, an infinite number of falling stars were seen to spread themselves like rain over the heavens from right to left, and this year was afterwards called the year of stars. In some Eastern annals of Cairo, it is related that "In this year (1029 of our era) in the month Redjeb (August) many stars passed, with a great noise, and brilliant light ;" and in another place the same document states:- "In the year 599, on Saturday night, in the last Moharrem (1202 of our era, and on the 19th of October), the stars appeared like wares upon the sky, towards the east and west; they 
flew about like grasshoppers, and were dispersed from left to right; this lasted till daybreak ; the people were alarmed." The researches of the Orientalist, M. Von Hammer, have brought these singular accounts to light. 'Theophanes, one of the Byzantine historians, records, that in November of the year 472 the sky appeared to be on fire over the city of Constantinople with the coruscations of flying meteors. The chronicles of the West agree with those of the East in reporting such phenomena. A remarkable display was observed on the 4th of April 1095 both in France and England. The stars seemed, says one, "falling like a shower of rain from heaven upon the earth;" and in another case, a bystander, having noted the spot where an aërolite fell, "cast water upon it, which was raised in steam, with a great noise of boiling." The chronicle of Rheims describes the appearance, as if all the stars in heaven were driven, like dust, before the wind. "By the reporte of the common people, in this kynge's time (William Rufus)," says Rastel, "divers great wonders were sene - and therefore the kyng was told by divers of his familiars, that God was not content with his lyvyng, but he was so wilful and proude of minde, that he regarded little their saying." There can be no hesitation now in giving credence to such narrations as these, since similar facts have passed under the notice of the present generation.

The first grand phenomenon of a meteoric shower which attracted attention in modern times was witnessed by the Moravian Missionaries at their settlements in Greenland. For several hours the hemisphere presented a magnificent and astonishing spectacle, that of fiery particles, thick as hail, crowding the concave of the sky, as though some magazine

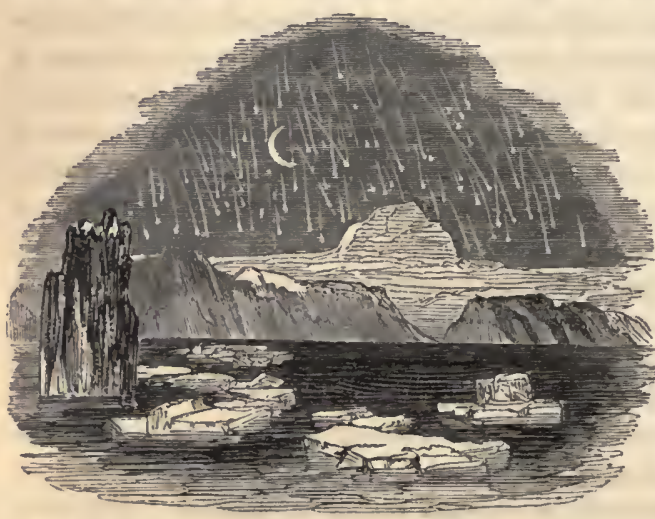
of combustion in celestial space was discharging its contents towards the earth. This was obscrved over a wide extent of territory. Humboldt, then travelling in South America, accompanied by M. Bonpland, thus speaks of it :"Towards the morning of the 13th November, 1799, we witnessed a most extraordinary scene of shooting meteor's. Thousands of bodies and falling stars succeeded each other during four hours. Their direction was very regular from north to south. From the beginning of the phenomenon there was not a space in the firmament equal in extent to three diameters of the moon which was not filled every instant with bodies or falling stars. All the meteors left luminous traces or phosphorescent bands behind them, which lasted seven or eight seconds." An agent of the United States, Mr. Ellicott, at that time at sea between Cape Florida and the West India Islands, was another spectator, and thus describes the scene:- "I was ealled up about three o'clock in the morning, to sce the shooting stars, as they are called. The phenomenon was grand and awful. The whole heavens appeared as if illuminated with sky-rockets, which disappeared only by the light of the sun after daybreak. The meteors, which at any one instant of time appeared as numerous as the stars, flew in all possible directions, except from the earth, towards which they all inclined more or less; and some of them descended perpendicularly over the vessel we were in, so that I was in constant expectation of their falling on us." The same individual states that his thermometer, which had been at $80^{\circ} \mathrm{Fahr}$. for four days preceding, fell to $56^{\circ}$, and, at the same time, the wind clianged from the south to the north-west, from whence it blew with great violence for three days without intermission. The Capuchin missionary at San Fernando, a 
village amid the savannahs of the province of Varinas; and the Franciscan monks stationed near the entrance of the Oronoco, also observed this shower of asteroids, which appears to have been visible, more or less, over an area of several thousand miles, from Greenland to the equator, and from the lonely deserts of South America to Weimar in Germany. About thirty years previous, at the city of Quito, a similar event occurred. So great a number of falling stars were seen in a part of the sky above the volcano of Cayambaro, that the mountain itself was thought at first to be on fire. The sight lasted more than an hour. The people assembled in the plain of Exida, where a magnificent view presented itself of the highest summits of the Cordilleras. A procession was already on the point of setting out from the convent of Saint Francis, when it was perceived that the blaze on the horizon was caused by fiery meteors, which ran along the sky in all directions, at the altitude of twelve or thirteen degrees. In Canada, in the years 1814 and 1819, the stellar sliowers were noticed, and in the autumn of 1818 on the North Sea, when, in the language of one of the observers, the surrounding atmosphere seemed enveloped in one expansive ocean of fire, exhibiting the appearance of another Moscow in flames. In the former cases, a residuum of dust was deposited upon the surface of the waters, on the roofs of buildings, and on other objects. The deposition of particles of matter of a ruddy colour has frequently followed the descent of aërolites; and may explain popular stories of the sky having rained blood. The next exhibition upon a great scale of the falling stars occurred on the 13th of November, 1831, and was scen off the coasts of Spain and in the Ohio country. This was followed by another in the ensuing year at exactly the same time. Captain Hammond, then in the Red Sea, off Mocha, in the ship Restitution, gives the following account of it:- " From one o'clock A.Mr. till after daylight, there was a very unusual phenomenon in the heavens. It appeared like meteors bursting in every direction. The sky at the time was clear, the stars and moon bright, with streaks of light and thin white clouds interspersed in the sky. On landing in the morning, I inquired of the Arabs if they had noticed the above. They said they liad been observing it most of the night. I asked them if ever the like had appeared before? The oldest of them replied that it had not." The shower was witnessed from the Red Sea westward to the Atlantic, and from Switzerland to the Mauritius.

We now come to by far the most splendid display on record; which, as it was the third in

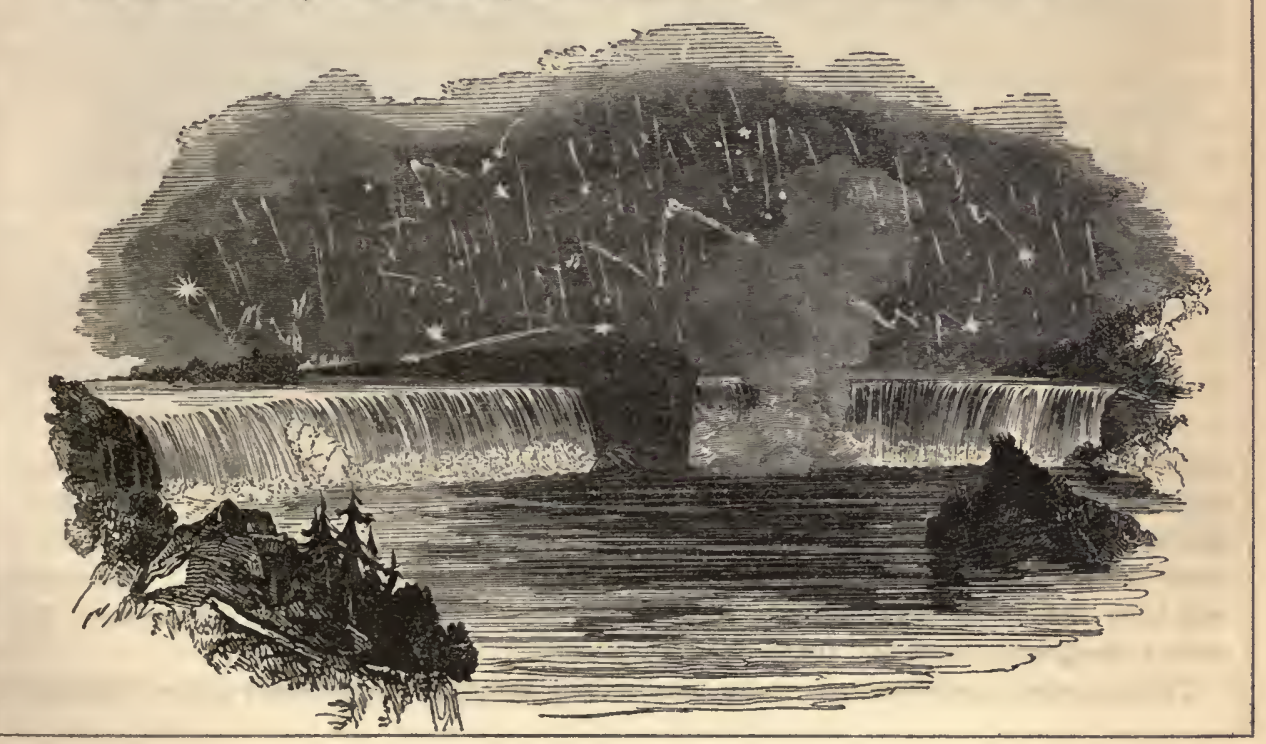


successive years, and on the same day of the month as the two preceding, seemed to invest the meteoric showers with a periodical character; and hence originated the title of the November meteors. The chief scene of the exhibition was included within the limits of the longitude of $61^{\circ}$ in the Atlantic Ocean, and that of $100^{\circ}$ in Central Mexico, and from the North American lakes to the West Indies. Over this wide area, an appearance presented itself, far surpassing in grandeur the most imposing artificial fire-works. An incessant play of dazzlingly brilliant luminosities was kept up in the heavens for several hours. Some of these were of considerable magnitude and peculiar form. One of large size remained for some time almost stationary in the zenith, over the Falls of Niagara, emitting streams of light. The wild dash of the waters, as contrasted with the fiery uproar above them, formed a scene of unequalled sublimity. In many distriets, the mass of the population were terror-struck, and the more enlightened were awed at contemplating so vivid a picture of the Apocalyptic image - that of the stars of heaven falling to the earth, even as a figtree casting her untimely figs, when sle is shaken of a mighty wind. A planter of South Carolina thus deseribes the effect of the scene upon the ignorant blacks :- "I was suddenly awakened by the most distressing cries that ever fell on my ears. Shrieks of horror and cries for mercy I could hear from most of the negroes of three plantations, amounting in all to about six or eight hundred. While earnestly listening for the cause, I heard a faint voice near the door calling my name. I arose, and taking my sworl, stood at the door. At this moment, I heard the same voice still beseeching me to rise, and saying ' $O$ my

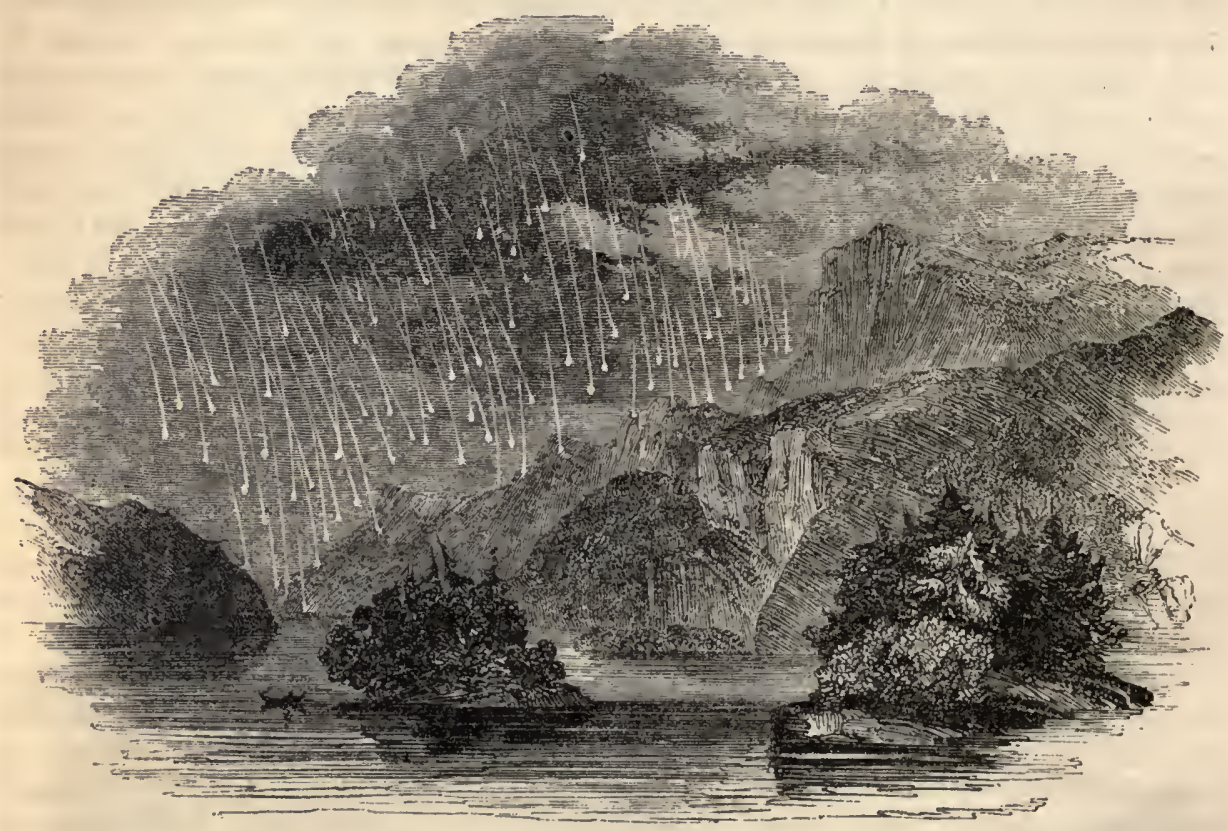

God, the world is on fire!' I then opened the door, and it is difficult to say which excited me most - the awfulness of the scene, or the distressed cries of the negroes. Upwards of one hundred lay prostrate on the ground - some speechless, and some with the bitterest cries, but with their hands raised, imploring God to save the world and them. The scene was truly awful; for never did rain fall much thicker than the meteors fell towards the earth ; east, west, north and south, it was the same."

This extraordinary spectacle commenced a little before midnight, and reached its heiglit 
between four and six o'clock in the morning. The night was remarkably fine. Not a cloud obscured the firmament. Upon attentive observation, the materials of the shower were found to exhibit three distinct varieties:-1. Phosphoric lines formed one class apparently described by a point. These were the most abundant. They passed along the sky with immense velocity, as numerous as the flakes of a sharp snow-storm. 2. Large fire-balls formed another constituency of the scenc. These darted forth at intervals along the arch of the sky, describing an arc of $30^{\circ}$ or $40^{\circ}$ in a few seconds. Luminous trains marked their path, which remained in view for a number of minutes, and in some cases for halt an hour or more. The trains were commonly white, but the various prismatic colours occasionally appeared, vividly and beautifully displayed. Some of these fire-balls, or shooting stars, were of enormous size. Dr. Smith of Nortl Carolina observed one which appeared larger than the full moon at the horizon. "I was startled," he remarks, "by the splendid light in which the surrounding scene was exhibited, rendering even small objects quite visible." The same, or a similar luminous body, secn at Newhaven, passed off in a north-west direction, and exploded near the star Capella. 3. Another class consisted of luminosities of irregular form, which remained nearly stationary for a considerable time, like the one that gleamed aloft over the Niagara Falls. The remarkable circumstance is testified by every witness, that all the luminous bodies, without a single exception, moved in lines, which converged in one and the same point of the heavens, a little to the southeast of the zenith. They none of them started from this point, but their direction, to whatever part of the horizon it might be, when traced backwards, led to a common focus. Conceive the centre of the diagram to be nearly overhead, and a proximate idea may be

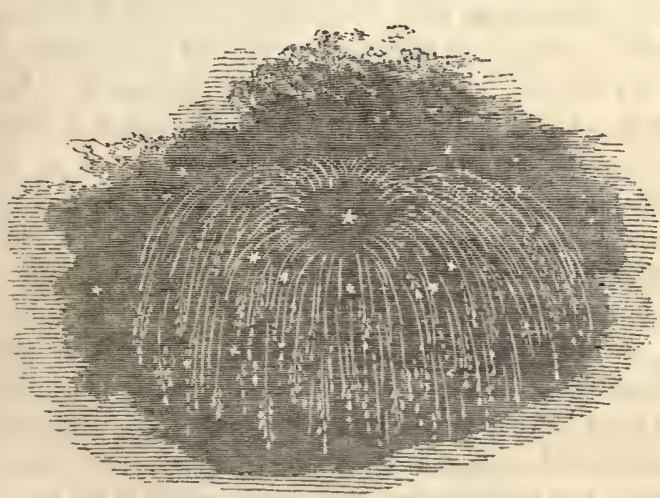
formed of the character of the scene, and the uniform radiation of the meteors from the same source. The position of this radiant point among the stars was near $\gamma$ Leonis. It remained stationary with respect to the stars during the whole of the exhibition. Instead of accompanying the earth in its diurnal motion eastward, it attended the stars in their apparent movement westward. The source of the meteoric shower was thus independent of the earth's rotation, and this shows its position to have been in the regions of space exterior to our atmosphere. According to the American Professor, Dr. Olmstead, it could not have been less than 2238 miles above the earth's surface.

The attention of astronomers in Europe, and all over the world, was, as may be imagined, strongly roused by intelligence of this celestial display on the western continent : and as the occurrence of a meteoric shower liad now been observed for three years successively, at a coincident era, it was inferred that a return of this fiery hail-storm might be expected in succeeding Novembers. Arrangements were therefore made to watch the heavens on the nights of the 12th and 13 th in the following years at the principal observatories; and though no such imposing spectacle as that of 1833 has been witnessed, yet extraordinary flights of shooting stars have been observed in various places at the periodic time, tending also from a fixed point in the constellation Leo. They were seen in Europe and America on November 13th, 1834. The following results of simultaneous observation were obtained by Arago from different parts of France on the nights of November 12th and 13th, 1836:- 


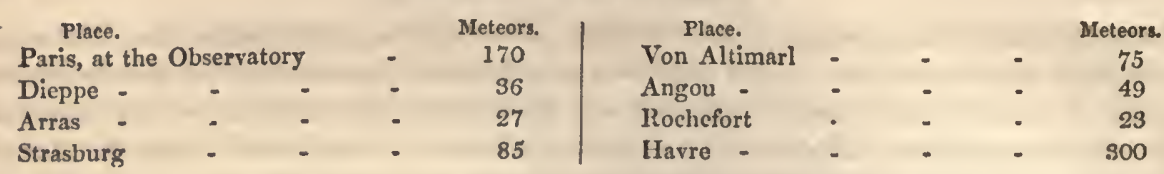

On November 12th, 1837, at eight o'clock in the evening, the attention of observers in various parts of Great Britain was directed to a brightluminous body, apparently proceeding from the north, which, after making a rapid descent, in the manner of a rocket, suddenly burst, and scattering its particles into various beautiful forms vanished in the atmosphere. This was succeeded by others all similar to the first, both in shape and the manner of its ultimate disappearance. The whole display terminated at ten o'clock, when dark clouds which continued up to a late hour, overspread the earth, preventing any further observation. In the November of 1838, at the same date, the falling stars were abundant at Vienna : and one of remarkable brilliancy and size, as large as the full moon in the zenith, was seen on the 13th by M.Verusmor off Cherburg, passing in the direction of Cape La Hogue, a long luminous train marking its course through the sky. The same year, the non-commissioned officers in the island of Ceylon were instructed to look out for the falling stars. Only a few appeared at the usual time ; but on the 5 th of December, from nine o'clock till midnight, the shower was incessant, and the number defied all attempts at counting them.

Professor Olmstead, an eminent man of science, himself an eye-witness of the great meteoric shower on the American continent, after carefully collecting and comparing facts, proposed the following theory:- The meteors of November 13th, 1833, emanated from a nebulous body which was then pursuing its way along with the earth around the sun; that this body continues to revolve around the sun in an elliptical orbit, but little inclined to the plane of the ecliptic, and having its aphelion near the orbit of the earth ; and finally, that the body has a period of nearly six months, and that its perihelion is a little within the orbit of Mercury. The diagram represents the ellipse supposed to be

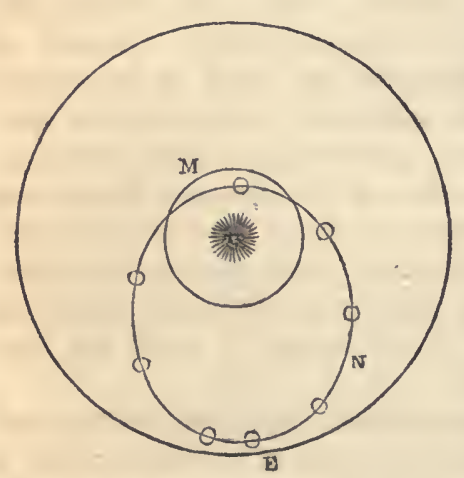
described, $\mathrm{E}$ being the orbit of the earth, ir that of mercury, and $\mathrm{N}$ that of the assumed nebula, its aphelion distance being about 95 millions of miles, and the perihelion 24 millions. Thus, when in aphelion, the body is close to the orbit of the earth, and this occurring periodically, when the earth is at the same time in that part of its orbit, nebulous particles are attracted towards it by its gravity, and then, entering the atmosphere, are consumed in it by their concurrent velocities, causing the appearance of a meteoric shower. Arago has suggested a similar theory, that of a stream or group of innumerable bodies, comparatively small, but of various dimensions, sweeping round the solar focus in an orbit which

periodically cuts that of the earth. More recently, a very complete catalogue of aerrolite falls, amounting to 175 , has been analysed with a curious result. By far the greater number are registered for the months of June and July, as compared with the opposite months, December and January. The earth is then at the greatest distance from the sun; and it appears probable, from Leverrier's investigations, that the mean mass or system of the planetoids is at the same time at its perihelion, and therefore nearest the carth. The conjecture is hence indulged, that aerrolites are minute outriders of that remarkable family. Though great obscurity rests upon the subject which may never be dissipated, it is agreed on all hands, that shooting stars, meteoric showers, and aërolites, are identical phenomena 
manifested in different ways ; that independently of the great planets and satellites of the system, there are vast numbers of bodies circling round the sun, both singly and in groups, some also moving as minute moons round the earth; and that in the course of their revolutions these "starlets," or "meteor-planets," as they have been called, come within the sphere of the earth's attraction, and ere precipitated upon its surface, "as weary and forlorn birds of passage, far out at sea, are entangled in the rigging of vessels, and fall helpless on deck."

\section{CHAPTER VII.}

\section{A GLANCE AT THE STARS.}

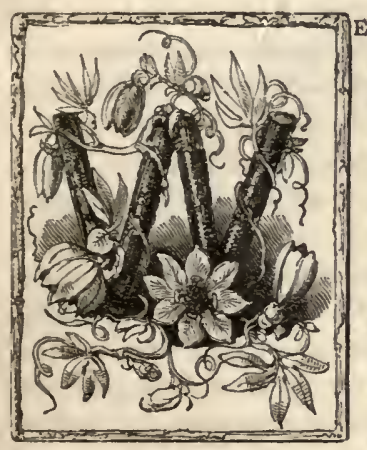

have been chiefly occupied hitherto with those celestial bodies, which from their conspicuous appearance or changes of position, and some of them from their obvious connexion with the convenience and existence of the human race, have in all ages been objects of special attention. Most of these bodies are situated within the limits of the zodiac, an imaginary zone or girdle extending round the hearens, of about sixteen degrees in breadth. It includes the sun and moon, and also all the planets, with the exception of the planetoids. But in the zodiac, and throughout the whole celestial concave, we see scattered every where a number of radiant points of varying brightness, which appear to have always the same position with regard to each other. This has originated the title of the fixed stars, by which they are popularly known. The term, in an absolute sense, is inaccurate; for recent observations have detected changes in the mutual relations of many of these bodies, and it is probable that all of them are subject to translation. Owing to their vast distance, their motions appear exceedingly slow to us, requiring the finest instruments to be perceptible; and hence they have a character of permanence in contrast with the planets, and the term "fixed" becomes comparatively applicable. The apparent immobility of these objects renders them of immense use in geography, navigation, and planetary astronomy; and hence the observation of the sidereal host, and the formation of accurate catalogues of its members, are among the most important of the labours of science. Sir J. Herschel, in magnificent langunge, before the Astronomical Society, thus referred to the catalogue of Piazzi, published in 1805, containing the places of no less than 7646 stars:- "For what has a Piazzi worn out his venerable age in watching? The answer is, not to settle mere speculative points in the doctrine of the universe; not to cater for the pride of man, by refined enquiries into the remoter mysteries of nature, - to trace the path of our system through infinite space, or its history through past and future eternities. These, indeed, are noble ends; the mind swells in their contemplation, and attains in their pursuit an expansion and hardihood which fit it for the boldest enterprise. But the direct practical utility of such labours is fully worthy of their speculative grandeur. The stars are the landmarks of the universe; and, amidst the endless and complicated fluctuations of our system, seem placed by its Creator as guides and records, not merely to elevate our minds by the contemplation of what is vast, but to teach us to direct our actions by reference to what is immutable, in His works. It is indeed hardly possible to over-appreciate their value in this point of view. Every well-determined star, from the 
moment its place is registered, becomes to the astronomer, the geographer, the navigator, the surveyor, a point of departure which can never deceive or fail him, the same for ever and in all places, of a delicacy so extreme as to be a test for every instrument yet invented by man, yet equally adapted for the most ordinary purposes; as available for regulating a town clock, as for conducting a navy to the Indies; as effective for mapping down the intricacies of a petty barony, as for adjusting the boundaries of trans-Atlantic empires. When once its place has been thoroughly ascertained and carefully recorded, the brazen circle, with which that useful work was done, may moulder, the marble pillar totter on its base, and the astronomer himself only survive in the gratitude of his posterity; but the record remains, and tranfuses all its own exactness into every determination which takes it for a groundwork, giving to inferior instruments, nay, even to temporary contrivances, and to the observations of $\mathrm{a}$ few weeks or days, all the precision attained originally at the cost of so much time, labour, and expense."

In the earliest times of which we have any account, mankind appear to have been acquainted with the use of the stars as celestial guideposts in their travels by land and royages on the deep. We may conclude their observance in the former circumstances to have had the precedence. Without being aware of some safe and sure method of directing their course by night, acquired in journeys on shore, men would hardly venture upon a night royage at sea. It is likely that in the great Oriental deserts, those immense plains with few natural landmarks, the useful discovery was made how accurately the traveller may direct lis footsteps by a cultivated acquaintance with the stars, which stimulated enterprize upon the patlless waters, and laid the foundations of maritime expeditions. Diodorus Siculus expressly states that travellers in the sandy deserts of Arabia were accustomed to direct their course by the Bears, the two constellations of that name, a fact which the Koran recognises in the passage: - "God has given you the stars to be guides in the dark both by land and sea." The honour of inventing nautical astronomy is usually assigned to the Phenicians, but some knowledge of it prevailed among the Greeks as carly as the time of the Trojan war. Ulysses is represented sailing on his raft, sitting at the helm, and watching the stars through the niglit. While, however, the Greck sailors chiefly confined their observations to Ursa Major, the Phenician navigators made a closer approximation to the north. Aratus tells us, referring to Ursa Minor:-

"Observing this, Phenicians plough the main."

The renowned pilot of the Trojan fleet, Palinurus, through intently watching the face of the nocturnal heavens at the helm, fell overboard, and for a time was lost to his companions. The Pleiades are supposed to derive their name from $\pi \lambda \varepsilon \varepsilon v$, to sail, because, during the winter months, they were of high importance to the benighted Greek mariner. It must appear marrcllons in the extreme to the uninformed, that now the skilful navigator, on a before unvisited ocean, can determine positively where he is, to within a few miles, by means of the stars; and ascertain his distance from, and true course to, any known meridian or harbour of the globe. From the deck of his ship he has merely to measure the moon's apparent distance from certain stars, to compare the result with their true places as given in the Nautical Almanack for every day in the year, and he finds his longitude. There are nine conspicuous stars which are chiefly used for this purpose, owing to their position being contiguous to the moon's path in the heavens; - a Arietis, Aldebaran, Pollux, Regulus, Spica Virginis, Antares, Altair, Fomalhaut, and Markab. The late Captain Basil Hall on one occasion was at sea for eighty-nine days, passing in the interval through a distance of eight thousand miles, without once making land or seeing a single sail on the voyage, but with unerring precision he came direct to his destination. His course lay from San Blas on the west coast of Mexico, through the Pacific Ocean, 


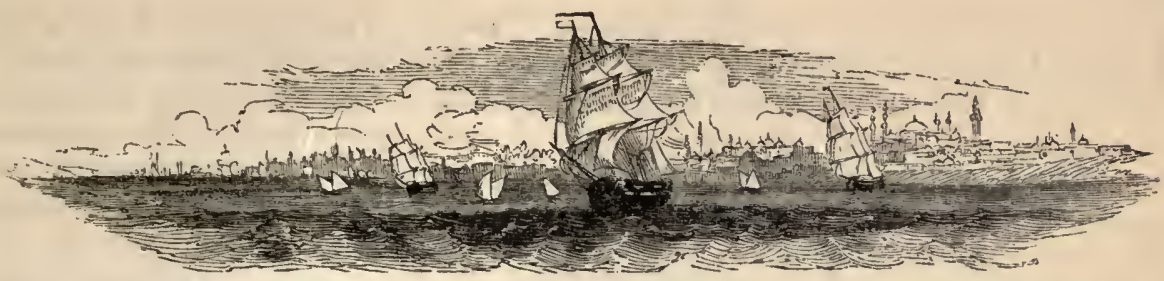

round Cape Horn, and across the South Atlantic to Rio Janeiro. Arrived within a few days' sail of Rio, he took a set of lunar observations, to ascertain his true position, and the bearing of the harbour, and shaped his course accordingly. Afterwards, as he remarks, "I hove to, at four in the morning, till the day should break, and then bore up; for, although it was hazy, we could see before us a couple of miles or so. About eight o'clock it became so foggy, that I did not like to stand in farther, and was just bringing the ship to the wind again, before sending the people to breakfast, when it suddenly cleared off; and I had the satisfaction of seeing the great Sugar-loaf rock, which stands on one side of the harbour's mouth, so nearly right ahead that we had not to alter our course above a point in order to hit the entrance of Rio. This was the first land we had seen for three months, afier crossing so many seas, and being set backwards and forwards by innumerable currents and foul winds." The crew might well cheer their skilful commander upon entering the port.

On a clear night in winter, when the moon is absent, the heavens exhibit an aspect of great briliiancy, attraetive to the eye of childhood and maturity. But to see the stars to advantage, in the utmost of that glory which they reveal to the gaze of man, we must cruise in tropical seas, or wander with the Bedouins in their deserts. There, through a more transparent medium, the lesser lights of heaven shine with a lustre and vivaeity of which we have no conception, who are only familiar with a denser atmosphere. Known to be at a distance from us, in comparison with which the interval between us and the farthest planet is but a hand-breadth, the stars far surpass that planet in their light, and henee it follows that they are not like him dependent upon the central luminary of our system, but self-luminous bodies, independent suns. This is rendered unquestionable by the fact, that while every reflected light is susceptible of polarisation, the light of the stars, like that of the sun, is ineapable of it. The tremulous emission of the stellar light, the scintillation or twinkling of the stars, is a remarkable feature, and was long a puzzle to philosophers. It is now generally supposed to arise from the molecules of the atmosphere constantly undergoing sudden compressions and dilatations, which produee changes in its refractive power, and consequent changes in the direction of the rays of light,

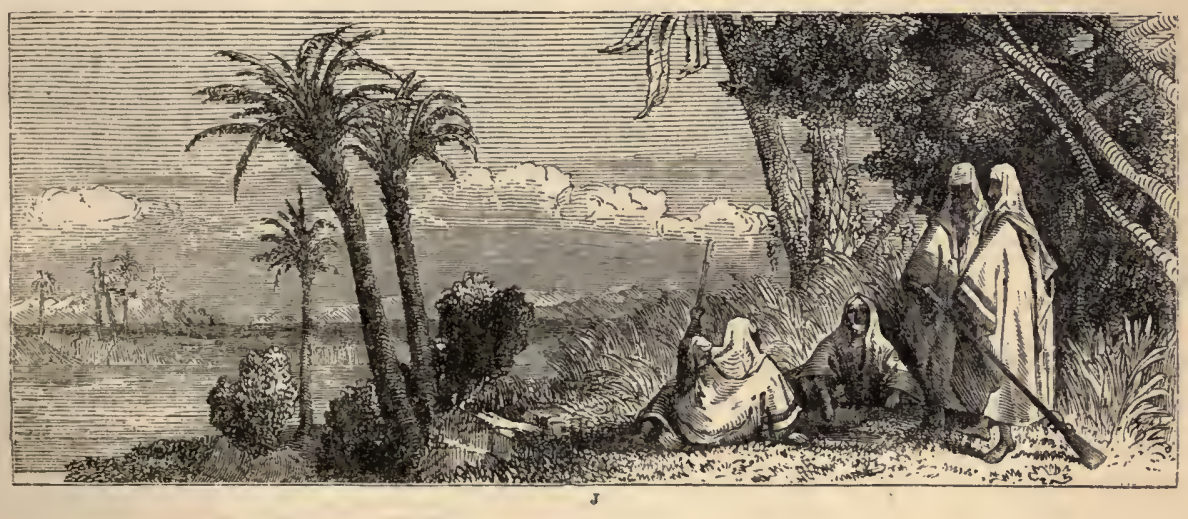


apparently every moment displacing the stars. The effect is not so sensible in the case of the planets because of their disks. These, though small, are of sufficient magnitude to bear without so much disturbance the minute agitations of the atmosphere, whereas the stars, being only brilliant points, without any perceptible diameter, are completely displaced. It has been observed, that in serene climates, and on the tops of high mountains, the twinkling of the stars is much less powerful than when viewed from other situations, which tends to confirm the preceding explanation as the true one.

On directing the eye to the celestial vault, the impression made upon the mind is that of an incalculable number of stars being visible - that of the army of hearen consisting of a host which our arithmetic will not suffice to reckon. It is well known that this is an optical illusion. Their twinkling and disorderly position in the sky confuse and deceive the sight. They are so scattered as not to be included at once in the field of vision. Hence arises the idea, that the visible number, which is really very limited, is, on the contrary, immense. This is the popular notion, and it is borne out by our first optical impressions. But an ordinary eye will not be able to discern much above a thousand in our firmament under the most favourable circumstances; and including both hemispheres, three thousand will be the outside number which a keen and experienced gaze will reach. The Greek and Arabian astronomers distinguished some of the brightest stars by particular names, which are recognised in our nomenclature of the heavens, as Sirius, Aldebaran, Rigel, Areturus, Capella, Canopus, and Fomalhaut, though a different mode of proceeding is now adopted, having become necessary by the large additions made to the ancient catalogues. To distinguish the stars in a constellation, the letters of the Greek alphabet are now employed; when these are exhausted, those of the Roman are used; and when these fail, numerals are resorted to. Thus a designates the most brilliant star of a group, $\beta$ the next most conspicuous, $\gamma$ the third, and $\delta$ the fourth. In this way, the relative brightness of the members of particular constellations is indicated, not that of the stars in general, for $\gamma$ Virginis is equal in brightness to $a$ Aquarii. This method was first introduced by John Bayer of Augsburg, in his "Uranometria," in 1603; who thus ranged the stars in the order of brilliancy, as they then appeared to the naked eye, and it has been adopted by most succeeding astronomers. Referring to the whole host of heaven, the stars are divided into classes, according to their apparent magnitudes, which range from those of the first magnitude, or the brightest, down to the sixteenth ; but all after the sixth are invisible to the naked eye, and are hence called telescopic objects. Of the stars in both hemispheres, within reach of a practised gazer, which in round numbers may be stated to be three thousand, the following are about the proportions belonging to the different classes:-

\begin{tabular}{|c|c|c|c|c|c|c|c|}
\hline First magnitude & - & - & 20 & Fourth & magnitude & - & 500 \\
\hline Second & - & - & 70 & Fifth & - $\quad-$ & - & 690 \\
\hline Third & - & - & 220 & Sixth & - & - & 1500 \\
\hline
\end{tabular}

From direct experiments with the photometer, an instrument for measuring the intensity of light, Sir W. Herschel inferred as follows :-

$\begin{array}{ll}\text { Light of a star of the average first magnitude } & =100 \\ \text { second } & =25 \\ \text { third } & =12 \\ \text { fourth } & =6 \\ \text { fifth } & =2 \\ \text { sixth } & =1 .\end{array}$

The intensity of the light, therefore, of a first class star, according to this estimate, is a hundred times greater than that of one belonging to the sixth. Sir John Herschel has arrived at a different conclusion, having found the light of Sirius, the brightest star in the heavens, about 324 times that of an average star of the sixth magnitude. 
The stars are further distinguished by being formed into artificial groups or constellations. This is a convenient arrangement in itself, analogous to the civil divisions of the globe, its empires, states and cities. But, unfortunately, celestial objects have not been grouped with judgment and care, having been the work, for the most part, of unknown authors in an age remote and rude. Hence we have constellations running into each other, men, animals, birds, and dragons, jumbled together in the most disorderly manner. Eudoxus of Cnidus, a contemporary of Plato, about 370 years before Christ, sent forth a description of the face of the heavens, containing the names and characters of all the constellations recognised in his time. Though this production has perished, yet a poetical paraphrase of it, written about a century later, is still extant, the work of Aratus, a Cilician, and probably a native of Tarsus. This astronomical poem opens with a statement of the dependence of all things upon Jupiter, whose children all men are, and who has given the stars as the guides of agriculture.

"With Jove we must begin; not from Him rove;

Him always praise, for all is full of Jove !

He fills all places where mankind resort,

The wide-spread sea, with ev'ry sbelt'ring port

Jove's presence fills all space, upholds this ball;

All need his aid, his power sustains us all.

For we his offspring are; and $\mathrm{He}$ in love

Points out to man his labour from above;

Where signs unerring show when best the soil

By well-tim'd culture shall repay our toil."

This passage has acquired great interest from the circumstance of the part in italics having been quoted by Paul in his address to the Athenians, himself a man of Tarsus. The poem of Aratus describes the configurations of all the constellations then in use, with their respective times of rising and setting, amounting to forty-five, all of which are represented on our present celestial globes. They are the twelve zodiacal, with twenty in the northern hemisphere, and thirteen in the southern. The next enumeration occurs in the "Almagest" of Ptolemy, which includes the preceding, with three additional, one northern and two southern constellations, making in all forty-eight. These are the ancient stellar groups. Large accessions have been made to the nomenclature in modern times, in consequence of maritime discovery having made us acquainted with regions of the heavens upon which the ancient eye never gazed. When the Europeans began to navigate the southern hemisphere and effected a passage round the Cape of Good Hope, many stars of course appeared which are never seen by the inhabitants of the north; and from these numerous additions have been made to the old constellations. Some stars also of the northern heavens not included in the ancient groups have been formed into new ones. In 1751 Lacaille went to the Cape for the purpose of making a catalogue of the southern stars, and forming them into constellations, an undertaking which he prosecuted with great ardour for nearly four years at the expense of the French government. Flattery has also contributed its mite towards the stellar nomenclature. Upon the restoration of Charles II., the evening before his return to London, Sir Charles Scarborough, the court physician, was gazing upon a star in the northern heavens, which shone with greater luminosity than usual, as might be expected from a loyal star on such an occasion. This, in connection with a few others, was formed into Cor Caroli, the heart of Charles II., by Halley, at the doctor's recommendation.

In the following list the constellations of both hemispheres at present recognised are given, with the number of stars in each, and the names of the constructors; but those of Aratus and Ptolemy merely denote the constellations that are found in their lists, and all that the former enumerates must be added to those recorded by the latter. 
SCENERY OF THE IIEAVENS.

ZODIACAL CONSTEILATIONS.

\begin{tabular}{|c|c|c|c|c|}
\hline Name of Consteilation. & Authot. & No. of Siars. & Principai Stars. & Magnitude. \\
\hline $\begin{array}{l}\text { Arles, the Ram } \\
\text { Taurus, the Bull, } \\
\text { Gemin, the Twins, } \\
\text { Cancer, the Crab, } \\
\text { Leo, the Lion, } \\
\text { Vlrgo, the Virgin, } \\
\text { Libra, the Balance, } \\
\text { Scorpio, the Scorpion, } \\
\text { Sagittarius, the Archer, } \\
\text { Capricornus, the Goat, } \\
\text { Aquarius, the Water-bearer, } \\
\text { Pisces, the Fishes, }\end{array}$ & $\begin{array}{r}\text { Aratus } \\
\text { ", } \\
\text { ", } \\
\text { ", } \\
\text { ", } \\
\text { ", }\end{array}$ & $\begin{array}{r}66 \\
141 \\
85 \\
83 \\
95 \\
110 \\
51 \\
44 \\
69 \\
51 \\
108 \\
113\end{array}$ & $\begin{array}{l}\text { a Arletis, } \\
\text { Aldebaran, } \\
\text { Castor, Pollux, } \\
\text { Acuhens, } \\
\text { Regulus, Denebola, } \\
\text { Spiea Virginis, } \\
\text { Zuhenich Miell, } \\
\text { Antares, } \\
\text { Scheat, }\end{array}$ & $\begin{array}{l}2 \\
1 \\
1 \cdot 2 \\
3 \\
1 \cdot 2 \\
1 \\
3 \\
1\end{array}$ \\
\hline
\end{tabular}

NOBTIERN CONSTELLATIONS.

Ursa Minor, the Iesser Bear,

Ursa Major, the Great Bear,

Perseus, and Head of Medusa,

Aurlga, the Waggoner,

Boötes, the Herdsman

Draco, the Dragon,

Cephes. Venaticl, the Greyhounds Asteria and Chara, Cor Caroli, Heart of Charles II.

Triangulum, the Triangle,

Trlangulum minus,

Musca, the Fly,

Lynx, Hinor, the Lesser Lion,

Coma Berenlces, Berenlce's Ilair.

Cameleopardalis, the Giraffe,

Cameleoparsus, Mount Menelaus,

Corona Borealls, the Nortbern Crown,

Serpens, the Serpent,

Scutum Sohieskl, Sobleski's Shield,

Scutum Sohiesk, Soblesi

Hercules with Cerberis,

Taurus Poniatorski, the bull of Poniatowski,

Lyra, the Harp.

Lyra, the Harp,
Vulpeculus et Anser, the Fox and Goose,

Vulpeculus et Anser,

Sagitta, the Arrow, with Antinous,

1) elphinus, the Dolphin,

Cygnus, the Swan,

Cyos,

Equulus, the Horse's Ilead,

Lquerta, the I, Azard

Pegasus, the Flying llorse,

Tarandus, the Reindeer,

\begin{tabular}{|l|}
\multicolumn{1}{|c|}{ " } \\
", \\
Hevclius \\
Halley \\
Aratus \\
Hevelius \\
Bode \\
Hevelius \\
Tycho" Brahe \\
Herelius \\
Aratus \\
Hevelius \\
Aratus \\
Poczobat \\
Aratus \\
Hevelius \\
Aratus \\
$\quad "$ \\
"" \\
"̈ \\
Ptolemy \\
Hevelius \\
Aratus \\
Lemounier \\
\end{tabular}

24
87
59
66
54
80
35
25
3
16
10
6
44
53
43
58
11
21
64
8
113
74
7
22
37
18
71
18
81
55
10
16
89
66
12

Dubhe, Alioth,

Algenlb, Algol,

Capella,

Arcturus,

Alderamin,

Ras Algratha,

Ras Aliagus

V'ega,

Altair,

Dencb,

Markab,

Almaric,

SOUTHERN CONSTELIATIONS.

The * indicates those constellations which never rise in North latitude $52^{\circ}$.

Phonlx*

Bayer

Eridanus Fluvins, the Rlver Po,

Hydrus *, the Water Snake,

Cetus, the Whale,
Fornax Chemica, the Chemical Furnace,

Horologlum * the Clock,

Rheticulus Rhomboldialus, * the Rhomboidal Net,

Xiphias Dorado*, the Sword Flsh,

Celapraxitellls, the Engraver's Tools,

Lepus, the Hare.

Columba Noachi, Noah's Dove.

Orlon,

Argo Navis, the Ship Argo,

Crno Major, the Great Dog,

Equuleus Pictorls, the Painter's Easel.

Ionoceros, the Unicorn,

Canis Minor, the little Dog,

Chamaleon *

Prxis Nautica, the Mariner's Compass,

Piscis Volans*, the Firing Fish,

Hydra, the Serpent,

Rextans, the Sextant,

Antlia Pneumatica, the Air Pump.

Crater, the Cup.

Crater, the Cup,
Corvus, the Crow,

Crux *, the Cross.

Apis Musca, the Bee, or Fly.

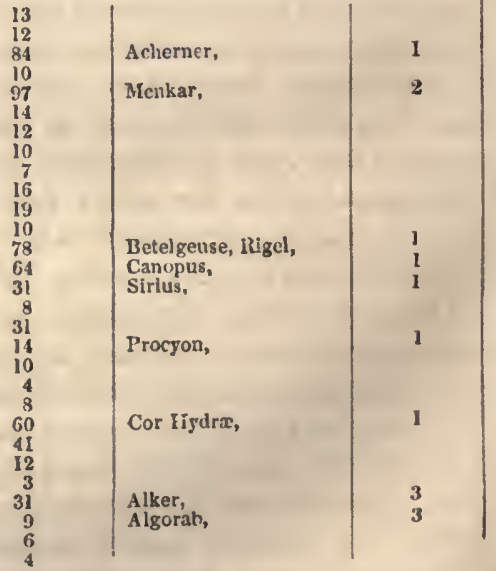




\begin{tabular}{|c|c|c|c|c|}
\hline Name of Constellation. & Author. & No. of Stars. & Principal Stars. & Magnitude. \\
\hline $\begin{array}{l}\text { Avis Indica*, the Bird of Paradise, } \\
\text { Circinus*, the Compass, } \\
\text { Centaurus, the Centaur, } \\
\text { lupus, the Wolf, } \\
\text { Norma, or Euclid's Square, } \\
\text { Triangulum Australis*, South Triangle, } \\
\text { Ara*, the Altar, } \\
\text { Telescopitum*, the Telescope, } \\
\text { Corona Australis, the Southern Crown, } \\
\text { Pavo*, the Peacock, } \\
\text { Indus *, the Indian, } \\
\text { Microscopium, the Microscope, } \\
\text { Octans Hadliensis*, Hadley's Octant, } \\
\text { Grus, the Crane, } \\
\text { Toucan, the American Goose, } \\
\text { Piscls Alistralls, the Southern Fish, } \\
\text { Mons Mensa*, the Table Mountain, }\end{array}$ & $\begin{array}{l}\text { Lacaille } \\
\text { Aratus } \\
\text { Lacaille } \\
\text { Bayer } \\
\text { Aratus } \\
\text { Lacaille } \\
\text { Ptolemy } \\
\text { Bayer } \\
\text { Lacaille } \\
\text { Bayer" } \\
\text { Aratı"s } \\
\text { Lacaille }\end{array}$ & $\begin{array}{r}11 \\
4 \\
35 \\
24 \\
12 \\
5 \\
9 \\
9 \\
12 \\
14 \\
12 \\
10 \\
43 \\
14 \\
9 \\
24 \\
30\end{array}$ & . & 1 \\
\hline
\end{tabular}

SUMMARY.

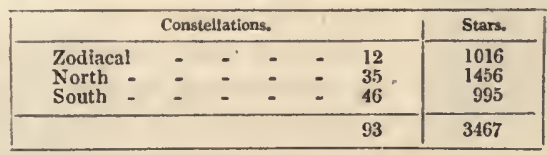

'The stars included in this list are not all visible to the naked eye. They are those whose declination and right ascension have been accurately ascertained, and inserted chiefly in Flamstead's cataloguc. Declination is the distance of any heavenly body either north or south of the equinoctial, measured on a meridian. Right ascension is its distance east from the first point of Aries, measured on the equinoctial. The former corresponds to terrestrial latitude, and the latter to terrestrial longitude; but while declination, like latitude, may extend to $90^{\circ}$, and no more, right ascension is reckoned only in one direction, and may therefore extend round the sphere, or to $360^{\circ}$, whereas terrestrial longitude, being reckoned east and west, can only extend to $180^{\circ}$.

Owing to the precession of the equinoxes, a change has occurred in the relation between the signs of the zodiae and their respective asterisms, which is somewhat puzzling to the general reader, who is apt to confound the sign with the constellation called after it. Two thousand ycars ago, in the days of Hipparchus, the zodiacal signs and asterisms corresponded, so that when the sun entered the first point of the sign Aries, he entered also the constellation of that name. Then the equinoctial colure, - an imaginary great circle

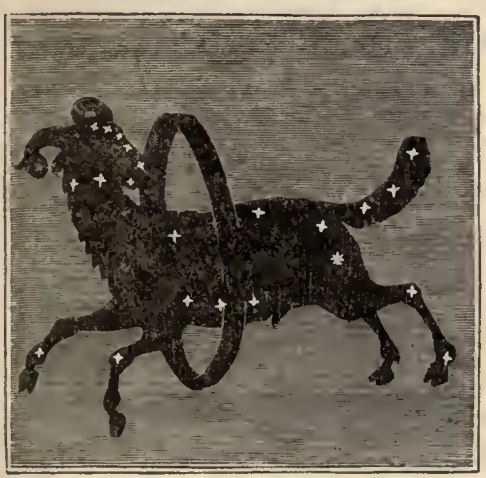
passing through the poles of the heavens and the sun's place at the vernal equinox, intersected the stellar ram, as some ancient representations testify. But as the equinoctial points retrograde about $50^{\prime \prime}$ annually, they have receded nearly $31^{\circ}$ since the time of Hipparchus, or more than a whole sign. The effect has been to separate the asterisms from their denominational signs, so that the constellation Pisces is now in the sign Aries, the constellation Aries in the sign Taurus, and the tropics of Cancer and Capricorn, according to the sun's place among the stars, have become the tropics of Gemini and Sagittarius. Four thousand years back, anterior to the time of the Hebrew patriarchs, the sun was in the asterism Taurus at the vernal equinox, and the Bull opened the astronomical year; and two thousand years hence, the asterism Aquarius will occupy the present position of Pisces, and lead on the celestial 
host for a similar period. All confusion will be avoided, by discriminating between the constellations and the signs of the zodiac, though bearing the same name, understanding by the former the asterisms, and by the latter certain sections of the ecliptic. In about twentythree thousand years, the zodiacal constellations and signs will again nominally agree.

The constellation ArIEs is situated in the heavens next east of Pisces, and midway between Triangulum and Musca on the north, and the head of Cetus on the south. It is readily distinguished by means of two bright stars in the head of the Ram, about $4^{\circ}$ apart, the

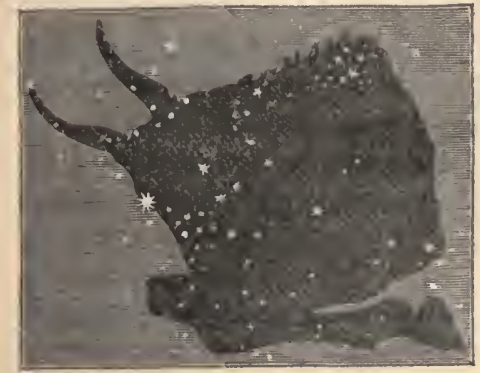
brightest being the most north-easterly of the two. This is the nautical star $a$ Arietis, called Hamal by the Arabs, of the second magnitude; the other, Sheratan, is of the third. Here is one instance out of many, where stars of more than ordinary brightness are seen together in pairs, the brightest being generally on the east.

TAUnes, one of the finest of the zodiacal asterisms, has Perseus and Auriga on the north, Gemini on the east, Orion and Eridanus on the south, and Aries on the west. It includes the two remarkable clusters, the Pleiades and IIyades, the former on the shoulder, and the latter in the face of the Bull, about $11^{\circ}$ apart. The Hyades consist of five stars, so placed as to form the letter V, the brilliant star, Aldebaran, of the first magnitude, being on the top of the letter to the left. This group is just rising in the east when Aries is about $27^{\circ}$ high.

The Pleiads have gone through some evil and good report. Figuring conspicuously in our winter sky, Statius calls them a snowy constellation; Valerius Flaccus speaks of their

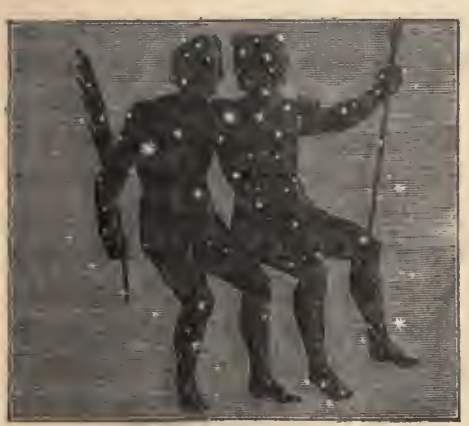

danger to ships; while Horace pictures the south-wind lashing the deep into storm in the presence of the stellar sisterhood. But as the Pleiades were more in juxtaposition with the sun at the vernal equinox in by-gone days than at present, the Romans sometimes called them Vergilix, or the "Virgins of the Spring."

GesnNI is situated with the Lynx on the north, Taurus on the west, Cancer on the east, Monoceros and Canis Minor on the south. It is easily known by the two principal stars, Castor and Pollux, the former of the first, and the latter of the second magnitude, about $4 \frac{1}{2}^{\circ}$ apart. The constellation was anciently represented by two kids, which the Greeks changed into the twin-brothers after whom the two stars are named, and which the Arabians altered into peacocks. A small

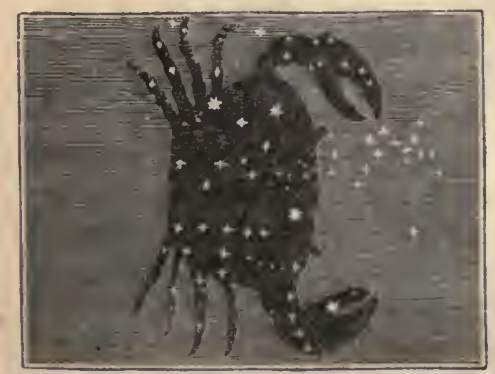
star of the fifth magnitude, Propus, is memorable on account of Herschel finding Uranus in its neighbourhood, and as having served for many years to guide astronomers to that planet.

CANCER is inferior to most of the other constellations along the solar highway, having no conspicuous stars. 'Two of the fourth magnitude the Romans called Aselli; and a nebulous cluster of very minute stars, sufficiently luminous however to be seen by the naked eye, exists at the distance of about $2^{\circ}$ from the Asses. This cluster goes by the name of Prosepe, or the Manger, out of accommodation to them. 


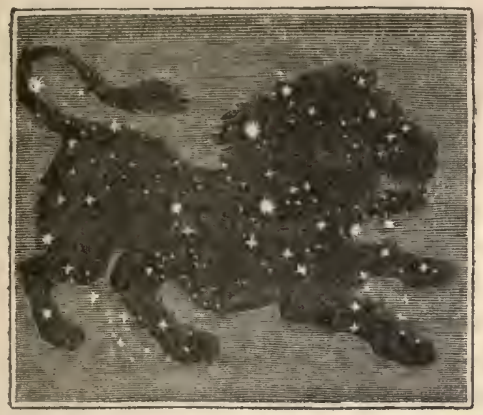

LEO, situated next east of Cancer, and directly south of Leo Minor and Ursa Major, makes a fine brilliant appearance in the sky, boasting

" Two splendid stars of highest dignity;"

with several that are conspicuous objects. Regulus, a star of the first magnitude, and Denebola, one of the second, are about $25^{\circ}$ apart, the former in the breast of the Lion, hence often called Cor Leonis, the other is situated in the tail.

VIRGo, represented as a woman holding an ear of corn, a mythological personage, has Leo on the east,

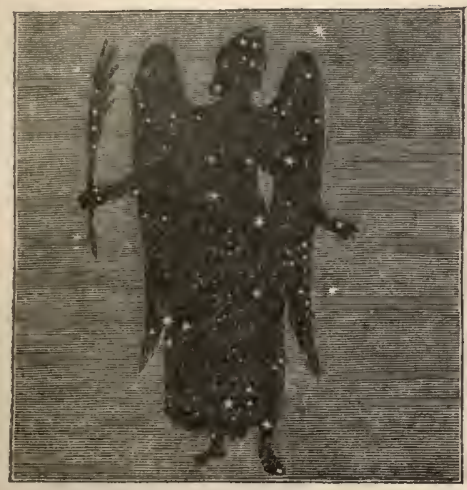
Coma Berenices on the north, and Corvus on the south. The asterism is rich in stars, the chief of which is Spica Virginis, a first-class star in the wheat-ear, known by its solitary splendour, there being no visible star near it but one of the fourth magnitude. For this reason, it was called by the Arabs As-Simàk-al-a'zal, the unarmed or defenceless Simàk. The place of this star, as determined by Hipparchus, compared with a similar determination a century and a half before, led to the discovery of the precession of the equinoxes.

LrBRA, the balance, the emblem of the office of Virgo as the goddess of justice, has four

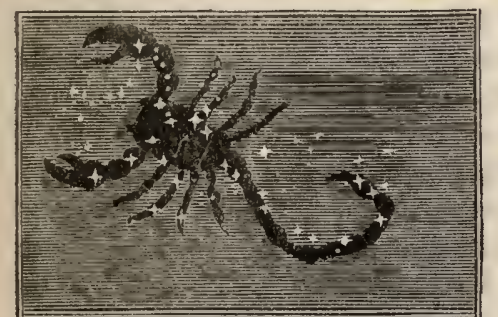
subordinate but still conspicuous stars. They form a quadrilateral figure, two on the northeast, about $7^{\circ}$ apart, and two on the south-west, about $6^{\circ}$ apart; distinguishing the Scales.

Scorpio exhibits a beautiful collection of stars. One of the first magnitude, the fiery Antares, is a paramount object in

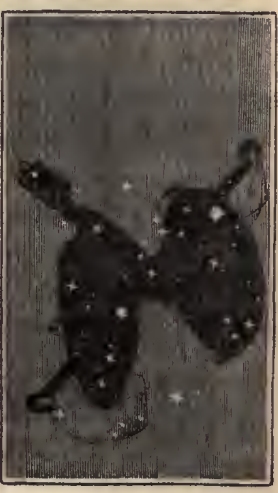

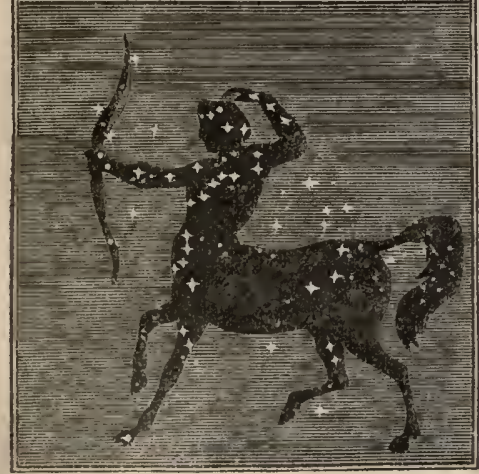
this region of the heavens. Four smaller stars form an arc over him not unlike a boy's kite, and ten more conspicuous extend from him in a crooked line, answering to a kite's tail.

SAgitTaRius has none but subordinate stars, but many of these are very distinct, and may be ranged into a variety of geometrical figures. Eight of the principal form two quadrangles, nearly alike, four in and four out of the Milky Way, by which the constellation is readily distinguished.

Capricornos, with Cancer, is one of the least striking of the zodiacal asterisms, but onc of the most celebrated among the ancients, as the sign under which Augustus and Vespasian were born, hence accounted the harbinger of good fortune, and as marking the southern 
tropic, or winter solstice, and therefore called the "Southern Gate of the Sun." Now,

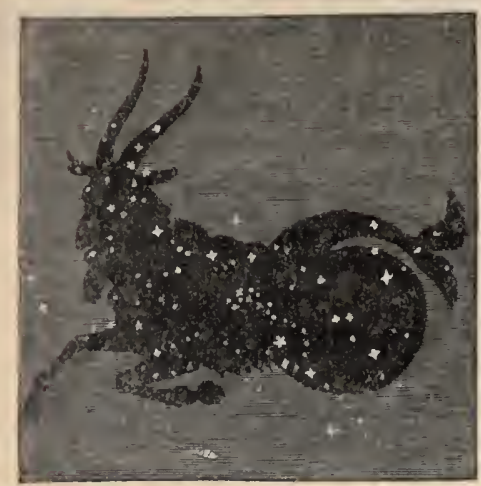
in consequence of the precession of the equinoctial and solsticial points, the sun is in the sign Capricorn at midwinter, but does not reach the constellation until the middle of January.

AQUARros is more easily recognisable by the eye, having four stars distinctly forming the letter $Y$ about the urn which the water-bearer is pictured emptying of its contents. 'The Arabs, not being allowed by their prophet to depict the human figure, represented this asterism by a mule carrying waterbarrels, and for the same reason they changed the twins Gemini into peacocks.

Pisces is a loose assemblage of small stars, diffcult to be traced, occupying a large triangular space

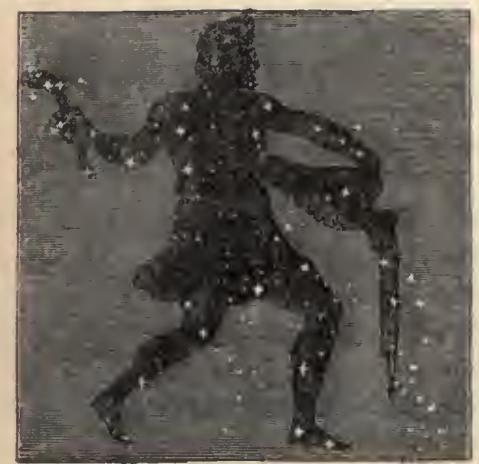
in the heavens. This is now the first constellation in order in the zodiac, that which presides over the vernal equinox, a position to be occupied for centuries to come, but ultimately resigned to Aquarius, after a tenure of office extending to somewhat more than two thousand years. It will be seen, that the most imposing of the zodiacal asterisms are those which the sun now traverses in our summer months. They are then lost to us by reason of his effulgence, but are splendid objects during the long nights of winter. The time, however, will arrive, when the sun's high road will lie through these asterisms in winter, and Taurus, Gemini, and Leo, will be lack-

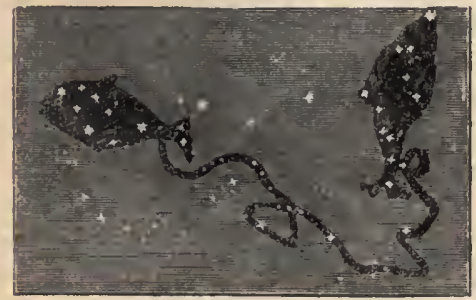
ing in our heavens during the wintcr nights, appearing in the nights of summer, but with less splendour, owing to the strength and duration of the twilight.

Directing attention to the constellated groups of the northern hemisphere, the most conspicuous and splendid is Ursa Major, supposed to have derived its name from its situation near the north pole, and from its constant visibility in our unclouded night sky, because the polar regions are the launts of the bear, an animal which neither makes extensive journeys nor rapid marches. It is singular that the Iroquois, a savage tribe in the back settlements of America, should have designated this region of the heavens by the name which the earliest Arabs of Asia applied to it, the Great Bear - two nations, fur remote from each other, employing a title which is purcly arbitrary, as the group of stars exhibits no resemblance to the animal. The asterism, however, figured as well to the ancient eye under the form of a waggon drawn by a team of horses, and the name of Charles's Wain is still its popular denomination in some of our rural districts, from the Karl-Wagen, or peasant's cart of our Gothic ancestors. Before the invention of timepieces, when the peasantry practised star-gazing to ascertain the time of the night, the position of this constellation was their common guide: hence the carrier's remark in Shakspeare, "An't be not four by the day, I'll be hanged, Charles's Wain is over the new chimney, and yet our horse not packed!" This is also the Helice of classical literature introduced in the celebrated deseription of the niglit in the "Argonauties:" - 


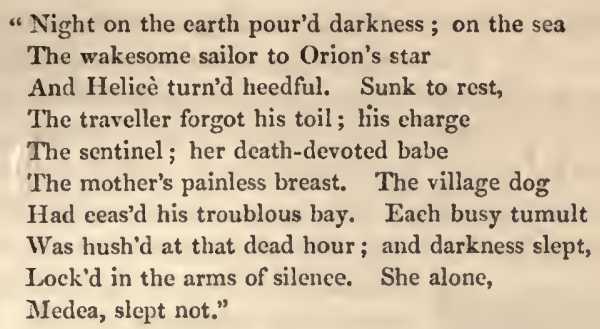

As Ursa Major is always above the horizon of Europe, it has been an objeet of universal observation to its inhabitants in all ages of the world, and is familiarly known to those who take no interest in astronomy by three stars which form a triangle in the tail, and four a quadrangle in the body of the Bear. Commencing with the former, the first star at the tip of the tail is Benetnasch of the second magnitude; the second Mizar, and the third Alioth; and passing to the latter the first star at the root of the tail is Megrez; the second below it, Phad; the third in a horizontal direetion, Merak ; and the fourth above the latter, Dubhe, of the first magnitude. By common consent, the two latter stars, Merak and Dubhe, are called the Pointers, because an imaginary line drawn from the lower to the

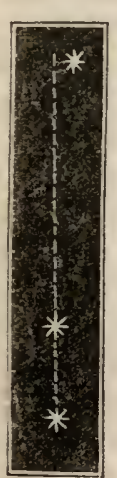
upper, and carried on in the same direction, passes almost over Polaris in Ursa Minor, a star close to the north polar point of the heavens, from which its name is derived. It may be useful here to state, for the purpose of measuring angular distances in the heavens with the eye, that the space between the Pointers may be approximatcly considered $5^{\circ}$, and between the Pointers and the pole-star, $29^{\circ}$. The direction merely of the polar star is exhibited in the diagram, and not the distanee. Ursa Minor has no conspicuous stars, nor any thing remarkable in its appearance; but from the important service rendered by its position to navigation and surveying, it has engrossed more of the serious attention of mankind than any other constellation in the skies. Polaris is a star between the second and third magnitude. It appears stationary during the apparent daily revolution of the sphere, the rest of the stars in the asterism making a complete swing round it every twenty-four hours, as in the diagram. The pole-star is not, however, the true polar point, but at present about $1^{\circ} 32^{\prime}$ from it, a distanee which will be lessened down to $26^{\prime} 30^{\prime \prime}$ about the year 2100. At the time when the Chaldean shepherds watched the heavens, a star in Draco, now $24^{\circ} 52^{\prime}$. from the polar point, was within $10^{\prime}$ of it, and was consequently the pole-star of that era. The proximity of Polaris to that point in the heavens which is directly opposite the north pole of the earth, enables the mariners

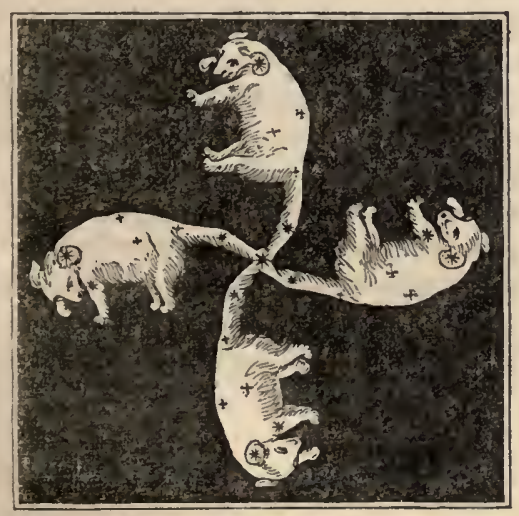
and travellers in the northern hemisphere with facility to find their latitude, for the distance of a place from the equator is always equal to the altitude of the pole. The navigator therefore applies his quadrant to the polar star, ascertains its elevation, and after making allowance for its polar aberration, he arrives at his latitude. The same advantage is not enjoyed on the other side of the equator, for the southern heavens have no guide so convenient to the south polar point. In close attendance upon the Bears, the ancients arranged the asterism Arctophylax, the Bear-keeper, otherwise called Bootes, the Herdsman, now represented holding in his left hand the leash of the two grey- 
hounds of Hevelius, apparently pursuing Ursa Major round the pole of the heavens. The fine star Arcturus, of the first magnitude, is in this constellation, once supposed to be the nearest to the earth of the stellar.host, but without authority.

Of the stars of the southern hemisphere, only a portion of course are visible to us, but these are by far the most important, and constitute the finest stellar objects upon which we gaze. There is the beautifully splendid Orion, visible to all the habitable world, because the equinoctial passes through the middle of the constellation, and when on the

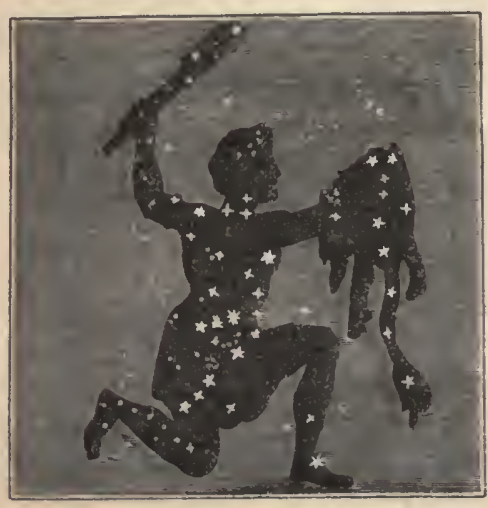
meridian with us, we have at the same time the most remarkable asterisms in the firmament above the horizon. The outline of Orion is very distinctly marked by four brilliant stars which form a long square or parallelogram. The most northerly is Betelguese of the first magnitude; $7 \frac{1}{2}^{\circ}$ westward is Bellatrix of the second; $15^{\circ}$ to the south is Rigel, a splendid star of the first magnitude; and $8_{\mathrm{g}}^{1^{\circ}}$ to the east is Saiph of the third. The two former form the upper ends of the parallelogram, and the two latter the lower. In the centre are three stars of the second magnitude, in a straight line of about $3^{\circ}$ in length, running from north-west to south-east. These form the well-known belt of Orion. The uppermost of the triad being less than $\frac{1}{2}^{\circ}$ south of the equinoctial, is almost exactly vertical to the equator. South of the Belt, a row of smaller stars running down obliquely towards Saiph forms the Sword. This fine asterism, in connection with the groups in its neighbourhood, constitutes the richest part of the visible heavens. But the ancients regarded Orion with fear and trembling, referring to him without ceremony those squalls upon the deep which were observed to be periodical at his rising at certain seasons of the year. Hesiod and Homer, therefore, call him fierce; Virgil connects him with storms and tempests; Horace points to his severity and turbulence; and Polybius divides the blame of losing the Roman fleet in the first Punic war between the malignity of the constellation and the fool-hardiness of the consuls. Fneas accounts in this way for the storm which east him on the coast of Africa when proceeding to Italy :-

\footnotetext{
"To that blest shore we steer'd our destin'd way, When sudden, dire Orion rous'd the sea :

All charg'd with tempests rose the baleful star,

And on our navy pour'd his wat'ry war.",
}

Orion has the bright clusters of Taurus giving splendour to his vicinity on the northwest; Canis Minor with Procyon, a star of the first magnitude, on the east; and Canis Major, a little on the south-east, universally known by the brilliancy of Sirius, the most refulgent and perhaps the nearest object to us in the sidereal heavens. The old Egyptians observed the heliacal rise of Sirius, or the appearance of the star in the morning above the horizon just before the sun, to occur at a period which immediately anteceded the annual overflow of the Nile, and supposing the two coincident events to be physically connected, the dog-star was adored as the author of the fertility of their country. To the Greeks, his heliacal rising taking place at the most sultry time of the year, when disease was rife, seemed to authorise a reference of all the plagues of the season to his influence. Hence the description of

$$
\begin{aligned}
& \text { Autumnal - of all stars, in dead of night } \\
& \text { Conspicuous most, and warn'd Orion's dog - }
\end{aligned}
$$


Brightest it shines, but ominous and dire

Disease portends to miserable man."

South-east of Canis Major is the asterism of the ship Argo, in which Canopus shines, the second of the stars in point of lustre, but invisible to all parts of the earth of higher latitude than the southern coast of the Mediterranean. An observer in the northern hemisphere can only see the stars as many degrees south of the equinoctial in the southern hemisphere as his own latitude lacks of $90^{\circ}$. All whose southern declination is greater never reach his horizon.

Among the stars of the south with which the stay-at-home Europeans are only acquainted by report, the constellation of the Cross is described as pre-eminent - the most interesting object in the sky of that hemisphere on account of the associations connected with it by a Christianised imagination. It consists of four bright stars, to which the fancy readily gives a cruciform shape, the upper and lower being the pointers to the

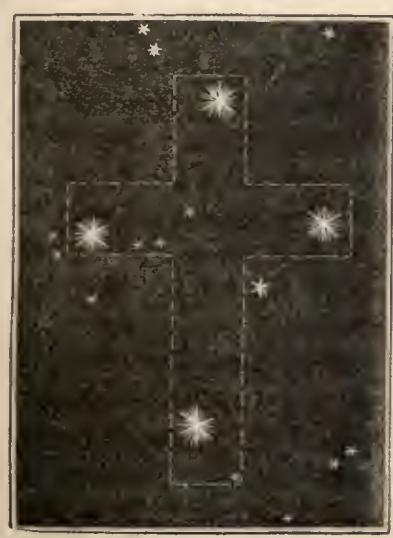
south pole. Von Spix and Martins, in their travels in Brazil, remark:- "On the 15 th of June, in lat. $14^{\circ} 6^{\prime} 45^{\prime \prime}$, we beheld for the first time that glorious constellation of the southern heavens, the Cross, which is to navigators a token of peace, and, according to its position, indicates the hours of the night. We had long wished for this constellation, as a guide to the other hemisphere; we therefore felt inexpressible pleasure when we perceived it in the resplendent firmament. We all contemplated it with feelings of profound devotion as a type of salvation; but the mind was especially elevated at the sight of it by the reflection, that even into the region which this beautiful constellation illumines, under the significant name of the Cross, the European has carried the noblest attributes of Christianity, and, impelled by the most exalted feelings, endeavours to spread them more and more extensively in the remotest regions." Humboldt also refers to his first view of this constellation with peculiar feeling: "We saw distinctly, for the first time," he observes, "the Cross of the South, on the night of the fourth and fifth of July, in the sixteenth degree of latitude; it was strongly inclined, and appeared from time to time between the clouds, the centre of which, furrowed by uncondensed lightnings, reflected a silver light. The pleasure felt on discovering the Southern Cross was warmly shared by such of the crew as had lived in the colonies. In the solitude of the seas we hail a star as a friend, from whom we have been long separated. Among the Portuguese and the Spaniards peculiar motives seem to increase this feeling; a religious sentiment attaches them to a constellation, the form of which recals the sign of the faith planted by their ancestors in the deserts of the New World. The two great stars which mark the summit and the foot of the Cross have nearly the same right ascension; it follows that the constellation is almost perpendicular at the moment when it passes the meridian. This circumstance is known to every nation that lives beyond the tropics or in the southern hemisphere. It is known at what hour of the night, in different seasons, the Southern Cross is erect, or inclined. It is a timepiece, that advances very regularly nearly four minutes a day; and no other group of stars exhibits to the naked eye an observation of time so easily made. How often have we heard our guides exclaim in the savannas of Venezuela, or in the deserts extending from Lima to Truxillo, 'Midnight is past, the Cross begins to bend!' How often these words reminded us of that affecting scene, where Paul and Virginia, seated near the source of the river of Lotaniers, conversed together for the last time; and when the old 
man, at the siglit of the Southern Cross, warns them that it is time to separate!" Mrs. Hemans has entered into the feeling here described, and sung of the Southern Cross in the spirit of a settler in the New World from old Spain :-

"But to thee, as thy lode-stars resplendently burn In their clear depths of blue, with devotion I turn, Bright Cross of the South! and beholding thee shine, Scarce regret the loved land of the olive and vine.

Thou recallest the age when first o'er the main My fathers unfolded the ensign of Spain, And planted their faith in the regions that sce Its unperishing symbol emblazon'd in thee.

Shine on - my own land in a far distant spot, And the stars of thy sphere can enlighten it not, And the eyes that I love, tho' e'en now they may be O'er the firmament wandering, can gaze not on thee !

But thou to my thoughts art a pure blazing shrine, A fount of bright hopes and of visions divine; And my soul, like an eagle exulting and free, Soars high o'er the Andes to mingle with thee!"

A powerful impression is made upon the mind by the changed aspect of the celestial vault upon a first voyage to the southern hemisphere. The thought of being far from home occurs with a power never known before. By degrees, many of the old stars, those which have been watched in the northern sky, in the days of childhood and youth, with such interest and delight, decline towards the horizon, sink below it, and are looked for in vain. Others customarily seen in the south approach the zenith, and pass to the north, while strangers rise above the southern horizon, ascending higher and higher, till a new heaven appears aloft, without any intimation that the old earth has passed away. Generally speaking, the southern celestial hemisphere is extremely dissimilar to the northern, not only in the grouping of the stars, but in its whole character. There are many large tracts or spaces of deep and solemn blackness-starless voids to the naked eye-which do not occur, or but rarely, in our own firmament. But these unlighted spaces give great effect by their darkness to the constellations; and render them in a high degree rich and magnificent. Fet notwithstanding these voids, as they appcar to the naked eye, the southern firmament, when telescopically examined, is thought to be rather richer in stars than the northern.

To examine those regions of the heavens which are hid by southern declination from the view of the stay-at-home Europeans, astronomers have frequently visited localities beyond the equator. They were first systematically and scientifically surveyed by Hallcy, who, though only in his nineteenth year, was expressly selected by the Royal Society for this mission. He sailed to St Helena, and spent two years, 1676-8, upon the island. Though its climate was found unfavourable for observation, he executed his work in a manner which procured him the name of the southern Tycho, in allusion to that astronomer's labours on an island of the Baltic. Lacrille next proceeded to the Cape of Good Hope, in 1751 , under the auspices of the French government, and resided there four years, during which he observed ten thousand stars, measured an arc of the meridian, and the length of the sccond's pendulum. In 1820 the British government established an observatory at the Cape, and appointed the Rev. F. Fallows its director, a post now honourably held by Mr 
Maclear. An observatory was also erected in 1821 at Paramatta, in New South Wales, by Sir T. Brisbane, the governor of the colony, who procured the Messrs Rumker and Dunlop to superintend it. Another was established by the government at St Helena in 1830, and placed under the care of a scientific officer who happened to be on duty in the island, Lieutenant Johuson, now director of the Radcliffe Observatory, Oxford. There is also one at Madras sustained by the East India Company. In 1835 Sir John Herschel repaired to the Cape, and executed an elaborate series of observations on the distribution of the stars of the southern firmament. Addressing an assembly held to commemorate his return from the successful enterprise in 1838 , he stated:- "I believe there is scarcely a corner in that part of the southern sky which I have not twice searched over, with almost the power of a microscopc; and it may easily bc supposed, in the course of a rummage of that kind, what an extraordinary turn-out there must have been, and what numerous objects worthy of attention must have shewn themselves; and often have I longed for some of those keen star-gazing eyes which I see now directed upon me. I need hardly say anything on the subject of the southern constellations. They are extremely superb things."

To know the heavens at night so as to recognise the principal constellations and stars visible in our hemisphere-the first step of the tyro-seems at first a difficult undertaking. But a little practice, with the aid of good celestial charts, will soon make him feel at home in a cruise along the firmament. After becoming acquainted with the more remarkable groups, and their chief constituents, these will serve as an index to those that are less conspicuous. The maps accompanying this work, with the directions connected with them, will supply every requisite help for the purpose.

The best time for a survey of the hearens is during the long nights of winter in the absenee of the moon; but in seeking to find his way among the stars by the aid of a celestial chart or globe, the student must bear in mind, that while their relative positions and distances are given, the constellations are continually varying their direction by reason of the apparent revolution of the sphere, after the manner of Ursa Minor swinging round Polaris, as represented in a previous diagram. By alignment, or drawing imaginary lines from star to star, forming a variety of geometrical figures, a general knowledge of them may be speedily acquired. Having become acquainted with the seren stars which compose the triangle and square of Ursa Major, his circumpolar neighbours are readily found by this method. Thus, while a straight line through the side of the square formed by the Pointers leads to Polaris, another through the top of the square inverse to the triangle leads to Capella, and from the first star of the triangle nearest the square a line carried through Polaris conducts to the bright cluster of Cassiopeia. From Capella a direct line through Polaris passes to the two stars Alwaid and Etamin in the head of Draco. Through the side of the square opposite the Pointers a line continued soutliward conducts to Regulus, east of which is Denebola, the two principal stars in Leo. Denebola forms an extensive square, with Cor Caroli occupying the northern point, Arcturus the eastern, and Spica Virginis the southern, in the interior of which is a cluster of small stars, the Coma Berenices of Tycho Brahe. The line joining Arcturus and Spica Virginis is also the base of a conspieuous triangle, of which Antares in Scorpio is the vertex to the east; and a large right-angled triangle is very nearly formed by Arcturus, Polaris, and Vega. Another remarkable figure, called the great square of Pegasus, is composed by the four leading stars in that constellation. Every one is familiar with the belt of Orion. A straight line drawn through it northerly leads to Aldebaran, and southerly to Sirius. The star north-east of the belt, Betelguese, forms a triangle, with Pollux at the northern, and Procyon at the eastern point. By the practice of alignment, guided by a good map, the leading objects of the firmament will soon be recognised, 
nor is any costly observatory necessary in order to cultivate a more intimate acquaintance. Ferguson sought fellowship with the stars lying on his back in the fields when a shepherd boy, and measured their relative distances by means of beads upon a thread. Harding discovered one of the planetoids from the house-top. Upon the bridge of Prague, which now spans the Moldau with its sixteen arches, Keppler was accustomed to watch the stars; and Lalande, in his old age, often took his station upon the Pont Neuf, for the same purpose, ready to accommodate a passing Parisian with a peep at Algol.

\section{CHAPTER VIII.}

NUMBER, DISTANCE, AND MLAGNITUDE OF STARS.

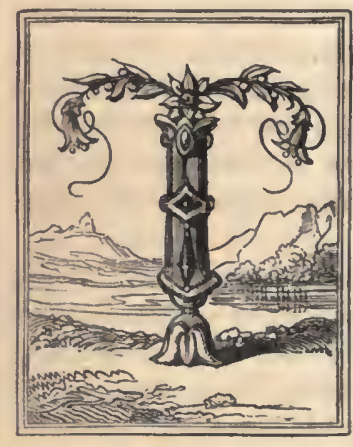

HE prevailing ideas of men concerning the multitude of the stars, though founded upon wrong premises, are yet in harmony with the literal fact, for the conclusion drawn from the hasty observation of the eye, which a persevering survey would at once disprove, is itself established by telescopic examination. So enormous is the number of the stars, yet so completely incalculable are they, as to admit of their being joined with the sand upon the sea-shore, as a figure of speech denoting a numeration which we cannot define. The common phrase of the Sacred Volume, the hosts of heaven, alludes to their multitude; and the fact is advanced as an illustration of the infinite grasp of the Creator's mind, that he is acquainted minutely with these multitudinous worlds, which immeasurably exceed our utmost estimates. "He calleth them all by names by the greatness of his might, for that he is strong in power; not one faileth." The earliest catalogue of the stars, that of Ptolemy, enumerates only 1022: that of Ulugh Beigh, the grandson of Tamerlane, made at Samarcand, contains 1017: but a comparison of the ancient with modern catalogues exhibits a striking difference in the assigned richness of the asterisms, of which a few samples may be advanced.

\begin{tabular}{|c|c|c|c|c|c|}
\hline & Ptolemy. & Tycho Brahe. & Hevelius. & Flamstead. & Bode. \\
\hline Aries - & - 18 stars. & 21 stars. & & & \\
\hline Ursa Major & $-\quad 35$ & 56 & 73 & & 398 \\
\hline Boötes & -28 & 28 & 52 & 54 & 319 \\
\hline Leo - & -35 & 40 & 50 & 95 & 537 \\
\hline Virgo & -32 & 39 & 50 & 110 & 411 \\
\hline Taurus & -44 & 49 & 51 & 141 & 394 \\
\hline Orion & $-\quad 38$ & 62 & 62 & 78 & 304 \\
\hline
\end{tabular}

Upwards of two thousand stars have however been counted within the trapezium or unequal square of Orion, and the telescope multiplies them in the hearens without end, revealing points of light profusely distributed throughout all space, every point a sun attended probably by a train of planets, a reasonable inference from the constitution of the solar universe. Lalande in the last century registered the positions of fifty thousand, the various astronomers of Europe upwards of a hundred thousand, and Struve alone has since observed no less than a hundred and twenty thousand stars. But this is only a feeble approximation to the whole amount within telescopic range, which a moderate com- 
putation gives at 100,000,000, a number from which, if our globe and system were stricken they would no more be missed than a unit taken from

$$
\text { In Vallambrosa." }
$$

There are several parts of the firmament in which stars appear to the naked eye closely packed together, and others which present a general indivisible luminosity to the unassisted vision. The chief of these are the Pleiades, Hyades, the Milky Way, and Presepe. The latter is a region faintly gleaming in the sombre districts of Cancer, which may be easily found by running a line through Castor and Pollux and continuing it to the southeast about three times the distance between those stars. The ancients were acquainted with Presepe, a speck of light which they supposed to be the general effect of three stars, as it is not resolvable into component parts by the unaided gaze; but Galileo with his imperfect means discovered it to be a congress of thirty-six. The Hyades appear to consist of five stars, but between thirty and forty are readily discernible under a moderate instrumental power. The Pleiades also yield a similar result, their optical number, six or seren, being largely multiplied by the application of a telescope. The constituents of the group are thus stated in modern catalogues :-

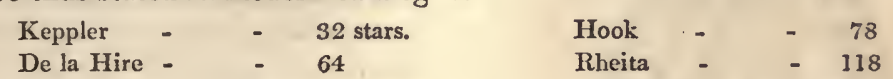

But the cluster easily resolves into about forty constituents. Of the Milky Way the Roman poet wrote, as the path leading to great Jupiter's abode, whose "groundwork is of stars." Milton, likewise, speaks of that "broad and ample road, whose dust is gold, and pavement stars." These poetical conceptions become verities when an instrument sufficiently powerful is directed to the zone in question. It is found to be composed of stars which assume the appearance of a tortuous consecutive girdle of light, owing to their grouping and distance. Some idea may be formed of their profuseness from the fact that Herschel was led to the conclusion, when examining this wonderful region, that in some parts of it no less than fifty thousand were included within a zone two degrees in breadth, which passed under his review in a single hour's observation. Yet this is but a specimen of countless combinations which are discoverable in the concavity of the heavens, so remote from us as to escape the observation of the eye, yet recognised by its aided vision, forming clusters of various shapes, as rich in stars as the zone which we can analyse proves to be.

That luminous celestial highway which the Greeks called the Galaxy, and the Romans the Via Lactea, from its whiteness, is more or less visible at all seasons of the year; but in northern latitudes it is seen to the best advantage in the interval between the close of July and the beginning of November. It varies in breadth from four to eighteen degrees, and also in brightness, being most resplendent in the southern hemisphere, about the constellations Argo Navis, Robur Carolinum, and the Cross. "The general aspect," says Sir John Herschel, "of the southern circumpolar region, including in that expression $60^{\circ}$ or $70^{\circ}$, is in a high degree rich and magnificent, owing to the superior brilliancy and larger development of the Milky Way; which from the constellation of Orion to that of Antinous, is in a blaze of light, strangely interrupted, however, with vacant and almost starless patches, especially in Scorpio near $a$ Centauri and the Cross; while to the north it fades away pale and dim, and is in comparison hardly traceable." This vast zone is a sensible annulus in the heavens, though this may be an optical illusion. It passes from the head of Cepheus about $30^{\circ}$ from the North Pole, through Cassiopeia, nearly covering Perseus, over part of Auriga, and crossing the ecliptic between the feet of Gemini and the horns of Taurus, proceeds over the equinoctial into the southern hemisphere to within $20^{\circ}$ 
of the South Pole. It then takes a northerly direction, and divides into two branches before again passing the ecliptic into the northern hemisphere. The eastern branch streams over the bow of Sagittarius, through Aquila and part of Cygnus. The western branch passes over the tail of Scorpio, the right side of Ophiucus to Cygnus. The two branches unite in that constellation, and pass to Cepheus, the point from whence we started, where the stream has its greatest breadth for a considerable space.

By some of the pagan philosophers the Via Lactea was regarded as an old disused path of the sun, of which he had got tired, or from which he had been driven, and had left some faint impression of his glorious presence upon it. Its stellar composition was, however, suspected long before it was proved, but its multitudinous host of stars remained a secret till Herschel turned his mighty instrument at Slongh upon the silvery belt. In a

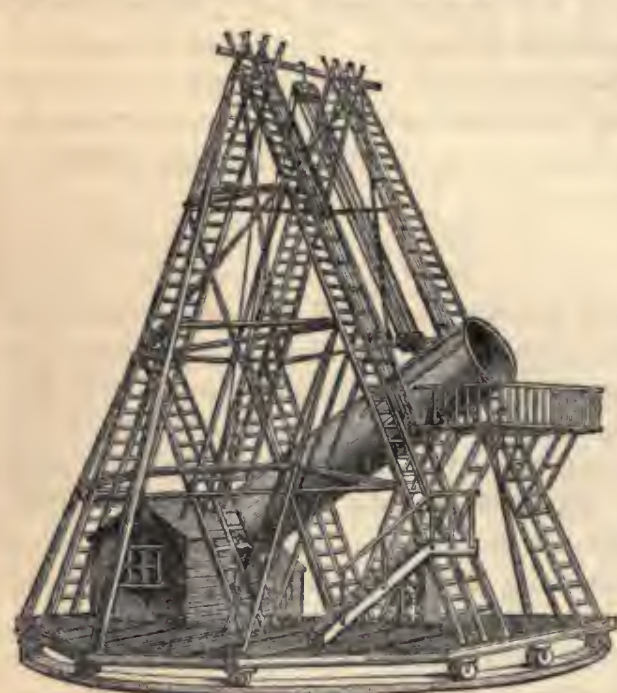
single spot he counted between five and six hundred without moving his telescope; and in a space of the zone not more extensive than $10^{\circ}$ long by $2 \frac{1}{2}^{\circ}$ wide, he computed that there were no fewer than 258,000 . "What Omnipotence!" was the involuntary exclamation of Schroeter of Lilienthal, upon examining a part of the same magnifieent girdle. Though the whole number of stars which the naked eye discerns on an ordinary night is small, yet, leaving the common haunts of men, and gazing upon the celestial vault at a high elevation in the atmosphere, largely improves the appearance of old familiar stellar faces, and many are caught sight of which were before wholly invisible. Visiting the peaks of lofty mountains, the unaided eye of the adventurer who is there at night forms fresh acquaintances among the stars, and its friends of long standing glitter with a brilliance which the denser regions of the atmosphere render obscure to the dwellers below. The son of Marshal Ney remarks, in a personal narrative of the ascent of one of the Pyrenean summits:- "How glorious were the heavens on that night! Ye who have never bivouacked on the Cardal know not what a fine night is." Brydone observes of the top of Mount Etna:- "We had now time to pay our adorations in a silent contemplation of the sublime objects of nature. The sky was clear, and the immense vault of the heavens appeared in awful majesty and splendour. We found ourselves more struck with veneration than below, and at first we were at a loss to know the cause, till we observed, with astonishment, that the number of stars seemed to be infinitely increased, and the light of each of them appeared brighter than usual. The whiteness of the Milky Way was like a pure flame that shot across the heavens, and with the naked eye we could observe clusters of stars that were invisible in the regions below. We did not at first attend to the cause, nor recollect that we had now passed through ten or twelve thousand feet of gross vapour, that blunts and confuses every ray before it reaches the surface of the earth. We were amazed at the distinctness of vision, and exclaimed together, 'What a glorious situation for an observatory! Had Empedocles possessed the eyes of Galileo, what discoveries must he not lave made!' We regretted that Jupiter was not visible, as I am persuaded we might have discovered some of his satellites with the naked eye, or at 
least with a small glass which I had in my pocket." "Surely," he adds in another passage, "the situation alone is enough to inspire philosophy."

To measure the distance of the stars, is a task which has baffled the ablest men, armed with the best instruments for the purpose, and using them with the utmost nicety and perseverance. Until our own day, the conclusion arrived at had only been negative. It could merely be demonstrated, that the nearest of these bodies must at the least be removed from us a certain space, the extent of which requires the billions of our arithmetic to express. It is clearly ascertainable, that the enormous interval intervening between us and that remote wanderer in our system, Neptune, is but a narrow chasm compared with the interval between him and the most contiguous of the stellar orbs. On observing the same star, lying in the plane of the earth's orbit, from the two extremities of the orbit, at the end of six months, no perceptible alteration in the apparent size of the star can be discerned, notwithstanding this vast change of situation. The inference therefore is, that the diameter of the earth's orbit, the immense line of 190 millions of miles, bears no sensible proportion to the real distance of the stars. But another method adopted to measure the great gulf, and most laboriously pursued for more than two centuries, has been the detection, if possible, of an annual parallax of the stars, or apparent change of place caused by being viewed from opposite extremities of the earth's orbit. All the planets, even the remotest, appear in very different places when viewed at the vernal and autumnal equinoxes, or at any two extreme points of our globe's path; and if the angle subtended be given, the distance may be calculated. But no parallax of a star amounting even to a single second has been detected, and Bradley makes the observation, which Sir John Herschel confirms, that if such an amount of parallax existed, it could not possibly have escaped notice. Supposing, however, a parallax of one second perceptible, that, by the rules of trigonometry, would give a distance from us of more than 19 billions of miles; but as there is no such quantity detectable, there is no star lying within that range-they all lie beyond it !

Parallax is the apparent change of place which an object undergoes through an observer shifting his own position. The traveller in journeying marks a great change in the same scenery, in the disposition of its various features, by the alteration of his own point of view. He observes the trees, fields, and hedgerows, which appeared in a direct line between him and some distant hill, at one station, making an angle with the eninence as seen from another station. Suppose we stand at $a$, and have two trees before us in

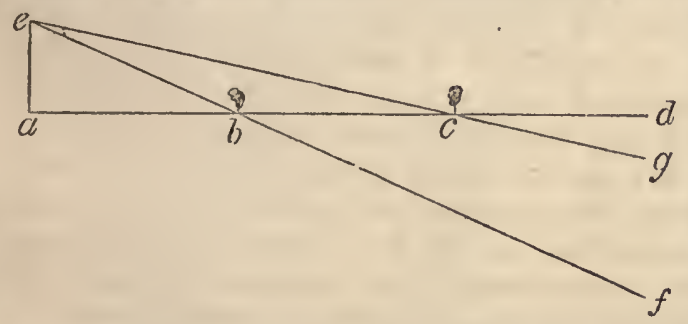
the direct line $a b c$, both will be projected to the same point $d$, but if we shift our position to $e$, then the nearest tree will be seen in the direction $f$, and the fartlest in the direction $g$. By measuring the base line $a e$, and the angles $a b e$, and a c e, or the parallax, the mathematician readily arrives at the distance of the trees from the points of observation. Now, with reference to estimating the distances of the stars, we have the diameter of the earth's orbit as a capital base line to work upon, a real change of place occurring annually on our part in relation to them amounting to 190 millions of miles. Yet, notwithstanding this vast alteration of position, no angle of the value of a second has been found with certainty in the case of any star.

The diagram now subjoined, exhibits the earth at two extreme points of its orbit. Let the reader keep in mind the 190 millions of miles between those points, and 
then he may form some idea of the awful gulf between us and the stars, from the

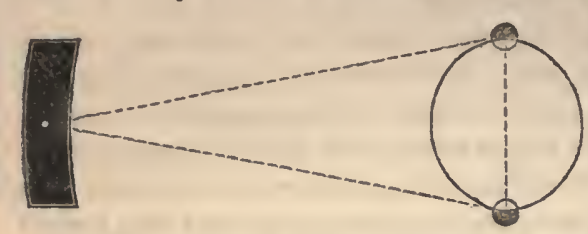
fact tlat the triangle formed by lines drawn from the extremes of the orbit to a star at the vertex, has defied the most perfect instruments of human invention to measure, so inappreciable is it. Supposing the whole of that orbit filled with a globe resplendent as the sun, it would have a circumference of 600 millions of miles, and yet have only the appearance of a twinkling atom as seen from the nearest of the stars.

Previous to the determinations of Newton, the discovery of an annual parallax of the stars was a point of great interest in order to confirm the Copernican doctrine of the earth's motion in space. It was remarked by opponents, that if we are really sweeping at a prodigious rate in an enormous ellipse around the sun, then ought the stars to appear continually displaced, just as do the trees of the forest to the traveller flying swiftly past them, instead of which, seen from any point, and at any time, their position is ever the same-fixed, immutable, eternal. Hence the stars were confidently appealed to as bright and unimpeachable witnesses of the falsity and extravagance of the Copernican system. This reasoning was well founded. Only one reply could be made to it, that such was the enormous distance of the sphere of the fixed stars, that no perceptible change was occasioned by the revolution of the earth in its orbit. More than three centuries have rolled away since the controversy commenced. Though long since terminated by the truth of the grand theory of Copernicus being triumphantly estabilished, yet astronomers have prosecuted with zeal the search after an annual parallax of the stars, in order to illustrate the scale upon which the universe is built; but no success attended the effort until our time. Bradley failed to detect the slightest indication of it in the instance of $\gamma$ Draconis, elaborately watched; but was unexpectedly led by the attempt to his great discovery of the aberration of light. Herschel, too, was equally unsuccessfnl in the pursuit of the same object, yet similarly fortunate, as his labours on the occasion were rewarded with the disclosure, that the double stars are not examples of accidental optical proximity, as before supposed, but bodies physically connected, magnificent systems of revolving suns.

The problem of stellar remoteness has been solved in the present age, in the first instance by the late Professor Bessel, of Konigsberg, and has been justly styled a magnificent conquest. The world is indebted for it to one of the refracting telescopes of the celebrated Frauenhofer, of Munich, an instrument of extraordinary power, specially adapted to the research for the parallax of the fixed stars. To give some idea of the delicacy of the contrivances with which these great telescopes are provided, Mr Mitchel, of the Cincinnati Observatory, states, that the micrometer of his refractor is capable of dividing an inch into 80,000 equal parts! When mechanical ingenuity friled to construct lines of mathematical minuteness, the spider lent his aid, and it is with his delicate web that these measures are accomplished. Two parallel spiders' webs are adjusted in the focus of the eye-piece of the micrometer, and when the light of a small lamp is thrown upon them, the eye, on looking through the telescope, sees two minute golden wires, straight and beautiful, drawn across the centre of the ficld of view, and pictured on the heavens. The observer has them completely under his control, and can so revolve them as to bring them into any position, increasing or decreasing their distance at pleasure. With machinery even more delicate than this, better adapted to the purpose, and of a somewhat different kind, Bessel renewed the search after the unattained parallax of the stars. His instrument, called the heliometer, was mounted in the year 1829, but various causes delayed his principal operations up to the month of October 1837. 
The astronomer selected the star 61 Cygni as the one on which to perform his operations. Several reasons influenced Bessel in the selection of this object. First, it is so near the pole, that, with the exception of a small part of the year, it can always be observed at night at a sufficient distance from the horizon. Second, it is a conspicuous binary star, specially adapted by its double character to the instrument employed. Both the constituents are yellow, but one smaller than the other has the deepest tint. Third, the region occupied by 61 Cygni contains a number of minute stellar points close to it, presenting admirable fixed points for measurement. Fourth, the star has long been known to be distinguished by the great rapidity of its proper motion. In watching this star, Bessel commonly took observations sixteen times every night whenever opportunity offered. Without detailing the course he pursued, which would be uninteresting and unintelligible to most readers, it will be sufficient to state, that after a most careful investigation, a variation in the apparent place of the star began to show itself, increasing preciselv' as parallactic variation ought to increase, and diminishing as it ought to diminish. The period of these changes was precisely a year; and in all particulars they corresponded exactly to the changes which ought to be produced by parallax. Still, on account of their minute character, the observer hesitated to place dependence upon them. But during another year of observation, the same results came out, and the previous values were confirmed. This was the case also during a third year; and all doubt being now removed, Bessel announced to the world that he had compassed the hitherto impassable gulf of space, and measured the distance to one of the fixed stars. The final conclusion deduced, confirmed by the subsequent researches of M. Peters at the Observatory of Pulkowa, assigns to 61 Cygni an annual parallax of $0^{\prime \prime} \cdot 349$, rather more than one-third of a second of space. This corresponds to the enormous distance of nearly 600,000 radii of the earth's orbit, or as many times $95,000,000$ miles. The distance of the star may therefore be set down in round numbers at sixty billions of miles.

The mighty gulf which separates us from the stars having been once passed, the route bas been followed; and succeeding observers have determined the parallax of a sufficient number of stars to show that their results are entirely trustworthy. That of $a$ Centauri, a double star of the first magnitude, and one of the brightest sidereal objects in the southern hemisphere, was next ascertained. This was effected by Professor Henderson, during his residence as astronomer at the Observatory of the Cape of Good Hope. This star exhibits the greatest amount of parallax hitherto observed; and is consequently the nearest of any yet examined. General dependence may be placed on the results given in the table :

\begin{tabular}{|c|c|c|c|c|}
\hline Stars. & Parallax. & $\begin{array}{l}\text { Distance in Radii } \\
\text { of the Earth's } \\
\text { Orbit. }\end{array}$ & $\begin{array}{l}\text { Distance in } \\
\text { Billions of } \\
\text { Miles. }\end{array}$ & Observers. \\
\hline 1. $a$ Centauri, & $0^{\prime \prime} \cdot 913$ & 225,920 & 21 & Henderson. \\
\hline 2. 61 Cygni, & $0 \cdot 348$ & 592,715 & 56 & Bessel. \\
\hline 3. a Lyræ, & $0 \cdot 261$ & 790,287 & 75 & Struve. \\
\hline 4. Sirius, & $0 \cdot 230$ & 896,804 & 84 & Henderson. \\
\hline 5. 1830. Groombridge, & $0 \cdot 226$ & 912,677 & 86 & Peters. \\
\hline 6. ŁUrsæ, . & $0 \cdot 133$ & $1,550,864$ & 147 & Peters. \\
\hline 7. Arcturus, & $0 \cdot 127$ & $1,624,134$ & 154 & Peters. \\
\hline
\end{tabular}

To aid the imagination in forming some idea of these distances, it may be stated, that the conflagration of these stars would not be announced to us under periods varying from upwards of three years to more than a quarter of a century, for a ray of light, which darts to us from the sun in eight minutes, would require that time to travel through the space between us and them. One delicate thread of a spider's web, placed before the 
eye of a spectator at $61 \mathrm{Cygni}$, would hide from his view the whole orbit of the earth; and a single hair would conceal the entire solar unirerse! The remark of Huygens is a sober speculation, that there may be worlds in the immensity of space, which have been long created, whose light, owing to their distance, has not yet reached our globe, though still destined to come within range of the eye.

\author{
"How distant some of the nocturnal suns! \\ So distant, says the sage, 'twere not absurd \\ To doubt, if beams, set out at Nature's birth, \\ Are yet arriv'd at this so foreign world; \\ Though nothing half so rapid as their flight."
}

However marvellous the statement, it is strictly true, that when we gaze upon the hearens, observe the stars, and note down their positions, we are witnessing and clironicling their appearances in by-gone time, and not the present aspect of the phenomena. The ray that meets the eye from the nearest sidereal object brings intelligence of its past estate; and that Past includes years in relation to the front ranks of the stellar army, and ages with respect to the general body. When we reflect upon these facts, and remember that the faint nebulous clusters are far more remote from the distinct stars than they from us - that the light which manifests their presence now may lave left its source when the Tudor, Norman, or Saxon race occupied the throne-we catch a glimpse of the inmensity of space, and of the infinity of that Being who originated the great government of which it is the scene, and conducts it with such nicety that a sparrow falleth not to the ground without Him.

We have nothing to guide us respecting the magnitude of the stars beyond their visibility, when so vastly remote. The planet Saturn is magnified by the telescope larger than the moon to the naked eye, though 900 millions of miles distant; but instrumental power fails in giving any appreciable magnitude to the stars. It brings countless multitudes into view lid from the unassisted sight; it makes us sensible of their presence; it increases their brilliancy: but beyond this, it supplies us witl no information respecting their volume and mass. Halley remarked, that "the diameters of Spica Virginis and Aldebaran are so small, that when they happen to immerge behind the dark edge of the moon, they are so far from losing their light gradually, as they must do if they were of any sensible magnitude, that they vanish at once with all their lustre, and emerge likewise in a moment, not small at first, but at once appear with their full light, even although the emersion happen when very near the cusp, where, if they were four seconds in diameter, they would be many seconds of time in getting entirely separated from the limb. But the contrary appears to all those who have observed the occultations of those bright stars." The largest and most brilliant of the stars, if occulted at the dark limb of the moon, Sir John Herschel observes, "is, as it were, extinguished in mid-air, without notice or visible cause for its disappearance, which, as it happens instantaneously, and without the slightest previous diminution of its light, is always surprising; and if the star be a large and bright one, even startling from its suddenness." The simple fact of the visibility of the stars across the mighty expanse which we know to exist between them and ourselves, necessarily gives us high jdeas of their dimensions. Calculations have been made, from a comparison of the light of the stars with that of the sun, but the result can only be regarded as a rude approximation. Let us consider the case of Sirius, the brightest in the heavens. The light of Sirius, as determined by Sir John Herschel, is 324 times that of an average star of the sixth magnitude. The ratio of his light to that of the sun has been calctulated to be, using round numbers, as 1 to $5,000,000,000$, that is, the illumination supplied by the star is that number of times less than the illumination afforded by the sun. But we have seen, that while the sun is ninety-five millions of miles from us, 
the star is 896,804 times the same distance; and it is a well-known law, that the light which the eye receives from a luminous object will diminish in the same proportion as the square of the distance increases. Now supposing the sun and the star to have equally brilliant surfaces, and the former to be removed to the same distance as the latter, it is computed that the stellar lustre would exceed that of the solar in the proportion of 146 to 1. The conclusion is thus arrived at, that the surface of Sirius is 146 times greater than the surface of the sun.

Now we cannot suppose the magnificent orb of Sirius to dwell alone. As our smaller sun has planets with their satellites circulating round him, rejoicing in his light, it is reasonable to infer that a much larger globe serves a similar purpose, and is the common centre of a more numerous family, refreshed and beautified by the glorious beams that emanate from it. The inference holds good with reference to every star, for that all the stars are suns admits not of a moment's doubt, and we are justified in attributing to each its dependent Jupiters and Saturns. Thus we gain some insight into the economy of the universe, and gather rational ideas of its immeasurable amplitude - its multitude of worlds-its couptless myriads of sentient beings. Sir John Herschel soberly answers the enquiry: "For what purpose are we to suppose such magnificent bodies scattered through the abyss of space? Surely not to illuminate our nights, which an additional moon of the thousandth part of the size of our own would do much better-not to sparkle as a pageant void of meaning and reality, and bewilder us among vain conjectures. Useful, it is true they are to man, as points of exact and permanent reference; but he must have studied astronomy to little purpose, who can suppose man to be the only object of his Creator's care, or who does not sec, in the vast and wonderful apparatus around us, provision for other races of animated beingș. The planets derive their light from the sun; but that cannot be the case with the stars. These doubtless, then, are themselves suns, and may perhaps, each in its sphere, be the presiding centre round which other planets, or bodies of which we can form no conception from any analogy offered by our own system, may be circulating."

These views are reasonable, elevating, and useful. It is well to become familiar with them. Though of the extent and arrangements of that wondrous fabric of which our system forms one of the minuter parts, it may be said, that such knowledge is too wonderful for us, yet some measure of intelligence is placed within our reach, and we may grasp it with high adrantage. He who has read but a few pages of the magnificent book of the universe, and has enstamped upon his mind a lively impression of the greatness of that scheme of existence with which he is connected, is in circumstances to steer clear of the two extremes into which unreflecting humanity is often betrayed, those of arrogant self-importance and puling imbecility. Man - the lord of a few acres - while absorbed with his terrestrial patrimony, is prone to forget the higher duties of life, and to rest content with taking part in the pageant of an hour, stepping across his fields in the pride of a self-satisfaction at being the proprietor of the scene. Or in other situations - in contact with the grander class of terrestrial phenomena - the thunder reverberating among the mountains, the lightning playing around their peaks, and the tempest-clouds discharging their torrents he is apt to feel and to display an abject spirit appropriate to the grovelling worm. But he who possesses a cultivated acquaintance with his true position in the scheme of the creation - that glorious whole of which the world is but an infinitesimal part, yet man a member of the intellectual part - will have views, which, legitimately used, will be a safeguard against self-idolatry and abasement. 


\title{
CHAPTER IX.
}

\author{
NEW, VARIABLE, AND COMTOUND STAIS.
}

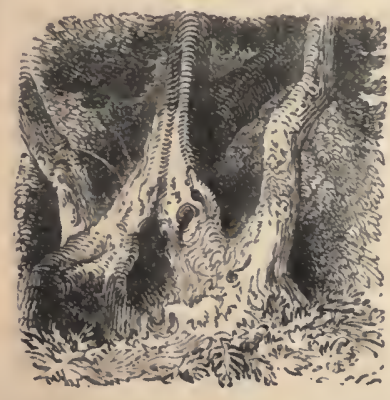

HEN we compare the present appearance of the sidereal heavens with the records of former catalogues, some stars are not to be found now whose places have been registered. There are four in Hercules, four in Cancer, one in Perseus, one in Pisces, one in Hydra, one in Orion, and two in Berenice's Hair, which liave apparently disappeared from the sky. Of the eight stars formerly mentioned which were marked in the catalogue of Ptolemy, but had been lost in the time of Ulugh Beigh, there were six near the Southern Fish, which have not been observed since; and, as four of these were of the third magnitude, Bailly conclúdes that they were really visible in the heavens in the age of Ptolemy, and disappeared in the interval between lim and the Tartar prince. It is no doubt probable that apparent losses liave often arisen from mistaken entries; yet, in many instances it is certain that there is no mistake in the observation or entry, and that stars have really been observed, and as really have disappeared. A star of the fifth magnitude, 55 Herculis, in the catalogue of Flamstead, was particularly observed by Herschel in 1781 and 1782 ; but nine years afterwards it was gone, nor has it since been seen. Sir John Herschel, in May 1828, missed a star in Virgo, inserted in Baron Zach's catalogue, and has never been able to perceive it. "There are now wanting in the heavens," Montanari observed in 1670, "two stars of the second magnitude, in the stern and yard of the ship Argo. I and others observed them in the year 1664, upon occasion of the comet that appeared that year. When they first disappeared I know not; only I am sure that on the 10th of April, 1668, there was not the least glimpse of them to be seen."

On the other hand, there are some stars now in the heavens which are supposed to have only recently become visible. No entry of them occurs in the catalogues of former observers, who have registered objects of inferior magnitude in their neighbourhood, and would not therefore have omitted these had they been present. Thus, a star in the head of Cepheus, one in Gemini, another in Equuleus, a fourth in Sextantis, a remarkable one between $\beta$ and $\delta$ Hydræ, a sixth in Hercules, and several others, are not given in Flamstead's catalogue. These are probably new, as that most accurate observer of the heavens could scarcely have omitted them. Since the year 1826 a star in the nebula of Orion has appeared; and attention has been specially called to it, owing to its having started as it were into existence in a situation which apparently strengthened the now exploded nebular hypothesis.

In addition to these changes, the occurrence of stars starting into temporary visibility, shining with great lustre, and then entirely vanishing, however unaccountable, is so well authenticated as to obtain a place in the class of unquestionable phenomena. An instance of this kind occurred in the year 389 of our era. In the neighbourhood of Altair, in the constellation Aquila, a star suddenly appeared, continuing as brilliant as Venus for three weeks. Other stellar apparitions are recorded in the years 945 and 1264 ; but the most memorable case occurred in 1572 , which we had occasion to notice in tracing the career 
of Tycho Brahe. The new star, which glowed with great splendour, and continued visible for eighteen months, appeared in Cassiopeia immediately under the scabellum or chair of

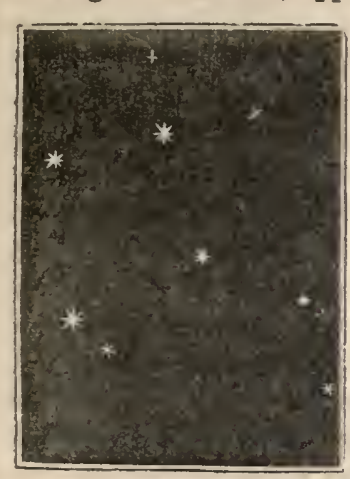
the Lady. It was first caught sight of at Wittemburg on August 6th, seen at Augsburg on the 7th, observed by Cornelius Gremma on November 9th, and by Tycho on the 11th. It formed an irregular square with three of the principal stars of the constellation, maintained the same position invariably with respect to them during the whole time of its apparition, exhibited no sensible parallax, which plainly declared its place to be in the region of the fixed stars. In the diagram, the largest star represents the stranger, with Caph above it on the left hand, Schedir a little higher to the right, and $\gamma$ below. To account for the appearance of this novel object, some philosophers of the time referred it to the Epicurean doctrine of a fortuitous concourse of atoms, whose combination in this stellar form was merely one of the endless varieties of ways in which they have been arranged. Kieppler, too enlightened to be attracted by such a worn-out hypothesis when advanced upon a subsequent occasion, thus alludes to it with his characteristic oddity:- "When I was a youth, with plenty of idle time on my hands, I was much taken with the vanity, of which some grown men are not ashamed, of making anagrams, by transposing the letters of my name written in Greek so as to make another

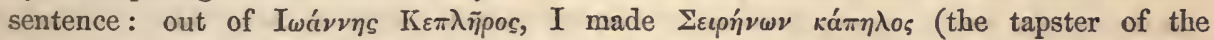
Sirens); in Latin, out of Iohannes Keplerus came Serpens in akuleo (a serpent in his sting). But not being satisfied with the meaning of these words, and being unable to make another, I trusted the thing to chance, and taking out of a pack of playing cards as many as there were letters in the name, wrote one upon each, and then began to shuffle them, and then at each shuffle to read them in the order they came, to see if any meaning came of it. Now may all the Epicurean gods and goddesses confound this same chance! which, although I spent a good deal of time over it, never showed me anything like sense, even at a distance. So I gave up my cards to the Epicurean Eternity, to be carried away into Infinity, and, it is said, they are still flying abore there in the utmost confusion among the atoms, and have never yet come to any meaning. I will tell these disputants my opponents, not my own opinion, but my wife's. Yesterday, when weary with writing, and my mind quite dusty with considering these atoms, I was called to supper, and a salad I had asked for was set before me. - "It seems then," said I aloud, "that if pewter dishes, leaves of lettuce, grains of salt, drops of water, vinegar and oil, and slices of egg, had been flying about in the air from all eternity, it might at last happen by chance that there would come a salad." "Yes," says my wife, "but not one so nice or well dressed as this of mine is."

The above amusing extract is taken from one of the treatises of this remarkable man, entitled:De Stellâ Novâ, a presentation copy of which to our James I. is in the library of the British Miuseum. It was written upon a new star which blazed forth in the year 1604 under somewhat remarkable circumstances. In that year the planets Saturn, Jupiter, and Mars were in conjunction in the three fiery signs Aries, Leo, and Sagittarius, to use the language of astrology, composing the fiery trigon, a phenomenon which occurs about once in every eight bundred years. The scene drew Keppler many a night to the bridge of Prague, his usual place of observation. Towards the close of September he observed the three planets, and on the 29th Mars and Jupiter were in conjunction, and that part of the heavens was attentively watched, but nothing peculiar otherwise was observable. On the 30 th a strange object was seen by his scholars at no great distance from Jupiter, 
far surpassing that planet in magnitude and equal to Venus in brilliancy. Owing to unfarourable weather at Prague, it was not until the 8th of October that Keppler obtained a view of it. It appeared near the right foot of Serpentarius, exhibited no parallax, displayed a variety of colours, and after an apparition of twelve months it vanished from the heavens, and has not again been visible. Comparing this new star with its predecessor, Keppler remarks :- "Yonder one," referring to that in Cassiopeia, "chose for its appearance a time no way remarkable, and came into the world quite unexpectedly, like an enemy storming a town, and breaking into the market-place before the citizens are aware of his approach; but ours" (the new star in Serpentarius) "las come exactly in the year of which astrologers have written so much about the fiery trigon that happens in it, just in the month in which (according to Cyprian) Mars comes up to a very perfect conjunction with the other two superior planets; just in the day when Mars has joined Jupiter, and just in the place where this conjunction has taken place. Therefore the apparition of this star is not like a secret hostile irruption, as was that of 1572 , but the spectacle of a public triumph, or the entry of a mighty potentate; when the couriers ride in some time before, to prepare his lodgings, and the crowd of young urchins begin to think the time over long to wait; then roll in, one after another, the ammunition, and money, and baggage waggons, and presently the trampling of horse, and the rush of people from every side to the streets and windows; and when the crowd have gazed with their jaws all agape at the troop of knights, then at last the trumpeters, and archers, and lackeys, so distinguish the person of the monarch, that there is no occasion to point him out, but every one cries out of his own accord, 'Here we have him!' What it may portend is hard to determine, and thus much only is certain, that it comes to tell mankind either nothing at all, or high and weighty news, quite beyond liuman sense and understanding. It will have an important influence on political and social relations, not indeed by its own nature, but as it were accidentally, through the disposition of mankind. First, it portends to the booksellers great disturbances and tolerable gains, for almost every Theologicus, Philosophicus, Medicus, and Mathematicus, or whoever else, having no laborious occupation intrusted to him, secks his pleasure in studiis, will make particular remarks upon it, and will wish to bring these remarks to the light. Just so will others, learned and unlearned, wish to know its meaning, and they will buy the authors who profess to tell them. I mention these things merely by way of example, because, although thus much can be easily predicted without great skill, yet may it happen just as easily, and in the same manner, that the vulgar, or whoever else is of easy faith, or, it may be, crazy, may wish to exalt himself into a great prophet; or it may even happen that some powerful lord, who has good foundation and beginning of great dignities, will be clieered on by this phenomenon to venture on some new scheme; just as if God had set up this star in the darkness merely to enlighten them."

Another example of a temporary star appeared in the year 1670. It was obscrred by Hevelius, and by Don Anthelme, on the 20tl June, in the head of Cygnus. 'The last instance occurred on the night of April 28, 1848, when Mr. Hind noticed a new star in a part of Ophiuchus. It exhibited no change of place, but diminished in brightness, and became extinct.

There are now about twenty well-attested cases of fixed stars suddenly glowing from out the sombre bosom of infinity, shining with great vivacity for an interval, so as to be visible even in the day time through the intensity of their light, then gradually fading away, and becoming entirely extinct. We are completely foiled by these apparent temporary stellar creations. Are they worlds which, having accomplished one cycle of their existence, have lad their physical structure dissolved by fire, to be remodelled? Are they thus bodies which have lain hid from terrestrial gaze by their remoteness, until 
some vast combustion has given them a transient visibility? "Worlds and systems of worlds," says Mason Good, "are not only perpetually creating, but also perpetually disappearing. It is an extraordinary fact, that within the period of the last century, not less than thirteen stars, in different constellations, seem to have totally perished, and ten new ones to hare been ereated. In many instances it is unquestionable, that the stars themselves, the supposed habitation of other kinds or orders of intelligent beings, together with the different planets by which it is probable they were surrounded, have utterly vanished, and the spots which they occupied in the heavens have become blanks! What has befallen other systems, will assuredly befall our own. Of the time and the manner we know nothing, but the fact is incontrovertible; it is foretold by revelation; it is inscribed in the heavens; it is felt through the earth. Such, then, is the awful and daily text; what then ought to be the comment?" The current of thought upon this subject, with reference to several eminent men, has run in the same channel. Vince remarks:- "The disappearance of some stars may be the destruction of that system at the time appointed by the Deity for the probation of its inhabitants; and the appearance of new stars may be the formation of new systems for new races of beings then called into existence to adore the works of their Creator." Laplace likewise observes:- "As to those stars which suddenly shine forth with a very vivid light, and then immediately disappear, it is extremely probable that great conflagrations, produced by extraordinary causes, take place on their surface. This conjecture is confirmed by their change of colour, which is analogous to that presented to us on the earth by those bodies which are set on fire and then gradually extinguished." . It has been said, that the existence and death of Alexander the Great - the rise and fall of the Roman empire-the destruction, by earthquake or volcano, of cities which were once the seats of commerce and the arts - have been handed down to us upon evidence in no respect whatever better entitled to our belief, than that of the astronomical facts to which we have been adverting. This is perfectly true; yet the facts themselves may be widely apart from any analogy with such terrestrial occurrences. We have choice of another theory, on many accounts preferable, though not free from great difficulties. It has been conjectured, that the temporary appearance of stars may be resolvable into a periodical translation from the depths of infinite space, to a station which brings them within the bounds of our vision. Their sudden and brilliant burst from the dark and distant void, upon this supposition, arises from a tremendous velocity; and their evanescent stay within our view, may be caused by one of the narrow extremities of an orbit

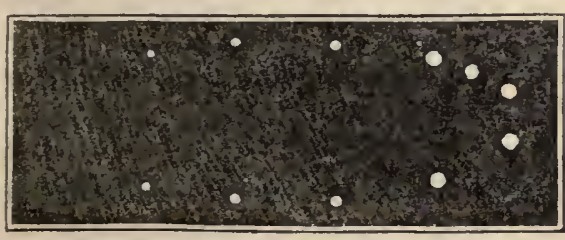
immensely elliptical lying in the direction of our system. The diagram represents part of this supposed orbit, that which approaches our position in the universe. It is further conceived, that the temporary stars of 945 . 1264, and 1572 were not different individuals. but in reality the same star. This is grounded upon the close accordance of the intervals separating the periods.

$$
\text { From } 945 \text { to } 1264 \text {, } 319 \text { years. }
$$

From 1264 to 1572,308 years.

It has been supposed, therefore, that the star has an orbit which it accomplishes in about three hundred years. With reference to this hypothesis, it will be for the present century to utter a verdict. If it be true, those who survive but a few years longer will see the star, upon which Tycho gazed in his manhood, and Keppler when a boy, return to its station in Cassiopeia, again to glitter, to wane, and vanish! In corroboration of this theory, it should be mentioned, that the stars of 945,1264 , and 1572 appeared in the 
same part of the heavens. The chief difficulty which lies in the way of the supposition, that the temporary stars are objects moving in orbits, which display them periodically to us, is, that no change of place has been observed during the whole time of apparition.

Besides cases of apparent stellar creation and complete extinguishment, there are a number of stars whose light undergoes a periodical inerease and diminution, forming the class called variable. Some retire for a time into absolute invisibility, while others merely suffer changes in their brightness, without being absolutely lost to view.

The earliest observed example of this class is o Ceti, ealled also Stella Mira, or the wonderful star, situated in the neck of the Whale. It was first particularly remarked by Fabricius, August 13, 1596, when it appeared as a star of the third magnitude, but before the end of the year it had retreated entirely from observation. Holward remarked it again in 1637, after which it disappeared for nine months, when he again saw it. The following are now its general phases, which are gone through in 331 days,

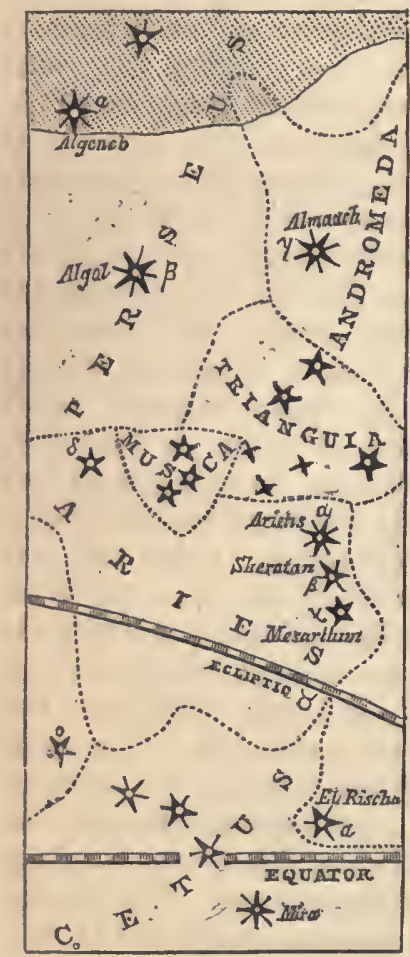

15 hours, and 7 minutes. When at the greatest brightness, it is equal to a star of the second magnitude, and remains so for about a fortnight. It then decreases during three months, passes entirely out of sight, continues invisible about five months, again comes into view, increases during three months, when it attains onee more its maximum lustre. It does not always, however, return to the same degree of brightness, or increase and diminish by the same gradations, or invariably remain invisible the same length of time. For the four years between October, 1672, and December, 1676, it was never seen at all, though Hevelius searched that part of the heavens diligently for it. On the other hand, it was unusually bright Oetober 5, 1839, as observed by Argelander. The relative position of Stella Mira is shewn in the diagram.

Algol, the name of the star $\beta$ in Perseus, in the head of Medusa, is another remarkable instance of stellar mutation. It varies from the second to the fourth degree of magnitude. This was determined by Maraldi in 1694 ; but Mr. Goodricke of York, in 1782, and about the same time Palitzch, near Dresden, first accurately fixed the period of its changes. The star goes through its variations in a remarkably short space of time: it continues at its brightest two days and fourteen hours. Then its splendour suddenly begins to diminish, and in three hours and a half it is reduced to its minimum. Its feeblest lustre lasts but little more than fifteen minutes. It then begins to increase, and in three hours and a half more, it is restored to its usual brightness. Its full period is therefore 2 days, 20 hours, and 48 minutes. The remarkable law of variation to which this star is subject suggested to Goodricke the idea of some opaque body revolving around it, which, interposing between the earth and the star, cuts off a portion of its light. Algol may be seen on any fine evening from August to May, as it continues above the horizon twenty hours out of the twenty-four. With Algenib in the side of Perseus, and Almaak in the foot of Andromeda, it forms a triangle, with the open part towards Cassiopeia.

x Cygni was ascertained to be variable, and its period determined by Kirch in 1686. 
It clianges from the sixth to the eleventh degree of magnitude, and consequently at its brightest is only visible to the naked eye under favourable circumstances. Halley observes respecting it:- "We watched, as the absence of the moon and the clearness of the weather would permit, to catch the first beginning of its appearance in a six-foot tube : that, bearing a very great aperture, discovers most minute stars. On June the 15 th last (1715), it was first perceived like one of the very least telescopical stars; but in the rest of that month, and in July, it gradually increased, so as to become, in August, visible to the naked eye, and so it continued all the month of September. After that, it again died away by degrees, and on the 8th of December, at night, was scarcely discernible by the tube, and, as near as could be guessed, equal to what it was at its first appearance on June 15; so that this year it has been seen, in all, near six months, which is but little less than half its period, and the middle, and consequently the greatest brightness falls about the 10th of September." Its maximum brightness, however, does not seem to be uniform, as, according to Cassini, it was scarcely perceptible in the years 1699,1700 , 1701, at those periods when it ought to have been most conspicuous. Its cycle consists of 396 days, 21 hours.

The most remarkable of the versatile stars in our hemisphere are stated in the following table, with their changes of magnitude, and periods of variation :-

\begin{tabular}{|c|c|c|c|c|c|}
\hline Stars. & \multicolumn{3}{|c|}{ Periods of Variation. } & Changes of Magnitude. & Authority. \\
\hline - Ceti (Mira) & \multicolumn{3}{|c|}{331 days 15 hours $7 \mathrm{~min}$. } & 2 to 0 & \multirow{3}{*}{$\begin{array}{l}\text { Herschel, WV. } \\
\text { Goodricke. } \\
\text { Pigot. }\end{array}$} \\
\hline$\beta$ Persei (Algol) & 2 & 20 & 48 & 2 to 4 & \\
\hline$\eta$ Antinoi & 7 & 4 & 15 & 3 to 5 & \\
\hline$\chi$ Cygni & 396 & 21 & 0 & 6 to 10 & \\
\hline$\gamma$ Hydræ & 490 & 0 & 0 & 3 to 10 & \\
\hline$\psi$ Leonis & \multicolumn{3}{|c|}{ Several years } & 6 to 0 & \\
\hline$\kappa$ Sagittarii & \multicolumn{3}{|c|}{ Ditto } & 3 to 6 & \\
\hline 18 Leonis & 311 & 23 & 0 & 5 to 10 & \\
\hline$\delta$ Cephei & 5 & 8 & so & 3 to 5 & Goodricke and Pigot. \\
\hline$\beta$ Lyræ (Sheliak) & 6 & 10 & 34 & 3 to 5 & Goodricke and others, \\
\hline a Herculis (Ras Algati) & 60 & 6 & $\mathbf{0}$ & 9 to 4 & Herschel, W. \\
\hline
\end{tabular}

There are altogether nearly forty stars ascertained to be variable, and others suspected to belong to the class.

Various conjectures have been hazarded to account for these cases of periodic stellar change. If we suppose the varying brightness of the bodies in question to be caused by varying distance, the same hypothesis as that which has been mentioned in connection with the temporary stars, it is singular that their position should be wholly unaltered during their respective changes. This appears fatal to the idea of orbital motion being the cause of their versatile appearance. Another surmise is, that dark bodies revolve around these stars, which, periodically intervening between them and us, temporarily cut off their light. Mr. Goodricke proposed this theory respecting the star Algol; but it is open to the objection that it requires us to assign a magnitude to the revolving body in relation to that which must be deemed its primary, which is out of all proportion to that which we are led to believe belongs to dependent orbs. The subservient bodies in our system are immensely inferior to their primary, the sun, and owing to this, to a distant observer of our part of the universe, the transit of the mighty globe of Jupiter across the sun's disk would produce no perceptible effect. Our knowledge of planetary motion is also adverse to that rigorous uniformity which is so marked a feature of the stellar changes.

It may appear a gratuitous assumption to take the solar system as a miniature picture of others; but we can only reason concerning what we know not from what we 
know. Minute white specks appear in the neighbourhood of the stars, $\gamma$ Hydrx, * Geminorum, and ` Ursæ, which in all likelihood are their encircling planets-tributary companions - plainly and vastly inferior, according to the analogy of subservient bodies in our system. Their intervention would have no perceptible effect upon the appearance of their primaries to our vision. The most probable hypothesis that has yet been proposed to account for the examples before us of stellar changeableness is that of axical rotation. The variable stars are supposed to have parts of their surface less luminous than the rest, which when presented to us in the course of rotation produce the periodical decay of light, and absolute invisibility observable. A variety of circumstances occur to favour this idea. Rotation upon an axis is a law to which erery orb is subject, with which we are sufficiently acquainted - as the sun, the planets, and their satellites. The greatest uniformity marks the execution of the law, and in this it differs from translation in space. The planets trarel in irregular paths and witl varying velocities in their orbits, but their axical motion is uniform. If, therefore, one of the hemispheres of a rotating body within the sphere of vision should be less luminous than the other, periods of decay, obscurity, revival, and vivacity, would be exhibited, of uniform occurrence and duration. Now, those who have paid most attention to solar phenomena are of opinion, that besides the sun having rariable spots upon lis disk, which at times have been so numerous and extensive as to impair his orb, there is reason to believe the illuminating power of his two hemispheres to be unequal, one being much fainter than the other. We may not be sensible of this, because, comparatively situated in immediate vicinity to his effulgence; but, removed to a vast remoteness, his rotatory motion might constitute him sensibly a variable star to us. Herschel remarks: "The rotary motion of stars upon their axes is a capital feature in their resemblance to the sun. It appears to me now, that we cannot refuse to admit such a motion, and that indeed it may be as evidently proved as the diurnal motion of the earth. Dark spots, or large portions of the surface less luminous than the rest, turned alternately in certain directions either towards or from us, will account for all the phenomena of periodical changes in the lustre of the stars so satisfactorily, that we certainly need not look out for any other cause."

We now proceed to notice the Multiple stars - a class unknown until a very recent date. Soon after the application of the telescope to the heavens, it was perceived that some of those brilliant points, which appear single stars to the naked eye, are in reality stellar combinations comprising two or more individuals. But little attention, however, was paid to them, and no suspicion entertained of their numerical amount. Dr. Hook, referring to $\gamma$ Arietis, states: "Of this kind, the most remarkable is the star in the left horn of Aries, which, whilst I was observing the comet which appeared in the year 1664, and followed till he passed by this star, I took notice that it consisted of two small stars very near together ; a like instance to which I have not else met with in all the heavens." It was reserved for the elder Hersehel to detect the richness of the mine, and to take precedence in bringing some of its treasures to light. A catalogue of five hundred stars, apparently single, but in fact binary, was produced by this distinguished observer, and presented to the Royal Society; and, when he ceased from his labours, his mantle fell upon successors worthy to receive it. The list of conjoined bodies, whose positions and relative distances have been accurately determined, now includes a number which is five or six times greater than that which appears in the general stellar catalogue of the ancient observers. Sir James South and Sir John Herschel produced a catalogue of 380 multiple stars in the year 1824, as the result of their joint labours. This was followed by one of 480 from South, and another of 3300 from Herschel - the fruits of solitary observation. M. Struve, of Dorpat, also has registered the data of 3000 . These are all included in the 
northern hemisphere, and within $15^{\circ}$ south of the equator. From the southern hearens an equally plenteous harrest may be gathered, of which Mr. Dunlop's catalogue of 250 , observed at Paramatta, may be regarded as the first-fruits. Upon the whole, the number of stars whose multiple character and respective positions have been determined, cannot be rated at less than 6000 . Of these the most numerous are twin-stars, or binary systems. Some of the more remarkable specimens are Castor, $\eta$ Coronæ, Rigel, Polaris, Mirac or $\varepsilon$ Boütis, $\gamma$ Leonis, $\gamma$ Virginis, $\xi$ Ursæ Majoris, $\alpha$ Herculis, 36 Andromedæ, $\lambda$ Ophiuchi, and $\pi$ Aquilæ.

Of all the binary stars in the heavens, Castor is the largest and the finest; the one also

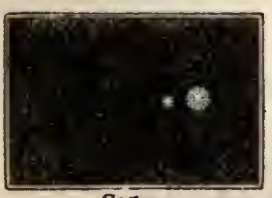
which has been the longest observed. Its structure and position were recorded by Pound in 1718, by Bradley and Maskelyne in 1759, and by Herschel in 1799; and, in the present day, it has been closely and perseveringly examined by Sir John Herschel, Struve, and Sir James South. Castor is a Geminorum, one of the bright stars in the head of the Twins, the most northerly of the two, and is easily scparated by a moderately good telescope. Its constituents are of the third and fourth magnitude, at present about $3^{\prime \prime}$ apart. The diagram shows the pair which now make an angle with Pollux, the other principal star in Gemini. But in Bradley's time the position was different, as appears from a memorandum of one of his observations :"Double star Castor. No change of position of the two stars: the line joining then at all times of the year parallel to the line joining Castor and Pollux in the heavens seen by the naked eye." Sir John Herschel speaks of this object as that whose unequivocal angular motion first impressed on his father's mind a full conviction of the reality of his long-cherished views on the subject of the binary stars. $\eta$ Coronæ, halfway between the Northern Crown and the club of Boötes, is a delicate double star, not to be seen but under favourable circumstances, requiring the most powerful and perfect instruments. Its compound character was discovered by Herschel

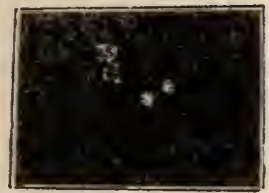

v Coronæ.

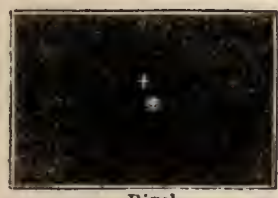

Rigel.

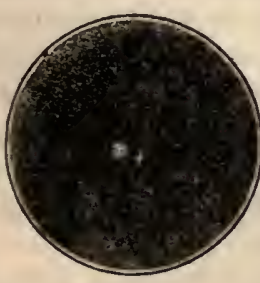

$y$ Leonis. in 1781, since which time its constituents have gone through more than a complete revolution, which renders it the most remarkable binary star known. Rigel, the well-known star in the foot of Orion, consists of one large and brilliant with a minute companion. The attendant point was seen by Herschel with a power of 227 , but has been reached by one of Dollond's two-foot telescopes with a power of 70. Polaris, the pole star, is resolved into two of very unequal size, the smaller appearing a mere point in comparison with its companion. Mirac, or $\varepsilon$

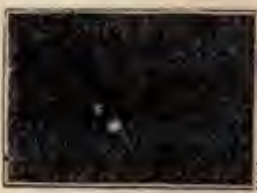
Polaris.

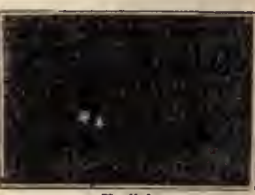

s Boötis. Boötis, about $10^{\circ}$ north-east of Arcturus, is one of the loveliest objects in the heavens, on account of the contrasted colours of the two stars composing it. It requires a power of 200 distinctly to define the pair. $\gamma$ Leonis, about $7 \frac{1}{2}^{\circ}$ north-east of Regulus, is another striking example of a double star.

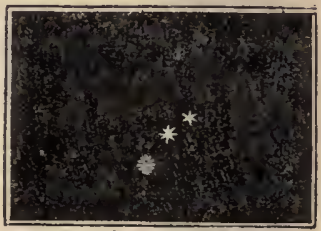

II Monocerotis.

Besides stellar pairs, there are many instances of triple combination, of points apparently individual resolving into three distinct bodies when examined by an instrument of high power. An object of this kind is in the constellation Monocerotis, or the 
Unicorn - a star in the right fore-foot, which is resolved at first into two; but one of

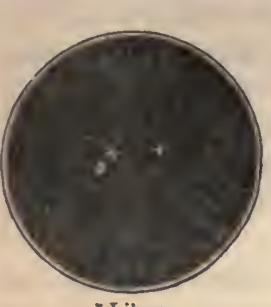

$\xi$ Libra. these, on minute inspection, is found to be double. Herschel, who discovered this triplicate in 1781 , pronounced it one of the most beautiful sights in the heavens. $\zeta$ Cancri, apparently a single star of the sixth magnitude, is another example of a ternary system, scparating into three of unequal size. $\xi$ Libræ is also treble, as well as $\gamma$ Andromedx, $\psi$ Cassiopeix, and 12 Lyncis. Eleven sets of bright triple stars, conjunctions of threc bodies, are specified by Struve, in a very small space of the heavens.

Combinations of four stars, constituting a quadruple scheme, composed of two double, have also been detected. $\beta$ Lyræ, $\pi^{2}$ Canis Majoris, 8 Lacerta, and $\varepsilon$ Lyræ are examples. The latter object the naked eye discerns as a star of the

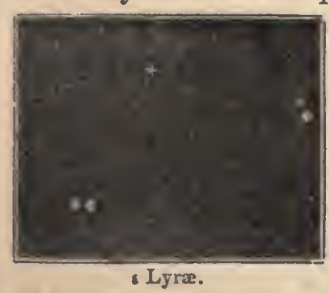
fourth magnitude, about $1 \frac{1}{2}^{\circ}$ from Vega, upon the frame of the Lyre. With slight instrumental aid it separates readily into two well-defined stars, distinctly apart, and each of these two becomes binary under a higher power. There are still morc extraordinary combinations than the preceding, or quintuple and sextuple stars. Thus $\theta$ Orionis, the trapezium, in the nebula, the first object upon which Hersehel turned his mighty telescope, appears as a star of the third magnitude to the naked eye. It was so classed by Ptolemy and Tycho Brahe, but has long been known to be quadruple. Struve has however announced it to be quintuple, that is, when thoroughly examined, it consists of five constituent bodies so closely wedged as to appear an individual object.

The phenomena of the multiple stars have already led to some interesting results. The Newtonian law of gravitation has by their means been opened to our view, operating in the far distant realms of the universe. When these proximate bodies were first discovered, it was not suspected that any physical connexion subsisted between them - any real contiguity. The proximity was supposed to be simply optical. It was imagined, that one star lying at a remote distance behind another, and seen in nearly the same visual line, produced the appearance of a double star, as described in the diagram. In some

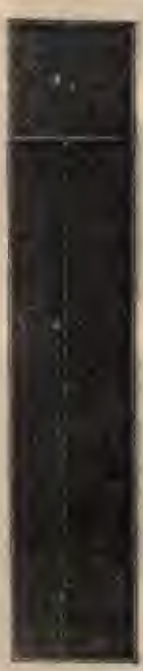
instances this is undoubtedly the case; and, while the prevalence of the binary arrangement was limited to a few specimens, the solution was satisfactory. But the heavens are so thickly sprinkled with double stars, as to render it in the highest degree improbable that their occurrence is merely the accidental effect of two stars separated by a wide interval, lying out in space in the same direction. The argument adopted has been illustrated in the following manner. If we suppose a number of peas to be thrown at random on a chess-board, we should certainly expect to find them occupying irregular or random positions. If, contrary to this, they were, in far more than average numbers, found to be arranged in pairs on each square, the rational inference would be, that here there was no random seattering. The excessive: prevalence of the binary arrangement would indicate forethought, design, and system.

This is the reasoning of Dr. Nichol, the force of which is obvious. Hence, when we find between the pole and $15^{\circ}$ south of the equator, 653 cases of conjunction, in which the bodies are not separated by the finest telescope from each other by more than the apparent diameter of Jupiter, and 612 cases of a lesser star associated with a greater, we are led to infer the real and designed proximity of these bodies. The principle now adverted to, led Herschel to 
the conclusion that casual situations will not account for these multiplied phenomena;

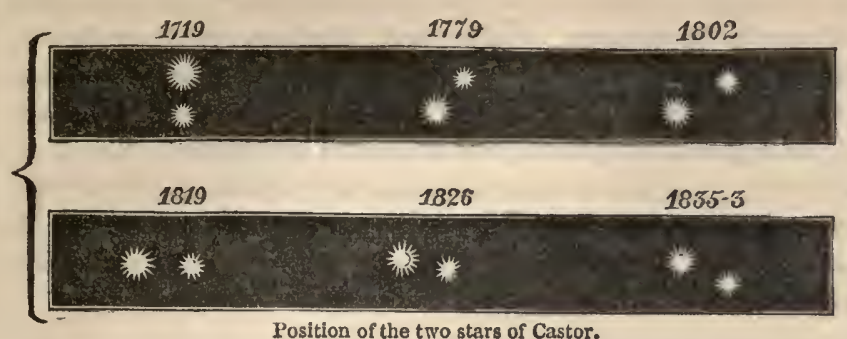
that consequently their existence must be owing to some general law of nature; and as the mutual gravitation of bodies toward each other is quite sufficient to account for the union of two stars, he felt authorised to ascribe such combinations to that principle.

This reasoning has been emphatically confirmed by physical facts. The conclusion has

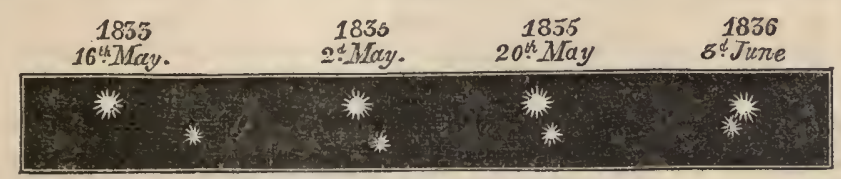
been established beyond all doubt, that the multiple stars are made up of bodies in real association - physically connected. The Position of the two stars of $\gamma$ Virginis. constituents of a double star, closely watched through a series of years, are found to change their relative position, and to repeat the same cycle of change, indicating their systematic union under control

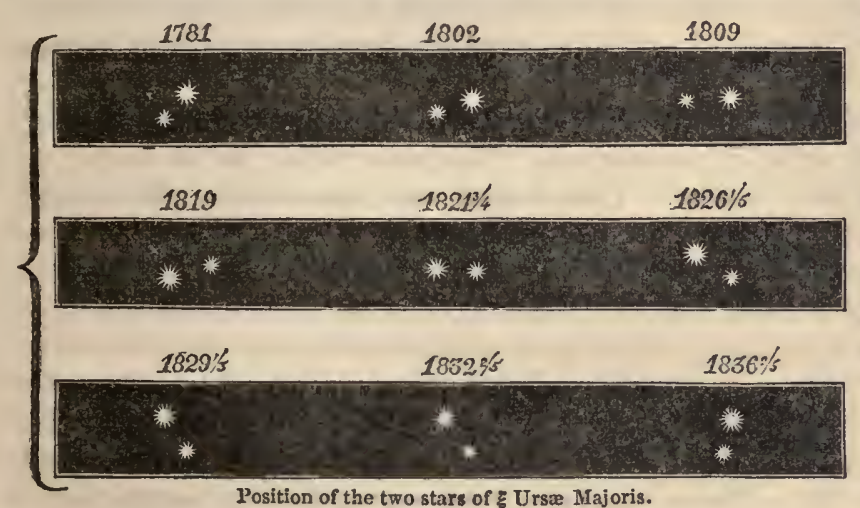
of the law of gravitation. The diagram exhibits the observed positions of the two stars of Castor, of $\gamma$ Virginis, and of $\xi$ Ursæ Majoris, at the respective times named. Here we have unquestionable signs of orbital motion, real binary systems of suns revolving around suns, the smaller around the greater, or both about a common centre of gravity.

One has accomplished a complete revolution, $\eta$ Coronæ, since observation was first directed to it; and, from the progress already made by others, their times of revolution have been estimated as follows:-

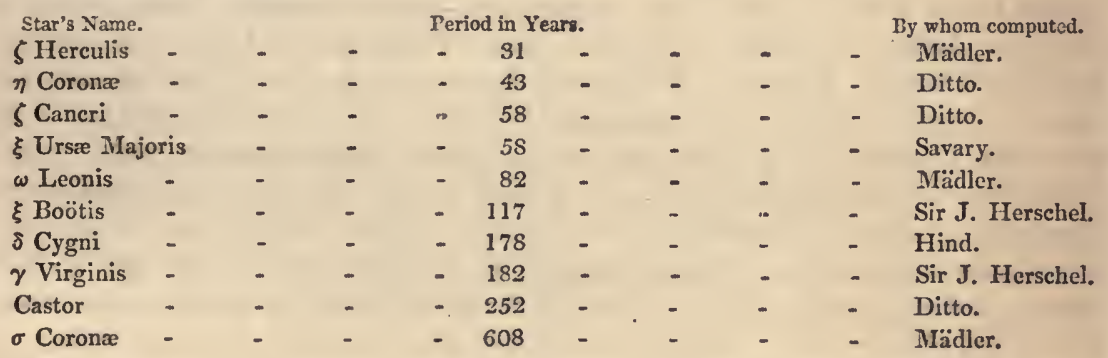

In consequence of revolution, the apparent distance between the constituents of a double: star varies remarkably. Thus the two stars of $y$ Virginis have apparently approached 
each other, and have become so close as to present the appearance of a single star to the telescope, their respective motions again opening as it were a breach between them. The constituents of Castor now appear to be closing. "This star," says Sir John Herschel, "seems on the point of undergoing, within the ensuing twenty-four years, a remarkable change, similar to that of which $\gamma$ Virginis has already furnished a striking instance, during the last century, and passing from a distinct double star of the second class to a close one of the first, and ultimately to one of extreme closeness and dificulty, such as only the very finest telescopes, with all the improvements we may expect in them, will be capable of showing otherwise than single." In the following years the distances of the constituents of Castor were as follows :-

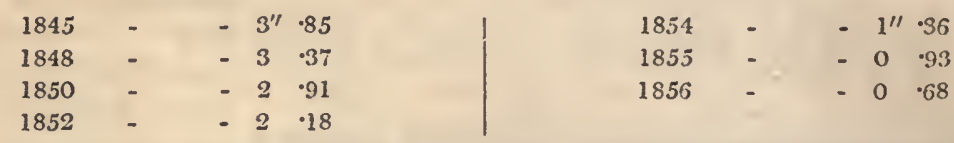

We have thus seen suns in motion around each other-or around some intervening point, in the case of quadruple and quintuple stars - as decisively evidenced by observed phenomena, as the translation of the distant planets of our system around the central luminary. It required the most acute geometricians to resolve the well-known problem of three bodies, and it may be quite beyond our mathematics to determine the curves described by connected suns with attendant planets acting and reacting upon each other; but the fact of the stellar universe being the scene of activities, incessant, complex, yet nicely balanced and harmonised, is clearly before us.

The contrasted colour of the multiple stars, the rich and varied hues with which they shine, is one of their most striking peculiarities. The stars visible to the naked eye, differ in the tints which they display. This, though very apparent, is not so clearly remarked in our own country by the unaided vision, owing to the general haziness of the atmosphere, as in other parts of the globe. But if we were encamped at night upon the plains of Syria, or on those of High Asia, the greatest projection upon the surface of our planet, where the firmament is displayed with greater clearness through the rarity of the circumambient air, the diverse colouring of the stellar light would be at once observed. Sirius, whose advance to the field of view, on directing a telescope to it, has been likened to the dawn of the morning, is so refulgent that for a time it las been found impossible to endure it, is brilliantly white. There has been some extraordinary changes in the history of this splendid object, for Sirius, now white, was known to the ancients as a red star, and is so characterised by Ptolemy and Seneca. This is not a solitary phenomenon, but one upon which it is quite useless to speculate. Within the last half century $\gamma$ Leonis and $\gamma$ Delphini have very perceptibly changed colour. Lyra, Spica Virginis, Bellatrix, Altair, and Vega are white stars. Procyon and Capella are orange. Aldebaran, Antares, Arcturus, Pollux, and Betelguese are red. The remark has been made by Struve, and it is corroborated by others, that Herschel assigns to many of the stars a redder tinge than has been verified, arising perhaps from some optical peculiarity, or instrumental defect. It is well known that some persons are unable to discriminate colours correctly, and to certain colours others are totally insensible. The eminent philosopher Dalton belonged to the latter class. He saw no difference between red and green, so that he thought the face of a leaf of laurel a good match to a stick of red sealing-wax. Dugald Stewart also laboured under the same defect.

While in many cases the constituents of a binary or multiple system are of the same complexion, and of equal intensity, in other instances, there is a striking diversity as to both. 
Among the binary stars catalogued by Struve, the following summary of 596 is given by him:

$\begin{aligned} & \text { Yairs of the same colour and intensity - - } \quad-\quad 375 . \\ & \text { Pairs of the same colour, but of different intensity } \\ & \text { Pairs of totally different colours }\end{aligned}-\begin{aligned} & \text { - } \\ & \text { - }\end{aligned}$

The white stars in the multiple systems are supposed to be $2 \frac{1}{2}$ times more numerous than the red, and the red twice as numerous as the blue. While insulated stars of a red colour as deep as blood are common in the heavens, and also white and yellow ones, it is a remarkable fact, that no specimen of an insulated blue, green, or violet-coloured star, has yet been found, though these occur in the binary and ternary systems. Struve furnishes the following statement of coloured primaries and blue attendants :-

\begin{tabular}{|c|c|}
\hline Pairs consisting of a blue & with a white principal \\
\hline & with a light yellow - \\
\hline & with a yellow or red \\
\hline 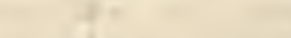 & with a green - - \\
\hline
\end{tabular}

The imagination is apt to run riot, in endeavouring to picture the effect of this variety of colour, to a planetary attendant of one of the suns in a binary or tertiary system. "It may be more easily suggested in words," remarks Sir John Herschel, "than conceived, what variety of illumination two suns - a red and a green, or a yellow and a blue one-must afford to a planet circulating about either; and what charming contrasts and grateful vicissitudes - a red and a green day, for instance, alternating with a white one and with darknessmight arise from the presence or absence of one or other, or both above the horizon." Here we have another example of that beautiful variety combined with evidences of sameness which we encounter in every region of physical nature, and which proclaim its far distant worlds to be the architecture of one infinitely potent and fertile Mind. While the double stars are governed by the same centrifugal and centripetal forces which maintain in harmony our planetary system, they display that diversity of operation in their various hues which is stamped in other forms upon the solar universe.

From the preceding statements it is clear, as has been previously observed, that the common term, fixed stars, is not rigidly applicable to the bodies so denominated. Orbital revolution is not only displayed by the constituents of the multiple stars, but there are observed instances of a proper motion in space common to the constituents of each. Thus the two stars composing 61 Cygni, have preserved nearly the same distance from each other for fifty years or more, but their common location in the hearens has been altered in that time through an extent of $4^{\prime} \cdot 23$. The annual proper motion of this double star in right ascension is $5^{\prime \prime} \cdot 46$ of space; and in declination $3^{\prime \prime} \cdot 19$. The estimated velocity with which it journeys through the vastness of space is supposed to exceed that of the planet Mercury. The two stars, $a$ Ophiuchi and 30 Scorpii, which are $13^{\prime}$ apart from each other in space, and which are not orbs revolving around each other, are yet moving along together through the universe, leaving the neighbouring stars behind them. The triple star, $\mu$ Cassiopeia, has a rapid course through space, at the rate of not less than 125,000 miles an hour, and Arcturus has also a considerable proper motion. The change of place in these stars requires perfect instruments, and a lapse of years for their observation; but a real movement of great magnitude is indicated, of which we should be sensible if we were nearer neighbours to them. In the sixteenth century, Jordano Bruno, an Italian, maintained that we are not warranted in supposing the stars to be all fixed in relation to each other, since their distance from the earth is so immense as to render their motions insensible to us; and he remarked that it could only be decided after a long course of observation, whether they revolved around each other, or what other 
movements they might have. This bold and original thinker suffered death at Rome, for apostatising from the Romish church; but it is believed that his rebellion against the physics of Aristotle contributed to his committal to the flames. "This sentence," said he, on being condemned, "pronounced in the name of a God of mercy, terrifies you more than it does me." Hooke, our own countryman, in the following century, surmised the improbability of the stars being absolutely fixed with respect to each other, and suggested that not only might these bodies be in a state of continual motion, but the whole solar system likewise. But Halley is the first person who, from observation, suspected the proper motion of the stars. In a paper of the year 1718, he stated, that since the days of the Alexandrian astronomers, the stars Aldebaran, Arcturus, and Sirius, must have slowly advanced to the south. A few years later, J. Cassini demonstrated, by the most conclusive evidence, that Arcturus had sensibly shifted in latitude since the time of Tycho Brahe. Bradley soon afterwards remarked, that the apparent motions of the stars might arise either from a movement of the solar system in space, or from a real change in the positions of the stars themselves; but he avowed the opinion, that many ages must elapse before it would be possible to come to a definite conclusion on the subject. In 1750 , the remarkable "Theory of the Universe," published by Wright, assumed the motion of the solar system in space, as well as that of all the stars of the firmament.

At last, in 1783, Herschel addressed himself to the resolution of the great problem, by forming a catalogue of stars situated in all parts of the heavens, in which an appreciable amount of proper motion had been detected and measured. He justly reasoned, that in case this apparent motion of the stars could be attributed to the movement of the solar system through space, a close scrutiny of the directions in which the stars appear to move, would indicate the direction in which the sun, with its train of planets, is moving. In illustration of the principle of investigation, it has been aptly remarked, that in the instance of a person travelling on a railway, in a direct line through a forest, as he advances, the trees towards which he is moving will appear to open out or separate from each other, while those left behind will appear to close up. "If, then, the astronomer, borne along by the movement of the sun through the vast forest of stars by which he is surrounded, desires to ascertain the direction in which he is progressing, let him search the heavens until he finds a point where the stars seem to be increasing their distance from each other. Should he find such a point, let him confirm his suspicions by looking in the direction precisely opposite, and in case he finds the stars located in this region closing up on each other, he may fairly conclude that he has found the direction in which he is moving, and a rigid coincidence of all the phenomena wonld demonstrate the accuracy of his conclusions." After an extended examination of the subject, Herschel announced his belief that a part of the proper motion of the stars must be attributed to the effect of systematic parallax, or to the movement of the solar system itself; and that this movement is directed towards a point in the heavens somewhat to the north of the star $\gamma$ Hercules.

This theory was not supposed in general by the astronomers of the day to be founded on well-determined observations. It was received, therefore, with hesitation and doubt; it fell into disrepute; and Herschel died before any confirmation of it had been obtained. But the recent researches of Argelander, Lundahl, Otto Struve, and Peters, on the stars of the northern hemisphere, combined with those of Mr Galloway on the stars of the southern sky, have demonstrated, in the most undeniable manner, not only the fact of the solar motion, but its direction, in close agreement with Herschel's announcement, and its rate. The results of perfectly independent observations have been thus summed up by the elder Struve :- "The motion of the solar system in space is directed to a point in the celestial sphere, situated on the right line, which joins the two stars of the third magnitude, $\approx$ and $\mu$ Hercules, at a quarter of the apparent distance between these stars, measured from 
Hercules. The velocity of this motion is such, that the sun, with the whole cortège of bodies depending on him, advances annually in the direction indicated, through a space equal to 1.623 radii of the terrestrial orbit, or 154 millions of miles." But though advancing towards a determinate point in the heavens, it would be inconsistent with analogy, and utterly incompatible with the principle of gravitation, to suppose our system to be continuously moving towards one and the same point. All the other celestial movements are curvilinear or orbital, instead of right lines. It can scarcely, therefore, be doubted, that the apex of the solar motion slowly shifts its position in the sphere; and that the sun, with the planetary and cometary system, is revolving round some centre in the visible heavens, which is probably a kind of grand pirot round which all the stars of our firmament describe immense orbits. M. Mädler has thrown out the surmise, that this common centre lies in the Pleiades; and that the star Alcyone in that group is the central sun. But such speculations are premature, being far in advance of practical astronomy, however probable the suppositions upon which they are based.

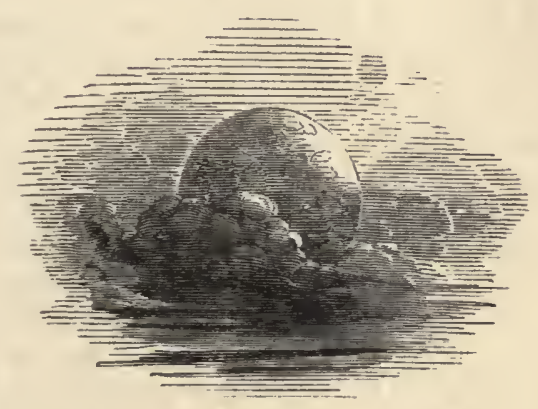




\section{CHAPTER $\mathrm{X}$}

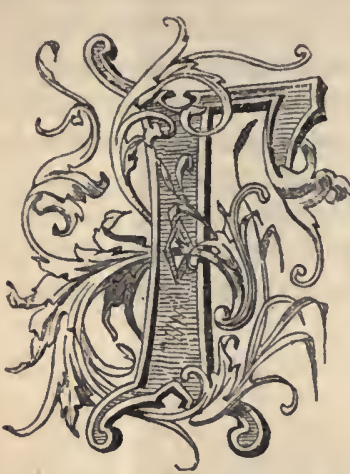

\section{STAR-SYSTEMS. - NEBULE.}

AR more astonishing than any of the details upon which we have hitherto dwelt, are those relating to the class of celestial objects we have now to consider, the investigation of which is at present the highest branch of practical astronomy. In directing our attention to them, we leave what may comparatively be called home regions, strange as the phrase appears, when we recollect the distance intervening between us and the nearest of the stars. But such language is strictly appropriate with reference to the stars visible to the naked eye, and reached by ordinary telescopic aid. They form our firmament or cluster, near the centre of which the solar system is supposed to be situated. Yet besides this province with which we are connected, incalculably vast as it is, perfectly inestimable both in length, breadth, depth, and height, there are other provinces within view, equally as capacious, distinct firmaments or clusters, scattered through those territories of the universe that are accessible to our gaze; and could we be removed to any of them, the whole of that great scheme of existence apparently circumscribed by the Milky Way, might seem compressed into a small globular patch in space, or sprawling spot, only to a trifling extent bedimming the azure of the heavens-the aspect presented by these star-systems, clusters, or nebulæ to ourselves.

It is a reasonable supposition that stars which are classed as belonging to the inferior orders of magnitude, only appear to be so generally, because of their greater distance. Now it is observable, that the most brilliant, or those of the first, second, and third magnitudes, are pretty evenly distributed over the surface of the heavens; but those of the fourth, fifth, and sixth magnitudes appear in crowds towards the margin of the Milky Way, while that remarkable zone of light is plainly demonstrated to be an cuormous aggregation of minute stellar objects, very expressively characterised as "star-dust." Hence the suspicion naturally arose, that there was some connection between the Galactic circle and the other portions of the heavens, so that the whole might form one great system. The extensive celestial surveys laboriously executed by Herschel-his telescopic gauging or sounding of the sphere-contributed to confirm this idea ; and all subsequent investigations, as those of Sir John Herschel in the southern hemisphere, have tended to the same result. So far, therefore, from being fortuitously dispersed through space, as was once supposed, the stars forming our firmament are definitely arranged; and the particular shape of the whole mass or cluster, as it would appear to spectators in remote clusters, has been examined and approximately sketched. The whole visible creation of stars is conceived to form a stratum or layer, extending to an immense but limited distance, and thin, in proportion to the length and breadth. If our position therefore is towards the central regions of this stratum, we shall obviously see a great gathering of stars, agglomerated into one mass, looking towards the elongations, forming an appearance answerable to that of the Milky Way; but looking towards either of the surfaces of the stratum, we shall see a far lesser number of stars, appearing also more distinct and scattered, answering to the aspect of the other parts of the heavens. Supposing likewise the stratum, on one side, to be split down the middle, the appearance in that direction will be that of the Milky Way, 
divided through a certain extent into two branches. The diagram may help to illustrate this view of the architecture of the visible stellar universe, the small circle indicating the

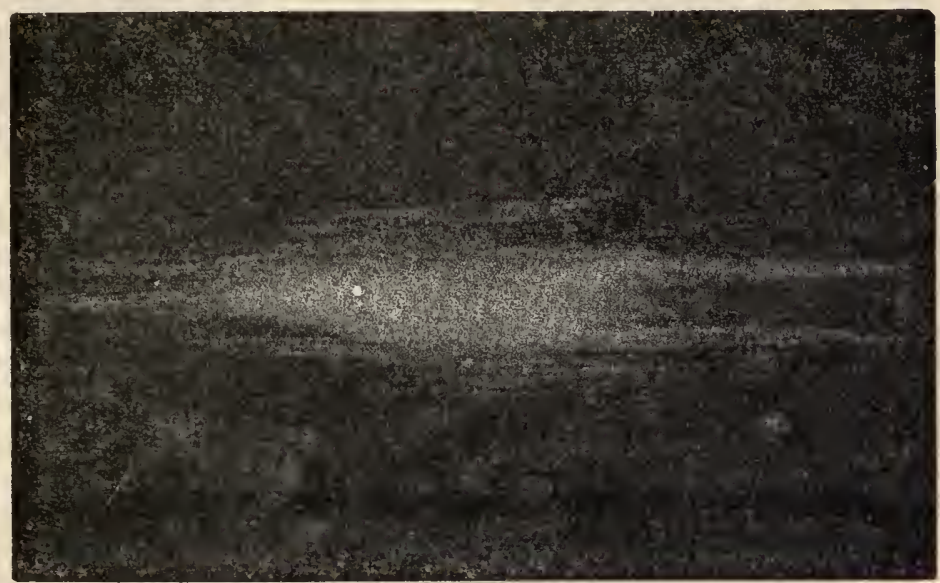

place of the solar system in it. It was the idea of Herschel, that the thickness and greatest elongation of this bed of stars might be equal respectively to eight and nine hundred times the distance of the nearest of the fixed stars from our system; and that our place in it is eccentric in relation both to the surfaces and the extremities.

We thus pass from the grand idea of an individual sun or star, with attendant planets, forming a solar system, to the incomparably grander conception of a vast mass, cluster, or universe of solar systems, many perhaps surpassing our own in magnitude, and doubtless held together in definite arrangement and unbroken harmony by the bond of gravitation. Yet this stellar scheme, mighty as are its dimensions, is but a sample of the contents of celestial space-a single member in a numerous family of similar sidereal assemblages, within hail of the modern telescope. These remote groups, "island universes" as the Germans call them, a few of which may be detected by the naked eye, are generally spoken of collectively as nebulce, from their cloud-like appearance, a denomination applied to them long before their real character was known or suspected. They vary considerably in shape, size, and luminosity; and occur in numbers, which every improvement of the telescope increases. In Halley's time the whole number known amounted to six; but he naively remarked, "there are undoubtedly more which have not yet come to our knowledge." Messier, the "comet-ferret," was the first who paid particular attention to these objects. While looking for Halley's comet, in 1758, whose return was then expected, he observed in the neighbourhood of $\zeta$ Tauri a whitish light, elongated like the flame of a taper. This led to the production of his list of these objects, containing a hundred and three, the result of his own personal observation. It appeared in the Connaissance des Temps, for the year 1784, an astronomical almanac published by the French Board of Longitude. Herschel discovered upwards of two thousand more, whose places were determined and catalogued by his sister. Sir John Herschel commenced in 1825 and finished in 1833 the most complete catalogue of nebulæ, containing his father's results, and five hundred additional objects, the fruits of his own observation. "I have already determined," he remarks, "with as much accuracy as the nature of such observations permits, the places; and obtained sufficient descriptions of the physical peculiarities, of between two and three thousand of these wonderful objects-a great part of them by many repeated observations, and made careful drawings of the most remarkable for their shape, size, or structure. 
Among these are objects so surprising, that I shall earnestly desire to see my observations verified by the powerful instruments (if sufficiently so) which are now become common in the hands of observers." More than 4000 have now been observed and catalogued.

Taking a favourable night in spring or autumn, a practised eye may discern a feeble speck between $n$ and $\zeta$ Herculis, two stars of the third magnitude north and south of each other, in that constellation, n being about $22^{\circ}$ nearly due west of Vega. This speck is the thirteenth nebula of Messier's list, described by him as nèbuleuse sans etoiles. It was observed by Halley in 1714, who remarks, "This is but a little patch, but it shows itself to the naked eye when the sky is serene, and the moon absent." Employing a common telescope, it assumes the appearance of a small and faint cometary body, of a globular shape ; but using an instrument of first-rate power, it resolves into a mass of stars, whose number must be enormous, but apparently so closely wedged together, owing to their remoteness, as to present the little indivisible streak of light which is scarcely perceptible

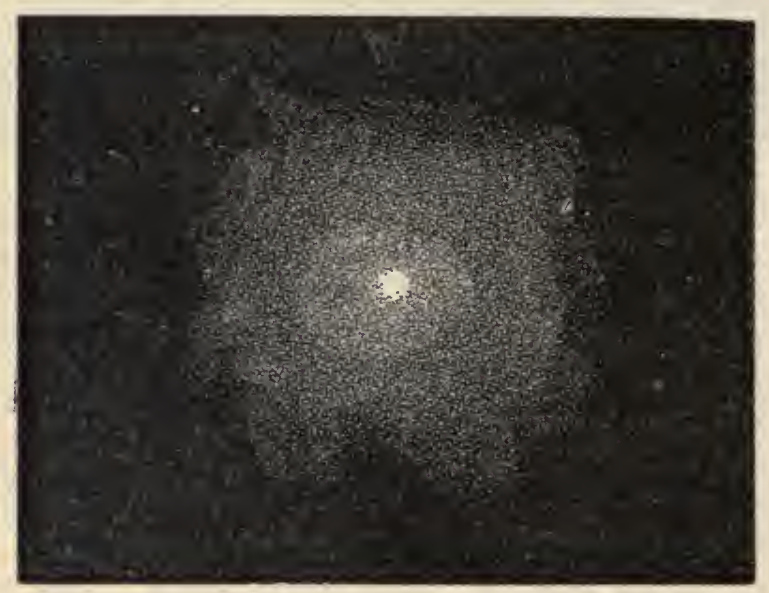

Nebula in Hercules.

without optical aid. The cut represents this object as seen in a reflector of 18 inches aperture, and 20 feet focal length. It is impossible, says an assiduous observer, to give a fitting representation of this magnificent cluster. Perhaps no one ever saw it for the first time through a large telescope, without uttering a shout of wonder. The heavens, as seen from a sun of this astral system, near its centre, must present a most gorgeous appearance. In all directions, innumerable stars of all magnitudes will be seen, forming a spectacle such as would be presented by our heavens, in case the Milky Way were cxpanded to cover the entire celestial spherc. Such spherical stellar clusters are common, the individuals of cach being no doubt separated from one another by as wide a gulf as that which exists between our sun and the nearest star, their apparent contiguity and compression to us arising from their immeasurable distance.

It is inferred from the appearance presented by many clusters, that the components of each are bound together by mutual relationships, and constitute a particular assemblage of stars governed by internal laws peculiar to itself, though corresponding generally with those which prevail in other sidereal systems. The common occurrence of the globular shape, and of great central condensation, the light there running up into an unbroken blaze, may perhaps be accepted as evidence of the attraction of gravitation. It is striking to catch a glimpse of a law with which we are so familiar-the law that 
unites the atoms that compose the earth, forms every rain-drop, and moulds the tear that trickles down the cheek of sorrow-in prevailing operation millions of leagues away from our terrestrial residence, binding together in spherical masses whole sidereal systems. Such a fact, however, commonly suggests no further remark than that the laws of nature everywhere prevail, and with this, thought in general ends. But "what," says Paley, "do we mean by the laws of nature, or by any law? Effects are produced by power, not by laws. A law cannot execute itself. A law refers us to an agent." An irresistible conviction is forced upon us, of the universal agency, and, consequently, the omnipresence of one Lawgiver, by the universal presence and execution of kindred law's; and confessedly incomprehensible as is the modus of His operation, it would be not more irreligious to stumble at this than unphilosophical, considering the immense amount of things of which we have certain evidence that they are, without having any glimpse as to how they are. We cannot at all understand the physical agency of the Deity ; but paying deference to the strong facts of nature, we are led to the conclusion that $\mathrm{He}$

"Lives through all life, extends through all extent,

The conclusions are marvellous that are forced upon us by these objects. Here we have firmaments or clusters, insulated in space, each constituting a sidereal family equal to that to which our sun belongs. "It would be a vain task," says the highest authority upon this subject, " to attempt to count the stars in one of these globular clusters. They are not to be reckoned by hundreds; and on a rough calculation, grounded on the apparent intervals between them at the borders (where they are seen not projected on each other), and the angular diameter of the whole group, it would appear that many clusters of this description must contain, at least, ten or twenty thousand stars, compacted and wedged together in a round space, whose angular diameter does not exceed eight or ten minutes; that is to say, in an area not more than a tenth part of that covered by the moon. Perhaps it may be thought to savour of the gigantesque to look upon the individuals of such a group of stars like our own, and their mutual distances, as equal to those which separate our sun from the nearest fixed star: yet when we consider that their united lustre affects the eye with a less impression of light than a star of the fifth or sixth magnitude (for the largest of these clusters is barely visible to the naked eye), the idea we are thus compelled to form of their distance from us may render even such an estimate of their dimensions familiar to our imagination ; at all events, we can hardly look upon a group thus insulated, in seipso totus, teres, atque rotundus, as not forming a system of a peculiar and definite character."

But the globular form, though common, is by no means unvarying. There are oval shapes, while some are of very irregular outline, and present a fantastic appearance. The 30 Doradûs, as sketched at Paramatta by Mr Dunlop, and examined by Sir John Herschel at the Cape of Good Hope, resembles a number of loops, or a kind of "true lover's knot" formed by a bunch of ribbons. An angular-shaped mass appears in the Twins, on a line drawn from Pollux to the middle of Orion's belt, discovered by Herschel in 1783 . Another, in the form of a distant flight of wild-fowl, discovered by Kirch in 1681, is on the shield which Hevelius framed among the stars in honour of Joln Sobieski, the deliverer of Vienna from the Turks.

One of the most conspicuous of these objects, called the "transcendently beautiful queen of the nebulx," and the oldest known, appears below the girdle of Andromeda. It is visible to the naked eye in the absence of the moon, and has often been mistaken for a 
comet. A notice of it occurs as early as the commencement of the tenth century. The first telescopic view was obtained by Simon Marius, 15th December 1612, who compared it to a candle shining through a horn; that is, a diluted light, increasing in density towards

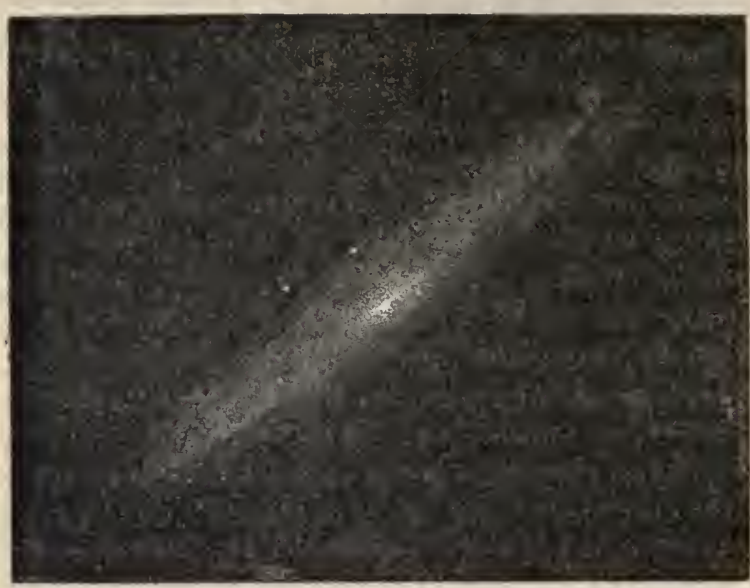

Nebula in Andromedia

a centre. This nebula is of lenticular shape, and forms nearly a right-angled triangle with Almaach and Mirac, the two principal stars of Andromeda A good eye may pick it up on a favourable night, by projecting a line from Sheratan, the second star in Aries, through Mirac, to about $4 \frac{1}{2}^{\circ}$ beyond. It is about half a degree long, and from $15^{\prime}$ to $20^{\prime}$ broad. Herschel believed this to be one of the nearest nebulæe in the heavens, though at a distance two thousand times greater than that of Sirius. Notwithstanding the improved optical means of the moderns, it has not been resolved into stars, though no doubt can be entertained of its stellar composition. Numerous telescopic stars appear involved in the glow, but are not supposed to have any connection with it, being interposed between it and our system.

There are examples of nebulæ presenting circular or slightly oval disks, resembling planets, but with different degrees of definition at the borders. In several instances they appear of "a fine and full blue colour, verging upon green." They are no doubt clusters of stars reduced by mutual proximity and vast distance to the form of planetary disks. Sometimes they are found combined in pairs, like the physically connected double stars;

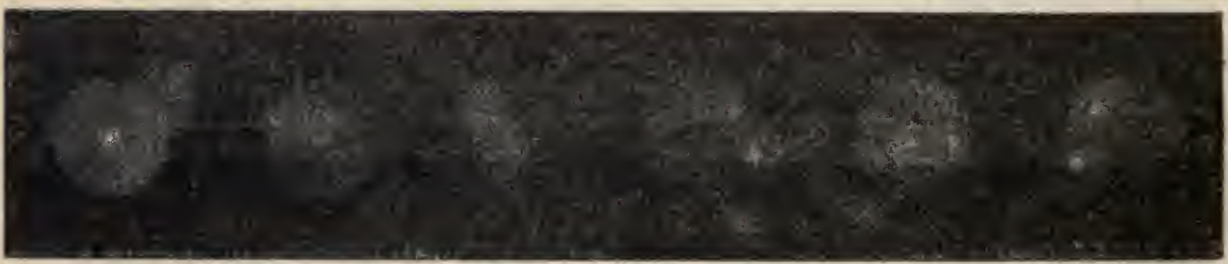

Planetary and Double Nebule.

and if they are to be regarded as two distinct star-systems, each having its own centre of condensation, yet revolving round each other by the tie of gravitation, the inagination can scarcely realise the vastness of the idea suggested. 
While generally exhibiting tolerably defined shapes in the depths of space, some of the more considerable nebulæ have a strangely irregular aspect and outline. This is especially the case with reference to the great nebula of Orion, one of the most extraordinary objects in the heavens, for its great extent, inequalities of light and shade, and capricious form. It occurs in the sword-handle of the figure which forms the constellation; and a good eye may discern it without the assistance of a glass. Huygens was the first to describe this object, though Galileo is said to have observed it through his telescope. "Astronomers," says the former, "place three stars close to each other in the sword of Orion: and, when I viewed, the middlemost with a telescope in the year 1656 , there appeared, in the place of that one, twelve other stars ; among these, three that almost touch each other, and four more besides, appeared twinkling as through a cloud, so that the space about them seemed much brighter than the rest of the heavens, which appearing wholly blackish, by reason of the fair weather, was seen as through a certain opening, through which one had a free view into another region which was more enlightened. I have frequently observed the same appearance in the same place without any alteration; so that it is likely that this wonder, whatever it may be in itself, has been there from all time; but I never took notice of any thing like it among the rest of the fixed stars." This nebula, as discerned by the naked eye, exhibits an indefinite, foggy appearance. It is brighter, more diffuse and strange, when a telescope is used ; but the whole light and power of Herschel's fortyfeet reflector could not resolve it into distinct stars. "This highly interesting object," he states, "engaged my attention in the beginning of the year 1774, when, viewing it with a Newtonian reflector, I made a drawing of it; and, having from time to time reviewed it with my large instruments, it may easily be supposed that it was the very first object to which, in February 1787, I directed my forty-feet telescope. The superior light of this instrument showed it of such a magnitude and brilliancy, that, judging from these circumstances, we can hardly have a doubt of its being the nearest of all the nebulæ in the heavens, and, as such, will afford us much valuable information." It seems composed of little flocky masses, or wisps of cloud, adhering to some small stars at its outskirts, and enveloping one with an atmosphere of considerable extent. "I know not," says Sir John Herschel, "how to describe it better than by comparing it to a curdling liquid, or a surface strewed over with flocks of wool, or to the breaking up of a mackerel sky, when the clouds of which it consists begin to assume a cirrous appearance. It is not very unlike the mottling of the sun's disk, only, if I may so express myself, the grain is much coarser, and the intervals darker; and the flucculi, instead of being generally round, are drawn into little wisps. They present, however, no appearance of being composed of stars; and their aspect is altogether different from that of the resolvable nebulæ. In the latter, we fancy, by glimpses, that we see stars, or that, could we strain our sight a little more, we should see them : but the former suggests no idea of stars, but rather of something quite distinct from them." From a comparison of the descriptions and drawings of this object, since the time of Huygens, great alterations might be inferred. But astronomical delineation was not then sufficiently advanced to render the diagrams at all satisfactory, nor were the instruments sufficiently powerful. The first rigidly accurate representation of it is that by Sir John Herschel, 'which justifies its familiar name, 'that of the Fish's Mouth, as it certainly resembles the head and yawning jaws of some monstrous animal, with. a kind of proboscis running out from the snout. Its apparent superficial magnitude is rather more than twice that of the moon's disk. The absolute dimensions must be enormous.

Such, down to a recent date, were the-only ascertained peculiarities of this wondrous mass. From the perfect irresolvableness of this and other nebulæ, together with a milky appearance, it was formerly supposed that a distinction must be: drawn between them and 
those of the resolvable class. The latter, with more or less difficulty, were separated by the telescope into stars; the former gave no indication of being similarly constituted when interrogated by the highest instrumental power. Hence arose the famous hypothesis, that a chaotic kind of material exists, occupying extensive spaces, self-luminous and phosphorescent, which presents an endless varicty of contour and condensation, resembling in many instances a sheet of fog, but exhibiting in others an aggregation into spherical or oblong masses. This was conceived to furnish a key to the origin of the worlds and systems of worlds disclosed around us-to unveil, likewise, the primitive state and early history of the solar universe-diffused nebulosities having advanced gradually by the mutual attraction of their particles into dense spheroids.

The theory was premature, for improved telescopic power has largely disproved its data. After looming mysteriously in the sky, the great nebula of Orion yielded to the giant instrument of Lord Rosse, and disclosed its stellar construction. The history of the event is thus given by Dr Nichol :- "About Christmas 1845, I had the pleasure of visiting Parsonstown, and saw the nebula, through that mighty tube. It was-owing to the incompleteness of the instrument and unfavourable weather-the first time that the grand telescope had been directed towards that mysterions object: and though Lord Rosse warned me that the circumstances of the moment would not permit him to regard the decision then given as final, I went in breathless interest to its inspection. Not yet the veriest trace of a star! Looming unintelligible as ever, there the nebula lay; but how brilliant its brighter parts! How much more broken the interior of its mass! How innumerable the streamers now attached to it on every side! How strange, especially that large horn to the north, rising in relief out of the dark skies, like a large cumulus cloud! It was still possible, then, that the nebula might be irresolvable by the loftiest efforts of human art; but doubt continued to remain. Why, in an inquiry like this, the concurrence of every farourable condition is needful to success, may be readily comprehended. It is its aim to discern, singly, a number of sparkling points-small as the point of a needle, and close almost as the particles of a handful of sand ; how easy, then, for any unsteadiness in the air, or any imperfection in the instrument, so far to diffuse the light of each that they would merge into each other, and thus become oonfounded in one mass!" Throughout the winter, the noble owner and constructer of the instrument resolved to scize every favourable opportunity to penetrate, if possible, the constitution of this wonderful object; and at length addressed the following note to Dr Nichol :- "March 19, 1846. In accordance with my promise of communicating to you the result of our examination of Orion, I think I may safely say, that there can be little, if any, doubt as to the resolvability of the nebula. Since you left us, there was not a single night when, in absence of the moon, the air was fine enough to admit of our using more than half the magnifying power the speculum bears; still we could plainly see that all about the trapezium is a mass of stars; the rest of the nebula also abounding with stars and exhibiting the characteristics of resolvability strongly marked.-RossE." It has subsequently been shown more fully to consist of an immense irregular assemblage of stars, which were not previously discernible for want of sufficient optical aid. Hence it is morally certain, that all these irresolvable objects are really star-systems, the components of which are not distinguishable by reason of their remoteness, though collectively they gleam across those spaces, the magnitude of which is perfectly confounding.

The different appearances presented by the same nebulæ, when viewcd by inferior and more powerful telescopes, is very striking. The following are examples of the same object as seen in Sir John Herschel's instruments and those of Lord Rosse. The Crab Nebula, which the right-hand figure in the cut shows with the strange appendages brought to light by the mirror of Lo:d Rosse, appeared to Sir John Herschel as a dull ellipse, like 
the figure to the left. A similar transformation was effected in the case of the Dumb-bell Nebula.

Crab Nebula.
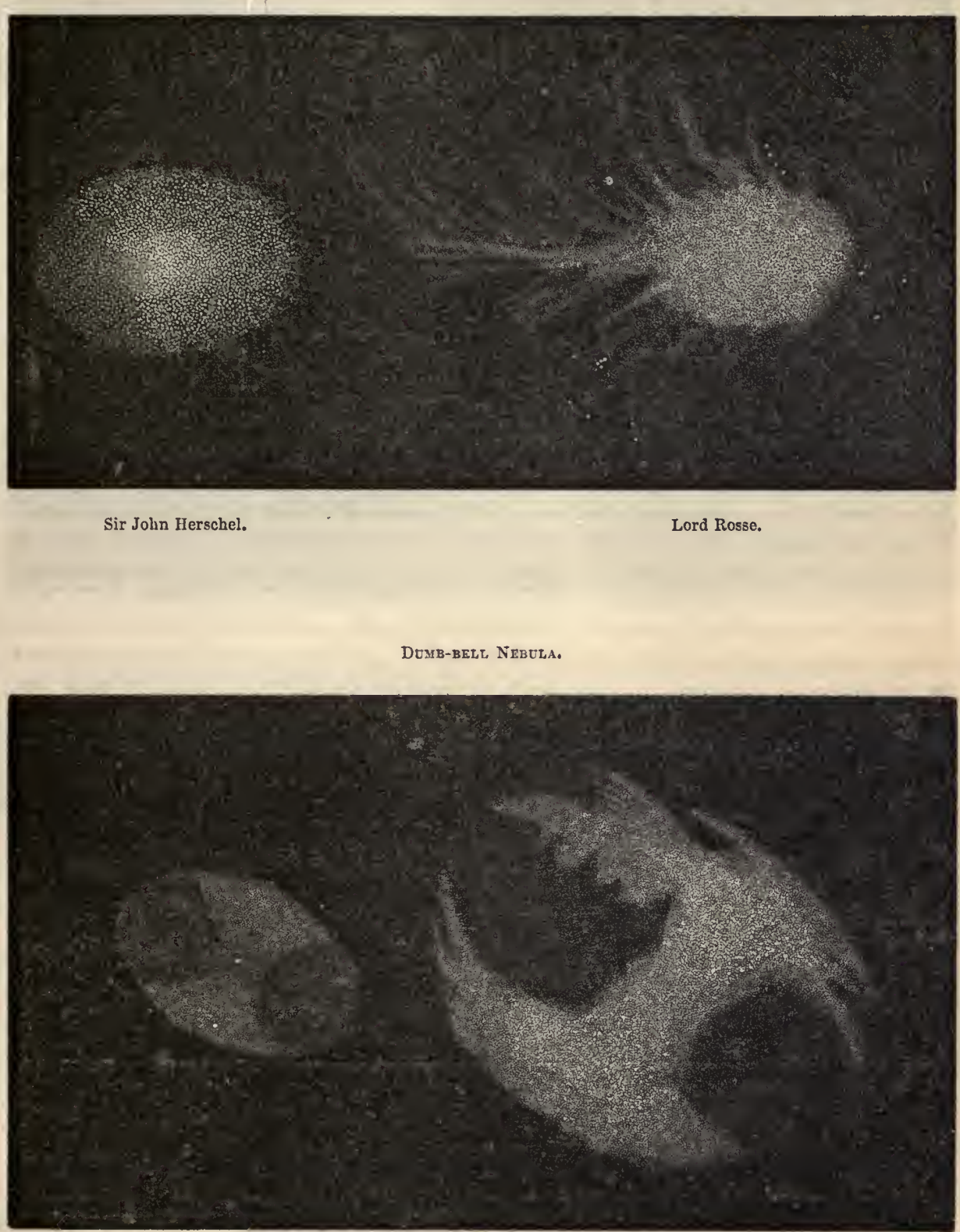
The most startling shapes which have hitherto turued up are of the spiral or whirlpool form, of which the annexed representations are specimens.

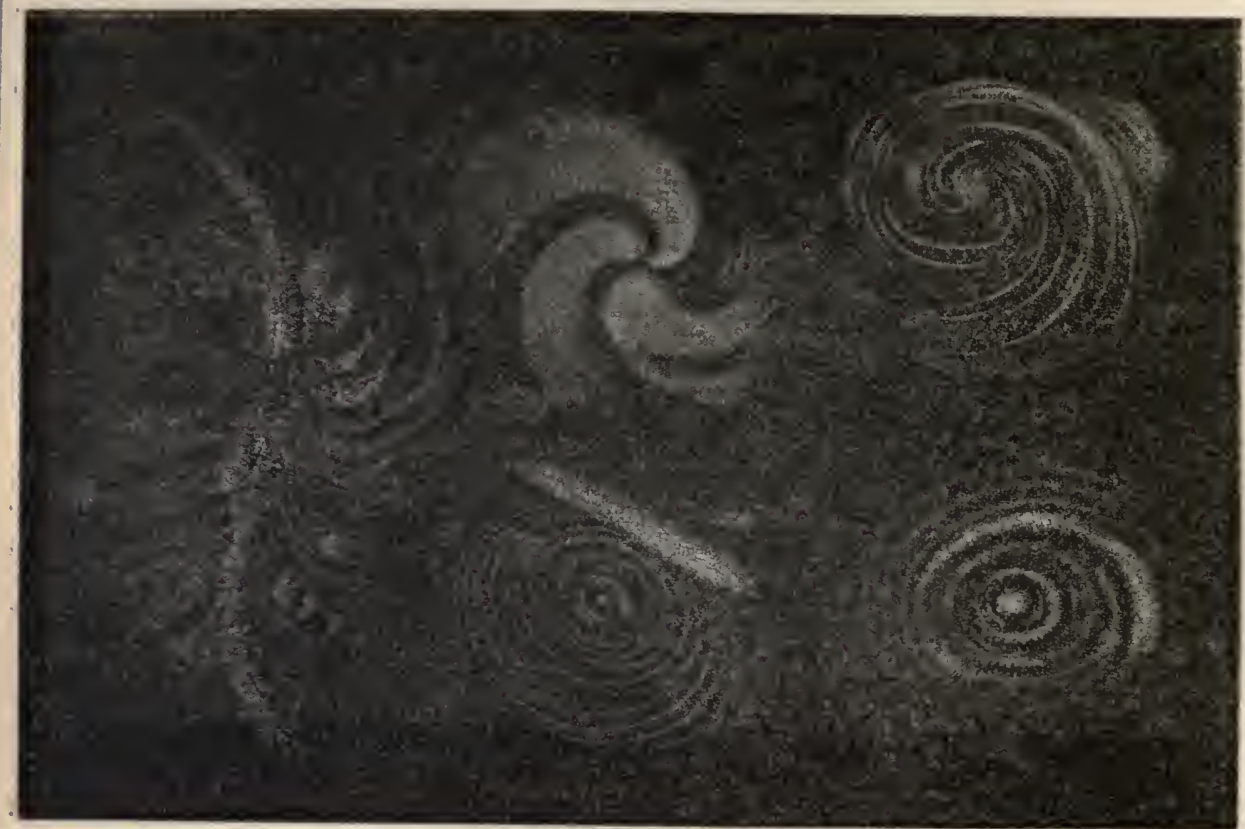

Spiral Netulæ.

Two very remarkable nebulæ, well known to the mariners, being visible to the naked eye, distinguish the southern firmament. They are cloudy masses of light, called the Nubecula Major and Minor, greater and lesser cloud, but familiarly referred to as the Magellenic clouds, after the navigator Magellan, who was one of their first European observers.

However it may savour of the gigantesque, it is sufficiently evidenced that an area of the heavens not exceeding $\frac{1}{10}$ th of the lunar dianeter, contains a system of stars rivalling in number those which constitute our, firmament, and appearing only as a single faint luminosity to us. Yet there are many areas so occupied. It follows therefore that our firmament is but one of a series, and probably one of the smaller chambers in the great mansion of the universe. All the stars and constellations that shine in the midnight sky, -constitute a stellar scheme which is but a unit of a countless number. As seen from the faint objects we discern in the side of Hercules and the sword-handle of Orion, our whole - sphere would be compressed into a small streak of light, and appear in space like a snowflake in our atmosphere! We may conclude, however, that as the firmament, which the unaided eye of man surveys, is but a member of a vast family of systems which his assisted vision scans, so that family may be no more than as a drop to the ocean, a grain of sand to the mass of the globe, compared with what lies beyoud the bounds of telescopic sight, hid in regions which mortal gaze will never explore or visit. Suppose we could actually travel across the space through which the terrestrial eye can penetrate, and take our station at the point which is now the limit of vision, would there not be a territory lying before us, equal to that we should have left behind, in the number, grandeur, and variety of its works? That the Divine capability has operated no further than where a limit is put to human invéstigation-that the length and breadth of the Divine dominions have been 
surveyed, when we have arrived at a point which we cannot pass-it were folly and presumption to imagine. That part of space beyond which the art and genius of man fail to conduct his glance, simply reminds us that we are finite beings, and that we have reached the limit which for the present circumscribes finite powers. It is not the boundary of the Creator's workmanship, but a point of indication, that His house, to us, is, like Himself, illimitable, and that its measurement is a task to. which His infinitude alone is equal.

With these notices, the view proposed to be taken of the Scenery of the Heavens concludes. It cannot close more appropriately than with the advice to Adam, which Milton puts into the mouth of the angel :-

\footnotetext{
"Yet not to earth are those bright luminaries Officious; but to thee, earth's habitant, And for the bearen's wide circuit, let it speak The Maker's high magnificence ; who built So spacious, and his line stretched out so far, THAT MAN MAY KNOW HE DWELLS NOT IN HIS OWN; An edifice too large for him to fill, Lodged in a small partition; and the rest Ordained for uses to his Lord best known."
}

\section{APPENDIX.}

\section{The Sun.}

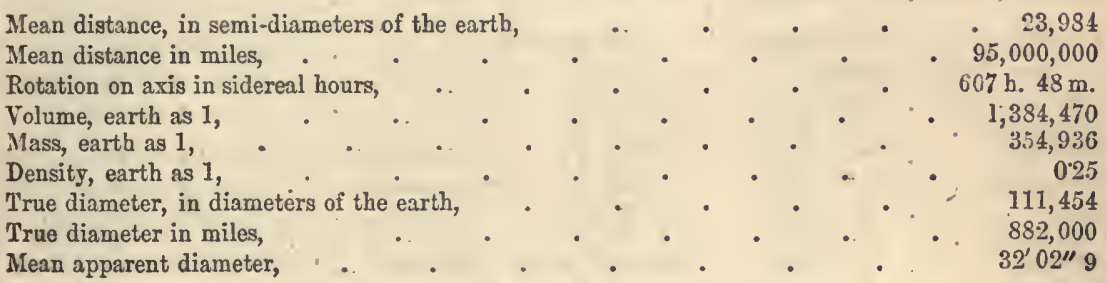

\section{The Planets.}

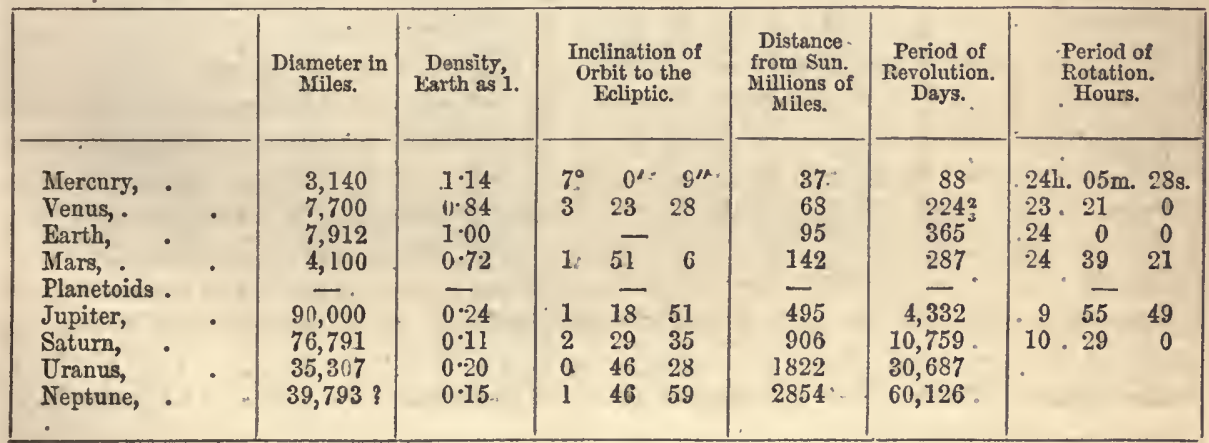


SCENERY OF TIIE HEAVEXS.

3. The Planetoids.

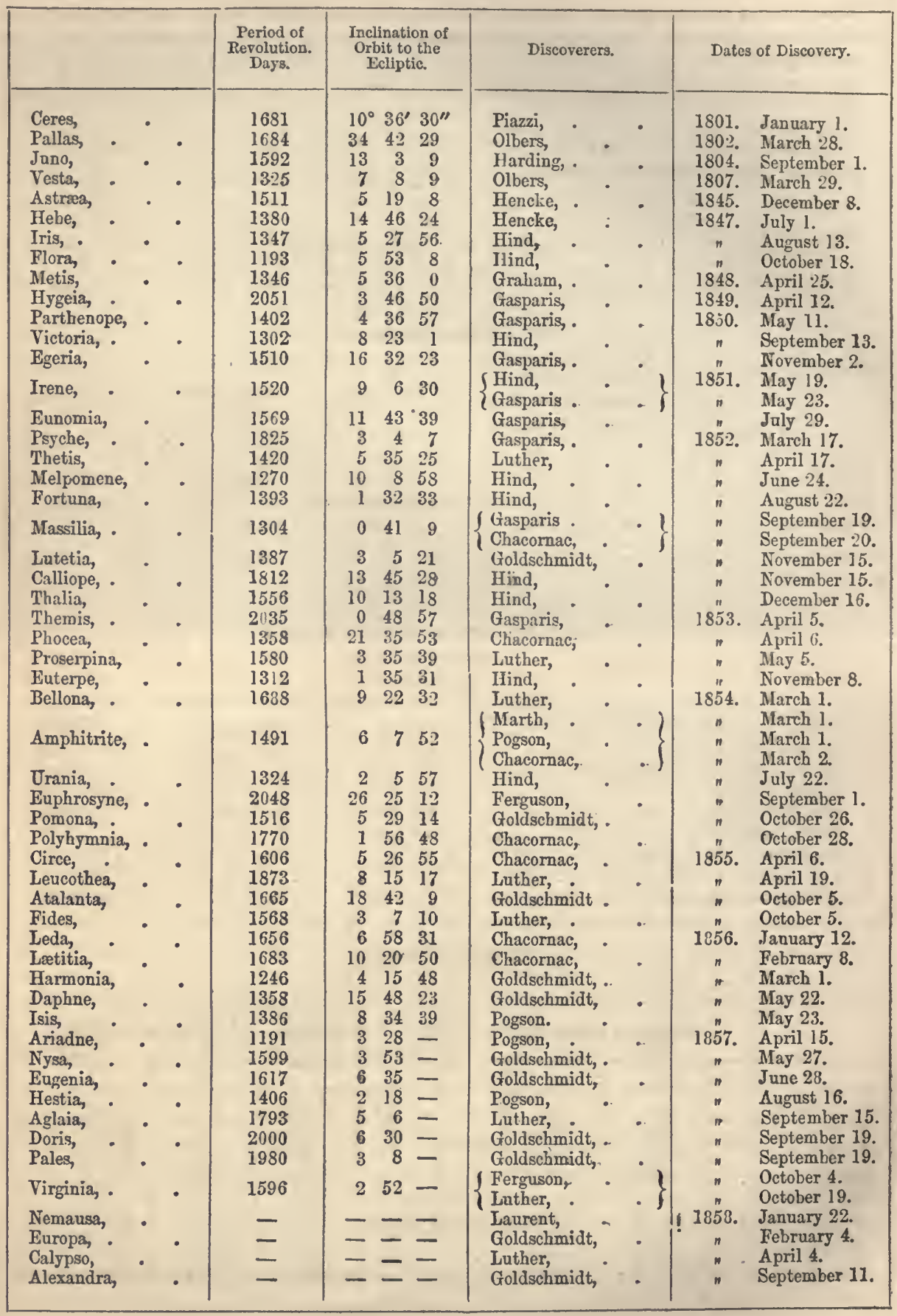




\section{The Moon.}

Mean distance from primary, 29.982175 times diam. terr. equator, above

Mean sidereal revolution, 27.321661423 solar days, or . . . 27d. 7h. 43m. 11s. Mean tropical revolution, $27 \cdot 321582418$ solar days, or _ . $\quad 27$ d. 7 h. $43 \mathrm{~m}$. $4 \mathrm{~s}$. Mean synodical revolution, $29 \cdot 5305887215$ solar days, or - . 2 29d. $12 \mathrm{~h} .44 \mathrm{~m}$. $2 \mathrm{~s}$. Mean motion in a mean solar day, . . . . . . . $13^{\circ} 10^{\circ} 35^{\prime \prime}$ Inclination of orbit, - . $5^{\circ} 8^{\prime} 47^{\prime \prime}$ Inclination of axis, . . . . . . . . . . . $1^{\circ} 30^{\prime} 10^{\prime \prime}$

Apparent diameter when nearest to us, . . . . . . . . . . . . $33^{\prime} 3 l^{\prime \prime}$ $31^{\prime} 07^{\prime \prime \prime}$ $29^{\prime} 21^{\prime \prime}$

Diameter, to earth, as 1 to $3 \cdot 6655$, or about . . . . . 2160 miles. Volume, earth as I,

Density, that of the earth being 1 ,

4. Satellites of Jupiter.

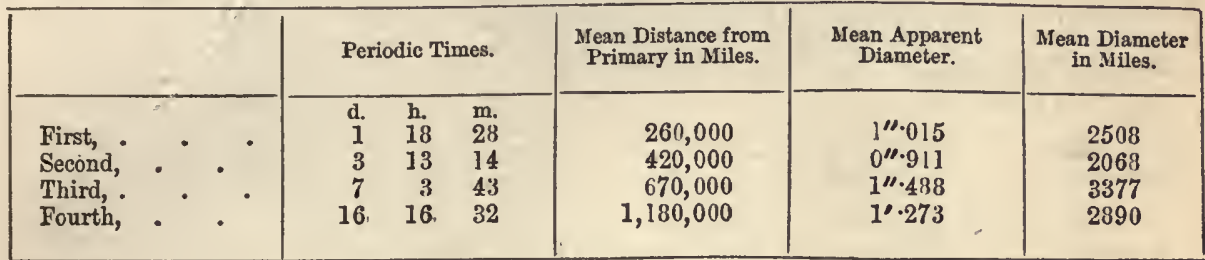

\section{Satellites of Saturn.}

\begin{tabular}{|c|c|c|c|c|}
\hline & Periodic Times. & $\begin{array}{l}\text { Mean Distance from } \\
\text { Primary in Miles. }\end{array}$ & Discoverers. & $\begin{array}{c}\text { Date of } \\
\text { Discovery. }\end{array}$ \\
\hline $\begin{array}{l}\text { 1. Mimas, } \\
\text { 2. Enceladus, . } \\
\text { 3. Tethys, - } \\
\text { 4. Dione, . } \\
\text { 5. Rhea, . } \\
\text { 6. Titan, . } \\
\text { 7. Hyperion, } \\
\text { 8. Iapetus, . }\end{array}$ & $\begin{array}{rrr}\text { d. } & \text { h. } & \text { m. } \\
0 & 22 & 37 \\
1 & 8 & 53 \\
1 & 21 & 18 \\
2 & 17 & 41 \\
4 & 12 & 25 \\
15 & 22 & 41 \\
22 & 7 & 7 \\
79 & 7 & 55\end{array}$ & $\begin{array}{r}120,000 \\
150,000 \\
190,000 \\
243,000 \\
340,000 \\
788,000 \\
1,000,000 \\
2,297,000\end{array}$ & $\begin{array}{l}\text { W. Herschel, } \\
\text { W. Herschel, } \\
\text { D. Cassini, } \\
\text { D. Cassini, } \\
\text { D. Cassini, } \\
\text { C. Huyghens, } \\
\left.\begin{array}{l}\text { W. Lassell and Prof. } \\
\text { Bond, } \\
\text { D. Cassini, }\end{array}\right\}\end{array}$ & $\begin{array}{l}1789 \\
1789 \\
1684 \\
1685 \\
1684 \\
1655 \\
1843\end{array}$ \\
\hline
\end{tabular}

\section{Satellites of Uranus.}

\begin{tabular}{|c|c|c|c|c|c|c|}
\hline & & \multicolumn{3}{|c|}{ Periodic Times. } & \multirow{2}{*}{$\begin{array}{l}\text { Discoverers. } \\
\text { Lassell, } \\
\text { Sir W. Herschel, } \\
\text { Sir W. Herschel, } \\
\text { Sir W. Herschel, }\end{array}$} & \multirow{2}{*}{$\begin{array}{r}\text { Dates of Discovery. } \\
1847 \\
1787 \\
1787 \\
1787\end{array}$} \\
\hline $\begin{array}{l}\text { 1. Ariel, } \\
\text { 2. Umbriel, } \\
\text { 3. Titania, } \\
\text { 4. Oberon, }\end{array}$ & ${ }^{\circ} \cdot{ }^{\circ} \cdot$ & $\begin{array}{r}\mathrm{d} \\
2 \\
4 \\
8 \\
1: 3\end{array}$ & $\begin{array}{c}\text { h. } \\
12 \\
3 \\
16 \\
11\end{array}$ & $\begin{array}{l}\mathrm{m} \\
29 \\
28 \\
56 \\
7\end{array}$ & & \\
\hline
\end{tabular}

\section{Satellites of Neptune.}

One certain ; periodic time, approximately, $5 \mathrm{~d}, 21 \mathrm{~h}, 2 \mathrm{~m} ., 43 \mathrm{~s}$. ; mean distance, about 21 semi-diameters of the planet. 


\section{Periodical Comets.}

\begin{tabular}{|c|c|c|c|c|c|c|c|c|}
\hline Period in Days, & . . & $\begin{array}{l}\text { Halley's. } \\
27,865\end{array}$ & $\begin{array}{c}\text { Encke's. } \\
1205\end{array}$ & $\begin{array}{c}\text { Biela's. } \\
2393\end{array}$ & $\begin{array}{c}\text { Faye's. } \\
2718\end{array}$ & $\begin{array}{c}\text { De Vico's. } \\
1993\end{array}$ & $\begin{array}{c}\text { Brorsen's. } \\
2042\end{array}$ & $\begin{array}{c}\text { D'A irest's } \\
2: 53\end{array}$ \\
\hline
\end{tabular}

\section{OBSERVATORIES.}

The following are registered in the "Nautical Almanac," with their latitudes and longitudes :-

\section{Public Observatories.}

Altona.

Armagh.

Athens.

Berlin.

Bilk.

Bonn.

Breslan.

Brussels.

Buda (Ofen).

Cambridge.

Cambridge, United States.

Cape of Good Hope.

Christiana.

Copenhagen.

Cracow.

Dorpat.
Dublin.
Durham.
Edinburgh.
Geneva.
Georgetown College,
United States.
Gotha (Seeberg).
Gottingen.
Greenwich.
Hamburgh.
Kazan.
Konigsberg.
Kremsmunster.
Leipsic.

Leyden.
Liverpool.
Madras.
Manheim.
Marburg.
Marseilles.
Milan.
Modena.
Moscow.
Munich.
Naples.
Nicolæf.
Oxford.
Padua.
Palermo.

Paris.

Petersburgh.

Portsmonth.

Prague.

Pulkowa

Rome.

St Fernando, near Cadiz.

Stockholm.

Turin.

Upsala.

Venice:

Vienna.

Warsaw

Washington.

Wilna.

\section{Private Olservatories.}

\begin{tabular}{|c|c|c|c|}
\hline $\begin{array}{l}\text { Birr Castle, } \\
\text { Bradstones (Liverpool), } \\
\text { Haddenham (Bucks),.. } \\
\text { Hartwell, } \\
\text { Haverhil,, } \\
\text { Kensington, . } \\
\text { Markree, . . }\end{array}$ & $\begin{array}{l}\text { Earl of Rosse. } \\
\text { W. Lassell, Esq. } \\
\text { Rer. W. R. Dawes. } \\
\text { Dr Lee. } \\
\text { W. W. Boreham, Esq. } \\
\text { Sir James South. } \\
\text { - E. J. Cooper, Esq. }\end{array}$ & $\begin{array}{l}\text { Olmutz, } \\
\text { Redhill, } \\
\text { Regent's Park, · · } \\
\text { Senftenberg, } \\
\text { Stone (Aylesbury), } \\
\text { Tarn Bank, } \\
\text { Wrottesley Hall, . }\end{array}$ & $\begin{array}{l}\text { Herr von Unkrechtsberg } \\
\text { R. C. Carrington, Esq. } \\
\text { G. Bishop, Esq. } \\
\text { Baron von Senftenberg. } \\
\text { Rev. J. B. Reade. } \\
\text { J. Fletcher, Esq. } \\
\text { Lord Wrottesley. }\end{array}$ \\
\hline
\end{tabular}

Note-While this sheet is passing through the press, we learn the discovery of another planetoid by Mr Searle, of Albany, in the United States, not yet named, making the fiftyfifth known member of the group.

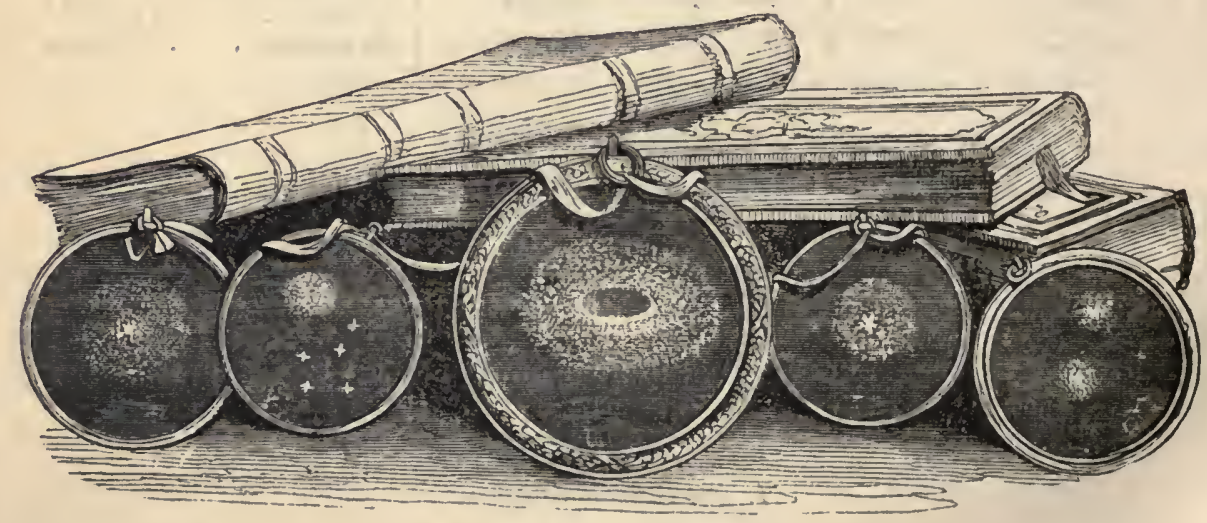




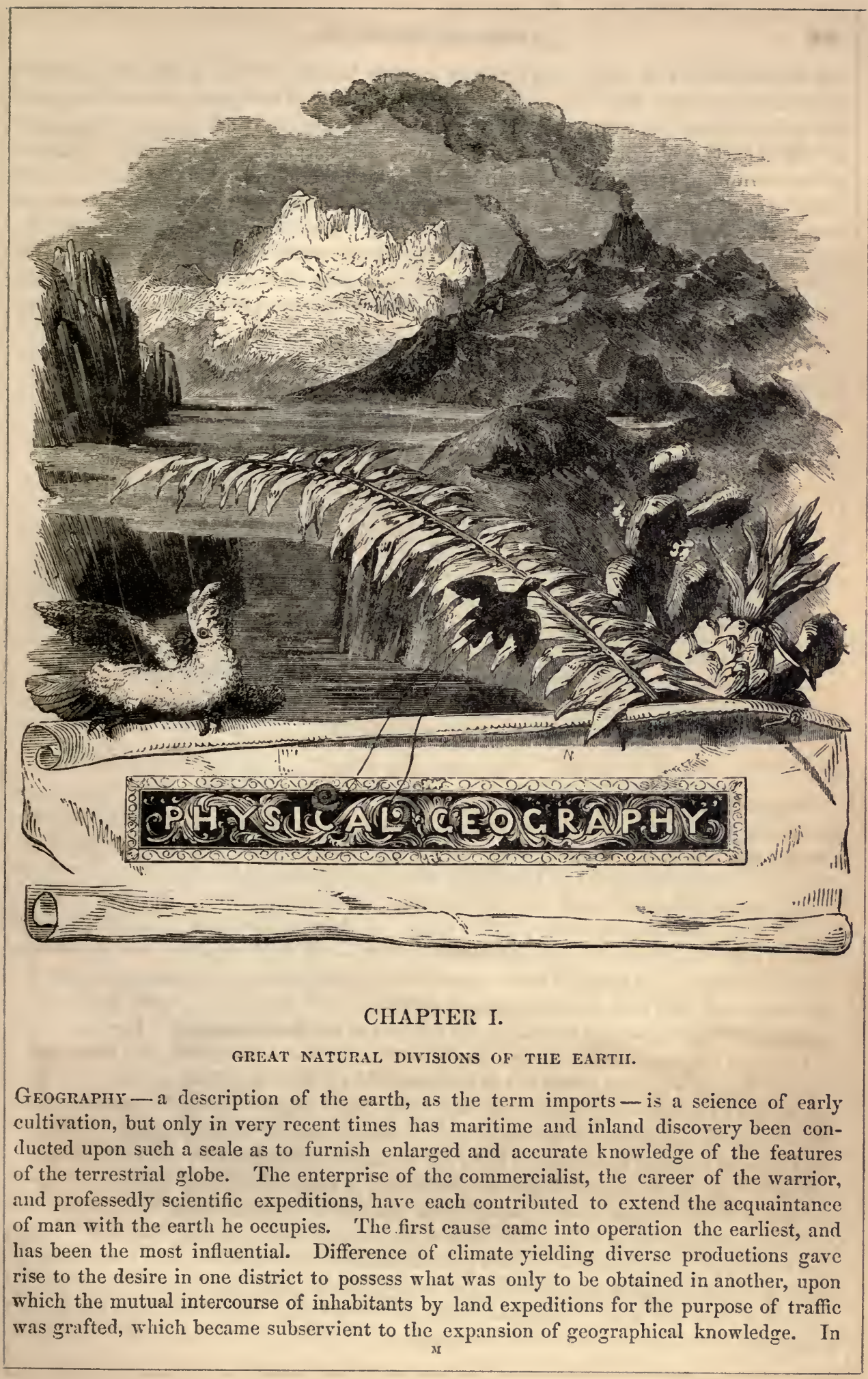


the earliest notices of Egypt that occur in profane history, we find it become the centre of an extensive land commerce. The merchants of Ethiopia brought gold, and ivory, and slaves; the Phonicians, wine and timber; the Arabians, incense and spice; the Egyptians giving in exchange their corn, fine linen, robes, and carpets. The company of traders going down to Egypt, to whom Joseph was sold by his brethren, is the earliest recorded instance of a foreign commercial transaction, and has all the genuine features of a caravan crossing the desert at the present hour. Commerce likewise matcrially assisted to lay the foundation of oceanic adventure, and gradually to improve the means of conducting it with safety, the frail and simple raft that was paddled along the rivers giving place to the stronger vessel fitted to encounter the perils of the sea. Tyre and Sidon communicated with

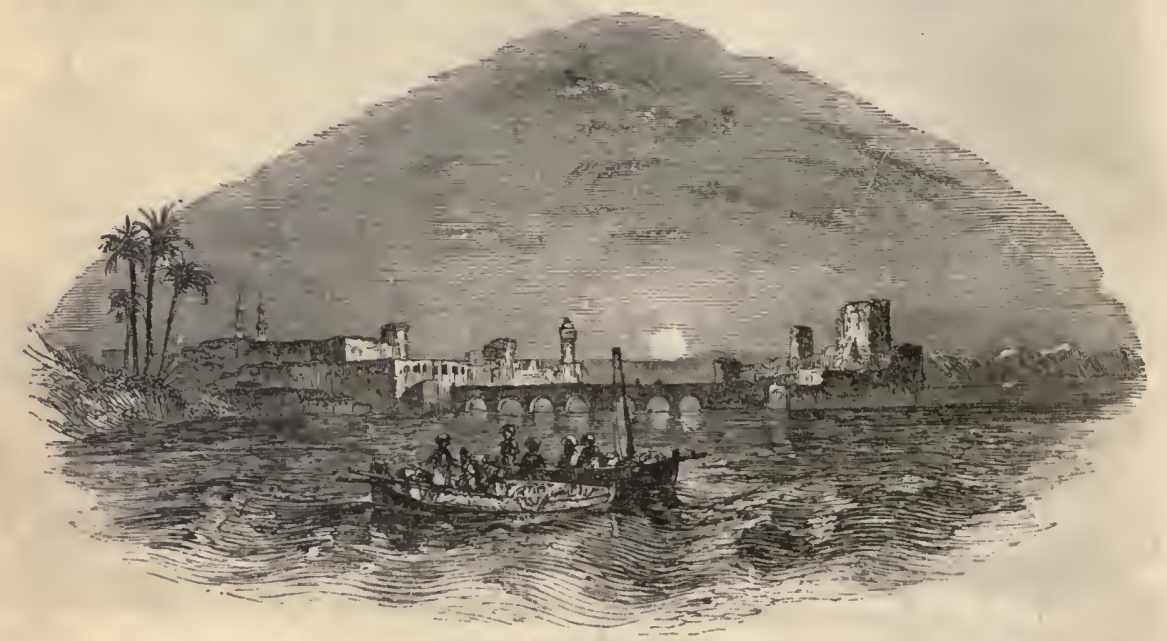

Port of Sidon from the Sea.

Western Europe through their mariners, and their merchant princes trafficked with India on the east. Thus was obtained by the nations on the east and south banks of the Mediterranean, and bordering thereto-the primitive seat of civilisation - a general acquaintance with each other's localities, and more distant regions, afterwards increased by the military expeditions of Alexander, and the all-absorbing ambition of Rome. But the world, as known to the ancients, was a very paltry span. Of the whole western Continent-of the greater part of Africa - of North-eastern Europe - of Northern Asia and its eastern limits - Ptolemy, the last and most accomplished geographer of antiquity, was entirely ignorant; and with him the cultivation of geography and astronomy may be said to have terminated, till their mutual revival by the subjects of the Eastern caliphs. In those views of the earth embraced by the Arabs, the Homeric notion of a circumambient ocean had a place. The dry land was conceived to be bounded by a zone of waters, which was its absolute limit; the Atlantic receiving the title of the Sea of Darkness, and the northern ocean that of the Sea of Pitchy Darkness. It is little more than three centuries and a half since the shroud of mystery was removed from the western flood by the bold hand of Columbus, and light was poured upon the Sea of Darkness. A course of discovery was then commenced which has now opened to our view a tolerably exact map of the world-the extent and configuration of its great natural divisions of land and sea, with their respective superficial characteristics. There yet remains however to be unveiled a considerable portion of "terra incognita," chiefly situated within the arctic and antarctic circles, in Central Africa, and in Australasia; and we have still much to learn with reference to the geographical character of regions which have long been known and repeatedly visited. 
Geography, in the widest acceptation of the term, embraces a description of the true figure and motions of the earth - the aspect of the superficies, and the mode in which its respective parts have been arranged; with the extent, population, resources, knowledge, and arts of particular localities. These are the Mathematical, Physical, and Civil branches of the subject; to the second of which the present section is devoted. It is the province of the physical geographer to deal with the features of the external surface of the earth's mass; and, in strictness of meaning, this is the boundary of his department. But it is customary also to treat of atmospheric phenomena and influence; of the variations of climate and temperature ; of the distribution of the different classes of organised beings ; and of the causes which have determined the distribution - an arrangement which it is difficult to follow without trenching upon ground occupied by other sciences. It is desirable, however, to respect the boundaries which belong to the various branches of physical enquiry; and thereforc, while it will be impossible to abstain from touching the domains of Geology, Botany, and Zoology, the avoidance of a trespass will be studied.

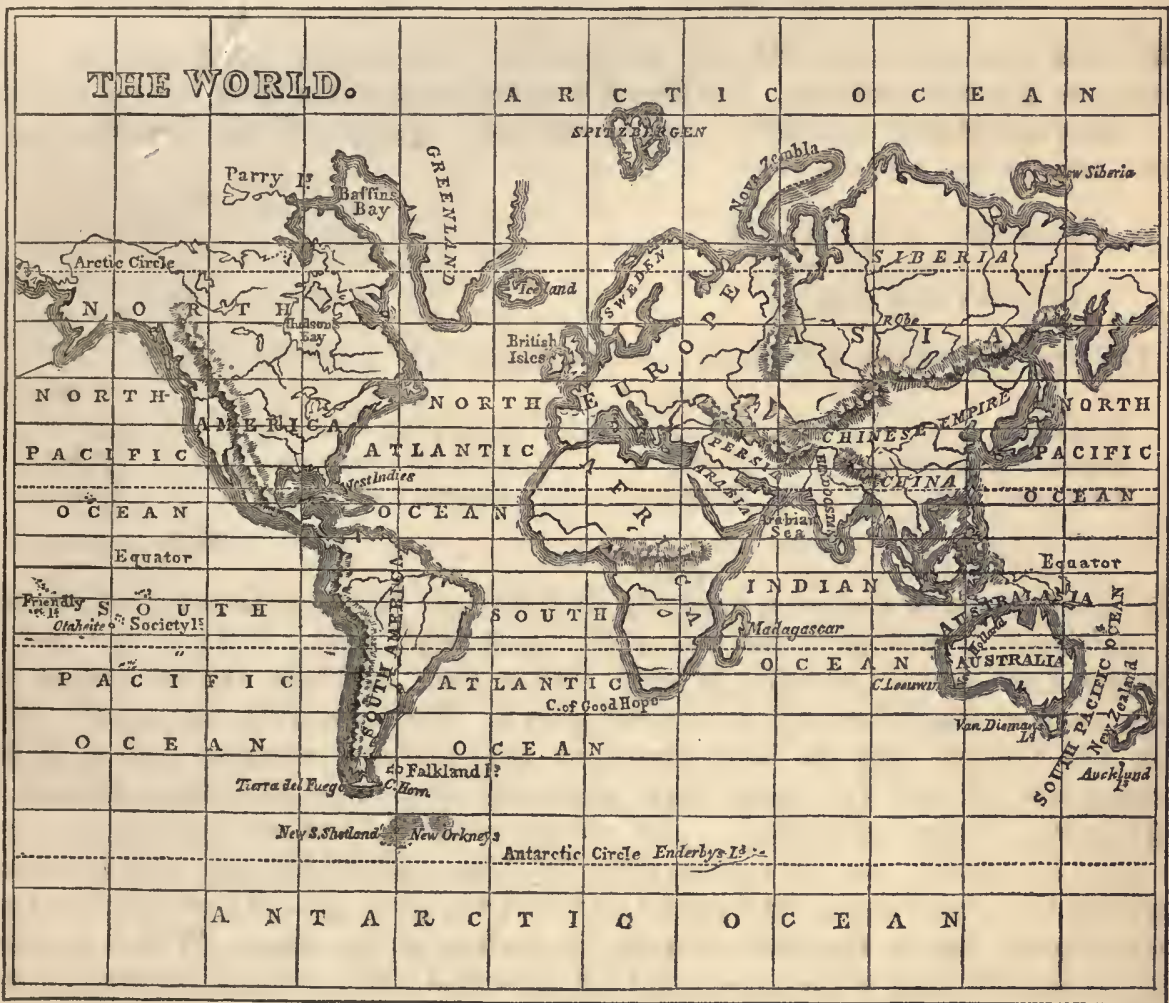

The terrestrial surface presents us with areas of Iand and water constituting two great Natural Divisions. The outlines of each are in a state of constant change; but the alteration proceeds so slowly, that apparently they are the same at present, with a few comparatively unimportant exceptions, as at the earliest date of geographical information. There is a remarkable difference in the extent of these divisions. The whole area of the globe includes about 197 millions of square miles, of which seven-tenths are usually given as the proportion of space occupied by the waters, approaching to 138 millions of square miles, leaving less than 60 millions for the area of the land. The distribution of the two is also as unequal as their extent. If we take London to be the centre of a hemisphere, 
it will contain by far the greater portion of all the land upon the face of the globe. The opposite hemisphere, of which the antipodes of London will be the centre-a point to the south-enst of New Zealand, near to Antipodes Island-will be a territory in which the ocean immensely preponderates, the principal tracts of land consisting of Australasia, and the southern extremity of South America. If we consider the two hemispheres into which the earth is divided by the equator, and the zones into which each is subdivided, the unequal distribution of the land and water will also be very apparent. Regarding the whole area of each zone as represented by 1 , the proportion of land has been stated as follows:-

In the northern part of the torrid zone
In the northern temperate zone

The great preponderance of the land on the north of the equator over that on the south is obvious from this estimate. The former is in proportion to the latter as 16 to scarcely 5. The proportionate quantity of each, in each zone, according to the preceling statement, may be thus expressed :-

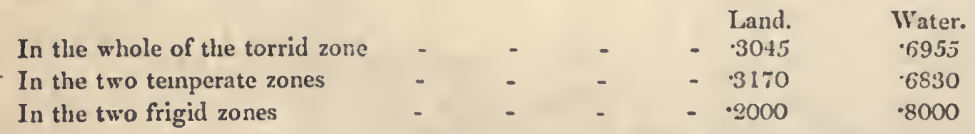

The superficial extent of the land in each zone is generally estimated to be :-

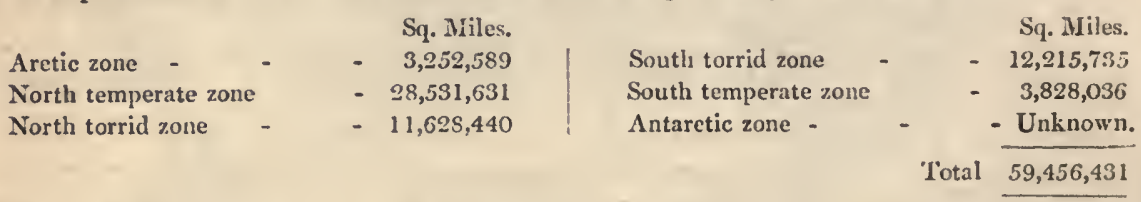

The course of recent discorery, especially since the year 1838, renders some modification of these tables necessary in the case of the south frigid zone. Down to the time of Captain Cook it was generally believed that a great continent existed around the antarctic pole, which figures in the ancient maps as "Terra Australis Incognita." This idea was founded upon the loose reports of some southern voyagers, and upon the presumption that such a continent must necessarily exist to counterbalance the mass of land in the northern hemisphere. The second voyage of Cook was expressly designed to solve the problem, and, after penetrating into high southern latitudes witlout finding anything but a few islands, the supposed continent was given up, and land was imagined to exist only slightly depressed beneath the surface of the ocean. Within a recent interval the enterprise of France has sent out Dumont d'Urville, that of America Charles Wilkes, and that of England James Clark Ross; and an extensive coast-line has been discovered, probably the boundary of a south polar continent. The preceding calculation, therefore, requires alteration so f:rr as it relates to the south frigid zone, but this will not affect the general statement of the quantity of land in the northern hemisphere being still vastly greater than that in the southern.

The waters of the globe circumscribing the land form one great continuous ocean. This is divided by imaginary lines into various parts, to each of which a distinct name is assigned, for the sake of clear and easy reference. The following are five grand divisions:- 
1. Northern Basin, or Arctic Oceain-Extends from the northern shores of Europe, Asia, Anerica, and the astronomical line of the arctic circle, around the north pole. It is largely covered with compact ice in winter; and its higher latitudes have never been penetrated.

2. Western Basin, or Atlantic Ocean-Extends between America on the west; Europe and Africa on the east; the arctic and antarctic circles on the north and south; and is divided by the equator into the North and South Atlantic. It has the general form of a grand canal, upwards of 9000 miles in length, by from 900 to 5000 in breadth; and covers about 25,000,000 square miles. This is the best known section of the world of waters. All civilised nations are either seated directly upon its coast-line, or are proximate to it.

3. The Eastern Basin or Pacific Ocean-Enclosed between America on the east; Asia, the Sunda Isles, and Australia on the west ; the polar circles on the north and south, being divided by the equator into the North and South Pacific. It extends upwards of 9000 miles from north to south, by 12,000 from east to west, following the line of the equator from Sumatra to Peru ; and covers an area of 50,000,000 square miles. This vast expanse was not known to Europeans till the sixteenth century. Its waters were first seen in 1513 by Vasco Nunes de Balboa, from the top of a mountain on the Isthmus of Panama ; and first navigated by Ferdinand Magellan in 1519, who originated the name from the favourable circumstances of the voyagc.

4. The South-Eastern Basin, or Indian Ocean-Bounded by Africa on the west; Asia on the north; the Sunda Isles and Australia on the east; and the antarctic circle on the south. It has an extreme extent of 6000 miles from north to south, by 5000 from east to west; and includes an area of $18,000,000$ square miles. The first known voyage made by Europeans upon any portion of its surface occurred during the return of Alexander the Great from his Indian campaign.

5. Southern Basin, or Antarctic Ocean-Extends around the unexplored lands of the south polar region.

Each of these vast oceanic tracts is divided into lesser compartments, or seas-the denomination given to considerable collections of water penetrating inland. Thus, the Northern Basin has the White Sea, and the Sea of Kara. The Western Basin embraces the Baltic, North, Mediterranean, and Caribbean Seas. The Eastern Basin includes the Yellow Sea, and the Sea of Ohkotsk; and the South-eastern Basin has the Red, Arabian, and Bengal Seas. Still smaller collections of water running into the land are classed as gulfs or bays, as the Gulf of Bothnia, a branch of the Baltic. Where the passage which connects a collection of water nearly land-locked with the outlying ocean is narrow, it is called a Channel; and, when still narrower, a Strait; and a Sound, when it is shallow. As an example of this, we have the English Channel, the Straits of Dover, and the Sound connecting the Baltic and the North Sea.

The other great natural division of the surface is distributed chiefly into two immense spaces, to which the term continent is applied - a Latin derivative, signifying that which is connected. One of these, including Asia, Africa, and Europe, is known as the enstern, and the other, comprising America, as the western continent, because the one lies to the east, and the other to the west, of the meridian of the Fcroe Isles, from which longitude was formerly reckoned. Those portions of the great tracts of land which have peculiar natural features are ranged in classes according to their contour. To a considerable projection from the mainland into the sea, so as to be nearly enclosed by it, and approaching almost to an island, as Italy, Spain, and the Morea, the term peninsula is applied. $\Lambda$ narrow slip of land connecting two great masses, having the sea on its other sides, is called an isthmus, as the Isthmus of Suez, connecting Asia and Africa. The smaller projections of land into the sea are variously denominated capes, headlands, and promontories. These 


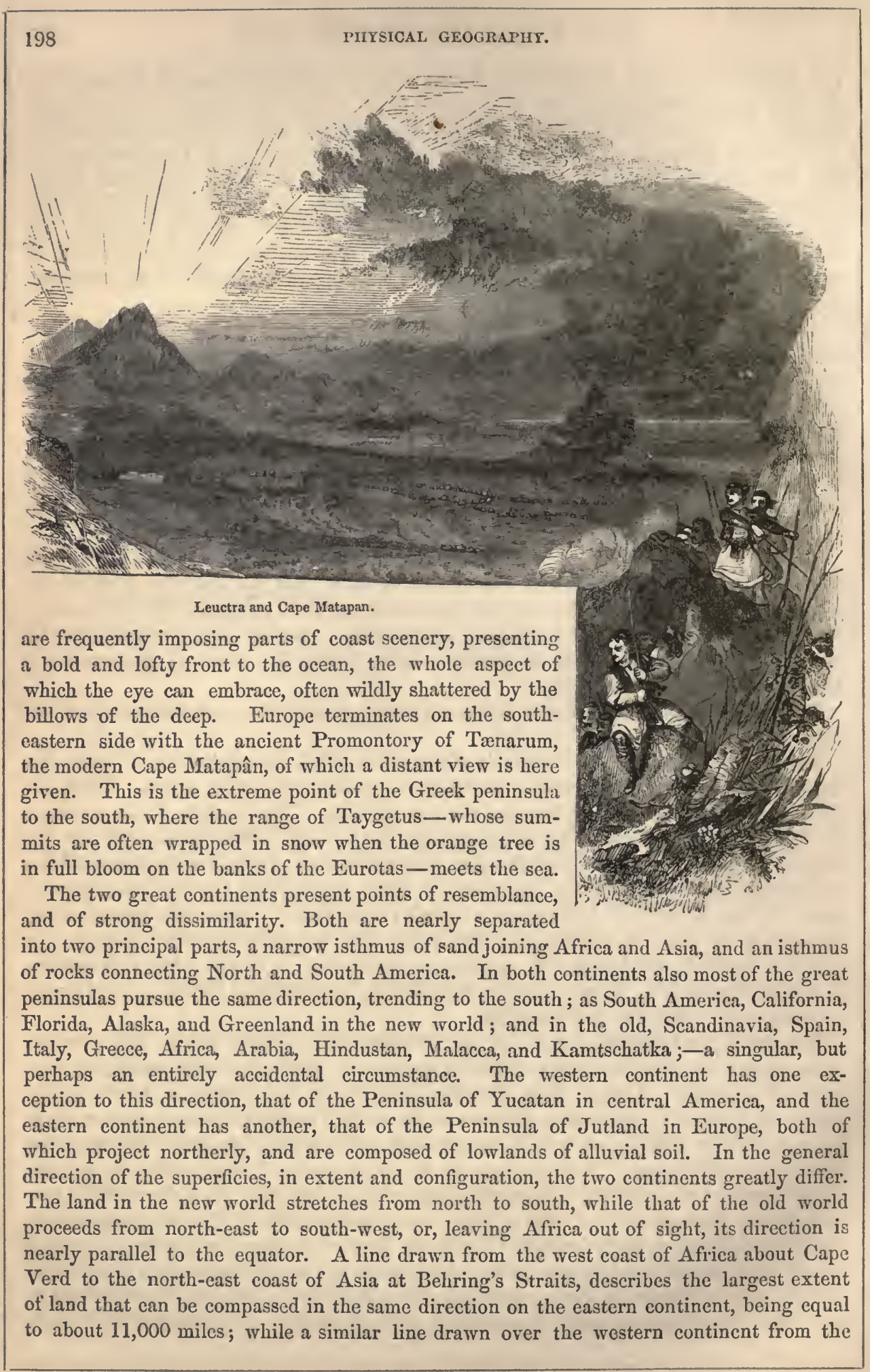


northern extremity of North America to Cape Horn will fall short of the former by an extent of about 2000 miles. Looking at the outline of the continents, we see the const of the old world, excepting Africa, indented perpetually by considerable bays, gulfs, and inland seas, while the whole western and the south-eastern sides of the new world are remarkably smooth, and present no example of a great inland sea. A mutual adaptation appears in the configuration of the coast lines of the continents between which the Atlantic rolls ; and, if joined together, the eastern projection of South America seems as though it would fit into the indentation of Central Africa, while the projection of Western Africa appears adapted to fill up the indentation of Central America. The impression naturally made by this peculiarity of outline is, that the two continents once formed an undivided territory, which some tremendous convulsion rent in twain, and put asunder.

Besides the great continents, there are smaller portions of land surrounded by water in their neighbourhood, or dispersed over the ocean. These are classed as islands, a group of which is called an archipelago, a word of doubtful origin, but first applied to the islands of the Egean Sea, and perhaps a corruption of Egean connected with pelagus, the sea. The continents are in reality vast islands, and Australia, ranked as an island, is considered by some geographers, as entitled to be regarded a continent, on account of its extent. The Pacific Ocean has several large families of islands, to which distinct names have been given. Those nearest the Asian coast, extending to $10^{\circ}$ south latitude and $130^{\circ}$ east longitude, form one great division, styled the Indian Archipelago. Australia, New Zealand, the New Hebrides and adjacent islands, form another division, under the name of Australasia, or southern lands. The remaining islands east of the Philippines and New Zealand are classed together, forming the Polynesia of the English, and the Oceanica of the French. Those clusters of islands which are found in the vicinity of the main land have frequently all the appearance of having been once connected with it, and separated by some great inundation of the ocean which submerged the levels and slighter elevations. A great number of islands are simple accretions of sand deposited by the ocean in the course of ages. Others are coral formations, or the work of submarine volcanic action; while many are undoubtedly the summits of chains of mountains rooted in the mysterious bed of the deep, often in continuity with mountain chains on shore. There are some examples of small patches of rock, peeping above the surface of the ocean, at a considerable distance from the coast, which are evidently the peaks of independent submarine mountains. Rockall in the Atlantic is a specimen of this class, perhaps without a parallel in all its circumstances. It lies 290 miles away from the mainland of Scotland, 260 from the north coast of Ireland, and 184 from any other land, and is nothing but a block of granite, seventy feet high, and a hundred yards in circumference, apparently from a distance floating on the waves. There is scarcely another instance to be found in the wide realm of the ocean of an isle so small and so solitary.

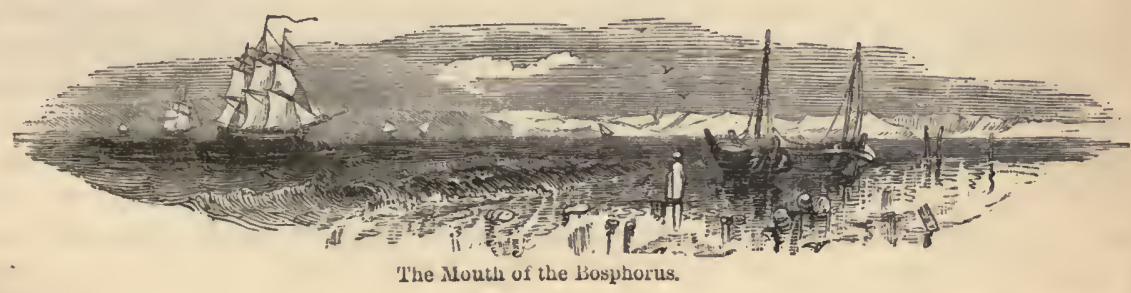




\section{CHAPTER II.}

HIGI LANDS OF TIIE EARTII.

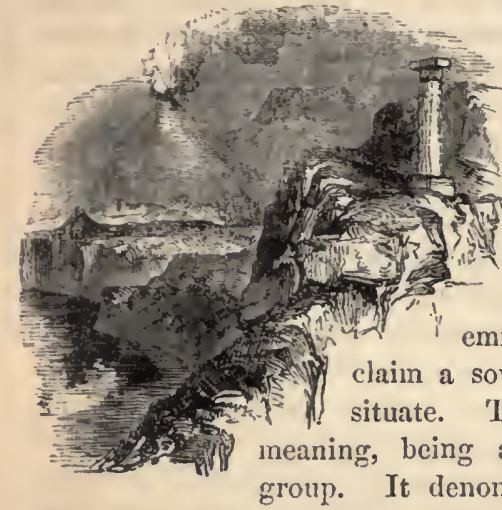
another district abounding with those of a superior class would be regarded as mere hillocks. It is impossible to avoid this indefinite nomenclature; but no confusion will arise in the particular application of the term, if reference is made to the general level of the adjoining surface. The slighter acclivities, whether crowned with grove and forest, - whether planted with vegetable productions by the cultivating hand of man, or left to the natural grasses, form the most pleasing features of the soil; while the loftier projections of the superficics, stamped with an air of dignity, and indicating an upheaving power of irresistible might in their construction, present to the eye a thousand imposing combinations. Fringed with the dark green pine, and spotted with the lighter mosseswith naked heads, as if in reverence of an invisible Superior-the mountains captivate while impressing the imagination. 'They are specimens of the fine arts of Nature, the gems of continents, wonderful examples of the diverse forms by which the ideas of Beauty, Majesty, and Power may be expressed.

The high lands occur in isolation, or in groups, ridges, and claains. Groups of mountains have sometimes the appearance of elevations radiating from a central point where the height is the greatest, forming a kind of circular cluster; but clusters of very irregular form occur without any principal eminence. 'The most general arrangement of mountains is in chains and ridges - a ridge being simply an inferior chain. To this class those elevations belong which are so distributed as to form a kind of zone or band, the breadth bearing iittle proportion to the length; and whatever direction the zone may take, and wliatever shape it may assume - that of a straight line, an angle, or a curve-it is said to constitute a chain. The term is not meant to signify an unbroken series of projections, answering to the appearance of a street in which the buildings, though diversified, are attached, but a series of parts, in many cases distinct, yet lying in the same general direction. Many chains consist of one grand central range, accompanied by two subordinate ranges of inferior elevation, one on each side, at a diverging distance from the main body, and sometimes closing up with it. Smaller chains frequently branch off from the main ridge in an angular direction, as the Apennines from the $\mathrm{Alps,}$ and minor branches shoot out from these, which are called spurs when their course is short. The highest points of a great chain are usually about the middle, as the pcals of the Alps, the Hinialaya, and the Andes; and the most elevated parts of a branch from the inain ridge are at 
the points of junction witl the parent stem. 'The first-class chains have almost uniformly an abrupt descent on one side, and a gentler declivity on the other. This is the case with the Andes, the Alps, the Pyrenees, the mountains of Scandinavia, and the Ghants of India. It was held by Berghaus that the western side of chains extending north and south is most abrupt, while it is the southern side that is so in the case of those running east and west. But the exceptions to this are numerous, and no general rule upon the point can be advanced, beyond one which applies to chains near the coast, which have their steepest sides fronting the ocean. Taurus, Atlas, and Lebanon present their most precipitous and craggy faces to the Mediterranean, and the Andes likewise to the Pacific. The great chains in general follow the direction in which the land of the continents where they are situated has its greatest extent. Thus the ranges, which, with only a few breaks, stretch from the south-west coast of Europe to the north-east coast of Asia, traverse the old world in the line of its maxinum longitude; and the Andes of South America, continued by the Rocky Mountains of the North, travel through the new world in the direction of its greatest length. 'The course of subordinate chains, also, as of the Apennines in Italy, the Dofrefeld in Norway and Sweden, and the Ghauts in Hindùstan, corresponds with the general direction of these peninsulas.

The length of the principal chains has been computed as follows :-

\begin{tabular}{lr|lr} 
Andes, South Ameriea & - & Miles. &
\end{tabular}

The insulated mountains, or those which are apart from any group or chain, are not

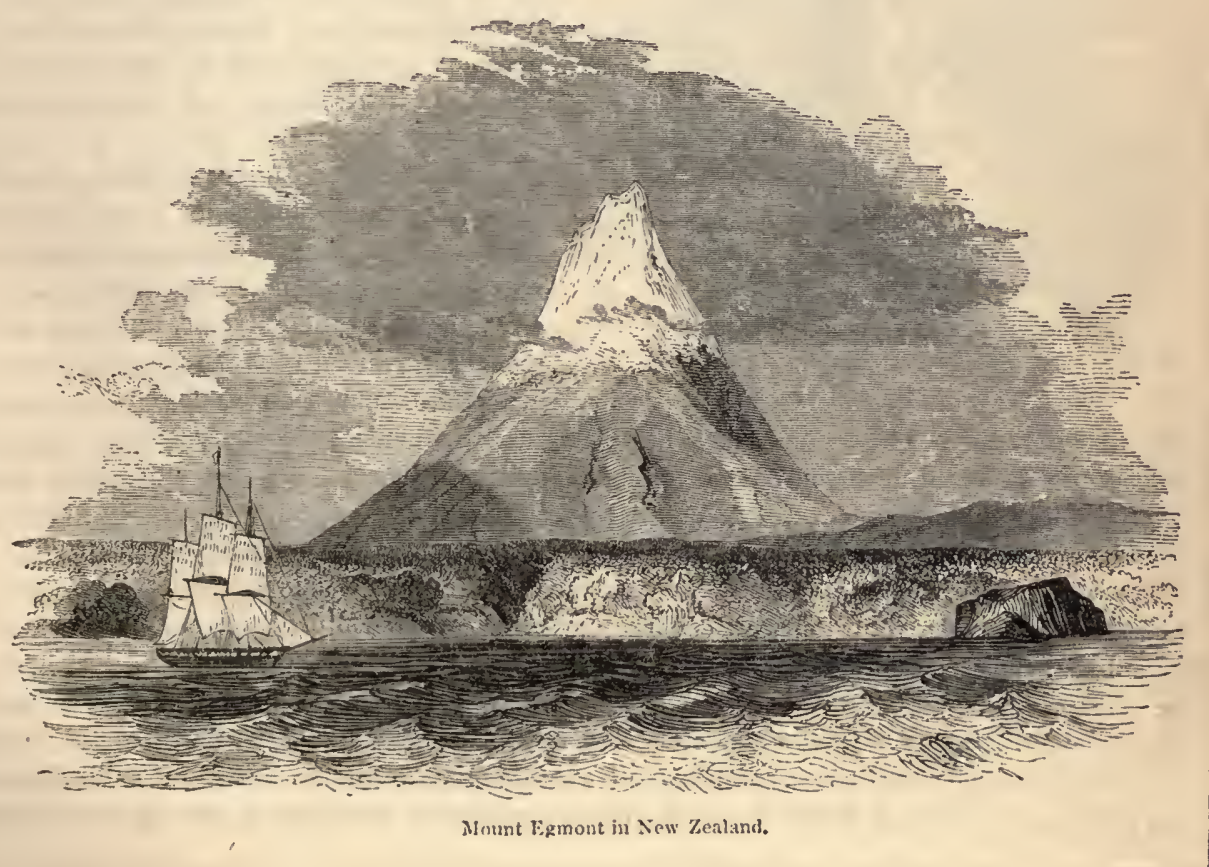


numerous. They are generally, though not always, either active or extinct volcanoes. The rock of Gibraltar, which rises up to the height of 1500 feet from the level beach of the Mediterranean, the Peak of Teneriffe, and Mount Egmont in New Zealand, are fine specimens of this class. The latter is an extinct volcano, and may be seen from a vast distance, ascending above the line of perpetual snow. The mountain is in shape a perfect cone, situated on a projecting headland, about twenty miles from the coast. The neighbourhood is one of the most fertile districts of New Zealand; and has been selected as the site of the settlement of New Plymouth, from whence the symmetrical form and white brow of Pouke-e-aupapa, the ancient name of Mount Egmont, forms a striking object.

The contour of mountains exhibits almost every kind of variety, and their aspect changes as an observer extends his distance from them, lesser irregularities being lost in the general outline, and different colours becoming merged in a uniform shade. The appearance of solitary individual objects is generally conical; but others are circular, elliptical, or saddle-backed. The Table Mountain at the Cape of Good Hope has the shape of a gigantic altar. In the case of a number of contiguous mountains, their summits are often needle-shaped, or like the domes of Roman architecture. In many instances the entire mass resembles a vast wall, with battlements and towers, after the manner of an ancient fortress, and sometimes mountains appear piled upon each other, forming a succession of gigantic terraces. One of the most extraordinary mountains in its configuration is in the Mauritius, a volcanic region, and bears the name of Peter

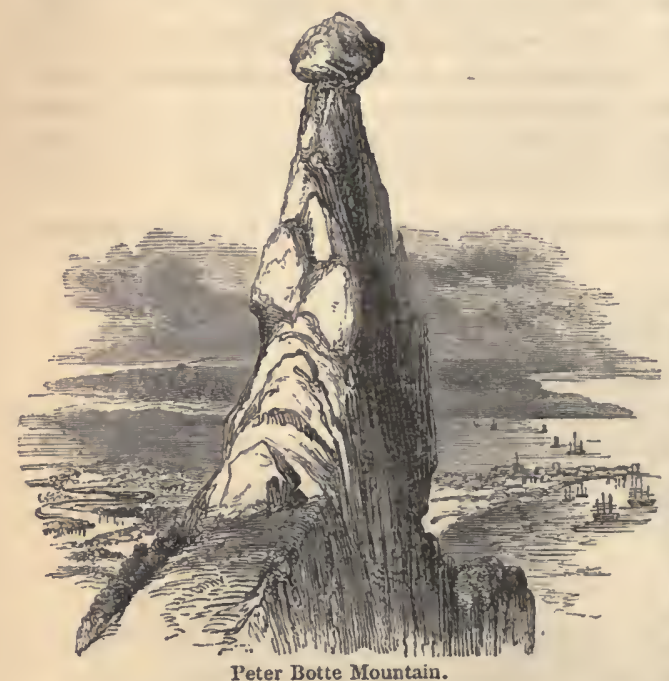

Peter Botte Mountain.

Botte. The name is derived from an unfortunate adventurer, who, according to tradition, after reaching the summit, perished in the descent. An enormous mass, of a globular shape, forms the head of the mountain. It rests upon a pedestal of rock, of a conical form, upwards of three hundred feet high, and overhangs it by several feet. At the bottom of the pedestal, a narrow strip of land runs out, about six feet broad, and twenty yards long, on two sides of which a precipice goes down direct fifteen hundred feet to the plain, the other side being a very steep wooded gorge. The view from the narrow ledge, as may be imagined, is tremendous in the extreme, and the still ascending conical rock with its overhanging head seems secure enough from the intrusion of man. The Peter Botte has been usually considered inaccessible. Many endearours to reach the top have been made without success, but the enterprise was at length effected in the year 1832, by the skill and daring of a party of British officers, who, after surmounting the uppermost block, spent the night immediately under it.

The internal structure of elevations, as well as their external shape, displays great diversities. In fact, their outward character has been determined in a great degree by the substances of which they are composed. The granite mountains are the loftiest upon the surface of the globe, and present the most rugged and broken aspect, with very precipitous sides. Those of gneiss and mica slate are not so wild and irregular, nor are their declivities so steep; and those composed of secondary formations-sandstone, "limestone, and greywacke-are of inferior elevation compared with the former, and the declivities 
are more gentle. Humboldt has pointed out a striking difference between the great mountains of the eastern and western continents. Mont Blanc, and others of the higher Alps, lift their granite heads far above the clouds, and, with the Himalaya, form the loftiest points of the old world; but in America the newest flotztrap or whinstone, which in Europe appears only in low mountains, or at the foot of those of great magnitude, covers the mightiest heights of the Andes. Chimboraço and Antisana are crowned by vast walls of porphyry, rising to the height of six or seven thousand feet; while basalt, which in our continent has never been observed higher than four thousand feet, is, on the pinnacle of Pichincha, seen rearing aloft its crested steeps, like towers amidst the sky. Other secondary formations, as limestone, with its accompaniment of petrified shells and coal, are also found at greater heights in the new than in the old world. though the disproportion is not so remarkable.

The most elevated European sites are found in the Alps, many of which have been reached by the foot of man, but not without great difficulty and peril, and in the attempt fatal accidents have repeatedly occurred. Mont Blanc, the centre and highest summit of the great Alpine range, an enormous mass of primitive rock, rises to the height of 15,750 feet above the sea level, and is visible at Dijon, a distance of one hundred and forty miles. The form of the mountain is pyramidal as seen from the north and south, but from the valley of Chamouni it resembles the back of a dromedary, on account of which Bosse de Dromedaire is one of its local titles. The extreme summit, a ridge nearly two hundred feet in length, was reached for the first time in August 1785, by Dr. Paccard and James Balma; and the year following, Saussure succeeded in the same enterprise, remaining five hours upon the top making scientific experiments. In the autumn of $1834, \mathrm{Dr}$. Barry ascended, passing by "chasms of unfathomable depth, towers of ice, caverns of almost crystal walls, splendid stalactites guarding the entrance." His principal guide had been up eight times before, the survivor of four swept away by an avalanche in Dr. Hamel's attempt in 1820. In the year 1804, the Archduke John offered a reward to whosoever reached the summit of the Ortler Spitz, the highest of the Rhætian Alps. A native of the Passayer, accompanied by two peasants, accomplished the enterprise, before considered impracticable, starting with the full moon at midnight. Travellers, naturalists, and the daring peasants of the country have scaled many of the other lofty Alpine peaks, and now the Jungfrau or Virgin Mountain, so called from its supposed inaccessibility, has had the foot of the man of science, Professor Forbes, upon her brow.

The highest points of Africa are on the eastern side, a little south of the equator, where Kilimandjero, from being covered with perpetual snow, must have an elevation of at least 20,000 feet. The Cameroons, on the west coast, with some summits of Atlas, and the Abyssinian highlands, are truly Alpine heights.

In south-western Asia, the Peak of Demavend, about forty miles from Teheran, in Persia, was ascended by Mr Taylor Thomson in the year 1837, who found its height, by barometric measurement, to be 14,300 feet above the level of the ocean. The snowcrowned head of the towering Kasibeck, situated towards the European extremity of the pass of the Caucasus from Russia into 'Georgia, is estimated by Professor Parrot at 2400 fathoms, or 14,000 feet, above the level of the Black Sea; but this is exceeded by Elbûrz; which attains the height of 18,490 feet. The loftiest peak of the celebrated Ararat is little inferior. "These inaccessible summits," says Sir Robert Ker Porter, " have never been trodden by the foot of man since the days of Noah." Tourneforte was obliged to abandon the enterprise in the year 1700, after having endured great fatigue. At a more recent period, the Pacha of Bayazeed fitted out an expedition, and built huts supplied with provisions at different stations; but his people suffered severely amid the snows and masses of ice, and returned without accomplishing their purpose. The state- 
ment of Porter, true in 1820, ceased to be so nine years afterwards. Professor Parrot in 1829 effected the ascent of Ararat, and in 1834 the mountain was again sealed by M. Autonomoff, in order to vindicate the reputation of the Prussian traveller, whose veracity had been called in question by the Armenian eeclesiastics. In 1857, an English party likewise gained the summit. Its height is given at 17,260 feet, which exceeds by 1525 feet the highest elevation of Europe; but the table-land of Armenia, from which it rises, is stated by Ritter to be 7000 feet above the level of the sea. There is a far greater elevation attained by some of the Himalaya Mountains, which separate the valleys of Cashmere from Thibet, and present the loftiest projections to be found upon the terrestrial surface. In this range, Dhwalagiri, 28,000 feet, was formerly supposed to be the highest point; but in 1848 , this distinction was given to Kunchinjinga, 28,178 feet. A still more elevated peak was found in 1857 , which, having no particular local name, has received that of Mount Everest, after a former surveyor-general. This is 29,000 feetnearly five miles and a half above the sea-level ; and is, as far as our present knowledge goes, the the culminating point of the world.

In America, the loftiest projections of the surface are the volcanic cones of the Andes. The lighest of these, Aconcagua, on the north of Valparaiso, in Chili, rises 23,910 feet, which is nearly a mile lower than Mount Everest. But it is a far greater altitude than is attained by any volcano of the old world. The mean height of the Andes, apart from projecting cones, is estimated at 8000 feet in Chili, and 15,000 in Peru.

The estimated heights of the principal mountains are given in the annexed table. A few of these have not been determined with accuracy. A remarkable instance of close approximation in calculating the height of Etna, occurred between independent observers, pursuing different methods, at distinct times, unknown to each other. The Sicilians, vain of their mountain, attributed to it an elevation of 13,000 feet, which Admiral Smyth, when surveying in the Mediterranean, reduced by more than 2000, an abridgment which raised no little anger and contention. The result was subsequently verified by Sir John Herschel :- "The height," observes the latter, "of the higher of the two summits of Etna, which I measured barometrically in 1824, came out to be 10,8721 English feet above the level of the Sea of Catania. Smyth's result, with which I was not acquainted till long after the calculation of my own, gave 10,874. I have also, somewhere or other, though I cannot lay my hands on it, a memorandum of a zenith distance, observed by Cacciatore, of the summit of Etna, from Palermo ; the result of which, calculated by a terrestrial refraction index, concluded by Cacciatore and myself, from observations by him and myself, on Monte Cuccio, gave a total altitude of $\mathbb{E}$ tna agreeing within a very few feet indeed of the same; so that I have no doubt the above is very good, unless that summit have since been blown up or blown down." It has been imagined that all the mountain systems form one grand consecutive scheme of high lands stretching through the extent of both continents, in the form of a vast irregular arch. Could a spectator command a view of the globe, supposing him to stand in Australia facing the north, he would see on his right hand a continuous system of high mountains extending along the entire coast of America, linked with Asia by the Aleutian Isles. He would see also a chain on his left hand running along the coast of Africa, passing through Arabia into Persia, mingling there with the range that traverses Europe from the Atlantic, and merging in the mountains of central Asia, which are continued north-easterly to Behring's Straits, and form the spine of the old world. Thus, while these chains of mountains, when viewed in detail, appear isolated and utterly unsystematic, yet when the globe is contemplated upon a grand scale, they seem to constitute one immense range in the form of an irregular curve, with outshoots from it, bounding the bed of the Pacific, on tine north, east, and west. 
Europe.

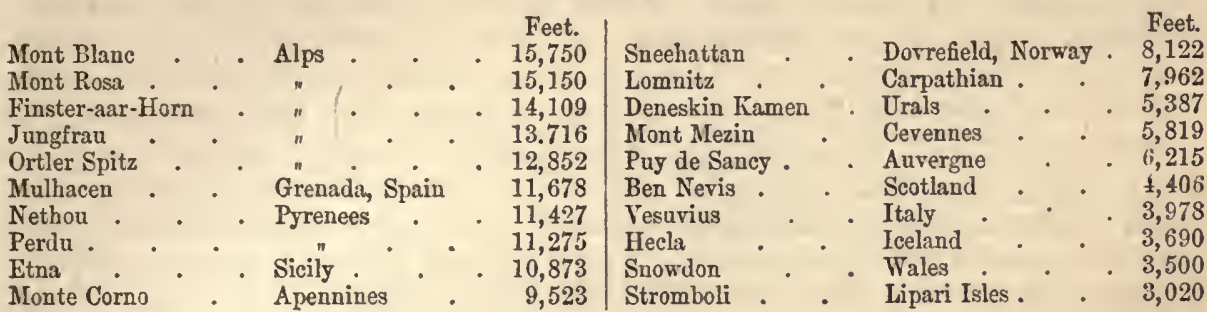

AsIA.

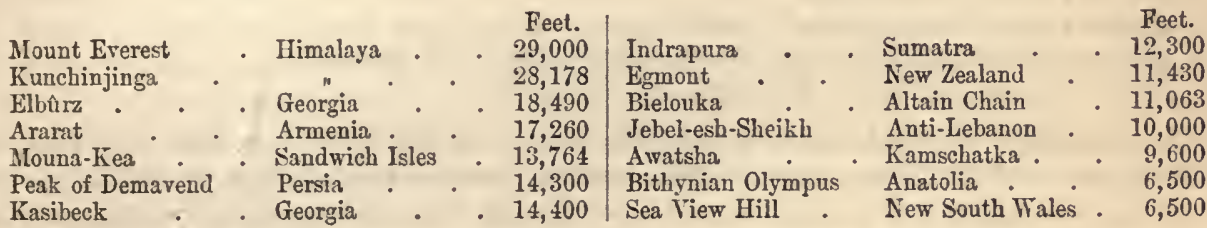

\section{Africa.}

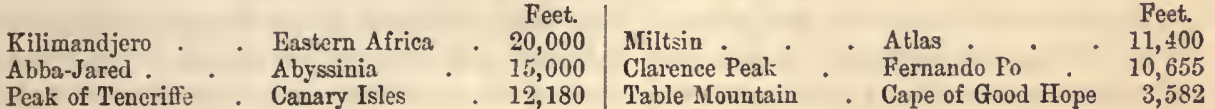

\section{A merica.}

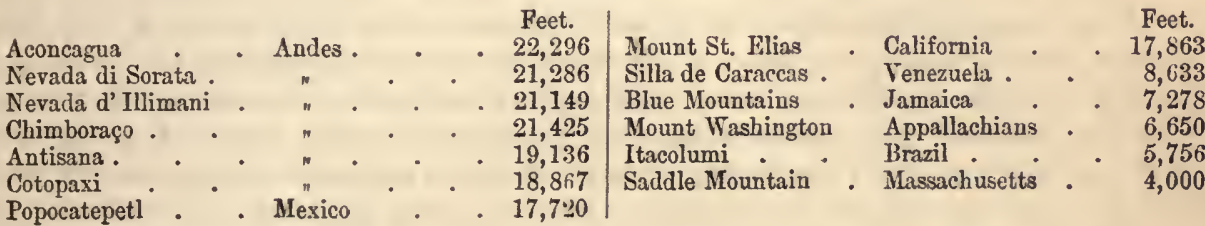

\section{Antarctic Continewt.}

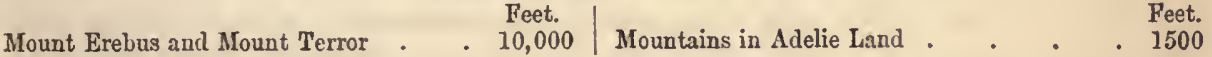

In the annexed list, the elevation of several remarkable localities are stated, with some of the highest altitudes occupied by man, and reached by him.

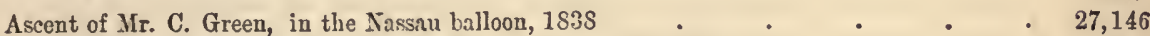

Greatest altitude attained by Boussingault and Ilall on Chimboraço _ . . 19,695

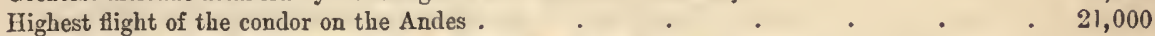

Mannering Pass in the Himalaya, crossed by Captain A. Gerard _ . . . 18,612

Absolute height of a villare in the Himalaya, visited by Gerard, perhaps the highest inhabited

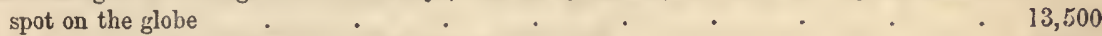

Farm of Antisana, the highest inhabited spot on the Andes _ . . . . . 13,435

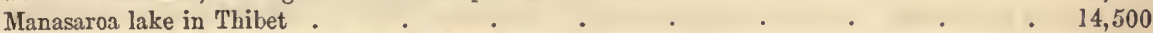

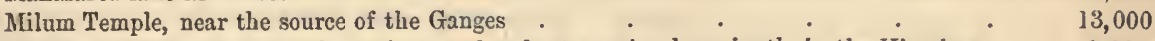

Greatest altitude of the peach, apricol, and walnut growing luxuriantly in the Himalaya 9,000

Thick woods of pines and birch trees in the Himalaya, the latter attaining a large size . $\quad 14,000$

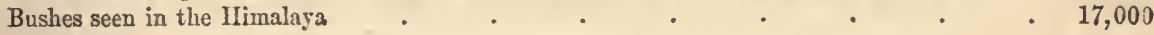




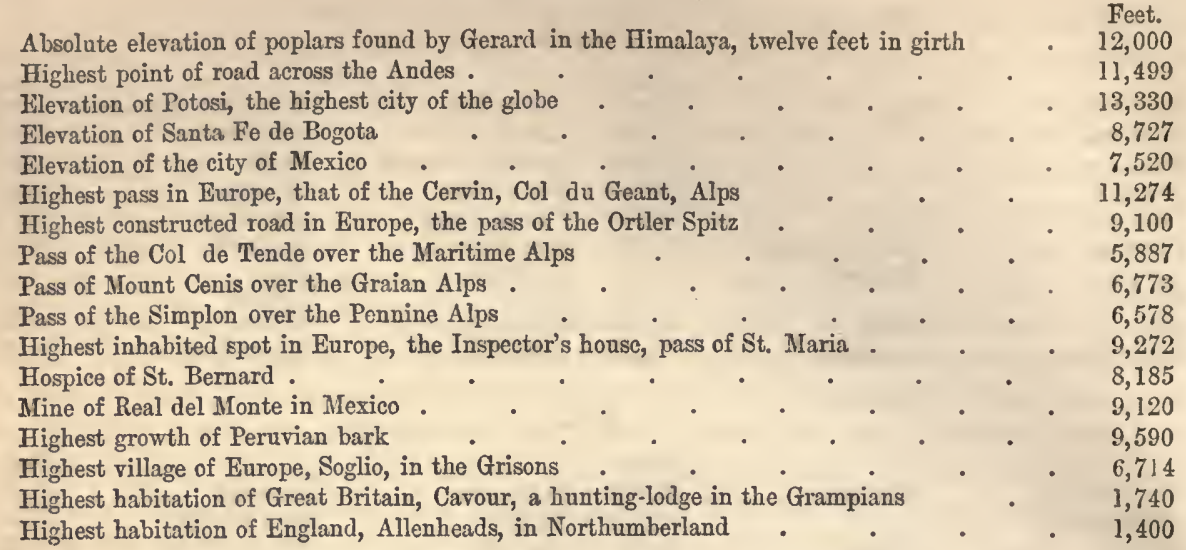

Contemplating the projections of the surface with reference to their absolute elevation above the level of the sea, some of them appear protuberances of enormous bulk, and we are apt to imagine that they must detract largely from the regularity of the earth's spherical form. But they become insignificant when compared with the volume of the globe itself, the highest eminence, that of between five and six miles, being only about $\frac{1}{800}$ of the semidiameter of the sphere. They bear therefore much the same proportion to the terrestrial spheroid as the little risings on the coat of an orange to the fruit. Books of travels abound with conflicting statements respecting the distance from which particular mountains may be seen. The length of the line of visibility is not only influenced by conditions of the atmosphere, but by the character of projections, apart from their height. The Peak of Teneriffe is not so frequently visible at the same distance as those tops of the Andes which are of corresponding elevation, not being, like them, invested with perpetual snow. Humboldt remarks, that the cone of the former, no doubt reflects a great degree of light on account of the white colour of the pumice with which it is covered; but its height does not form a twenty-second part of the total elevation, and the sides of the mountain are coated with blocks of dark-coloured lava, or with luxuriant vegetation, the masses of which reflect little light, the leaves of the trees being separated by shadows of greater extent than the illuminated parts. He refers therefore the Peak to that class of mountains which are seen at a great distance only in a negative manner, or because they intercept the light transmitted from the extreme limits of the atmosphere. Still, it has been observed at the distance of 124, 131, and even 138 miles; and the summit of Mowna-Roa in the Sandwich Isiands has been seen, at a period when it was destitute of snow, skirting the horizon from the distance of 183 miles. This is the most remarkable example yet known of the visibility of high land, and as Mowna-Roa was negatively seen, both cases refute the theory of Bouguer, that mountains seen negatively cannot be perceived at distances exceeding 121 miles.

The summits of the superior elevations are regions of perpetual snow and ice, and below the limits of constant congelation there is a zone in which snow lies upon the surface through the greater part of the year. The accumulations above and near the line where perpetual frost commences, constitute some of the most dangerous and terrible phenomena of high mountain districts. When the mass becomes so great that the inclined plane on which it rests can no longer support it, or when the pile which has been heaped together by the winter snow-storms becomes loosened by the action of the sun in spring and summer, it descends with immense violence from its site into subjacent 
valleys, sometimes filling them up with its volume, and burying man, beast, and village beneath its load. The avalanches composed simply of drifts, are not so dangerous and destructive as those of snow rendered clammy by a thaw. The former may frequently be removed without much damage being sustained, but the latter are precipitated in compact masses, and carry awryy or crush the objects that lie in their patl. In the canton of the Grisons, an avalanche descended in the year 1749, upon the valley of 'Tawich, and entirely covered the whole village of Rueras. The snow torrent fell in the night without disturbing some of the inhabitants, who, on awaking in the morning, were surprised that the day did not break; - sixty out of a hundred persons were rescued from their perilous situation alive, a sufficient quantity of air to support life being obtained through interstices in their snowy canopy. In the same canton, an avalanche descended upon Val Calanca in 1806, which removed a forest from its site to an opposite side of the valley, and fixed a fir-tree upon the roof of the parsonage house. Avalanches occur in the Pyrenees and in Norway, but are most frequent in the high Alps owing to their abrupt and precipitous declivities. They are often set in motion by vibrations of the air, such as the discharge of a musket, or a peal of thunder, or the mere passage of a traveller will produce it; and hence in districts subject to them a cautious silence and wary footsteps are enjoined upon the inexperienced visitor. Professor Forbes gives a striking instance of encountering a highly electrical condition of the atmosphere, when at a considerable elevation in the Alps: "We were still above 9000 feet above the sea, when I noticed a curious sound which seemed to proceed from the Alpine pole with which I was walking. I asked the guide next me whether he heard it, and what he thought it was. The members of that fraternity are very hard pushed indeed, when they have not an answer ready for any emergency. He therefore replied with great coolness, that the rustling of the stick proceeded from a worm eating the wood in the interior. This answer did not appear to me satisfactory, and I therefore applied the experimentum crucis of reversing the stick, so that the point was now uppermost. The worm was already at the upper end. I next held my hand above my head, and my fingers yielded a fizzing sound. There could be but one explanation we were so near a thunder cloud as to be highly electrified by induction. I soon perceived that all the angular stones were hissing round us like points near a powerful electrical machine. I told my companions of our situation, and begged Damatter to lower his umbrella, which he had hoisted against a hail shower, and whose gay brass point was likely to become the paratonnerre of the party. The words were scarcely out of my mouth when a clap of thunder, unaccompanied by lightning, justified my precaution." The thunder clap, the hunter's horn, or even the human voice, has frequently shook the nicely poised avalanche from its site, and hurled it into lower regions, crushing trees, sweeping away rocks, and damming up the streams that have lain in its course.

Besides accumulations of snow, we meet with glaciers in high regions, or extensive fields of ice. These are formed from the snow-fields, partially thawed and subsequently frozen. The water yielded by the melting of the surface, in connection with rain, percolates through the mass, which acquires consistency, and is converted into compact ice by a depressed temperature. Iceland is appropriately named from the number and extent of its glaciers, which are there known by the name of Yokuls, signifying large masses of ice. The most extensive, the Klofa Yokul, in the eastern quarter of the island, is a vast chain of ice and snow mountains, supposed to fill a space of not less than three thousand square miles. Some of the Yokuls are remarkable for their vacillation, not remaining in a settled position, a peculiarity common to the Alpine glaciers. These ice: formations are found among the Norwegian highlands, in the chain of the Pyrenees, upr 1 the Sierra Nevada of Spain; but their grand European site is the Alps. "If," si, s 
Saussure, "a spectator could be placed at a suffieient height above the Alps, to cmbrace at one view those of Switzerland, Savoy, and Dauphiné, he would see a mass of inountains intersected by numerous valleys, and composed of several parallel chains, the liighest in the middle, and the others decreasing gradually as they recede. The central and highest chain would appear to him bristled with craggy rocks, covered, even in summer, with snow and ice in all those places that are not absolutely vertical; but on both sides of the chain, he wonld see deep and verdant valleys, well watered and covered with villages. Examining still more in detail, he would remark that the central range is composed of lofty peaks and smaller chains, covered with snow on their tops, but having all their slopes that are not very much inclined, covered with icc, while the intervals between them form elevated valleys filled with immense masses of ice, extending down into the deep and inhabited valleys which border on the great chain. The chain nearest to the centre would present to the observer the same phenomenon, but on a smaller scale, beyond which he would see no more ice, nor even snow, save here and there on some of the more elevated summits." Saussure therefore recognised two kinds of glaciers; the first contained in the valleys, more or less deep, and which, though at great elevations, are still commanded on all sides by mountains higher still the second not contained in valleys, but spread out on the slopes of the higher peaks.

The glacier system of the Alps embraces an extensive arca. Mr. Ebel estimates, that there may be at least four hundred of the larger sized glaciers, or varying from three to thirty miles in length. The aggregate superficial extent of all those of the Tyrol, Switzerland, Piedmont, and Savoy, is calculated by some authorities to amount to not less than fourteen hundred square miles. The greatest breadth of an individual specimen is seldom more than two miles. The thickness varies from a hundred to six hundred feet. The glaciers are moving masses, urged down the inclined planes upon which they are situate by the mutual pressure of their parts, a movement which the seasons accelerate or retard according to their character. This motion gives rise to the extraordinary spectacle, of summer productions and winter formations being sometimes in immediate contact with each other, the ice-ficlds obtruding into flowery meadows, and gradually forcing their way into the regions of cultivation. According to Professor Forbes, the very huts of the peasantry are sometimes invaded by this moving ice, and many persons now living have seen the full ears of corn touching the glacier, or gathered ripe cherries from the trees with one foot standing on the ice! The rate of advance of different glaciers varies considerably. M. Ebel states, that in the valley of Chamouni, they travel at about fourtecn feet a year, while in that of Grindelwald, the glaciers move rather faster, at the rate of twenty-five feet in a year, a difference probably attributable to the ground being variously inclined. 'The same glacier will also make more progress in one year than in another, according as a summer of lesser or greater warmtl renders its liberation more or less complete. Captain Hall remarks upon the ploughing up of the ground lying before a glacier by its snout as an obvious proof of its progression, and instances the remarkable case of the glacier of Brenva falling into the lower part of the Allée Blanche, fairly crossing from one side of the valley to the other, and being so irresistibly pressed forward by the weight of snow on its shoulders, high up the sides of Mont Blanc, that on reaching the opposite side of the valley, it actually travels for a considerable distance up the bank. "The guides," he remarks, "pointed out the corners of green fields, peeping out from the sides of the glacier in the middle of the valley, and showed us traces of walls and fences which had belonged to large villages, now entirely obliterated by the moving mass. I took notice of one circumstance, which told the fa' al story very well. We had walked along a well-worn footpath till our course was ab "ptly stopped by the edge of the glacier; but on crossing over it, we re-discovered 
our footpath, which had been quite lidden by the intervening mass." There is a limit, however, put to the encroachments of the glaciers. The lower extremities are gradually thawed away in the warm atmosphere of the valleys, so that though pushed forward by the weight of ice and snow accumulated at the upper extremities during the winter, there is a "bound fixed by a perpetual decrce," beyond which they cannot pass. Coleridge strikingly alludes to these formations in his Hymn before Sunrise in the Vale of Cliamouni ; and science will not quarrel with him for the line which expresses the optical appearance, rather than the philosophical trutl.

\footnotetext{
"Ye ice-falls! ye that from the mountain's brow Adown enormous ravines slope amain -

Torrents, methinks, that heard a mighty Voice, And stopp'd at once amid their maddest plunge! Motionless torrents! Silent cataracts !

Who made you glorious as the gates of heaven

Beneath the keen full moon? Who bade the sun

Clothe you with rainbows? Who with living fluwers

Of loveliest blue, spread garlands at your fect?

God! let the torrents, like a shout of nations,

Answer! and let the ice-plains echo, God!

God ! sing, ye meadow-streams, with gladsome voice!

Ye pine-groves, with your soft and soul-like sounds!

And they, too, have a voice, yon piles of snow,

And in their perilous fall shall thunder, God!"
}

The glaciers exhibit a singularly diversified aspect, hues varying from the purest white to a blue and green tinge, surfaces resembling in some parts a smooth and polished mirror, and in others a sea frozen when angry and tempest-tost.

But of all the phenomena exhibited by the highlands of the globe, those of the active rolcanoes are the most peculiar and sublime. 'The term is derived from Vulcanus, the imaginary god of fire among the Romans, and is applied to those mountains which are the vents of igneous action, ejecting from their sides or summits flame, smoke, ashes, and lava streams. They are in general elevations of a conical form, terminating at the summit with a hollow, called a crater or cup from its shape. Smoke is constantly issuing from the tops of some of these mountains, but the violent paroxysms during which stones are discharged, and torrents of red-hot lava, occur only at distant and irregular intervals. The eruptions frequently issue from several openings or smaller craters, within the superior one, the number and size of which are considerably varied by eras of disturbance. These eras are generally preceded, in some instances for several weeks, by the shocks of earthquakes, or by immense colunins of smoke issuing from the volcano about to exhibit explosion, often involving the neighbouring country in darkness. Sounds resembling the successive discharges of a park of artillery are then heard, followed by sudden flashes of flame, and showers of stones. A stream of lava next bursts forth from the side of the mountain, or in a great eruption from the crater, flowing in a sluggish fiery current down the declivities. After the lava ceases to flow, the volcanic ashes, composed of various materials, are thrown out of the summit in immense quantities, sufficient to cover the vicinity for miles. The products of volcanoes differ to some extent, those of America casting out water, and in some instances fish, besides the ordinary materials. It is singular, also, that in the New World, the active volcanic sites are chiefly continental, while in the Old World they are mostly found in the islands. In both regions, however, they are almost invariably situated near the sea, or some inland collection of water. Upwards of three hundred are known to exist, distributed as follows, according to Girardin's table, which, however, is only approximative:- * 


$\begin{array}{lrrrr}\text { Europe, - on the Continent, } & 1 . & \text { On Islands, } 20 \\ \text { Asia and Oceania, } & " & 17 . & , & 137 \\ \text { Africa, } & " & 2 . & , & 9 \\ \text { America, } & " & 86 . & , & 25\end{array}$

In addition to the above, Mount Erebus, on the south polar continent, is an active volcano of immense size. The mass and elevation of volcanoes seem to regulate the occurrence of eruptions, the smallest being the most active. Thus Stromboli, an inferior elevation, is almost always flaring as the great lighthouse of nature in the Mediterranean. Vesuvius, far less than Etna, is the most active of the trwo, while some of the enormous Andean cones repose for centuries.

Of existing volcanic action, the most sublime and imposing example perhaps to be found in the world, is in the island of Hawaii, formerly called Owhyhee. The whole island seems to be an immense hollow cone, having an area of 4000 square miles, and attaining an elevation of 16,000 feet, the height of Mowna Roa. It forms a pyramidal chimney over a vast incandescent mass burning beneath it, and also under some part of the bed of the surrounding ocean, having numerous vents through which the furnace below communicates with the atmosphere above. Lord Byron and a party of officers from the Blonde frigate, with the Rev. Mr. Stewart, visited the crater of Kilauen, near the base of Mowna Roa, and witnessed a scene, says the deseriber, more horribly sublime than any thing he had erer imagined to exist even in the idler visions of unearthly things. Arrived at the brink of the crater, they stood looking down into a fearful gulph, fifteen hundred feet in depth, and upwards of two miles in circumference. The edge of the crater was so steep, that it seemed as if by a single leap they could plunge into the lowest abyss. Its surface had all the agitation of an ocean. Billow after billow tossed its monstrous bosom into the air, and occasionally the waves from opposite directions met with such violence as to dash the fiery spray in the concussion forty or fifty feet high. Such was the agonising struggle of the action within - the appalling sounds of the conflicting elements, muttering and sighing, groaning and blowing, that one of the party shrunk back exclaiming:- " Call it weakness, or whatever you please, but I cannot look again!" About fifty cones of various height, active chimneys of voleanic fire, were counted in the abyss. Volumes of smoke and steam were ascending from these vents, but as the evening closed, fire after fire appeared glimmering through the vapour. Some of the cones were ejecting fragments of rock; others, ashes, lava, and boiling water; streams of fire seemed to be running among the labouring craters; forming a scene which, in connexion with the roar of the elements bursting from their prison, reminded the party, as one of them expressed it, of the lake that burneth with fire and brimstone. To the bottom of the abyss it is well known that a Christian convert descended, and plunged a stick into the fiery deluge ! an act of female heroism to dispel the illusion of her countrymen, who were spectators at a distance, and who fancied that Peli, the god of the Kilauea fires, wonld punish with instant destruction any violation of his sanctuary.

One of the most tremendous volcanic eruptions ever recorded, was that which issued from the Tomboro mountain in the island of Sumbawa, for an account of which we are indebted to Sir Stamford Raffles. It began on the 5th of April, 1815, and continued with some intermissions until the June following. The sound of the explosion was heard at Ternate on the western coast of Gilolo, a distance of seven hundred and twenty geographical miles: and in Sumatra, which is nine hundred and seventy. In some parts of the island violent whirlwinds carried up men, horses, and cattle into the air; the sea was covered with the trunks of trees which had been torn up; and the ashes from the mountain, wafted to Tara and Celebes, a distance of three hundred miles, caused a darkness in the daytime more profound than had ever been known in the darkest night. To the west 


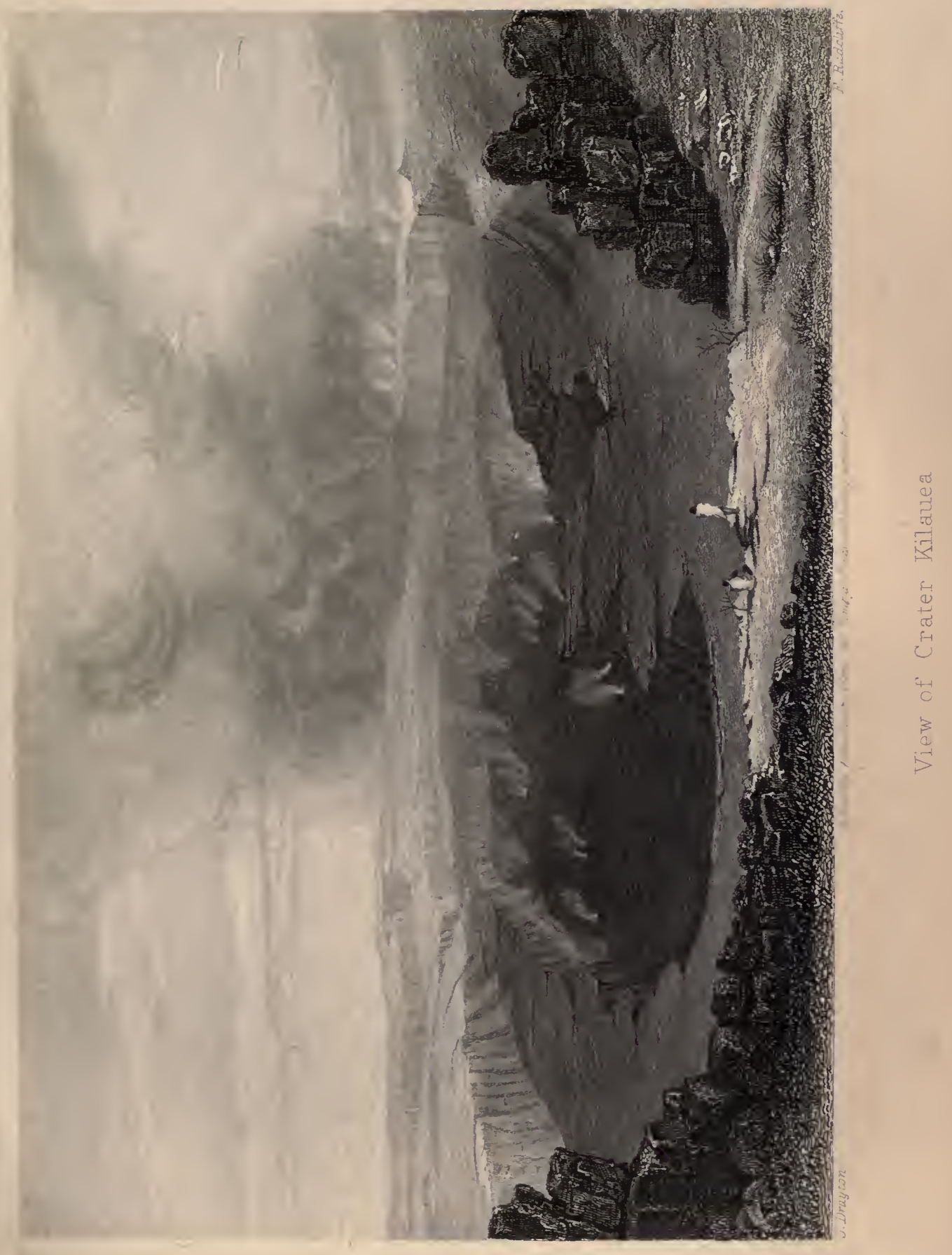


of Sumatra the sea was coated with a mass of cinders two feet thick, and many miles, in extent, and ships with difficulty forced their way through it. "We grounded," says one of Sir Stamford's correspondents, "on the bank of Bima town. The anchorage of Bima must have been altered considerably, as, where we grounded, the Ternate eruiser lay at anchor in six fathoms a few months before." The area orer which the effects of the eruption extended was upwards of two thousand English miles in circumference: the surface of Sumbawa was considerably altered; acclivities were turned into valleys, and valleys into elevations; and of its unfortunate inhabitants, out of a population of twelre thousand, only twenty-six persons escaped.

The volcanic regions include those where there are active vents and extinct craters, with intervening districts often shaken by earthquakes and abounding with hot springs, the evidences of subterranean igneous action. There are three large continuous areas of this kind.

To the island at the southern extremity of America, F. Magellan gave the name of Terra del Fuego, or the land of fire, no doubt from the sensible display of igneous activity; for the assertion of Malte Brun is corroborated by the cvidence of Captain Hall with reference to the existence of an active volcano at the present time. Proceeding northward along the coast which fringes the Pacific Ocean, there is scarcely one degree of latitude from $46^{\circ}$ to $27^{\circ}$ in which there is not an active rent. The Chilian volcanoes rise up through granitic mountains. Villarica, one of the principal, is always burning, and so lofty as to be distinguished at the distance of a hundred and fifty miles. A year never passes without some slight shocks of earthquakes in the province, and about once in a century, or oftener, tremendous convulsions shake the land from one end to the other. In Peru there is the same continual disturbance of the surface, more or less violent, though only one active volcano is at present known. Still further north, about the middle of Quito, where the Andes attain their loftiest altitude, the peaks of Tunguragua, Cotopaxi, and Antisana are in frequent play. From the sides of the former a mass of mud was ejected in 1797, which dammed up rivers, occasioned new lakes, and filled up valleys a thousand feet wide to the depth of six hundred feet. In the province of Pasto, farther north, there are three volcanoes; in Papayan, three others ; in Guatimala and Nicaragua, no less than twenty are in an active state. Hitherto we have followed this great volcanic chain

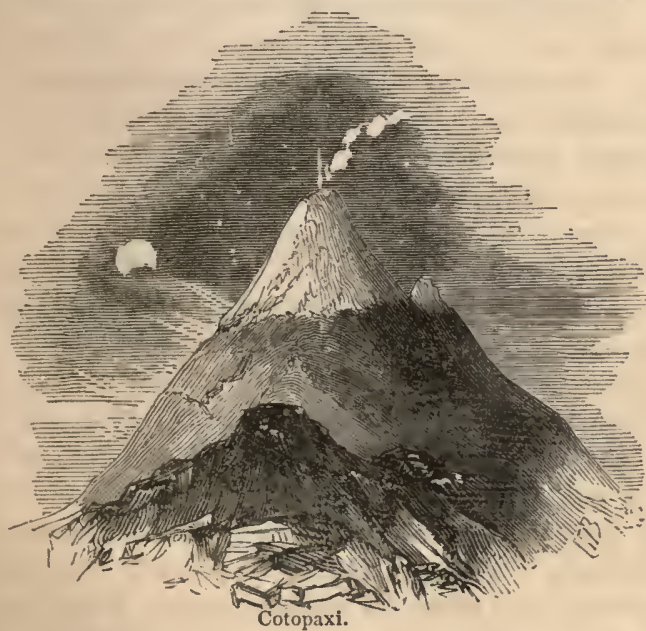
almost due north. In Mexico, however, it turns off in a side direction, extending on the west to the isles of Revilagido and the Californian peninsula, and embracing eastward the whole of the West Indian isles. The length of this enormous chain, from Cape Horn to New Madrid in the United States, is greater than from the pole to the equator. Its westward extent is hid from us by the waters of the Pacific; but probably it reaches across the whole of its immense bed. Cotopaxi is described by Humboldt as the most beautiful and regular of all the colossal summits of the Andes, being a perfeet cone, which is covered with snow, and shines with dazzling splendour at sunset. There are no rocks projecting through its icy mantle, except near the edge of the crater, which is surrounded by a small circular wall. The traveller tried to reach the summit, 
but failed, owing to the cone being surrounded by deep ravines, and pronounees the ascent to the crater impossible. This is the highest of the Andean voleanoes which have recently been in an active state. If the 3932 feet of Vesuvius were planted upon the top of Etna, which lias an clevation of 10,873, Cotopaxi would not be cqualled in altitude by 4073 feet. Its eruptions have been upon a scale corresponding with its magnitude. In 1738 its fires ascended 2953 feet above the crater, and in 1744 its voice was heard at Honda, on the river Magdalena, a distance of nearly seven hundred miles. In 1768 the inhabitants of two neighbouring towns were obliged to use lanterns by day in the streets, owing to the quantity of ashes ejected, and at two lundred miles' distance Humboldt and Bonpland heard its noises day and night, like the discharges of a battery, during the explosion of 1803.

A second line of rolcanic action, upon as gigantic a scale as the preceding, commences at one of the most western points of North America, the peninsula of Alaska, in latitude $55^{\circ}$. It pursues a western course for about two liundred geograplical miles, embracing the Aleutian isles, and reaching to the opposite coast of Kamtschatka. 'Throughout the whole of this tract earthquakes are of frequent occurrence, and the bed of the sea and the surface of the land are often altered by their tremendous violence. Seven active volcanoes are found at the southern extremity of the peninsula of Kamtschatka, and from thence the chain trends to the Kurile isles, where nine more are known to have been in eruption. Still southerly, the line extends to the Japanese group, where there are a considerable number, and where the disruption of the surface of the land in some districts is almost incessant, and sometimes violent. Passing the tropic of Cancer, the range embraces the Loo Choo archipelago, the Philippine and Ladrone islands, and is prolonged south to New Guinea. Here it branches off in a vast transverse line, extending on the one hand into the heart of the Pacific, and on the other through Java and Sumatra into the Bay of Bengal.

A third chain traverses the whole of the southern part of the European continent, a distance of above a thousand geographical miles. It commences at the Azores, and extends to the Caspian Sea, having for its northern boundaries the Tyrolian and Swiss Alps, and for its southern bounds the northern kingdoms of Africa. This district has fiequently been visited with earthquakes, those of Lisbon and Calabria causing the whole continent to vibrate at the shock. Etna, Vesuvius, and Stromboli are at present the chief active vents, but anciently Vesuvius was in a state of torpor, and the island of Ischia was the scene of volcanic explosion. This small spot, about eighteen miles in circumference, now containing a population of twenty-five thousand, was frequently abandoned by its inhabitants on account of its violent convulsions. Before the Christian era, the Erythreans, the Chalcidians, and a colony established by Hiero king of Syracuse, were successively driven from it. Ischia howerer sunk into repose, which has not sinee been disturbed, only with one exception, when Vesuvius, in the year 79 , burst forth from the stillness of ages, and overwhelmed the cities of Herculaneum and Pompeii with its ashes. The eruptions of Etna are mentioned as occurring from the earliest periods to which history and tradition extend. Thucydides speaks of three between the colonization of Sicily by the Greeks and the commencement of the Peloponnesian war in the year B. C. 431. It was a fable of the Greek mythology, that the giant Typhos was confined beneath Sicily, his outstretched limbs extending under the Italian peninsula, and the terrible natural phenomena of the region were assigned to the struggles of the imprisoned monster. Pindar, in his first Pythian ode, says: "The sea-girt heights above Cuma, and Sicily too, press upon his shaggy breast; and the pillar of heaven, snowy Etna, the perennial nurse of sharp pinching snow, holds him fast. From the recesses of Litna are romited forth the purest streams of fire, immeasurable in extent. By day the fiery 
current pours forth a burning torrent of smoke, but by night, the red flame, rolling along masses of rock, plunges them with loud crash into the surface of the sea. That monster

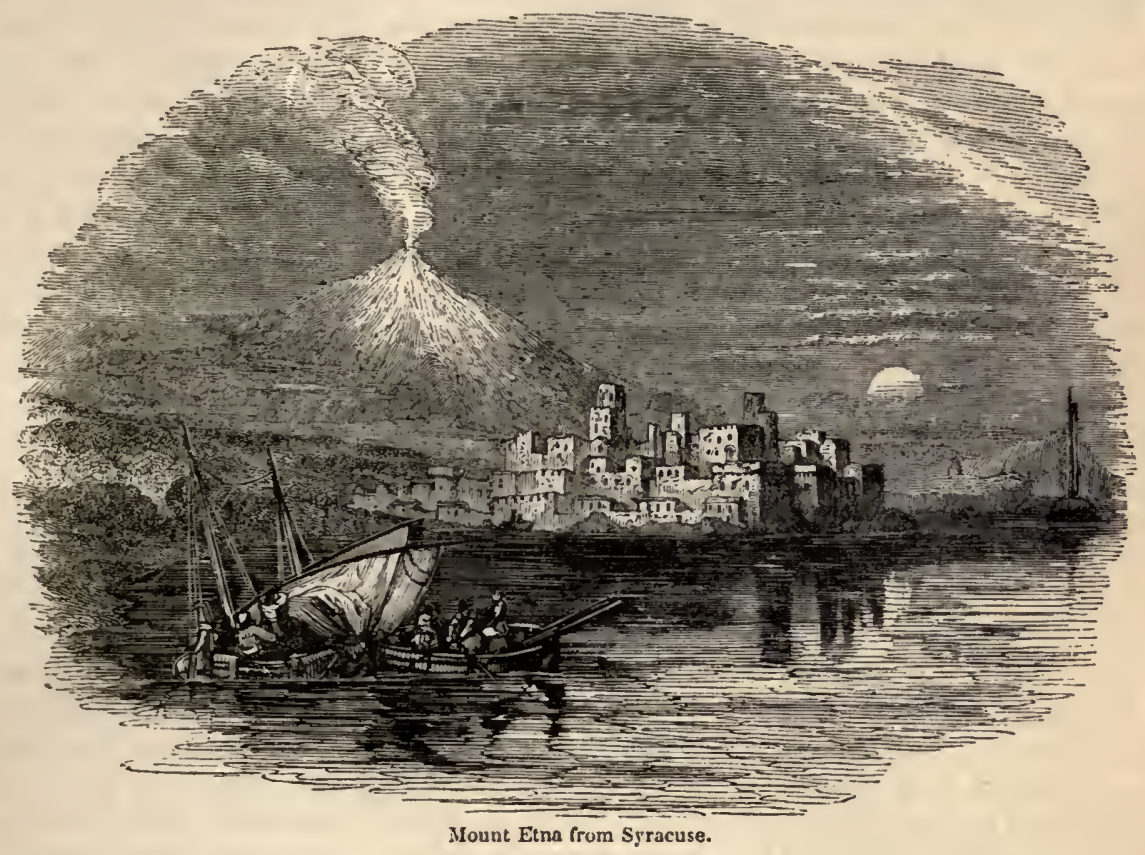

sends up such horrid streams of Hepliæstus (Vulcan) - a sight wonderful to look on; wonderful, too, to hear of from those who have seen it." Etna, when viewed from a distance, appears a very symmetrical cone, but there are upwards of eighty minor yet conspicuous cones upon its sides. At a late eruption, which oceurred in Norember 1832, the mountain sent forth a stream of liva eighteen miles long including its windings, a mile broad, and thirty feet thick, which approached within two miles of the town of Bronte, and threntened it with destruction.

In addition to this general outline of extensive voleanic regions, there are isolated spots where similar phenomena are displayed. The Peak of Teneriffe, in the Canary Islands, is an imposing volcano, with its highest erater apparently sealed up, but lateral eruptions are of recent date. Iceland, Jan Mayen, and the south coast of Greenland, constitute a considerable volcanic system.

Fatal to human life as the cruptions of the voleano have oecasionally been, large views of such physical erents will awaken impressions at variance with those which their detached observation often excite. He who, living on the slopes of Vesuvius, witnesses his vine-clad dwelling, or his native village, orerwhelmed with the lava and ashes of the mountain, is apt to become exclusively occupied with the disaster, and will not readily reflect upon the many millions of mankind who enjoy a quiet habitation, and whose locality has never been disturbed within the period that history and tradition have chronicled such oceurrenees. Yet nothing is more true than that the same agency which is occasionally destructive in a few spots upon the world's expanse, has operated in forming or upheaving the universal erust of the globe, and has thus been the means of building up sure resting places for unnumbered myriads of the human family. It is that protruding or elevating power also that has rendered the coal formations and mineral reins 
accessible, and thus supplied commerce with its sinews; and comparing the plyysical history of the globe with the eareer of its inlabitants, how harmless the Etnas and Cotopaxis of nature appear, in contrast with the Cresars and Napoleons of mankind! A slight survey of the features of the external world is sufficient to show, that the tendency of their general arrangement is to minister to the happiness of man, to give him pleasure in the act of contemplation, as well as to contribute to his convenience. Its surface, so finely diversified, is eminently calculated for the gratification of its oceupiers, and expands around them in every clime an array of beauty and grandeur, sometimes apart from each other, but often blended in wild yet tasteful and imposing combinations. Wherever the traveller penetrates, he finds the terrestrial configuration so arranged in ever-varying outline as to spread before him an inviting pieture of natural scenery, which captivates, or soothes, or elevates, or excites the mind, and furnishes such pleasurable emotions as dull uniformity would not have yielded. Especially do the elevations which mark the face of the eartl, whether rising to the stately proportion of mountains, or forming only the rounded, greenclad hill, give interest, grace, or sublimity to the landscape. But the mountains perform a more important office than that of giving imposing effect and picturesque beauty to the scenery of the earth. Occupying a portion of its surface nearly equal to that which the sandy desert claims, they stand associated with political and other results of the lighest importance to mankind. Where the ocean does not extend its waters to divide the families, kindreds, and tongues of the human race, the granite snow-crowned rampart is frequently the line of demarcation. Nations have thus been kept apart from each other by natural boundaries; and. the difficulties connected with aggressive wars between communities thus separated, have contributed to promote peace and maintain independence. The mountains also officiate in arresting and condensing the vapours by their cold summits, and storing up their precipitated waters in interior reservoirs, from whenee they issue by a thousand springs; and in the dens and eaves that perforate their deelivities liberty and religion have often found a secure asylum, when assailed by persecuting power and grasping ambition. "The precious things of the lasting hills"- the phrase of the dying Hebrew patriarch - is not without its appropriate significancy. Inglis, wandering in the Tyrol, recognised its truth, when, as he remarks, he emerged from the mountains after a day's ramble, with pleasant recollections of lights and shadows yet lingering on the vision - of solitude and stillness, and the small mountain sounds that are more akin to silence than noise- and of all the thousand deep-felt but inexpressible emotions, that are born among the eternal hills, when evening fills their valleys, creeps over their declivities, and throws its mantle on their summits.

While mountains, whether volcanic or otherwise, occasionally rise on one side from a low level, and descend abruptly to it again on the other, they are far more generally connected with extensive tracts of elevated country, which is either intersected or bounded by them. These highly raised regions may undulate with hill and vale, but have comparatively level surfaces, and are known as plateaus or table-lands. The principal example in Europe is in Spain, which consists of a high central nucleus, surrounded by a narrow belt of maritime lowlands. Madrid, the capital, on a plain, is 2170 feet above the sea. But the royal palace of the Escurial has an elevation of 3520 feet, very little lower than the top of Snowdon; and the site of La Granja, the summer residence of the sovereigns, is elevated 3943 feet. This would appear a castle in the air, if isolated, and viewed from the sea-level, being at a greater altitude than the summit of Vesuvius. The grand examples of plateau formations are Trans-Atlantic and Asiatic.

A considerable portion of Bolivia and Upper Peru, is a plateau remarkable for its altitude, 13,000 feet. It is formed by the top of the main mass of the Andes, and stretches between the mountain-knots of Cuzco and Potosi, north and south, and the Cordillera 
Real, and the Cordillera of the coast, east and west. The included area, far exceeding that of Great Britain, has a surface varied with hills and valleys, streams and lakes. Upon it lie the waters of lake Titicaca, twenty times larger than the lake of Geneva, with the decayed mining cities of Cuzco and Potosi.

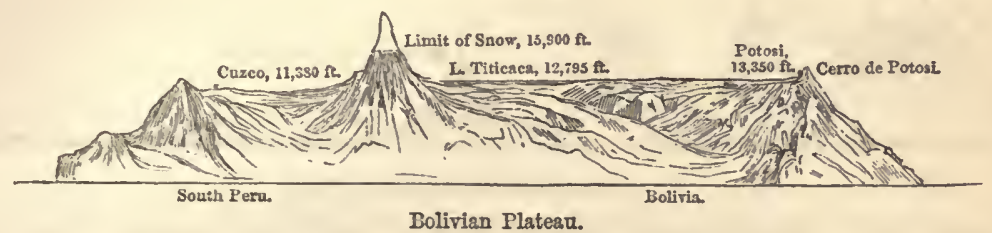

Less elevated and extensive, but grandly situated, is the table-land of Quito, a plain, two hundred miles long; by thirty broad, at the height of 9500 feet, engirdled by magnificent projections of the Andes. "From the terrace of the government palace," says Humboldt, speaking of the city of Quito, "there is one of the most magnificent prospects that human eye ever witnessed, or nature ever exhibited. Looking to the south, and glancing along towards the north, eleven mountains covered with perpetual snow present themselves, their bases apparently resting on the verdant hills that surround the city, and their heads piercing the blue arch of heaven, while the clouds hover midway down them, or seem to crouch at their feet." In the same region, the upland plain of Santa Fè de Bogota, is an almost perfect level, $\$ 600$ feet high, and forty-five miles, by twenty in extent, environed with high mountains, through which the waters of the plain escape by a narrow outlet, and form the celebrated falls of Torquedama. In North America, nearly the whole of Mexico consists of high table-lands, mutually connected, at the mean height of 7000 feet. They are interspersed with numerous streams and lakes; and form a platform for the colossal cones of Colima, Popocatepetl, Orizaba, and Nevada de Toluca, crowned with eternal snow.

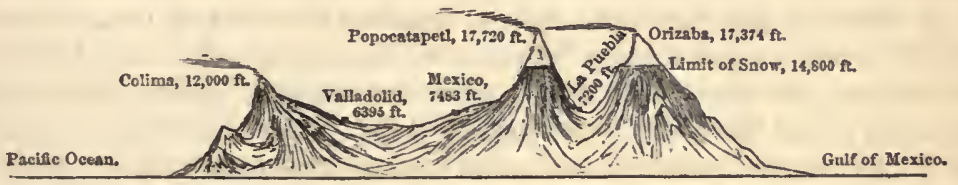

Mexican Plateau.

In consequence of this configuration of the country, while the heat common to tropical lands is experienced on the low shores, the climate becomes temperate as the traveller ascends the interior highlands, and it is cold and frigid at the altitudes attained by the mountains.

The loftiest and most extensive plateau region on the face of the globe is the vast protuberance of Central or High Asia, which comprises different systems of table-lands. Between the Himalaya and the Kowenlun chains, lie the Thibets, a district of various but great elevation, called the platean of Great Tatary. At a house of the Dalai-lama, near the margin of the two lakes, Manasa and Kawana-hrada, Captain Webb makes the height 14,502 feet, thus far exceeding that of the waters of Lake Titicaca. To behold the lake Manasa, an oval basin, fifteen miles by eleven in extent, is deemed by the Hindoos a felicity beyond every other on earth, but prodigious difficulties attend the pilgrimage. 
High Asin is walled in on the western side by the Bolar ehain or Cloudy Mountains, in connection with which there is still loftier table-land. This is the remarkable region of

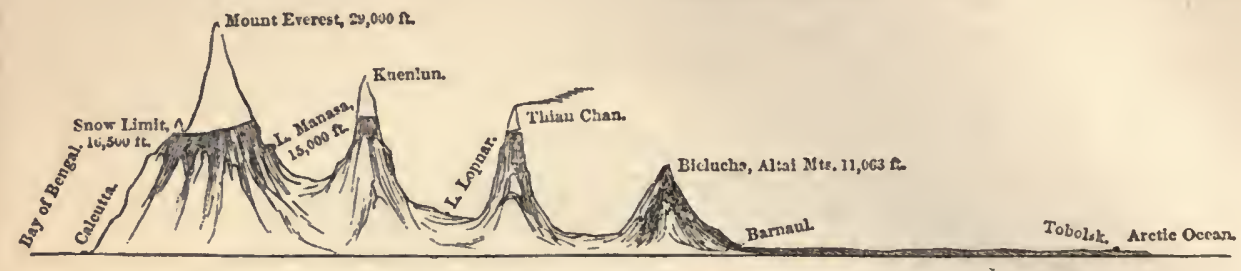

Platean of Central Asia.

Pamir, locally called Bam-i-duniah, or the "Pnof of the World," a plain at the height of 15,600 feet, but a trifle lower than Mount Blanc. The Oxus has here its souree; and it forms the water-parting between its basin and that of the Indus, with other rivers, which run off to different seas.

The locality is a remarkable one, dreary in its aspect, and hard to climb, owing to the encumbering snow and steep declivities, while it is also difficult for the stranger to reach, on account of the rarefaction of the atmosphere. Still it is occupied by various forms of animal and regetable life, and is annually for a time the residence of a native wandering people. The snow lies deep upon the "Roof" for the greater part of the year, but disappears in summer, though masses remain unmelted in hollows and shaded places. During this season, the spot is a favourite resort of the Kirghis, for the pasturing of their cattle, who retire into the sheltered valleys at lower levels as the winter approaches. It is also traversed by merchants as the commercial route between Bokhara and the Chinese empire. A fine sheet of water lies upon the table-land. This is the Sir-i-kol, the loftiest lake of the globe. Marco Polo, the Venetian traveller, in the last half of the thirteenth century, passed through this region on his remarkable Oriental journey, and has left on record accurate notices. He particularly observed, without understanding the cause, that fire did not burn with the same vivacity and strength as in other places, neither did it cook victuals so well. He was the first to point out this eircumstance, which has been verified by others at high elevations, and is doubtless the effect of the rarefaction of the air. For five centuries and a half afterwards, we have no record of any European having reached the spot, till Lieutenant Wood, after surmounting innumerable difficulties and dangers, stood, to use the native expression, upon the "Roof of the World," and beheld the expanse of lake Sir-i-kol stretched out before him, covered with thick ice, with the infant and classical river Oxus issuing from it. This was on the 19th of February 1838, at fivo o'clock in the afternoon. He ascended by the valley of the river from Eokhara, accompanied by a party of natives. On approaching its source, the snow lay deeper and deeper every step in advance, for the winter season added immensely to the difficulty of the undertaking. Two hours were occupied in forcing a passage over a field of snow not five hundred yards in extent. On attempting to proceed more rapidly over a favourable site, a guide seized the bridle of his horse, and cautioned bim against the "wind of the mountain," alluding to the highly rarefied air, which speedily arrests exertion. Wishing to ascertain the depth of the lake, he tried to make an opening in the ice, but found the slightest muscular effort too exhausting to proceed. Half a dozen strokes of the axe prostrated the workman; and though a few minutes' respite sufficed to restore the breath, anything like continual labour was impossible. A short run made the runner gasp; the pulse throbbed at a fearful rate; the voice was sensibly affected; and conversation in a loud tone was too painful to be maintained. 


\section{CHAPTER IIT.}

valleys AND GREAT LEVELS OF TIIE EARTH.

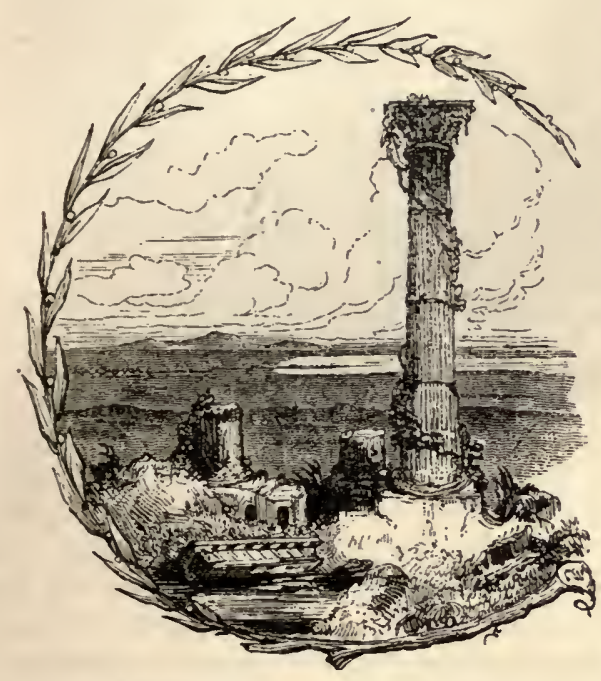

T lias been observed, that the ridge line of a chain of mountains is marked with great irregularities, numerous breaks and depressions occurring. Though the base of these depressions is at a high elevation above the general superficies, yet when internally surveyed they have all the appearance of being sunk far below it. The traveller slowly wending his way through them, shut out from any extensive observation of the country, and seeing on each hand eminences towcring far aloft, might imagine himself at an immense depth beneath the surface land of the globe. They are mountain chasms, through which communication is maintained between opposite sides of the ridge they intersect, and are called Cols in the Alps, Ports in the Pyrences, Gaps in the United States, and in gencral, gates, or passes. They abound with scenes of striking grandeur - overhanging rocks, undefended precipices, patches of wood, and cascades of water, rendered the more impressive by the seclusion of their sites. Some of the present passes across the Alps have been frequented from a rery early period, but many natural obstacles have in modern times been removed by the art and labour of man, and the difficult mule paths of a former age been converted into carriage roads. The Carthaginians are supposed to have entered Italy under Hannibal by the pass of the Great St. Bernard ; at least the weight of evidence is in favour of this route, which was made practicable for cars by order of Augustus, and along this course Pepin certainly led his army to attack the Lombards. "It is natural," says Mr. Inglis, "to compare one mountain pass with another ; and after having for the first time crossed any celebrated mountain, one naturally calls to mind the journeys which one may have made across other mountains, and the comparative interest with which such journeys have been attended. I need scarcely say, that there are certain features common to all mountain passes; that there is sublimity in clevation; that mountain clefts are filled by rivulets, which swell as they descend; that plants of less or more interest attract the eye; that from certain heiglits, extensive prospects of the country below are laid open; and that the phenomena of clouds, rain, and rainbows, and the effects of lights and shadows are common to all great elevations. But notwithstanding these features of common resemblance, mountains and their passes widely differ in interest, and consequently in the features by which nature has distinguished them. These differences, supposing the mountains to be equal in height, arise from the diversity in conformation, and the variety in their geological character. When we talk of one mountain pass being finer than annother, we mean that the views it affords are more 
sublime, or more picturesque; that sublimity, and that pieturesqueness, are the result of their shape and surface. I have never passed either Alount Cenis, or the Simplon; I

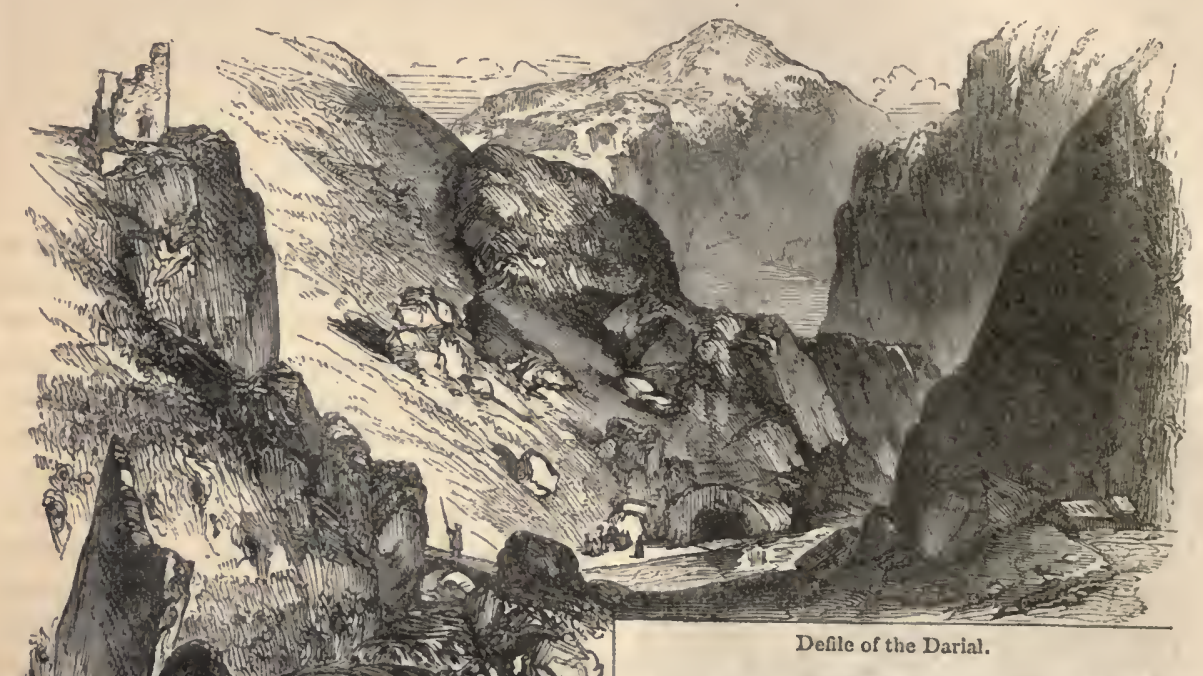

cannot therefore speak of them. The passes with which I am aequainted are, St. Go-

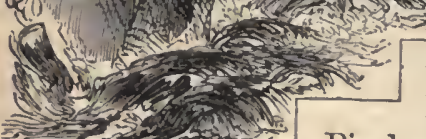
thard; Mount Albula; the pass by the sourees of the Rhine; the Rhetian Alps; the Brenner ; the limb of the Pic du Midi; the pass of the Pyrenees from Perpignan to Catalonia, and from Gavarnie by the Brêche de Roland to Arragon; some of the mountain passes of Norway; and the Spanish Sierras. Now it may seem singular, that of these, the lowest passes should be the finest; yet so it is in my estimation. Mount Albula, and the Brêche de Roland, are certainly lower than St. Gothard, and yet their features are more striking; and the truth is, that besides the causes $I$ have already mentioned, arising from diversity in conformation and surface, the very lowness is itself the chief cause of superiority. Nor is that apparent paradox difficult to explain. Where a road traverses the summit of a mountain, there cannot be precipices above; and the mere fact, that a road is necessarily led over the lighest part of a mountain, is itself a proof that it is not indented by those deep valleys, clefts, and ravines, which, did they exist, would permit the road to be conducted across at a lower elevation. Where a road traverses the summit of a mountain the views may be extensive; but they must yield in sublimity to those which are presented where the road conducts the traveller through the leart of the mountain, - among its deep recesses, its forests, and cataracts."

The ancients esteemed the passes of the mountains bounding their respective territories, or intersecting them, of great military importance, and added to their natural strength to render them impregnable. Pliny thus describes the defiles of the Caueasus, and the mode of maintaining them:- "Each pass was closed by large beams of wood pointed with iron. In the midst of the narrow valley flowed a river. The southern extremity was protected by a castle built on a high rock. This defence was to prevent incursions from the people of the north." Three great passes through the Caueasus are spoken of by the classical writers, the Pyle Sarmatx, the Pyle Albania, and the Via Caspia. The former, probably the Porta Caucasia of Strabo, is the particular one 
referred to by Pliny, now the pass or valley of the river Terek, one of the ancient keys of the East. The river has its rise towards the centre, and flows northward, a foaming torrent, by the side of which the emperor Alexander eaused the present road out of Europe into Georgia to be constructed in the year 1804. The road winds by the edge of precipices rising up from/the roaring waters of the Terek, while above, large projections of rock, many thousand tons in weight, hang from the beetling steep of the mountains, threatening destruction on all below - not always a vain apprehension. After the winter season, many of these huge masses have been launched downwards by the effect of a sudden thaw, blocking up the narrow pathway, or flooding it by the obstruction offered to the course of the river. The mountain sides of this pass - from one of which the lofty Kasibeck rises four thousand feet above the limit of perpetual snow - are so high, close, and overhanging, that even at mid-day the whole is covered with a shadow bordering on twilight.

At Darial, about a day's journey up the European side of the pass, the Russians have a military post. The scene is here one of great magnificence. The walls of rock reach the height of mearly four thousand feet above the bed of the river. The passes of the Taurus, which are the channels of communication between the interior plains of Asia Minor and the southern coast, have milder features. The most celebrated in antiquity - the Pylx Cilicix-through which the younger Cyrus and Alexander poured their armies, consists of a narrow defile, with cliffs covered a considerable way up with evergreens and pine-trees, hanging in some places like a vast canopy over the road, while bare and desolate peaks tower above the clouds. The passes of the Andes and Himalaya exhibit Nature in her wildest and most terrific aspects, and are perilous sites. The latter especially, owing to their elevation in the regions of eternal ice and snow, are seldom traversed without the loss of human life, and yet are annually travelled by crowds of people journeying to and from the Indian and Tartarian sides, on purposes of traffic, rarely proceeding a mile, at the higher points, without meeting with the remains of some ill-fated wayfarer. Captain A. Gerard accomplished the ascent of the Mannering Pass, 3000 feet higher than Mont Blanc, and thus describes the scene and its dangers : - "The river Darboong was lost among the fields of snow and ice by which it was generated; the whole space on every side was floored by ice, half hid under stones and rubbish. In some places the snow is of an incredible thickness, and lies in heaps. Having accumulated for years together, it separates by its gravity, and spreads wide desolation in its route. Nowhere, in all my travels, have I observed such enormous bodies of snow and ice, or altogether such a scene. So rapid and incessant is the progress of destruction here, that piles of stone are erected to guide the traveller, since the pathway is often obliterated in a few days by fresh showers of splinters. Our elevation was now upwards of 16,000 feet, although we had but ascended in company with the river. Here only began our toils : we scaled the slope of the mountain very slowly; respiration was laborious, and we felt exhausted at every step. The crest of the pass was not visible, and we saw no limit to our exertions. The road inclined to an angle of $30^{\circ}$. Vast benches of limestone, like marble, were passed under; the projections frowned over us in new and horrid shapes! Our situation was different from any thing we had yet experienced : it cannot be described. Long before we got up, our respiration became hurried and oppressive, and compelled us to sit down every few yards; and then only could we inhale a sufficient supply of air. The least motion was accompanied by debility and mental dejection: and thus we laboured on for two miles. The last half-mile was over the perpetual snow, sinking with the foot from three to twelve inches, the fresl covering of the former night. The direct road leads to the centre of the gap, where the snow is very deep and treacherous; and we made a circuit to the right, to avoid the 
danger of being swallowed up in one of the dark rents into which often shepherds and their flocks have sunk, never to rise. The day was eloudy, and a strong wind half froze us. The roeks were falling on all sides, and we narrowly escaped destruction. I myself twice saw large blocks of rock pass with dreadful velocity through the line of people, and between two of them not four feet apart. At half-past two I reached the summit."

The broad and deep depressions in mountainous distriets - properly speaking, valleys - are ranged into two elasses, aceording to their direction in relation to the main elevations. Those which are situated between two prineipal ridges are termed longitudinal, and those which are at right angles with a great chain, or variously inclined, are called transverse. Valleys also are styled lateral whielı feed, with tributary streams, a great watercourse; and by the terms upper and lower valley, parts of the same valley, near and more remote from the source of a river flowing through it, are denoted. The canton of the Valais in Switzerland-one of the most remarkable spots upon the globe, combining, within a very contracted area, the produetions and temperature of every latitude from the arctic to the torrid zone - is a longitudinal valley, the largest in the Swiss Alps. Its axis is parallel to the main chain of Mont Blanc and Mont Rosa on the south, and the ridge of the Bernese Alps, with the grand heights of the Jungfrau and Finster-Aar-Horn, on the north. The Rhone passes through it, rising at its western extremity among the glaciers of Mont Furea, at the height of 5726 feet above the sea, descending to an elevation of 1350 feet before it escapes out of the valley towards the Lake of Geneva. The valley is nearly a hundred miles long, the breadth of the base varying from a quarter of a mile to three miles. It can only be entered on level ground at one point, where the Rhone rushes out of it through a narrow gorge formed by the Dent de Midi and the

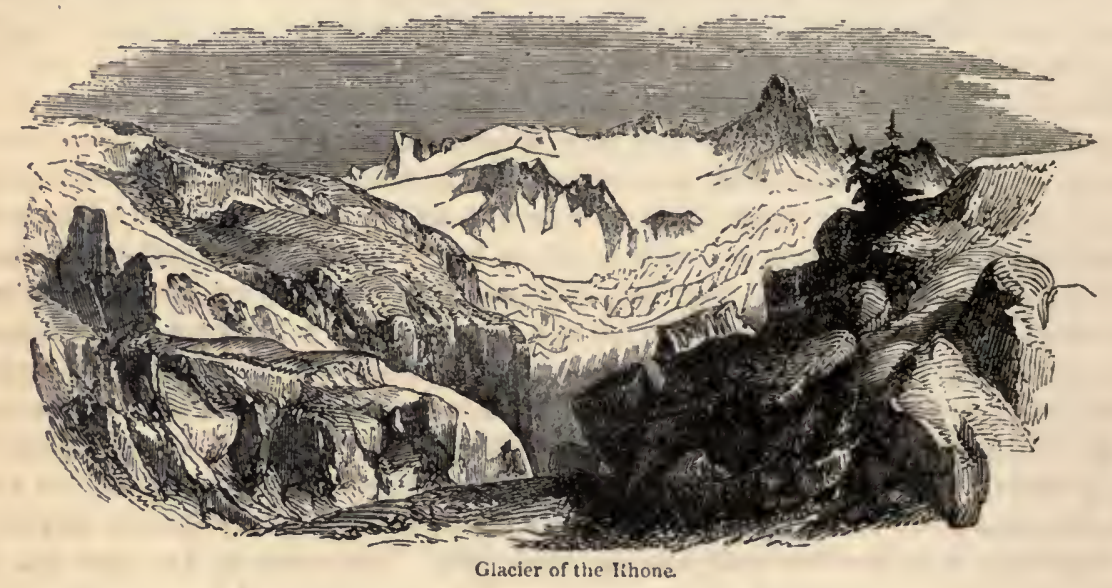

Dent de Morcles, which rise 8000 feet above its waters. Connected with this great longitudinal valley, there are thirteen lateral valleys on the south side, and three on the north, which bring down the waters of its enelosing mountains. The canton of the Grisons also comprises upwards of sixty transverse valleys, belonging chiefly to those which are longitudinal - those of the upper and lower Rhine, and the Inn. These bye-valleys are often nooks into which man seldom pries, and where no specimens of his handiwork are to be found. There are no sights or sounds but those of Nature, exhibiting herself in rock, wood, heatl, and mossy flower, and speaking by the rippling rivulet, as if inviting the enquiry - 
" Free rover of the liills, pray tell me now

The chances of thy journey, since first thou

From thy deep-prison'd well away didst break,

A solitary pilgrimage to take.

Among the quiet valleys, I do ween

Thou with the daisied tufts of tender green

Hast loving linger'd; didst thou not awake,

With thy soft kiss, the hare-bell bending low,

Stealing her nectar from the wild bee's wooing?

And thou hast toy'd (though thou wilt tell me, no!)

With many a modest violet, that looks

Into thy grassy pools in secret nooks.

Come, tell me, rover, all thou hast been doing!"

The larger Pyrenean valleys differ from the Alpine in being transverse, running at various angles with the principal range. There are those which are longitudinal, but not of equal extent with the former. It is common also for a Pyrenean valley to present the form of a succession of basins, at various distances from each other, called "oules," meaning pots or boilers, in the language of the mountaineers. These basins are large circular spaces covered with alluvial soil, sometimes eight miles in length by four in breadtl, through which the streams flow sluggishly, owing to their level surfaces. They have all the appearance of having once been lakes, the beds of which have been emptied, by the waters bursting through their mountain ramparts. In fact, in the upper parts of these valleys, the basins exhibit lakes at present, some of which are on very elevated sites. Malte Brun enumerates eight which are at the height of 6557 feet; but that of the Pic-du-Midi is 8813 , and is perpetually covered with ice. In the regions of the Andes, the longitudinal and transverse valleys constitute the most majestic and varied scenes which the Cordilleras present, and produce; says Humboldt, the most striking effects upon the imagination of the European traveller. The enormous height of the mountains cannot be seen as a whole except at a considerable distance, when in the plains which extend from the coast to the foot of the central chain. The table-lands which surround the summits covered with perpetual snow are, for the most part, elevated from 8000 to 10,000 feet above the level of the ocean. That circumstance diminishes to a certain degree the impression of grandeur produced by the colossal masses of Climboraço, Cotopaxi, and Antisana, when seen from the table-land of Quito. Deeper and narrower than those of the Alps and Pyrenees, the valleys of the Cordilleras present situations so wild as to fill the mind with fear and admiration. They are formed by vast rents, clothed with a vigorous vegetation; and of such a depth that Vesuvius might be placed in them without overtopping the nearest heights. Thus, the sides of the celebrated valleys of Chota and Cutaco are 4875 and 4225 feet in perpendicular height; their breadth does not exceed 2600 feet. The deepest valley in Europe is that of Ordesa in the Pyrenees, a part of Mont Perdu ; but this, according to Ramond, is not more than 3200 feet deep.

The valley form in more open regions is that of a depression, generally a water-course, with rounded and gently swelling embankments. The largest specimens of this class in Europe are found along the coast of the Danube, and the other great rivers, which frequently open out into extensive plains, and are the grand seats of population. Of a similar character are the vales of York, Aylesbury, and Exeter, in our own island. Some of the spots, too, which pass in our own country under the humble name of dales, are true pictures, though in a miniature form, of the high-walled valleys of Alpine and Andean districts. Perhaps the best representation, and certainly one of the most exquisite specimens of scenery we have, is the Dovedale of the Peak, so styled from its locality being in the Peak of Derby- 
shire, and from the name of the stream, the Dove, that flows through it. This is a valley between high and precipitous limestone rocks, three miles in extent, the sides closely approximating in some places, and again expanding. It seems as if it had been formed at once by some convulsion of nature, which rent asunder what had before been a vast compact mass, an impression often made by the appearance of valleys in mountain regions. Sometimes their opposite sides prescnt salient and re-entering points, which so exactly
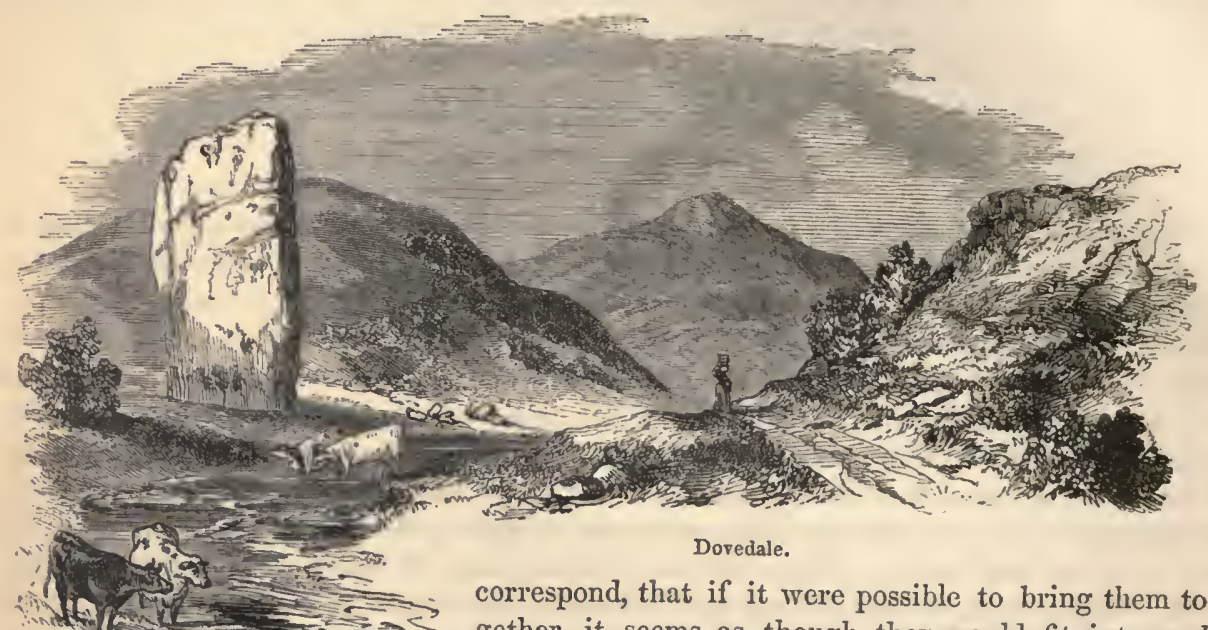

correspond, that if it were possible to bring them together, it seems as though they would fit into each other, leaving little trace of their former separation. Dovedale is approached on the west through a confined defile remarkable for its deep seclusion, of which Dr. Plot states, that the side-walls are so high that in rainy weather their tops may be seen above the clouds, and they are so close, that the inhabitants, a few cottagers, in that time of the year when the sun is nearest the tropic of Capricorn, never see it; and when it does begin to appear, they do not see it till about one o'clock, which they call Narrowdale noon, using it as a proverb when anything is delayed.

\footnotetext{
"Valley of Shadow! thee the evening moon

Hath never visited; the vernal sun

Arrives too late to mark the hour of noon

In thy deep solitude: yet hast thou One

Will not forsake thee: here the Dove doth run

Mile after mile thy dreary steeps between."
}

In Dovedale itself, the high eminences that form the lateral walls of the valley - the projecting rocks assuming the most fantastic shapes - sharp pinnacles and bold bluffs - the stream that flows at their base, now still, now murmuring, and dashing over a barrier of stones that have fallen from the heights into its bed - the wild flowers common to the limestone stratum - the copses of mountain ash - all combine to form a scene that satisfies at first sight, and increases in interest the more it is examined.

This is an example, therefore, of valleys of dislocation, so called from having apparently been formed by the breakage of the general mass in the process of upheaval. Sometimes there has been upheaval without fracture, but with more effect at particular points, causing intervening depressions, which are termed valleys of undulation, of which an example is given at page 630 , from the Jura mountains. Valleys of denudation are those which appear to have been formed by the action of water upon soft and practicable strata; but 
there can be little doubt that most valleys, from the grand rents of mountain ranges to the wide and gently sweeping hollows of the general surface, are mainly due to internal causes of disturbance, their physiognomy being subsequently modified by aqueous and atmospheric agency. The great depression of Western Asia, embracing many thousands of square leagues, of which the Caspian Sea and the Sea of Aral are the lowest points, is supposed to be intimately connected with the upheaval of the Caucasus, the plateau of Persia, and of High Asia.

When the valley form of the earth occurs upon a grand scale, there are points at which the traveller loses sight completely of the high lands that environ it. He beholds, stretching out on every side, a tract of level land, or at least the diversity of hill and vale occurs in such an unimportant degree as not essentially to disturb the idea of being in a flat country. The forces which have given such a peculiar character of variety to mountainous districts have only affected, to a comparatively feeble extent, these portions of the terrestrial superficies. In the former, the difference between high and low is often that of thousands of feet in a very small space, while in the latter frequently it does not amount to fifty feet, nor in some cases to ten, through a wide area. The surface rises and falls in gentle wavy undulations, here and there interrupted with bolder features, while occasionally a dead level is exhibited. These tracts may be collectively called plains, using the term in its geographical sense, not as meaning a perfectly horizontal surface, but an extent of generally level country. They are known in the Old World under a variety of names, as heaths, landes, steppes, tundras, and deserts.

Europe contains an immense extent of low flat land. It comprises part of northern France, the greater part of Belgium and northern Germany, all Holland and Denmark, the whole of Poland and southern Russia, thus stretching from the banks of the Seine to the terraces of the Ural and the waters of the Black Sea. This region, in general very level and fertile, traversed by numerous navigable rivers, is the birth-place and surface land of a large amount of modern civilisation. It is a vast plain with two grand declivities, inclining north and south-easterly, which determine the course of the superficial waters either to the Baltic Sea and the German Ocean, or to the basin of the Black Sea. As an instance however of the little inclination of the surface in some places, a prevailing north wind will drive the waters of the Stattiner-Haf into the mouth of the Oder, and give the stream a backward flow for an extent of thirty or forty miles. At the northern confine of the European lowlands, to a considerable distance from the shore, there is only a very slight elevation above the sea, and hence extensive marshes are formed along the coast. Holland is to a great extent so near the level of the waters as to require artificial means to protect it from inundation; and on approaching it, the trees and spires seem as if planted upon the ocean. Notwithstanding the general fertility of this tract of country, we meet with many spots incapable of cultivation, either wholly bare of vegetation, or only producing a few grasses and dicotyledonous plants, which constitute true heaths and landes. The moor and bog-lands of Westphalia are remarkable for their flat and tableformed surfaces. From the middle of the Beerktanger Bog, heaven and earth seem to mingle; no tree, no bush is to be seen far as the eye can reach; while here and there the play of refraction magnifies to elephants the small and coarse-woolled sheep which find a scanty subsistence on the Erica vulgaris, which vegetates on the scattered productive portions of the bog. The infertile plains, for the most part sandy, occur chiefly in north Germany and Prussia, those of Luineburg and its vicinity occupying a space of about six thousand square miles. Similar sandy plains, interspersed with heaths and marshes, occupy an extensive space in the south of France between the Gironde and the Pyrenees. 'Towards its eastern extremity, the great level of Europe abounds with enormous tracts of pasture land, which appear to have been rendered smooth by a long abode of the waters 
upon their surface. On these pastures nothing interrupts the view. 'The eye only firds a resting point at the horizon, and the traveller may pass over them for miles without

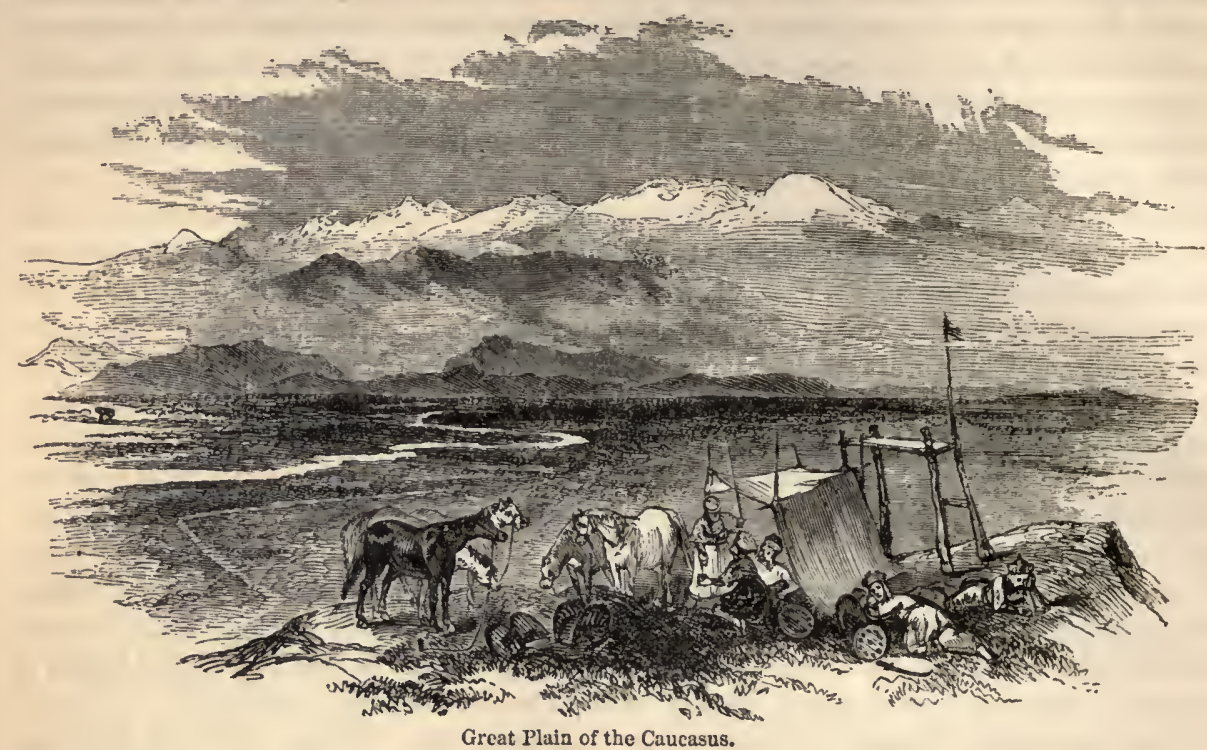

meeting with a village or a single house. From the mouths of the Danube, along the coasts of the Black Sea to the Don, these green plains terminate at the horizon with an azure line, such as is commonly perceived in the open sea. They possess the finest soil, a black rich mould, which with slight cultivation produces in great abundance all the cerealia, and even hemp and poppies. Nature, here left to herself, affords the most luxuriant and succulent pastures, in which herds of splendid oxen, such as are found in Holstein and Holland, graze night and day. From time to time, a few huts are met witl, indicated on the charts as inns or post-houses. 'The transition from cultivation to nomadic life, is recognised in this region, which is more palpable as an easterly direction is pursued, and gradually the aspect of the country changes, becomes wavy, undulating, and less fertile. Everything here, says Humboldt, speaking of the district east of the Don, awakes the anticipation of the steppes of Asia - the climate itself, with its hot summer, its cutting and sharp winter, and dry east wind, and even man himself !

The region of the steppes commences in Europe, and occupies almost the whole of the north-west of Asia. They are extensive and almost treeless plains, intersected with barren ridges and hills, with vegetation of rank coarse grass in the intervening spaces; at least this is their general character on the European side of the Volga. Mr. Stephens, the American traveller, thus describes his first acquaintance with them : - "At daylight we awoke, and found ourselves upon the wild steppes of Russia, forming a part of the immense plain which, beginning in northern Germany, extends for hundreds of miles, having its surface occasionally diversified by ancient tumuli, and terminates at the long chain of the Urals, which, rising like a wall, separates them from the equally vast plains of Siberia. The whole of this immense plain was covered with a luxuriant pasture, but bare of trees, like our own prairie lands, mostly uncultivated, yet everywhere capable of producing the same wheat which now draws to the Black Sea the vessels of 'Turkey, Egypt, and Italy, making Russia the granary of the Levant; and which, within the last year, we have seen brought six thousand miles to our own doors. Our road over these steppes was in its natural state, that is to say, a mere track worn by caravans of waggons ; there 
were no fences, and sometimes the route was marked at intervals by heaps of stones, intended as guides when the ground should be covered with snow. I had some anxiety about our carriage; the breaking of a wheel would have left us perfectly helpless in a desolate country, perhaps more than a hundred miles from any place where we could get it repaired. Indeed, on the whole road to Chioff there was not a single place where we could have had any material injury repaired; and the remark of the old traveller is yet emphatically true, that "there be small suceour in these parts." Nothing is more remarkable than the successive appearance of thousands of tumuli, which orerspread the great levels of southern Russia. 'They are mounds of earth - the mansions of the dead of past ages - oceupying sites which are now tenantless for leagues around them, and only visited occasionally by droves of eattle and the passing traveller. Observing only a few specimens, they might be coneluded to be indications of the route between different places, did not their number, symmetrieal form, general resemblance, and contents, whenever opened, disprove the idea. The earliest adventurers from the west of Europe into these waste places mention the tumuli. "We journeyed," says William de Rubruquis, "with no other objects in view than earth and sky, and ocensionally the sea upon our right, which is ealled the sea of 'Tanais; and moreover the sepulchres of the Comani, which seemed about two leagues distant, construeted aceording to the mode of burial which characterised their ancestors." Simple as these funereal monuments are of an ancient world, their very simplicity is sublime, harmonising with the appearances of nature in the steppes, unaffected by the liand of Time, by which the Parian marble is speedily defaced. Among the oecurrences of the steppes, that of a grass fire is not uneommon, occasioned by the unextinguished embers left by parties who have bivouacked in them, which lay hold of the hight and dry vegetation in their neighbourhood, and spread temporary desolation over large tracts of country. The monotony of these plains gives great effect to the appearance of the Caucasus. On the approach from the nortl, these mountains are seen at a rast distance, rising abruptly from a level country, apparently an

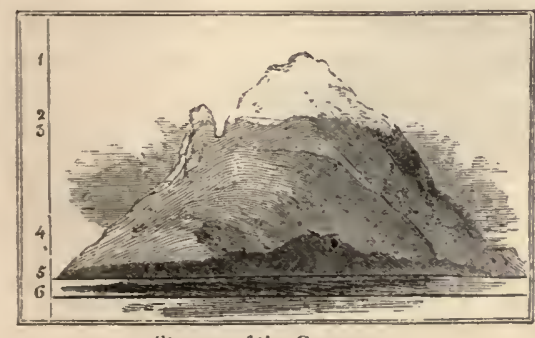

Steppes of the Caucasus. impassable barrier stretching from the Caspian to the Black Sea, the white head of Elbûrz towering above the lower summits of the range. In the diagram is represented Mount Kasibeck, the snowy region beginning at fig. 2., a height of 10,200 feet; opposite $f i g .3$. is the bed of the Terek; fig. 4. shows the profile of hill near the Steppe; 5. the level of the Caspian, and 6 . of the Black Sea. On the castern side of the Volga, the steppes extend fir into the heart of Asia; but their physiognomy greatly alters. 'The soil becomes more unfruitful; regetation only shows itself here and there; the salt steppes appear, abounding in pools and streams of salt and bitter waters, on the banks of which the willow and the reed only grow - the sole means of supporting the lierds of the Tureoman in winter, whom circumstanees therefore render nomadic.

The desert plains - meaning not merely solitudes, but sandy and stony wastes - oceupy an cnormous space of the lowland regions of the globe. They are rare on the continent of America, but occur in the lower part of Peru, where a considerable distriet is found, exhibiting the features of a true Sahara - a surface of roek covered with moveable sand, not a drop of rain falling upon it. Still such tracts are seldom met with in the New World, while they are so abundant upon the ancient continent as to constitute a marked distinction between the two regions. The reproach is of old standing against $A$ frica, of being the most barren and unproauctive of the great divisions of the earth - a reproacl 
which especially applies to an immense domain extending on both sides of the tropic of Cancer, but having its main direction from west to east, and including more than a fifth part of the whole of that territory. This is the Sahara-bela-ma of the Arabs, or desert without water, called also the Bahar-bela-ma, or ocean without water. Upon a large space of this district there is neither rain nor dew, to awaken in the glowing bosom of the earth the germs of vegetable life. From the west coast of Africa, and between Morocco on the north and the Senegal river on the south, this wilderness extends easterly to the Red Sea, contracted towards the west by a projecting part of the kingdom of Fezzan, and interrupted on the east by the narrow valley of the Nile. It embraces a space of more than $46^{\circ}$ of longitude and $15^{\circ}$ of latitude, or a length of 3000 miles by a breadth of 1000. A large extent of the Sahara is a dead level; but low sand hills, wadys or valleys, and projecting rocks are frequent. "Now the naked rock" says Humboldt, describing its characteristics, "appears to view perfectly smooth and level, which the traveller may pass over for days together without meeting even a grain of sand, where one sees only the heaven above and the hard stone pavement beneath; now we beliold a flat plain covered with rolled pebbles, here and there intersected with ravines and valleys extending to about thirty feet below the surface; and now an ocean of sand presents itself, frequently containing so large a quantity of salt, that whole tracts appear coated with it, and resemble fields of ice. Occasionally spots of verdure are found, known under the name of oases, which display palm trees and springs of water." 'The Egyptians, says Strabo, give the name of oases to inhabited spots surrounded by vast deserts of sand, and resembling islands in the sea. There are, he states, many such in Lybia, while three border on Egypt, and are referred to that country. Modern discovery has, however, made us aequainted with several of these isles of the African ocean of sand, which are rich in streams and vegetation. In the western part of Fczzan, in a lollow surrounded by

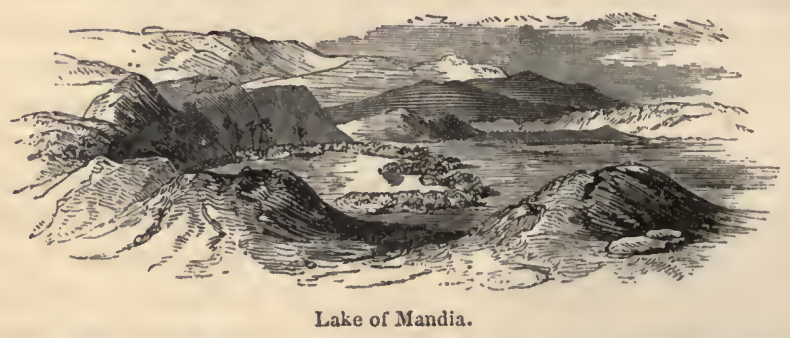

rocks, lies the small lake of Mandia, celebrated for the occurrence of Trona, or pure natron (soda). Oudney and Clapperton, on their memorable expedition from Tripoli, visited this lake. Clapperton, as Oudney tells us, was sitting on the top of a ligh sand hill, and so pleased with the view, that he called out several times to his companion to dismount from his camel to enjoy the treat. 'Ihe appearance was beautiful. There was a deep sandy valley, containing only two large groves of date trees, enclosing a fine lake. The contrast between the bare lofty sand hills, and the two insulated spots, was the great cause of the sensation of beauty. There is something pleasing in a lake surrounderl witl vegetation; but when every other object within the sphere of vision is dreary, the scene will become doubly so. No doubt the oases in general owe much of their reputation to the contrast they form with the absolute barrenness of the desert. With the exception of these spots, the Sahara is uninhabitable for man; and it is only at periodic times that it is traversed by the trading caravans, which proceed across it from 'Tafilet to 'Timbuctoo, and from Fezzan to Bornou. 'These are bold undertakings, the practicability of which depends upon the life of the camel-the ship of the desert, as the animal is 
termed in the poetical language of the Orientals. One chief source of danger arises from the Simoom, a hot southerly wind, which rolls along in suffocating masses the sandy billows, darkening the air, and frequently orerwhelming every object in their path.

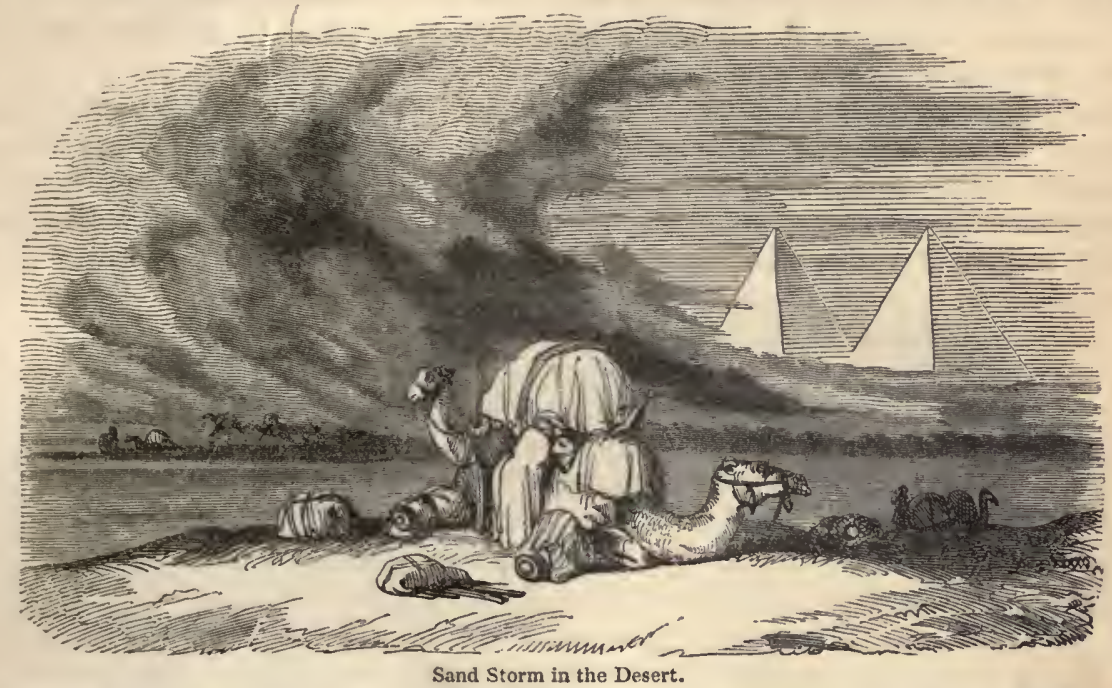

This wind in passing orer the desert acquires an extraordinary degree of heat and dryness, and stops respiration at once upon exposure to it. To avoid its effects, the Arabs drop the Kafieh, a handkerchief which they wear upon their heads, so as to cover their faces. If the immediate perils of this fierce burning blast are escaped, it often happens that the water contained in the skins borne by the camels is absorbed; and in such circumstances, if at too great distance to obtain a fresh supply in time, the whole company fall victims to intolerable thirst. In this way an aklabah or caravan, consisting of 2000 persons and 1800 camels, was cut off in the year 1805. The Sahara is one principal theatre of that singular optical illusion called the "mirage," to which the Arabs apply the more poetical name of the Lake of the Gazelles. This is the appearance of tructs of water in the desert - a deception supposed to arise from the refiection which takes place between strata of air of different densities, owing to the radiation of heat from the plains of sand. These mock lakes - the "waters that fail," or that hare no reality - often torment the passenger oppressed with heat and thirst. Major Skinner describes a deception of this kind, the most perfect that could be conceived, which for a time exhilarated the spirits of the party with whom he journeyed in the desert, and promised an early resting-place. They had observed a slight mirage two or three times before; but the one in question surpassed all that could well be fancied. Although aware that these appearances have often led people astray, he could not bring himself to believe that this was unreal. Even the Arabs were doubtful. The seeming lake was broken in several parts by little islands of sand, which gave strength to the delusion. The dromedaries of the sheikhs at length reached its borders, and appeared to have commenced to ford, as they advanced and became more surrounded by the vapour. They seemed to have got into deep water, and to be moving with greater caution. In passing over the sand-banks, their figures were reflected in the water. So convinced was one of the party of its reality, that he dismounted and walked towards the deepest part of it, which was on the right hand. He followed the deceitful lake for a long time, and appeared to be strolling on its banks, his shadow stretching to a great length beyond. There was not a breatl of wind; and the sultriness of the day would have added dread- 
fully to the disappointment, if the party had been much distressed for want of water. The Sihara is now well known to be advaneing from east to west, besides being in a condition of internal instability, owing to the sand-storms altering the appearanee of the surface. The prevailing currents of air that sweep over it are from enst to west, and the flying sands travelling in that direction, there enlarge its bounds. The Wandering Sea is one of the Arab titles of a sandy desert.

The Sahara apparently terminates at the valley of the Nile, but the same identical region is prolonged beyond that channel. It embraces nearly the whole of the Arabian peninsula, which, excepting a few enclosed valleys, is a stony and barren tract, and generally an infertile level, presenting great sandy plains, producing little besides the acacia vera, or Egyptian thorn, and a few other plants. North of this is the Syrian

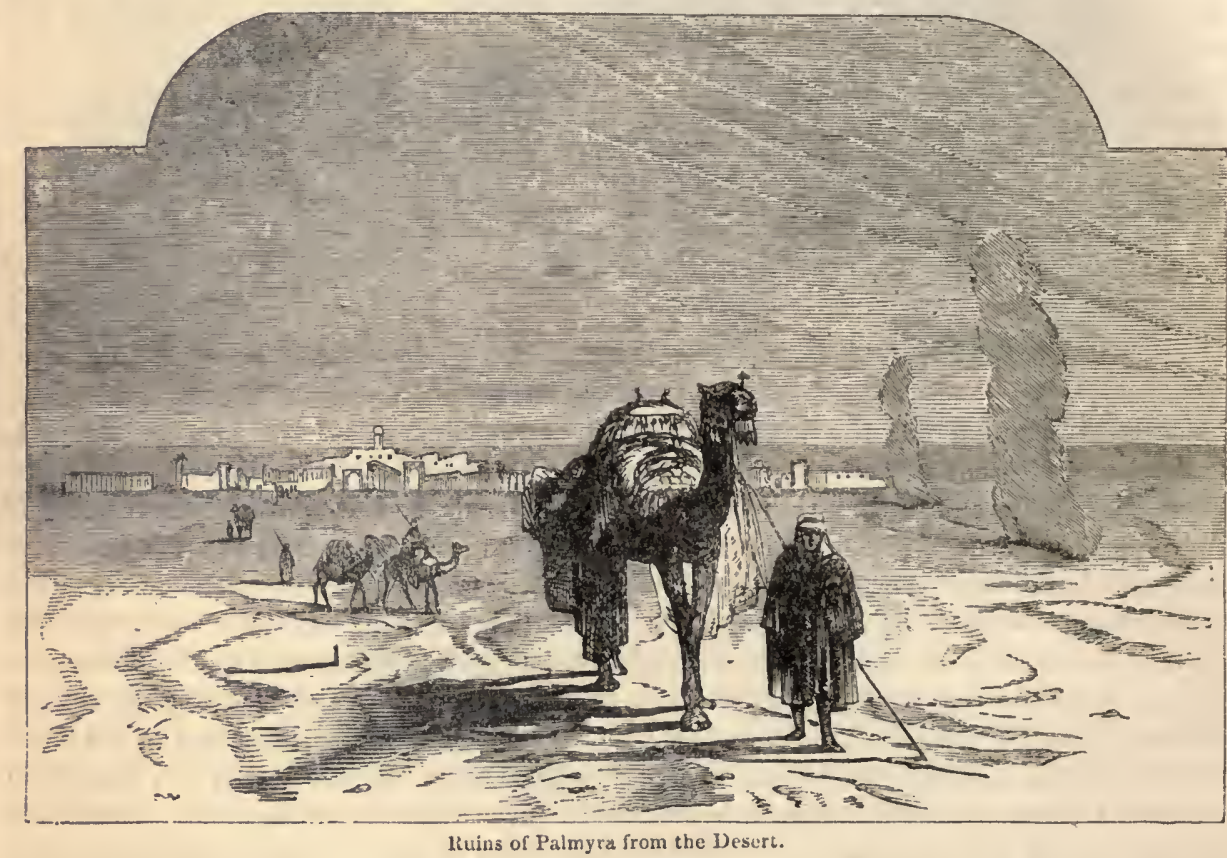

desert, which lies between the range of Lebanon and the Euphrates, in the heart of which is the oasis, containing the relics of one of the nysterious cities of antiquity, the Tadmor in the wilderness of a remote time, the Palmyra of a more modern age. It is not diflicult to conceive of the effect of its ruins after passing through a waste in many places without a single object showing either life or motion; Corinthian columns of white marble contrasting finely in their snowy appearance with the apparently boundless yellow sands, the monuments of an opulence and art, every other trace of which has vanished with the people by whom it was enjoyed. $\mathrm{A}$ day in this desert is admirably described by the author of Ë̈then :- "As you are journeying in the interior you have no particular point to make for as your resting-place. The endless sands yield nothing but small stunted shrubs; even these fail after the first two or three days, and from that time you pass over broad plains - you pass over newly-reared hills - you pass through valleys that the storm of the last week las dug; and the hills and the valleys are sand, sand, sand, and only sand, and sand, and sand again. 'The earth is so sandy, that your eyes turn towards heaven - towards hearen, I inean, in the sense of sky. You louk to the sun, for he is your task-master, and by him you know the measure of the work that you have done, 
and the measure of the work that remains for you to do; he comes when you strike your tent in the early morning, and then, for the first hour of the day, as you move forward on your camel, he stands at your near side, and makes you know that the whole day's toil is before you: then for a while, and for a long while, you see him no more - for you are veiled and shrouded, and dare not look upon the greatness of his glory; but you know where he strikes over head by the touch of his flaming sword. No words are spoken; but your Arabs moan, your camels sigh, your skin glows, your shoulders ache; and for sights you see the pattern and web of the silk that veils your eyes, and the glare of the outer light; but conquering Time marches on, and by and by the descending sun has compassed the heaven, and now softly touches your right arm, and throws your lank shadow over the sand, right along on the way to Persia." Beyond the Euphrates to the Tigris, with the exception of slips along the two rivers, the country is a desert of burning sands and sterile gypsum, thickly studded with saline and sulphurous pools; and farther eastward the zone of deserts may be traced through Persia, Grand Tartary, and the great central plateau of Asia, extending thus in an almost continuous band of varying breadth from the Atlantic Oeean to the wall of China. Analogous phenomena to those of the Sahara - the mirage and encroaching sands - are displayed through the greater part of this zone, which proceeds in a cirele, the are of which is directed towards the south, through the whole of the ancient world. Especially in some regions of south-western Asia has the dry element sensibly advanced. Once rich and blooming territories, celebrated by the Persian poets as paradisiacal, the theatre of heroic deeds, the seat of politieal power and intellectual culture, the site of cities which in size and splendour were second to none in Asia, have been visited by the moveable sand, leaving but few evidences of former grandeur and fertility apparent. At Samarcand and Bokhara, celebrated sovereign cities, from which, in the middle ages, bold and chiralrous princes overspread the East with their flying squadrons, the sands lave with difficulty been kept at bay. The river Sihun has been compelled to alter its course, and the mighty Oxus of the ancients, according to historical evidence, has lost its Caspian arm in a struggle with the desert. Setting aside the fertile oases, Humboldt supposes the area of the sandy deserts, leaving out those of central Asia, to be 300,000 square leagues. Those of the Tartarian table-land cannot be less than 100,000 morc, and adding 100,000 for similar traets in Midland and Southern Africa, with some other districts, we have a grand total of half a million of square leagues of such surface in the Old World; a space equal to the whole extent of Europe.

The deserts to which the preceding notices refer, are for the most part hot sandy districts, or experience great alternations of heat and cold. Independently of these, there are cold tracts of lowland, chiefly found in the northern regions of Asia. From the declivities of the Ural on the west, to the coast of Kamtschatka on the east, and from the foot of the Altaian Mountains on the south, to the icy margin of the Arctic Ocean on the north, there is a country almost as large as Europe, a melancholy desert, in which, in latitude $67^{\circ}$, the growth of trees censes altogether; and a little higher up the soil is frozen the whole year through, some few inches of the surface alone being subject to an annual thaw: but at a short distance from the surface, throughout Siberia, a bottom of perpetually frost-bound soil is met with. Gmelin the elder, in his travels, states that shortly after the foundation of the town of Yakutsk, in lat. $622_{2}^{\circ}$ north, at the end of the seventeenth century, the soil of that place was found to be frozen at a depth of ninety-one feet, and that the people were compelled to give up the design of sinking a well, a statement corroborated in our days by the travels of Erman and Humboldt. Until very lately nothing was known respecting the thickness of. the frozen surface; but within these few years a merchant of the name of Schargin, having attempted to sink a well at Yakutsk, was 
about to abandon the project in despair of obtaining water, when Admiral Wrangel persuaded him to continue his operations till he liad perforated the whole stratum of ice. This was done, and at the depth of 382 feet the soil was found very loose, and the temperature of the earth was $31^{\circ}$ Fahrenheit. The external appearanee of these cold distriets is admirably depicted by a writer quoted by Berghaus. With painful feeliugs, he states, the traveller observes the trees diminishing in height the nearer lie approaches the iey sea. At ninety German miles from the sea, erect and lofty lareh trees afford a veil to expiring nature, but from this point their number diminishes, and they become small and crippled. The coating of moss that covers the tree is thicker than the stem itself; but nothing ean save it from the destroying breath of the north. Some thin birches endeavour to contend against this fearful foe, but they perish when searcely sprung from the bosom of the earth, and $70^{\circ}$ latitude may be assigned as the limit of the growth of trees. It is only the moss, the true ehild of the north, which thrives and blooms even in the midst of winter, and seantily cover's a soil which has been barren for thousands of years. From the last tree to the frozen ocean extends an enormous desert eovered with lakes and lagunes. Some of the lakes are large and deep, and rich in fish, their lofty banks consisting of level beds of earth and ice, the ice eovering the earth. Throughout this region a deathlike silence reigns, seldom interrupted except by the summer birds of passage.

We now proceed to notice the flat lands of the New Continent. A large portion of South Amerien is only slightly. raised above the level of the ocean. Supposing, as the effect of some particular attraction, the waters of the Atlantic to be raised fifty fathoms at the mouth of the Orinoco, and two hundred fathoms at that of the Amazon, the flood would cover over more than one-half of that part of the New World, and the billows of the sea would dash against the eastern slope or foot of the Andes, which is now nearly 2000 miles from the coast of Brazil. Comparatively low transverse ridges, running east and west, divide South Ameriea into three great distriets. Through the northern distriet the Orinoco flows; through the central, the Amazon; and through the southern, the La Plata. The eountry on each side of these rivers consists of enormous levels, to which the terms Llanos, Selvas, and Pampas, are applied, distinguishing the regions bordering on these mighty streams, in the order in which they have been named.

The Llanos border on the Orinoco, and are plains, ineluding the vast area of 260,000 square miles, at the mean height of 200 feet above the level of the sea, sluggishly therefore bearing tributary streams to the great watercourse. 'The name is an abbreviation of loca plana, and was applied to them by the first Spanish eonquerors, on aceount of their singular flatness. Humboldt has described the Llanos with great felieity, and presents us with the following graphic pieture:- "The sun," he thus commenees, "on our entrance into the basin of Clanos, stood almost in the zenith; the ground, wherever it was naked and destitute of plants, was of a temperature whieh attained 48 or 50 degrees. No breeze was pereeptible at the height on which we were sitting on our mules, yet there arose, in the midst of this apparent repose, an ineessant cloud of dust driven by light breaths of wind which swept only the surface of the ground, and produeed differences of ternperature, which were imparted to the naked sand and the spots of grass. These sandwinds inerease the suffocating heat of the air. Every grain of sand, hotter than the atmosphere which surrounds it, beams on all sides, and it becomes diffieult to measure the temperature without the grains of sand beating against the ball of the thermometer. All around us, the plains seemed to rise to heaven, and this vast and silent desert appeared to our eyes like a sea which is covered with sea-weed, or the algæ of the deep sea. Aceording to the inequality of the mass of vapour floating in the atmosphere, and the alternating temperature of the breezes contending against each other, was the appearance of the horizon; - in some places clear and sharply defined, in others wavy, crooked, and, as it 


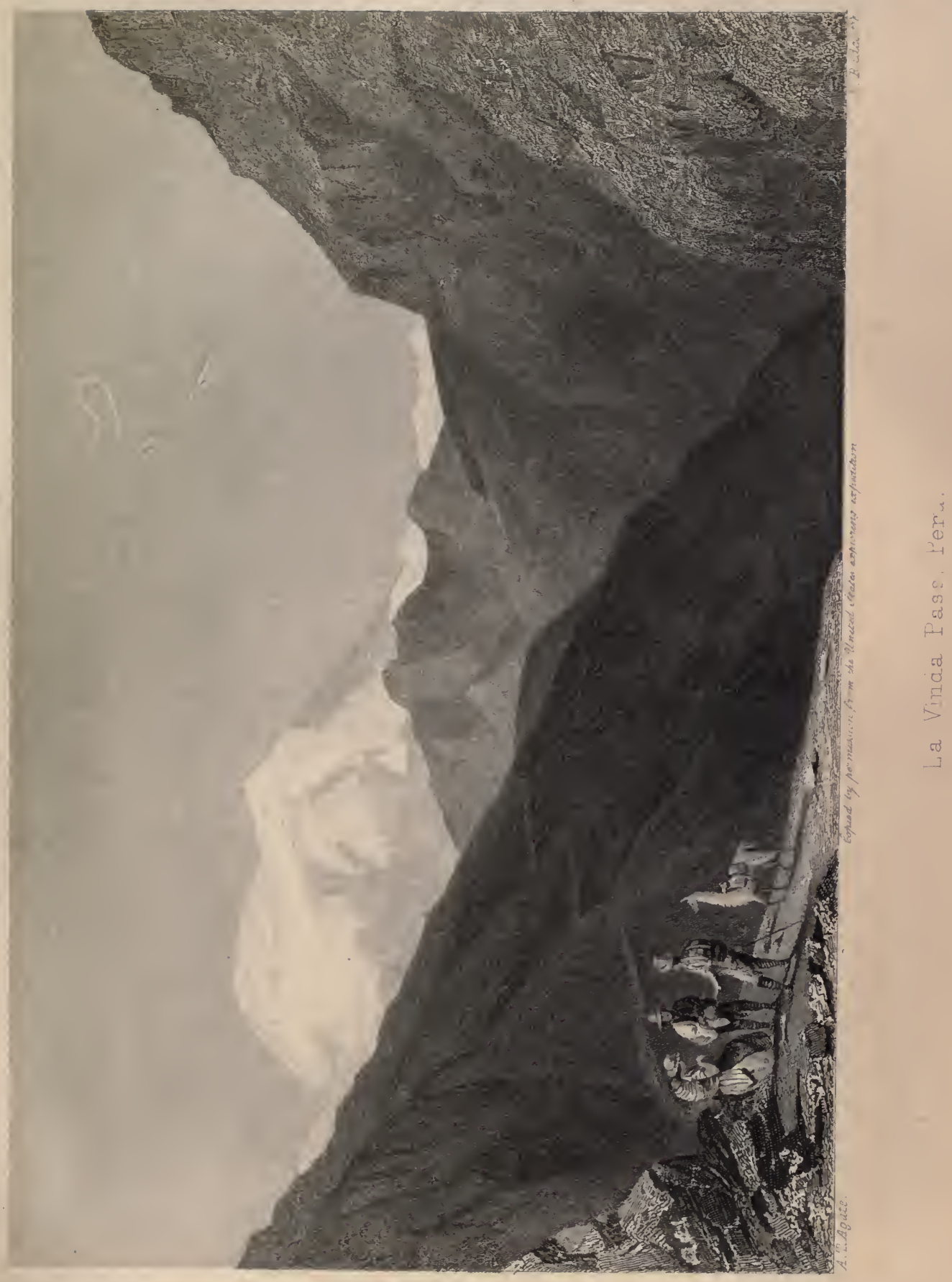


were, striped. The earth, there, seemed to mingle with heaven. Through the dry mist we perceived palm trees in the distance. Stripped of their leaves and their green summits, these stems resembled the masts of a ship which one descries in the horizon at sea. There is something sublime, yet mournful, in the uniform spectacle of these steppes. Everything in them appears inmoveable, except that perchance, occasionally, the shadow of a small cloud which passes over the zenith and announces the approach of the rainy season, falls on the savannah. I know not whether the first feeling of surprise at the first view of the Llanos is not as great as at the first view of the chain of the Andes. Mountainous regions, however high eren their highest points may be, have an analogous

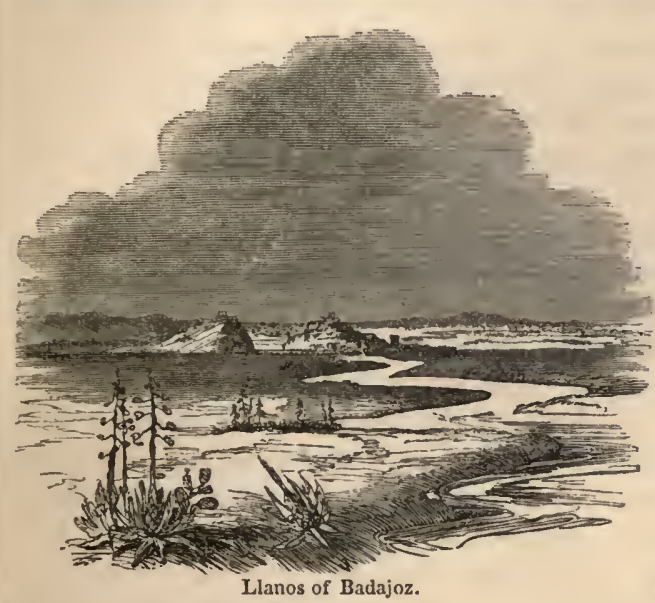
physiognomy; but it is only with difficulty that the eye can accustom itself to the Ilanos of Venezuela and Casanareto the Pampas of Buenos Ayres and of Chaco, which incessantly, and during journeys of from twenty to thirty days, remind one of the watery mirror of the tropic sea. I had seen the Llanos or plains of La Mancha in Spain, and the Haiden, which extend from the extreme point of Jutland, through Luneburgh and Westphalia, to the mouth of the Scheldt. These Haiden are true steppes, from which during centuries mankind have only been able to win a few small spots for the plough; yet these plains of the west and north of Europe afford but a faint image of the immeasurable Llanos of South America."

The Llanos exhibit a somewhat various aspect, the grasses rising to the height of four feet in the neighbourhood of the streams, which only reach a few inches at a distance from them. The palms and dicotyledonous plants are also more abundant in such situations, and here is the favourite haunt of the jaguar, the tiger of the western continent, lying in wait for some straggler from the droves of horses that occupy these plains. But different seasons of the year produce a wonderful alteration in the appearance of these districts, particularly those which are removed from the watercourses. 'The surface displays a beautiful green verdure in the rainy season, but in the dry months its aspect is that of a desert. At that period the grasses wither, and are reduced to powder, the ground cracks, the crocodiles and great serpents remain imbedded in the dried mud, till the showers of returning spring awaken them from their lethargy, when the whole scene changes, and puts on an air of great luxuriance. Humboldt determined by barometrical observations that the Llanos have not more than a height of from forty to fifty fathoms above the level of the sea. Hence the streams are sluggish, their motion in some places scarcely perceptible, and the slightest wind upon the Orinoco contrary to its course will suffice to raise its waters, and drive back the rivers that are tributary to it. There is then the phenomenon exhibited of water ascending and descending in the same channel, a mass of standing water separating the two, in which whirlpools are formed by the disturbance of the equipoise. The same authority strikingly dilates upon the almost liquid uniformity of the surface of these regions, large spaces occurring without an elevation a foot ligh. But notwithstanding their apparent uniformity of level, the Llanos offer two kinds of inequalities. There are banks of limestone and sandstone or bancos, standing four or five feet above the plains, sometimes several leagues 
in length, quite flat at the top; and raulted elevations, or mesas, rising imperceptibly a few feet, which occasion the divertic aquarum of Livy, the parting of the waters, where the rivers flow in opposite directions. 'The streams which proceed southward to the Orinoco, and northward to the coast of Terra Firma, have their course determined by these convexities of the surface which lie between them, and are of rery trivial elevation.

According to Humboldt, the general level face which these regions present; the extraordinary rareness of habitations; the periodieal difficultics of traversing dried downs, under a burning sky, and in an atmosphere darkened with dust; the aspect of the horizon, which incessantly seems to fly before the traveller; the isolated stems of palm trees which all possess the same physiognomy, and which appear never to be reached, because confounded with other stems which gradually appear to view; - all these eauses, taken together, make the Llanos apparently much larger than they really are. Still they unfold immense spaces of surfice completely monotonous, equal in extent to the distance between Paris and Naples, and in some instances from 'Timbuctoo to the northern margin of the Saliara.

The central level of South America bears the local name of Selvas (woods), and extends along both sides of the river Amazon, from the Andes to the ocean. It embraces an area about six times larger than France, and of equal size with European Russia. It is an immense forest region, with open patches of a similar character to the Llanos, intersected by numcrous rivers flowing into the great basin of the Amazon. This district is but little known to Europeans, except on the borders of the streams; and many of these have not been traversed through the whole of their course. The powerful regetation here conceals, in a great measure, the uniform level of the soil. 'The trees attain a great height, with straight clear stems, the foliage uniting in a canopy above, and leaving all benenth in perfect shade and quiet. This longitudinal development is unfarourable to protracted existence, as age and climate soon attack the trees; but other's very speedily fill up their vacant places. These primeval woods occupy about 719,000 square miles of territory; and including the waters, enclosed open plains, and some ranges of hills, the whole surface presents an area of $2,340,000$. 'The trees vary greatly in species, scarcely any two trees standing together being of the same kind. Thirty or forty different species are found in an area of twenty square yards. Bushes and creepers fill up the intervals between them, uniting the whole together, and constituting a woody fabric which defics the intrusion of man. "The industry of man," says a recent writer, "has in all otler countries succeeded in subjecting the productive power of nature to his sway, and to direct its operation to his ends. In the Sahara it has taken possession of all the resourecs of the country till it has arrived at the very limits which Nature lierself has fixed. No farther improvement can there take place. In some countries situated within the polar circle, a course of improvement has been adopted, and is pursued with success. Its progress is slow, but certain. The ungrateful soil of the Falkland Islands has even fallen under the fertilising hand of man, and will doubtless be converted into fruitful fields in the progress of time. But there is little hope that sucl will ever be the ease with the plain of the Amazon. The productive powers of this country, it appear's, are too great and too active to be subdued. If its soil was but half as fertile, its air half as moist, and its vegetation half as vigorous as it is, man would easily master nature, and compel it to administer to his wants, or to supply him with riches. But he finds here that all the efforts of his industry are in vain; he is overwhelmed by the bounties of nature. His mind sinks into despair when he contemplates the immense work before him, whilst his body feels the exhaustion produced by that climate which imparts to the soil its never ceasing power of reproduction. He finds limself reluctantly compelled to abandon his plans, and to leave to Nature that portion of the globe which she seems to have reserved for her 
exclusive property, and for her unfettered operations. The plain of the Amazon is, perliaps, destined to remain for ever a wilderness."

South of the forest-covered plain of the Amazon, we come to the third great level of South America - the region of the Pampas, an Indian word signifying a flat, given to districts which are true steppes - plains rich in grass, but without trees. They extend in an almost uninterrupted band from latitude $15^{\circ}$ south to $45^{\circ}$, or about 1800 geographical miles, by a width varying from 300 to 900 ; and while at one extremity we find the palm, at the other, where the ground is extremely low, it is covered with perpetual ice. Sir Francis Head describes the pampas, stretehing from Buenos Ayres to the Andes, as a vast piain, divided into regions of different climate and produce. The first of these regions is covered with clover and thistles; the second region produces long grass; and the third region, which reaches the base of the Cordillera, is a grove of low trees and shrubs. The second and third of these regions exhibit nearly the same appearance throughout the year. The trees and shrubs are evergreens, and the immense plain of grass only changes its colour from green to brown. But the first region varies with the four scasons of the year in a most extraordinary manner. In winter the leaves of the thistles are large and luxuriant, and the whole surface of the country has the rough appearance of a turnip-field. The clover in this season is extremely rich and strong; and the sight of the wild cattle grazing in full liberty on such pasture is very beautiful. In spring the clover has vanished, the leaves of the thistles have extended along the ground, and the country still looks like a rough crop of turnips. In less than a month the change is most extraordinary; the whole region becomes a luxuriant wood of enormous thistles, which have suddenly shot up to a height of ten or eleven feet, and are all in full bloom. 'Theroad or path is hemmed in on both sides; the view is completely obstructed; not an animal is to be seen; and the stems of the thistles are so close to ench other, and so strong, that, independently of the prickles with which they are armed, they form an impenetrable barrier. The sudden growth of these plants is quite astonishing; and though it would be an unusual misfortune in military history, yet it is really possible, that an invading army, unacquainted with this country, might be imprisoned by these thistles before they had time to escape from them. 'The summer is not over before the scene undergoes another rapid change: the thistles suddenly lose their sap and verdure; their heads droop; the leaves shrink and fade; the stems become black and dead; and they remain rattling with the breeze one against another, until the violence of the pampero or hurricane levels them with the ground, where they rapidly decompose and disappear - the clover rushes up, and the scene is again verdant. Such, in the main, is Captain Head's description of the extraordinary spectacle, which has doubtless been annually exhibited by this division of the pampas ever since its emergence from the ocean under whose billows it once lay. It must not be imagined, however, that the region of the pampas displays uniformly this vigorous vegetation. There are large spaces which are absolutely sterile tracts of sand and stone, but surrounded with districts sufficiently luxuriant to pasture enormous droves of cattle which are more or less under the dominion of man.

The northern division of the western continent contains a single connected tract of flat country, which forms the central part of North America, reaching from the consts of the Mexican Gulf to the inhospitable shores of Hudson's Bay and the Arctic Ser. This vast region, almost as large as the whole of Europe, is the site of two of the greatest river-systems of the earth, that of the Mississippi with its affluents, and that of the St. Lawrence with the chain of the Canadian Lakes. No prominent elevation appears between these rivers pursuing different directions, serving as a water-shed; and as little observable is the elevation of the partition which separates the streams flowing to the St. Lawrence and to Hudson's Bay. Both have a very gentle descent, and proceed 
from unimportant heights above the lerel of the sea. Lake Superior is only 600 feet above the level of the ocean, Lake Erie 528 feet, and Lake Ontario 216 feet, while the plains about Cincinnati have scarcely an absolute height of 480 feet, and yet the Ohio is there 1400 miles from its confluence with the sea by means of the Mississippi. In this great district a person may have been born, may have lived to old age, and travelled much, without once seeing an elevation worthy of the name of mountain. It extends through all zones of vegetation, having palms and bamboos in its southern portions, while its northern margin, during great part of the year, is covered with snow and ice. Flint, the American geographer, classes under the three distinct aspects of the Wooded, the Barreiis, and the Prairie country, the general surface of this territory, the Far West, as it is termed by the inhabitants of the Atlantic portion of the United States. In the timber region the trees are remarkable for the grandeur of their form and size. Frequently there are but few low shrubs, and the large tall trees are branchless a considerable way up, their smooth straight trunks appearing like stately pillars. The rays of the sun playing upon the magnificent upper foliage, and glancing through it, give to the forest the aspect of a cathedral in which the light is modified by the stained windows, and falls in tinted streams upon the Gothic arches and columns. 'The Barrens, or barren grounds, exhibit an undulating surface covered with long coarse grass, interspersed with copses of hazel and underwood, and a few stunted oaks scattered here and there, which resemble the masts of ships seen at a distance. They are found east and west of the Mississippi, and occupy extensive spaces, but are chiefly situate along the margin of the Alleghany and Rocky Mountains, where they form a series of small' plateaus. The remaining, and by far the most extensive division, is that of the Prairies, which exhibit no inconsiderable diversity of aspect. These are immense meadows, classed as wet or dry, or heathy, according to their character. The heathy prairies are covered witl bushes of hazel and furze, small sassafras shrubs, with grape vines, and an infinite variety of flowers in the summer season. The wet prairies occur by the side of the great watercourses, and are scenes of exhaustless fertility, almost dead levels; but they are found also apart from the rivers, and form insalubrious marshes, like the Dismal Swamp in Virginia, and the great morasses of Florida. The dry prairies constitute the most extensive class, and are for the most part destitute of springs, and of all vegetation but weeds, flowering plants, and grass. They are the plains over which the buffiloes range, without wood or water, on which the traveller may wander for days, beholding the heavens on every side sinking to contact with the grass, and hearing little beyond his own footfall. They have gently undulating and wavy surfaces, which has originated the name of the rolling prairies. "After a toilsome march," says Washington Irving, "of some distance through a country cut up by ravines and brooks, and entangled by thickets, we emerged upon a grand prairie. Here one of. the characteristic scenes of the 'Far West' broke upon us. An immense extent of grassy, undulating, or, as it is termed, 'rolling' country, with here and there a clump of trees dimly seen in the distance like a ship at sea, the landscape deriving sublimity from its vastness and simplicity. To the south-west, on the summit of a hill, was a singular crest of broken rocks, resembling a ruined fortress. It reminded me of the ruin of some Moorish castle crowning a height in the midst of a lovely Spanish landscape. The weather was verging into that serene, but somewhat arid season, called the Indian summer. There was a smoky haze in the atmosphere that tempered the brightness of the sunshine into a golden tint, softening the features of the landscape, and giving a vagueness to the outlines of distant objects. This haziness was daily increasing, and was attributed to the burning of distant prairies by the Indian hunting parties." The richer prairies are scenes of astonishing beauty during the months of vegetation, owing to the variety and hues of the flowering plants, 
with their tall arrowy stems, and spiked or tassellated heads. Through the summer months there is a distinct succession of dominant colours, the prairie appearing like a carpet of purple velvet in spring, passing to one of red at midsummer, and gold in autumn.

Striking examples of these districts in the western world, upon a small scale, appear upon the surface of the level land of Europe. Though this has already been cursorily noticed, yet, as a home territory, it deserves another glance. The great space extending from the shores of the Black to the coasts of the White Sea, and from the western foot of the Ural Mountains to the English Channel and the Atlantic Ocean, presents savannahs, primeval forests, barrens, morasses, and the most richly cultivated plains, alternating with each other in a manner the most diversified, inhabited in some parts by nations of the highest degree of intelligence, while in others nomadic tribes wander on its surface from pasture to pasture. Surprise has often been excited at the enormous droves of oxen, horses, and mules that feed upon the plains of America; but the aggregate amount which find pasture upon the European levels is not less prodigious, the number of oxen, cows, and calves alone, sustained upon those flats of the Danube that are within the limits of the Austrian monarchy, being estimated at upwards of thirteen millions. The south and south-western parts of the vast Sarmatian plain, which includes nearly the whole of European Russia, has large districts of rich black loam of almost incredible fertility. This is remarkably the case with the great wide plateau of Podolia and Volhynia, which abuts against the outliers of the Carpathian Mountains. "The traveller," says a very attentive observer, "who proceeds from the north to the south, sees it afar in the blue horizon, hails it as a happy island after having traversed for days together monotonous fields of sand, or the melancholy and gigantic morasses of Katner and Pinsk; nor will he find himself deceived in his expectations. He reaches a region as rich and fruitful as it is kind and hospitable; he finds lovely landscapes and beautiful tracts of country." The origin of the peculiar black vegetable earth which distinguishes this southern margin of the Sarmatian plain, has thus been intimated by Dubois. If we remember, he remarks, that this territory was in early times covered with a splendid growth of trees - that even at the time of Herodotus the Scythians cultivated it, rooting up the woods, according to their ancient usage, considering them as so many encroachments upon their tracts of pasture - that those nomadic races, the Tartars, who drove their numerous herds on this great highway of Oriental nations, inherited the Scythian aversion to trees;-if we remember these facts, we shall not be surprised at finding that these beds of thick black vegetable earth now form a mine of gold to the country. Westward, along the banks of the Vistula, between the town of Thorn and the sea, we have plains celebrated for their fertility and productiveness, which now fill the granaries of Dantzic with corn, and which the German knights rescued from the waves in the thirteenth century, and rendered them integral portions of the continent by artificial mounds similar to those which at present, to a greater extent, defend them from the waters of the Baltic. The dyke of the plain of Marienburg, it is known, existed before the year 1397; and that of the plain of Thorn has now an extent of forty-five German miles, without including its numerous small windings and turns. Immediately contiguous are plains which remain in their original condition, and are only in part used as pastures, being overgrown with bushes, the haunts of wild animals. Here also lie the remains of one of the aboriginal forests of Lithuania, a waste of wood consisting of firs, pine-trees, and oaks, which man has seldom visited, and into the interior of which the axe of the woodman has never penetrated. It bears the name of Niezearow, or the "unknown country," as the number of stems which have fallen upon and across one another render it thoroughly impassable. An abundance of moose deer, bears, lynxes, and wolves inhabit this forest region, in the 
heart of Europe, which is analogous to the selras of the Amazon. Compared with the north of Germany, the spring lere begins late, and is short; the summer is foggy and stormy: and the mean temperature lower than that of more northerly districts.

Proceeding in a westerly direction, the flat land traverses the north of Germany, and liere forms a series of ascents and descents from the shores of the Baltic to the foot of the Alps, in which however the ascent becomes more marked as the south is approached. A line drawn from the island of Usedom at the mouth of the Oder, througl New Strelitz, Berlin, Leipsic, Greitz, Baireuth, Ratisbon, and Munieh, to the Tegern Lake, divides Germany into two parts, the east and west; and along its whole extent, there is only a single mountainous tract to pass over, which commences at Greitz about the middle distance. Following this line from the north, the traveller gradually rises by a series of terraces, the loftiest of which, at whose southern margin the Alps with their high masses plunge into the deptlis beneath, stands about 1400 feet above the spot where he commenced his journey. 'The pliysiogonomy of the country through which he passes is of the most varied kind. At its northern extremity are the gently undulating hills of Usedom, with their beautiful and verdant forests, affording in open spots, on the one hand, a view of that billowy sea which only terminates with the sky, and on the other the tranquil waters of the mouth of the Oder are seen, with the coast of Pomerania, cnlivened by numerous sails which the active commerce of Stettin sends into distant lands beyond the ocean, into other hemispheres and other climates. The coast of Pomerania is to a considerable extent an open cornfield, without a tree or busl, a fruitful solitude, wearisome from its sameness. Beyond, at the horizon, a sharp line arrest3 the eye, the heights of Mecklenburg, a district where the scene alters, and the abodes of a rich population appear, enclosed in fruitful gardens, around the capital of the beautiful country of New Strelitz. Fartlier towards the south the soil elianges; sand becomes the prevailing element, and woods of the gloomy pine and common fir intermingle with the meagre sand-fields on wlich man can only obtain a scanty subsistence from the earth. This is the prevailing character of the country through the Mark of Brandenburg, the whole of which is covered with erratic blocks, many of enormous size, which some great inundation has apparently borne lither from their native Scandinavian bed. Reacling the Elbe, a new soil commenees on its southern bank; luxuriant corn-fields appear, which only become more productive, till the fruitful ficlds of Leipsic open before us. 'The great plain we have been following from the Baltic, ends at Greitz, on the White Elster; and, at the south bank of the river, the traveller ascends the first terrace of the platean of Southern Germany. It is not, however, a ridge which he attains, but a plain, reaching to Gera, where he beholds before him plains again and again, which rise like terraces one above the other. Farther on, he wanders through narrow valleys overshadowed by the powerful stems of the red and white fir, leading to the foot of the mountain chain which abuts against the ramparts of Bolıemia. The valley plain of the Maine is now entered, presenting variegated meadows, rich corn fields, the red roofs of innumerable villages; and afterwards we proceed to the plateau of the Upper Palatinate, which, by its barrenness, strikingly contrasts with the region we have just left. The northern fir, here and there mixed with the pine, becomes again the prevailing tree; and the country has all the aspect of the plains of Brandenburg, tili we arrive, by a wood of pines passing over a mountain ridge, within sight of the venerable Ratisbon. Wild and deep rushes the Danube past its walls, not so much splashing as foaming against the pillars of the lofty bridge which conducts us across a fertile plain, with wavy elevations, to the valley of the Isar, which forms only a moderate depression in it. Here, standing on some heights near the small town of Freising, the traveller sees on the southern horizon what he thinks at first a mere vapour in the aira heap of clouds, the edges of which appear serrated. It is the Alps! Over a plain more 
smooth and level than any which are observed in the north of Germany, we travel to the capital Munich, which, with all its palaces and monuments, stands in the midst of a large unattractive level, extending with few interruptions to the Tegern lake, one of the entrance gates of the Alps.

The level land of the north of Germany extends westward througl Holland, Belgium, and France; and in the latter country it surrounds in a great are, with but few interruptions, that system of mountains, which, rising in Cevennes, extends to the Lower Rhine. Great diversity in the form and soil of the surface, and the nature of its cultivation, is the character of this part of the neighbouring kingdom, which, with fertile and most fruitful distriets, exhibits true steppes and actual deserts. 'The following sketch of a portion of this flat land - that on the western coast - is indebted for several of its features to the lively pictures of modern travellers. Setting out from the Pyrenees, and proceeding to Bourdeanx, we pass orer the department of the Landes, the direct track lying through a wild sandy desert, in many parts too unproductive even for sheep walks, in others presenting forests of pine of vast extent. 'The peasantry live in solitary cabins ; employed in cultivating the soil where it is not absolutely sterile; tending liardy sheep, or making charcoal in the woods; traversing the deserts on stilts in order to pass the intervening morasses dry-shod. Reaching the wide and bay-formed moutl of the Gironde, in which its waters lose the wild tempestuousness which marks their early career in the Pyrenees, we meet with a country on the right bank, which in appearance is tolerably

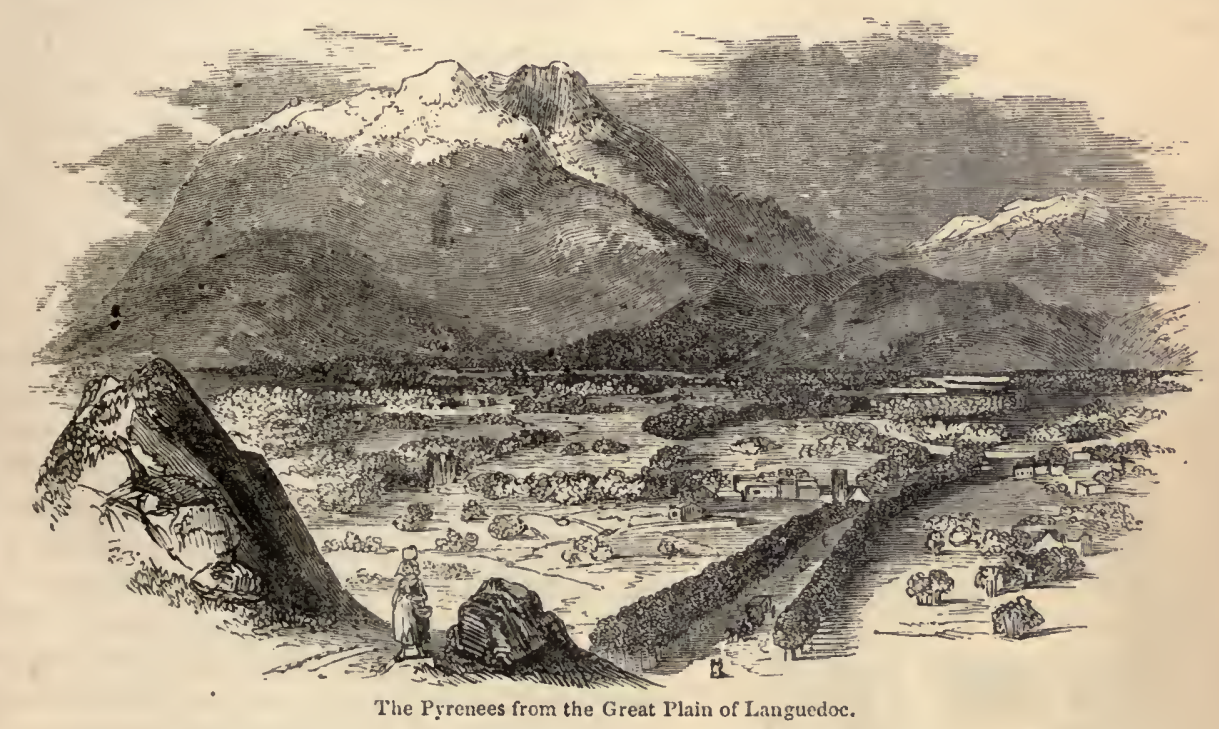

rich, covered with plantations of vines, and sinking softly in innumerable hills clown to the sea. The chain of sand on the sea-coast is bordered by a beautiful alternation of fields, woods, and meadows, with villages bearing the aspect of eleanliness and comfort, their white houses and green window-shutters contributing to the agreeable effect of the landscape. Here is the district of Saintonge, which, with its waving valleys and classic reputation, acquired in poetry the name of the Flower of France. Along the whole coast, lighthouses liave been erected, that of the tower of Cordouan, built by order of Henry IV., being the most ancient and admired, and the most celebrated in France. It stands on a rock two miles out amid the waves, announeing the vicinity of a dangerous const; and 
the fancy readily turns to it as a memorial of sorrow, on the grave of a city engulfed by the encroaching waters - the Novioregum of antiquity.

A melancholy spectacle is presented farther north, towards Rochefort, that of flat barren wastes, and salt marshes, with here and there a spot planted with trees, and occasionally there is a village deserted and in ruins, high grass, and elder bushes mingling with its remains. It is hence with pleasure that the traveller descries the dome of the hospital and the walls of Rochefort; but, notwithstanding its fresh and smiling aspect, and the pleasant murmuring of its large elms, the town has been literally snatched, at an immense cost, from the morass, and no sooner is it passed than the dismal swamp again appears. The whole road to La Rochelle is of a melancholy character, and especially so if traversed under a cloudy sky. It crosses a dreary steppe, of which the sea is the limit on one hand, and which is apparently boundless on the other. At distant intervals are a few tamarind trees; or a lonely farm-house sends out its gloomy smoke; or some conical hay ricks are passed, standing round a neglected barn; or a meagre horse, with scanty mane, stands beside the road, and neighs at the approaching storm. The sea beats against the foundations of the road, and the sea-mews cross it, driven by the wind, their white wings contrasting strongly with the dark and louring clouds. Thus, at both extremities of the flat land of Furope, - the western, where it reaches the Atlantic, and the eastern, where it ends with the Caspian, - we find the same superficial aspect - a monotonous, desolate, and treeless waste.

\section{CHAPTER IV.}

CATERNS AND SUBTERRANEAN PASSAGES.

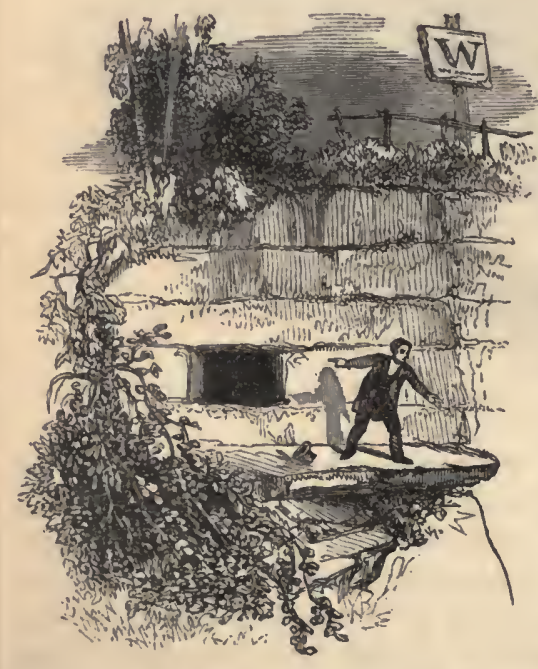

turbance. Their seclusion and gloom torch-light upon their numerous crystallisations - the augmentation of sound and its reverberation - together with their unknown extent in many cases - all these causes - their fantastic architecture-the effect of

IneN we reflect upon the manner in which the solid crust of the earth appears to have been formed, upon the powerful upheaving force by which its clevated sites have been raised, and the posterior agency of subterranean gases, volcanoes, and earthquakes, it is natural to expect chasms in the surface of tremendous depth, spaces also in the interior which have not been filled up with mineral masses similar to the materials of the those cavities of grotesque and romantic appearance that are found in mountainous regions. There are few natural objects which have more awakened curiosity, or more strongly affected the imagination, than the hollow places, of various form and size, common in districts which have been subject to great physical disearth itself, but by water, air, or vapour, with 
contribute to invest the cavities of the earth with exciting interest; nor is it strange to find them interwoven with the traditions and mythologies of unenlightened nations. On account of thcir sombre interior and strange outline being adapted to impose upon an ignorant populace, and give effect to religious observances, the priesthoods of antiquity localised in caverns their false divinities, and celebrated sanguinary rites upon the natural altars found in their recesses. A cave, with a priestess seated upon a tripod at its mouth, pretending to inhale a vapour from the interior which inspired a knowledge of future events, the gift of Apollo, was the original Delphian oracle, reverenced by the mind of Grecce, and resorted to by the proudest monarchs of the ancient world. The cavern, along with the deep forest, commended itself to the primitive inhabitants of northern Europe by its mystery and gloom as an appropriate spot for the performance of a barbarous worship, and many local titles of such sites preserve the memory of their former uses. An instance of this we have in Thor's care, or, as Darwin calls it,

"The blood-smear'd mansion of gigantic Thor,"

a broad excavation on the face of a huge rock in the limestone district of Derbyshire, divided into two chambers, one beyond the other, with a detached stone at the further extremity, where the light of day is very much subdued. But in India the largest use has been made of caverns for religious purposes, and immense pains have been taken with their adornment, extension, and architecture, at Eleplanta, Salsette, and Ellora, where there are elaborately wrought temples constructed, probably out of small natural crevices in the rock. We shall now refer to a few of those cavities which are entirely the workmanship of nature, with wliose form man has not intermeddled, and notice the principal phenomena which they exhibit.

That extensive eavities exist in the interior of the crust of the globe is evident from the phenomena of volcanoes and earthquakes. They are not accessible to observation, but the repcated tremblings of the soil in various places, and experiments made of oscillations of the pendulum, point to the conclusion, that there are large underlying hollows, at no great distance from the surface, of which the superficial land forms the

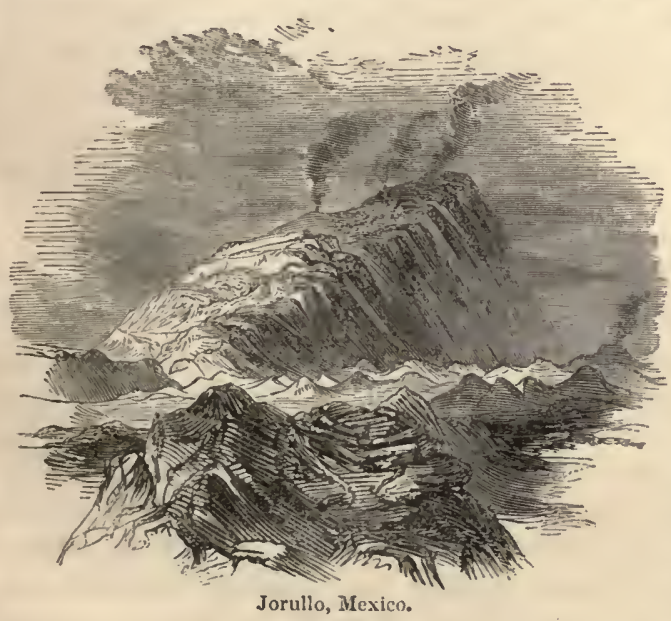
roof. The table-land of Quito, surrounded by the most powerful volcanoes upon the eartl, and the remarkable plain of Jorullo, are supposed to be examples of this. Condamine believed that a considerable portion of the former district was to be regarded as the dome of an enormous vault; and Parrot has shown it to be lighly probable, by a careful calculation, that a cavity of at least a cubic mile and a half exists beneath its surface. The rumbling noise, like that of distant thunder, which on the testimony of Humboldt usually precedes and accompanies the eruption of its volcanoes, affords evidence in favour of this supposition, and as an increase of the subterranean vacuity must be the necessary consequence of every outbreak, it is not at all an improbable event, that the blooming landscape will ultimately fall in, and this piece of table-land become an immense depression. The quantity of material scooped out of the interinr of the earth by volcanic action is 
immense, and ealculated to produce racuities in which the largest mountains would have ample space. It has been estimated that Etna in one of its last most important eruptions, that of the year 1769, threw out a mass of lara equal in volume to a cone 5820 feet in height, and 11,640 feet in breadth, or nearly four times larger than Vesuvius. Fourteen such eruptions would produce a mass equal to Mont Blanc, reckoning from the level of the sea, and twenty-six such large eruptions have occurred since the twelfth century. In the year 1783, when the earthquake of Calabria occurred, the Sliaptar volcano in Iceland poured furth a stream of lava fifty miles long, between twelve and fifteen broad, and from one to six hundred feet in thickness, which must have been equal to six times the mass of Mont Blanc, and two and a half times that of Chimboraço.

From the discovery of America to the year 1759, the plain of Malpais, a volcanic district in Mexico, had remained undisturbed, and was covered with plantations of indigo and sugar-cane at the latter period. In the month of June, a succession of earthquakes commenced, and on the night of September the 28th a tract not less than from three to four miles in extent rose up in the shape of a dome; and six great masses suddenly appeared, having an elevation of from 1312 to 1640 feet above the original level of the plain. The most elevated of these is the volcano of Jorullo, which is continually burning, the projection of which, with its kindred masses, must have ereated a eonsiderable subterranean racuity, and probably the whole dome-shaped plain of Malpais is hollow. Hence, it is a common event, in countries subject to great volcanic activity, for portions of the surface to fall in, the subsidence frequently becoming the bed of a lake. A part of the forest of Aripas in the Caraccas thus subsided in the year 1790; a lake was formed nearly half a milc in diameter, and from eighty to a hundred yards in depth, and for several months after the trees of the forest remained green under the water. In the same year, in Sicily, at Santa Maria de Nissemi, a portion of the country three Italian miles in circumference sank thirty fect deep. Occurrences of the same lind appear to take place in the depth of the sea, the filling in of its bed being indicated on the surface of the waters by their sudden retreat and violent agitation on their return. A remarkable example of this phenomenon took place at Marseilles, on June 28, 1812, when the water in the harbour suddenly sank, then rushed out with great rapidity, and returned with equal violence; a movement which was repeated several times, till the equilibrium was restored, occasioning considerable damage to the shipping. Instances of similar events are innumerable, which serve to prove the existence of eavities, both in the interior of the exposed crust of the earth, and those parts of it over which the ocean rolls.

'To Humboldt we are indebted for a large amount of information respecting the cavities which appear upon the surface, the ehief differences of their form, the beds in which they are found, and the causes which may have originated them. In the primary rocks, caverns are relatively fewer than in the later deposits, while the oldest masses of the granite and gneiss formations are particularly destitute of them. The principal are wide fissures, sometimes of unknown depth, and those lollow passages which occur in Switzerland and Dauphiné, called crystal caves, owing to their walls being richly furnished with pillars of rock crystal. Similar vacuities occur in the gneiss of the Pine mountain in the neighbourhood of Wiesenthal, but they are not important. In Sweden and Norway, the granite presents fissures and caves of extraordinary extent, and perfectly unexplored, hitherto; such as the cave of Marienstadt, the end of which is not known, and the enormous deep lole at Frederickstall, where it stone thrown in only gives the echo of its fall in a minute and a half or two minutes; an observation which, if well founded, would give, on the calculation of Perrit, a precipitous depth of 59,049 feet, the highest estimate, or 39,866 feet, the least ; that is, from twice to 
three times the heiglit of Climboraço. It is the primitive limestone that supplies the most numerous examples of caves and grottos in the primary rocks; and if these yield in point of size to the later limestone formations, this arises from the inferior extent of the primitive limestone, rather than from its incapacity to form caves. In the transition mountains, and those of stratified structure, it is still the limestone in which the more extensive caves are found, of which those of the Hartz, the splendid caverns of Derbyshire, and those of the Carpathians, are well known. Caverns most frequently occur in the mountains of stratified limestone; and among these, one of the most modern formations, the Jura limestone, is particularly distinguished, and was therefore termed the cavern-limestone by the early geologists. The celebrated caves of Franconia, the grotto of Notre Dame between Grenoble and Lyons, and many others, occur in this formation. That of Kirkdale, in Yorkshire, is in oolitic strata. Next to the limestone in the stratified formations, the so-called older gypsum which contains salt is the most abundant in caverns. They are of rare occurrence in the sandstone, have generally broad openings but of no great extent. Sucl are the Cow-stall in Saxony, and a few caves in Bohemia.

In the volcanic rocis, cavern formations are very common, and one of the most splendid examples in the world occur's in the basalt, a rock of comparatively modern igneous origin. This is the well-known cave of Fingal, in the island of Staffi, a small island on the western coast of Scotland, composed entirely of amorphous and pillared basalt. The name of the island is derived from its singular structure, Staffa signifying, in the Norwegian language, a people who were early on this coast, a staff, and, figuratively, a column. The basaltic columns liave in various places yielded to the action of the waves, which have scooped out caves of the most picturesque description, the clicf of which are the Boat cave, the Cormorant cave, so called from the number of these birds visiting the spot, and the great cave of Fingal. It is remarkable that this grand natural object should have remained comparatively unknown, until Sir Joseph Banks had his attention accidentally directed to it, and may be said to have discovered it to the inhabitants of South Britain. This great cavern consists of a lava-like mass at the base, and of two ranges of basaltic columns resting upon it, which present to the eye an appearance of regularity almost architectural, and supporting an irregular cciling of rock. According to the measurements of Sir Joseph Banks, the cave from the rock without is 371 feet 6 inches; the breadth at the mouth, 53 feet 7 inches; the height of arch at the mouth, 117 feet 6 inches;

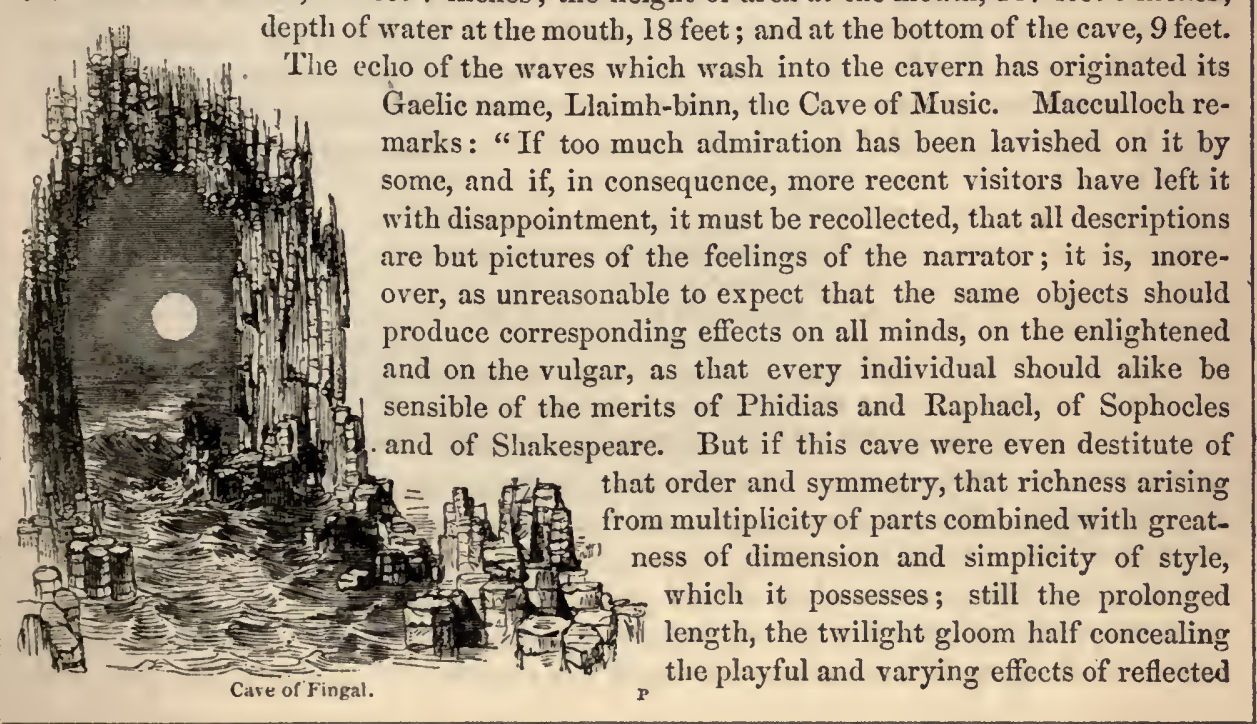


light, the echo of the measured surge as it rises and falls, the transparent green of the water, and the profound and fairy solitude of the whole scene, could not fail strongly to impress $\Omega$ mind gifted with any sense of beauty in art or in nature, and it will be compelled to own it is not without cause that celebrity has been conferred on the Cave of Fingal." Caverns occur in modern porphyry in the neighbourhood of Quito, and even in modern lavas, the ejection of which has taken place within the memory of man. Flinders has made us acquainted with caves in the lava of the Isle of France; and in the lava of Vesurius of 1805, Gay Lussac found sevcral upon a small scale. But caverns of an cnormous extent occur in the lava of Iceland, that of Gurtshellir, situated in the torrent which has flowed from Bald Yökul, being forty feet in height, by fifty in breadth, and nearly a mile in length. Beautiful black volcanic stalactites hang from the high and spacious vault, and the sides present a succession of vitrified horizontal stripes, a thick coating of ice clear as crystal covering the floor. Henderson, in particular, describes one spot, the grandeur of which surpassed all expectation, the light of the torches rendering it peculiarly enchanting. The roof and sides of the cave were decorated with the most superb icicles, crystallized in every possible form, many of which rivalled in minuteness the finest zeolites; while from the icy floor rose pillars of the same substance, assuming all the curious and fantastic shapes imaginable, mocking the proudest specimens of art, and counterfeiting many well-known objects of animated nature. A more brilliant scene, says Henderson, perhaps never presented itself to the human eye, nor was it easy for us to direst ourselres of the idea that we actually beheld one of the fairy scenes depicted in Eastern fable.

Among the forms under which caverns present themselves, Humboldt distinguishes three principal kinds, which essentially differ from each other, notwithstanding all their apparent irregularities.

The first appear in the form of cracks or fissures, like empty veins of ore, of greater or . less extent, but narrow and considerably prolonged, often penetrating far into the hard rock, and only reaching the day at one end. Eldon hole, in the Peak of Derbyshire, is an example of this class. This is a deep yawning chasm in the limestone strata, but no longer considered one of the wonders of the region, as its presumed unfathomable depths have been satisfactorily measured. In the reign of Queen Elizabeth, the Earl of Leicester is said to have hired a man to go down into it to ascertain its extent and form. The account of the adventure states, that he was let down about two hundred ells, and after he had remained at the length of the rope awhile, he was drawn up again, with great expectation of some discoveries; but he came up senseless, and died within eight days in a phrensied condition. Cotton alludes to this circumstance in his rude English verses, -

\footnotetext{
"Once a mercenary fool, 'tis said, exposed His life for gold, to find what lies inclosed In this obscure vacuity, and tell Of stranger sights than Theseus saw in hell; But the poor wretch paid for his thirst of gain -

For, being craned up with a distempered brain, A faltering tongue, and a wild staring look, He lived eight days, and then the world forsook."
}

Eldon Hole is a fissure about sixty feet long, twenty wide, and two hundred deep. In the Philosophical Transactions for the year 1781, there is an account of the descent of Mr. Lloyd, who was let down with a rope by eight men, and found the light sufficiently strong at the bottom to allow him to read print. He discovered a fissure in the rock at the bottom, through which a strong current of air proceeded, but as the aperture was nearly filled up with huge stones, he could not examine it. A formcr owner of the 
pasture in which the chasm is situated, having lost cattle by falling into it, made the attempt to fill it up, and threw down many loads of stones without any visible effect, some of which were probably those which choked the aperture reached by Mr. Lloyd. The whole extent and actual depth of Eldon Hole have not therefore been ascertained.

There is a second kind of caverns which are essentially distinguished from the first by the circumstance that they reach the daylight at both ends, piercing through the rocks in which they are situated, and forming natural shafis. Their appearance is very remarkable when they occur on the top of isolated mountain-peaks, or of independent masses of rock ; and when they are so straight that the day-light appears through them, they present a very remarkable aspect, and have been designated by the name of transparent caverns. On this account, the so-named Martin's hole is particularly celebrated. It penetrates the Tschingel-peak, one of the highest mountains of the Dodi chain; and twice in the year, in March and in September, the sun appears as if through a pipe, and gives to the valley beneath a highly singular and pleasing light. A similar phenomenon has been described by Pontoppidan as occurring in Norway, where there is a perforation of the mountain of Torghatten in Helgeland, of fifty fathoms in height, and a hundred fathoms in length, through which the daylight appears. Like phenomena present themselves at the hollow stone of MIuggendorf; likewise in Saxon Switzerland, and a whole series of these perforations occur on the coast of the island of Heligoland, and on the coast of New Zealand.

The third and most frequent form of caverns is unquestionably that in which there is a series of extensions of nearly similar height and direction, which are connected with each other by passages of greater or less extent. This is the form of the caverns of the Hartz, the cave of Caripe visited by Humboldt, of Antiparos, and of the Peak of Derbyshire,

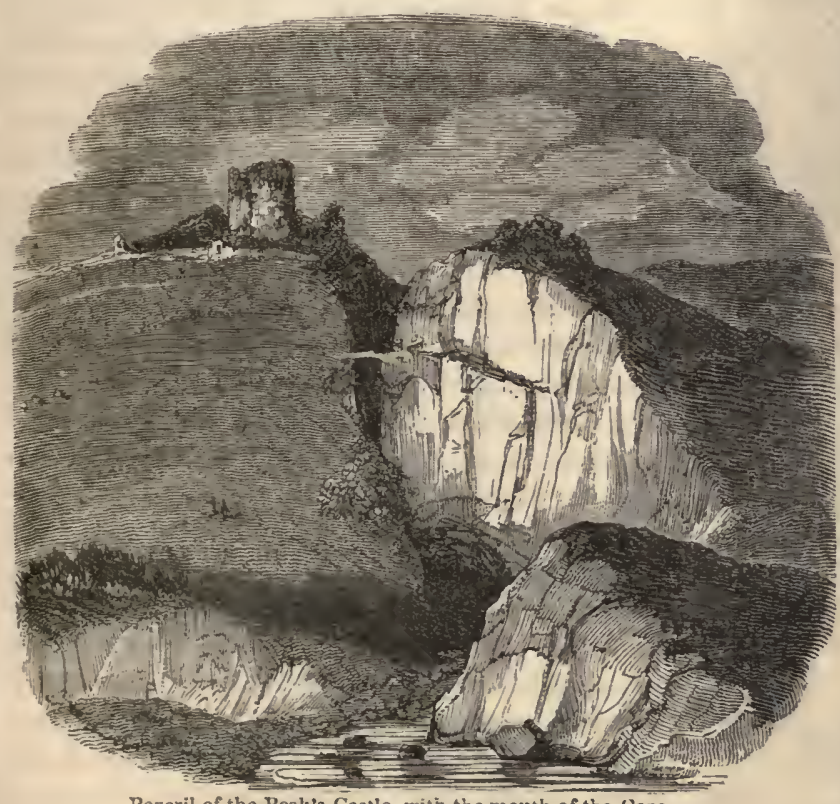
the entrance to which, with the castle on its summit, is here represented. This is also the form of the more important caves of Franconia. The extent of these penetrations into the mountains, in particular of such as are situated in limestone, is often very extraordinary. In many of them the extremity has never been reached; and it appears from concurrent testimony that some of them have been explored for more than a mile in length. In this respect, the cave of Adelsberg, six miles from Trieste, is mentioned as the greatest of all, excelling all known caverns, not only in length, but in height. Deep abysses of five and six hundred feet often occur in it; and in one of these, it was found necessary to give up the attempt to proceed farther. The entrance resembles a fissure in a huge rock caused by an earthquake. Here torches are always lighted to conduct visiters. The carity itself 


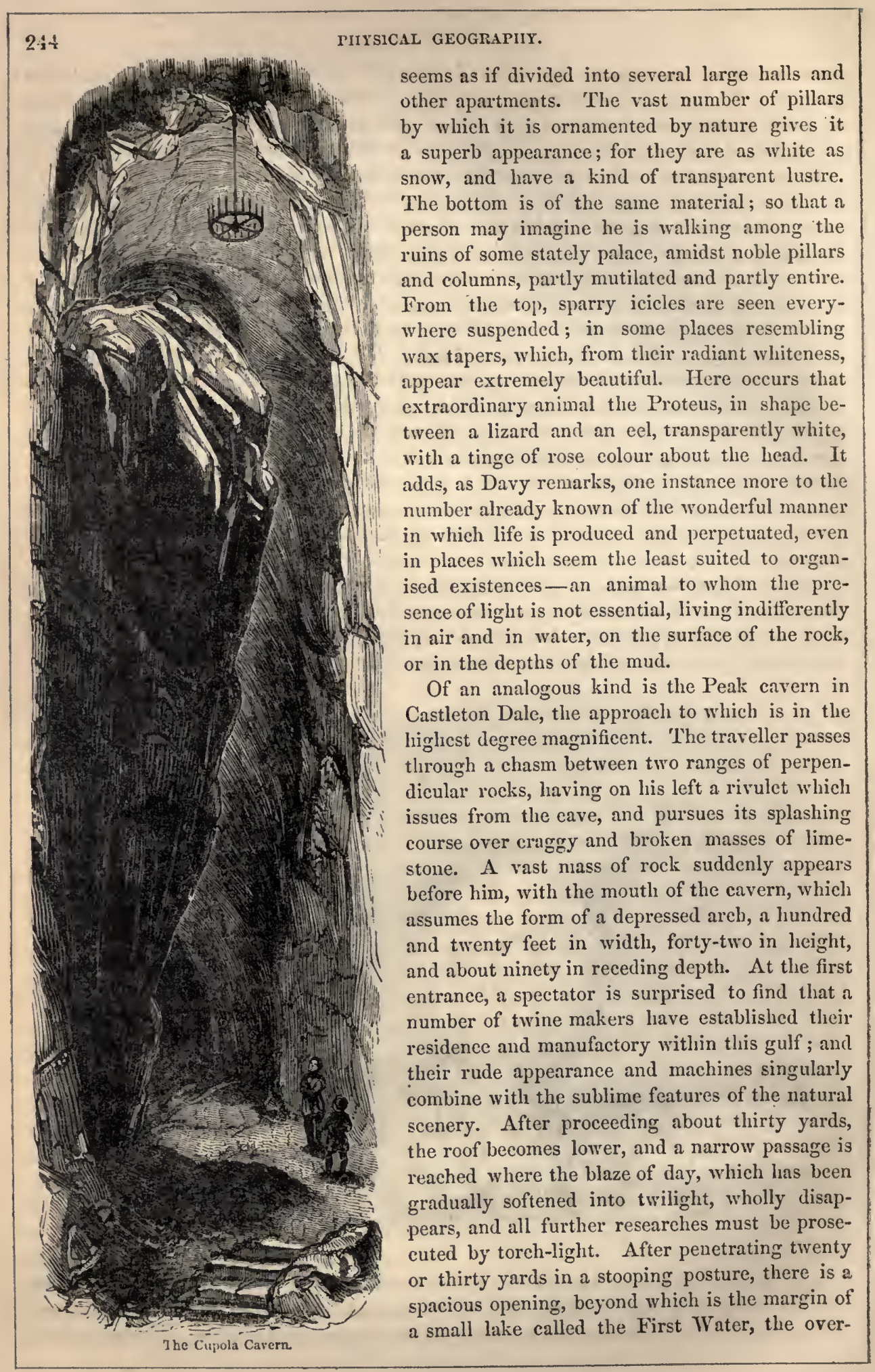


hanging rock descending in one place to within twenty inches of its surface. The lake is crossed in a boat or skiff, partly filled witl straw, in which tlıe passenger lies down, and is conveyed to the other side, where a spacious vacuity opens 220 feet in lengtl, 200 feet broad, and in some parts 120 feet high; but from the want of light, neither the roof nor the sides of this' great cavity can be plainly discerned. Proceeding onwards by the side of the Second Water, there is a projecting pile of rocks popularly called Roger Rain's House, on account of the water incessantly dripping from the crevices of the roof. Beyond this, another hollow opens, ealled the Chancel, where the rocks appear much broken, and the sides are covered with stalactical incrustrations. Here the stranger is generally surprised by an invisible vocal concert, which bursts in wild and discordant tones from the upper regions of the cavern, where a group of women and children are stationed for the purpose, the inlabitants of some of the huts at the entrance. After leaving the Chancel, and passing the Devil's Cellar, and the Ilalf-way House, the path leads beneath three natural arches to another vast concavity, termed Great 'Tom of Lincoln, from its resemblance to a bell. Here, under the influence of a strong light, the arrangements of the rock, the spiracles in the roof, and the flowing stream, produce a striking scene. From this point the vault gradually descends, the passage contracts, and at length leaves only room suficient for the stream. The entire length of this great excavation is 2250 feet, and its depth from the surface of the mountain about 620 . A striking effect is frequently produced by the explosion of a small quantity of powder, wedged into a crevice of the rock, the report of which rolls along the roof and sides like a lieavy and prolonged peal of overwhelming thunder. On returning from this dark recess, the effect of the light is singularly impressive. The rocks appear as if highly illuminated, and the plants and mosses upon them so vividly green, as to produce the impression that the sun must be shining brilliantly upon them, when the day is really dull and hazy. The Peak cavern is thus an example of a succession of great chambers connected together by narrow passages; and when we remember the soluble nature of the stone, and the stream that flows through it, there can be no doubt that, if not formed altogether by the action of water, it yet owes its present condition to that agency. A more extrao dinary spot, perhaps, is in the neighbourhood, at the foot of the Winnats, or Windgates, called also the "portals of the winds," a deep and narrow inclined chasm, about a mile in length, the lower descent of which commands a fine view of the beautiful vale of Castleton. Here is the Speedwell mine, an artificial excavation, leading to a great natural cavern. After descending upwards of a hundred steps, and reaching the blackness of darkness, the visitor embarks upon a canal so narrow as to be able to touch the rock on both sides, and the ceiling above. Proceeding along this channel, which is not far short of half a mile in length, the guide pushing along the boat, an immense vacuity in the mountain is reached, and landing upon a ledge of rock, the scene becomes indescribably strange and appalling with the aid of a Bengal light. On the one hand there is an abyss of unknown depth, appropriately called the Bottomless Pit, into which the water from the level falls with a startling sound, and which swallowed up forty thousand tons of material in the excavation of the mine. On the other hand an enormous cavity opens above, the ceiling of which no light can reach, for rockets have been here let off, and have given out their brilliant coruscations as freely as from the surface of the earth.

Humboldt describes a somewliat dissimilar but very remarkable eavern in the western world, in the province of New Andalusia, not far from the convent of Caripe, called the Cavern of the Guacharo - the name of a class of nocturnal birds who make it their abode. The exterior of the place was majestic even to one accustomed to the picturesque scenery of the Alps. He had visited the Peak Cavern, and was acquainted with the different caves 
of Franconia, the Hartz and Carpathian mountains; and the uniformity generally observable in all these, led him to expect a scene of a similar character in that which he explored in the New World: but the reality far exceeded his expectations; for, if the structure of the cave resembled those he had elsewhere witnessed, the majesty of equinoctial vegetation gave an individual character and indescribable superiority to the entrance of the Cavern of the Guacharo. The entrance is a vaulted arch, eighty feet broad and seventy-two feet high; the steep rock that surmounts this opening is covered with gigantic trees, mixed with creeping and climbing plants and shrubs, brilliant with blossoms of the richest colours and the most varied forms. These form natural festoons, which hang from the mouth of the cave, and are gently agitated by the passing currents of air. Among them Humboldt enumerates a Dendrobium, an orchideous plant, with golden flowers spotted with black, and three inches long; a Bignonia, with a violet blossom; a purple Dolichos; and a magnificent Solandra, the decp orange flower of which has a fleshy tube four inches long. But this luxuriant vegetation was not alone confined to the exterior. 'The traveller, on following the banks of a subterranean stream into the grotto, beheld them, with astonishment, adorned for thirty or forty yards with the Praga palm tree, plantain-leaved heliconias, eighteen feet high, and arms that resembled trees in their size! It was not found necessary to light their torches till they had reached the distance of 430 feet, owing to the continuous direction of the cavern, which allows the light of day to penetrate thus far; and when this began to fail, the hoarse cries of the nocturnal birds began to be audible from a distance. The shrill discordant noise made by thousands of these birds, brought from the inmost recesses of the cave, and reverberated from the arched roofs, formed an indescribable clamour. The Indian guides, by fixing torches to the ends of long poles, showed the traveller the nests of the bird, which were constructed in funnel-shaped holes, with which the roof of the grotto was pierced in all directions, and generally at about sixty feet high. Still pursuing the course of the river, the cavern preserved the same width and height to the distance of 1458 feet from the mouth. The traveller, on turning round, was struck with the singularly beautiful appearance which a hill covered with the richest vegetation, immediately fronting the entrance of the grotto, presented. This, brilliantly illumined by the sun's rays, and seen through the vista of the dark care, formed a striking contrast to the surrounding obscurity; while the large stalactites depending from the roof were relieved against the luminous back-ground of verdure. After surmounting, with some difficulty, an abrupt rise in the ground where the stream forms a small cascade, he found that the cave diminished in height to forty feet, but retained its original direction. Here a blackish mould was found, either brought by the rivulet, or washed down from the roof by the rain-water which penetrates the crevices of the rock; and in this he found seeds growing, which had been brought thus far by the birds, but so altered by the deprivation of light, that the species of plant, thus produced under such unfavourable circumstances, could not even be recognised. It was found impossible to persuade the Indian guides to advance further. The cries of the birds, rendered still more horrible by the contraction of the cave, had such an effect on their minds, that they absolutely refused to proceed; and, to the regret of Humboldt, he was compelled to retrace his steps.

Caverns, especially those which are situated in limestone, commonly present the formations called stalactites, from a Greek word signifying distillation or dropping. The manner of their production admits of a very plain and simple explanation. They proceed from water trickling through the roofs containing carbonate of lime, held in solution by carbonic acid. Upon exposure to the air the carbonic acid is gradually disengaged, and a pellicle of lime is deposited. The process proceeds, drop after drop, and, cventually, descending points hanging from the roof are formed, resembling icicles, which are ccm- 
posed of concentric rings of transparent pellicles of lime, presenting a very peculiar appearance, and, from their connection with each other, producing a variety of singular shapes. These descending points are the stalactites properly so called, from which the stalagmites are to be distinguished, which cover the floors of caverns with conical inequalities. These are produced by the evaporation of the larger drops which have fallen to the bottom, and are stalactites rising upwards from the ground. Frequently, in the course of ages, the ascending and descending points bave been so increased as to meet together, forming natural columns, a series of which bears a striking resemblance to the pillars and arches of Gothic architecture.

The amount of this deposition which we find in caverns capable of producing it, is, in fact, enormous, and gives us an impressive idea of their extraordinary antiquity. The grotto of Antiparos - one of the islands of the Grecian Archipelago - is particularly celebrated on account of the size and diversity of form of these deposits. It extends nearly a thousand feet beneath the surface, in primitive limestone, and is accessible by a narrow entrance which is often very steeply inclined, but divided by level landing-places. After a series of descents, the traveller arrives at the Great Hall, as it is called, the sides and roof of which are covered with immense incrustations of calcareous matter. The purity of the surrounding stone, and the thickness of the roof in which the unfiltered water can deposit all impure admixtures, give to its stalactites a beautiful whiteness. Tall pillars stand in many places free, near each other, and single groups of stalagmites form figures so strongly resembling plants, that Tournefort endeavoured to prove from them a regetable nature in stone. The remark of that intelligent traveller is an amusing example of over confidence:- "Once again I repeat it, it is impossible this should be done by the droppings of water, as is pretended by those who go about to explain the formation of congelations in grottoes. It is much more probable that these other congelations we speak of, and which hang downwards or rise out different ways, were produced by our principle, namely, vegetation." The sight of the whole is described, by those who have visited this cavern, as highly imposing. In the middle of the Great Hall there is a remarkably large and fine stalagmite, more than twenty feet in diameter, and twenty-four feet high, termed the Altar, from the circumstance of the Marquis de Nointel, the ambassador from Louis XIV. to the Sultan, having caused high mass to be celebrated here in the year 1673. The ceremony was attended by five hundred persons; the place was illuminated by a hundred large wax torches; and four hundred lamps burned in the grotto, day and night, for the three days of the Christmas festival. This cavern was known to the ancient Greeks, but seems to have been completely lost sight of till the seventeenth century. Some of the caves of France and Germany have a high reputation for the number and beauty of their deposits; but the finest examples are found in the Cave of Adelsberg, to which reference has been made. The stalagmites here have formed two bridges over the subterranean river, which are situated almost a mile apart from each other, the inner one of which hangs suspended from eighty to a hundred fathoms over the abyss. An American visitor graphically describes some of the principal objects : - "We advanced with ease," he states, "through the windings of the cavern, which at times was so low as to oblige us to stoop, and at times so high that the roof was lost in the gloom. But every where the most wonderful varieties of stalactites and crystals met our admiring view. At one time we saw the guides lighting up some distant gallery far above our heads, which had all the appearance of verandahs adorned with Gothic tracery. At another, we came into what seemed the long-drawn aisles of a Gothic cathedral, brilliantly illuminated. The whimsical variety of forms surpasses all the powers of description. Here was a butcher's shop, which seemed to be hung with joints of meat; and there, a throne with a magnificent canopy. There was the appearance of a statue with a 
bearded liead, so perfect that you could have thought it the work of a sculptor; and further on, toward the end of our walk, the figure of a warrior with a helmet and coat of mail, and his arms crossed, of the illusion of which, with all my efforts, I could not possibly divest my mind. Two stalactites, descending close to each other, are called, in a German inscription orer them, with sentimentality truly German, 'the union of two hearts.' 'The resemblance is certainly very striking. After passing 'The Hearts,' we eame to the 'Ball Room.' It is customary for the inhabitants of Adelsberg, and the surrounding country, to come on Whit-Monday to this grotto, which is brilliantly illuminated; and the part called the ball room is actually employed for that purpose by the peasantry. A gallery, very appositely formed by nature, serves the musicians for an orchestra; and wooden chandeliers are suspended from the vaulted roof. It is impossible for me to describe minutely all the wonderful varieties; the 'Fountains' seeming, as they fall, to be frozen into stone; the 'Graves,' with weeping willows waving over them; the 'Picture,' the 'Cannon,' the 'Confessional,' the 'Pulpit,' the 'Sausage-maker's Shop,' and the 'Prisons.' I must not omit mentioning one part, which, though less grand than many others, is extremely curious. The stalactites have here formed themselves like folds of linen, and are so thin as to be transparent. Some are like shirt-ruffles, having a liem, and looking as if they were embroidered; and there is one, called the 'Curtain, which hangs exactly in natural folds like a white and pendent sheet. Every where you liear the dripping as of a continual shower, showing that the mighty work is still going on, though the several stages of its progress are imperceptible. Our attention was so excited, that we had walked two hours without feeling the least fatigue, or being sensible of the passage of time. We liad gone beyond the point where most travellers had stopped, and had been rewarded for it by seeing stalactites of undiminished whiteness, and crystals glittering, as the light shone upon them, like unnumbered diamonds."

Stalactical depositions vary in colour according to the nature of the surrounding rocks, and Humboldt remarks in general that the formations occur more beautifully and completely in proportion as the cares are narrow and enclosed, since the deposition of crystals is less disturbed by the circulation of the surrounding air. On this account those of the wide open cavern of Caripe, which he explored, were far inferior to the stalactites of Adelsberg. In our own country the spot most remarkable for these formations is the Blue Joln mine, another of the celebrated places of the Peak, near its great cavern. This is a natural cavity, worked as a mine for the sake of obtaining the elegant fluor spar which gives its name to the site, and which is here found in small detached pieces in the limestone rock. Rude steps, leading downwards about sixty yards, conduct to a series of eaverns and passages encrusted with depositions of lime, which have assumed a variety of interesting forms. In our illustrated instance, stalactites, of a delicate pearly yellow colour, of fine texture, and fantastically varied one from the other, have grown downwards until they rested upon some shelf of a lower stratum, probably of earthy matter. Arriving at such a plane, the waters in future spread more widely around, forming a deposit, and connecting the former stems with an inferior tablet of similar composition. The earthy or mineral stratum having been by some chance removed, the fairy columns attached to their kindred floor now remain suspended in middle space. These are graphically termed "the Organ." It is much to be regretted that a Continental reproach against us, that of an Englishman's eyes being in his fingers, here receives an illustration of its truth. Some unprincipled and vagabond sight-scer's have wantonly mutilated this rarity, and deprived it of its earlier proportions, for which cause the relics are now upbraidingly exhibited in a rude wooden cage. Here, as at Antiparos, the principal subterranean apartment is termed the "Hall," a wide and lofty envity, such as imagination conecives 
would be a fitting home for the romantic outlaws pictured by Salvator Rosa, or described in the pages of Schiller. In this spot, not a long time ago, a popular

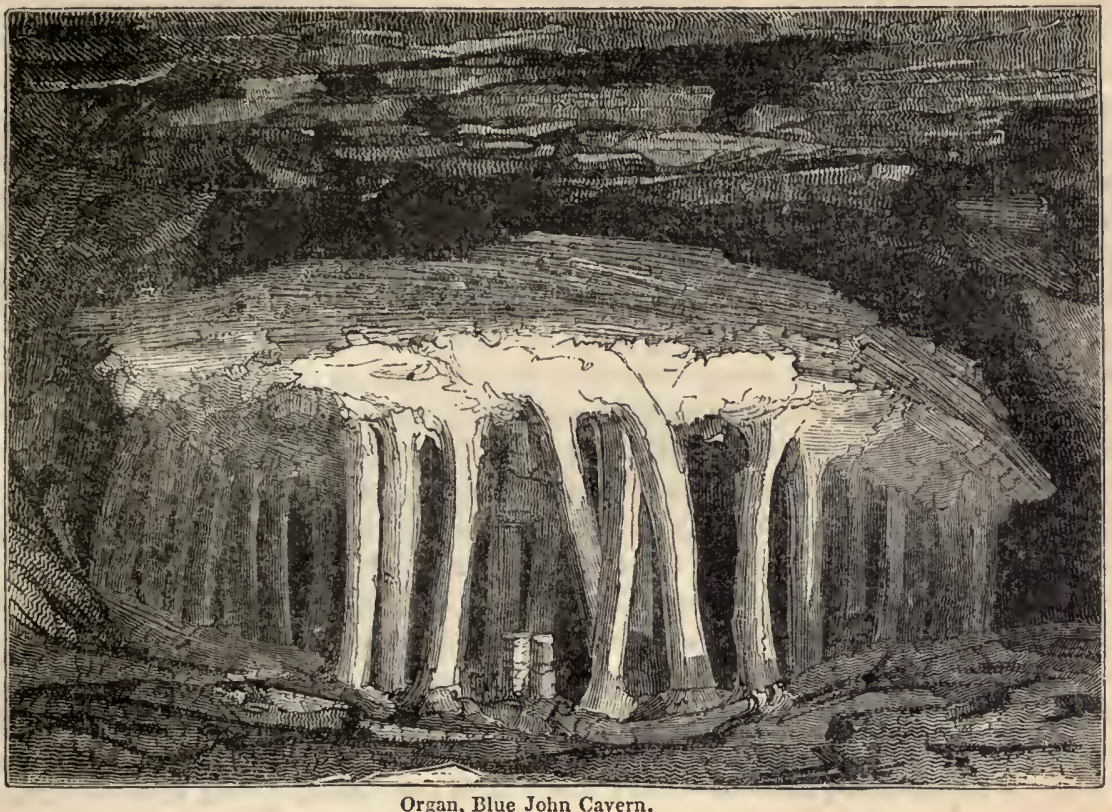

nobleman, who prosecuted adventurous researches in the most dangerous recesses of the mine, feasted a multitude of his friends, and made the wet rock resound to the toasts and sentiments imported from a more fashionable atmosphere. In a certain direction from this grand focus the visiter is led to a narrower and more irregular space, presenting a towering cupola, the grandeur of whose shivered sides can only be exhibited by drawing upwards, with cord and pulley, a round of lighted candles supplied by the conductor: these illuminate successively the varied and peculiar stages of the internal surface. The perpetual waters which trickle down have left a residuum of lime, which has been moulded, by accident, and by industrious and gentle operation, into a thousand free tresses and waving bands. The whole is fashioned by Nature with less of the abrupt form which characterises the congelation of fountain streams by cold, and presents a grotesque enamel of exquisite polish and gracefulness, giving to the artificial plain or coloured lights, uplifted within the conical abyss, beautiful reflections from its unrivalled crystallised surfaces. Frequently, while attention is riveted to the precinct of gloom and awful solitude, a chaunt of voices is heard from the summit of the dome, accessible by hidden performers from other avenues of the mine. The flecting and distant expression of sound, with the mournful intervals of the strain, seems like a song of captive spirits, obedient to the rigid discipline of some invincible gnome.

The temperature of caverns exhibits great diversities, dependent upon their extent and form, and that of the same cavern will greatly vary at different seasons. In those which are dry and deep, covered with a thick stony roof, and withdrawn from the influence of the alteration of the external air, by having only a limited opening, the temperature can vary but little, and will continue through the whole year at nearly the same degree of warmth which is peculiar to their geographical situation. Before the warmer air of summer has so penetrated the roof that the temperature of the cavern can be somewhat 
raised, the cooler air of the autumn and of the winter begins to penetrate; but before this lower temperature can establish itself, it is again overtaken by the warmth of the following spring and summer. The consequence of all this is a temperature subject to little alteration, but lower than the mean temperature of the surrounding atmosphere. The ancient Romans, hence, according to Seneca, were accustomed to erect their country seats in the vicinity of those natural cavities which abound about the capital, for the purpose of enjoying their refreshing chilliness in the summer season. It was in one of these volcanic caverns that Tiberius was nearly destroyed while at supper; for, during the baaquet, the roof suddenly gave way, and buried several of his attendants beneath its ruins, when Sejanus threw himself upon the emperor to preserve him from the falling stones.

Many caverns, however, vary greatly in their temperature, and exhibit the appa. rently strange anomaly of being cold when the external air is warm, and warm when it is cold, in some instances carrying this contrast to the extreme, so as to be coated with ice amid the heat of summer, and affording a comfortable warmth amid the cold of winter. In the neighbourhood of Szelitze, a village of Hungary, there is a cave in the transition limestone of the Carpathians which displays this phenomenon. The country in the vicinity abounds with woods, and the air is sharp and cold. The entrance of the cavern, which fronts the north, is eighteen fathoms high, and eight broad; consequently, wide enough to receive a large supply of external air, which here generally blows with great violence; but the subterranean passages, which consist entirely of solid rock, winding round, stretch away farther to the north than has been yet discovered. In the midst of winter the air in this carern is warm; but in summer, when the heat of the sun without is scarcely supportable, the cold within is not only very piercing, but so intense that the roof is covered with icicles of great size, which, spreading into ramifications, form very grotesque figures. When the snow melts, in spring, the inside of the cave, where its surface roof is exposed to the sun, emits a pellucid water, which immediately congeals as it drops, and thus forms the above icicles, and the very water that drops from them on the sandy ground freezes in an instant. It is even observed that the greater the heat is without, the more intense is the cold within, so that in the dog days all parts of this cavern are covered with ice, which the inhabitants use for cooling their liquors. The quantity of ice is so great that a narrator estimates that it would require six hundred waggons to remove it in a week. In autumn, when the nights grow cold and the heat of the day begins to abate, the ice in the cavern begins to dissolve, so that by winter no more ice is seen. The cavern then becomes perfectly dry, and has a mild warmth. At that season it is the haunt of swarms of flies, gnats, bats, owls, and even of hares and foxes that resort hither, as to their winter retreat, and remain till the return of spring. An instance almost as singular occurs at Besançon, in a grotto which extends 364 feet into the rock, the mouth of which, like that of Szelitze, is towards the nortl, and covered with vegetation. During the whole summer this cavern contains masses of ice, which melt away in October and November.

This apparently anomalous phenomenon is supposed to be caps ble of being explained by the relation which subsists between the moisture in these caverns and the external air. When it is hot and dry outside, as in summer, evaporation takes place, and by this means a considerable degree of warmth is withdrawn from the enclosed air, the vapours making their escape through the openings, and through fissures in the roofs. The greater the exterior temperature the more vigorously the evaporation is carried on, producing a degree of cold in the interior which may sink beneath the freezing point, just as in the greatest heat we can most readily freeze water if we surrround it with ether. It is upon this principle that travellers, in some regions, are accustomed to cool their drinks, which they bury in 
the earth, and light a quickly blazing fire over it, when the desired coolness is produced. On the contrary, the more the warmth and dryness of the external air are diminished, as in winter, the less will be its capability to promote evaporation in the cavern, the warmth contained in the air will no longer be absorbed, and the ice which has been produced must melt. The cooling in these caverns, however, so as to sink below the freezing point, can only occur where there is a certain relation, which but rarely subsists, between the openings and the evaporating surface of the interior. If the opening is too large, too much warm air is introduced, and the temperature of the interior is thereby much more increased than it can be diminished by evaporation. If it is too small, the vapours cannot withdraw themselves fast enough, and the evaporation is lessened, because the surrounding air is saturated with moisture. The ice-caverns, therefore, are comparatively rare; but, in addition to those named, there is a cave at Vesoul, in France, where a stream flowing through it is frozen over in summer, and clear of ice in winter. Sir Roderick Murchison, in the course of his geological surveys in Russia, met with a freezing cavern near the imperial salt-works at Iletski, to the south of the Ural mountains, situated at the southern base of a hillock of gypsum, one of a series of natural hollows used by the peasantry for cellars or stores. The cave in question is however the only one in the district which possesses the singular property of being partially filled with ice in summer, and of being destitute of it in winter. "Standing on the heated ground and under a broiling sun, I shall never forget," he remarks, "my astonishment when the woman to whom the cavern belonged unlocked a frail door, and a volume of air so piercingly keen struck the legs and feet, that we were glad to rush into a cold bath in front of us to equalise the effect." Three or four feet within the door, and on a level with the village street, beer and quash were half frozen. A little further the narrow chasm opened into a vault fifteen feet high, ten paces long, and from seven to eight feet wide, which seemed to send off irregular fissures into the body of the hillock. The whole of the roof and sides were hung with solid undripping icicles, and the floor was covered with hard snow, ice, or frozen earth. During the winter all these phenomena disappear; and when the external air is very cold, and all the country is frozen up, the temperature of the cave is such, that the Russians state they could sleep in it without their sheep-skins.

There is another circumstance of high interest disclosed by the interior of many caverns, the occurrence of extinct animals of the ancient earth; on which account these receptacles have obtained the name of zoolithes or bone caverns. These sites are observed in almost every country of Europe and America, but the fact was not much known till the late Dr. Buckland published the result of his investigations. He made it the subject of his peculiar study, and with great felicity, illustrated the light which it throws upon the ancient condition of the earth, and the changes which the surface has undergone. His researches into the condition of a cave discovered in 1821 at Kirkdale in Yorkshire are highly valuable, and deserve a notice here. Its mouth had long been choked up with rubbish, and overgrown with grass and bushes, but was accidentally found by some workmen. The cave is situated on the older portion of the oolite formation (in the coral rag and Oxford clay) on the declivity of a valley. It extends as an irregular narrow passage 250 feet into the hill. There are a few expansions, but scarcely high enough to allow a man to stand upright. The sides and floor were found covered with a deposit of stalagmite, beneath which there was a bed of from two to three feet of fine sandy and micaceous loam, the lower portion of which in particular contained an innumerable quantity of bones, with which the floor was completely strewn. The greatest part of them were very well preserved, and still retained a great portion of their natural gluten, in consequence of the peculiar nature of their investiture. The animals 
to which they belonged were the hyæna, bear, tiger, and lion, elephant, rhinoceros, hippopotamus, horse, ox, deer of three species, water-rat, and mouse, belonging wholly to extinct species, and the same with those with which weare acquainted in the steppes of Asia. The most plentiful of all were the remains of the hyæna, and from the amount which lie saw, Buckland estimated the number of the individuals interred here to be between two and three hundred. The animal must have been one half larger than the living species, in its structure resembling the liyæna of the Cape. 'The bears, which were less abundant, belonged to the

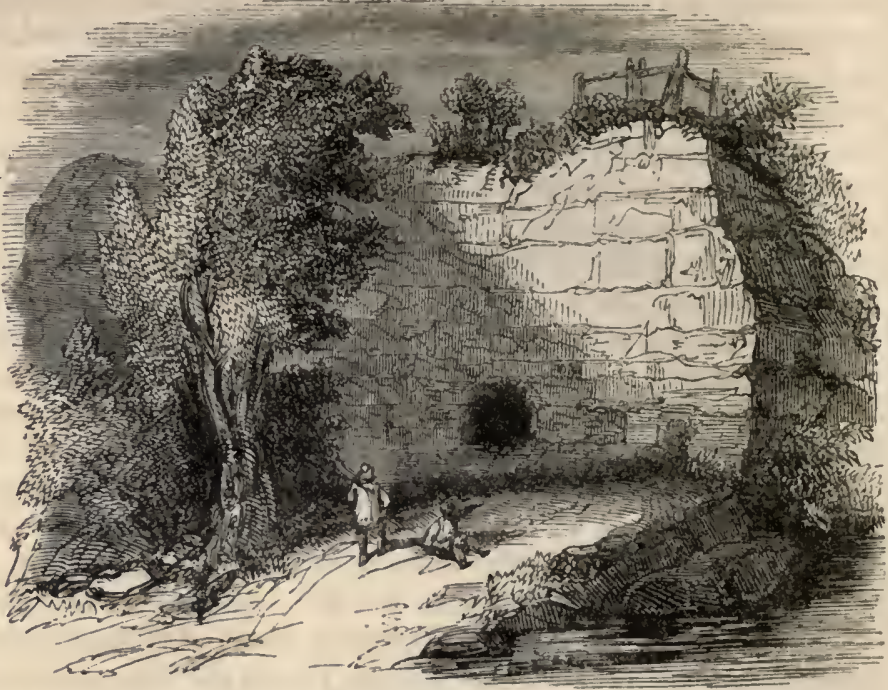

Kirkdale Cave.

large cavern species, which, according to Cuvier, was of the size of a large white horse and about eighteen feet in length. The elephants were the Siberian mammoth. Of the stags the largest was of the size of the moose deer. Of the ox two species were distinguished, and its bones were most frequent next to those of the hyæna. All these bones lay irregularly strewed one with another, but those of the largest animals were in the most remote and narrowest corners, into which they never could have penetrated while living. 'The teeth, and the hard marrowless bones of the extremities, as well as those of the fore and hind feet, were uninjured: these were so numerous that they must have belonged to a much greater number of individuals than could be estimated as belonging to the other bones. Many of the bones bore marks which exactly corresponded with the form of the incisor teeth of the hyæna, and the broken horns of the stag were evidently marked by gnawing. These facts warrinted the conclusion, that the liyænas must have lived for a long time in this cave, and have dragged the bones of the larger animals, particularly the oxen, into this den, as their prey. The supposition was confirmed in the most striking manner by a variety of other facts. Dr. Bucliland found that bones which he caused to be gnawed by living hyænas had exactly the same appearance as those found in the cavern, and the teeth and harder bones were thrown aside by them. He even found in great abundance excrements of the liyæna, which offered the closest resemblance to those of the living animal. From the facts described, it appears that the Kirkdale cave was for a long series of years a den inlabited by hyænas, who dragged into its recesses the other animal bodies whose remains are there commingled with their own,- some great catastrophe causing an inundation in this region which destroyed the whole race.

Similar zoolithic caverns occur in the following places in our own country: - 1 . Kent's Cavern, in the limestone of North Devon, about a mile from Torquay. It is said to be nearly six hundred feet long, varying in width from two to seventy feet, and in height from one to six yards. The bones of extinct species of animals are found buried in a mass of mud, covered over with a crust of stalaymitic formation. From certain appear- 
ances in this cavern, it seems to have been in former times the habitation of man, perhaps the bandit's home. 2. Cave near the village of Hutton in the Mendip Hills. This

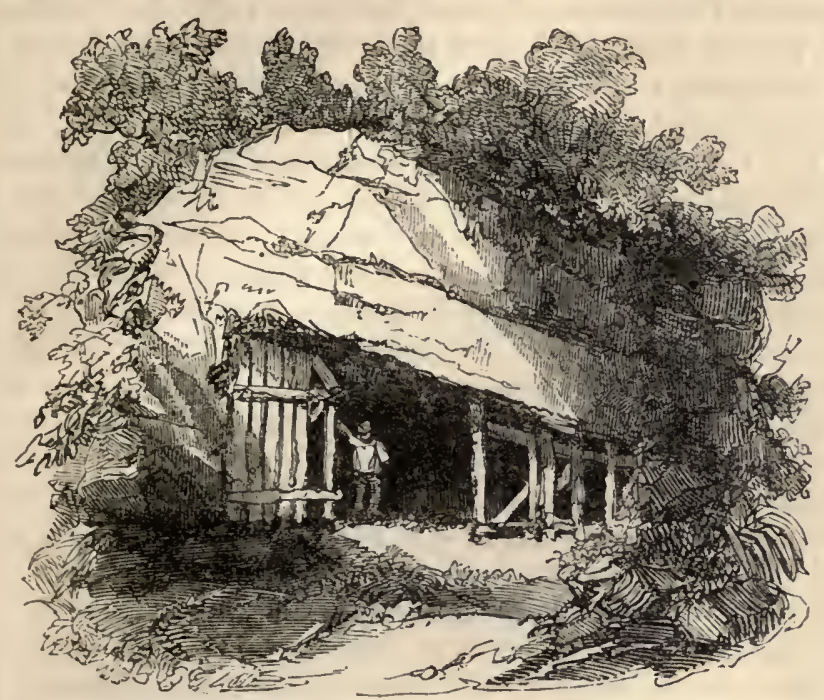

Kent's Cave, near Torquay. is a series of cavernous chambers found by the labourers in working for ochre, which occurs in fissures of the mountain limestone. In the first chamber, about twenty feet square and four high, a large stalactite depends from the roof in the centre, and beneath a stalagmite rises from the floor, nearly touching it. The bones from this cavern are those of the elephant, horse, ox, deer, bear, and hog. 3 . Cave at Balleye, near Wirksworth. Bones and molar teetl of the elephant were discovered here in a cavity of mountain limestone by the lead miners, mentioned in the following record of a workman : - "In sinking for lead at Baulee, within two miles of Wirksworth, A.D. 1663, they came to an open place as large as a church, and found a skeleton reclining against the side, so large that his brain-pan would have held two strike of corn, and so big that they could not get it up without breaking it. My grandfather having a share in the said mine, they sent him a tooth, weighing four pounds three ounces. - Greorge Mower." Some of these remains are still preserved. 4. Dream Cave, near Wirksworth. This was likewise discovered by the miners in pursuing a rein of lead. After sinking about sixty feet through solid mountain limestone, they came to a large cavern filled with argillaceous earth and stony fragments. Here were found the remains of a rhinoceros, in a high state of preservation. They belonged apparently to the same individual, and formed probably an entire skeleton, though several parts were wanting, having been separated from the rest through the subsidence of the mass in which they were imbedded into an underlying hollow, owing to the workmen disturbing the site. Bones of deer and fragments of horns were found in the same spot, all of which are now deposited in the Oxford Museum. 5. Cave on Derdham Down, near Clifton; a fissure which contained fragments of stone and stalagmite, with bones incrusted witl stalactitic matter, among which was a fossil joint of the horse. 6. Caves at Oreston, near Plymouth. Several caverns were discovered in removing materials for the construetion of the Breakwater from a hill of transition limestone. They contained bones belonging to a species of rhinoceros, the tiger, hyæna, horse, ox, wolf, and deer. 7 . Cave of Crawley Rocks, near Swansea. This cavity was aceidentally intersected in working a quarry. It has now been entirely cut away. Various parts of the elephant, rhinoceros, hyæna, ox, and stag were found in it. 8. Caves of Paviland. Two cavities oceur in a lofty cliff of limestone facing the sea on the coast of Glamorganshire, which the waves reach in considerable'storms. The remains of an immense number of animals of extinet species have been found in them.

It is clear from these facts, that anciently, as Dr. Buckland remarks, "extinct species of hyæna, tiger, bear, elephant, rhinoceros, and hippopotamus, no less than the wolves, 
foxes, horses, oxcn, deer, and other animals which are not distinguishable from existing species, had established themselves from one extremity of England to the other - from the caves of Yorkshire to those of Plymouth and Glamorganshire - whilst the diluvial gravel beds of Warwickshire, Oxford, and London, show that they were not wanting also in the more central parts of the country; and MI. Cuvier lias established, on evidence of a similar nature, the probability of their having been spread in equal abundance over the continent of Europe. But it by no means follows, from the certainty of the bones having been dragged by beasts of prey into the small cavern at Kirkdale, that those of similar animals must have been introduced in all other cases in the same manner; for, as all these animals were the antediluvian inhabitants of the countries in which the caves occur, it is possible that some may have retired into them to die; others have fallen into the fissures by accident, and there perished : and others have been washed in by the diluvial waters. By some one or more of these latter hypotheses, we may explain those cases in which the bones are fow in number and not gnawed, the caverns large, and the fissures extending upwards to the surface; but where they bear marks of having been lacerated by beasts of prey, and where the cavern is small, and the number of bones and teeth so great and so disproportionate to each other as in the care at Kirkdale, the only adequate explanation is, that they were collected by the agency of wild beasts." In Germany the zoolithic caverns are much more numerous and important than in England. There is a remarkable example on the north-east border of the Hartz Mountains, called Bauman's Höhle, after an unfortunate miner who, in the year 1670, ventured into it alone in search of ore; and, after having wandered three days and nights in its solitude and darkness, at length found his way out, but in such a state of exhaustion that he died almost immediately. It is a suite of natural chambers in a bed of transition limestone, the floor of which is composed of a thick crust of stalagmite, beneath which lies an accumulation of several feet of mud mixed with bones and pebbles. But the caves of Franconia are by far the richest and most beautiful of this class. They lie on the north-east extremity of the chain of the Jura between Nuremburg and Baireuth, in the valley of the Wiesent, a tributary stream of the valley of the Maine. The most important is the Cave of Gailenreuth, situated in a perpendicular rock, its mouth being upwards of three liundred feet

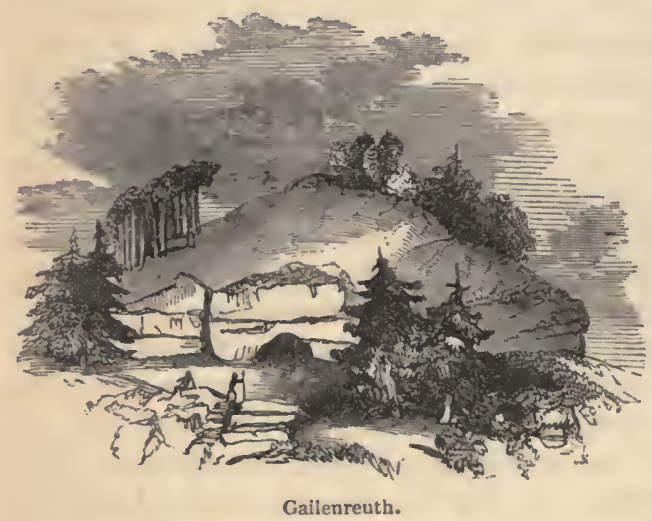
above the bed of the river, consisting of an aperture seven feet high and twelve broad. An open fissure in the rock extends from the cave to the table-land above, as shown in the illustration. The floor consists of stalagmite lying over a bed of slime which contains the animal remains. The cave has two chief chambers, the roof of which is abundantly hung with stalactites. From the first to the second chamber the visitor descends by a ladder, as represented in the section, which exhibits the breccia of bones, pebbles, and loam, and the artificial extension of the cavern by the removal of it. Almost all the bones belong to the bear of the caverns, and are admirably preserved. Those of a species of cat, resembling the American jaguar, have also been discorered, and those of the hyæna; but the latter are of rare occurrence. In conformity with the habits of the bear, the remains of prey, dragged in, are almost entirely wanting. There are two neighbouring caverns of the same class; those of Zahnloch (teeth-hole) and Kühloch. 
The latter is supposed to contain animal matter equal to at least 2500 individuals of the cavern bear; and allowing an annual mortality of $2 \frac{1}{2}$, it follows that here we have the history of a thousand years; for probably these animals retired to the solitude of this spot upon the approach of death, as is the well-known custom of many creatures. The bone caverns in our own country and the continent decisively prove that, previous to a great inundation in by-gone time, animals inhabited these districts, known not to have lived there, from the earliest

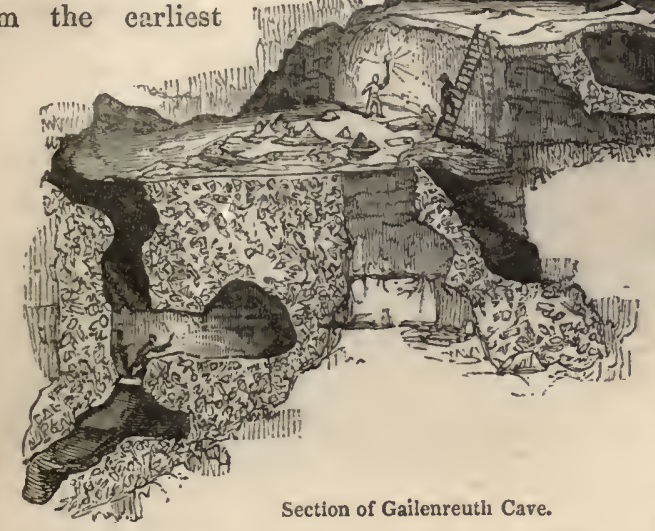
ceeds from the interior of the earth. The first class are principally caves of gypsum. The gypsum is not, however, the cause of the phenomenon, the component parts of which are not susceptible of any decomposition from the air. There is commonly fotid limestone intimately mixed up with it, which forms connected wavy stripes, and even single beds of considerable thickness. This earthy limestone, which is penetrated with bitumen, and often very clayey in its composition, has the property of giving out all its carburetted hydrogen in the air; and in every case where caves exist in it, its presence, on account of its connection with gas, is offensive and much dreaded. In the limestone caves of the sandstone formations, on the contrary, there commonly prevails a very pure air, possibly because they are filled with mouldering animal remains. The development of irrespirable gases from the interior of the earth, which, penetrating through fissures, collect in caves, is a constant result of volcanic activity. The chemical processes continually going on in volcanic regions must produce the liberation of great quantities of gas, which are connected with the world above by these chimneys of the perpetual forge. Caverns of this nature occur therefore only in the neighbourhood of volcanoes, or at points where volcanic processes may be supposed to be going on beneath. The gases so developed are almost entirely the carbonic and sulphuric acids. Among the most important of the grottos which give out carbonic acid, there is the Grotto del Cane at Naples, in the neighbourhood of the Lago d'Agnano, near Pozzuoli. It was known to the ancients, and is mentioned by Pliny, who refers to it as one of a class of excavations called, in his time, "Charon's ditches." Its size is very unimportant; ten feet deep, four feet broad, and nine feet high. The carbonic acid collects itself on the soil in a bed of about six inches deep; and, on account of its specific gravity, does not mingle with the atmospheric air. Its actual height may be clearly ascertained by lighting some candles, which, when they reach its surface, are extinguished at once. Small animals falling 
in are speedily suffocated; and it takes its name from the dogs which are placed in it by way of experiment. The cave and its neighbourhood appear to have undergone

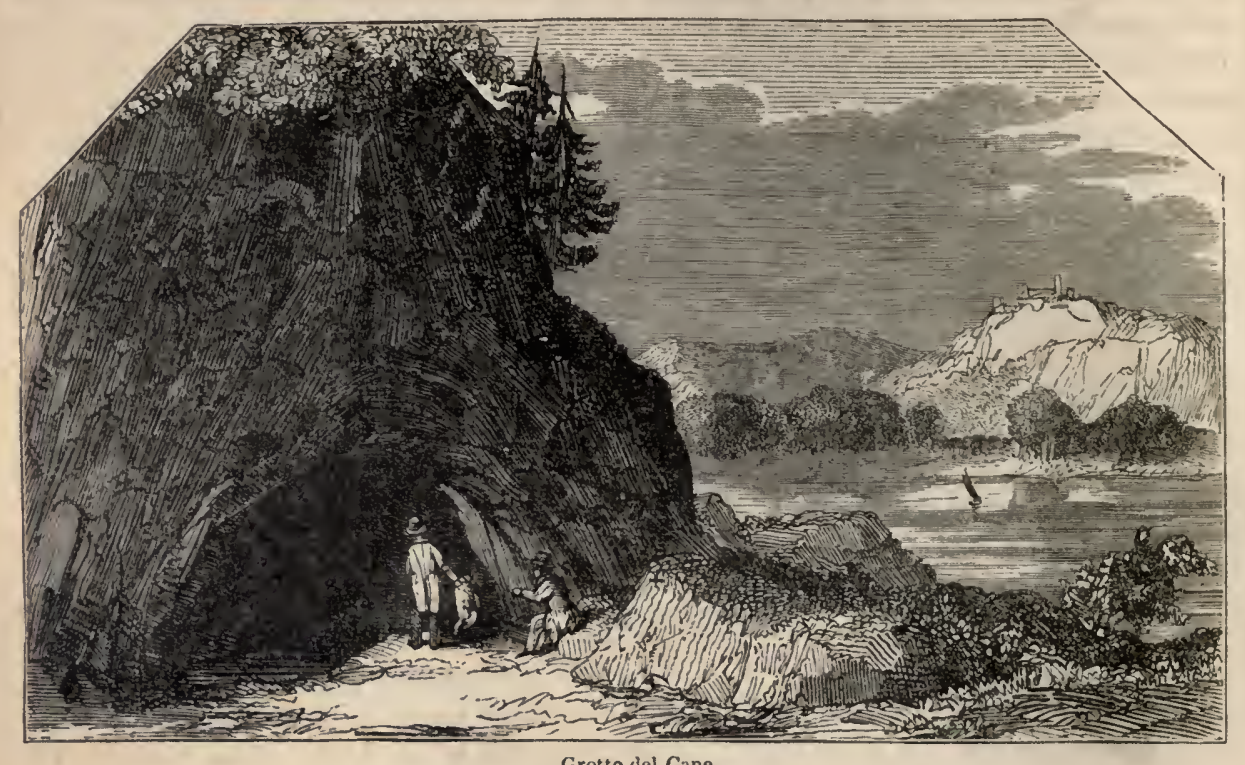

Grotto del Cane.

some considerable changes; for, from Pliny's reference to the meplitic gas, it would seem to have been fatal to luman life, which is not possible now, owing to the small height of the stratum, unless an individual threw himself upon the surface of the floor. According to some ancient accounts, bubbles were constant upon the lake Agnano close by, occasioned by the escape of gas, of which there is no appearance now ; so that the quantity of deadly air exhaled has been much reduced, if dependence may be placed upon these autliorities. A similar instance, on a much larger seale, is seen in the crater of the extinct volcano of St. Leger, or of Neyruc in the south of France, on the banks of the Ardêche, amid the great number of volcanic remains of that region. This crater exhibits a cultivated, and in part inhabited, district, which is surrounded like an ampliitheatre by the ancient walls of volcanic débris. Its soil is one vast sieve for the ascent of carbonic acid. Perforations have been made in it to facilitate the emission of the gas, and guide it from the fields, to which its contact is very injurious. The height of the bed of gas, over the ground of these loles, has been found to be, in the most farourable circumstances, about one foot and a lialf. Changes of weather have the most important influence on it; and in violent rains the whole mass of gas is absorbed. 'The quantity of this gas, which issues from the soil of the whole neighbourhood, has a very striking influence on the health of the inhabitants who work in these fields; and if the proprietors do not yearly clear out these perforations, their harrest is lost by means of the poisonous vapours. Another example occurs near Pyrmont, where there is a cavern of mephitic gas, named Dunsthohle, which exhibits the same phenomena as the dog grotto near Naples; and of a kindred kind is the extraordinary valley in the island of Java, called by the natives Guwo-upas, poisoned valley; which is without vegetation, and strewed with the skeletons of human beings, quadrupeds, and birds, being generally half-filled with a noxious gas which destroys life in a few minutes.

In addition to the cavities which are the handiwork of nature, immense subterranean 
spaces have been excavated by the labour of man, chiefly in the limestone, coal, and salt formations, to obtain the products which are essential to the arts of life. At certain points and limits of the Soutl Staffordslire "Coal Basin," the limestone stratification is abruptly exalted from its normal position, which is several luundred fect below the regular surface, and forms a striking object in seenery, and a picturesque mountain boundary, to the district of towns, hamlets, and villages, in which the usual mining operations for coal and iron stone are pursued. It is worked to procure a valuable flux for the iron furnaces - cement for building - and a manure for agricultural purposes. Dudley Castle Hill is

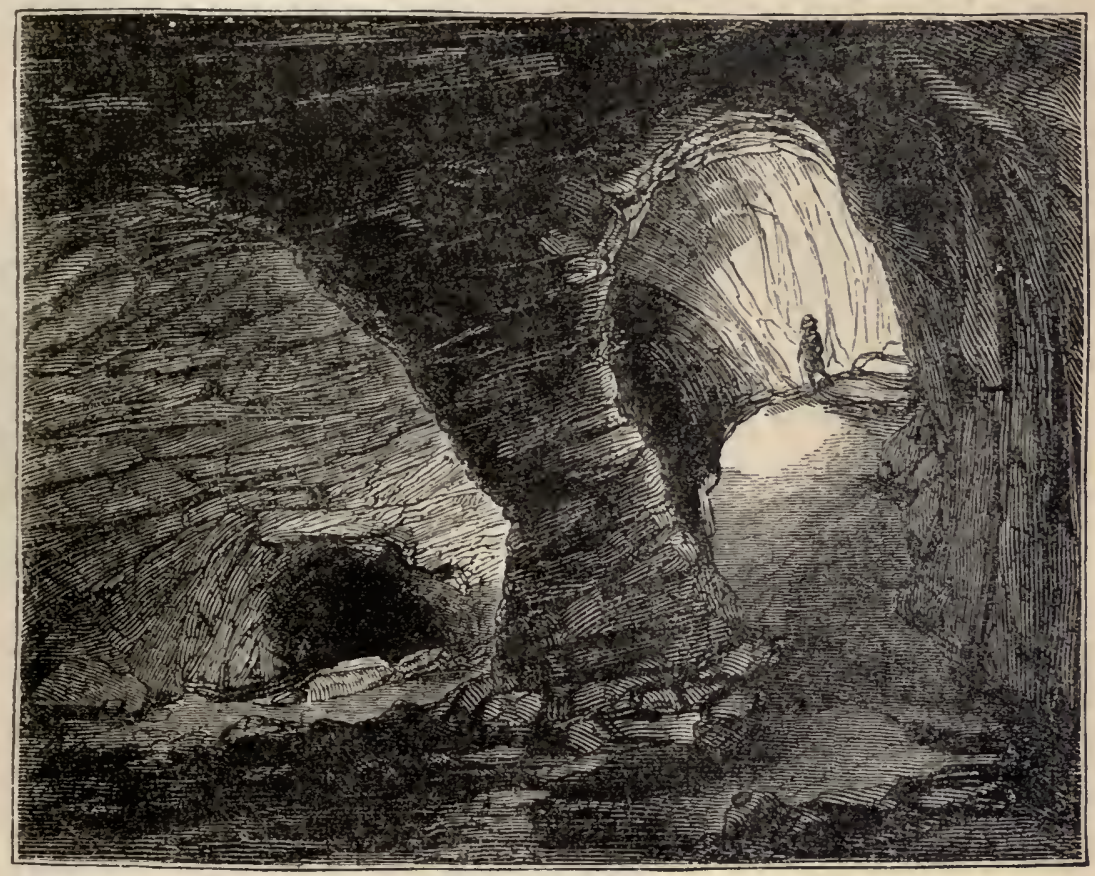

Caverns of Dudley Castle.

a bogld and rugged prominence, where the quarries were primarily worked. The excavations at first were open to the light, commencing from the protruding ridges and peaks, and forming in time a deep hollow or ravine. Clearing the rock as far as was convenient, the rapid inclination of the stratum was followed, and the work was then continued at a much lower level, in the form of gloomy tunnels, afterwards threaded by dark and dangerous canals, necessary for the conveyance of the product of the perforated region. At the lower part of the castle grounds, and not far distant from the Eastern Lodge, is the descent to one of the great caverns, answering to our illustration. By a few uncertain slippery steps the visitor arrives at the moist crumbled floor of a wondrous avenue of rock works. Indistinctly, and at an inferior plane, glimmer the dull waters of the canal, the line of which is only broken in part by a corered way, to re-appear in the onward distance of the hazy mine. As the strata are sometimes at an angle of eighty degrees, sometimes less, the enormous broad-footed pillars of material left to support the irregular roof, answer to such inclination, and are perpendicular to it, presenting a wild and singular appearance. The force and sublimity of this scenery by torchlight are most interesting, and the frowning boundaries of the spacious crypts, the pillars, and the rude chambers, remind one distinctly of the mazes of the Memphic tombs. Proceeding to the left, 
and near to the porch of the cavern delineated, as also in progress towards the other extremity, yawning apertures aloft and laterally communicate with the celebrated ravine in the castle bounds, and receive a blue misty light into the gigantic casemate which illuminates the glistening and sparry walls, displaying the white frosted vapour upon the lips of the attendants and their guide. In sultry weather much danger is incurred by entering the caverns insufficiently protected from an altered temperature.

The demand for the mineral treasures of the earth, and especially its coal, created by the adrance of civilisation, has caused the undermining of its surface upon an extraordinary scale in modern times, though some of our own mines date their origin from the era of the ancient Britons. This is the case, as the name imports, with Odin's mine, at the southern foot of Mam Tor in Derbyshire, a place deserving a visit. A shaft, nearly

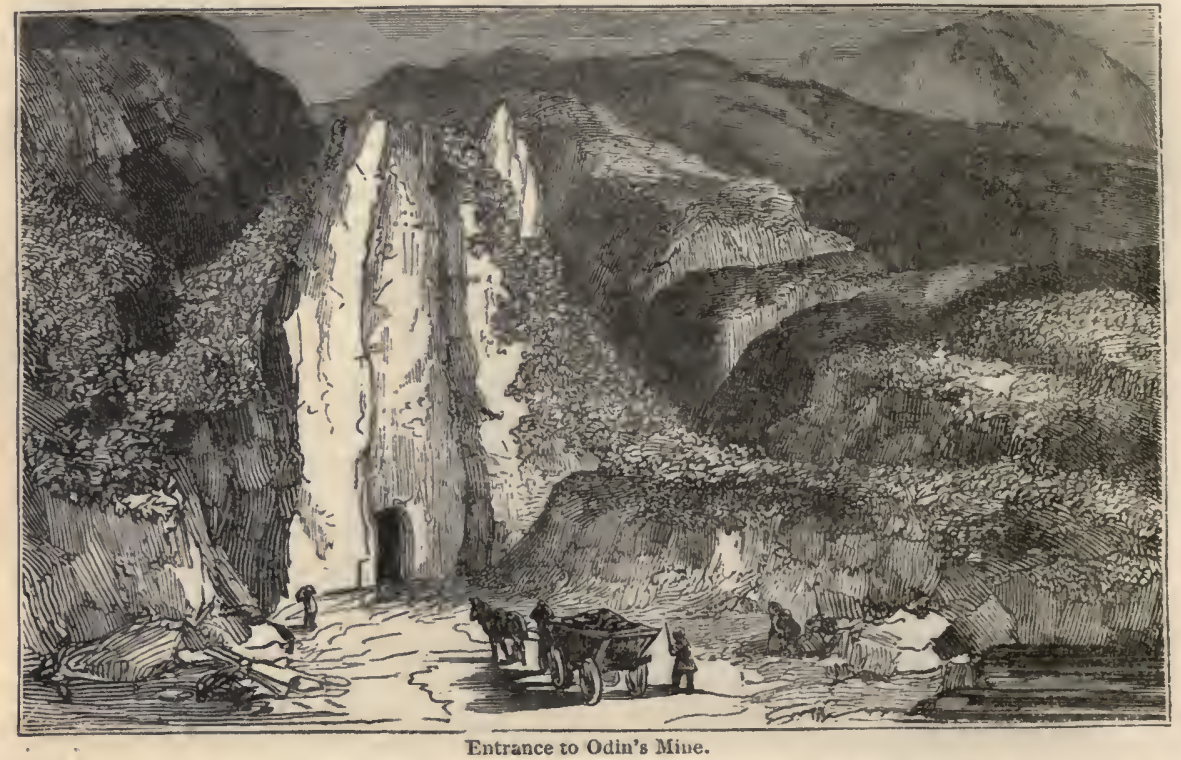

a mile in length, leads to the vein of ore that is now worked, which varies in thickness from two or three inches to as many feet. Beautiful crystallisations of blende, barytes, calcareous spar, and selenite are found in this extensive excavation, as well as the curious and dangerous mineral called slikensides. "The effects of this extraordinary mineral," says Mr. Rhodes, "are not less singular than terrific. A blow with a hammer, a stroke or a scratch with a miner's pick, are sufficient to rend those rocks asunder with which it is united or embodied. The stroke is immediately succeeded by a crackling noise, which is sometimes accompanied with a sound not unlike the mingled hum of a swarm of bees; shortly afterwards an explosion follows, so loud and appalling that even the miners, though a hardy race of men and little accustomed to fear, turn pale and tremble at the shock. This dangerous combination of matter must consequently be approached with caution. To avoid the use of the common implements of mining, a small hole is carefully bored, into which a little gunpowder is put and exploded with a match, which gives the workmen time to withdraw to a place of safety, there to await the result of their operations. Sometimes not less than five or six successive explosions ensue at intervals of from two to ten or fifteen minutes; and occasionally they are so sublimely awful that the earth has been violently shaken to the surface by the concussion, even when the discharge has taken place at the depth of more than one hundred fathoms." 
SPRINGS.

\title{
CHAPTER V.
}

\author{
SPRINGS.
}

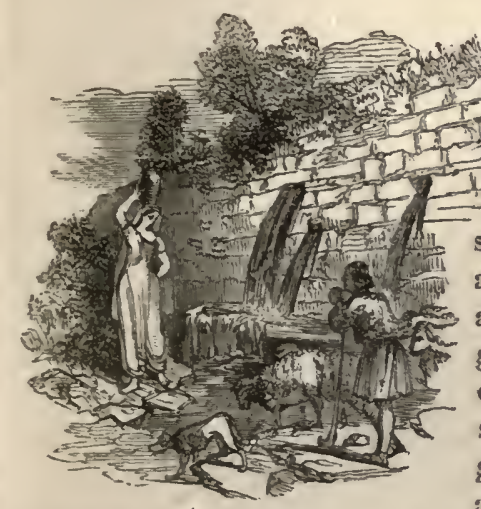

(4) the fertility of the soil, occurs in each of the physical conditions which bodies are capable of assuming - the gaseous, solid, and liquid states. In the form of vapour, sustained in the atmosphere, it will be treated of in another section. In the solid condition, one of its aspects has been previously referred to - that of the glaciers of high mountain regions; and in the lowland districts of the temperate zones, water annually assumes a solid form, a mantle of snow lying upon the ground in winter, and a coating of ice upon the pools and rivers. Upon high elevations, also, even within the tropics; these phenomena are perpetual; and, upon the lerel surface of circumpolar countries, snow and ice are constant features of the landscape. In a liquid state, the continental waters have the character of springs, rivers, or lakes, which vary greatly in their external appearance, and in the chemical composition of the fluid. The oceanic waters likewise display these characters; for we may regard the broad expanse of different seas as vast lakes, while the numerous, strong, and permanent currents that occur are the rivers of the deep; and in various places it is certain that jets of fresh-water rise from the bottom of the ocean, which materially lessen its saltness in their neighbourhood. In the Gulf of Spezzia, a branch of the Gulf of Genoa-one of the finest harbours in the world, and of exquisite beauty - there is a powerful jet of fresh water rising in a liquid column from the bed of the sea ; and on the south coast of Cuba, at a considerable distance from the shore, there are fresh-water jets of such force, that boats cannot approach them without hazard. The general division of the waters of the globe is into salt, mineral, and fresh water. The ocean is the grand example of the former; but there are many continental specimens of saline springs and lakes, which proceed from combination with rock-salt or sulphate of magnesia. The mineral waters arise from sulphur, arseniates, or other metallic substances, derived from the circumjacent earth, held in solution. For the most part, howerer, the continental waters are fresh, or somewhat similar to distilled water, whether resulting from rain, or the melting of snow and ice, and constituting either springs, rivers, or lakes.

Springs, whether gushing rapidly from rocky clefts, or gently oozing out of banks of earth, are interesting objects in the landscape, from the general purity of their waters, the frequent seclusion of their situations, their murmuring flow, and the green enamel of mosses and flowering plants to which the refreshing. virtues of their streams give birth. There are not a few springs whose history may be traced back thousands of years, and which have acquired celebrity from their association with events and personages of a far remote antiquity. Who has not heard of the fountain of Arethusa, with its dark water, to which the hero of the Odyssey was directed by the goddess, npon returning to his native Ithaca?

" Go, first the master of thy herds to find,

Where Arethusa's sable water glides." 
This fountain is about six miles in the interior of the island, the road ascending all the way. It is a small basin at the top of a ravine, and is supplied by unceasing percolations tlirough the superincumbent rock. Seated on a broken arch before it, the sides of the glen appear clothed with leafy plants and odoriferous shrubs; and onwards through it a glimpse of the blue sea is caught, while the summit of the cliff above the fountain commands a view of the islands and mountains of Greece. Hither, it may be soberly believed, the autlior of the Odyssey, if not the hero, was a pilgrim, near three thousand years ago, and drank of the limpid spring at which now the goatherds of Ithaca quench their thirst. Dodwell, who visited this spot, describes its water" as "clear and good, trickling gently from a small cave in the rock, which is covered with a smooth and downy moss.' It has formed a pool four feet deep, against which a modern wall is built to check its overflowing. After oozing through an orifice in the wall, it falls into a wooden trough placed there for cattle. In the winter it overflows, and finds its way, in a thin stream, througll the glen to the sea. The French had possession of Ithaca in 1798, and the rocks of the Arethusan fountain are covered with republican inscriptions, 'Vive la République!' 'Liberté, égalité, et fraternité,' are seen scattered on all sides, but are becoming effaced." Who also has not heard of the fountain of Castalia, in which the Delphian Pythoness laved her limbs, and from which she, and the poets who versified her answers, were believed in part to derive their inspiration? The poetical expression, the "dew of Castalie," refers to the spray of a cascade which descends througl a cleft of Parnassus, fed by the snows upon its summit; but the fount of inspiration, the bath used by the Pythia, is supposed to be a small shallow basin on the margin of the rill of the cascade, supplied with its own perennial stream, which unites its superabundant water with that of the adjacent stream. Here 
a striking change las taken place within the period of authentic history. Where are the rich tributes of the Lydian king? the spoils of Marathon and Salamis? the sacred hall of the Amphictyonic council? the temple of Apollo? the city of Delphi, whose buildings are mentioned, in the records of its former magnificence, as covering two miles of ground? There is not a vestige to be identified; but Parnassus still exhibits its bold heights and transparent waters, unaffected by the passage of ages.

" The shrine hath sunk! but thou, unclang'd, art there!

Mount of the voice and vision, rob'd with dreams!

Unchang'd, and rushing through the radiant air,

With thy dark waving pines, and flashing streams,

And all thy founts of song! Their bright eourse teems

With inspiration yet; and each dim haze,

Or golden cloud, which floats around thee, seems

As with its mantle veiling from our gaze

The mysteries of the past, the gods of elder days!"

The Castalian spring is now dedicated to St. John; a pretty chapel bearing his name is by its side; pendent ivy, moss, lurambles, flowering shrubs, and a large fig-tree, throw a cool and refreshing gloom over the spot. Upon a buttress of the chapel, the inscription occur's, "Byron, 1806." But the poet has left another memorial of his visit.

" Happier in this than mightiest bards liave been,

Whose fate to distant homes confin'd their lot,

Shall I unmov'd behold the hallow'd scene,

Which others rave of, though they know it not?

'Though here no more Apollo haunts his grot,

And thou, the Muses' seat, and now their grave,

Some gentle spirit still pervades the spot,

Sighs in the gale, keeps silence in the cave,

And glides with glassy foot o'er yon melodious wave."

Dr. Cliandler speaks of the excessive coldness of the water of Castaly. "I began," he states, "to wash my lands in it, but was instantly chilled, and seized with a tremor, which rendered me unable to stand or walk witlout support. This incident, when Apollo was dreaded, might have been embellished with a superstitious interpretation. Perhaps the Pythia, who bathed in this icy fluid, mistook her shivering for the god."

It is in the sandy deserts bordering on the tropics that springs acquire their highest importance and value, owing to the rarity of water, and the increased demand made for it by the heat of the climate. Here they are frequently connected with verdant spots, similar to that of the interview between the Scottish Knight and the Emir in the brilliant tale of the "Talisman." "It was a scene," says Scott, "which, perhaps, would elsewhere lave deserved little notice; but as the single speck, in a boundless horizon, which promised the refreshment of shade and living water, - these blessings, held cheap where they are common, rendered the fountain and its neighbourliood a little paradise. Some generous or charitable hand, ere yet the evil days of Palestine began, had walled in and arched over the fountain, to preserve it from being absorbed in the earth, or choked by the flitting clouds of dust with which the least breath of wind covered the desert. 'The arch was now broken, and partly ruinous; but it still so far projected over, and covered in the fountain, that it excluded the sun in a great measure from its waters, which, hardly touched by a straggling beam, while all around was blazing, lay in a steady repose, alike delightful to the eye and the imagination. Stealing from under the arch, they were first received into a marble basin, much defaced indeed, but still cheering the eye, by showing that the place was anciently considered as a station, that the hand of man had 
been there, and that man's accommodation had been in some measure attended to. The thirsty and weary traveller was reminded by these signs that others had suffered similar difficulties, reposed in the same spot, and, doubtless, found their way in safety to a more fertile country. Again; the scarcely visible current which escaped from the basin, served to nourish the few trees which surrounded the fountain; and where it sunk into the ground and disappeared, its refreshing presence was acknowledged by a carpet of relvet verdure." Some of the wells that occur in the wilderness of Arabia were halting-places to the descendants of Jacob in their migration through it, and appear under the same character now as then, shaded by a few palms, often supplying brackish and bitter water, capable of being sweetened by artificial means, and claimed as valuable property by the parties having territorial right to the soil. "And when they came to Marah, they could not drink of the waters, for they were bitter;" but the juices of a plant thrown into 'them, rendered them palatable. There is every reason to suppose this spot to be the fountain Hawârah, a basin of unpleasant, saltish, and somewhat bitter water, near which Dr. Robinson found many bushes of the shrub Ghŭrkŭd in blossom, - a low thorny plant producing a red berry, which ripens in June, which is juicy and slightly acidulous, capable of correcting the bad qualities of the spring by mingling with it. "And they came to Elim, where were twelve wells of water, and threescore and ten palm trees." This is identified upon good grounds with Wady Gharandel, a valley about seven miles from the former station, a mile in breadth, with date trecs, tamarisks, acacias of different species, and a copious fountain producing a small rivulet. The non-existence at present of twelve wells is no evidence, as Burckhardt remarks, against the conjecture, for water here is readily found by digging for it, and wells are frequently formed which the drifting sands fill up. Drawing water has ordinarily been the employment of females throughout the East, without distinction of rank, from a remote antiquity, - an onerous duty, as the wells are often at considerable distances from their habitations. "The daughters of the men of the city came out to draw water," is a remark which refers to a period separated by two thousand years from the time of a similar record, "there cometh a woman of Samaria to draw water." Equally ancient and general is the oriental practice of making the neighbourhood of a spring the scene of occasional festivity and mirth, a usage which was primarily a tribute of gratitude for its waters. "When I was at Ain, in Palestine," says Maritis, "a young Arab woman, at whose wedding I had been present on the first day of our arrival at the village, came hither to draw water. She was accompanied by some other women who were singing a song allusive to her marriage." We have a song of the Israelites, of the recitative kind, commemorating a spring, encountered soon after their emergence from the dry and thirsty desert.

"Spring up, O well! Answer ye to it!"

One party sung these words, and called upon another band to reply; and they replied -

"The well! - The princes searched it out."

And the chorus was, -

"The nobles of the people have digged it,

By decree; upon their own borders."

Dr. Clarke informs us that the Eleusinian women practised a dance about a well, that was called Callichorus; the dance was also accompanied by songs in honour of Ceres; and these songs of the well are still sung in parts of Greece and Syria. There is a similar practice in our own country, which will be adverted to upon a subsequent page.

The origin of springs, a subject invested with considerable obscurity, has been referred to the rains and melted snow which the earth absorbs; to the subterranean combination 
of the oxygen and hydrogen gases, which decompose each other, and produce water; and to the filtering of water from the sea into internal cavities and reservoirs prepared by nature, from whence they make their way to the surface. Some writers contend for the former cause exclusively. Marriotte has examined the point, whether the quantity of rain water is sufficient to feed all the springs and rivers, and so far from finding a deficiency, he concludes upon the amount being so great as to render it difficult to conceive how it is expended. According to experiments which have been made, there falls annually upon the surface of the earth about 19 inches of water, but to render his calculation still more convincing, Marriotte supposes only 15 , which makes 45 cubic feet per square toise, and $238,050,000$ cubic feet per square league of 2300 toises in each direction. Now the rivers and springs which feed the Seine, before it arrives at the Pont-Royal at Paris, comprehend an extent of territory, about 60 leagues in length, and 50 in breadth, which makes 3000 leagues of superficial area; by which, if $238,050,000$ be multiplied, we have for the product $714,150,000,000$, for the cubic feet of water which falls, at the lowest estimate, on the above extent of territory. Let us now examine the quantity of water anmually furnished by the Seine. The river, above the Pont-Royal, when at its mean height, is 400 feet broad, and 5 deep. When the river is in this state, the velocity of the water is estimated at 100 feet per minute, taking a mean between the velocity at the surface, and that at the bottom. If the product of 400 feet in breadth, by 5 in depth, or 2000 square feet, be multiplied by 100 feet, we shall have 200,000 cubic feet for the quantity of water which passes in a minute through that section of the Seine above the Pont-Royal. The quantity in an hour will be $12,000,000$; in a day $288,000,000$; and in a year $105,120,000,000$ cubic feet. This is not the seventh part of the water which, as previously stated, falls on the extent of country that supplies the Seine, the large remainder, not received by the river, being taken up by evaporation, besides a prodigious quantity employed for the nutrition of plants. A further calculation has been made by the same writer, of the water which ought to be furnished naturally by a spring that issues a little below the summit of Montmartre, and which is fed by an extent of ground 300 toises in length, and 100 in breadth; making a surface of 30,000 square toises. At the rate of 18 inches for the annual quantity of rain, there will fall on that extent an amount equal to $1,620,000$ cubic feet. A considerable part of this water, perhaps three-fourths, immediately runs off, so that no more than 405,000 forces its way through the earth and sandy soil, till it meets with a bed of clay at the depth of two or three feet, from which it flows to the mouth of the fountain, and feeds it. If 405,000 therefore be divided by 365 , the quotient will be 1100 cubic feet of water, which it ought to furnish daily, or about 38,500 French pints. This makes about twenty-seven pints per minute, which is nearly the produce of the spring.

It appears from this and other calculations, that the rain which falls in particular districts is more than sufficient to account for all their springs and rivers; and some very obvious circumstances show that the origin of springs is almost, if not entirely, owing to the rains which continually moisten the surface of the globe. In seasons of long drought, the greater part decrease in a considerable degree, and some absolutely fail, while they are renewed in the same progression as the descending showers are abundant. It is possibly the case, indeed, that the ocean filtering through pores of the earth-the salt particles being lost in the passage-may give rise to many springs; but as the preceding cause is amply sufficient to explain their formation, we need not recur to any other. The rains and melted snow which the earth absorbs, percolate through crannies, or ooze through the strata, and collect in vast internal reservoirs in mountainous regions, from which the superabundant water finds its way again to the surface, breaking out through fissures in the side and at the bottom of the hills. Copious springs thus issue from the 
mountain limestone of England, through the fissures of the rocks, produced in the course of the consolidation and shrinking of the mineral masses. They seldom appear, however, on the sides of limestone hills, but break out in great numbers, and often with extraordinary impetuosity, around their bases. In other conditions of the surface, the water percolates through the masses of sand, grarel, or chalk, that compose it, till it meets the solid rock, or a bed of impervious clay, which arrests its further descent, and springs are then formed at the point of the lowest level, on the edge of the rock or clay that dams it up. With few exceptions, the lower beds of the chalk formation are completely saturated with water which has percolated through the superior strata to the base, where its downward course is stopped lyy a subsoil of blue elay, which occasions the accumulation in the lower regions of the chalk, and the springs and rivulets which issue near the foot of every chalk hill. It is more difficult to aecount for springs where the country is neither hilly nor uneven, but constitutes a great level or plain. The water in these instances reaches the surface by ascension, or flows in a direction contrary to that produced by the force of gravitation. 'There can be little doubt, however, that many of these springs derive their supply from distant elevations, and are produced by the natural tendency of liquids to find their level. Other examples are perhaps due to capillary attraction, in consequence of which water ascends through the pores of the earth in the same manner as it rises in capillary tubes - in sponge or sugar-lonf - so long as the latter remains undissolved.

In order to give a distinct though general view of the curious and complicated phenomena of springs, they may be advantageously considered under different heads.

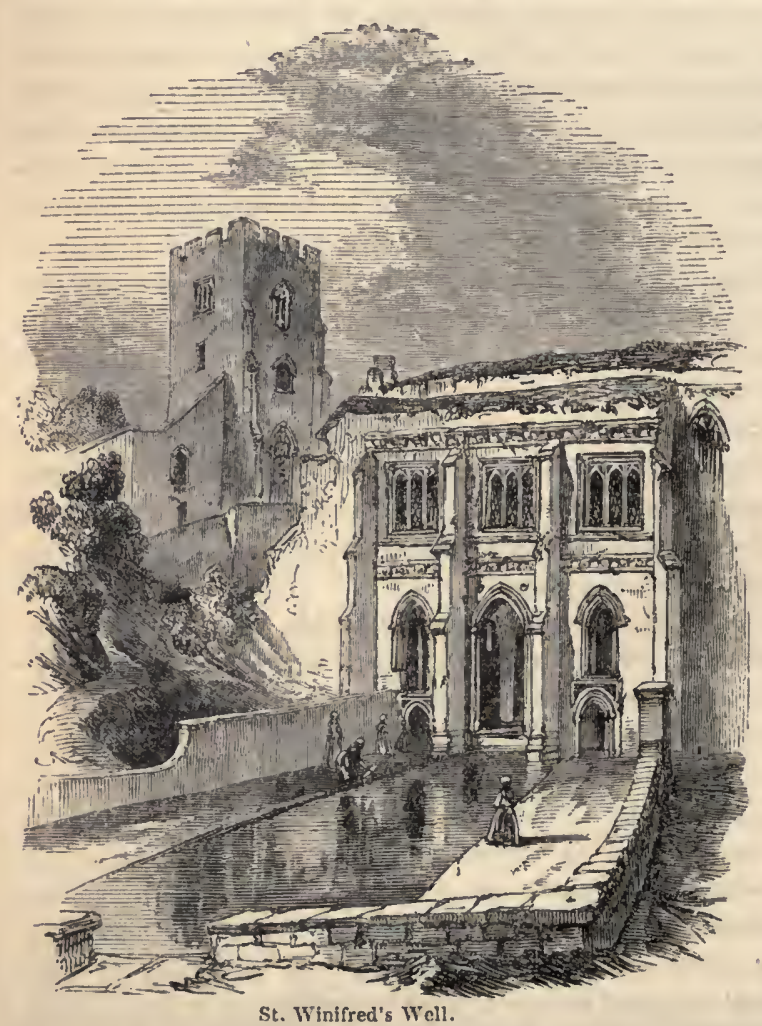

1. Perennial. Some springs are ever-flowing, and answer to the expression of sacred poetry-the "fountains of living water." 'They do not dry up during the longestcontinued drought, and suffer little or no diminution in their volume. These are obviously quite independent of the last showers that have fallen, though their supply may primarily proceed from the rain and melted snow. It is reasonable to suppose that they gush from a body of water collecterl in subterranean cavities, so vast as not to be drained off by the constant stream during the most protracted season of dry weather, before the interior basin is replenished. Of this nature is the celebrated spring of St. Winified, at Holywell, in Flintshire, one of the finest in the world, which appears to be situate at the point where the limestone first comes in contact with the coal measures. 'The quantity of water thrown up is estimated at eighty-four hogsheads, or twenty-one tons, in a minute. It has never been known to fail, but is subject to reduction during drought. 'The stream never 
freezes; and though its course is little more than a mile before it arrives at the sea, yet eleven mills are put in motion by it. The spring issues from the rock into a beautiful polygonal well, over which the Stanley family erected a chapel about the time of Henry VII. Upon the windows the chief events of St. Winifred's life are painted. The saint is reported to have been a virgin martyr who suffered upon this spot, the spring miraculously rising from her blood; and hence the veneration for the well in popish times. Pennant says of his own time: "The custom of visiting this well in pilgrimage, and offering up devotions there, is not yet entirely set aside. In the summer a few are still to be seen in the water, in deep devotion, up to their chins for hours, sending up their prayers, or performing a number of evolutions round the polygonal well. In the year 1686 James II. visited this well, and received as a reward a present of the very shift in which his great grandmother, Mary Qucen of Scots, lost her head." There are springs similarly powerful along the confines of the limestone district, which vary very little in their quantity of water, either in drought, or after the heaviest rains. About Denton, in Yorkshire, the roaring of the waters is incessant.

2. Intermittent. Many springs gush with veliemence, then subside, shrink away, and disappear, renewing their tide in its full strength at irregular intervals. They clearly derive their supply from the last rains, and hence fail altogether in dry seasons. On the chalk downs of the south of England, in Wilts and Dorset, it is a very common circumstance for the valleys to be quite dry in one part of the year, and rery fully watered in another; and hence a Wiltshire proverb says,

"As the days lengthen, the springs strengthen."

But we may suppose such a cavity in a hill as $\mathrm{A}$ in the diagram, a reservoir fed by rain percolating through the superior rocks, and communicating with the surface by an arched chamel, like I: C D. As long as the water in the cavity is above the level of the channel

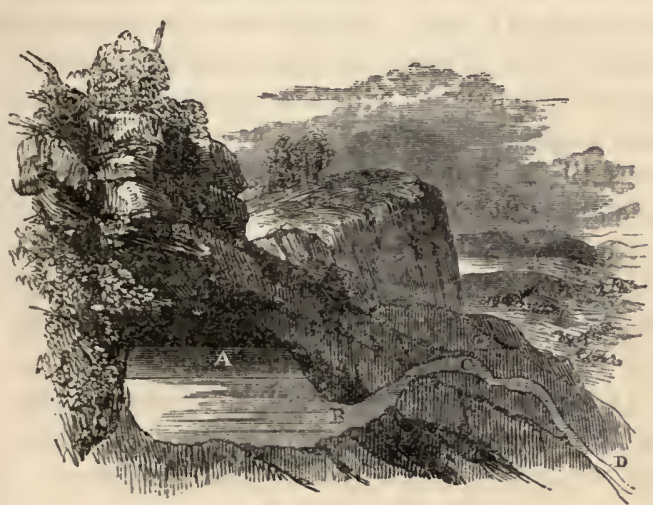
at $\mathrm{C}$, it will escape through it, and gush out at $\mathrm{D}$; but the spring will cease when the water of the interior basin has been reduced to that level, and not be renewed until it rises above it. The flow of the spring will also be more impetuous in proportion as the water of the cavity accumulates above the vertex of the siphon-formed arch. This is the principle of the Artesian wells, which have been constructed with signal success near many large cities occupying level sites, and formerly inconvenienced by the want of natural springs, or by the bad quality of the surfuce water. 'The action of these wells, puits Artésiens-so named from the province of Artois, where they have been long in use - is due to the constant endeavour of liquids to find their level. If we suppose a basin-shaped country, or a plain enclosed with heights, the rain which falls on the circumjacent hills being absorbed among the rocks, may be conducted through one of the underlying strata of the plain, completely occupying it, and yet be prevented from sinking lower, and also from reaching the surface, by inferior and superincumbent beds of solid rock or impervious clay. In such circumstances a perpendicular perforation or boring into the ground is made, penetrating the superior impervious bed, and reaching the saturated stratum through which the water rises to the surface. Thus suppose a town situated upon a bed of clay 
or mass of rock impervious to water, as A A ; B B a stratum through which it readily circulates, and which crops out or rises from beneath $\mathbf{A} \mathbf{A}$ on each side; $\mathrm{c} \mathrm{C}$ also a rock through which it cannot pass. It is clear that rain, falling on the permeable stratum where it crops out, and being absorbed by it, yet prevented from passing downward under the action of gravity by the rock $\mathrm{C} \mathrm{C}$, will travel laterally through the stratum

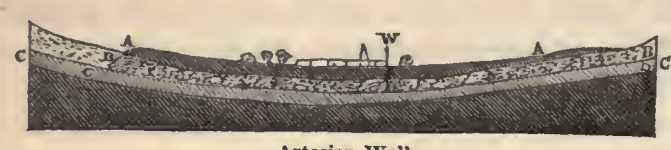

Artesian Well. under the town, unable however to find its level, and force its way to the surface through the superincumbent rock $A$ A. This is a condition in which an artificial boring at $\mathrm{W}$, through $\mathrm{A} A$ to $\mathrm{B} B$, will

liberate the water of the latter, which will rise in the vent to the surface of the plain, in proportion as its source is elevated above it. Artesian wells, notwithstanding their modern name and its local derivation, appear to have been well known in various countries and in ancient times, without perhaps any apprehension of their principle. Neibuhr quotes an ancient writer as saying, "Wells are sunk in the oases from two to four hundred yards in depth (the yard in question being equal to half a foot), whence water rises and flows over."

3. Reciprocating. There are springs which exhibit phenomena analogous to the flux and reflux of the tides of the ocean, some at regular intervals during the day, and others at more distant and uncertain periods. In one of the two letters addressed by the younger Pliny to Licinius, he describes a spring of this kind by the Larian lake-the modern Lake of Como: - "I have brought you," he remarked, "as a present, out of the country, a query which well deserves the consideration of your extensive knowledge. There is a spring which rises in a neighbouring mountain, and, running among the rocks, is received into a little banqueting room, from whence, after the force of its current is a little restrained, it falls into the Larian lake. The nature of this spring is extremely surprising; it ebbs and flows regularly three times a day. The increase and decrease is plainly visible and very amusing to observers. You sit down by the side of the fountain; and whilst you are taking a repast, and drinking its water, which is extremely cool, you see it gradually rise and fall. If you place a ring or any thing else at the bottom when it is dry, the stream reaches it by degrees till it is entirely covered, and then gently retires; and if you wait you may see it thus alternately advance and recede three successive times. Shall we say that some secret current of air stops and opens the fountainhead as it approaches to or retires from it, as we see in bottles, and other vessels of that nature, when there is not a free and open passage; though you turn their necks downwards, yet, the outward air obstructing the vent, they discharge their contents as it were by starts? But may it not be accounted for upon the same principle as the flux and reflux of the sea? Or as those rivers which discharge themselves into the sea, meeting with contrary winds and the swell of the ocean, are forced back into their channels, so may there not be something that checks this fountain, for a time, in its progress? Or is there rather a certain reservoir that contains these waters in the bowels of the earth, which, while it is recruiting its discharges, the stream flows more slowly and in less quantity; but, when it has collected its due measure, it runs again in its usual strength and fulness? Or, lastly, is there I know not what kind of subterraneous counterpoise, that throws up the water when the fountain is dry, and stops it when it is full? You, who are so well qualified for the enquiry, will examine the reasons of this wonderful phenomenon : it will be sufficient for me, if I have given you a clear description of it. Farewell."

The fact of the flow and ebb was reported, in antiquity, of a fountain, the celebrity of which is co-extensive with the prevalence of Christianity itself : - 
"Siloa's brook that flow'd

Fast by the oracle of God."

The puol of Siloam is a reservoir of artificial construction, fifty-three feet long by eighteen broad, into which a small stream flows, and is led off to irrigate the gardens of

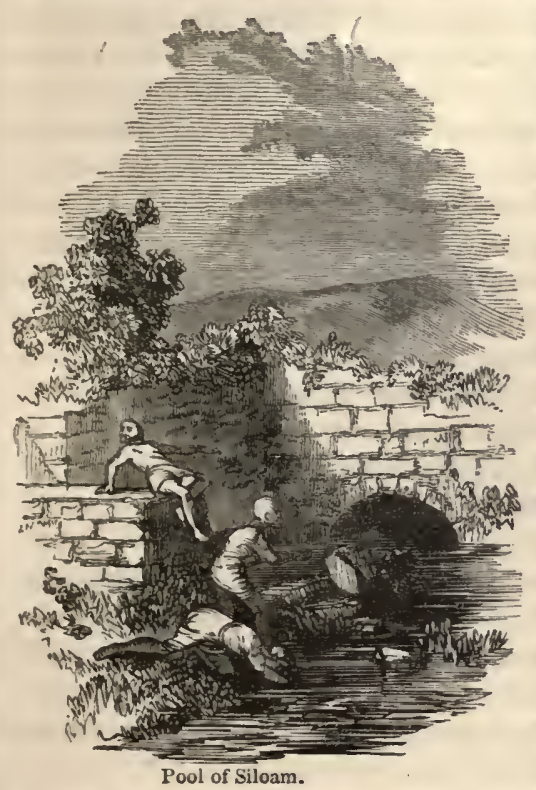
fig and fruit trees that lie along the slope of the Valley of Jehoshaphat. The stream enters the pool through a subterranean channel cut in the solid rock, and comes from the fountain of the Virgin, higher up in the valley. The irregular flow of the water is first distinctly mentioned by Jerome in one of his Commentaries, towards the close of the fourth century, who remarks:"Siloam is a fountain at the foot of Mount Zion, whose waters do not flow regularly, but on certain days and hours, and issue with a great noise from hollows and caverns in the hardest rock." An carlier record in the same century - that of a still extant Itinerary from Bourdeaux to Jerusalemmagnifies this circumstance into a flowing for six days and nights, and a resting on the seventh day; an ancient popular legend, which might originate the statement of the elder Pliny, of there being a river in Judea that dries up on the sabbath day. The popular belief is still firm among the inhabitants of Jerusalem, respecting the flow and $\mathrm{ebb}$ of the water; but most modern travellers seem to have regarded it as an idle story, till Dr. Robinson was enabled to establish its truth. He has given the following account of the event:- "Having been, very unexpectedly, witnesses of the phenomenon in question, we are enabled to rescue another ancient historical fact from the long oblivion, or rather discredit, into which it has fallen for so many centuries. As we were preparing to measure the basin of the upper fountain (in the afternoon of April 30th), and explore the passage leading from it, my companion was standing on the lower step near the water, with one foot on the step and the other on a loose stone lying in the basin. All at once he perceived the water coming into his shoe; and, supposing the stone had rolled, he withdrew his foot to the step, which, however, was also now covered with water. This instantly excited our curiosity; and we now perceived the water rapidly bubbling up from under the lower step. In less than five minutes it had risen in the basin nearly or quite a foot; and we could hear it gurgling off through the interior passage. In ten minutes more it had ceased to flow ; and the water in the basin was again reduced to its former level. Thrusting my staff in under the lower step, whence the water appeared to come, I found that there was here a large hollow space; but no further examination could be made without removing the steps. Meanwhile a woman of Kefr Selwân came to wash at the fountain. She was accustomed to frequent the place every day; and from her we learned that the flowing of the water occurs at irregular intervals; sometimes two or three times a day, and sometimes, in summer, once in two or three days. She said, she had seen the fountain dry, and men and flocks, dependent upon it, gathered around and suffering from thirst; when all at once the water would begin to boil up from under the steps, and (as she said) from the bottom in the interior part, and flow off in a copious stream. In order to account for this irregularity, the common people say " " that a great dragon lies within 
the fountain ; when he is awake, he stops the water ; when he sleeps, it flows." The farfamed pool of Siloam is thus to be classed with the ebbing and flowing wells, though it does not appear that any character of periodicity belongs to the phenomenon.

We have similar examples nearer home. In the diocese of Paderborn, in Westphalia, there is a spring which disappears twice in every twenty-four hours, returning always with considerable noise after six hours, and hence called by the inliabitants the bolderborn, or boisterous spring. Lay Well, near Torbay, also ebbs and flows very visibly, several times every hour, the distance between ligh and low-water mark, according to one observer, being somewhat less than half a foot. Another irregularly reciprocating spring occurs in the neighbourlood of Giggleswick, in Yorkshire, at the foot of the Scar, an almost perpendicular cliff of limestone and gravel, apparently about 150 feet high, and extending above three miles in length. The water discharged from the roek falls immediately into a stone trough, in the front of which are two holes near the bottomthe outlets of two streams that flow constantly from the artificial cistern. An oblong notch is also cut in the same side of the trough, whieh extends from the brim of it nearly to the level of the two holes already mentioned. This aperture is intended to show the fluctuations of the well : for the water subsides in the notch when the stream issuing from the rock becomes languid ; on the contrary, the surface of the water rises again in the notch, so soon as the influx into the trough begins to be more copious. The reciprocations of the spring are easily observed by this contrivance; and they appear to be very irregular, both in respect of duration and magnitude. The interval of time betwixt any two succeeding flows is sometimes greater, and at other times less, than a similar interval which the observer may happen to take for lis standard of comparison. The rise of the water in the cistern, during the time of the well's flowing, is also equally uncertain; for it varies from one incli to nine or ten inches in the course of a few reciprocations. The spring discharges bubbles of air, more or less copiously, into the trough. These appear in the greatest abundanee at the commeneement of the flow, and cease during the ebb, or at least issue from the rock very sparingly at that time. The water is limpid, cold, and wholesome, and has no particular taste. Weeding Well, in the Peak of Derbyshire, otherwise called the Elbbing and Flowing TVell in the locality where it is situated, exhibits the same characteristic. It lies in a field by the road-side in the neighbourhood of Castleton Dale, surrounded with mud and weeds. The motion of the witer depends upon the quantity of rain during the season, and is by no means regular, as it has ceased to flow for several weeks during a drought ; but, in very wet weather, it will flow and ebb more than once in an hour. The time which it continues to flow varies; but it is sometimes four or five minutes, the water appearing at first slightly agitated, and then issuing forth from nine small apertures with a gurgling sound. After remaining stationary, it then ebbs to its ordinary level. The well is seareely inclosed, and has the appearance of a pool; but the height to which it would rise would probably exceed a foot, if the margin were protected so as to prevent the overrunning of the water. It has been known to discharge twenty-three hogsheads in a minute. No theory has yet been proposed to account for the peculiarity of these springs which is perfectly satisfactory; but probably the interposition of columns of gas conveying pressure, somewhat on the principle of Hero's fountain, acts an important part, as well as the common hypothesis of an interior cavity of water discharging itself by a siphon-formed channel.

4. Thermal. Springs characterised by a higher temperature throughout the year than the mean of the latitude where they are situated, abound in active voleanie distriets, as in the Neapolitan territories and Iceland, and are obviously referable to the aetion of subterranean fire. They are frequent also in localities which have been the seenes of volcanic activity in past ages, as in Asia Minor, the neighbourlıood of Rome, and Au- 
vergne. They are found, likewise, in countries far apart from both active and extinct volcanoes, and are probably due to a variety of causes - to the disengagement of subterranean gases powerfully combined with caloric, to the decomposition of mineral substances, and to the internal heat of the globe. There are varieties of pyrites which are converted into sulphate of iron, by the contact of water, an evolution of heat accompanying the change; and supposing a spring to flow tlurough a bed of such pyrites, its waters might become thermal by such a decomposition. It is, however, a well-known fact that the internal temperature of the globe increases with the distance from the surface, and many of the warm springs may be simply occasioned by the superficial waters pereolating through cracks and fissures to an immense depth, where they are variously heated by the high temperature of the interior, according to the extent of their penetration, and returned to the surface before being cooled down. Warm springs occur at Buxton, Stoney Middleton, and Matlock in Derbyshire, which, on account of their properties, and the beautiful localities in which they are situated, annually attract a number of visitors, and verify the remark of Seneca, "wherever warm springs abound, new places of amusement arc sure to rise up." The heat of the Matlock water manges from $66^{\circ}$ to $68^{\circ}$ Fahrenheit; that of Stoncy Middleton, where it is believed the Romans established a bath, is $2^{\circ}$ higher ; while that of the Buxton water is $82^{\circ}$, and never varies at any hour of the day, or season of the year. At the latter spot, some lines are still shown, as those which Mary Queen of Scots is said to have scratched upon one of the windows of the apartment she occupied :-

Buxtona, qua calidx celebrabere nomine lymphx,

Forte mili posthac non adeunda, vale.

"Buxton, farewell! no more perhaps my feet

Thy famous tepid streams shall ever greet."

The south thermal waters of England, in the counties of Gloucester and Somerset, excepting Bristol, have a higher temperature than those of the north division, that of three of the springs of Bath being as follows :- Cross Bath $109^{\circ}$, King's Bath $114^{\circ}$, Hot Bath $117^{\circ}$. It appears somewhat remarkable that the tepid springs of Matlock rise from fifteen to thirty yards above the level of the river Derwent, while those that rise above and below that range are cold; and the common occurrence of hot and cold springs, in close juxtaposition, seems not less anomalous. Homer, in describing the flight of Hector before Achilles, attributes to the Scamander, two fountain-heads, the one hot and the other cold :-

\footnotetext{
“ Next by Scarnander's double source they bound, Where two fam'd fountains burst the parted ground; This hot through scorching clefts is seen to rise, With exhalations streaming to the skies;

That the green banks in summer's heat o'erflows, Like crystal clear, and cold as winter snows."
}

Homer is wrong in assigning such a source to this particular river, which bursts at once from a dark chasm in the Idxan mountains, amid scenery of the grandest description; but the fact of hot and cold springs in the immediate vicinity of each other, blending their waters in one stream, is not an uncommon physical occurrence. The commander of the recent exploring expedition from the United States, Mr. Wilkes, witnessed a remarkable example of this in one of the islands of the Feejee group. On landing, the beach was found absolutely steaming, warm water oozing through the sands and gravel, in some places too hot to be borne by the feet. The springs were five in number, at some distance from the beach, occupying a basin forty feet in diameter. A small rivulet of 
fresh water passed close to the basin, so that one hand might be put into a scalding spring, and the other in water of the temperature of $75^{\circ}$. That of the spring was from $200^{\circ}$ to $210^{\circ}$. The waters joined below, and the united streams stood at $145^{\circ}$, diminishing in temperature until they entered the sea. No gas appeared to be disengaged from the springs, in which the natives customarily boil their food, which is well done in about a quarter of an hour. Strange as it appears to find hot and cold streams pouring from the bosom of the earth within a few paces of each other, their subterranean courses may be far apart, and be prosecuted under widely different circumstances, the one percolating through substances which occasion the erolution of heat, or rising up from an immense depth where it has been heated by interior fires, and the other confined entirely to the superficial strata. When the Romans came into Gaul, they found a warm spring in Provence, which furnished an abundant supply of water, and which received the name of Aquac Sextice, from Sextus Calvinus, who established baths, and laid the foundation of the modern city of Aix upon the spot. Through digging in the neighbourhood, about a thousand paces distant, some cold springs were laid open, and the spring of Sextus gradually diminished, and became perfectly dry. In 1721, the plague then raging at Aix, the physicians declared that the warm spring would be highly beneficial for bathing, and the other springs were accordingly stopped, and in twenty-two days that of Sextus reappeared. It seems evident, therefore, that their waters are identical, cold and hot within the superficial distance of a thousand paces, but their passage from the one point to the other is no doubt that of a descent to a great depth, where the warm temperature is acquired, from whence they remount to the surface.

Thermal springs are common in the Alps and Pyrenees, and in the districts lying around their roots, particularly in the Grand Duchy of Baden, where they have occasionally a very high temperature. The town of Baden was the Civitas Aurelia Aquensis of the Romans, and possesses thirteen warm springs, the principal of which, called the Ursprung, produces $7,500,000$ cubic inches of water in twenty-four hours, with a temperature of $153 \frac{1}{2}^{\circ}$. The temperature of the thermal springs on the northern side of the Alps is - Leuk, twelve springs, varying from $117^{\circ}$ to $126^{\circ}$; Naters, $86^{\circ}$; St. Gervaise, $94^{\circ}$ to $98^{\circ}$; Aix les Bains, $114^{\circ}$ to $117^{\circ}$; Moutiers, $101^{\circ}$; and Brida, $97^{\circ}$. These springs rise near the bottom of the great calcareous formation that covers the northern side of the Alps, and near its junction with the mica slate that covers the granite. Mr. Bakewell refers the temperature of the thermal waters of the Alps and Pyrenees to interior combustion, to the agency of which, the original elevation of the mountains may be due; and the conclusion is supported by the fact, that the districts where the ho: springs are situated, have been subject to great and frequent convulsions, particularly the Haut Vallais, where the temperature of the water is the highest. In the year 1755, at Brieg, Naters, and Leuk, the earth was agitated with earthquakes every day for four months, and some of the shocks were so violent, that the steeples of churches were thrown down, the walls were split, many houses became uninhabitable, and the waters of the Rhone were observed to boil. It is probably true of most hot springs, that they owe their temperature to subterranean fire, as much as those in the neighbourhood of Vesuvius, though occurring in countries where no indications of igneous action are exhibited by the superficial crust of the earth. It is corroborative of this statement, that during the great earthquake that destroyed Lisbon in 1755, the hot springs at Moutiers, in Savoy, ceased to flow for fortyeight hours, and increased in quantity when they flowed again; and similar springs at Töeplitz, in Bohemia, became turbid, then ceased, and subsequently discharged an increased volume of water. At the same time, the temperature of the Source de la Reine, at Bagnères de Luchon, in the Pyrenees, was raised $75^{\circ}$; and the hot springs at Bristol were discoloured. 
The temperature of springs, hot, tepid, and cold, is remarkably uniform, under ordinary circumstances, as measured by the thermometer immersed in the water. But it may apparently vary diumally in tropical countries, like that of rivers and lakes, as estimated by the immersion of the hand-a fact which the ancients converted in one instance into a marvel. Thus wrote Lneretius :-

"A fount, 'tis rumour'd, near the temple purls

Of Jove Ammonian, tepid through the night,

And cold at noon-day ; and th' astonish'd sage

Stares at the fact, and deems the punctual sun

Strikes through the world's vast centre, as the shades

Of midnight shroud us, and with gay reverse

Madden the well-spring : creed absurd and false.

Pliny refers to this fountain, with some exaggeration, as cold in the daytime, and scorching hot at night ; and Ovid likewise :-

"Thy stream, 0 horn-crown'd Ammon ! in the midst
Chills us at noon, but warms at morn and eve."

The reported prodigy is a very common-place occurrence, entirely caused by the strongly contrasted temperature of the air in the Libyan desert, which renders the waters still flowing around the ruined temple of Ammon cooler to the senses by day than by night.

5. Ebullient. - Springs displaying violent ebullition, sending off rast clouds of steam, and throwing up their scalding water to a considerable height in the form of a jet, are the common phenomena of volcanic regions. In the island of St. Michael, one of the Azores, there is a round, deep, and lovely valley, its sides covered with myrtles, laurels, and mountain grapes, with wheat, Indian corn, and poplars waving upon its fields, in which many boiling fountains occur. The principal, called the Caldeira, is on a gentle eminence by the side of a river, and boils with great fury, and the river itself exhibits ebullition in various places, where the water is too hot to be borne by the hand. But the most remarkable of these springs are found in Iceland, and constitute, owing to their diversified appearances, sublime, beautiful, and terrible objects in that strange region, where the extremes of heat and cold, in the form of ice and fire, are in near proximity. They are found in various parts of the island, but the chief are situated in its south-western division, on a plain at the base of a low range of hills, about thirty-six miles from Hecla. Here, within a circle of two miles, above a hundred are contained, some of which boil incessantly, without any discharge of their contents, while others cast their waters high into the air. To the principal of these springs the name of Geyser is applied-a term derived from the Icelandic geysa, signifying to burst forth with vehemence and impetuosity. There are two, more remarkable than the rest, called the Great Geyser and the New Geyser, whose columns of vapour are seen by the traveller long before he reaches their site. "At the distance of several miles," says Henderson, "on turning round the foot of a high mountain on our left, we could descry, from the clouds of vapour that were rising and convolving in the atmosphere, the spot where one of the most magnificent and unparalleled scenes in nature is displayed." The Geysers are intermittent hot springs; and on approaching the Great Geyser, when in a quiet state, it presents the appearance of a large circular mound, formed by the depositions of the fountain. Ascending the mound, a spacious basin is seen, partly filled with hot water, clear as crystal, and gently bubbling. In the centre there is a cylindrical pipe or funnel, about eighty feet in depth, and from eight to ten feet in diameter, widening at the top, and opening gradually into the basin. The inside exhibits a whitish surface, consisting of a siliceous incrustation, which has been rendered smooth by the action of the boiling water. The basin is about 150 feet round; and, when full, the water it contains is about four feet deep, measuring from the surface 
to the commencement of the pipe. The water, occasionally running over the edges of the mound, has acted upon the surrounding peat, mosses, and grass, incrusting them with stone, and furnishing fine specimens of petrifaction.

Such is the Greyser when asleep! The whole scene changes when it is in action, which occurs at irregular intervals. Explosions in the bowels of the earth, like reports of cannon, shake the ground, and warn the visitor to retire to a distance, for they announce an eruption. The water in the basin becomes more and more agitated; it boils furiously: and at last it is suddenly projected into the air, in a suceession of jets, which are at first inconsiderable, but become more powerful, till a magnificent column is sent up to a great height, finishing the display, as though the Geyser, like a thing of life, summoned all her power to dignify her retreat. This is the grandest part of the exhibition. The atmosphere is filled with immense volumes of steam, rolling orer each other as they ascend, through which the columns of water, shivering into foam and spray, are seen spreading in all directions. As the jets rise out of the basin, the water reflects the most beantiful colours - sometimes a pure and brilliant bluc, or a bright sea green; but, in its farther ascent, all distinctness of colour is lost; and the tops of the jets, receiving the rays of the sun, are white as snow: It appears, from the observations of various visitors, that the height of the jets is very irregular, and the power of the Geyser very unequal. In Olafsen and Povelsen's time, the water was carried to the height of three hundred and sixty feet! When seen by Von Troil, in 1772, it rose to ninety-two fect. Sir John Stanley states the highest jet observed by his company, in 1789 , to have been ninety-six feet. Lieutenant Ohlsen, a Danish officer, in 1804, found by a quadrant that the lighest jet rose to two hundred and twelve feet. In $1809 \mathrm{Mr}$. Hooker inentions its rising to upwards of a hundred feet; and Sir George Mackenzie states ninety feet to have been the lieight to which he saw the water thrown in 1810 .

The New Geyser is somewhat different in its external structure from the preceding fountain, but its eruptions are marked with the same characteristic features. The name of Stockr is applied to it by the Icelanders, signifying, to agitate - originally the name of a fountain close by, which, immediately after an earthquake in 1789 , became entirely tranquil, when New Stockr began to erupt. Henderson witnessed the joint eruption of both Geysers, of which he gives the following description:- "About ten minutes past five in the morning we were aroused by the roaring of Stockr, which blew up a great quantity of steam; and when my watch stood at the full quarter, a erash took place as if the earth had burst, which was instantaneously succeded by jets of water and spray, rising in a perpendieular column to the height of sixty feet. As the sun happened to be behind a cloud, we had no expectation of witnessing any thing more sublime than we had already seen. But Stockr had not been in action above twenty minutes, when the Great Geyser, apparently jealous of her reputation, and indignant at our bestowing so much of our time and applause on her rival, began to thunder trẻmendously, and emitted such quantities of water and steam, that we could not be satisfied with a distant view, but hastened to the mound with as much curiosity as if it had been the first eruption we had beheld. However, if she was more interesting in point of magnitude, she gave the less satisfaction in point of duration, having again become tranquil in the course of five minutes; whereas her less gaudy but more steady companion continued to play till witlin four minutes of six o'clock." Henderson mentions the singular fact, that by throwing a great quantity of large stones into the pipe of Stockr, he could awaken the slumbering giant, and bring on an eruption in a few minutes. It has been thought a remarkable circumstance, that the old Icelandic annals should be entirely silent respecting these marvels of the island. An apparent allusion to them occurs in the ancient poem, the Völuspâ, in the Edda:- 
6. At the end of time

The vapours rage (geysar),

And playful flames

Involve the skies."

Ari Frode, the first historiographer of the north, who flourished in the eleventh century, was educated within a mile of the Geysers, yet makes no mention of them; nor are they referred to by a native Icelander, till the time of Svenson, bishop of Skalpolt, in the seventeenth century. But no argument can be founded upon this fact, to prove that

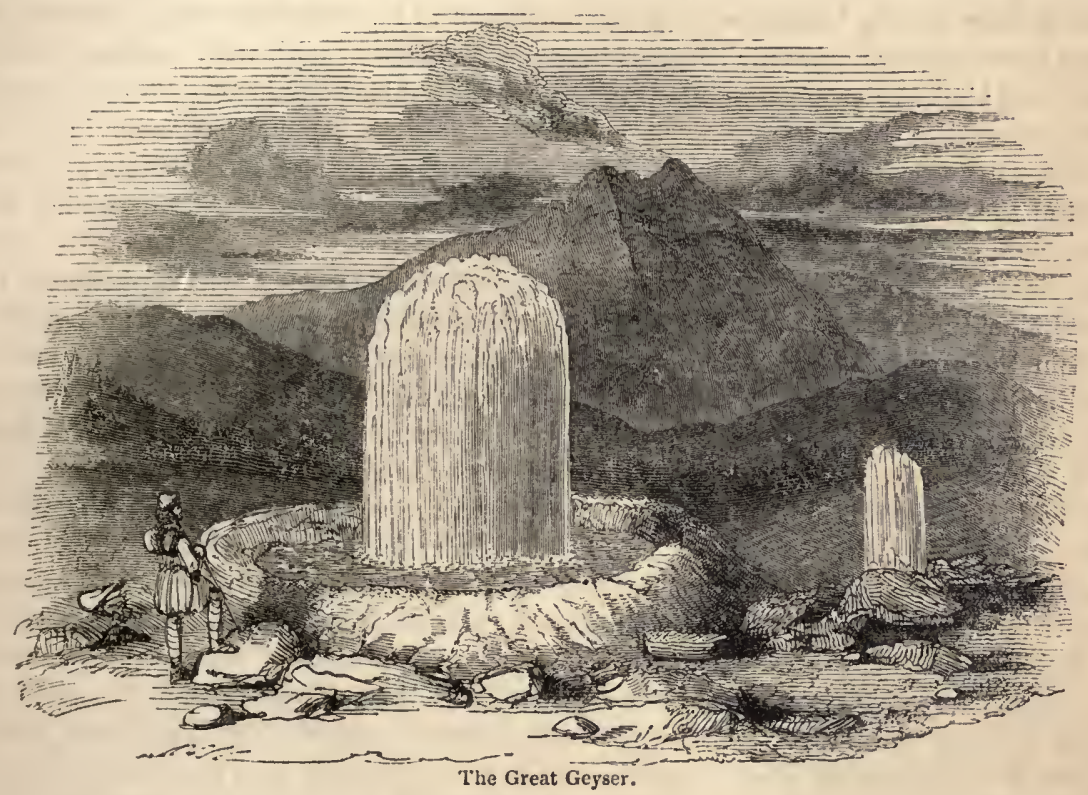

the boiling fountains were not in full play when the first Norwegian colonists tnok possession of the soil, in the ninth century, more than that Hereulaneum and Pompeii were not overwhelmed by the eruption of Vesuvius in the year 79, because Pliny, who saw the voleano explode, who lost his uncle by it, and minutely describes the event, omits all notice of the buried cities - one of the most unaccountable eireumstances in the range of history.

The explanation of these great efforts of nature, given by Sir C. Lyell, is simple and ingenious, founded upon the general supposition of a subterranean cavity where water

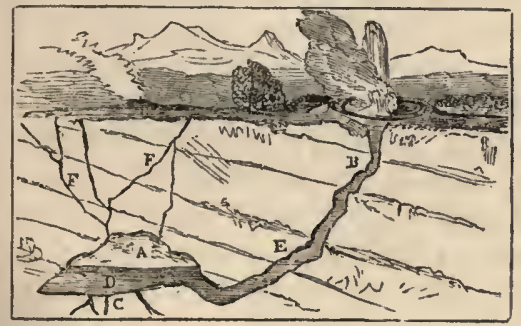
and steam collect, and where the free escape of the steam is prevented till it acquires sufficient force to diseharge the water. He supposes water from the surface of the eartli to penetrate into the cavity $\Lambda \mathrm{D}$ by the fissures $\mathrm{FF}$; while at the same time steam, at an extremely high temperature, rises upwards through the fissures $\mathrm{c} c$. When the steam reaches the cavity, a portion of it is at first condensed into water; and it gradually raises the temperature of the water already there, till at last the lower part of the cavity is filled with boiling water, and the upper part with steam under high pressure. $\Lambda$ s the pressure of the steam increases, its expansive force becomes greater; and at length it forces the 
boiling water up the fissure or pipe $\mathrm{E} \mathrm{B}$, and a considerable quantity runs over the rim of the basin. When the pressure on the steam in the upper part of the cavity is thus diminished, it expands till all the water, $\mathrm{D}$, is driven to $\mathrm{E}$, the bottom of the pipe; and when this happens, the steam rushes up with great velocity, as on the opening of the valve of a steam-boiler. Sir C. Lyell, upon the same principle, accounts for the eruption of volcanoes, referring it to the agency of steam upon melted lava accumulated in cavities in the bowels of the earth - a theory which, though not demonstrable, is invested with a high degree of probability. Incidental notice may here be taken of some springs which appear to boil, but are cold to the touch and to the thermometer. They are occasioned by currents of pure air or gases being in connection with their waters. 'There is one of this kind at Peroul, near Montpellier, which bubbles and heaves up furiously ; and some parts of the river Etang, in the vicinity, exhibit the same appearance. Dr. Robinson found, in several dry places of the ground in that district, many small passages or clefts, at the mouth of which he placed light bodies, such as feathers, straws, and leaves, which were speedily blown aside.

A remarkable spot was visited by Humboldt in South America, where phenomena of a class similar to those of the ebullient springs appeared-the eruption of water, mud, and air from the surface. The scene of this exhibition was near the Indian village of Turbaco, in the neighbourhood of Carthagena $-a$ beautiful district adorned with luxuriant vegetation. After pushing his way through thickets of palm-trees, he reached an open space almost entirely devoid of verdure, called, by the natives, Los Volcanitos. They affirmed that, according to a tradition preserved in the village, the ground had formerly been ignited; but that a monk had extinguished it by frequent applications of holy water, and converted the fire volcano into a water volcano. The volcanitos consistcd of several small truncated cones, having a height of about twenty feet, and their circumference at the base near eighty yards. At the top of each cone there was an aperture, about two feet in diameter, filled with water, through which air-bubbles obtained a passage. Each of the bubbles contained upwards of a cubic foot of elastic fluid; and their power of expansion was often so great, that the water was projected over the brim of the cone. Some openings by which air escaped were observed in the plain, without being surrounded by any prominence of the ground. The natives asserted that there had been no observable change in the form and number of the cones for twenty years, and that the little cavities are filled with water even in the driest seasons. The temperature of the water and mud was not higher than that of the atmosphere; the latter having been $81.5^{\circ}$, and the former $80.6^{\circ}$ or $81^{\circ}$, at the time of Humboldt's visit. A stick could easily be pushed into the apertures to the depth of six or seven feet; and the dark-coloured clay or mud was exceedingly soft. An ignited body was immediately extinguished on being immersed in the gas collected from the bubbles, which was found to be pure azote. Here, botanising in the magnificent woods around, the traveller spent several liappy days with Bonpland-the scientific companion of his journey, afterwards seized by the tyrant Francia - the subject of the following pleasing allusion, written in 1831: "At Turbaco we lived a simple and laborious life. We were young; possessed a similarity of taste and disposition; looked forward to the future with hope; were on the eve of a journey which was to lead us to the highest summits of the Andes, and bring us to volcanoes in action in a country continually agitated by earthquakes; and we felt ourselves more happy than at any other period of our distant expedition. The years which have since passed, not all exempt from griefs and pains, have added to the charms of these impressions; and I love to think that, in the midst of his exile in the southern hemispliere, in the solitudes of Paraguay, my unfortunate friend, M. Bonpland, sometimes remembers with delight our botanical excursions at Turbaco - the little spring of Torecillo - the first sight of 
a Gustavia in flower-or of the Cavanillesia loaded with fruits, having membranous and transparent edges."

6. Inflammable. Springs capable of firing and supporting flame are found in several parts of the globe, and, though not very numerous, they have been known from a very early era. They arise from combination with combustible substances of hydrogen gas. The substance usually found oozing out of the earth, in connexion with their waters, passes under the various names of pitch, naphtha, petroleum or rock oil, and bitumen. Naphtha is the purest state of this substance, which becomes petroleum upon a certain exposure to the air, and bitumen upon a continued exposure to it. The fountain by the temple of Jupiter, at Dodona, was inflammable, according to the account given of it by the Roman natural philosopher and poet Lucretius :-

\footnotetext{
"A fount there is, too, which, though cold itself, With instant flare the casual flax inflames

Thrown o'er its surface; and the buoyant torch Kindles alike immediate, o'er its pool

Steering the course th' etherial breeze propels."
}

Pliny confirms this representation; and if, with Colonel Leake, we suppose Dodona to have been in the valley south of the lake of Ioannina, in Epirus, the statement may be true ; for now, in Illyria and Zante, at no great distance, there are pitch springs; and, in the latter, they were certainly in existence 2300 years ago, as we learn from Herodotus. "In Zacynthus," says the historian, "I saw pitch brought up out of the water of a pond. Indeed there are several of these ponds; but the largest of them is about seventy feet square, and twelve feet deep. The mode of procuring the pitch is the following:- They take a pole, and push it into the water with a myrtle branch at the end; and, on pulling it up, they find the pitch adhering to it, which in smell is like asphaltus, but of a better quality than the common pine pitch. They collect this pitch in a kind of vat or receptacle which they have dug near the pond; and, when the quantity is considerable, they put it in large jars or barrcls." The historian might be describing an operation of the present day, so exactly do the proceedings of the modern Zanteotes correspond with his account. The great region of naphtha springs is to the west of the Caspian, in the territory of Baku, where a scene presents itself alike marvellous and unique. The naphtlia streams spontaneously through the surface, and rises wherever a hole is bored. Speaking of a spot where it most abounds, Colonel Rottiers states :- "It appears to undergo distillation as it ascends to the surface, and thence falls down the sides of the mountains into reservoirs, constructed at some unknown period. It is conjectured, that entire forests of resinous trees were once engulfed by some violent effort of nature, and that their decomposition is the origin of this inflammable liquid. The colour of the oil is black; but it shines with a reddish tint when the sun's rays are upon it." Not far from the same spot he observed a current of white oil gushing out, which readily inflames and burns upon the surface of water ; and in calm weather the people of the country amuse themselves by pouring whole tons of it into a bay of the Caspian. They then set fire to it; and it is borne out of sight, giving the wares the appearance of a sea of fire; and, in comparison with this splendid exhibition, our finest illuminations and fireworks sink into insignificance. Petroleum springs occur in the territory of Modena and Parma, in Sicily, and in the Birman empire, where, in one locality, there are said to be upwards of five hundred wells, yielding annually 400,000 hogsheads. Around the island of Trinidad, also, fluid bitumen oozes from the bottom of the sea, and rises to the surface of the water; while, in the interior of the island, there is a vast collection of bituminous matter, forming a great pitch-lake, with frequent crevices and chasms filled with water. The origin of the substance in this locality is referred by some writers to the immense quan- 
tities of woody and vegetable bodies brought down in the course of ages by the river Orinoco, which, becoming arrested in particular plaees by the influence of currents and eddies, and subject to the ageney of subterranean fire in this region of voleanie action, have undergone those transformations and chemical changes which produce petroleum, converted into pitch upon being foreed up to the surface and exposed to the air. There are waters, however, uneonnected with bitumen, from whose surfaces flames dart out, without the liquid being at all hot. 'These contain inflammable gases, disengaged from masses of iron, zine, and tin, dissolved by sulphuric and muriatie acids. Such are the fountains of Poretta Nuova, and a brook near Bergerae, which may be kindled by a lighted straw. Similar springs have appeared near Wigan in Laneashire, and Brosely in Salop, by the banks of the Severn.

7. Mineralised. Water is seldom found in a pure state, that is, without colour, taste, or odour. It is generally met with possessing these properties; and even when its odour is not eognizable by man, the keener sense of the eamel will scent it afar off in the desert. Rain water is impregnated with whatever forcign ingredients may exist in the atmosphere through which it descends; and spring water, besides betraying the ingredients usually found in the rains from which it proeeeds, beeomes charged with a variety of substances and gases in percolating through the superficial strata of the earth. When these are present in an extraordinary degree, so as to produce some sensible effeet upon the animal economy, the springs so constituted are termed mineral, and are both cold and thermal. The mineral waters may be grouped generally into the four following classes, and oceur at the places annexed to them:-

Saline Aperient Waters. - In Germany, at Carlsbad, Marienbad, Egra, Kissengen,

Wiesbaden, Baden-Baden, Seidlitz, and I'ullna. In England, at Cheltenham, Lea-

mington, Harrowgate, Northwich, Epsom, and Ashby-de-la-Zoucl. In Scotland, at Dumblane and Piteaitlly.

Alkaline Waters. - In Germany, at Carlsbad, Marienbad, Ǩissengen, Pullna, Saidschutz,

Ems, Töplitz, and Wiesbaden. In England, at Harrowgate, Scarborough, Cheltenliam,

Leamington, and Bath. In France, at Vichy and Mont d'Or.

Chalybeate and Acidulous Waters. - In Germany, at Spa, Pyrmont, Schwalbach, Marienbad, Aix-la-Chapelle, and Seltzer. In England, at Tonbridge, Harrowgate, and Brighton. In Seotland, at Peterhead.

Sulphureous Waters. - In Germany, at Aix-1a-Chapelle. In the Pyrenees, at Bareges.

In England, at Harrowgate, Askern, and Kedleston. In Scotland, at Moffat and Strathpeffer. The foreign sulphureous springs mentioned are hot; the domestic, cold.

The waters of many of the chalybeate springs frequently loold in solution so large a quantity of iron, as to encase with a ferruginous deposit the channels through whieh they pass, depriving of their natural green the mosses and grasses which are laved by the stream, and covering them with a yellow inerustation. The brine springs of Northwich, which rise up through beds of rock-salt, are also so fully saturated, as to yield an annual supply of upwards of forty thousand tons of salt manufactured from them, besides the large quantity taken from the mines. But of all mineral ingredients, lime combined with carbonic acid occurs in the greatest abundance in springs, some of which are thermal. The deposition of the ealcareous matter held in solution takes place when the acid is dissipated in the atmosphere, and extensive formations are produced. So rapid is the precipitation of earbonate of lime at the hot baths of St. Vignone, in Tuseany, that half a foot of solid travertine is the annual product near their source. The hot waters of Hierapolis have been similarly produetive. This city, now a site of desolate ruins, was formerly one of the most flourishing in Asia Mlinor, and was resorted to for its thermal 



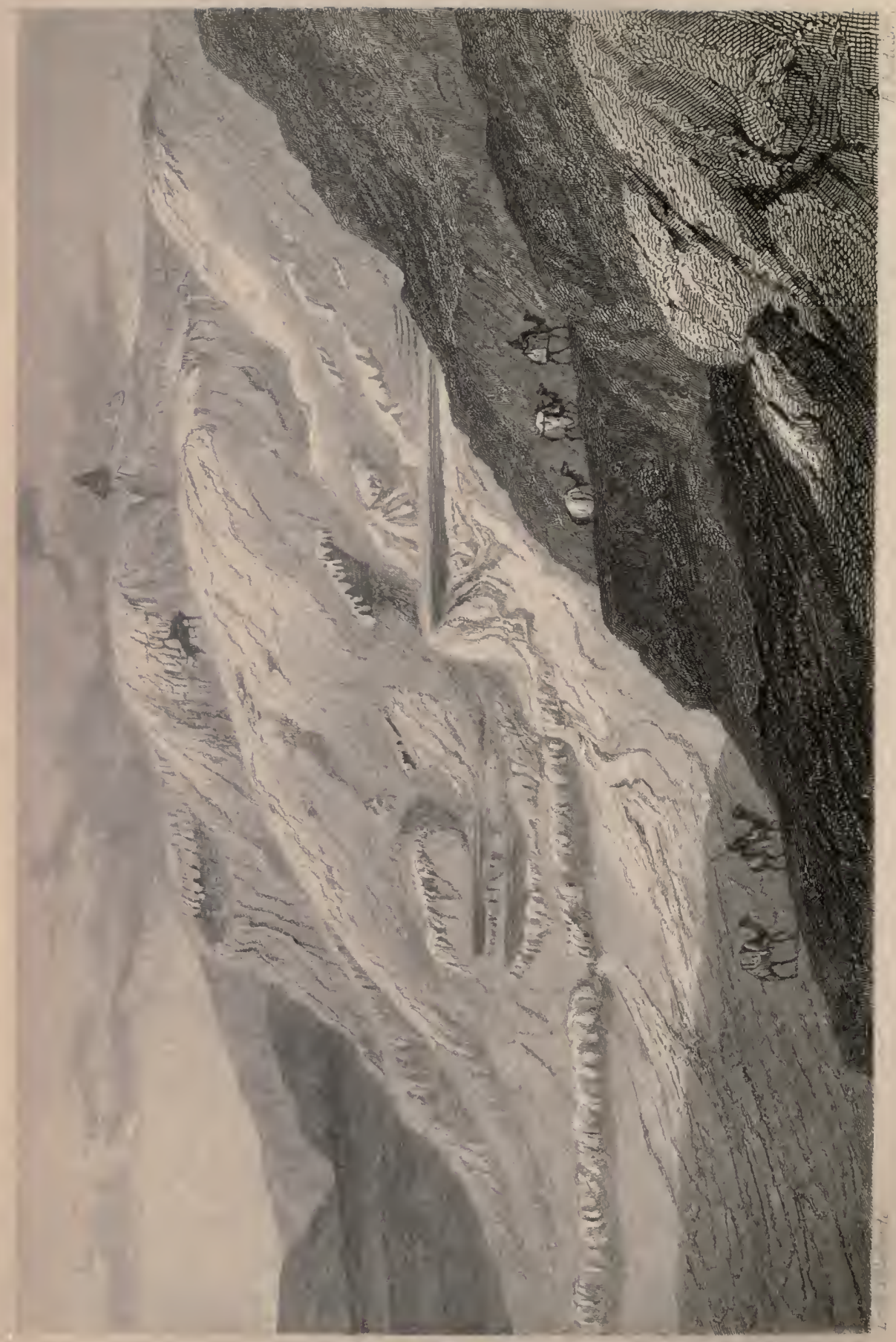

है 
springs, celebrated in a still extant inscription:- "Hail golden city Hierapolis! the spot to be preferred before any in wide Asia, revered for the rills of the nymphs, adorned with splendour!" The ancients speak of the transforming power of the waters, and relate that being conducted about the vineyards and gardens, the channels beeame long fences, each a single stone. There is now a powerful hot spring feeding numerous rills, and a caleareous cliff, an entire deposition from it. The occurrence of petrifactions, which puzzled science a eentury ago, and which rustic ignorance aceepted as instances of the real transmutation of different objects into stones, is now well known to arise from the deposition upon them of the earthy ingrcdients of the waters to which they are exposed, investing them with a calcareous or siliceous crust. The Dripping Well at Knaresborough, on the

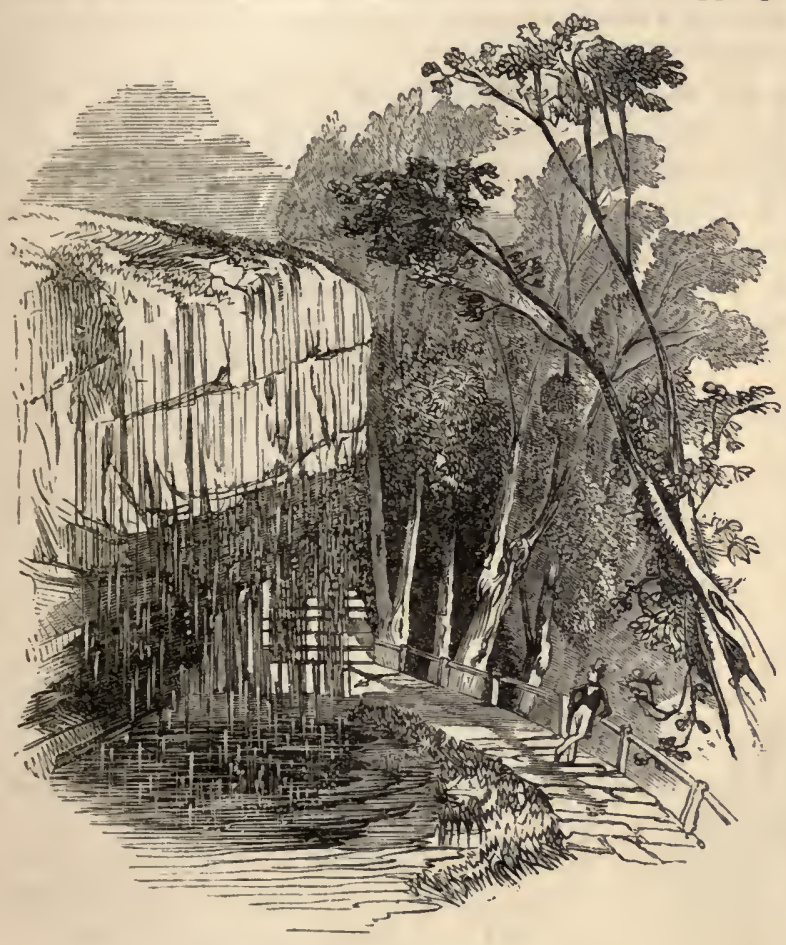

Dripping Well, Knaresborough. banks of the Nidd, often visited on aceount of its inviting scenery, and the eave of Eugene Aram in the neiglbourhood, is a curious petrifying spring; and at the Matlock Wells the process of petrification is shown, objects which are put into them becoming soon encrusted with the limestone precipitated from the water as it evaporates. A considerable number of springs liase recently been found to contain iodine or bromine. 'Those which issue from the lias at Leamington, Gloucester, 'Tewkesbury, and Cheltenham, contain iodine. 'The saline aperient waters of Epsom contain a small quantity of bromine, which is also found in the springs from the coal formation of $\Lambda$ sliby-de-la-Zouch, Neweastle, and Kingswood. In several European springs, a remarkable animal substance

has been detected, termed glairine, which may be derived from strata containing animal fossil remains, througl which the water pereolates.

Such are the chief peculiarities of the subject of this chapter. No apology need be oflered for devoting so much space to it; for, however incompetent to explain all the plienomena, there can be no difference of opinion as to the ligh interest and practical utility of the phenomena themselves. The springs are the sources of the rivers which fertilise the soil through which they flow, and form the navigable channels which offer nations a convenient medium of intereommunication. To the geologist, they speak in the language of comment respecting the interior constitution of the globe, by their occasional high temperature and mineral composition, and the mode in which many of its strata have been produced, by the solid products in course of formation from their waters. The medicinal virtue of their streams is also a beneficial item of no mean importance; and whether welling through the loose sand and stony pavemcnt of the Arabian desert, or breaking 
forth at the grassy foot of a grove-crowned hill, the fountains of the earth are inviting objects of contemplation, through their association with the ideas of purity and benevolence, independently of being beautiful parts of natural scenery. Hence we may sympathise with the sentiment that inspired the ancient song of the Well, and regard as an appropriate homage, when under due restraints, that principle of veneration for the waters which pervaded the mind of all antiquity, and has survived in some rural customs to the present day. Milton, in his Comus, alludes to the honours formerly paid to the Severn :

" The shepherds at their festivals

Carol her good deeds loud in rustic lays,

And throw sweet garland wreaths into her stream,

Of pansies, pinks, and gaudy daffodils."

There is an elegant custom still observed by the villagers of Tissington, in Derbyshire, of a similar kind-that of dressing their wells with flowers on Ascension day. There are five copious springs issuing out of the limestone, which are decorated with boughs of laurel and white thorn, interspersed with the flowers of the season, arranged in various patterns and inscriptions. The effect is singularly beautiful; and the procession of the peasantry to sing at each well-a graceful usage handed down from a remote age - forms a very agreeable spectacle.

\section{CHAPTER VI.}

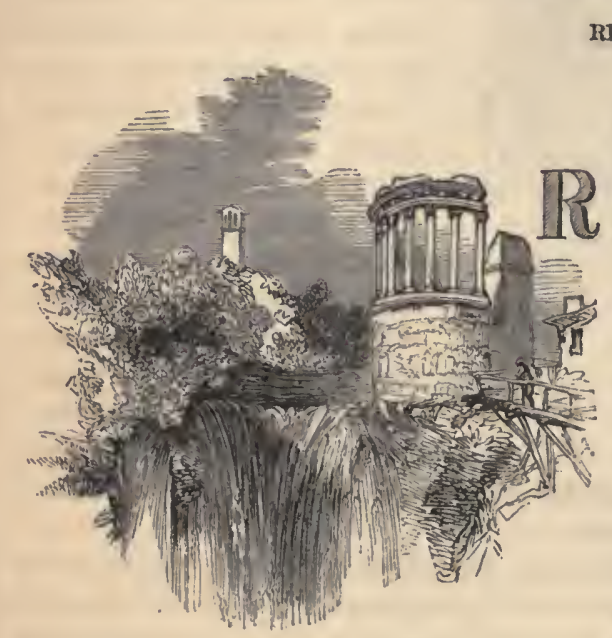

RIVERS.

IVERS constitute an important part of the aqueous portion of the globe. With their tributaries, the small streams and rivulets, they form a numerous family, of which lakes, springs, or the meltings of ice and snow, upon the summits of high mountain chains, are the parents. The Shannon has its source in a lake; the Rhone in a glacier; and the Abyssinian branch of the Nile in a confluence of fountains. The country where some of the mightiest rivers of the globe have their rise, has not yet been sufficiently explored to render their true source ascertainable. The origin of others is doubtful, owing to a number of rills presenting equal claims to be considered as the river-head; but many are clearly referable to a single spring, the current of which is speedily swelled by tributary waters, ultimately flowing in broad and deep channels to the sea. Inglis, who wandered on foot through many lands, had a fancy, which he generally indulged, to visit the sources of rivers, when the chances of his journeys threw him in their vicinity. Such a pilgrimage will often repay the traveller by the scenes of picturesque and secluded beauty into which it leads him; and even when the primal fount is insignificant in itself, and the surrounding landscape exhibits the tamest features, there is a reward in the associations that are instantly wakened up - 
the thought of a humble and modest commencement issuing in a long and victorious career - of the tiny rill, proceeding, by gradual advances, to become an ample stream, fertilising by its exudations, and rolling on to meet the tides of the ocean, bearing the merchandise of cities upon its bosom. The Duddon, one of the most picturesque of the English rivers, oozes up through a bed of moss near the top of Wrynose Fell, a desolate solitude, yet remarkable for its luge masses of protruding crag, and the varied and vivid colours of the mosses watered by the stream. Petrarch's letters and verses have given celebrity to the source of the Sorgues - the spring of Vaucleuse, which bursts in an imposing manner out of a cavern, and forms at once a copious torrent. The Scamander is one of the most remarkable rivers for the grandeur of its source- a yawning chasm in Mount Gargarus, shaded with enormous plane-trees, and surrounded with high cliffs, from which the river impetuously dashes in all the greatness of the divine origin assigned to it by ancient fable. To discover the source of the Nile, hid from the knowledge of all antiquity, was the object of Bruce's adventurous journey; and we can readily enter into his emotions, as he stood by the two fountains, after all the toils and hazard he had braved. "It is easier to guess," he remarks, "than to describe the situation of my mind at that moment-standing in that spot which had bafled the genius, industry, and inquiry of both ancients and moderns, for the course of three thousand years. Kings had attempted this discovery at the head of armies; and each expedition was distinguished from the last, only by the difference of the numbers which had perished, and agreed alone in the disappointment which had uniformly, and without exception, followed them all. Fame, riches, and honour, had been held out for a series of ages to every individual of those myriads these princes commanded, without having produced one man capable of gratifying the curiosity of his sovereign, or wiping off this stain upon the enterprise and abilities of mankind, or adding this desideratum for the encouragement of geography. Though a mere private Briton, I triumphed here, in my own mind, over kings and their armies; and every comparison was leading nearer and nearer to presumption, when the place itself where I stood - the object of my vain-glory - suggested what depressed my short-lived triumphs. I was but a few minutes arrived at the sources of the Nile, through numberless dangers and sufferings, the least of which would have overwhelmed me, but for the continual goodness and protection of Providence; I was, however, but then half through my journey; and all those dangers, which I had already passed, awaited me again on my return. I found a despondency gaining ground fast upon me, and blasting the crown of laurels I had too rashly woven for myself." Bruce, however, laboured under an error, in supposing the stream he had followed to be the main branch of the Nile. He had traced to its springs the smaller of the two great rivers which contribute to form this celebrated stream. The larger arm issues from a more remote part of Africa, and has not yet been ascended to its source.

Upon examining the map of a country, we see many of its rivers travelling in opposite directions, and emptying their waters into different seas, although their sources frequently lie in the immediate neighbourhood of each other. The springs of the Missouri which proceed south-east to the Gulf of Mexico, and those of the Columbia which flow north-west to the Pacific Ocean, are only a mile apart, while those of some of the tributaries of the Amazon flowing north, and of the La Plata flowing south, are closely contiguous. There is a part of Volhynia, of no considerable extent, which sends off its waters, north and south, to the Black and Baltic seas; while, from the field on which the battle of Naseby was fought, the Avon, Trent, and Nen receive affluents, which reach the ocean at opposite coasts of the island, through the Humber, the Wash, and the Bristol Channel. The field in question is an elevated piece of table-land in the centre of England. The district referred. to, where rivers proceeding to the Baltic and the Euxine take their rise, is a plateau about 
a thousand feet alove the level of the sea. The springs of the Missouri and the Colurnbin are in the Rocky Mountains; and it is generally the case, that those parts of a country from which large rivers flow in contrary directions, are the most elevated sites in their respeetive distriets, consisting either of mountain-chains, plateaus, or high table-lands. There is one remarkable exception to this in European Russia, where the Volga rises in a plain only a few hundred feet above the level of the sea, and no hills separate its waters from those which run into the Baltic. 'The great majority of the first-class rivers commence from chains of mountains, beeause springs are there most abundant, perpetually fed by the melting of the snows and glaciers. They have almost invariably an easterly direction, the westward-bound streams being few in number, and of very subordinate rank. Of rivers flowing east, we have grand examples in the St. Lawrence, Orinoco, $\Lambda$ mazon, Danube, Ganges, Amour, Yang-tse-Kiang, and Hoang Ho. The chief western streams are the Columbia, Tagus, Garonne, Loire, and Neva, which are of far inferior rank to the former. The rivers running south, as the Mississippi, La Plata, Rhone, Volga, and Indus, are more important, as well as those which proceed to the north, as the Rhine, Vistula, Nile, Irtish, Lena and Yenisei. The easterly direetion of the great rivers of America is obviously due to the position of the Andes, which run north and south, on the western side of the continent, while the chain of mountains which traverses Europe and $\Lambda$ sia, from west to east, causes the great number of rivers which flow north and south. In our own island, the chief course of the streans is to the east. This is the case with the 'Tay, Forth, 'Tweed, Tyne, Humber, and Thames, the Clyde and Severn being the most remarkable exeeptions to this direction. 'The whole extent of country from which a river receives its supply of water, by brooks and rivulets, is termed its basin, beeause a region generally bounded by a rim of high lands, beyond which the waters are drained off into another channel. The basin of a superior river includes those of all its tributary streams. It is sometimes the case, however, that the basins of rivers are not divided by any elevations, but pass into each other, a connection subsisting between their waters. 'This is the ease with the hydrographical regions of the Amazon and Orinoco, the Cassiquiaire, a branch of the latter, joining the Rio Negro, an affluent of the former. The vague rumours that were at first afloat respecting this singular circumstance, were treated by most geographer's with diseredit, till Humboldt aseertained its reality, by proceeding from the Rio Negro to the Orinoco, along the natural canal of the Cassiquiaire.

Rivers have a thousand points of similarity, and of discordance. Some exhibit an unbroken sheet of water through their whole course, while others are diversified by numerous islands. This peculiarly characterises the vast streams of the American continent, and contributes greatly to their scenical effect, of which our illustration gives us an example, selected from the beautiful Susquehanna, the largest Atlantic river of the United States. The St. Lawrence, soon after issuing from the Lake Ontario, presents the most remarkable instance to be found of islands oceurring in a river-ehannel. It is here called the Lake of the Thousand Islands. The vast number implied in this name was considered a rague exaggeration, till the commissioners employed in fixing the boundary with the United States actually counted them, and found that they amounted to 1692 . They are of every imaginable size, shape, and appearance; some barely visible, others covering fifteen acres; but in general their broken outline presents the most picturesque combinations of wood and rock. The navigator in steering through them sees an ever-changing scene, which reminds an elegant writer of the Happy Islands in the Vision of Mirza. Sometimes he is enclosed in a narrow channel; then he discovers before him twelve openings, like so many noble rivers; and soon after a spacious lake seems to surround him on every side. River-islands are due to original surface 


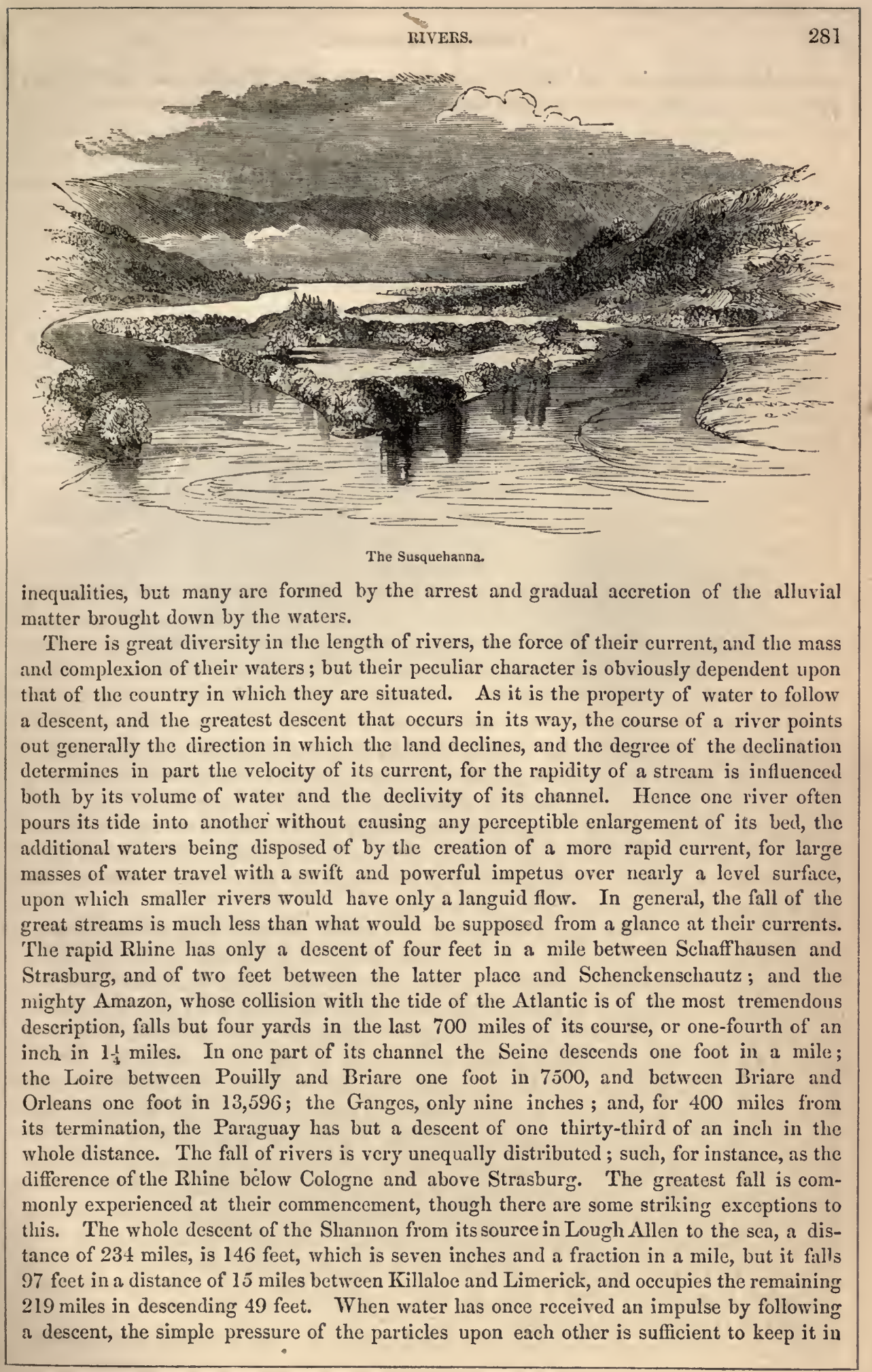


motion long after its bed has lost all inclination. The chief effect of the absence of a declivity is a slower movement of the stream, and a more winding course, owing to the

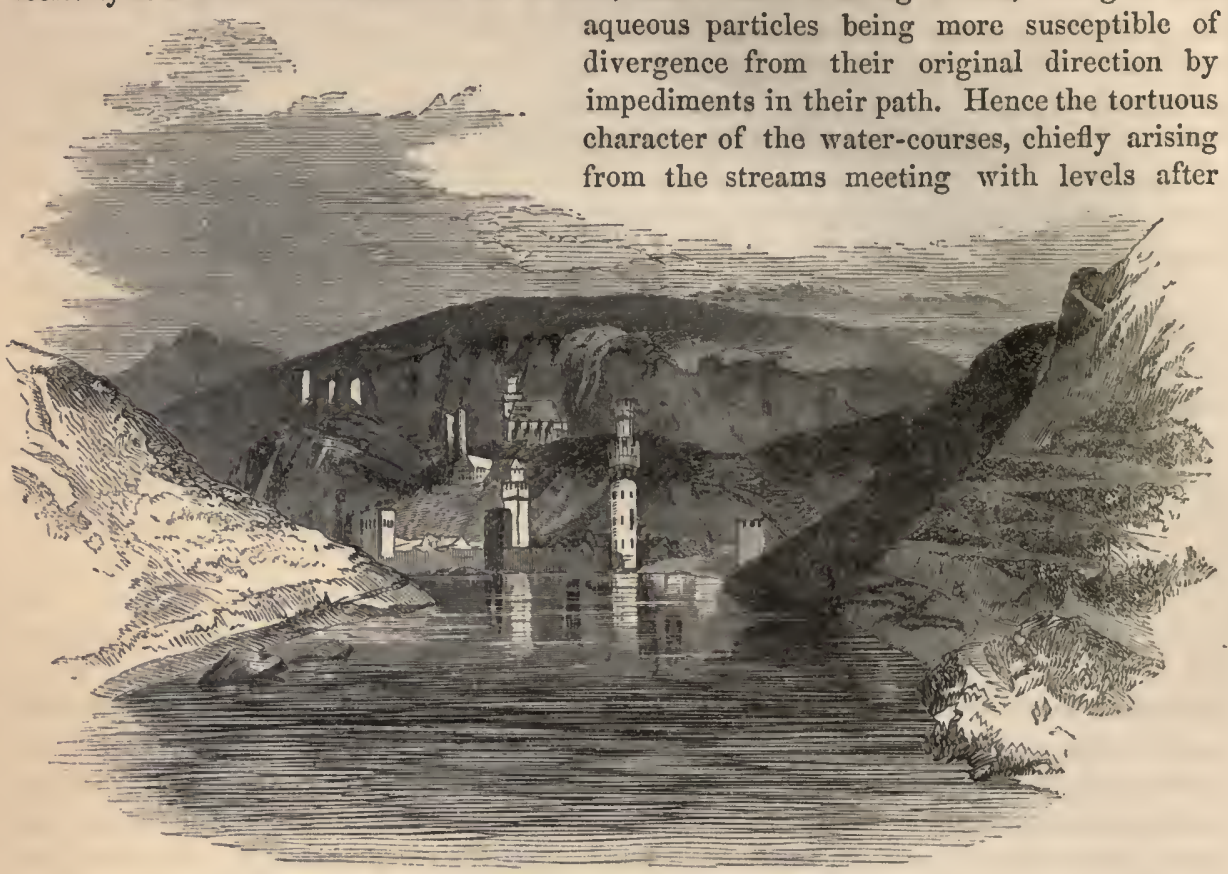

The Rhine at Oberweisel.

descending inclined planes, which so slackens their speed that they are easily diverted from a right-onward direction by natural obstacles, to which the force of their current is inferior. The Mæander was famed in classical antiquity for its mazy course, descending from the pastures of Phrygia, with many involutions, into the vine-clad province of the Carians, which it divided from Lydia near a plain properly called the Mæandrian, where the bed was winding in a remarkable degree. From the name of this river we have our word meandering, as applied to erratic streams.

This circumstance increases prodigiously the extent of their channels, and renders their navigation tedious, but the absence of that velocity of the current which would make it difficult is a compensation, while a larger portion of the earth enjoys the benefit of their waters. The sources of the Mississippi are only 1250 miles from its mouth, following a straight line, but 3200 miles, pursuing its real path; and the Forth is actually three times the length of a straight line drawn from its rise to its termination. The rivers which flow through flat alluvial plains frequently exhibit great sinuosities, their waters returning nearly to the same point, after an extensive tour. The Moselle, after a curved course of seventeen miles, returns to within a few hundred yards of the same spot; and a steamer on the Mississippi, after a sail of twenty-five or thirty miles, is brought round again, almost within hail of the place where it was two or three hours before. In high floods, the waters frequently force a passage through the isthmuses which are thus formed, converting the peninsulas into islands, and forming a nearer route for the navigator to pursue. By the "grand cut off" on the Mississippi, vessels now pass from one point to another in half a mile, in order to accomplish which they had formerly a distance of twenty miles to traverse.

Rivurs receive a peculiar impress from the geological character of the districts through 
which they flow. Those of primary or transition countries, where sudden declivities abound, are bold and rapid streams, with steep and high banks, and usually pure waters, owing to the surface not being readily abraded, generally emptying themselves by a single mouth which is deep and unobstructed. The streams of secondary and alluvial districts flow with slow but powerful current, between low and gradually descending banks, which, being composed of soft rocks or alluvial grounds, are ensily worn away by the waters, and hence great changes are effected in their channels, and a peculiar colour is given to their streams by the earthy particles with which they are charged. Many rivers have their names from this last circumstance. The Rio Negro, or Black River, which flows into the Amazon, is so called on account of the dark colour of its waters, which are of an amber hue wherever it is shallow, and dark brown wherever the depth is great. The names of the two great streams which unite to form the Nile, the Bahr-el-Abiad, or White River, from the Mountains of the Moon, and the Bahr-el-Azrek, or Blue River, from Abyssinia, refer to the colour which they receive from the quantity of earth with which they are impregnated. The united rivers, for some distance after their junction, preserve their colours distinct. This is the case likewise with the Rhine and the Moselle, the St. Lawrence and the Ottawa. The Upper Mississippi is a transparent stream, but assumes the colour of the Missouri upon joining that river, the mud of which is as copious as the water can hold in suspension, and of a white soapy hue. The Ohio brings into it a flood of a greenish colour. The bright and dark red waters of the Arkansas and Red River afterwards diminish the whiteness derived from the Missouri, and the volume of the Lower Mississippi bears along a tribute of vegetable soil, collected from the most distant quarters, and of the most various kind, - the marl of the Rocky and the clay of the Black Mountains - the earth of the Alleghanies - and the red-loam washed from the hills at the sources of the Arkansas and the Red River. Mr. Lyell states that water flowing at the rate of three inches per second will tear up fine clay; six inches per second, fine sand; twelve inches per second, fine gravel; and three feet per second, stones of the size of an egg. He remarks, likewise, that the rapidity at the bottom of a stream is every where less than in any part above it, and is greatest at the surface; and that in the middle of the stream the particles at the top move swifter than those at the sides. The ease with which running water bears along large quantities of sand, gravel, and pebbles, ceases to surprise, when we consider that the specific gravity of rocks in water is much less than in air.

It is chiefly in primary and transition countries that the rivers exhibit those sudden descents, which pass under the general denomination of falls, and form either cataracts or rapids. They occur in secondary regions, but more rarely, and the descent is of a more gentle description. The falls are generally found in the passage of streams from the primitive to the other formations. Thus the line which divides the primitive and alluvial formations on the coast of the United States, is marked by the falls or rapids of its rivers, while none occur in the alluvium below. Cataracts are formed by the descent of a river over a precipice which is perpendicular, or nearly so, and depend, for their sublimity, upon the height of the fall, and the magnitude of the stream. Rapids are produced by the occurrence of a steeply-inclined plane, over which the flood rushes with great impetuosity, yet without being projected over a precipice. The great rivers of England - the Thames, Trent, and Severn - exhibit no example of either cataract or rapid, but pursue a generally even and noiseless course; though near their sources, while yet mere brooks and rivulets, most of our home streams present these features in a very miniature manner. A true rapid occurs in the course of the Shannon, just above Limerick, where the river, forty feet deep, and three hundred yards wide, pours its body of water through and above a congregation of huge rocks and stones, extending nearly half 
a mile, and beeomes quite umnavigable. Inglis had never heard of this rapid before arriving in its neighbourhood; but ranks it, in grandeur and effect, above either the Welsh waterfalls, or the Geisbach in Switzerland. The river Adige, in the Tyrol, near Meran, rushes, with resistless force and deafening noise, down a deseent nearly a mile in length, between quiet, green, pastoral banks, presenting one of the most magnificent spectacles to be met with in Europe. The celebrated cataracts of the Nile are, more properly speaking, rapids, as there is no considerable perpendicular fall of the river; but for a hundred miles at Wady IIafal, the second eataract reckoning upwards, there is a succession of steep descents, and a multitude of rocky islands, among which the river dashes amid clouds of foam, and is tossed in perpetual eddies. It is along the course of the American rivers however that the most sublime and imposing lapids are found, rendered so by the great volumes of water contained in their channels. The more remarlable are those of the St. Lawrence, the chief of which, called the Coteau du Luc, the Cedars, the Split Rock, and the Caseades, occur in suecession for about nine miles above Montreal and the junction of the Ottawa. At the rapid of St. Anne, on the latter river, the more devout of the Canadian voyageurs are aecustomed to land, and implore the protection of the patron saint on their perilous expeditions, before a large cross at the village that bears her name. The words of a popular song have familiarised English ears with this habit of the hardy boatmen :-

" Faintly as tolls the evening chime, Our voices keep tune and our oars keep time. Suon as the woods on shore look dim, We'll sing at St. Ann's our parting hymn. Row, brothers, row, the streim runs fast, The Rapids are near, and the daylight's past.

"Utawa's tide I this trembling moon Shall see us float over thy surges soon. Saint of this green isle hear our prayers, Oh grant us cool heavens and favouring airs. Blow, breezes, blow, the stream runs fast, The Rapids are near, and the daylight's past."

The Kaaterskill Falls here represented are celebrated in America, for their picturesque beauty. The waters which
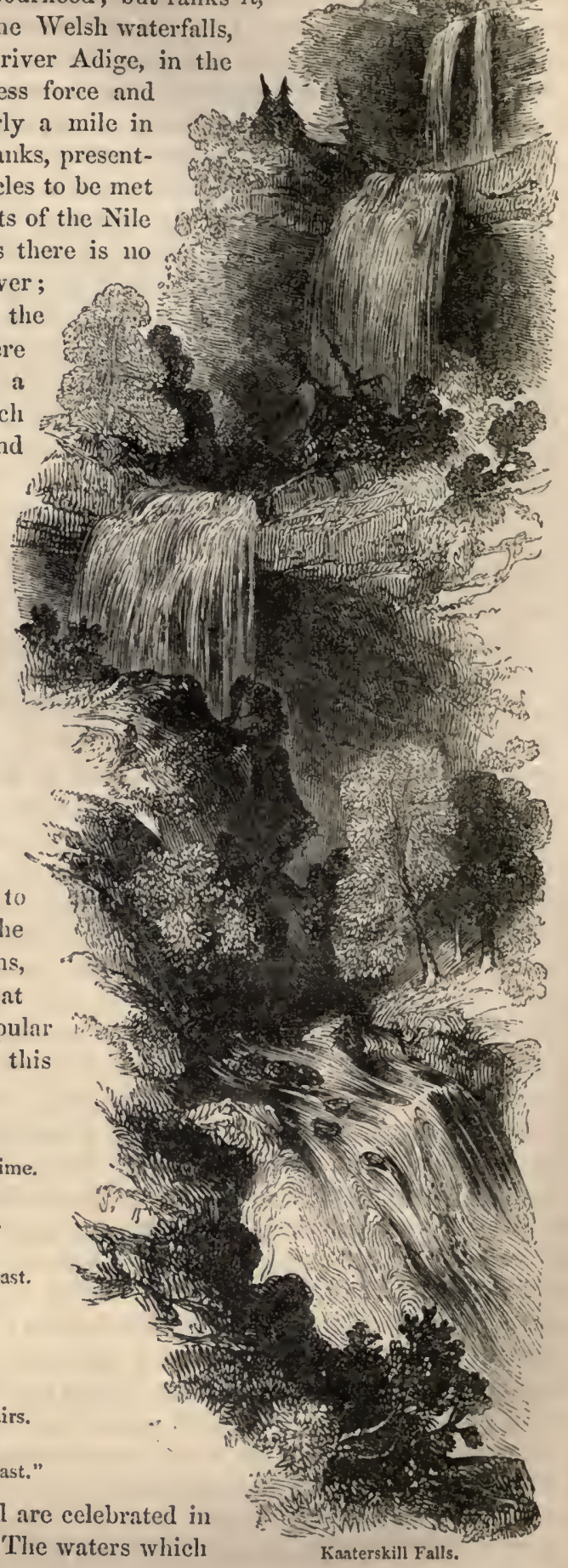
supply these cascades flow from two small lakes in the Catskill Mountains, on the West Bank of the Hudson. The upper cascade falls one hundred and seventy-five feet, and a few rods below, the second pours its waters over a precipice eighty feet high, passing into a picturesque ravine, the banks of which rise abruptly on each side to the height of a thousand or fifteen hundred feet.

In the grandeur of their cataracts, also, the American rivers far surpass those of other countries, though several falls on the ancient continent have a greater perpendicular height, and are magnificent objects. In Sweden, the Gotha falls about 130 feet at Trolhetta, the
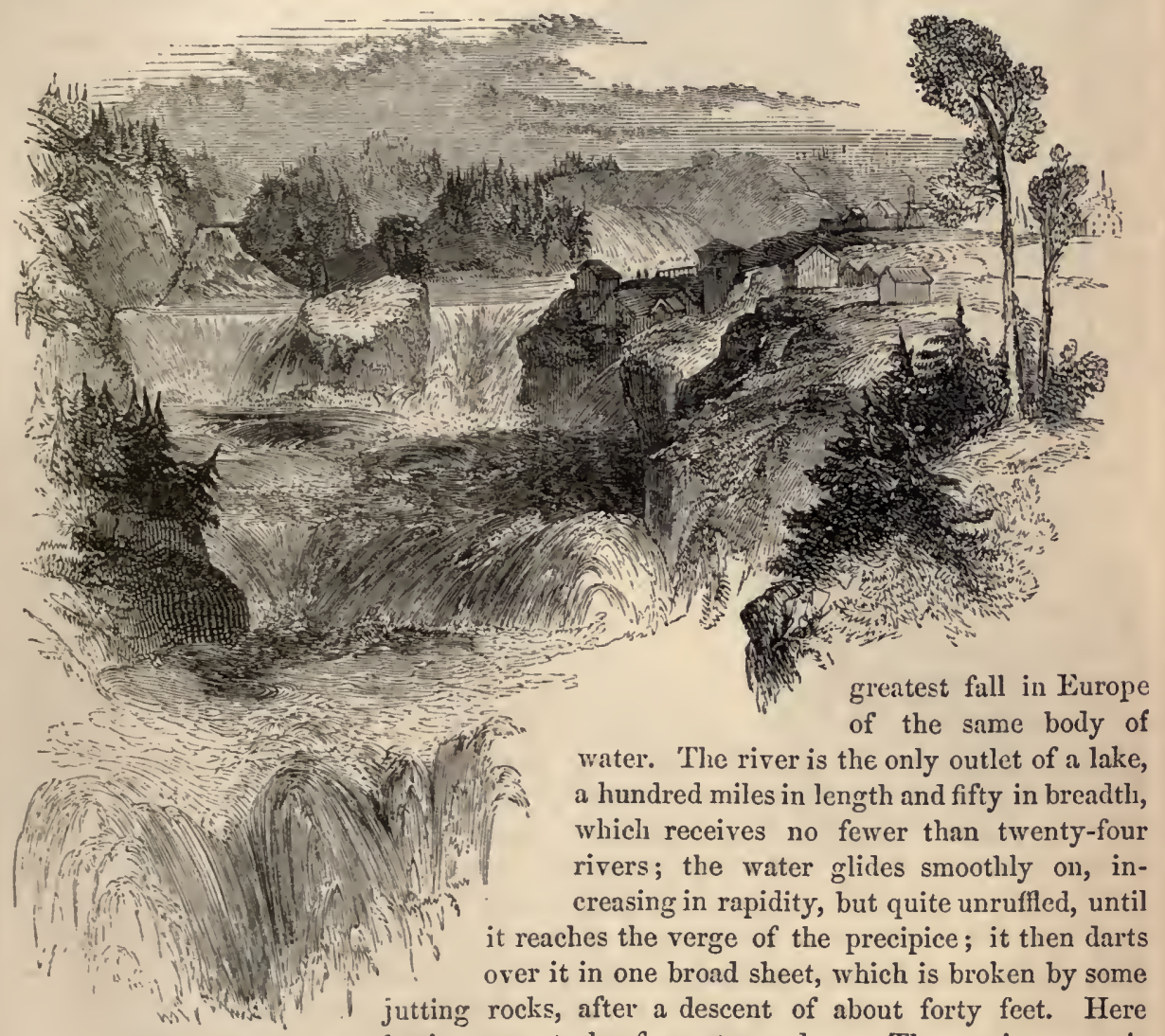

water. 'The river is the only outlet of a lake, a hundred miles in length and fifty in breadth, which receives no fewer than twenty-four rivers; the water glides smoothly on, increasing in rapidity, but quite unruffled, until it reaches the verge of the precipice; it then darts over it in one broad sheet, which is broken by some Falls of Trolhetta. begins a spectacle of grent grandeur. The moving mass is tossed from rock to rock, now heaving itself up in yellow foam, now boiling and tossing in huge eddies, growing whiter and whiter in its descent, till, completely fretted into one beautiful sea of snowy froth, the spray, rising in dense clouds, hides the abyss into which the torrent dashes; but when momentarily cleared away by the wind, a dreadful gulf is revealed, which the eye cannot fathom. Upon the arrival of a visitor at Trolhetta, a $\log$ of wood is sent down the fall, by persons who expect a trifle for the exhibition. It displays the resistless power of the element. 'The $\mathrm{log}$, which is of gigantic dimensions, is tossed like a feather upon the surface of the water, and is borne to the foot almost in an instant. In Scotland the falls of its rivers are seldom of great size; but the rocky beds over which they roar and dash in foam and spray - the dark precipitous glens into which they rush - and the frequent wildness of the whole scenery around, are compensating features. The most remarkable instances are 
the Upper and Lower Falls of Foyers, near Loch Ness. At the upper fall, the river precipitates itself, at three leaps, down as many precipices, whose united depth is about 200 feet; but, at the lower, it makes a descent at once of 212 feet, and, after heavy rains, 7. 70 . Rhine at Schaffhausen is only 70 feet; but the
great mass of its waters, 450 feet in breadtl,
gires it an imposing character. The Tegives it an imposing character. The Te-
verone, near Tivoli, a comparatively small (1) 1 (I) stream, is precipitated nearly 100 feet: . 5 and the Velino, near Terni, falls 300. which is generally considered the finest
of the European cataracts. This " hell

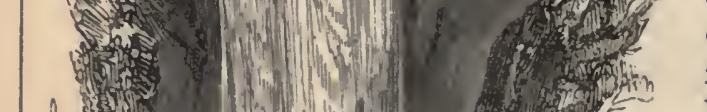

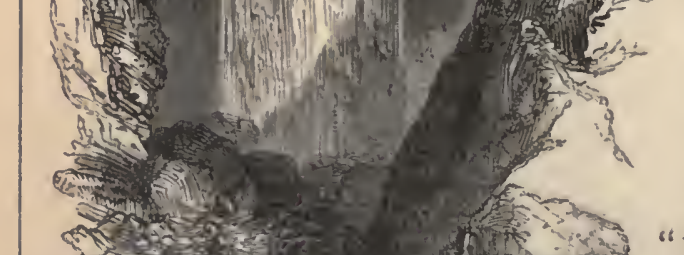
of waters," as Byron calls it, is of artifieial construction. A channel was dug by the Consul Curius Dentatus in the year 274 B. C., to convey the waters to the precipice, but having become filled up by a deposition of calcareous matter, it was widened and deepened by order of Pope Paul IV. "I saw," says Byron, "the Cascata del Marmore of Terni twice at different periods; once from the summit of the precipice, and again from the valley below. The lower view is far to be preferred, if the traveller has time for one only; but in any point of view, either from above or below, it is worth all the cascades and torrents of Switzerland put togetlier."

The falls of the Leeambye, otherwise the Zambese, discovered by Dr Livingstone in his remarkable African explorations, are very peculiar. This river seems to lose itself suddenly in the earth, rushing into a fissure of the hard basaltic rock by a leap of a hundred feet; and a stream of a thousand yards broad, is at once, and for some distance, compressed in a trough scarcely twenty yards wide.

Waterfalls appear upon their grandest scale in the American continent. They are not remarkable for the height of the precipices over which they descend, or for the picturesque forms of the rocky cliffs amid which they are precipitated, like the Alpine cataracts; but while these are usually the falls of streamlets merely, those of the western world are the rush of mighty rivers. The majority are in the northern part of the continent, but the greatest vertical descent of a considerable body of water is in the southern, at the Falls of Tequendama, where the river of Funza disembogues from the elevated plain or valley of Santa Fe de Bogota. This valley is at a greater height above the level of the sea than the summit of the great St. Bernard, and is surrounded by lofty mountains. It appears to have been formerly the bed of an extensive lake, whose waters were drained off when the narrow passage was forced through which the Funza river now descends from the elevated enclosed valley towards the bed of the Rio Magdalena. Respecting this physical occurrence Gonzalo Ximenes de Quesada, the conqueror of the country, found the following tradition disseminated among the people, which probably 
contains a stratum of truth invested with a fabulous legend. In remote times the inhabitants of Bogota were barbarians, living without religion, laws, or arts. An old man on a certain occasion suddenly appeared among them of a race unlike that of the natives, and having a long bushy beard. He instructed them in the arts, but he brought with him a malignant, although beautiful woman, who thwarted all his benevolent enterprises. By her magical power she swelled the current of the Funza, and inundated the valley, so that most of the inhabitants perished, a few only having found refuge in the neighbouring mountains. The aged visitor then drove his consort from the earth, and she became the moon. He next broke the rocks that enclosed the valley on the Tequendama side, and by this means drained off the waters. Then he introduced the worship of the sun, appointed two chiefs, and finally withdrew to a valley, where he lived in the exercise of the most austere penitence during 2000 years. The Tequendama cataract is remarkably picturesque. The river a little above it is 144 feet in breadth, but at the crevice it is much narrower. The height of the fall is 574 feet, and the column of vapour that rises from it is visible from Santa Fe at the distance of 17 miles. At the foot of the precipice the vegetation has a totally different appearance from that at the summit, and the traveller, following the course of the river, passes from a plain in which the cereal plants of Europe are cultivated, and which abounds with oaks, elms, and other trees resembling those of the temperate regions of the northern hemisphere, and enters a country covered with palms, bananas, and sugar-canes.

In Northern America, however, we find the greatest of all cataracts, that of the Niagara, the sublimest object on earth, according to the general opinion of all travellers. More varied magnificence is displayed by the ocean, and giant masses of the Andes and Himalaya ; but no single spectacle is so striking and wonderful as the descent of this sea-like flood, the overplus of four extensive lakes. The river is about thirty-three miles in length, extending from lake Erie to lake Ontario, and three quarters of a mile wide at the fall. There is nothing in the neighbouring country to indicate the vicinity of the astonishing phenomenon here exhibited. Leaving out lake Erie, the traveller passes over a level though somewhat elevated plain, through which the river flows tranquilly, bordered by fertile and beautiful banks; but soon a deep awful sound, gradually growing louder, breaks upon the ear - the roar of the distant cataract. Yet the eye discerns no sign of the spectacle about to be disclosed until a mile from it, when the water begins to ripple, and is broken into a series of dashing and foaming rapids. After passing these, the river becomes more tranquil, though rolling onwards with tremendous force, till it reaches the brink of the great precipice. The fall itself is divided into two unequal portions by the intervention of Goat Island, a façade near 1000 feet in breadth. The one on the British side of the river, called the Horse Shoe fall, from its shape, according to the most careful estimate, is 2100 feet broad, and 149 feet 9 inches high. The other or American fall is 1140 feet broad, and $\mathbf{1 6 4}$ feet high. The former is far superior to the latter in grandeur. The great body of the water passes over the precipice with such force, that it forms a curved sheet which strikes the stream below at the distance of 50 feet from the base, and some travellers have ventured between the descending flood and the rock itself. Hannequin asserts that four coaches might be driven abreast through this awful chasm. The quantity of water rolling over these falls has been estimated at 670,250 tons per minute. It is impossible to appreciate the scene created by this immense torrent, apart from its site.

"The thoughts are strange that crowd into my brain,

While I look upward to thee. It would seem

As if God pour'd thee from his hollow hand,

And hung his bow upon thine awful front; 
And spoke in that loud voice which seem'd to him Who dwelt in Patmos for his Saviour's sake, The sound of many waters; and had bade Thy flood to chronicle the ages back, And notch his centuries in the eternal rocks Deep calleth unto deep. And what are we, That hear the question of that voice sublime Oh! what are all the notes that ever rung From war's vain trumpet, by thy thundering side? lea, what is all the riot man can make, In his short life, to thy unceasing roar? And yet, Bold Babbler! what art thou to Him, Who drown'd a world, and heap'd the waters far Above its loftiest mountains? - a light wave, That breaks, and whispers of its Maker's might."

It has been remarked that at Niagara, several objects composing the chief beauty of other celebrated waterfalls are altogether wanting. There are no cliffs reaching to an extraordinary height, crowned with trees, or broken into picturesque and varied forms; for, though one of the banks is wooded, the forest scenery on the whole is not imposing. The accompaniments, in short, rank here as nothing. 'There is merely the display, on a scale elsewhere unrivalled, of the phenomena appropriate to this class of objects. There is the spectacle of a falling sea, the eye filled almost to its utmost reach by the rushing of mighty waters. There is the awful plunge into the abyss beneath, and the rererberation thence in endless lines of foam, and in numberless whirlpools and eddies; there are clouds of spray that fill the whole atmosphere, amid which the most brilliant rainbows, in rapid succession, glitter and disappear; above all, there is the stupendous sound, of the peculiar character of which all writers, with their utmost efforts, seem to have vainly attempted to convey an idea. Bouchette describes it as "grand, commanding, and majestic, flling the vault of heaven when heard in its fulness" - as "a deep, round roar, an alternation of muffled and open sounds, to which there is nothing exactly corresponding." Captain Hall compares it to the ceaseless, rumbling, deep-monotonous sound of a vast mill, which, though not very poetical, is generally considered as approaching near to the reality. Dr. Reed states, "it is not like the sea ; nor like the thunder; nor like any thing $I$ have heard. There is no roar, no rattle; nothing sharp or angry in its tones ; it is deep, awful, One." The diffusion of the noise varies according to the state of the atmosphere and the direction of the wind, but it may be heard under favourable circumstances through a distance of forty-six miles: at Toronto, across Lake Ontario. To the geologist the Niagara falls have interest, on account of the movement which it is supposed has taken place in their position. The force of the waters appears to be wearing away the rock over which they rush, and gradually shifting the cataract higher up the river. It is conceived that by this process it has already receded in the course of ages through a distance of more than seven miles, from a point between Queenstown and Lewiston, to which the high level of the country continues. The rate of procession is fixed, according to an estimate, mentioned by $\mathbf{M r}$. MI'Gregor, at eighteen feet during the thirty years previous to 1810 ; but he adds another more recent, which raises it to one hundred and fifty feet in fifty years.

The following account of a visit to the Falls of Niagara has been communicated by Mr. N. Gould. It forms a part of his unpublished Notes on America and Canada.

"My attention had been kept alive, and I was all awake to the sound of the cataract; but, though within a few miles, I heard nothing. A cloud hanging nearly steady orer' the forest, was pointed out to me as the 'spray cloud;' at length we drove up to Forsyth's hotel, and the mighty Niagara was full in view. My first impression was that 
of disappointment - a sour sort of deep disappointment, causing, for a few minutes, a kind of vacuity ; but, while I mused, I began to take in the grandeur of the scene. 'This impression is not unusual on viewing objects beyond the ready catch of the senses; Stonehenge and St.Paul's eathedral seldom excite much surprise at first sight; the enormous Pyramids, I have heard travellers say, strike with awe and silence on the near approach, but require time to appreciate. The fact is, that the first view of Niagara is a bad one; and the cye, in this situation, can comprehend but a small part of the wonderful scene. You look down upon the cataract instead of up to it; the confined channel, and the depth of it, prevent the astounding roar which was anticipated; and, at the same time, the eye wanders midway between the water and the cloud formed by the spray, which it sees not. After a quarter of an hour's gaze, I felt a kind of fascination - a desire to find myself gliding into eternity in the centre of the Grand Fall, over which the bright green water appears to glide, like oil, without the least commotion. I approached nearly to the edge of the 'Table Rock,' and looked into the abyss. A lady from Devonshire had just retired from the spot; I was informed she had approached its very edge, and sat with her feet over the edge - an awful and dangerous proceeding. Having viewed the spot, and made myself acquainted with some of its localities, I returned to the lotcl (Forsyth's) which, as well as its neighbouring rival, is admirably situated for the view; from my chamber-window I looked directly upon it, and the first night I could find but little sleep from the noise. Every view I took increased my admiration; and I began to think that the other Falls I had seen were, in comparison, like runs from kettle-spouts on hot plates. I remained in this interesting neighbourhood five days, and saw the Fall in almost every point of view. From its extent, and the angular line it forms, the eye cannot embrace it all at once ; and, probably, from this cause it is that no drawing has ever yet done justice to it. The grandest view, in my opinion, is at the bottom, and close to it on the British side, where it is awful to look up through the spray at the immense body as it comes pouring over, deafening you with its roar; the lighter spray, at a considerable distance, hangs poised in the air like an eternal cloud. The next best view is on the American side, to reach which you cross in a crazy ferry-boat : the passage is safe enough, but the current is strongly agitated. Its depth, as near to the falls as can be approached, is from 180 to 200 feet. The water, as it passes over the rock, where it is not whipped into foam, is a most beautiful sea-green, and it is the same at the bottom of the Falls. The foam, which floats away in large bodies, feels and looks like salt water after a storm: it has a strong fishy smell. The river, at the ferry, is 1170 feet wide. There is a great quantity of fish, particularly sturgeon and bass, as well as eels; the latter creep up against the rock under the Falls, as if desirous of finding some mode of surmounting the heights. Some of the visiters go under the Falls, an undertaking more curious than pleasant. Three times did I go down to the house, and once paid for my guide and bathing dress, when something occurred to prevent me. The lady before alluded to performed the ceremony, and it is recorded, with her name, in the book, that she went to the furthest extent that the guides can or will proceed. It is described as like being under a heavy shower-bath, with a tremendous whirlwind driving your breath from you, and causing a peculiarly unpleasant sensation at the chest; the footing over the débris being slippery, the darkness barely visible, and the roar almost deafening. In the passage you kick against eels, many of them unwilling to move, eren when touched : they appear to be endeavouring to work their way up the stream."

Supposing the cataract to be receding at the rate of fifty yards in forty years, as it is stated by Captain Hall, the ravine which extends from thence to Queenstown, a dis- 
tance of seven miles, will have required nearly ten thousand ycars for its excavation; and, at the same rate, it will require upwards of thirty-five thousand years for the falls to recede to Lake Erie, a distance of twenty-five miles. The draining of the lake, which is not more than ten or twelve fathoms in average depth, must then take place, causing a tremendous deluge by the sudden escape of its waters. In addition to the gradual crosion of the limestone, which forms the bed of the Niagarn at and above the falls, huge masscs of the rock are occasionally detached, by the undermining of the soft shale upon which it rests. This effect is produced by the action of the spray powerfully thrown back upon the stratum of shale; and hence has arisen the great hollow between the descending flood and the precipice. An immense fragment fell on the 28th of December, 1828, with a crash that shook the glass ressels in the adjoining inn, and was felt at the distance of two miles from the spot. By this disintegration, the angular or horse-shoe form of the great fall was lessened, and its grandeur heightened by the line of the torrent becoming more horizontal. $\Lambda$ similar dislocation had occurred in the year 1818; and the aspect of the precipice is always so threatening, owing to the wearing away of the lower stratum, as to render it an affair of some real hazard to venture between the falling waters and the rock. Miss Martineau undertook the enterprise, clad in the oil-skin costume used for the expedition, and thus remarks concerning it:- "A hurricane blows up from the cauldron; a deluge drives at you from all parts; and the noise of both wind and waters, reverberated from the cavern, is inconceivable. Our path was sometimes a wet ledge of rock, just broad enough to allow one person at a time to creep along: in other places we walked over heaps of fragments, both slippery and unstable. If all had been dry and quiet, I might probably have thought this path above the boiling basin dangerous, and have trembled to pass it; but, amidst the hubbub of gusts and floods, it appeared so firm a footing, that I had no fear of slipping into the cauldron. From the moment that I perceived we were actually behind the cataract, and not in a mere cloud of spray, the enjoyment was intense. I not only saw the watery curtain before me like tempestdriven snow, but, by momentary glances, could see the crystal roof of this most wonderful of Nature's palaces. The precise point where the flood quitted the rock was marked by a gush of silvery light, which of course was brighter where the waters were shooting forward, than below, where they fell perpendicularly." There bave been several hairbreadth escapes, and not a few fatal accidents, at Niagara, the relation of which is highly illustrative of Indian magnanimity. Tradition preserves the memory of the warrior of the red race, who got entangled in the rapids above the falls, and, seeing his fate inevitable, calmly resigned himself to it, and sat singing in his canoe till buried by the torrent in the abyss to which it plunges. The celebrated Chateaubriand narrowly escaped a similar fate. On his arrival he had repaired to the fall, having the bridle of his horse twisted round his arm. While he was stopping to look down, a rattlesnake stirred among the neighbouring bushes. The horse was startled, reared, and ran back towards the abyss. He could not disengage his arm from the bridle; and the horse, more and more frightened, dragged him after him. His fore-legs were all but off the ground; and, squatting on the brink of the precipice, he was upheld merely by the bridle. He gave himself up for lost; when the animal, astonished at this new danger, threw itself forward with a pirouette, and sprang to the distance of ten feet from the edge of the abyss.

The erosive action of running water, which is urging the Niagara falls towards Lake Erie, is strikingly exhibited by several rivers which penetrate through rocks and beds of compact strata, and have either scooped out their own passage entirely, or widened and deepened original tracks and fissures in the surface, into enormous wall-sided valleys. The current of the Simeto - the largest Sicilian river round the base of Etna - was crossed by a great stream of lava about two centuries and a half ago; but, since that cra, 
the river lias completely triumphed over the barrier of homogeneous hard blue rock that intruded into its channel, and cut a passage through it from fifty to a hundred feet broad, and from forty to fifty feet deep. The formation of the magnificent rock-bridge which orerhangs the course of the Cedar creek, one of the natural wonders of Virginia,

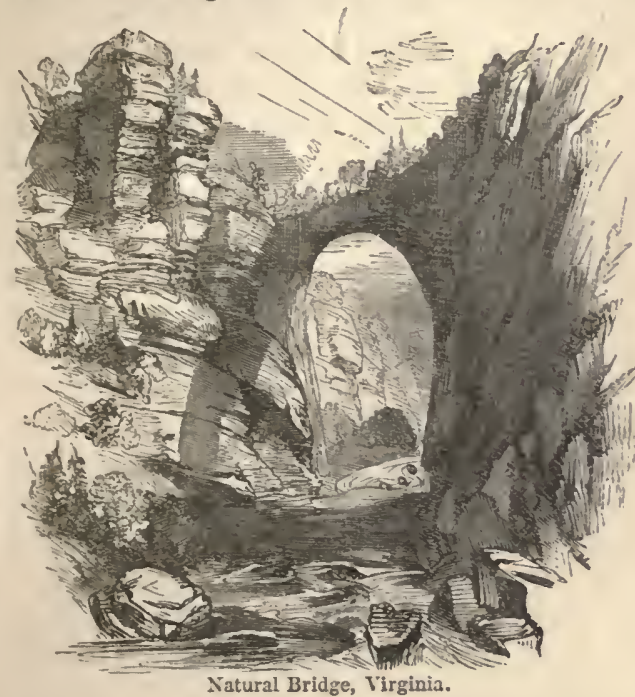
is very probably due in part to the solvent and abrading power of the stream. This sublime curiosity is 213 feet above the river, 60 feet wide, 90 long, and the thickness of the mass at the summit of the arch is about 40 feet. The bridge has a coating of earth, which gives growth to several large trees. To look down from its edge into the chasm inspires a feeling answering to the words of Shakspeare:-

"Come on, sir; here's the place: — stand still. How fearful

And dizzy "tis, to cast one's eyes so low !"

Few have resolution enough to walk to the parapet, in order to peep over it. But if the view from the top is painful and intolerable, that from below is pleasing in an equal degree. 'The beauty, elevation, and lightness of the arch, springing as it were up to heaven, present a striking instance of the graceful in combination with the sublime. This great arch of rock gives the name of Rockbridge to the county in which it is situated, and affords a public and commodious passage over a valley which cannot be crossed elsewhere for a considerable distance: Under the arch, thirty feet from the water, the lower part of the letters G. W. may be seen, carved in the rock. They are the initials of Washington, who, when a youth, climbed up hither, and left this record of his adventure. We have several examples of the disappearance of rivers, and their emergence after pursuing for some distance a subterranean course. In these cases a barrier of solid rock, overlaying a softer stratum, has occurred in their path; and the latter has been gradually worn away by the waters, and a passage been constructed through it. Thus the Tigris, about twenty miles from its source, meets with a mountainous ridge at Diglou, and, running under it, flows out at the opposite side. The Rhone, also, soon after coming within the French frontier, passes under ground for about a quarter of a mile. Milton, in one of his jurenile poems, speaks of the

"Sullen IIole, that runneth underneath;"

and Pope calls it, after him, the

"Sullen Mole, that hides his diving flood."

The Hamps and the Manifold, likewise - two small streams in Derbyshire - flow in scparate subterraneous channels for several miles, and emerge within fifteen yards' of each other in the grounds of Mlam Hall. That these are really the streams which are swallowed up at points several miles distant, has been frequently proved by watching the exit of various light bodies that have been absorbed at the swallows. At their emergence, the waters of the two rivers differ in temperature about two degrees - an obvious proof that they do not anywhere intermingle. On the side of the hill, which is overshadowed with spreading trees, just above the spot where the streams break forth into daylight, there is a rude grotto, scooped out of the rock, in which Congreve is said to have written 
his comedy of the "Old Bachelor" and a part of his "MIourning Bride." In Spain a similar phenomenon is exhibited by the Guadiana; but it occurs under different circumstances. It disappears for about seven leagues - an effect of the absorbing power of the soil - the intervening space consisting of sandy and marshy grounds, across which the road to Andalusia passes by a long bridge or causeway. The river reappears with greater power, after its dispersion, at the Ojos de Guadiana - the Eyes of the stream.

Many rivers are subject to a considerable elevation of the level of their waters. This is periodical or irregular in its occurrence, according to the nature of the producing cause. Casual temporary floodings, as the effect of extraordinary rains, are common to the streams of most countries, and sometimes occasion great changes of the surface, and destruction of life and property. One of the most remarkable instances of this kind in modern times, occurred on the 4th of August, 1829, in Scotland, when the Nairn, Spey, and Findhorn rose above their natural boundaries, and spread a devastating deluge over the surrounding country. The rain which produced this flood fell chiefly on the Manadhleadh Mountains, where the rivers in question have their feeders, situated between the south of Loch Ness and the group of the Cairngorums. Sir Thomas Dick Lauder, in his interesting account of this inundation, considers the westerly winds, which prevailed for some time previously after a season of unusual heat, to have produced a gradual accumulation of vapour, somewhere north of our island; and the column being suddenly impelled by a strong north-easterly blast, it was driven towards the south-west, till arrested in its course by the lofty mountains upon which it discharged itself in torrents perfectly unexampled. The rain fell occasionally in heary drops, but was for the most part broken by the blast into extremely minute particles, so thick, that the very air itself seemed to be descending in one mass of water upon the earth. It deluged every house whose windows were exposed to the south-east. The lesser animals, the birds, and especially game of all kinds, were destroyed in great numbers, by the rain alone; and the mother partridge, with her progeny and mate, were found chilled to death amidst the drenching wet. At Huntly Lodge, according to an accurate observation, between five o'clock of the morning of the $3 \mathrm{rd}$ of August and the same hour of the succeding day, there fell $3 \frac{3}{4}$ inches of rain, or about one-sixth of our annual allowance of rain descended there in twenty-four hours. This was at a considerable distance from the mountains - the central scene of the rain where its quantity must have been prodigiously greater, sufficient to account for the tremendous flood that followed, far exceeding in its risc, duration, and havoc, any otlier that ever affected the same locality. The Findhorn and Spey assumed the appearance of inland seas; and, when the former began to ebb, a fine salmon was driven ashore and captured, at an elevation of fifty feet above its ordinary level. IIost of the rivers of the temperate zones are subject to these irregular floodings from the same cause, especially those which take their rise in high mountain regions, the St. Lawrence being the most remarkable exception, the level of which is not affected by either rains or drought. 'The vast lakes from which this river issues, furnish its channel with an inexhaustible supply of water, and present a surface too extensive to be sensibly elevated by any extraordinary rains. A strong westerly wind, however, will affect the level of the St. Lawrence, and occasion a rise of six feet in the waters to the eastern extremity of Lake Erie. An easterly wind also upon the Orinoco will check its current, elevate the upper part of the stream, and force its waters into the channels of its tributaries, giving them a backward flow, and causing them to be flooded; and a northerly wind will drive the Baltic up the mouths of the Oder, and raise its level for a considerable distance. In a similar manner, the Neva rises when a strong wind blows from the Gulf of Finland; and that oecurrence, taking place coincidently with high water and the breaking up of the icc, would create an inundation sufficient to drown the whole population of St. Petersburg, and convert that 
brilliant capital, with all its sumptuous palaces, into a chaotic mass of ruins. We have the materials of this statement from M. Kohl. The Gulf of Finland runs to a point as it approaches the mouth of the Neva, where the most violent gales are always those from the west; so that the mass of waters on such occasions is always forcibly impelled towards the city. The islands forming the delta of the Neva, on which St. Petersburg stands, are extremely low and flat; and the highest point in the city is probably not more than twelve or fourteen feet above the average level of the sea. A rise of fifteen feet is therefore enough to place all St. Petersburg under water, and a rise of thirty feet is enough to drown almost every human being in the place. Hence the inliabitants of the capital are in constant danger of destruction at the period referred to, and can never be certain that the 500,000 of them may not, within the next twenty-four hours, be driven out of their loouses, to find, in multitudes of instances, a watery grave. 'This is not a chimerical danger; for, during its short continuance, the city of the Czar las experieneed some formidable inundations. The only lope of this apparently doomed city is, that the three cireumstances may never be coincident, namely, high water, the breaking up of the ice, and a gale of wind from the rest. It is nevertheless true, that the wind is very often westerly during spring, and the ice floating in the Neva and the Gulf of Finland is of a bulk amply sufficient to oppose a formidable obstacle to the egress of the water; so that it will not be surprising if St. Petersburg, after suddenly rising like a meteor from the swamps of Finland, should still more suddenly be extinguished in them.

The periodical rise of rivers is either diurnal, semi-annual, or annual, and proceeds from a variety of causes. Where streams descend immediately from mountains covered with snow, the heat of the sun melting the snow produces high water every day, the increase being the greatest in the hottest days. In Peru and Chili there are small rivers which flow only during the day, because they are fed entirely by the melting of the snow

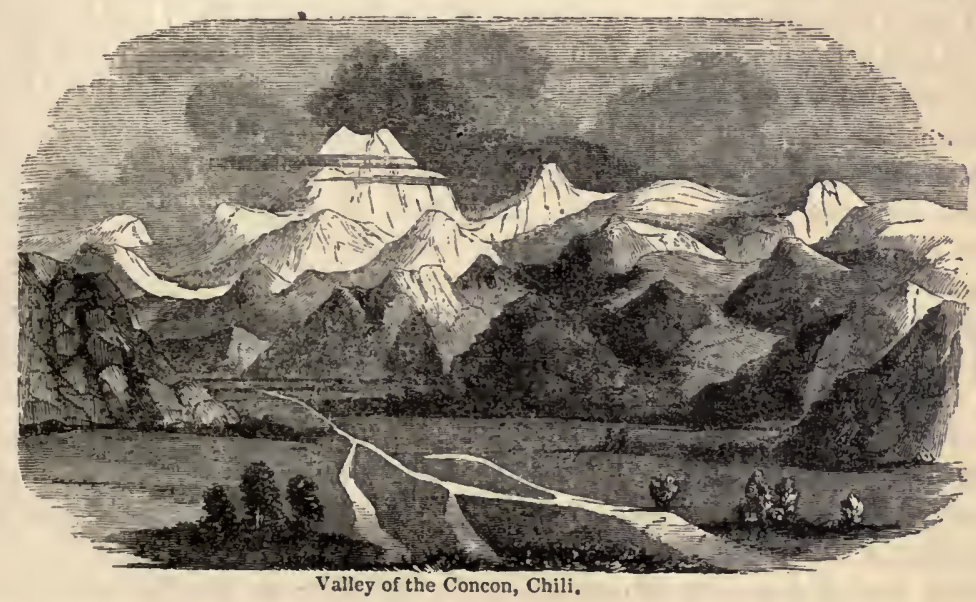

upon the summit of the Andes, which takes place only when the solar influence is in action. In Hindûstan, and some parts of Africa, rivers exist, which, though they flow night and day, are, from the accession of snow-water, the greatest by day. Those rivers also which fall into the sea have their level daily varied by the tidal wave for some distance from their mouths, the extent through which the influence of the tides is feit being modified by the breadth and shape of their channels and the force of their current. The wider and more direct the bed of a stream eommunicating with the ocean, and the 
slower its motion, the farther the tide will penetrate; whereas a narrow and sinuous course, and a great velocity, offer obstructions to its progress. The tide of the Atlantic is perceived four hundred miles along the course of the Amazon, and that of the German Ocean extends about seventy miles up the Thames. Important facilities are afforded to the navigation of many rivers by this circumstance, for they are only accessible to vessels of large burden at high water. The rapid of Richelieu, on the St. Lawrence, where the river contracts, and has its course obstructed by rocks, impedes the navigation between Montreal and Quebee, except at high tide, when the water rises fifteen or eighteen feet, and the rapid entirely disappears. A semi-annual or an annual rise alone distinguishes the rivers of inter-tropical regions and of countries bordering on the torrid zone. The semi-annual rise is a feature of those rivers which drain high mountain ranges, and proceeds from the two independent causes, of the melting of the snows in spring or summer, and the great seasonal rains to which such districts are subject. The rivers which have only one annual rise are influenced by the latter cause alone, or by the two acting coineidently, and producing a grand periodical flood. The Tigris rises twice in the yearfirst, and most remarkably, in April, in consequence of the melting of the snows in the mountains of Armenia; and secondly, in November, through an accession from the periodical rains. The Mississippi likewise is subject to two rises in the year-one about January, occasioned by the periodical rains that fall towards the lower part of its course; but the grand flood commences in Mareh, and continues till June, proceeding from the melting of the ice in the upper part of the eontinent, where the Missouri and other tributary streams have their origin. A very striking spectacle is exhibited by this river in the season of inundation. It rises from forty to fifty feet in some parts of its course, and is from thirty to a hundred miles wide, all overshaded with forest, exeept the interior stripe consisting of its bed. The water stands among the trees, from ten to fifteen feet in height, and the appearance is exactly that of a forest rising from a lake, with its waters in rapid motion. For the protection of the cultivated lands, and to prevent their conversion into permanent swamps, an embankment, called the Lessee, has been raised, which extends two hundred miles on the eastern shore of the river, and three hundred on the western. In Asia, the Ganges, Indus, and Euphrates exhibit inundations upon a similarly great scale. The Euphrates slightly increases in January, but the grand flood begins soon after the middle of March. It attains its height about the 20th of May, after which it falls rapidly till June. The decrease then proceeds gradually until the middle of November, when the stream is at its lowest. The rise of the water at Anah, above the site of ancient Babylon, oceasionally amounts to eighteen feet, sometimes entering that town, running with a velocity exceeding five miles an hour. The moment that the waters of the river recede, the rice and grain erops are sown in the marshes, and villages of slightly made reed cottages are reared in their neighbourhood. These last, in consequence of being suffered to remain too long, are often surprised by the returning inundation, and it is no uncommon spectacle for their occupants to be seen following the floating villages in canoes, for the purpose of recovering their property. But of all inundations, that of the Nile, if not the most extensive, is the most regular, and has become the most celebrated, from the knowledge of it going back to the earliest periods to which history recurs. The rise of the river commences about the time of the summer solstice, attains its maximum height at the autumnal equinox, remains stationary for some days, and then gradually diminishes till the time of the winter solstice. The ancients, unaequainted with the climate of the interior country from which it descends, and not caring in general to inquire for physical causes, possessing also a very limited knowledge of terrestrial phenomena, deemed the annual overflow of the Nile a unique event, and attributed it to the special interfercnce of a supernatural power. Lucretius, 
however, who soared in many respects above the prejudices of his age concerning the natural world, assigned it to a proper cause; though he wrongly ascribes influence to the Etesian wind, and shows his imperfect acquaintance with the geography of the globe, by supposing the occurrence without a parallel.

"The Nile now calls us, pride of Egypt's plains :

Sole stream on earth its boundaries that o'erflows

Punctual, and scatters plenty. When the year

Now glows with perfect summer, leaps its tide

Proud o'er the champaign; for the north wind, now

Th' Etesian breeze, against its mouth direct

Blows with perpetual winnow; every surge

Hence loiters slow, the total current swells,

And wave o'er wave its loftiest bank surmounts.

For that the fix'd monsoon that now prevails

Flows from the cold stars of the northern pole,

None e'er can doubt; while rolls the Nile adverse

Full from the south, from realms of torrid heat,

Haunts of the Ethiop tribes; yet far beyond

First bubbling, distant, o'er the burning line.

Then ocean, haply, by th' undevious breeze

Blown up the channel, heaves with every wave

Heaps of high sand, and dams its wonted course;

Whence, narrower, too, its exit to the main,

And with less force the tardy stream descends.

Or, towards its fountain, ampler rains, perchance,

Fall, as th' Etesian fans, now wide unfurl'd,

Ply the big clouds perpetual from the north

Full o'er the red equator; where condensed,

Ponderous and low, against the hills they strike,

And shed their treasures o'er the rising flood.

Or, from the Ethiop-mountains, the bright sun

Now full matur'd with deep-dissolving ray

May melt th' agglomerate snows, and down the plains

Drive them, augmenting hence, th' incipient stream."

The annual overflow of the Nile is now well known to proceed from the heavy periodical rains within the tropics. They fall in copious torrents upon the great plateau of Abyssinia, which rises, like a fortress, 6000 feet above the burning plains with which it is surrounded. The vapours, arrested and condensed by this highland rampart, often densely shroud Ankobar, the capital, while, whenever the curtain of mist is withdrawn, the strange contrast is presented of the sulphureous plains, visible below, where the heat is $90^{\circ}$, and the drought excessive. A peculiar character has been given to this district by the violence of the periodical rains. Bruce speaks of the mountains of this tableland, not remarkable for their height, but for their number and uncommon forms. "Some of them are flat, thin, and square, in shape of a hearth-stone or slab, that scarce would seem to have base sufficient to resist the winds. Some are like pyramids, others like obelisks or prisms, and some, the most extraordinary of all, pyramids pitched upon their points, with their base uppermost." Mr. Salt confirms this delineation in the main. The peculiar shapes referred to have been formed by the action of the torrents discharged from the clouds, which have, for ages, been skeletonising the country, dismantling the granite with its kindred masses of the softer deposits, gradually wearing away also these harder rocks, and carrying along the soil of Ethiopia, strewing it upon the valley of the Nile, to the shores of the Mediterranean. When Bruce was ascending Taranta, a sudden noise was heard on the heights louder than the 
loudest thunder, and, almost directly afterwards, a river, the channel of which had been dry, came down in a stream several feet in depth, and as broad as the whole bed. Hence the steeple and obelisk form of the rocks, with their naked aspect, - which has, not unaptly, been compared to bones stripped of their flesh.

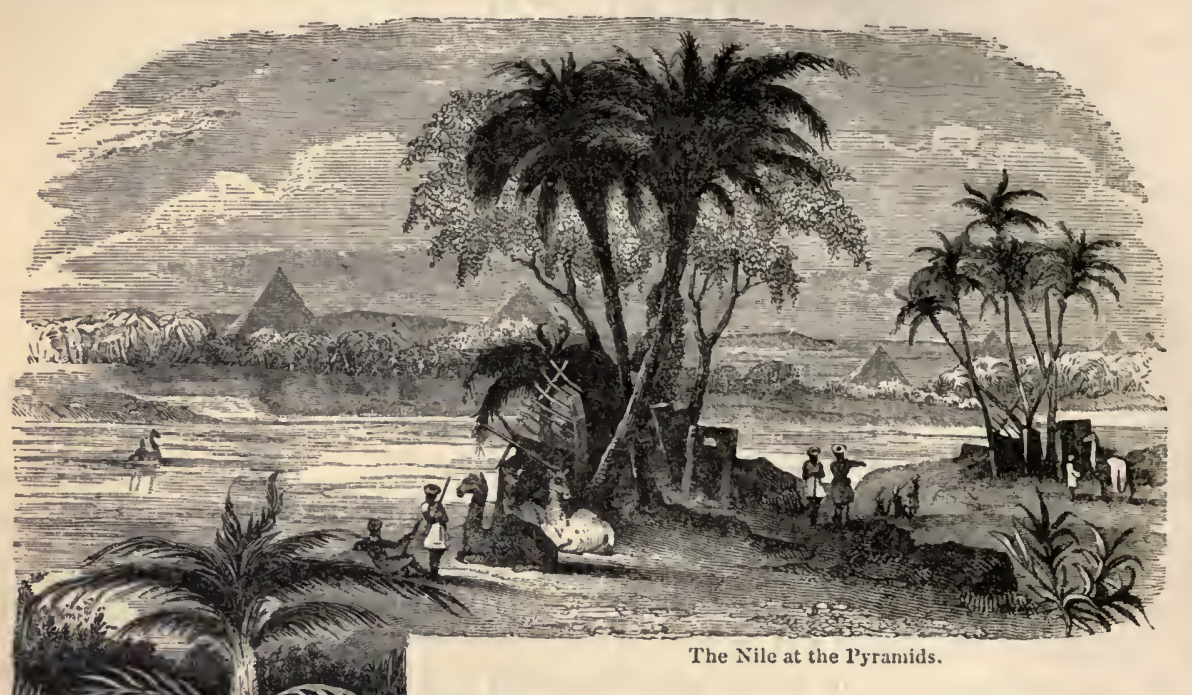

In the tropical countries of South America, the seasonal rains are, perhaps, more intensely copious than in any other part of the torrid zone, and the floods of its rivers are of corresponding magnitude. At the mission of San Antonio de Javita, on the Orinoco, during the wet season, the sun and stars are seldom visible, and Humboldt was told by the padre, that it sometimes rained for four and five months without intermission. The traveller collected there, in five hours, 21 lines of water in height on the first of May, and 14 lines on the $3 \mathrm{~d}$, in three hours; whereas at Paris there fall only 28 or 30 lines in as many weeks. Humboldt traces the transition from the one great season of drought to that of rain, which divides the year, in an interesting manner, with the atmospheric phenomena which accompany the change. About the middle of February in the valleys of Araqua, he observed clouds forming in the evening, and in the beginning of March the accumulation of vesicular vapours became visible. "Nothing," he remarks, in beautifully graphic style, "can equal the purity of the atmosphere from December to February. The sky is then constantly without clouds, and should one appear, it is a phenomenon that occupies all the attention of the inhabitants. The breeze from the east and north-east blows with violence. As it always earries with it air of the same temperature, the vapours cannot become visible by refrigeration. Towards the end of February and the beginning of March the blue of the sky is less intense; the hygrometer gradually indicates greater humidity; the stars are sometimes veiled by a thin stratum of vapours; their light ceases to be tranquil and planetary; and they are seen to sparkle from time to time at the height of $20^{\circ}$ above the horizon. At this period the breeze diminishes in strength, and becomes less regular, bcing more frequently interrupted by dead calms. Clouds accumulate towards the south-enst, appearing like distant mountains with distinct outlines. From time to time they are seen to separate from the horizon, and traverse the celestial vault with a rapidity which has no correspondence with the feebleness of the wind that prevails in the lower strata of 
the air. At the end of March the southern region of the atmosphere is illuminated by small electric explosions, like phosphorescent gleams, confined to a single group of vapours. From this period the breeze shifts at intervals, and for several hours, to the west and south-west, affording a sure indication of the approach of the rainy season, which, on the Orinoco, commences about the end of April. The sky begins to be overcast, its azure colour disappears, and a gray tint is uniformly diffused over it. At the same time the heat of the atmosphere gradually increases, and, instead of scattered clouds, the whole vault of the heavens is overspread with condensed vapours. 'The howling monkeys begin to utter their plaintive cries long before sunrise. 'Tlie atınospheric electricity, which, during the period of the greatest drought, from December to March, had been almost constantly in the day-time from $1 \cdot 7$ to 2 lines to Volta's electrometer, becomes extremely variable after March. During whole days it appears null, anil again, for some hours, the pith-balls of the electrometer diverge from three to four lines. The atmosphere, which in the torrid as in the temperate zone is generally in a state of positive electricity, passes alternately, in the course of eight or ten minutes, to a negative state. The rainy season is that of thunder-storms. 'The storm rises in the plains two lours after the sun passes through the meridian, and therefore shortly after the period of the maxinum of the diurnal heat in the tropics. In the inland districts it is exceedingly rare to hear thunder at night or in the morning, nocturnal thunder-storms being peculiur to certain valleys of rivers which have a particular climate." The substance of the explanation of the preceding phenomena, by the philosophic writer of the statement, may be briefly given: The season of rains and thunder in the northern equinoctial zone coincides with the passage of the sun through the zenith of the place, the cessation of the breezes, or north-east winds, and the frequency of calms, and furious currents of the atmosphere from the south-east and south-west, accompanied with a cloudy sky. While the brecze from the north-east blows, it prevents the atmosphere from being saturated witl moisture. The hot and loaded air of the torrid zone rises, and flows off again towards the poles, while inferior currents from these last, bringing drier and colder strata, take the place of the ascending columns. In this manner the humidity, being prevented from accumulating, passes off towards the temperate and colder regions, so that the sky is always clear. When the sun, entering the northern signs, rises towards the zenith, the breeze from the north-east softens, and at length ceases; this being the season at which the difference of temperature between the tropics and the contiguous zone is least. The column of air resting on the equinoctial zone becomes replete with vapours, because it is no longer renewed by the current from the pole; clouds form in this atmosphere, saturated and cooled by the effects of radiation and the dilatation of the ascending air, which increases its capacity for heat in proportion as it is rarefied. Electricity accumulates in the higher regions, in consequence of the formation of the vesicular vapours, the precipitation of whieh is constant during the day, but generally ceases at night. The showers are more violent, and accompanied with electrical explosions, shortly after the maximum of the diurnal heat. These phenomena continue until the sun enters the southern signs, when the polar current is re-established, because the difference between the heat of the equinoctial and temperate regions is daily increasing. The air of the tropics being thus renewed, the rains cease, the vapours are dissolved, and the sky resumes its azure tint.

The Orinoco, when in flood, inundates a vast extent of country, six hundred miles in length and from sixty to ninety in width. Its waters cover the savannahs along its banks to the depth of twelve or fourteen feet, giving to them a lake-like appearance, in the midst of which farm-houses and villages are seen rising on islands but little elevated above the surface. The wild cattle perish in great numbers, and fall an easy prey to the carrionvultures and alligators. In one part of the river Humboldt found marks of recent inun- 
dation at 45 feet above the ordinary level; but above the greatest height to which its waters are now elevated, he traced its ancient action at 106 or even 138 feet. "Is this river, then," inquires he, "the Orinoco, which appears to us so imposing and majestic, merely the feeble remnant of those immense currents of fresh water which, swelled by Alpine snows or by more abundant rains, every where shaded by dense forests, and destitute of those beaches that favour evaporation, formerly traversed the regions to the east of the Andes, like arms of inland seas? What must then have been the state of those low countries of Guiana, which now experience the effects of annual inundations! What a prodigious number of crocodiles, lamartines, and boas must have inhabited these vast regions, alternately converted into pools of stagnant water and arid plains! The more peaceful world in which we live has succeeded to a tumultuous world. Bones of mastadons and real American elephants are found dispersed over the platforms of the Andes. The megatherium inhabited the plains of Uruguay. By digging the earth more deeply in high valleys, which at the present day are unable to nourish palms or tree-ferns, we discover strata of coal, containing gigantic remains of monocotyledonous plants. There was therefore a remote period when the tribes of regetables were differently distributed, when the animals were larger, the rivers wider and deeper. There stop the monuments of nature which we can consult."

This grand stream, when more than five hundred miles inland, has a breadth measuring upwards of three miles. In its regular rise and fall, with the delta at its mouth, the numerous crocodiles, the cataracts or rapids in the upper part of its course, and the level plains of the lower, it bears a close resemblance to the Nile. It is remarkable also for the varying direction of its course, setting out from east to west, then turning north, and finally running from west to east, so as to bring its estuary and source into nearly the same longitude. The disturbance caused by the collision of the powerful current of the river with the Atlantic, led the inexpert early navigators to denominate that part of the ocean the Bay of Sadness, Golfo Triste; and the channel between the continent and the island of Trimidad, they similarly styled the Dragon's Mouth, Boca del Drago. The Orinoco is historically memorable as having been entered by Columbus, who sagaciously inferred from its volume the continental character of the adjoining region. It is physically remarkable for its basin so running into that of the Amazon, that water communication subsists naturally between the two primary streams. This fact has already been mentioned; but as a rare feature in the physics of the earth, and as illustrating the energy of Humboldt, the great traveller of modern times, by whom it was decisively determined, we may recur to it.

He and Bonpland left Caraccas in the year 1800, crossed the valleys of Aragua, and the Llanos of Calabozo - excellent pastures, which separate the cultivated part of Venezuela from the region of the forests and missions-and embarked at San Fernando, on the Rio Apure, to follow its course downwards to its discharge into the principal branch of the Orinoco. They then ascended the Orinoco, passing its two great cataracts of Apures and Maypures, and reached the village of San Fernando de Atabapo, situated at the junction of the Guaviare and Atabapo, and near lat. $4^{\circ} \mathrm{N}$. Here they left the river, and sailed up the Atabapo to the mouth of the Rio Temi; which latter they followed as far as its confluence with the Tuamini, and arrived at the village of San Antonio de Javita, formerly mentioned as remarkable for its amount of rain. From this point the Indians carried their boat across the isthmus which separates the Tuamini from the Rio Pimichin, the travellers following on foot, passing through dense forests, often in danger from the number of snakes that infested the marshes. Embarking on the Pimichin, they came in four hours and a half into the Rio Negro. "The morning" says Humboldt, "was cool and beautiful. We had been confined thirty-six days in a narrow canoe, so unsteady 
\}

(

7 


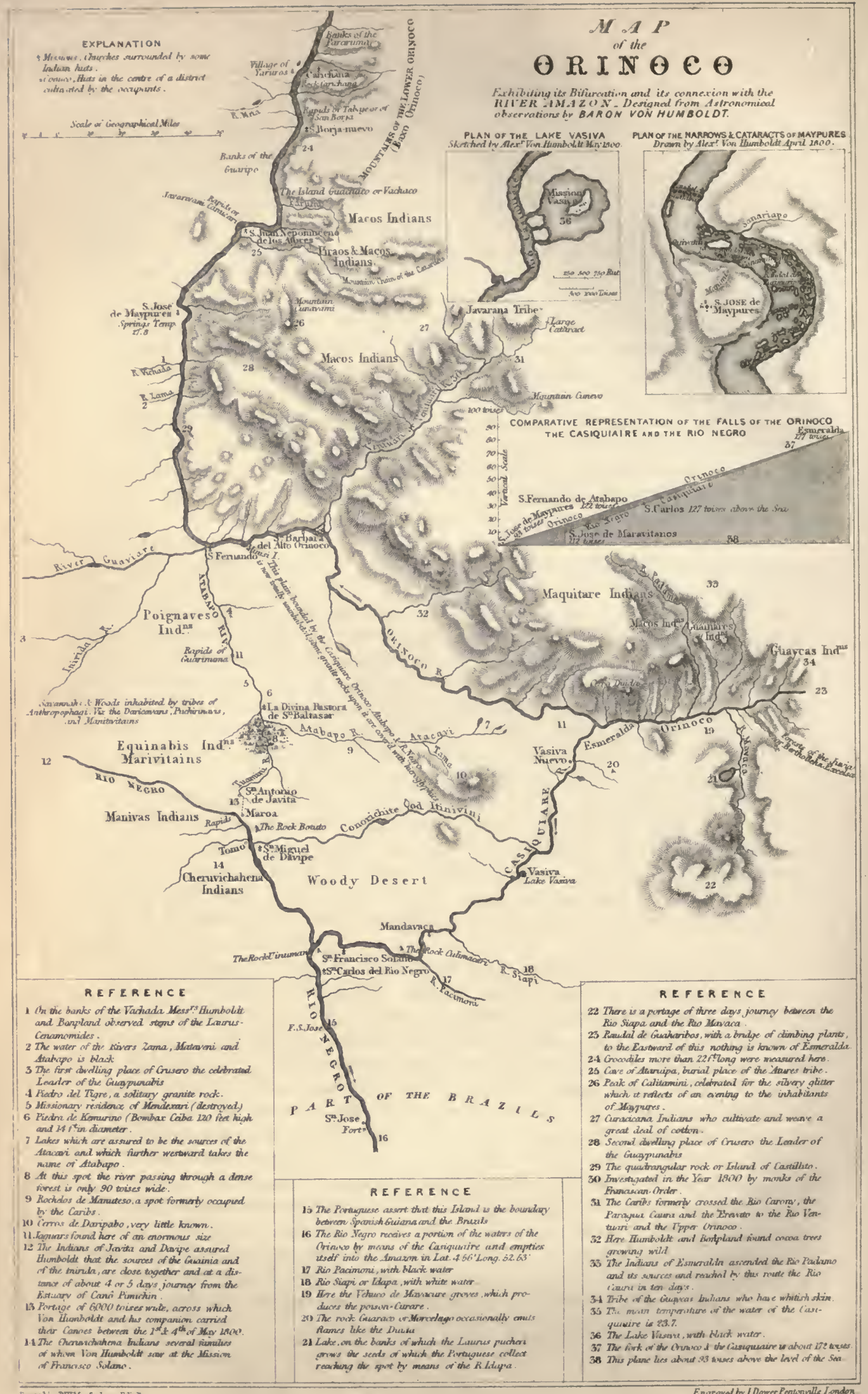

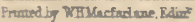


that it would have been upset by any one rising imprudently from his seat, without warning the rowers to preserve its balance by leaning to the opposite side. We had suffered severely from the stings of insects, but had withstood the insalubrity of the climate; we had passed without accident the numerous falls and bars that impede the navigation of the rivers, and often render it more dangerous than long voyages by sea. After all we had endured, I may be allowed to mention the satisfaction which we felt in having reached the tributaries of the Amazon." The Rio Negro, which flows into that river, was navigated downwards as far as San Carlos, then supposed to lie under the equator, but actually about $2^{\circ} \mathrm{N}$. From thence the travellers retraced the river, passed from it into the Cassiquiare, and again entered the main channel of the Orinoco, three leagues below the mission of Esmeralda; thus demonstrating a junction between the two great floods of the Amazon and Orinoco, which had been, in the year 1798, declared by Bauche to be a geographical monstrosity. The bifurcation of the Orinoco takes place in the following manner :- The river, issuing from among the mountains, reaches the opening of a valley or depression which terminates at the Rio Negro. Here it divides into two branches, the smaller, or the Cassiquiare, turning off to the south, while the main stream continues its original direction-west-north-west. A reference to Humboldt's map, of which we give a translated copy, will render further explanation unnecessary.

The preceding notices refer to what have been appropriately styled the "might rivers," and the "great rivers," none of which are to be found in Europe. Its noblest running waters belong to a third grade. "These," says Inglis, "I would designate the large rivers; for great and large are not entirely synonymous; and, to most minds, the term great river and large river, will present a distinct image. The lower we descend in the scale, the more numerous do we find the species. The continent of Europe abounds with examples of the third class - such as the Rhine, the Danube, the Rhone, the Elbe, the Tagus, the Ebro, and the Guadalquivir. The fourth class is still more numerous; and of this class, which I would call considerable rivers, we may find examples at home. Father Thames takes the lead; and the Severn, and perhaps the Trent, the Clyde, the Tweed, the Tyne, and the Tay, may be entitled to the same distinction. On the Continent, it would be easy to name a liundred such; let me content myself with naming the Loire, the Meuse, the Saone, the Garonne, the Adige, and the Maine. Fifthly, come the small rivers. Multitudinous they are; but as examples, I may name the Wye, the Dart, the Derwent, the Dee, the Aire, the Spey, the Ex, and a thousand such ; while on the continent, of the same class, may be mentioned the Gare, the Seine, the Reuss, or the Sambre. The word river can no longer be employed, for now come the family of streams-nameless, except to those who live upon their banks: the rivulets follow; and, lastly, we close the enumeration with rills." The small rivers, with the streams subordinate to them, are especially rife in countries where there is the vicinage of the sea, and high elevations on the land. This renders them so abundant in such districts as the Greek peninsula. There, Alpine tracts of territory collect from the atmosphere the vapours of the contiguous sea, arrest the castellated glories of cloud-land, and awaken in the valleys and plains the refreshing music of the voice "of many waters." The commerce of kingdoms distinguishes not the rivers of this classic soil, but they are familiar with the charms of nature, add effect to the sublime and wild in its scenery, and clothe with heightened grace the soft and pastoral. Following the course of the Angitas up to its source, we come to one of the most picturesque sites in Macedonia, supposed to be the nymphrum or grotto of Onocaris. Blocks of marble, rudely piled, as if tossed together by an earthquake, obstruct its entrance, which can only be passed in a crawling posture; but these difficulties being overcome, a cave like a tefople appears, from the farther end of which runs the limpid stream, flowing silently over a sand bed, but rippling when it escapes 
from the grotto. In a recess, there are some remains of ancient masonry below an aperture, through which a mysterious light finds its way.

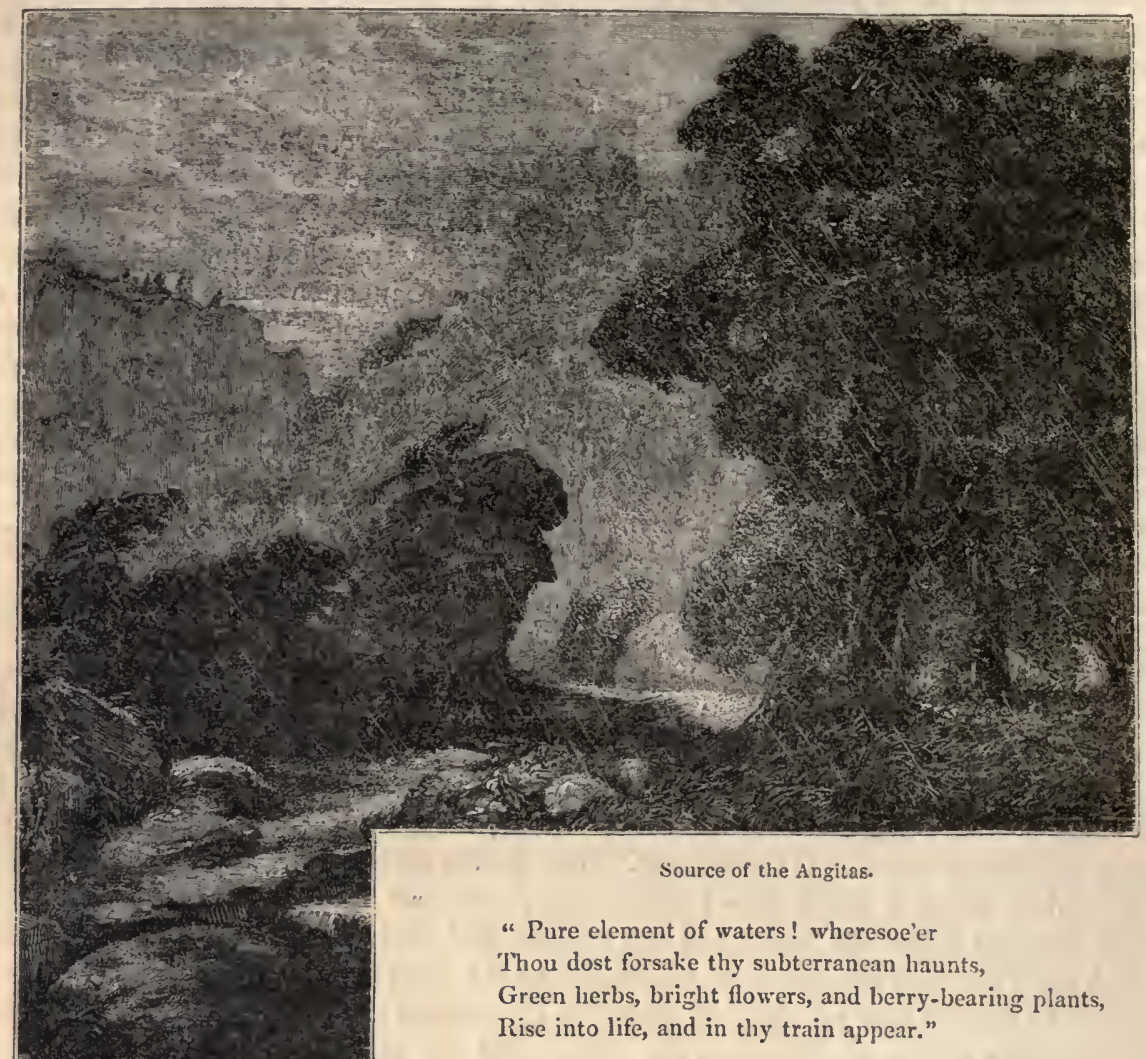

Upon the large circular valley-plain of Bœotia, the heiglits of Parnassus on the west, Helicon on the south, and Cithæron on the east, send down streams, covering the undulating surface of this Classic Land with a life-sustaining vegetation.

The same physical causes - high lands and the contiguous sea - operate, in Judea as in Greece, to render it a well-watered country - a "land of brooks," according to its scripture designation. There are no considerable rivers, owing to the scanty extent of its hydrographical basins; but the melting of the snow on the high mountains of Syria, and the periodical sound of an "abundance of rain," contribute to furnish an ample irrigation. Its principal stream - the Jordan-though only one of the fifth class, and not remarkable for picturesque beauty except in the upper part of its course, has a saered and historic interest which will always strongly attract attention to it, while it exlibits a singular physical peculiarity. This is the depression of the valley, in which it flows, below the level of the Mediterranean, through the whole distance between the Sea of Tibcrias and the Dead Sea; and the great inclination of its descent from the one to the other, amounting at a mean to very nearly eighteen feet per mile. Hence the force of its current, notwithstanding a comparatively small volume of water, and the few windings that. mark its channel. Speaking of its appearance near the site of Jericho, Dr. Robinson states: "There was a still though very rapid current. We estimated the breadtl of the 
stream to be from eiglity to one hundred feet. The guides supposed it now to be ten or twelve feet deep. The current was so strong, that even Komeh, a stout swimmer of the Nile, was earried down several yards in crossing." Upon the authority of some phrases in the English version of the Scriptures, which perhaps do not express the sense of the original Hebrew, it has been generally supposed that the Jordan periodically inundated the country in its neighbourhood, at, and for some time after, the Israelitish conquest of it. If this were so, either the river must have worn for itself a deeper bed, or the quantity of rain in Palestine must have largely diminished, for there is now 110 overflow of its banks. At present, the "swellings of Jordan" - one of the phrases alluded to - amount only to a slight annual rise. Copious rains descend upon the mountains round its sources, and the melting of the snows of Lebanon supply numerous temporary torrents; but these contributions are received into the capacious basins of the lakes Merom and Tiberias, and are there spread over an extensive surface, so as to prevent the level of the river from rising into inundation.

In exactly the same manner, the great Canadian lakes prevent any rise to the St. Lawrence, by the immense floods that rush into them in the spring spreading over their vast beds, and producing only an almost inappreciable elevation of their level. Lebanon,

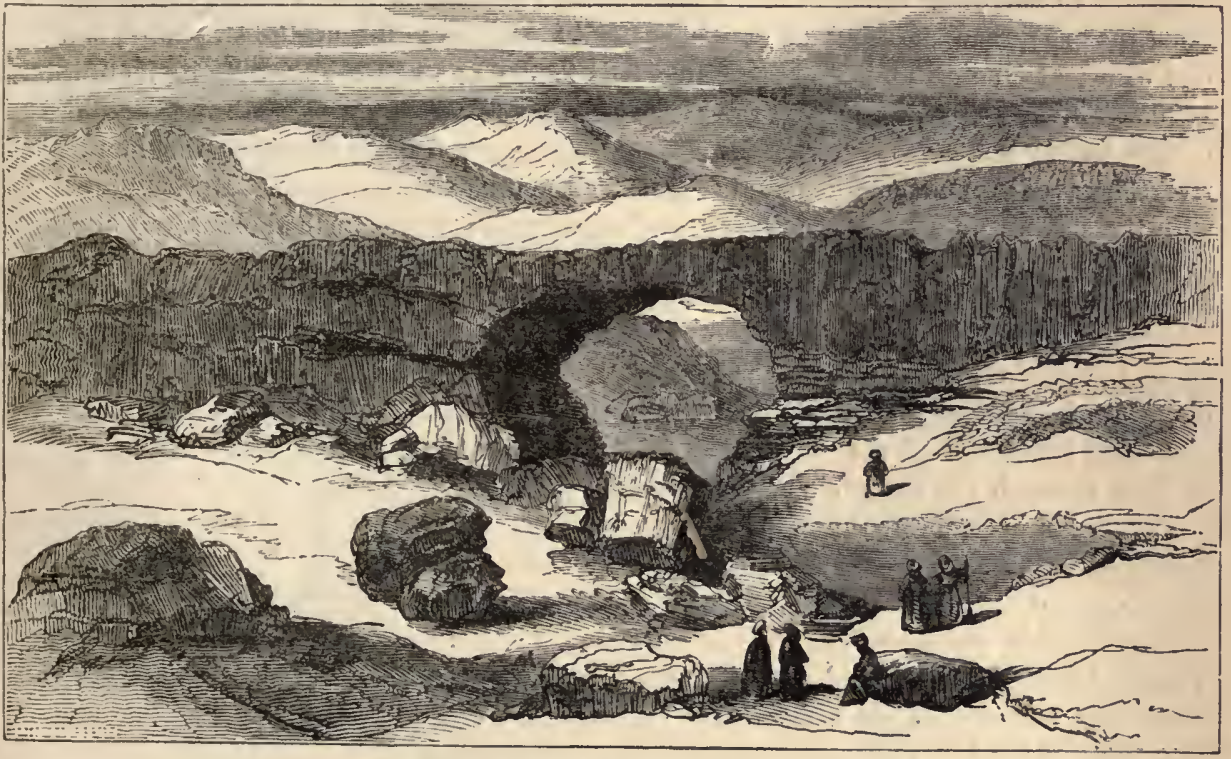

Natural Bridge of Ain el Leban.

the feeder of the Jordan from its internal reservoirs, along with "Abana and Pharpar, rivers of Damascus," and the Orontes, gives birth to many rapid and brawling streams, and a thousand cascades, when its snows melt, which strikingly display the erosive power of running water. Deep passages have been cut in the rocks, bestrided by natural arches, like the rock-bridge of Virginia. Of this deseription is the natural bridge over the Ain el Leban, rising nearly two liundred feet above the torrent which has gradually dug the excavation, as annually the spring has renewed its strength. The brook flows into the Beyrout river, and its channel would be quite dry in summer, were it not for the impediments its mountain course presents. It was the spring season, the time of the melting of the snow, when the monarch of Israel, during his temporary exile from the throne, retreated for a refuge towards the fastnesses of Lebanon. He saw the torrents falling 
from height to height into the valleys. He heard the voices of the waters as they leaped from rock to rock. His imagination converted this external scenery into a picture of the force of his adversities; and hence the allusion, in the plaintive elegiac, commemorative of his condition, to the "noise of cataracts," and to "dcep calling unto deep."

In advancing towards their termination, and at their embouchure, the great rivers present several striking peculiarities. It has already been remarked, that a junction of two large streams often occurs without any expansion of the surface of their waters being the consequence, but a greater velocity of current and depth of channel. In some cases, instead of a wider course being created by increased volume of water, there is actually a narrower bed. Thus the Mississippi is a mile and a half wide, and the Missouri half a mile wide, at their confluence, yet from that point to the mouth of the Ohio, the medium width of the united rivers is but three quarters of a mile, and through the lower parts of its course the main stream has, if any thing, a less surface-breadth, though vast accessions are made to it by the Arkansas, Red River, and others of great depth and body of water. Most of the tributaries of the Mississippi also are wider a thousand miles apart from it than at the point of junction, and the same feature is characteristic of other great streams, that as they increase their volume of water, and approach their termination, they flow in narrower though deeper channels. The Nile is not so broad at Cairo as at Siout, nor so broad at Siout as at Thebes. At Assouan, high up the stream, it is 3900 feet wide; at Oudi, 36 miles abore Cairo, it is 2900 ; and at Rosetta, near its mouth, but 1800. This is one of the many examples of benign adjustment with which the realms of nature teem; for hereby, a rich legacy of fertile soil, usually found at the mouths of rivers, is saved from submergence, and becomes the inheritance of man. In their junction with the sea, rivers display the diversity of sometimes pouring forth their waters through a single mouth, and distributing them into a variety of channels; circumstances mainly dependent upon the country through which they flow being easily susceptible of excavation or not, and upon the power of the stream. The Ganges pours its flood through the many channels here represented.

The Volga is celebrated for its seventy mouths; and the Rhine, the Nile, Mississippi, and Orinoco pour out their current through several branches. The space enclosed within these various channels is called a delta,

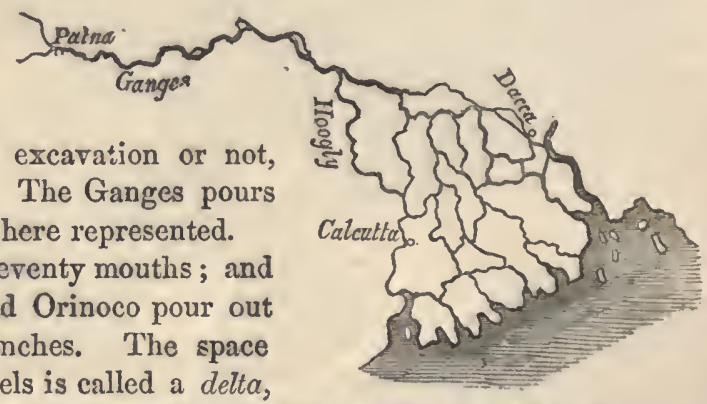
from its triangular form, and general resemblance to the shape of the Greek letter $\Delta$. So powerfully do many of the great rivers rush into the ocean, that their waters are distinct from those of the briny deep, when out of sight of the land. A British fleet lying opposite to the mouth of the Rhone occasionally took up fresh water at a considerable distance from the shore; and Columbus found his vessel in the fresh water of the Orinoco before he discorered the continent of South America. The collision of a great river current and the opposing tide of the sea is sometimes so violent as to occasion an elevated ridge of waters, heaving and tossing in a tremendous manner, shattering to pieces the illfated vessel that comes into contact with it. The passage of the Garonne into the Bay of Biscay, and of the Ganges into the Bay of Bengal, exhibit this plienomenon. Upon the rivers meeting the advancing tides, a conflict ensues for the mastery, and the force of the sea triumphing in the struggle, often sends a mountain-wave up the streams, overturning boats, inundating the banks, and causing extensive destruction. The most remarkable example of this struggle for empire, between the waters of the land and of the deep, occurs off the mouth of the Amazon, and is the Indian pororoca. When 
the tide flows out of the river, it pours forth its unshackled current with-greater fury, and meeting at right angles with the ocean current that runs from Cape St. Roque along the north-east coast of Brazil, the shock of these two bodies raises their waters into an embankment, upwards of a hundred feet in height. The roar of the clashing waves is heard for miles around, and the fishermen and mariners fly in terror from the scene till the strife is over, speedily to be renewed.

In treating of the magnitude of rivers, some writers refer to the elevation of the range of mountains from which they descend; and it is obviously true, that the greater the height of the mountains, the more extensive are their snows and glaciers, and the larger the supply of water furnished by springs and torrents. But the magnitude of a stream is more especially regulated by the extent of country which forms the declivities of its basin, though there is no invariable proportion here, for a small basin in a humid region will yield a greater quantity of water than one much more considerable in a different situation. High mountains, a humid climate, and a wide superficial drainage, are the three physical circumstances which lead to the accumulation of vast bodies of water, the magnitude of which will be proportionate to the degree in which these causes are in combined operation. Upon the surface of the New World, we have these causes acting with greater intensity than upon that of the Old, which explains the superior character of the streams of the western continent. The following table exhibits the extent of the hydrographical regions of the principal rivers of the globe, with the proportionate size of their basins :

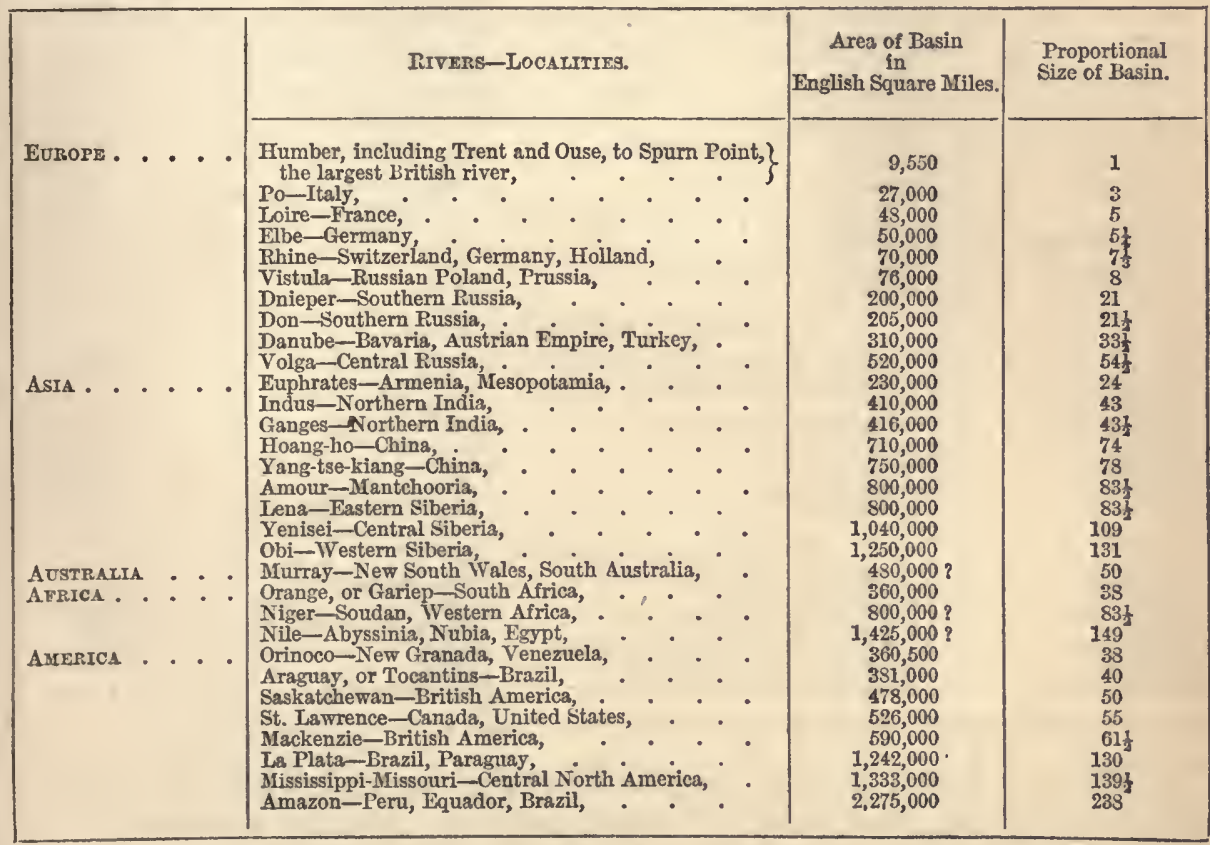

Rivers, according to their termination, may be grouped in two grand classes, the continental and the oceanic. The continental are those which have no communication at all with the ocean, but discharge their waters into completely insulated lakes, or lose themselves in sands and swamps. Thus the Volga, Kour, Terek, and Ural, terminate in the Caspian; the Amou, or Jihoon (ancient Oxus), the Sir, or Sihoon (ancient Jaxartes), flow to Lake Aral ; and the Jordan finishes its course in the Dead Sea. On the lofty tablelands of Mexico, Bolivia, and Central Asia, there are respectively the Rio Grande, Desaguadero, and Yarkand, which are entirely confined to those elevated regions, termi- 
nating in lakes, marshes, or sands. This is the case also with many streams in the interior of Africa. On the contrary, the oceanic rivers either flow direct into the main ocean, or into seas, bays, and gulfs, directly communicating with it. This class embraces the great majority, which are referred to their respective oceanic basins in the annexed table.

\section{I.-SYSTEM OF THE ARCTIC OCEAN.}

\begin{tabular}{|c|c|c|c|}
\hline Iivers. & RISE. & TERMINATION. & $\begin{array}{c}\text { Iength in } \\
\text { English Miles. }\end{array}$ \\
\hline $\begin{array}{l}\text { Lena. } \\
\text { Olensk. } \\
\text { Yenisci. } \\
\text { Obi. } \\
\text { Petchora. } \\
\text { Dwina. } \\
\text { Mackenzie. }\end{array}$ & $\begin{array}{l}\text { Heights near Irkutsk, E. Siberia. } \\
\text { Eastern Siberia. } \\
\text { Mongolian Desert, Chincse Empiro. } \\
\text { South slope of the Altai Mountains. } \\
\text { Ural Mountains. } \\
\text { Heights of Vologda. } \\
\text { West side of the Rocky Mountains. }\end{array}$ & $\begin{array}{l}\text { Asiatic Arctic Ocean. } \\
\text { Ditto. } \\
\text { Ditto. } \\
\text { Ditto, Gulf of Obi. } \\
\text { European Arctic Ocean. } \\
\text { Ditto, White Sea. } \\
\text { American Arctic Ocean. }\end{array}$ & $\begin{array}{r}2,770 \\
1,150 \\
3,230 \\
2,670 \\
695 \\
1,000 \\
2,440\end{array}$ \\
\hline \multicolumn{4}{|c|}{ II.-SYSTEM OF THE ATLANTIC OCEAN. } \\
\hline $\begin{array}{l}\text { Humber (Trent Dranch). } \\
\text { Vistula. } \\
\text { Elbe. } \\
\text { Rhine. } \\
\text { Loire. } \\
\text { Rlione. } \\
\text { Po. } \\
\text { Danube. } \\
\text { Dnieper. } \\
\text { Don. } \\
\text { Nile. } \\
\text { Senegal. } \\
\text { Niger. } \\
\text { Orange, or Gariep. } \\
\text { Saskatchewan. } \\
\text { St. Lawrence. } \\
\text { Mississippi-Nissouri. } \\
\text { Rio-del-Norte. } \\
\text { Magdalena. } \\
\text { Orinoco. } \\
\text { Amazon. } \\
\text { Araguay or Tocantins. } \\
\text { St. Francisco. } \\
\text { La Plata. }\end{array}$ & $\begin{array}{l}\text { Moorlands of North Staffordshire. } \\
\text { Austrian Silesia. } \\
\text { Elb-brunnen, Bohemia. } \\
\text { Rhetian Alps. } \\
\text { Mont Gerbier-le-Joux, Cevennes Mountains. } \\
\text { Glacier of Mont Furca, Switzerland. } \\
\text { Monte Viso, Cottian Alps. } \\
\text { Black Forest, Swabia. } \\
\text { Alaunian Hills, government of Smolensk. } \\
\text { Lake Ivanhof, government of Tula. } \\
\text { Unknown, but South of the Fquator. } \\
\text { Near Teembo, N. E. of Sierra Icone. } \\
\text { Base of Mount Ioura, Soudan. } \\
\text { Mountains N. W. of Jort Natal. } \\
\text { West slope of Rocky Mountains. } \\
\text { West of Lake Superior. } \\
\text { West slope of Rocky Mountains. } \\
\text { Sierra Verde, New Mexico. } \\
\text { Andes of New Granada. } \\
\text { Mountains of Spanish Guiana. } \\
\text { East slope of the Andes, in Teru. } \\
\text { Southern Brazil. } \\
\text { Sierra dos Vertentes, Brazil. } \\
\text { South-Westcrn Brazil. }\end{array}$ & $\begin{array}{l}\text { German Ocean, or Nortli Sea. } \\
\text { Baltic, Gulf of Dantzic. } \\
\text { North Sea. } \\
\text { Ditto. } \\
\text { Bay of Biscay. } \\
\text { Gulf of Lyons, Mediterranean. } \\
\text { Adriatic Sea. } \\
\text { Black Sea. } \\
\text { Ditto. } \\
\text { Sea of Azof. } \\
\text { Mediterranean. } \\
\text { North Atlantic. } \\
\text { Ditto, Bight of Benin. } \\
\text { South Atlantic. } \\
\text { Hudson's Bay. } \\
\text { North Atlantic. } \\
\text { Gulf of Mexico. } \\
\text { Ditto. } \\
\text { Caribbean Sea. } \\
\text { North } \Lambda \text { tlantic. } \\
\text { South Atlantic. } \\
\text { Ditto. } \\
\text { Ditto. } \\
\text { Ditto. }\end{array}$ & $\begin{array}{r}171 \\
600 \\
790 \\
695 \\
600 \\
648 \\
500 \\
1,725 \\
1,210 \\
1,110 \\
3,600 ? \\
1,140 \\
3,000 ? \\
1,000 ? \\
1,920 \\
2,070 \\
4,100 \\
1,400 \\
1,050 \\
1,560 \\
3,550 \\
1,400 \\
1,600 \\
2,210\end{array}$ \\
\hline $\begin{array}{l}\text { Amour. } \\
\text { Ifoang-ho. } \\
\text { Yang-tse-kiang. } \\
\text { Si-kiang. } \\
\text { Meinam. } \\
\text { Cambodia. } \\
\text { Columbia. } \\
\text { Colorado. }\end{array}$ & $\begin{array}{l}\quad \text { III.-SYSTEM OF THE PACIFIC } \\
\text { Fronticr of Russlan and Chinese Empires. } \\
\text { Koulkoun Mountains, Chinese Fmpire. } \\
\text { Ditto. } \\
\text { Interior of China Proper. } \\
\text { Interior of Siam. } \\
\text { Thibet. } \\
\text { Rocky Nountains. } \\
\text { Unexplored. }\end{array}$ & $\begin{array}{l}\text { OCEAN. } \\
\text { Sea of Okhotsk. } \\
\text { Yellow Sea. } \\
\text { Ditto. } \\
\text { Gulf of Canton. } \\
\text { China Sea. } \\
\text { Ditto. } \\
\text { North Pacific. } \\
\text { Ditto, Gulf of California. }\end{array}$ & $\begin{array}{l}2,740 \\
? \\
? \\
1,110 \\
1,080 \\
2,000 ? \\
1,570 ? \\
900 ?\end{array}$ \\
\hline \multicolumn{4}{|c|}{ IV.-SYSTEM OF TIIE INDIAN OCEAN. } \\
\hline $\begin{array}{l}\text { Euplirates. } \\
\text { Indus. } \\
\text { Ganges. } \\
\text { Brahmapootra. } \\
\text { Irawaddy. } \\
\text { Murray. }\end{array}$ & $\begin{array}{l}\text { Highlands of Armenia. } \\
\text { Ilimalaya Mountains. } \\
\text { Glacier in Himalaya Mountains. } \\
\text { North Slope of Himalaya Mountains. } \\
\text { Mountains eastward of Assam. } \\
\text { Coast Chain of New South Wales. }\end{array}$ & $\begin{array}{l}\text { Arabian Sea. } \\
\text { Ditto. } \\
\text { Bengal Sea. } \\
\text { Ditto. } \\
\text { Ditto. } \\
\text { Encounter Bay. }\end{array}$ & $\begin{array}{l}1,720 \\
2,060 ? \\
1,000 \\
2,000 ? \\
2,000 ? \\
1,000 ?\end{array}$ \\
\hline
\end{tabular}

It will be -seen from the table, that the Atlantic receives a much larger proportion of river-water than any other ocean. Of twenty-one rivers, previously enumerated, which drain areas of 300,000 square miles, and upwards, eleven pour their waters into its bed.

The first place among the rivers of the globe is due to the Amazon, if not for the length of its course, yet for the volume of its waters. It traverses the equatorial regions of South America, chiefly in a direction from west to east, and has its embouchure nearly under the equator. Its mouth was discovered in the year 1500 by Pinzon, one of the captains who sailed with Columbus on his first voyage ; and thirty-nine years afterwards, 
the stream was traced downward from Peru by Francisco Orellana, whose name was given to the river by his countrymen, to preserve the memory of his bold enterprise. But the Spaniard's report of having met with armed women on its banks, deprived him of the honour, for it originated the common title of the river of the Amazons. Its principal afluents rival the largest rivers of the Eastern continent, as appears from the following statement of their supposed lengths :-

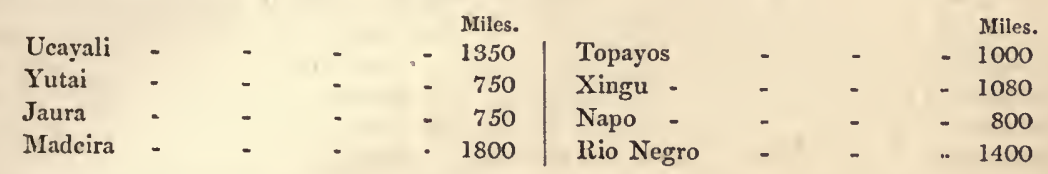

The width of the Amazon arerages from one to two miles in the upper parts of its course, but towards its termination its opposite banks are seen with difficulty, and it widens to upwards of a hundred miles, which is about its breadth upon joining the Atlantic. For two thousand miles in a direct line from the ocean, the river is navigable by vessels of any burden, for at the confluence of the Tunguragua and Ucayali, where the Amazon, properly so called, commences, no bottom was found, in March 1836, with a line of 35 fathoms, or 210 feet. The tide rushes up its channel with immense violence at the period of the full moon, in two, three, and sometimes four successive waves, each presenting a perpendicular front of from ten to fifteen feet. When the tide ebbs in the rainy season, the liberated waters of the river rush out of their channel with tremendous force, and create a current in the ocean, which is perceptible five hundred miles from its mouth. It is difficult to sound the river, owing to the rapidity of its current, which runs commonly at the rate of from three to four miles an hour, - a momentum not arising from the inclination of its bed, the fall of which is very gradual, but from the immense quantity of water which descends in it. The climate of its basin is perhaps the most humid to which any country is subject. The quantity of rain which annually descends upon this region has not been ascertained with precision; but taking that at the town of Maranhão as a sample, which is not less than two hundred inches, the amount of rain poured upon the district of the Amazon every year must be prodigious. The heat also is excessive through the whole year, the thermometer in the shade frequently rising to $106^{\circ}$ when the sun is near the line, a degree of heat not much inferior to that experienced in the Sahara; and as moisture and heat are the most efficient agents in promoting vegetation, hence the luxuriance and energy of vegetable life in the fertile soil on the banks of the river, where the noblest woodland scenery in the world is to be found. Notwithstanding the rapid current of the Amazon, its navigation is easy to ressels both descending and ascending its course, the ascent being facilitated by the far-penetrating tide of the Atlantic, assisted by the wind, which is always blowing from the east, a direction contrary to that of the stream. But the effect of the presence and absence of civilisation is nowhere more strikingly exhibited than on the waters of the South American river, and those of its rivals, the Mississippi, and the Yang-tse-Kiang of the Chinese empire. The ressels that annually appear upon the surface of the Amazon are, probably, not more than those which monthly navigate the Mississippi, or daily pass along the course of the Yang-tse-Kiang.

At the head of rivers, classed according to their length, the Mississippi is to be placed, taking the Missouri branch, which ought to be the name of the united stream, not only on account of its longer course, but because it brings down a greater body of water, and imparts its turbid character to its rival. Geographers have, however, given the former name to the joint rivers, the "Father of Waters," according to its Indian signification, which may be aptly applied to the great central valley of North America, furnishing the 
following streams, which unite in the channel of the Lower Mississippi, and pour down through it into the Gulf of Mexico:-

\begin{tabular}{|c|c|c|c|c|c|c|c|c|c|}
\hline St. Peter's & - & - & - & $\begin{array}{r}\text { Miles. } \\
-\quad 500\end{array}$ & Kaskaskia & - & - & - & $\begin{array}{l}\text { Miles. } \\
300\end{array}$ \\
\hline Penaca, or I & Turkey & - & - & - 200 & Maramee & - & - & - & 200 \\
\hline Iowa & - & - & - & 350 & St. Francis & - & - & - & 450 \\
\hline Chacaguar & - & - & - & 200 & White & - & - & - & - 600 \\
\hline Des-moines & - & - & - & 600 & Arkansas & - & - & - & - 2500 \\
\hline St. Croix & - & - & - & 300 & \multicolumn{2}{|c|}{ Canadian } & - & - & - 1000 \\
\hline Chippewa & - & - & - & 300 & \multicolumn{2}{|c|}{ Neosho - } & - & - & - 800 \\
\hline Wisconsin & - & - & - & 600 & Red River & - & - & - & - 2000 \\
\hline Rock River & - & - & - & 450 & \multicolumn{2}{|c|}{ Washita - } & - & - & - 800 \\
\hline Illinois & - & - & - & 500 & Ohio - & - & - & - & -1250 \\
\hline Salt - & - & - & - & - 250 & \multicolumn{2}{|c|}{ Alleghany } & - & - & $-\quad 350$ \\
\hline Missouri & - & - & - & - 3300 & \multicolumn{2}{|c|}{ Monongahela } & - & - & 300 \\
\hline Yellows & stone & . & - & -1000 & \multicolumn{2}{|c|}{ Kanawha } & - & - & 450 \\
\hline Little I & Missouri & - & - & - 300 & \multicolumn{2}{|c|}{ Kentucky } & - & - & 360 \\
\hline Shienne & - & - & - & 300 & Green & - & - & - & 300 \\
\hline Quicour & & - & - & 500 & \multicolumn{2}{|c|}{ Cumberland } & - & - & 600 \\
\hline Platte & - & - & - & -1200 & \multicolumn{2}{|c|}{ Tennessee } & - & - & -1500 \\
\hline Kansas & - & - & $=$ & - 800 & \multicolumn{2}{|c|}{ Muskingum } & - & - & 200 \\
\hline Osage & - & - & - & 500 & \multicolumn{2}{|c|}{ Scioto - } & - & - & 200 \\
\hline Gascona & ade & - & - & 300 & \multicolumn{2}{|c|}{ Waybash } & - & - & 550 \\
\hline Jacques & - & - & - & 600 & \multicolumn{2}{|c|}{ White River } & - & - & 200 \\
\hline Sioux & - & - & - & 500 & Hatchy & - & - & - & 200 \\
\hline Grand & - & - & - & 500 & Yazoo & - & - & - & 300 \\
\hline \multicolumn{2}{|c|}{ Chariton } & - & - & 200 & Big Black & - & - & - & 200 \\
\hline
\end{tabular}

The most beautiful tributary of the Mississippi is the Ohio, the Belle rivière of the early French settlers, the only large river it receives from the east. No stream rolls for the same distance so uniformly and peacefully; its banks are adorned with the largest sycamores, its waters clear, and studded with islands covered with the finest trees. All the other great tributaries flow from the west, its confluence with the Missouri, which enters it like a conqueror, and carries its white waves to the opposite shore, presenting one of the most extraordinary views in the world. The country around these vast watercourses is of the most varied description, alternately exhibiting wild rice lakes and swamps, limestone bluffs and craggy hills, deep pine forests and beautiful prairies, the prairies showing an almost perfect level, in summer covered with a luxuriant growth of grass and flowers, without a tree or a bush, the only tenants of which are elks and buffaloes, bears and deer, and the savages that pursue them. The bluffs of the Mississippi are for the most part perpendicular masses of limestone, often shooting up into towers and pinnacles, presenting at a distance the aspect of the battlements and turrets of an aneient city. In the season of inundation below the mouth of the Ohio, the river presents a rery striking spectacle. It sweeps along in curves or sections of circles, from six to twelve miles in extent, measured from point to point, and not far from the medial width of a mile. On a calm spring morning, and under a bright sun, this sheet of water shines like a mass of burnished silver, its edges being distinctly marked by a magnificent outline of cotton wood trees, at this time of the year of the brightest verdure, among whicl those brilliant birds of the country, the black and red bird, and the blue jay, flit to and fro, or wheel their flight over them, forming a scene which has all of grandeur or beauty that nature can furnish, to soothe or enrapture the beholder. The curvilinear course of the Mississippi is one of its most striking peculiarities. It meanders in uniform bends, which, in many instances, are described with a precision equal to that obtained by the point of a compass. The river sweeps round the half of a circle, and is then precipitated in 
a diagonal direction across its own channel, to another curve of the same regularity upon the opposite shore. Instead of calculating distances by miles or leagues, the boatmen and Indians estimate their progress by the number of bends which they have passed. This conformation, which distinguishes most of the streams of the Mississippi valley, must have transpired under the operation of some law, but hitherto no solution of the problem has been given which is quite satisfactory. Geological appearances indicate that this stream, like the Orinoco, had in former ages a much broader volume, though a shorter course; that, in fact, it once found its estuary not far below the present mouth of the Ohio, the alluvial country now stretching from thence to the south, near a thousand miles, being then an arm of the sea. "No thinking mind," says Flint, "can contemplate this mighty and resistless wave, sweeping its proud course from point to point, curving round its bends through the dark forests, without a feeling of sublimity. The hundred shores, laved by its waters; the long course of its tributaries, some of which are already the abodes of cultivation, and others pursuing an immense course without a solitary dwelling of civilised man on their banks; the numerous tribes of savages that now roam on its borders; the affecting and imperishable traces of generations that are gone, leaving no other memorial of their existence, or materials for their history, than their tombs, that rise at frequent intervals along its banks; the dim, but glorious anticipations of the future; - these are subjects of contemplation that cannot but associate themselves with the view of this river."

Though far inferior to these streams of the western world, in point of length and volume, the Nile of the ancient continent may be placed at the head of remarkable rivers. One of its chief peculiarities is the solitary grandeur of its flow, for not a single affuent enters it, from the junction of the Tacazze to the sea, a distance of 1500 miles, a circumstance without a parallel in the physical condition of rivers. Another of its striking features is its long course through a desert, dry, barren, and hideous, depositing by its annual inundation, the richest soil on those portions of it which lie contiguous to its banks; and hence has originated the apt comparison of its career to the path of a good man amidst an evil generation. Egypt would be completely sterile, were it not for the periodical overflow of its only stream, which both covers a large part of its surface with a layer of alluvion, and imparts to it the requisite moisture.

$$
\begin{aligned}
& \text { "Rich king of floods ! o'erflows the swelling Nile - } \\
& \text { The joyless desert, down the Nubian rocks } \\
& \text { From thund'ring steep to steep, he pours his urn, } \\
& \text { And Egypt joys beneath the spreading wave." }
\end{aligned}
$$

It requires the river to attain a medium rise in order to benefit the country; too little, involving scarcity and famine; too much, compromising the safety of the people and their dwellings. Wilkinson calls a rise of 19 cubits tolerable ; 20 good; 21 sufficient, while a rise of 22 cubits is abundant enough to fill every canal ; and a rise of 24 cubits would overwhelm and ruin the villages. A cubit is rather more than 21 inches, so that in order fully to meet the wants of the country, a perpendicular rise of 38 feet is necessary. The Nile is also distinguished among rivers for the pleasant taste and salubrity of its waters, when not in flood; properties highly extolled by the ancients, and acknowledged to belong to it by modern travellers. It is a common saying with the Egyptians, that if Mahomet had tasted of its stream, he would have sought a terrestrial immortality in order to enjoy it for ever. The physical circumstances of the river easily account for the possession of this attribute. The air above is pure and serene. But little rain falls upon the country through which the greater part of its course is prosecuted, and no snow or hail. Hence there is little drainage into it from the surrounding land, and its waters are kept free 
from any noxious taint derived from earths and minerals, except from those in its immediate channcl. The same property of being remarkably pure and salutary, is ascribed by Herodotus to one of the Susianic rivers, of which alone, according to tradition, none but the kings of Persia drank.

“There Susa, by Choaspes' amber stream,

The drink of none but kings."

The Susianic streams, along with the Nile, may not improperly be styled the oldest rivers of the globe, because of their place in its most ancient traditions and histories; and however subordinate to the gigantic currents of the western hemisphere, those of the eastern in general present higher points of interest, in their long known identification with the destinies of mankind. If not the actual birth-place of man, the great plains on the banks of the Tigris and the Euphrates were the abode of the founders of the diluvian race. There, the two greatest citics of the ancient world, Nineveh and Babylon, rose into magnificence. There, a supernatural finger traced the doom of the latter upon the palace wall of its trembling monarch, while an exiled Jew, in the majesty of inspiration, gave him the interpretation of the mystic writing. There, too, in later ages, the same neighbourhood witnessed the catastrophe of Cunaxa, and the bold bearing of the indomitable ten thousand-the splendid empire of the Medes and Persians overthrown by the Macedonian on the field of Arbela-the defeat and death of Crassus-the retreat of Mark Antony - the fall of the apostate Julian-and the short-lived glory of Bagdad. How different the associations connected with the Arkansas and the Osage to those of the Euplrates and Tigris!

\section{CHAPTER VII.}

LAKES.

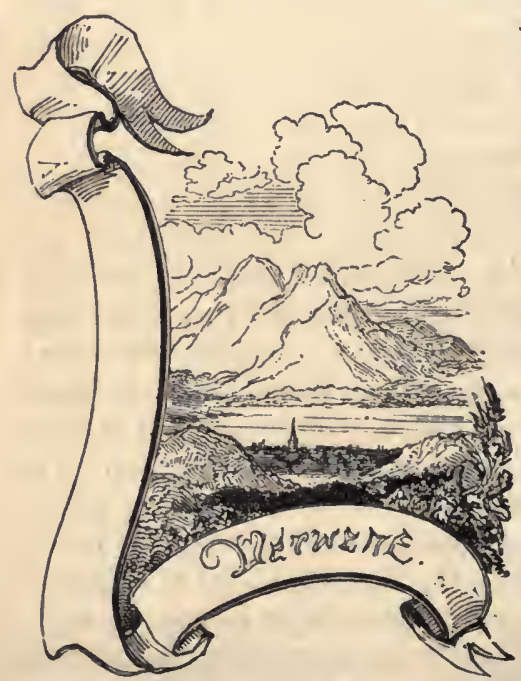

ARGE or small collections of water, fresl or saline, and surrounded by land, are termed lakes, and have an aspect, upon the face of the continents, similar to that of islands in the ocean. They differ from reservoirs in not being artificial, but natural, formations; and from lagoons, which are simply the overflowings of rivers in the season of flood, or portions of the sea which have encroached upon the land, and becn separated from the parent deep by the gradual accumulation of banks of sand, or barriers of earthy material. They differ also from pools, which are mere collections of rain-water in hollow places, generally dried up in periods of drought; whereas true lakes are formed in vacuities, either by streams flowing into them from the surface, or by springs gushing up from their bed. These fluvial formations may be referred to a great varicty of causes, the action of some being of ancient, and others of comparatively modern date. It is supposed that many lakes are the remains of the universal ocean which once covered the earth, the waters of which have 
retained their saltness where there was no outlet, but have lost it in other cases, by receiving constant supplies of fresh water through rivers, and continually letting off the salt through outlets. Owing to the subsidence of the soil, or the falling in of the roof of a subterranean cavity, in periods of internal convulsion, the superficial waters of the surrounding country have been drained into the hollows thus created, and aqueous expansions have been formed. Others have been caused by land avalanches, and the projection of lava currents across streams, occurring within the memory of man; but the great majority of lakes date their existence from the time when the crust of the globe received its present general outline, and were produced by the waters encountering those inequalities of the surface which mark its configuration. A river, impeded in its course by mountainous elevations, either effects its passage by winding about their lateral extremities; or, if enclosed on all sides, it forms a lake, which, rising to a level with some gorge in the interposing barrier, pours its surplus waters through it. A river, also, meeting with an abrupt and broad depression in the plain or valley which it traverses, fills the basin, and forms itself into a lake, the superfluous waters flowing away at the opposite extremity. There is a striking, though in one respect insensible, relation subsisting between rivers and considerable lakes. The former visibly feed the latter; and the latter no less certainly feed the former, thougl in a manner that is not so apparent to our senses. By a process of evaporation, the lakes are continually giving off a portion of their mass, which rises in the atmospliere in the form of vapour, and again visits the earth in the form of rain, originating the springs and rills, which unite in rivers, flow into the lakes, and replace their waste. 'There is no machinery of nature more complicated, beautiful, nicely adjusted, and benign in its results than this; for hereby the earth is preserved either from perpetual barrenness, through want of moisture; or from submergence, through the ocean overfowing its present bounds.

The lakes of primary regions are distinguished by the wild and romantic character of their scenery, rugged precipices and dark forests usually lining their shores, and rocky

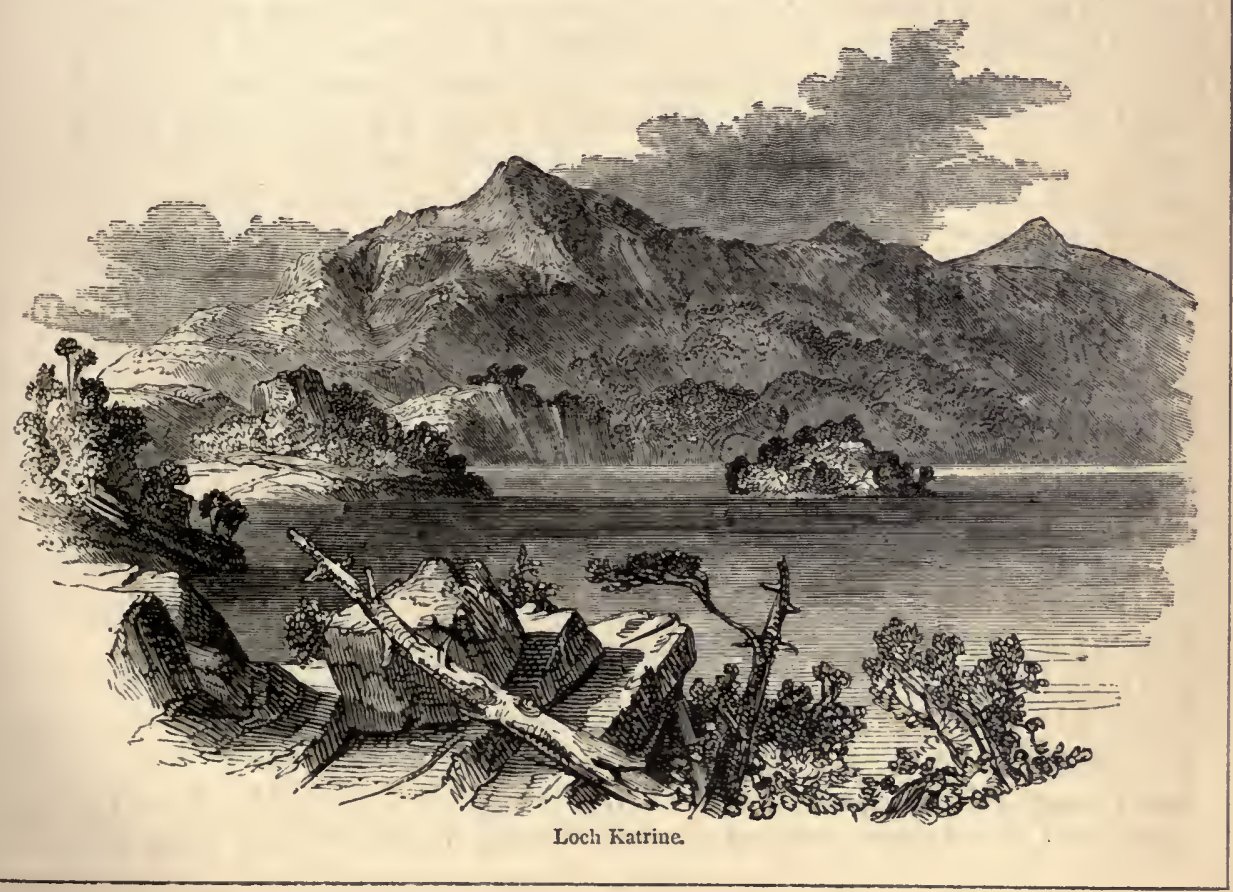




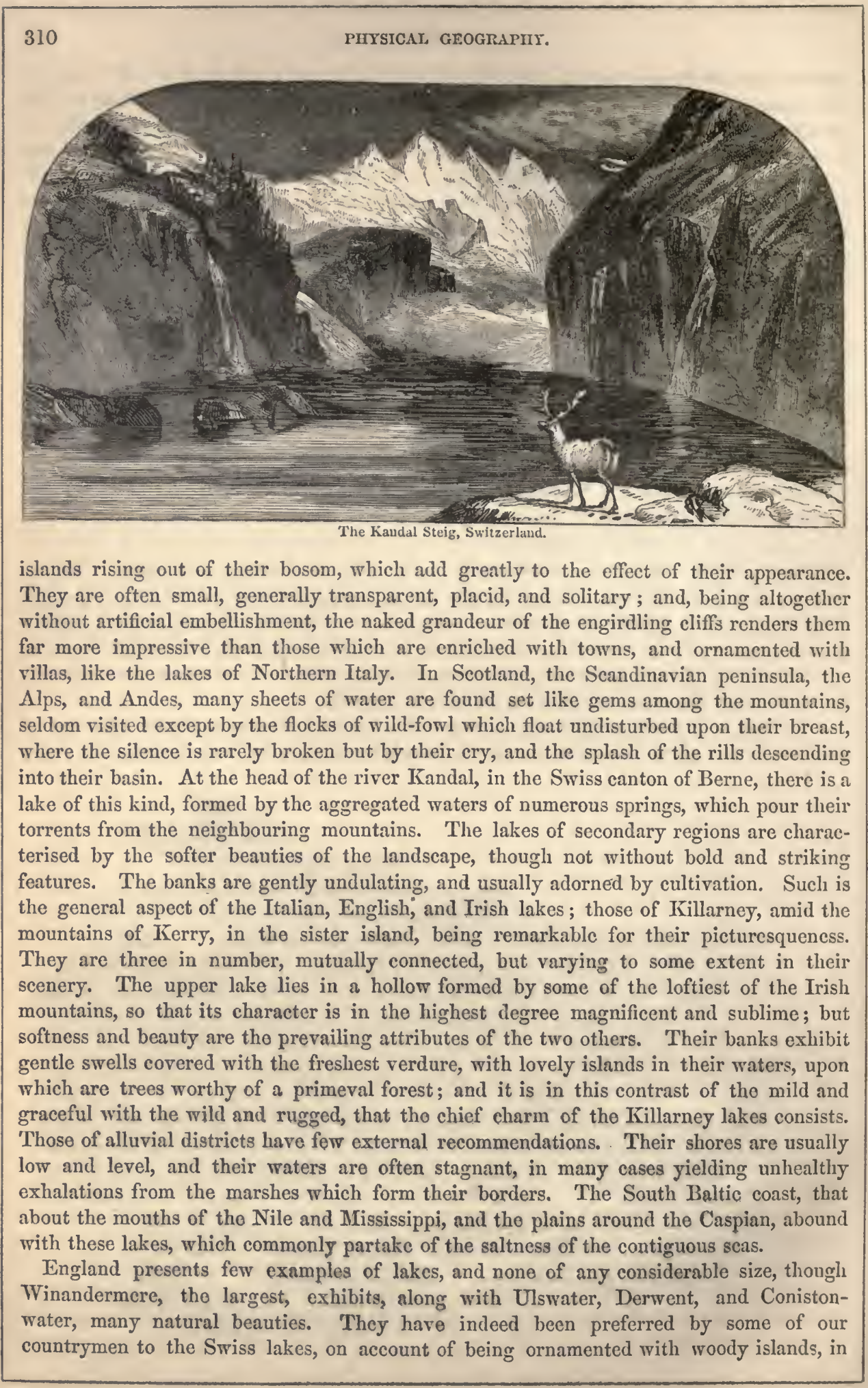


which those of Savoy and Switzerland are deficient; and perhaps, apart from this, a physical cause may be found for the preference, in the case of passing visitors, independent of all national partiality. Owing to the greater transparency of the atmosphere in Switzerland, the giant mountains east of the Lake of Geneva do not appear at first more elevated than the comparative dwarfs at the head of Ulswater, to an eye unaccustomed to so clear a medium. Hence, the first impressions of the Alps are commonly the feeblest, a due appreciation of their magnitude being the fruit of acquaintance; whereas, a denser atmosphere gives to our scenery fictitious features, which acquaintanceship corrects. In Scotland the lakes are more numerous and important, the superficial dimensions of each of the following twenty-four exceeding the area of Winandermere.

\begin{tabular}{|c|c|c|c|c|c|c|c|c|c|}
\hline Loch Lomond & - & - & - & $\begin{array}{l}\text { Sq. Miles. } \\
-45\end{array}$ & Loch Ericht & - & - & - & $\begin{array}{l}\text { Sq. Miles. } \\
-10\end{array}$ \\
\hline Awe & - & - & - & -30 & Earn & - & - & - & $\begin{array}{l}-9 \\
-\end{array}$ \\
\hline Ness & - & - & - & -30 & Naver & - & - & - & 9 \\
\hline Shin & - & - & - & -25 & Stennis & - & - & - & 8 \\
\hline Maree & - & - & - & -24 & Rannoch & - & - & - & 8 \\
\hline Tay & - & - & - & -20 & Leven & - & - & - & 7 \\
\hline Arkeig & - & - & - & -18 & Fuir & . & - & - & 6 \\
\hline Shiel & - & - & - & $: 16$ & Lydoch & - & - & - & 6 \\
\hline Lochy: & - & - & - & -15 & Ken & - & - & - & 6 \\
\hline Laggan & - & - & - & -12 & Loyal & - & - & - & 6 \\
\hline Morier & - & - & - & -12 & Glas & - & - & - & \\
\hline Fannich & - & - & . & $=10$ & Katterin & - & - & - & 5 \\
\hline
\end{tabular}

In Ireland they are still more considerable, Lough Neagh, in the centre of Ulster, being the largest lake in the United Kingdom, more than three times the size of Loch Lomond, having a superficial extent of nearly 100,000 acres. The total superficial area of the Irish Lakes is supposed to amount to 455,399 imperial acres.

The annexed table gives the extent of the principal European lakes.

\begin{tabular}{|c|c|c|c|c|c|}
\hline Ladoga, Russia & - & $\begin{array}{l}\text { Sq. Miles. } \\
-\quad 6330\end{array}$ & Ilmen, Russia - & - & $\begin{array}{l}\text { Sq. Miles. } \\
-\quad 275\end{array}$ \\
\hline Onega, ditto & - & -3280 & Lexa, ditto - & - & - 229 \\
\hline Wener, Sweden & - & - 2136 & Ulea, Finland - & - & - 229 \\
\hline Saimas, Finland & - & -1602 & Garda, Italy - & - & -183 \\
\hline Peipouss, Russia & . & $-\quad 839$ & Maggiore, ditto & - & - 152 \\
\hline Wetter, Sweden & -. & 839 & Nesi, Finland - & - & -152 \\
\hline Mælar, ditto & - & 763 & Balaton, Hungary & - & - 152 \\
\hline Enara, Lapland & - & 656 & Neufchatel, Switzerlang & - & -114 \\
\hline Kuopio, Finland & - & 610 & Lake of the Four Cant & ons, ditto & - 99 \\
\hline Geneva, Switzerland & - & 336 & Zurich, ditto - & - $\quad-$ & -76 \\
\hline Constance, ditto & - & 290 & Bielo, Osero, Russia & - & $-\quad 53$ \\
\hline
\end{tabular}

The largest lake in the world, the Caspian, is geographically situated both in Europe and Asia, but is commonly classed with the physical features of the latter country, and styled a sea from its size and saltness. Measured according to its curvilinear shape, in the middle of its breadth, it exceeds 900 miles in length, with an average width of 200 , and has an area of nearly 160,000 square miles. The next in extent, that of Aral, has, with the Caspian, received the denomination of an inland sea, and is nearly a fourth part of its size. The Lake Baikal, in Siberia, has a computed area of 20,000 square miles, and, both in central and western Asia, there are large expanses of nearly equal extent. In Africa, lagoons occur along the coasts; small briny pools, also, are common in the deserts; but the interior is a great mass of solid land, seldom broken by either rivers or lakes. The chief of the latter, and the best known, is that of Dembia, nearly centrical in Abyssinia, measuring, in Bruce's map, 65 miles in its greatest length. The Tchad, in Central Africa, is much larger, but has extensive shallows, and varies vastly in its volume, according 
to the scason. This is the case also with the Ngami, in Southern Africa, the first of the discoveries of the intrepid Dr. Livingstone. The northern part of the western world is precminently the country of lakes, presenting the largest masses of fresh water to be found upon the surface of the globe. The following statement shows the area of the principal:-

\begin{tabular}{|c|c|c|c|c|c|c|c|c|c|}
\hline \multicolumn{2}{|c|}{ Lake Superior } & - & - & $\begin{array}{l}\text { Sq. Miles. } \\
-\quad 40,000\end{array}$ & Winnipeg & - & $=$ & . & $\begin{array}{r}\text { Sq. Miles. } \\
-\quad 9,000\end{array}$ \\
\hline Huron & - & - & - & - $\quad 25,000$ & Athabasca & - & - & & 3,000 \\
\hline Michigan & - & - & - & $-\quad 25,000$ & Great Slave & Lake & - & & - $\quad 12,000$ \\
\hline Erie & - & - & - & - 11,000 & Great Bear & Lake & - & & - $\quad 8,000$ \\
\hline Ontario & - & - & - & - 10,000 & Champlain & - & - & & 500 \\
\hline
\end{tabular}

In South America, the Lake of Titicaca, in Upper Peru, covers a surface of about 4000 square miles; and immense swampy plains and lagoons are common along the course of the rivers.

Lakes are sometimes considered under the two divisions of fresh and salt water, but there are many occupying intermediate stations with reference to these extremes. We shall follow another arrangement of them, into four classes, which will more fully embrace their physical conditions, and then notice some remarkable phenomena, by which several are distinguished.

1. There is a class which have no apparent affluents or outlets. They are fed cliefly by subaqueous springs, and occur frequently in hollows, which have the appearance of extinct volcanic craters. 'They are generally small, but of more stable character than the larger sheets of water formed by rivers. Not receiving any great superficial current, they are not subject to those changes of their depth and outline, which take place in the lakes with affluents, through deposition of the mud and sand brought into them by turbid torrents. Collections of water of a similar kind abound in the great steppes of northern and western Asia. They are called lakes, but are perhaps more properly pools, being formed of accumulated rains and melted snow, which are largely, and in somc cases entirely, evaporated by the summer heat, though several have a circumference of from ten to twelve miles, and a depth of six or seven feet. Their waters are commonly saline, and what is most remarkable, and hitherto unexplained, sheets of fresh water are found in their immediate vicinity. The most considerable example of this class is the Lake of Tuzla, which lies northward of the great range of Taurus, on the high central plateau of the Lesser Asia. Though narrow, it extends fifty miles in length, and is so extremely salt, that no fish or aquatic animal can live in it. Even the wild fowls are afraid to venture upon its waters, for by so doing their wings become stiff with a thick coating of salt, and any substance thrown into them speedily receives a saline incrustation. Strabo, the geographer of antiquity, a native of the peninsula, was personally acquainted with this lake, and mentions these circumstances, the accuracy of which, modern travel has confirmed. The Sultan Murad IV. made a causeway across it, upon the occasion of marching lis army to the attack of Bagdad, for, owing to cxcessive evaporation during the summer and autumn heats, the lake is extremely shallow. The remains of this causeway are now almost concealed by a saline encasement, and a thick crust of solid salt covers the bed of the lake.

2. Another class have outlets, but no apparent affluents. 'These lakes usually occupy a high elevation above the level of the sea, and derive thcir supplies from subterranean springs. One on Monte Rotondo, in the island of Corsica, is at the lieight of 9000 fect. They are not inconsiderable in number, and are frequently the sources of important rivers. The course of the great Volga may be traced up to a lake of this kind, but which is only slightly elevated above the sea-level.

3. A third class receive affluents, but have no outlets. Lakes of this description are exceedingly rare, but they are the most peculiar of all. That of Celano in Italy, the 


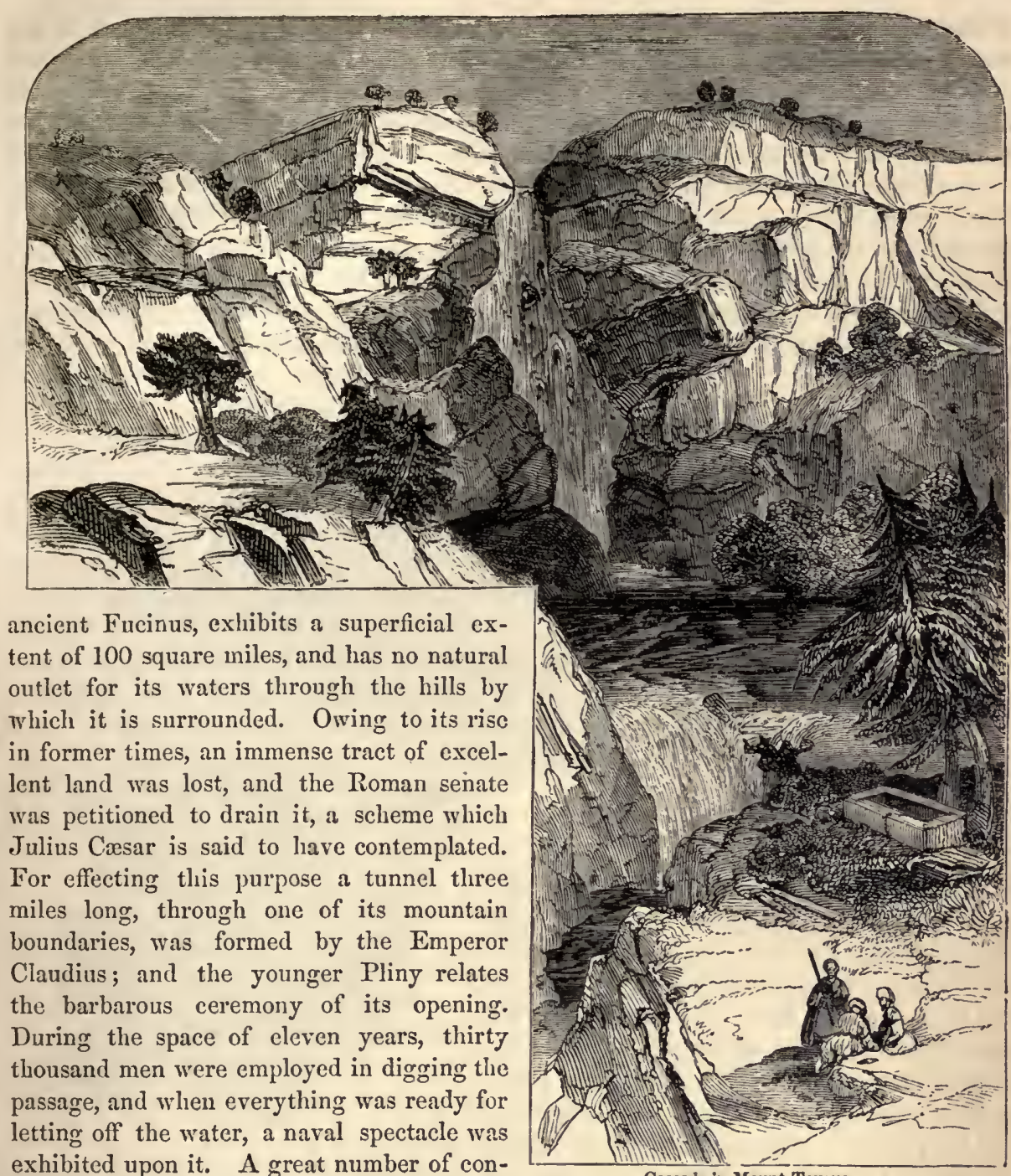

exhibited upon it. A great number of condemned eriminals were ranged in separate

Cascade in Mount Taurus.

fleets, obliged to engage in earnest, and to destroy one another for the entertainment of the court, and the multitude of spectators who covered the hills. A line of wellarmed ressels and rafts, loaded with soldiers, surrounded the scene of action, in order to prevent any of the victims from escaping. Pliny states, however, that when this savage diversion was ended, and the operations for opening the tunnel commenced, the emperor was very near being swept away and drowned, by the sudden rush of the waters towards the rent. The tunnel was speedily choked up, and the Celano lake rose so much as to cover ten thousand acres of fertile soil, when it was again re-opened, and other hydraulic means adopted to keep the waters to a low level. Lakes of this description, without any outward current, though continually receiving large streams, are principally found in Asia, and are for the most part salt. Such is the great Lake of Urumiah on the Persian frontier, which, according to Colonel Kinneir, is three 
hundred miles in circumference, and is land-locked amid the picturesque mountains and valleys of Azerbijan. Though constantly fed by numerous currents, it has no outlet; yet there is no increase of its waters, but a gradual diminution, the waste through evapora. tion being greater than the supply. The lake is intensely salt, as appears from the depositions left upon the beach. For some distance from the brink, a perfect parement of the solid mineral may be seen under the shallows. A village is pointed out as having once overhung its waters, which is now separated from them by a strand covcred with salt, a quarter of a mile broad. Beyond a chain of hills to the north-west lies another cxample, the Lake Van of Armenia, sa celebrated for its beauty by the eastern writers, both in prose and verse. It occupies the bottom of a volcanic amphitheatre, is upwards of 240 miles in circumference, and receives the waters of eight rivers without sending off any stream.

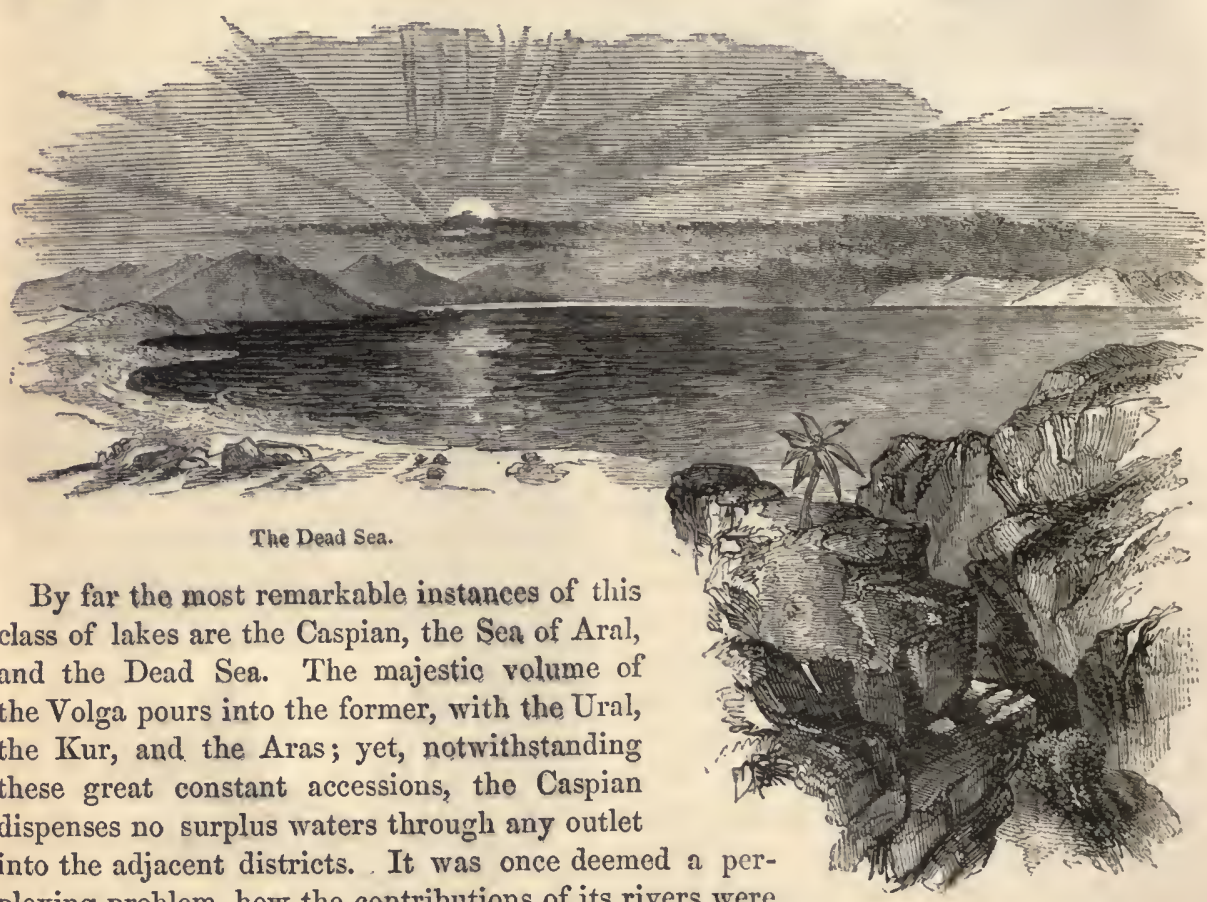
plexing problem, how the contributions of its rivers were

disposed of ; but the evaporation from so vast an expanse during the lieat of summer must be enormous, fully adequate not only to prevent any permanent rise of its level, but gradually to diminish it. The sea of Aral likewise, to the eastward, exhibits the same peculiarity. It received the Jaxartes and Oxus of the ancient geographers, now the Sihoun and Amou, but no stream issues from its banks. Both these bodies of water are salt, and abound with marine productions. All the varieties of sea animals are common to them that are found in the Black Sea, except those transient visitors which arrive in the latter for the purpose of spawning; and hence it has been conceived probable that both were once connected, forming a branch of the main ocean - an extension of the Euxine. The separation of the three, if ever they were united, may have arisen from the deposition of the alluvial conveyed in the course of ages by the Volga and the Don, together with the subterranean action of elastic fluids which belong to this volcanic territory. The Dead Sea, in the south of Palestine, called also by the Latin geographers Lacus Asphaltites, and by the Arabs Bahr Lout, or Lot's Sea, though very insignificant in size, 
when compared with the former, has greater historical and physical interest. It receives that venerated stream, the Jordan, and flows over the presumed site of judgment-stricken cities, while its waters have a peculiar character, owing to their holding salts in excess. The general breadth of the lake, which is very uniform, is estimated by a recent and careful survey at about nine geographical miles, and the length at thirty-nine; but the length appears to vary two or three miles in different years, or seasons of the year, according as the water extends more or less upon the flats at its southern extremity. During the rainy season, the influx derived from the Jordan and other streams is sufficiently copious to raise the level ten or fifteen feet, which is gradually lowered by evaporation under the burning heat of an unclouded sun in summer and autumn. Irby and Mangles speak of observing the effect of the evaporation arising from it, in broad transparent columns of vapour, not unlike water-spouts in appearance, but very much larger. The lake lies in a deep cauldron, surrounded by lofty cliffs of naked limestone rock, the western range running up to the height of 1500 feet above the water, and the eastern to 2500. Sterility and death-like solitude prevail upon its shores, nor is it surprising, considering its dreary aspect, the tremendous catastrophe of the cities once associated with it, and the nature of its waters, that such wild stories should have been so long current respecting this spot. Josephus, after speaking of the conflagration of the plain, remarks, that "there are still to be seen ashes re-produced in the fruits; which, indeed, resemble edible fruits in colour, but on being plucked with the hands are dissolved into smoke and ashes." These are the far-famed apples

"which grew

Near that bituminous lake where Sodom stood,"

but which, stripped of the marvellous, are the 'Ösher of the Arabs. This fruit externally resembles an apple or orange, but is filled chiefly with air, and bursts upon pressure. So far, however, from being peculiar to this region, it is found in great abundance in the Arabian peninsula, and along the valley of the Nile. In July, 1835, the Dead Sea was surveyed for the first time in a boat by Mr. Costigan, an Irishman, with a Maltese sailor as his servant, but who died soon after completing its tour. ML. Stephens was informed by the servant, whom he found at Beyrout, that they had moved in a zig-zag direction, crossing the lake several times; that every day they sounded frequently with a line of 175 brachia, each about 6 feet ; that they found the bottom rocky, and of very unequal depth, sometimes ranging $30,40,80$, and 20 brachia, all within a few boats' length; that sometimes the lead brought up sand, like that of the neighbouring mountains; that they failed but once to find the bottom, and in that place there were large bubbles all around for thirty paces, rising probably from a spring; that in four different places they found ruins, and could clearly distinguish large hewn stones, which seemed to have been used for buildings; that at the south end of the lake a long tongue of high land projects into the water, and is composed of solid salt, which has at a distance the appearance of an island, the extremity being higher than the isthmus. The lake was again surveyed in a boat in March, 1837, by Messrs. Moore and Beke, who found its depth in some places 1800 feet. The aspect of the Mare Mortuum - the deep mountain ravine in which it rolls - the wilderness around-the silence, solitude, and infertility of the district-together with the remembrance of ancient disaster, make a deep impression upon the mind of the visitor, and explain the tales of the ignorant and enthusiastic pilgrims of a former age, who transformed the howling of the wind upon its surface into the cry of guilty spirits haunting its recesses. "The view of this evening," says Dr. Robinson, "from our lofty encampment was most romantic. The whole Dead Sea lay before us. The full moon rose in splendour over the eastern mountains, and poured a flood of silvery 
light into the deep, dark cliasm below, illuminating the calm surface of the sluggish waters. All was still as the silence of the grave. Our Arabs were sleeping round us on the ground; only the tall pensive figure of the sheikh was seen sitting before the door of our tent, his eyes fixed intently upon us as we wrote."

The waters of the Dead Sea are intolerably salt, bitter and nauseous to the taste, so pungent that the eyes smart severely after bathing in them, and extremely buoyant. "Two of us," says the traveller just quoted, "bathed in the sea ; and although I could never swim before, either in fresh or salt water, yet here I could sit, lie, or swim in the water, without difficulty." The following are the analyses of Dr. Marcet in 1807; of Professor Gmelin of Tübingen in 1826; and of Dr. Apjohn of Dublin in 1839. 'The water analysed by the latter was taken from a point just below the mouth of the Jordan, after the rainy season, and hence the smaller proportion of salts, and the less specific gravity, presented by his analysis.

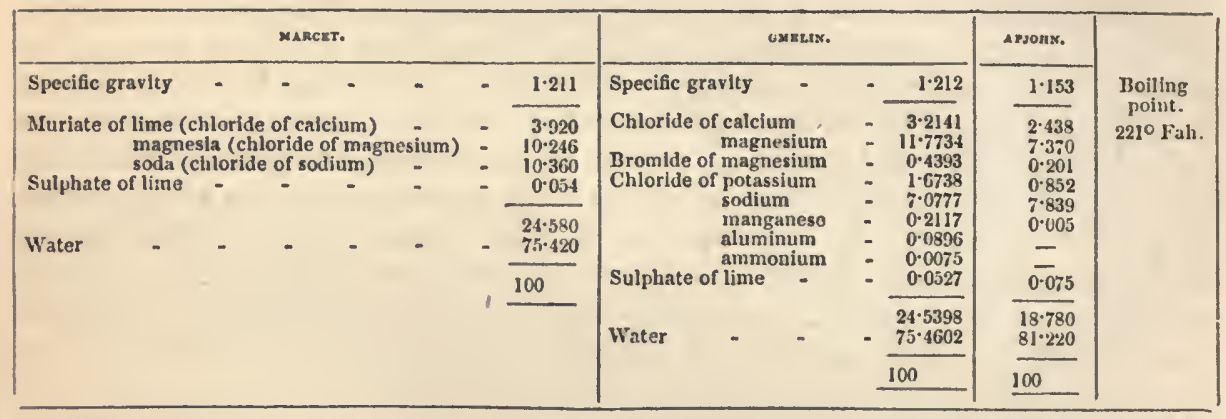

There appears to be no animal or vegetable life in this supersalt sea, and the water-fowl are not attracted to its surface, owing to the absence of their customary food. "I dismounted," says Seitzen, "and followed for a time the shore of the sea, to look for conchylia and sea-plants, but found none of either. And as fish live upon these, it might naturally be expected that no tenants of the waters would exist here ; and this is confirmed by the experience of all whom I have inquired of, and who could know about it. Snails and muscles I have not found in the lake; some that I picked up on the shore were land snails." It is not inprobable, however, that the Jordan, when swollen by the rains, may carry down fish into the lake, or they may voluntarily forsake the rivercurrent; but, as the naturalist Schubert remarks, "they soon pay for this love of wandering with their lives;" and hence small dead fishes are often picked up, which the waves liave thrown upon the strand.

The most remarkable of all the characteristics of the Mare Mortuum, is the depression of its level below that of the Mediterranean. There is no doubt respecting this fact, though estimates vary as the depth of the depression. From several observations on the temperature of boiling water, and by the barometer, Messrs. Moore and Beke inferred its surface to be 500 feet below the level of the ocean. Professor Schubert concluded it to be 600 feet; but MM. Russegger and Bertou, in 1838, made the depression extend to the enormous amount of 1400 feet. The preceding measurements were barometrical; but Lieutenant Symonds of the royal engineers has since surveyed the country intervening between the two seas, and trigonometrically ascertained the level of the Dead Sea to be 1337 feet below that of the Mediterranean. He proceeded from level to level by two different routes, and the results of each differ by merely an insignificant fraction, so that the question may now be said to be decided with exactness. A similar extraordinary circumstance characterises the Caspian and the Sea of Aral, and extends far into the 
interior of the continent, stretching northward to Orenberg on the Ural river, which is 500 versts, or about 335 miles, in a direct line from the shores of the Caspian. The surface of the latter has been found, by levelling across the isthmus, to be about 81 feet below that of the Black Sea. Humboldt considers the depression of this part of the continent to have an intimate connexion with the upheaving of the Caucasian mountains, of the elevated plain of Persia, and perhaps, more to the eastward, with the elevation of the great mass of land which is designated by the vague and incorrect name of the central plain of Asia. These are the more recondite speculations of geology, in favour of which a strong probability pleads. In the desert east of the gulf of Tajura, at the mouth of the Red Sea, one of the hottest and most detestable corners of the globe, a lake has recently become known to European geographers, the Bahr Assal, which is marked by the feature wc are noticing. It is about six or seven miles long, and partially fills a deep hollow in a country of volcanic formation, being 570 feet below the levcl of the neighbouring sea, from which it is divided by a belt about six miles across. The waters are extremely salt, and are constantly receding by evaporation under the action of the intense heat, for when the British mission to Shoa had a day's bivouac in this terrestrial pandemonium, the mercury in the thermometer stood at $126^{\circ}$. The depression of the level of this lake is thus conjecturally, but in a natural and simple manner, accounted for by M. Rochet d'Hericourt. The depth of the innermost basin of the gulf of 'Tajura is not less than 600 feet, or 120 feet below the surface of the salt lake. He supposes the lake to have been anciently a part of the gulf, and to have been dyked off from it by volcanic action. Receiving no fresh water, except after rains, it has been gradually diminished by eraporation, and five hundred cubic feet of depth may be supposed to have been lost since the upheaving took place. According to this conjecture, the bed of the lake and of the adjacent sea are on the same level, but the surface of the lake has been reduced below that of the sea, in the lapse of years, by the evaporation of a torrid climate, acting without sufficient compensation.

In striking contrast with the depression of these lakes, is the height of others in the following table, which exhibits remarkable variations.

\begin{tabular}{|c|c|c|c|c|c|c|c|c|}
\hline \multirow[b]{2}{*}{ Killarney, } & \multirow[b]{2}{*}{ Ireland } & \multirow[b]{2}{*}{ - } & \multirow[b]{2}{*}{-} & $\begin{array}{l}\text { Feet aboro } \\
\text { the Level } \\
\text { of the Sea. }\end{array}$ & & $\begin{array}{l}\text { Feet above } \\
\text { the Level } \\
\text { of the Sea. }\end{array}$ \\
\hline & & & & -50 & Micligan, North & erica & - & $-\quad 594$ \\
\hline Neagh, & ditto & - & - & $4 S$ & Nicaragua, Centr & merica & - & - 134 \\
\hline Corrib, & ditto & - & - & 16 & Titicaca, Peru & - & - & $-18,000$ \\
\hline Erne, & ditto & - & - & 140 & Sir-i-Kol, Central & & - & $-15,600$ \\
\hline Derg, & ditto & - & - & 98 & Geneva, Switzerl & 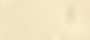 & - & - 1152 \\
\hline Allen, & ditto & - & - & -160 & Neufchâtel, ditto & - & - & - 1437 \\
\hline Skene, Sco & tland & 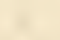 & - & -1300 & Lucerne, ditto & - & - & - 1320 \\
\hline Wetter, Sw & veden & - & - & - $\quad 288$ & Annecy, & - & - & -1460 \\
\hline Wener, d & litto & & - & $-\quad 144$ & Zurich, ditto & - & - & - 1279 \\
\hline Strand, No & orway & - & - & -1137 & Maggiore, Italy & - & - & - 640 \\
\hline Miose Van & d, ditto & - & - & -1576 & Como, ditto & - & - & 650 \\
\hline Oresund & ditto & - & - & - 2400 & Iseo, & - & - & 630 \\
\hline Superior, & North A & erica & - & -623 & Garda, & - & - & 256 \\
\hline Huron, & ditto & - & - & - $\quad 591$ & Albano, & - & - & $\begin{array}{l}-\quad 919\end{array}$ \\
\hline Eric, & ditto & - & - & 565 & Nemi, ditto & - & - & - 1022 \\
\hline Ontario, & ditto & - & 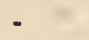 & 234 & Van, Armenia & - & - & - $\quad 5467$ \\
\hline
\end{tabular}

4. The last class of lakes have both affluents and outlets. These are the most numerous. They are sometimes formed by a number of streams flowing into a central basin, from whence the superabundant waters escape by one principal outlet, or they occur in the channel of a great river, and are the receptacles of its waters, which re-issue 
at a point opposite to where they entered. Such are the principal lakes of Switzerland, and the Scandinavian peninsula, of Ladoga and Onega in Russia, and the Lake Baikal in Southern Siberia. The latter is the Holy Sea of the Russians, the largest body of fresh water on the eastern continent, and the largest of all mountain lakes. It lies embosomed in the ranges which form part of the northern rampart of the high central table-land of Asia, and is supposed to be not less than 1200 miles in circumference, occupying a space more than equal to the half of Scotland. Its principal tributary, among upwards of 160 , is the Selinga, from the south, which has a course of 700 miles, and drains a country not inferior in extent to the whole of Great Britain; and through a narrow and deep crevice in the mountains on the north-west it discharges its surplus waters by the Lower Angura, which joins the Yenesei, and is conducted to the Arctic Ocean. Naturalists have been unable to account for the existence of the salmon, the scal, and a kind of sponge, in the fresh water of the Baikal, otherwise than by supposing that in some remote age it was connected with the northern sea. To the same class the large inland seas of Canada belong, which form a chain of magnificent fresh-water expanses, upon the smallest of which frigates of the first magnitude have sailed, war been waged, and whose surface is tempest-tost like the ocean. The river St. Louis enters Lake Superior, the first of the chain in point of size, or reckoning from the west, besides an immense number of nameless streams from the surrounding country, where dense woods and long-continued frosts prevent evaporation from carrying off any large quantity of the superficial waters. The surplus tide of Lake Superior, which has a circumference of 1750 miles, passes by river channels into the Huron, Erie, and Ontario Lakes, which, together with Lake Michigan, form one of the most important inland water-communications of the globe. Scarcely inferior to these in size are the lakes to the north, which occupy the fur countries of America, and occur in chains. The communication is direct from $55^{\circ} \mathrm{N}$. lat. in a north-westerly course, through Deer, Wollaston, and Athabasca Lakes, to the Great Slave and Bear Lakes, a distance of near 2000 miles, only interrupted by falls and rapids in the connecting rivers. From the eastern extremity of the Great Slave Lake another chain extends in a northeasterly direction, which Captain Back traversed to the Polar Sea in his celebrated expedition in search of Captain Ross. Through great part of the year these lakes are ice-bound, adventurous travellers and the fur traders commonly passing over their frozen surface in dog-sledges. This is the case with the north European and Asiatic lakes, across.which an active commerce is carried on in the winter season. But some defy the rigour of the climate to bind up their waters, owing to their depth, or peculiar agitations to which they are subject. Loch Ness, in Scotland, never freezes; and though ice is found in the bogs and morasses around Lake Baikal, even during the heat of summer, it does not cover up the lake itself before the middle or close of December.

Passing from this arrangement of lakes into systems, we proceed to glance at a few of the more striking peculiarities which characterise them indifferently. Floating islands, in several instances of considerable size, are found in some of the lakes of Scotland, Irelaud, Sweden, Germany, and Italy. We have an account of one in the latter country in the following letter addressed by Pliny to Gallus. It is only necessary to remark, that the lake Vadimon, the scene of the phenomenon, is now the Lago di Bassanello.

"Those works of art or of nature, which are usually the motives of our travels, are often overlooked and neglected, if they happen to lie within our reach; whether it be that we are naturally less inquisitive concerning those things which are near us, while our curiosity is excited by remote objects; or because the easiness of gratifying a desire is always sure to damp it; or, perhaps, that we defer, from time to time, viewing what we know we have an opportunity of seeing whenever we please. Be the reason what it 
may, it is certain there are several rarities in and near Rome, which we not only have never seen, but have never so much as heard of ; and yet, if they had been the production of Greece, or Egypt, or Asia, or any other country which we admire as fruitful in wonders, they would, long since, have been the subjects both of our reading, conversation, and inspection. For myself, at. least, I confess $I$ have lately been entertained with a sight of one of these our indigenous singularities, to which $I$ was an entire stranger before. My wife's grandfather desired I would look upon his estate near Ameria. As I was walking over his grounds, I was shown a lake that lies below them, called Vadimon, which I was informed had several very extraordinary qualities attending it. This raised my curiosity to take a nearer view. Its form is exactly circular; there is not the least obliquity or winding; but all is regular and even, as if it had been hollowed and cut out by the hand of art. The water is of a clear sky-blue, though with somewhat of a greenish cast; it seems, by its taste and smell, impregnated with sulphur, and is deemed of great efficacy in all fiactures of the limbs, which it is supposed to consolidate. Notwithstanding it is but of a moderate extent, yet the winds have a great effect upon it, frequently throwing it into violent commotions. No vessels are suffered to sail here, as its waters are held sacred, but several floating islands swim about in it, covered with reeds and rushes, together with other plants, which the neighbouring marsh and the borders of the lake produce. These islands differ in their size and shape; but the edges of all of them are worn away by their frequent collision against the shore and each other. They have all of them the same height and motion, and their respective roots, which are formed like the keel of a boat, may be seen hanging down in the water, on whichever side you stand. Sometimes they move in a cluster, and seem to form one entire little continent ; sometimes they are dispersed into different quarters by the winds; at other times, when it is calm, they float up and down separately. You may frequently see one of the larger islands sailing along with a lesser joined to it, like a ship with its long-boat; or, perhaps, seeming to strive which shall out-swim the other: then again they all assemble in one station, and afterwards joining themselves to the shore, sometimes on one side and sometimes on the other, cause the lake to appear considerably less, till at last uniting in the centre, they restore it to its usual size. The sheep which graze upon the borders of this lake frequently go upon these islands to feed, without perceiving that they have left the shore, till they are alarmed by finding themselves surrounded with water; and in the same manner, when the wind drives them back again, they return, without being sensible that they are landed. This lake empties itself into a river, which after running a little way sinks underground; and if any thing is thrown in, brings it up again where the stream emerges. I have given you this account, because I imagined it would not be less new nor less agreeable to you than it was to me; as I know you take the same pleasure as myself in contemplating the works of nature."

There are various examples of these floating islands. Those of the lake Gerdau in Prussia are said to afford sufficient pasturage for a hundred head of cattle, which have actually been found grazing on them, and noble elms grow upon one in the lake Kolk, in Osnabrück. These islands have been formed by the gradual agglomeration of vegetable matter, reeds from the marshes and roots of trees, upon which the waters have deposited fine sand and gravel held in suspension, and have obviously required ages for their growth. The great raft near the mouth of the Mississippi is a production of an analogous kind. This is composed of the wood annually drifted down that river and its tributaries, consisting of the magnificent trees growing upon their banks, which fall into the waters, owing to the floods undermining their foundations and loosening their roots. Arrested by some obstruction in the river, a mass of timber has thus accumulated, and become consolidated by the interlacing of weeds and the deposition of alluvium, so as to form what 
is called "the raft," the dimensions of which in 1816 amounted to a length of 10 miles, a width of 220 yards, and a depth of 8 feet. 'This is an island afloat in the bosom of the waters, having externally the appearance of solid land, for green bushes and a varicty of beautiful flowers bloom upon its surface. The age of the raft, at the time when the preceding dimensions were given, is supposed to have been not more than thirty-eight years, from which some idea may be formed of the immense quantity of drift-wood borne down by the wares of the Mississippi.

The Swiss lakes exhibit some peculiar and interesting features. That of Zurich presents annually what is called the flowering of its waters. This is the appearanee upon the surface of a very minute vegetation. But the lake of Geneva, or Lac Leman, furnishes the most remarkable phenomenon. This is generally considered the finest inland sheet of water in southern Europe. It fills a great cavity in the rocky strata of Switzerland, extending about forty-seven miles in its greatest length, and nine miles in its greatest breadth. High and rugged mountains form its boundary to the east, with more gentle slopes to the west, enriched with corn fields, villas, and vineyards. The turbid and discoloured waters of the Rhone are filtered in it, and issue forth beautifully clear and pellucid. Owing to this deposition from the river, the lake has been largely contracted at the point where the stream enters, so that the Roman town, Portus Valesiæ, which was close to the water's edge, is now separated from it by a tract of land more than a mile and a half in breadth. Among the peculiarities of the lake of Geneva, is that called Seiches, by the people of the neighbourhood. It consists in a sudden rising of the water, in the form of a tidal wave, sometimes to the height of five or six fect in the course of a few hours. A few of the Italian lakes, and some other's of the Swiss, are subject to the same great undulatory movement, the cause of which is by no means certain, but conceived to lie in some local and transient variation of the pressure of the atmosphere. There is another phenomenon of which this lake is the scene, called the Vaudaise. This is the ebullition of its waters, arising perhaps from the escape of subaqueous currents of air or gases. The agitation produced is at times so violent as to render the navigation of the lake dangerous.

The appearance of tumult upon the surface of lakes without any sensible cause for it, is far from being uncommon, however strange it must seem, to see their waters tossing to and fro, in the calmest weather, when not a twig is stirring in the woods upon their banks. On the 1st of November 1755, without the least apparent cause, agitation seized the before peaceful waters of Loch Lomond, and they suddenly rose against their shores to a perpendicular height of two feet, and then subsided below their ordinary level. This was soon afterwards explained by the coincident occurrence of the earthquake at Lisbon. But Loch Lomond, along with lake Wetter in Sweden, often exhibit great disturbance, the cause of which must lie in themselves, and is probably due to the escape of currents of air from below their bed, though obscurity rests upon the manner of the formation of this subaqueous and subterranean prison-house of the winds, or upon the opening of its doors. In the winter season, a lake near Boleslaw in Bohemia, which has never been sounded, also exhibits upon its surface the effects of the action of some internal force; large masses of ice being whirled from it into the air. But of all phenomena of this kind, those which mark the Baikal are the most singular and unaccountable. They give it somewhat of a prophetic character, and would justify incredulity were they not well attested. It is rarely the case that its waters are smooth and calm, but when they are so, vessels upon their surface are often so violently shaken as to make it difficult to stand in them. There is commonly an undulation, which the sailors call kolychen or $z y b$, which increases previous to a wind arising. This undulation proceeds from the quarter of the wind, and its increase precedes it by about an hour; but while a moderate wind will be 
attended with great disturbanee on the lake, a storm will produce much less effect. These eircumstances have some connection with the physical condition of the district-a focus of earthquakes - but the links between the two are unknown to us; another evidence, that, in the physies of the earth, there is much yet beyond the reach of our philosopliy. A small expanse of water near Beja in Portugal is said to announce a storm by its commotions; but, in general, the movements of lakes are confined to those produced by their own river-currents, and the action of the external atmosphere. Winds produce an effect upon their surface, regulated by the extent exposed to their influence, and the character of the surrounding shores. The heavy autumnal gales that sweep over the ample volume of Lake Superior, rouse it into tempest, and raise its waters several feet upon the opposite beach; and small mountain-lakes are often violently agitated by the winds, which rush with greater power through the openings in their boundary, from the interruption which its walls present to their course.

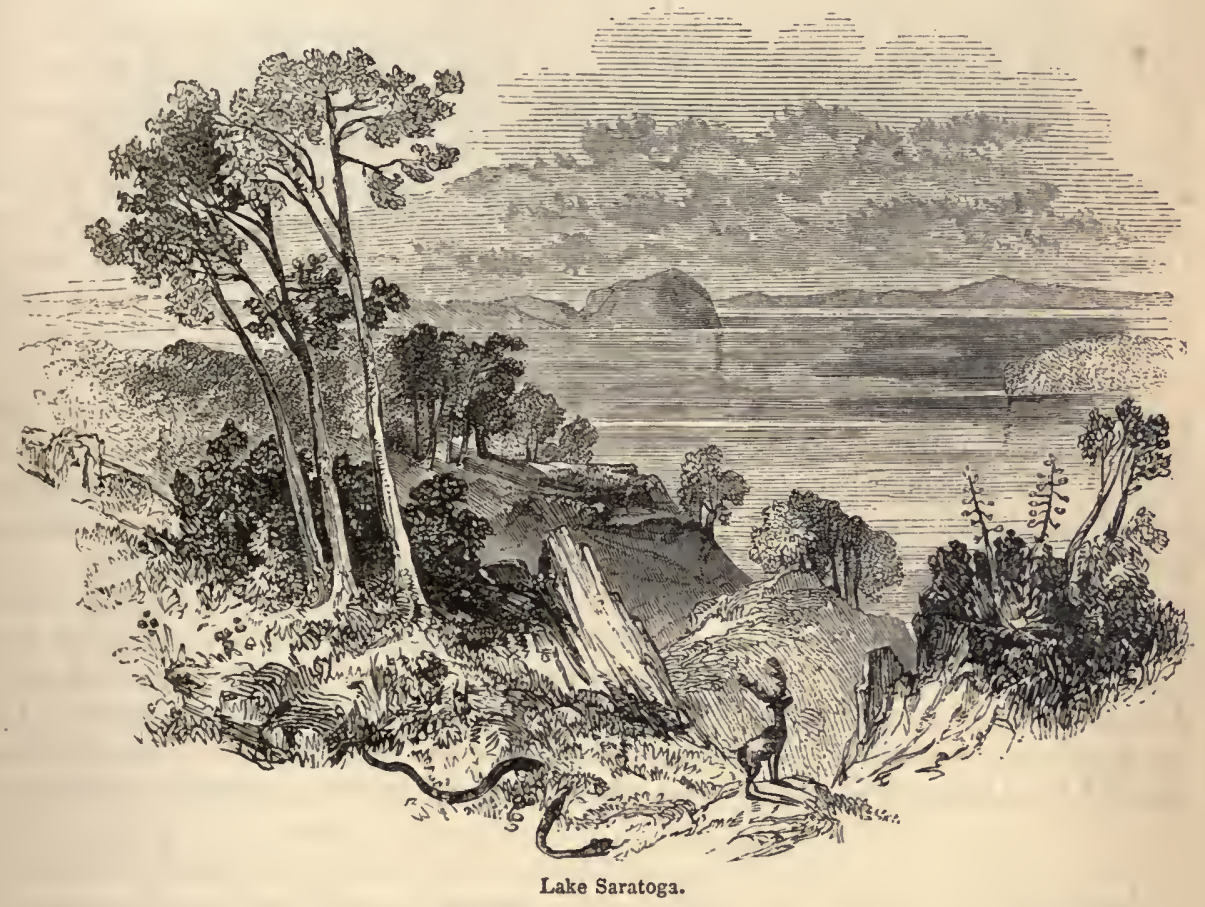

The smaller lakes of America, whose wild and solitary shores attract the tourist, of which the above view of Lake Saratoga affords a specimen, have some singular physical peculiarities. One of the carly explorers of its northern regions, Sir Alexander Mackenzic, was the first to notice the attractive power of the mud at the bottom, which is sometimes so great, that boats can with difficulty procecd along the surface. This extraordinary fact is thus stated:- "At the portage or carrying place of Martres, on Rose Lake, the water is only three or four feet deep, and the bottom is muddy. I have often plunged into it a pole twelve feet long, with as much ease as if I merely plunged it into the water. Nevertheless, this mud has a sort of magical effect upon the boats, which is such that the paddles can with difficulty urge them on. This effect is not perceptible on the south side of the lake, where the water is deep, but is more and more sensible as you approach the opposite shore. I have been assured that loaded 
boats have often been in danger of sinking, and could only be extricated by being towed by lighter boats. As for myself, I have never been in danger of foundering, but I have sereral times had great difficulty in passing this spot with six stout rowers, whose utmost efforts could seareely overcome the attraction of the mud. A similar phenomenon is observed on the Lake Saginaga, whose bottom attracts the boats with such force that it is only with the greatest diffieulty that a loaded boat can be made to advance : fortunately the spot is only about four hundred yards over." This statement has received confirmation from the experience of Captain Back, during the recent aretic land expeditions. A part of Lake Huron, likewise, in the same distriet, appears to be the centre of a remarkable electrical attraction. There is a bay in the lake, over which the atmosphere is constantly highly charged with electricity, and it has been affirmed that no person has ever traversed it without hearing peals of thunder.

Lakes differ greatly in their colour, clearness, and deptll. It is diffieult to aceount in every case for the tints of water. They are referable to a variety of causes. The geological character of the beds of lakes, of the surrounding objects from which shadows are cast, and of the soil drained by them; their depth, with the nature and quantity of the subaqueous regetation, lave influence in determining the colour of their waters. Those of the Great Bear Lake are a beautiful light blue, espeeially in the vicinity of the primitive mountains of $M^{\prime}{ }^{\prime}$ Tavish Bay, where they are very transparent. A piece of white rag, when sunk here, did not disappear till it had descended to the depth of ninety feet. This remarkable transpareney belongs to the waters of Lake Superior, which are so pellucid that the fish and rocks are distinctly visible at most extraordinary depths. Those of Lake Huron also are brilliantly crystalline; and to a voyager on some of the Scandinavian lakes, the density of the medium on which he is floating appears little greater than that of the atmosphere. So completely are the senses here sometimes deceived, that the stranger has recoiled in involuntary alarm from his situation, impressed with the idea of being about to be precipitated among the rocks and chasms disclosed below him. "Nothing," says Elliot, in his letters from the north of Europe, "appears more singular to a foreigner than the transparency of the waters of the Norwegian lakes. At the depth of 100 or 120 feet the surface of the ground beneath is perfectly visible ; sometimes it may be seen wholly covered with shells, sometimes only sprinkled with them; now a submarine forest presents itself to view, and now a subaqueous mountain." A farthing has been seen at the depth of 120 feet in Lake Wetter in Sweden. The depth of lakes, of which a few examples are given below, is very various; and all efforts to sound some have failed, owing to the line running out without reaching the bottom.

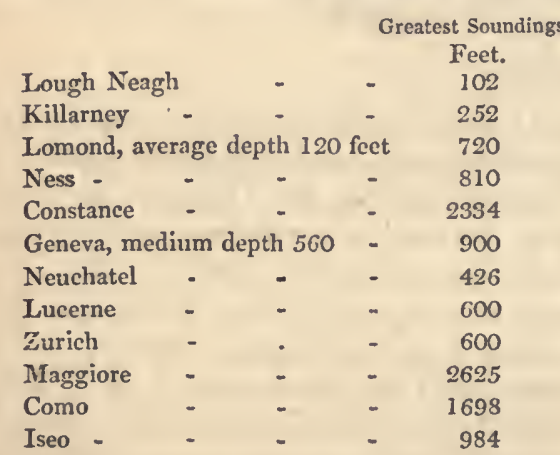

$\begin{array}{lll}\text { Garda } & - & - \\ \text { Nemi } & - & - \\ \text { Wetter } & \text { - } & - \\ \text { Wena, arerage depth } & 240 \\ \text { Møla } & - & - \\ \text { Caspian Sea } & \text { - } & - \\ \text { Superior } & - & - \\ \text { Huron } & - & - \\ \text { Erie - } & - & - \\ \text { Ontario } & - & - \\ \text { Michigan } & - & -\end{array}$

Greatest Soundings.

Some lakes are periodieal, their waters retiring into subterranean reservoirs through creviees in their beds, from whenee they successively re-issue. This is the ease with 
lake Cirknitz in Illyria, which displays frequent intermission, dependent, in the period of its occurrence, upon the season. It has been full for three or four years together, and dry twice or thrice in the year. We may here infer a connexion with a body of water at a lower level, whose increase and diminution, through rain and drought, cause the alternate appearance and failure of the lake. By a subterraneous channel, the lake of Joannina

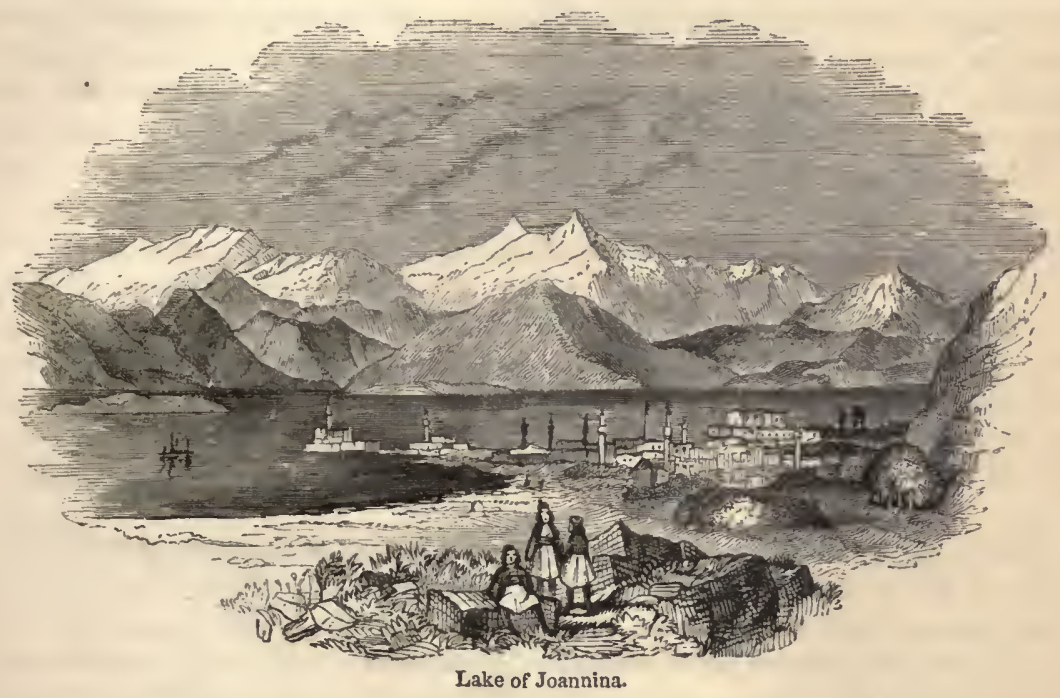

communicates with the river Kalamá, the đíaus, Thyamis, of the ancient Greeks, by which its dimensions are much reduced in summer, and maize is grown upon the deserted ground. This lake, the only one of importance within the limits of ancient Greece, has acquired celebrity in modern times from its connection with the fortunes of Ali Pacha, whose capital appears in our view, and whose death took place, after a bloody struggle, in the castle which crowns the end of the peninsula that abruptly juts out into the water. Directly opposite this peninsula, the illustration, shows a small island, upon which the Pacha kept his herd of red deer, in the height of his prosperity, and to which he often retreated for pastime. The waters of the Caspian Sea are said to be subject to a change of level of a very anomalous kind, increasing and decreasing through periods of about thirty years; a statement which, if true, is perfectly inexplicable. But notwithstanding any temporary alterations of their level, it is a well-attested fact, that the majority of lakes have undergone a sensible depression since the historic period commenced, and are in process of a gradual permanent reduction. This wasting is due to evaporation, to the deposition of the soil conveyed by streams and torrents, and to the accumulation of drift-wood lodged by rivers in their bed. The latter operation is rapidly proceeding in some of the more northern lakes of America. Dr. Richardson noticed a shoal of many miles in extent, formed on the south side of Athabasca Lake, by the drifttimber and vegetable debris brought down by the Elk river ; and the Great Slave Lake itself, he remarks, must in process of time be filled up by the matter daily conveyed into it by the Slave river. Vast quantities of drift-timber are buried under the sand at the mouth of the river; and enormous piles of it are accumulated on the shores of every part of the lake. There are lines of shingle, consisting of rolled stones and shells, around the Canadian lakes, at an elevation of forty or fifty feet above the utmost height to which their waters at present are lashed by the winds. These bear witness to their ampler 
volume in ancient times, and to the enormous reduction to which they have been subject; and appearances indicate that long before the time, previously stated, required for the Niagara to gnaw its way back from the falls to lake Erie, the lake itself will have been converted into dry land by its own sediment. There are hills forty miles inland from lake Aral, composed of indurated marl, full of marine shells, which seem to lave been its ancient shores. "I mentioned to our Kirghisians," says Baron Meyendorff, " the traces of water on Sari-boulak (one of the hills in question), and they assured me that their fathers had seen the waters of the Aral Lake extend to the foot of this hill, although it is at present sixty versts distant from it. So great a number of the Kirghisians have told ne the same thing, that $I$ consider it as an undoubted fact, and it proves how very considerable, and at the same time how rapid, the diminution of the waters of the Aral lake has been. It continues to dimiminish, and one of our guides pointed out a place in our route, far inland, which he himself remembered to have seen the waters reach." It has been stated by Colonel Monteith, that during his residence in that part of Asia, from 1811 to 1828, the Caspian Sea, as well as every other lake in Persia, had decreased most sensibly in depth. It requires ages, however, for such pliysical changes to transpire to any great extent; nor need the present generation be alarmed at the thought of being deprived of the waters on the shores of which their lot may be cast, however certain, in many instances, their conversion into marshes, and ultimate disappearance, may be.

Before parting from this subject, we may cast a glance at the lakes of Wales, as those of England, Scotland, and Ircland have been the subject of a slight reference. Though occurring upon a vastly reduced scale, in comparison with the grand Continental expanses, they exhibit in many cases a minuteness of extreme beauty, and form in combination with rock, island, wood, and monastic ruin, scenes of the most pleasing or impressive description. The recesses of the Welsh mountains are plentifully sprinkled with sheets of water:

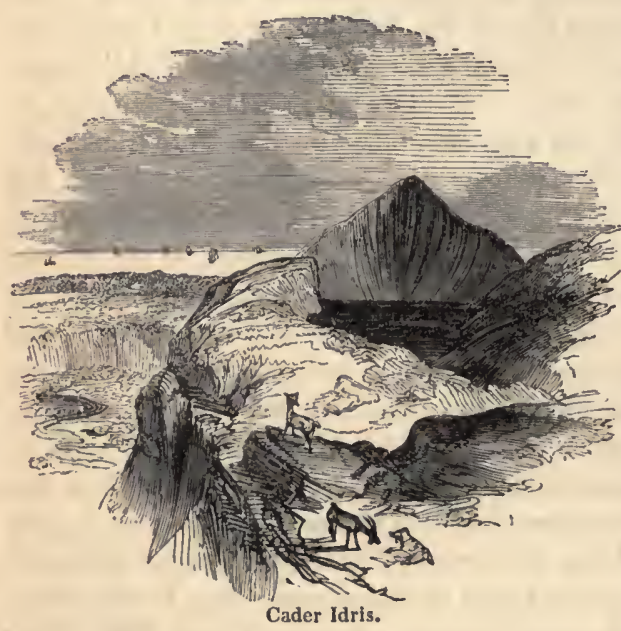
varying in size from the most inconsiderable to a circumference of several miles, which, with their craggy islets, bold and precipitous shores, and placid surface, rank among the chief attractions of the Principality. Some are situated in crater-like hollows, as the annexed, on Cader.Idris, the monarch of the surrounding country, whose towering summit, often capped with clouds, is a magnificent object from the surface of the water. 'The Maes-y-Pandy, a small stream, debouclies from the lake, and falls into the sea after a course through romantic gorges, where it forms a variety of cascades.

The cormorants visiting the lake are subject to a peculiar ceonomy. It is said, that there are never more than two haunt-

ing its waters. These come from Craig-a-Deryn, or the Bird Rock, some miles distant, which is thronged with them. The neighbouring lakes and rivers seem apportioned to a certain number for their support, and that number is never exceeded, so that, if one is killed, another is immediately sure to supply its place. The Welsh lakes are remarkable for their pitchy blackness, and several of the streams, as the Dee, are of a deep tan colour, perhaps arising from impregnation with peat, in the beds over which they flow. 
It is certain, however, that earthy impregnations will not always account for the lue of lakes and rivers, for the Jumna and the Ganges both take their rise in the snow, flow almost in parallel lines, run through nearly a similar soil, and yet the water of the one is pure as crystal, and that of the other yellow and thick. The Bala-Pool, or Pimble-Mere, is an exception to the general aspect of the lakes of Wales, its water being so pure, that the nicest chemical tests can detect scarcely any quantity of foreign admixture. It refuses to mingle with the tan-coloured Dee, whose waters run through it in a streak of almost inky blackness.

\section{CHAP'TER VIII.}

- THE OCEAN.

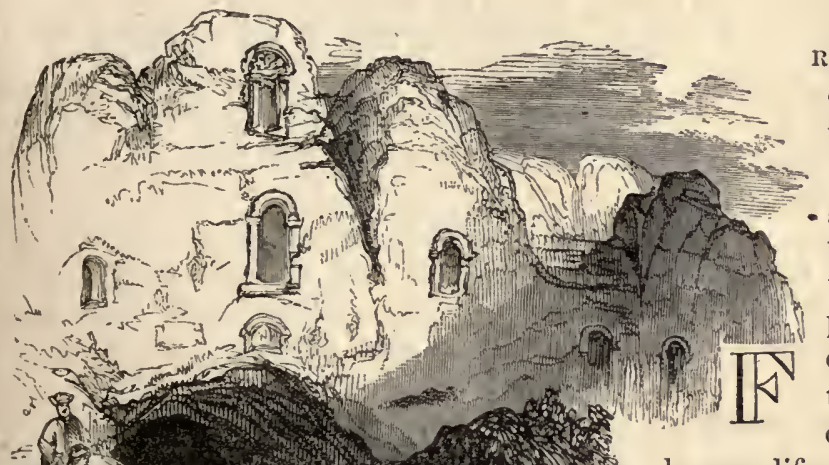

now the land-enclosed waters of the globe, we now pass to consider those which enclose the land, occupying the greater part of the surface of the earth, in various places to an unknown depth, and presenting a thousand interesting and astonishing features. However occasionally disastrous by its tempests to human life and property, the ocean is essential to the existence of man and of all vegetation, purifying the atmosphere he breathes by its constant motions, and sending off from its immense reservoir a perpetual supply of vapours, which condense into clouds, and are the

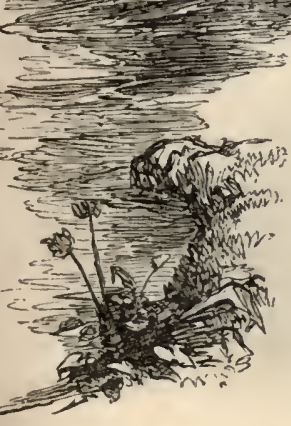
sources of moisture and fertility to the soil. Nor is the facility afforded by the great deep for the intercourse of distant nations an unimportant circumstance, while numerous marine productions, in the hands of civilisation, minister to the comfort and improvement of society. Owing to the enterprise of scicntific individuals, to commercial adventure, and to costly $\mathrm{cx}-$ peditions fitted out by different governments, the surface of the ocean has been largely traver'sed, and the sinuositics of its consts explored, though the line of its circumference has not yet been fully traced, and various parts of it which have been visited have not been accurately surveyed. The passage of the Polar Sea to the earth of America has hitherto baffled our countrymen, though accomplished by the crew of the "Investigator," by travelling over the ice; and the configuration of its shores to the north of Asia is a very recent geographical achievement, due 
to the efforts of the Russian authorities. But enough is known of the great world of waters, of its extent, utility, and varying phenomena, -

\footnotetext{
" Calm or convuls'd, in breeze, or gale, or storm,

Icing the pole, or in the torrid clime

Dark heaving," -
}

to invite the eye of admiring contemplation, and enrich the mind with conceptions of grandeur, beauty, and beneficence. Unstable as it appears, so as to have become a common emblem of inconstancy with the nautical races, it has far more permanent stability than the solid earth; nor is the language of the modern poet -

"Time writes no wrinkle on thy azure brow;

Such as creation's dawn beheld, thou rollest now," -

any violation of philosophical truth, for the level of the ocean, however temporarily fluctuating, appears to experience no enduring change.

The bed of the ocean corresponds in various respects to the surface of the dry land. It is luxuriantly clothed with marine vegetation in several localities, and entirely barreu in others. Earthquakes exert their mighty action upon it; and volcanic ageney effects displacement. It is diversified also with plains, valleys, and mountains, the summits of the latter often just peeping above the waves. Hence the depth of water is very various, from that of the stratum which is scarcely navigable to that of the enormous mass which no plummet has ever sounded. But this of course does not prove the ocean to be anywhere a bottomless abyss because it is unfathomable; it only overreaches the limited extent of our sounding lines. Nor perhaps do such experiments show the approximate depth in those places, for an under-current may have carried the lead far away from a perpendicular direction. Along a low, level, and sandy shore, the sea is generally shallow, but the reverse in the neighbourhood of a bold and towering coast. The recession of the tide off the flats of Lincolnshire and Holland, converts large tracts into dry land, while the Mediterranean, where mount Athos rises abruptly from it to the height of 6000 feet, has a depth of from 500 to 600 feet close in shore. Around low islands, except those of coral formation, shoals and shallows are common, often at a considerable distance from the beach ; but around those which project from the bosom of the ocean to a great elevation, as St. Helena, the depth frequently cannot be sounded.

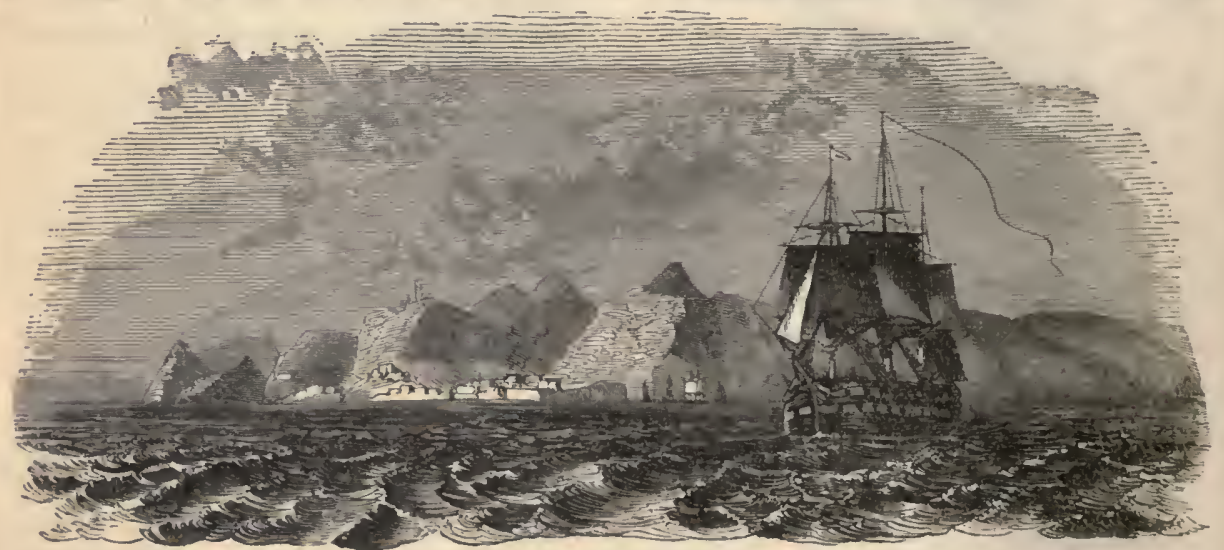

Saint IIelena.

On approaching Aurora Island, one of the Panmato group of South Sea Islands, the officers of the American expedition sounded at one hundred and fifty feet from its perpendicular cliff, and found no bottom at a lundred and fifty fathoms. 
In the year 1843, while in the South Atlantic, the weather calm and the water smooth, Sir James C. Ross sounded with a line of 4600 fathoms, or 27,600 feet, equal to nearly $5 \frac{1}{4}$ miles, and found no bottom. The particular spot was in latitude $15^{\circ} 3^{\prime} \mathrm{S}$., and longitude $23^{\circ} 14^{\prime} \mathrm{W}$., about midway between the coast of South America and the island of St Helena. Subsequently, to the south of the great banks of Newfoundland, no bottom has been found with a line of 34,200 feet; but in latitude $36^{\circ} 49^{\prime} \mathrm{S}$., longitude $37^{\circ} 6^{\prime} \mathrm{W}$., in the South Atlantic, bottom has been found with a line of 46,236 feet. This is the longest line that has ever been used, upwards of eight miles; but Lieutenant Maury believes that no depth has yet been ascertained beyond all possibility of doubt greater than 25,000 feet. It is, however, very certain that the ocean has depths corresponding to the height of the loftiest terrestrial mountains. Between Valentia Bay in Ireland and St John's in Newfoundland, the points selected for the establishment of telegraphic communication between the two continents, the Atlantic has a soft and uniformly level bed, the greatest depth of which is 12,480 feet. This is at a point somewhat nearer Ireland than the opposite coast. As the pressure of the ocean increases with the depth, it must be enormous in its profound abysses. A sensible proof of it came under the notice of Captain Scoresby. A piece of wood that got entangled, and was drawn down by a whale, was found when hauled up so saturated with water forced into its pores, that it sank like a stone for a twelvemonth afterwards instead of floating.

Some variations of level are observed between different sections of the universal ocean, chiefly occurring in land-locked seas, as the effect of local currents. Thus the equatorial current flowing westward across the Atlantic causes an accumulation of water in the Gulf of Mexico, where its progress in that direction is arrested by the continent, and raises the surface above the level on the opposite coast of Africa where the current commences. The detached basin of the Black Sea is likewise considerably higher than the Mediterranean, for it receives a much larger proportionate supply of river-water, and is subject to much less evaporation. Hence there is a strong and powerful stream constantly flowing from the former to the latter, through the Bosphorus, the Sea of Marmora, and the Dardanelles.

The saltness of the ocean is one of its prime characteristics; but we are profoundly ignorant of its cause, and are almost equally in the dark as to its design. In addition to pure water, it has been ascertained by the analysis of different chemists, to hold in solution chloride of sodium, or common salt, the chlorides of potassium and magnesium, the sulphates of magnesia and lime, besides the animal and vegetable matter, in a state of decomposition, mechanically suspended in the fluid. The curious fact las also been recently ascertained that it contains a certain proportion of silver. The great specific gravity of sea-water, resulting from these ingredients, explains its buoyancy. The proportional gravity of different kinds of water may be stated to be as follows :-

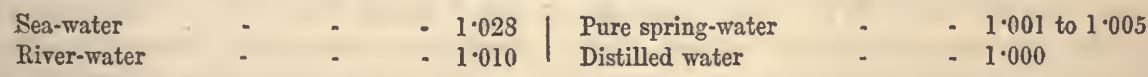

The sea was formerly supposed by physical inquirers to be the saltest under the equator; but Humboldt has deduced from good experiments conclusions as follows:-

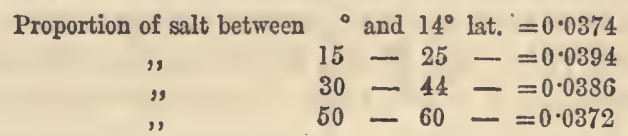

From this table it appears that the saltness of the ocean is greater towards the tropics than at the equator, and least towards the poles; for which a reason may be found in the 
immense amount of the equatorial rains, and the neighbourhood of the polar snows, which diminish its intensity. In the water of the Firth of Forth, an analysis of Dr. Thomson gives $\frac{1}{30}$ th of saline contents, and in the neighbourhood of Great Britain $\frac{1}{3} \frac{1}{8}$ th of the whole weight is salt. The origin and object of this peculiar constitution of sea-water is one of the mysteries of physics. Why so great a difference between the waters of the ocean and of the land? Why are the former hateful alike to man and beast, covering such a mighty expanse as they do, and feeding by evaporation, and in some cases by filtration, the pure springs and streams which keep both man and beast alive? The saline quality of the ocean water alone does not preserve it from corruption. The water of the Nile never becomes putrid, although kept for any length of time in small ressels in a house, or in large cisterns out of doors. But that of the ocean soon becomes offensive in the hold of a ship, and the state of the equatorial seas, after a long calm, apparently answers to the strong phrase of Coleridge, "the very deep doth rot!" With reference to the eause of its saline quality, we only know the fact, that different salts are constituents of the terraqueous system; that beds of rock-salt of cnormous thickness, as in Cheshire and Poland, form part of the crust of the globe; and analogy leads to the conclusion, that immense banks of the mineral exist in the bed of the deep.

Local causes operate in various parts of the ocean to lessen its saltness; as at the mouths of rivers, where large volumes of fresh water are constantly mingling with its waves. The singular circumstance also has previously been referred to of freshwater springs rising up in the midst of the sea. Humboldt was informed by Don Francisco le Maur, that in the Bay of Xagua, to the south-east of the island of Cuba, springs of this kind gush up from the bottom with such force as to prove dangerous to small canoes; and that vessels sometimes take in supplies from them, while the lamartin, or freshwater cetacea, abound in the vicinity. There are similar fountains in the Persian Gulf, which furnish the inhabitants of Aradus with their ordinary drink ; and in several places in the volcanic regions of the Mediterranean, the sea is fresher at great depths than at the surface, owing to the presence of these springs; a phenomenon which is not uncommon near the islands of the Pacific.

The waters of inland seas are commonly less saline than those of the main ocean, especially where they communicate with it by very narrow channels, and receive numerous and extensive rivers. This is strikingly the case with the Baltic. Analysis shows that three pounds of its water will yield about 390 grains of salt, while the same quantity taken from the German Ocean, with which it is connected, contains 747 grains. This small degree of saltness is to be attributed to the narrowness of its outlet, and to the numerous rivers that flow into it, which drain more than one fifth of the surface of Europe, and are fed by a larger amount of snow than falls in any other inluabited country of the world. The average weight of the Baltic water, taken from the centre, is to that of fresh water as 1.038 or 1.041 to 1.000 , while that of the Atlantic is as 1.288 . There are some variations in the quality of the waters of this inland sea, which seem to depend upon their locale, with reference to the ocean and the rivers. Thus, those of the Gulf of Bothuia contain less salt than other portions of the Baltic, and here the in-flowing streams are the most numerous, and the out-lying ocean at the greatest distance. The quality of the water also changes according to the seasons; for while at midwinter 50 tons of water taken from the Gulf of Bothnia will yield a ton of salt, it will require 300 tons at midsummer to produce the same quantity. It is the larger amount of fresh water poured into the gulf, through the melting of the snows at the commencement of the summer, that contributes to this result. The direction of the wind likewise largely influenees the character of the Baltic water. Its specific gravity, as ascertained by the experiments of Wilcke, under the circumstances stated, is as follows:- 
Specific Gravity.

1.0030 Wind at $\mathrm{E}$.

$1 \cdot 0047$ Wind at $\mathrm{W}$.
Specific Gravity .

1.0118 Storm at W.

1.0098 Wind at $\mathrm{N}$. W.

It appears from this table, that the proportion of salt in the waters of the Baltic is least when the wind is east, greater when it is west, and greatest during the prevalence of a westerly storm. This is readily explained. An east wind eo-operates with the natural current of the Baltic to keep out the waters of the open sea, while a west wind ehecks the current, changes its direetion, and causes an influx from the ocean. Sometimes, during a strong easterly gale, the Baltic water is sufficiently fresh to be fit for domestic use. It is owing to its inferior saltness and scanty depth, that its shores are ice-bound, and large portions of its surface are frozen over, during a severe season. In the year 1333, the sea presented a surface of solid ice from the Danish islands to the coast of Prussia, over which for some time communication was uninterruptedly maintained, and public-houses were erected along the road. The Swedish monarch Charles $\mathrm{X}$. marched his army in 1559 over both Belts to the conquest of Zealand, and in 1809 the Russian soldiers travelled across the ice from Finland to Sweden. The water of the Mediterranean exhibits a striking difference to that of the Baltic, containing a somewhat larger proportion of salt than the ocean. The specific gravity of the Atlantic west of the Straits of Gibraltar has been found to be 1.0294, while that of the Mediterranean to the east of the Straits is 1.0338. This is perhaps the combined effect of a varicty of causes, and may be due to the mineral character of its bed, to the strong current which sets into it from the Atlantic, and to the extensive evaporation to which the water of this close sea is subject, produced by a temperature which is five or six degrees higher than that of the ocean under the same latitude.

From a series of experiments made some years ago by Dr. Mareet, the following general conelusions were deduced: -1 . That the Southern Ocean contains more salt than the Northern Oeean, in the ratio of 1.02919 to 1.02757 . 2. That the mean specific gravity of sea water near the equator is 1.0277 . 3. That there is no notable difference between sea water under different meridians. 4. That there is no satisfactory evidence that the sea at great depths is more salt than at the surface. 5. That the sea in general contains more salt where it is deepest, and that its saltness is always diminished in the vicinity of large masses of ice. 6. 'That small inland seas, though communicating with the ocean, are much less salt than the ocean. 7. That the Mediterranean contains rather larger proportions of salt than the ocean.

Sea water taken from the surface has a bitter as well as a saline taste, which does not belong to it when taken from a considerable deptl. 'This is supposed to arise from animal and vegetable matter, in a state of decomposition, impregnating the surface fluid. 'To the same eause, the extraordinary presence of sulphuretted hydrogen in various parts of the ocean is attributed. The evolution of this gas has been observed in water brought by Captain Hall from the Yellow Sea in the Chinese Ocean; in a specimen brought by MLr. Sehmidtmeyer from N. L. $10^{\circ} 50^{\prime}$ and W.L. $24^{\circ} 26^{\prime}$, which had an hepatic smell, and blackened the bottle in which it was contained; and it exists in large quantities in the waters along the north-west coast of Africa. Vessels going to the latter region were observed to lave their copper sheathing speedily injured; a fact which attracted attention to the composition of the water, of which eight bottles, taken up in different places, were submitted to Professor Daniell for analysis. He found the saline contents in the proportions usually appertaining to sea-water, but analysis disclosed a strong impregnation with sulphuretted hydrogen, which in the ease of a portion taken from Lopez Bay amounted to almost as much per gallon as in the Harrowgate waters. It was shown by subsequent investigations that this gas impregnated the seas and rivers along shore, in 
enormous quantities, through an extent of more than $16^{\circ}$ of latitude. Speculating upon its cause, the distinguished chemist remarks:- "It appears to me, that there are only two sources to which it can with any probability be referred, namely, submarine volcanic action, in which case its evolution might be considered direct or primary; and the reaction of vegetable upon the saline contents of the water, in which case it would be secondary. The probability of a volcanic origin is, I think, small, from the absence, I believe, of any other indications of volcanic action, and from the great extent of the coast along which it has been traced. What is known of the action of vegetable matter upon the sulphates, and the immense quantities of vegetable matter which must be brought by the rivers within the influence of the saline matter of the sea, renders, on the contrary, the second origin extremely probable. Decaying vegetable matter abstracts the oxygen from the sulphate of soda, and a sulphuret of sodium is formed. This again, acting upon water, decomposes it, and sulphuretted hydrogen is one of the products of the decomposition." There can be no doubt but that extensive banks of vegetable detritus have been formed at the mouths of the rivers of the west coast of Africa. They flow from an interior country rich with the luxuriance of a tropical vegetation, and roll along in immense floods in the rainy season, bringing down masses of decaying foliage into the ocean; and what renders the preceding explanation the more certain, is, that those inlets along the coast of India, where the bottom contains carbonaceous matter, display the evolution of the same gas. With this circumstance, the unhealthiness of the West African stations, which has obtained for Sierra Leone the title of "the white man's grave," is intimately connected, for it has been experimentally found that so small a mixture as a fifteen hundredth part of sulphuretted hydrogen in the atmosphere acts as a direct poison upon small animals. The mangrove swamps in all parts of the world are notoriously unhealthy, arising from the tree requiring salt water for its growth, the sulphates of which are decomposed by the decaying regetable matter which is annually furnished.

The colour of the ocean is one of its sensible properties which has exercised the sagacity of a great number of inquirers to account for it, but the problem has not yet been entirely resolved. Sea-water is colourless when viewed in small quantities, but appears to be of a blue tint when seen in the mass. Scoresby compares the general hue of the polar seas to an "ultramarine blue;" M. Costaz assimilates that of the Mediterranean to a perfectly transparent solution of the "most beautiful indigo," or to "celestial blue;" and Captain Tuckey characterises the waves of the Atlantic in equinoctial regions as of " bright azure." A blue, more or less deep, is undoubtedly the prevailing tint, for the blue rays of light are most apt to he reflected from masses of transparent fluid; and hence both the sea and the air appear of this colour. But the ocean remarkably varies its hue at the same place. It is ubserved by Humboldt, that towards evening, when the edges of the waves, as the sun shines upon them, are of an emerald green, the surface of the shaded side reflects a purple hue. Nothing, he states, is more striking than the rapid changes which the ocean undergoes beneath a serene sky, where no variations whatever are to be perceived in the atmosphere. In the midst of the tropical deep the water passes from an indigo blue to the deepest green, and from this to a slate grey, without any apparent influence from the azure of the sky or the colour of the clouds. In general the sea between the tropics is of a more intense and purer azure than in high latitudes. The ocean often remains blue when, in fine weather, the greater part of the sky is covered with light and floating fleecy clouds. Humboldt concludes his observations upon the tints of the ocean, and its changes from blue to green, with some general remarks, the substance of which is embodied in the succeeding paragraphs. Whatever relates tc the colour of water is extremely problematic. The green tint of the snow waters that flow from the Alpine glaciers, which contain very little air in solution, might induce 
the belief that this colour is appropriate to water in its greatest purity. Chemistry is addressed in vain to explain this phenomenon, or that of the beautiful greenish blue colour of ice in a mass, or that of the blue of the Rhone near Geneva. There is hitherto no proof that waters exist which contain a greater or less degree of hydrogen; and the refrigeration of the seas in tempests is much too weak to permit us to attribute the reflection of different coloured rays to the mere change of density. It is improbable that the green colour of the water is owing to the mixture of yellow rays from the bottom, and blue rays reflected by the water; for the open sea is often green where it is more than four thousand feet deep. Pcrhaps, at certain hours of the day, the red or yellow light of the sun contributes to the colouring it green. The waves, like moveable and inclined mirrors, progressively reflect the shades and tints of the atmosphere from the zenith to the horizon. The motion of the surface of the water modifies the quantity of light that penetrates towards the inferior strata; and it may be conceived that these rapid changes of transmission, which act as it were like changes of opaqueness, may, when they are united to other causes unknown to us, change the tint of the ocean.

The colour of the general body of the sea-a blue more or less intense-is far from being universal. In various parts of its basin other shades appear, the causes of which are local, and are due to the existence of vast numbers of minute animalculæ; to a marine vegetation at or near the surface; to the nature of the soil at the bottom, or to the infusion of earthy substances in the water. The Mediterranean, towards its eastern extremity, has occasionally a purple hue. In the Gulf of Guinea the sea is white; about the Maldive Islands, black; / and near the shores of California it has a reddish appearance. The reddish tinge marks the waters near the mouth of the La Plata, and prevails also in the Red Sea - whence its name. The colour in this latter locality has been definitely investigated by Ehrenberg, who refers it to the prevalence of a species of Oscillatoria, a family of microscopical animalculæ. In the spring of the year 1825, it was observed that the waters of the Lake of Morat, in Switzerland, had almost the hue of blood, which De Candolle demonstrated to proceed from an animal, figured and described by the botanist under the name of Oscillatoria rubescens, which confirms the conclusion of Ehrenberg respecting the peculiar tinge of the Red Sea waters. It will be recollected, that on the return of Captain Ross from his first expedition to the polar seas, much surprise was excited by his account of the red snow, as it was termed, observed upon some of the snow mountains near the shores of Baffin's Bay. But a similar phenomenon is of annual occurrence in the Alps, though not much noticed, because of its occurrence at a season when few travellers visit the country. Minute red grains appear scattered upon the snow in March, which usually are entirely gone by the close of May. Saussure has given an account of this appearance as occurring on the Great St. Bernard, but it is most abundant on Mount Breven, situated on the sunny side of the valley of Chamouni. 'The grains penetrate two or three inches into the snow, and are of a lively red colour, occurring chiefly where the snow lies in a cavity, deepest near the centre, and very faint upon the borders. Saussure came to the conclusion that it was the pollen of an Alpine plant, but no plant has ever been discovered in Switzerland to yield such a product. A similar opinion was entertained with reference to the red snow brought home by Ross, when the residue was examined, after the water had been evaporated. In all probability, the red tinge observed on the Aretic and Alpine snows, proceeds from precisely the same cause as that which coloured the waters of the Lake of Morat, and originates the tinge of the ocean at the mouth of the La Plata, in the Red Sea, and along the coast of California-the presence of minute forms of animal life.

The waters of the ocean vary in their clearness, from a crystalline transparency to a dulness bordering on opacity. Those of the North Sea, along the west coast of 
the Scandivanian peninsula, have been remarked by all observers for being of an extraordinary transparency, which has, perhaps, no parallel in any other region. Here are

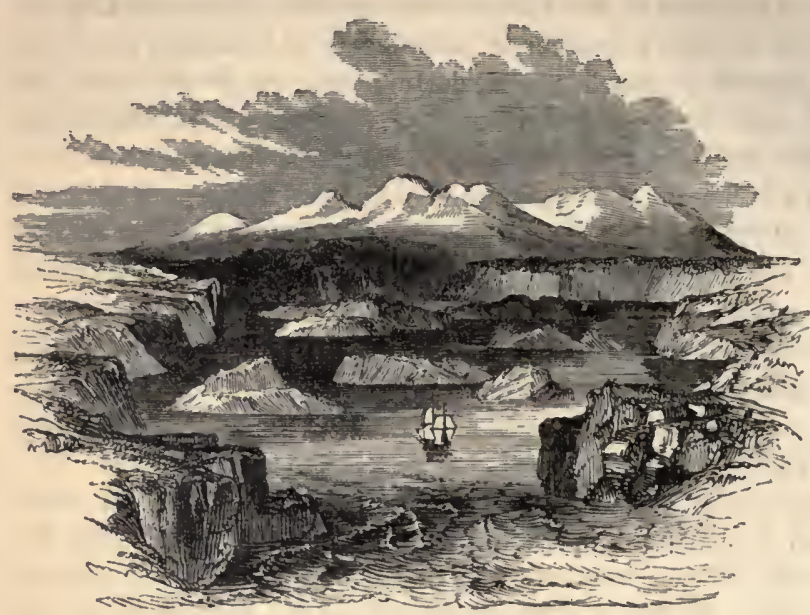

Fiord of Norwar. those inlets of the sea, wild and romantic in their aspect, called the fiords of Norway, a name analogous to the Scottish firth, both having the same Norse derivation. "Nothing can be more surprising," says Sir A. de Capell Brooke, "and beautiful than the singular clearness of the Northern seas. As we passed slowly over the surface, the bottom, which here was in general a white sand, was clearly visible, with its minutest objects, where the depth was from twenty to twenty-five fathoms. During the whole course of the tour I made, nothing appeared to me so extraordinary as the inmost recesses of the deep thus unveiled to the eye. The surface of the ocean was unruffled by the slightest breeze, and the gentle splashing of the oars scarcely disturbed it. Hanging over the gunwale of the boat, with wonder and deliglit I gazed on the slowly-moving scene below. Where the bottom was sandy the different kinds of asterix, echini, and even the sinallest shells, appeared at that great depth conspicuous to the eye; and the water seemed, in some measure, to have the effect of a magnifier, by enlarging the objects like a telescope, and bringing them seemingly nearer. Now, creeping along, we saw, far beneath, the rugged sides of a mountain rising towards our boat, the base of which, perhaps, was hidden some miles in the great deep below. 'Though moving on a level surface, it seemed almost as if we were aseending the height under us; and when we passed over its summit, which rose in appearance to within a few feet of our boat, and eame again to the descent, which on this side was suddenly perpendicular, and overlooking a watery gulf, as we pushed gently over the last point of it, it seemed almost as if we had thrown ourselves down this precipice, the illusion, from the crystal clearness of the deep, actually producing a sudden start. Now we came again to a plain, and passed slowly over the submarine forests and meadows, which appeared in the expanse below; inhabited, doubtless, by thousands of animals, to which they afford both food and shelter - animals unkinown to man ; and I could sometimes observe large fishes of singular shape gliding softly through the watery thickets, unconscious of what was moving above them. As we proceeded, the bottom beeame no longer visible; its fairy seenes gradually faded to the view, and were lost in the dark green depths of the ocean." Mr. Barrow, while remarking the extraordinary clearness of the northern waters, in language equally as strong as that of the preceding statement, speaks of the reflection of the mountains being often as well-defined upon their surface as the rocks themselves, so that when viewed at a short distance it is no easy matter to decide where the line is that separates the water from the shore. This uncertainty, when crossing one of the fiords in a boat, has a most singular effect. Every thing appears upside down; houses upset, trees growing the wrong way, men walking on their heads, cattle on their backs; the whole appearance having an air of reality which for the moment beguiles the senses. 
Great transparency, in various places, belongs also to the tropieal deep. This is its feature around the Bahamas - that solitary and singular eluster of several hundred rocks in the Atlantie, aptly compared to one of the beautiful nebula in the heavens, which to ordinary sight seems an indivisible pateh of eloud, but when viewed through a teleseope is found to be a collection of stars. "The number," says Moore, "of beautiful islets, the singular elearness of the water, and the animated play of the graceful little boats, gliding for ever between the islands, and seeming to sail from one eedar grove to another, form altogether the sweetest miniature of nature that ean be imagined. The water," he adds in another place, "is so beautifully elear around these islands, that the rocks are seen to a very great depth; and as we entered the harbour they appeared to us so near the surface, that it seemed impossible we should not strike on them." In verse, addressed to the Dowager Marehioness of Donegal, as well as in prose, the writer has eelebrated the waters of the Bahama eoves and coasts :-

\footnotetext{
"Believe me, lady, when the zephyrs bland Floated our bark to this enehanted land, These leafy isles, upon the ocean thrown, Iike studs of emerald o'er a silver zoneNever did weary bark more sweetly glide, Or rest its anehor in a lovelier tide!"
}

It is in the tropical seas, towards the heart of the torrid zone, that several remarkable phenomena are witnessed in perfection: the phosphoreseence of the ocean - the flying-fish chased by the dolphin - suecessive regions of steady breezes, and ealms interrupted by sharp and sudden squalls - and enormous deluges of rain, which generally descend in equatorial distriets in a perfectly still state of the atmosphere. No spectacle is more imposing and magnificent than the luminous appearanee of the sea at night in these latitudes. The path of a vessel seems like a long line of fire, and the water thrown up in her progress, or dashed by the waves upon deck, flashes like vivid and lambent flame. Sometimes myriads of luminous stars and spots float and dance upon the surface, assuming the most varied and fantastie aspeets. This phosphorescent or shining appearance of the ocean is by no means uneommon, but most frequent in the equatorial seas; and is usually ascribed to animalculæ, which exist there in ineoneeivable numbers, and to the semiputrescent matter of plants and fishes, developing electricity. As Humboldt entered the torrid zone, the phosphorescence of the ocean seemed to augment greatly the mass of light diffused through the air, so that he was able to read, for the first time, the minute divisions of a small snuff-box sextant, witliout the assistance of a taper. A most remarkable display of this phosphorie light is thus related by Mrs. Somerville:- "Captain Bonnyeastle, eoming up the Gulf of St. Lawrenee, on the Tth September, 1826, was roused by the inate of the vessel, in great alarm, from an unusual appearanee. It was a starlight night, when suddenly the sky became overcast, in the direetion of the high land of Cornwallis eounty, and an instantaneous and intensely vivid light, resembling the Aurora, shot out of the hitherto gloomy and dark sea, on the lee bow; which was so brilliant, that it lighted every thing distinctly, even to the mast-head. The light spread over the whole sea between the two shores; and the waves, which before had been tranquil, now began to be agitated. Captain Bonnycastle deseribes the scene as that of a blazing sheet of awful and most brilliant light. A long and vivid line of light, superior in brightness to the parts of the sea not immediately near the vessel, showed the base of the high, frowning, and dark land, abreast. The sky beeame louring, and more intensely obscure. Long tortuous lines of light showed immense numbers of very large fish, darting about as if in consternation. The spritsail-yard and mizen-boom were lighted by the refleetion, as if gas-lights had been burning directly below them; and until just before daybreak, at four o'eloek, 
tlie most minute objects were distinctly visible. Day broke very slowly, and the sun rose of a fiery and threatening aspect. Rain followed. Captain Bonnycastle caused a bucket of this fiery water to be drawn up; it was one mass of light, when stirred by the hand, and not in sparks, as usual, but in actual coruscations. A portion of the water preserved its luminosity for seven nights. On the third night, the scintillations of the sea reappeared; this evening, the sun went down very singularly, exhibiting in its descent a double sun; and, when only a few degrees high, its spherical figure changed into that of a long cylinder, which reached the horizon. In the night the sea became nearly as luminous as before ; but on the fifth night, the appearance entircly ceased. Captain Bonnycastle does not think it proceeded from animalcula, but imagines it might be some compound of phosphorus, suddenly evolved, and dispersed over the surface of the sea; perhaps from the exuvix or secretions of fish connected with the oceanic salts, - muriate of soda, and sulphate of magnesia."

In the region of the tropical calms, lying between that of the north and south steady breczes, day after day is often passed without a whisper of the wind upon the deep, or the flap of a sail, and the ocean has no movement but that of a long huge swell, like the heaving chest of a giant in his sleep. But for the occasional occurrence of short squalls, the passage of this region would be almost impossible to sailing vessels, and parts of Byron's striking picture might soon be realised :-

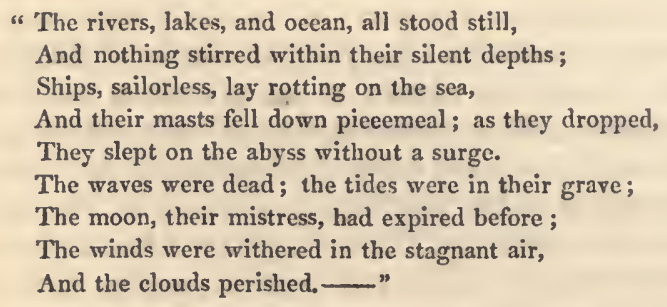

The squalls offer a brief but grateful interruption to the calms, and occur under singular circumstances. Amid the scorching heat of noon, a cloud appears, generally in the east, black and well-defined, when suddenly the wind springs up, blows violently for a few minutes, suddenly subsides, and the calm returns. It is by the aid of these fitful gusts that the passage of the tropical region of calms is effected. The ocean, in other parts of the torrid zone, as quickly changes its aspect from that of a smooth shining mirror to a surface shattered and tortuous, reflecting the hue of the black louring clouds; and the storm sometimes rages with violence for days together. Captain Hall describes one of the tropical storms, when off the west coast of Mexico :- "On the evening of the 24 th of February the sun set with astonishing splendour, but with a wild lurid appearance, which, in any other country, would have put us more upon our guard. The sun itself, when still considerably above the horizon, became of a blood-red colour, and the surrounding clouds assumed various bright tinges of a fiery character, fading into purple at the zenith: the whole sky looked more angry and threatening than any thing I ever saw before. The sea was quite smooth, but dyed with a strange and unnatural kind of redness by the reflection from the sky. In spite of the notions we held of the fineness of the climate, I was made a little uneasy by such threatening appearances, and upon consulting the barometer, which in these low latitudes is seldom of much use, was startled by finding it had fallen considerably. This determined me immediately to shorten sail; but before it could be fully accomplished, there came on a furious gale, which split many of our sails, broke our ropes like cobwebs, and, had it not been for great exertions, we might have been dismasted. At length we got things put in proper trim to withstand the storm, 


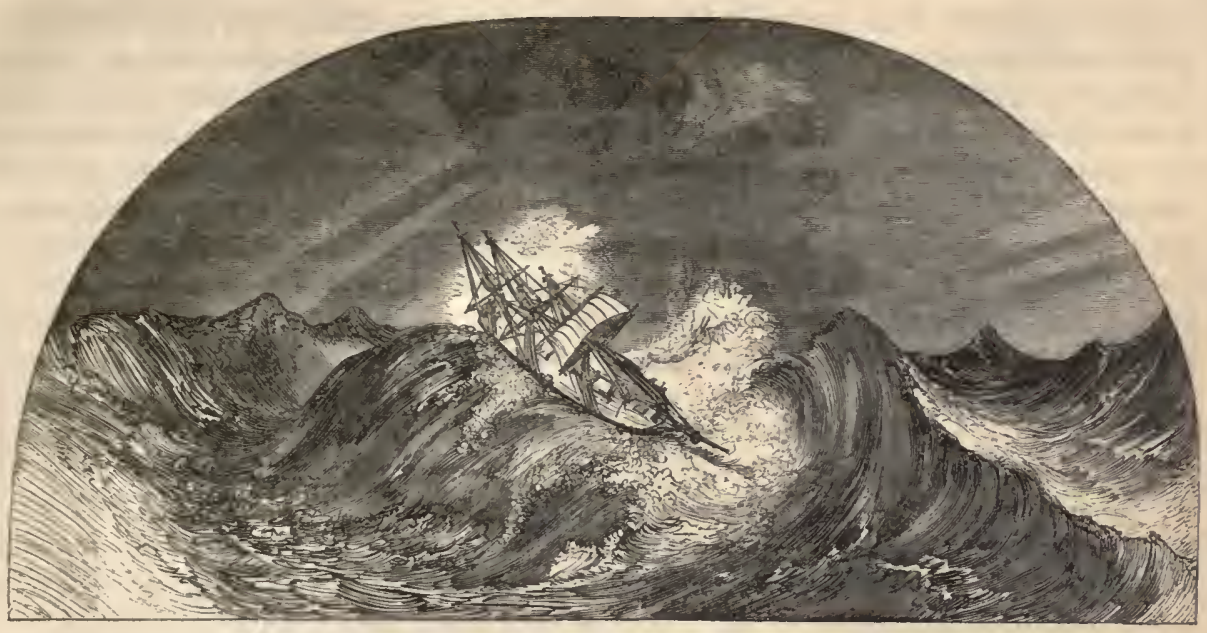

Gale in the Pacific.

which lasted with unabated violence for two days. During the greater part of the gale the wind was fair, but blowing so hard, and with so mountainous a sea, that we could make no use of it, nor show even the smallest stitch of sail, without its being instantly blown to rags."

The temperature of the ocean has occupied the attention of many physical inquirers. Water, being a slow conductor of heat, its temperature is less affected by change of seasons, and is therefore more stable than that of the atmosphere. In the ocean, the influence of seasonal vicissitudes is imperceptible at the depth of about 300 feet; and at a depth which varies with the latitude, the same temperature appears to be invariably maintained-that of $39 \frac{1}{2}^{\circ}$-marking the limit of the influence of solar heat. This interesting result was ascertained with reference to the southern seas during the Antarctic Expedition, under Sir James C. Ross. In equatorial latitudes, the line of unvarying temperature is reached at the depth of 1200 fathoms. From thence, it is found at a lesser depth, till it comes to the surface in latitude $56 \frac{1}{4}^{\circ} \mathrm{S}$; ; and here the water has the temperature of $39 \frac{1}{2}^{\circ}$ at all depths. From the latitude named, to near $70^{\circ}$, the line descends to 750 fathoms, beneath which, to the greatest depths, the temperature of $39 \frac{1}{2}^{\circ}$ obtains, while that of the upper stratum is much lower. The thermal condition of the ocean in the northern hemisphere may be assumed to be much the same in closely corresponding latitudes; and thus there exist, in the upper part of the oceanic expanse, two great thermic basins, one warmer, and the other colder, than the temperature named.

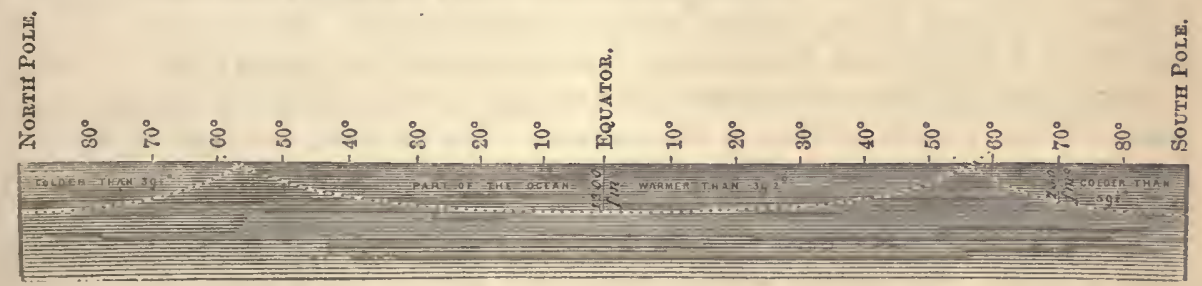

The diagram, founded upon Ross's data; and applied to the northern hemisphere, exhihits the ocean from pole to pole, and approximately the two basins respectively warmer and colder than the stratum of unvarying temperature. 
The temperature of the surface is of the most importance, in relation to physical climate, as the superior stratum of the ncean is the only one that has an immediate influcnce upon the thermal condition of the atmosphere. It diminishes gradually from within the tropics as the latitude increases, till towards the poles the sea is ice-bound. But in high latitudes the waters of the northern hemisphere are warmer than those of the sonthern; and, as compared with the other oceans, the temperature of the Atlantic is higher in high latitudes, and lower in equatorial regions. This appears from the following table :

\begin{tabular}{|c|c|c|c|c|c|c|c|}
\hline $\begin{array}{c}\text { Nortla } \\
\text { Latitude. }\end{array}$ & $\begin{array}{c}\text { Atlantic } \\
\text { Ocean. } \\
\text { Temperature. }\end{array}$ & $\begin{array}{c}\text { Indian } \\
\text { Ocean. } \\
\text { Temperature. }\end{array}$ & $\begin{array}{c}\text { Pacific } \\
\text { Ocean. } \\
\text { Temperature. }\end{array}$ & $\begin{array}{c}\text { South } \\
\text { Latitude. }\end{array}$ & $\begin{array}{c}\text { Atlantic } \\
\text { Ocean. } \\
\text { Temperature. }\end{array}$ & $\begin{array}{c}\text { Indian } \\
\text { Ocean. } \\
\text { Temperature. }\end{array}$ & $\begin{array}{c}\text { Pacific } \\
\text { Ocean. } \\
\text { Temperature. }\end{array}$ \\
\hline $60^{\circ}$ & $42 \cdot 8$ & - & $38 \cdot 3$ & $60^{\circ}$ & - & - & $31 \cdot 5$ \\
\hline 50 & 54.0 & - & $49 \cdot 6$ & 50 & 48.0 & $41 \cdot 9$ & $43 \cdot 2$ \\
\hline 40 & $62 \cdot 2$ & - & $59 \cdot 5$ & 40 & $58 \cdot 6$ & $56 \cdot 5$ & $36 \cdot 3$ \\
\hline 30 & $69 \cdot 8$ & - & $70 \cdot 0$ & 30 & $69 \cdot 3$ & $69 \cdot 8$ & $66 \cdot 7$ \\
\hline 20 & $74 \cdot 3$ & - & 76.8 & 20 & $73 \cdot 6$ & $76 \cdot 1$ & $75 \cdot 2$ \\
\hline 10 & $78 \cdot 2$ & 86.0 & $81 \cdot 7$ & 10 & $77 \cdot 7$ & $79 \cdot 7$ & 80.8 \\
\hline Jiquator. & 79.0 & $83 \cdot 3$ & $83 \cdot 1$ & Equator. & $79 \cdot 0$ & $83 \cdot 3$ & $83 \cdot 1$ \\
\hline
\end{tabular}

A considerable number of observations have yielded the following results, upon which general dependence may be placed:

1. At noon, the open sea is colder than the atmosphere noticed in the shade, and at midnight warmer; an assertion first made by M. Peron, and confirmed by a large number of observations. 2. Morning and evening, the temperature of the sea and of the atmosphere usually correspond. 3. Observations taken at six in the morning, at midday, at six in the evening, and at midnight, of the temperature of the ocean at the surface, and of the atmosphere, show the mean to be higher with reference to the sea in every latitude. The ocean is thus in general warmer than the atmosphere with which it is immediately in contact. 4. Banks diminish the temperature of the sea, so that it is always colder over them than where it is deeper; and the difference is greater, the greater the shallows. 5. The oceanic warmth equator, or the line of greatest warmth at the surface, does not coincide with the geographical equator, but runs for the most part on the north of it. At one point, in the Gulf of Mexico, the greatest heat is situated $28^{\circ}$, or about 1500 miles to the north.

\section{GREATEST OCEANIC HEAT.}

Atlantic Ocean.-The line of the greatest heat of the surface-water is entirely north of the equator, the temperature varying in different places from $77^{\circ}$ to $88^{\circ} 5^{\prime}$. The minimum is found near the coast of Guinea : the maximum in the Gulf of Mexico.

Indian Ocean.-The line of the greatest heat is here also in the northern hemisphere, except in the eastern region, between Sumatra and New Guinea. The minimum temperature, $85^{\circ} 5^{\prime}$, is found in the Molucca Sea ; the maximum in the Arabian Gulf.

Pacific Ocean.-In the eastern portion, the warmth equator lies in the northern hemisphere; in the western portion, in the southern. The minimum temperature, $81^{\circ} 7^{\prime}$, is found between the Galapagos and Sandwich Islands; the maximum, $88^{\circ} 5^{\prime}$, in the haven of Dororei, New Guinea.

There is no sensible difference between the general temperature of the tropieal waters, north or south. Beyond the southern tropic, also, as far as $35^{\circ}$ or $40^{\circ}$, the temperature corresponds with that of -similar extra-tropical northern latitudes; yet it is generally supposed that towards the poles the cold of the seas is greater in the southern than in the northern hemisphere, though the difference between the temperature of these high 
latitudes is less than was onee conceived. A very sensible effect in diminishing the temperature of the ocean is produced by the ice annually borne by the polar currents from the arctic and antaretic zones into lower latitudes. It has been met with in the South Atlantic, off the Cape of Good Hope, but this is a very rare occurrence; and did that of the North Atlantic drift to a corresponding latitude, that of Cape St. Vincent, it might be swept through the funnel of the Gibraltar Straits, appear in the Mediterranean, reduce the temperature of that warm sea, and cloud with cold fogs the beautiful landscapes of Italy. The lowest limit to which the northern ice descends appears to be $40 \frac{3}{4}^{\circ} \mathrm{N}$. latitude. Here it is occasionally encountered in a state of rapid thaw, cooling the warm water of the Gulf stream to a distance of forty or fifty miles around it, the thermometer gradually sinking sometimes from $60^{\circ}$ to $43^{\circ}$ in its neighbourhood. The ice is not found, however, in every part of the Atlantic under the latitude stated, but is confined to the district between $42^{\circ}$ and $56^{\circ} \mathrm{W}$. longitude, which it visits in the height of summer. There is only one instance on record of the ice being met with at any considerable distance on the European side of this tract. This took place in the year 1817, and is suffieiently remarkable to be noticed here. For nearly four centuries a large quantity of ice, having an area of many thousand square miles, had occupied the sea to the north of Iceland, chiefly along the eastern coast of Greenland. This icy continent, in the before-mentioned year, was suddenly broken up, separated into fragments, and scattered over the waters of the North Atlantic. Large masses were then found as far east as $32^{\circ}$ of longitude, or about eight hundred miles from the most westerly part of Ireland. It was conceived probable that the breaking up of the great body of ice referred to had opened the navigation of the sea all the way to the pole, which gave rise to the first of the expeditions of the present

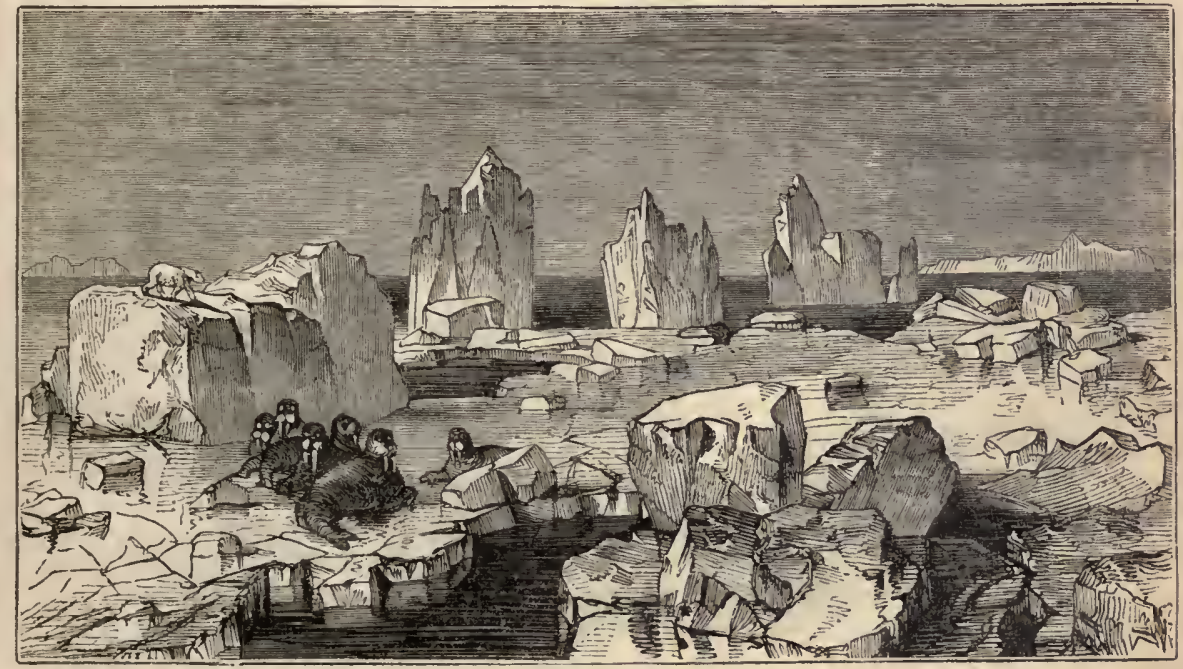

Ice Fields.

century, to effect the north-west passage of America - that under Captain Ross. This dispersion of the polar ice had been ascribed at home to a diminished rigour of the climate; but upon the expedition arriving at one of the Danish factories in Baffin's Bay, the resident informed the commander that during the eleven winters he had passed there not one had been so severe or protracted as the last. The experience of the navigators themselves speedily showed the fallacy of those sanguine anticipations which some had been ready to indulge, respecting the winter of the whole northern hemisphere speedily 
mitigating its cold, the climate of England approximating to that of Italy, and vineyards flourishing where apple-trees now can with difficulty be reared.

The great ice formations of the poles are due to the spherical form of the earth, and the obliquity of its axis, by which the presence of the sun is entirely withdrawn from arctic and antarctic regions for a considerable portion of the year, when intense frost reigns through the long and dreary night that prevails. In high northern latitudes, as early as the month of August, snow begins to fall, and a formation of ice rapidly ensues. The hoar-frost covers with fantastic clusters every prominence on land; and the frostsmoke appears upon the sea, giving it the aspect of a vast steaming lime-kiln, the vapour being produced by the temperature of the water being relatively higher than that of the incumbent atmosphere. The fresh water poured from rivulets, or drained from the former collections of snow, becomes quickly congealed along the shores and bays, and the surface of the ocean is converted into one solid mass of ice, to some distance from the coasts. Parry found the Bay of the Hecla and Griper, in which he passed the winter, in N. lat. $74^{\circ} 44^{\prime} 20^{\prime \prime}$, and W. long. $110^{\circ}$, so completely covered with new ice by the middle of September, that his men were obliged to open a canal with saws to admit the passage of the ships; an operation which occupied the greatest part of three days, during which they cut through more than two miles of new ice, the average thickness of which was seven inches. The sun left them on the 11th November, in a seene marked with death-like stillness, dreary desolation, and the total absence of animated existence. The silence was only interrupted occasionally by the sound of their own voices, which could easily be heard at the distance of a mile, owing to the peculiar state

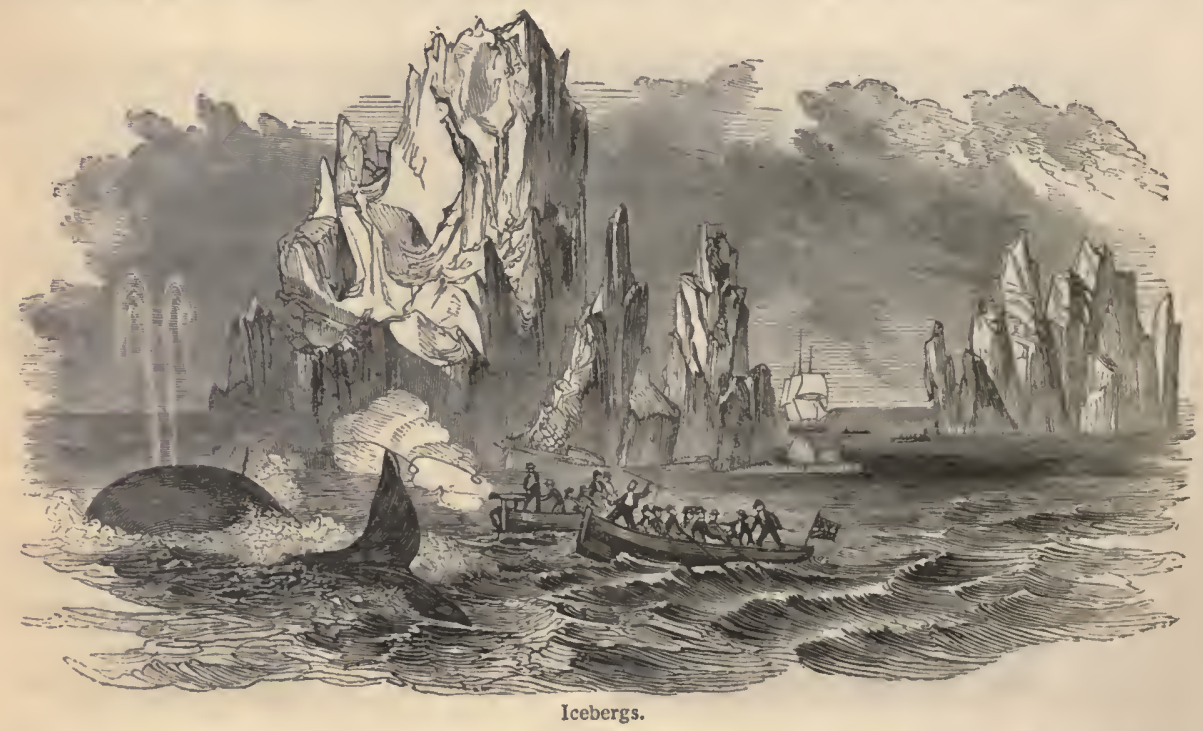

of the atmosphere, and the absence of all obstruction in a scene of universal calm. $\Lambda t$ the shortest day, or rather what in that latitude is the middle of the long night, there was a little light afforded at noon, so that print could be read, but only by turning it directly towards the south. On February $3 \mathrm{~d}$ the upper limb of the sun was seen from the Hecla's main top, after an absence of eiglity-four days; and on the 7 th of the month lis full orb was above the horizon. It was not, however, till the 30th of April that the thermometer rose to the freezing, or rather thawing point, having been below it for nearly eight months. The first ptarmigan made its appearance on the 12th of May; the first shower of rain in the 
evening of the 24th; and on the 1st of June the indications of approaching summer were unequivocal. Upon the return of the sun, and as the power of his beams increases, the bonds which connect the masses of ice with the land are dissolved; and the ice itself, broken up into a thousand fragments of various size and thickness, is set afoat upon the sea under the direction of the winds and currents. The general course of the north polar current is at first south-south-west, passing through the narrow sea which separates Iceland from Greenland, and after a deviation into Davis's Strait, descending upon the shores of Labrador and Newfoundland. It then proceeds to the south-east, reaches the centre of the Atlantic, and is lost in the gulf stream. It is by this current that the ice of the northern regions is borne to the south, far away from the place of its birth, where it is rapidly dissolved by the warmer temperature of the water and of the atmosphere. A slight attention to the direction of this current will at once explain the non-appearance of the polar ice off the northern shores of Europe, though at a much higher latitude than that which it visits in the heart of the ocean. If its course at first was south, or southeast, large masses would be impelled to the coasts of Norway and Scotland, and make their appearance in the German Ocean ; but as it sets in to the south-west, these districts are kept free from their presence, and they are conducted along the other side of the Atlantic.

The masses of ice by which the ocean is thus traversed assume a vast variety of shapes, but may be comprehended in two general classes. The first consist of sheets of ice, analogous to those which annually cover the lakes and rivers of northern lands. They present a surface which is generally level, but here and there diversified by projections, called hummocks, which arise from the ice having been thrown up by some pressure or force to which it has been subject. Sheets of ice, which are so large that their whole extent of surface cannot be seen from the mast-head of a vessel, are called fields. They have sometimes an area of more than a hundred square miles, and rise above the level of the sea from two to eight feet. When a piece of ice, though of a considerable size, can be distinguished in its extent, it is termed a floe. A number of sheets, large or small, joining each other, and stretching out in any particular direction, constitute a stream. Captain Cook found a stream extending across Behring's Straits, connecting eastern Asia with the western extremity of North America. Owing to the vast extent of some fields of ice, they would undoubtedly be conducted to a lower latitude in the Atlantic before their dissolution, under the influence of the warmer climate, but for the intervention of other causes. It frequently happens that two masses are propelled against each other, and are both shivered into fragments by the violence of the concussion. The ordinary swell of the ocean also acts with tremendous power upon a large tract, especially when it has been so thawed as to have become thin, and breaks it up into a thousand smaller pieces in a very short period. The danger of being entrapped between two ice-fields coming into contact with each other is one of the perils which the navigator has frequently to encounter in the northern seas; and fatal to his vessel and his life has the occurrence often been, while in a vast number of instances escape has seemed almost miraculous.

"At half-past six," says Captain Ross, relating his first voyage of discovery in the Isabella to the arctic regions, with Parry in the Alexander, "the ice began to move, and, the wind increasing to a gale, the only chance left for us was to endeavour to force the ship through it to the north, where it partially opened; but the channel was so much obstructed by heary fragments, that our utmost efforts were ineffectual; the ice closed in upon us, and at noon we felt its pressure most severely. A large floe, which lay on one side of the Isabella, appeared to be fixed; while, on the other side, another of considerable bulk was passing along with a rapid motion, assuming a somewhat circular direction, in consequence of one side having struck on the fixed field. The pressure con- 
tinuing to increase, it became doubtful whether the ship would be able to sustain it; every support threatened to give way, the beams in the hold began to bend, and the iron tanks settled together. At this critical moment, when it seemed impossible for us to bear the accumulating pressure much longer, the hull rose several feet; while the ice, wlich was more than six feet thick, broke against the sides, curling back on itself. The great stress now fell upon our bow; and, after being again lifted up, we were earried with great violence towards the Alexander, which had hitherto bcen, in a great measure, defended by the Isabella. Every effort to avoid their getting foul of each other failed; the ice-anchors and cables broke one after another; and the sterns of the two ships came so violently into contact, as to crush to pieces a boat that could not be removed in time. The collision was tremendous, the anchors and chain-plates being broken, and nothing less than the loss of the masts expected : but at this eventful instant, by the interposition of Providence, the force of the ice seemed exhausted; the two fields suddenly receded, and we passed the Alexander with comparatively little damage. A clear channel soon after opened, and we ran into a pool, thus escaping the immediate danger; but the fall of snow being very heavy, our situation still remained doubtful, nor could we conjecture whether we were even yet in a place of safety. Neither the masters, the mates, nor those men who had been all their lives in the Greenland service, had ever experienced such imminent peril ; and they declared, that a common whaler must have been crushed to atoms."

Captain Scoresby relates a similar narrow escape from destruction owing to the same cause. "In the year 1804," he observes, "I had an opportunity of witnessing the effects produced by the lesser masses in motion. Passing between two fields of ice newly formed, about a foot in thickness, they were observed rapidly to approach each other, and, before our ship could pass the strait, they met with a velocity of three or four miles per hour. The one overlaid the other, and presently covered many acres of surface. The ship proving an obstacle to the course of the ice, it squeezed up on both sides, shaking her in a dreadful manner, and producing a loud grinding or lengthened acute tremulous noise, according as the degree of pressure was diminished or increased, until it had risen as higl as the deck. After about two hours the motion ceased, and soon afterwards the two sheets of ice receded from each other nearly as rapidly as they had before advanced. The ship in this case did not receive any injury; but, had the ice been only half a foot thicker, she might have been wrecked." Other navigators have not been so fortunate; and the annual loss of whaling vessels in the polar seas is considerable, the Dutch having had as many as seventy-three sail of ships wrecked in one season. Between the years 1669 and 1778 , both inclusive, or a period of 107 years, they sent to the Greenland fishery 14,167 ships, of which 561 , or about four in the hundred, were lost. Every one will remember the intense and mournful interest occasioned by the loss of the President steamer, which left New York in the year 1841 to cross the Atlantic to our shores, but perished in the passage, without leaving a survivor to tell the story of her fate. It has been deemed highly probable that this vessel got entangled in the ice, and was destroyed by collision with its masses ; for during that year, in the month of April, the Great Western steamer encountered a field extending upwards of a liundred miles in one direction, surrounded with an immense number of floes and bergs, and had great difficulty in effecting its passage by this floating continent in safety.

Another form under which the ice appears in the ocean is that of bergs, which differ from the ice-fields in shape and origin. They are masses projecting to a great height above the surface of the water, and have the appearance of chalk or marble cliffs and mountains upon the deep. They have been seen with an elevation of two liundred feet - a circumference of two miles; and it has been shown by experiments on the buoyancy of ice floating in sea water, that the proportion above the surface is only about one- 
seventl of the thickness of the whole mass. During the first expedition of Ross, he found an iceberg in Baffin's Bay, at the distance of seven leagues from the land, which was measured by a party under Lieutenant Parry. Considerable difficulty was experienced in the attempt to land, as, in rowing round the berg, they found it perpendicular in every place but one. When they had ascended to the top, which was perfectly flat, they discovered a white bear in quiet possession of the mass, who plunged into the sea without hesitation, and effected his escape. The party found the iceberg to be 4169 yards long, 3869 yards broad, and 51 feet high, being aground in 61 fathoms. Its appearance was like that of the back of the Isle of Wight, and the cliffs resembled those of the chalk range to the west of Dover. The weight of this mass was calculated to amount to 1,292,397,673 tons. An iceberg examined by Captain Graah, on the east coast of Greenland, rose 120 feet out of the water, had a circumference of 4000 feet at the base, and its solid contents were estimated to be upwards of nine hundred millions of cubic feet. When viewed at a distance, nothing can be more interesting than the appearance of a considerable number of these formations, exhibiting an infinite variety of shape, and requiring no stretch of imagination to convert them into a series of floating towers, castles, churches, obelisks, and pyramids, or a snowy range of Alpine heights. No pencil, an observer has remarked, has ever given any thing like the true effect of an iceberg. In a picture, they are huge, uncouth masses, stuck in the sea; while their chicf beanty and grandeur-their slow stately motion, the whirling of the snow about their summits, and the fearful groaning and crackling of their parts - the picture cannot give. The ice of the bergs is compact and solid, of a fine green tint verging to blue; and large pieces may be frequently obtained, equal to the most beautiful crystal in purity and transparency. It is stated by Scoresby, that with a portion of this ice, of by no means regular convexity, used as a burning lens, he has frequently burnt wood, fired gunpowder, melted lead, and lit the sailors' pipes, to their no small astonishment, the ice itself remaining in the mean while perfectly firm and pellucid.

'The great distinction of icebergs from sheet ice, besides that of shape, is, that they are fresh-water formations, have their origin upon the land, and are identical with the glaciers of the Alps and Himalaya. They are formed by the congelation of the fresh water that pours annually from mountains of snow under the action of the solar rays, and have their principal birth-place on the eastern shores of Greenland, and along the coasts of Spitzbergen. In treating of glaciers, the undoubted fact of their motion was referred to, with the circumstances which give rise to it. In relation to those of the Alps, an attempt has been recently made to ascertain the rate of the movement by Professor Forbes, who arrived at the following results with reference to part of the Mcr de Glace, at Montanvert, near Chamouni : -

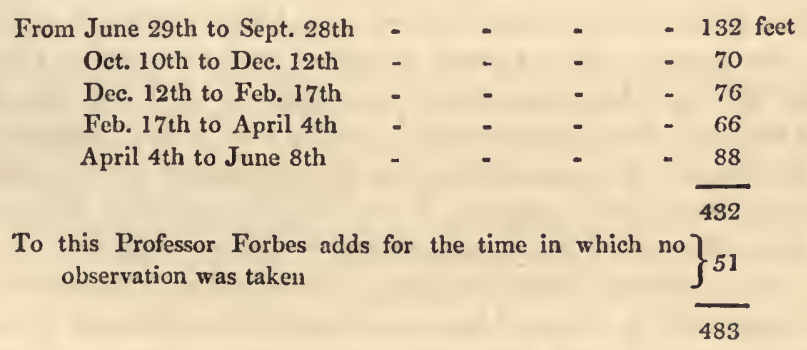

The annual movement of the glacier may therefore be estimated at nearly five hundred feet. By a similar slow yet sure progress, those of the northern regions, formed along the coasts, advance to the sea, where enormous blocks are broken off by the action of the 
waves, and set afloat as icebergs. The shores of Spitzbergen, literally the Peaked Mountains, consist of conical elevations rising abruptly from the sea to a height of between 1500 and 3700 feet, which are separated from each other by narrow valleys opening towards the ocean, all of which arc occupied by glaciers. This is the physical condition also of the east coast of Greenland, and of various parts of its western shores, which together are supposed to present a breast-work of ice to the play of the waves upwards of 600 miles in length. The separation of masses from the main body, by the undermining and wrenching power of the sea, has often been witnessed by the Danish residents in that region; and the calving of the glacier is a phrase commonly applied by the natives to the operation. Henderson gives an interesting description of the arrival of these immense fragments at Iceland, drifted from a more northern latitude. They are sometimes seen moving towards the coast, not unfrequently piled one above another, more resembling islands, with mountains, castles, and spires, than bodies of ice. They have been known to run aground in five hundred feet of water. Their motion, when accelerated by the wind and current jointly, is often so great that no six-oared boat is able to keep up with them. During the agitation of a storm, the icebergs are dashed against each other in the most tremendous manner; the noise arising from the crash is heard at a great distance; and it has occurred that drift timber, jammed in between the masses, has taken fire from. the friction, presenting a scene the most incongruous that can possibly be imagined. The arrival of the drift ice produces a great effect upon the climate, the thermometer sinking several degrees; and the Greenland bear is often a passenger with it, to the terror of the natives; for, having been long at sea, the natural ferocity of the animal is strengthened by the keenness of hunger.

The constitution of icebergs, and the immense distances to which they are transported from the scene of their birth by the oceanic currents, are thought to offer a solution to a common geological phenomenon. This is the occurrence of erratic blocks, or boulders, isolated fragments of rock, which have no identity with those of their immediate site, nor with any to be found within hundreds of miles of the place of their deposition. Blocks of granite of extraordinary magnitude lie upon the limestone slopes of the Jura range of the Alps; and some parts of England, and the great level to the south of the Baltic, are strewed with pieces of primitive rock, of a nature kindred to that of the mountains of the Scandinavian peninsula. Different explanations have been given of the means by which these erratic blocks have been conveyed from their native beds to their present sites; and, with great probability, they have been referred to the agency of icebergs, or drifting glaciers. Almost every ice formation of this kind in the Alps is found thickly corered with rocks and débris, which have been disintegrated by the action of frost and thaw, heat and cold. They are carried along with the glaciers in their downward course, and quietly deposited upon the levels and slopes of the lower valleys on the melting of their icy vehicles. The glaciers of the polar regions present precisely the same features. They are precipitated into the ocean laden with strata of earth and stones, or with rocky masses of great size, which are transported by them into lower latitudes, and are finally strewed upon the floor of the great deep, upon the dissolution of the icebergs. Captain Scoresby mentions having seen some far from land in the polar seas, which supported fragments of rock and soil, conjectured to be above fifty thousand tons in weight. Let but the bed of the sea where these fragments are deposited be elevated, so as to become dry land, - a change which we know has taken place with reference to large tracts of the present surface of Europe, - and erratic blocks would be exposed to the eye of the spectator, similar to those which now cover the sandy plains of Pomerania.

It is easy to conccive of the incessant vigilance and practical skill which the navigation of the polar seas requires, in order to be conducted without a fatal catastrophe. 
Beset with ice fields, bergs, and floes, often in fogs by day, and subject to the long nights of those high latitudes, not all the experience and resources of the commander can avert situations of imminent peril and apparently inextricable difficulty. Scoresby relates a remarkable instance of this kind. Having moored his vessel to a floe, during a gale, attended by a heary fall of snow, he states:- "About 6 P. M. the snow became so thick that we could scarcely see a hundred yards distinctly, and the wind was, if possible, more furious. 'Two small icebergs now appeared setting towards the ship; but as they were not of a magnitude sufficient to endanger us without auxiliary pressure, we quietly awaited their approach. 'The first, which was about thirty-six feet above the level of the sea, struck the ship on the starboard quarter, and turned her broadside to the wind; it then slipped clear, without occasioning us any damage whatever. The second iceberg approached us with more alarming rapidity; but as we had not the power of getting clear of it, we were obliged to receive the shock upon whatever part of the ship it might chance to fall. It came in contact with the rudder, and slightly bruised one of its timbers; then grazing the ship's quarter and broadside, it passed forward to the bows, and being fortunately kept from close contact aloft by a tongue projecting from its base, it cleared all our boats. At this juncture, when the ship was so much involved with icebergs as to render casting off impracticable, had the state of the weather permitted it, two floes came in sight from different quarters. One of them appeared to be rapidly closing upon us from the west, and the other from the south, which with the floe that we were moored to, occupying the eastern quarter, almost completely locked us in. To secure ourselves as far as possible against the crush which now appeared certain, we fastened by a hawser a large heary piece of ice ahead of the ship where the floes threatened the first contact, with the view of subjecting the interposed mass to the pressure, and with the hope of being then defended from partaking of it. The first shock of the floes was sustained by this mass with full effect, and for some time afterwards all things seemed quiet and safe. Suddenly, however, the pressure was renewed, in consequence. it was supposed, of some new stoppage to the drift of the floes, with tenfold violence. Our barrier was squeezed deeply into the floe, and prodigious blocks of ice were broken off and raised up by the pressure. While we contemplated their mighty effects with much anxiety, the berg which shortly before had passed the ship began a revolving and a retrograde motion, so quick as to overtake us before we could get the ropes off to slack astern, and suddenly nipped the ship on the larboard beam and bow against the floe by which we rode. The force was irresistible: it thrust the ship completely upon a broad tongue (or shelf under water) of the floe, until she was fairly grounded, and continued to squeeze her rapidly up the inclined plane formed by the tongue, until the ice came in contact beneath the keel. This was the work of a few moments, and in ten minutes all was again at rest. When the pressure ceased, we found that the ship had risen six or eight feet forward, and about two feet abaft.

"The floe on the starboard side was about a mile in diameter and forty feet in thickness, having a regular wall-side of solid ice five feet in height above the sea; on the tongue of this the ship was grounded. The iceberg on the larboard side was about twenty feet high, and was in contact with the railing of the bows, and with the gunwale and channclbends amidship. This berg was connected with a body of floes to the westward, several leagues in breadth. The only clear space was directly astern, where a small interstice and vein of water was produced by the intervention of the bergs. Any human exertion for our extrication from such a situation was now in vain, the ship being firmly cradled upon the tongue of ice which sustained her weight. Every instant we were apprehensive of total destruction, but the extraordinary position of the ice beneath her was the means of her preservation. The force exerted upon the ship to place her in such a situation 
must evidently have been very violent. Two or three sharp cracks were heard at the time the ship was lifted, and a piece of plank, which proved to be part of the false keel, was torn off and floated up by the bower, but no other serious injury was yet discovered. Our situation, however, was at this time as dangerous and painful as possible. Every moment threatened us with shipwreck, while the raging of the storm, the heavy bewildering fall of sleet and snow, and the circumstance of every man on board being wet to the skin, rendered the prospect of our having to take refuge on the ice most distressing. We remained in this state of anxiety and apprehension about two hours. On the one hand we feared the calamity of shipwreck; on the other, in case of her preservation, we looked forward to immense difficulties before the ship, so firmly grounded, could be got afloat. While I walked the deck under a variety of conflicting feelings, produced by the anticipation of probable events, I was suddenly aroused by another squeeze of the ice, indicated by the cracking of the ship and the motion of the berg, which seemed to mark the moment of destruction. But this renewed pressure, by a singular and striking Providence, was the means of our preservation. The nip took the ship about the bows, where it was received on a part rendered prodigiously strong by its arched form and the thickness of the interior fortifications. It acted like the propulsion of a round body squeezed between the fingers, driving the ship astern, and projecting her clear of all the ice fairly afloat with a velocity equal to that of her first launching!"

The year 1830 was one of the most disastrous ever known in the navigation of the northern seas, happily not for the loss of life, but of the ships employed in the whale fishery. A group of vessels consisting of the St. Andrew of Aberdeen, the Baffin and the Rattler of Leith, the Eliza Swan of Montrose, the Achilles of Dundec, and the Ville de Dieppe from that port, while entangled with icebergs and floes, encountered a violent gale, which drove in upon them the stupendous masses. On the evening of the 24 th of June, the ships were ranged in a line stem to stern, pressed on each side by the ice, when the tempest arose that sealed their fate. In little more than a quarter of an hour, the Baffin, Achilles, Ville de Dieppe, and Rattler were crushed into fragments by the huge floes which the storm dashed against them, the noise of the ice rending asunder and splintering their timbers, the falling of the masts, and the cries of the sailors compelled to betake themselves to the frozen surfaces as their only refuge, forming a scene easier to imagine than describe. Another frightful tempest on the 2nd of July, accompanied with showers of hail and snow, accomplished in a similar manner the destruction of several of their companions. "The dark and fearful aspect of the sky gave warning of approaching danger. At seven in the morning a signal of distress was hoisted by the William of Hull, and in a short time she appeared almost buried under masses of ice. About ten, the North Briton was reduced to a complete wreck; and at eleven the Gilder was in a similar predicament. During six hours the storm slightly abated, but returning after that interval with augmented fury, pressed the ice with additional force upon the Alexander of Aberdeen and the Three Brothers of Dundee-two fine vessels, so strongly built that an observer might have supposed them capable of withstanding any shock whatever. They made accordingly a very stout resistance. The conflict was dreadful, and was beheld with awful interest by the sailors as they gazed around. At length their timbers gave way at every point-the sides bursting open, the masts crashing and falling with an astounding noise: the hull of the Three Brothers was so much twisted, that the two ends of the ship could scarcely be distinguished; finally, only some broken masts and booms appeared above the ice. The crews, spectators of this awful scene, gave three cheers in honour of the gallant resistance made by their vessels to the overpowering element by which they had been vanquished." This was a verification of one of Parry's remarks, that a ship, even the strongest that can be built, becomes like an cgg-shell when 
exposed to the full force of the agency in question. Nearly a thousand seamen, during this season of peril, were obliged by the wreck of their vessels to commit tliemselves to the ice, saving what food and clothing the time admitted of being preserved, and were ultimately brought off in safety by other vessels.

The "deep sea fryseth not." This was a notion of the ancient mariners, once held, too, by some of the learned, on the ground of its saltness, but sufficiently refuted by modern observation. In the severe winter of the year 1348, the ocean was completely frozen over around Iceland, so as to admit of the inhabitants riding on horseback from one promontory to another at some distance from the shore. It is found that sea-water, containing the ordinary quantity of saline ingredients, freezes at the temperature of about $27^{\circ}$ Fahrenheit, five degrees below the freezing point of fresh water; but as the arctic winters vary in their severity, like those of the temperate zones, some seasons being comparatively mild, the amount of ice formed varies correspondingly. Hence some navigators have found the sea open at one period, where to others it has presented an impassable icy barrier at the same season in a different year, and the latter have found it impossible to penetrate to the high latitudes reached by the former. Several of the early adventurers to the polar seas succeeded in advancing to extreme northerly points. Davis, in 1587, attained to the latitude of $72^{\circ} 12^{\prime}$; Baffin, in 1616 , to $78^{\circ}$; Hudson, in 1607 , to $81^{\circ}$; and Captain $M^{\circ}$ Cullam, in 1751 , to $83 \frac{1}{2}^{\circ}$, where he found the sea still open to the north. This was remarkably the case in the year 1754, when Captain Wilson passed through floating ice between the latitudes of $74^{\circ}$ and $81^{\circ}$, where he found a completely clear sea, and advanced as high as $83^{\circ}$. During the same year, a southerly wind, which blew for several days, carried Mr. Stephens from the coast of Spitzbergen; and he actually reached the latitude of $841_{2}^{\circ}$, meeting with very little ice in his passage, and experiencing no excessive cold. The elder Scoresby, in 1806, attained the latitude of $81^{\circ} 50^{\prime}$; but, in the year succeeding, he was unable to pass beyond $78 \frac{1}{2}^{\circ}$." The obstacles presented by the ice have hitherto prevented the northern coast-line of America from being traced by sea. A lamentable loss of life has been incurred in attempts to effect this enterprise-that of Sir John Franklin and his crews-though, if accomplished, it could never be productive of any practical benefit to commerce, but is simply a point of geographical intcrest and scientific inportance.

Of the two principal basins in which the waters of the ocean chiefly roll - the Atlantic and the Pacific - the coast line of the former is the most extensive, though its superficial area is far less than that of the latter.

European shores of the Atlantic from the Strait of Waigatz between the island of that name and the main land of Archangel, to the Strait of Kaffa, at the entrance of the Sea of Azov 17,000 miles

Asian shores along the Black Sea, the sea of Marmora, and the Mediterranean Sea $\quad-\quad 3,000$

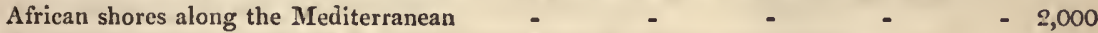

West African shores from the Straits of Gibraltar to the Cape of Good Hope - $\quad-\quad 6,000$

Whole eastern shores of the Atlantic - - _ _ - $\quad$ - 28,000

American shores of the Atlantic, including Greenland as a part of the continent, though

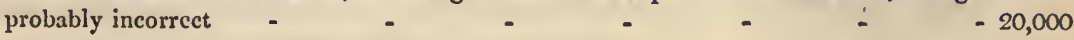

Whole coast line of the Atlantic - _ _ _ _ $\quad$ - $\quad \overline{48,000}$

American shores of the Pacific Occan from Cape Horn to Behring's Strait - $\quad-\overline{11,000}$

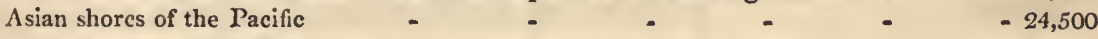

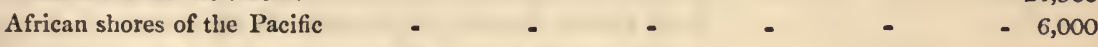

Whole coast line of the Pacific _ $\quad$ - $\quad \ldots \quad \ldots \quad-\overline{41,500}$

The greater geographical extent of the outline of the Atlantic is due to its numerous 
projections into the land, especially in its northern regions, where it forms many mediterranean, or close seas, of immense size. This feature of its basin confers important advantages upon the nations that occupy its coasts, facilitates inter-communication, and has contributed in no slight degree to their superior civilisation. It is now the great highway of the world's commerce, has constantly property amounting to many millions in value upon its surface, and day and night the lives of thousands are at the mercy of its winds and waves. According to Humboldt, the form of the Atlantic basin is that of a longitudinal valley, whose projecting and retiring angles correspond to one another. Theorising with reference to its origin, he refers it to a very violent rush of the waters from the south, which, upon being obstructed in their course by the Brazilian mountains, took an easterly direction, and scooped out that remarkable indentation of Africa now forming the Gulf of Guinea. He supposes, that being stopped by the high coast of Upper Guinea; the stream ran again to the west, and gave origin to a similar indentation of the American shore, now occupied by the waters of the Gulf of Mexico; and issuing thence, it proceeded between the mountains of Western Europe and those of North America, gradually diminishing in its velocity and force, until it at length subsided. We have had occasion before to remark upon the striking configuration of the cast and west sides of the Atlantic, as though its continental shores had once been united, and been riven asunder by some grand catastrophe.

The Mediterranean arm of the Atlantic is its most important branch, extending through

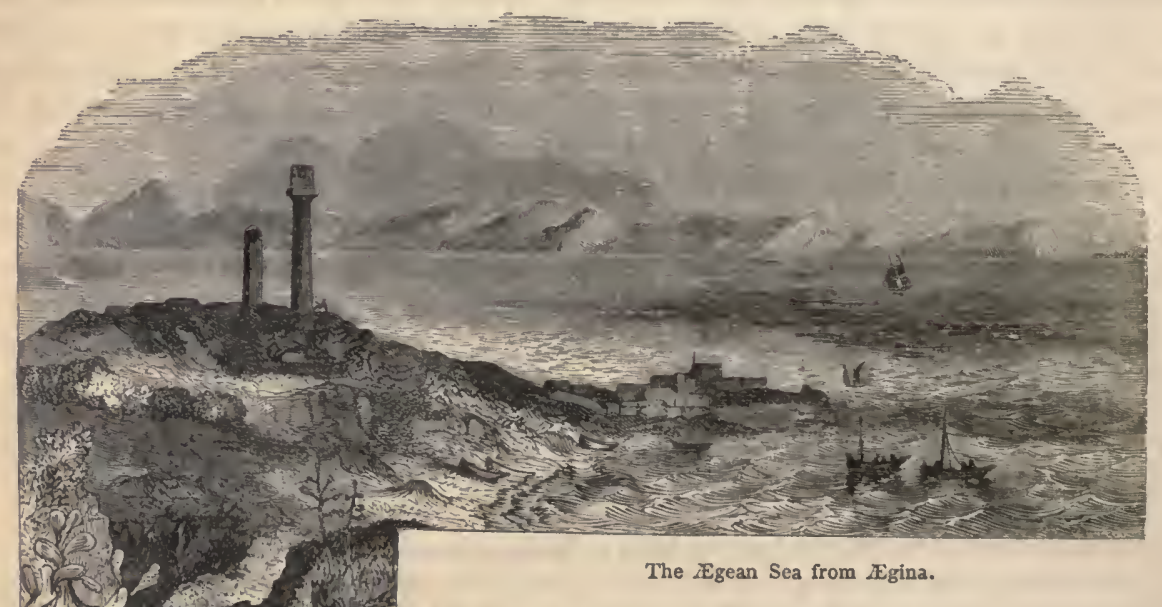

$48^{\circ}$ of longitude. No second example occurs of the ocean penetrating inland to such an extent, or one at all comparable with it. This was the Great Sea of the ancients, a title which proclaims their limited knowledge of physical geography. It is, however, an ocean en petit, daily becoming of greater commercial and political importance, since the overland route through Egypt to the East has been established. In no other part of the globe is there such a variety of coast-line within a few days' sail - the rich landscapes of Spain, the hot stony pavement of Libya, the sandy plains of the Nile, the volcanic shores of Italy and Sicily, the bold southern heights of Asia Minor, the rugged promontories of the Greek peninsula, and the white 
marble cliffs of its archipelago of islands. Nothing can exceed in beauty the scenery of the Grecian seas, whether by the Ananes rocks rising perpendicularly from the deep like the coral reefs of the Pacific, or in the gulfs of Corinth, Nauplia, and IEgina, or passing between Samos and the mainland of Asia, or breasting the current of the Dardanelles and the Bosphorus. A remarkable feature of the Archipelago is the great depth of its water - a line of 1200 feet generally finding no bottom at the distance of less than a mile from the shore, and one of 2400 feet failing to reach it in some parts of the Gulf of Nauplia. The Mediterranean shows also an immense depth in other places; that of 1800 feet between Italy and Greece, 6000 between Sardinia and Sicily, 4800 north-west of Sardinia, and 8000 feet between Spain and Africa, while the deepest part of the North Sea, lying between Kinnaird's Head, Scotland, and the Naze of Norway, does not exceed 900 feet. Another peculiarity of the Mediterranean is the depression of its level below that of the Atlantic and the Black Seas, arising from a prodigious evaporation, which is supposed to carry off three times the amount of water brought into it by the rivers. Hence there is a constant current setting into it from the Atlantic through the Straits of Gibraltar, and from the Black Sea through the Dardanelles. Every thing, as Humboldt observes, that relates to the formation of this sea, which has had so powerful an influence upon the first civilisation of mankind, is highly interesting. Ascending from its shores, in his journey through Spain into the kingdom of Valencia, towards the lofty plains of La Mancha and the Castiles, he hailed far inland, in the lengthened declivities, indications of the ancient coast of the Peninsula. The physical aspect of the region recalled the traditions of the Samothracians, and other historical testimonies, according to which the bursting of the waters of the Euxine through the Dardanelles augmented the basin of the Mediterranean, then a lake, and overflowed the southern part of Europe.

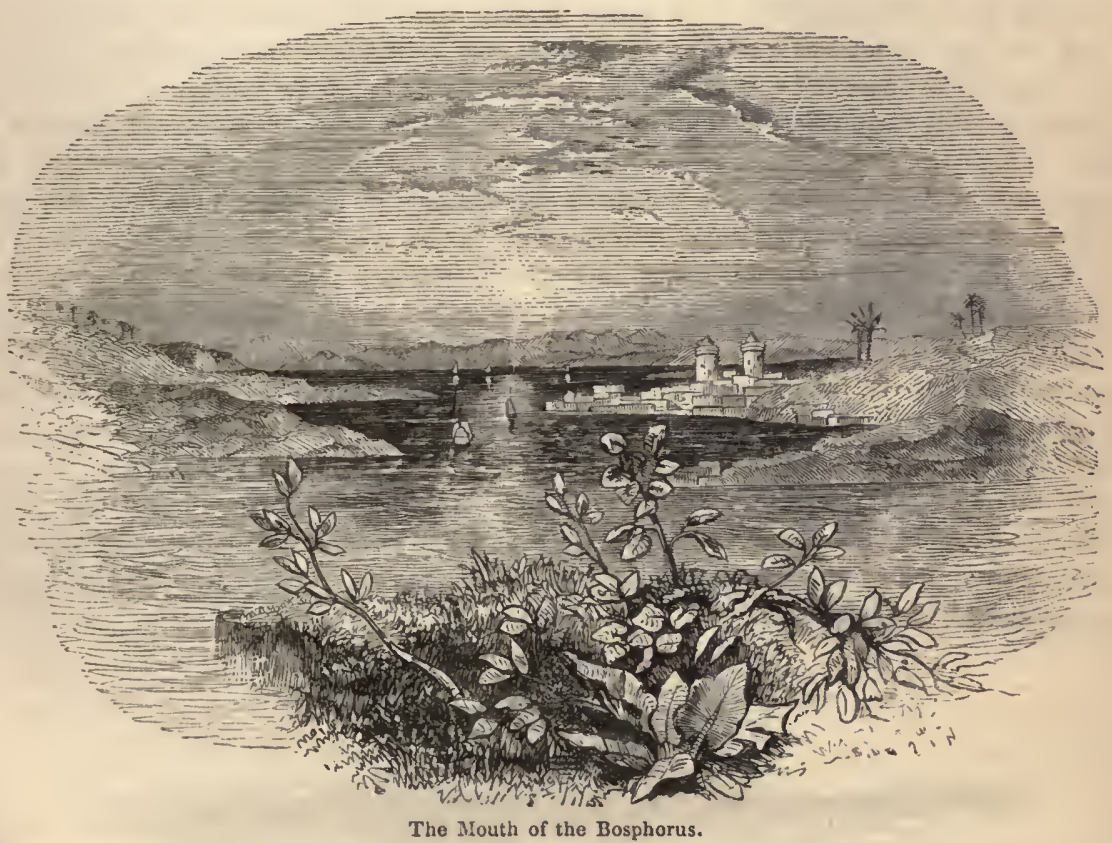

The central elevated plain of Spain was a barrier to the inundation on the one hand, till the Pillars of Hercules were rent asunder by the force of the flood, when the draining off of the waters, through the intervening strait that was formed, brought the Mediterranean 
progressively to its present level, while Lower Egypt emerged again from its surface on the one side, and the fertile valleys of 'Tarragon, Valencia, and Murcia on the other. This is not a modern geological reverie, but the opinion of the ancient geographers, Strabo and Eratosthenes, founded upon the configuration of the land, and a traditional report of some great catastrophe in early ages, to the oceurrence of which a different sentiment, which impressed the mind of antiquity, still points, that the irruption was made by the waters of the Atlantic.

The Phonicians - the earliest known navigators of the Mediterranean - are said to have come, in thirty days' sail, with an easterly wind, to the "weedy sea." This is a modern denomination of the Atlantic, Mar de Sargasso, in the language of the Spanish and Portuguese sailors. The occurrence of floating sea-weed, Fucus natans, is one of its peculiarities. It is found in immense quantities, in two separate regions of the Atlantic, covering the ocean like a mantle, a little to the west of the meridian of Fayal, one of the Azores, between $25^{\circ}$ and $36^{\circ}$ of latitude, where it forms a vast marine meadow. The other region occupies a smaller space between lat. $22^{\circ}$ and $26^{\circ}$, and about long. $70^{\circ}$ and $72^{\circ}$, two hundred and seventy-six miles to the east of the Bahamas. Though there is a species of sea-iveed, observed by Lamouroux, with stems upwards of eight hundred feet long, yet, in the latitude stated, the weed is not fixed to the bottom, but floats in scparate masses on the surface of the water. It owes its origin doubtless to submarine rocks, which continually replace at the surface what is carried off by the equinoctial currents, the growth of marine cryptogamia being extremely rapid. There is some obscurity resting upon the manner in which these weeds are uprooted, at depths where it is generally thought the sea can only experience a very slight agitation. Lamouroux, however, observes, that if the fuci adhere to the rocks with the greatest firmness before the display of fructification, they separate with great facility after that period; and, added to this, the fish and the molluscas gnawing the stems may contribute to the separation in question. Humboldt observed a vine-lcaved fucus regetating at the bottom of the ocean, at the depth of 192 feet, notwithstanding which its leaves were as green as those of our grasses. He estimated that, at such a depth, the fucus could only have received light equal to half of that supplied by a candle at the distance of a foot. This fact, and other's of a kindred nature, offer formidable difficulties to the common opinion, that absence of light must always produce blanching; and clearly indicate that it is not under the infuence of the solar rays alone that the carburct of iron is formed, the presence of which gives the green colour to the parenchyma of plants. Upon a scale equally grand and extensive, the occan exhibits the boundless profusion of creative power, in the animal as well as the vegetable life, of which it is the repository. There is a portion of the Grcenland sea occupied by microscopic Medusan races, to an extent of not less than twenty thousand square miles; yet Scoresby estimates that two square miles must comprehend $23,888,000,000,000,000$ of these creatures - a number which he illustrates by observing, that to count it would require 80,000 persons, and a period equal to the interval between the present and the Creation.

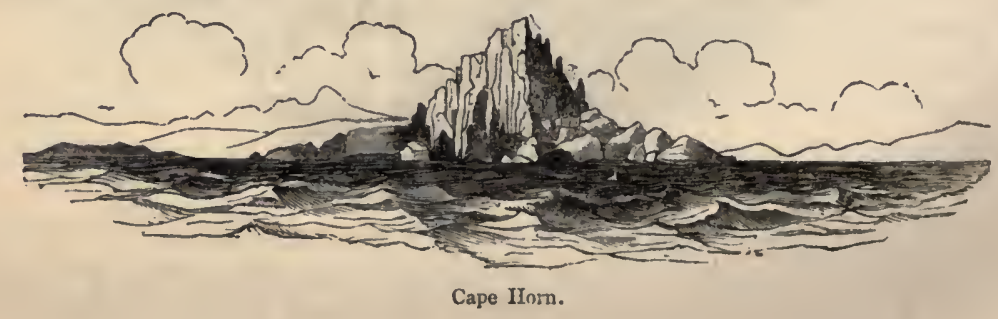




\title{
CHAPTER IX.
}

\author{
TIDES AND OCEANIC HIGHWAYS.
}

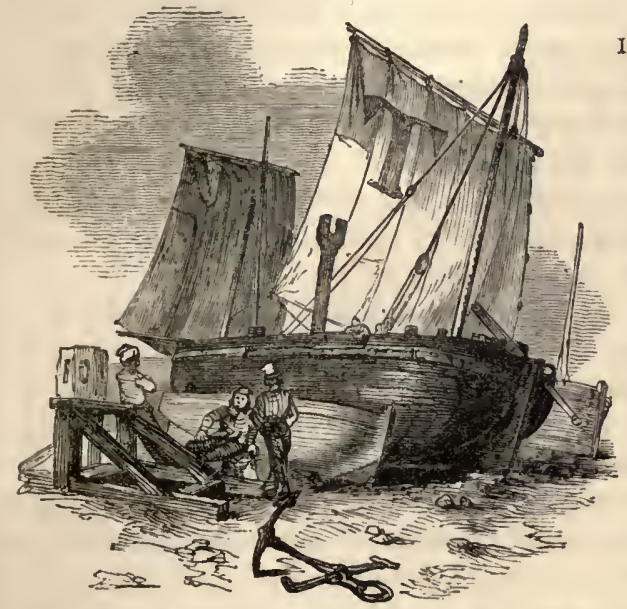

IIERE are various movements to which the waters of the ocean are subject, which are of great importance to navigation, and of high interest to the physical enquirer. 'They are chiefly the effect of external causes of disturbance, either atmospheric or astronomical, which operate with mighty though changeful energy upon the yiclding fluid. Waves, tides, and currents are three distinct forms under which its principal agitations appear. As water is susceptible of impression from the slightest force, the equilibrium at the surface is disturbed by the aerial currents in contact with it, and upon the particles of the fluid being displaced, the adjoining particles immediately rush in to restore the balance. The cause continuing to act, the effect follows, in accordance with its duration and potency. In this manner waves are formed, from the power of the atmosphere in a state of motion, displacing the surface waters, and their own tendency to preserve an equilibrium. As the force of the wind varies, its impression upon the ocean varies proportionately. A gentle breeze wrinkles the surface; a brisk galc produces undulations which rock to and fro the largest vessels upon their bosom; a storm creates waves of enormous volume and appalling violence. These agitations of the sea may be compared to the waving of a forest, or of a field of grain, where commotion is displayed, apart from any continuous onward movement. They have far less resemblance to the motion of a river current. In a field of corn, under the action of the zephyr or a ligh wind, we see waves formed by the bending tops of the corn, apparently chasing one another across the field, yet without any advancing motion of the parts that form them. In like manner, the motion of waves of water is not necessarily accompanied by a current in the same direction, and though a continuous high wind produces this effect, the progress of the water is at a very slow rate, and has no correspondence with the impression which its outward aspect makes upon the mind of the spectator. The proof of this may be easily obtained, by throwing any light substance into the sea, a little beyond the breakers, or into a picce of standing water, the surface of which is ruffled. Sucl a floating body will rise and fall with the motion of the waves, but make little perceptible advance towards the shore.

Waves vary in their height, form, velocity, and extent. These diversities depcnd upon the depth of the sea, the size of its basin, and the force of the wind. A wave-summit produced by a breeze from the land, maintains constantly the same height while the impulse is the same; but the heights increasc according to the distance from the shore. In open seas, where the wind blows upon the water in a parallel manner, through a considerable tract, the waves are generally in the shape of straight and long furrows; but in more confined situations, they appear in short straight lines, or in arcs of circles, according to 
the configuration of the coasts, and their contiguity. When the wind blows fresh, the motion of the waves not being sufficiently quick, their thin and light tops are impelled forward and broken, falling upon their own slopes in a torrent of white foam, particles of which, in the form of spray, are carried to a vast distance by the gale. It is no uncommon circumstance during a violent gale, for persons far inland to be sensible of a saline impregnation in the atmosphere, the spray of the waves, which have been torn by the blast. In severe tempests, enormous volumes of water are accumulated in ridges, which literally consist of wave on wave; for owing to the permanence of the wind, its action will raise a second upon the first, and a third upon the second, in the same manner as it raised the first upon the flat surface of the water. From a number of experiments, and the experience of divers, it appears that the disturbance of the sea by the action of the winds, extends but a comparatively small way below the surface. The observations of the Committee appointed by the British Association in 1836 show that, with a depth of water equal to 12 feet, waves nine inches high and four or five feet long did not sensibly affect the water at the bottom; and probably at the depth of 200 feet the sea is undisturbed in the roughest weather. After the subsidence of the wind which has put the surface in motion, wares continue to roll for some hours, upon the principle of the pendulum swinging for some time after it has received an impulse. Hence in a completely calm state of the atmosphere, the ocean exhibits a great undulatory movement, called the swell, which seldom entirely dies away, before the action of the disturbing cause is renewed. The swell proceeds from the combined influence of winds and currents, and upon the mighty oscillation being checked in its career by sand banks, or a rocky coast, a roaring and violent surge is produced. Such is the surf at Madras, caused by the swell of the ocean across the Bay of Bengal, a sweep of nearly five hundred miles, coming into contact with the shore, where it exhibits the "wild waves' play," whose voice is heard far over the level plains of the Carnatic. It frequently occurs, that while the swell is advancing in one direction, the wind is blowing from an opposite quarter, or the wind suddenly chops about, or the surface of the ocean receives impulses in various directions from different breezes; and in any of these cases, a series of compound waves is produced, and the aspect of the deep becomes complex in the extreme.

The Sound at Plymouth was formerly exposed to a heavy swell occasioned by the south-west gales, incommoding and endangering the shipping of that great naval arsenal; but this has been remedied by the construction of the Breakwater, one of the most stupendous undertakings ever accomplished by the genius and power of man.

\footnotetext{
"The billows sleep

Within the shelter of a wondrous pile

Of man's best workmanship - that new-made isle,

That marble isle - brought piecemeal from the shore,

To break the weltering waves, and check their savage roar."
}

The Breakwater is a barrier or dyke, nearly a mile in length, raised above the surface of the water, and stretching across the Sound so as to leave entrances at both ends. It was formed by an immense quantity of large stones, quarried from some limestone hills, which were shipped in vessels specially constructed for the purpose, and precipitated into the sea at the spot where it was proposed to keep the waves at bay. About fifty ressels were employed in this service, by which were deposited in the year 1812 about 16,000 tons of stone; in 1813, 71,000; in 1814, 240,000; in 1815,264,000; in 1816, 300,000; the whole quantity amounting to nearly $40,000,000$ cubic feet. Baron Dupin inspected this extraordinary work while in progress, and enthusiastically records the impression made upon his mind by the "order, regularity, and activity which reign throughout all the operations; the embarking and disembarking of the materials; the working and 
placing of the enormous blocks which form the upper part of the breakwater; the diffculties conquered by the dexterity and ingenuity of the workmen; the transport of the blocks, and, above all, their extraction from the quarries. When we visit the workshops of the artificers and the operations of the quarry-men," he continues, "it is admirable to observe man, so weak and so feeble, manage at his will the enormous masses he has detached from their beds, in order to precipitate them into the ocean, to form other hills. The roads formed in the air for the transport of the useless earth and broken fragments; the lines of cranes and their combined labour; the movements of the carriages; the arrival, the loading, and the departure of the vessels - present to the eye of an admirer of great works and of the mechanical arts, one of the most pleasing and imposing spectacles it is possible to contemplate." The artificial barrier has answered the purpose for which it was constructed, as admirably as if a natural rampart of rock occupied its site; and Plymouth Sound is now a safe and convenient roadstead for the largest menof-war.

The effect attributed to "a soft answer," the moderation of wrath, has frequently been illustrated by a reference to the action of oil upon waves. From the time of Plutarch and Pliny, who relate, that the mariners of their day were accustomed to still waves in a storm by pouring oil into the sea, it has passed current in popular speech, that this effect by such means may be produced, and though treated with discredit in modern times, experiment proves that there is some truth in the statement. Among the facts reported in favour of it, the following occurs in a letter to Count Bentinck from M. Tengragel, dated Batavia, Jan. 5th, 1770:- "Near the islands Paul and Amsterdam we met with a storm, which had nothing particular in it worthy of being communicated to you, except that the captain found himself obliged, for greater safety, in wearing the ship, to pour oil into the sea, to prevent the waves breaking over her; which had an excellent effect, and succeeded in preserving us. As he poured out but a little at a time, the East India Company owes perhaps its ship to only six demi-aumes of olive oil. I was present upon deck when this was done, and I should not have mentioned this circumstance to you, but that we have found people here so prejudiced against the experiment, as to make it necessary for the officers on board, and myself, to give a certificate of the truth on this head, of which we made no difficulty." It was the practice of the fishermen of Lisbon, when about to return into the river, if they saw before them too great a surf upon the bar, which they apprehended might fill their boats in passing, to empty a bottle of oil into the sea, to suppress the breakers. Previous to the time of Franklin, no man of science made experiments upon the subject; but his attention was called to it by a circumstance which he thus narrates:- "In 1757, being at sea in a fleet of ninety-six sail bound for Louisbourg, I observed the wakes of two of the ships to be remarkably smooth, while all the others were ruffled by the wind, wlich blew fresh. Being puzzled with the differing appearance, I at last pointed it out to our captain, and asked him the meaning of it. 'The cooks,' said he, 'have, I suppose, been just emptying their greasy water through the scuppers, which has greased the sides of those ships a little;' and this answer he gave me with an air of some little contempt, as to a person ignorant of what everybody else knew. In my own mind I at first slighted his solution, though I was not able to think of another." The issue of one of Franklin's experiments upon a pond on Clapham Common, is detailed in a volume of the Philosophical Transactions. After dropping a little oil into the water, he states: "I saw it spread itself with surprising swiftness upon the surface, but the effect of smoothing the waves was not produced; for I had applied it first upon the leeward side of the pond, where the waves were largest, and the wind drove my oil back upon the shore. I then went to the windward side, where they began to form; and there the oil, though not more than a tea-spoonful, pro- 
duced an instant calm orer a space several yards square, which spread amazingly, and extended itself gradually till it reached the lee-side, making all that quarter of the pond, perhaps half an acre, as smooth as a looking-glass." Franklin again experimented at the entrance of Portsmouth harbour, opposite to Haslar hospital, in eompany with Sir Joseph Banks, Dr. Blagden, and Dr. Solander, where the waves, though not destroyed, were reduced to caln and gently swelling undulations. It seems evident, therefore, that the mollifying effect attributed to the action of oil upon disturbed waters is not without some foundation. Though the course of large waves is not arrested by it, for these have acquired a power of oscillation independent of the foree of the wind, yet it will smooth their surface, and perhaps prevent their formation altogether under the influence of but a gentle breeze. "I imagine," says Franklin, accounting for the effect, " that the wind blowing orer water covered with a film of oil eannot easily catch upon it, so as to raise the first wrinkles, but slides over it, and leaves it smooth as it finds it."

The second great movement which the waters of the ocean exhibit is the Tides. Here we have periodical fluctuations of its level, the eauses of which are astronomical, and arise from the attractive influence of the sun and moon, the latter being the more potent agent of the two. The sea rises, or flows, as it is called, by degrees, about six hours; it remains stationary about a quarter of an hour; it then retires, or ebbs, during another six hours, to flow again after a brief repose. Thus every day, or the period elapsing between suecessive returns of the moon to the meridian of a place, which is 24 hours $50 \frac{1}{2}$ minutes, the sea ebbs and flows twice, much less, indeed, towards the poles than within the tropies, where the waters lie under the direct influence of the lunar attraction. The connection between the periodieal flux and reflux of the sea, and the positions of the moon, is too obvious to have escaped the attention of mankind in early ages, whose geographical situation brought oceanic phenomena under their notice, for the highest tides occur at the period of new and full moon, and the lowest when her phase is a semicircle in the lieavens. Accordingly, the philosophers of antiquity remark upon the tides rarying with the moon; and the elder Pliny, in a very striking passage in his Natural History, attributes them to lunar action, and proceeds to give a very accurate description of their leading circumstances. Keppler elearly indicated the principle of gravitation, and referred the tides to the attraction of the moon; an explanation which Galileo regretted, who ascribed them to the rotation of the earth combined with its revolution about the sun. Dr. Wallis, in 1666, in letters to Mr. Boyle, attributed the alternate rise and depression of the ocean to the consideration, that the common centre of gravity of the moon and the earth deseribes an orbit about the sun, while they revolve about this common centre. In answer to an objection which was made to him in the form of a query, how two bodies which have no tie can have one common centre of gravity? Wallis states :- "It is harder to show how they have, than that they have it. - As to the present case, how the earth and moon are connected, I will not undertake to show, nor is it necessary to my purpose; but that there is somewhat that does connect them, as much as what connects the loadstone and the iron which it draws, is past doubt to those who allow them to be carried about the sun, as one aggregate or body, whose parts keep a respective position to one another, like as Jupiter with his four satellites, and Saturn with his one. Some tie there is that makes those satellites attend their lords and move in a body, though we do not see that tie, nor hear the words of command." This language evinces great sagacity, but it is the language of surmise merely. To Newton the glory belongs of demonstrating the existence of a prineiple which had previously been a matter of philosophical speculation, of explaining its laws, and showing how the tides are produced by the influence of gravitation, the grand agent of the movements of the universe, and the 
conservator of its harmony. The theory of the tides is exceedingly simple in its principles, but the most complex of all physical problems in its details.

If we suppose a zone of water to surround the globe in every part, and to be subject to no external influence, it is obvious, that the waters would uniformly maintain the same level, and be arranged upon its surface at an invariable depth, assuming the form of the circle E. It is easy, however, to perceive what effect, according to the law of gravity;

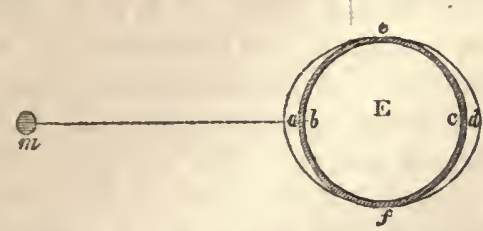
the presence of a body like the moon will produce upon the zone of water, a fluid so susceptible of mobility, yielding to the slightest impressions. As a solid body draws toward it any other body, by a force which varies with its distance from the point attracted, then if $m$ be the moon, the particles of water at $a$ will feel more powerfully the effect of her attraction than those on either side, or than the particles of land at the bottom of the water, $b$, which are at a greater listance, and the result will be a bulging out of the watery zone, as in the diagram, immediately next the lunar globe. But while high water is thus produced at $a, b$, it is also produced at the same time in the opposite hemisphere at $c, d$, owing to the varying distance of $c$ and $d$ from $m$, while at $e$ and $f$ no such diversity of attraction can be experienced, and the effect is, the reduction of the watery zone to the form of an ellipsoid, instead of that of a sphere. There is some difficulty to many minds in conceiving of the moon's influence raising the waters directly under her, and producing at the same time the like effect upon the waters on the opposite side of the earth. But a little consideration will at once remove it; for, obviously, the earth's centre, $\mathrm{E}$, will be more powerfully drawn towards the moon than the waters at $c d$, and recede from them, producing the same effect as though they receded, or rose up from the centre of the earth. Now, as the waters cannot rise in one place without falling in another, they are depressed at $e$ and $f$ when elevated at $a$ and $d$; and as the moon is a month in making her circuit round the earth, there would be two elevations and depressions of the waters in the month in each place, if the earth remained stationary upon its axis. But by the diurnal rotation, the moon passes every day the superior and the inferior meridian of every part of the globe, producing daily two seasons of high and low water. The tidal swell of the ocean, or high water, at any given point, is thus occasioned by the point in question being in the direct line of the lunar attraction, or the moon being upon the meridian of its position; and the ebb of the tide, or low water at the point, is caused by the moon being upon a circle which cuts the meridian at right angles. But the facts of the case do not exactly tally with what we should expect from the theory, for the times of high and low water are not coincident with the fulfilment of the conditions stated. Thus, if the moon passes the meridian of Ushant, on the north-west coast of France, at twelve o'clock in the day, -high water will not take place until about three hours afterwards, or three o'clock in the afternoon. The explanation of this is, that the impulse received by the waters of the sea in being brought by the rotation of the earth under the influence of the lunar attraction, continues to act for some time after the rotation has carried them away from it, so that there is still a tendency to ascend, as the effect of the impulse received, though the immediate action of the planet is not so strong as it was.

Besides the action of the moon in elevating the waters of the ocean, there is that of the sun to be considered. The solar attraction is not so influential a cause in the production of the tides as the lunar, because, though a much larger body, the sun is at far greater distance from the earth. Still the sun acts upon the ocean in precisely the same manner, though in a feebler degree, and his influence is sufficiently energetic to produce 
a flux and reflux of the sea. The tidal influence of the sun has been calculated to be about three times less than that of the moon. Sometimes these bodies act in conjunction, as at the seasons of new and full moon, and then the tides rise the highest, and are called spring-tides; but when the moon is in quadrature, the relative position of the two bodies is such that their influence is antagonistic, and then occur the lowest or neap-tides. Let

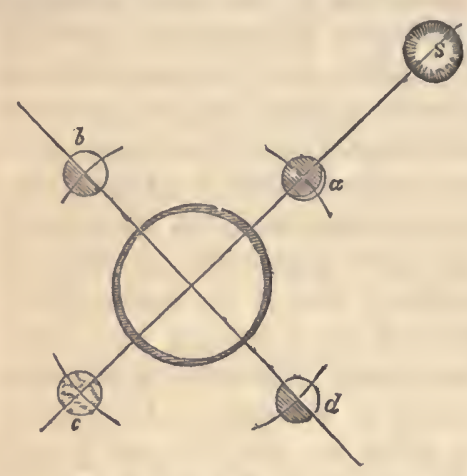
$\mathrm{s}$ be the position of the sun, and $a, b, c, d$ that of the moon in four parts of her orbit. It is clear that when the moon is at $b$ and $d$, her action and that of the sun upon the earth are in opposite dircetions. Hence the lunar and solar attraction counteract each other to some extent, and the tides are low. But when the moon is at $a$, or it is new moon, sle unites her influence with the sun, and both act with the greatest intensity upon the ocean. So when the moon is at $c$, or full, the influence of the two bodies is again united, for they are in the same meridian, and while the sun draws away the waters on the side nearest to him, the moon draws away the earth from them, and while the moon attracts the waters on the side nearest to her, the sun attracts the earth towards him. Thus are produced those mighty movements in the ocean which aid the mariner on his course, and which, being periodical, are consistent with the security of life and property on the coasts. As far, then, as astronomical causes affect the level of the ocean, we have an alternate rise and fall produced twice a day, with augmented or spring tides, and neap or low tides, occurring at the times of new and full moon, and when she is in quadrature. But in addition to this, we have the highest floods and the lowest ebbs at the new and full moon near the equinoxes in March and September, when the moon is in perigee, or nearest the earth.

Hitherto we have been proceeding upon the supposition of the earth being completely environed with a zone of water of uniform depth. If that were the case, and the solar and lunar attraction acted always upon the line of the equator, there would always be high water at some point directly under the equator, and no tide whatever at the poles, and the calculation might be made with precision of the elevation and depression of the waters in every latitude. But various causes operate to introduce irregularity in the phenomena of the tides. The positions of the sun and moon vary with reference to each other and the equator, the moon being sometimes as much as $28 \frac{3}{4}^{\circ}$ on each side of the plane of the latter. The action of the winds also, and their varying force, with currents in the ocean, affect the disturbance of its level by the solar and lunar influence. But the most energetic causes of complexity in the tides, are the inequalities that mark the bed of the sea, and its geographical distribution in contact with immense masses of dry land in its basin. Shoals, peninsulas, and promontories, offer obstructions to the flow of its waters, and vary their direction. In some narrow seas, channels, and gulfs, they are prodigiously accumulated, so that the tides rise to a far greater height than in the main ocean. Thus, on the coasts of the islands of the South Sea, the tides have only an elevation of one or two feet; and at St. Helena, a solitary islet in the heart of the South Atlantic, the rise very rarely exceeds three feet; but in the Irish Sea and English Channel the periodical flow attains a much greater height. At the mouth of the Wye the tidal rise amounts to about fifty feet; at the mouth of the Avon, to forty-two feet; at Miiford Haven, to thirty-six feet; at London and Beachy Head, to eighteen feet; at the Needles, off the Isle of Wight, to nine feet; and at Weymouth, to seven. The consequence of these extraordinary elevations is, that large tracts are alternately oceanic and 
parts of the mainland, where the shores are low. This is particularly observable along the south coast of Lincolnshire and in the Bay of Lancaster. The latter estuary becomes

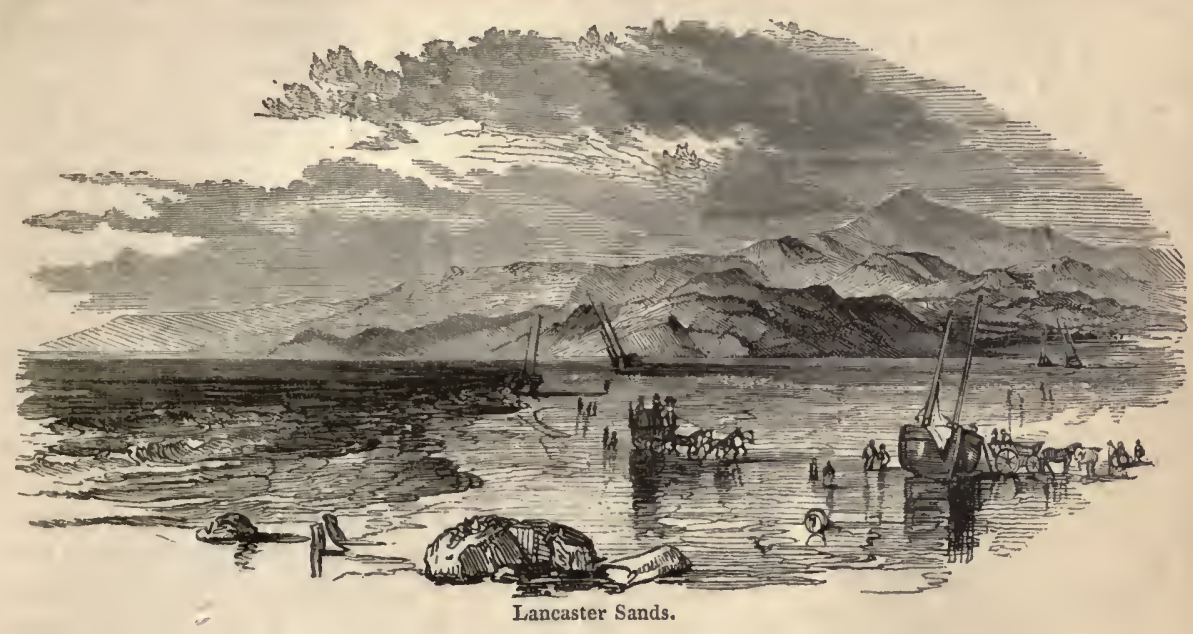

at low water an expanse of sand, across which there is a road, the channel of the river Lune presenting the chief obstacle to the passage dry-shod. In other narrow seas, however, there is scarcely any perceptible tide at all, owing to the conditions under which they communicate with the general sweep of the deep. The distribution and configuration of the land, together with the influence of the winds, greatly involve the problem of the tides, and render it one of the most difficult in the whole range of physics. We shall merely mention a few of its leading features.

The diurnal rotation of the earth being from west to east, the apparent course of the moon is from east to west, and consequently in an ocean of considerable extent in that direction, a tidal wave is formed following the lunar course. The only great belt of water which answers to this condition is the Pacific Ocean, for the general direction of the Atlantic is from north to south, its breadth from east to west being comparatively small. It is the southern part of the Pacific, including the Indian Ocean, that exhibits the greatest extent of surface in the direction of the moon's path; and accordingly a very regular tide-wave is there produced, the general course of which is from east to west, but running towards the tropics, the region of the direct line of the lunar attraction. From the mouth of the Red Sea to the Cape of Good Hope the whole east coast of Africa is reached about the same time by the summit of a single tide-wave, causing the hours of high water at its different stations to be coincident. It is otherwise with the tides of the Atlantic, along the coasts of which the hours of high water are successively later as we travel northward, that being the general direction pursued by its tidal waves, which the

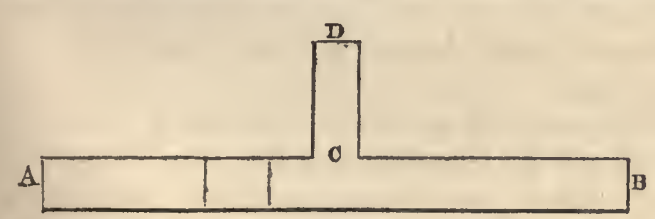
annexed diagram will explain. Suppose A B a belt of water, and $C D$ another narrower belt opening into it, the other lines being ridges of waves passing along $\mathbf{A B}$. It is obvious that when a wave has arrived at $c$, part of it will run along the belt $\mathbf{C} \mathbf{D}$ to find its level, and there will be a succession of waves in $\mathrm{CD}$ numerically the same as in A B, but pursuing a different direction. The relation between the Atlantic and the Pacific 
and Great Southern Oceans, is analogous to that of the upper to the lower belt; and upon the tide-waves of the Pacific reaching the mouth of the Atlantic, they move along its basin, with some local exceptions, in the line of its direction, from south to north, across from the African to the American coast. In the deep and open ocean, the undulation travels with immense velocity, amounting to nearly 1000 miles an hour.

The tide-waves of the Atlantic thus advaneing northwards cause the time of high

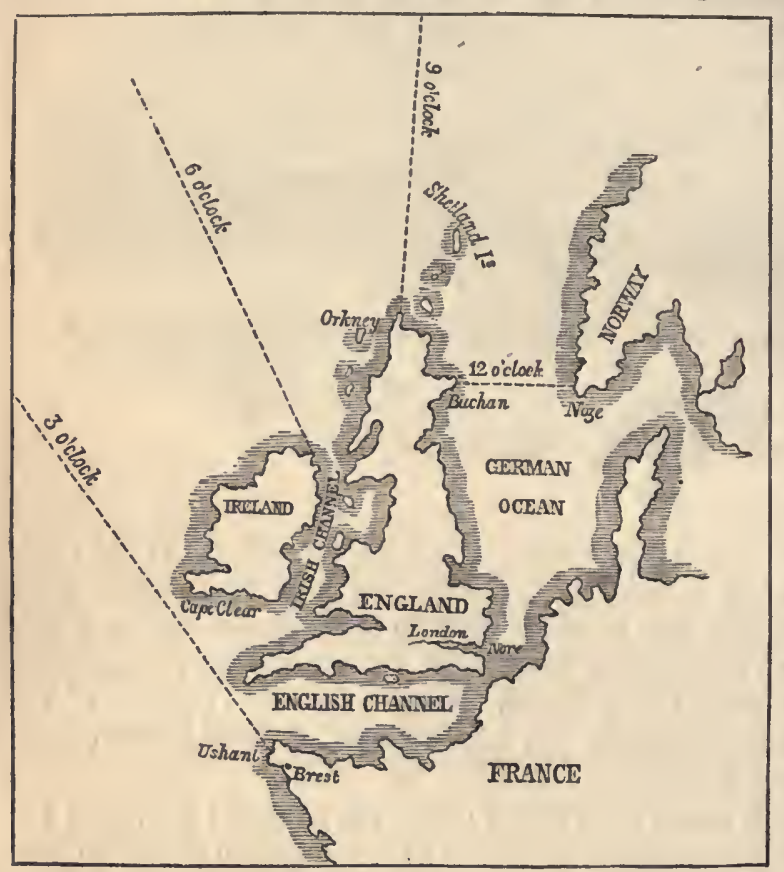
water to be successively later at
the different ports on the west
coasts of Africa and Europe,
and the east coast of North and
South America, except from Rio
Janeiro to the Falkland Islands,
where the advance of the wave-
summits is from east to west.
The tide-wave, which is at
the Cape of Good Hope at a
certain hour, is at the British
Isles about fifteen hours after-
wards, where, interrupted in its
progress, it divides into three
branches: one branch flows
eastward up the English Chan-
nel, passing through the Straits
of Dover, and is off the mouth
of the Thames at the Nore in
about eight hours from the time
it entered the Channel ; a se-
cond branch advances tlurough
St. George's Channel into the Irish Sea; while the third and principal branch of the same ware proceeds along the west coasts of Ireland and Seotland, rounds the northern extremity of the latter, flows slowly down the North Sea, and meets the first branch at the mouth of the Thames, having taken about twenty hours to compass the distance. The annexed sketch represents the course of the latter around Great Britain. Supposing the moon to have passed the meridian of Brest, at the north-western extremity of the French coast, at twelve o'clock in the day, it is high water there soon after thrce o'clock in the afternoon, the ridge of the tide-wave stretching out into the Atlantic in a north-west direction from Ushant, falling a little to the south of Cape Clear, in Ireland. By six o'clock the wave has gained the north coast of Ireland, the ridge maintaining the same direction; and three hours afterwards it has reached the Orkneys, the ridge bearing due north. By twelve o'clock the wave has entered the German Ocean, the ridge-line extending eastward from the Scottish coast to the south point of Norway: and in about eleven hours afterwards it has flowed down the eastern extent of England to the entrance of the Thames.

- It has been observed, that while in open seas, as around the islands of the Pacific, and St. Helena in the South Atlantic, the tides have only an elevation of one or two feet, in many narrow channels, like the English and St. George's, they rise to a far greater height, owing to the confined space into which the water is crowded. The Bristol Channel opens widely to the south-west, where it receives the tide-wave of the Atlantic, but it is very contracted at its upper end, and the water is heaped up in consequence, much above the level to which it otherwise would rise, attaining to an elevation of forty 
and fifty feet. At St. Maloes, on the north coast of France, the tide attains the height of fifty feet, and even sixty in the Bay of Fundy in the United States, where its rise is at the same time so rapid, that cattle feeding on the shores have been surrounded and swept off by it. On the contrary, in narrow seas situated like the Mediterranean and the Baltic, there is scarcely any tide whatever; while in Hudson's and Baffin's Bays and the Red Sea, the influence of the tidal current is strongly felt. A slight inspection of their geographical position will explain the reason of this. The mouths of the latter oceanic estuaries open in the direction of its advancing tide-waves, while the entrances of the Mediterranean and the Baltic are at acute angles with reference to them, and being turned from the main direction of the Atlantic tide, but a small portion of its waters passes through them, not sufficient to produce any marked alteration in the level of those seas. In addition to this, their dimensions are too limited to allow of the moon's action being unequally exerted upon them, were they in the direct line of her attraction, so that the equilibrium of the surface is not greatly disturbed. The highest tidal rise in the Mediterranean occurs to the eastward of Sicily, where a wave is raised which flows up the Adriatic, elevating the waters of that close sea nearly four feet at new and full moon, and half that height at neap tides, alternately covering and laying bare the bottom of the Venetian lagoons. At Antium, Mr. Trevelyan found, by a series of observations, regular tides in the summer of 1836, rising there to fourteen inches; and a tide was noticed by M. D'Angos, at Toulon, on the coast of France, where the sea rose a foot about three hours and a half after the moon passed the meridian. In the east of the Mediterranean also the tides are felt, and slightly so in the Grecian Archipelago, where a gentle rise of the waters in the port of Agina and the gulf of Corinth has been observed. But the general level of the Mediterranean fluctuates only a few inches.

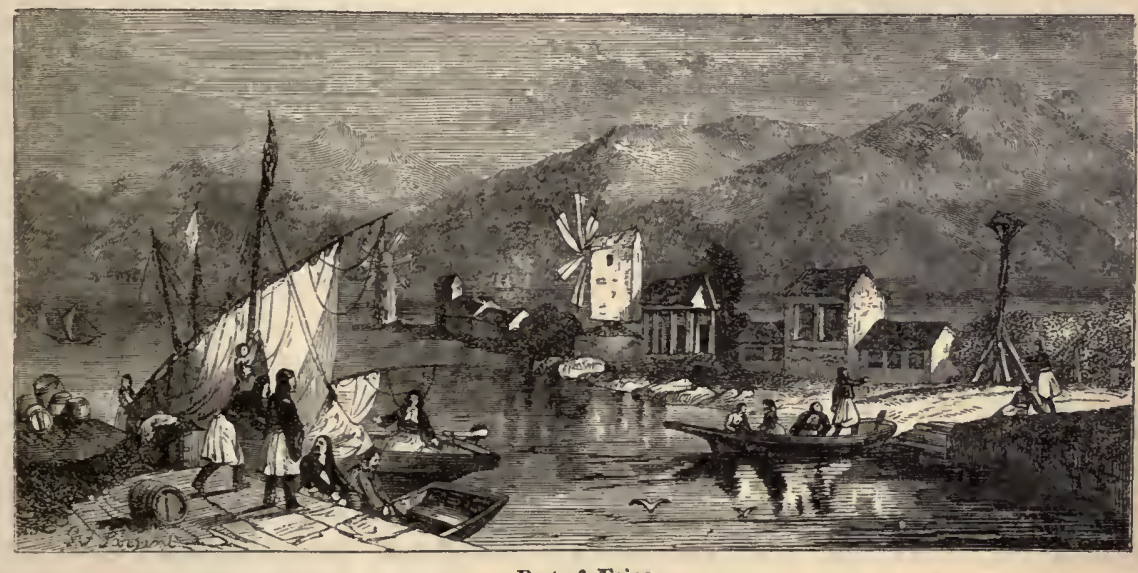

Port of IEgina.

Hence the soldiers of Alexander were alarmed on beholding the high tide at the mouth of the Indus, and the troops of Cæsar were filled with consternation on witnessing a similar spectacle upon our own coast, - their previous knowledge of oceanic phenomena having been confined to the seas of Italy and Greece.

Winds have a powerful influence upon the tidal currents, especially in narrow seas and river channels, keeping them back when blowing from an opposite quarter, and accelerating their flow when pursuing the same direction; so that the tide will rise above its usual level, or fall below it, according as a strong wind co-operates with it or not. An experiment made by Smeaton shows, that in a canal four miles long, the level of the 
water at one end was four inches higher than at the other, owing to the action of the wind upon it. Major Rennell states, that a piece of water, ten miles broad, and generally only three feet deep, has, by a strong wind, had its waters driven to one side, and so sustained as to become six feet deep, while the windward side was laid dry. In rivers also, when they are swollen by the rains, the increased force of their current materially affects the advance of the tide; and when their waters are low the tidal wave will proceed along their channel to a greater distance, and hold up in them during a longer interval than under opposite circumstances. The astronomer Flamstead, who had frequent occasion to go to Greenwich by water, turned his attention to the subject of the tide in the Thames; and he remarks: "When, by reason of great droughts in summer, or extreme frosts in winter, the springs are low, and the fresh waters less than usual, the tides may hold up longer than the times noted in the table; also when strong northwesterly or northerly winds blow, which bring in an extraordinary flood from the northern seas, and keep it up longer than other times; so, on the contrary, when the winds blow hard on the opposite points of the compass, or when we have much rain and great freshes, the tides hold not out so long as the times shown in the table, the freshes overpowering and checking them sooner; yet have I never found that the difference between the calculated and observed high waters have much exceeded half an hour-most commonly they are scarce half so much." There are some singular circumstances connected with the tides of rivers which have thus been noticed by a recent writer:- "They are not of equal duration, as is the case in most parts of the sea; but the ebb tides frequently last twice as long as the flowing tides. At Rotterdam the tide flows for about four hours and five minutes, but the ebb lasts seven hours and fifty-five minutes. The Meerwede at Dordrecht flows against the current of the river for three hours and fifty-one minutes, and with it eight hours and nine minutes. This difference is easily explained when the force of the river current is taken into account. The same circumstance explains the difference in the velocity of the ebbing and flowing tide. Between the North Sea and Hamburgh the flowing tide takes five minutes to run up a mile, but the ebb tide performs the same distance in less than four minutes. But it is difficult to explain the wellestablished fact that the tides advanee much farther into a river than might be expected. When the tide at the mouth of a river rises four feet, we might suppose that it would advance only to such a point in the river where the surface is four feet above the sea; but it has been ascertained that it advances farther. It seems that the volume of water which is carried up by the tide is pushed onwards by the.mass behind it, and carried to a greater distance than the inclination of the river bed would seem to allow. It has also been observed, that during the flowing of the tide the surface of the water in the river presents a somewhat convex form, the water along the banks being a little lower than in the middle of the river, and that during the ebb the contrary takes place. The flowing tide raises the water from below, and thus sooner affects the main body of the river, where it has more room to operate than the water near the margin. In accordance with this explanation, it is observed that the flowing tide is perceptible in the middle, while it is still ebbing along the banks, and that vessels which are at anchor near the banks are turned round before the water on the surface of the river near the banks begins to flow upward."

The change produced in the aspect of rivers by the advance of the tide is of the most striking description, and confers important advantages upon the towns seated along their banks, rendering them essentially maritime, though at a considerable distance from the sea. The Avon at Bristol supplies a remarkable example of the alteration, and of the commercial benefits resulting from it. Its natural character at St. Vincent's rocks is that of a shallow brawling stream, scarcely navigable by the smallest craft; but upon the flow 
of the tide it receives an accession of near forty feet to its depth of water, which enables the largest West Indiamen and steamers to communicate directly with the city. The change brings not only a supply of water adequate for navigation, but an alternate current every twelve hours, which is just as useful as having a fair wind up and down the river, the regular occurrence of which being certain may immediately be turned to account by previous preparation. The same phenomenon is exhibited on the Solway Firth, the sands of which are so dry at low water that travellers on horseback can cross them, while the tide returns so rapidly as to render this a somewhat hazardous
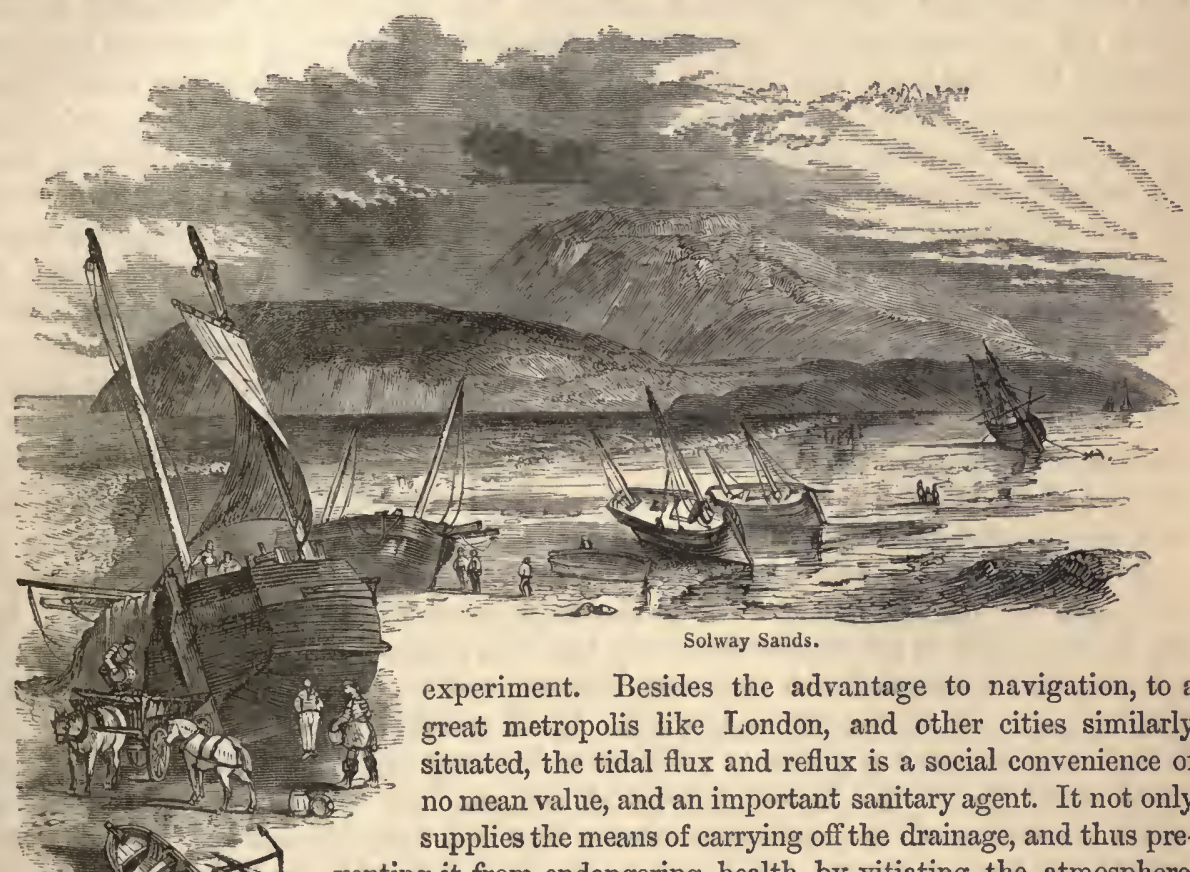

experiment. Besides the advantage to navigation, to a great metropolis like London, and other cities similarly situated, the tidal flux and reflux is a social convenience of no mean value, and an important sanitary agent. It not only supplies the means of carrying off the drainage, and thus preventing it from endangering health by vitiating the atmosphere, but of having fresh water and air regularly furnished -an arrangement which has been aptly compared to a system of lungs adapted to promote the healthy vital action of maritime populations.

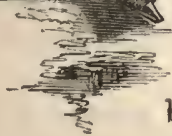

A third movement to which the ocean is subject is known by the name of Currents, which involve not merely the surfacestratum of the sea, but probably extend far below it, where they prevail, and constitute great oceanie highways. The effect of currents was perceived long before any thing was known of their direction and velocity; and Columbus was strengthened in his belief, that land might be reached across the Atlantic westward, by substances which had been drifted from that quarter. A pilot in the service of the King of Portugal, Martin Vicenti, assured him, that after sailing four hundred and fifty leagues to the west of Cape St. Vincent he had taken a piece of carved wood from the sea, evidently not laboured with an iron instrument, which must have floated from some unknown land in a westerly direction. Columbus was also informed by his brother-in-law, Pedro Correo, that he had seen a similar piece of wood off Porto Santo, a small island to the north-east of Madeira, which seemed to have come from the same region; and it was commonly reported that reeds of an immense size had floated to those islands from the west, which the great discoverer fancied were identical with 
those described by Ptolemy as growing in India. From the inlabitants of the Azores he learnt that trunks of huge pine-trees had been cast upon the shores, of a species different to any that grew upon the islands; while, towards the close of the fifteenth century, the bodies of two dead men had been drifted to the island of Flores, whose features proclaimed them to belong to an unknown race. These circumstances contributed to confirm Columbus in his theory respecting the existence of a western continent, and strengthened his purpose to venture upon the untracked waste of waters in order to reach it. After the commencement of his great undertaking, when day after day nothing had been seen but a shoreless horizon, and hope had nearly expired in his own breast, while his crew were on the verge of open rebellion, the effect of the oceanic currents restored his confidence, and allayed their clamours. Herbage, fresh and green as if recently plucked, floated by. A branch of thorn, with berries on it, appeared; a reed was picked up, and a staff artificially carved, - significant intimations that an inhabited land lay before the adventurers, which was at length revealed to their gaze, and terminated for ever the mystery which had rested upon the western flood. Upon his second voyage, Columbus found, near one of the islands, to which the Spaniards gave the name of Guadaloupe, the stern-post of a European vessel, the fragment of some wreck which had been borne in a contrary direction across the Atlantic. The preceding facts are doubtless referable to the action of the equatorial current and the gulf stream. Previously, the inhabitants of the Canaries had considered the vegetable productions thrown upon their shores as coming from the enchanted isle of St. Borondon, which, according to the reveries of the pilots, and certain legends, was placed towards the west in an unknown part of the ocean, enveloped with eternal fogs.

It is little more than half a century since the oceanic currents began to be accurately investigated. We are indebted to M. Rossel, Colonel Sabine, and Major Rennell, for the principal part of the information which has been collected concerning them. Though tolerably well acquainted with their site, direction, and velocity, the causes in which they originate are not thoroughly understood. In all probability they are chiefly due to the influence of permanent winds, to a difference in temperature or saltness between two parts of the sea, to the annual melting of the polar ice, to the unequal evaporation which the surface of the ocean experiences in high and low latitudes, and to the greater velocity with which the equatorial regions are carried round in the daily rotation of the globe. The sea-currents have been compared to the continental rivers, and both exhibit the phenomena of volumes of water moving in a certain direction, but in extent of surface and depth they are utterly disproportionate; and if the former were transferred to the land, they would constitute great inland seas, or arms of the ocean.

There are two great currents flowing from the poles towards the equator, north and south, which preserve their direction through a considerable space. The drifting of the ice from the polar regions into the temperate seas, on each side of the line, evidences the existence of streams following that coursc. The north polar current appears to strike the shores of Asia, and, passing round the north cape of Europe, it crosses the upper part of the Atlantic, running to the south-west till it reaches the east coast of Greenland. It then traverses the narrow sea between that country and Iceland, turns round Cape Farewell, the southern extremity of Greenland, and proceeds northward into Davis's Strait. It follows the eastern side of the strait as far to the north as Holsteinborg, in latitude $67^{\circ}$, where, from causes of which we are ignorant, it abruptly turns to the west, and strikes the opposite shore at Cape Walsingham. From thence its course is southward to Labrador, and south-east to the north bank of Newfoundland, where it mingles with the Gulf stream, which will hereafter be noticed. The breadth of the arctic current is in some places from 250 to 300 miles. Its velocity varies, in different parts of its course, 
from eight or nine to fiftecn or sixteen miles per day. The icy masses it bears along are supposed to be about two months in making the before-mentioned circuit from Cape Farewell to the coast of Labrador. We are not so familiar with the antarctic or south polar current, but have similar evidence of its action in the transportation of the ice from high to low latitudes, where its course is checked by a counter stream passing westward by the Cape of Good Hope and Cape Horn. Various circumstances operate to put these streams in motion. . The greater intensity of the centrifugal force at the equator, which is the result of the earth's rotation, and the greater evaporation of the sea between the tropics, owing to the powerful heat of the torrid zone, must necessarily produce a movement of the waters from the poles towards the equator, in order to restore the equilibrium which the preceding causes are perpetually destroying. It is however a singular fact, only recently ascertained, with reference to the arctic current, and quite impossible to explain at present, that it appears to be annually suspended for about three months, from the middle of October to the middle of January; and no perceptible evidence whatever of its action at that period is found at Cape Farewell, as at other seasons, in the accumulation of ice around it. Upon the inhabitants of Iceland this great oceanic stream confers no unimportant benefit in the drift timber which it casts upon their shores, affording them an abundant supply of wood for fuel, and for the construction of boats, their own forests having been improvidently exhausted. The immense quantity of it, amounting to whole forests of pines and firs, has attracted much attention; and it has been deemed difficult to explain from what country it can have been derived. Captain Parry found a large quantity thrown by the sea upon the coasts of Spitzbergen; and Crantz informs us, that the masses of floating wood thrown upon the island of Jan Mayen often equal the whole of the island in extent. The most probable solution of its origin is, that the rivers of Northern Asia carry the timber of the Siberian forests into the Arctic Ocean, from whence it is borne by the current to mitigate the cold of the Icelandic winter. It was the north polar current that presented the most formidable obstacle to Parry in his attempt to reach the pole by means of boat-sledges and reindeer, and led to the failure of the daring enterprise. Having travelled over the frozen surface of the deep to nearly latitude $83^{\circ}$, which seemed to be the utmost limit of animal life, the adventurers found that when, according to their reckoning, they had made ten or eleven miles of direct northing, they had actually gone four miles to the south, owing to the current carrying the snow-fields in that direction. An invisible power was thus continually undoing what they were labouring to accomplish, which rendered the success of the expedition hopeless.

The grandest movement of the ocean in the form of a stream-current proceeds from east to west, on each side of the equator, and is therefore called the equatorial or tropical current. In the Pacific Ocean it sweeps westward from the coast of Peru in one immense volume, till, reaching Australia and the islands of the Asian Archipelago, it is broken into smaller branches of different divergence; and hence the numerous and variable currents prevailing in the Indian Ocean, which render the navigation so dangerous. A great branch passes to the south of Australia, preserving a generally uniform westerly direction, till it is obstructed by the island of Madagascar and the east coast of Africa, from which it glides off to the south round the Cape of Good Hope. In the Atlantic Ocean the equatorial current is very perceptible, the westward flow of the waters commencing in the Bay of Benin and at the Canaries, and proceeding across its basin to the opposite shore of Amcrica, where, off Cape St Roque, on the Brazilian coast, it is separated into two branches. One branch, called the Brazil current, proceeds southward along its coast-line, crosses the mouth of the La Plata, passes through the Straits of Magellan and round Cape Horn, and mingles with the westward flow of the Pacific. 
The other and principal branch, known by the name of the Guiana current, is properly a direct continuation of the equatorial. It runs from off Cape St. Roque, across the mouth of the Amazon; and after skirting the low coast of Guiana, and passing through the Caribbean Sea, it enters the Gulf of Mexico, where a course is commenced in a fresh direction. Mention has previously been made of the Gulf stream. This originates in the Mexican Gulf, and is the efflux of the waters accumulated there by the equatorial current. The stream is first clearly perceptible to the north-west of the island of Cuba, where it flows weakly to the east; but upon being turned from that direction by the opposition of immense sand-banks, it proceeds northward, and, owing to the narrowness of the channel, rushes with great velocity through the Strait of Florida. Obeying the impulse there given to its waters, the Gulf stream runs along the coast of the United States; and, being there free from obstruction, it gradually expands in rolume, and diminishes in rapidity. On striking the banks of Newfoundland it sets again to the cast, and to the south-east upon joining the north polar current. It then traverses the basin of the Atlantic to the Azores, enters the equatorial current on the coast of Africa, and is conducted again to the west, to re-enter into itself in the Gulf of Mexico.

The equatorial current and the Gulf stream thus constitute a whirlpool of prodigious extent in the Atlantic Ocean, which cuts laterally the gorge between Africa and the Brazils, scours round the indentation of Central America, recrosses the bed of the Atlantic following an opposite direction, and is perpetually circulating in the same route. Humboldt remarks, that supposing a particle of water returns to the same place from which it departed, our present knowledge of the swiftness of currents will enable us to estimate, that this circuit of 3800 leagues will require not less than two years and ten months for its accomplishment. "A boat which may be supposed to receive no impression from the winds, would require thirteen months from the Canary Islands to reach the coast of Caraccas; ten months to make the tour of the Gulf of Mexico, and reach Tortoise Shoals opposite the port of the Havannah; while forty or fifty days might be sufficient to carry it from the Straits of Florida to the bank of Newfoundland. It would be difficult to fix the rapidity of the retrograde current from this bank to the coasts of Africa: but estimating the mean velocity of the waters at seven or eight miles in twenty-four hours, we find ten or eleven months for this last distance. A short time," he continues, "before my arrival at Teneriffe, the sea had left in the road of St. Croix a trunk of a Cedrela odorata covered with the bark. This American tree vegetates exclusively under the tropics, or in the neighbouring regions, and it had no doubt been torn up on the coast of the continent, or of that of Honduras. The nature of the wood, and the lichens which covered its bark, were evident proofs that this trunk did not belong to those submarine forests which ancient revolutions of the globe have deposited in lands transported from the polar regions. If the Cedrela, instead of having been thrown on the strand of Teneriffe, had been carried farther south, it would probably have made the whole tour of the Atlantic, and returned to its native soil with the general current of the tropics." The conjecture in the last passage is supported by a fact recorded in the history of the Canaries by the Abbe Viera. In the year 1770 a small vessel laden with corn, and bound from the island of Lancerotte to Vera Cruz in Teneriffe, was driven to sea while none of the crew were on board, and was carried by the westward motion of the waters across the bed of the Atlantic, where it went ashore at $\mathrm{L}_{\mathrm{a}}$ Guayra, near Caraccas. It was the equatorial current that conveyed the fragment of the vessel to Guadaloupe which Columbus found floating near the island; and the Gulf stream brought those productions of the New World to the Canaries, upon which he seized as indications of the existence of western regions, before the discovery of them had been effected. A complete view of this great water-course would require a notice of several subordinate currents; but it may be sufficient to observe, that the 
western flow of the Pacific, mentioned as sweeping round the Cape of Good Hope, mingles with it as a perpetual feeder, while, from its northern region, a branch is sent off towards the coasts of Great Britain and Norway. This arm of the gulf stream leaves it in latitude $45^{\circ}$ and $50^{\circ}$, near the bank of Bonnet-Flamand. It runs to the north-east, and becomes very strong when the winds have blown a long time from the west. By this current, plants, seeds, and the fruit of trees, which belong to the torrid zone of America, are annually borne through the North Atlantic, and deposited on the western coasts of Ireland, Scotland, and Norway. On the shores of the Hebrides, the seeds are collected

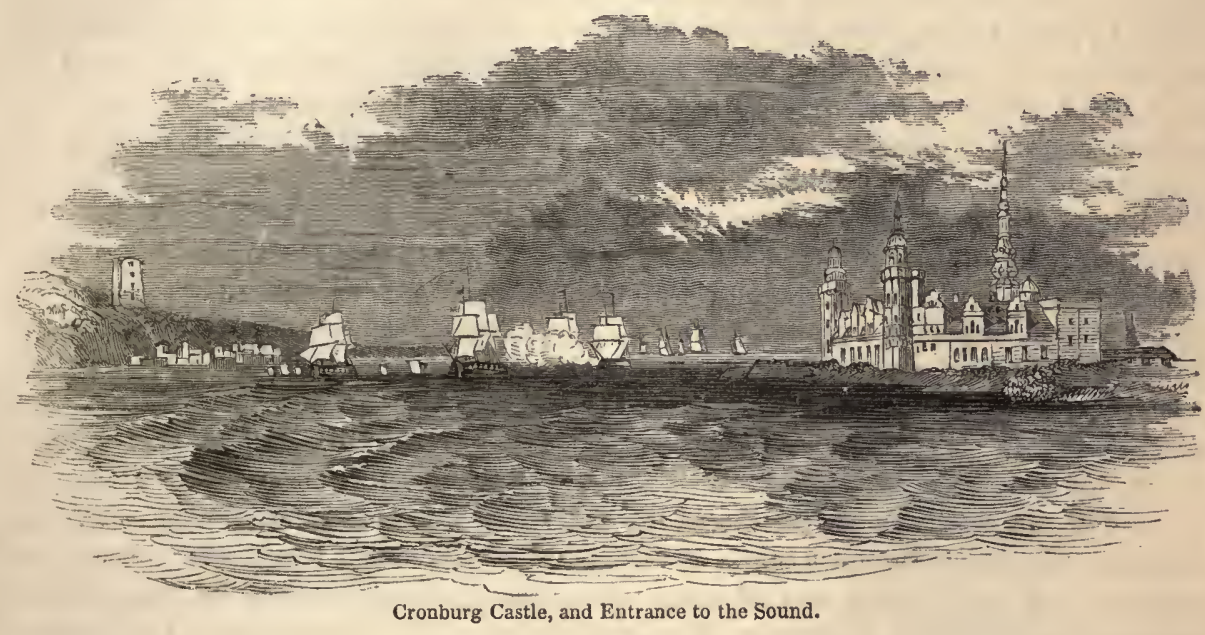

of several plants belonging to Jamaica, Cuba, and the neighbouring continent; and the remains of cargoes of vessels wrecked in the West Indian seas have been drifted to the same quarter. The fragments of the English vessel, the Tilbury, burnt near Jamaica, reached the coast of Scotland; and tortoises inhabiting the waters of the Antilles have undergone a similar transportation. A most remarkable case is related by Wallace, that twice, in 1682 and 1684, American sarages of the race of the Esquimaux, driven out to sea in their leathern canoes during a storm, and left to the guidance of the currents, reached the Orkneys - an example of involuntary migration, which shows how, when the art of navigation was yet in its infancy, the motion of the waters of the ocean may have contributed to disseminate the different races of men over the face of the globe.

It is natural to inquire concerning the origin of this extraordinary and vast whirl of the waters of the ocean. The westerly movement in equatorial regions is in a direction contrary to that of the earth's rotation, and appears to be connected with this last phenomenon, along with the trade winds, which follow the same course. Owing to the action of the current and the wind, the waters of the Atlantic are crowded into the great American bay which terminates with the Gulf of Mexico, entering it on the south, where, upon being repulsed by the shores of the continent, they accumulate, and flow off to the north-east, forming the gulf stream. It has been calculated that the waters of the gulf, 4000 miles distant from the Cape de Verde islands on the coast of Africa, are elevated 325 feet above the level of the ocean in the latter locality. This arises from the pressure exerted by the particles of water upon each other under the influence of the wind and current, and the resistance offered to their farther westward progress by the shores of Central America. It has frequently been observed, that a prolonged wind 
blowing up the English Clannel, causes a very perceptible elevation of the sea-level in the Straits of Dover, oceasioned by large volumes of water being driven from the Atlantic into the close confinement of a narrow passage. The configuration of that remarkable break in the eastern coast-line of America, where the Gulf stream originates, at once explains how a permanent wind and eurrent, pursuing the direction indicated, must heap up the waters of the ocean in it, which necessarily run off, where a vent occurs, in order to find their level. The high temperature of the Gulf stream, in all parts of its course, is one of its striking peculiarities. It is a current of warm water, so greatly above the average heat of the ocean, that the navigator may at once detect his entrance into it by the sudden rise of the thermometer. The difference often amounts to $9^{\circ}, 12^{\circ}$, and $15^{\circ}$ of Fahrenheit, and sometimes to much more. Near Cape Hatteras, on the coast of North Carolina, under the meridian of $63 \frac{1}{2}^{\circ}$, the thermometer shows $81^{\circ}$ in summer, which is from $10 \frac{1}{2}^{\circ}$ to $11 \frac{1}{2}^{\circ}$ above the water of the ocean, in the same latitude, immediately contiguous to the stream. At Corvo, one of the Azores, its temperature is from $75 \frac{1}{2}^{\circ}$ to $77 \frac{1}{2}^{\circ}$, which is from $8^{\circ}$ to $10^{\circ}$ above that of the ocean. It is in the Mexican Gulf, which may be properly called a caldron for heating water, that this high temperature is acquired, which is there in summer $4^{\circ}$ above that of the open ocean under the equator. Upon issuing from thence, the water retains its warmth across the Atlantic, though subject to a gradual reduction as it travels eastward, till, after being cooled dow $\mathrm{n}$ to the general temperature of the circumjacent sea, it is transferred again by the westerly current to the coast of Caraccas, to undergo the same heating process as it slowly proceeds along its shores, and those of Mexico and Florida. There can be little doubt, but that as the high temperature of the Mediterranean Sea contributes to the mild climate of the countries on its shores, so the warm water distributed over the North Atlantic, and sent to the west coasts of Europe, causes the mean temperature of England to be sensibly higher than that of many other places situated within the same limits of latitude, but differently circumstanced with reference to the Gulf stream. Two plyssical phenomena, also, off the island of Newfoundland, are supposed to be produced by the action of this current-the formation of its bank, and the fogs which mantle its shores. After rushing with great velocity through the strait of Florida, the force of the stream gradually diminishes as it coasts along the United States, when the matter it has sustained while in rapid motion is deposited, which in process of time has formed the huge shoals of Nantucket, and the great bank of Newfoundland. In the same locality, the Gulf stream encounters the arctic current, and those extraordinary banks of fog with which it abounds, are probably referable to the different temperature of their waters and of the incumbent atmosphere.

The currents of the ocean materially affect its navigation. While an intimate knowledge of them is necessary in order to avoid the danger of mistaking the true position of a vessel, its progress to port may be facilitated by falling in with a local stream, or steering clear of it, according as its direction is favourable or adverse. The great highway across the Atlantic formed by the Gulf stream is of course avoided as much as possible by ships proceeding from Europe to America, because the flow of the current is opposite to their path, and to attempt to stem it would increase by a fortnight the time of the passage. On the contrary, a vessel proeeeding from North America to Europe, will save about five days' sailing by following its track; but it has been found, that, owing to its course lying through stormy latitudes, where heavy seas and continual gales are encountered, the damage suffered through wear and tear counterbalances the gain of a few days in the voyage. Accordingly, it is only entered at a few points, a general route to the south of it being pursued by ships coming to Europe from the West Indies, and one to the north by those that sail from New York. As the velocity of the oceanic 
currents is not invariable, but is much accelerated or retarded by the prevalence of hard gales, the navigator sailing. with or against them has to take this element into the account, in order to be sure of his place. In proceeding from the American coast to Bermuda, Captain Hall found that an unusual increase in the rate of the Gulf strcam had carried him so far beyond his mark, that when from his reckoning, the weather having prevented observations for the longitude, he supposed himself about forty miles on the western side of the island, and was therefore beating to the eastward, he was actually about the same distance on the eastern side, and had to sail westward to gain his port. By not making due allowance for the force of the current that sweeps round the Cape of Good Hope from the Pacific, navigators proceeding to India have often fancied themselves east of the Cape when they have been still west, and have been driven ashore on the African coast, which, according to their reckoning, lay behind them. A similar cause has led to many a disastrous shipwreck on the Senegal coast, upon which a branch current from the Gulf stream rushes, and upon the savage shores of the Great Desert, it has been the fate of many a gallant crew, either to perish of hunger or to be sold into slavery. A more accurate acquaintance with oceanic regions, and the accomplished nautical education of commanders, have diminished such accidents in recent times. Still, besides the great sea-streams, there are an immense number of offsets from them, some of which are cnly occasional currents, and others have not been noticed, which may deceive the most skilful commander, and hurry his vessel ashore, when his reckoning gives him a considerable distance from it. This misfortune happened to the fine frigate the Challenger, in the year 1835, which struck upon the south coast of Chili, owing to the action of an unusual and unexpected current, against which it was impossible to guard. At eight o'clock in the evening there was a careful examination of the ship's place upon the charts. At nine, the weather was hazy, the wind moderate, the water smooth, the stars occasionally appearing overhead, and an expected moon at midnight promised a fine and quiet night to the crew. At a quarter to ten the breakers were seen, and immediately the ship dashed upon the rocks along the beach, became a complete wreck, the officers and men reaching the shore with difficulty.

The existence of under-currents, running in a direction opposite to the flow of the surface stratum, has been surmised in various places, but chiefly owing to circumstances

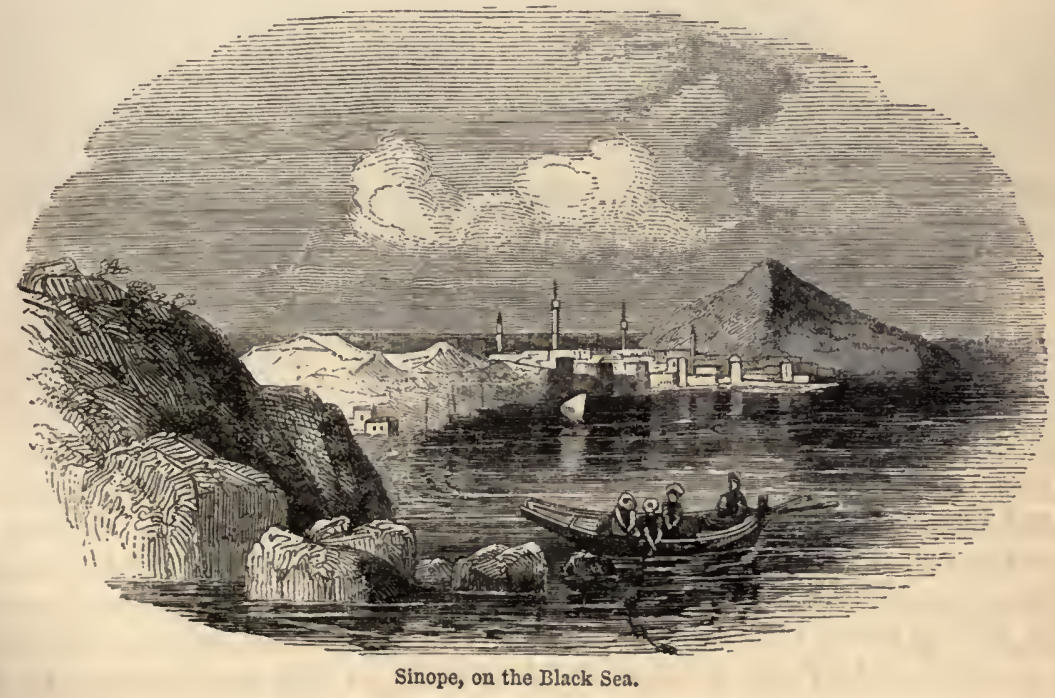


which may bo differently explained. It has been mentioned, that the Black Sea pours its surplus waters, through the Bosphorus and the Hellespont, into the Grecian Archipelago. The current lere flows at the rate of from two to four miles an hour, and is occasionally so strong that ships experience great difficulty in making way against it. The exploit of Leander and Byron, who swam across the Hellespont, conquering the power of the stream, has acquired celebrity. This is one of the sites where it has been imagined that there is an under-current flowing upwards from the Archipelago to the Black Sea. The saltness of the water of the latter, which is only one-seventh less than that of the Atlantic, and fully one-tenth more than that of the Baltic, has suggested this idea. While receiving an immense influx of fresh water from numerous large rivers, and having a constant outflow, this degree of saltness is certainly a singular problem; and it has been thought difficult to account for it, otherwise than by supposing an under-current communicating the saltness of the Archipelago to the Euxine. But salt prevails extensively in the countries along its north and north-eastern shores, a considerable portion of which, finding its way to the sea, may be the true cause of its waters being so largely impregnated by it. 'The physical condition of the Mediterranean has also been deemed inexplicable, except upon a similar supposition. While a perpetual stream flows into it from the Black Sea through the channels named, there is another from the Atlantic through the Straits of Gibraltar; and to account for the disposal of the quantity of water flowing inward, a submarine current, flowing outward at the Straits, has been maintained by many philosophers. The following circumstance has been considered to be confirmative of this opinion. M. Du L'Aigle, the commander of a privateer called the Phœnix, of Marseilles, gave chase to a Dutch merchant ship, near Ceuta Point, and came up with her in the middle of the Straits, between Tariffa and Tangier, and gave her a broadside which directly sunk the

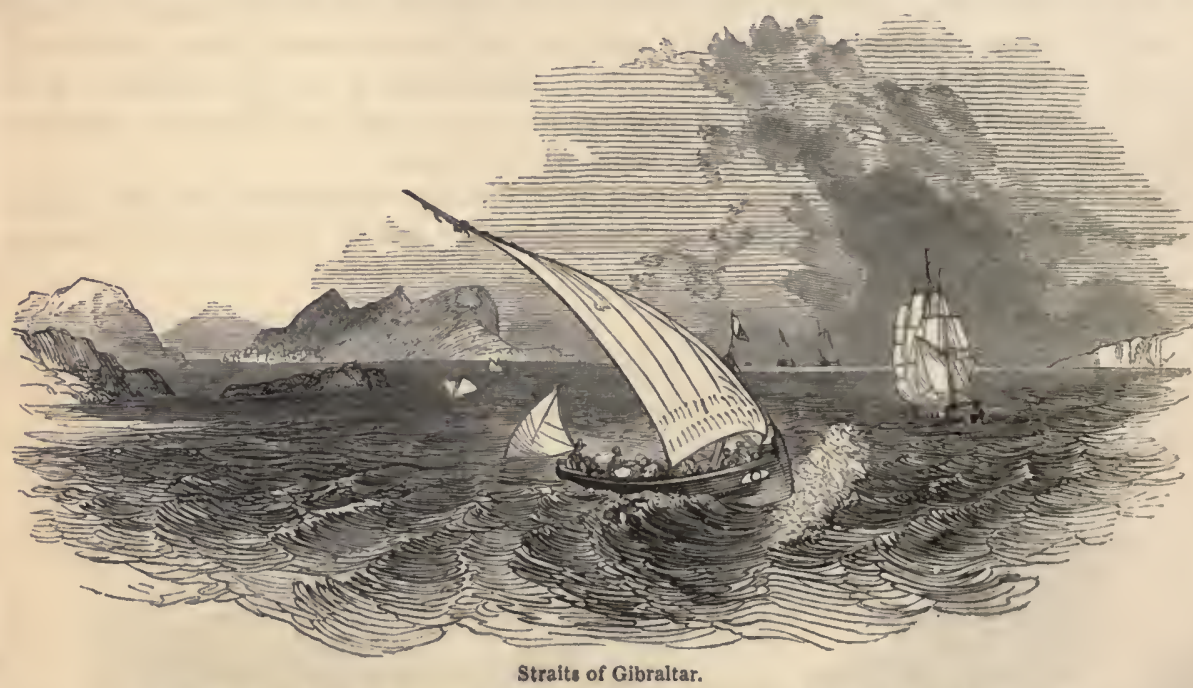

vessel. A few days after, the sunk ship, with its cargo of brandy and oil, arose on the shore near Tangier, which is at least four leagues to the westward of the place where she sunk, and directly against the strength of the current from the Atlantic. Besides, however, this current, there are two lateral currents in the Straits, one on the European and the other on the African side, which alternately flow outward and inward with the tide; and the drifting of the vessel to the rear of the spot in the main stream where she sank might be occasioned by one of these lateral currents, at that time flowing out of the 
Straits. With reference to the immense body of water which is constantly pouring into the Mediterranean from the Atlantic, there is no necessity to have recourse to an undercurrent conveying it back into the ocean to account for its disposal; for a considerable portion may be returned there by the lateral currents, while an enormous evaporation expends the rest. We have no evidence whatever of the existence of such a phenomenon as the superior and inferior stratum of the same volume of water flowing in opposite directions. Ray long ago remarked: "I do not understand how waters can run backward and forward in the same channel at the same time. For, there being but one declivity, this is as much as to affirm that a heavy body should ascend. It is a crossing of

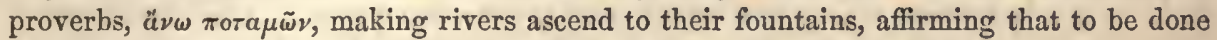
which all the world hath hitherto looked upon as absurd and impossible."

Currents pursuing an inverse course sometimes meet and conflict; and when this occurs in narrow channels, it renders their passage troublesome and dangerous to the mariner. When two currents, thus meeting together, are nearly of equal force, they often cause eddies or whirlpools, of which the Maelstrom, off the coast of Norway, is a remarkable example. Its influence is felt for more than nine miles, and its power is such, that vessels drawn into its grasp have been unable to extricate themselves, and have perished in its vortex. In a storm, the roar of the contending waters is heard through a wide area upon the surface of the deep. Charybdis, in the straits of Messina, is another instance, so famed in antiquity, with its companion Scylla, for offering perils to the ancient navigators. Homer pourtrays Scylla as a rock so lofty that its summit is continually cloudcapt, and so steep, smooth, and slippery, that no mortal could scale its height, though the capabilities of his physical frame for the ascent were largely multiplied :-

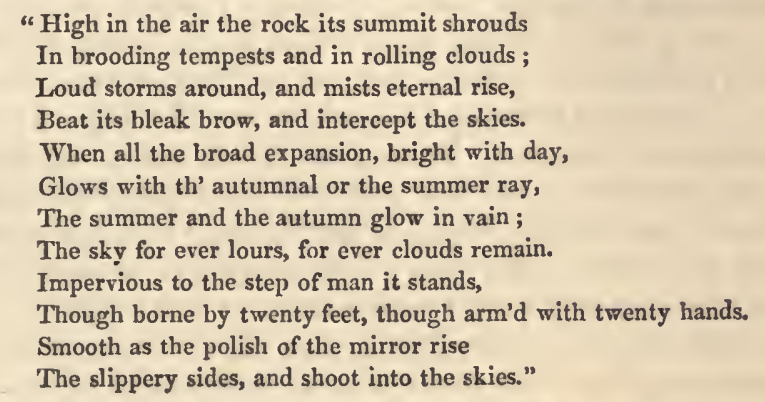

The Greek poet, and Virgil after him, personify this rock as a sea monster, lurking in the darkness of a vast cavern, surrounded by ravenous, barking mastiffs, together with wolves, increasing the horror of the scene:-

\footnotetext{
"Here Scylla bellows from her dire abodes,

Tremendous pest ! abhorr'd by man and gods !

Hideous her voice, and with less terrors roar

The whelps of lions in the midnight hour."
}

Not less terrible is the description of Charybdis, represented by Homer as a companion monster, three times in a day drinking up the water, and three times vomiting it forth:-

$$
\begin{aligned}
& \text { "Beneath Charybdis holds her boisterous reign } \\
& \text { 'Midst roaring whirlpools, and absorbs the main; } \\
& \text { Thrice in her gulfs the boiling seas subside, } \\
& \text { Thrice in dire thunder she refunds the tide." }
\end{aligned}
$$

This language of poetical fable and exaggeration rests upon a stratum of truth. In the Straits of Messina - the site of Scylla on the Calabrian shore, and of Charybdis by the 
opposite coast of Sicily - there are numerous and variable currents. The centre of the channel is occupied by a stream, which runs alternately north and south, six hours each way, at the rate of from two to five miles an hour. On each side there is a counter or returning stream, running at a varying distance from the beach, and numerous eddies or whirlpools are formed by the contact of the lateral and central currents. In rough weather, when a high wind is blowing in the direction of the main stream, it becomes sufficiently powerful to stop the course of the lateral currents, but the collision gives rise to strong whirls in the water, which are sent off to each shore. It is easy to conceive, that to the inexpert mariners of ancient times, such a navigation would be alarming in dark, rainy, blustering nights, and would often involve the wreck of their feeble craft, disasters upon which the poets seized, and magnified the causes beyond the reality. At the same time, it is not improbable, that the physical paroxysms to which the adjacent districts have been subject, may have so altered the bottom of the straits, either by elevation or depression, as to have really diminished the danger of the passage. During the great Calabrian earthquake, the quay of Messina sank fourteen inches, vast masses of sea-cliff on the coast of the straits fell down, and one such mass, detached from Mount Jaci beside the rock of Scylla, rolled by night to the margin of the Mediterranean, which immediately rose with a ware twenty feet high.

"I first," says the Abbé Spallanzani, "proceeded in a small boat to Scylla. This is a lofty rock which rises almost perpendicularly from the sea, on the shore of Calabria, and beyond which is the small city of the same name. Though there was scarcely any wind, I began to hear, two miles before I came to the rock, a murmur and a noise, like a confused barking of dogs, and on a nearer approach readily discovered the cause. This rock in its lower part contains a number of caverns ; one of the largest of which is called by the people there, Dragara. The waves, when in the least agitated, rushing into these caverns, break, dash, throw up frothy bubbles, and thus occasion these various and multiplied sounds. Such is the situation and appearance of Scylla: let us now consider the danger it occasions to mariners. Though the tide is almost imperceptible in the open parts of the Mediterranean, it is very strong in the Strait of Messina, in consequence of the narrowness of the channel, and it is regulated, as in other places, by the periodical elevations and depressions of the water. Where the flow or current is accompanied by a wind blowing the same way, vessels have nothing to fear; since they either do not enter the Strait, both the wind and the stream opposing them, but cast anchor at the entrance; or, if both are favourable, they enter on full sail, and pass through with such rapidity that they seem to fly over the water. But when the current runs from south to north, and the north wind blows hard at the same time, the ship, which expected easily to pass the Strait with the wind in its stern, on its entering the channel is resisted by the opposite current, and, impelled by two forces in contrary directions, is at length dashed on the rock of Scylla, or driven on the neighbouring sands; unless the pilot shall apply for the succour necessary to his preservation. For to give assistance in case of such accidents, four and twenty of the strongest, boldest, and most experienced sailors, well acquainted with the place, are stationed night and day along the shore of Messina, who, at the report of guns fired as signals of distress from any vessel, liasten to its assistance, and tow it with one of their light boats."

The site of Charybdis is defined by Strabo, "in the strait, a little before we reach the city" Messina. It is off the entrance of the harbour, distant about 6047 yards from Scylla, according to the measurement of Admiral Smyth, and about 700 feet from the shore, upon a promontory of which a lightlouse warns the sailor by night of the spot. The classical name is no longer its local title, but Kalofaro, from ra "beautiful tower," alluding to the lighthouse. It is not a vortex of the ordinary kind, 
endangering vessels by suction, but rather a tumultuous movement of the water, which circulates in several quick eddies, varying with the force and direction of the winds and currents. When the wind and the current oppose each other, the Kalofaro becomes a scene of extensive and violent agitation, and will wheel round even ships of war upon its surface; but there is no appearance of an absorbing gulf answering to the ancient imagination, though smaller vessels are exposed to the peril of being driven ashore, or destroyed by the waves beating over them. In order to avoid the danger arising from Charybdis, the mariners of former times went as near as possible to the coast of Calabria, and sometimes went too near, provoking the dangers arising from Scylla; and hence the proverb still applied to those who, in attempting to eseape one evil, encounter another:-

\section{Incidat in Scyllam, cupiens vitare Charybdim.}

"Who flics Charybdis, upon Scylla strikes."

Brydone, after referring to the aecounts given of it by the classieal writers, remarks :"It certainly is not now so formidable, and very probably the violent motion, continued for so many ages, has by degrees worn smooth the rugged rocks and jutting shelves that may have intercepted and confined the waters. The breadth of the straits, too, in this place, I nake no doubt, is considerably enlarged. Indeed, from the nature of things, it must be so; the perpetual friction occasioned by the current must wear away the bank on each side, and enlarge the bed of the water."

Of all the oceanic movements exhibited in the form of waves, tides, and currents, of which a summary notice has been given, the latter are the most influential in affecting the displacement of its waters. 'The tides alternately elevate and let down the surface, rather than produce an actual stream, exeept along shore, and in confined channels; for when we spcak of the motion of a tide-wave, and of its rate of advance, we do not mean a shifting of the water from place to place, but the progressive elevation of its surface stratum. The influence of the winds in creating waves is very circumscribed in forcing the sea to change its situation, except where they are strong and permanent; and it is the upper stratum that they chiefly affect. It may here be mentioned that the common saying of the waves running "mountains high" is a popular exaggeration, for in the rudest parts of the deep, as the Bay of Biscay, the vicinity of Cape.Horn, and the Cape of Good Hope, no wave rises more than thirty feet during the most violent storms. Currents, on the contrary, involve extensive areas of the ocean ; extend in many instances to the bottom of the sea, and transfer its waters from one hemisphere to anotherfrom the Pacific to the Atlantic, and to the Pacific again, in perpetual revolution - from the congelation of polar regions to the heat of the equatorial. Owing to the joint influence of winds, tides, and currents, there is no part of the ocean, for any long interral, in a state of rest - an obriously benign arrangement of Providence; for if it became for any length of time a vast stagnant pool, its waters, charged with an immense amount of decomposing animal and regetable matter, notwithstanding their saltness, would soon become fœtid, would give off noxious exhalations, infect the whole atmosphere, and reduce the world to an uninhabitable desert. It has been wisely ordained, therefore, that the physical condition of this enormous mass of water should answer to the apostrophe-

"Roll on, thou deep and dark blue ocean, roll l" 


\section{CHAPTER $\mathbf{x}$.}

\section{CHANGES IN OCEANTC REGIONS.}

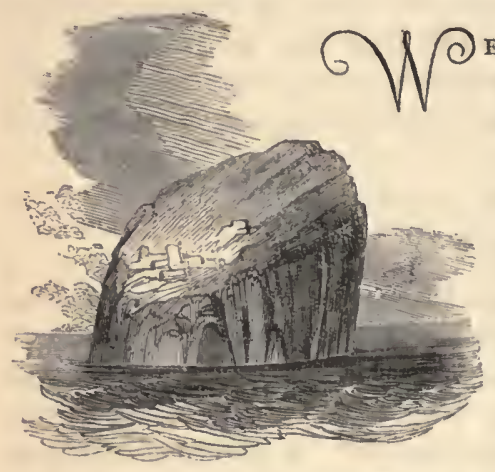

$\mathbf{E}$ have now arrived at a very interesting department of Physical Geography - the consideration of the changes to which the surface of the globe is subject, and of the causes which produce them, already indicated in the preceding pages. From the expcrience of many an individual life, it might be imagined, that "all things continue as they were from the beginning of the creation" - that an immutable character belongs to the earth's external aspect-so uniform are the appearances presented by nature during the course of man's threescore years and ten. The grandsire, trembling with age and infirmity, and living in a country distant from the centres of volcanic action, sees no alteration in the configuration of the hills and valleys with which he has been surrounded from his childhood. The stream wanders in the same channel, with as much transparency, and with as many circling eddies, now that he is old and grey-headed, as when in youth he romped upon its banks, and plucked with careless hand the daisy or the cowslip from its grassy slopes. There is, however, no part of the globe free from physical change, whether bare to the light and air of heaven, or lying a thousand fathoms deep below the waters, though it may require the lapse of ages to discover the signs of alteration, and though circumstances may forbid the mutation being the subject of sensible evidence. The bed of the ocean must of necessity be constantly undergoing changes, extensive and diversified, wrought in secret places, into which the inquisitive eye of man cannot penetrate, and which are often beyond the reach of his longest sounding-line. "All the rivers run into the sea, yet the sea is not full: unto the place from whence the rivers come, thither they return again." Denudation, or the carrying away a portion of the solid materials of the land through which they flow, is one effect of their action. It transpires with varying energy, according to the velocity of their current, and the nature of the contiguous soil; and the distribution of the material of which the land is robbed takes place under the control of these two particulars. The heavier debris of rivers may be generally deposited in their own channels, where there is a marked diminution in the power of the stream, arising from its course lying through an extensive level; but the finer particles are transported to a more distant locality, and are either deposited at the confluence of rivers with the sea, where the tides meet them with sufficient force to produce stagnation, or they are conveyed to a more remote resting-place by the tremendous rush of the fresh water into the bed of the deep, and the action of the oceanic currents.

According to Major Rennell, a glass of water taken from the Ganges in the floodseason will yield about one part in four of mud. The mean quantity of water discharged by the river throughout the year he estimated to amount to 80,000 cubic fect in a second, but to be 405,000 cubic feet when the river is in flood. Calculating upon these data, Sir C. Lyell states, that if the mud be assumed to be equal to one half the specific gravity of granite, a supposition below the truth, the weight of matter daily 
carried down in the flood season would be about equal to seventy-four times the weight of the Great Pyramid of Egypt. He observes :- " 405,000 cubic feet of water per second gives in round numbers 100,000 cubic feet of mud per second, which $\times 86,400$, the numbers of seconds in twenty-four hours, $=8,641,100,000$, the quantity of cubic feet of mud going down the Ganges per diem. Assuming the specific gravity of mud to be half that of granite, the matter would equal 4,320,550,000 feet of granite. Now about twelve and a half cubic feet of granite weigh one ton; and it is computed that the Great Pyramid of Egypt, if it were a solid mass of granite, would weigh about 6,000,000 of tons." There is some reason to doubt the accuracy of Rennell respecting the quantity of earthy matter in the water of the Ganges, though it is generally agreed to be the most turbid river upon the face of the globe, owing to the lightness of the soil of the Bengal plains favouring its transportation by the current, and the great violence of the tropical rains. Supposing it therefore to hold but ${ }_{10} \frac{1}{0}$ th part of mud in suspension, instead of $\frac{1}{4}$, - an estimate given with reference to the Rhine when most flooded, - the result will still be, that the river discharges in two days a mass of matter equal in bulk and weight to the Great Pyramid. A considerable portion of this goes to form new land along the coast at the mouth of the Ganges, but a large quantity is swept onwards into the Bay of Bengal, and contributes to lay upon its floor a carpet of soil in course of perpetual renewal.

The Sea of Azov, well-known to the Greeks and Romans under the name of Mrotis, was believed in the time of Aristotle to be filling up by the earthy matter conducted into it by its rivers. Its excessive shallowness now has no doubt been produced by the alluvium principally discharged by the Don, the average depth of the main body of the sea being only between six and seven fathoms. The Yellow Sea, an arm of the Chinese Ocean, so called from its waters being coloured by an intermixture of particles of yellow mud, supplies a similar example of the accumulation of debris in its bed. It receives the rapid Hoang $\mathrm{Ho}$, one of the largest rivers of China, which carries along with it an immense quantity of earthy material in a state of solution in its waters. Sir George Staunton calculated that this powerful stream brought down in a single hour two million feet of earth, or forty millions daily; so if the Yellow Sea be taken to be 120 fect deep, the river will convert an English square mile into firm land in seventy days. Currents carry far away into the ocean much of the sediment it receives, but the immediate deposition of the major part produces gradually increasing shoals and slallows, which interfere with the navigation. Captain Hall in the Lyra, sailed across this sea in 1816 on his voyage to Loo Choo, and had occasion to apprehend fairly sticking in the mud several times in the passage. When no land could be perceived from the mast-head, the ship was in less than five fathoms of water, and npon the ebb of the tide, its bottom was within three feet of the ground. It was discovered, at one time, that the Lyra was actually sailing along with her keel in the mud, indicated sufficiently by a long yellow train in her wake. There was more apparent than real danger in this extreme shallowness, as it was found, by forcing long poles into the ground, that for many fathoms below the surface on which the sounding lead rested, and from which level the depth of water is estimated, the bottom consisted of nothing but mud formed of an impalpable powder, without the least particle of sand or gravel. The fact unquestionably is, that the bottom of the Yellow Sea is gradually rising, from the deposits of innumerable streams flowing into it from China and Tartary, and in process of time, this arm of the ocean, which has probably an extent of 125,000 square miles, will become terra firma, exhibiting a horizontal plain like the great deltas of the Nile and the Ganges.

While, by the action of rivers, soil is transported from far inland situations, and brought into the sea, it is borne by the currents of the ocean, which sweep along the coasts, to a 
much greater distance from its original site. $\Lambda$ t not less than three hundred miles from the mouth of the Amazon, Captain Sabine found the sea discoloured by the waters of the river, where they were still lunning with considerable rapidity ; but the stream does not deposit its load of earthy material off its own estuary, for the great tropical oceanic current westward crosses its course, takes up a part of its burden, bears it towards the Caribbean Sea, and may even strew it over the bed of the Gulf of Mexico. In like manner, the sedimentary matter which the mighty Mississippi discharges, and the rivers of the United States east of the Alleghanies, is taken up by the majestic current of the Gulf stream, and distributed over the floor of the North Atlantic. The greater part of our own eastern coast is annually deprived of a large mass of material by the storny action of the German Ocean. It undermines and sweeps away the granite, gneiss, trap rocks, and sandstone of Shetland, and removes the gravel and loam of the cliffs of Holderness, Norfolk, and Suffolk, which are between fifty and two hundred feet in height, and which waste at the rate of from one to six yards annually. It bears away the strata of London clay on the coast of Essex and Sheppy-consumes the chalk with its flints for many miles continuously on the shores of Kent and Sussex - commits annual ravages on the fresh-water beds, capped by a thick covering of chalk flints in Hampshire, and continually saps the foundations of the Portland limestone. It receives, besides, during the rainy months, large supplies of pebbles, sand, and mud, which numerous streams from the Grampians, Cheviots, and other chains send down to the sea. To what regions is all this matter consigned? This question is no doubt answered in part by those immense banks which are found along the coasts of England, Holland, and Denmark, and penetrate to the central regions of the German Ocean, equal to about $\frac{1}{5}$ of its whole area, or $\frac{1}{3}$ of the whole extent of Great Britain. 'There are thus formations proceeding upon a gigantic scale, elevating and variously shaping the bed of the ocean, the result of the deposition there of the solid materials abraded from the land by the agency of rivers and sea-currents.

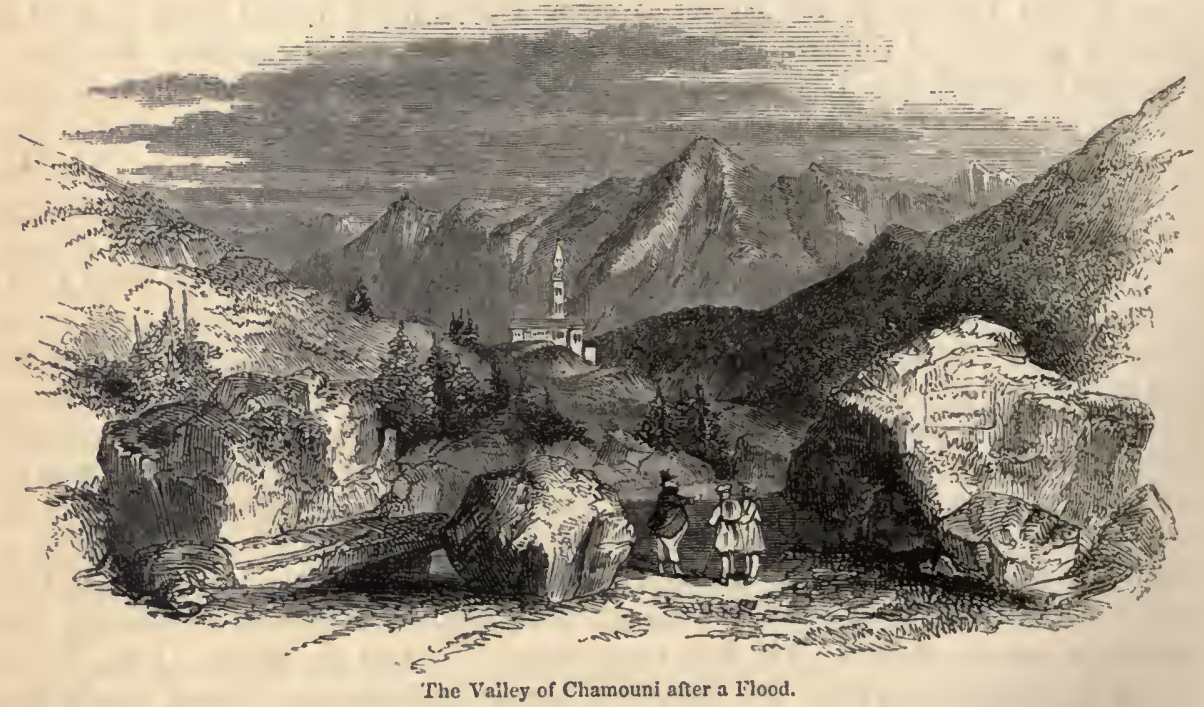

It is easy to perceive, that should any upheaving cause expose to the gaze of man the bottom of the existing seas, precisely similar phenomena would be exhibited to those which the continents now present. Vast spaces of regular strata would appear, bearing clear marks of having been formed by aqueous deposition, sluwly and horizontally, however inclined and fractured by the power of the elerating agent. 
In addition to the soil transported from inland regions into the heart of the ocean, the plants and trees which fall into the river-channels through the undermining of their banks, or which are uprooted by their agency in floods, undergo a similar transference, and are finally imbedded in the sediment accumulating below the waters of the deep. When we reflect upon the combined influence and constant action of innumerable streams in this respect, we shall readily admit that, in the course of a few ages, a prodigious quantity of animal and vegetable remains, derived from the existing continents, receives a subaqueous deposition. Similar remains of marine species contribute largely to augment and diversify the formations in process at the bottom of the seas. We have referred to huge fragments of rock borne by icebergs firom the shores into the central parts of the occan, and there submerged upon the dissolution of their frozen vehicles; and this single operation must, in a century or two, work great changes, scattering isolated blocks upon the sandy slopes and plains over which the North Atlantic rolls its waves, or piling them upon each other in every variety of form. Shakespeare, in describing the dream of Clarence, draws a vivid picture of other contributions which the occurrence of disaster annually submerges, involving many of the human race, with the monuments of their industry, and the signs of their opulence.

\author{
Methought that I had broken from the Tower, \\ And was embarked to cross to Burgundy; \\ And, in my company, my brother Gloster: \\ Who from my cabin tempted me to walk \\ Upon the hatches; thence we look'd toward England, \\ And cited up a thousand heavy times, \\ During the wars of York and Lancaster, \\ That had befillen us. As we paced along \\ Upon the giddy footing of the hatches, \\ Methought that Gloster stumbled : and in falling, \\ Struck me, that thought to stay him, overboard, \\ Into the trembling billows of the main. \\ O Lord! methought what pain it was to drown! \\ What dreadful noise of water in mine ears! \\ What sights of ugly death within mine eyes! \\ Methought I saw a thousand fearful wreeks; \\ A thousand men, that fishes gnawed upon, \\ Wedges of gold, great anchors, heaps of pearl, \\ Inestimable stores, unvalued jewels, \\ All scattered in the bottom of the sea. \\ Some lay in dead men's skulls; and in those holes \\ Where eyes did once inhabit, there were crept, \\ (As if in scorn of eyes) reflecting gems, \\ That woo'd the slimy bottom of the deep, \\ And mock'd the dead bones that lay seattered by."
}

During the modern wars of this country, the navies of the continental powers, Spain, France, and Denmark, were almost annihilated, and our own losses amounted to an enormous aggregate, a large number of stately vessels being battered to pieces, and consigned to the bottom of the deep. "In every one of these ships were batteries of cannon, constructed of iron or brass, whereof a great number had the dates and places of their manufacture inscribed upon them in letters cast in metal. In each there were coins of copper, silver, and often many of gold, capable of serving as valuable historical monuments; in each were an infinite variety of instruments of the arts of war and peace, many formed of materials, such as glass and earthenware, capable of lasting for indefinite ages, when once removed from the mechanical action of the waves, and buried under a mass of matter which may exclude the corroding action of sea-water. But the reader 
must not imagine that the fury of war is more conducive than the peaceful spirit of commercial enterprise to the accumulation of wrecked vessels in the bed of the sea. From an examination of Lloyd's lists, from the year 1793 to the commencement of 1829, it has appeared that the number of British vessels alone lost during that period amounted on an average to no less than one and $a$ half daily, - a greater number than we should liave anticipated, although we learn from Moreau's tables that the number of merchant vessels employed at one time in the navigation of England and Scotland, amounts to about twenty thousand, having one with another a mean burden of one hundred and twenty tons. Out of five hundred and fifty-one ships of the royal navy lost to the country during the period above mentioned, only one hundred and sixty were taken or destroyed by the enemy, the rest having either stranded or foundered, or having been burnt by accident, - a striking proof that the dangers of our naval warfare, however great, may be far exceeded by the storm, the hurricane, the shoal, and all the other perils of the deep. Millions of dollars and other coins have been sometimes submerged in a single ship, and on these, when they happen to be enveloped in a matrix capable of protecting them from chemical changes, much information of historical interest will remain inscribed, and endure for periods as indefinite, as have the delicate markings of zoophytes or lapidified plants in some of the aneient secondary rocks. In almost every large ship, moreover, there are some precious stones set in seals, and other articles of use or ornament composed of the hardest substances in nature, on which letters and various images are carved-engravings which they may retain when included in subaqueous strata, as long as a crystal preserves its natural form." This interesting statement of Mr. Lyell shows, that, independent of the remains of plants and animals washed down by rivers from the land into the ocean, a vast variety of substances, diverse in kind and form, must necessarily be included in the strata now building up below its waters; and reflecting upon the action of that power, which, at different epochs, has upheaved our mountain ranges, we may conceive of the singular spectacle that would be presented to the inquirer long ages hence, and of its close resemblance to that exhibited by the stratified rocks upon which we gaze, should an elevating cause raise up the "ooze and bottom of the deep," submerging the existing continents in compensation.

In referring to the elevation of the oceanic bed, we are not indulging in any extravagant speculation, for, besides a gradual change as the effect of deposition, a series of wellattested facts proclaim the occurrence of violent catastrophes. The sudden formation of new islands, the result of submarine volcanic action, constitute a distinct class of those mutations to which the oceanic realm is subject. Some of these islands, after a hasty start into existence, have subsided, and either entirely disappeared, or become shoals slightly depressed below the level of the water, while others have remained permanent. Some also have consisted merely of volcanic matter, while others have presented marine strata, and been literally the upheaved floor of the sea.

The gulf of Santorin, one of the Cyclades, in the Grecian Archipelago, nearly encloses several small islands which have emerged from the deep witlin the period of authentic listory. Rather more than a century before the Christian era, the small isle of Palaia Kameni was thrown up in the gulf. In the year 1573 another appeared, called the Little Kameni, a large disengagement of vapour and the discharge of pumice accompanying its elevation, and telling the story of its birth. A third was formed in the years 1707 and 1709, called the New Kameni, which still exhales sulphureous vapours. These islands consist of volcanic products, lava, scorix, and pumice, and of strata uplifted by the cxpansive force which produced the ejection of these materials.

Similar instances have repeatedly happened in connection with the Azores. The first on record is that mentioned by Kircher in 1538; another took place in 1720; and a 
third in 1587, when an earthquake shook the island of St. Greorge, and eighteen small islets rose in the ocean near its shores. The last example in this locality, and the most celebrated, occurred in the year 1811, when the temporary island of Sabrina rose from the deep off the coast of St. Michael. A dangerous shoal was first thrown up from a depth of two hundred and forty feet of water. This took place in February. On the 13th of June the island showed itself above the surface of the sea, and continued rapidly to increase for several days, till it attained the height of three hundred feet, and was about a mile in circumference. It had a beautiful crater, with an opening thirty feet wide, from which hot water poured into the sea. In the month of October of the same year the island began gradually to disappear, and by the end of February, 1812, no trace of it was visible above the waves, though vapours occasionally rose from the spot. Mr. Bakewell states, upon the authority of a person who visited the Azores in 1813, that there was near five hundred feet of water at the place where Sabrina formerly had stood.

Barren Island, in the Indian Ocean, is one of the most remarkable volcanic islands now in active existence; and declares its own origin. The cone, near the centre, emits vast

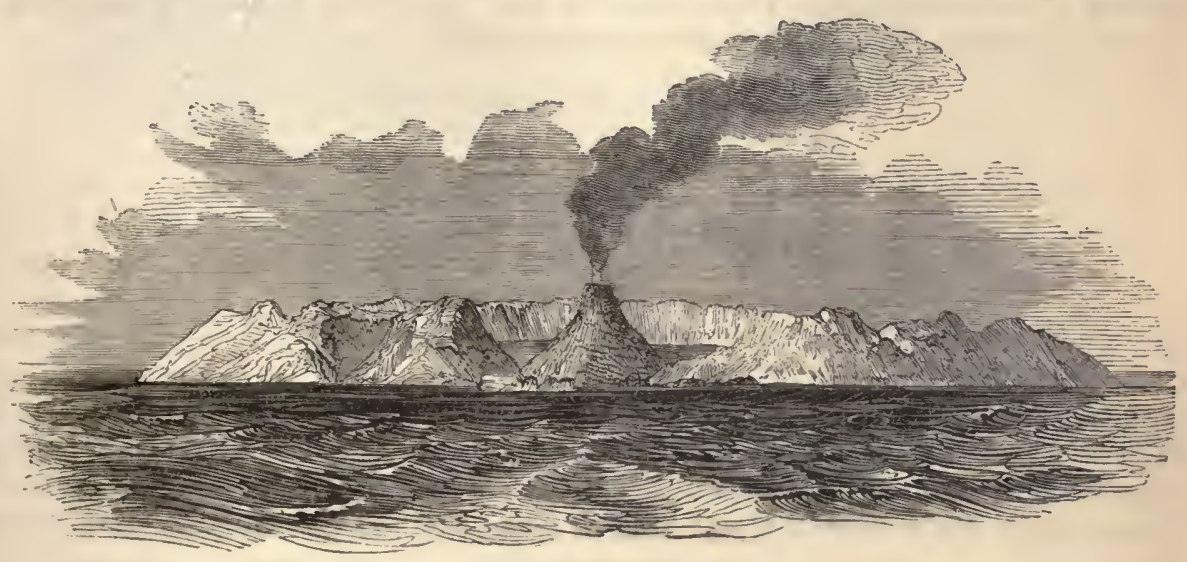

Barren Island.

volumes of smoke, and showers of red-hot stones, some of which weigh three and four tons, and are cast to a distance of some hundreds of yards beyond the base; a scanty vegetation finds a precarious existence on the outer ridges, often blasted by the violence of the eruptions : it is about six leagues in circumference, and may be distinguislied from the rest of the Andaman Islands for a distance of thirty-six miles in clear weather; the base of the cone or crater is but very little higher than the level of the ocean, although the cone itself rises abruptly to the height of 1800 feet; it is surrounded by a wall of nearly equal height, which drops almost perpendicularly into the sea. At a quarter of a mile from the shore there is no bottom found at 150 fathoms.

Among the Aleutian isles, a group in the North Pacific, stretching from Asia to Nortl America, which consist of black masses of lava, rising perpendicularly from the sea, and peering above the clouds, a new island arose in the year 1806, which has remained firm. Its general form was that of an immense peak, studded with small conical hills, upwards of four geographical miles in circumference. Another new isle was here produced in the year 1814, which rose up to the height of three thousand feet, then slightly subsided, and has firmly established itself as a member of the Aleutian group.

In the year 1783 an island was formed by elevation at the distance of seventy miles 
from Cape Reykiawas in Iceland. This was attended by the ejcction of such an immense quantity of pumice, that the surface of the ocean was covered with it to the distance of a hundred and fifty miles, and the spring ships were considerably impeded in their course. The island consisted of high cliffs, and emitted fire, smoke, and pumice from two or tliree different points. It was claimed by the King of Denmark, who denominated it Nyöe, or the New Island, but before a year liad elapsed, the sea resumed its ancient domain, a rocky recf remaining under the surface at the spot where this portentous production had appeared. The submarine eruption was a prelude to some of the most violent convulsions that have marked the annals of Iccland. After repeated shocks of carthqualies, the Skaptar volcano was roused into terrific activity, and threw out the largest body of lava ever witnessed since the period of authentic reeords. 'The quantity of ashes was so great as to affect the whole European atmosphere with obscurity, and in the Faroe Islands the ground was evcrywhere covered with particles of sand and pumice. The great carthquake in Calabria which occurred in the same year-the luminous meteors observed in England, Holland, and various parts of the continent-the fog which covered Europe from north to south, rising above the summits of its highest mountains, and continuing upwards of a month_lender 1783 one of the most remarkable years of nodern times, and drew from Cowper the Expostulation in his "Task:"-

\footnotetext{
"Fires from beneath, and meteors from above,

Portentous, unexampled, unexplained,

Have kindled beacons in the skies; and the old

And erazy earth has had her shaking fits

More frequent, and foregone her usual rest.

Is it a time to wrangle, when the props

And pillars of our planet seem to fail,

And nature, with a dim and sickly eye,

To wait the close of all 2 "
}

Such was the destruction of pasturage, corn-fields, and property in Iceland, caused by its physical convulsions at this period, as to bring upon its inhabitants the additional miseries of famine, so that in the short space of two years, not fewer than 9,336 luman bcings, 28,000 horses, 11,461 head of cattle, and 190,488 sheep perished on the island.

The most recent instance of new formations of this class, which excited extraordinary interest from its locality, oecurred off the coast of Sicily in the year 1831. The first notice of it was published in the following terms, in the Messager des Chambres:"Towards 11 o'clock on the 10th of July, 1831, Captain John Corrao, commander of the brig Thérésine, going from Trapani to Girgenti, in Sicily, at the distance of about twenty miles from Cape St. Mark, perceived at the distance of a gun-shot a mass of water, which rose 60 feet above the level of the sea, and presented a circumference of nearly 400 fathoms; a smoke proceeded from it, exhaling an odour of sulphur. The preceding day, in the Gulf of Trois Fontaines (Three Fountains) he had seen a great quantity of dead fisli and of black matter floating on the water, and he heard a noise like that of thunder, which the captain attributed to a volcanic eruption. He continued his voyage to Girgenti; and all the time that he was oecupied in lading his ship, he saw a thick smoke rise incessantly from the same point, before which he arrived on the 16th, on his return from Girgenti. A new spectacle was then presented to lim, namely, a tract of land, of the same circumferenee as that of the mass of water which he liad observed on his first royage. 'This island, which we sliall call Corrao, from the name of him who saw it formed, is elevated twelve feet above the level of the sea; it has in the middle a kind of plain, and the crater of a volcano, whence a burning lava is seen to 
proceed during the night. The island is bordered by a girdle of smoke. The sounding all around the island gives a depth of 100 fathoms. The lat. $37^{\circ} 6^{\prime} \mathrm{N}$., and long.

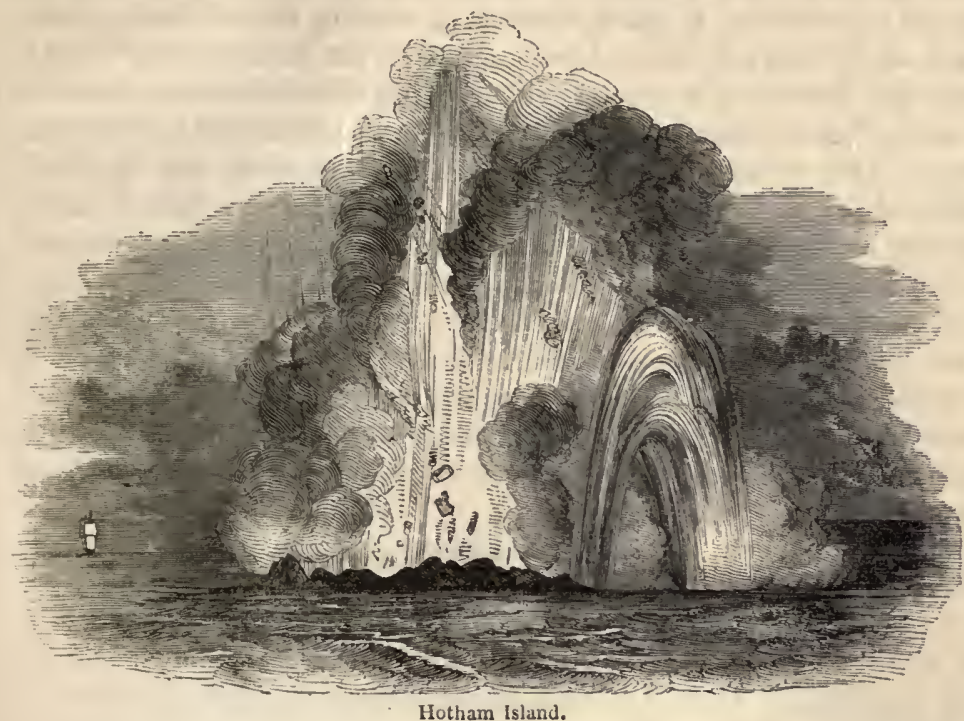
$10^{\circ} 26^{\prime} \mathrm{E}$. from the meridian of $\mathrm{Pa}$ ris." Dr.'Turnbull Christie, writing to P'rofessor Jameson from Malta, July 23, observes: — "It would appear that the volcano commenced on the 11 th instant, when it was seen by the master of a small vessel sailing towards Terra Nova, who describes it as having had the appearance of a large rugged island eoming up and falling with force back into the sea, so that the sea flew up to a great height, and fell down in the form of foam. This was seen to be repeated at short intervals, for nearly two lours. The masters of two small vessels, one from Sardinia, and the other from Palcrmo, state:-' On the 13th instant, about 2 o'clock, P. M., being between Sciaeca and Pantellaria, 25 miles southward of Seiacca, we discovered three eolumns of smoke, apparently issuing from the sea. On approaching it we heard a gl'eat noise, like the rolling of the wheels of a steam-ressel.' The Admirnl upon the Mediterranean station, Sir H. Hotham, immediately despatched an officer to examine and ascertain the exact position of the new volcanic island, which was named Hotham Island in honour of the commander, and the following interesting particulars were reported:-

" On the 18th of July, 1831, at 4 P. xr., the town of Marsala bearing by compass E. half N., nine miles, I observed from on board His Majesty's sloop Rapid, under my command, a highly irregular column of very white smoke or steam, bearing S. by E. I steered for it, and continued to do so till $8 \mathrm{~h} .15 \mathrm{~m}$. P.Mr., when, having gone about thirty miles by the reekoning, I saw flashes of brilliant light mingled with the smoke, which was still distinctly visible by the light of the moon.

"In a few minutes the whole column became black and larger; almost immediately afterwards sereral suecessive eruptions of lurid fire rose up amidst the smoke; they subsided, and the column then became gradually white again. As we seemed to near it fast, I shortened sail and hove-to till daylight, that I might aseertain its nature and exact position. During the night the changes from white to black, with flashes, and the eruption of fire, continued at irregular intervals, varying from half an hour to an hour. At daylight I again steered towards it, and about 5 A.Mr, when the smoke had for a moment cleared away at the base, I saw a small hillock of a dark colour, a few feet above the sea. This was soon hidden again, and was only visible through the smoke at intervals between the more violent eruptions.

"The voleano was in a constant state of activity, and appeared to be diseharging dust and stones, with vast volumes of steam. At $7 \mathrm{~h} .30 \mathrm{~m}$. the rushing noise of the erup- 
tions was heard. At 9 , being distant from it about two miles, and the water being much discoloured with dark objects at the surface in various places, I hove to, and went in a boat to sound round and examine it. I rowed towards it, keeping on the weather-side, and sounding, but got no bottom till within twenty yards of the western side, where I liad eighteen fathoms, soft bottom; this was the only sounding obtained, except from the brig, one mile true north from the centre of the island, where the depth was 130 fathoms, soft dark brown mud. The crater (for it was now evident that such was its form) seemed to be composed of fine cinders and mud of a dark brown colour; within it was to be seen, in the intervals between the eruptions, a mixture of muddy water, steam, and cinders, dashing up and down, and occasionally running into the sca, over the edge of the crater, which I found, on rowing round, to be broken down to the level of the sea, on the W.S. W. side, for the space of ten or twelve yards. Here $I$ obtained a better view of the interior, which appeared to be filled with muddy water, violently agitated, from which showers of hot stones or cinders were constantly shooting up a few yards, and falling into it again; but the great quantity of steam that constantly rose from it prevented my seeing the whole crater.

" $\mathrm{A}$ considerable stream of muddy water flowed outward through the opening, and, mingling with that of the sea, eaused the discolouration that had been observed before. I could not approach near enough to observe its temperature; but that of the sea, within ten or twelve yards of it, was only one degree higher than the average; and to leeward of the island, in the direction of the current (which ran to the eastward), no difference could be perceived, even where the water was most discoloured; however, as a 'mirage' played above it near its source, it was probably hot there. The dark objects on the surface of the sea proved to be patches of small floating einders. The island or crater appeared to be seventy or eighty yards in its external diameter, and the lip as thin as it could be consistent with its height, which might be twenty feet above the sea in the highest, and six feet in the lowest part, leaving the rest for the diameter of the area within. These details could only be observed in the intervals between the great eruptions, some of which I witnessed from the boat. No words can describe their sublime grandeur. Their progress was generally as follows:- After the volcano had emitted for some time its usual quantities of white steam, suddenly the whole aperture was filled with an enormous mass of hot cinders and dust, rushing upwards to the height of some hundred feet with a loud roaring noise, then falling into the sea on all sides with a still louder noise, arising in part, perhaps, from the formation of prodigious quantities of steam which instantly took place. The steam was at first of a brown colour, having embodied a great deal of dust; as it rose it gradually recovered its pure white colour, depositing the dust in the shape of a shower of muddy rain. While this was being accomplished, renewed eruptions of hot cinders and dust were quickly succeeding each other, while forked lightning, accompanied by rattling thunder, darted about in all directions within the column, now darkened with dust and greatly inereased in volume, and distorted by sudden gusts and whirlwinds. The latter were most frequent on the lee side, where they often made imperfect water-spouts of curious shapes. On one occasion some of the steam reached the boat; it smelt a little of sulphur, and the mud it left became a gritty, sparkling, dark brown powder when dry. None of the stones or cinders thrown out appeared more than half a foot in diameter, and most of them much smaller.

"From the time when the volcano was first seen till after I left it, the barometer did not fall or rise; the sympiesometer underwent frequent but not important changes; and the temperature of the sea did not bespeak any unusual influence. After sunset, on the 18th, soundings were tried for every hour, to the average depth of eighty fathoms; no bottom. The wind was N.W.; the weather was serene. On the forenoon of the 19th, with the 
centre of the volcano bearing by the compass S. by W. $\frac{1}{2}$ W., one mile distant, good sights, for the chronometer gave longitude $12^{\circ} 4 \mathrm{l}^{\prime} \mathrm{E}$; and at noon on the same day, when it bore W. by $\mathrm{N}$. $\frac{1}{2} \mathrm{~N}$. by compass, the meridian altitude of the sun gave the latitude $37^{\circ} 7^{\prime} 30^{\prime \prime} \mathrm{N}$.; an amplitude of the sun the same morning gave the variation of $1 \frac{1}{2}$ point westerly. It is worthy of remark, that on the 28 th of June last, at $9 \mathrm{~h} .30 \mathrm{~m}$. P. M., when passing near the same spot in company with the Britannia, several shocks of an earthquake were felt in both ships."

These records of modern change and convulsion are highly instructive; and may be regarded as relating the story of many formations which have marked the superficies of the globe for ages, transpiring before history commenced its annals, or physical phenomena had any intelligent human witness. Whole groups of islands bear evident marks of having been formed by volcanic activity, consisting either wholly of an accumulation of volcanic substances, or in connection with marine strata upheaved from the bottom of the sea. A great number of solitary islets likewise display the same character, and have been built up by the occurrence of violent catastrophes. The South Atlantic presents a

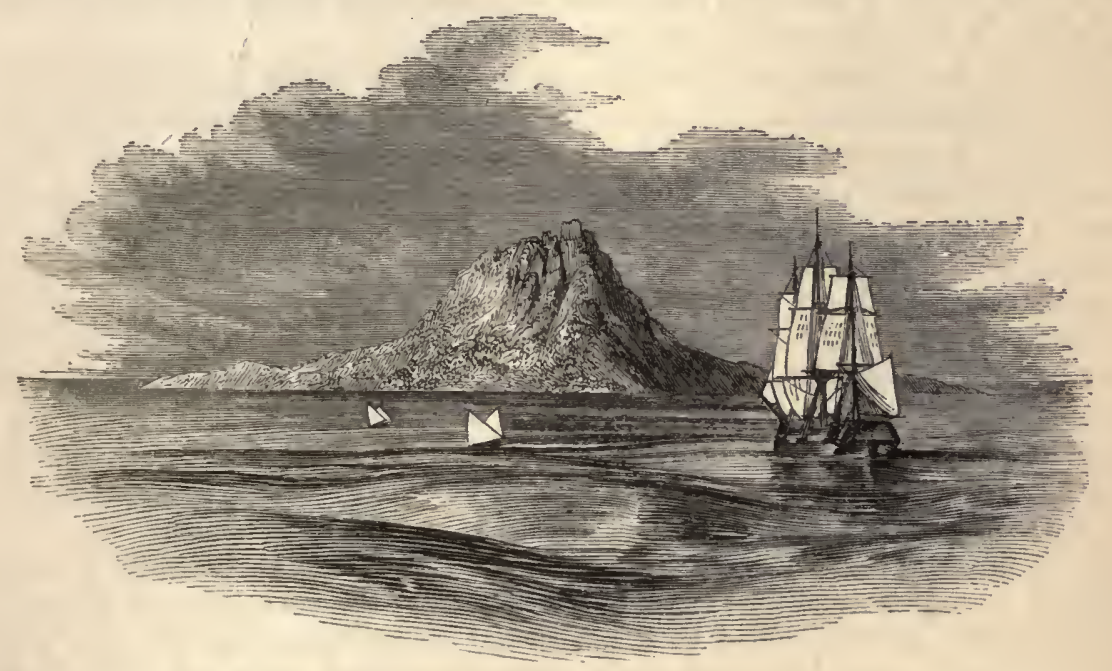

Island of St. Eustatia, West Indies.

remarkable example of this class in Ascension Island, one of the most isolated solid sites above the waves of the ocean, 1450 miles from the coast of Africa, 685 from St. Helena, and 520 from the nearest particle of visible land, the island of St. Matthew. Its shore exhibits black nitrous lava. Its surface presents rugged conical hills of different kinds of lava, some with perfect craters, scorix, pumice, and other volcanic products being everywhere strewed in large quantities. Not a shrub was to be seen upon its first discovery on Ascension-day, in 1501; by Joāo de Nova Galego, and the only vegetation consisted of some coarse grasses and ferns. There can be little doubt respecting the events denoted by the physical characteristics of this island. Probably the ocean here once rolled its waters unobstructed by any visible land, when, at some era in the past which no chronicle has marked, a grand revolution took place, from the action of that power which in recent times has invaded the dominion of the sea, and reared rocky edifices beyond the reach of its waves. The disturbing cause at length expended its energy, as it has done with reference to the Peak of Teneriffe, and the extinct volcanoes of Auvergne, and an age of tranquillity ensued, marked by the ordinarily gradual and quiet operations of nature. Each of the existing continents furnishes innumerable proofs of having undergone similar grand 
revolutions, proceeding from some expansive power which has lifted up, broken, and overturned their masses in a thousand ways. The lowest and most level parts of the earth, says Cuvier, when penetrated to a rery great depth, exhibit nothing but horizontal strata composed of various substances, and containing, almost all of them, innumerable marine productions. Similar strata, with the same kind of productions, compose the hills even to a great height. 'Sometimes the shells are so numerous as to constitute the entire body of the stratum. They are almost every where in such a perfect state of prescrvation, that even the smallest of them retain their most delicate parts, their sharpest ridges, and their finest and tenderest processes. They are found in elevations far above the level of every part of the ocean, and in places to which the sea could not be conveyed by any existing cinse. 'The summits of the Pyrenees and of the Andes, at the height of 13,000 or 14,000 feet above the level of the sca, present them to our notice. These facts bear witness to the great and wonderful changes which have marked the ancienthistory of the earth; for it is obvious that the present continents once occupied a submarine position, from which they have been uplifted - a change analogous to that involved in the formation of new islands by a process of elevation, and probably brought about by the same agency, though acting with an incomparably greater energy.

While the more terrible and destructive instruments of nature occasionally interpose with a disturbing effect in oceanic regions, there is another class of interesting and extensive changes in constant process, wrought by the peaceful labours of organic life. In inappreciable numbers, the coral insects - minute and apparently insignificant agents swarm in the bosom of the deep, the architects of the production ealled coral. This was generally decmed a vegetable substance until the year 1720, when M. de Peyronnel of MIarseilles commenced, and continued for thirty years, a series of observations, by which he ascertained the coral to be the production of a living animal of the polypi tribe. The gencral name of zoöphytes, or plant-animals, has since been applied to these marine insects, though sometimes called lithophytes, or stone-plants. Various species are inclnded in the genera, but the most abundant is the muricated madrepore, madrepora muricata of Limnæus. They occur most frequently in the tropical seas, where entire islands and vast reefs have been formed by them, and are in progress of formation.

One of the coral islands, visited by the American expedition, is described by Captain Wilkes as showing three distinct stages of shelving coast: the one submerged, narrow, and dipping rapidly ; the other broad, level, and covered at high-water, but quite bare at lowwater; the third, above high-water mark, consisting of coral debris and sand on which

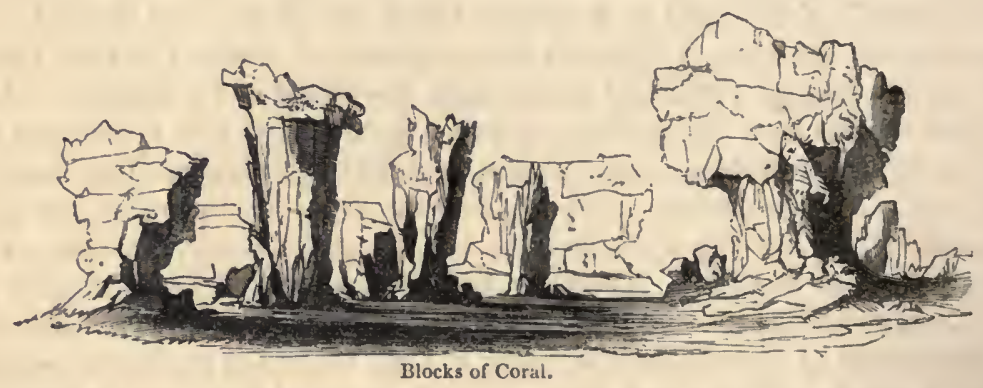

vegetation takes place. The annexed cut represents the form of several of the coral blocks washed up, and left stranded, by the stormy swell of the ocean.

The most remarkable island of coral formation observed by this expedition, was Metia, or Aurora Island, in lat. $50^{\circ} 49^{\prime} \mathrm{S}$., long. $148^{\circ} 13^{\prime} \mathrm{W}$. It was totally difierent in appearance from any they had yet met with, being a coral island, uplifted, and exposing its 
formation very distinctly. On approaching its castern side, Captain Wilkes sounded 150

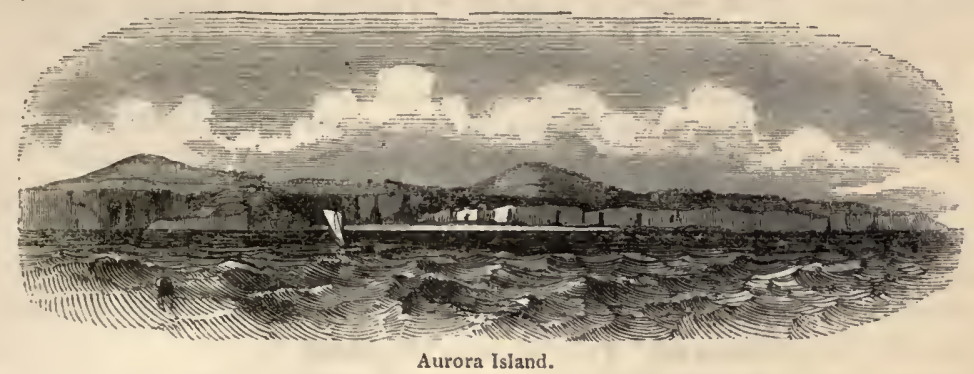

fathoms from its perpendicular cliff, but found no bottom with 150 fathoms of line. The cliff; which, when measured, proved to be 250 feet high, appeared to be worn into caverns: the coral shelf was found to be 550 feet wide, extending on the northern side of the island, and gradually diminishing in width until it lost itself at the western end.

"As far as our observation went," Captain Wilkes remarks, "the upper portion of this island is composed of limestone or compact coral rocks; the cliff, on its eastern side, where we first landed, appeared stratified, horizontally, in beds of ten to twelve feet thick, of a sort of conglomerate, composed of shells, coral, and pieces of compact rock, cemented together by a calcareous deposit. The under part of this bed had been much worn by the sea ; the rich soil was composed of deeayed vegetable matter and decomposed limestone, and the slabs that were lying loose on the surface had a clinky metallic sound when struck. The island has unequivocal marks of having been uplifter at different periods, the cliff, at two diflerent heights, appearing to have suffered abrasion by the sea. Stalagmites were observed under the cliff, and also some stalactitic columns, fourteen feet high by six in diameter."

Another island of this group was surveyed by the expedition - the Arutua Island,

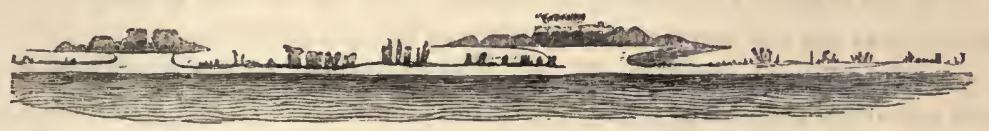

1)ean's Island.

which sas found to be connected with Nairsa, or Dean's Island. The coral blocks here showed themselves more conspicnously and in greater numbers.

The zoophytes are frail gelatinous creatures of varying size, apparently linited in their range, operating only from high-water mark downwards to the depth of eighteen or twenty fathoms. The various species of these animals appear to be furnished with minute glands, secreting gluten, which, upon exudation, converts the carbonate of lime in the ocean, and other earthy matters, into a fixed and concrete substance, twisted and fashioned in every variety of shape. The formation of coral is one of those chemical processes in the great laboratory of nature, which the skill of man has not enabled him either to imitate or to comprehend; but the fact is clear, that huge masses of solid rock are formed by these diminutive living agents-sea-workers toiling and spinning to the music of the waves, whose constructions are capable of resisting the tremendous power of the ocean, when most agitated by winds and tempests, and ultimately become a secure habitation for man himself. The coral substance appears to bear the same relation to the insect, as the shell of a snail or an oyster does to either of those animals, without which they cannot long exist; and it is upon the death of the animalcules, that their separate homes and skeletons are knit together by some mysterious cement, and serve as a basin for the memorials of fresh races, which, as they die off, increase the growth of the firm and solid fabric. 
"Millions of millions thus, from age to age, With simplest skill, and toil unweariable, No moment and no movement unimproved, Laid line on line, on terrace terrace spread, To swell the heightening, brightening gradual mound, By marvellous structure elimbing towards the day. Each wrought alone, yet all together wrought, Unconscious, not unworthy, instruments, By which a hand invisible was rearing A new creation in the secret deep. Omnipotence wrouglit in them, with them, by them; Hence what Omnipotence alone could do Worms did. I saw the living pile ascend, The mausoleum of its architects, Still dying upwards as their labours closed: Slime the material, but the slime was turn'd To adamant, by their petrific touch; Frail were their frames, ephemeral their lives, Their masonry imperishable. All

Life's needful functions, food, exertion, rest, By nice economy of Providence

Were overruled to earry on the process

Which out of water brought forth solid rock.

"Atom by atom thus the burthen grew, Even like an infant in the womb, till Time Deliver'd ocean of that monstrous birth A coral island stretching east and west."

Nothing more perfeetly demonstrates the power of Nature to effect her vast designs through apparently feeble and inefficient agents, than the coral formations. It requires, indeed, ocular proof of the labours of the madrepores, to credit what stupendous submarine reefs and islands, many miles in eompass, are indebted for at least a great part of their structure to the seeretory economy of these minute artificers.

The coral inseets are abundant in the Mediterranean, where corallines of beautiful forms and colours are produced; but it is in the Pacific Ocean and its branches that these tiny workmen are effecting those mighty ehanges which far exceed the most remarkable labours of man. Interesting details have been furnished by many navigators respecting these formations. They attracted the attention of Captain Hall in the seas around Loo Choo, where the zoophytes belonging to the genera Astrea are most common, who remarks : "The examination of a coral reef, during the different stages of one tide, is particularly interesting. When the sea has left it for some time, it becomes dry, and appears to be a compact rock, exceedingly hard and ragged; but no sooner does the tide rise again, and the waves begin to wash over it, than millions of coral worms protrude themselves from holes on the surface which were before quite invisible. These animals are of a great variety of shapes and sizes, and in such prodigious numbers, that in a short time the whole surface of the rock appears to be alive and in motion. The most common of the worms at Loo Choo was in the form of a star, with arms from four to six inches long, which it moved about with a rapid motion in all directions, probably in search of food. Others were so sluggish, that they were often mistaken for pieces of the rock: these were generally of a dark colour, and from four to five inches long and two or three round. When the rock was broken from a spot near the level of high water, it was found to be a hard solid stone; but if any part of it were detached at a level to which the tide reached every day, it was discovered to be full of worms of all different lengths and colours, some being as fine as a thread and several feet long, generally of a very bright 
yellow, and sometimes of a blue colour ; while others resembled snails, and some were not unlike lobsters and prawns in shape, but soft, and not abore two inches long. The growth of coral ceases when the worm which creates it is no longer exposed to the washing of the tide. Thus a reef rises in the form of a gigantic cauliflower, till its top has gained the level of the highest tides, above which the worm has no power to carry its operations, and the reef, consequently, no longer extends itself upwards. The surrounding parts, however, advance in succession till they reach the surface, where they also must stop. Thus, as the level of the highest tide is the eventual limit to every part of the reef, a horizontal field comes to be formed coincident with that plane, and perpendicular on all sides. 'The reef, however, continually increases, and, being prevented from going higher, must extend itself laterally in all directions; and this growth being probably as rapid at the upper edge as it is lower down, the steepness of the face of the reef is preserved; and it is this circumstance which renders this species of rocks so dangerous in navigation. In the first place, they arc seldom seen above the water; and in the next, their sides are so abrupt that a ship's bows may strike against the rock before any change of soundings indicates the approach of danger." As an instance of the caution requisite in navigating amongst coral, Captain Hall mentions, that his ship, the Lyra, was at one time within three or four yards of a reef, the ragged tops of which were distinctly visible two or three feet below the surface, while, at the same moment, the leadsman on the opposite side of the vessel sounded in nine fathoms.

Captain Flinders, while surveying the coasts of Australia, examined the coral formations in process there, particularly those of Half-Way Island, on the north coast of that region. "This little island, or rather the surrounding reef, which is three or four miles long, affords shelter from the south-east winds; and being at a moderate day's run from Murray's Isles, it forms a convenient anchorage for the night to a ship passing through Torres' Straits. I named it Half-Way Island. It is scarcely more than a mile in circumference, but appears to be increasing both in elevation and extent. At no very distant period of time, it was one of those banks produced by the washing up of sand and broken coral, of which most reefs afford instances, and those of 'Torres' Straits a great many. These banks are in different stages of progress: some, like this, are become islands, but not yet habitable; some are above high-water mark, but destitute of vegetation; while others are overflowed with every returning tide. It seems to me, that when the animalcules, which form the corals at the bottom of the ocean, cease to live, their structures adhere to each other, by virtue either of the glutinous remains within, or of some property in salt water; and the interstices being gradually filled up with sand and broken pieces of coral washed by the sea, which also adhere, a mass of rock is at length formed. Future races of these animalcules erect their habitations upon the rising bank, and die in their turn to increase, but principally to elevate, this monument of their wonderful labours. The care taken to work perpendicularly in the early stages, would mark a surprising instinct in these diminutive creatures. Their wall of coral, for the most part, in situations where the winds are constant, being arrived at the surface, affords a shelter to leeward of which their infant colonies may be safely sent forth; and to this, their instinctive foresight, it seems to be owing, that the windward side of a reef exposed to the open sea, is generally, if not always, the highest part, and rises almost perpendicular, sometimes from the depth of two hundred, and perhaps many more, fathoms. To be constantly covered with water, seems necessary to the existence of the animalcules; for they do not work except in holes upon the reef, below low-water mark; but the coral, sand, and other broken remnants thrown up by the sea, adhere to the rock, and form a solid mass with it, as high as the common tides reach. That elevation surpassed, the future remnants, being rarely covered, lose their adhesive property, and, remaining in a 
loose state, form what is usually called a kcy upon the top of the reef. The new bank is not long in bcing visited by sea-birds; salt-plants take root upon it, and a soil begins to be formed; a coeoa-nut or the drupe of a pandanus is thrown on shore; land-birds visit it, and deposit the seeds of shrubs and trees; every high tide, and still more erery gale, adds something to the bank; the form of an island is gradually assumed; and last of all comes man to take possession.

"Half-way Island is well adraneed in the above progressive state; having been many years, probably some ages, above the reach of the highest spring tides, or the wash of the surf in the lieaviest gales. I distinguished, however, in the rock which forms its basis, the sand, coral, and shells, formerly thrown up, in a more or less perfect state of cohesion, small pieces of wood, pumice stone, and other extraneous bodies which chance had mixed with the ealcareous substanees when the coliesion began, were inclosed in the rock, and in some eases were still separable from it without much foree. The upper part of the island is a mixture of the same substances in a loose state with a little vegetable soil ; and is covered with the casuarina and a rariety of other trees and shrubs, which give fond to parroquets, pigeons, and some other birds, to whose ancestors, it is probable, the island was originally indebted for this vegetation."

Captain Beechey, during his expedition to the Pacific in the ship Blossom, eollected a large mass of interesting information respecting the peculiarities of form and structure exlibited by the coral islands. Of thirty-two exanined by lim the largest was thirty miles in diameter, and the smallest somewhat less than a mile. They were of various shapes, and all formed of living coral, exeept one, called Henderson's Island, which was partially surrounded by it. They all appeared to be increasing their dimensions by the active operations of the zoophytes, which are gradually extending their structures, and bringing the immersed part to the surface of the water. Twenty-nine of the number lad lagoons or lakes in their eentres, a proportion sufficiently large to render it highly probable that the remainder also had them in the early period of their formation, and that this is a peculiar structure common to the coral islands. 'The depth of these lagoons is rarious; in some which were entered, it was from twenty to thirty-eight fathoms, but in others, to which no access was gained, it appeared from the light blue colour of the water to be very small. The bases of the lagoons are formed of coral, and are gradually filling up by tle labours of the insects, and by the deposition of sand and zooplyytic substances; so that the lakes will in process of time vanish, and one connected mass of land present itself. At Ducie's Island, the lagoon in the centre was partly enclosed by trees, and owing to the transpareney of the water, the bottom presented a submarine picture of extreme beauty. 'The corallines were of various colours, pink, blue, white, lilae, and yellow ; and numerous small fish of brilliant hues, threading the labyrinths of the eoral branches, or, when alarmed, darting rapidly for shelter into the recesses of the stony thickets, afforded a singularly pleasing and almost kaleidoseopic effect. It is remarkable, that as almost all these islands are situated within the action of the trade winds, tlicy follow one general rule in having their windward sides higher and more protected than the others, and not unfrequently well wooded, while the opposite ones are only halfdrowned reefs, or wholly under water. At Gambia and Matilda islands this inequality was very conspicuous, the weather sides of both being wooded, and of the former inbabited, while the other sides were from twenty to thirty feet under water. It would seem that the coral insects pursued their labours under the guidance of a surprising instinct, apprehending from what quarter danger threatened their structures, and hence ereeting buttresses to oppose the action of the waves impelled by the trade wind. The observations of Captain Horsburgh and other hydrographers upon the coral islands of other seas are in liarmony with the preceding statements, chiefly derived from Captain Beecliey. The 
Chagos Isles in the Indian Ocean are coral formations of a horse-shoe shape opening to the north-west, while the prevailing wind blows regularly from the south-east.

Coraline formations are distributed into the four great classes of lagoon-islands, encircling-reefs, fringing-reefs, and barrier-reefs. 1. Lagoon-islands, to which their Indian name of atolls is generally applied, consist of a belt of coral enclosing a lagoon, or vacant space of the ocean. The belt is usually narrow, and so low, that it would not be perceptible at a trifling distance, but for the palms, cocoa-nuts, and other vegetation established upon it. These formations are variously circular, oval, and irregular in shape; they occur solitary, and in groups, but commonly form elongated archipelagoes, and occupy an immense area of the Pacific Ocean. 2. Encircling-reefs differ only from the preceding class in having one or more islands within the central expanse. Tahiti, the principal of the Society Islands, is a fine example. It rises in mountains to the height of 7000 feet, and is surrounded by a lagoon, like an enormous moat, from half a mile to three miles broad, which is separated from the outlying ocean by a reef of coral. Both in the case of atolls and encircling-reefs, the coral has openings or channels in its circuit, by which ships enter the lagoons, where they find excellent harbourage. 3. Fringing-reefs are mere ribands of coral, enclosing no lagoons, but immediately lining the shores. 4. Barrier-reefs extend in straight lines in front of the shores of a continent or large island, frequently at a considerable distance from the land. The most remarkable example is the great Australian reef. Externally, it starts up with little inclination from a fathomless ocean, stretches upwards of a thousand miles along the north-east coast of Australia, varies in breadth from two hundred yards to a mile, and in distance from the shore from twenty to seventy miles. There are transverse openings by which vessels enter the interior ocean, which is everywhere safely navigable. "The long ocean swell," remarks an observer, "being suddenly impeded by this barrier, lifted itself in one great continuous ridge of deep blue water, which, curling over, fell on the edge of the reef in an unbroken cataract of dazzling white foam. Each line of breaker runs often one or two miles in length, with not a perceptible gap in its continuity. There was a simple grandeur and display of power and beauty in this scene that rose even to sublimity. The unbroken roar of the surf, with its regular pulsation of thunder, as each succeeding swell fell first on the outer edge of the reef, was almost defeaning, yet so deep-toned as not to interfere with the slightest nearer and sharper sound. Both the sound and sight were such as to impress the spectator with the consciousness of standing in the presence of an overwhelming majesty and power." We have here a mound constructed by animals of low organisation, in comparison with which, the great wall of China, or the pyramids of Egypt, or the Plymouth Breakwater, shrink into insignificance, formed, too, amid the waves of the ocean, in defiance of its storms.

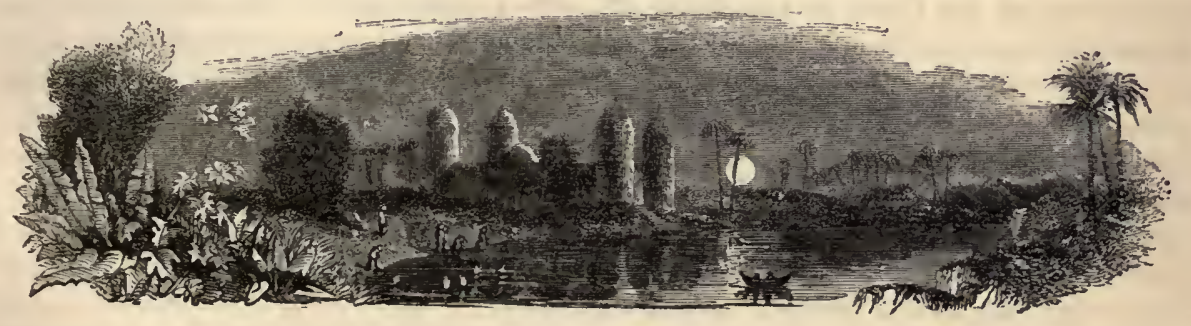




\section{CHAPTER XI.}

ALTERATIONS OF COAST IINE.

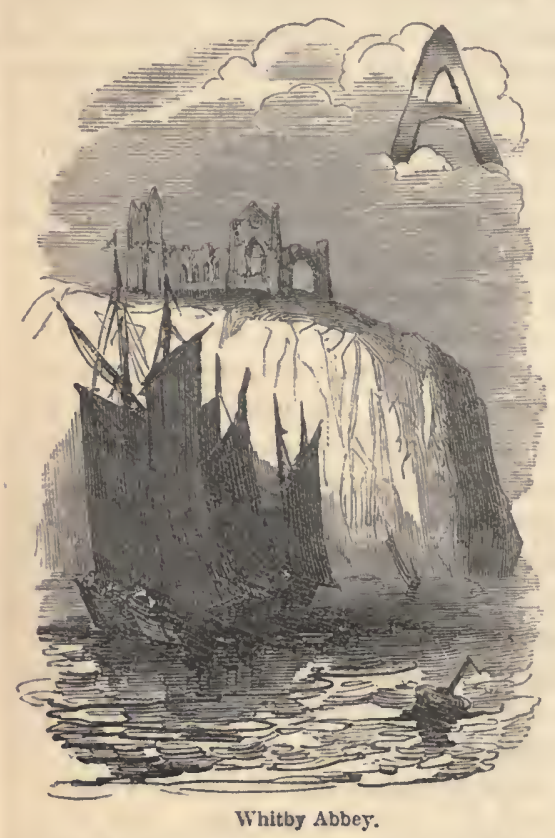

CONFLICT for the mastery is perpetually going on between the sea and the dry land, in the course of which extensive changes are effected in the disposition of the coast, though mutual losses in the struggle are compensated by corresponding gains, so as to leave each of the contending agents in possession of about the same amount of territory. In some places the ocean obtains the superiority by very gradual advances, which only become sensible after long intervals of time, but occasionally, under the action of extraordinary storms, it bounds over the embankments of a low shore, sweeps them away entirely, overflows interior levels, and retains a permanent hold of its conquest. In other places its waters retire before the slow advance of the land, large tracts of which are formed by the constant accumulation of sand or the alluvium of rivers, and the const invades the dominion of the deep, so that where its waves have gently played or wildly raged, a new theatre is created for human industry and the purposes of vegetation. 'The instances in which the sea encroaches in a sudden and violent manner are of rare occurrence; but taking a view of physical operations through several centuries, we find no inconsiderable number of examples of these hasty and terrible inroads. It has frequently happened in earthquakes, that the sea has rushed upon the shores in tremendous waves, dashed away whole masses of coast, and accomplished a lodgement for its floods where fields were verdant, and man had long enjoyed a quiet habitation. During the great earthquake at Lisbon, the water retired from the harbour and left the bar dry, but it suddenly rolled in again in an immense volume, which rose in some places to the height of sixty fect, inundating the western shores of Portugal, and a sea-port called St. Eubal's, about twenty miles south of the Tagus, was engulfed, and totally disappeared. The carthquake which desolated Peru in 1746 was attended with a similar attack upon the land by the ocean. The Pacific broke with resistless fury upon the coast, destroying several sea-ports, carrying ships a considerable distance up the country, and converting a large tract of inhabited land in the neighbourhood of Callao into a permanent bay. A remarkable swell of the sea occurred at Jamaica in 1780 , the effect of submarine disturbance, when a great wave assailed the western coast, and swept away the whole town of Savanna la Mar in an instant, so that not a vestige of man, beast, or habitation survired the irruption. But in 1692 the coast of the island suffered still more extensive ravages from the violence of an earthquake. At Port Royal, then the capital, three quarters of the buildings, and the ground they stood upon, sunk down with their inhabitants entirely under 
water. Large storehouses, erected near the harbour, subsided till they were from twentyfour to forty-eight feet under the level of the sea. Many of the buildings appear to have sunk without falling; for the chimney-tops were afterwards seen projecting, in some instances, above the surface of the water, with the mast-heads of several ships wrecked in the harbour. A frigate - the Swan - which was undergoing repairs at the wharf, was driven over the tops of many of the submerged houses, and at last rested upon the roof of one of them, through which it broke. During the first shock, a tract of land adjoining the town, to the extent of about a thousand acres, was depressed, and the sea immediately rolled in. Such events as these may commend to our attention the ancient accounts of similar catastrophes as substantially true, though invested with fictitious details by the Greek historians and poets - the Ogygian flood, the Samothracian deluge, with

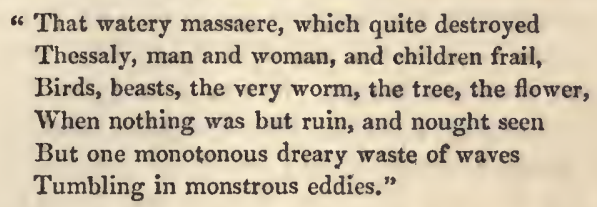

These great disturbances, and the changes that transpire in a more gradual manner, led Aristotle to remark, that the "same tracts of the earth are not some always sea, and others always continents, but every thing changes in the course of time."

Violent tempests, without any submarine convulsions, have frequently brought large portions of the coast under the dominion of the ocean. According to popular tradition, the Goodwin Sands, off the Kentish coast, once formed part of the estate of Goodwin, earl of Kent, which the sea overwhelmed in the year 1099. It is certain that such catastrophes have repeatedly occurred, and our early annalists mention extensive depredations committed by the ocean upon our shores at that time. Florence of Worcester says :- "On the third day of the nones of Nov. 1099, the sea eame out upon the shore, and buried towns and men very many, and oxen and sheep innumerable." The Saxon Chronicle likewise for that year states :- "On St. Martin's-mass day, the 11th of Novembre, sprung up so much of the sea-flood, and so myckle harm did, as no man minded that it ever afore did, and there was the ylk day a new moon." The Goodwin Sands are now separated from the coast of Kent by the well-known roadstead of the Downs, a channel which is from three to six miles wide. It has been a common impression that they possess an ingurgitating property, so that ships striking on them are very speedily swallowed up; but the sand, which rests on blue clay, is found to be of the same quality with that on the shore about Deal; and, all circumstances considered, there is nothing improbable in the idea, that in the Saxon age this large bank, which is completely covered at high water, was either a cultivated island, or an integral portion of the neighbouring county. An obscure tradition likewise floats about Cornwall, that the western extremity of that county once extended farther than at present, and that a tract of country, called, according to Camden, Lionnesse, which the sea has washed away, anciently connected the Scilly Islands with the mainland, and formed part of the territory of the renowned King Arthur and his valorous knights. Although there is no evidence for this story, it may yet be deemed not unlikely, when we consider the general violence of the sea in that region, and the changes which have transpired there within the period of authentic history, and are still in progress. The Scilly Islands, though consisting chiefly of granitic rock, are at present slowly yet surely wasting away, owing to the rude assaults of the billows of the Atlantic, while an insulated rock, called the Wolf, lies between them and the main, composed of limestone, which yields more readily to the action of the waves, and may be a surviving fragment of the destroyed Lionnesse. Some Cornish writers suppose the Bay of Pen- 
zance, in which the striking insulated rock of St. Michael's Mount occurs, to have once been a part of the mainland of Cornwall, submerged by a violent inroad of the ocean. The surface of the rock is every where covered by long hoary moss, which gives it a venerable ruin-like appearance, and perhaps originated the name it is said to have borne in the time of the Druids - the "Hore Rock in the Wood." 'There is evidence, which deserves attention, that the wide expanse of sea surrounding the rock at high water was, in ancient times, the site of a wood; and the Mount itself is believed to have been distant five or six miles from the former shore. At low water, many large trees have been dug up from the surrounding sands, which the miners regard as monuments of the vegetation of the antediluvian world. But the druidical name indicates that these trees were flourishing here at a comparatively recent period: and the freshness and preservation of some of them support the conclusion; for, besides the roots and trunks of large forest-trees, there are many small bushes with leaves and nuts upon their branches, which appear to have been growing where they are found. It has been inferred, from the circumstance of ripe nuts and leaves remaining together, that a sudden irruption of the sea must have taken place in autumn, which submerged this woodland district, and has since buried the vegetation beneath a bed of sand from one to two feet in thickness. In the time of Edward the Confessor, the rock of St. Michael's Mount was the site of a monastery, described as being near the sea; and as the storm of 1099, mentioned in the Saxon Chronicles, occurred in the autumn, the submersion of the district has been referred to that inundation. A series of more authentic notices of extensive inroads of the sea when agitated by storms upon the coast of Sussex, occurs in Dr. Mantell's account of the geology of that county. Within a period of no more than eighty years, twenty of these invasions are mentioned, in which tracts of land of from twenty to four hundred acres in extent have been swept away at once, the value of the tithes being mentioned by Nicholas in his Taxatio Ecclesiastica. Brighton, when a mere fishing village, in the reign of Elizabeth, stood upon a site where the sea now rolls, and the chainpier stands.

The more important of these sudden and terrible actions of the sea, since the eighth century, are mentioned in chronological series in the following table, taken from the work of M. Hoff, with some additions from other sources.

Years.

800. The sea carries off a large quantity of the soil of Heligoland, islands in the German Ocean, off the mouth of the Elbe, previously of considerable extent, but subsequently much reduced.

800-900. Tempests change the coasts of Brittany: valleys and villages are swallowed up. The Bretons have a tradition, which has descended from the fabulous ages, of the destruction of the south-western part of Brittany.

800-950. Violent storms agitate the lagunes of Venice. The isles of Ammiano and Costanziaco disappear.

1044-1309. Terrible irruptions of the Baltic on the coasts of Pomerania, which commit great ravages, and give rise to the popular rumour of the disappearance of the fabulous city of Vineta.

1106. Old Malamocea, a considerable town near Venice, engulfed by the sea.

1218. A great inundation formed, near the mouth of the Weser, the gulf of Jadhe, so named from the small river which watered the fertile country destroyed by this catastrophe.

1219, 1220. Terrible storms form the island of Wieringen. This lies to the south of 
Years.

1221, 1246. the Texel, and was part of the mainland of North Holland in the year 1251. 1205. It was detached from the continent by the high floods which occurred in the annexed years.

1277 , 1278, Inuudations engulph the fertile country of Reiderland, an alluvial plain 1280, 1287. at the mouth of the Ems in the time of the Romans, stretching between Groningen and East Friesland. Two small streams, the Tiam and the Eche, which watered this district, disappeared. The town of Torum, a considerable place, was destroyed, along with upwards of fifty markettowns, villages, and monasteries. A new gulf, called the Dollart, now occupies their site.

1282. Violent tempests break the isthmus which united Holland with Friesland, and form the Zuider Zee.

1240. An irruption considerably changes the western coast of Schleswig; many fertile territories are swallowed up, and the arm of the sea which separated the island of Nordstrand from the continent is greatly enlarged.

1300, 1500, Three fourths of Heligoland are swept away.

1649.

1300. Ciparum, in Istria, destroyed.

1303. A great part of Rugen engulfed, and many villages on the coast of Pomerania.

1337. An inundation carries off fourteen villages in the isle of Cadsand, in Zealand.

1421. An inundation covers a district named Bergseweld, in Holland, destroys twenty-two villages, and forms the Bies-bosch, a large sheet of water extending from Gertruidenberg to the isle of Dordrecht.

1475. Land near the mouth of the Humber swept away, and several villages destroyed.

1500. The parish of Bourgneuf, in Brittany, and several others in that neighbourhood, overflowed.

1510. The Baltic forms the mouth of the Frisch-haff.

1530-1532. The sea engulfs the town of Kortgene, in the island of North Beveland. In the latter year the eastern portion of South Beveland is carried away, with several villages, and the towns of Borselen and Remerswalde.

1570. A violent storm destroys half of the village of Scheveningen, north-west of the Hague. The church, once in the middle of the village, now stands on the shore.

1625. The sea detaches part of the peninsula of Dars, in Swedish Pomerania, and forms of it the island of Zingst.

1634. An irruption submerges the whole island of Nordstrand, a large and populous district, which had originally been a part of the continent, and detached by a previous inroad of the waters. On the evening of the 11th of October, 1634, the sea broke over it, destroying 1358 houses, churches, and towns, 50,000 head of cattle, and upwards of 6000 persons. There now remains of this once flourishing and fertile island, the three islets named Pelworm, Nordstrand, and Lütze-moor.

1658. The island Orisant annihilated.

1719. Land torn away at Catwyck, which, though once far from the sea, is now upon the shore. 
Years.

1726. A violent storm changes the salt marslı of Araya, in the province of Cumana, into a gulf sereral leagues wide.

1770-1785. Currents and tempests hollow out a channel between the high and the low parts of Heligoland, and transform into two islets this island, so extensive before the eighth century.

1784. A violent storm, according to M. Hoff, forms the lake of Aboukir, in Lower Egypt.

1791-1793. New irruptions destroy the dykes, and carry off other parts of the already reduced island of Nordstrand.

1803. 'The sea sweeps away the last remains of the priory of Crail, in Fifeshire.

The most remarkable alteration of the coast line mentioned in this record, as the effect of a sudden invasion of the ocean, is that which originated the present Zuider Zee, or the South Sea, so called to distinguisl it from the North Sea, or German Ocenn, a great gulf dividing Friesland, Drenthe, and Gelderland from Holland and Utrecht. This gulf covers an area of about 12,000 square miles, and is about twice the size of the county of York. It was not in existence in the time of the Romans, but a low swampy marsh occupied its place, drained by the river $Y_{\text {ssel. In this district there were several }}$ lakes, particularly the great lake Flevus, mentioned by Tacitus and Pomponius Mela. The former relates the arrival at it of the Roman fleet under Germanicus, through the canal of Drusus, an artificial branch connecting the Rhine and the Yssel. No material change appears to have occurred here before the commencement of the thirteenth century. Then the sea broke over the isthmus which connected Friesland with North Holland, ultimately cut it away, forming the present Straits of Staveren. The lake Flevus was absorbed, a considerable portion of the surrounding country was submerged, and the Zuider Zee was constructed by the advance of the ocean in the form and depth which it still preserves. If, as the Persic verses affectingly state, describing the transitory nature of human greatness,

"The spider has wove his web in the imperial palace,

And the owl hath sung her watch-song on the towers of Afrasiab,

it is no less true that the features of nature lave alternated as strikingly, marine inhabitants sporting in sites where land animals have roamed in sylvan scenes; and we may fairly accept these changes, which are known to have transpired since the date of authentic history, as samples of the revolutions that occurred at a more remote period, of which no clironicle has been preserved. It has been supposed, that as the Straits of Staveren were closed prior to the thirteenth century, the sea then cutting its way through the isthmus, so were the Straits of Dover once occupied by. an isthmus, connecting the eoasts of England and France, which a violent irruption of the ocean partially destroyed, and then gradually scooped out the present channel. There is nothing contrary to the analogy of undoubted physical events in this supposition, and it is supported by some striking evidence. Desmarest argued in its favour from the identity of the cliffs in composition on each side of the channel, from the fact of a submarine chain running from Boulogne to Folkestone only fourteen feet under low water, and from the circumstance that the same noxious animals are common to both countries, which could never have themselves effected the passage of the straits, and which man would not have introduced.

The bolder coasts seem to present an impregnable front to the attack of storms and tempests, both by their leight and the rocky materials of which they are composed; yet, however they resist the farther progress of the waves, when the sea, swollen by tides, 
and agitated by the blast, rises and beats against them with inconceivable fury, the continual action of the water slowly consumes their masses. The perpetual play of waves, tides, and currents gradually wastes away the base of towering cliffs; and when this process of undermining has reached a certain extent, the upper parts, deprived of support, fall down, and, after their destruction, a fresh attack commences upon the coast line. This demolition proceeds at a varying rate, according to the hardness or yielding nature of the material that forms the shore. The granite rocks endure for centuries the wear and tear of the ocean with but little loss, while the limestone and chalk cliffs are more easily subdued. The chalk cliff at Dover has suffered large and repeated losses since Shakespeare wrote the notice of it in King Lear:-

" The crows and choughs that wing the midway air Show searce so gross as beetles. Half-way down

Hangs one that gathers samphire; dreadful trade!

Methinks he seems no bigger than his head:

The fishermen that walk upon the beach

Appear like mice; and yon tall anchoring bark,

Diminished to her boat - her boat, a buoy

Almost too small for sight. The murmuring surge,

That on th' unnumber'd idle pebbles chafes,

Cannot be heard so higb:-I'll look no more,

Lest my brain turn, and the deficient sight

Topple down headlong."

Immense fragments have frequently fallen from this cliff, owing to the undermining of its base, some of which have shaken the neighbouring town as by an earthquake, and the height of the cliff has been considerably abridged by these detachments, the slope of the hill being towards the land. The slipping down of large masses of steep coast is a phenomenon due to the same cause-the loosening of the foundations by the incessant

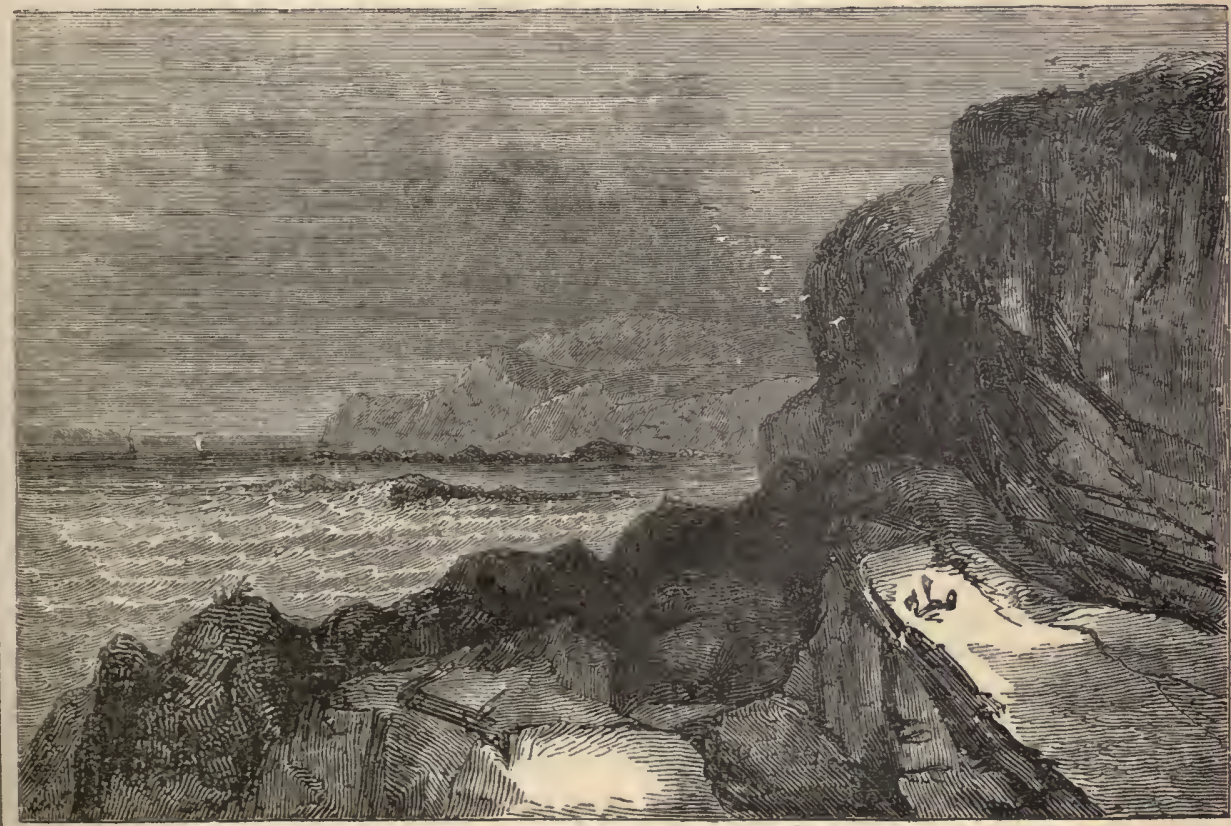

Undercliff, Isle of Wight. 
assaults of the ocean upon it, in connection with the action of springs, which filter through, displace the softer strata, and leave the more solid formations destitute of support. The Undercliff in the Isle of Wight, a series of terraces, some of which have been long settled, while others are more recent and ruinous, is an example of these landslips. They occur upon a grand scale along the coast of the Crimen, where extensive tracts of the shore are often dislodged, sinking down as they slide forwards, sometimes bearing with them the trees, and the houses of the natives, uninjured. $\Lambda$ slip of this kind took place at Folkstone, on the coast of Kent, about the year 1716, when a solid mass of chalk resting on clay moved gradually towards the sea, "just as a ship is launched on tallowed planks;" and part of the promontory of Beachy Head, three hundred feet in length, in a similar manner gave way in the year 1813. Hutchins records a memorable slide in his History of Dorsetshire, which happened on that shore in 1792 :- " Early in the morning the road was observed to crack. This continued increasing, and before two o'clock the ground had sunk several feet, and was in one continual motion, but attended with no other noise than what was occasioned by the separation of the roots and brambles, and now and then a falling rock. At night it seemed to stop a little, but soon moved again, and before morning the ground, from the top of the eliff to the water-side, had sunk in some places fifty feet perpendicular. The extent of ground that moved was about a mile and a quarter from north to south, and six hundred yards from east to west."

Electricity - the action of ordinary atmospheric changes - the incessant percolation of springs - the violent, and more gentle yet constant dash of the waves - these are causes which operate to dislodge the masses from a rocky coast which are found lying in chaotic confusion upon many a beach, doomed finally to decay from the still continued influence of some of the agencies that liave effected their disruption, but undergoing great annual changes in their disposition when situated upon an exposed shore. In the Shetland Isles, upon which the Atlantic bears with unchecked power, enormous blocks are every winter shifted by the might of its waves, and sometimes transported to a considerable distance, even up the slope of an acclivity. "The Isle of Stenness," says Dr. Hibbert, "presents a scene of unequalled desolation. In stormy winters, huge blocks are overturned, or are removed from their native beds, and hurried up a steep acclivity to a distance almost incredible. In the winter of 1802 , a tabular-shaped mass, eight feet two inches by seven feet, and five feet one inch thick, was dislodged from its bed, and rernoved to a distance of from eighty to ninety feet. I measured the recent bed from which a block had been carried away the preceding winter (1818), and found it to be seventeen feet and a half by seven feet, and the depth two feet eight inches. 'The removed mass had been borne to a distance of thirty feet, when it was shivered into thirteen or more lesser fragments, some of which were carried still farther-from thirty to one hundred and twenty feet. A block, nine feet two inches by six feet and a half, and four feet thick, was liurried up the acclivity to a distance of one hundred and fifty feet." Speaking of the island of Roeness, he states: "A mass of rock, the average dimensions of which may perhaps be rated at twelve or thirteen feet square, and four and a half or five in thickness, was first moved from its bed, about fifty years ago, to a distance of thirty feet, and has since been twice turned over. But the most sublime scene is where a mural pile of porphyry, escaping the process of disintegration that is devastating the coast, appears to have been left as a sort of rampart against the inroads of the ocean; the Atlantic, when provoked by wintry gales, batters against it with all the force of real artillery, the waves having, in their repented assaults, forced themselves an entrance. This breach, named the Grind of the Navir, is widened every winter by the overwhelming surge that, finding a passage through it, separates large stones from its sides, and forces them to a distance of no less than one hundred and eighty feet. In two or three spots, the fiagments which have been 
detached are brought together in immense heaps, that appear as an accumulation of cubical masses - the product of some quarry." We have other examples of the resistless power of the element, in the hollowing out of eaverns in the rocks exposed to a boisterous sea, and in the fretted and columnar appearance of promontories. Some fine instances occur in the Flamborough chalk cliffs, the Filey Bridge rocks, and those of schistus near Whitby, in the latter of which the cave called Hob-Hole lad some years ago a most romantic appearance, having a double pillar in the middle of the entrance. But these aspects are destined to undergo further change, by the continuous agency of the cause which has produced them. The pillar in Hob-Hole has been demolished by the waves,

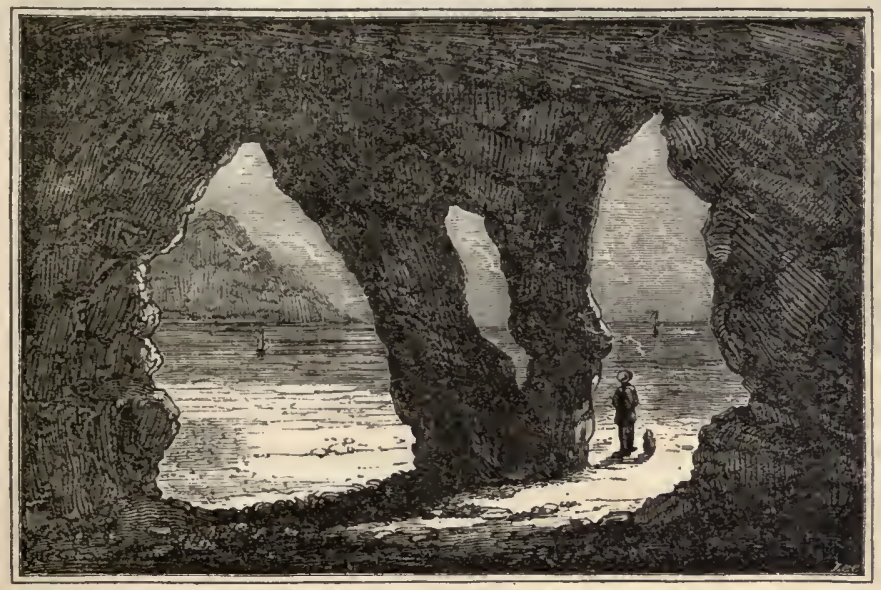

Hob-Hole, Whitby. but the cavern is still seventy feet long by twenty wide at the mouth. There are groups of insulated rocks, which have evidently been one connected mass, separated into fragments of fantastic and needleshaped form, while others have been parted from neighbouring coasts, by the constant lashing of the ocean. The Arched Rock in the Bay of Freshwater, off the Isle of Wight, and several insulated masses in its vicinity, plainly bespeak their original connection with the cliffs on shore, though now six hundred feet from them, the perforation of the former having been effected by the same devastating power to which the detachment of the rock itself from the parent island is to be attributed. In the same district, there can be no doubt that the five rocks called the Needles once formed the western extremity of the island, and have been insulated from it and from each other, and reduced to their present shape and size, by the fury of the waves. Though now of considerable extent and altitude, their ultimate fate is not questionable, the original Needle or spiral rock which gave the name to the group, and which was 160 feet high, having vanished below the surface of the water in 1764, in consequence of the undermining of its base. Since the year 1770, a current has cut a passage through the remaining portion of Heligoland, once a celebrated stronghold of the Saxons, but largely reduced by the sea during the middle ages, and ships now sail between the two islands into which it has been formed. The formation of Start Island out of the north-east promontory of Sanda, one of the Orkneys, divided by the sea, is an operation of modern times; and appearances indicate that the Isle of St. Mary - one of the Scilly group - will, in no long course of time, be cut in two.

The authentic details which have been collected respecting the gradual waste of several parts of our own coast, are of singular interest, and exhibit a large amount of land swept away by the encroachments of the ocean. The Castle of St. Andrews, on the coast of Fife, had in Cardinal Beaton's time a tract of land intervening between it and the sea; but this has entirely disappeared, with some of the ruins of the castle, the rest of its remains, standing on the edge of a cliff, serving as a landmark for seamen. Mr. Stevenson, an engineer, states, that from St. Andrew's northward to Eden Water and the river Tay, the coast presents a sandy beach, and is so liable to shift, that it is difficult to trace 


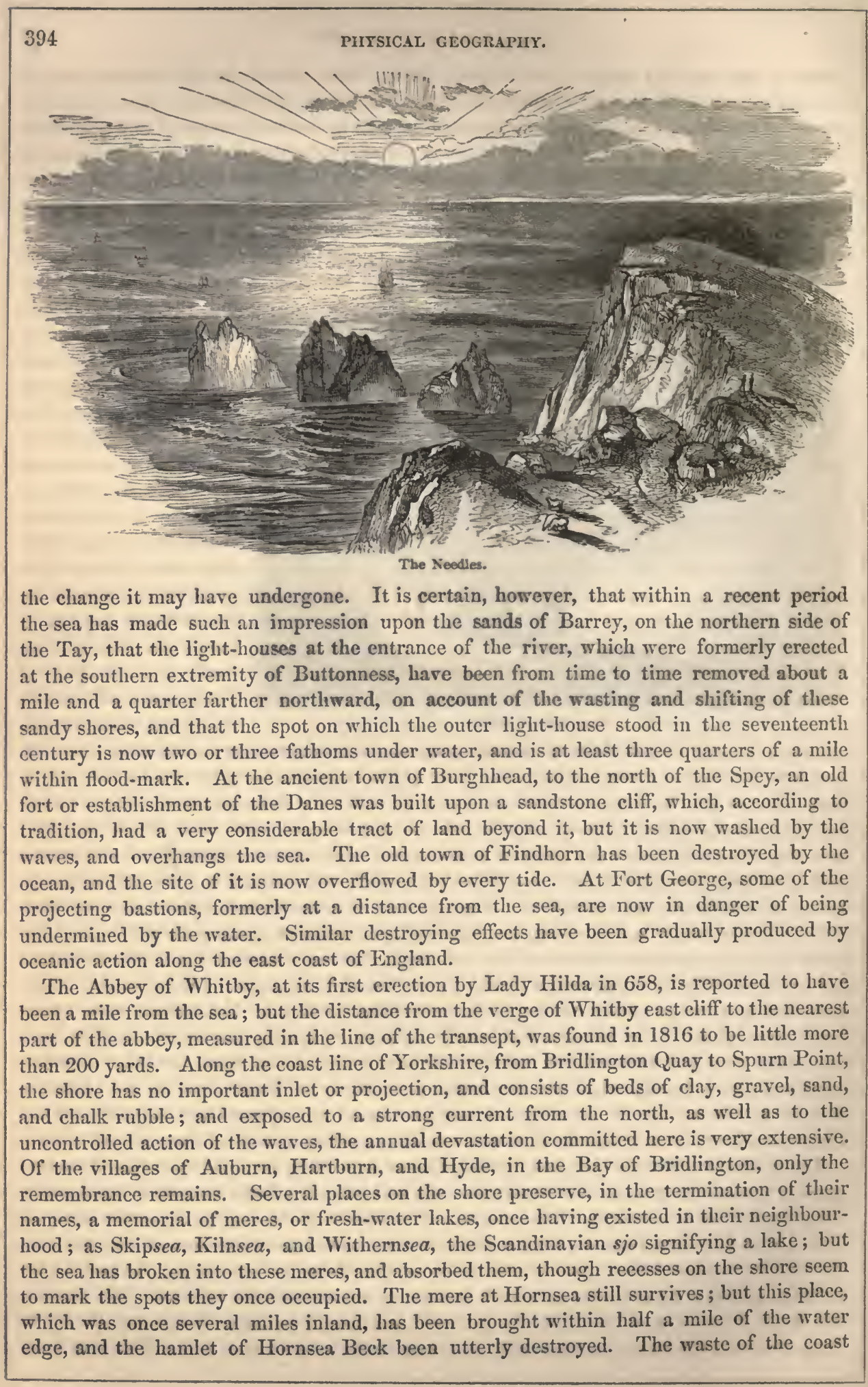


amounts to about four yards a year; and farmers may be met with who have witnessed the corn wave where the sea now prevails. The depredations of the ocean towards Spurn Point, at the entrance of the Humber estuary, have been still more considerable; nor is it unlikely that the Point will ere long become an island. Ravenspur-with the latter part of which word the name Spurn seems to be connected, an important place in this locality - has long since been lost, with a number of other places in the vicinity, belonging to Birstal Priory; and the site of the priory itself has been totally swept away. Pennant remarks: "The site, and even the very names of several places, once towns of note upon the Humber, are now only recorded in history; and Ravenspur was at one time a rival to Hull, and a port so very considerable in 1332, that Edward Baliol and the confederated English barons sailed from hence to invade Scotland; and Henry IV., in 1399, made choice of this port to land at, to effect the deposal of Richard II. ; yet the whole has long since been devoured by the merciless ocean : extensive sands, dry at low water, are to be seen in their stead."

Sir C. Lyell makes a remarkable statement respecting Sheringham, on the coast of Norfolk: "I ascertained, in 1829, some facts which throw light upon the rate at which the sea gains on the land. It was computed, when the present inn was built, in 1805 , that it would require serenty years for the sea to reach the spot, the mean loss of land being calculated, from previous observations, to be somewhat less than one yard annually. The distance between the house and the sea was fifty yards; but no allowance was made for the slope of the ground being from the sea, in consequence of which the waste was naturally accelerated every year, as the cliff grew lower, there being at every succeeding period less matter to remove when portions of equal area fell down. Between the years 1824 and 1829, no less than seventeen yards were swept away, and only a small garden was then left between the building and the sea. There is now a depth of twenty feet sufficient to float a frigate - at one point, in the harbour of that port, where, only fortyeight years ago, there stood a cliff fifty feet high, with houses upon it. If once in half a century an equal amount of change were produced at once by the momentary shock of an earthquake, history would be filled with records of such wonderful revolutions of the earth's surface; but, if the conversion of high land into deep sea be gradual, it excites only local attention. The flag-staff of the Preventive Service station, on the south side of this harbour, has, within the last fifteen years, been thrice removed inland, in consequence of the advance of the sea."

Dunwicl, on the coast of Suffolk, a small village containing about twenty houses and a liundred inhabitants, was once one of the most important places upon our eastern shores, and has been reduced to its present insignificance by the aggressions of the sea. While East Anglia subsisted as a separate kingdom, it was the seat of the first East Anglican bishopric, which may be considered as the predecessor of that now fixed at Norwich. Two tracts of land which were taxed in the time of Edward the Confessor, had been devoured by the ocean when the Doomsday survey was made. Ray states, that ancient writings make mention of a wood a mile and a half to the east of the place, the site of which must at present be so far witlin the sea, as it subsequently invaded the town. At different periods a monastery has perished, seven churches, the old port, four hundred houses at once, the town hall and gaol; and coffins and skeletons have been exposed to view in its cliffs, as the waves have reached its churchyards. A scene depicted in one of Bewick's cuts, described in the following terms by Sir C. Lyell, might have been suggested by the fate of Dunwich: "On the verge of a cliff, which the sea has undermined, are represented the unshaken tower and western end of an abbey. The eastern aisle is gone, and the pillars of the cloister are soon to follow. The waves have almost isolated the promontory, and invaded the cemetery, where they have made sport with the mortal 
relics, and thrown up a skull upon the beach. In the foreground is seen a broken tombstone, erected, as its legend tells, to 'perpetuate the memory' of one whose name is. obliterated, as is that of the county for which le was 'Custos Rotulorum.' A cormorant is perched on the monument, defiling it, as if to remind some moraliser like Hamlet of the 'base uses' to which things sacred may be turned. Had this excellent artist desired to satirise certain popular theories of geology, he might have inscribed the stone to the memory of some philosopher who taught 'the permanency of existing continents' - 'the era of repose' - 'the impotence of modern causes.' " The most eastern point of Essexthe Naze-was formerly extended much further to the east, as the ruins of buildings have been found at considerable distances from land. 'The cliffs, composed of London clay eapped with crag yielding fossils, have been gradually worn away, probably from a shoal called West Rock, which is now five miles from the shore. Upon the coast-line of Kent large inroads have been made, and are proceeding with undiminished rapidity. About the North Foreland - the promontory Acantium, 'Axávrıov ákpov of Ptolemy-the chalk wastes, upon an average, at the rate of two feet per annum; and at Reculver, to the west of the Isle of 'Thanet, the sea has made extensive depredations. The ancient church here, now dismantled - a well-known sea-mark in the centre of a Roman station - is on the verge of the cliff; but in the middle of the last century there was some considerable space intervening between the northern boundary of the churchyard and the shore. In the time of Henry VIII. the church was nearly a mile inland; and the Roman town of Regulbium is supposed to have occupied a site to the north of the station now undermined and washed away. Another century can scareely elapse without witnessing the entire demolition of the place.

These instances are sufficiently illustrative of the fact that the physical outline of our coast has suffered largely by depredation from the sea, as the effect both of its occasional violent action in storms, and the milder but incessant play of its waters; and if we pass to other consts exposed to the influence of ligh tides and strong currents, precisely similar devastations occur. It has been found, by observations made between 1804 and 1820 , that, in the intervening sixteen years, the average advance of the ocean on the north side of Delaware Bay, in the United States, amounted to above nine feet per annum, while in three years, towards the close of the last century, no less than a quarter of a mile of land was carried away from Sullivan's Island, near the entrance of the harbour of Charlestown. But if at various points the influence of the sea diminishes the mass of land by eneroachment upon its coast, there are other points where compensation is made by the growth of the land, through the silting up of the sand of the ocean, or the deposition of the sediment of rivers ; and the case is common for the coast line to be changing by aggression and addition in the same neighbourhood. Within the times of history new land has been formed in the estuary of the Humber, along the Lincolnshire shore, that of Norfolk, Kent, and Sussex, where, in the latter county, the rich level of Romney Marsh has been largely augmented. Dover is situated at the opening of a deep valley, formed by a depression in the chalk, which runs into the interior for several miles, and is the basin of a small stream. It would appear from the account of Cæsar's first advance to the coast, that the sea then occupied the present site of the town, and advanced to some distance up the valley, from which it las subsequently been expelled by the gradual accumulation of sand and shingle washed up by the tide. In digging for the foundation of houses corroborative evidence of this fact appears in the character of the soil, while at the present, the sea threatens to block up the existing harbour by the amount of debris it heaps together at its mouth. A similar but more extensive ehange has taken place at Norwich, which, in the time of the Saxons, was situated on the banks of an arm of the sea, an estuary which has 
since become a region of cultivated fields. In the Gulf of Bothnia several maritime sites have become inland, islands have been joined to the eontinent, and sunk slips have been found below the soil of Pomerania.

The chief examples of the advance of coasts are found where the sea throws up sand, and large rivers bring down alluvial matter, thus, in the language of Cuvier, creating provinees, and even entire kingdoms, which usually become the richest and most fertile regions if their rulers permit human industry to exert itself in peace. These two sauses have been in operation at the mouth of the Nile, and there accessions have been made to the coast of Lower Egypt, though not, perhaps, to such an extent as has been frequently stated, at least within the historical period. "Egypt," says Herodotus, "like the Red Sea, was once a long narrow bay, and both gulfs were separated by a small neck of land. If the Nile," he adds, "should by any means have an issue into the Arabian Gulf, it might choke it up with earth in twenty thousand, or even, perhaps, in ten thousand years; and why may not the Nile have filled with mud a still greater gulf in the space of time which has passed before our age?" This observation proves that it was a wellascertained fact in the time of the historian that the habitable surface of the country was receiving additions from the alluvium of the river; but the poriod when its delta may be supposed to have been a gulf of the sea is of a date long anterior to that of the

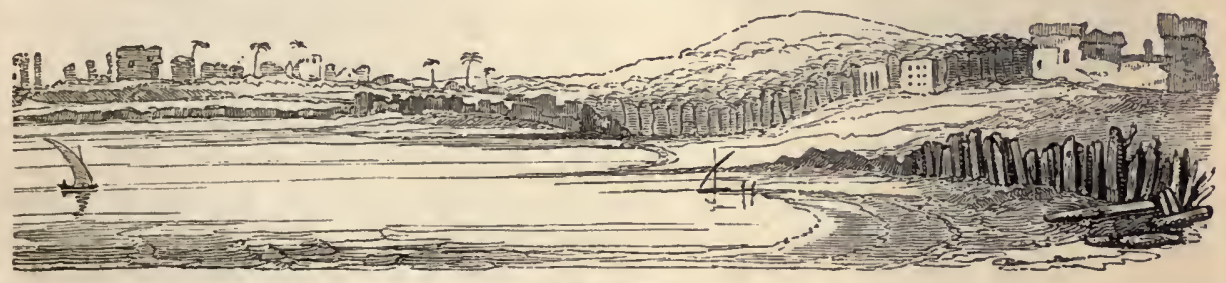

Bay of Alexandria.

earliest Pharaohs of whom any record remains, in whose time the whole of Lower Egypt seems to have been densely inhabited. Still there is evidence of great changes having occurred in the form of the delta, and of its protrusion to some extent, within the age of history. The modern Alexandria is built near the site of the ancient eity, upon a narrow tongue of land, which has been formed by the sand thrown up by the sea, and the continual deposition of alluvial matter. Mareotis, a lake of six leagues in length, in the time of Strabo, about the commencement of the Christian era, has been reduced to nothing by the accumulation of debris. Thamiates, the old Damietta, was on the sea, and possessed a good harbour under the Byzantine emperors, but its scanty remains are now about two miles from the shore. Pharos, an island in the time of Homer, has long been a part of the continent. It is certain, therefore, that within the last two thousand years the coast of Lower Egypt has been advanced as well as considerably modified, but at present it seems asecrtained that no extension of the shore is going on, for having reached the general coast-line of the Mediterranean, the current which sweeps along the north of Africa receives the alluvium of the Nile, and bears it away to a foreign region. The direction of this current is from the straits of Gibraltar to the shores of Syria and Asia Mlinor, where large tracts of new land have been formed, to which the material brought down by the Nile from the highlands of Ethiopia, and drifted eastward by the current, may now be contributing. Since the first Greek colonists occupied the coasts of Asia Minor, important additions have been made to them, the combined effect of oceanic deposition and of the sediment conveyed from the interior country by numerous streams. Strabo remarks upon the gain of land on the southern shore, and Captain Beaufort has 
pointed out great changes by the accession of soil since the era of that geographer, by which havens have been filled up, islands joined to the continent, and the coast line advanced several miles into the ancient territory of the sea.

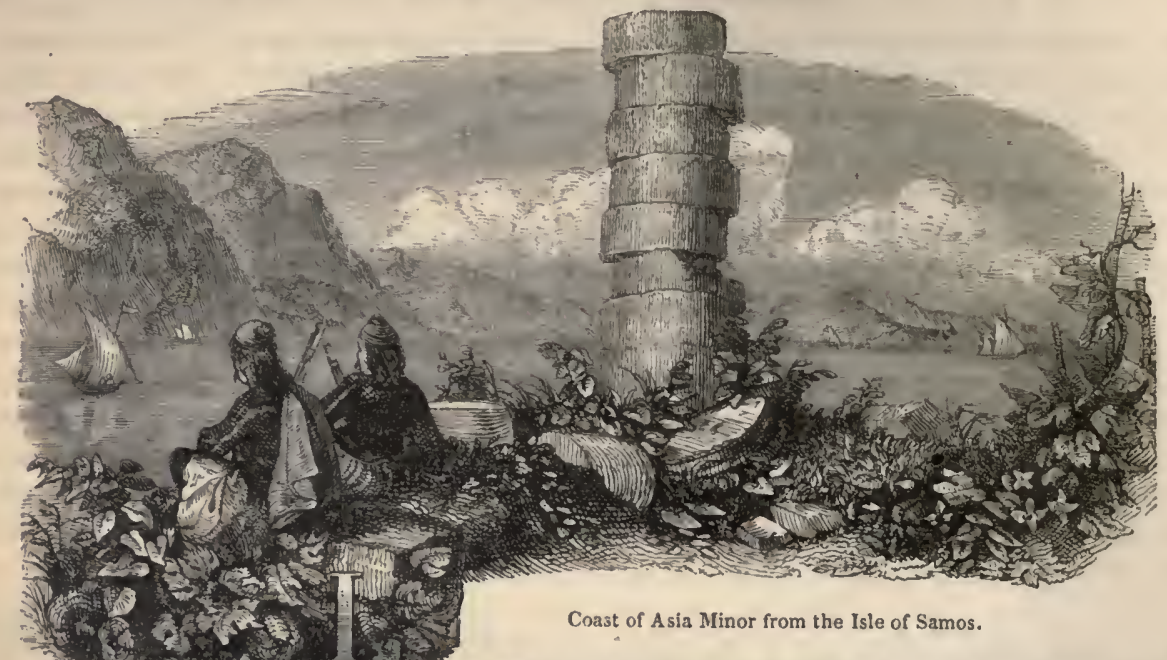

$n$ the same manner extension has taken place on the western coast, though there is no foundation for the speculation of Dr. Chandler, that Samos will join the mainland, unless some great convulsion should elevate the bed of the sea, and cleck the force of the current. The Meander was anciently noted for the production of new land, so that the sophist affirmed, thougl with characteristic exaggeration, that the river liad taken the sea from the navigator, and given it to the husbandman to be divided into ficlds; that furrows were seen in the place of waves, and kids sporting in the room of dolphins; and that, instead of hearing the hoarse mariner, you were delighted with the sweet eclio of the pastoral pipe. The river was indictable for removing the soil when its margin fell in, and the person who recovered damages was paid from the income of the ferries. At the sitc of Ephesus a similar alteration has transpired. The branch of the sea which formed the port is now a vast morass, overgrown with trees and brushwood. The mud of the Cayster has propagated new tracts of soil, and the ocean has been driven back by the augmented plain two or three miles from its former boundary, so that a visitor to the ruins of the city now, destitute of previous information, would never suppose it to have had at any time a free communication with the sea.

The detritus, transported by the affluents of the Rhone from the Alps of Dauphiny and the mountains of Central France, has contributed to an augmentation of the land at the mouth of the river, so that its arms liave become longer by three leagues since Gaul was a Roman province, and many places once situated by the sea are now removed several miles from it. Sir C. Lyell cites from M. Hoff some striking proofs of the accession made to the delta of the Rhone during the period embraced by the annals of history. Mese, described under the appellation of Mesua Collis by Pomponius Mela, and stated by him to be nearly an island, is now far inland. Nôtre Dame des Ports, also, was an harbour in 898 , but is now a league from the shore. Psalmodi was an island in 815 , and is now two leagues from the sea. Several old lines of towers and sea marks occur at different distances from the present coast, all indicating the successive retreat of the sea, for each line has in its turn become useless to mariners, the tower of Pignaux, erected on the 
shore no farther back than the year 1737, being already a French mile from it. At the mouth of the Tiber an increasing delta has, since the classical times, forced the waters three miles back from Ostia; and the watch-tower of San Michele, built on the sea-side in the middle of the sixteenth century, is already nearly a mile inland. The water which the Tiber receives from the volcanic district around Rome, particularly from the lake of the Solfatara, lolds an abundance of carbonate of lime in solution, and precipitates immense quantities of travertin, a circumstance which may contribute to the rapid formation of new land at its mouth. Sir Humphry Davy placed a stick in this lake, and after an immersion of nearly a year he had some difficulty in breaking with a hammer the mass of travertin which adhered to it, and which was several inches in thickness. Referring to the high temperature of the Solfatara, and to the quantity of carbonic acid it contains,

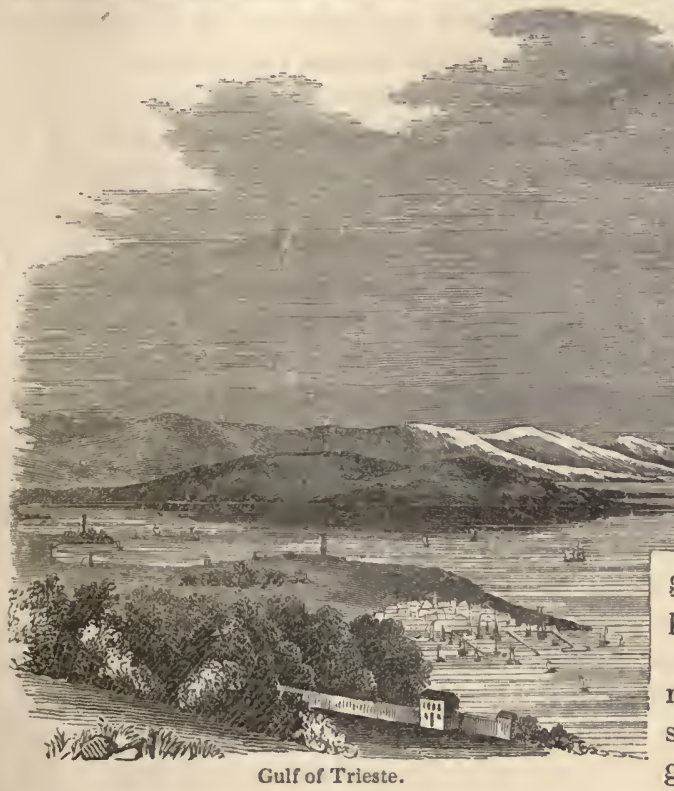
favouring regetation, as well as to its rapid deposition of calcareous matter, he states:"There is, I believe, no place in the world where there is a more striking example of the opposition or contrast of the laws of animate and inanimate nature, of the forces of inorganic chemical affinity, and those of the powers of life."

Along the banks of the Adriatic, for more than a hundred miles, from the south of Ravenna to the head of the gulph of Trieste, the land, receiving during the last two thousand years constant accessions from the matter carried down by the rivers, as well as from that thrown up by the ocean, has encroached on the sea to a breadth nowhere less than two miles, and in some places amounting to twenty. The Isonzo, Tagliamento, Piave, Brenta, Adige, and Po, drain one side of the Alps and of the Apennines, and carry away a vast quantity of their material, the deposition of which has wrought surprising changes in the outline of the coast. Ravenna, once a sea-port, is now five miles from the water side. In the intervening space, traversed by vessels in ancient times, is the Pineta, or forest of pines, in which Dante, Boccaccio, Dryden, and Byron have wandered, and rendered famous.

" Sweet hour of twilight ! - in the solitude Of the pine forest, and the silent shore,

Which bounds Ravenna's immemorial wood,

Rooted where once the Adrian wave flow'd o'er,

To where the last Cæsarian fortress stood,

Evergreen forest! which Boccaccio's lore

And Dryden's lay made haunted ground to me,

How have I lov'd the twilight hour and thee ? 
The shrill cicalas, people of the pine, Making their summer lives one ceaseless song, Were the sole echoes, save my steed's and mine,

And vesper bells that rose the boughs along."

Cuvier has given an extract from the researches of M. de Prony on the hydraulic system of Italy, who was employed to remedy the disastrous inundations of the Po, which contains an account of the enlargement of that part of the eoast occupied by its mouth. According to the statement, no exact detail can be given of the successive progress of the changes, and more especially of their precise measures, during the ages which preceded the twelfth century of our era. One fact however is certain, that Adria, which gives its name to the Adriatic, a confederate city of the Romans, and a municipium, was a sea-port town, between the mouths of the Po and the Adige, and a station for the Roman fleet under the emperors. This eity has a modern representative upon the old site, and by this we not only attain a known fixed point upon the primitive shore, but the means of measuring the extent of alteration that has occurred. The following results have been clearly established: that in the twelfth century the shore had been already removed to the distance of 9000 French metres, or between five and six miles, from Adria; that by the sixteenth century, or in four hundred years, it had been extended farther to the medium distance of 18,500 metres, or nearly eleven miles and a half, giving from the year 1200 an average yearly increase of the alluvial land of 25 metres, or rather more than 27 yards; that by the present century it had advanced to near 33,000 metres, or about twenty miles, whence the average annual progress is about 70 metres, or $76 \frac{1}{2}$ yards, during the last two hundred years, being greatly more rapid in proportion than in former times. The precise date cannot now be ascertained when the waves of the Adriatic washed the walls of Adria, but they certainly did in the time of Augustus, and the nearest part of the present coast, at the mouth of the Adige, is at the distance of fifteen miles and a half, while the extreme point of the alluvial promontory formed by the Po is upwards of twenty miles. In consequence of the melting of the snows in the Alps, the Po is periodically flooded in the summer months, and its inundations, now guarded against by immense embankments, have in past ages raised the level of the country subject to them, by the deposition of alluvium, especially towards the sea-coast. The level of its own bottom has, at the same time, been so much raised, that the surface of its waters is now higher than the roofs of the houses in Ferrara, and both the Adige and the Po are higher than the whole tract of country between them, which would be invaded by their waters but for the artificial bulwarks constructed along their course. In the same manner the delta of the Nile has been altered by elevation as well as extension, the cultivated soil having increased vertically seven or eight feet since the time of the Ptolemies, at the rate of about four inches in a century, the bed of the river rising in proportion.

Where the sea acts alone upon a low coast, without the aid of rivers, considerable alterations are effected in its line and aspect, but of a far less beneficial nature than those just noticed. If the bottom is sandy, the waves then drive the sand towards the shore, which becoming partially dry at every reflux of the tide, a certain quantity is heaped up on the beach by the action of the wind. Around stones, bushes, and tufts of grass, the sand accumulates, and becomes a continuous ridge where these arresting obstacles are contiguous, or where they are thinly scattered, a number of small hillocks are produced, which increase into mounds of considerable height. These formations are called downs, or dunes, which occupy an immense extent of coast, and frequently penetrate to a considerable distance inland. In situations where the habitual direction of the wind is from the sea, the particles at the surface of the sand hills or ridges are carried forward by it, giving a gradually increased breadth to the downs; but where the wind blows generally 
along the shore, the downs make no progress towards the interior, but are extended coastwisc. From Calais to Dunkirk the coast trends in the direction of the wind, and there the sand cast up by the occan is formed into chains or hills parallel to the shore; but in various parts of the globe, where the conditions are different, it is perpetually drifting inwards, and by this means the cultivable soil has been largely invaded, fertile plains have been covered with sterile particles, and rendered unfit for the habitation of mankind, and whole villages have been swallowed up by the sand floods. Indurated or hardened downs, which occur extensively upon the coast of New Holland, are formed of sand mixed with various marine substances, by which it becomes consolidated. Several points of the Lancashire coast exhibit these formations from the ocean, particularly the neighbourhood of Southport, a town which lies between parallel ranges of sand-hills. 'The loose particles subject to the action of a gale of wind are shifted, and sometimes in enormous quantities, so as to produce serious effects, covering the gardens to a considerable depth, and overtopping the lower apartments of the houses. After a heavy shower of rain, the sand-hills, which are almost impassable in a dry state, "bind instantaneously, conceding free leave and licence to the pedestrian to range over these mimic mountains, and affording ready means of visiting spots, which just before were all but inaccessible. The intervals between the hills present recesses where nothing but the sky is seen, and which seem as wild and solitary as the heart of an eastern desert. Some progress has here been made by the industry of man to convert into cultivable tracts these waste places, by the application of "sea-sluch" to the pure sand of the ocean, a kind of marl dug below high water-mark, which has the double advantage of preventing drift, and conquering sterility. To accomplish the former object, small parcels of Arundo arenaria, sand-reed, have been planted with success along several parts of the Scottish coast; by which means, also, the inhabitants of the Bouillonnais have almost wholly arrested the advance of their downs.

If Holland is subject to the encroachment of the ocean, the latter supplies its coast at other points with huge masses of sandy downs, which effectually defend it from invasion there. These formations, the result of the natural process which is still going on, are in some places so high as to shut out the view of the sea even from the tops of the spires; but during the prevalence of sea-winds, clouds of sand are raised from the beach into the air, and showercd down upon the inland country, giving it an air of painful desolation. The materials of the following statement occur in Professor Jameson's edition of Cuvier's Theory, and give a striking example of the sand-flood on the coast of Elgin, or MIorayshire, in Scotland, as well as of the folly of the inhabitants of the district. West of the mouth of the Findhorn, a clistrict of more than ten square miles in area, chiefly included in the barony of Coubine, was once termed the granary of Moray, on account of its extreme fertility. This has been rendered unproductive and depopulated by the shifting of the sand-hills. The first irruption commenced about the year 1677, and twenty years afterwards, in 1697 , not a vestige remained of the manor-place, orchards, and offices of Coubine, and two-thirds of the barony wcre reduced to ruin. The irruption came from the shore at Mavieston, about seven miles west from the mouth of the Findhorn, where, from time immemorial, large heaps of sand had been accumulated. The sand-hills there had been till then fixed, by being covered with vegctation, but were set at liberty, by the inhabitants inconsiderately pulling up the bent and juniper for various uses, when a drifting immediately commenced to the north-east. A high wind has been known to carry the finer particles of the sand across the whole bay of the Findhorn. In the winter of 1816, a large portion of the only remaining farm, on the west side of the river, situated in the line of the progress of the sand, was overwhelmed, and a marked change has been produced upon the river itself. Nany years ago, its 
mouth having become blocked up, the water cut out the present more direct channel. By this change the old town of Findhorn, which originally stood on the east side of the river, was left upon its western bank; and the inhabitants, in consequence, removed the materials of their houses across the new channel, and erected the present village on the eastern side. The site of the old town is now covered by the sea. When the tide retires, the river almost entirely disappears, being absorbed by the sand; and, owing to the bar formed across its entrance, it is unable at spring tides to force its way into the sea, so that it flows back and inundates a considerable extent of land at the liead of the bay. Of late, however, the great accumulations of sand have disappeared from Coubine, and the ancient rich soil has in some places been left bare, so that it is not unlikely that the barony will resume its former fertility. Such a result would be rendered much more certain, if, by putting in proper kinds of plants, an attempt were made to fix the Mavieston hills, and thus prevent fresh inroads from that quarter; but, notwithstanding the destruction which has happened, the lessons of experience have been lost upon the inlabitants, who persist in gathering what little vegetation spontaneously appears.

The coast of France presents the most remarkable examples of these formations of sandy downs, and of the mischiefs arising from their drifting inland, which are chicfly found along the shore from Brittany to the Pyrenees. In the former province, a village near St. Pol de Leon has been entirely covered, so as to leave no part visible but the spire of the church. Southward from the Gironde, the coast forms almost a straight line, broken by only one small inlet, and is bordered by the Landes, which are vast undulating tracts of sand accumulations from the Atlantic. These have advanced easterly into the interior of the country, within the period embraced by historic notices, under the influence of the westerly gales. A great number of villages mentioned in the records of the middle age have been overwhelmed, and the town of Mimazan, which has long been struggling with the sands, is apparently destined to be engulfed by them. Intercepting the flow of the inland waters into the sea, the sand-hills give rise to large stagnant pools, which, in 1802, covered five farming establishments at the village of St. Julien. 'The old Roman road leading from Bayonne to Bourdeaux has, in many parts, long been immersed, which, half a century back, might be seen when the waters were low. In former times, the growth of the sands blocked up the mouth of the Adour at Bayonne, when the river forsook its channel, flowed northward on the inner side of the downs upon the coast, and found an outlet into the sea at Vieux Boucan, forming a haven which gave considerable importance to the place, Bayonne losing the reputation which caused the formation of its name from the Basque words baia, ona, a good bay or port. For nearly two centuries the Adour pursued its new course, until, in the year 1579, the old mouth was cleared of its sand by the citizens of Bayonne, and re-opened, occasioning the downfall of Vieux Boucan, which has now scarcely thirty inhabited houses. At various parts of this coast, the land is now in process of invasion from the material constantly brought by the sea, which advances between the mouths of the Adour and the Gironde at the alarming rate of about sixty feet yearly, and even seventy-two feet in some places. The Gascon peasants endeavour to preserve their cabins from the enemy, when the wind blows towards the sea, by tossing the sand high into the air with shovels, by which the retreat of a small portion is secured; but obviously these feeble efforts offer no effectual resistance to its progress. It has been calculated, that at the present rate of advance, it will require two thousand years for the downs to reach Bourdeaux.

In addition to the statements made at the commencement of this chapter respecting alterations of coast-line by depression effected by extraordinary natural conrulsions, examples of elevation meet us from the same cause on the south-west shores of Italy and America, which are too important to be overlooked. We shall first go to the western 
side of the Bay of Naples, to the shore of the small Bay of Baia, a district which has received the poetical name of the Phlegrxan Fields, and which Italian partiality has called a piece of heaven fallen down upon earth. It was the favourite resort of the Romans under the republic and the empire. Its abundant hot springs, its genial winterless climate, its seclusion from the northern blasts, the eastern breeze blowing across the bay, together with the delightful view - these attractions drew the opulent Romans to Baia, weary of the noise and bustle of the capital, for tranquillity and health. Silius, Martial, and Statius have celebrated its beauties; Ciccro, Hortensius, Lucullus, Julius Cæsar, Augustus, and many of the succeeding emperors had villas on its shores; the youthful invalid Marcellus was removed hither to find a grave; and here the men of letters delighted in fixing the most famous scenes of Homeric fable - identifying the Lucrine lake with one or other of the lakes or rivers of Hades, and recognizing in the Avernus, which formerly emitted exhalations, the theatre of the nekuia, that awful vision of the dead which passed before Ulysses at the barriers of the earth.

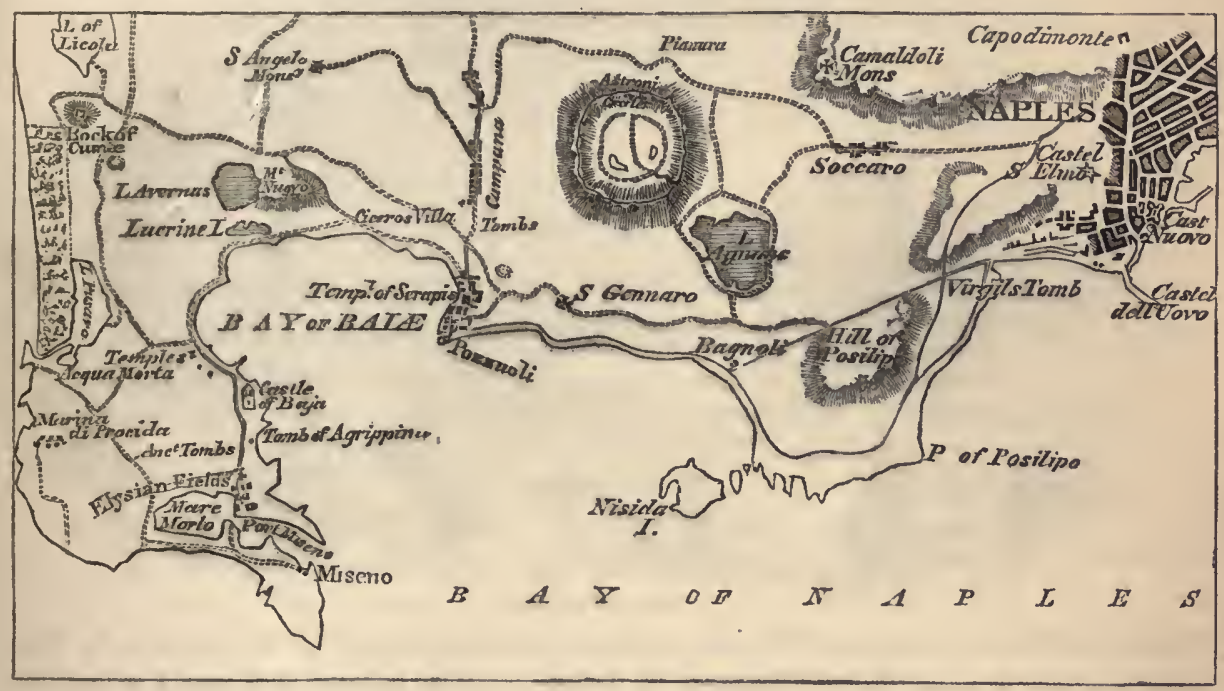

The whole coast of Baia is now comparatively a desert, with a few masserie or farms and vineyards scattered on its hills, - a consummation in which natural convulsions have cooperated largely with political reverses and social degeneracy. The most recent disturbance of the Phlegræan Fields occurred in a night of September 1538, after twenty shocks of earthquakes had been experienced in the neighbourhood of Pozzuoli within twenty-four hours. That night, the inhabitants of Tripergoli, a small watering-place on the bank of the Lucrine lake, witnessed the opening of an abyss between the town and its suburbs, which speedily dislodged them from their houses, and destroyed their habitations by its discharges of fiery stones. Dark smoke covered the spot four days, which unveiled a most extraordinary scene of change when it cleared off. 'There is an eminence marked on the map near the lake Avernus, the Monte Nuovo, which was then formed and still remains, npwards of four hundred feet high and a mile and a half round. The town of Tripergoli was demolished; its suburbs had been engulfed in the earth; the Lucrine lake was crippled in its dimensions by the new mountain, and reduced to a shallow pool ; while the lake Avernus ceased to throw out those exhalations which had led to its identification with the Homeric nekuia. But by far the most extraordinary fact disclosed was the elevation of the coast manifest by the retirement of the sea more than twenty feet from its former 
boundary. Sir William Hamilton, in his work Campi Phlegræi, gives extracts from two letters written at the time testifying to this occurrence. The first is from Falconi, who states:- "It is now two years since there have been frequent earthquakes at Pozzuoli, Naples, and the neighbouring parts. On the day and in the night before the eruption (of Monte Nuovo) above twenty shocks great and small were felt. 'The next morning the poor inhabitants of Pozzuoli quitted their habitations, some with their children in their arms, some with sacks full of goods, others carrying quantities of birds of various sorts that had fallen dead at the beginning of the eruption, others again with fish that they had found, the sea having left them dry for a considerable time. I accompanied Signor Moramaldo to behold the wonderful effects of the eruption. The sea had retired on the side of Baiæ, abandoning a considerable tract, and the shore appeared almost entirely dry

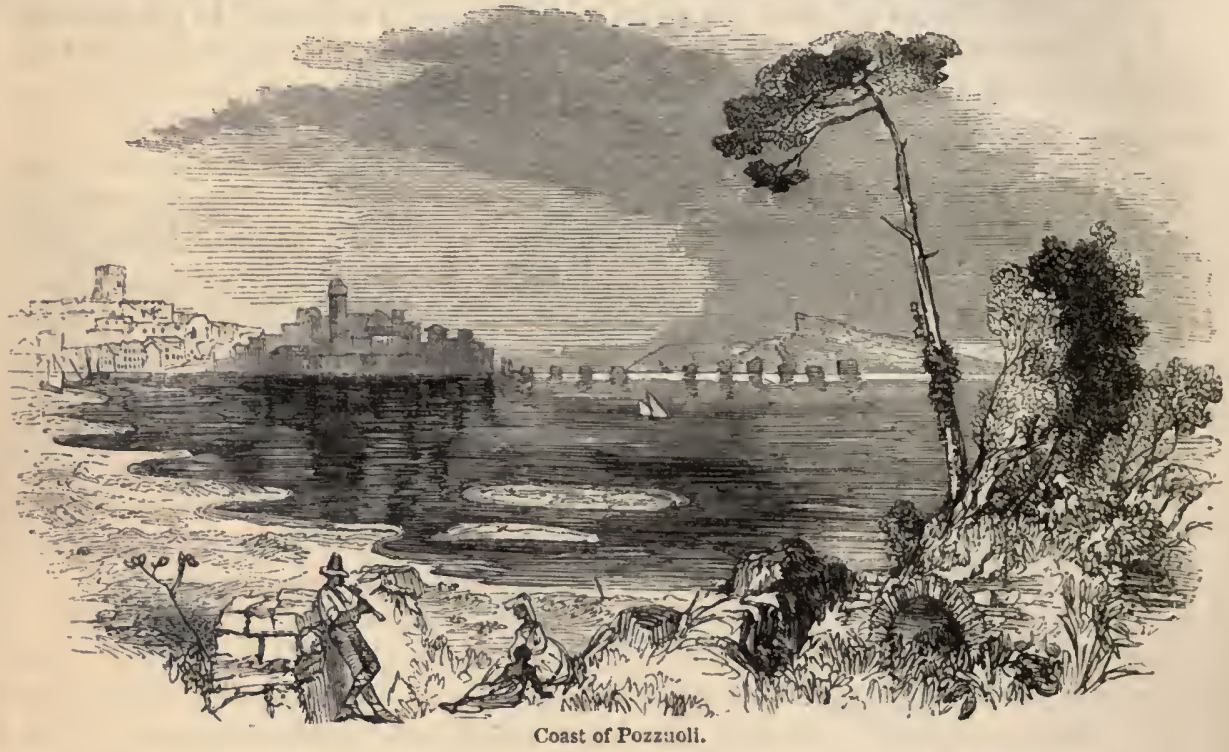

from the quantity of ashes and broken pumice-stones thrown up by the eruption." 'The other extract is from Pietro Giacomo di Toledo:- "It is now two years since this province of Campagna has been afflicted with earthquakes, the country about Pozzuoli much more so than any other parts; but the 27 th and 28 th of the month of September last, the earthquakes did not cease day or night in the town of Pozzuoli. That plain which lies between lake Arernus, the MIonte Barbaro, and the sea, was raised a little, and many cracks were made in it, from some of which issued water; at the same time the sea immediately adjoining the plain dried up about two hundred paces, so that the fish were left on the sand a prey to the inhabitants of Pozzuoli."

Distinct testimony is here borne to the recession of the sea from the coast-line which appears to have been caused by an clevation of the shore. The testimony is confirmed by an examination of the district between Naples and Pozzuoli, and around the Bay of Baia. Stretching along the present sea-beach, there is a low strip of land bordered with cliffs, the level consisting of sedimentary matter, shells, and marine remains, over which the waters have evidently once lain, the cliffs constituting their former boundary. The retirement of the sea cannot be referred to any ordinary gradual recession, as its tendency here is to encroach upon the land; and as there are no tides of any consequence in the Mediterranean, no depression of the level of high water can be supposed, in consequence of some change in the direction of the currents. There is every reason to suppose that 
the coast rose upwards of twenty feet during the terrible disturbance of 1538 , reducing the Lucrine lake to its present shallowness, and causing the sea to retreat from its former limit. But evidence exists of repeated changes of level along this coast, which has rendered it one of the most interesting and valuable regions to the geologist. Upon the shore near Pozzuoli, there are three remaining pillars of an ancient building, commonly called the Temple of Serapis, though antiquaries differ considerably respecting its character. The pillars exhibit unequivocal signs of having once, and for a long period, been immersed in the waves, exhibiting marks of the dactylides, a species of shell-fish which burrows in the stone. 'The lower and upper parts of the columns are uninjured, the former having been protected by accumulations of rubbish, and the latter having been above the level of the water; but a zone in the middle, twelve feet in height, is every where pierced by marine perforating bivalves. "The holes of these animals are pear-shaped, the external opening being minute, and gradually inereasing downwards. At the bottom of the carities, many shells are still found, notwithstanding the great numbers that have heen taken out by visitors. The perforations are so considerable in depth and size, that they manifest a long-continued abode of the lithodomi in the columns ; for as the inhabitant grows older, and increases in size, it bores a larger eavity, to correspond with the increasing magnitude of its shell. We must consequently infer a long-continued immersion of the pillars in sea-water, at a time when the lower part was covered up and protected by strata of tuff and the rubbish of buildings, the highest part at the same time projecting above the waters, and being consequently weathered, but not materially injured." It thus seems to be settled, almost to demonstration, that the floor of this temple or building, of course originally placed upon a site abore the reach of the sea, has subsided so as to have sunk below the level of its waters, and afterwards been elevated again - an oscillation shared by the adjacent district. Captain Hall was shown, near the remains of an amphitheatre, what are called the ruins of Cicero's Villa - a mass of rubbish upon the dry land at the foot of the cliff, considerably above the present level of the sea, the guide describing the orator as having fished out of his parlour window. However doubtful the identity of the spot, it is perfectly possible for such a fact to have transpired; and, as the narrator observes, the gossip of the guide shows the established belief, and carries with it great interest, as corroborating the supposition that the ground lias been raised by the volcanic forces which we know to be in action in that quarter. Loffredo, writing in 1580, is quoted by Sir C. Lyell as affirming that, fifty years previously, the sea washed the base of the hills which rise from the level strip of land before alluded to, and expressly stating that a person "might liave fished" then from the site of the ruins of the amphitheatre.

An elevation of the coast transpired upon a grand scale during the great Chilian earthquake in 1822, so well described by Mrs. Grabam, who was then a resident in that country. Upon the night of its occurrence, attracted by the fineness of the evening, she had been sitting in her rerandah, watching the lightning which played uninterruptedly over the Andes till after dark, when a delightful calm moonlight night followed a quiet and moderately warm day. It was so pleasant, that she quitted the verandah with regret, and returned into the house, where she sat quietly conversing with her friends till about a quarter past ten, when they were all sensible of a violent shock, and lieard a noise like the explosion of a mine. One of the party started up, exclaiming, "An earthquake! an earthquake!" and ran out of the house; but another - a connexion of the relator - was in delicate health, and unfit to be exposed to the night air, and she, unwilling to leave him, remained. In a little time the motion of the earth, increasing, threw down the chimneys, and the walls of the house opened. The urgency of the danger now overcame lesser fears, and every body fled for refuge to the lawn. In a few minutes, the quick 
vibration of the earth was changed to a rolling motion, like that of a ship at sea. Though there was not a breath of air, yet the trees were so agitated, that their topmost branches seemed on the point of touching the ground. The lowing of the frighted cattle, and the screaming of the sea-fowl, never ceased till the morning; while the rational witnesses of this awful convulsion of nature experienced, in its full extent, a sensation which only those who have felt it can entirely conceive - the certainty of great and sudden danger, which no exertion can avert or mitigate. Though they fled from the falling house, who could assure them that the next moment the ground would not open beneath their feet?

The shock of this earthquake was felt throughout a tract of country extending 1200 miles from north to south. St. Jago, Valparaiso, and some other towns were much injured; but the chief peculiarity of the event was, that at Valparaiso the shore was found to have been lifted up three feet above its former level; and, on further examination, it appeared that the whole coast, for above one hundred miles, had been elevated in the same manner. Part of the bed of the sea was also raised, and remained bare and dry at high water, with beds of oysters, museles, and other shell-fish adhering to the rocks on which they grew. The fish were all dead, and exhaled an offensive smell. Conical mounds of earth, about four feet ligh, were thrown up in several districts, by the forcing up of water mixed with sand, through funnel-shaped hollows. The whole extent of country lifted up above its former level was estimated at 100,000 square miles. The whole surface, from the foot of the Andes to a great distance under the sea, is supposed to have been raised, so that the soundings in the harbour of Valparaiso were in consequence materially altered, the depth of water being much less than before. In the course of a few hours the change of level was effected; but the shocks continued from Norember 1822 to September 1823, and even then two days seldom passed without one being experienced, and sometimes two or three were felt during twenty-four hours. After this earthquake, Mrs. Graham observed, that besides the beach newly raised above higlh-water mark, there were several more ancient lines of beach, one above another, consisting of shingle mixed with shells, and extending along the shore in parallel lines, the uppermost being fifty feet above the sea. Perhaps these may be indications of the coast having been repeatedly elerated by the same means. Sir C. Lyell has introduced other particulars respecting this great disturbance, gathered from the Transactions of the Geological Society, confirmative of the leading phenomenon - the elevation of the coast. The wreck of a ship which could not be approached previously, became accessible from the land, although its distance from the original shore had not altered. The water-course of a mill, a mile from the sea, gained a fall of fully a foot in a hundred yards. The rise upon the coast was from two to four feet, but in some inland situations it amounted to as much as seven feet.

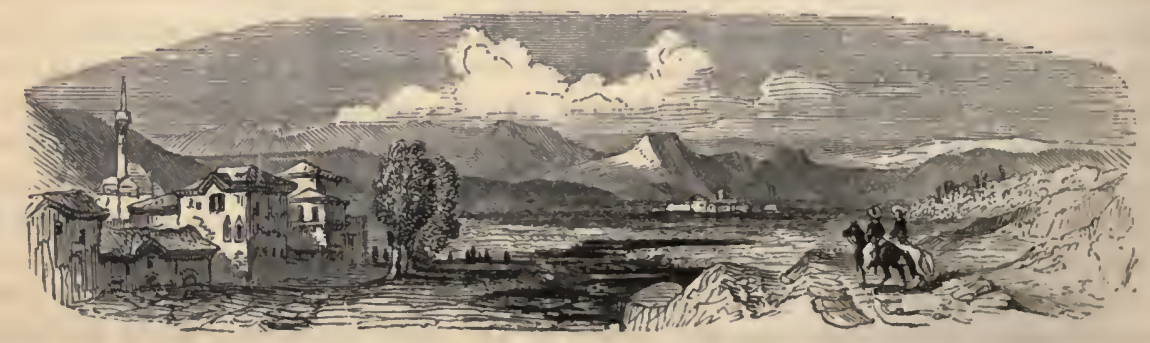




\title{
CHAPTER XII.
}

\author{
INTERIOR LAND CHANGES.
}

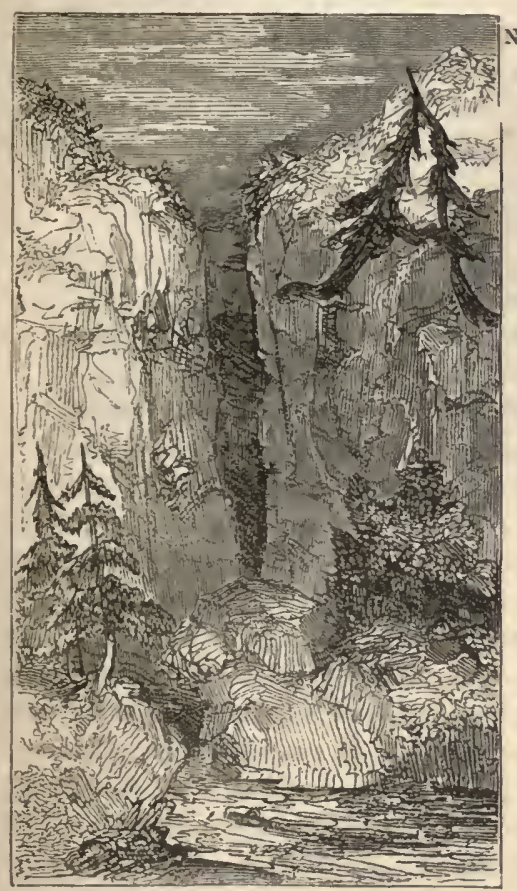

ND surely the mountain falling cometh to nought, and the rock is removed out of its place." "The everlasting mountains were scattered; the perpetual hills did bow. I saw the tents of Cushan in aftliction, and the curtains of the land of Midian did tremble." "The sea saw it, and fled; Jordan was driven back. The mountains skipped like rams, and the little hills like lambs. What ailed, $O$ thou sea, that thou fleddest? thou Jordan, that thou wast driven back? Ye mountains, that ye skipped like rams; and ye little hills like lambs?" This language of the more ancient scriptures is not that of poetical exaggeration, but derived from an acquaintance with the physical history of the earth, obtained by testimony or observation. The trembling of the most solid masses - the tottering of rocks, hills, and mountains, are not imaginative pictures, but representations founded upon the realities of nature; and when the earth is described as reeling to and fro like a drunkard, when the wilderness of Kadesh is declared to shake, and Lebanon and Sirion to leap like the unicorn, we know the source to which the statement is to be referred. The country of the writers, in almost every century since the first Hebrew patriarch pitched his tent upon its soil, has suffered from the eruption of violent eternal forces, acting with greater energy, perhaps, in ancient than in modern timcs; and from, the great physical changes consequent upon these convulsions, they drew those lofty and terrible descriptions of terrestrial disturbance with which their songs, odes, and elegies abound. Before referring to these subterranean causes of superficial derangement and their phenomena, some of the more ordinary forms of interior land changes may be noticed.

In mountainous regions, the detachment of fragments of rock and earth from abrupt and precipitous elevations is the gradual yet sure effect of the wear and tear of the atmosphere, accelerated by the occurrence of scvere storms, heavy rains, and intense frost. Mam 'Tor, a hill on the Peak of Derbyshire, has become celebrated on account of the waste of its mass; and hence it is popularly called in the neighbourhood, the "shivering mountain." The summit of the lill rises about eight hundred feet above the level of the valley, and commands an extensive prospect of the high eminences of the district and its beautiful dales, retreats secluded from the bustle of the world, to which the imagination is ready to assign the attributes under which the happy valley of Rasselas is described. According to vulgar rumour, the shivering of the hill has been going on for ages, without occasioning any diminution of its bulk ; but, apart from fable, Mam Tor is a mass consisting of alternate layers of shale and gritstone, and the former readily decomposes under the influence of the 
weather, falling into the valley below, bringing with it detached fragments of the grit. In the winter season, after unusual rains, or in severe frost, the decomposition is the most rapid, the 'Tor discharging from its side immense pieces of its material, the noise of which in their descent may be heard in the adjacent villages, and is described as singularly impressive in the night. In all Alpine regions, subject to great seasonal vicissitudes, frost is a powerful agent in the destruction of rocks. When the water that has entered their pores and fissures becomes frozen, it acts by its expansion with irresistible force, and detaches enormous masses, which fall from their parent bed thundering to a lower level. In the upper parts of North America, even in latitude $51^{\circ}$ in some places, where the winter climate is so severe that brandy congeals and the lakes freeze eight feet thick, the rocks split with a noise resembling the explosion of artillery, and the shattered fragments fly to a considerable distance.

'The action of water, in another way, operates to dislodge from their situation the ligher parts of mountains, and sometimes to reduce their whole mass to ruins, producing land or mountain slips. 'This is by a slow process of erosion and undermining, which, having proceeded to a sufficient extent, brings on in a moment the eatastrophe of a slide or fall. 'The occurrence cannot take place in the case of unstratified rocks, which are only subject to the gradual abrading of their entire mass, and the detachment of small fragments ; but with referenee to the stratified mountains, where layers of different kinds of rock overlay one another, it is easy to conceive of such slides transpiring. Water percolating by rents and fissures through an upper stratum, and reaching another which readily yields to its solvent power, the lower stratum may be so far carried away in the course of ages as to be unable to support the upper, which, in consequence, falls down. But little harm would ensuc, if the different strata were of uniform breadth and horizontally disposed, like a number of equal volumes piled upon each other, instead of displaying varying thickness and all manner of inclination. It is this last condition chiefly-the differently inclined plane upon which the upper stratum descends - that causes its precipitation upon the country at the base, covering it with its ruins, and oceasionally overwhelming its inliabitants. Other circumstances concur to the production of land and mountain slips; but the principal agent is water, operating by a process of undermining, which, however slow and subtle, is grand and terrible in the crisis that ensues. Such events are by no means uncommon; but they generally occur in secluded and uninhabited sites, so as not to attract any wide notice, unless they happen upon a grand scale. On the night of the 29th of January 1840, in the distriet of Jura, a mountain called the Carnans came down in mass on the surrounding plain, and a portion of the royal road from Dijon to Portalier sunk with this eboulement to a depth of more than fifty mètres. 'That portion known as the Rampe de Carnans, the ladder or stairease of Carnans, was rendered impassable, and all communication between the places on each side was entirely suspended. A fresh mass of rock and earth, during the following day, was detached, and was distinctly seen from a great distance as it slid down. It was supposed that a fountain, which ceased to play upwards of a quarter of a century before, had then taken a new subterranean direction, and mined out a portion of the mountain. Switzerland has repeatedly exhibited these extensive falls from her giant mountains, which may form a subject of interesting reference.

It has sometimes happened that the waters of an elevated lake have insinuated themselves between the strata composing the mass of a mountain, gradually loosening and removing a quantity of material, by which the superior body of rock or earth being deprived of its support has fallen. In this way, the catastrophe of the Rosenberg, otherwise called Mont Ruffi, is conceived to have been occasioned in the year 1806. Nearly in the centre of Switzerland, in the canton of Zug, is the lake of that name, a 


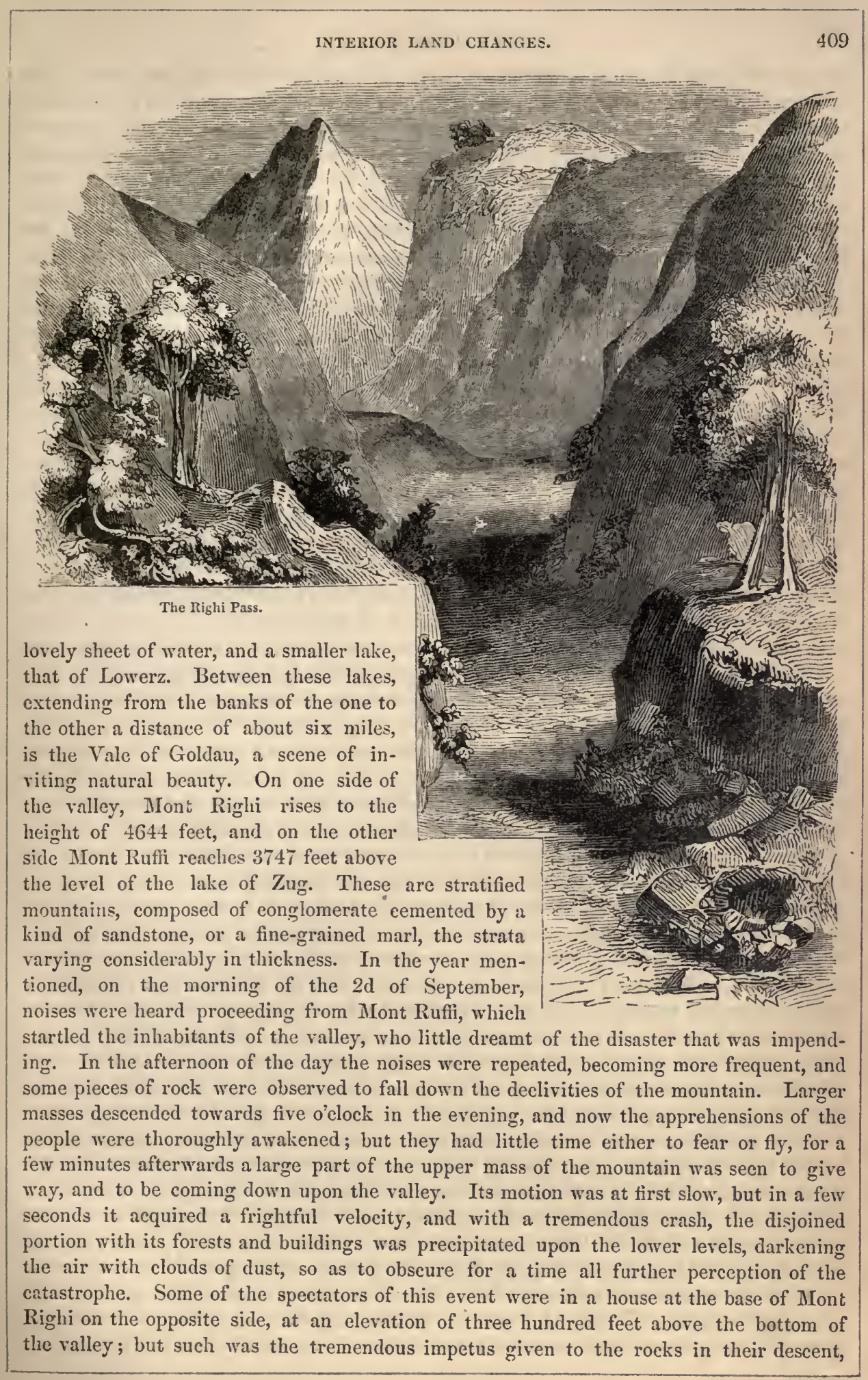


that large blocks were forced up the acclivity, and nearly reached their situation. The movement was so sudden, that nine out of thirteen travellers who happened to be passing were overwhelmed, and the mass that fell was so prodigious, that it formed a ridge in the valley one liundred feet in height, and a league and a half in length and breadth. In little more than five minutes, the greater part of the whole vale of Goldau was transformed from a happy and cultivated retreat into a mass of ruins. The villages of Goldau, Busingan, Lowerz, Ober and Unter Rother, were either entirely or in part buried; four hundred and eighty-four of the inhabitants lost their lives; a great number of cattle and sheep perished; and property destroyed, according to an estimate made by the government of the canton, to the amount of nearly 100,000l. A portion of the mountain dashing into the lake of Lowerz raised a succession of vast waves, one of which swept over the small island of Schwanan, though sixty feet above the ordinary level of the water. The cause of this tremendous occurrence was not doubtful. About half a century before the year 1806, some considerable rents of great depth had been formed in Mont Ruffi, by which the water of the rains and melted snows, as well as some from the adjacent lakes, was freely admitted into the interior of the mountain. The marl and clay which united the strata of conglomerate exposed to its action was gradually washed away, depriving the upper masses of the foundation on which from immemorial time they had securely rested, which were precipitated forwards upon being displaced. On the site once occupied by the village of Goldau there is now a small chapel, where the pious Switzers pray for preservation from a similar calamity, holding a service for the purpose annually on the $2 \mathrm{~d}$ of September.

A disruption, equally sudden but far more fatal in its effects, took place in the year 1618 with reference to Mont Conto, which formerly overlooked a pleasant and well-built town and adjacent village in the Val Bregaglia, in the Lombardo-Venetian kingdom. Of the particulars we have less information than in the former case, as it happened in the night. While the air was calm, the sky cloudless, and most of the people of the valley were wrapt in sleep, the summit of the mountain came down, completely burying the town with its ruins, upon which a forest of chestnuts now flourishes. Only one house escaped destruction, and three inhabitants who were absent on business, 2430 persons perishing. There had been beforehand intimations of danger sufficient to have induced observant and reflecting persons, aware of the dreadful incidents to which such localities are subject, to have removed to a safer spot. For ten years previous, large chasms had been formed in the mountains, into which the rains descended, and ultimately wrought the mischiefs that occurred. On the afternoon before the fatal night some fragments of rock had fallen; but in the spirit of confident and happy security, the inhabitants of the Val Bregaglia retired to rest among their native and much-loved mountains, and saw them no more! It has been correctly enough observed, that " until the fatal moment of destruction arrives, or, at all events, till the hour of danger approaches, mankind, all the world over, are pretty nearly equally indifferent, and go on dancing and singing, marrying and giving in marriage, under the very jaws of death, with as much unconcern as if they were living in perfect safety. The inhabitants of Portici and Resina, for instance, living at the base of Vesuvius; or those of Catania, at the foot of mount Etna, where torrent upon torrent of lava has flowed in endless succession, never dream of an eruption till the parcled volcano drinks up their wells, and, in the language of Scripture, 'fire runs along the ground!" In like manner the writer remarks, "I have observed the gay voluptuaries of Lima scarcely disturbed in their reckless enjoyment of life by the shock of an earthquake, which interrupted only for a transient moment of fear and impatient prayer their darling ' 'Tertullas,' while the ceilings and walls of their houses cracked in their ears, and church steeples toppled round them." It is clear that in the two preceding 
cases of mountain-falls, which involved a large sacrifice of human life, much of it might liave been avoided by heeding the warnings given. But thus it happens, that men are slow to believe themselves endangered, and when the disaster comes, the survivors of friends, relatives, and property are apt to dwell only upon the physical evils of their condition, forgetful of their own imprudence, and of the millions of terrestrial sites secure from the catastrophe.

An elevated piece of table-land between the cantons of Valais and Berne, which rises nearly to the snow line, was the scene of the same phenomenon in the year 1714 and 1749. Three sharp peaks ascend from it to the height of 10,620 feet above the level of the sea, called Les Diablerets, or the Devil's horns. Originally there were four, but one was demolished at the two periods named, covering the plain with its fragments. The shattered blocks and heaps of rubbish upon it are indeed so extensive, as to lead to the conclusion that the group of the Diablerets has lost other members in bygone ages, but of any occurrence of this nature prior to 1714 no account exists. The event of that year has been related in the following words :- "Before the first catastrophe a subterraneous noise was heard, and some of the herdsmen, who had brought their herds to the pastures in the vicinity, took this hint and returned home ; others, however, were buried under the rocks. When the mount precipitated itself down, the whole country in its vicinity trembled, and a thick smoke rose to a considerable height in the air. It was only dust, which was detached from the rocks when they broke to pieces. The compression of the air was so great, that some of the trees which were near the places along which the rocks descended were bent to the ground or broken. Many of the summer huts of the Alpine herdsmen were destroyed, fourteen persons lost their lives, and a large number of cattle and sheep were killed. One of the herdsmen belonging to the village of Aren in Valais was among those who had not returned home, and was considered as having lost his life. His children were declared orphans by the court. 'Three months afterwards, on Christmas Eve, he suddenly appeared in his village - pale, thin, covered with rags, resembling a spectre. All the inhabitants of the village were frightened. The doors of his own house were shut to him. Some people ran to the priest, requesting him to exorcise the supposed spectre. After some delay, the man succeeded in convincing the people that he was alive, and then he told them, that the moment on which the mountain-slip took place, he had been on his knees praying to the Preserver of life, when an enormous fragment of rock in descending struck the ground before his hut, and resting leant over against the rocky wall at the base of which his hut was built. It was immediately followed by a terrible crash, and by an immense quantity of stones and rubbish, entirely covering the piece of rock which protected his hut. When all became quiet, he continued, 'I was no longer in fear; I did not lose my courage; and directly I set myself to work to open an issue. A few pieces of cheese which I had made were my food, and a rill of water, which descended among the ruins, quenched my thirst. After many days, which I was unable to count in the long darkness of my subterraneous prison, I discovered, by creeping about among the rocks, an opening. I saw again the sun's light, but my eyes were for some time unable to bear it. The Almiglity, in whom I always confided, and who always kept alive my hope of preserving life, has sent me back to my family, to be a witness and a proof of his power and bounty.'" The second slip of the Diablerets in 1749 took place without injury to the peasantry, who obeyed a warning giren by the mountain to escape in time; but five Bernese citizens, travelling in the neighbourhood, refused to fly, believing the fears of the people to be unfounded, and the house in which they remained is thought to be five hundred feet below the present surface.

A part of Mont Grenier, about five miles south of Chamberry in Saroy, gave way in 
the year 1248, and exhibits marks of the disruption in its present appearance, which has been sketched by Mr. Bakewell, to whose Trarels in the 'Tarentaise we are indebted for most of the particulars concerning the event. The ruins of the mountain entirely buried five parishes, 'with the town and church of St. André, spreading over an extent of about nine square miles. These ruins are now called les Abymes de Myans; and, notwithstanding the lapse of many centuries, and the presence of numerous vineyards which have since been planted, they present in many places a singular and impressive scene of desolation. A favourable view of the fall, at a safe distance, was afforded by the locality, for Mont Grenier is almost isolated, advancing into a broad plain, which extends to the valley of the Isere. It is several miles in length, but very narrow, and attains the height of 4000 feet above the plain, being an abutment of the mountains of the Grand Chartreux. The summit is capped with an immense mass of limestone strata, not less than six lundred feet in thickness, presenting on every side the appearance of a wall. The strata dip gently to the side which fell into the plain. This mass of limestone rests on a foundation of mollase, a term applied by the Genevese to the softer beds of sandstone, and undernenth this, strata of limestone alternate with it. There can be little doubt that the disruption was occasioned by the gradual erosion of the soft strata, which undermined the mass of limestone above, and projected it into the plain. The part that fell had probably been for some time nearly detached from the mountain by a shrinking of the southern side, where there is at present a large rent; upwards of 2000 feet deep, which seems to have cut off a section, that

"Hangs in doubtful ruins o'er its base,"

and threatens a renewal of the event of 1248. The projected portions forming the Abymes des Myans exhibit a series of small conical hills, varying in height from twenty to thirty feet, composed of fragments of calcareous strata, precipitated to the distance of two and three miles from the mountain. Falling from the upper bed of limestone with which Mont Grenier is capped, the velocity they would acquire by descending from so great a lieight, making due allowance for the resistance of the atmosphere, $\mathrm{Mr}$. Bakewell estimates at not less than three hundred feet a second. The projectile force gained by striking against the base of the mountain, or against each other, has spread them orer the plain; where, in the course of years, the rains and currents of water from dissolving snows have washed away the loose earth, and furrowed channels, giving to the masses of stone the aspect they now present, that of detached conical hills. 'The chronicles which have preserved a record of this occurrence do not state whether the fall of the mountain was preceded by any forewarnings that allowed to the inhabitants the opportunity to escape. Certain it is that the town of St. André, then a place of some importance, being the ancient seat of the deanery of Savoy, and other parishes, were so entirely overwhelmed, and to such a vast depth, that nothing has ever been discovered belonging to them except a small bronze statue. It has been calculated that the quantity of matter that fell, would be more than four hundred millions of tons in weight, occasioning a shock inconceivably awful, being precipitated from the height of three quarters of a mile into the plain. The dislodged material stopped a little short of the church at Myans, dedicated to the Virgin, and called Notre Dame des Myans. Hence the church acquired celebrity, and pilgrimages are made to its shrine by the Savoyards, to whom it would be heresy to intimate, that the elevation of the ground assisted the efforts of the Virgin in arresting the calamity.

The sudden descent of masses from mountains, whether of rock and earth, or snow and ice, in the form of an ordinary Alpine avalanclie, has frequently propagated a series of striking and destructive changes. Choking up to a certain height a contracted valley, and arresting the progress of its stream, the formation of a lake ensues, which becomes permanent if the barrier is composed of solid materials in a quantity sufficient to resist the 


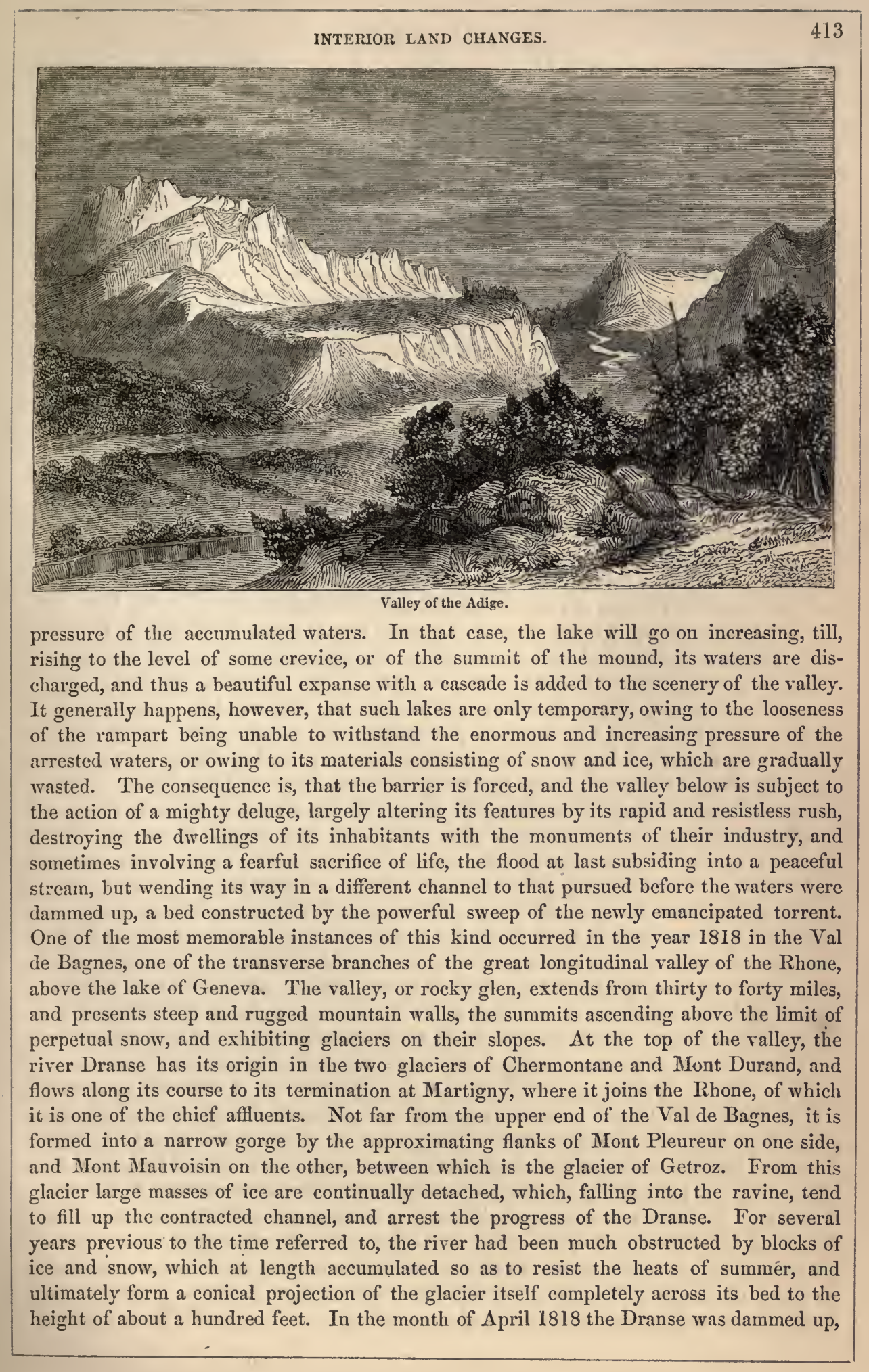


and a lake began to form, which soon attained a considerable magnitude. It was obviously in the highest degree probable that the icy barrier would not be able to hold out long against the increasing pressure of the waters, and the sudden efflux of such a mighty volume as was collected, would as certainly desolate the Val de Bagnes. To aroid this calamity, which every day became more impending, an engineer started the bold scheme of tunnelling the rampart of ice, and was employed by the government of the canton for that purpose. This scheme, says the memoir of M. Escher upon it, "was begun on the 10th of May, and finished on the 13th of June, under the direction of M. Venetz. The gallery was sixty-eight feet long, and during its formation the workmen were exposed to the constant risk of being crushed to pieces by the falling blocks of ice, or buried under the glacier itself." The lake at this time contained at least 800 millions of cubie feet of water, which in three days was reduced to 530 millions, by the discharge from the gallery. The sequel may best be related in the words of the memoir :-

"As soon as the water flowed from the lower end of the gallery the velocity of the cascade melted the ice, and thus wore away the gallery at its mouth. The water which had penetrated the crevices of the glacier caused enormous fragments of ice to fall from the lower sides of it ; so that owing to these causes the body of the glacier, whieh formed the retaining wall of the lake, was so much diminished in thiekness that the floor of the gallery was reduced from its original length of 600 to 8 feet. $\Lambda$ s soon as the caseado had cut through the cone of ice, it attacked the debris of the base of Mauroisin, upon which the cone rested; that is to say, the torrent undermined the glacier by washing away the loose materials forming the bed of the stream, on which the mass of ice had been piled up; and having carried it off by degrees, it became able to push the soft soil from the foot of Mont Mauvoisin, and excavate for itself a passage between the glacier and the rocky beds which compose the mountain. As soon as this happened, the water rushed out, the ice gave way with a tremendous crash, the lake was emptied in half-an-lour, and the sea of water which it contained precipitated itself into the valley, with a rapidity and violence which it is impossible to describe. The fury of this raging flood was first stayed by the narrow gorge below the glacier formed between Mont Pleureur and a projecting breast of Mont Mauvoisin ; here it was engulfed with such force that it carried away the bridge of Mauvoisin, ninety feet above the Dranse, and even rose several fathoms above the advanced mass of the mountains. From this narrow gorge, the flood spread itself over a wider part of the valley, which again contracted into another gorge; and in this way, passing from one basin to another, it acquired new violence, and carricd along with it forests, rocks, houses, barns, and cultivated land. When it reached Le Chable, one of the principal villages of the valley, the flood, which seemed to contain more debris than water, was pent up between the piers of a solid bridge, nearly fifty feet above the Dranse, and began to attack the inclined plane upon which the church and the chief part of the village is built. An additional rise of a few feet would have instantly undermined the village; but at this critical moment the bridge gave way, and carried off with it the louses at its two extremities. The flood now spread itself over the wide part of the valley between Le Chable and St. Branchier, undermining, destroying, and hurrying away the houses, the roads, the richest crops, and the finest trees, loaded with fruit. Instead of being encumbered with these spoils, the moving chaos received from them new force; and when it entered the narrow valley extending from St. Branchier to Martigny, it continued its work of destruction till its fury became weakened by expanding itself over the great plain formed by the valley of the Rhone. After ravaging Le Burg and the village of Martigny, it fell with comparative tranquillity into the Rhone, leaving behind it the wreck of houses and of furniture, thousands of trees torn up by the roots, and the bodies of men and of animals whom it had swept away." 



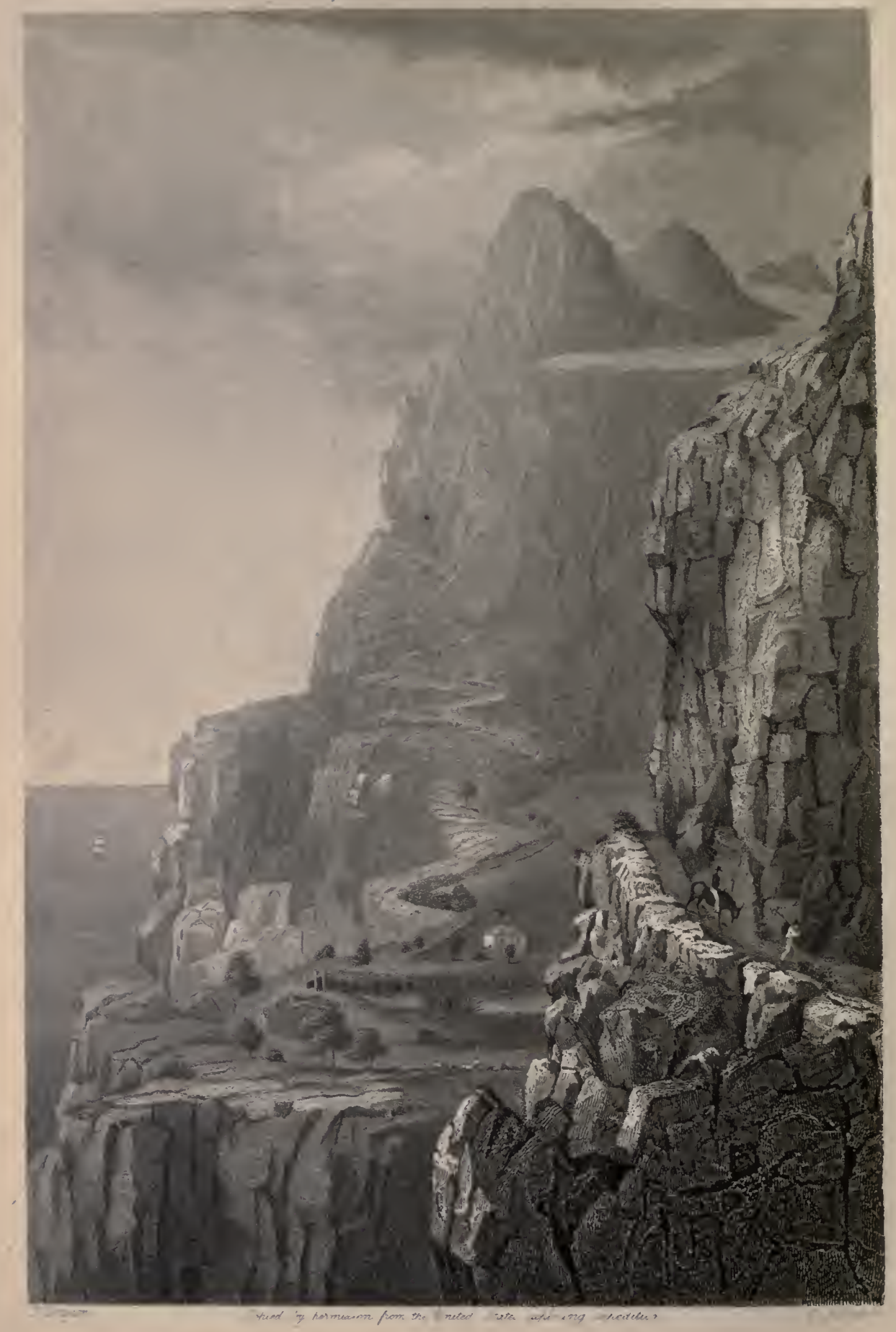

Estroza Pass, Mrdeir 
It was calculated by the writer of the memoir, that the flood for the first four miles swept along at the rate of twenty miles an hour, nearly the speed of a locomotive, and furnished about 300,000 cubic feet of water every second - an efflux five times greater than that of the Rhine at Basle. In six hours and a half, it arrived at the Lake of Geneva, having passed into the Rhone, a distance of forty-five miles. Among the physical alterations effected by this debacle, there was the deposition of a stratum of alluvial matter orer the whole of the lower part of the Val de Bagnes. This was several feet in thickness, and was so distributed that roads were obliged to be eut through it in some places, as when the snows have blocked up our thoroughfares. There was the transportation of an immense number of isolated masses of roek to a considerable distance, some of which must have been many tons in weight. One of these, fairly projected out of the gorge of the valley into the plain, measured twenty-seven paces round, twelve feet in heirght, and twelve feet across in one direction, and even larger masses bore indubitable marks of having been in motion. For some time the course of the Dranse fluctuated, and when at last it settled down into a channel, it was one widely different from that which had before been followed. Captain Hall visited Martigny a few weeks after this visitation, and found every land-mark obliterated under one uniform mass of detritus, which had levelled all distinetions in a "sweeping and democratic confusion."

The removal of loose materials, the tearing up of fragments of rock, and their transportation to a distant site, transpire under the action of those temporary torrents which are produced by heary rains in mountainous districts. The pen of Captain Hall has sketched in a lively manner a specimen of their vigour as exhibited in the high lands behind the town of Funchal in the island of Madeira. The whole of the upper part of the mountain is split into crevices, in some instances deep enough to be called ravines, or in the larger eases even valleys, which have been cut by the rapid rush of the descending currents. Many of these crevices run into one another, so that when the rain falls in any quantity, the whole series are set in operation at once, like so many gigantic sluices, to conduct the water into the main channels which convey it into the sen. In less precipitous countries, the minor streams take some time to collect their waters; but at Madeira, where the hills are steep, the whole is done almost at a blow, and with an impetuosity that seems formidable to eyes unaccustomed to it. A few hours after a heavy rain has commenced, the torrents are all at work. Behind Funchal, the side of the mountain is indented by a valley of considerable dimensions, into which a number of ravines run, and bring down the discharges of rain from the highest ridges of the island. This is frequently the bed of a torrent, filled to the depth of twenty feet, partly with water and partly with stones, many of them of great dimensions, and moving together with a noise like continuous loud thunder. The angle which the bed makes with the horizon is sufficient to cover the surface of the stream with waves more tumultuous than those of the Canadian rapids, bearing along rocks with the utmost velocity, which the St. Lawrence would not cause to budge an inch. Sometimes huge blocks áre jerked half out of the stream by the violence with which they are dashed against one another, or against some opposing angle of the channel, the bottom and sides of which, every time the torrent is in action, undergo an amount of wear and tear which effects great changes in the course of years. The writer before referred to describes this torrent, when in full play, as the grandest thing possible, requiring an effort of considerable resolution to advance to its brink, and far surpassing the surfs, breakers, and rapids, in any part of the world, in the impression of irresistible power it makes upon the senses. The roar is such that hardly any elevation of the voice can make two persons audible to one another, though standing side by side, while the ground trembles in a manner indicating the enormous weight passing over the surface. Soon after the rain ceases, this immense 
water-course becomes dry, and exhibits a parement covered with blocks of stone, various!y distributed, which the current has conveyed from the upland regions, to be transported farther when its flow is renewed.

Many remarkable cases of change produeed by streams in flood might be quoted from the records of ancient and modern times. One of the rivers of the Roman plain, the Anio, now called the Teverone, has repeatedly committed extensive ravages in that land of classic recollections. Silius Italicus speaks of its gentle flow into the Tiber, but Horace gives it the epithet of proceps, impetuous or headlong, with an cye probably to its appearance in inundation. 'The patrician families of Rome retired to villas upon its banks in summer, attracted by the coolness of its waters, a quality mentioned by Virgil, and by the striking scenery, as at Tivoli, where the beautiful remains of the temple of Vesta, and the fall of the river, constitute a picture which has few equals. In the time of the younger Pliny, there was a flood on the Anio, which is the subject of one of his letters to Macrinus :- "Is the season with you as rude and boisterous as it is with us? All here is tempest and inundation; the Tiber has swelled its cliannel, and overflowed its banks far and wide; though the wise precaution of the Emperor had guarded against this evil, by cutting several outlets to the river; it has nevertheless flooded all the fields and valleys, and entirely overspread the whole face of the flat country. It scems to have gone out to mect those rivers which it used to receive and carry off in one intermingled stream ; and has driven them back to deluge those countries it could not reach itself. That most delightful of rivers, the Anio, which seems invited and detained in its course by the charming villas that are situated upon its banks, has almost entirely rooted up and carried away the woods which shaded its borders. It has overthrown whole mountains, and in endeavouring to find a passage through the ruins that obstructed its way, has forced down houses, and rises over the desolation it has occasioned. The inhabitants of the hill countries, who are situated above the reach of this inundation, have been the melancholy spectators of its dreadful effects, having seen costly furniture, instruments of husbandry, ploughs, and oxen with their drivers, whole herds of cattle, together with the trunks of trees, and beams of the neighbouring villas, floating about in different parts. Nor indeed have these higher places themselves, to which the waters could not rise, escaped the calamity. A continued heavy rain, as destructive as the river itself, poured down in torrents upon them, and has destroyed all the enclosures which divided that fertile country. It has damaged likewise, and even overturned, some of the public buildings, where numbers had been miserably buried in the ruins." Sueh is Pliny's account of a rise of the Anio, probably in the first century of the Cliristian era. It is an interesting illustration of the constancy of natural phenomena, that after the lapse of some seventeen centuries, in the year 1826, the seene upon its banks might be described in nearly the words of the preceding relation. After heavy rains in November the river broke its bounds, at the same time permanently widening its own channel in many places, by the power of the current undermining and destroying the cliffs along its course. A considerable eminence, on which stood the church of St. Lucia, and near forty houses of the town of Tivoli, were carried away, and the precipice erowned with the relies of Vesta's temple might have shared the same fate, had the flood risen a few feet higher.

During the storm of 1829 , which ravaged Morayshire and some of the neighbouring countries, a storm, which bore a more remarkable resemblance to a tropical hurricane than any which lias visited our climate, at least in recent times, some striking examples occurred of the power of a strong current, in detaching fragments of rock, apparently firmly fixed in their native beds, bearing them away in a mass, and the whole district subject to the influence of the swollen waters of the Spey, Findhorn, Divie, Dee, and Dow, was, at various points, largely modified in its physical aspect. The heary con- 
tinuous rain which descended was accompanied with violent and sudden gusts of wind, as well as with extraordinary thunder and lightning. Speaking of the appearance of the river Don, about the old Brig of Balgownie, an eye-witness, Mr. George 'Tulloch, of King's College, Aberdeen, remarked, that he had seen the waves of the Atlantic rolling down the Pentland Firth, and wasting their gigantic strength on the bold and iron-bound coasts of the north; but even there the impression of power was less vivid than that produced by the rush of the river, compared with which the united exertions of the human race seemed but a fecble conception. The Don, upon the premises of Mr. Farquharson, forced a mass of four or five liundred tons of stones, many of them of great size, up an inclined plane, rising six feet in ten yards; and one of nearly four tons weight,

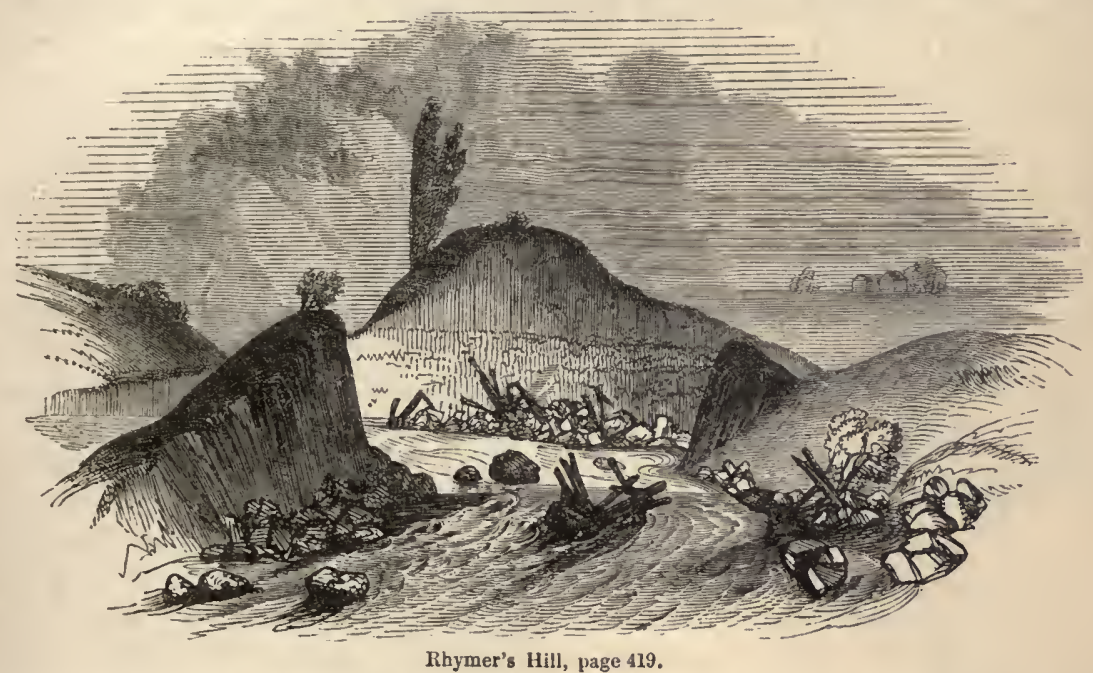

which he had long known in a deep pool of the river, was borne upwards of a hundred yards from its place. Yet evidence appears of the transporting power of water having been in action, at some former period, in this locality, with more gigantic energy than was developed in 1829, for a block of gneiss, weighing about a hundred tons, and lying below the junction of the Divie and the Dorback, upon a shelf of schistus, was not moved an inch by the latter flood, which must have been translated to its present position, and therefore by a more formidable inundation, as there is no rock of a similar kind for a considerable distance from it. The mill at Logie, on the Findhorn, standing fifteen feet above the ordinary level of the stream, was saved by the lower story being completely filled up to the ceiling with sand by the flood, which prevented the water working within it, though it rose in the upper story three feet deep. Sir Thomas Dick Lauder, in his singularly interesting and graphic volume on this local deluge, mentions upon his own estate at Relugas the loss of ten thousand points of locality, on which hung many longcherished associations, with the memory of those who can never return to sanctify the new scenes resulting from the catastrophe. "On Sunday," he observes, "the $2 \mathrm{~d}$ of August, I returned from church by the river walk. The day was sultry and cloudy, and a gentle shower began to fall, which hardly penetrated the canopy of leaves overhead, and but added freslness to the surrounding natural objects, and especially to the roses and rhododendrons that were flowering among the rocks; this was the beginning of the rain, that continued without intermission all the night, and for the next two days." The river walk referred to was on one of the banks of the Divie, leading down to the point of its junction with the Findhorn, a pleasure-walk whicl had been constructed with 
especial care to conduct the line at an elevation considered to be beyond tho reach of injury from floods. "The rocks and recesses of the wooded banks, and the little grassy slopes, were corered in a wild way with many thousand shrubs, of all kinds, especially with laurels, rhododendrons, azaleas, lilacs, and a profusion of roses, which were thriving vigorously, and beginning to bear blossoms, whilst the rocks were covered with the different saxifrages, liung with all sorts of creepers, and enamelled with a variety of garden flowers, all growing artlessly, as if sown by the hand of nature. The path was therefore considered to be not unworthy of the exquisite scenery through which it led; but the flood of the 3d and 4th of August left not one fragment of it remaining, from one end to the other. Not a tree, or shrub, or flower, or piece of soil, nay, or of moss or lichen, is to be seen benenth that boldly and sublimely sketched line of flood, that appears on either side, and from end to end of these rocks, like the awful handwriting of God on the wall!" Principal Baircl, then on his way to Relugas, called to the post-boy to stop as he was crossing the Divie Bridge, that he might enjoy the view of the scenery : but " $\mathrm{Na}$, na, Sir," was the reply, "these are ower kittle times to be stopping on brigs!"

The difference in the condition of Relugas immediately before and after being subjected to the action of the flood remarkably illustrates the tremendous power with which the Divie rushed down its beautiful glen. Its sloping banks were converted into perpendicular walls, and a mass of rock appears in the mid-channel which before was at the side of the stream. The offices of the house, originally more than fifty yards from the water edge, and forty feet in perpendicular height above its level, were within a yard of the crumbling precipice. The Divie was before remarkable for the depth of its pools, but owing to the accumulations of sand and gravel brought into its bed, these were so completely obliterated, that, for many weeks afterwards, a dog might have walked down its whole course, from Edenkillie Church to the Findhorn, without difficulty. The swimming pool at Relugas hat a depth of sixteen feet of water; but a deposit of gravel twenty feet deep was laid in it, changing the pool into a shallow, the bottom of which was four feet higher than the former surface of the water. "The whole scene," remarks the proprietor, while enacting, "liad an air of unreality about it that bewildered the senses. It was like some of those wild melodramatic exhibitions where nature's operations are out-heroded by the mechanist of a theatre, and where mountains are thrown down by artificial storms. Never did the unsubstantiality of all earthly things come so perfectly home to my conviction." What transpired in this neighbourhood may be taken as a sample of the changes tlat were produced through the wide extent of country reached by the waters of the flood. At Loch-na-mhron, a small lake, with a swampy island in the centre, a current drore into it with such force as to undermine and tear up the island, and carry it in mass to the opposite shore, where it was left stranded upon the bank. We have a record of remarkable transitions at a point of the river Nethey, extremely interesting to the geologist, the work of successive floods occurring during the interval of about a lundred years. A Company once were pounding iron-ore with their ponderous hammers, moved by active machinery, in its bed. These actors disappeared, and the river soon obliterated all traces of them and of their works, by filling up its channel there with rounded masses of stone mingled with gravel, upon which its waters were compelled to seek another bed considerably to the westward. But flood succeeded flood; and the quieter portions of ench successive inundation spread over the ground, where, by degrees, they deposited a deep and fertile soil, forming a rich piece of land, the surface of which was six or cight feet above the level of the ground the works of the Company had occupied. The greater part of this beautiful flat was soon subjected to tillage; and, the seeds of some neighbouring alder trees finding their way into a portion of it, a grove speedily made its appearance. The trees grew till they became tall and majestic, and agricultural labour went on, till the 
flood of 1829 came down, when the mantle of alluvium was torn off, the corn land and the grove were swept away, and the memorials of manufacturing industry were again exposed to the light.

The excavating power of water when confined to a channel too narrow for it, and where
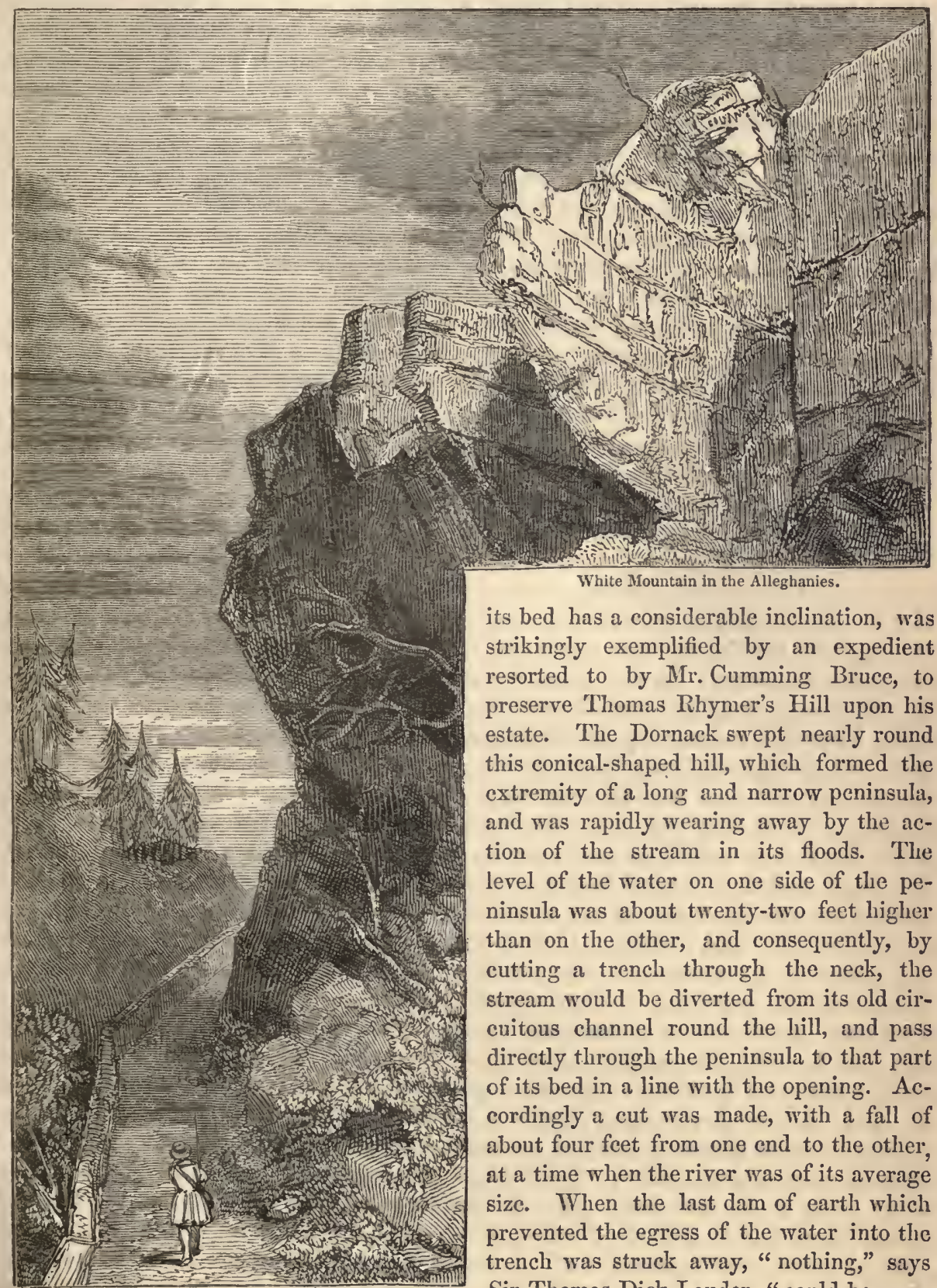

its bed has a considerable inclination, was strikingly exemplified by an expedient resorted to by Mr. Cumming Bruce, to preserve 'Thomas Rhymer's Hill upon his estate. The Dornack swept nearly round this conical-shaped hill, which formed the extremity of a long and narrow peninsula, and was rapidly wearing away by the action of the stream in its floods. The level of the water on one side of the peninsula was about twenty-two feet higher than on the other, and consequently, by cutting a trench through the neck, the stream would be diverted from its old circuitous channel round the lill, and pass directly through the peninsula to that part of its bed in a line with the opening. Accordingly a cut was made, with a fall of about four feet from one end to the other, at a time when the river was of its average sizc. When the last dam of earth which prevented the egress of the water into the trench was struck away, " nothing," says Sir Thomas Dick Lauder, "could be more interesting and striking than this event, where the effect of a single blow was, in 
one moment, to produce so great a change in nature's works - a change which, though wrought by a single hand, was, in itself, and in its consequences, so vast and un. controllable, that, if thousands of men had been on the spot, they could not have turned that river back again. On swept its devouring columns, with the low hissing sound of a serpent, but with the foree and swiftness of an eagle sweeping to its prey." The view of the trench at the time it was opened, and twenty four hours afterwards, was most striking. The banks, being undermined, rapidly gave way, falling in huge masses at a time, and ultimately the Dornack reduced its new eourse to an inclined plane, extending a considerable way back from the opening, with a channel sufficient in width to accommodate a mueh larger river. The Rhymer's Hill, for whose preservation this turn was given to the Dornack, is connected with a tradition respecting the extinetion of the last wolves from the district, and was therefore a spot of some interest in the neighbourhood. Two brothers having watched the parent animals from their den, one stationed himself at the entrance to give the alarm in case they returned, while the other went in to destroy the cubs. Before this was aceomplished the wolves eame back, when the sentinel fied without giving any signal, under the influence of a sudden panie. Ashamed of his cowardice, and not doubting the fate of his brother, he gave out that he had been killed in the den, and wounded himself in several places to make it appear that he himself had with difficulty escaped. But after a severe contest with the enraged animals the brother succeeded in despatching them; and upon the diseovery of the treachery and deceit of the other, the laird adjudged him to be hanged on the Rlyymer's Hill.

A sudden and extensive landslip occurred in the year 1826, in the White Mountains, the name of that part of the Alleghanies, which lies in New Hampshire, one of the United States, so ealled from the greyish white colour of the bare rocks at their summits. Here there is a pass, or notch, according to the language of the district, about six miles in lengtl. The mountains on each side rise from 1800 to 2000 feet, at an angle of about $45^{\circ}$, and form a valley less than half a mile in width, along which a roaring streamlet, the Saco, takes its course. At the period in question, a farmer of the name of Willey, with his wife, five children, and two labourers, occupied a small farm at the upper end of the valley, hospitably entertaining the benighted travellers who sought the shelter of their roof. It was the only house in the notch, and their nearest neighbours were six miles distant. At that time, the hills were mantled with large forest-trees and shrubs, so that no disturbance of their site could have happened for ages, nor had anything occurred to render the family doubtful as to the perfect safety of their position. But in the month of June, a small slide of earth took place from the top of the surrounding hills, which so alarined the dwellers below by the devastation it made, as to induce them to retreat half a mile down the Saco, erecting a temporary camp upon an apparently safer spot. After two unusually dry seasons, in the beginning of July, the clouds collected about the summits of the mountains, and commenced the discharge of a deluge of rain, while the wind blew a hurricane, which continued with unabated violence for several days. On the night of the 26th, the tempest raged with tremendous fury, accompanied with loud thunder and vivid lightning. The valley was inaceessible, owing to the great swelling of the Saco; but when a peasant entered it by swimming his horse across an eddy, the terrible spectacle presented itself, of the entire face of the hills having descended in one confused mass into the valley. The Willeys' house appeared upon its old site uninjured in the midst of the vast ehaos. But the home was desolate. The lifeless bodies of its former inmates, after some days' search, were found 'buried beneath a mass of wood and rubbish, not far from their own door. It seems, that, after retiring to rest, they had been alarmed by the noise of the descending materials, and flying out of their dwelling, they had been swept away by the torrent of earth, stones, trees, and water that eame rushing 
down the hills with the impetuosity which an abrupt declivity of 1800 feet would give it. What was most remarkable, the torrent, after coming within four feet of the house, had divided into two branches, sweeping round it, and forming a junction within a few yards of the front, so that a flock of sheep under the lee of the house were saved, while the family leaving it perished. Every other part of the valley was covered with the dislodged matter of the hills to the depth of several feet, and a person from the rear of the house might step upon its roof with ease. The sides and summits of the mountains presented immense scars and seams, from which masses of earth and rock, with the vegetation upon them, had slid down. Some days afterwards, a small mass bearing a thick pine forest was seen to be in motion, and after proceeding slowly from its place, it began to totter, and then fell headlong into the valley. In accounting for this fearful incident, which answered to what fancy pictures of the wreck of nature, it may be supposed, that the previous hot seasons had so dried and cracked the ground, that the subsequent rains found easy admission to a considerable depth below the surface, their violence rapidly undermining the substratum, and the action of the wind upon the trees contributing to put the whole in motion.

Turning to those parts of the globe where the sandy deserts are situated, a series of changes are there in process, the wind perpetually altering the disposition of the sand, and scattering it far and wide in flying clouds. Hence the domains of the desert have in several places been extended since the date of authentic history, and many fertile spots been converted into sterile regions. Cities and towns to the west of the Nile, flourishing in the times of the Pharaolis, and even the Ptolemies, have been buried by the sand-drifts, and more modern erections likewise, for the summits of minarets and mosques remain visible above the surface. In the course of ages, the desert had so completely overwhelmed the great temple of Ebsamboul, one of the most stupendous of those rock-hewn wonders for which the ancient Egyptians were so famous, that of the four colossal statues in front, sixty feet high, nothing remained visible but the solitary bust of one of these figures. It required from July 11 th to August 1st, for Mr. Belzoni and Captains Irby and Mangles, with their servants and some Nubian retainers, to effect the clearance of the doorway, and the accumulated sand was of so fine a description that every particle of it would have gone through an hour-glass. Professor Jameson gives a statement from the Mercure de France, written by a brother of M. de Luc, to the effect that the sands of the Lybian deserts, driven by the west winds, have left no lands capable of tillage on any part of the western banks of the Nile not sheltered by mountains. The encroachment of these sands on soils which were formerly inhabited and cultivated is evidently seen. M. Denon informs us, that summits of the ruins of ancient cities buried under these sands still appear externally: and that but for a ridge of mountains called the Libyan chain, which borders the left bank of the Nile, and forms, in the parts where it rises, a barrier against the invasion, the shores of the river, on that side, would long since have been uninhabitable. Nothing, he says, can be more melancholy than to walk over villages swallowed up by the sand of the desert, to trample underfoot their roofs, to strike against the summits of their minarets, to reflect that yonder were cultivated fields, that there grew trees, that here were even the dwellings of men,-and that all has vanished! Jameson remarks upon these statements, that the great population of Egypt, announced by the vast and numerous ruins of its cities, was in a great part due to a cause of fertility which no longer exists, and to which sufficient attention has not been given. The desert was formerly remote from Egypt, the oases, or habitable spots, still appearing in it, being the remains of the soils formerly extending the whole way to the Nile, which the sands transported hither by the western winds lave overwhelmed, and thus doomed to sterility a land which was once remarkable for its fruitfulness. He concludes, therefore, that Egypt owes the loss of her ancient 
splendour, not solely to lier revolutions and changes of sovereigns, but also to her having been invaded by the desert, deprived by it of a tract of land by which her wants liave been abundantly supplied. The preceding paragraphs require some modifieation, for, though the sand has spread over the irrigated land on the west of the Nile, where valleys open, running out towards the Lybian desert, yet this effect is by no means general throughout the valley of the river, while in other places the alluvinl deposit from it has been extended over a wider surface, compensating for the loss from the sand-flood. The plain of Thebes, in the time of Amunof III., about 1430 s. C., was not more than two-thirds of its present breadth. The alluvial nuud around the statues of that monarch,

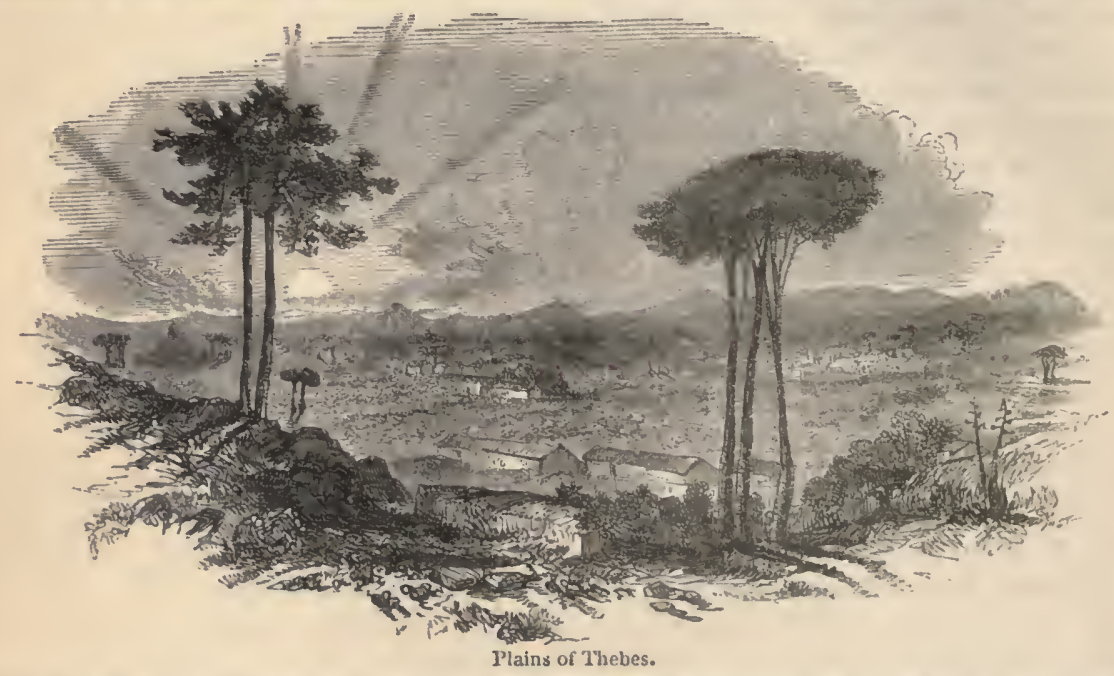

which has been collected to the height of nearly seren feet, rests on sand, which shows that if the desert has invaded the cultivable soil yielded by the Nile, the river has returned the visit. While great and disastrous changes hare undoubtedly taken place at many points in the physical condition of the country, since the time when the gigantic statue of Memnon was ereet, and the temples were frequented, the social and political causes have been far more influential in reducing Egypt from a state of advanced civilization to a level with the " basest of kingdoms."

The aspect of the whole region of deserts, extending with few interruptions laterally through the heart of the old world, where the sand lies loose, fluctuates under the influence of the wind. The finer particles, caught up by it, are drifted to some arresting object, the carcase of a camel, a block of stone, or a shrub, around which they collect, and form those mounds which relieve the level surface, and are variously modified under the action of the cause that produces them. In several localities upon the great plain of ancient Babylon, these sandhills appear, styled by the Arabs El Aïyat, a miracle, or Iyad, a large heap of sand, or Wilayat Beni Ismael, the dominions of the sons of Ismael. They occur on the level plain, and exhibit the curious phenomenon of constantly shifting their place and varying in amount, and yet always remaining in the same general locality. 'They are thought to owe their existence to the presence of springs, which moisten the sand and cause its accumulation, while the prevailing winds alter their form witlout varying their position, owing to their bases having a fixed point of attraction. To the Arabs they are objects of superstition, who look upon them as the sepulchres of brethren fallen in battle, and hence recognise them as the dominions of the sons of Ismael. The lamented Sir A. Burnes mentions vast fields of soft sand formed into ridges lying between 
Bokhara and the Oxus, utterly destitute of vegetation, which have a remarkably uniform aspect. 'The whole of them had the shape of a horse-shoe, the outer rim presenting itself to the north, the direction of the prevalent winds of the country. Towards this direction, the mounds sloped, but were invariably precipitous on the interior side, showing plainly the influence of the winds in heaping them up, and arranging their contour. While a high wind was blowing, the particles at the surface passed from one mound to another, and wheeled in the interior of the semicircle. The great river of this district, the Oxus, is supposed to have been compelled to alter its course, or at least to have lost one of its branches, by the advance of the descrt. According to Strabo, goods from India were brought along this river into the Caspian, and from thence were transferred into Europe; a fact, which Varro informs us was ascertained by Pompey in the Mithridatic war. The Oxus now enters the sea of Aral, but dry river-beds between Astrabad and Khiva are thought to be the memorials of the channcl from which the encroachment of the sand has expelled its waters.

In active volcanic districts, we have an instrument of change occasionally at work, of irresistible encrgy, sublime in the manifestations of its power, but happily having a more confined field of operation than any of the causes which hare been noticed as modifying the aspect of the slobe. It is near the centres of volcanic action that alterations are effected by the play of the subterranean furnaces, and thesc occur here upon a vast scale, a permanent rise being frequently given to the surface of the adjacent country by the discharge upon it of enormous volumes of lava, stones, and ashes. The complete burial of the ancient cities of Pompeii and Herculaneum illustrates the immense amount of matter then ejected from Vesuvius, the first recorded instance of its eruption, in the month of August, A. D. 79. We are told by Diodorus Siculus that the mountain had "many signs of having been burning in ancient times," and Strabo infers its igneous origin from the nature of its rocks; but at the time in question, its slopes were richly cultivated and proverbially fertile, and just before, its top, a slightly concave plain, according to Virgil's description, had been the camp where the Romans besieged the brave Spartacus and his revolted slaves. Martial's epigram testifies to the harmlessness of Vesuvius anterior to the disturbance to which we refer, a character which had certainly belonged to it for several ages.

"Here verdant vines o'erspread Vesuvius' side;

The generous grape here pour'd her purple tide,

This Bacchus lov'd beyond his native scene;

Here dancing satyrs joy'd to trip the green,

Far more than Sparta this in Venus' grace;

And great Alcides once renowned the place.

Now flaming embers spread dire waste around,

And gods regret that gods can thus confound."

It was during the first movement of Vesurius after ages of inaction, and perhaps the most formidable of its eruptions in modern times, that the elder Pliny lost his life, of which we have a description by his nephew in two letters to Tacitus. "He was at that time," remarks the narrator, "with the fleet under his command at Misenum," the Portsmouth of the Roman navy, as it has been styled. "On the 24th of August, about one in the afternoon, my mother desired him to observe a cloud which appeared of a very unusual size and shape - he immediately arose, and went out upon an eminence, from whence he might more distinctly view this very uncommon appearance. It was not at that distance discernible from what mountain this cloud issued, but it was found afterwards to ascend from Mount Vesuvius. I cannot give you a more exact description of its figure, than by resembling it to that of a pine-tree, for it shot up to a great height in the form of a 
trunk, which extended itself at the top into a sort of branches." The phenomenon cxcited the philosoplical curiosity of Pliny to have a nearer view, and he was preparing to obtain it, when a pressing message was delivered to him for help, from the occupants of some villas in peril. "When hastening to the place from whence others fled with the utmost terror, he steered his direct course to the point of danger, and with so much calmness and presence of mind, as to be able to make and dictate his observations upon the motion and figure of that dreadful scene. He was now so nigh the mountain, that the cinders, which grew thicker and hotter the nearer he approached, fell into the ships, together with pumice-stones, and black pieces of burning rock. 'They were likewise in danger, not only of being aground by the sudden retreat of the sea, but also from the rast fragments which rolled down from the mountain, and obstructed all the shore. Here he stopped to consider whether he should return back again, to which the pilot advising him, 'Fortune,' said he, "befriends the brave. Carry me to Pomponianus." Proceeding to Stabia, he found Pomponianus in the greatest alarm, and the paroxysms of the mountain became still more violent, so as to compel them to an instant flight. "They went out then, having pillows tied upon their heads with napkins; and this was their whole defence from the storm of stones that fell around them. It was now day every where else, but there a deeper darkness prevailed than in the most obscure night, which, however, was in some degree dissipated by torches and other lights of various kinds. They thought proper to go down farther upon the shore, to observe if they might safely put out to sea, but they found the waves still run extremely high and boisterous. There my uncle, having drank a draught or two of cold water, threw himself down upon a cloth which was spread for him, when immediately the flames, and a strong smell of sulphur, which was the forerunner of them, dispersed the rest of the company, and obliged him to rise. He raised himself up with the assistance of two of his servants, and instantly fell down dead, suffocated, as I conjecture, by some gross and noxious vapour. As soon as it was light again, which was not till the third day after this melancholy accident, his body was found entire, and without any marks of violence upon it." No lava was emitted from Vesuvius upon this occasion, but the shower of sand, stones, and cinders, lasting eight days and eight nights, accompanied with violent falls of rain, was so great, as to overwhelm the cities of Stabix, Herculaneum, and Pompeii, which vanished from the face of the country, and lay buried under horizontal beds of loose tuff and lapilli till the commencement of the last century. Herculaneum, indeed, was subsequently covered to the depth of eighty or a hundred feet with solid volcanic masses, the consequence of repeated eruptions, so as to render its total disinterment hopeless; but Pompeii has remained with tlie mantle of ashes which originally destroyed it, about twenty feet thick, the loose material rendering its removal comparatively easy. Here, in the Street of the Tombs, as it has been called, a part of the suburbs of the city, seventeen skeletons were found huddled together in one of the vaults of a villa, while two others, one bearing a key, and supposed to have been the master of the house, lay stretched in the garden. Two of those in the vault were the remains of children, whose fair hair was well preserved; most of the rest were females, the impression of their forms on the volcanic sand indicating youth and beauty.

Professor Silliman has made admirable use of these unfortunate cities, in illustrating the nature of geological evidence. Referring to the very singular fact, that while history mentions the existence of the cities repeatedly, and records the eruption of Vesuvius, as in the letter of Pliny, no allusion whatever occurs to their destruction, he observes:"When, in 1738, the workmen, in excavating a well, struck upon the theatre of Herculaneum, which had been buried for seventeen centuries beneath the lava of Vesuvius; when, subsequently (1750), Pompeii was disencumbered of its volcanic ashes, and thus two ancient cities were brought to light; had history been as silent respecting their existence 
as it was of their destruction, would not all observers say, and have not all actually saidHere are the works of man, his temples, his houses, furniture, and personal ornaments; his very wine and food; his dungeons, with skeletons of the prisoners chained in their awful solitudes, and here and there a victim overtaken by the fiery storm? Because the soil had formed, and grass and trees had overgrown, and successive generations of men had erected their abodes over the entombed cities, and because these were covered by lava and cinders, - still does any one hesitate to admit that they were once real cities; that they stood upon what was then the surface of the country; that their streets once rang with the noise of business; their halls and theatres with the voice of pleasure; and that they were overwhelmed by the eruptions of Vesuvius, and their places blotted out from the earth and forgotten? These inferences no one can dispute-all agree in the conclusions to be drawn. When, moreover, the traveller sees the cracks in the walls of the houses of Pompeii, and observes that some of them have been thrown out of the perpendicular, and have been repaired and shored up with props, he infers that the fatal convulsion was not the first, and that these cities must have been slaken to their foundation by the effects of previous earthquakes. In like manner the geologist reasons respecting the physical changes that have taken place on the surface of our globe. The crust of the earth is full of crystals and crystallized rocks; it is replete with the entombed remains of animals and vegetables, from mosses and ferns to entire trees - from the impressions of plants to whole beds of coal. It is stored with the remains of animals, from the minutest shell-fish to the most stupendous reptiles. It is chequered with fragments, from fine sand to enormous blocks of stone. It exhibits in the materials of its solid strata every degree of attrition; from the slightest abrasion of a sharp edge or angle, to the perfect rounding which produces globular and spheroidal forms of exquisite finish. It abounds in dislocations and fractures; with injections and filling up of fissures with foreign rocky matter; with elevations and depressions of strata in every position, from the horizontal to the vertical. It is covered with the wreck and ruin of its former surfaces; and, finally, its ancient fires, although for a while dormant, have never been wholly extinguished, but still find an exit through volcanic mouths. When we reflect upon these phenomena, we cannot hesitate to infer that the present crust of the earth is the result of the conflicting energies of physical forces, governed by fixed laws; that its changes began from the dawn of the creation, and that they will not cease till its materials and its physical laws are annihilated."

The mass of matter ejected from many volcanoes, whether lava, stones, or ashes, has frequently been of gigantic magnitude, adding thick layers of material to the surface of the country over which the currents have streamed, and upon which the showers have fallen. Vesuvius, in 1737, gave out a stream of lava, which passed through Torre del Greco to the sea, and contained upwards of $33,587,058$ cubic feet; and in 1794 a lava current pursued the same course, its solid contents amounting to $46,098,766$ cubic feet. In 1669, Etna gave forth 93,838,950 cubic feet; and the sand and scorix formed the Monte Rossi near Nicolosi, a cone two miles in circumference, and about 450 feet high. The lava contained in two currents from the Skaptar Yokul in Iceland in 1783, which was so hot twelve months afterwards as to be impassable, has been subjected to the following calculation. "Assuming the average breadth of the first current as six miles, and of the second as three, both probably below the truth, the one would cover 300 square miles, the other 120 , or 420 in all. With an average depth of fifteen yards, the combined mass would contain $420 \times 3097600 \times 15=19,514,880,000$ cubic yards, or nearly twenty thousand millions. But this comprises only that portion which flowed into the inhabited district, whilst it is likely that an equal or greater quantity remained heaped up around the crater, or flowed off into the unknown regions of the interior. To this must 
also be added the pumice, sand, and ashes, scattered not only over the whole island, but to a distance of 300 miles round, in such abundance as to destroy the fisheries in the neighbouring sea. With these additions it would amount, we may believe, to fifty or sixty thousand millions of cubic yards, exceeding the solid contents of Hecla, which, if six miles in diameter at the base, and 1700 yards high, would contain nearly fifty thousand millions $(49,537,270,000)$ of cubic yards. This is probably larger than any individual mass of the older igneous rocks known to exist." This one discharge of this volcano, if spread over the coal fields of Great Britain, would cover them with a coating of basaltic rock twenty feet thick, or accumulated together upon the site of London, the product would be a mountain rivalling the Peak of Teneriffe.

Besides the deposition of horizontal beds of cjected matter, the bulging up of the surface in the form of cones and hills of considerable elevation and diameter, on the flanks of volcanic mountains, or on plains subject to volcanic action, is a common instance of change wrought by the mighty disturbing foree exerted. Thus the entire volcano of Jorullo arose out of a plain to the west of Mexico, to the height of 1680 feet, the surrounding district, through an area of three or four miles, being swelled up like a bladder, studded with cones of inferior size. The formation of Monte Nuovo in the neighbourhood of Naples, and of Monte Rossi upon the side of Etna, are instances of similar phenomena. Extensive subsidences also frequently attend volcanic eruptions. The greater part of the Papándayang, on the western extremity of Java - one of the largest volcanic mountains of the island-was swallowed up in the year 1772. On the night of this event, the inhabitants on the declivities and at the foot of the mountain were alarmed by the appearance of a luminous cloud, which seemed to envelop the higher regions; but before they could retire from the vicinity, the mass began to give way, and disappeared with a tremendous noise in the earth. An extent of ground belonging to the mountain itself and the environs, fifteen miles long and six broad, subsided by this convulsion. The formation of cracks and fissures is another feature of change effected by volcanic ageney. In 1669, in the plain of St. Lio, upon the side of Etna, a fissure six feet broad and of unknown depth opened with a loud crash, traversing a length of twelve miles, and emitting a vivid light, indicating the presence of incandeseent lava. Five other parallel fissures also opened, extending a considerable way; and the same effect has been often produced by the paroxysmal excitement of Vesuvius. The external appearance of active volcanic mountains is thus in a state of striking instability; and in not a fer instances great changes may be traced, both of form, elevation, and magnitude. Though the altitude of Etna may not have materially varied during the last 2000 years, yet the cone has repeatedly fallen in, and been reproduced. It was 320 feet high in the year 1444, but fell in during the earthquake of 1537 ; and, after reproduction, the cone lost so much of its height in 1693, that, from several places in Val Demone, it ceased to be visible where it had been seen. The summit of Vesuvius, about a quarter of a century ago, was a rough and rocky plain, covered with blocks of lava and seorix, and cut by numerous fissures, from which clouds of vapour were erolved. These were all removed by the violent eruptions of October 1822; and a vast elliptical chasm was formed, three miles in circumference, three quarters of a mile in the longest diameter, and about two thousand feet deep. Upwards of eight hundred feet of the ancient cone were carried away, which reduced the height of the mountain from 4000 to 3200 feet. But whaterer changes may have transpired within the period embraced by the records of history, they are utterly insignificant to those anterior to that date, of which the geological appearance of Etna exhibits indisputable evidence. All the most conspicuous of its eighty lateral cones are older than the era at which authentic history commences, and bear witness to violent catastrophes in the hoar antiquity of time; and as one in three eruptions is supposed to 
take place from the summit - as every eruption from the flanks does not produce a cone - and as great intervals of rest occur between successive explosions, in some instances amounting to a century, the mere superficies of Etna develops a series of changes which carry us back to a vastly remote date.

However limited the field of active rolcanic operation, and local the effects of the enormous fires that occasionally flare up, and perpetually smoke, large tracts of country furnish unquestionable proof of having formerly been scenes where "fire ran along upon the ground," though no record exists of such explosions but that written by the eruptive force upon the face of the territory subject to its ravages. The Roman plain is one of these districts. Nowhere east of the Apennines, or in the central range, is any trace discoverable of volcanic eruptions, except along a line drawn eastwards from Campania to Horace's Mount Vultur - a conical hill of lava and tuff, from whose sides issue carbonic acid and sulphuretted liydrogen. But a great part of the Campagna of Rome is, in one sense or another, a volcanic formation, a fact which illustrates some of the traditions of the Eternal City. Westphal and Hoffmann have minutely examined the geology of the Roman plain, from whose memoirs upon the subject the following account of the changes that have transpired is condensed. At a time when the sea washed the sides of the Sabine and Volscian mountains, and the plain lay deep beneath the waters of the ocean, it was thrown into disorder by the breaking out of numerous volcanoes. One of the principal centres of disturbance was at the northern extremity in the Ciminian Hills, where a chain of volcanic heights now appear, among which Monte Soriano lias an elevation of 4000 feet above the level of the sea, and is covered with currents of trachytic lava. The Alban Mount was another centre in the southern quarter, from which a great stream of lava may be traced for rather more than eight miles, ending near the tomb of Cecilia Metella, and was largely used by the old Romans as material for paving their roads. Both centres discharged a prodigious quantity of ashes and scorix, which by long deposition beneath the waters became agglutinated into the earthy rock called tuff, of which several varieties are frequent in large masses about Rome. The catacombs are excavated in the "tufa granulare," a soft, dark-coloured, granular sort, which furnishes the Roman cement of commerce. In the "tufa lithoides"-a more compact rock-the cavities were quarricd, which were afterwards the prisons of the Capitol. The Seven Hills are composed of these volcanic products, resting upon marine alluvial deposits. In that of the Capitol, upon a bed of sand and clay - the uppermost marine formation there is granular tufa ten feet in thickness, and about a hundred feet of lithoid tuff over it, rising to the summit. The Palatine, Viminal, Quirinal, and Pincian hills are chiefly composed of granular tuff, which appears mixed with the lithoid in the Esquiline, Cælian, and Aventine. For a long period after the volcanoes began to play, the sea must have rested upon the plain, to allow of the formation of these tufaceous beds beneath its waters, derired from the ashes and scorix, and now overlying the alluvial marine strata. At length the fires died away; the waves withdrew, through the land rising suddenly or by degrees; a series of lakes remained, gradually drained by the Tiber and the Anio as they scooped out their channels; the Latins came down from the Apennines; and Rome arose to become for a season the mistress of the world. Of these physical changes we have an enduring memorial graven, as with a pen of iron, upon the Campagna. Its lava currents, its tufaceous masses, and its crateriform mountains, proclaim the occurrence here of unwritten catastrophes.

Equally significant are the appearances presented by a district in the southern part of Central France, more than forty miles in length and twenty in breadth, which was formerly comprised in the provinces of Auvergne and Languedoc. Here are found unquestionable evidences of long-extinguished subterranean fires, in more than two hundred 
cones, craters, volcanic hills and mountains, which have discharged their red-hot streams of lava, and showers of ashes, at some former period of the history of the globe, the antiquity of which, the application of thousands of years will go but a little way to measure. This district has been attentively examined by Mr. Bakewell and Mr. Poulett Scrope, whose memoirs upon it are full of interesting and striking facts to the plysical inquirer. It was not till the year 1751 that the existence of this volcanic region was known, when II. Gnettard and a companion naturalist, returning from Vesuvius, stopped to botanise upon the mountains in Auvergne, and were surprised at the resemblance they bore to the Italian voleano, and at the similarity of the lavas and minerals in both. The valley of Clermont exhibits a series of fresh-water limestone strata upon a substratum of granite, which appear in the surrounding hills interposed between the granite and voleanic rocks; but, ascending towards the west, all traces of the limestone disappear, and the volcanic rocks rest immediately upon an elevated granitic plain. From this plain a number of conical and dome-shaped mountains rise, the highest of which - the Puy de Dôme celebrated by the barometrical experiments of Paseal, ascends 3451 feet above the town of Clermont, and 4797 feet above the level of the sea. Some of the mountains preserve the forms of well-defined craters, from which currents of lara may be traced descending into the present valleys. 'The crater of the Puy de Pariou, 3800 feet above the level of the sea, is as perfect as that of any recent voleano, and from it, or from the flanks of the mountain, a lava current has streamed, now lying upon the plain, from thirty to sixty feet thick, covered with seoriæ and basaltic lava. All the aceompaniments of voleanic action, with the exception of the phenomenon of an actual eruption, are found in Auvergne in as perfect a manner as at Etna and Vesuvius, in the Lipari Islands and Iceland; and the interposition of stratified formations among the voleanic products show different and distinot periods separating the eruptions from each other. The lavas have been cut by the action of rivers, which have not only exposed the columnar basalt which now forms the precipitous walls of their ehannels, but have eaten their way into the granitic rock beneath, these exeavations having of course been executed subsequent to the eruptions which poured the fiery floods into the valleys. "Yet when did these fires burn? When took place this amazing combination of voleanic eruptions and their terrible accompaniments? How long ago was the last of them? And by what interval of time could we ascend, from that last, to the earlier eruptions, and to the earliest - of the astounding number?" It is certain that we must go by several thousands of years at least to arrive at the era of the last disturbance.

The general history of Europe contains no record of any volcanic eruption in Auvergne, nor does any thing occur in any rhyme or legend of the monkish chroniclers from which it might be inferred. Some, indeed, have deemed it not improbable that in a thinly inhabited country like that of the mountain parts of this province, the voleanoes might have been in action after the fall of the western empire, without being noticed or known by the historians of the barbarous ages, when men were too earnestly engaged in destroying each other, or in providing for their own safety, to bestow much thought on natural phenomena. But this supposition will not bear examination, for monastic pens were busy enough at the time in question; and to surmise the occurrence of such physical convulsions in the heart of Gaul, without the rumour of them gaining a wide circulation, and long surviving in the traditions of the locality, is obviously extravigant. Going farther back, we find Cæsar encamped at Gerzovia in this very district during his Gallic wars; yet, though his Commentaries show that he surveyed the country with a careful eye, he mentions no volcanic outbreaks, nor records any tradition picked up in the neighbourhood of such events having formerly oceurred. But the water-worn lavas conduct us much farther back into the past. It requires a long period for the action of a river to cut 
into a hard rock to any extent; yet the beds of basalt in the district have in several places been corroded by the streams to the depth of from 150 to 160 feet, and the underlying granite rocks have been penetrated. The production of effects of this magnitude, by a cause which is so slow in its operation, requires an amount of time, in comparison with whieh the historic period is a trifling span; and hence it follows that the volcanic fires which discharged the liquid masses of these various lavas belong to an era incaleulably remote. "Such analogies," says Dr. Smith, "as may be inferred by comparative examinations of the condition of Etna, Vesuvius, and other active voleanoes, earry us to the contemplation of a period which runs back, not to the age of Noah merely, but immeasurably beyond the date of the creation of man, and his contemporary plants and animals." The geological state of Auvergne, in several respects to which we have not adverted, fully warrants the use of this language. Another important and interesting inquiry has been proposed, - Whether the volcanic fires that once raged in this district are absolutely extinct, or have periods of returning activity at distant intervals of time? In reply, it can only be stated, that at Guadaloupe, in Teneriffe, the Azores, and the Grecian archipelago, volcanic eruptions have been renewed after a cessation of from one to four centuries. Vesuvius also, for four centuries, from the twelfth to the sixteenth, was in a state of repose, so that a forest of chestnut trees was growing in the crater prior to the great outbreak of 1531 ; but previous to the first recorded instance of its activity in 79 , it had certainly been idle for at least seren or eight hundred years, and perhaps for a much longer period. These intervals are however so short when compared with that which has intervened since Auvergne began to repose, that obviously they supply nc data upon which a conjecture of renewed disturbance can be built. There are springs of hot water in the district, as Mount d'Or and Vichy, where the temperature is from $120^{\circ}$ to $125^{\circ}$, which indicate a subterranean source of heat : yet, apart from the extant memorials of volcanic action, nothing can be inferred from the indication, as it is common to localities where those memorials are not found.

A third site, displaying remarkable monuments of volcanic combustion in past ages, may be briefly noticed. 'This is the region of ancient Sardis and Philadelplia, in the

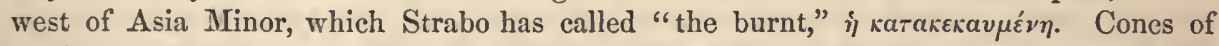
scorie of different ages, lava-flowings forming plateaux upon the summits of isolated hills, and lava currents worn through by the action of running water, are here the monuments of successive eruptions, between which long intervals have occurred, the last of which cannot have transpired for at least three thousand years, otherwise history would have preserved some record of it. Mr. Hamilton has sketched some of the principal features of the Catecucaumene, or burnt-up region of the geographer, as seen from a neighbouring ridge. "Beginning with the north, on our extreme right was the barren termination of the ridge on which we stood; to the west of which a black and dome-shaped lill of scoriæ and ashes rose about 500 feet above the plain. This was the Karedevlit, or Black Inkstand, the voleano of Koula-so near to us that none of the effects of its wild and rugged character were lost, and so steep that to ascend its slope of cinders appeared impossible. In front of us a black and rugged stream of lava extended from right to left, the surface of which, broken up into a thousand forms, looked like the breakers of a sea converted into stone amidst the fury of a gale, and forming, as it issued from the base of the cone, a striking contrast with the rich plain through which it seemed to flow. Beyond, to the N.W., were other voleanic cones, which, from their smooth and cultivated appearance, the vineyards reaching to their summits, must have belonged to a much older period. Further to the left was the town of Koula itself, with its tall and graceful minarets rising above the lava, on the southern point of which it has been built." The Kare-

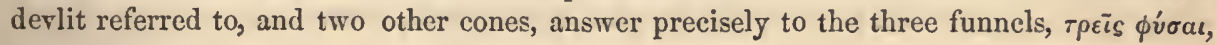


spoken of by Strabo as distinguishing the geography of Lydia, about forty stadia, or five miles, apart; but we may infer the inaction of the rolcanoes in his time, and for a long period before, or otherwise the fact would have been known and recorded. From the foot of each of the cones, a flood of rugged black vesicular lava has streamed, encircling their bases, and flowing down the inclined face of the country towards the bed of the Hermus. In the same region there are upwards of thirty other cones, of a more ancient date than the preceding, as their surfaces show a long course of smoothing from atmospheric influence

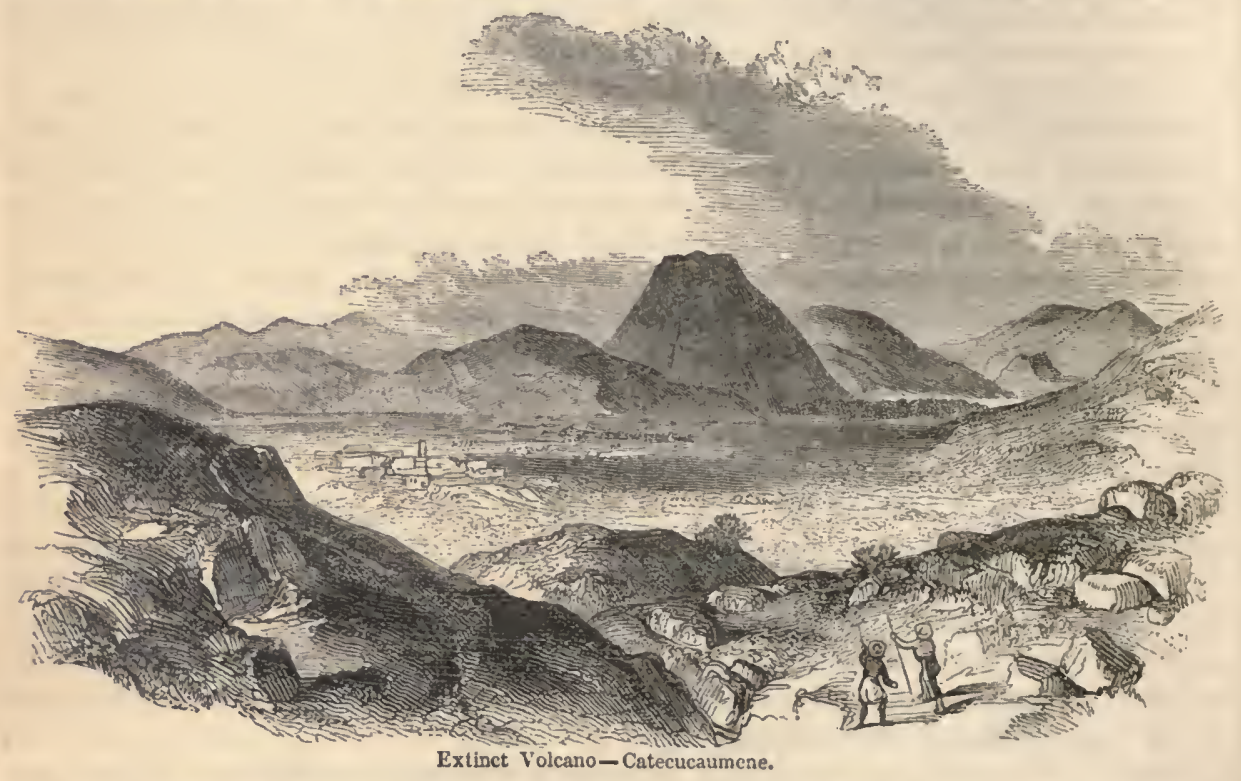

and aqueous action, whereas the dark and cindery sides of the former are rough and undecomposed. From the silence of history, the age of thirty centuries is at least due to the more recent cones, and a greater antiquity belongs to the rest. Thus the Catecucaumene bears silent testimony to physical changes in the remote past, and yet it proclaims the uniformity of those causes of disturbance to which our planet for ages has been subject.

The action of earthquakes, to which we now glance, is a far more potent cause of change in the condition of the terrestrial superficies than that of volcanoes, and far more tremendous to the human race, affecting those level sites upon which they congregate, and often transpiring without a warning. The voleano generally gives preparatory signals of an eruption, by denser columns of smoke issuing from the crater, and loud rumbling sounds proceeding from the interior; its immediate effects are commonly confined either to the mountain itself, or to a scanty area around it: but in the case of an earthquake, the suddenness of the crisis, the extent of its influence, and the nature of the event-the rery ground rocking beneath the feet of its inhabitants - render the visitation the most formidable physical source of peril with which our species have to contend. Both phenomena have unquestionably a common origin, and hence in countries where active volcanoes exist, the people are in expectation of an earthquake, if the former, which operate as a kind of safety-valve, remain long in complete repose. 'The Creoles of South America distinguish two kinds of earthquakes by the terms tremblores and terremotos. The tremblores are slight tremors of the ground, which effect no derangement of the surface, are in some districts of daily occurrence, and transpire with perfect security to 
life and property. The terremotos, on the contrary, indicate violent horizontal oscillations similar to the wave-movements of the sea, or perpendicular upliftings, as if a power was operating upon the roof of a cavern from the interior, struggling to force it open, and dash it away in fragments with everything upon it. By these last forms of the earthquake, buildings are levelled, cities become heaps of ruins, fissures in the ground are opened, rocks are split, lakes are formed, streams receive a new direction, springs are stopped to gush out in fresh sites, and the general level of considerable regions is sometimes depressed or elerated. Such are the features which enter into these natural convulsions, either in combination, or in a more partial manner.

The influence of an earthquake of more than ordinary severity extends to an immense distance from the central seat of action. That which occurred in Chili, in the year 1835 , was felt at all places between the parallels of $27^{\circ}$ and $40^{\circ}$ through thirteen degrces of latitude, approximating to a thousand miles, and through ten degrees of longitude. The most recent formidable earthquake in Europe, that of which Lisbon was the focus in 1755 , was experienced at very remote points of the continent. It turned some of the rivers in Switzerland suddenly muddy without any rain, plainly showing a disturbance of their bed, and at Neufchatel the lake swelled to the height of nearly two feet above its usual level. At Portsmouth, a ship in dock and well secured, the Gosport, was pitcled backwards and forwards several times by the sudden and violent motion of the water. In the moat around Shirburn Castle in Oxfordshire, there was a regular flux and reflux of the water produced. Two miners at work in one of the lead mines at Eyam in Derbyshire, at a depth of more than six hundred feet, noticed the vibration of the earth, which caused some loose pieces of material to drop from the roof and sides of the mine. The lakes of Scotland and Norway, the canals at the Hague, and the springs of Toplitz in Bohemia, gave sensible indications of participating in the catastrophe, which suddenly, after the sun had risen in a serene sky over Portugal, half annihilated the capital, and left signal instances of physical change in that part of the peninsula as monuments of its terrific energy. Extensive, however, as the area through which a severe shock exerts its influence, its more destructive ravages are confined within a comparatively narrow range, which may be called the centre of disturbance, though sometimes there seem to be several foci.

Humboldt, in the narrative of his journey to the equinoctial regions of the New Continent, has recorded all that could be learnt respecting the earthquake of the 26th of March 1812, which destroyed the city of Caraccas, with twenty thousand inhabitants of the province of Venezuela. An abridgment of this account will not only illustrate the human disasters common on such occasions, but the vast area shaken by the subterranean commotions, indicating a common agency exerted at a great depth in the interior of the globe, and bearing witl fatal energy upon particular points. Drought was prevalent through the province of Venezuela at the time, and not a drop of rain had fallen for five months around the eapital. The day of its destruction broke with a calm air and a cloudless sky, and beeame excessively hot. It was Holy Thursday, and the population gathered to the churehes as usual on the festival. Not any token of danger appeared, till seven minutes after four in the afternoon, when a commotion was felt sufficiently strong to make the bells of the churches ring. The ground continued in a state of undulation, heaving like a fluid under ebullition, till a noise was heard louder and more prolonged than the thunder of the fiercest tropical storm, when the undulations became more violent, and proceeding from opposite directions, and crossing each other; Caraccas was overthrown. Subsidences occurred at the churches of the Trinity and Alta Gracia, and the barracks called $E l$ Quartel de San Carlos almost entirely disappeared by the sinking of the ground. The night of Holy Thursday presented a distressing scene of desolation and sorrow, which contrasted sadly with the beautiful aspect which nature 
speedily resumed. The thick clouds of dust which rose from the ruins and darkened the air, had fallen to the ground. The slocks had ceased. Never was there a finer or a quieter night. The rounded summits of the Silla mountain were illuminated by the moon, nearly at the full, and the serenity of the lieavens seemed to mock the disturbed state of the earth, where under a heap of ruins lay nearly ten thousand of the inhabitants of Caraccas. "In this city," says Humboldt, "was now repented what liad taken place in the province of Quito, after the dreadful earthquake of the 4th of Febrnary 1797. Marriages were contracted between persons who for many years had neglected to sauction their union by the sacerdotal blessing. Children found parents in persons who had till then disavowed them; restitution was promised by individuals who had never been accused of theft; and families who had long been at enmity, drew together from the feeling of a common evil." Caraceas was at this period one of the foci of subterranean commotions, which from the beginning of 1811 to 1813 operated on a vast extent of the earth's surface, an area limited by the meridian of the Azores, the valley of the Ohio, and the cordilleras of New Grenada. The shocks fatal to the city were sensibly felt at Honda on the banks of the Magdalena, 620 miles distant. Large masses of earth fell in the mountains, and enormous rocks were detaclied from the Silla. The lake of Maracaybo underwent considerable diminution, but at Valecillo, the ground opened, and emitted so great a mass of water, that a new torrent was formed, the same phenomenon taking place near Porto Cabello. In all parts the disturbance was more violent in the cordilleras of gneiss and miea-slate, or immediately at their base, than in the plains.

A personal examination was made by Dolomieu and Sir William Hamilton of the surface of the Calabrias after the earthquakes which continued from the beginning of 1783 to the close of 1786, and their survey illustrates the superficial changes produced by the action of such events. Those provinces have been subject to such visitations since the first Greek colonists landed upon their shores, but the most terrible instances in modern times occurred in 1633 and 1783, in the latter of which Sicily largely participated. The soil of the mainland is chiefly composed of modern marine strata, immensely thick, generally of calcareous clay, of a very yielding nature, which was greatly disturbed, and assumed a variety of new forms, under control of the irresistible force acting upon it.

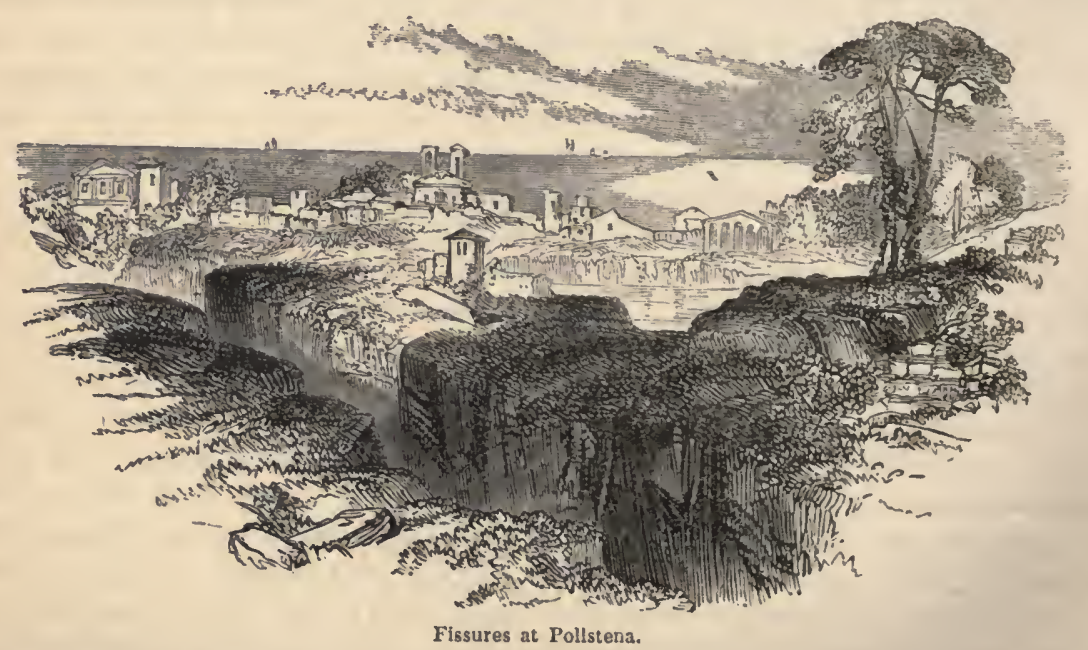

The earth exhibited a variety of motions, called in the Italian accounts vorticoso, orizontale, and oscillatorio, whirling like a vortex, horizontal, or by pulsations or beatings from 
the bottom upwards. Valleys underwent extensive and striking alterations through the precipitation into them of masses from the neighbouring hills. Fissures, radiating from a central point, or single horizontal openings of the ground, appeared in various places,

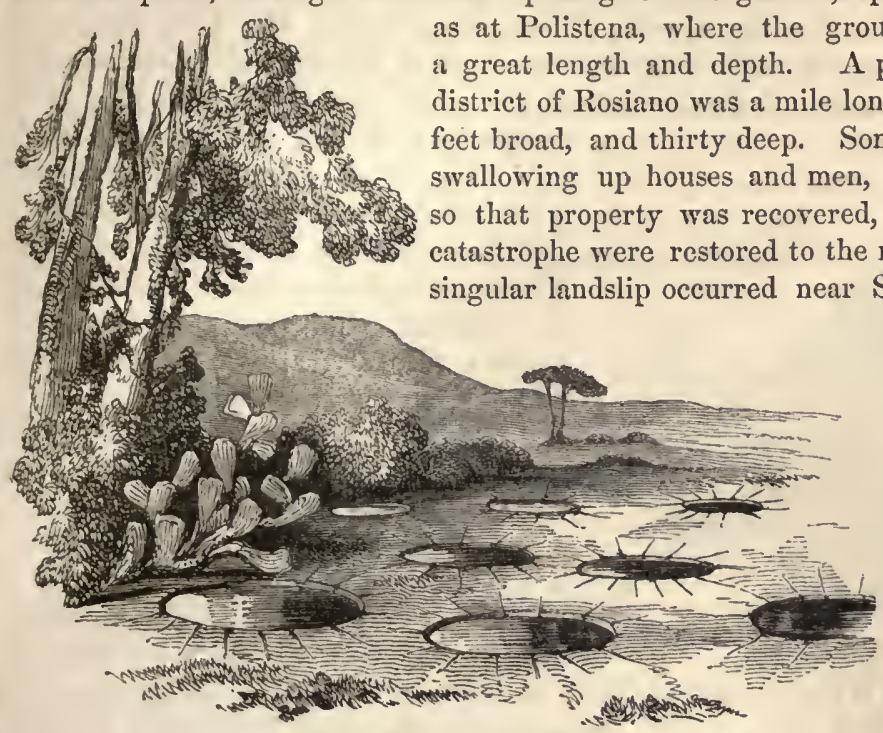

Circular llollows at Polistena. A permanent chasm in the ong, upwards of a hundred Some of these fissures, after $d$, and the victims of the rites of burial. The most Seminaria, where a large olive-ground descended from the heights into the valley, retaining its compactness, a house upon it standing firm, and the olives continued to grow in their new situation, bearing an abundant crop the same year. In the plains, a considerable number of circular funnel-shaped hollows were formed,

filled with water or sand, a consequence of the vorticose or whirling motion of the earth. These are a sample of the effects in one region, of a cause, to the influence of which a vast area of the globe is exposed. We are presented with a continued series of such operations from the earliest times of which we have any knowledge, and hence the fact is sufficiently obvious, that the aggregate has largely altered the physical condition of the globe, though we cannot estimate the amount of the change. The ancients were not much addicted to physical inquiry; they contented themselves with general allusions in their writings to natural phenomena; yet we learn enough from these slight notices to know that, in their day, "Vulcan's habitation" was rife with " terrific flashes," with "noise and terror ;"

\section{Vulcani domus -}

Fulgores terrificos, sonitumque metumque:-

and, brief as is the reference of Thucydides to the earthquake at Eubœe, writing four centuries before Christ, the leading features of the account will apply to that at Lisbon, or Messina, twenty-one centuries afterwards.

We are left entirely to hypothesis as to tlie cause of earthquakes and volcanic eruptions, but of the oneness of that cause no doubt remains. The theory first started by Sir Humphry Davy, suggested by his discovery of the metallic bases of the earths and alkalis, and since elaborated by Dr. Daubeny, has found very general acceptance. According to this lypothesis, which is that of Subterranean Oxidation, the earth is supposed to contain in its interior, at a great depth and in sufficient quantity, the earthy and alkaline metalloids, iron, sulphur, and sulphuretted salts. These are substances which combine with oxygen with avidity, a high temperature and strong inflammation being the result of the combination. A supply of water reaching the interior of the earth, becomes decomposed by contact with the metalloids, and yields its oxygen to them, occasioning the phenomena of combustion and explosion, which may be imitated upon a 
small scale, by burying in the ground a moistened mixture of sulphur and iron filings, when the mass becomes gradually heated, takes fire, and explodes. The lava which flows out to the surface in volcanic eruptions, or is driven up in dust and scorix, is owing to the violent extrication, through a vent, of the steam which has been generated, accumulated, and confined, the oscillations and heavings of the ground in earthquakes being produced by the action of elastic vapours and gases endeavouring to effect their

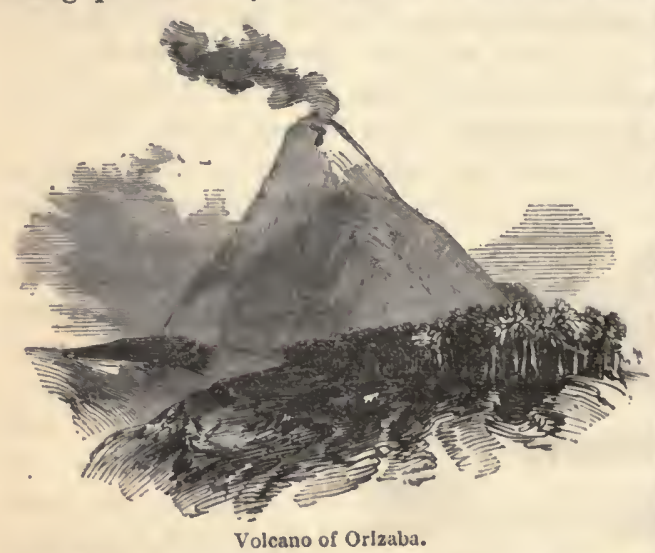
escape by a rending of the strata. Such is the hypothesis. It requires the metalloids to exist in the interior of the earth, and the admission of water in sufficient abundance to them, a condition which may be conceded. But we have choico of another theory, that of Central Heat, which, upon the whole, is moro probable, and has received greater countenance. It supposes the interior of the globe, at a varying distance from the surface, to be in a state of actual incandescence; nnd it is a well-attested fact, that everywhere a higher temperature is met with, in proportion to the depth to which the crust of the earth is perforated. Water, gaining access to the heated interior mass, through fissures, generates steam and other gases, which, struggling to disengage themselves, produce tremors of the surface, or earthquakes, while occasionally they find their way to open vents, and signalise their liberation by the ejection of volcanic products.

It is difficult to form just views of events occasioning such calamities to the human race as the reduction to instability of the before fixed and firm foundations of the globe. When in a few passing seconds peaceful homes become the sepulchres of their inhabitants, and the roof that long has sheltered them from inclement elements is the engine of their destruction - when scenes verdant through the industry of man are converted into frightful desolations, and cities fall, involving youth, beauty, and innocence in indiscriminate ruin with proficient and inveterate vice - men are prone to reflections questioning the goodness and fitness of things, challenging the arrangements of the Creator in the scheme of the creation. Yet in most cases this is the offspring of a miserable selfishness; for the same parties will gloat over a battle in which their nation has been victorious, though destructive to more than ever perished by any one natural visitation of earthquake, volcano, or pestilence; the human action, at the same time, involving a deep moral guilt which belongs not to the physical phenomena. It may be well to recollect, in relation to these paroxysms of nature, that science and philosophy step in, and suggest relieving considerations. They unfold the long antiquity of the earth, teach us to contemplate it in connection with an era compared to which an age is a span, and unfold the tendency of those milder agencies which are in incessant action upon it, and which, though slow workers, would effect extensive and disastrous changes in the succession of centuries, if there was no counteraction to them. Inequalities of the surface eminently adapt the globe to be the residence of man during his threescore years and ten, and of the myriads of different races of beings that inhabit it. But the waste of the elevated dry land is a gradual yet sure effect produced by the atmospheric and aqueous causes that constantly act upon it. These, without an antagonist power, would, in time, reduce the inequalities of alluvial countries nearly to a uniform level, bring the habitable part of our planet down to the ocean line, and convert scenes of fertility and busy life into vast lagunes and 
marshes, which only inferior orders of animals can occupy. The antagonist power is the subterranean upheaving agency - a rare visitant-often at rest for ages-and then counteracting in the twinkling of an eye the effect of the rains, rills, torrents, rivers, atmosphere, and seas, that have been preying upon the soil.

\section{CHAPTER XIII.}

THE ATMOSPHERE AND ITS CURRENTS.

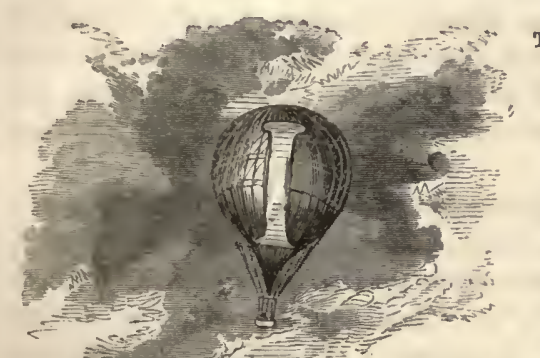

T has been mentioned as a part of the planetary constitution of our globe, that a gaseous envelope environs its mass - the atmosphere-which requires the attention of the astronomer, on account of its influence in displacing the celestial bodies, and contributing to their visibility by refracting and reflecting the rays of light. This elastic fluid is the scene of interesting phenomena, and performs important functions in the economy of nature. Besides being essential to the life of man, and the animal races, whose existence would terminate in a few minutes without the respiration of it; - the exhalation of moisture from the surface of the earth is mainly owing to the common air we breathe, which receives and sustains the vapours formed into clouds, distributes them over different regions by its incessant motions, and tempers by its currents those extremes of heat and cold to which various localities are subject. It is in these last-named offices that the atmosphere demands the notice of the physical geographer. The consideration of its actual constitution does not belong to his province, but a general view of the fluid may be appropriate before we proceed to those agitations and changes which are in constant action, and upon which the welfare of organised beings so materially depends.

The atmosphere is, then, an integral portion of the earth, a body of air revolving with the solid mass upon its axis, the higher strata, of course, increasing in velocity with the distance from the axis of revolution. From hence a conclusion may be drawn respecting its height, for an absolute limit is put to its elevation by this feature of its physical condition. There is a point where the centrifugal force, or the tendency to fly off from the centre, will counterbalance the centripetal, or the gravitation towards the centre, and beyond that point the latter will be vanquished. It is obvious that no portion of the atmosphere can extend beyond the point where the two influences balance, or are in equilibrium, and the projectile force becomes greater than that of gravitation, or its projection into space would follow. At the distance of 6.6 radii from the centre of the earth, or at an eleration of 22,200 miles, about the eleventh part the distance of the moon, this point is fixed, beyond which it is impossible for the atmosphere in the smallest quantity to extend. This consideration is only of importance to show that physical laws rigidly restrict it within finite bounds, for any portion of air at that distance must have a tenuity which is utterly inconceivable. The indications of the height of the atmosphere drawn from its weight, as shown by the barometer, reduce its elevation within a vastly circum- 
scribed limit. $\Lambda$ column of the whole cireumambient air is nearly equal in weight to a similar column of mercury of thirty inches, or of water of thirty-four feet, which would give it an elevation of but 27,000 feet, or rather under five miles, if its density were uniform. But the elasticity of the air causes it to expand with the diminution of its own pressure, which becomes less at every step from the surface of the earth; and owing to this expansion we must place the limit to its height at a far greater distance than that suggested by the simple barometrical measurement of its weight. A pretty common opinion prevails that its extreme boundary does not exceed forty or fifty miles, and we have sensible evidence on the high lands of the globe, that for all the purposes serviceable to vegetable and animal life, the atmospheric zone is of very contracted elevation. It is a well-known property of the air that the temperature diminishes with its height, a circumstance referable to the general physical law, that as the density of gases decreases they acquire an increased capacity for heat. The higher, therefore, a body ascends in the atmosphere, the greater is the quantity of heat abstracted from it, the surrounding fluid becoming more rare. Hence the perpetual snow, and the piles of glaciers, that crown the summits of mountains, at whose base the orange and the citron bloom, and man pants in the fierce sultriness of a torrid climatc.

But while the atmosphere may be considered generally as an aerial zone of the earth, the companion of the massy spheroid in its annual revolution round the sun, and rotating with it upon its axis, it has independent movements which present very complex phenomena, however clear the causes which put them in operation. The particles of air are constantly suffering displacement, and it is easy to conceive of various circumstances disturbing the dilatable and elastic fluid in which we live. A body in movement will communicate its motion to the adjoining particles, which may be sensibly propagated by them to a considerable distance; but this cause operates so slightly in the production of atmospheric currents that it might be entirely overlooked. It will be sufficient to state that some of the vast oceanic streams are supposed to produce a corresponding flow in the air. The varying attractions of the sun, moon, and planets on the atmosphere, will occasion tides in it analogous to those of the ocean, or an alteration in the heights of vertical columns of air, winds and currents arising from the resulting inequalities of horizontal pressure; but Laplace has proved the action of this cause to be scarcely appreciable. The atmospheric agitations of which we are sensible, both the more violent and gentle, appear to proceed either from a change in the temperature of a portion of the air, or from a change in the quantity of water which it holds in a state of vapour. In both these cases a temporary destruction of the equilibrium subsisting between different parts of the atmosphere is produced, and its particles are set in motion to restore the balance. The effect of heat upon a volumc of air is to rarefy and expand, to increase its bulk and diminish its density. When any portion, therefore, of the earth's surface is more heated than the surrounding districts, the air there ascends and flows over the adjoining cooler and denser strata, causing an upper outward current, while the colder and denser fluid rushes towards the spot where the balance has been lost by expansion, and a lower inward current is produced. An easy experiment will illustrate this interchange. In a room warmed by a good fire, if a candle be held at the crevice between the door and the floor, an inward current will be observed from the exterior colder air, but near the ceiling, by the same means, an outward flow will be detected. In the other condition an addition of vapour to the atmosphere gives rise to a wind blowing on all sides away from the district of evaporation, while an abstraction of it by showers creates a partial vacuum, towards which the air rushes from all points of the compass. 'The diversity of the winds in power is prineipally owing to the different degrees of vigour with which these causes act. 
The currents of the atmosphere display an endless variety in their relocity and force, from the zephyr which scarcely stirs the leaves of the forest, to the gale under which its mightiest branches bend, and the hurricane which tears up its trees by the roots, and destroys the habitations of mankind. It lias been observed that in the temperate zones the most violent winds occur, when neither the heat nor the cold common to such localities is at its maximum - that they generally extend over a considerable tract of country and are accompanied by sudden and great falls in the mercury of the barometer. The latter circumstance attends the storms of the tropics, but they are often confined within narrower limits than the extra-tropical hurricanes. It was noticed by the superstitious as a coincidence, not without meaning, that at the time of Cromwell's death the enchained winds were liberated, and went forth raving and howling through the land, uprooting the largest trees, and whirling them about like straws, and toppling down chimneys and turrets; but the same tempest, at the self-same hour, dashed the vessels of the Baltic seamen upon the strand, and buried Venetian argosies in the Adriatic, shivered the pines of Norway, and swept before it the cypresses of the Bosphorus - a similar war of the elements attending the termination of the earthly career of Cardinal Wolsey, Buonaparte, and George IV. Sornetimes the upper regions of the atmosphere have been remarkably agitated, while the lower. stratum of the air lias been quite calm. Lunardi, on one occasion, travelled at the rate of seventy miles an hour in his balloon, while at Edinburgh, where he ascended, the air was quite tranquil, and continued so throughout his expedition. 'To ascertain the velocity and force of winds, a variety of experiments have been conducted with instruments constructed for the purpose. 'The following table contains some results obtained by Smeaton, inserted in a volume of the Philosophical Transactions :-

VELOCITY OF THE WIND.

\begin{tabular}{|c|c|c|c|}
\hline Miles per Ilour. & Feet per Second. & $\begin{array}{l}\text { Ferpendicular Force on one Square Foot, } \\
\text { in Avoirdupois Pounds and Parts. }\end{array}$ & Characteristics. \\
\hline 1 & $1 \cdot 47$ & .005 & Hardly perceptible. \\
\hline 2 & $2 \cdot 93$ & .0207 & Iust pereontible \\
\hline 3 & $4 \cdot 4$ & $.044\}$ & Just perceptible. \\
\hline 4 & $5 \cdot 87$ & $.079\}$ & Gentle plensant wind \\
\hline 5 & $7 \cdot 33$ & $.123\}$ & Gentle, pleasant wind. \\
\hline 10 & $14 \cdot 67$ & $\cdot 492\}$ & Rrick mind \\
\hline 15 & 22 & $1 \cdot 107\}$ & Brisk wind. \\
\hline 20 & $29 \cdot 34$ & $1.968\}$ & Yerv brisk yind \\
\hline 25 & $36 \cdot 37$ & $3.075\}$ & Very brisk wind. \\
\hline 30 & 44.01 & $4 \cdot 429\{$. & Hi rind \\
\hline 35 & $51 \cdot 94$ & $6.027\}$ & High wind. \\
\hline 40 & $58 \cdot 68$ & $7 \cdot 873\}$ & Very high wind. \\
\hline 45 & 66.01 & $9 \cdot 963\}$ & Very high wind. \\
\hline 50 & $73 \cdot 35$ & $12 \cdot 300$ & Storm. \\
\hline 60 & $88 \cdot 02$ & $17 \cdot 715$ & Great storm. \\
\hline 80 & $117 \cdot 36$ & $31 \cdot 490$ & Hurricane. \\
\hline 100 & $147 \cdot 7$ & $49 \cdot 200$ & $\begin{array}{l}\text { Hurricane carrying trees and } \\
\text { buildings before it. }\end{array}$ \\
\hline
\end{tabular}

The currents of the atmosphere far surpass in velocity those of the rivers and the ocean, a gentle pleasant wind blowing at a rate equal to that of the mighty Father of Waters when in flood, but a hurricane will outstrip the swiftest locomotive in its speed. In speaking of the direction of, currents of air and water, the indicating terms are employed in an inverse sense, an easterly wind signifying a breeze coming from that quarter, an easterly stream a flow of water towards it. Winds may be divided into three classes or genera, the Permanent, the Periodical, and the Variable; of which, the first excepted, there are many different species. We shall prefer, however, to consider them under their local recognised titles 


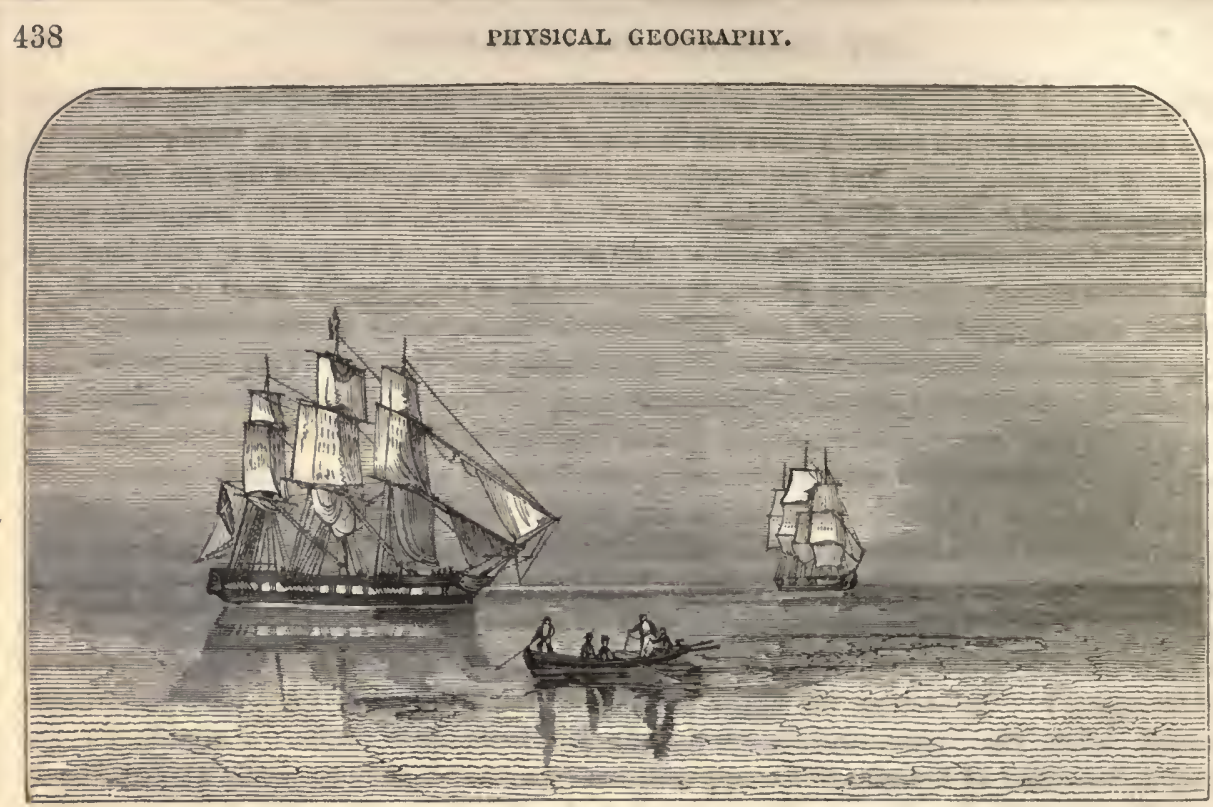

A Calm at Sea.

1. Trade winds. These are permanent, following the same direction throughout the year. They are met with between the tropies, and a few degrees to the north and south of those limits. The well-known name applied to them is a phrase of doubtful origin, but probably derived from the facilities afforded to trade and commeree by their eonstant prevalence and generally uniform course, though Hakluyt speaks of the "wind blowing trade," meaning a regular tread or track. The parallels of $28^{\circ}$ north and south latitude mark the medium external limits of the trade winds, between which, with some variations, their direction is from the north-east, north of the equator, and from the south-east, on the other side of the line, hence ealled the north-east and south-east trades. They are separated from each other by the region of calms, in which a thick foggy air prevails, with frequent sudden and transient rains attended by thunder and lightning. This region, in the Atlantic, extends across the whole ocean from the coasts of Africa to those of Ameriea, but its position shifts, being sometimes entirely north of the equator, and but rarely reaching one or two degrees south; and hence it may be considered as belonging to the northern hemisphere. The region also varies in breadth from two and a half to ten degrees, but usually occupies a width of four or five. These variations are dependent upon the position of the sun, which has an influence likewise upon the strength, direction, and situation of the trade winds themselves. When the sun has a northern declination, and approaches the tropic of Cancer, the boundary line of the north-east trade wind extends to $32^{\circ}$ north latitude, and the wind has a more easterly direction, but the parallel of $25^{\circ}$ is its northern boundary, and the wind inclines more north when the sun is south of the equator, and approaches the tropic of Capricorn. At that season, the southern boundary of the south-east trade wind extends to $30^{\circ} \mathrm{S}$. lat., and the whole ocean is swept by it between that line and about $1^{\circ} \mathrm{N}$. lat. The general width of the south-east trade is about $9^{\circ}$ greater than that of the north-cast, the region of calms, as before stated, being almost wholly in the northern hemisphere. In the basin of the Atlantic, the zone of the trade winds becomes broader, and their direction more ensterly, as the coast of America is approached, the breezes blowing to the very shore. This is not the case on the $\Lambda$ frican side of the Atlantic, where, through a tract of sea extending from fifty to eighty miles off 
shore, these winds are not found at all, but contrary westerly breezes prevail. The irregularity is easily explained. Owing to the rarefaction which the air undergoes over the great hot desert of the Sahara, the colder air from the contiguous sea rushes in to supply the partial vacuum created, and keep up the equilibrium of the atmosphere, producing winds blowing torvards the shore.

In the Pacific Ocean, a similar zone is occupied by permanent north and south-easterly brcezes, or trade winds, though subject to a variety of interruptions. An instance of irregularity occurs along the coasts of Peru and Chili, where the general direction of the wind is south, and a steady south-easterly wind is only experienced at the distance of five or six hundred miles from the shore. The numerous shoals and islands which are found in the Pacific, prevent uniformity in the tropical movements of the atmosphere. That intelligent hydrographer Captain Horsburgh has observed, that where shoal coral banks shoot up out of the deep water in many places between the tropics, a decrease of the prevailing wind is frequently experienced; for when a steady wind is blowing over the surface of the deep water, no sooner does a ship get upon the verge of a shoal coral bank, than a sudden decrease of the wind is often perceived. This he supposes to be oceasioned by the atmosphere over these banks being less rarefied by the increased evaporation than that over the deep water, and consequently not requiring so great a supply of air to restore the equilibrium as the circumjacent parts, which are more rarefied and heated. It would undoubtedly be the case, if the earth were entirely covered with a mantle of water of uniform depth, that the trade winds would everywhere prevail, throughout a zone, bounded by the parallels of from $25^{\circ}$ to $32^{\circ}$ on each side of the equator. But the large masses of land of uneven surface which occur between the tropics, and the consequent inequalities of temperature, check the tendency of the intertropical atmosphere to a regular course, introduce derangement in its movements, so that it is only in the great open seas that the trade winds are experienced. Still, it has been observed, that in some countries under and near the equator, constant easterly winds are found, which are no doubt identical in their cause with those that distinguish the equatorial regions of the ocean. They are met with on lands which exhibit extensive level plains, where nothing occurs to obstruct their passage and alter their direction. Thus, along the immense low tract drained by the Amazon an easterly wind prevails, by the assistance of which, the voyager is enabled to ascend rapidly against the strong current of the river. This wind blows from the estuary of the Amazon, where it is moderate, to its sources at the foot of the Andes, where it has gathered such strength, that Humboldt found it difficult to make head against it. The plain traversed by the lower course of the Orinoco has a similar easterly breeze, but of less force.

We owe the discovery of the trade winds to Columbus, and this would have been prominently connected with his name, had it not been supplanted by the glory of a greater achievement, the revelation of a new world to the knowledge of mankind. The ancients were entirely unacquainted with these permanent breezes, and though maritime adventure had been largely prosecuted by the Portuguese at the instigation of Prince Henry, they had not penetrated into the region of the trades. Proceeding cautiously along the shores of Barbary, they had explored the coasts of Africa to Cape de Verde, rescued the Azore Islands from the "oblivious empire of the ocean," and afterwards under Vasco di Gama doubled the Cape of Good Hope; but these voyages carried them clear of the district of the north and south-east trade winds. But soon after leaving the Canaries in the Santa Maria, Columbus fell in with the former, which in the summer extend to the latitude of those islands, and, for the first time, a sail from the Old World swelled before the steady breath of the northern tropic. This circumstance, favourable to the success of his expedition, speedily excited the apprehensions of his crew, who found themselves borne, 
day after day, by a permanent breeze, farther from their native shores, and inferred the impossibility of returning, as they observed no change in its direction. Fortunately for his fame, and for the world, the great navigator firmly held on his course, reached the bounds of the before supposed illimitable ocean, and re-crossed it in the region of the variables, to the north of the northern trade wind. Now, in passing from the Canaries to Cumana, on the north coast of South America, it is scarcely ever necessary to touch the sails of a ship; and with equal facility the passage is made across the Pacifie, from Acapulco, on the west coast of Mexico, to the Philippine Islands. If a channel were cut through the istlimus of Panama, the voyage to China would be remarkably facilitated by the trade winds of the Atlantic and Pacific Oceans, be more speedy, agreeable, and safe, than the usual route by the Cape, the chief interruption to its uniformity occurring in the Caribbean Sea and the Gulf of Mexico, where the trade wind blows impetuously, the sea is stormy, and the sky grey and cloudy.

The theory respecting the origin of the trade winds, adopted by Dr. Dalton, Professor Daniell, and Sir John Herschell, was first proposed by George Hadley, the brother of the inventor of the quadrant, and embodies features of the previous theories of Halley and Galileo, who both grappled with this great geographical phenomenon. It is founded upon the rarefaction of the atmosphere of the torrid zone by the powerful heat to which that region is subject, in connection with the different velocities of the earth's surface, in different degrees of latitude, in the diurnal rotation. Heat rarefies and expands a volume of air in a ratio equivalent to an addition of about seventy feet to the ordinary height of the atmosphere for every degree of thermometrical measurement. As the sun is always vertical at some place within the tropics, the average temperature of the earth's surface in that region, bounded by the parallels of $23 \frac{1}{2}^{\circ}$ on each side of the equator, is much higher than in latitudes to the north and south; and the incumbent air acquiring this higher temperature, is thereby rarefied and expanded. The conscquence is, that in obedience to hydrostatical laws, masses of air are continually buoyed up from the surface, or swelled round the torrid zone in the form of a protuberant belt, the upper strata flowing over, and running off in streams north and south towards the poles, where, having been cooled and condensed, they descend, and flow over the surface towards the equator, pouring in a perpetual current of air to supply the place of that buoyed up by the heat of the tropics. Thus, there is a constant current in the higher regions of the atmosphere, proceeding from the equator northward and southward to the poles; and if the earth were at rest, there would be a constant wind in the lower regions of the atmosphere blowing directly from the poles to the equator, while in equatorial regions the two streamlets would meet and neutralise each other's influence. But the earth is not at rest! It is incessantly whirling upon its axis, the surface moving at a rate which varies according to the extent of the circumference. 'The velocity at the equator, where the circumference is the greatest, is about sixteen miles a minute; at $30^{\circ}$ of latitude, which is below the most southerly point of Europe, it is about fourteen miles in the same time; and at $45^{\circ}$, or about the centre of France, it is about eleven miles. As the distance from the equator increases, north and south, the rate of the rotation thus becomes less, because the circle of the earth's circumference diminishes in extent. Now a current of air flowing from the north or south polar regions, and setting towards the equator, will encounter as it proceeds an increased rotatory motion eastward, the direction of the earth's axical revolution, and, not acquiring the new velocity at once, it will be left behind, and seem to deflect towards the west just in proportion as it does not keep up with the earth to the east. Hence, what would simply be a north or south wind but for the earth's rotatory motion, becomes a north-east and soutli-east wind as it approaches those regions where, the velocity of the globe being so much greater than where it 
originated, it lags behind it in its easterly course. This is the exact path of the trade winds - breezes, with few exceptions, uniform in their direction, perpetual in their motion, and steady in their force-which wafted Columbus across the Atlantic, impelled the Portuguese from their southerly course and bore them to the Brazils, and have since been important auxiliaries to the communication of the eastern with the western continent.

The existence of a current in the upper regions of the atmosphere counter to that below, assumed by the preceding theory, is not mere hypothesis. Clouds, though of rare occurrence in the district of the trade winds, have been observed to take a direction contrary to that which the surface breezes would have given them. A circumstance remarkably in favour of the counter-current inferred from theory, oceurred in the year 1812. There was then an eruption of the volcano of St. Vincent, one of the West India islands, which covered the island of Barbadoes with a quantity of the ashes and volcanic matter ejected. The trade wind liere blows with great power, and it is certain that the volcanic ashes would have been conveyed in a direction from Barbadoes, instead of towards it, by its action. 'To account for their transportation thither, it is necessary to suppose, that the volcano ejected them to an elevation within reach of a superior stratum of air blowing contrary to the course of the inferior current. When Humboldt was upon the Peak of Teneriffe the west wind blew with such violence that he could scarcely stand, though the island below was under the influence of the ordinary north-east trade wind; and the remark has often been made, that in the elevated parts of the Canary Islands a contrary wind has been experienced to that which has been prevailing over the general surface.

All mariners and passengers have spoken with delight of the region of the trade winds, not only on account of the favouring gale, but its genial influence, the transparent atmosphere, the splendid sunsets, and the brilliancy of the unclouded heavens, day and night. Columbus, in recording his first voyage into their territory, compares the air, soft and refreshing without being cool, to that of the pure and balmy April mornings he had experienced in Andalusia, wanting but the song of the nightingale and the sight of the groves, to complete the fancy that he was sailing along the Guadalquivir. "It is marvellous," observes Las Casas, "the suavity which we experience when half way towards these Indies; and the more the ships approach the lands so much more do they perceive the temperance and softness of the air, the clearness of the sky, and the amenity and fragrance sent forth from the groves and forests; much more certainly than in April in Andalusia." Humboldt lingers with pleasure, upon his first acquaintance with the tropical regions at sea, upon the mildness of the climate and the beauty of the southern sky, gradually opening new constellations to the view, stars contemplated from infancy progressively sinking and finally disappearing below the horizon, an unknown firmament unfolding its aspect, and seattered nebulæ rivalling in splendour the milky way. "A traveller," he states, "has no need of being a botanist, to recognise the torrid zone, on the mere aspect of its vegetation; and without having acquired any notions of astronomy; without any acquaintance with the celestial charts of Flamstead and De la Caille, he feels he is not in Europe, when he sees the immense constellation of the Ship, or the phosphorescent clouds of Magellan, arise on the horizon. We pass those latitudes, as if we were descending a river, and we might deen it no hazardous undertaking, if we made the voyage in an open boat." Mr. Bailey, in his Four Years in the West Indies, relates an adventure, nearly answering to that here referred to. The master of one of the small fishing smacks that ply along the coasts of Scotland, who had no other knowledge of navigation than that which enabled him to keep his dead reckoning, and to take the sun with his quadrant at noon-day, having heard that sugar was a very profitable cargo, determined, by way of speculation, upon a trip to St. Vincent, to bring a few hogsheads 
of the commodity on his own aceount into the Scottish market. Accordingly, he freighted his vessel; made sail; erossed the Bay of Biscay in a gale; got into the trade winds, and seudded before them, at the rate of seven knots an hour, trusting to his dead reckoning all the way. He spoke no vessel during the whole voyage; and never once saw land until on the morning of the thirty-fifth day, when he descried St. Vincent's right ahead, and running down, under a light breeze, along the windward coast of the island, eame to anehor. The private signal of the little vessel was unknown to any of the merchants, and it immediately attracted notice. The natives were perfectly astonished - they had never heard of such a feat before; and deemed it quite impossible that a mere fishing smack, worked only by four men, and commanded by an ignorant master, should plougl the billows of the Atlantic, and reach the West Indies in safety - yet so it was. 'This relation justifies the title given by the Spaniards to the zone where the trade winds are constant, el Golpo de las Damas, the Sea of the Ladies, on account of the ease with which it may be navigated, the uniform temperature prevalent night and day, and its pacific aspect.

2. Monsoons. These are periodical winds, which sweep the northern part of the Indian Ocean, changing their direction after an interval of about six months, and hence the term Monsoon, the Anglicised form of the Persic mousum, or the Malay moossin, signifying a season, referring to their periodicity. Avoiding all minute detail, we shall merely give the range, direction, and duration of these singular, yet highly useful currents, and that in a very general way. From $3^{\circ}$ south of the equator to the northern shores of the Indian Ocean, including the Arabian Sea, the Bay of Bengal, and the Chinese Sea, a south-west wind blows from April to October, and then a north-east wind sets in, and prevails through the next half year, from October to April. From $3^{\circ}$ to $10^{\circ}$ south of the equator a south-east wind blows from $A$ pril to October, and a north-west during the suceeding six munths. Without attending to local variations, these are the general phenomena. There is a south-zvest wind prevailing north of the equator from April to October, and southward of this, through a certain space, at the same season, a south-east wind. There is a northeast wind north of the equator from October to April, and coincidently, a north-zvest wind between $3^{\circ}$ and $10^{\circ}$ south of the line. The western boundary of the region of the monsoons is the African shoro; its eastern limit is supposed to be about the meridian of $136^{\circ}$ east longitude, which cuts the island of New Guinea; its northern confine is near the parallel of $27^{\circ}$ north latitude, which intersects the Loo Choo islands ; its southern extremity has been already stated. The monsoons are much stronger than the trade winds, and may be called gales, but they are by no means of uniform force, either as it respects themselves or ench other, the same monsoon occasionally blowing with such violence that ships are obliged to reef their sails. It must not be imagined that these winds are confined to the ocean. They extend over the whole of Hindûstan to the Himalaya, the north-east monsoon bringing copious rains to its eastern shores, and the south-west monsoon performing the same office for its western coast.

'The change of the monsoon - the periodical shifting of the wind - the most singular feature of the case, is a gradual process, usually occupying about a month, which reduces the reign of the two annual monsoons, north and south of the equator, to five montlis each, the remaining two months being spent in the transitions. In each interval of change, calms, light variable breezes, alternate with storms of tremendous violence. Mr. Caunter thus describes the scene at Madras, in the interim between the cessation of one monsoon and the setting in of another: "On the 15th of October, the flag-staff was struck, as a signal for all vessels to leave the roads, lest they should be overtaken by the monsoon. On that very morning some premonitory symptoms of the approaching 'war of elements' had appeared. As the house we occupied overlooked the beach, we could behold the 
setting in of the monsoon in all its grand and terrific sublimity. The wind, with a force which nothing could resist, bent the tufted heads of the tall, slim cocoa-nut trees almost to the earth, flinging the light sand into the air in eddying vortices, until the rain had either so increased its gravity, or beaten it into a mass, as to prevent the wind from raising it. The pale lightning streamed from the clouds in broad sheets of flame, which appeared to encircle the heavens as if every element had been converted into fire, and the world was on the ere of a general conflagration, whilst the peal, which instantly followed, was like the explosion of a gunpowder magazine. The heavens seemed to be one vast reservoir of flame, which was propelled from its voluminous bed by some invisible but omuipotent agency, and threatened to fling its fiery ruin upon every thing around. In some parts, however, of the pitchy vapour by which the skies were by this time completely overspread, the lightning was seen only occasionally to glimmer in faint streaks of light, as if struggling, but unable, to escape from its prison, igniting, but too weak to burst, the impervious bosoms of those capacious magazines in which it was at once engendered and pent up. So heary and continuous was the rain, that scarcely anything, save those vivid bursts of light which nothing could arrest or resist,-was perceptible through it. The thunder was so painfully loud, that it frequently caused the ear to throb; it seemed as if mines were momentarily springing in the heavens, and I could almost fancy that one of the sublimest fictions of heathen fable was realised at this moment before me, and that I was hearing an assault of the Titans. The surf was raised by the wind and scattered in thin billows of foam over the esplanade, which was completely powdered with the white feathery spray. It extended several hundred yards from the beach; fish, upwards of three inches long, were found upon the flat roofs of houses in the town during the prevalence of the monsoon, either blown from the sea by the violence of the gales, or taken up in the water-spouts, which are very prevalent in this tempestuous season. When these burst, whatever they contain is frequently borne by the sweeping blast to a

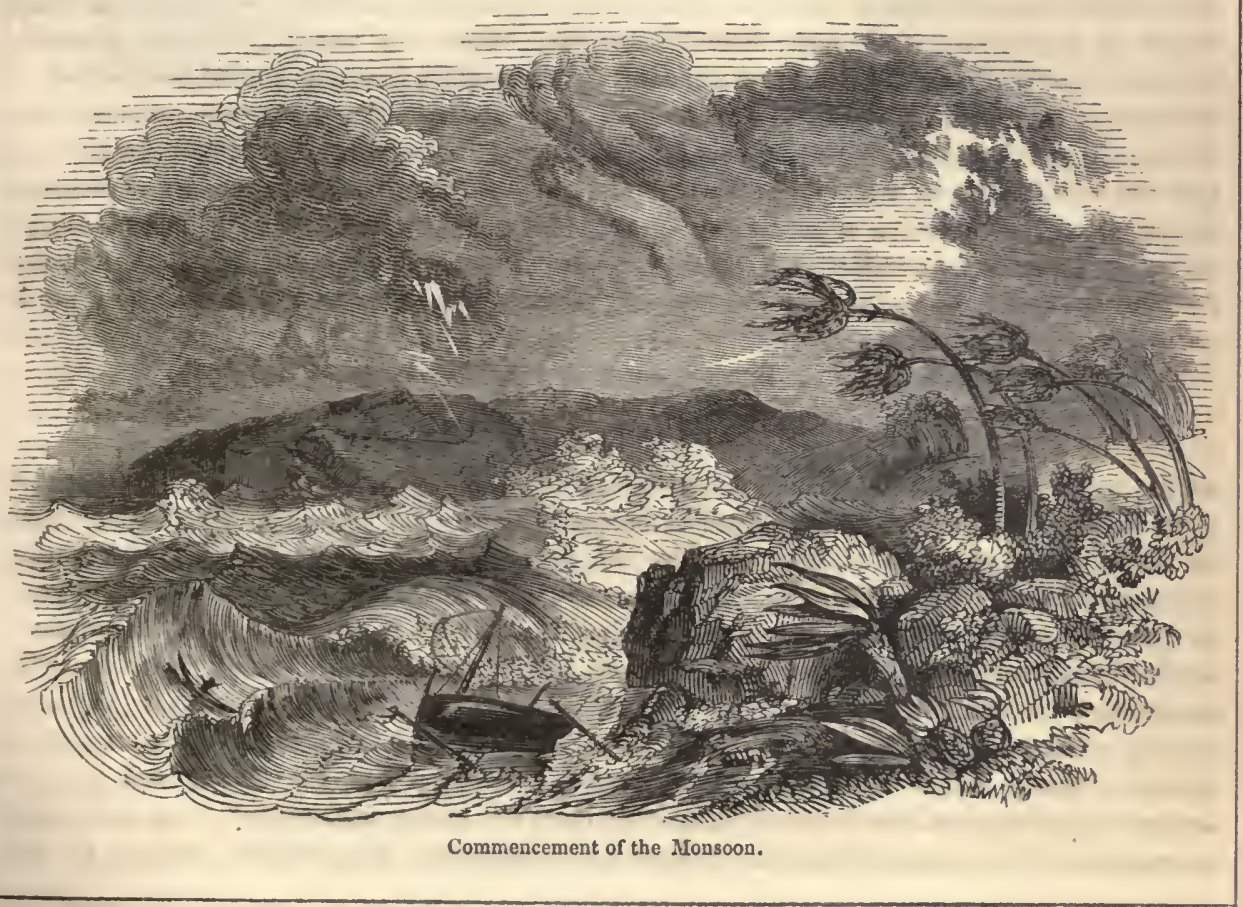


considerable distance over-land, and deposited in the most uncongenial situations; so that now, during the violence of these tropical storms, fish are found alive on the tops of houses; nor is this any longer a matter of surprise to the established resident in India, who sees every year a repetition of this singular phenomenon. During the extreme violence of the storm, the heat was occasionally almost beyond endurance, particularly after the first day or two, when the wind would at interrals entirely subside, so that not a breath of air could be felt, and the punka afforded but a partial relief to that distressing sensation which is caused by the oppressive stillness of the air so well known in India." It is an extraordinay but well-ascertained fact, that as soon as one monsoon ceases, though a month may elapse before the succeeding one appears, the clouds take the direction of the approaching monsoon, and thus from the regions of the atmosphere herald its advent to the dwellers below.

We naturally inquire concerning the origin of these peculiar movements, but must be content with a very scanty measure of information upon the subject. The laws which nature obeys in these periodical changes are undoubtedly identical with those which give rise to atmospheric currents in general, but their mode of operation is in this case obscure. The north-east and south-east monsoons, the former on the north and the latter on the south side of the equator, may be considered as trade winds, explicable upon the same principles, but counteracted for a certain time by causes which produce winds from a different quarter, the south-west and north-west monsoons. It has been observed that the south-west monsoon, which prevails to the north of the equator, is coincident with the sun being vertical to that region, when Hindûstan, Siam, and the adjacent countries receive their maximum of heat. Consequently, the incumbent air, being rarefied, ascends, and a sush of colder air to supply its place is produced from the southward, which is then receiving the oblique rays of the sun, and which presenting a surface of water is immensely less hented than the lands to which the luminary is perpendicular. In like manner, the north-west monsoon, which prevails south of the equator, is coincident with the sun being south of it likewise, and vertical to the region, when the sandy plains of Australia become powerfully heated, and the air over them rarefied, creating a wind by the rush of the colder northern air towards the point of rarefaction. These are the explanations commonly given, and though in several respects they do not account for all the plenomena, yet the probability is, that they present the correct theory, anomalous circumstances arising from the influence of causes which are local and as yet unknown. The monsoons are more valuable as auxiliaries to commerce than the trade winds, owing to the change in their direction, for a ship may procced to a distant port with one monsoon and be aided on its return by its successor.

\section{Land and sea breezes. A line in one of our popular songs,}

"How sweetly the breeze blows off the shore,"

refers to the wind which begins at evening to blow from the coasts situated between and near the tropics; and an equally grateful breeze blows by day from the sea to the shore in those warm climates. The inequality of the solar action on the land and water, together with the tendency of the atmosphere to preserve an uniform density, is the cause of these periodically shifting currents. During the day the land acquires a temperature higher than that of the ocean, and the air over it is therefore rarefied and ascends, and the cooler air from the sea glides in to fill the partial vacuum produced. At night, the land rapidly cools with the atmosphere over it, but the sea and the air in connexion with it retain a nearly equal temperature, in consequence of which, the colder and heavier land-air displnces the less dense or lighter air over the water, and a wind from the shore is created. The smoke of Vesuvius beautifully exemplifies this diurnal change in the 

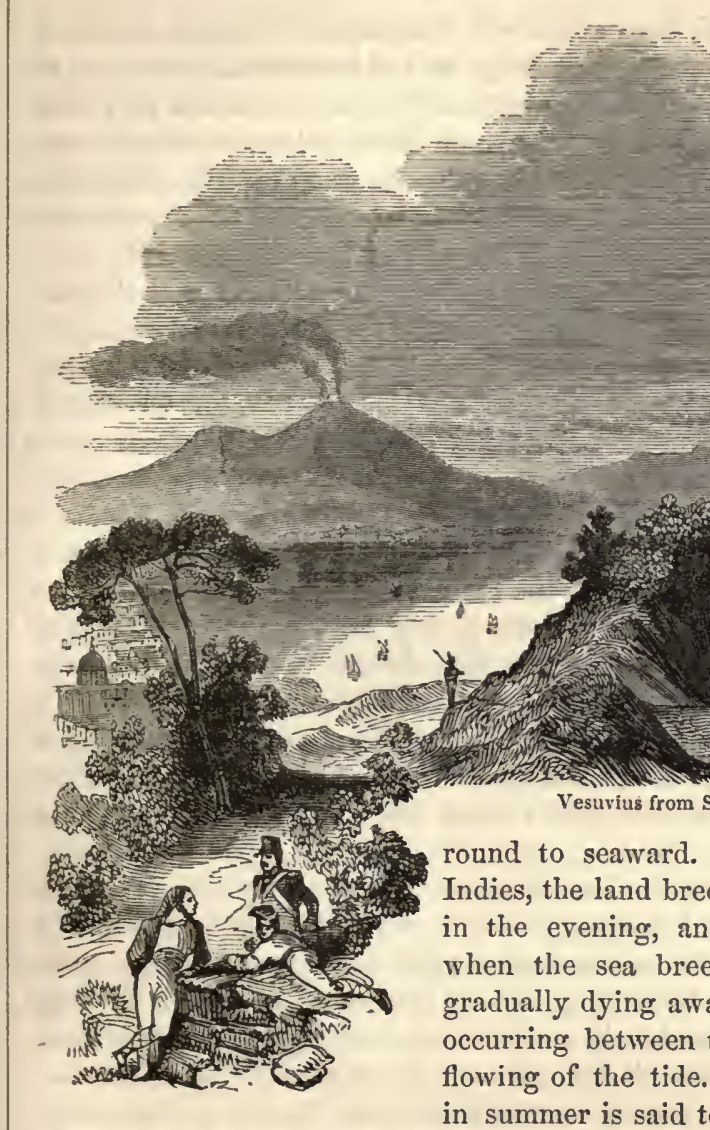

as Norway. These draughts of the cool air of the ocean are important benefactions to various countries, where the heat would otherwise be insupportable. Along the coast of Malabar, the alternate breezes are powerfully felt, the land wind extending in summer a considerable distance out to sea, redolent with the roses and spices of the shore. Though the land and sea breezes are most sensible in tropical countries, yet in far remote latitudes, and especially around lakes, the same diurnal shifting in the direction of the wind is experienced. The change of temperature in the air over a spacious lake, caused by the succession of day and night, has been computed to be about thirty times less than that which takes place in the atmosphere of the surrounding land - the air over the land being much more heated during the day, and much less heated during the night, than that over the lake - an inequality of temperature which necessarily occasions a breeze from the lake by day, and towards it by night.

The old and faithful voyager, Captain Dampier, in a quaint but pleasing style, has given the most exact description of these remarkable winds, as they occur in tropical latitudes. "These sea-breezes do commonly rise in the morning" about nine o'clock, sometimes sooner, sometimes later; they first approach the shore so gently, as if they were afraid to come near it, and ofttimes they make some faint breathings, and, as if not willing to offend, they make a halt, and seem ready to retire. I have waited many a time, both ashore to receive the pleasure, and at sea to take the benefit of it. It comes in a fine small black curl upon the water, whereas all the sea between it and the shore, 
not yet reached by it, is as smooth and even as glass in comparison. In half an hour's time after it has reached the shore, it fans pretty briskly, and so increaseth, gradually, till twelve o'clock; then it is commonly strongest, and lasts so till two or three a very brisk gale; about twelve at noon it also veers off to sea two or three points, or more in very fair weather. After three o'clock, it begins to die away again, and gradually withdraws its force till all is spent; and about five o'clock, sooner or later, according as the weather is, it is lulled asleep, and comes no more till the next morning.

Land-breezes are as remarkable as any winds that I lave yet treated of; they are quite contrary to the sea-breezes; for those blow right from the shore, but the sen-breeze right in upon the shore; and as the sea-breezes do blow in the day and rest in the night, so, on the contrary, these do blow in the night and rest in the day, and so they do alternately succeed each other. For when the sea-breezes have performed their offices of the day, by breathing on their respective coasts, they, in the evening, do either withdraw from the coast, or lie down to rest. Then the land-winds, whose office it is to breathe in the night, moved by the same order of divine impulse, do rouse out of their private recesses, and gently fan the air till the next morning, and then their task ends, and they leave the stage. There can be no proper time set when they do begin in the evening, or when they retire in the morning, for they do not keep to an hour, but they commonly spring up between six and twelve in the evening, and last till six, eight, or ten in the morning. They both come and go away again earlier or later, according to the weather, the season of the year, or some accidental cause from the land. For, on some coasts, they do rise earlier, blow fiesher, and remain later than on other coasts, as I shall show hereafter.

These winds blow off to sea, a greater or less distance, according as the const lies more or less exposed to the sea-winds; for, in some places, we find them brisk three or four leagues off shore; in other places, not so many miles, and, in some places, they scarce peep without the rocks; or if they do sometimes, in very fair weather, make a sally out a mile or two, they are not lasting, but suddenly vanish away, though yet, there are every night as fresh land-winds ashore, at these places, as in any other part of the world. Indeed, these winds are an extraordinary blessing to those that use the sea in any part of the world within the tropies; for as the constant trade-winds do blow, there could be no sailing in these seas; but by the help of the sea and land-breezes, ships will sail 200 or 300 leagues, as particularly from Jamaica to the Lagune of Trist, in the Bay of Campeachy, and then baek again, all against the trade-wind. The seamen that sail in sloops or other small vessels in the West Indies do know very well when they shall meet a brisk landwind by the fogs that hang over the land before night; for it is a certain sign of a good land-wind to see a thick fog lie still and quiet, like smoke over the land, not stirring any way; and we look out for such signs when we are plying to windward. For if we see no fog over the land, the land-wind will be but faint and short that night. These signs are to be observed chiefly in fair weather; for in the wet season fogs do hang over the land all the day, and it may be neither land-wind nor sea-breeze stirring. If in the afternoon, also, in fair weather, we see a tornado over the land, it commonly sends us forth a fresh land-wind. These land-winds are very cold, and though the sea-breezes are always much stronger, yet these are colder by far. The sea-breezes, indeed, are very comfortable and refreshing; for the hottest time in all the day is about nine, ten, or cleven o'clock in the morning, in the interval between both breezes; for then it is commonly calm, and then people pant for breath, especially if it is late before the sea-breeze comes, but afterwards the breeze allays the heat. However, in the evening again, after the sea-breeze is spent, it is very hot till the land-wind springs up, which is sometimes not till twelve o'clock or after." 
4. Etesian winds. The ancients gave this designation, from írnoial, annual, to periodical winds which blow from the north-east in the summer months, for about six weeks, throughout the Mediterranean and adjacent countries, but mostly in the eastern branch, including the Adriatic and the Archipelago. The term Meltem is now applied to them by the fishermen, a corruption, probably, of mal temps, referring to the fury with which they blow, and to the danger to which their small craft become exposed. On land, they are more favourably regarded. These winds are noticed by Pliny, Seneca, and Cicero, the latter of whom says, that in Italy they are equally comfortable and salutary to men, beasts, and birds, and likewise beneficial to vegetation, by moderating the violent heat of the weather during the inclement season of the dog-days. In the Levant, they commence towards the middle of July, about nine in the morning, continuing only in the daytime. The sun at that season is powerfully heating the earth under the tropic of Cancer, and rarefying the atmosphere south of the Mediteranean, thus giving birth to the north-east etesian gales.

5. Khamsin, Samiel, Simoom, Harmattan, Sirocco. These are local titles of winds differing greatly in geographical position and direction, and also in some of their properties, but prevalent in desert regions, or in countries adjacent to them, and having one universal character of being hot blasts. The Khamsin is a hot south wind, which soon after the vernal equinox begins to blow in Egypt, continuing at intervals during a period of about fifty days, to which the name refers. The two next are entirely identical, the Samiel being the name given by the Turks to the wind which the Arabs called the Simoom. It is common in Syria, Arabia, and Nubia, deleterious in its mildest forms, occasionally destructive, many a pilgrim to the shrine of the prophet at Mecca, and merchant to the marts of Bagdad, having perished by its noxious suffocating influence. Bruce suffered from it when ascending the Nile, he and his company becoming so enervated as to be incapable of pitching their tents, oppressed as well by an intolerable head-ache. "The poisonous simoom," he remarks, when at Chendi, "blew as if it came from an oven; our eyes were dim, our lips cracked, our knees tottering, our throats perfectly dry; and no relief was found from drinking an immoderate quantity of water." The most complete account of the simoom and its effects has been given by Volney, whose accuracy here has been repeatedly confirmed. "Travellers," he states, "have mentioned these winds under the name of poisonous winds; or, more correctly, hot winds of the desert. Such in fact is their quality ; and their heat is sometimes so excessive that it is difficult to form an idea of their violence without having experienced it ; but it may be compared to the heat of a large oven at the monent of drawing out the bread. When these winds begin to blow, the atmosphere assumes an alarming aspect. The sky, at other times so clear in this climate, becomes dark and heavy; the sun loses its splendour, and appears of a violet colour. The air is not cloudy, but grey and thick; and is in fact filled with an extremely subtle dust, that penetrates everywhere. This wind, always light and rapid, is not at first remarkably hot, but it increases in heat in proportion as it continues. All animated bodies soon discover it by the change it produces in them. The lungs, which a too rarefied air no longer expands, are contracted and become painful. Respiration is short and difficult, the skin parched and dry, and the body consumed by an internal heat. In vain is recourse had to large draughts of water; nothing can restore perspiration. In vain is coolness sought for; all bodies in which it is usual to find it deceive the hand that touches them. Marble, iron, water, notwithstanding the sun no longer appears, are hot. The streets are deserted, and the dead silence of night reigns everywhere. The inhabitants of torrns and villages shut themselves up in their houses - and those of the desert in their tents, or in pits they dig in the earth - where they wait the termination of this destructive heat. It usually lasts three days, but if it exceeds that time it becomes 
insupportable. Woe to the traveller whom this wind surprises remote from shelter ! he must suffer all its dreadful consequenees, which sometimes are mortal. The danger is most imminent when it blows in squalls, for then the rapidity of the wind increases the heat to such a degree as to cause sudden death. This death is a real suffocation; the lungs being empty are convulsed, the circulation disordered, and the whole mass of blood driven by the heat towards the head and breast; whence that hrmorrhage at the nose and mouth which happens aftcr death. This wind is especially fatal to persons of a plethoric habit, and those in whom fatigue has destroyed the tone of the muscles and ressels. The corpse remains a long time warm, swells, turns blue, and is easily separated; all of which are signs of that putrid fermentation which takes place when the humours become stagnant. These accidents are to be aroided by stopping the nose and mouth with handkerchiefs ; an efficacious method is also that practised by the camels, who bury their noses in the sand, and keep them there till the squall is over. Another quality of this wind is its extreme aridity, which is such, that water sprinkled upon the floor evaporates in a few minutes. By this extreme dryness it withers and strips all the plants, and by exhaling too suddenly the emanations from animal bodies, crisps the skin, closes the pores, and causes that fererish heat which is the invariable eflect of suppressed perspiration." The current of the simoom is seldom of any considerable breadth, but different examples of it have been traversing a tract of country of but scanty area at the sąme time, and several cases of disaster from it upon an extensive seale are upon record. 'The opinion is now commonly held, that the destruction of the Assyrian army, when

"The angel of death spread his wings on the blast,

And breath'd in the face of the foe as he pass'd,

And the eyes of the sleepers wax'd deadly and chill,

And their hearts but once heav'd, and for ever grew still,"

was accomplished by the agency of the simoom, directed by the Almighty Will over the host of Senacherib, - an interpretation which the terms of the prophetic announcement of the avenging stroke remarkably support: "Behold, I will send a blast upon him."

The Harmattan, a periodical hot wind from the desert, differs remarkably from the simoom. It blows from the interior of the great Sahara, from the north-east, over Senegambia and Guinea, to that part of the coast of Africa lying between Cape Verde in $15^{\circ}$ north latitude to Cape Lopez in $1^{\circ}$ south latitude, a coast line of upwards of two thousand miles. It occurs during December, January, and February, generally three or four times in that season. The harmattan is the local name of the wind among the Fantees, a nation on the Gold Coast. It comes on indiscriminately at any hour of the day, at any time of the tide, or at any period of the moon, continuing sometimes only a day or two, at other times five or six days, and it has been known to last upwards of a fortnight. A fog or haze is one of the peculiarities which always accompanies this wind, occasioning a gloom which frequently renders even near subjects obscure, through which the sun appears for a short time about noon, having a wild red aspect. Though the wind blows out to sea for ten or twelve leagues, the fog is confined to the land, and leaves a deposition of fine whitish particles upon the grass and trees. Extreme dryness is another property of the harmattan. No dew falls during its continuance, nor is there the least appearance of moisture in the atmosphere. Vegetables of every kind suffer; all tender plants and most of the productions of the garden are destroyed; the grass withers, and becomes dry like hay; vigorous evergreens feel the pernicious influence; the branches of the lemon, orange, and lime trees droop, the leaves become flaccid, and so parched as to be easily rubbed to dust between the fingers, should the harmattan blow for sereral successive days. Among other extraordinary effects of the extreme dryness, it is stated, that the covers of books, though closely shut up in a trunk, are bent as if they had been 
exposed to a fire. Household furniture cracks, the panels of doors split, and any veneered work flies to pieces. Another, and the most striking feature of the harmattan, is its salubrity. Though prejudicial to vegetable life, and occasioning disagrecable parching effects on the human species, yet it is highly conducive to health. Those labouring previously under fevers generally recover during its prevalence, the feeble gain strength, and malignant diseases disappear. It seems that as this wind immediately follows the rainy season on the African coast, during which diseases are induced by an excess of moisture, the harmattan, invested with extraordinary dryness, removes humidity from the atmosphere, and counteracts its effects.

The Sirocco is analogous to the Khamsin, but milder. It is a hot south-east wind, prevailing in the Mediterranean, in Italy and Sicily, but felt most violently in the country around Naples, and at Palermo. It sometimes commences faintly about the summer solstice, but blows occasionally with great force in the month of July. Mr. Brydone, writing from Palermo, and referring to July 8th, observes :- "On Sunday we had the long-expected sirocco wind, which, although our expectations had been raised pretty high, yet I own greatly exceeded them. Friday and Saturday were uncommonly cool, the mercury never being higher than $72 \frac{1}{2}$; and although the siroceo is said to have set in early on Sunday morning, the air in our apartments, which are very large, with high ceilings, was not in the least affected by it at eight o'clock, when I rose. I opened the door without having any suspicion of 'such a change, and indeed I never was more astonished in my life. The first blast of it on my face felt like the burning steam from the mouth of an oven. I drew back my head and shut the door, calling out to Fullarton that the whole atmosphere was in a flame. However, we ventured to open another door that leads to a cool platform, where we usually walk; this was not exposed to the wind; and here I found the heat much more supportable than I could have expected from the first specimen I had of it at the other door. It felt somewhat like the subterraneous sweating-stoves at Naples, but still much hotter. In a few minutes we found every fibre greatly relaxed, and the pores opened to such a degree, that we expected soon to be thrown into a profuse sweat. I went to examine the thermometer, and found the air in the room as yet so little affected that it stood only at 73 . The preceding night it was at $72 \frac{1}{2}$. I took it out to the open air, when it immediately rose to 110 , and soon after to 112 ; and I am confident, that in our old lodgings, or any where within the city, it must have risen several degrees higher. The air was thick and heary, but the barometer was little affected - it had fallen only about a line. 'The sun did not once appear the whole day, otherwise I am persuaded the heat must have been insupportable; on that side of our platform which is exposed to the wind, it was with difficulty we could bear it for a few minutes. Here I exposed a little pomatum, which was melted down as if $I$ had laid it before the fire. I attempted to take a walk in the street, to sce if any creature was stirring, but I found it too much for me, and was glad to get up stairs again. This extraordinary lieat continued till three o'clock in the afternoon, when the wind changed at once, almost to the opposite point of the compass." All nature languishes under the influence of this wind; vegetation droops and withers; the Italians suffering from it not less than strangers. When any feeble literary production appears, the strongest phrase of disapprobation they can bestow is, era scritto in temps del sirocco, "it was written in the time of the sirocco." There can be little doubt but that this hot south-east wind sweeps across the Mediterranean from the shores of Africa. It is some compensation that the season of this oppressive blast is also that of the north-east Etesian winds, and not unfrequently, after a few hours' experience of the enfeebling influence of the sirocco, the tramontane, or north wind follows with its invigorating breath.

Hot winds resembling the sirocco of Sicily and Italy prevail in New South Wales, and 
are supposed to derive their heat from tracts of unknown deserts in the intertropical regions of that island-continent. "One might almost fancy," says Mrs. Meredith, " the Aucient Mariner to have experienced one during his ghostly voyage, he so accurately describes their aspect:-

- All in a hot and copper sky,

The bloody sun, at noon,

Right up above the mast did stand,

No bigger than the moon." "

The sirocco of that country always blows from the north-west. At Sydney, its oven-like temperature is moderated by the mid-day sea-breeze; but in the interior, it is severely felt, and is often fatal to the vegetation. Every green thing droops and dies, dried up like half-burnt paper. Large tracts of cultivated land, covered with luxuriant green crops of wheat or barley, just going into ear, are scorched, shrivelled, and absolutely blackened by the heat, and become fit for nothing but to be cut as litter; and of course the delicate plants and flowers of the gardens are not spared by the "burning breath of the fervid Air-king."

6. Mistral. Autun. Bise. These are local atmospheric currents prevalent in the southeast of France. Pliny mentions the first, under the name of Circius, as remarkable for its violence. The Mistral blows from the north-west, descending from the mountains of Central France, and sweeping over the ancient provinces of Provence and Languedoc, where it is supposed to contribute greatly to the salubrity of the air, by dispelling the exhalations from the marshes and stagnant waters common in that region of extensive levels. In the Gulf of Lyons it frequently occasions great damage to the shipping, and to the inhabitants upon the coast, owing to the opposition offered to the course of the wind by the Alps and the Pyrenees, causing it to rush through the opening between them with an increased momentum. Hence the name of the gulf, not derived, as commonly imagined, from the city of Lyons, but from the lion-like violence of its tempests. Malte Brun quotes from William of Nangis, a monk of the middle ages, a remark to this effect:- "It is called the Lion's sea, because it is ever rough, tempestuous, and destructive." The Autun blows in an opposite direction, from the east and south-east, hot and unwholesome, producing morbid effects upon the human system, like the sirocco. It is experienced through the country extending from the coast about Narbonne to the neighbourhood of Toulouse, and frequently blows with great force in the more westerly parts of its track in the vicinity of Castelnaudary. The vent de Bise, or black wind, is a cold piercing current from the Alps and the mountains of Auvergne, which chiefly follows the course of the Rhone, in the valley through which it runs, from north to south, rendering the climate in winter very severe. The currents we are now noticing, confined within a comparatively narrow range, are uniform in their direction; and innumerable examples might be cited of localities where the same uniformity is found, caused by the irregularities of the surface, the position of mountains and valleys. In many cases, local winds are merely branches of a great atmospheric current, diverted from the main stream into an inverse course by the superficial inequalities. Thus, at Liverpool, the prevalent south-west wind of England is scarcely ever felt, owing to the situation of the town, while the predominating wind is the south-east, which is rarely experienced in the kingdom at large. The movements of the atmosphere over the Red Sea are plainly determined by its channel, for the wind never blows in any other direction than to one of its extremities. Captain Parry always found the wind either east or west in Lancaster Sound, and during the whole year, excepting about two months, it blows constantly up the valleys of the Mississippi and the Ohio. Saussure mentions a valley at the foot of the Pyrences, wholly environed with mountains, except towards the nortl-west, and a few other very narrow 
openings, where a cold north-west wind blows regularly during the nights of summer, so that the inhabitants of the village of Bland can winnow their corn at no other time.

7. Ifurricanes.-Sudden and tremendous bursts of storm are eommon in mountainous districts, and in the plains which lie at the base of those vast piles of nature's building. Their peaks, exposed by elevation to intense cold, and covered with perpetual snow, cool and eondense the warm air rising up from the regions below which descends with an impetus proportioned to its own gravity and the lighter condition of the air over the regions below, and a tempest ensues upon considerable condensation and rarefaction in adjoining regions of the atmosphere. This is the origin of the pamperos, or south-west winds, which rush from the snows of the Andes, and sweeping over the level pampas with unchecked violence, become hurricanes before their arrival at Buenos Ayres, and

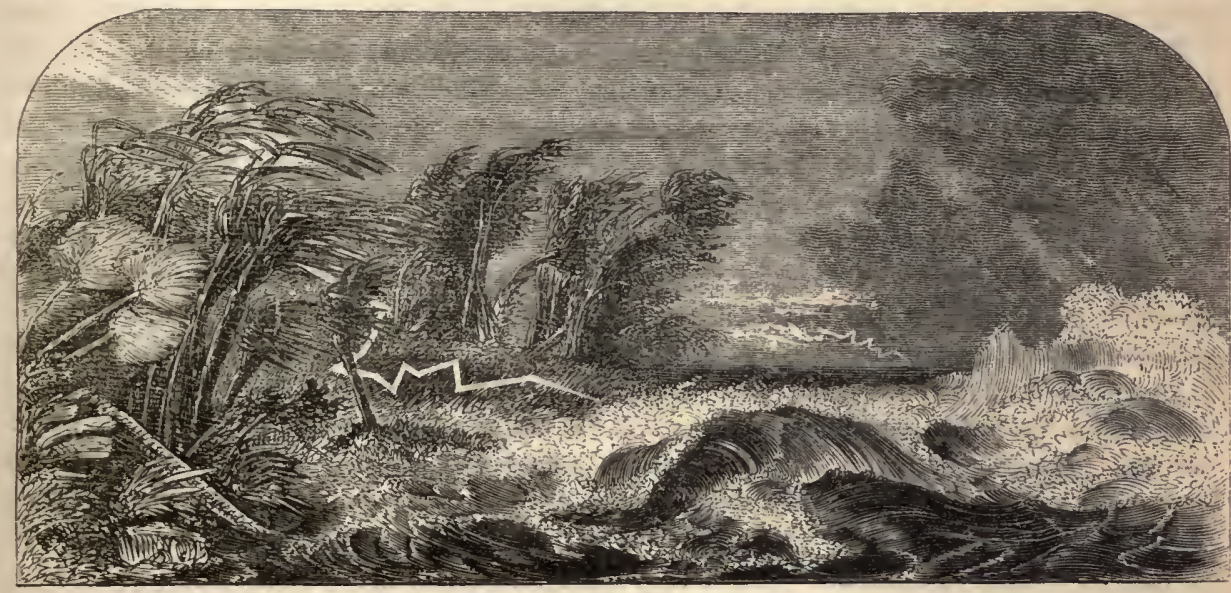

Hurricane in the Tropics.

carry to the city clouds of dust collected from the plains, oceasioning almost total darkness in the streets. So sudden is the operation of the pampero, that persons bathing in the river Plate have been drowned by the agitation of its waters through the tempest before they could possibly reach the shore. Captain Fitzroy relates, when in his ship upon the river, that a small boat had been hauled ashore above high-water mark, and fastened with a strong rope to a large stone, but the pampero set in, and afterwards the boat was found far from the beach, shattered to pieces, but still fast to the stone, which it had dragged along. But this violent movement of the atmosphere is remarkably beneficial in its general effect to the inhabitants of the pampas of Buenos Ayres and on the banks of the Plata. The prevailing winds through a great part of the year are northerly, and these passing over extensive marshy tracts bring with them a degree of humidity, which renders the land rife with fever and pestilence, till the pampero rushes down from the Andes and elears the atmosphere. A somewhat similar wind, is one of our own physical phenomena, hitherto unexplained, to the violence of whieh the tourist to the Cumberland lakes may oceasionally be exposed in spring and autumn. This is the Helm-wind. Hutchinson, in the history of the county, and the Rev. J. Watson, in a report to the British Association, have given an account of its singular features. When not a breath of air is stirring, or a cloud is to be seen, a line of clouds will be suddenly formed over the summits of the lofty ridge of mountains at Hartside, extending several miles on the western side. To this collection of vapours the term Helm is applied from its shape. It exhibits an awful and solemn appearance, spreading a gloom over the regions below, like the shadows of night. Parallel to this, another line of clouds, called the Bar. begins to form. The two lines unite 
together at their extremities, and embrace between them an elliptical cloudless space, from half a mile to four or five miles in breadth, and from eight to thirty miles in length, the breadth being from east to west, and the length from north to south. Soon after the complete formation of the Helm-bar, a violent wind issues from the space between the clouds, generally blowing directly from the east, and with such power that trees have been dismantled of their foliage, stacks of grain dispersed, and heavy vehicles overturned. 'The helm-wind has continued for as much as nine days together, with a noise resembling that of a violent sea-storm, but it is seldom accompanied with any rain. It has been suggested, that the air from the coast of Northumberland, being cooled as it rises to the summit of the mountains, and there condensed, descends from thence with great force, by its gravity, into the district to the west of Hartside, the scene of the phenomenon: but obviously a variety of other causes must enter into its production.

In several parts of the globe, an extensive vacuum being suddenly created by the rapid condensation of Fapour, the surrounding air rushes in with immense impetuosity from all points of the compass, blowing in gusts of resistless power, destroying all the productions of the earth, levelling forests and the firmest buildings, and inundating wlole tracts of country by the deluge of rain with which they are accompanied. These storms seldom occur far out in the open ocean, or beyond the tropies, or nearer the equator than nine or ten degrees. Their principal localities are the West India islands, those of Madagascar, Mauritius, and Bourbon, the north-west coast of Africa, the Bay of Bengal, and the Chinese Sea, where they are variously called hurricanes, tornadoes, and typhoons. A heavy swell upon the sea, a dusky redness of the sky, a close oppressive air, and a wild irregularity in the appearance of things, are the usual precursors of a tropical tempest. Though generally confined to the districts mentioned, where they are of frequent occurrence, the extratropical latitudes, at more distant intervals, experience the force of the hurricane.

"When were the winds

Let slip with such a warrant to destroy?

When did the waves so haughtily o'erleap

Their ancient barriers, deluging the dry ?"

This is the language of Cowper in the Task, respecting the year 1783, when, amid the other events of that portentous season, noticed upon a previous page, a succession of storms, accompanied with violent rains, visited the whole of Great Britain, and caused considerable damage. But what is known in our records as the "Great Storm," occurred on the night of the 26th and the morning of the 27th of November, 1703, and has been referred to by almost all the writers of that period. Derham, in the Philosophical Transactions for the year following, states: "Of the preceding parts of the year (1703), the months of April, May, June, and July were wet in the southern parts of England, particularly in May, when more rain fell than in any month of any year since 1690 ; June also was very wet; and though July had considerable intermissions, yet on the 28th and 29th there fell violent showers of rain, and the newspapers gave accounts of great rains that month from divers places of Europe. On Thursday, November 25th, the day before the tempest, in the morning there was a little rain, the winds high in the afternoon. In the evening there was lightning, and between nine and ten o'clock at night a violent but short storm of wind, and much rain. Next morning, November 26th, the wind was S. S. W., and high all day, and so continued till I was in bed and asleep. About twelve that night the storm awakened me, which gradually increased till near three that morning, and from thence till near seven it continued with the greatest violence; then it began to abate slowly and the mercury to rise swiftly." This tempest filled the whole kingdom with terror, and produced immense commercial loss, and many melancholy accidents. The country between the 
Loire in France and the Trent in England was the chief scene of its ravages. The historians of those times give an affecting account of the dismal appearance of the district. Houses unroofed - steeples blown down-stacks of corn scattered abroad - vessels dismasted or wrecked-and upwards of eight thousand persons drowned. "The wind," says Oldmixon, "blew west-south-west, and grumbled like thunder, accompanied with flashes of lightning. It threw down several battlements and stacks of chimneys at St. James's Palace; tore to pieces tall trees in the Park; and killed a servant in the house. The Guard-house at Whitehall was much damaged, as was the Banqueting-house. A great deal of lead was blown off Westminster Abbey; and most of the lead on churches and houses either rolled up in sheets or loosened. The pious and learned prelate Dr. Richard Kidder, bishop of Bath and Wells, and his lady, were killed by the fall of part of the old episcopal palace at Wells. The bishop of London's sister, Lady Penelope Nicholas, was killed in like manner at Horsely in Sussex, and Sir John Nicholas, her husband, grievously hurt." Upwards of 800 houses, 400 windmills, and 250,000 timber trees were thrown down; 100 churches unroofed; 300 sail lost upon the coast; 900 wherries and barges destroyed on the Thames; the Eddystone lighthouse, built by Winstanley, was overthrown; 15,000 sheep, besides other cattle, wcre drowned by the overflowing of the Severn ; and Rear Admiral Beaumont, with the crews of several ships, perished on the Goodwin Sands.

The West Indies and the vicinity of the Mauritius seem to be two principal foci of hurricanes, from their frequency and tremendous violence in those localities. Of thirteen hurricanes, described by Colonel Reid, in his interesting attempt to develop the law of storms, eleven took place in the neighbourhood of the Mauritius and Madagascar, which sanctions an opinion prevalent among seamen, that gales are commonly avoided by ships steering in a course so as to keep well to the eastward of the Mauritius. To give some idea of a tropical hurricane, the particulars gathered by Colonel Reid from various sources, respecting that which desolated several of the West India islands in the year 1831, are here introduced. It passed over Barbadoes, St. Lucia, St. Domingo, and Cuba, swept the northern shores of the Gulf of Mexico, raged simultaneously at Pensacola, Mobile, and New Orleans, entered the adjoining states, and seems. to have been disorganised by the opposition offered to its progress by the mountain region of the Alleghanies. The hurricane accomplished the distance of 2000 miles in 150 hours, at an average velocity of $13 \frac{1}{2}$ miles an hour, but the rate of its progressive motion was insignificant in comparison with that of its rotatory movement, a feature hereafter to be adverted to. Before its arrival at St. Vincent, a cloud was observed to the north by a resident, so threatening in its aspect and peculiar in its colour, that of olive green, that, impressed with a sense of impending danger, he hastened home, and by nailing up his doors and windows saved his house from the general calamity. In this island, the most remarkable effect of the storm was the destruction of an extensive forest at its northern extremity, the trees of which were killed without being blown down. In 1832, these trees were frequently examined by Colonel Reid, and appeared not to have been killed by the wind, but by the immense quantity of electric matter rendered active during the storm. When at its height, two negroes at Barbadoes were greatly tcrrified by sparks of electricity passing off from one of them, as they were struggling in the darkness; in the garden of Coddrington College, to reach the main building, after the destruction of their hut. Such was the quantity of spray carried inland from the sea by the wind, that it rained salt water over the whole island, which killed the fresh-water fish in the ponds, and several ponds continued salt for some days after the storm. The afternoon that ushered in the hurricane, that of the 11th of August, was one of dismal gloom, but about four o'clock, there was an obscure circle of imperfect light towards the zenith subtending an angle of $35^{\circ}$ or $40^{\circ}$. Variable squalls of 
wind and rain, with intervening calms, prevailed till midnight, when the lightning flashed fearfully, and a gale blew fiercely from the north and north-east. At one A.Mr. the wind increased, but suddenly shifted its quarter, blowing froin north-west and intermediate points. Towards three o'clock, after a little intermission, the hurricane again burst from the western points, hurling before it thousands of missiles - the fragments of every unsheltered work of human art. The strongest houses vibrated to their foundations, and the surface of the earth trembled as the destroyer passed over it. There was no thunder at any time distinctly heard, but the horrible roar and yelling of the wind, the noise of the ocean, whose waves threatened the destruction of every thing in Barbadoes that the other elements might spare, the elattering of tiles, the falling of roofs and walls, and the combination of a thousand other sounds, formed a hideous and appalling din. As soon as the dawn rendered outward objects visible, and, the storm abatiug, permitted the inhabitants of Bridgetown to venture out, a grand but distressing picture of ruin presented itself. From the summit of the cathedral tower, the whole face of the conntry appeared the wreck of its former condition. No sign of vegetation could be observed, except here and there a few patches of sickly green. 'The surface of the ground exhibited the scorching and blackening effect of the lightuing. A few remaining trees, stripped of their boughs and foliage, wore a cold and wintry aspect; and the numerous villas in the neighbourhood, formerly concealed amid thick groves, were exposed and in ruins.

In the year 1837, three hurricanes occurred in the West Indies, and adjacent parts of the Atlantic, the narratives of which, as collected by Colonel Reid from different observers, present some singular features. The first passed over Barbadoes on the 26th of July. The sky assumed a blue-black appearance, with a red glare at the verge of the horizon. The flashes of lightning were accompanied with a whizzing noise, like that of a red-hot iron plunged in water. The barometer and sympiesometer fell rapidly and sunk to 28.45 inches. The Antigua hurricane, the second of that year, commenced in the Atlantic, on the night of the 31 st of July, and was encountered by Captain Seymour, in the brigantine Judith and Esther of Cork. He observed near the zenith a whice appearance of a round form, and while looking stedfastly at it, a sudden gust of wind carried away the topmast and lower scudding sails. During the hurrieane the eyes of the crew were remarkably affected, their sight became dim, and every one of their fingernails turned quite black, and remaiued so nearly five weeks afterwards. The captain inferred, from the universality of the effect, that it could not have been produced by the firmness of the grasp with which they were holding by the rigging, but that the whole was caused by an electric body in the elements. On the 2nd of August, in another situation, the Water Witch was caught by the skirts of the same storm, the wind blowing in squalls from the W. and N.N.W. till the evening, when "a calm succeeded," states Captain Newby, "for about ten minutes; and then, in the most tremendous unearthly screech I ever heard, it recommenced from the south and south-west." The third hurricane of the year was met with by the Rawlins, about midnight of the 18th of August, when, after blowing violently for twelve hours from the north, in an instant a perfect calm ensued for an hour, and then, quick as thought, the wind sprung up with tremendous foree from the south-west, no swell whatever preceding the convulsion. During this hurricane, an extraordinary phenomenon presented itself, resembling a solid black perpendicular wall about $15^{\circ}$ or $20^{\circ}$ above the horizon, which disappeared and became visible again several times, described by one of the observers, as "the most appalling sight he had ever seen during his life at sea." A similar spectacle is described by an officer on board the king's ship Tartarus, during a hurricane on the American coast in the year 1814: - "No horizon appeared, but only a something resembling an immense wall within ten yards of the ship." 'The power of the wind was remarkably exemplified during the great hurricane of 1780 . 
which at Barbadoes forced its way into every part of the Government-house, and tore off most of the roof, though the walls were three feet thick, and the doors and windows had been well barricaded. Obliged to retreat from thence, the Governor and his family fled to the ruins of the foundation of the flag-staff, and, compelled to relinquish that station, they with difficulty reached the cannon of the fortifications, under the carriages of which they took shelter. But here they were not secure, for the cannons were moved by the fury of the wind, and they dreaded every moment that the guns would be dismounted, and crush them by their fall. From the preceding accounts it appears, that the agency of electricity is frequently extensively developed in hurricanes; that they have a progressive motion; that calms of short duration occur during their continuance; after which the wind bursts forth from a quarter different to that from which it has been blowing;-peculiarities which have led to a theory respecting storms which may be considered as established in its leading principles.

Down to the present century, a hurricane was generally deemed to be simply a gale of wind pursuing with immense velocity a rectilinear direction. Colonel Capper departed from this idea after investigating the storms of the Indian Ocean, and published the conclusion in the year 1801, that the hurricanes he had examined in that region were real whirlwinds of varying diameter, having a progressive as well as a rotatory motion. The evidence collected from the records of an immense number of storms in the Atlantic by Mr Redfield of New York, and in the Indian Ocean by Colonel Reid, has established beyond all dispute the fact, that they are eddies in the atmosphere, having an outer circle, where the air revolves with intense velocity, and an interior space, the diameter of which is sometimes equal to several hundred miles, the vortex of the whirlwind, which is the scene of gusts and lulls, a comparatively slow progressive motion on the surface of land and sea distinguishing the whole. A hurricane, which occurred at New Brunswick in the year 1835, strikingly exhibited the character of a revolving storm; for, while about the centre bodies of great weight were carried spirally upwards, at the extremities the trees were thrown in opposite directions. The same circumstance was observed at Barbadoes in 1831 , near the northern coast: the trees which the hurricane uprooted lay from N.N.W. to S.S.E., having been thrown down by a northerly wind, while in some other parts of the island they lay from S. to N., having been prostrated by a southerly wind. It is evident, therefore, that the direction of the wind at a particular point affords no indication of the course in which the whole revolving mass of the atmosphere is advancing. Another singular conclusion is, that the rotatory motion of the air, in the northern hemisphere, is in a direction against the hands of a watch; and the reverse in the southern hemisphere, or with the hands of $a$ watch. It is also ascertained, that while the axis of a storm in the North Atlantic has a progressive motion from the equator obliquely towards the north pole, that of one in the Indian Ocean proceeds obliquely from the equator towards the south pole. In the Pacific Ocean, a region of hurricanes, their revolving motion is decisively sanctioned by the evidence which has been obtained respecting them. Mr Williams, the missionary, describes a hurricane at Raratonga, one of the Hervey islands, during which the rain descended in deluging torrents, the lightning darted in fiery streams among the dense black clouds, the thunder rolled deep and loud throngh the heavens, and the island trembled to its very centre as the war of the elements raged over it. Scarcely a banana or plantain tree was left, either on the plains, or in the valleys, or upon the mountains; hundreds of thousands of which, on the preceding day, covered and adorned the land with their foliage and fruit; and immense chestnuts, which had withstood the storms of ages, were laid prostrate on the ground, while those that remained erect had scarcely a branch, and were all leafless. It was observed, that when the gale ended, the wind was in the 
wcst, whereas in the early part of its action the east end of the chapel had been blown in, which shows the wind then to have been in the east. The hurricanes of New South Wales have been observed to develop the same peculiarity. Mr. Meredith traced the path of one in the centre, and found at the termination a circle plainly shown, in which the trees lay all ways.

The cause of this rotatory motion of storms remains in obscurity, but it is probably due in part to the same law under which eddies or whirlpools are formed in water, by two currents being obliquely impelled against each other. The great hurricanes may thus be considered identical with the small loeal whirlwinds, which are common with us in the summer season, carrying upwards and along the dust and loose grass in spiral columns, exhibiting a progressive and rotatory motion. In the region of the sandy deserts these atmospherie whirls transpire upon a great scale, raising up immense quantities of the loose particles in columns to a considerable height, which sweep along with prodigious violence, and have occasionally swallowed up whole caravans in their tremendous vortex.

\footnotetext{
" Man mounts on man, on camels camels rush,

Hosts march on hosts, and nations nations crush,

Wheeling in air the winged islands fall,

And one great earthy ocean covers all."
}

"One of the largest of these pillars of sand," says a modern traveller, Caillie, "crossed our camp, overset all the seats, and whirling us about like straws, threw one of us on the other in the utmost confusion. We knew not where we were, and could not distinguish anything at the distance of a foot. The sand wrapped us in darkness like a fog, and the sky and the earth seemed confounded and blended in one. Whilst this frightful tempest lasted we remained stretched on the ground motionless, dying of thirst, burned by the heat of the sand, and buffeted by the wind. We suffered notling, however, from the sun, whose disk, almost concealed by the clouds of sand, appeared dim and deprived of its rays." Bruce has sketched with spirit several of these desert whirlwinds of which he was an eyewitness : - "At one o'clock," he states, "we alighted among some acacia trees at Waadi el Halboub, having gone twenty-one miles. We were here at once surprised and terrified by a sight, surely one of the most magnificent in the world. In that vast expanse of desert, from W. to N. W. of us, we saw a number of prodigious pillars of sand at different distances, at times moving with great celerity, at others stalking on with a majestic slowness; at intervals we thought they were coming in a very few minutes to overwhelm us; and small quantities of sand did aetually more than once reach us. Again they would retreat so as to be almost out of sight, their tops reaching to the very clouds. There the tops often separated from the bodies, and these, once disjoined, dispersed in the air, and did not appear more. Sometimes they were broken in the middle, as if struck with large cannon shot. About noon they began to advance with considerable swiftness upon us, the wind being very strong at nortl. Eleven of them ranged alongside of us about the distance of three miles. 'The greatest diameter of the largest appeared to me at that distance as if it would measure ten feet. They retired from us with a wind at S.E. leaving an impression upon my mind to which I can give no name, though surely one ingredient in it was fear, with a considerable deal of wonder and astonishment. It was in vain to think of flying; the swiftest horse, or fastest sailing ship, could be of no use to carry us out of this danger; and the full persuasion of this rivetted me as if to the spot where I stood. The same appearance of moving pillars of sand presented themselves to us this day in form and disposition like those we had seen at Waadi Halboub, only they seemed to be more in number and less in size. They came several times in a lirection close upon us, that is, I believe, within less than two miles. They began 
immediately after sunrise like a thiek wood, and almost darkened the sun. His rays shining threw them for near an hour, gave them an appearance of pillars of fire. Our people now became desperate; the Greeks shrieked out and said it was the day of judgment ; Ismael pronounced it to be hell ; and the Turcorories, that the world was on fire." The procession of tall columns of dust, the upper end seeming to vanish off, or puff away like light smoke, and the lower apparently touching the eartl, is not unusual on the large plains of New South Wales, in dry weather. They move in a perpendicular position, quietly and majestically gliding along one after another, but really so fast that the fleetcst horse is unable to keep pace with them. According to Mrs. Meredith, when they are crossing a brook, the lower portion of the dust is lost sight of, and a considerable agitation disturbs the water, but immediately on landing the same appearance is resumed. "As some vanish," she remarks, "others impereeptibly arise and join the giant waltz; and when I first observed this most singular display, I amused myself by fancying them a new species of genii relaxing from their more laborious avoeations, and having a sedate and stately danee all to themselves. When the dance ends, these dusty performers always appear to sit down among the neighbouring hills." To the same class with these rotating and progressing pillars of sand, that singular phenomenon called the waterspout clearly

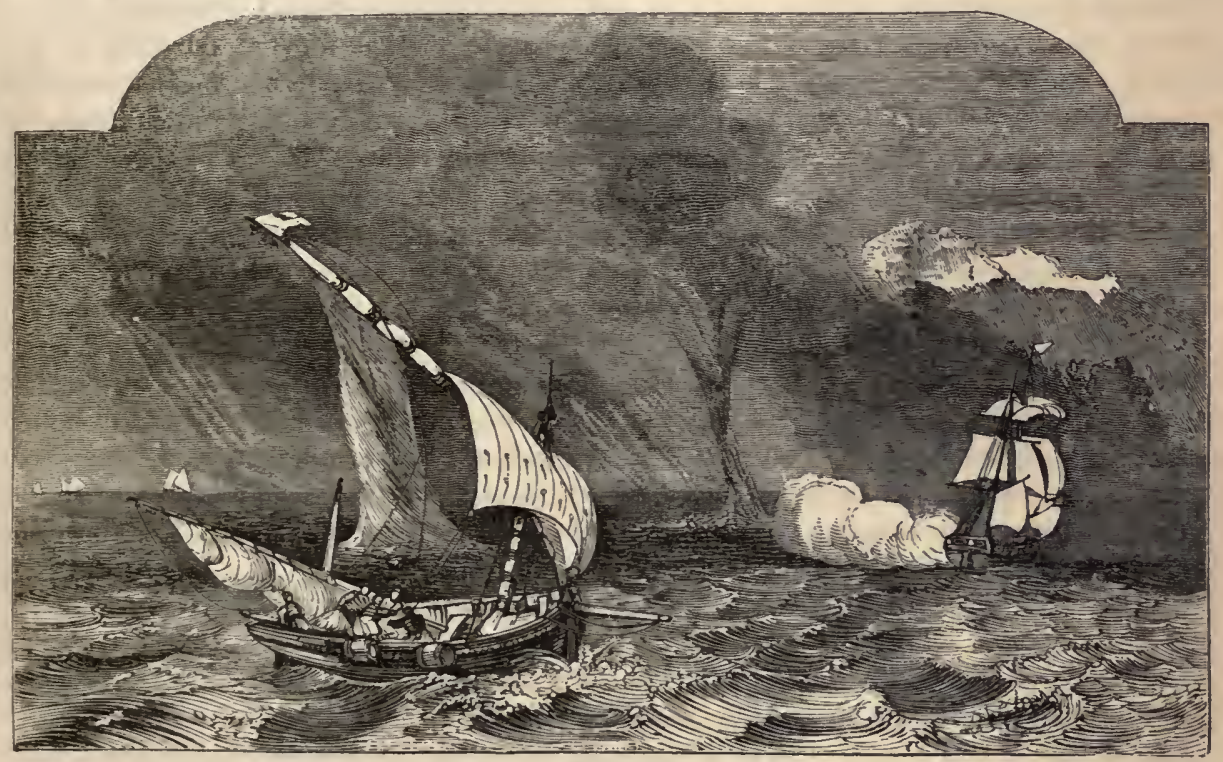

Waterspout.

belongs, a whirlwind raising into a columnar mass the waters of the sea, and causing the aqueous vapours in the atmosphere to assume the same form, the two frequently uniting, the whole presenting a magnificent spectacle.

The Greeks applied the term Prester to the waterspout, which signifies a fiery fluid, from its appearance being generally accompanied with flashes of lightning, and a sulphureous smell, showing the activity of the electrical principle in the air. Lucretius refers to it in the following terms:-

" Hence, with much ease, the meteor may we trace Term'd, from its essence, Prester by the Greeks, That oft from heaven wide hovers o'er the deep. Like a vast column, gradual from the skies, Prone o'er the waves, descends it; the vex'd tide 
Boiling amain beneath its mighty whirl,

And with destruction sure the stoutest slip

Threat'ning that dares the boist'rous scene approach."

Waterspouts exhibit various aspects, but a frequent appearance has been thus described, as it has been observed at sea. Under a dense cloud, a circular area of the ocean, in diameter from 100 to 120 yards, shows great disturbance, the water rushing towards the centre of the agitated mass, from whence it rises in a spiral manner towards the clouds, assuming a trumpet-shape, with the broad end downwards. At the same time, the cloud assumes a similar form, but the position of the cone is inverted, and its lower extremity, or apex, gradually unites with the upper extremity of the ascending column of water. At the point of junction, the diameter is not more than two or three feet. There is thus a column of water and vapour formed, extending from the sea to the cloud, thin in the middle, and broad at the two extremities, the sides of which are dark, which gives it the appearance of a hollow tube. It moves with the wind, and even in calm weather, when no wind is perceptible, the position shifts. Sometimes the spout preserves the perpendicular in its motion, but frequently, from the wind not acting with equal force upon its upper and lower extremities, or the one being more susceptible of impulsion than the other, it assumes an inclined position, and the column is speedily ruptured by the unequal velocity of its parts. A few minutes suffices in general for the duration of the phenomenon, but several have been known to continue for near an hour. Instances of repeated disruption and formation have been witnessed, and in the Mediterranean, as many as sixteen waterspouts have been observed at the same time. The mariners of former days were accustomed to discharge artillery at these moving columns, to accelerate their fall, fearful of their ships being crossed by them, and sunk or damaged-a practice alluded to by Falconer in the opening of the second canto of The Shipwreck: but the principal danger arises from the wind blowing in sudden gusts in their vicinity, from all points of the compass, sufficient to capsize small vessels carrying much sail. Waterspouts on land are not uncommon, and in this case there is no ascending column of water, but only a descending inverted cone of vapour. Vivid flashes of lightning frequently issue from them, and deluges of rain attend their disruption. A remarkable spout appeared and burst on Emott Moor, near Coln in Lancashire, in the year 1718, about a mile distant from some labourers digging peat, whose attention was directed to it by hearing an unusual noise in the air. Upon leaving the spot in alarm, they found a small rippling stream converted.into a roaring flood, though no rain had fallen on the moor; and at the immediate scene of action, the earth had been swept away to the depth of seven feet, the naked rock appeared, and an excavation had been made in the ground by the force of the water discharged from the spout, upwards of half a mile in length.

It is a time of fear and peril to man and beast when the hurricane developes its giant strength, yet, contemplated apart from the probability of some fatal catastrophe, there is no scene more intensely sublime in the varied panorama of nature, than that exhibited to the senses of sight and hearing, by the dense black masses of clouds that roll in wild confusion through the air, the tumultuous aspect of the ocean, the agitation of the woods, and the voice of the tempest, varying from the melancholy wail to the piercingly shrill ery and deafening roar, and occasionally combining every kind of intonation in its sound. However destructive these extraordinary agitations of the atmosphere-however terrible such a situation as that of Fneas on the stormy sea, helpless and hopeless, stretching his folded hands to the stars, and lamenting that he had not fallen with fierce Hcctor on the Ilian plains - it is unquestionable, that neither " breeze, or gale, or storm," could be dispensed with in the economy of nature; for the various forms of life which the common air sustains, are preserved in vigour by that conflict of the elements which works occa- 
sional disaster. A variety of natural causes in operation upon the surface of the globe, and in its interior, concur to derange that constitution of the atmosphere which is alone salubrions, to vitiate the fluid, convert the medium of life and health into a cause of feres, pestilence, and deatl, thus changing every seene where the machinery of human existence is in movement into a Grotto del Cane, completely arresting all its wheels - an effect which would undoubtedly transpire without an antagonistic influence in constant action. In the process of supporting mankind and animals, the atmosphere is deprived of its oxygen, and exhaled in a morbid condition unfit for combustion and the sustenanee of life; and the respiration of plants contributes also to its derangement. The exhalations from the low swampy regions of the earth are a further cause of deterioration, and hence the malarious mass to which the Pontine marshes, and similar districts, give birth. The provision against the reduction of the atmosphere to a universally disorganised and vitiated condition is the currents that prevail in it, which disperse and separate the poisonous ingredients, render them innocuous by bringing them into new combinations, and thus keep up that due proportion between the component parts of the aerial envelope, upon which its life-conserving property hinges, yet which the functions of life are perpetually destroying. The ordinary play of the winds, whispering in gentle breezes and rushing in powerful gales, has been ordained by the Author of life to subserve this purpose, and the dread tornado is also an efficient agent in the regeneration. In its alembic, it has been remarked, "the isolated poisons will be redistilled; by the electric fires which it generates, their deleterious sublimations will be deflagrated; and thus will the great Alehymist neutralise the azotic elements which he has let loose, and shake the medicinal draught into salubrity." The baneful effects of a stagnant condition of the atmosphere are exemplified in the feeble physical frame, and short term of years, of those who in the "city full" are cooped up in sites were there is no sufficient ventilation, and the inhabitants of many deep enclosed valleys exhibit physical and mental deterioration as a consequence of the same eause. The numerous examples of crétinism, or idiocy, with goitres, found about the village; and hamlets of the Lower Valais, and the Val d'Aosta in Switzerland,--valleys, which h.sve low marshy spots at the bottom, surrounded by high mountains, where the fresh air does not circulate freely, and where the reflected rays of the sun are very powerful in summer,-Saussure attributed to the stagnation of the atmosphere; and though such instances of physical deformity and intellectual incapacity may be the combined effect of various causes, it is in harmony with the known effect of the one referred to, to suppose it materially to contribute to the result. The cagots of the deep Pyrenean valleys answer to the cretins of the Alps.

In closing this notice of atmospheric currents, we refer to observations made upon the ordinary winds of Great Britain. From an average of ten years of the register kept by order of the Royal Society, it appears that at London the wind blows annually in the following proportions:-

\begin{tabular}{|c|c|c|c|c|c|c|c|}
\hline & & & Days. & & & & Days. \\
\hline South-west & - & - & -112 & South-cast & • & - & \\
\hline North-east & - & - & - $\quad 58$ & East - & - & - & 26 \\
\hline North-west & - & - & 50 & South & - & - & 18 \\
\hline West - & - & - & 53 & North & - & - & 16 \\
\hline
\end{tabular}

The same register shows, that the south-west wind blows at an average more frequently than any other wind during every month of the year, and that:it blows longest in July and August; that the north-cast blows most constantly during January, March, April, May, and June, and most seldom during February, July, September, and December; and that the north-west wind blows oftener from November to March, and more seldom during September and October, than any other months. At Bristol, the south-west winds are 
also most frequent, and next to them are the north-east. At Lancaster, $₫$ register kept during seren years exhibits the following average results :-

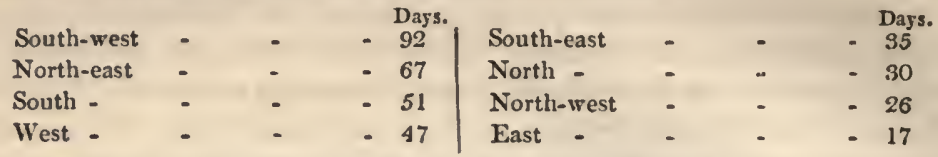

An abstract of nine years' observations made at Dumfries, gives

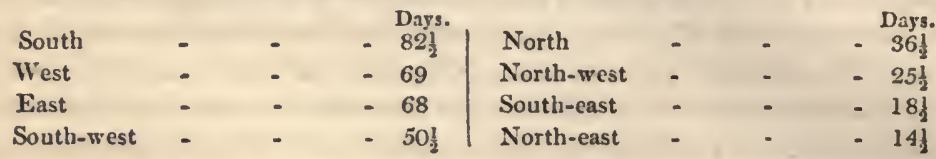

Dr. Meek's observations during seven years at Cambuslang, near Glasgow, show

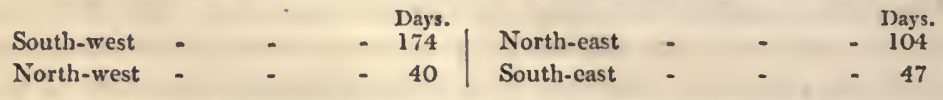

The register from which this table is extracted shows the north-east wind to blow most frequently in April, May, and June, and the south-west in July, August, and September. The next table exhibits a view of the number of days during whicl the westerly and easterly winds blow in a year in different parts of the island, including under the term westerly, the north-west, west, south-west, and south, and taking the term easterly with the same latitude:-

\begin{tabular}{|c|c|c|c|c|c|c|c|c|}
\hline \multirow{2}{*}{$\begin{array}{c}\begin{array}{c}\text { Years of } \\
\text { Observations. }\end{array} \\
10\end{array}$} & \multicolumn{6}{|c|}{ Places. } & \multirow{2}{*}{$\frac{\text { Westerly. }}{293}$} & \multirow{2}{*}{ Easterly. } \\
\hline & London & - & - & - & - & - & & \\
\hline 7 & Lancaster & - & - & - & - & - & 216 & 149 \\
\hline 51 & Liverpool & - & - & - & - & - & 190 & 175 \\
\hline 9 & Dumfries & - $\quad-$ & - & - & - & - & $227 \cdot 5$ & 137.5 \\
\hline 10 & Brancxolm & in Northumberl & and & - & - & - & 232 & 133 \\
\hline 7 & Cambuslan & $g \quad-$ & - & - & - & - & 214 & 151 \\
\hline \multirow[t]{2}{*}{8} & Hawkhill, & near Edinburgh & - & - & - & - & $229 \cdot 5$ & $135 \cdot 5$ \\
\hline & & & & & & & lean 220.3 & $144 \cdot 7$ \\
\hline
\end{tabular}

The result given by Professor Daniell from these and other observations, is, that in Great Britain, upon an average of ten years, the westerly winds exceed the easterly in the proportion of 225 to 140 ; and the northerly winds exeeed the southerly as 192 to 173. The winds between north and east are almost invariably cold; those between south and west are warm; and those between north and west of a mixed character. But in our climate, and still farther north, two or three winds are often found blowing from different points within the distance of a few leagues.

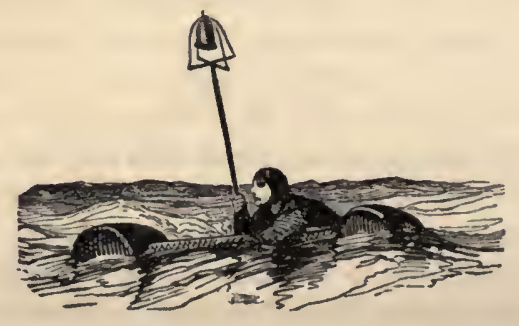




\section{CHAPTER XIV.}

AQUEOUS ATMOSPHERIC PHENOMENA.

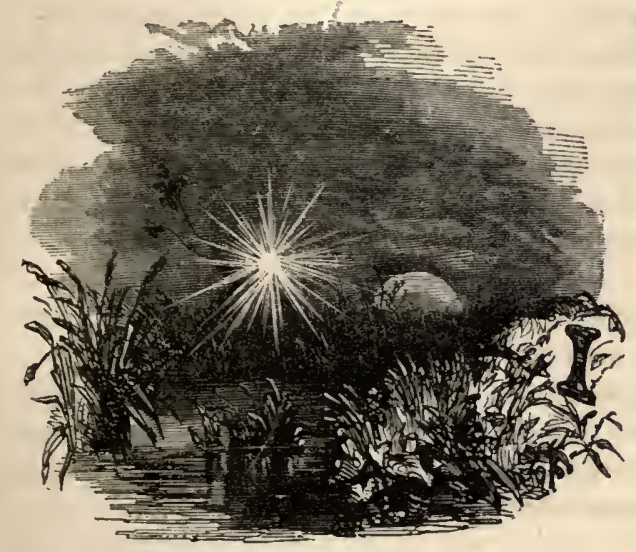

$\mathrm{N}$ addition to common air, a combination chiefly of the oxygen and nitrogen gases, united in different proportions, the atmosphere contains a mass of invisible vapour insinuated between the particles of the gases, and filtering through them, in a manner which may be compared to that of the diffusion of water through a sponge, or visible in the form of fogs and clouds. This vaporous atmosphere is the result of the ever-active agency of heat and electricity, which, by a process of marvellous subtilty and energy, evaporates the waters from the surface of the earth, and trans. fers them for a time to an aerial home. The process is entirely untraceable by the eye of man, but its product appears in the clouds that are reared aloft in fantastic shapes, in the mists that occasionally slroud the landscape, the rain and the snow that come down from heaven, the dew glistening in the morning liglit, and the loar-frost which adorns the forest with a beauty that throws the results of human artistic skill into insignificance. The words of the sacred writer are philosophically true: "He calleth for the waters of the sea, and poureth them out upon the face of the earth;" but the supply of humidity furnished to different countries varies prodigiously in its amount, and hence other differences as the consequence - barrenness here and fertility there- a comparative solitude abandoned to the occupancy of the inferior orders of the animal creation, and a land studded with the homes of peasantry, the palaces of nobles, the halls of science, and the marts of commerce. Though we have spoken of the process of evaporation as untraceable by the human eye, yet that refers to the exhaling agency, for sensible evidence is frequently afforded that the ever-operating machinery is actually at work before us, in the visible exhalations we behold at early dawn, and in the calm evening of a summer's day. It is generally the case, however, that the formation of visible vapours takes place in the higher regions of the atmosphere, though at the earth's level, the metamorphosis of its waters into an invisibly vaporous state is constant, and is proceeding as powerfully when no outward sign of the process appears, and the air is perfectly transpafent, as when a misty mantle, of feathery shape and texture, rests upon the lakes and rivers, and lies upon the surface of the valleys.

It is not merely from the great collections of water in oceans, lakes, and rivers, that evaporation takes place, but from the pasture grounds and forests; and Leslie makes the remark that even ploughed land will supply as much moisture to the exhaling fluid as an equal sheet of water. But the atmosphere is only capable of receiving a certain quantity of vapour in an invisible state, its capacity depending upon temperature, and being invariable in its extent at the same temperature. When all the interstices of the gaseous fluid are full, it is then said to be at its point of saturation, and any further supply of vapour becomes visible in the form of steam or mist. The lower the temperature, the greater the condensation of the air and the tightness of its particles, so that only a certain 
amount of moisture can enter ; but the higher the temperature, the greater the expansion, and the consequent capacity of a volume of the atmosphere to entertain the aqueous vapour. It has been computed, that a cubic mass of air measuring 40 inches each way, at a temperature of $68^{\circ}$ Fahrenheit, can contain 252 grains of water, or, taking a cubic mass measuring 20 yards each way, at the same temperature, it will require 252 pounds troy of water to bring it to the point of saturation. Various causes contribute to accelerate or check the process of evaporation, but other things being equal, it will proceed most vigorously, the higher the temperature of the air above that of the surface upon which it acts, and be least active when the two temperatures are the same. 'The process is materially affected by the state of the air as to dryness and moisture, for water is rapidly evaporated by a stratum of dry air even when the temperature is low, whereas it is conducted tardily, if the atmosphere should contain much vapour, although the temperature may be high. The process also is powerfully promoted by the play of the winds, which bring the atmosphere into immediate and stronger contact with the moist earth and surface waters, and hence every one is familiar with the more rapid drying of the ground after rain, when the air is disturbed, than when it is still.

By the hygrometer, an instrument employed to ascertain the lumidity of the atmosphere, as the name signifies, the measure of moisture, Professor Daniell caleulated the average annual amount of evaporation in the vicinity of London to be 23.974 inches, proceeding at the following rate in the different month :-

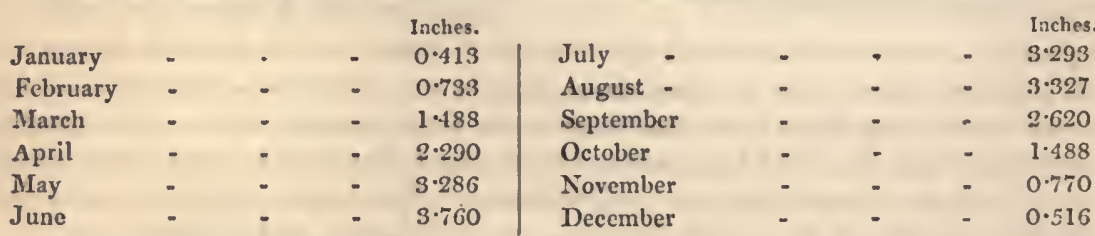

Thus, in that locality, evaporation is most active, and the largest amount of water is elevated into the atmosphere, in June, the reversc taking place in January. The annual evaporation from the whole surface of Great Britain is supposed to be equal to 32 inches of water. Now, water extended over the surface of the island to the depth of one inch, would amount to $309,696,038,000,000$ cubic inches, which is equal to $1,116,931,402,691$ imperial gallons, or $4,432,267,441$ tons. If we multiply this quantity by 32 , we have the prodigious sum of $141,832,558,752$ tons of water, aseending in vapour every year from the face of the country. The power of the agency employed in this operation of nature must be tremendous; but equally for its utility does. it command attention, as for its wondrous potentiality. For supposing this spontaneous evaporation to cease, the world being deprived of the elements that cause it, the heavens would drop no fatness; the springs would dry up, and the rivers be exhausted; the earth would soon be without any vegetation to adorn its surface, or any living creature to inhabit its wilds; the whole water of the globe accumulated in the ocean would overflow the land, and submerge its now fertile plains. In the temperate zone in general, with a mean temperature of $521_{4}^{\circ}$, the annual evaporation is estimated at between 36 and 37 inches; but in the torrid zone, where the temperature is much higher, the annual evaporation is greater. At Guadaloupe, one of the West India islands, it has been found to amount to 97 inches, and at Cumana, on the north coast of South America, to 100 inches.

The formation of visible vapours, and their aggregation in masses, take place generally in high regions of the atmosphere under the action of currents, in consequence of a decrease of temperature and a due supply of aqueous elastic vapour being present in those parts where clouds arise. It is easy to perceive that these two conditions, necessary to 
the production of cloud-land, may be fulfilled in one stratum of the atmosphere and not in another, and hence the frequent diversity in the appearance of the sky, the clear blue fields and patches of ether alternating with visible vaporous structures. The clouds are supposed to consist of vesicular vapours, or minute globules of water filled with air, but there is great difficulty, even with the aid of this view of their structure, most probably correct, in explaining their suspension aloft, for the globules must be specifically heavier than the air by which they are upborne. The theory of ascending currents of heated air has been proposed by M. Gay Lussac to account for their position; and the retention of solar heat in the clouds themselves, buoying them up, and causing them to float, by M. Fresnel; but this is a point respecting which we are left without the guidance of any positive data. The clouds float at different elevations, but the higher we ascend, the drier the atmosphere is found, and the less loaded with vapours. "We shall not err much," says Mr. Leslie, "if we estimate the position of extreme humidity at the height of two miles at the pole, and four miles and a half under the equator, or a mile and a half beyond the limit of congelation." Dr. Dalton asserts that small fleecy patches of cloud are frequently from three to five miles in height, and such have been observed sailing above the most elevated peaks of the Andes, which rise 25,000 feet above the level of the sea ; but other authorities clain for some visible clonds a still greater elevation. The height varies at different seasons of the year, and there is little doubt that it is much more frequently below than above a mile. Dalton gives a table from observations made by Mr. Crosthwaite of Keswick, who fixed marks on the side of Skiddaw, a mountain 1050 yards high, by which he was able to ascertain by inspection the height of the clouds when they did not exceed that of the mountain. During five years he conducted observations, three times each day, excepting a few intermissions which amounted only to missing less than a week per year. The table gives the number of times, in the respective months, that the clouds were at the height stated. The last column gives the number of times in which either the clouds were above Skiddaw, or there were no clouds at all.

\begin{tabular}{|c|c|c|c|c|c|c|c|c|c|c|c|c|c|}
\hline Months. & $\begin{array}{c}\text { Under } \\
\text { 100 } \\
\text { sards. }\end{array}$ & $\begin{array}{c}\text { From } \\
100 \text { to } 200\end{array}$ & $\begin{array}{c}200 \\
\text { to } \\
300\end{array}$ & $\begin{array}{c}300 \\
\text { to } \\
400\end{array}$ & $\begin{array}{c}400 \\
\text { to } \\
500\end{array}$ & $\begin{array}{l}500 \\
\text { to } \\
600\end{array}$ & $\begin{array}{l}600 \\
\text { to } \\
700\end{array}$ & $\begin{array}{c}700 \\
\text { to } \\
800\end{array}$ & $\begin{array}{l}800 \\
\text { to } \\
900\end{array}$ & $\begin{array}{c}900 \\
\text { to } \\
1600\end{array}$ & $\begin{array}{l}1000 \\
\text { to } \\
1050\end{array}$ & $\begin{array}{c}\text { Above } \\
1050\end{array}$ & $\begin{array}{c}\begin{array}{c}\text { Number } \\
\text { of } \\
\text { Observations. }\end{array}\end{array}$ \\
\hline January & 0 & 9 & 12 & 28 & 53 & 39 & 37 & 32 & 30 & 39 & 36 & 116 & 431 \\
\hline February - & 5 & 10 & 5 & 15 & 41 & 45 & 45 & 27 & 43 & 38 & 29 & 94 & 397 \\
\hline March & 2 & l & 6 & 11 & 22 & 40 & 32 & 36 & 24 & 32 & 49 & 184 & 434 \\
\hline April - & 0 & 4 & 5 & 18 & 24 & 34 & 37 & 26 & 23 & 38 & 35 & 206 & 450 \\
\hline May - & 0 & 1 & 4 & 8 & 13 & 31 & 22 & 25 & 30 & 34 & 27 & 270 & 465 \\
\hline June - & 0 & 2 & 2 & 6 & 24 & 24 & 29 & 21 & 34 & 41 & 34 & 233 & 450 \\
\hline July - & 0 & 2 & 2 & 18 & 25 & 36 & 35 & 25 & 35 & 48 & 38 & 191 & 465 \\
\hline August - & 0 & 4 & 5 & 13 & 27 & 39 & 35 & 26 & 25 & 45 & 30 & 215 & 464 \\
\hline September & 0 & 1 & 7 & 13 & 38 & 33 & 32 & 30 & 27 & 51 & 27 & 186 & 450 \\
\hline October - & 2 & 0 & 5 & 13 & 26 & 49 & 31 & 31 & 46 & 61 & 37 & 164 & 465 \\
\hline November & 0 & 0 & 3 & 13 & 30 & 58 & 42 & 38 & 46 & 45 & 47 & 128 & 450 \\
\hline December & 1 & 8 & 6 & 23 & 41 & 53 & 39 & 50 & 47 & 46 & 35 & 111 & 450 \\
\hline Total & 10 & 42 & 62 & 179 & 374 & 486 & 416 & 367 & 410 & 518 & 409 & 2098 & 5381 \\
\hline
\end{tabular}

It thus appears, that, for 12 times that the clouds were from 200 to 300 yards high, in the month of January during the five years, there were 36 times in which they were from 1000 to 1050 yards high; and for twice that they were at the former elevation in the month of June, there were 34 times in which they were at the latter.

The forms assumed by the clouds are so infinitely diversified, as to render it apparently hopeless to attempt their arrangment in a few general modifications. But a classification has been made with some success, which reduces these varied aerial objects into seven genera, each of which is susceptible of such perspicuous description as to be readily recognised, and referred to its appropriate class and name. Mr. Luke Howard's ingenious 
scheme is now universally adopted, which will be briefly given, placing Mr. Foster's English names beside the Latin nomenclature of the former writer.

Fig. 1. Cirrus - Curlcloud. This form of cloud exhibits light, flexuous, or diverging fibres, sometimes shooting out from a nucleus in all directions, resembling a lock of hair, or a crest of feathers. The name refers to this feature of its external character. It occurs, however, in parallel bars, or thread-like lines, spanning a vast extent of the atmosphere, the whole breadth of the sky being insufficient to show the extremities. Other lines also are occasionally presented, crossing these at right or oblique angles, as in a piece of network. In the former condition we have linear cirrus, and in the latter reticular cirrus. These are the cobwebs of the sky. They frequently appear stretching their white and delicate fibres between the dark and dense masses, as if spun to connect them, though really distinct and far separated. 'The cirri appear in the higher regions of the atmosphere, and are the most elevated of the clouds. Viewed from the summits of high mountains, while the traveller looks down upon other forms of cloud, he beholds these still above him, and apparently at as great a distance as when seen from the plains. The appearance of true cirrus, or curlcloud, is supposed to indicate variable weather; when most conspicuous and abundant, to presage high winds and rain; and when the streaming fibres have pointed in a particular direction for any length of time, the gale may be expected to blow from that quarter.

Fig. 5. Cumulus - Stackencloud. This modification of cloud occurs in the lower regions of the atmosphere, and is easily recognised. It is commonly under the control of the surface winds, and frequently exhibits a very magnificent appearance. It consists of a vast hemispherical or conical heap of vapour rising gradually from an irregular horizontal base, and increasing upwards. Hence the names, cumulus, a pile or heap, and stackencloud, a number of detached clouds stacked into one large and elevated fabric. Cumuli are the accompaniments and prognostics of fine weather. 'They begin to form soon after sunrise, from irregular and scattered specks of cloud, which then appear at a moderate elevation, and are the nuclei of the ultimate formations. As the morning adrances the nucleus enlarges, or several coalesce, and early in the afternoon, when the temperature of the day is at its maximum, the cumulus attains its greatest magnitude. The cloud decrenses as the sun declines, and is usually broken up towards sunset, rapidly separating into fragments, after the manner of its construction. The cumulus may be called the cloud of day, from the interval between morning and evening generally measuring the term of its existence. Its appearance considerably varies in the detail, and often exhibits a brilliant silvery light, and a copper tinge, when in opposition to the sun, indicating a highly electrical condition of the atmosphere.

Fig. 7. Stratus - Fallcloud. The former name, meaning a bed or corering, alludes to the position occupied by this cloud, immediately contiguous to the surface of the earth; and the latter to its origin, by the subsidence of vapour in the atmosphere. Unlike the cumulus, it eminently belongs to the night, appearing at eventide, reaching its maximum density soon after midnight, and commonly vanishing with the opening morn. This class of clouds comprehends all those fogrs and creeping mists, which, in the calm evenings of hot summer and autumnal days, appear spread like a mantle over the surface of the valleys, plains, lakes, and rivers. The Roman poet held the nocturnal visits of the stratus to the lower levels to be an indication of continued fair weather :-

$$
\text { "Then mists the hills forsake, and shroud the plain,"- }
$$

a meteorological axiom, founded upon the popular experience, as true now as in the days of Virgil. The dissipation of the stratus does not always take place with the opening morn, no more than the wreck of the cumulus with the return of night, though in both 


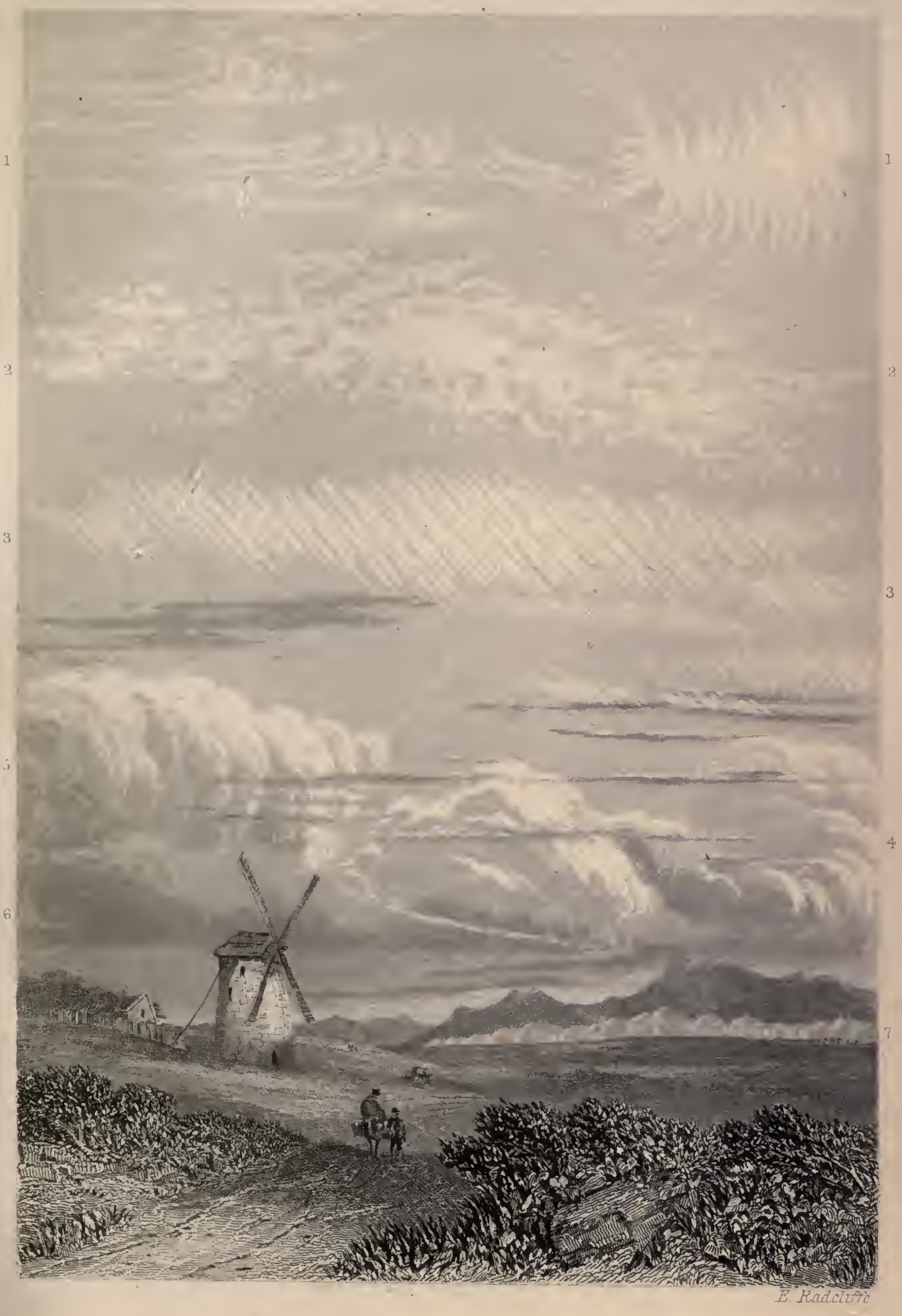

CLOUDS

1 Cirrus - 2 Cirró Cumulus - 3 Cirro Stratus - 4 Cumulo Stratus 5 Comulus - 6 Nimbus -7 Stratus. 
cases this is the general rule. It sometimes survives throughout the entire day, or maintains a successful conflict with the solar beams to an advanced period of the morning, accumulating first in heaps, then separating from the eartll, and losing its continuity,

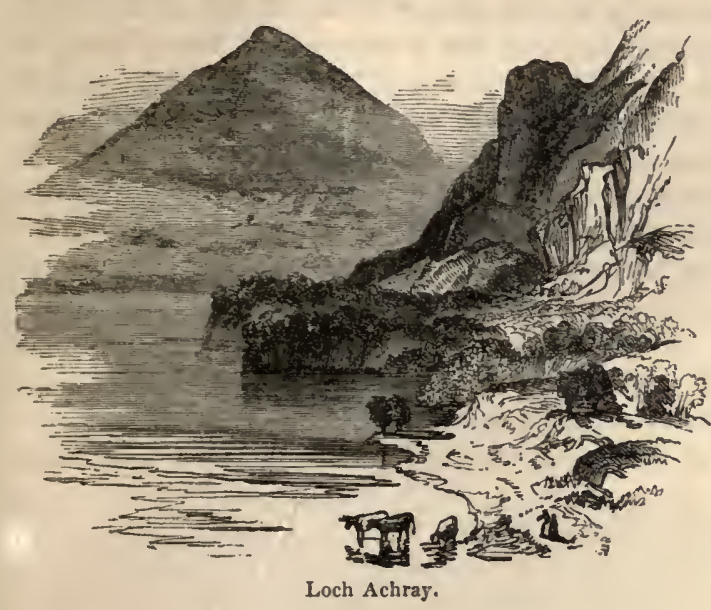
before retiring from the field. The effect is striking, when from an eminence which commands a view of an extensive plain or valley, we see this gossamer curtain of the night resting upon the surface, gradually rent and torn by the action of the sun's rays, reflecting as it disappears their golden hue. Many of the most felicitous images of poetry are derived from this source, as in Ossian:"The soul of Nathos was sad, like the sun in a day of mist, when his face looks watery and dim;" and again, when two contending factions are silenced by Cathmor:- "They sunk from the king on either sidc, like two columns of morning mist, when the sun rises between them on the glittering rocks."

The stratus is occasionally seen under peculiar and striking circumstances, extending over the surface of a sheet of water, without passing the boundary of its banks. 'Thus a lake or river will exhibit a white cloud of visible vapour resting upon it, from which the adjacent land is perfectly free. When in the neighbourhood of Loch Achray, well known to the readers of Scott,

"The minstrel came once more to view.

The eastern ridge of Ben-venue,

For, ere he parted, he would say

Farewell to lovely Loch Achray -

Where shall he find, in foreign land;

So lone a lake, so sweet a strand?"

at the close of a calm and warm September day, the expanse was nearly covered with a beautiful stratum of mist, while the atmosphere of its borders presented no trace of visible vapour. Mr. Harvey repeatedly observed a similar cloud hovering over the stream which supplies Plymouth with water, whose boundaries on a calm night would exactly coincide with the banks of the stream, however winding and irregular its ontline. Sir Humphry Davy thus explains this curious phenomenon:- "All persons who have been accustomed to the observation of nature, must have frequently witnessed the formation of mists over the beds of rivers and lakes in calm and clear weather after sunset; and whoever has considered these phenomena in relation to the radiation and communication of heat and the nature of vapour, since the publications of MIM. Rumford, Leslie, Dalton, and Wells, can hardly have failed to discover the true cause of them. As, however, I am not aware that any work has yet been published in which this cause is fully discussed, and as it involves rather complicated principles, I shall make no apology for offering a few remarks on the subject to the Royal Society. As soon as the sun has disappeared from any part of the globe, the surface begins to lose heat by radiation, and in greater proportions as the sky is clearer ; but the land and water are cooled by this operation in a very different manner: the impression of cooling on the land is limited to the surface, and very slowly transmitted 
to the interior; whereas in water abovo $40^{\circ}$ Fahrenheit, as soon as the upper stratum is cooled, whether by radiation or evaporation, it sinks in the mass of fluid, and its place is supplied by water from below, and till the temperature of the whole mass is reduced to nearly $40^{\circ}$ Fahrenheit, the surface cannot be the coolest part. It follows, therefore, that wherever water exists in considerable mass, and has a temperature nearly equal to that of the land, or only a few degrees below it, and above $40^{\circ}$ Fahrenheit at sunset, its surface during the night, in calm and clear weather, will be warmer than that of the contiguous land; and the air above the land will necessarily be colder than that above the water; and when they both contain their due proportion of aqueous vapour, and the situation of the ground is such as to permit the cold air from the land to mix with the warmer air above the water, mist or fog will be the result." He thus accounts for the formation of mists over water, by the difference in the rate of cooling, in the absence of the sun in fluid and in solid bodies. The atmosphere reposing on the water continues warmer after sunset on a clear night than the air of the adjoining land. It obtains also a greater supply of moisture from its position over an aqueous surface, which is condensed into visible vapour by the colder air of the land intermingling with it. On descending

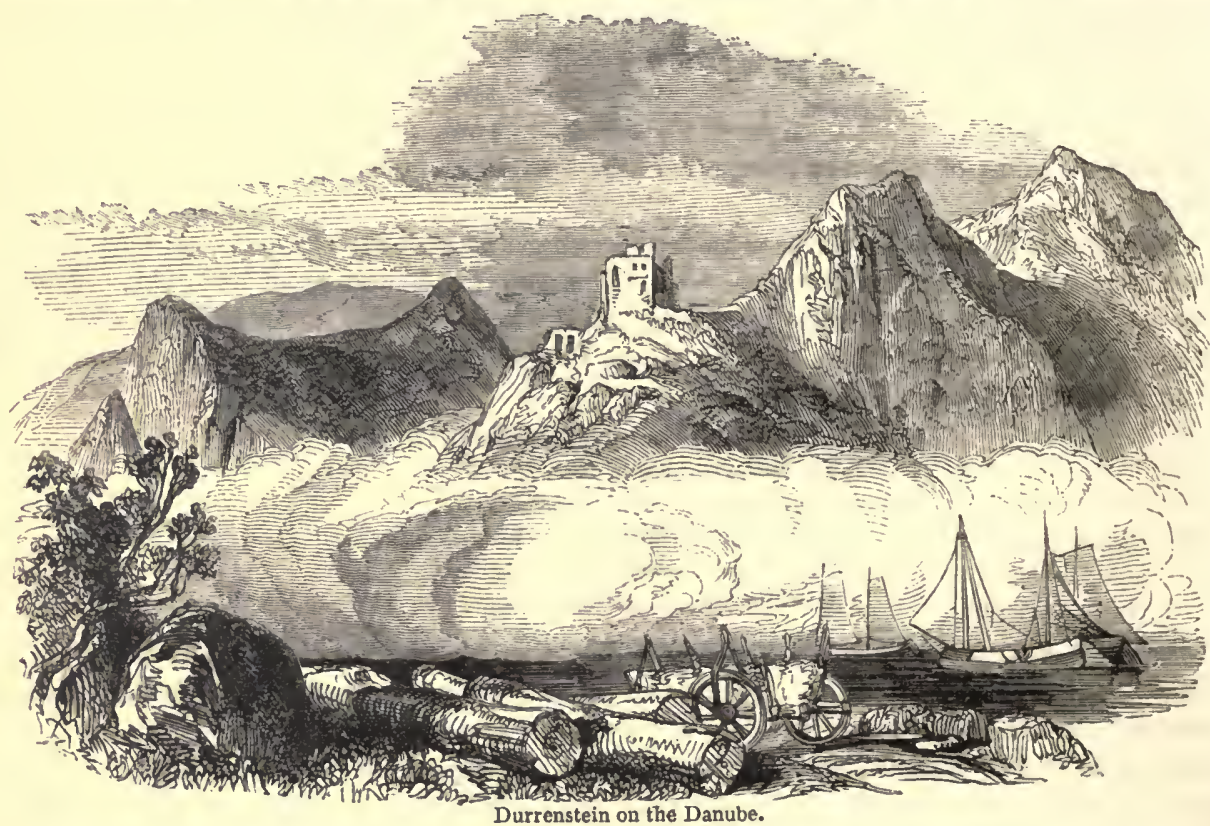

the Danube during the three nights of June 9th, 10th, and 11th, 1818, Sir H. Davy observed, that the mist regularly appeared over the river in the evening, when the temperature of the air on its banks was from $3^{\circ}$ to $6^{\circ}$ lower than that of the stream, and that it as regularly disappeared when the temperature of the air on the banks surpassed that of the river. Below Passau, where the milky blue waters of the Inn, and the perfectly pellucid Ilz join the green current of the Danube, he found their temperature and that of the atmosphere on shore, with the appearance of the rivers, as follows, at six o'clock in the morning :-

Temp, of the Air
on the Banks.

$54^{\circ}$
Temp, of the Rivers.

Danube, $62^{\circ}$

Inn, $56 \frac{1}{2}^{\circ}$

$\mathrm{Ilz}, 56^{\circ}$
State of the Rivers.

Thick fog on the whole breadth. Slight mist. Haziness. 
About a hundred yards below the junction, the temperature of the central part of the Danube was $59^{\circ}$, and here the quantity of mist was less. The evening of June 12 th was cloudy, preventing radiation, and the temperature of the atmosphere remained till after dark higher than that of the river, when there was not the slightest appearance of mist. Similar observations were made on the Rhine, the Save, the Izonzo, the $\mathrm{Po}$, the Tiber, and on the small lakes in the Campagna of Rome, and in no instance was there the formation of mist, but under the circumstances which have been detailed.

2. Cirrocumulus - Sondercloud. - This is a form of cloud of an intermediate nature betwcen the cirrus and cumulus, and hence its Latin compound name. The cirrus, after laving exhibited itself for a time, frequently passes into this modification, descending at the same time to a lower station in the atmosphere. Its parallel bars are broken into a number of small cumuli, of irregular shape, but generally orbicular, arranged in extensive beds, the component parts being quite distinct, or asunder, which explains the Saxon derivative title, the sondercloud. The previous appearance of the cirrus is not, however, necessary to the production of cirrocumulus, which often starts into existence independent of any other modification. The prevalence of this cloud in summer augurs an increase of temperature; and in winter, the termination of frost. Sometimes its different members are of very regular round form, dense structure, in close contact with each other, and arranged on a curved base, in which state the cirrocumulus is commonly the natural harbinger of thunder-storms. In another variety, the small masses of cloud exhibit no uniformity of shape, and appear of a very light fleecy texture. Bloomfield's description of this cloud, -

"The beauteous semblance of a flock at rest," -

aptly pictures its aspect at night in the presence of the moon.

3. Cirrostratus-Wanecloud. - These names point to the frequent origin and form of the cloud they indicate. It results from fibres of the cirrus waning or subsiding in the atmosphere, drawing closer to each other, and becoming arranged in horizontal strata. 'The cirrostratus exhibits several varieties:- a series of thin, inclined, and wavy streaks; a row of short thick patches of cloud; and a long horizontal sheet, very narrow in proportion to its extent, and attenuated at the edges. The appearance and prevalence of this cloud indicate wind, rain, or snow; and the second arrangement of it generally precedes storms, or occurs in the intervals of them. It is sometimes seen cutting the sun and the moon's disc with a dark line, or hanging over them like a thin hazy veil, one of the surest prognostics we have of a fall of rain or snow. Virgil in his Georgics gives it this interpretation:-

" Or should his rising orb distorted sline

Through spots, or fast behind a cloud's dark line

Retire eclipsed; then let the swain prepare

For rainy torrents; a tempestuous air

Swift from the southern deep comes fraught with ill,

The corn and fruits to waste, the flocks to chill."

4. Cumulostratus - Twaincloud.-This is the most magnificent form of cloud, as cirrocumulus is one of the most beautiful. It is formed either by two or more cumuli uniting together, or a single cumulus increasing laterally, so as to exhibit several vast hemispherical heaps overhanging the base. These mountainous masses form a multiple or twaincloud, and resting upon a common stratum are called cumulostratus. Nothing can be more imposing than the spectacle occasionally presented by these compound clouds, which the eye is disposed to contemplate as the architecture and home of giant spirits. The formation of cumulostratus takes place under different temperatures, and may precede a tempest of 
snow, and a thunder-storm. It is the common herald of the latter, and may be seen rapidly forming during the calm which precedes a discharge of electricity, swelling to a stupendous magnitude, its protuberances, like the domes of an aerial city, shining with a strong silvery or golden light, finely contrasting with the darkness and density of its central regions. Borne by the currents of air, the cirrostratus is often conducted towards the summit of cumulostratus, and appears cutting through its whole extent.

5. Nimbus-Raincloud. - Ally of the preceding modifications of cloud may so increase as to veil the sky completely, and put on an appearance of density, from which an experienced observer will augur rain. But they frequently dissolve without any shower, and no rain falls till another modification has been experienced, which commonly occurs in the case of cumulostratus. After exhibiting a great increase of density, and assuming a louring aspect, the blackness of darkness is followed by a lighter shade, evidencing a fresh disposition of the aqueous particles in the cloud, or the formation of nimbus, from which rain falls. This change may frequently be very distinctly observed when the cloud is over a distant spot; and the transition from considerable blackness to a gray obscurity is sure evidence that the shower has commenced, and may be expected to reach the locality of the spectator, should the wind be blowing in lis direction, and the nimbus not be previously extinguished. Hence Virgil's reference to the husbandmen anxious to gather in the harvest:-

\footnotetext{
"So while far off at sea the storm-cloud lours, And on the darken'd wave its fury pours,

Mid crops unreap'd the hapless peasants stand, And shuddering view its rapid course to land."
}

The nimbus - the least interesting modifieation of the clouds to the eye - is first in point of attraction when the rainbow appears upon its front. 'The precipitation of the aqueous vapours to the earth in the form of rain, is caused by contending aerial currents commingling saturated strata of different temperatures, promoting a condensation of the particles beyond what the air is capable of supporting, when the resulting mass gives out a portion of its moisture, which descends by its own gravity in rain, snow, or hail, according to the temperature of those regions of the atmosphere which it has to traverse. This is the last stage of an extensive pilgrimage which the evaporating forces in action constrain the waters of the globe to undertake through localities apart from its surfacea pilgrimage in which there is no halt, and which some portions of the element are perpetually completing, commencing, and pursuing. How different and far apart the sites which are the starting and terminating points of the journey! Exhaled from the surface of a ruffled ocean or tranquil lake, the aqueous particles ascend invisibly into the upper air, where they are ealled into sensible existence by a change of temperature, and are built up into the variously-formed beautiful and majestic clouds. These are wafted by the atmospheric currents far apart from the scene of the ascension, change their shape and direction at the will of the winds, pass into a state of invisibility, and again emerge from it as warmer or cooler strata are encountered in their aerial flight, till, perhaps, a thousand leagues away from the spot where the liquid element assumed its vaporous form, that combination of circumstances occurs, which reduces it to its original condition, and deposition ensues upon some thirsty prairie or parching field.

The copiousness and energy of rain depend upon the amount of rapour in the atmosphere, and the gradual or rapid manner in which its particles are brought into mutual contact. We have a slow drizzle in the one case, and a violent shower in the other. The drops of rain vary in size, according to Leslie, from the twenty-fifth to the fourth of an inch in diameter. He remarks, that in parting from the elouds, their descent accelerates, 


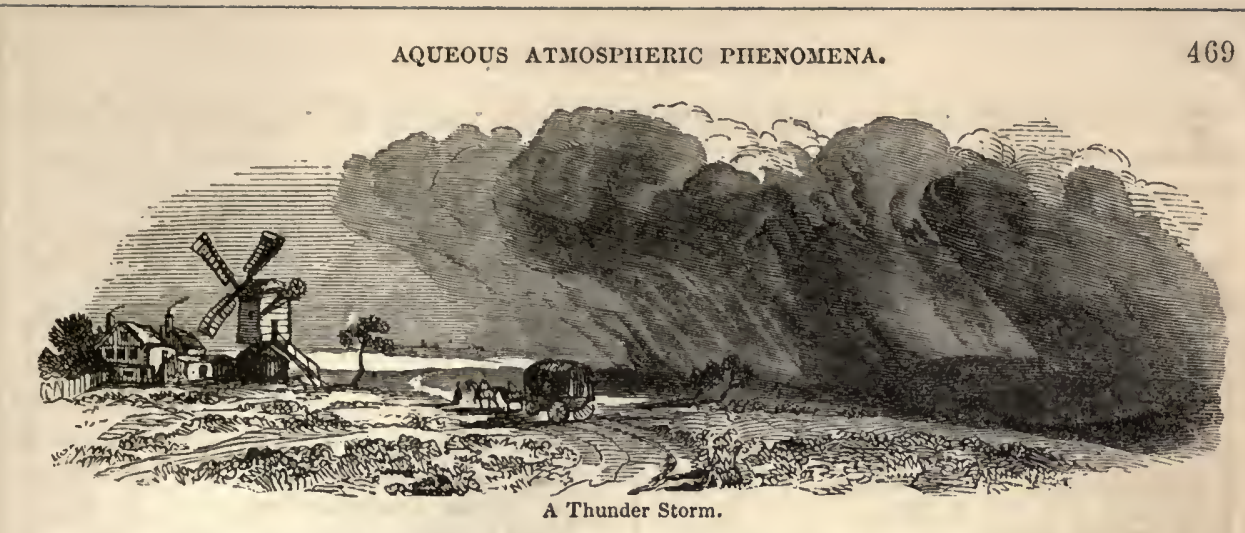

till the resistance opposed by the air becomes equal to their weight, when they continue to fall with an uniform velocity. The velocity bears a eertain ratio to the diameter of the drops; those of a thunder shower, which are large, pouring down faster than those of an ordinary rain. The celerity of a small drop, $\frac{1}{25}$ th of an inch in diameter, he estimates at $11 \frac{1}{2}$ feet per second, upon acquiring its uniform velocity; that of a larger one, $\frac{1}{4}$ th of an inch, at $33 \frac{1}{4}$ feet. A great number of experiments have verified the remarkable circumstance, that a greater quantity of rain falls upon a low site than upon one a little elevated above it. Thus a rain-gauge placed at the bottom of a hill, will collect a larger amount of water in a given time than another placed upon the summit. Dr. Heberden found that the annual depth of rain at the top of Westminster Abbey was 12.099 inehes; at a lower altitude, on the top of a neighbouring house, it was 18.139 inches; and on the ground, in the garden of the house, it was 22.608 inches. MI. Arago gives a similar result, from observations made during ten years at Paris. On the terrace of the Observatory the annual depth was 50.471 centimetres, or 19.88 inches; while thirty yards below, in the court of the building, it was 56.371 centimetres, or 22.21 inches. Comparing, however, an extensive tract of mountainous country with a low level district, the annual fall of rain in the former greatly exceeds that in the latter, though contrary to the natural presumption suggested by the fact, that the lower regions of the atmosphere are much more saturated with vapour than the upper. At Keswick in Cumberland-a mountainous distriet - the average anuual depth of rain is 67.5 inches, while on the sea-coast it is not half that amount. On the Great St. Bernard it is 63.13 inches, and at Paris only 21 26 . The description of Judea by the sacred writer, contrasting it with the flat lands of Egypt, though not intended to be philosophic, is in harmony with the teaching of science respecting the important part performed by mountains in the general economy of the earth :"For the land whither thou goest in to possess it, is not as the land of Egypt, from whence ye came out; but the land whither ye go to possess it, is a land of hills and valleys, and drinketh water of the rain of heaven." By arresting the course of the clouds, and producing a condensation of aqueous vapour when a warm current of air lights upon their cold summits, the elevations contribute to precipitate the moisture of the atmosphere, often amid a terrible display of electric phenomena - a blaze of fiery honours, and the echo of heart-thrilling sounds.

The statement respecting a greater amount of rain being colleeted by a low than an elevated guage, in the same time, in a given district, is strikingly illustrated by $\mathrm{Mr}$ Miller's report on the amount of precipitation in the lake regions of Cumberland and Westmoreland.

Seathwaite, near Derwentwater, . From June 1846 to November 1847, . 242 feet, . 193.69 inches.

Styhead,

Seatotler,

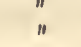

" $1290 " .164 \cdot 12 "$
$.1334 "-155 \cdot 75$ 
The amount collected at a low level is the greatest, because the drops enlarge in their descent. They bring with them the low temperature of the upper regions of the atmosphere, and condense on their surfaces the vapour in the inferior and warmer strata.

1. The average annual fall of rain is the greatest within the tropics. It decreases in quantity as we recede from thence towards the poles, because heat, the cause of vapour, diminishes. In the table, the amount is contrasted as observed in tropical and mean or high latitudes :-

\begin{tabular}{|c|c|c|c|}
\hline Tropleal Iatitudes. & Inches, & Mean and High Latitudes. & Inches. \\
\hline $\begin{array}{l}\text { Mahabaleshwar, Western Ghauts, } \\
\text { San Luis de Maranhas, Brazil, } \\
\text { Parimaribo, Guiana, } \\
\text { Sierra Leone, Guinea, . } \\
\text { Cape Haiti, St Domingo, . } \\
\text { Grenada, Little Antilles, } \\
\text { Adam's Peak, Cejlon, } \\
\text { Columbo, } \\
\text { Harannah, Cuba, . . } \\
\text { Bombay, } \\
\text { Macao, China, . . . . }\end{array}$ & $\begin{array}{r}302 \cdot 66 \\
276 \cdot 12 \\
229 \cdot 20 \\
189 \cdot 69 \\
127 \cdot 88 \\
103 \cdot 41 \\
100 \cdot 00 \\
99 \cdot 21 \\
90 \cdot 66 \\
80 \cdot 04 \\
68 \cdot 30\end{array}$ & $\begin{array}{l}\text { South slope of the Alps, } \\
\text { Charlestown, South Carolina, } \\
\text { Rhone Valley, } \\
\text { North France and Belgium, } \\
\text { Sicily, } \\
\text { Rome, } \\
\text { Geneva, . } \\
\text { North Germany, . } \\
\text { England (Dalton's Mean), . } \\
\text { Petersburg, } \\
\text { Uleaborg, Finland, . }\end{array}$ & $\begin{array}{l}57 \cdot 57 \\
47 \cdot 60 \\
35 \cdot 18 \\
22 \cdot 47 \\
23 \cdot 55 \\
30 \cdot 00 \\
42 \cdot 06 \\
20 \cdot 35 \\
31 \cdot 03 \\
17 \cdot 05 \\
13 \cdot 05\end{array}$ \\
\hline $\begin{array}{l}\text { Annual quantity of rain within the } \\
\text { tropics of the New Worid, } \\
\text { Annual quantity within the tropics } \\
\text { of the Old World, } \\
\text { Average for the tropics generally, }\end{array}$ & $\begin{array}{l}115 \\
76 \\
95 \frac{1}{8}\end{array}$ & $\begin{array}{l}\text { Annual quantity of rain in the tem- } \\
\text { perate zone of the New World, } \\
\text { In the temperate of the Old World } \\
\text { (Europe), . } \\
\text { Temperate zone generally, }\end{array}$ & $\begin{array}{l}37 \\
\\
31 \frac{8}{4} \\
34\end{array}$ \\
\hline
\end{tabular}

Though the amount of precipitation is thus far greater within the tropics than in the temperate zone, yet the number of rainy days is less, because the fall, intense while it lasts, is a periodical event. Two seasons divide the year- wet and dry; and during the dry season, entire months frequently pass away without a shower descending, or a cloud being seen. In the temperate zone, also, passing from south to north, the number of rainy days increases, although the intensity of rain diminishes. The average annual number of days on which rain falls at the places mentioned has been given as follows :-

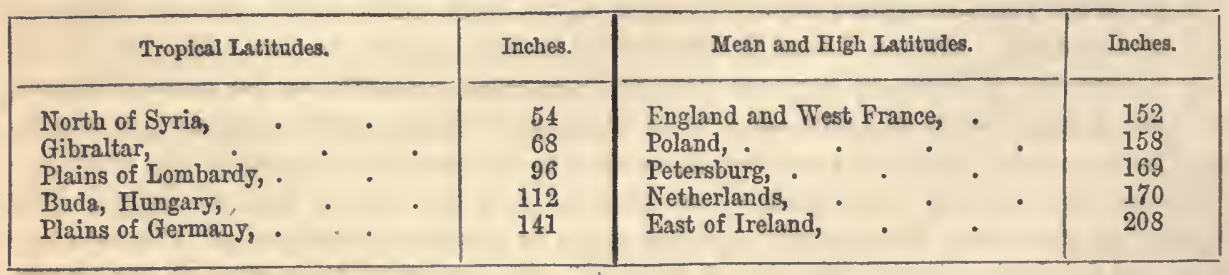

But while in the east of Ireland the rainy days amount to 208 in the year, a far less quantity of rain descends than is precipitated at Gibraltar in 68 days.

North of the equator, the periodical tropical rains fall during the northern declination of the sun, and commence south of the equator with its southern declination, except in India, where the wet and dry seasons are regulated by the monsoons. This is a benign arrangement, offering relief from the rays of a vertical sun by the screen of cloud which is coincidently expanded. In some parts of the American continent, and in the West Indies, two wet seasons mark the year; but one is of much shorter duration, and has lighter showers, than the other. Two periods of rain are also mentioned in relation to Judea ; the "first" or autumnal rains, which fall in seed-time, towards the close of October"; and the "latter" or spring rains, in April, after the cold season. " "I will give you the rain of 
your land in his due season, the first rain and the latter rain, that thou mayest gather in thy corn, and thy wine, and thy oil." These two seasonal events were of vast importance to the Jews, though it is a mistake to suppose that rain seldom falls in Palestine except at those eras. It falls copiously then, and also occasionally through the winter months, its entire cessation being in the interval between May and October. Prominence is given to the two rains referred to, on account of their abundance, and especially the time of their occurrence, the success of the agriculturist depending in a great measure upon those plentiful showers. The periodical tropical rains do not fall for any considerable time without an intermission. After a fine morning, the clouds in general gather towards noon; the shower descends with great violence for four or five hours; and towards sunset, the sky clears, and remains cloudless through the night.

There is a considerable diversity in the amount of rain during the wet seasons in tropical countries, at different places, and in different years. In the ten years from 1817 to 1826 inclusive, at Bombay, the average annual quantity was 78.1 inches; but in the course of 1822 there fell 113 inches, while in 1824 the supply did not rise above 34 inches; and hence came famine and pestilence. At Bombay, also, the gauge has received as much as 16 inches of the 78 in the course of twenty-four hours; and while, there, the average annual quantity is as stated above, at Tellicherry, $12^{\circ}$ north latitude, it is 116 inches, and in the delta of the Indus not more than 20 inches. There is great discrepancy between the amount at Calcutta and Benares ; 72 inches at the former place, and only 46 at the latter. The greatest fall in those districts appears to take place on the eastern boundaries of the Bay of Bengal, where, in 1825, at Arracan, nearly 60 inches were registered in the month of July, and about 43 in August, from which, by a rough estimate, the annual amount is inferred to be not less than 200 inches. A more extraordinary quantity appears to fall in certain sites on the western continent, as in the forests of Guiana, where incessant rains of four or five months are no uncommon occurrence. 'The mast remarkable instance of excessive rain mentioned by Humboldt is upon the authority of Captain Roussin, who states that more than 160 inches have fallen at Cayenne in the single month of February. A parliamentary report on the sickness among the troops at Sierra Leone in 1828, states that during the three months of June, July, and August, there fell 313 inches; and for the whole year, the amount was estimated at 400 inches. But the greatest fall on record is that observed by Mr Yule at Churra, north-east of Calcutta, among the Khasian Mountains. In the single month of August there fell 264 inches, of which 150 inches fell in the space of five consecutive days. Another observer at the same station measured 500 inches in the space of seven months.

2. Both within the tropics, and near their limits, there are extensive tracts of the globe in which rain is either entirely unknown, or it occurs so rarely, and in such small quantities, that a copious shower is quite a phenomenon. These districts consist for the most part of rocky or sandy deserts, where the highly-heated atmosphere does not contain sufficient moisture to admit of precipitation, under any decrease of temperature. In the New World, the rainless regions comprise portions of California and Guatimala, the Mexican table-land, and the coast-line of Peru. Those of the Old World comprehend an immense territory, stretching from Western Africa through the Sahara, a part of Egypt, Arabia, and Persia, into Beloochistan, with another great zone, north of the Himalayas, including the table-land of Thibet, the desert of Gobi, and a portion of Mongolia

3. In both continents, likewise, districts within and near the zone of the periodical rains are subject to an occasional intermission, and become rainless for considerable intervals, the drought inflicting terrible suffering upon man and beast. Mr Darwin speaks of the South American droughts being somewhat periodical, for upon comparing the dates of several, he found regular intervals of fifteen years between them. The 
period included between the years 1827 and 1830 bears the name of the gran seco, or the great drought, in the state of Buenos Ayres; and on account of the light it throws on the cases where vast uumbers of animals of all kinds have been found imbedded together, Mr. Darwin's record of it has great interest. "During this time," he remarks, "so little rain fell that the vegetation, even to the thistles, failed; the brooks were dried up, and the whole country assumed the appearance of a dusty ligh road. This was especially the case in the northern part of the province of Buenos Ayres and the southern part of St. Fé. Very great numbers of birds, wild animals, cattle, and horses perished from the want of food and water. A man told me that the deer used to come into his courtyard to the well, which he had been obliged to dig to supply his own family with water; and that the partridges had hardly strength to fly away when pursued." Captain Owen, in the account of his surveying voyage, relates a similar effect of drought on the elephants, at Benguela, on the west coast of Africa. 'They invaded the town in a body, to get possession of the wells, not being able to procure any water in the country. A desperate battle ensued between the inhabitants, amounting to nearly three thousand, and the animals. It terminated in the defeat of the latter, but not until they had killed one man, and maimed a great number. Dr. Malcolmson also states, that during a drought in India, the wild animals entered the tents of the troops at Ellore, and that a hare drank out of a vessel held by the adjutant of the regiment.

"The lowest estimation of the loss of cattle in the province of Buenos Ayres alone, was taken at one million head. A proprietor at San Pedro had previously to these years 20,000 cattle; at the end not one remained. San Pedro is situated in the middle of the finest country; and even now abounds again with animals; yet during the latter part of the gran seco, live cattle were brought in vessels for the consumption of the inhabitants. The animals roused from their estancias, and wandering far southward, were mingled together in such multitudes, that a government commission was sent from Buenos Ayres to settle the disputes of the owners. Sir Woodbine Parish informed me of another and very curious source of dispute; the ground being so long dry, such quantities of dust were blown about, that in this open country the landmarks became obliterated, and people could not tell the limits of their estates. I was informed by an eye-witness that the cattle in herds of thousands rushed into the Parana, and being exhausted by liunger, they were unable to crawl up the muddy banks, and thus were drowned. The arm of the river which runs by San Pedro was so full of putrid carcasses, that the master of a vessel told me that the smell rendered it quite impassable. Without doubt several hundred thousand animals thus perished in the river; their bodies when putrid were seen floating down the stream; and many in all probability were deposited in the estuary of the Plata. All the small rivers became highly saline, and this caused the death of vast numbers in particular spots; for when an animal drinks of such water it does not recover. Azara describes the fury of the wild horses on a similar occasion, rushing into the marshes, those which arrived first being overwhelmed and crushed by those which followed. He adds, that more than once he has seen the carcasses of upwards of a thousand wild horses thus destroyed. I noticed that the smaller streams in the Pampas were paved with a breccia of bones, but this probably is the effect of a gradual increase, rather than of the destruction at any one period. Subsequently to the drought of 1827 to 1832 , a very rainy season followed, which caused great floods. Hence it is almost certain that some thousands of the skeletons were buried by the deposits of the very next year. What would be the opinion of a geologist, viewing such an enormous collection of bones, of all kinds of animals and of all ages, thus embedded in one thick earthy mass? Would he not attribute it to a flood laving swept over the surface of the land, rather than to the common order of things?" 
4. In countries beyond the tropics, where the periodicity of rain disappears, and it falls at any hour of the day, or on any day of the year, the quantity is not uniformly distributed through the different months, but the largest amount usually descends in some particular season. Thus, at Lisbon, the quantity is insignificant in summer, and at its maximum in winter ; while in the interior of Germany, it is just the reverse. Europe may be divided into three great regions of scasonal predominant rains.

Province of the winter rains, .

Province of the autumn rains,

Province of the summer rains,

- South of Portugal, Spain, and Italy, with Greece.

f Remainder of Southern Europe, with the West and North coast of $\{$ France, Great Britain, the Netherlands, and Norway.

- Interior Europe, with Denmark, Sweden, and Russia.

5. The amount of precipitation decreases generally in proportion as countries are removed from the ocean, because the land supplies a less quantity of vapour than the sea. Thus it declines from a fall of between 30 and 35 inches on the shores of Great Britain and France, to less than half that quantity in the interior of Russia. But mountainchains occasion several exceptions to this rule.

6. More rain falls on mountainous districts than on low and level regions, for their lofty heights arrest the course of the clouds, and promote the condensation of vapour by their cold summits. Proceeding from Paris to the Alps, the following differences occur :-

Paris,

Valley of the Middle Rhine,

Berne, at the foot of the Alps,

Great St Bernard, highest meteorological station in Europe, $\quad 63$ "

Highlands and predominant winds sometimes occasion an excess of rain in a country on one side of the chain, while a vast reduction occurs on the other. This is strikingly exemplified in the instance of Norway and Sweden, divided by the Scandinavian Alps. At Bergen, on the Norwegian coast, there fall annually 82 inches, or more than at any other city in Europe, and more than the amount at many places within the tropics. The clouds brought from the Atlantic by the prevailing south-west winds, are arrested by the mountains and confined in the fiords, where they accumulate, and lose their moisture, as it were, by mechanical compression, so that the sea-winds discharge nearly all the water held in suspension in passing the chain. Hence it frequently rains for entire days in Norway, while only a few drops fall in Sweden, on the opposite side of the range; and the mean annual fall in the latter country is only 20 inches.

7. The highlands which line the west coast of Great Britain, along with the prevailing south-west winds, sweeping from an enormous expanse of the ocean, render the annual amount of rain greater on the western side of the island than in the central and eastern districts. This appears from the table :-

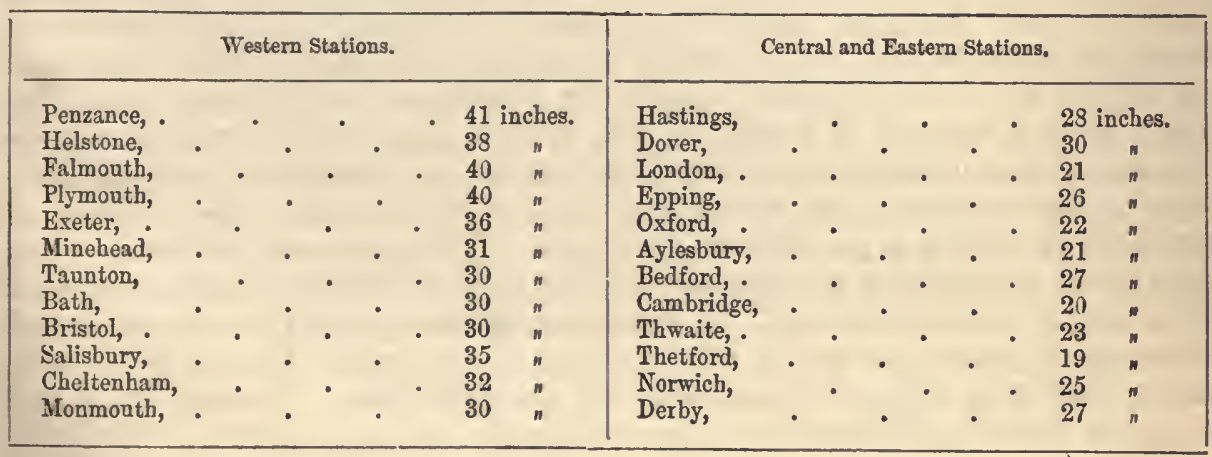




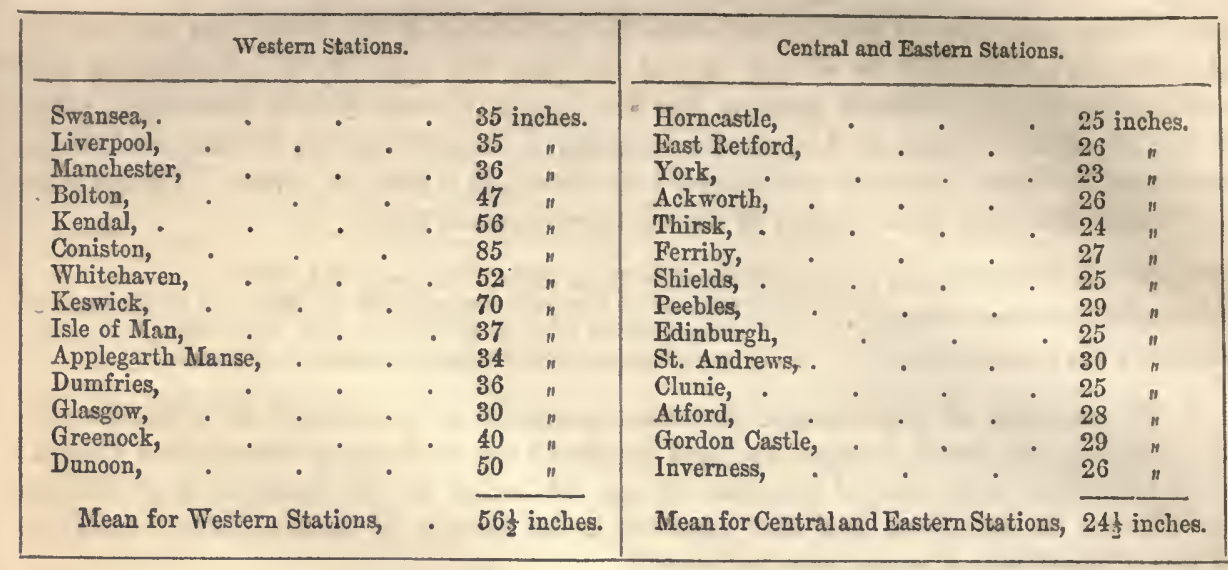

The average annual amount of precipitation for the whole of England may be very moderately estimated at 30 inches, or two feet and a half of water. According to this estimate, nearly two millions of tons of water-are annually discharged fron the clouds upon every square mile of the surface, or three thousand tons for each English acre. Rain-water, when collected immediately upon its descent, apart from towns and other sources of contamination, is the purest that can be obtained without having recourse to distillation.

A considerable portion of aqueous vapour in the atmosphere is frozen in the cold season in extra-tropical latitudes, and the particles of ice uniting together in their descent become converted into flakes of snow, and cover the surface of the earth with a mantle of the purest white, stretching over bush and brake, lawn and mountain. Snow, examined with the aid of a microscope, exhibits structures of exquisite beauty, regularity, and endless variety, though it sometimes presents no peculiarity of form, but falls in very minute globular particles. Commonly a snow-flake consists of a series of crystals formed independently in the upper regions of the air. These are united in groups while descending through the atmosphere, by its agitations striking them against each other. The flickering and gradual descent of the flakes is owing to their great extent of surface in comparison with their volume. A number of brilliant icy spiculæ, or points diverging from a common centre, resembling stars having so many rays, apparently wrought with the nicest art, is the usual form of the crystals, which are for the most part hexagonal, presenting a nucleus with six divergences. This stelliform shape is the ordinary appearance of snow, but the detail varies, as in the adjoining illustration. -Dr. E. D. Clarke, speaking of the breaking up of the winter season at St.Petersburg, remarks:- "Snow, in the most regular and beautiful crystals, fell gently on our clothes, and on the sledge, as we were driving through the streets; all of them possessed exactly the same figure, and the same dimensions. Every particle consisted of a wheel or star, with-six equal rays, bounded by circumferences of equal diameters; they had all of them the same number of rays branching from a common centre. The size of each of these little stars was equal to the circle presented by dividing a pea into two equal parts. This appearance continued during three hours, in which time no other snow fell, and there was sufficient leisure to examine them with the strictest attention." A microscope applied to a flake of snow will unfold this mode of structure, as well as other varieties in our climate; but it is in the polar regions that snow assumes its most beautiful and varied forms. Scoresby has figured ninety-six varieties, distributed into classes of lamellar, spicular, and pyramidal crystals, 
from the first of which the annexed representation is taken. Upon examining some snow which fell at Yverdon in Switzerland, in 1829 and 1830, M. Huber Burnand found its crystals to consist of stellar plates with six rays, along each of which filaments were
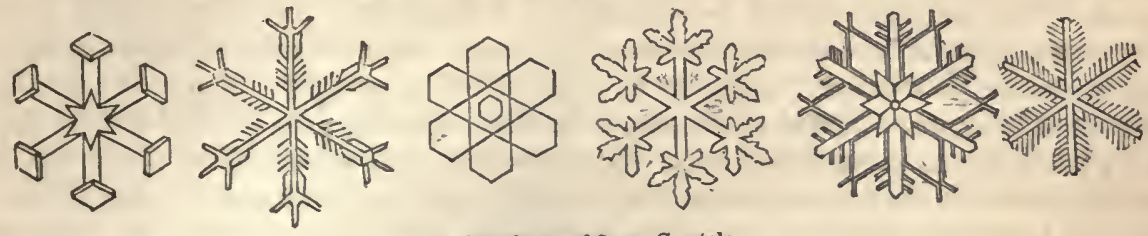

Various forms of Snow Crystals.

disposed after the form of feathers, and these also had finer filaments similarly arranged. He observed that in the former year almost every day the crystals presented a new variety
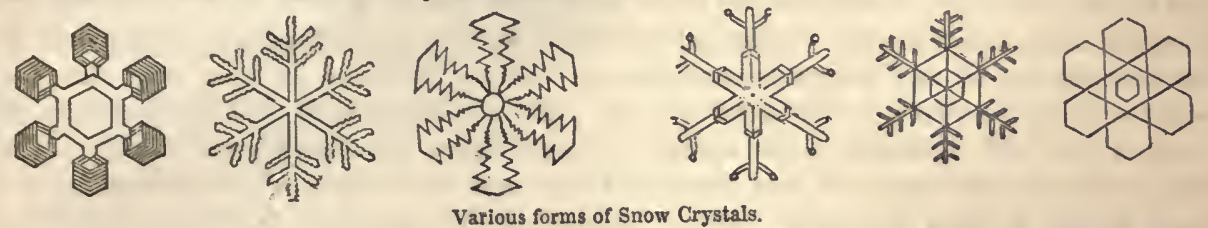

of shape, sometimes resembling parallel fillets, leaves, and spines, with a rosette termination.

It is rarely that snow is seen in the northern hemisphere below latitude $30^{\circ}$ in America, and $36^{\circ}$ in the eastern world, the latitude of Algiers, and for some distance above those limits its appearance is very infrequent and brief, except in the upland regions. During the severe winter of 1830 , when there was an average depth of six feet of snow in Denmark, and it accumulated on the low grounds of Wiltshire in some places to the depth of fifteen or sixteen feet, the crest of Vesuvius, in latitude $41^{\circ}$, was covered with it for the space of ten days - a most unusual occurrence. A fall of snow occasionally intrudes into our summer, but seldom in any quantity, though Kent and Sussex have been wrapped in this garb of winter in the month of June. It has also visited low levels within the limits of the torrid zone, as at Canton, in latitude $23^{\circ}$, in February 1836. The following letter, which appeared in one of the public journals, contains an interesting account of this event, which may not be repeated for many generations:- "I write you under the inspiration of a most unprecedented meteorological event - the phenomenon of a very heavy fall of snow in Canton. I woke an hour and a half ago, and could not beliere my eyesight. Huge and thick flakes of real snow, and not white paper, summoned me from my warm bed; and on looking out, sure enough the whole scene was 'winter in its roughest mood,' - the snow on every house-top two, three, and four inches deep, and in the corners and ridges of course much more. The thermometer in our southern verandah was then standing at $37^{\circ}$. There was a light air from the north, in which direction the wind has been without intermission for three days past, sometimes blowing hard. Five or six days ago the wind was from the S.E., a most unusual occurrence in this monsoon; and the weather was so mild then, that we breakfasted with open windows; and a water excursion in the evening was by no means unpleasant, even to the idle steersmen in the wherry. But though the cliange was rapid, and the cold all yesterday very intense, no one predicated the length it would go. The thermometer was yesterday $47^{\circ}$ in the morning, and rose to $51^{\circ}$ and $52^{\circ}$ during the day. The astonishment and mirth among the Chinese, not one of whom about us has ever beheld snow before, is unbounded; and the elders of our European society are at this moment in the ecstasy of revived associations, pelting each other with snow-balls from 
the house-tops with all their might. On one of these terraces, which may be no more than 25 or 30 feet square, they have rolled a snow-ball which stands three feet high, so that you may judge how considerable the fall has been. I think it must have been snowing before midnight to have accumulated as it has done. The circumstance is certainly unprecedented here within the memory of man - whether any record of its occurrence in former time exists, remains to be seen. I can as yet learn or perceive nothing at all out of the natural course of our season in other respects, save the few days of S.E. wind a week ago, as above mentioned. $8 \frac{1}{2}$ A. M. - The snow ceased falling about half an hour ago; and the sun has now burst forth on the scene, and perfected its magnificence. The river is a very curious feature in the landscape. The huge mat-sails of the junks fold up so massily, that they retain large volumes of snow upon them. The Chinese have now taken to pelting one another in the streets. A poor Bengalee servant found his way to our house-top, to collect some snow to show his Parsee master, who did not dare to leave his bed; and the man's exotic appearance in such an employment, and particularly the incongruity of our Bengalee conversation in the midst of it, was very strange. Since writing the above, a few hours ago, the thaw has commenced, and the last trace of snow, which will, perhaps, never again be beheld here, has disappeared. Mingqua, a very venerable old Chinaman, has just called, and says he never heard of such an occurrence before, as snow in Canton. Being himself of this province, this is the first time he has ever seen it in his life."

In the higher regions of the Alps, prodigious falls of snow are the ordinary phenomena of the winter season. They occur in sudden storms, and being drifted upon the ground by the winds, the path of the traveller is speedily blocked up by the accumulations, while-

\section{"On every nerve}

The deadly winter seizes; shuts up sense

And o'er his inmost vitals creeping cold,

Lays him along the snows, a stiffened corpse,

Stretch'd out, and bleaching in the northern blast."

At the great elevation of some of the Alpine passes, that of the St. Bernard for instance, the snow is formed in the atmosphere immediately over the surface. It consequently falls in fine hard particles, and not in flakes as in lower situations; and instead of consolidating under the pressure of the wayfarer, he sinks in it as in a volume of fine sand. Around the hospice of St. Bernard, the highest fixed habitation in Europe, close upon the line of perpetual congelation, and rarely four months in the year clear of snow, its average depth is seren or eight feet in the midst of winter. Sometimes the drifts accumulate against the building to the height of forty feet, for which reason, the entrance is attained by a flight of steps. But in the most rigorous seasons, the smuggler, the pedlar, and courier, brave the perils of the pass, in defiance of the snows and avalanches, not unfrequently perishing in the attempt to gain the Swiss or the Italian side of the Alps, and often indebted to the monks and dogs of the hospice for the preservation of life. The duty of the monks calls them to set forth in the hour of tempest, to render help to the exhausted or overwhelmed passenger, whose voice and foot step, their great nicety of ear, attained by practice, enables them to discriminate at a surprising distance. "The night was calm and beautiful," says a summer guest at the hospice, "and so warm for this elevation that we enjoyed looking out at the window upon the still and deeply solemn scene which surrounded us. One of the brethren said, "There is company ascending the mountain on the Swiss side ;' but silent as the grave was everything around us, our ears were not susceptible of such nice distinctions of sound. He said that they were rery distant. He was right; the party arrived long enough after to astonish us at the percep- 
tion which he must have had of their approach." 'The spaniels of the St. Bernard have

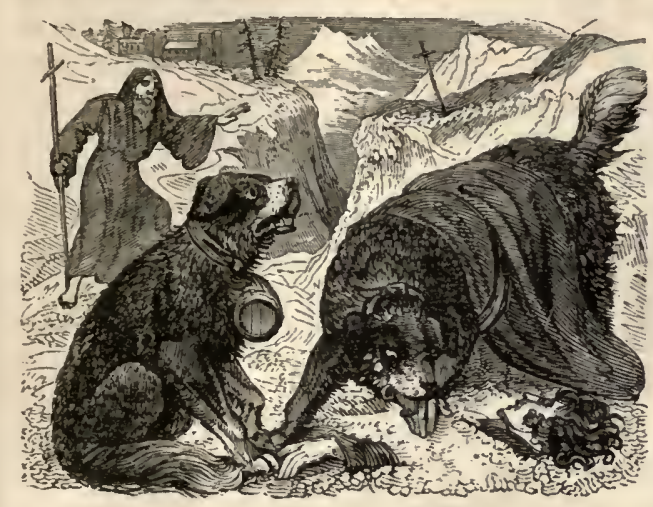
become celebrated through the civilized world for the fine intelligence they display in discovering and aiding the perishing traveller, scenting his person lying many fect below the snow, scratching away the drift, rousing the victim from his stupefying sleep, and informing their human allies of the discovery by commencing their peculiar bark. One of these dogs, during lis career, saved the lives of forty persons, and is known to fame, by finding a child in a frozen state, succeeding in restoring animation, and then bearing him upon his back to the hospice.

In North Britain, in severe winters, the fall of snow in storms, with its long continuance on the ground, has often led to melancholy disasters to man and beast. In Scotch annals the "thirteen drifty days," in the year 1620, designate a dismal snow-storm, the memory of which long survived in the traditionary stories of the shepherds, and was oft recurred to at their hearths. The snow fell during thirteen days and nights with very little intermission, accompanied with great cold, and a keen biting wind. About the fifth and sixth days the young sheep fell into a torpid state and died; and about the ninth and tenth days, the shepherds began to build up large semicircular walls of their dead, in order to afford some shelter for the living; but the protection was of little service. Impelled by hunger, the sheep were frequently seen tearing at one another's wool with their teeth. On the fourteenth day from the commencement of the storm, when it began to abate, there was on many a high-lying farm, not a survivor of extensive flocks to be found. Large misshapen walls of dead, surrounding a small prostrate group, likewise dead, and stiffly frozen in their lairs, met the eye of the forlorn shepherd and his master. Of upwards of twenty thousand sheep maintained in the extensive pastoral district of Eskdale moor, only about forty-five were left alive. The years 1709, 1740, and 1772, were also remarkable for their snows and consequent calamities. In the latter year, the soil was not once exposed from the middle of December to the middle of April, but retained its covering throughout of hard frozen snow. The south of Scotland, between Crawford-muir and the border, was the scene of a violent storm in the year 1795, when whole flocks were overwhelmed in a few hours by the drifting snows, and seventeen shepherds perished. After the thaw, and the subsidence of the flood it occasioned, there were found, in a place called the beds of Esk, where the tide of the Solway throws up what has been brought into it by the rivers, the carcasses of 1840 sheep, nine black cattle, three liorses, two men, one woman, forty-five dogs, and a hundred and eighty hares, besides a number of smaller animals. But these are evils incidentally connected with a natural production of great utility. Owing to the snow being an imperfect conductor of heat, the earth beneath it is kept at a higher temperature than that of the exterior air, and the bulbs and roots of plants are sheltered from the ungenial cold. Hence also it offers a bed to the polar traveller warmer than the atmosphere, and furnishes a readymade material to the Esquimaux for the construction of an abode, whose walls will screen lim from the cold blast without, and not minister to the abstraction of the heat from within. There are several remarkable instances on record, of unquestionable authority;, of persons liaving been kept alive for a considerable period when completely buried in snow, a result to which its imperfect conduction of heat has contributed. Hearne 


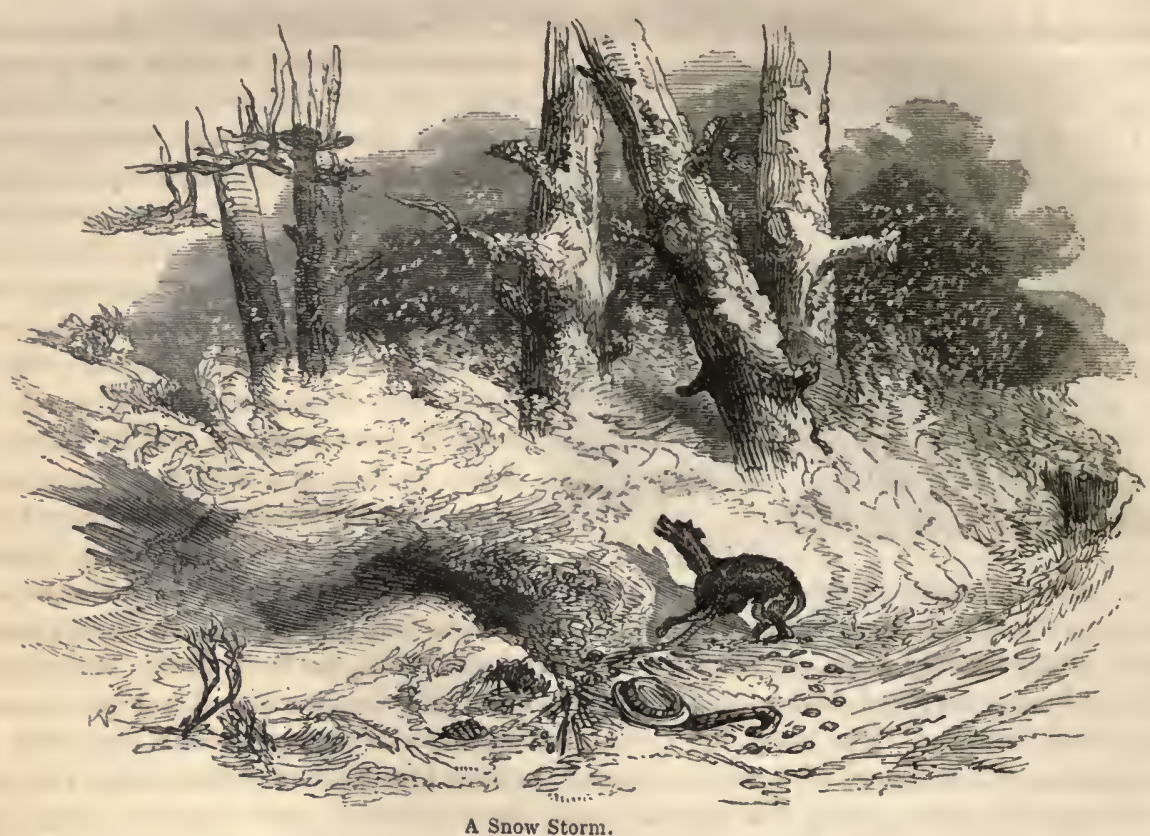

mentions the case of a woman near Yeovil in Somersetshire, who remained thus entombed for seven days, and was taken out alive, and recovered. A similar imprisonment in the snow for eight days was endured by another in Cambridgeshire in the year 1799, who heard the bells go two Sundays for church while in the drift, was at last rescued, but died through well-intended, but injudicious treatment. The fertility of the soil is also largely promoted by the nitrogen which the snow takes up from the atmosphere.

Hail is another form under which the aqueous vapours abstracted from the earth are occasionally returned to it. The theory of Volta refers the formation of hail to the play of electricity rapidly abstracting heat from the molecules of vapour in the atmosphere. The common liypothesis is that of the congelation of globules of rain in their fall, by passing through a stratum of dry and cold air. To account for the production of such an intense degree of cold, very partial in its range, is the grand difficulty, for hail generally falls in hot sultry weather. It has been remarked, that hail very rarely falls at night, and is scarcely known at all in latitudes higher than $60^{\circ}$. The course of a hailstorm is commonly very narrow in proportion to its length. In July 1788, a storm, memorable for the havoc it made, passed over France in two parallel lines from south-west to north-east. The one line extended about 500 miles in length, and the other about 600 miles, each having a mean breadth of only 9 miles, an interval of 15 miles occurring between them, in which the rain fell in torrents. Halley describes, in the Philosophical Transactions, a hail-storm of very scanty breadth, in the year 1697, which passed from Snowdon in Wales, through Flintshire, cutting the north-west corner of Cheshire, and extending through Lancashire in a right line from Ormskirk to Blackburn, on the borders of Yorkshire. The hail-stones of this storm were of very considerable dimensions, ploughing up the earth and burying themselves in the ground, killing poultry and sheep, and completely ruining the rising corn. Leslie estimates that hail-stones, an inch in diameter, fall with a velocity of 70 feet per second, or at the rate of abont 50 milcs 
in the hour. "Striking the ground," he states, "with such impetuous force, it is easy to conceive the extensive injury which a hail shower may occasion in the hotter climates. The destructive power of these missiles in stripping and tearing the fruits and foliage, increases besides in a faster ratio than the momentum, and may be estimated by the square of their velocity multiplied into their mass. This fatal energy is hence as the fourth power of the diameter of the hail-storm." In the narrative of the Jewish wars mention is made of a shower of hail acting with destructive effect upon the routed Canaanites, and in the mountainous districts of Palestine, terrible storms of the kind occur. The cattle have been destroyed in the fields, in the elevated regions of Persia, by the falling stones. Sir Robert Wilson gives the following account of a hail-storm encountered by the British fleet, while at anchor in 1801, in Marmorice bay, in Asiatic Turkey :"On the 8th of February commenced the most violent thunder and hail storm ever remembered, and which continued two days and nights intermittingly. The hail, or rather the ice-stones, were as big as large walnuts. The camps were deluged with a torrent of them two feet deep, which, pouring down from the mountains, swept every thing before it. The scene of confusion on shore, by the horses breaking loose, and the men being unable to face the storm, or remain still in the freezing deluge, surpasses description." Hail-stones exhibit various forms, the spherical, the oval, the pointed, flat, and ragged; and their size occasionally surpasses that of those which have been already mentioned. At Lisle in the Netherlands, in May 1686, the stones that fell during a storm were from a quarter of a pound to a pound in weight. In Hertfordshire, in May 1767, they were from one to fourteen inches in circumference. In the Pyrenees, several of twenty-three ounces avoirdupois, fell in 1784 ; and a paper by the Abbé Maury read before the Royal Society in 1798, mentions the fall of hail-stones, or masses of ice, in Germany, from half an inch in diameter to the weight of eight pounds.

The preceding statements receive confirmation from the experience of Mr. Darwin in South America, as recorded in the intensely interesting journal of that eminent naturalist. Referring to a posta at the foot of the Sierra Tapalguen, in the state of Buenos Ayres, he observes: - "We were here told a fact which I would not have credited, if I had not partly ocular proof of it; namely, that during the previous night hail as large as small apples, and extremely hard, had fallen with such violence, as to kill the greater number of the wild animals. One of the men had already found thirteen deer (Cervus Campestris) lying dead; and I saw their fresh hides; another of the party, a few minutes after my arrival, brought in seven more. Now I well know that one man without dogs could hardly have killed seven deer in a week. The men believed they had seen about fifteen dead ostriches, part of one of which we had for dinner; and they said that several were running about evidently blind in one eye. Numbers of smaller birds, as ducks, hawks, and partridges, were killed. I saw one of the latter with a black mark on its back, as if it had been struck with a paving-stone. A fence of thistle-stalks round the hovel was nearly broken down, and my informer, putting his head out to see what was the matter, received a severe cut, and now wore a bandage. The storm was said to have been of limited extent; we certainly saw from our last night's bivouac a dense cloud and lightning in this direction. It is marvellous how such strong animals as deer could thus have been killed; but $I$ have no doubt from the evidence $I$ have given, that the story is not in the least exaggerated. I am glad, however, to have its credibility supported by the Jesuit Dobrizhoffer, who, speaking of a country much to the northward, says, hail fell of an enormous size, and killed vast numbers of cattle: the Indians hence called the place Lalegraicavalca, meaning the 'little white things.' Dr. Malcolmson also informs me that he witnessed in 1831, in India, a hail-storm which killed numbers of large birds, and much injured the cattle. These hail-stones were flat, and one was ten inches in 
circumference, and another weighed two ounces. They ploughed up a gravel-walk like musket balls, and passed through glass windows, making round holes, but not cracking them."

The aqueous vapour in the atmosphere assumes another form, that of dew, under circumstances favourable to its production. These occur when the sun is absent, the sky clear and nearly serene, and when the air, replete with moisture, is chilled by contact with some surface or substance colder than itself. It was once supposed that the dew, fringing the blades of grass and the leaves of the trees with silvery beads, sparkling in the morning sunlight, dropped

"Like the gentle rain from heaven."

Hence our phrase, the drops of dew, alludes to its presumed descent from the upper strata of the atmosphere. It is surprising that this should have been the popular belief down to a very recent period, for dew may be seen upon an under surface which nothing falling can touch, and upon a side surface, which nothing, by either rising or falling, can reach. "The dew-drop is familiar to every one from earliest infancy. Resting in luminous beads upon the down of leaves, or pendant from the finest blades of grass, or threaded upon the floating lines of the gossamer, its orient pearl varies in size, from the diameter of a small pea to the most minute atom that can be imagined to exist. Each of these, like the raindrops, have the properties of reflecting and refracting light; and hence, as from so many minute prisms, the unfolded rays of the sun are sent up to the eye in similar brilliant colours to those of the rainbow. When the sunbeams traverse horizontally a very thickly bedewéd grass-plot, these colours arrange themselves so as to form an iris or dew-bow; and if we select any one of the drops for observation, and steadily regard it while we change our position, we shall find the prismatic colours follow each other in their regular order." The poets of nature in all ages and countries have seized upon the clear, tremulous, pendant, and sparkling drops of dew, as images of purity, gentleness, and beauty; and on account of their service to mankind in the economy of the vegetable kingdom, and the interesting mode of their formation, they claim the attention of the scientific inquirer. With us, the dew is most copious in spring and autumn ; and it has been produced, during a single night, in a quantity sufficient to be measured by the rain-gauge. 'This occurs chiefly in the autumn. Mr. Howard found by his instrument a deposition of dew equal to one-tenth of an inch, on the morning of September 1st, 1818, the production of the preceding night. Dr. Dalton estimates the annual deposit in this country to be five inches, or about $22,161,237,355$ tons, reckoning the ton to be equal to 252 imperial gallons.

The deposition of dew was first satisfactorily explained by Dr. Wells, in the year 1814, in an Essay which has been pronounced by a high authority - Dr. Thomson - "one of the most beautiful examples of inductive reasoning in the English language." When the sun is below the horizon, and for a short period before his setting, bodies upon the surface of the earth, exposed to the aspect of a clear sky, cool by the radiation of the particles of heat absorbed, and at a more rapid rate than the atmosphere. The air in immediate contact with these bodies, replete with humidity in the form of transparent aqueous vapour, is chilled by their cold embrace; and, owing to the increase of its density, it becomes incapable of holding in suspension the moisture with which it is charged in the same quantity as before. The surplus is therefore disengaged, and appears upon the surface of the refrigerating object in globules of dew. It is essential to this process, that the night should not be a cloudy one; because when the sky is overcast, the radiant caloric proceeding from the surface of the earth, and which otherwise would go off into free space, is intercepted by the clouds, and returned by them in sufficient quantity to prevent the decrease of temperature necessary to compel the atmosphere to surrender a 
portion of its hoard of aqueous particles. On nights that are perfectly cloudless, therefore, the deposition of dew is greater than when the sky is partially screened; on those that are both cloudy and windy there is none whatever formed; but a gentle motion in the air on a clear night is favourable to its production in the greatest copiousness, by bringing fresh portions of the atmosphere, laden with moisture, into contact with the colder bodies at the surface. The theory of the dewing process at once explains the rationale of the practice adopted by gardeners, to protect tender plants and fruit trees in blossom on clear nights from cold, by spreading over them a mat or awning. The covering performs the same office as the clouds. It returns the heat radiated from the plants to them, and thus a temperature is preserved which prevents refrigeration. It is often observable that substances exposed at night to the action of the same circumstances, differ greatly in the amount of dew deposited on them, some being thickly coated with its pearls, while others are without a single globule. This arises from the varying capacity of bodies for the radiation of heat. Light downy substances part with it more freely than the solids; so that the former cool down to the dew-point, or that degree of the thermometer at which its disengagement from the atmosphere commences, while the latter, remaining above it, receive no deposition. The following enumeration has been given of the substances which dew, in its formation, has been-remarked more particularly to cling to :-

\section{Threads of the gossamer \\ Sivansdown \\ Fine raw silk}

Fine unwrought cotton.
Flax, wool, grass, hair

Low plants and vegetables, both dead and living Glass

Auimal substances.

As the temperature of substances must be reduced below that of the atmosphere in order to the formation of dew, it is never observed, in temperate climates, upon the naked parts of a living and healthy human body.

The substances that show a marked inaptitude to receive dew, are

\section{Rocks}

Bare earth

Considerable masses of watcr.
The metals, in the following order:Platina, least inaptitude.

Iron, steel, zinc, and lead, the next.

Gold, silver, copper, and tin, the greatest.

Dr. Stocke recorded the following results as to the relative quantity of dew deposited upon a variety of bodies :-

\begin{tabular}{|c|c|c|c|c|c|c|c|}
\hline Glass - & - & - & - Much dew. & Polished lead & - & - & A little. \\
\hline Polished bra & ss - & - & Very little. & Silver - & - & - & None. \\
\hline Rough brass & - & - & - A little more. & Silver, gilded & - & - & None. \\
\hline Rough iron, & tinned & - & Very much. & Blue porcelain & - & - & None. \\
\hline Smooth & do. & - & - Scarcely any. & A stone slab & - & - & Much. \\
\hline Rusty & do. & - & - None. & Basket of India & n cane & - & A little. \\
\hline Quicksilver & - & - & - None. & Smooth white o & ak plank & & Very much. \\
\hline Smooth tin & - & - & - None. & Ditto black. & - & - & Much less. \\
\hline Rough lead & - & - & - Much. & Ditto fir plank & - & - & Little. \\
\hline
\end{tabular}

In opposition to the moisture of dew, that of mists is deposited upon all substances exposed to it alike; and another distinction is, that the moisture of mists exists previous to deposition in a visible state, and is produced quite independent of the bodies that receive it.

A preceding statement, that in temperate climates dew is never observed upon the naked parts of a living and healthy human body, is not true of tropical countries, where, after the high temperature of the day, under a perfectly clear sky; the earth radiates its 
heat with grent rapidity. This is the probable solution of some cases of physical injury sustained by persons sleeping in the open air with the face exposed, commonly supposed to be the effect of the moonlight. Messrs. Bennet and Tyerman, in their travels, state: - "Lunar influence seems to occasion phenomena of a very curious nature. It is confidently affirmed, that it is not unusual for men on board a ship, while lying in the moonlight with their faces exposed to the beams, to have their muscles spasmodically distorted, and their mouths drawn awry-affections from which some have never recovered. Others have been so injured in their sight, as to lose it for several months. Fish, when taken from the sea-water, and hung up in the light of the moon during a night, have acquired such deleterious qualities, that, when eaten the next day, the infected food has produced violent sickness and excruciating pains. We have conversed with pcople who have been themselves disordered after having partaken of such fish. It is hazardous to touch on this subject; we repeat what we heard from those who ought to be believed, and who would not affirm that of which they were not themselves persuaded." Now the circumstances under which these effects transpired-a clear tropical moonlight night-are. precisely those favourable to the production of dew, which promotes the putrefaction of animal matter, and renders it deleterious; and the injury sustained by the parties sleeping exposed to the moonbeams - not a solitary example of such an occurrence - was far more probably caused by the cold and moisture produced by the immense radiation of heat, consequent upon a cloudless night sky after a hot day, than by the lunar light, which all scientific examination shows to be innocuous and uninfluential.

Anacreon-inhabiting the southern part of the north temperate zone-in a wellknown ode pictures Cupid wet with the dews:-

\author{
“' 'Twas midnight deep - the glimmering Bear \\ Show'd near the pole his shaggy hair; \\ And every heart, by toil oppress'd, \\ Enjoy'd the genial balm of rest; \\ Secure from harm, my door was lock'd, \\ When Love approach'd, and loudly knock'd. \\ 'Who's there?' I cried - 'What vagrant foe \\ Thus wakes me with repeated blow?' \\ - Fear not,' said he, with piteous din; \\ - Pray ope the door, and let me in; \\ A poor unshelter'd boy am I, \\ For help who know not where to fly; \\ Lost in the dark, and with the dews \\ All cold and wet that midnight brews." "
}

A bard, still more tropically situated than he of Teos, has written in a similar vein :"I sleep, but my heart waketh; it is the voice of my beloved that knocketh, saying, Open to me; for my head is filled with dew, and my locks with the drops of night." The abundance of this deposition from the atmosphere in Palestine-in certain specified localities, chiefly the hilly districts - is frequently alluded to in the sacred writings. "We were sufficiently instructed," says Maundrell, "by'experience, what the Psalmist means by the ' dew of Hermon,' our tents being as wet with it as if it had rained all night." Its value is fully appreciated there, and throughout Western Asia, where it seldom rains from April to September - the season of the greatest heat - the vegetation consequently then mainly depending upon its copious supply. "God give thee of the dew of heaven" - a patriarchal blessing at the close of life-illustrates its importance in the estimation of a pastoral chieftain; nor could the imagination conceive of a direr calamity than that expressed in the Hebrew elegiac:- "Ye mountains of Gilboa! let there be no dew, neither let there be rain upon you!" 
Hoar-frost - the ice of dew and mist-is formed by the temperature of the atmosphere falling below $32^{\circ}$, the freezing point; or by the powerful radiation of heat from the substances receiving moisture depressing their temperature to the point of refrigeration, in which case the particles freeze, even while a thermometer may be several degrees above $32^{\circ}$. Nature never appears more beautiful than on the mornings of a strong hoar-frost, when the fogs have vanished, and the bright cerulean of the sky is expanded over the productions of the earth, which, from a state of nakedness, have put on vestal garments of the most exquisite purity and delicate finish, the suddenness of the change giving it the aspect of a work of cnchantment. Every part of the vegetable kingdom, from the humble blade of grass to the gnarled and majestic oak of the forest, has acquired a character of mysterious lovclincss, which surpasses any idea of the scenes of fairy-land, and affects the mind by the silence, rapidity, and extent of the creation, as well as by the consciousness of its speedy departure. In the woods, the dark boles of the trees render more impressive their silvery crests, from which the rime descends in snowy showers as the birds twitter among their branches. The forms assumed by the ice of dew are classed by Mr. Howard into the spicular and granular. The former are very minute ieicles which appear upon fibrous surfaces; the latter are globules frozen as they hang pendant from the substances upon which moisture has been deposited. But in whatever solid form the vapours of the atmosphere are returned to their native terrestrial home, their reduction to a liquid state speedily follows, except towards the poles, and on high mountain elevations. The snow of the fields, the hoar-frost, and the ice of the rivers, dissolve under a change of tempernture, yet in obedience to a very peculiar law which ensures their gradual retirement. The moment the change arrives at a particular and invariable degree of heat, thaw commences; but any further addition of heat is absorbed or rendered latent, and the temperature of the thawing mass remains stationary till the dissolving operation is complete. But for this circumstance, which has been called a violation of law, the operation would be instantaneous, and productive of the most disastrous effects. Under the first touch of the warmth necessary to ensure a thaw, the magical spectacle of hoar-frost would be gone in a moment. The snow would rush from the fields in a resistless inundation to the rivers, and the frost-bound streams would be relieved of their ice before the skater could reach their banks.

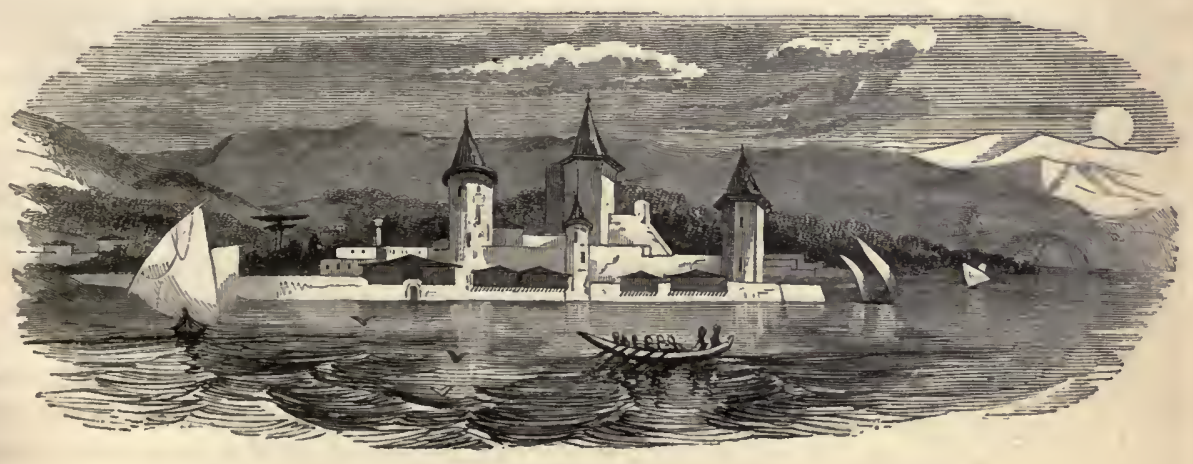




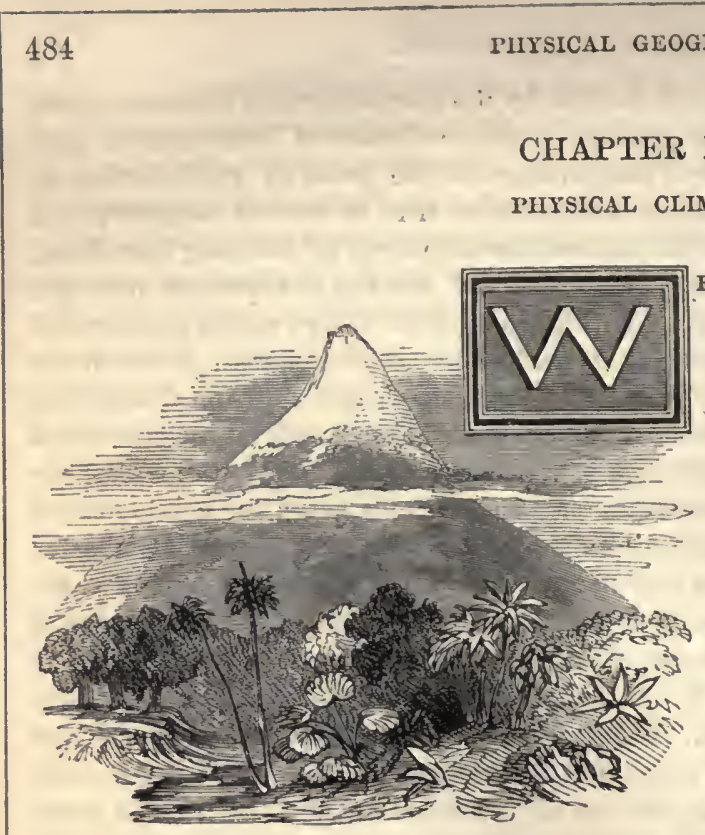

E use the word climate to denote the temperature of the air in various regions of the globe-an all-powerful cause in the determination of their pliysical aspeet. Great diversities meet us here, from the extreme of cold, which produces perpetual congelation towards the poles, where no vegetable life is found, to the fervid heat of an equatorial district, under the action of which, in connection with the prevailing moisture, vegetation attains its greatest lnxuriance. It has been remarked that it is easy to conceive of an astronomical arrangement, according to which all parts of the earth would have liad the same, or nearly the same, climate. But, liad this been the case, our planet, though full of life, would not have been furnished with that useful and agreeable variety of vegetable productions and animal forms which it now presents, and many articles of convenience and luxury which the existing arrangement affords to the human race would have been wanting. It is an instance of wise and benign adaptation that the human frame has been so constituted as to be able to bear the striking diversities of climate which distinguish the abode of mankind, both the heat of the burning plains of Beloochistan, and the cold of the icy shores of Greenland. It has been proved by experiment that the body is capable of enduring very great extremes of temperature, and sudden changes of it, without being seriously affeeted. Dr. Fordyce exposed himself to an atmosphere raised to the temperature of $200^{\circ}$ of Fahrenleit, or nearly to the boiling point of water, for ten minutes, and a thermometer fixed under his tongue indicated only $98^{\circ}$, so that his body resisted the impression of the artificial heat, and retained nearly its natural temperature, which the surrounding air exceeded by more than $100^{\circ}$. On the other hand, a degree of cold which depressed the mercury in a thermometer $52^{\circ}$ below the freezing point, las been borne with only a slight addition to the ordinary clothing. Owing to this capacity of the frame, man can accommodate himself to the circumstances of the earth he inhabits, live amid the perpetual ices of the north, or under the fierceness of a torrid climate, and pass without difficulty fiom the one to the other, for the purposes of commerce and enterprise. Though many members of the vegetable kingdom show a marked indifference to change of temperature, and hence are transportable with success from cold to heat, or from heat to cold ; yet vast numbers exhibit as marked an incapacity for the transition. The cinnamon bushes that clothe the surface of Ceylon would not endure a removal to the bleak moors of England, nor our highland pines a transplantation to the level plains of Hindostan; but the different members of the human family, in varying degrees, display a plyysical adaptation for emigration into any of the habitable parts of the earth, however discordant their temperature, the frost biting in one region, the fire-king breathing in another.

We proceed to mention the causes which determine plysical climate, and induce its differences : - 
1. The geographical position of a country with reference to the equator is one of the leading circumstances by which its temperature is determined. At the equator, and within the tropics, the greatest heat is experienced, because the sun is always vertical to some place within those limits, and the solar action is the more intense in proportion as the rays are perpendicular to the earth. As we recede from the equator, north or, south, their direction becomes more oblique, and less influential in promoting temperature. It is for this reason that a declivity towards the equator, which receives the solar rays more directly than a lerel surface, is always the warmest, and hence the importance attached to an inclination of the surface with a southern aspect in our elimate. The latitude of a place is therefore a prime determining eause of the temperature to which it is subject, a decrease of heat taking place with an increase of distance from the equatorial localities, though with various modifications, which will be hereafter noticed. One exception taken to this general rule may here be stated. It is true of countries lying between the tropies and the poles, that heat decreases with an increase of latitude, but it is thought not to be true of countries between the tropics and the equator. Tracing the path of the sun as delineated upon an artificial globe, we perceive an advance of $12^{\circ}$ of latitude made in the first month after the equinox, only $8^{\circ}$ in the second, and but $3 \frac{1}{2}^{\circ}$ in the third; and upon retiring from the tropic to the equator, he follows the same course inversely, traversing $3 \frac{1}{2}$ of latitude in the first month, $8^{\circ}$ in the second, and $12^{\circ}$ in the third. It follows, therefore, that to all places situated within $3 \frac{1}{2}^{\circ}$ of each tropic, his rays at noon are vertical, or make but a slight angle for two months respectively; whereas those places which are under the equator have but the sun as near their zenith for about a week at each equinox. From this circumstance it has been inferred that in receding from the equator there is no decrement in the mean annual temperature till we have passed $23 \frac{1}{2}^{\circ}$, the latitude of the tropics. 'This cannot yet be regarded as an established fact, though it is quite certain that the mean temperature in summer near the tropics is higher than near the equator. In the northern hemisphere the countries where the greatest heat is experienced-the banks of the Senegal, the Tehama of Arabia, and Mekran in Beloochistan - coineide with the tropic of Cancer; and it has been observed that the snow-line of the Andes in $17^{\circ}$

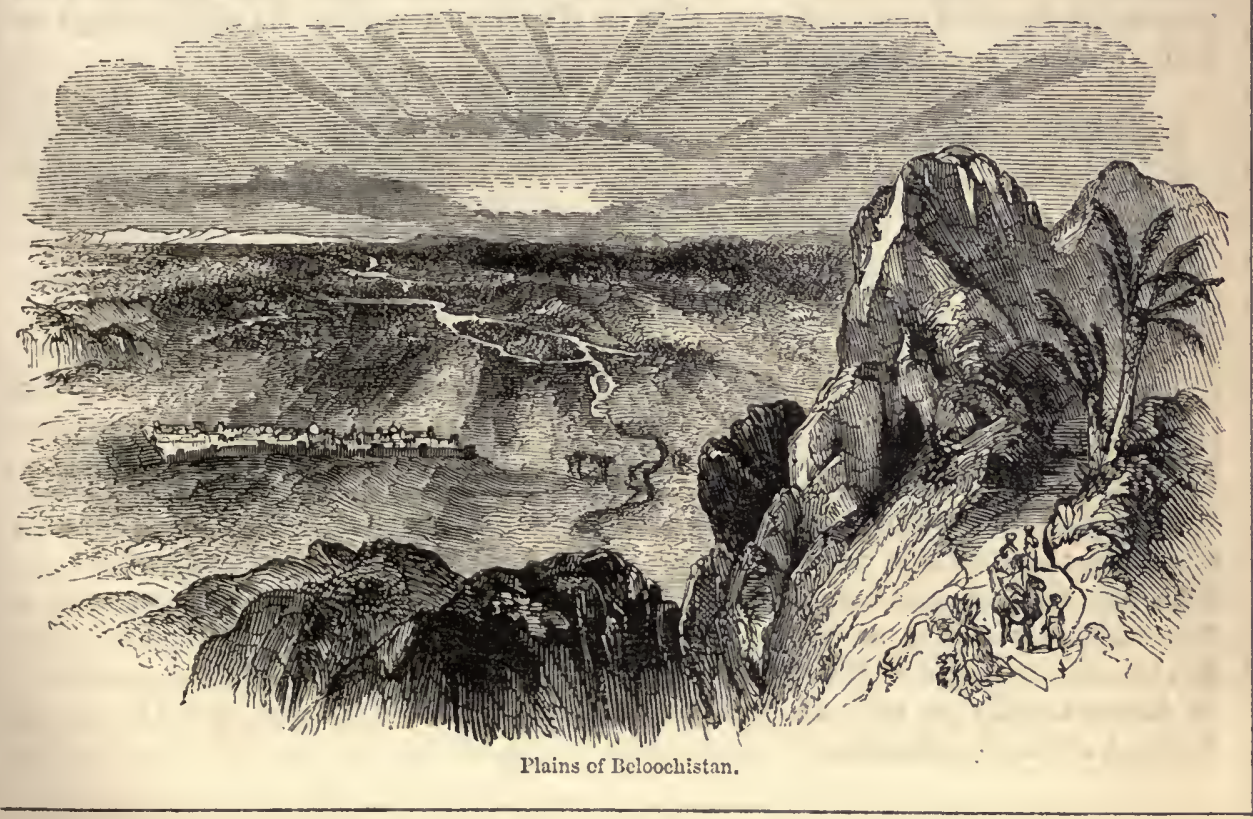


south latitude is higher than at the equator, an evidence of a higher temperature. With this exception, if admitted to be one, the decrement of heat proceeds gradually as we travel along the same level from the line to the poles.

2. The temperature of countries is largely affected by the extent of their elevation above the level of the sea. It is well known that as we ascend in the atmosphere the cold increases, - an effect due to the rarefaction of the air, and to the circumstance of being further from the heat reflected from the surface of the earth. We must travel several hundred miles along the surface from the equator, before we become sensible of a diminished temperature; but an ascent there of only a thousand yards will sink the thermometer $10^{\circ}$, or $1^{\circ}$ for 310 feet, and the decrease of heat will go on as we ascend higher, with a little irregularity, till at the height of somewhat less than 16,000 feet, or about 3 miles, we come to the line of perpetual congelation. The ratio of the diminution of temperature usually given, is $1^{\circ}$ for 300 feet of altitude; $2^{\circ}$ for 595 feet; $3^{\circ}$ for 872 feet; $4^{\circ}$ for 1124 feet ; $5^{\circ}$ for 1347 feet; and $6^{\circ}$ for 1539 feet. In the temperate zone generally, if one site is a thousand yards higher than another adjoining, it will have a climate $12^{\circ}$ colder; and the higher the latitude the lower the snow-line becomes, till it osculates with the surface of the earth in the frigid zone. The following diagram

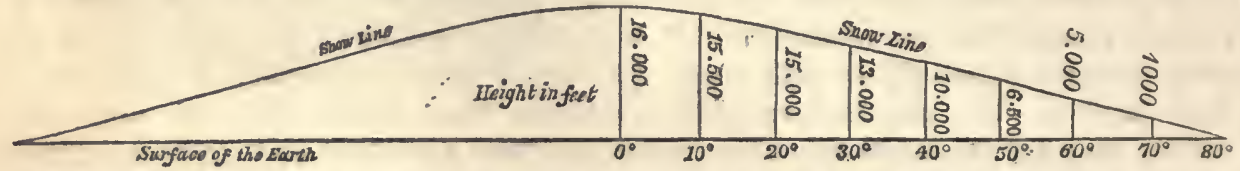

represents the line of perpetual snow, forming the arc of an ellipsoid, passing over the equator, from pole to pole.

But this important boundary-line, as it exists in nature, exhibits no continuous curvature, though attaining a considerable elevation at the equator, and level with the surface in high latitudes. It repeatedly oscillates, suddenly ascends and descends, under control of the physical peculiarities of different regions. The snow-line of the Andes, at the equator, is found at the height of 15,748 feet; but not a particle of permanent snow was seen by Mr Pentland at the following sites on the Bolivian part of the chain, though in from $17^{\circ}$ to $19^{\circ}$ of south latitude :-

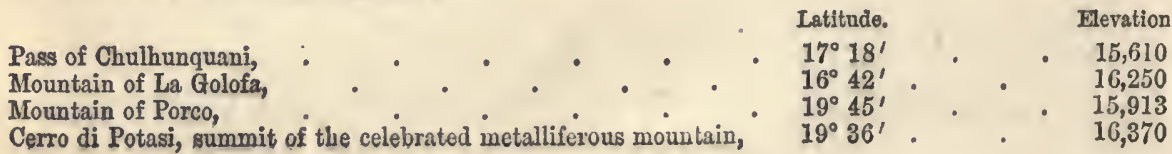

A remarkably great and sudden fall of the Andean snow-line occurs further south, unparalleled in any other part of the globe.

\begin{tabular}{|c|c|c|c|}
\hline Place. & Latitude. & $\begin{array}{c}\text { Height in Feet of } \\
\text { Snow Line. }\end{array}$ & \multicolumn{1}{c|}{ Authorities. } \\
\hline $\begin{array}{l}\text { Cordillera of Central Chili } \\
\text { Cordillera of Chiloe }\end{array}$ & $\begin{array}{c}33^{\circ} \mathrm{S} . \\
\mathbf{4 3} \mathrm{S},\end{array}$ & $\begin{array}{c}14,500 \text { to } 15,000 \\
6000\end{array}$ & $\begin{array}{l}\text { Gillies, and Mr. Darwin. } \\
\text { Officers of the Beagle, and Mr. Darwin. }\end{array}$ \\
\hline
\end{tabular}

Thus, within the distance of only $10^{\circ}$ of latitude, the snow line experiences a difference of elevation of 9000 feet, an effect attributed to the fact of Chiloe being covered with forest trees dripping with moisture, indicating a clouded sky and little heat in summer, while in Central Chili rain does not fall for the seven summer months; the sky is generally clear, and the climate hotter. The subjoined table gives the height of the curve of congelation in different latitudes, exclusively from calculation founded upon the known law of the decrease of heat by elevation. 
referable to the fact that the soutl side of the range ascends abruptly from the low level plains of Bengal, while the nortl side descends into a plain which is itself immensely elevated, and a higher temperature is produced there, elevating the snow-line by the reflection of the solar action from the large and contiguous masses of land. 'The Pyrenees, likewise, and the Caucasus, under the same parallel of latitude, exhibit a great discrepancy. Though the general climate of the adjacent country is warmer in the case of the Pyrenees, yet the snow-line on Mont Perdu, according to Raymond, is found at the height of 8700 feet, while on Elbürz it occurred at the elevation of 10,880 feet, as observed by Englehardt and Dr. Parrot. South of Elbürz, by only $3^{\circ}$ of latitude,

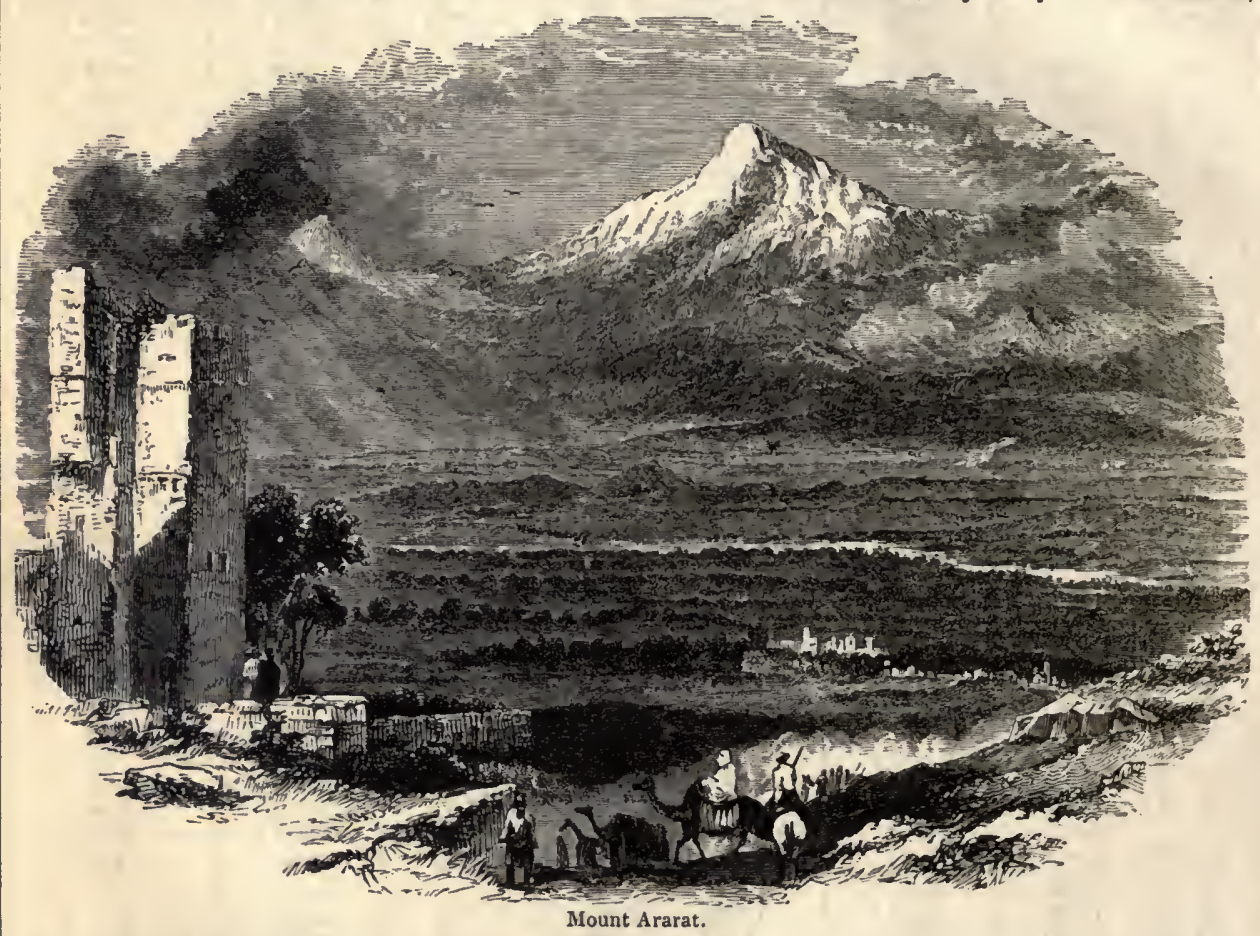

Parrot found the snow-line on Ararat at 14,080 feet, which is 5000 feet above its eleration, under the parallel of $40^{\circ}$, as registered in the table.

The Russian traveller, Parrot, justly remarks that the time of the year when the snow limits are observed should be particularly noted, in order to be capable of being determined with tolerable precision. "On that point it may be laid down, in general, that it is only in the end of autumn, before winter has brought much new snow, and when the heat of autumn shall have melted as much as it can of the old, that such observations can lead to a correct result. For mountains such as Ararat, Caucasus, the Alps, the Pyrenees, and, in general, all mountains in middle latitudes, August and September are the only months which can be used for determining the true limits of perpetual snow, because, during these months, although the great heat is for the most part gone by, yet large masses of snow still go on melting away, till the actual setting in of winter in these regions puts a stop to the process." The difference observed in the elevation of the curve of congelation between places under the same parallel of latitude may, in several cases, have been owing to the observations being made at different times of the year. He thus accounts for the height of the snow-line in the instance of Ararat:- 
"In the country around there reigns an extraordinary degree of heat, the rays of the mid-day sun striking directly on the south side of the mountain, while on its northern side the valley of the Araxes preserves to a late season of the year the heat received from the slopes of the Gorkchai mountains. In July and August the people fly from the sultriness of the plain - a sultriness which did not allow me, in the latter half of October, to make any exertions out of doors in my usual clothing. At the end of that month the thermometer still stood at $68^{\circ} \mathrm{Fahr}$. This excessively lot air continually ascends during the summer up the sides of Ararat, warming its soil, and encroaching uninterruptedly on its snows. In this way alone can I explain the great heat which allowed me, in the latter end of September (old style), to spend two nights on bare rocks in the open air, without a pelisse, and at the height of 13,800 feet above the sea. If to the circumstance of the warm streams of air rushing up the sides of Ararat the greater part of the year we add the isolated position of that mountain, the icy head of which is the only one in a very wide tract that rises to a great height above the surrounding country, and which is, therefore, of course, less able to resist the influx of warmth from below, than a more widely extended mass of snow, such, for example, as occurs in the Alps, we can explain satisfactorily enough the extraordinary height of the snow limits on Ararat, which, according to my observations, are 14,080 feet above the level of the sea."

From this effect of elevation upon temperature it is obvious that a country may have all the varieties of climate within a very scanty area; and accordingly, in several parts of the torrid zone, an unfortunate geographical position is compensated by a happy physical contour. The low coasts of Mexico, and the table-land nearly 9000 feet above the sea, with its ridge of lofty peaks, of which Popocatapetl and Orizaba rise above the snow-line, exhibit a striking example of a hot climate in close contiguity to one mild and equable, and to another bordering upon aretic rigour. 'The hot regions, tierras calientes, include the country along the eastern and western shores under the elevation of 2000 feet, where the mean temperature is about $77^{\circ}$, and sugar, indigo, cotton, and bananas flourish luxuriantly. Above these are the temperate regions, tierras templadas, which lie along the slopes of the mountains at an elevation of from 2000 to 5000 feet. Here the yellow fever, the scourge of the low grounds, is unknown; and the mean lieat of the year is from $68^{\circ}$ to $70^{\circ}$. The traveller enjoys a genial air, and encounters the oaks, cypresses, pines, tree-ferns, and the cultivated cereal plants of Europe. He next arrives at the cold regions, tierras frias, which include the table-lands and the mountains above 5000 feet. On the borders of this zone the climate is still pleasant, but beyond the elevation of 8000 feet it becomes severe, and gradually assumes the character of the polar latitudes.

Switzerland, in a similar manner, exhibits a variety of climates within the area of a few square miles, with the vegetable productions peculiar to each, as the effect of its surface-elevations and irregularities. The Valais, one of the cantons, displays this diversity very remarkably. In that narrow and deep longitudinal valley, the extremes of temperature occur at a trifling distance from each other, the cold of Iceland and the heat of a Sicilian summer; and while in some of its inhabited parts fruit will not ripen, in others the wild asparagus is seen to grow, and the almond, the fig, and the pomegranate attain the greatest perfection. : This high temperature arises from its lofty mountain walls preventing the free passage of the air, and reflecting from their sides the heat they receive from the rays of the sun, which impinge upon them more directly than on a level surface; and hence the singular fact has been witnessed, in an elcvated valley of Mont Blanc, of the temperature in the centre being so much increased by reflection, that the spot lias been covered with flowers and verdure in the midst of perpetual snows and glaciers. Vines grow in the Valais to the height of 2380 feet above the level of the sea ; 
trees to 6700 feet; shrubs to 8500 ; a few plants to 10,600 , beyond which are a few lichens; and vegetation ceases entirely at the height of 11,000 feet, amid arctic cold. The following is the extreme line of elevation above the sea-level observed here by individual classes of regetation :-

\begin{tabular}{|c|c|c|c|c|c|c|c|c|}
\hline Maize - & - & $\begin{array}{r}\text { Feet: } \\
-2772\end{array}$ & The cherry & - & $\begin{array}{r}\text { Feet. } \\
-4270\end{array}$ & The silver birch & - & $\begin{array}{r}\text { Feet. } \\
-\quad 5500\end{array}$ \\
\hline The oak & - & -3518 & Potato - & - & -4450 & The larch - & - & -6000 \\
\hline The walnut & - & -3620 & The nut & - & -4500 & The fir le sapin & - & . 6300 \\
\hline The yew & - & -3740 & The beech & $=\quad-$ & -4800 & Pinus cembra & - & -6600 \\
\hline Barley - & - & -4180 & The mounta & ain maple & -5100 & Rhododendron & - & -7400 \\
\hline
\end{tabular}

The valley of the Adige extending from near the summit of Mont Brenner in the

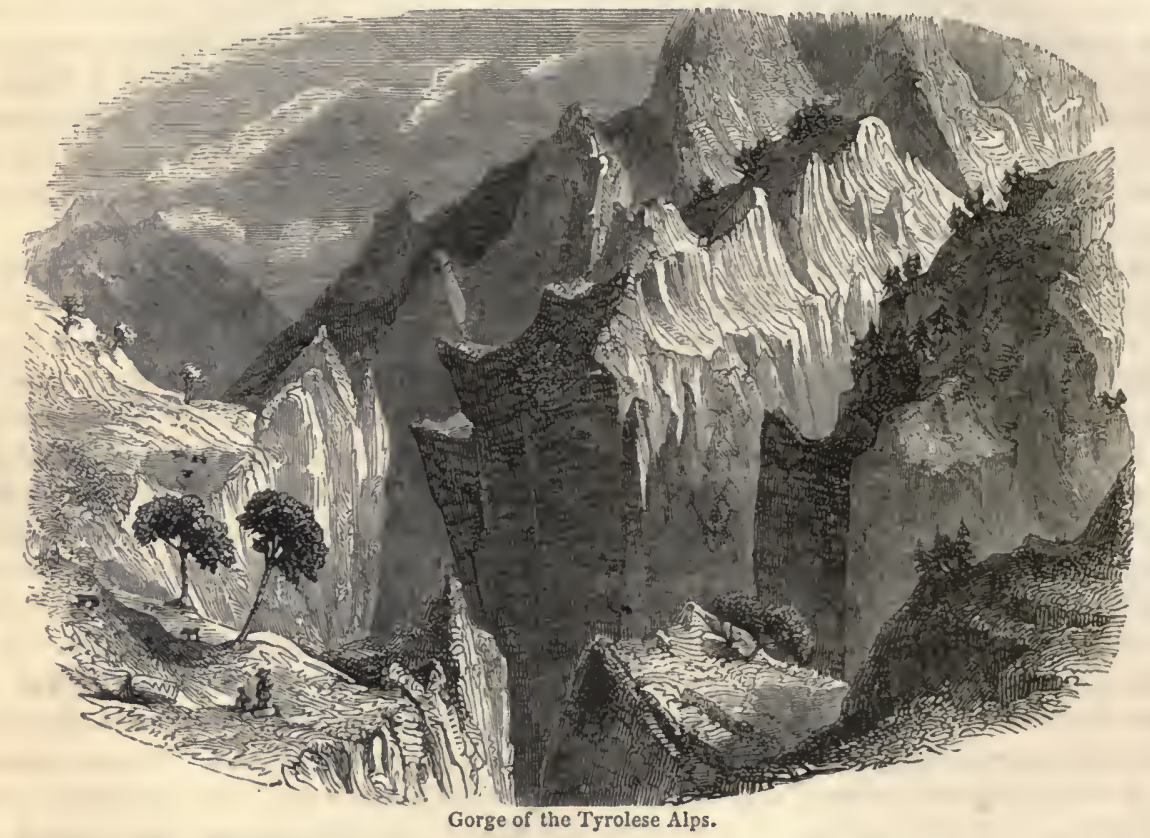

Tyrolese Alps to the Lago di Garda, reposing on the edge of the softer scenes of Italy, exhibits a scale of productions which marks the alteration of climate, in the course of about a hundred miles, the effect of a descent from a high to a low elevation. "We have first," says Inglis speaking of its northern extremity, "Alpine productions; but to pass these over, and to note only the productions of cultivated land,-we have first then, barley, thin and scanty, and a few hardy vegetables. We come next to Indian corn of a poor growth, with barley more vigorous, oats, grass, and firs. The third gradation brings us to a little wheat, mingled with all these, and to some walnut trees, besides fir. In the fourth division of the valley, we find Indian corn and wheat growing luxuriantly, vines beginning to appear, and fruit trees, especially the cherry, in abundance. 'The fifth gradation shows us, with all these productions, vines in luxuriance, and magnificent walnut trees entirely superseding the hardier wood. At the sixth step we find some additions to these: the mulberry begins to appear, and fruits of the more delicate descriptions are found. The seventh division presents the vine in its perfection, the mulberry in its abundance, and the fruits we have seen before, in greater luxuriance. The eighth and last gradation shows us, with all that we have seen before, the olive, the 
pomegranate, and the fig. The valley of the Adige is indeed peculiarly calculated for the display of this scale : the low temperature, which in its upper parts accompanies its great elevation, gives us the productions of a northern latitude; while as we descend, the valley being open to the south, and shut in in every direction, a vegetation is produced that belongs to a more southern latitude than the country enjoys."

Etna exhibits a striking example of variety of climate, that of the valleys at its base being as different from the higher parts, as an equatorial from a polar latitude. The whole mountain is divided into three districts, called La Regione Culta, or the fertile region; La Regione Sylvosa, the woody region; and La Regione Deserta, the barren region. The temperature and productions of these districts are as diverse from each other as those of the three zones of the earth, and, with almost equal propriety, they might be styled, the torrid, the temperate, and the frigid zones. But these zones are again subdivided, the limits of their respective parts being determined by families of plants which require a certain amount of temperature for their growth. Seven distinct botanical regions are noticed upon Etna. The first, or lowest, is confined to the elevation of about a hundred feet above the level of the sea. Here the palm tree is met with, the banana, the Indian fig, and the sugar-cane, with varieties of mimosa and acacia in the gardens, which require a conservatory in the northern parts of Europe. The second region presents cotton, maize, the orange, the lemon, and the shaddock, and most of the plants of southern Spain, France, and Italy. Its limit is about 2000 feet above the level of the sea, where the culture of the vine ceases. The third or woody zone lies between the height of 2000 and 4000 feet. Here the cork-tree flourishes, the oak, the maple, and the chestnut attain a magnificent size, the Castagno dei cento cavalli, or chestnut of a hundred horses, being more than two hundred feet in circumference, as measured by Brydone. It presented five large and distinct trunks, without any appearance of bark in the inside, which sanctions the popular belief of these having been united in one stem. The canon Recupero, an ecclesiastic, was at the expense of carrying up peasants with tools to dig round the tree, and found the trunks proceeding from one root. The fourth region occupies a belt on the mountain between the elevation of 4000 and 6000 feet, and is characterised chiefly by the birch and Scotch fir. The ffth zone, between 6000 and 7500 feet, is sub-alpine, and produces the barberry, soap-wort, and juniper, which are found in the sixth, between 7500 and 9000 feet, in connection with a few plants peculiar to it. The seventh region extends from the preceding two hundred feet higher, which marks the extreme limit of regetation. It presents only a few lichens, and beyond the height of 9200 feet utter harrenness prevails.

The Island of Teneriffe, with its celebrated Peak rising to the height of 12,176 feet, presents five zones of vegetation, arranged in stages one above another, extending through a perpendicular elevation of $11,190 \mathrm{feet}$, to which vegetation ascends in that tropical latitude. The region of Vines rises from the level of the sea to a height varying from 1200 to 2000 feet, and exhibits various kinds of arborescent Euphorbiæ, Mesembryanthema, the Cacalia Kleinia, the Dracœna, and other plants, whose naked and tortuous trunks, succulent leaves, and bluish-green tints are distinguishing features of African vegetation, The great dragon-tree of Orotava, a species of very slow growth, Humboldt found to be sixty feet high, with a circumference of forty-eight feet near the roots, the trunk separating at a particular point into a variety of branches in the form of a candelabrum. In this zone, the date-tree flourishes, the sugar-cane, the plantain, the Indian fig, the olive, wheat, and the fruit-trees of Europe. The region of Laurels includes the woody part of Teneriffe; and abounding with springs, the ground is never parched with drought, but presents an ever-verdant turf. Four species of laurel, one of oak resembling that of the table-land of Thibet, two of iron-tree, and a variety of evergreen trees of the myrtle 
family, characterise this zone. The soil, covered with mosses and tender grass, is enriched with showy flowering plants. Next comes the region of Pines, commencing at the height of 5760 feet, and extending to 8610 , entirely filled with trees resembling the Scotch fil, intermingled with the juniper. 'The region of Retama, a species of broom, and of Gramina or grasses, occupy heights equal to the loftiest summits of the Pyrenees, where the snow is perpetual ; beyond which nothing presents itself but the naked pumice, obsidian, and lava of the cone of the volcano.

We find therefore within the torrid zone, countries enjoying a moderate temperature, as the effect of their elevation above the level of the sea. This is the cause of the delightful climate of the valleys of Cashmere, and of portions of Hindûstan lying on the declivities of the Himalaya mountains. The table-land between the eastern and western Ghauts, in the south of that peninsula, partakes a climate of the same character. There are no long days to produce the excessive heats of more northern latitudes, and the summers are even cooler than in the temperate zone, a vertical sun maintaining the temperature of a perpetual spring throngliout the year. The streams are perennial, the verdure constant, the air mild and salubrious, and the whole scene cheering at all seasons. The same agreeable effect of elevation upon temperature in a region geographically placed in the hottest parts of the globe, is experienced on the plateau of Abyssinia, and on the slopes and table-lands of the Andes. The inhabitants of Quito experience a genial and almost invariable climate, in which vegetation never ceases, while on the one hand, they behold the paramos, or mountain ridges, some of the summits rising above the clouds, covered with perpetual snow, and at the distance of a few leagues, an intense and sickly degree of heat oppresses the plains and lower levels. On the plains of the Orinoco the temperature throughout the year is that of the month of August at Rome; at Papayan, at an elevation of 2988 feet, it is that of the montl of August at Paris; at Quito, 4894 feet, that of the month of May; in the paramos, 5904 feet, that of the montl of March at Paris.

Upon proceeding from Acapulco, on the western coast of Mexico, into the interior country, Humboldt speaks of ascending by burning valleys at the base of the Cordilleras, where the thermometer stood at 89.6 in the shade, crossing streams on fruits of Crescentia pinnata, attached to each other by ropes of agave, till, gaining the ligher districts from 3500 to 5900 feet above the sea, he entered a region blessed with a tempcrate climate, and producing oaks, cypresses, pines, tree-ferns, and the cultivated cereal plants of Europe.

3. The relation subsisting between a country and the ocean is another important element in the determination of its climate.

The ocean preserves a much more uniform temperature than the land, far lower than its extreme of heat, and higher than its extreme cold. The atmospheric currents that sweep over it have this character. to some extent impressed upon them, and enstamp it upon the physical climate of countries situated within the range of their influence. Hence islands and maritime districts have universally milder climates than inland regions under the same parallel of latitude, the cooler currents of air from the ocean tempering their summer heat, and warmer currents moderating their winter cold. The temperature at London corrected by that of the contiguous sea is lower in summer than at Paris, and higher in winter, though in a more northern latitude.

The same cause explains the mild winters and cool summers of Ireland; and the contrast between the climate of the south-west coast of England, and the interior of the island, not half a degree of latitude differing from it. At the port of Salcombe in Devonshire, called the Montpelier of the north, an agave flowered in 1774, after liaving lived twenty-eight years without being covered in winter; and in some parts of that 
district, the myrtle, the Camellia japonica, the Fuchsia coccinea, the Buddleia globosa pass the winter without shelter in the open ground, and orange trees are seen on espaliers, only sheltered, as at Rome, by means of matting. On the coasts of Brittany, in the department of Finisterre, the arbutus, the pomegranate tree, the Yucca gloriosa and Aloifolia, the Erica Mediterranea, the Hortensia, the Fuchsia, and the Dahlia, resist in open ground the winter, the mean temperature of the peninsula being above $56^{\circ} 3^{\prime}$; and Humboldt states, that in the interior of France, where the land is not much elevated above the sea, we must go south $3^{\circ}$ of latitude in order to find an annual temperature equal to it. The milder winter of places on the Atlantic coast of France, as compared with interior situations of corresponding latitudes, appears from the table:-

\begin{tabular}{|c|c|c|c|c|c|c|c|c|}
\hline \multirow{2}{*}{ Places on the Coast. } & \multirow{2}{*}{ Latitude. } & \multicolumn{2}{|c|}{ Mean Temperature. } & \multirow{2}{*}{ Places in the Interior. } & \multirow{2}{*}{\multicolumn{2}{|c|}{ Latitude. }} & \multicolumn{2}{|c|}{ Mean Temperature. } \\
\hline & & Of Winter. & OrSummer. & & & & of winter. & Of Summer. \\
\hline St. Malo & $48^{\circ} 39^{\prime}$ & $42 \cdot 4^{\circ}$ & $66 \cdot 9^{\circ}$ & Chalons sur Marne & $48^{\circ} 5$ & $57^{\prime}$ & $36 \cdot 1^{\circ}$ & $66 \cdot 6^{\circ}$ \\
\hline St. Brieux & $48 \quad 31$ & $41 \cdot 7$ & $64 \cdot 4$ & Paris & $48 \quad 5$ & & $38 \cdot 7$ & $65 \cdot 3$ \\
\hline Vannes & $47 \quad 39$ & $39 \cdot 7$ & $64 \cdot 4$ & Chartres & 48 & 26 & 370 & $64 \cdot 6$ \\
\hline Nautes & 13 & $40 \cdot 5$ & $68 \cdot 5$ & Troyes & 48 & 18 & $38 \cdot 3$ & $67 \cdot 3$ \\
\hline La Rochelle & 14 & $40 \cdot 3$ & $66 \cdot 6$ & Chinon & 47 & 26 & $38 \cdot 7$ & $69 \cdot 1$ \\
\hline Oleron & $45 \quad 56$ & $44 \cdot 6$ & $68 \cdot 5$ & Poitiers & 46 & 39 & $39 \cdot 7$ & $67 \cdot 1$ \\
\hline Bordeaux & $44 \quad 50$ & $42 \cdot 1$ & $70 \cdot 9$ & Vienne & 45 & 31 & $38 \cdot 7$ & $71 \cdot 6$ \\
\hline Dax & $43 \quad 53$ & $44 \cdot 4$ & $67 \cdot 9$ & Montauban & 44 & 01 & $42 \cdot 6$ & $69 \cdot 3$ \\
\hline
\end{tabular}

Interior countries likewise, which abound with rivers, lakes, and marshes, are less subject to the extremes of heat and cold than those which have an opposite physical character. The heat experienced upon the well-watered plains of Hindûstan is never so excessive as in the dry corresponding regions of Northern Africa; and around the Canadian lakes, the winter is milder than in other localities under the same latitude. 'There is an anomaly in climate, which is very satisfactorily explained by a reference to the temperature of the adjoining ocean. This is the well-known fact, that in travelling from the equator northward to the pole, the cold increases in a slower ratio about the meridian of London, than in any other part of the world. The climate of western Europe in general is milder than that of countries under the same parallel at its eastern extremity, or in Asia, or in America. The decrement of the mean annual temperature in Western Europe and in North America, prolonging the scale to the equator, is given in the following table from Humboldt :-

\begin{tabular}{|c|c|c|c|}
\hline Latitude. & Old World. & New World. & Difference. \\
\hline $0^{\circ}$ & $81 \cdot 5^{\circ}$ & $81 \cdot 5^{\circ}$ & $0^{\circ}$ \\
20 & $77 \cdot 9$ & $77 \cdot 9$ & 0 \\
30 & $70 \cdot 7$ & $67 \cdot 1$ & $3 \cdot 6$ \\
40 & $63 \cdot 5$ & $54 \cdot 5$ & $9 \cdot$ \\
50 & $50 \cdot 9$ & $38 \cdot 3$ & $12 \cdot 6$ \\
60 & $41 \cdot 0$ & $25 \cdot 0$ & 16. \\
70 & $33 \cdot 0$ & 0.0 & 33. \\
\hline
\end{tabular}

Thus, at the latitude of $40^{\circ}$, that of Madrid and Philadelphia, the mean annual temperature of Western Europe is $9^{\circ}$ higher than that of North America. At latitude $60^{\circ}$, that of St. Petersburg, Upsal, Christiania, South Shetland, the south point of Greenland, the north point of Labrador, and the lower extremity of the Great Slave Lake, it is $16^{\circ}$ higher, and $33^{\circ}$ higlier at latitude $70^{\circ}$. A similar difference appears in favour of Western Europe comparing it with Eastern Asia. 


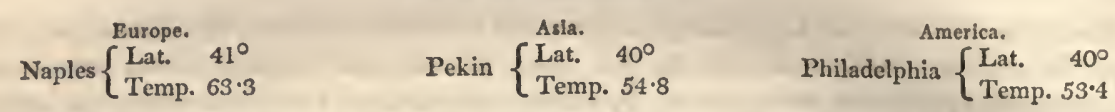

It is also the case, that the western region of North America, between the Rocky Mountains and the Pacific Ocean, is warmer than the eastern between the Alleglanies and the Atlantic; and it was once imagined, that, comparing the two sides of the Alleghany mountains, the country to the westward, including the states of Ohio and Tenessee, and

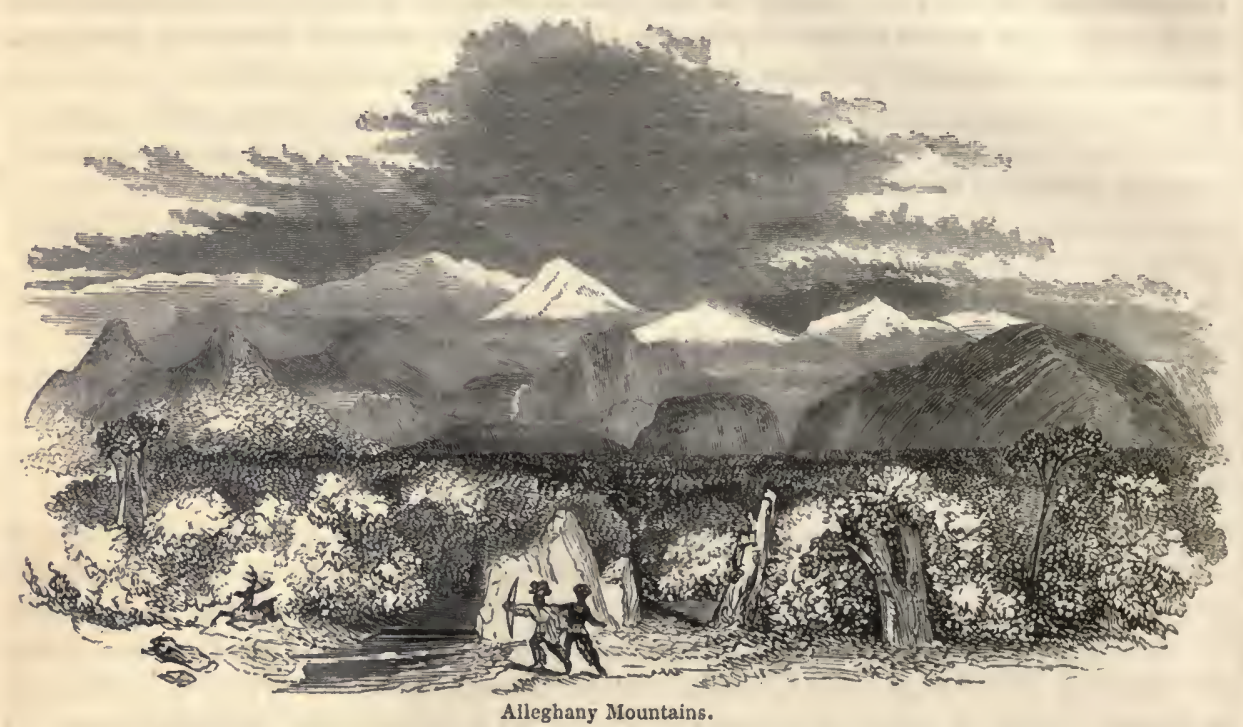

the vast basin of the Mississippi, had a milder climate, than the Atlantic states to the eastward, under the same parallels. But the mean temperature is nearly equal on the east and west of the range; and the more northerly migration of certain vegetables on the western side, which originated the surmise, is referable to the Mississippi valley, lying in that direction, favouring their transport, while in the eastern provinces the valleys are transverse, and consequently offer no facility to their passage to the-north. It cannot, however, be doubted, taking the whole continent into consideration, that the eastern districts of North America are colder than the western; and in proceeding from Western Europe, in an easterly direction, there is a gradual increase of cold experienced. Thus at St. Petersburg it is $3^{\circ}$ colder than at Upsal on the same parallel, and $5^{\circ}$ colder at Moscow than at Copenhagen.

It is an interesting point to determine the cause of the greater warmth experienced under the meridian of London, and through the whole of Western Europe, than in corresponding latitudes. There ean be no doubt that the solution is to be found in the warm water of the Gulf stream in the North Atlantic, and the prevalence of west and southwest winds. We have before referred to this remarkable current of warm water, not inferior to the Mediterranean in its extent, which sweeps through the ocean towards the continent of Europe, having a temperature from $3^{\circ}$ to $10^{\circ}$ higher than that of the contiguous sea. The winds that blow over it have its character impressed upon them, and rush up from the west and south-west, invading Europe from Cape Finisterre to the North Cape with currents of warm air, reaching into the heart of the continent to the plains of Russia, through the great gate between the Scandinavian and the Harz mountains. It may be objected to this, that the Gulf stream ought in a similar manner 
to warm the Atlantic States of America by which it sweeps, whereas the mean temperature there is lower than in Western Europe; but this is owing to the narrowness of the current in that quarter, and to the prevailing winds being from the west and south-west, which carry the hot circumambient air away from the shore. With reference to the lower degree of heat experienced over the whole continent of America, as compared with corresponding latitudes in the eastern portion of the earth, Humboldt advances the following statement in his Tableaux de la Nature: "The comparative narrowness of this continent-its elongation towards the icy poles - the ocean, whose unbroken surface is swept by the trade winds - the currents of extremely cold water which flow from the straits of Magellan to Peruthe numerous chains of mountains, abounding in the sources of rivers, and whose summits, covered with snow, rise far above the region of the clouds - the great number of immense rivers, that, after innumerable curves, always tend to the most distant shores-deserts, but not of sand, and consequently less susceptible of being impregnated with heatimpenetrable forests, that spread over the plains of the equator, abounding in rivers, and which, in those parts of the country that are the farthest distant from mountains and from the ocean, give rise to enormous masses of water, which are either attracted by them, or are formed during the act of vegetation :- all these causes produce, in the lower parts of America, a climate which, from its coolness and humidity, is singularly contrasted with that of Africa. To these causes alone must we ascribe that abundant vegetation, so vigorous and so rich in juices, and that thick and umbrageous foliage, which constitute the characteristic features of the new continent."

4. There are various other circumstances which enter into the constitution of climate, such as the soil of a country, whether light and porous, or clayey and compact, whether open to the solar action and to the play of the winds, or covered with forests, and screened by mountains from the free operation of atmospheric currents. Barren sands admit of a much more intense heat than a loamy soil, and pasture lands are not so susceptible of it as the bare ground. The clearing of a country from trees has the effect of raising the mean annual temperature, but at the same time greater extremes of heat and cold are introduced. Dr. Williams found the temperature of open grounds $12^{\circ}$ higher in summer and $7^{\circ}$ lower in winter, than that of forests. Open grounds are always frozen deeper than the woodlands, and hence the spring advances later; but being more heated in summer, the winter commences later. Several countries have, however, suffered severely from the incautious destruction of the forests, having been deprived thereby of a natural protection needed by their geographical position from the intensity of the solar rays, or from the heated air of neighbouring districts, besides the amount of moisture in the atmosphere being lessened by the loss of the vegetation which promotes evaporation. The climate of some parts of Southern Europe has been deterioriated from this cause, and the oppressive heats and dreadful droughts of the Cape Verde Islands are due to it. In addition to the direct effect of the sun's rays, contiguous parts of the earth exert a continual influence upon each other, by reciprocating their temperature through the medium of the winds. In this way, the deserts of Arabia and Africa are like immense furnaces warming all the regions on the Mediterranean Sea, in the south of Europe and the west of Asia; and in a similar manner, the mountains and table-land of Tartary increase the cold of the surrounding countries. At Bagdad and at Bushire, where the south wind arrives heated by the burning sands of Arabia, the thermometer sometimes stands at $125^{\circ}$, and on the west coast of Africa, when a similar cause operates, it has been observed at $130^{\circ}$. In the August of 1819 , when the fierce simoom blew at Bagdad, the thermometers rose to $120^{\circ}$ in the shade, and at midnight were at $108^{\circ}$ in the open air, and a heavy rain falling, an unprecedented event, the whole region was converted into a vast hot steam-bath. Multitudes of people, both in the country and in the streets, dropped down dead, owing to the intense heat. A 
small caravan lost twenty-two persons in this manner during the last three days of its journey across the Desert towards the city.

In the United States, the prevailing winds remarkably affect the temperature, producing the cold of the polar regions and the warmth of the torrid zone, according as they blow from the frozen shores of Hudson's Bay or from the hot regrions of the Gulf of Mexico. In Venezuela, the temperature, which is from $87^{\circ}$ to $90^{\circ}$ in March, rises to $104^{\circ}$ or $105^{\circ}$, whenever the wind blows from the parched surface of the llanos or great plains. Siberia, and the northern parts of North America, have their cold greatly increased by the polar winds, which are not intercepted by mountains, in addition to the effects of a northern declivity. But the same wind, in various conntries, will produce opposite effects upon the temperature at different seasons of the year. Poeppig mentions a singular instance of this in the southern districts of Chili. The east winds, called los Puelches, blowing in spring, are so cold as rapidly to depress the temperature $15^{\circ}$ or $18^{\circ}$; but towards the end of summer they raise it nearly as much. The former effect is attributed to the deep snow lying in spring upon the Andes chilling the adjacent air, and the latter to the heat which the sandy pampas of Buenos Ayres acquire in the summer months. The east winds of England exhibit this alternating character. Late in spring, having passed over the plains of the Baltic, yet bearing the chill of winter, they are cold; but in autumn, they are warm enough to raise the temperature, the sandy plains in their passage having been heating through the summer.

The preceding causes are those by which physical climate is chiefly determined. A few results of observation respecting the mean annual temperature in different localities, and seasonal temperature, may now be stated, chiefly upon the authority of Humboldt, Dove, Kaemtz, and other meteorologists.

The mean temperature of a locality is the average of heat and cold throughout the year, and may be obtained by observing at stated periods, during each day, the indications of the thermometer, taking a series of such observations continued through an interval of ten or fifteen years. This is a tedious and protracted process, and the lessons of experience have superseded the necessity for it to some extent. Thus, the mean temperature of the

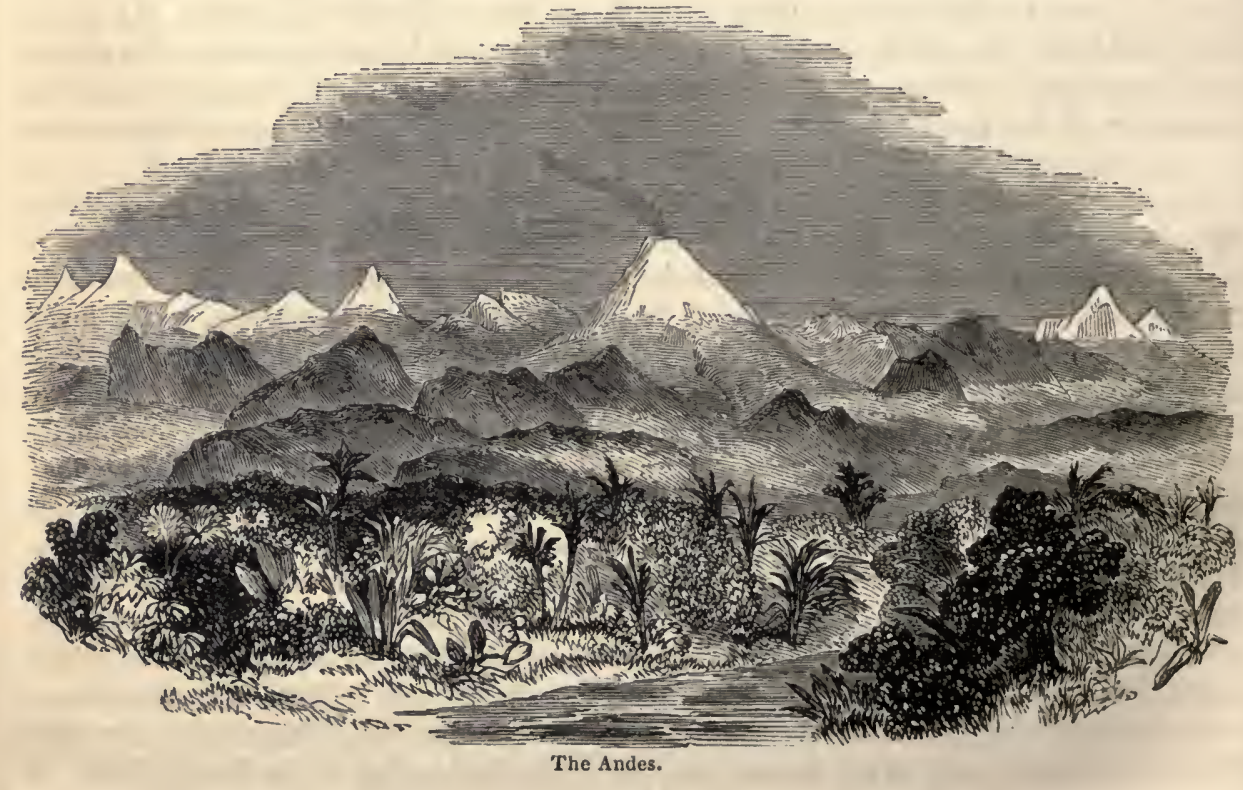


day may always be obtained by three readings of the thermometer, namely, at sunrise, at two o'clock in the afternoon, and at sunset ; and then dividing the sum of the temperatures by three. When the mean temperature of all the days of the month bas been found, the sum of the diurnal temperatures divided by the number of days, gives the mean temperature of the month. In like manner, the sum of the mean monthly temperatures in the year divided by the number of months, gives the mean temperature of the particular year. By comparing a series of these annual returns, and striking the average, the standard annual mean temperature of a place is deduced. It is a curious and highly useful result of thermometric observation, that at many places in the north temperate zone, where alone meteorological notices have been multiplied, the mean temperature for the months of April and October is identical, or very nearly so, with the mean temperature of the year. The close approximation of the mean temperature of these months to the annual mean is apparent from the comparison in the table; and is most conspicuous with reference to October.

\begin{tabular}{|c|c|c|c|c|c|c|c|}
\hline \multirow{2}{*}{ Places. } & \multicolumn{3}{|c|}{ Mean Temperature. } & \multirow{2}{*}{ Places. } & \multicolumn{3}{|c|}{ Mean Temperature. } \\
\hline & o: the Year. & Of October. & Of April. & & Of the Year. & Of October. & Of April. \\
\hline Cairo & $72 \cdot 5^{\circ}$ & $72 \cdot 3^{\circ}$ & $77 \cdot 9^{\circ}$ & Gottingen & $46.9^{\circ}$ & $47 \cdot 1$ & $44 \cdot 4$ \\
\hline Algiers & $69 \cdot 8$ & $72 \cdot 1$ & $62 \cdot 6$ & Franeker & $52 \cdot 3$ & $54 \cdot 9$ & $50 \cdot 0$ \\
\hline Natchez & $65 \cdot 0$ & $68 \cdot 4$ & $66 \cdot 4$ & Copenhagen & $45 \cdot 7$ & $48 \cdot 7$ & $41 \cdot 0$ \\
\hline Rome & $60 \cdot 4$ & $62 \cdot 1$ & $55 \cdot 4$ & Stockholm & $42 \cdot 3$ & $42 \cdot 4$ & $38 \cdot 5$ \\
\hline Milan & $55 \cdot 8$ & $58 \cdot 1$ & $55 \cdot 6$ & Christiana & $41 \cdot 6$ & $39 \cdot 2$ & $42 \cdot 6$ \\
\hline Cincinnati & $53 \cdot 6$ & $54 \cdot 9$ & $56 \cdot 8$ & Upsal & $41 \cdot 7$ & $43 \cdot 3$ & $39 \cdot 7$ \\
\hline Philadelphia & $53 \cdot 4$ & $54 \cdot 0$ & $53 \cdot 6$ & Quebec & $40 \cdot 9$ & $42 \cdot 8$ & $39 \cdot 6$ \\
\hline New York & $53 \cdot 8$ & $54 \cdot 5$ & $49 \cdot 1$ & Petersburg & $98 \cdot 8$ & $39 \cdot 0$ & $37 \cdot 0$ \\
\hline Pekin & $52 \cdot 7$ & $55 \cdot 4$ & $57 \cdot 0$ & Abo & $40 \cdot 4$ & $41 \cdot 0$ & 408 \\
\hline Buda & $51 \cdot 1$ & $52 \cdot 3$ & $49 \cdot 1$ & Drontheim & $41 \cdot 7$ & $39 \cdot 2$ & $34 \cdot 3$ \\
\hline London & $50 \cdot 8$ & $52 \cdot 3$ & $49 \cdot 8$ & Uleo & $33 \cdot 1$ & $37 \cdot 9$ & $34 \cdot 2$ \\
\hline Paris & $51 \cdot 1$ & $51 \cdot 3$ & $48 \cdot 2$ & Umeo & $35 \cdot 3$ & $37 \cdot 8$ & 34.0 \\
\hline Geneva & $49 \cdot 3$ & $49 \cdot 3$ & $45 \cdot 7$ & North Cape & $32 \cdot 0$ & $32 \cdot 0$ & $30 \cdot 2$ \\
\hline Dublin & $48 \cdot 6$ & $48 \cdot 7$ & $45 \cdot 3$ & Enontekies & $27 \cdot 0$ & $27 \cdot 5$ & $26 \cdot 6$ \\
\hline Edinburgh & $46 \cdot 8$ & $48 \cdot 2$ & $46 \cdot 9$ & Nain & $25 \cdot 4$ & $33 \cdot 1$ & $27 \cdot 5$ \\
\hline
\end{tabular}

In almost all northern latitudes, January or February is the coldest month of the year, and July or August the warmest. The greatest cold during the day is usually about an hour before sunrise. The greatest heat in latitudes between $35^{\circ}$ and $60^{\circ}$ is from two to three o'clock, and from one to two o'clock between the equator and $35^{\circ}$.

The mean temperature of different months, in various places, takes a very wide range above and below the mean annual temperature, and constitutes what Buffon has indicated by the name of "excessive" climates, where the winter and summer are in violent contrast. 'These are chiefly found in North and Eastern Europe, in Asia and America.

'The climates of the northern United States, Canada, a great part of Russia, and northern China, are among the most "excessive," the winters and summers strongly contrasting in their temperature. Thus, at New York, says Humboldt, we find the summer of Rome and the winter of Copenhagen. At Quebec, grapes sometimes ripen in the open air, whereas the winter is that of Petersburgh, during which the snow lies five feet deep for several months, and travelling is performed in sledges, frequently on the ice of the St. Lawrence. At Pekin in China, where the mean temperature of the year is that of the coasts of Brittany, the scorching heats of summer are greater than at Cairo, and the winters as rigorous as at Upsal. These violent contrasts render such climates trying to the constitution of a western European, unused to such extremes of temperature, the excessive heat of summer, after the rigour of winter, increasing the irritability of the nervous system. 


\begin{tabular}{|c|c|c|c|c|c|}
\hline Places. & Latitude. & $\begin{array}{l}\text { Coldest } \\
\text { Month. }\end{array}$ & $\begin{array}{l}\text { Warmest } \\
\text { Month. }\end{array}$ & Difference. & Observations. \\
\hline Cumana & $10^{\circ} 27^{\prime}$ & $80 \cdot 1^{\circ}$ & $84 \cdot 4^{\circ}$ & $4 \cdot 3^{\circ}$ & Uninterrupted trade winds. \\
\hline Pondicherry & 1155 & $76 \cdot 1$ & $91 \cdot 4$ & $15 \cdot 3$ & Monsoons. Radiation of the sands. \\
\hline Manilla & 1436 & $68 \cdot 0$ & $86 \cdot 9$ & $18 \cdot 9$ & Monsoons, \\
\hline Vera Cruz & 19 & $70 \cdot 0$ & $81 \cdot 7$ & $11 \cdot 7$ & North winds in winter. \\
\hline Cape Français & 46 & $77 \cdot 0$ & $86 \cdot 0$ & $9 \cdot 0$ & Uninterrupted trade winds. \\
\hline Havannah & 10 & 700 & $83 \cdot 8$ & $13 \cdot 8$ & North winds in winter. \\
\hline Funchal & 37 & $64 \cdot 0$ & $75 \cdot 6$ & $11 \cdot 6$ & Insular climate. \\
\hline Natchez & 28 & $46 \cdot 9$ & $78 \cdot 8$ & $31 \cdot 9$ & Transatlantic region. Interior. \\
\hline Cincinnati & 39 & $29 \cdot 6$ & $74 \cdot 4$ & $44 \cdot 8$ & Same system of climate. \\
\hline Pekin & 39 & $24 \cdot 8$ & $84 \cdot 2$ & $59 \cdot 4$ & Region of Eastern Asia. \\
\hline Philadelphia & 56 & $29 \cdot 8$ & $77 \cdot 0$ & $47 \cdot 2$ & Transatlantic region. Eastern coasts. \\
\hline New York & 40 & $25 \cdot 3$ & $80 \cdot 8$ & $55 \cdot 5$ & Dittu. \\
\hline Rome & 53 & $42 \cdot 1$ & $77 \cdot 0$ & $34 \cdot 9$ & Cisatlantic region. \\
\hline Milan & 28 & $93 \cdot 8$ & $55 \cdot 2$ & $21 \cdot 4$ & Interior land. \\
\hline Buda & 29 & $27 \cdot 7$ & $71 \cdot 6$ & $49 \cdot 9$ & Ditto. \\
\hline Paris & 50 & $35 \cdot 1$ & $69 \cdot 8$ & $34 \cdot 7$ & Nearer the western coast. \\
\hline Nantes & 13 & $39 \cdot 0$ & $70 \cdot 0$ & $31 \cdot 0$ & Ditto. \\
\hline Upsal & 07 & $24 \cdot 2$ & $61 \cdot 8$ & $37 \cdot 6$ & North Europe. \\
\hline Quebec & 46 & $14 \cdot 0$ & $73 \cdot 4$ & $59 \cdot 4$ & Transatlantic region. Eastern coast. \\
\hline Dublin & 53 & $37 \cdot 6$ & $60 \cdot 3$ & $22 \cdot 7$ & West Europe region. Insular climate. \\
\hline Edinburgh & 55 & $98 \cdot 3$ & $59 \cdot 4$ & $2 I \cdot 1$ & Ditto. \\
\hline Warsaw & 52 & $27 \cdot 1$ & $70 \cdot 3$ & $43 \cdot 2$ & Interior land. \\
\hline Petersburgh & 56 & $8 \cdot 6$ & $65 \cdot 7$ & $57 \cdot 1$ & East of Europe. \\
\hline North Cape & 71 & $22 \cdot 1$ & $46 \cdot 6$ & $24 \cdot 5$ & Climate of coasts and islands. \\
\hline
\end{tabular}

The greatest difference between the temperature of the warmest and the coldest months registered in the above table amounts to $59^{\circ}$, at Quebec and Pekin. But the contrast is far stronger at Yakutsk, in Siberia, which has a January temperature of $43^{\circ}$ below zero, alternating with a July temperature of $70^{\circ}$, the difference between the extremes amounting to $113^{\circ}$.

The farther we recede from the equator to the poles, the greater is the difference between the mean temperature of summer and winter.

\begin{tabular}{|l|c|c|c|c|}
\hline & \multirow{2}{*}{ Latitude. } & \multicolumn{2}{|c|}{ Mean Temperature. } & Difference. \\
\cline { 2 - 4 } & & of winter. & of Summer. & \\
\hline Algiers & $37^{\circ}$ & $61 \cdot 5^{\circ}$ & $80 \cdot 2^{\circ}$ & $18 \cdot 7^{\circ}$ \\
Buda & $47 \frac{1}{2}$ & $34 \cdot 0$ & $70 \cdot 5$ & $26 \cdot 5$ \\
Upsal & 60 & $26 \cdot 0$ & $60 \cdot 2$ & $35 \cdot 2$ \\
\hline
\end{tabular}

But, however great the oscillations of the thermometer in the course of a single year, a comparison of years shows that the mean annual temperature in every place is remarkably uniform, and seldom varies from the standard peculiar to the locality to any extent, even in those years that are marked by excessive scasonal heat or cold. Thus, in the year 1788, when the frost was so serere at London that the Thames was passable on the ice, the mean temperature for that year was within the fraction of a degree of the standard. This was the case also in 1796, when the greatest cold that was ever observed at London occurred; and in 1813-14, when the Thames, Tyne, and other large rivers werc completely frozen over, the variation amounted to little more than a degree below the standard. When also, in 1808, the summer was so hot in London that the thermometer stood at $93 \frac{1}{2}^{\circ}$, the mean temperature for the year did not rise above the usual arerage. A large collection of data justifies the remark of Humboldt, that the quantity of heat which any point of the globe receives, is much more equal during a long series of years than we should be led to believe from the testimony of our sensations and the variable product of our harvests. It is more a change in the distribution of the heat through the 
different months, than a failure in the mean temperature, that disappoints the expectations of the husbandman, and causes a scanty crop. A comparison of twenty jears at Geneva exhibits but slight variations of the mean temperature.

\begin{tabular}{cc|c} 
Years. & Mean Temp. & Years. \\
1796 & $49 \cdot 3^{\circ}$ & 1801 \\
1797 & 50.5 & 1802 \\
1798 & 50.0 & 1803 \\
1799 & 48.7 & 1804 \\
1800 & 50.5 & 1805
\end{tabular}

\begin{tabular}{c|l} 
Mean Temp. & Years. \\
$51 \cdot 1^{\circ}$ & 1806 \\
$50 \cdot 9$ & 1807 \\
$50 \cdot 4$ & 1808 \\
$51 \cdot 1$. & 1809 \\
$47 \cdot 8$ & 1810
\end{tabular}

Mean Temp.
$51 \cdot 4^{\circ}$
$49 \cdot 3$
$46 \cdot 9$
$48 \cdot 9$
$51 \cdot 1$

Mean of twenty years $49 \cdot 7^{\circ}$.

The mean temperatures of seven of the summers were -

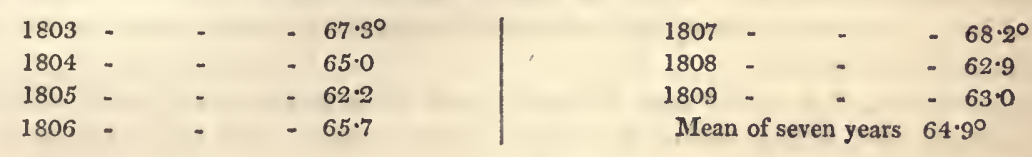

M. Arago states, that in the two years 1815 and 1816, the last of which was destructive to the crops in a great part of France, the difference of the mean annual temperature was only two degrees from the standard. In the interval between 1803 and 1813, the oscillations from the standard never went beyond it by more than $3.4^{\circ}$, or fell short of it by more than $2 \cdot 9^{\circ}$. It thus appears, that, though temperature is continually varying, and exhibits occasionally extraordinary degrees of heat and cold, there is great uniformity in the mean condition of climate. It las been justly observed, that could we obtain a clear insight into the complex machinery which regulates the seasons, we should behold the same beautiful harmony, and the same system of compensation for temporary and apparent irregularities, which we are able to discern in the movements of the heavenly bodies.

In order to exhibit a more distinct view of the distribution of temperature, Humboldt originated the convenient plan of connecting places which have the same, or nearly the same, annual temperature, in lines on the charts, called isothermal, signifying lines of equal heat. With indefatigable industry he made observations on both continents for this purpose, consulted the records of modern travel, and the European registers of observed temperature; while the situation of particular plants furnished an index of practical importance, and sometimes of greater certainty than the tables of thermometrical heat, on account of the inaccuracy of instruments, or the unskilful use of them.- The isothermal lines strikingly illustrate the operation of other causes besides the solar action in the constitution of climate, otherwise they would be curves coincident with the parallels of latitude. In the torrid zone this is nearly the case; but in the temperate and frigid zones they become very irregular, ascending towards the pole in Western Europe and America, and sinking towards the equator in Eastern Asia and America. The annexed meteorological map of the world, constructed by Dr. Petermann, shows the distribution of the temperature of the air by isothermal lines, as far as adequate data exist for the purpose, the entire course of which remains to be ascertained. The figures attached to each curve indicate the mean annual temperature of the region traversed by it. A glance at the map shows the divergence of the lines of equal heat from those of equal latitude. In Europe they are convex with reference to the Pole; in Asia and America, concave; becoming less and less concave as they approach the equator.

In the northern hemisphere, the curve line on the map, indicating the mean annual temperature of $80^{\circ}$, crosses central America about the Gulf of Honduras, passes north of 
Jamaica, and through St. Domingo, descending across the Atlantic to the west coast of Africa, which it cuts a little above Sierra Leone. It rises in that continent to the northern tropic, runs closcly parallel to it through Arabia to Hindostan, descends in that peninsula, and cuts descendingly Siam and Cochin China, intersecting the group of the Philippines to the south. This line forms the north boundary of the hot zone, coloured deep carmine on the map, in which the warmth equator, distinguished by a deeper shade, shows the districts of the greatest heat, which have temperatures varying from $81^{\circ}$ to $88^{\circ}$. The warmth equator, it will be perceived, does not coincide with the geographical; but lies almost wholly to the nortl of it, attaining its greatest distance in eastern Africa. It passes along the north coast of South America, intersects Africa from the Gulf of Guinea to Ábyssinia, and cuts the extremities of the southern peninsulas of Asia. The minimum temperature, $81^{\circ}$, occurs at sea in various places; the maximum, $87.3^{\circ}$, the greatest heat hitherto observed, at Massowah in Abyssinia, much nearcr to the northern tropic than to the equator.

The isothermal line of $70^{\circ}$ cuts the west coast of America in the south of California about latitude $25^{\circ}$, falling below the tropic in the interior, and rising above it on the opposite coast. It passes by the delta of the Mississippi, through East Florida, north of St. Augustine, in about latitude $30^{\circ}$, reaches the coast of Africa above the Canary Islands, ascends towards Tunis about latitude $34^{\circ}$, runs througl the Mediterranean south of Candia, enters Syria north of Beirout, traverses Asia south of the Hindoo-Koosh and Himalaya mountains, descends in China nearly to the tropic. This line marks the nortl boundary of the warm zone, coloured light carmine on the map, and is generally the southern limit of the fall of snow at the sea level.

The isothermal line of $50^{\circ}$, central to the temperate zone, passes from Fort George at the mouth of the Columbia river, on the west coast of America, latitude $46^{\circ}$, descends in the interior, and reaches the shores of the Atlantic near New York, latitude $41^{\circ}$. It then rises abruptly to latitude $56^{\circ}$ in the north Atlantic, descends by Dublin, London, and through Midland Europe to the mouth of the Danube, latitude $45^{\circ}$, cuts the north of the Black and Caspian Seas, falls in the interior of Asia; rising on the eastern const.

The isothermal line of $30^{\circ}$, indicating an average temperature below the freezing point, lenves the west coast of America in latitude $61^{\circ}$, rises and declines in the interior, falling to latitude $53^{\circ}$ on the shores of Labrador. It then ascends abruptly to latitude $74^{\circ}$ in the Arctic ocean, and passing round the North Cape of Europe, as abruptly descends to latitude $50^{\circ}$ in the interior of Asia. This line marks the southern limit of permanently frozen ground, which, in Asia, occurs in a latitude as low as that of London.

The isothermal lines, indicating a lower degree of temperature, can only be traced with certainty through portions of their course.

It has been already stated that places where the mean annual heat is the same vary considerably in their mean summer and winter temperatures. Hence isocheimal lines, or lines of equal winter temperature, and isotheral lines, or those which show equal summer, unite points which are upon different isothermal curves. 'Thus Belgium on the isothermal line of $51^{\circ} 8^{\prime}$, Scotland on that of $45^{\circ} 5^{\prime}$, and Milan on that of $55^{\circ} 8^{\prime}$, under widely different parallels of latitude, are on the same isocheimal line. Moscow also, and the mouth of the Loire, are on the same isotheral line, notwithstanding a difference of $11^{\circ}$ of latitude; and London and Pekin are on the same isothermal curve, though on widely different lines of mean summer and winter temperature.

Isogeothermal lines are curves connecting points where the temperature of the ground is equal, at or below the surface of the earth. The interior temperature of the earth is measured by that of subterranean excavations, natural or artificial, and by that of springs. It appears to decrease, as might be expected, from the plains to the tops of mountains: - 


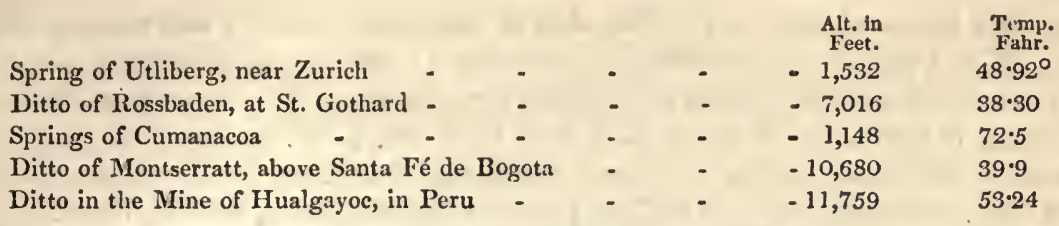

The interior temperature appears to increase as we approach the equator.

\begin{tabular}{lllllll} 
& & & \multicolumn{2}{c}{ Lnt. } & Depth in Feet. & Temp. \\
Salt Mines at Wielicksa, in Poland & - & - & - & $-50^{\circ}$ & 320 & $50^{\circ}$ \\
Joseph's Well, at Cairo, in Egypt - & - & - & - & -30 & 210 & 70 \\
Mines of Mexico - & - & - & - & -20 & 1650 & $74 \frac{3}{4}$
\end{tabular}

In equinoctial regions the heat of the earth at but a short distance below the surface, and that of permanent springs, is nearly uniform at all seasons, and usually corresponds to the mean annual temperature of the external air; but beyond latitude $45^{\circ}$ the mean heat of springs and caves is generally above that of the atmosphere. At Enontekies, at the parallel of $68 \frac{1}{2}^{\circ}$, the difference between the mean temperature of the earth and of the air amounts to $7 \cdot 74^{\circ}$. Humboldt accounts for this by referring to the thick stratum of snow which covers the earth in high latitudes, and prevents the loss of heat during the winter months, by radiation, and by the contact of cold winds. But we have striking and sufficient evidence that the superficial shell of the globe is not only heated by the solar impressions, but is raised to a temperature at some distance from the surface above that of the ambient air, by the action of its own deep-seated fires. There is strong reason to suppose that below the solid crust of the earth upon which we dwell, the next contiguous matter is in a state of fusion, at a temperature higher than any that man can produce by artificial means. Hence, onitting all reference to the active volcanoes, and to thermal springs at all temperatures below that of boiling water, found in all parts of the world, it is a well-known fact, that in descending into deep mines the temperature is greatly above that of the mean of the exterior air, and increases progressirely with the depth. This was first remarked by Gensanne, about the year.1740, in the lead mines of Giromagny, near Béport. Saussure afterwards observed the same fact in the salt mines at Bex, in Switzerland; but the attention of naturalists was not generally directed to the temperature of the lower strata, till Humboldt had executed an extensive and interesting series of experiments in the mines of Freyburg, in 1791. The best set of observations we possess on the temperature of deep places, is that which has been uninterruptedly continued for more than half a century in the caves under the observatory of Paris. In 1783 the Count de Cassini, in concert with Lavoisier, placed a very delicate thermometer in one of these excavations, for the purpose of observing the curious phenomenon of an invariable temperature, which had been noticed to exist in the same place, by the first Cassini, in 1671, and by La Hire, in 1730. The thermometer is placed at the depth of rather more than thirty yards under the surface, in a bed of fine sand, and has indicated no change of temperature, or at least its oscillations have not exceeded the $\frac{1}{33}$ of a centesimal degree. The constant temperature exceeds at that depth, by $2 \cdot 16^{\circ}$ of Fahrenheit's scale, the mean temperature at the surface: and supposing a uniform increase at the same rate, we should arrive at the temperature of boiling water at the depth of 2542 yards under the city of Paris. We may quote a few other results of observation. In the coal mines of the north of England the temperature is $70^{\circ}$ at the depth of 800 or 900 feet, when the air at the surface is only $48^{\circ}$ or $49^{\circ}$; and in the mines of Valenciana in Mexico, it is $92^{\circ}$ when the surface-air is at $60^{\circ}$. The following are additional examples :-

In a copper mine at Dolcoath, in Cornwall, a thermometer was kept eighteen montlis buried in the rock to the depth of a yard. The depth of the mine was 1377 feet. The 
temperature indicated was $75.5^{\circ}$, while that of the country is $50^{\circ}$; and consequently the increase of heat there is at the rate of $1^{\circ}$ for every 54 feet.

At Giromagny, in the Vosges, the annual temperature at the surface is $49^{\circ}$; at 330 feet depth it is $53.6^{\circ}$; at 1008 feet, $65.8^{\circ}$; at 1416 feet, $74.6^{\circ}$.

In four of the deepest mines of Saxony the annual temperature at the surface is $46.4^{\circ}$; at from 510 to 600 feet depth, it is $54.5^{\circ}$; at 840 feet, $58^{\circ}$; at 1080 feet, $62.6^{\circ}$.

In the deepest British coal mine, that of Killingworth, the annual temperature at the surface is $48^{\circ}$; at 900 feet depth it is $70^{\circ}$; at 1200 feet, $77^{\circ}$. A similar gradation is found in many of the deeper mines at home and abroad.

There is thus in the Vosges an increase of temperature in descent below the surface amounting to about $1^{\circ}$ in every 60 feet; in Saxony $1^{\circ}$ in every 66 feet; and in Britain $1^{\circ}$ in every 45 feet. After the ratio observed in the Vosges, the temperature of the hot springs at Bath, $113^{\circ}$, will be found at three-quarters of a mile in the interior of the earth, and that of boiling water at a depth of nearly two miles. "The facts strongly support three conclusions:- First, that the heat of an interior shell of the earth is greater than the superficial shell. Second, that this heat augments progressively as we descend towards this region, in a ratio bearing some relation to the depth. Third, that, even at moderate depths, this heat is greater than the mean heat of the globe ought to be, if entirely derived from the sun. The heat of such an interior mass must be constantly diffusing itself towards the surface; and at the surface it may be kept down, so as to affect the temperature derived from the solar action very feebly, by the greater or less rapidity of its dissipation. But as it is very improbable that it should be diffused with perfect equality round the whole exterior shell of the globe, it may be the true source of some of those anomalies of climate, such as the discrepancy in the annual heat under the same parallel, which cannot be easily referred to other known causes." If the heat of the globe were entirely derived from the sun, Pekin, at an inconsiderable elevation above the sea, ought to have the same mean annual temperature as Naples, being under the same parallel of latitude; but instead of this being the case, the temperature falls short of that at Naples by nearly $9^{\circ}$. Other causes may contribute to produce this discrepancy; yet it is not unreasonable to suppose that the mean heat at Naples is raised by its proximity to a focus of internal leat which smokes and flashes through the chimney of Vesuvius.

No reference has yet been made to physical climate in the southern hemisphere, respecting which opinion has recently been considerably modified. The idea long prevailed that the whole region south of the equator had a much lower temperature than the northern side; but it is now sufficiently ascertained, that there is no discrepancy whatever in its equinoctial districts. The Isle of France has the same annual temperature, $80 \cdot 1^{\circ}$, as Jamaica and St. Domingo, under a corresponding northern parallel. The mean temperature at Rio Janeiro is $74.5^{\circ}$, and at Havannah, at a similar latitude north, it is $76.4^{\circ}$. The amount of annual heat about the parallel of $34^{\circ}$ of south and north latitude exhibits a remarkable equality, as appears from the following comparison:-

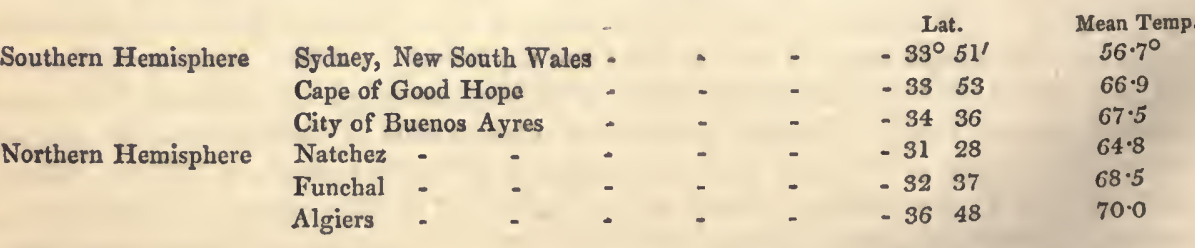

Under the parallel of $51^{\circ} 25^{\prime}$ south, the mean temperature of the Falkland Isles is $47.3^{\circ}$; and at the same latitude north we find the mean temperature in Europe from $50^{\circ}$ 


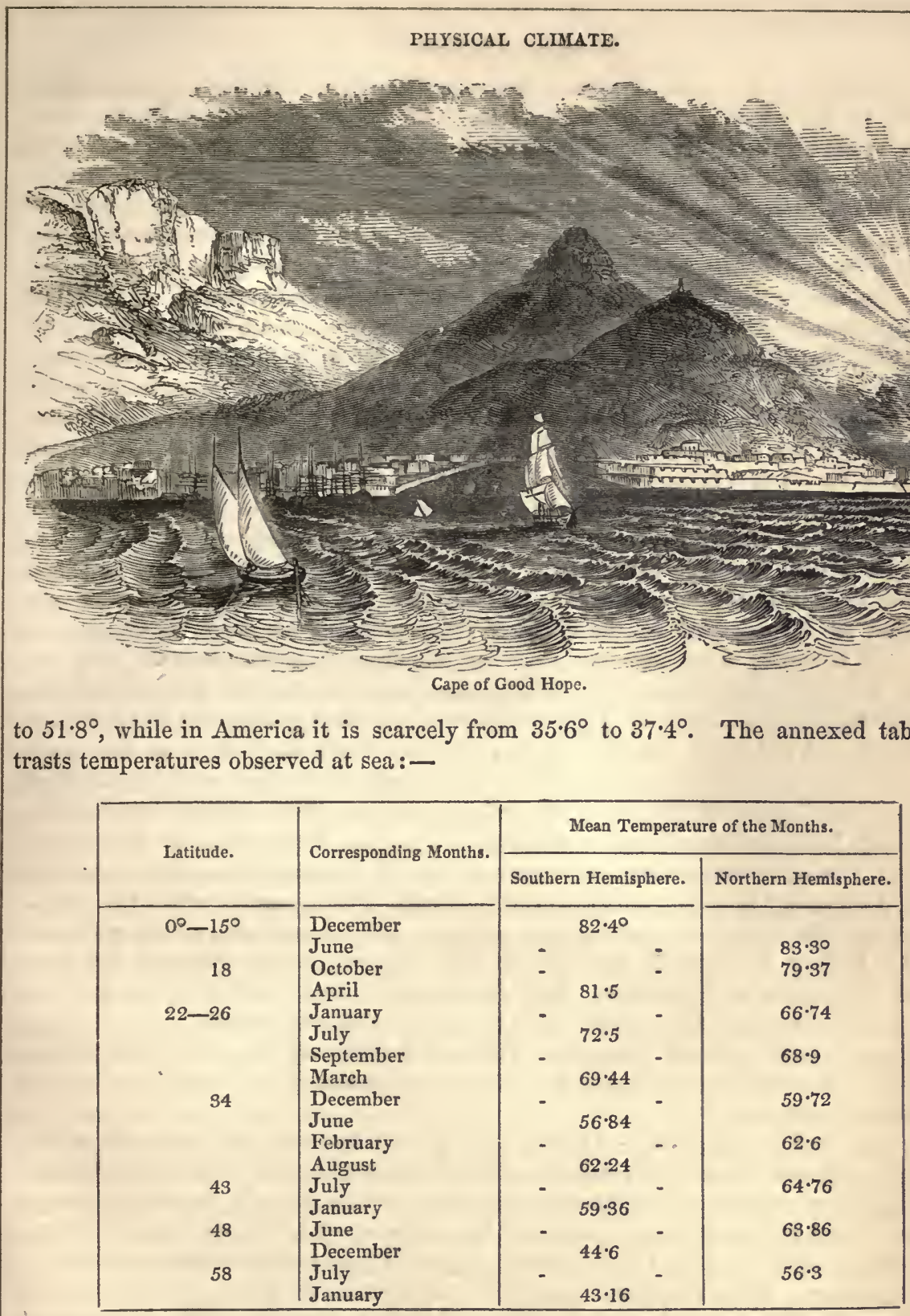

It may be concluded, therefore, that as far as $40^{\circ}$ of latitude, the warmth of the southern hemisphere is equal to that of the northern, while, considering the Transatlantic climates apart from the Cisatlantic, it is certain that the mean temperatures of the year, within the bounds referred to, under the corresponding geographical parallels, are even greater in South than in North America. Beyond those limits the southern hemisphere appears to have a lower temperature than the northern. Hence large masses of ice descend towards the equator from the southern pole to a much greater distance than is the case in the northern seas. During the surveying voyages of the Adventure and 
Beagle, along the south coast of South America, the glacier furthest from the pole, descending to the sea coast, was found in latitude $46^{\circ} 50^{\prime}$, in the Gulf of Penas; but a few miles to the north of this glacier, in the Laguna de San Rafael, some Spanish missionaries encountered icebergs, in a narrow arm of the sea, on the $22 \mathrm{~d}$ of the montl corresponding with our June, and in a latitude answering to that of the Lake of Geneva ! According to Von Buch, the most southern European glacier which comes down to the sea is met with on the coast of Norway in latitude $67^{\circ}$. This is more than $20^{\circ}$ of latitude, or 1230 miles nearer the North Pole than the Gulf of Penas is to the South. Mr. Darwin puts the occurrence of this glacier in the southern hemisphere in a striking point of view, by remarking, that it descends to the sea-coast within $7 \frac{1}{2}^{\circ}$ of latitude, or 450 miles of a harbour, where three species of oliva, a voluta, and a terebra, are the commonest shells, within less than $9^{\circ}$ from where palms grow, within $4 \frac{1}{2}^{\circ}$ of a region where the jaguar and puma range over the plains, less than $2 \frac{1}{2}^{\circ}$ from arborescent grasses, and, looking to the westward in the same lemisphere, less than $2^{\circ}$ from orchideous parasites, and within $1^{\circ}$ of tree-ferns! In South Georgia, an island discovered by Cook in lis cruise of 1775 , in latitude $53^{\circ}$, answering to the parallel which passes over the central counties of England, the eternal snows come down to the sea-shore, while the curve of perpetual congelation with us is at the leight of more than 5000 feet. The perpetual snow does not descend to the sea-level on the north of the equator till we arrive at the parallel of $80^{\circ}$, which is twenty-seven degrees nearer the pole than the point where the same fact transpires in the southern hemisphere. This greater degree of cold was at first attributed to an astronomical cause - that of the acceleration of the earth's motion in its perihelion, in consequence of which the sun is a shorter time, by nearly eight days, on the south, than on the north side of the equator. But the true cause is undoubtedly geographical, the great preponderance of the ocean in southern regions, which radiates less absolute heat than dry land, and contributes to diminish the annual temperature of that part of the globe. 'The same cause, however, operates to free the south-temperate zone from "excessive climates," or those violent seasonal contrasts of temperature which the AngloAmerican and the inhabitants of Pekin experience, mild winters alternating with cold summers. Sydney, in a latitude answering to that of Cairo, has the winter of the latter city, and the summer of Marseilles. In Van Diemen's Land, corresponding nearly in latitude to Rome, there is the summer of Paris and the winter of Naples.

We may now cast a general glance over different districts of the globe which present strongly-marked diversities of climate and productions, confining our attention chiefly to the northern hemisphere.

Equatorial and Hot Regions. - These occupy a zone extending on each side of the line to a few degrees beyond the northern and southern tropic. As before remarked, the mean temperature appears to be higher in situations verging towards the tropics than at the equator; and by this is to be understood the temperature of the air near the surface of the earth, as determined by a thermometer, protected from radiation and every kind of foreign influence. Thus the mean equatorial temperature is given by Humboldt at $81 \frac{1}{2}^{\circ}$; but at Pondicherry, in latitude $11^{\circ} 55^{\prime}$ north, it is at least $85^{\circ}$. This is the region of the finest spices, the sugar-cane, the palm and banana tribes. It includes the islands and continent of Southern Asia, the middle and northern countries of Africa, and the central parts of America. In its level midland portions, frost and snow are unknown, and the uncivilised natives of various localities have often deemed the statement a fable of the Europeans, that rivers became solidified by cold. In the well-watered countries, the trees are covered with perpetual verdure, the fields exhibit a constant carpet of beautiful and odoriferous flowers, and the only season resembling winter is the season of rain; but after the rains, the heat occasions noxious exhalations from the fruitful soils, and espe- 
cially from the marshy districts, which originate formidable remittent and continued fevers, the well-known scourges of hot climates. The dry portions of this zone are sandy or stony wastes, with little or no vegetation except in a few oases, and with scarcely an animal besides the camel. Towards the tropics, the temperature is less equable than at the equator; the seasonal heat is excessive; and travelling, or any kind of exertion, through several hours of the day becomes impossible. The wooden furniture in dwellings warps and shrinks; glass is sometimes cracked; thirst is continual; the body is debilitated; all disposition to effort is destroyed; and motion often becomes painful. The sun-stroke, or coup-de-soleil, is the frequent consequence of exposure to the intensity of the solar action, and was fatal to numbers in the crusading armies, who, unaware of danger, encountered the fierce beams of mid-day on the plains of Syria.

Warm Regions. - These extend from the northern limit of the sugar-cane to the northern boundary of the olive and the fig ; and include the southern districts of Europe, part of midland and south-western Asia, and portions of the southern United States. The frosts here are not severe in the plains; snow is also rare; and the rivers are seldom frozen over. The winters are more distinguished by dampness than cold, resembling the spring of the temperate regions. Vegetables on the south of this zone grow during seven or eight months in the year, and the trees are not stripped of their foliage more than two months. The air of the European warm regions is in general clear and salubrious; but, owing to the abundance of vegetation, and numerous marshes in corresponding transatlantic climates, noxious effluvia are continually formed. The autumns are uniformly sickly; and the countenances of the inhabitants have a pale and sallow cast, instead of the bloom and freshness which belong to those of more northern districts, or to the brunette of the southern Europeans.

Temperate Regions. - This zone reaches from the northern limit of the olive and fig to that of the wine-grape, and has a mean temperature varying from $50^{\circ}$ on the northern border to $59^{\circ}$ on the southern. The transition from winter to summer is here gradual, and the four seasons are distinctly marked. The winter is commonly from three to five months long in the northern parts, attended with a considerable quantity of snow ; and the waters are often strongly frozen. In the southern parts, the winter does not exceed two or three months; the fall of snow is less, and the frosts are seldom severe. Grain, regetables, and many fine fruits are produced in abundance, with excellent pasturage, but the fruits often ripen with difficulty, and the harvests are injured by moisture and rains. France, Germany, and southern Russia are included in this region, with Holland, Belgium, England, and Ireland, on account of their maritime situation. The same climate characterises a part of the east coast of Asia, the northern and midland United States, the interior country south of Lake Huron, and the basin of the Columbia rirer. At Nootka Sound the rivers do not freeze until January; and at the mouth of the Columbia, the first frost observed by Lewis and Clark was in that month.

Cold Regions. - The country in Europe between the wine-grape and the northern limits of the oak, is included in this zone, or midland Russia and southern Scandinavia, with southern Siberia in Asia, and the British provinces in North America. The summers are short, hot, and oppressive, and the winters severe and protracted. Nearly six months in the year, the temperature of Stockholm and Petersburg is below the freezing point. The rivers are frozen during that period; the snow is permanent; and the wolf becomes dangerous to the traveller. The air, keen and penetrating, is remarkably clear, still, and salubrious. Where the ground is clear of timber, and level, the winter-picture is that of a frozen sea, which spreads for many a shining league, the sun often careering through the heavens cloudless from morn till night, and then giving place to the moon, soft, clear, and yellow, the rim strongly and beautifully defined on the 
deep concave of the sky. "There is something," observes the authoress of the spirited Letters from the Baltic, "very exhilarating in this breathless, still, bright cold - with a clean white expanse, a spotless world, before you - every tree fringed-every stream stopped-freedom to range over every summer impediment; while the erystal snow, lighting up into a delicate pink, or pearly hue, or glittering with the brightest prismatic colours beneath the clear, low sun, and assuming a beautiful lilac or blue where our long shadows intercept his rays, can no longer be stigmatised as a dead lifeless white." The thermometer is frequently several degrees below zero. The severity of the cold appears in icicles pendant from the eye-lashes of the Russian boor, and the conversion of his beard into a lump of ice from the congelation of the vapour of his breath. The most singular feature of this zone is the rapidity with which the change from winter to summer transpires, observable in Canada as well as in northern Europe. The spring is almost obliterated as a season. The snow melts, the hard-frozen ground is unlocked, and the rivers are unsealed with astonishing quickness; and a few days will suffice for the transition of the trees from wintry nakedness to the sprouting out of their full complement of leaves.

Frozen Regions. - This zone extends from the northern boundary of the oak to the pole, and is of much narrower dimensions in Europe than in America and Asia. . The birch, the hardiest of trees, generally ceases to grow about latitude $70^{\circ}$ in Europe, where man is compelled to give up the cultivation of grain. Shrubs and bushes linger on farther north; grasses and lichens then are only to be met with; and eternal snows and ice succeed. In regions north of $59^{\circ}$ in Asia, $71^{\circ}$ in Europe, and $54^{\circ}$ in America, the mean annual temperature is below the freezing point. In winter brandy and mercury freeze. Around Hudson's Bay and in North Siberia, lakes and standing waters of no great depth are frozen to the bottom; the inhabitants remain crowded together in small huts; and if the cold air suddenly enters a habitation, the vapours fall in a shower of snow. Notwithstanding the efforts of our enterprising countrymen, the central region of this zone, the geographical pole of the world, has not been reached, and consequently the mean temperature is yet a matter of surmise. From the different indications of temperature in high northern latitudes in the Old and New World, it has been inferred that the point of greatest cold is not coincident with the pole, but that the lowest temperature is found at two points situated at about $80^{\circ}$ of latitude, and $95^{\circ}$ east longitude, and $100^{\circ}$ west. Captain Parry, who wintered at Melville Island, often observed the thermometer in the ship at $50^{\circ}$, and at a distance from the ship at $55^{\circ}$ below zero, perhaps the lowest temperature, upon which entire dependence may be placed, that has been remarked. He wintered on the south coast of the island in about latitude $74^{\circ}$, and obtaimed the following results of observation:-

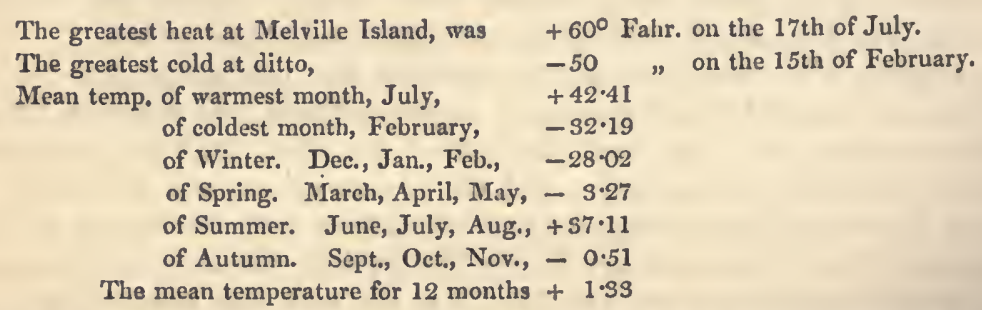

These results indicate a very extrnordinary degree of cold, far surpassing what had ever been supposed to exist in the imagination of the poets, or what the calculations of science formerly assigned to the pole itself, where the hoary desolations of the arctic regions were conceived to be concentrated. According to a table given by Leslie, the mean 
temperature of Melville Island should have been nearly $36^{\circ}$, whereas it was only $1 \frac{1}{3}^{\circ}$, or upwards of $30^{\circ}$ below the freezing point. This severity of cold, though generally borne without inconvenience when proper precautions were observed, had a striking influence on the mental as well as the corporeal faculties when imprudently encountered, producing a wild look, an indistinct utterance, and an air of stupidity resembling that which is often caused by intoxication.

It is an inquiry of some interest, whether the general temperature of the globe is stable, or is gradually undergoing change through diminution or addition. We have no means of deciding this point, because our thermometrical determinations are confined to a comparatively modern date. The instrument was not brought to perfection until the year 1724, by Fahrenheit, and therefore beyond that period we are dependent upon the recorded experience and sensations of observers, and upon the details of agricultural failure or success, for our knowledge of temperature in former times. We are not warranted to infer from these casual notices any change of physical climate generally within the era of authentic history, though in particular localities, there is strong reason to suppose that an alteration has taken place; but this has been the very reverse of an impression that once prevailed respecting it. The existence of a colony on the east coast of Greenland, cut off from communication with the external world, and destroyed by the gradual accumulation of the ice upon its shores - the fact of immense forests anciently clothing the lighest parts of Britain, and other northern countries, where a tree now can scarcely be made to grow - of the period of the vintage formerly commencing sereral weeks earlier in France than at present - of vineyards having been planted in the south of England during the time that the Romans held possession of the island, where hops can only be raised with difficulty - and of the sides of the Scottish hills bearing evident traces of the plough, which have long been surrendered to the heaths as incapable of cultivation; - these circumstances have been appealed to, as evidence of a milder and more genial climate having once characterised the northern regions of Europe. Sir John Leslie has remarked upon these details, "that a patch of wood will not thrive in cold situations, merely for want of the shelter which is afforded by extensive plantations. In Sweden and Norway, which are mostly covered with natural forests, it has become an object of police to prevent their indiscriminate destruction. The timber in those sylvan countries is cut at stated periods of its growth, and in detached portions; the vacant spaces being left as nurseries, embosomed amidst an expanse of tall trees. Some places in Sweden, where the forests have been accidentally destroyed by fire, present the image of sterility, and of wide desolation. It is probable, that the vines grown in ancient times were coarser and hardier plants than those which are now cultivated. A similar observation extends to all the productions of gardening. A succession of diligent culture softens the character of the vegetable tribes, and renders them more delicate, while it heightens the flavour of their fruit. The Roman soldiers stationed in Britain would naturally prefer wine, their accustomed beverage, however harsh and poor, to the cervisia, or unpalatable ale brewed by the rude arts of the natives. The marks of tillage left on our northern hills evince only the wretched state of agriculture at a remote period. For want of a proper system of rotation, and the due application of manure, the starving tenantry were then tempted to tear up with the plough every virgin spot they could find, and after extracting from it a pitiful crop or two of oats, to abandon it to a lasting sterility." With reference to the colony supposed to have been planted on the east coast of Greenland, now an uninhabitable region of glaciers, there is reason to believe that its name, Oestre Bygd, the eastern settlement, simply refers to its position in relation to another settlement, both of which were on the western coast, now occupied by the Danish factories. From the name of Snowland, afterwards supplanted by that of Iceland, given 
by the roving pirates of the Baltic to that island upon its discorery in the ninth century, it may certainly be concluded that the climate of the north was then analogous to what it is at present.

A different opinion, that the climate of the midland part of the temperate zone, especially in Europe, is less rigorous now than it was sixteen or seventeen centuries ago, appears to be supported by sufficient evidence. After making allowance for inaceuracy and exaggeration in the statements of the classical writers, they will still be found descriptive of a cold in various districts, as a feature of the ordinary temperature, whicl is not realised at present. The epistles written by Ovid from Pontus, whither he was banished by order of Augustus, describe the rigour of the climate there, in terms which would suit the winter of Hudson's Bay. He mentions, among other instances of the extreme cold, the Euxine Sea being frozen orer, so as to bear men and cattle upon it. 'Tertullian, one of the Christian fathers in the second century, writing in the style of the fierce zealot and florid rhetorician, against the heretic Marcion, thus refers to the same region:- "That tract, which is called the Pontus Euxinus, the hospitable sea, has been refused all favours, and is mocked by its very name. The day is never open, the sun never shines willingly, there is but one atmosphere - fog ; the whole year is wintry; every wind that blows comes from the north; liquors are only such before the fire; the rivers are blocked up with ice, the mountains are heaped higher with snow; all things are benumbed, all things are stiff with cold, nothing but cruelty lias there the warmth of life; that kind of cruelty, I mean, which has supplied the stage with fables concerning the sacrifices of the Tauri, and the loves of Colchis, and the tortures of Caucasus. But there is nothing so barbarous and miserable in Pontus, as that it has given birth to Marcion; he is more savage than a Scythian, more unstable than the wild inhabitant of a waggon, more inhuman than the Massageta, more audacious than the Amazon, darker than the mist, colder than the winter, more brittle than the ice, more treacherous than the Danube, more precipitous than Caucasus." Virgil refers to the winter on the banks of the Ister of the Greeks, the modern Danube, in the third Georgic, in a manner which at present is inapplicable to any part of its course:-

"The sun from far peeps with a sickly face,

Too weak, the clouds and mighty fogs to chase,

When up the skies he shoots his rosy head,

Or in the ruddy ocean sceks his bed.

Swift rivers are with sudden ice constrain'd,

And studded whcels are on its back sustain'd;

A hostry now for waggons, which before

Tall ships of burden on its bosom bore.

The brazen cauldrons with the frost are flaw'd;

The garment, stiff with ice, at hearths is thaw'd.

With axes first they cleave the wine; and thence

By weiglit, the solid portions they dispense.

From locks uncomb'd, and from the frozen beard,

Long icicles depend, and crackling sounds are lieard.

Meantime perpetual sleet, and driving snow,

Obscure the skies, and hang on herds below.

The starving cattle perish in their stalls;

Huge oxen stand enclos'd in wintry walls

Of snow congeal'd; whole herds are buried there

Of mighty stags, and scarce their horns appear.

The dexterous huntsman wounds not these afar

With shafts or darts, or makes a distant war

With dogs, or pitches toils to stop their flight,

But close engages in unequal fight ; 
And, while they strive in vain to make their way

Through hills of snow, and pitifully bray,

Assaults with dint of sword, or pointed spears,

And homeward on his back the joyful burden bears.

The men to subterranean caves retire,

Secure from cold, and crowd the cheerful fire:

With trunks of elms and oaks the hearth they load,

Nor tempt th' inclemency of heaven abroad."

The allusions to the elimate of Italy in the Georgics, referring to the Augustan age, are in several respects irreconcilable with its present character. The writer speaks of the freezing of the rivers in the southern part of the peninsula as an ordinary occurrence, and gives frequent directions for the protection of sheep and goats from snow and frost, as if addressing a shepherd of the plains of Holstein or the highlands of Scotland. It is a well-attested fact, that the savage inhabitants of Gaul and Germany usually selected the winter-season for their warlike incursions into the Roman provinces, on account of the facility afforded by the ice for the transport of their armies, horses, and baggage, across the great rivers, which have never been so frozen in modern times as to admit of such an occurrence. In the time of Crsar, also, the rein-deer, now confined to the colder regions north of the Baltic, was found, along with the elk and the wild bull, in the Hercynian forest, which then overshadowed a great part of Germany and Poland. A volume published at Vienna in 1788 , contains some remarkable passages concerning the state of the weather for more than a thousand years back, gathered from the old chronicles, which detail the state of the harrest, the quality of the vintage, or the endurance of frost and snow in the winter. From this work, Sir John Leslie, in an article furnished to one of the public journals, quoted the following record of excessive winters and summers, to which some additions have been made.

\section{EXCESSIVE WINTERS.}

In A. D. 401 , the Black Sea was entirely frozen over.

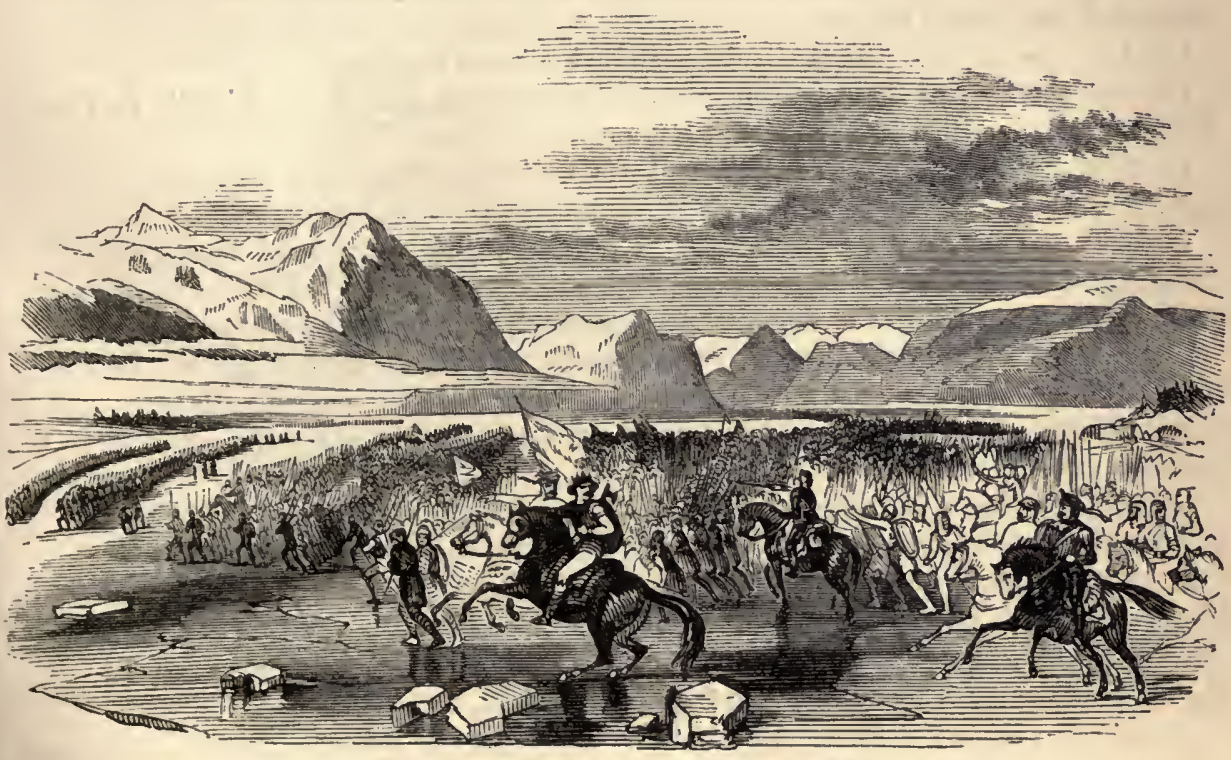

Theodomer marching his Army across the Danube. 
In 462 , the Danube was frozen, so that Theodomer marched over the ice to avenge his brother's death in Suabia.

In 545 , the cold was so intense in winter that the birds allowed themselves to be caught by the hand.

In 763, not only the Black Sea, but the Strait of the Dardanelles was frozen over. The snow in some places rose fifty feet high, and the ice was so heaped in the cities as to push down the walls.

In 800 , the winter was intensely cold.

In 822 , the great rivers of Europe, such as the Danube, the Elbe, and the Seine, were so hard frozen as to bear heavy waggons for a month.

In 860 , the Adriatic was frozen.

In 874 , the winter was very long and severe. The snow continued to fall from the beginning of Norember to the end of March, and encumbered the ground so much that the forests were inaccessible for the supply of fuel.

In 891 , and again in 893 , the vines were killed by the frost, and the cattle perished in their stalls.

In 991, the winter lasted very long with extreme severity. Every thing was frozen; the crops totally failed; and famine and pestilence closed the year.

In 1044, great quantities of snow lay upon the ground. The vines and fruit-trees were destroyed, and famine ensued.

In 1067 , the cold was so intense, that most of the travellers in Germany were frozen to death on the roads.

In 1124 , the winter was uncommonly severe, and the snow lay very long.

In 1133, it was extremely cold in Italy. The Po was frozen from Cremona to the sea; the heaps of snow rendered the roads impassable; the wine casks were burst, and even the trees split by the action of the frost, with immense noise.

In 1179, the snow was eight feet deep in Austria, and lay till Easter. The crops and vintage failed; and a great murrain consumed the cattle.

The winters of 1209 and 1210 were both of them very severe, insomuch that the cattle died for want of fodder.

In 1216, the Po froze fifteen ells deep, and wine burst the casks.

In 1234, the Po was again frozen; and loaded waggons crossed the Adriatic to Venice. A fine forest was killed by the frost at Ravenna.

In 1236, the Danube was frozen to the bottom, and remained for a considerable time in that state.

In 1269, the frost was most intense in Scotland, and the ground bound up. The Categat was frozen between Norway and Jutland.

In 1281, such quantities of snow fell in Austria as to bury the very houses.

In 1292, the Rhine was frozen over at Breysach, and bore loaded waggons. One sheet of ice extended between Norway and Jutland, so that travellers passed with ease; and in Germany 600 peasants were employed to clear away the snow for the advance of the Austrian army.

In 1305 , the rivers in Germany were frozen ; and much distress was occasioned by the scarcity of provisions and forage.

In 1316, the crops wholly failed in Germany. Wheat, which some years before sold in England at six shillings a quarter, now rose to two pounds.

In 1323, the winter was so severe, that both horse and foot passengers travelled over the ice from Denmark to Lubeck and Dantzie.

In 1339, the crops failed in Scotland; and such a famine ensued that the poorer sort of people were reduced to feed on grass, and many of them perished miserably in the 
fields. Yet in England, wheat was at this time sold so low as three shillings and fourpence a quarter.

In 1344, it was clear frost from November to March, and all the rivers in Italy were frozen over.

In 1392 , the vineyards and orchards were destroyed by the frost, and the trees torn to pieces.

The year 1408 was one of the coldest winters ever remembered. Not only the Danube was frozen over, but the sea between Gothland and Oeland, and between Norway and Denmark; so that wolves, driven from their forests, came over the ice into Jutland. In France, the vineyards and orchards were destroyed.

In 1423 , both the North Sea and the Baltic werc frozen. Travellers passed on foot from Lubeck to Dantzic. In France, the frost penetrated into the cellars. Corn and wine failed, and men and cattle perished for want of food.

The successive winters of 1432,1433 , and 1434 were uncommonly severe. It snowed forty days without interruption. All the rivers in Germany were frozen; and the very birds took shelter in the towns. The price of wheat rose, in England, to twenty-seven shillings a quarter, but was reduced to five shillings in the following year.

In 1460, the Baltic was frozen, and both foot and horse passengers crossed over the ice from Denmark and Sweden. The Danube, likewise, continued frozen two months; and the vineyards in Germany were destroyed.

In 1468, the winter was so severe in Flanders, that the wine distributed to the soldiers was cut in pieces with hatchets.

In 1544, the same thing happened again, the wine being frozen into solid lumps.

In 1548, the winter was very cold and protracted. Between Denmark and Rostock, sledges drawn by horses or oxen travelled over the ice.

In 1564, and again in 1565, the winter was extremely severe all over Europe. The Scheldt froze so hard as to support loaded waggons for three months.

In 1571, the winter was severe and protracted. All the rivers in France were covered with hard and solid ice; and fruit-trees even in Languedoc were killed by the frost.

In 1694, the weather was so severe, that the Rhine and the Scheldt were frozen, and even the sea at Venice.

The year 1608 was uncommonly cold, and snow lay of immense depth even at Padua. Wheat rose in the Windsor market from 36 to 56 shillings a quarter.

In 1621 and 1622, all the rivers of Europe were frozen, and even the Zuider Zee. A sheet of ice covered the Hellespont; and the Venetian fleet was choked up in the lagoons of the Adriatic.

In 1655 , the winter was very severe, especially in Sweden. The excessive quantities of snow and rain which fell did great injury in Scotland.

The winters of 1658, 1659, and 1660 were intensely cold. The rivers in Italy bore henvy carriages ; and so much snow had not fallen at Rome for several centuries. It was in 1658, that Charles X. of Sweden crossed the Little Belt over the ice from Holstein to Denmark, with his whole army, foot and horse, followed by the train of baggage and artillery. During these years, the price of grain was nearly doubled in England; a circumstance which contributed, among other causes, to the Restoration.

In 1670, the frost was most intense in England and in Denmark, both the Little and the Great Belt being frozen.

In 1684, the winter was excessively cold. Many forest trees, and even the oaks in England, were split by the frost. Most of the hollies were killed. Coaches drove along the Thames, which was covered with ice eleven inches thick. Almost all the birds perished. 
In 1691, the cold was so execssive that the famished wolves entered Vienna, and attacked the cattle, and even men.

The winter of 1695 was extremely severe and protracted. The frost in Germany began in October, and continued till April; and many people were frozen to deatl.

The years 1697 and 1699 were nearly as bad. In England, the price of wheat, which in preeeding years had seldom reached to 30 shillings a quarter, now mounted to 71 .

In 1709 occurred that famous winter, called by distinction the cold winter. All the rivers and lakes were frozen, and even the seas, to the distance of several miles from the shore. The frost is said to have penetrated three yards into the ground. Birds and wild beasts were strewed dead in the fields, and men perished by thousands in their houses. The more tender shrubs and vegetables in England were killed; and wheat rose in its price from two to four pounds a quarter. In the south of France, the olive plantations were almost entirely destroyed; nor have they yet recorered that fatal disaster. The Adriatic Sea was quite frozen over, and even the coast of the Mediterranean about Genoa, and the citron and orange groves suffered extremely in the finest parts of Italy.

In 1716, the winter was very cold. On the 'Thames, booths were ereeted, and fairs held. The printers and booksellers pursued their professions upon its surface.

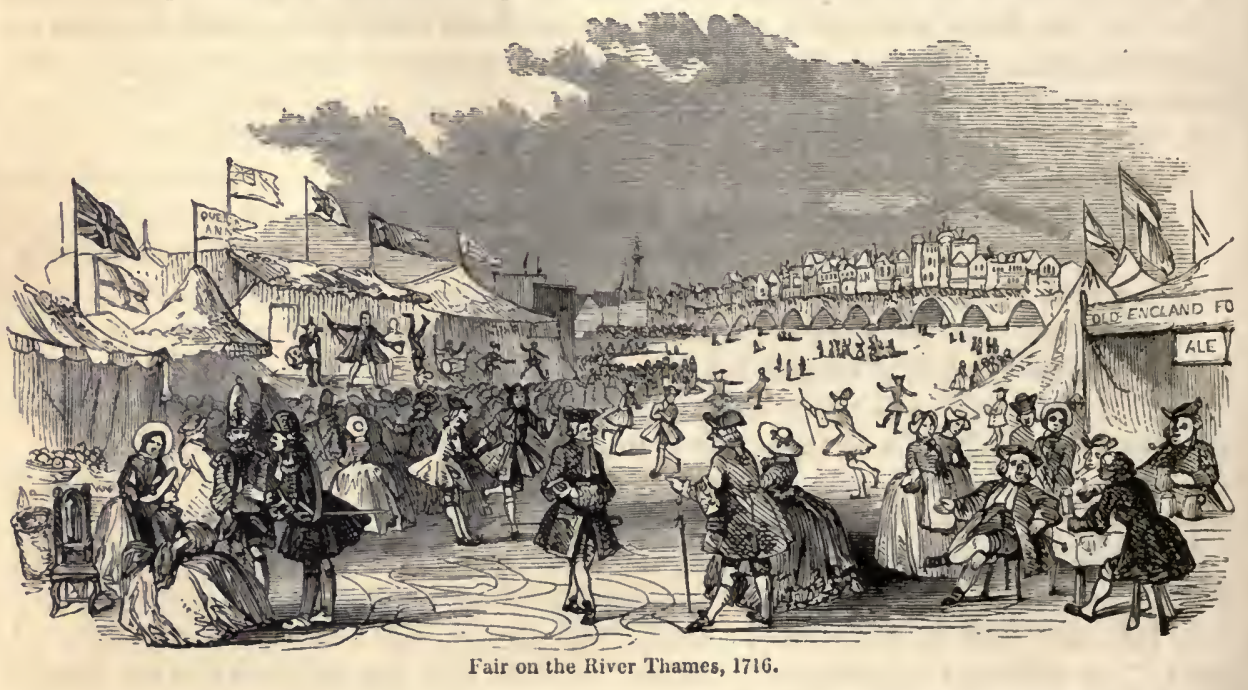

In 1726 , the winter was so intense that people travelled in sledges across the strait from Copenhagen to the province of Seania in Sweden.

In 1729, much injury was done by the frost, which lasted from October till May. In Scotland, multitudes of cattle and sheep were buried in the snow; and many of the forest trees in other parts of Europe were killed.

The suceessive winters of 1731 and 1732 were likewise extremely cold.

The cold of 1740 was scarcely inferior to that of 1709. The snow lay eight and ten feet deep in Spain and Portugal. The Zuider Zee was frozen over, and many thousand persons walked or skated on it. At Leyden, the thermometer fell $10^{\circ}$ below the zero of Fahrenheit's seale. All the lakes in England froze; and a whole ox was roasted on the Thames. Many trees were killed by the frost; and postilions were benumbed on their saddles. In both the years 1709 and 1740, the General Assembly of the Church of Scotland ordained a national fast to be held on account of the dearth which then prevailed. 
In 1744 the winter was again very cold. The Maine was covered seven weeks with ice; and at Erora, in Portugal, people could hardly creep out of their houses for heaps of snow.

The winters during the five successive years, $1745,1746,1747,1748$, and 1749 , were all of them very cold.

In 1754, and again in 1755, the winter was particularly cold. At Paris, Fahrenheit's thermometer sank to the beginning of the scale; and in England, the strongest ale, exposed to the air in a glass, was covered, in less than a quarter of an lour, with ice an eighth of an inch thick.

The winters of 1766,1767 , and 1768 were very cold all over Europe. In France, the thermometer fell six degrees below the zero of Fahrenheit's scale. The large rivers and the most copious springs in many parts were frozen. The thermometer, laid on the surface of the snow at Glasgow, fell two degrees below zero.

In 1771 the snow lay very deep, and the Elbe was frozen to the bottom.

In 1776 much snow fell, and the cold was intense. The Danube bore ice five feet thick below Vienna. Wine froze in the cellars both in France and in Holland. Many people were frost-bitten; and vast multitudes both of the feathered and of the finny tribes perished. Yet the quantity of snow that lay upon the ground had checked the penetration of the frost. Van Swinden found, in Holland, that the earth was congealed to the depth of twenty-one inches, on a spot of a garden which had been kept cleared, but only nine inches at another place near it, which was covered with four inches of snow.

The successive winters of 1784 and.1785 were uncommonly severe, insomuch that the Little Belt was frozen over.

In 1789 the cold was excessire; and again in 1795, when the republican armies of France overran Holland.

The successive winters of 1799 and 1800 were both very cold.'

In 1809 , and again in 1812 , the winters were remarkably severe.

\section{EXCESSIVE SUMHERS.}

In 763 the summer was so hot that the springs dried up.

In 870 the heat was so intense, that near Worms the reapers dropped dead in the fields.

In 993, and again in 994, it was so hot that the corn and fruit were burnt up.

The year 1000 was so hot and dry, that, in Germany, the pools of water disappeared, and the fish, being left in the mud, bred a pestilence.

In 1022 the heat was so excessive, that both men and cattle were struck dead.

In 1130 the earth yawned with drought. Springs and rivers disappeared, and even the Rhine was dried up in Alsace.

In 1159 not a drop of rain fell in Italy after the month of May.

The year 1171 was extremely hot in Germany.

In 1232 the heat was so great, especially in Germany, that it is said that eggs were roasted in the sands.

In 1260, many of the Hungarian soldiers died of excessive heat at the famous battle fought near Buda.

The consecutive years of 1276 and 1277 were so hot and dry as to occasion a great scarcity of fodder.

The years 1293 and 1294 were extremely hot; and so were likewise 1303 and 1304, both the Rhine and the Danube having dried up.

In 1333 the corn-fields and vineyards were burnt up. 
The years 1393 and 1394 were excessively hot and dry.

In 1447 the summer was extremely hot.

In the successive years 1473 and 1474 the whole earth seemed on fire. In Hungary, a person might wade across the Danube.

The four consecutive years $1538,1539,1540$, and 1541 were excessively hot, and the rivers dried up.

In 1556 the drought was so great that the springs failed. In England, wheat rose from 8 shillings to 53 shillings a quarter.

The years 1615 and 1616 were very dry all over Europe.

In 1646 it was excessively hot.

In 1652 the warmth was very great, the summer being the driest ever known in Scotland. A total eclipse of the sun had happened that year, on Monday the 24th of March, which hence received the appellation of Mirk Monday.

The summer of 1679 was extremely hot. It is related, that one of the minions of tyranny, who in that calamitous period harassed the poor presbyterians in Scotland with captious questions, having asked a shepherd in Fife, whether the killing of the notorious Sharp, Archbishop of St. Andrew's, which had happened in May, was murder; he replied, that he could not tell, but there had been fine weather ever since.

The year 1700. was excessively warm, and the two following years were of the same description.

In 1718 the weather was extremely hot and dry all over Europe. The air felt so oppressive, that all the theatres were shut in Paris. Scarcely any rain fell for the space of nine months, and the springs and rivers were dried up. The following year was equally hot. The thermometer at Paris rose to $98^{\circ}$ of Fahrenheit. The grass and corn were quite parched. In some places the fruit trees blossomed two and three times.

Both the years 1723 and 1724 were dry and hot.

The year 1745 was remarkably warm and dry; but the following year was still hotter, insomuch that the grass withered, and the leaves dropped from the trees. Neither rain nor dew fell for several months; and, on the continent, prayers were offered up in all the churches to implore the bounty of refreshing showers.

In 1748 the summer was again very warm.

In 1754 it was likewise extremely warm.

The years 1760 and 1761 were both of them remarkably hot, and so was the year 1763.

In 1774 it was excessively hot and dry.

Both the years 1778 and 1779 were warm and very dry.

The year 1788 was also very hot and dry; and of the same character was 1811 , famous for its excellent vintage, and distinguished by the appearance of a brilliant comet.

It may be concluded from these notices, that the climate of Europe during the last fourteen centuries has been gradually acquiring a more genial character, and that the seasons of intense cold occur at more distant intervals than formerly. This effect is no doubt due to the destruction of the immense forests that once overspread the face of Gaul, Germany, and Britain; to the extinction of bogs and morasses by drainage; and to the more careful and vastly extended cultivation of the soil. Capricious as the occurrence of great seasonal heat and cold appears in the preceding record, it has been thought that we obtain a glimpse of those great cycles, which result from the varied aspects of the sun, combined with the feebler influence of the moon, such as the intermediate period of nine years, answering nearly to the semi-revolution of the lunar nodes and apogee. "Thus," observes Leslie, " of the years remarkably cold, 1622 was suc- 
ceeded, after the interval of four periods, or 36 years, by 1658, whose severity lasted through the following year. The same interval brings us to 1695 , and five periods more extend to 1740 , a very famous cold year; three periods now come down to 1767 , nine years more to 1776 , and eighteen years more to 1794 , the cold continuing through 1795 . Of the hot years, it may be observed, that four periods of nine years extend from 1616 to 1652 , and three such again to 1679 . From 1701 to 1718 , there was an interval of 17 years, or very nearly two periods, while three periods reack to 1745 , another period to 1754 , and one more falls on 1763 ; and from 1779 to 1788 there are just nine years."

But if Europe has a somewhat milder climate now than a thousand years back, the evidence is irresistible, of an age of very high temperature, corresponding to that of the torrid zone, having once characterised the whole northern hemisphere. The fossil flora of our coal deposits plainly indicate a tropical climate by their gigantic size; and the carboniferous formation occurs in Melville Island, a latitude within fifteen degrees of the pole. The fossil corals in the arctic limestone show that its waters once supported polypi analogous to those which are found in our warm equatorial seas. The remains of the elephant are found on the very shores of the frozen ocean in North Siberia ; turtles, tortoises, and large saurians occur abundantly in the European strata; and skeletons of genera now confined to the hot regions are common in rigorous wintry latitudes. The transport of these remains from the equinoctial zone to the places of their present deposit cannot be admitted, owing to the perfect state in which they have been preserved, the leaves and most delicate parts of the tree-ferns being quite uninjured, which is plainly inconsistent with the assumption of a slow drift of one or two thousand miles having been undergone. They have undoubtedly flourished at or near the sites of their deposition, where there must have been the elevated temperature requisite for their growth, equal to that now enjoyed by the vigorous vegetation of equatorial districts. What has produced this change of climate is a question which we cannot answer; but as we have evidence of a progressive increase of heat with the depth of mines, the high temperature of the interior might not have left the external shell of the earth, when the mammoth roamed on the plains of the north, the turtle inhabited its waters, and enormous arborescent ferns clothed its surface.

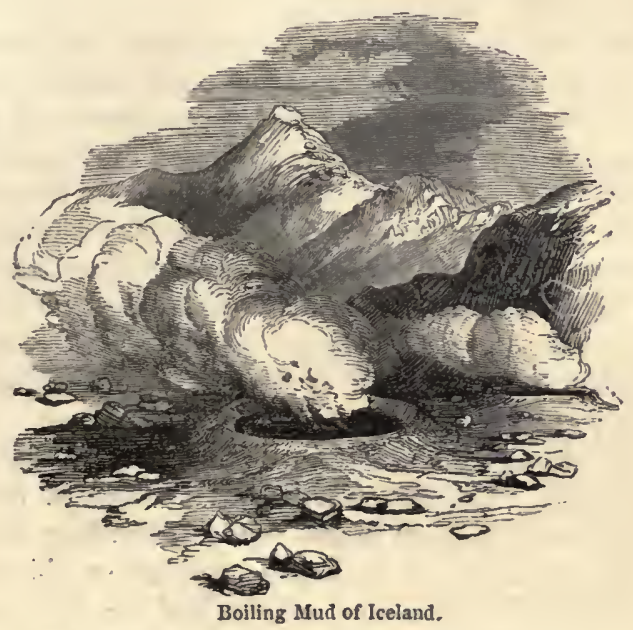




\title{
CHAPTER XVI.
}

\author{
OPTICAL PHENOMENA.
}

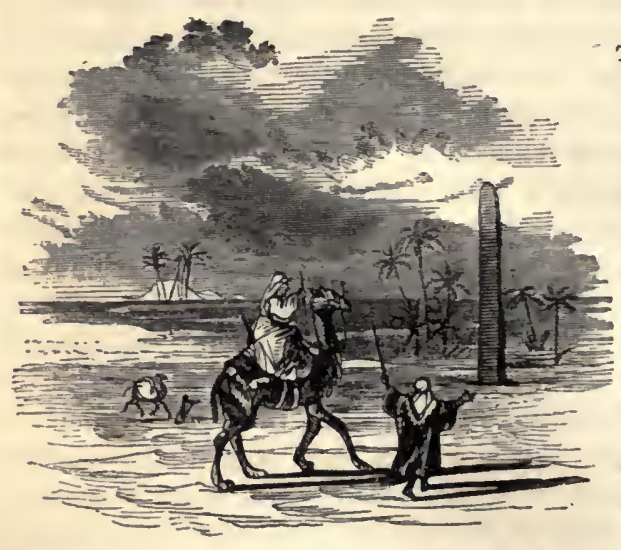

T is convenient to place an indefinite title at the head of this chapter, in order to notice various classes of independent phenomena which immediately address themselves to the eye; and which are either plain developments of electrical action, or simply atmospheric meteors, or appearances resulting from its reflecting and refractive propertics, or of obscure origin, but manifested in the atmosphere. To the former class the lightning belongs, beautifully playing among the distant clouds, or flashing with blinding glare and tremendous effect near the surface of the earth, warning man and beast of the presence of an agency able to extinguish animal and vegetable life in a moment, and utterly inappreciable in its swiftness, subtility, and power. At the close of a hot sultry day, over a level country, the igneous meteor often exhibits itself, in rapidly succeeding, broad, noiseless, and imposing sheets of flame, lighting up the whole range of the horizon, revealing for the moment the contour of the distant landscape upon which the shadows of the night have gathered, and discovering the outline of the clouds in the dusky sky. These displays, however startling to "the poor Indian, whose untutored mind" is alarmed at the slightest deviation from the ordinary aspect of things, are always harmless, and invite by their innocuousness and fascination the cultivated races to watch the bounding coruscations of the elastic element, besides contributing to render the fields of corn ripe unto the harvest. But it is otherwise when heat has overcharged the atmosphere with vapours, becoming piled into clouds of gigantic dimensions and massive architecture, which are often propelled by antagonist currents, and in different electrical conditions. After an unusual calm of nature, oppressive to the animal system, during which not a movement of the air is perceptible, and the leaves hang motionless upon the trees, while the brute creation indicate some intelligence of an impending change by their restlessness, an explosion commences. The flash is seen, the thunder heard, and the clouds open their watery storehouse, a few distant and heavy drops increasing into a cataract of rain. Flash rapidly follows flash, and the interval between each appearance, and the accompanying thunder peal becomes less. The pale hue of the lightning is exchanged for a vivid glare, in which a deep yellow, red, or blue is the predominant colour, a variety of aberrations marking its course, the zigzag form showing that the fearful agent is near terrestrial objects. In this manner, "the destruction that wasteth at noonday" is frequently exhibited, now striking man and beast to the earth, or rending asunder the mighty oak of the forest, or firing the vessel of the hapless seaman, or shivering "the cloud-capt towers and gorgeous palaces," the fanes of religion and the fortresses of war. Man has th.cn a solemn sense of his helplessness and danger ; and almost every creature sympathises with him. The eel is restless in his muddy bed - the horse trembles beneath his rider - 
the cattle gather lowing to a covert - the eagle nestles in the cleft of the rock with folded wings - the hart looks wild and anxious : only the poor seal seems to experience agreeable sensations, for he will come out of his hiding-place in the deep, at the call of the thunder, and repose upon some overhanging leuge, as if calmly enjoying the convulsion of the elements.

Since the month of June 1752, when Franklin performed the celebrated kite experiment, by which he became the modern Prometheus, bringing down the celestial fire to the earth, the identity of lightning and electricity has been universally known. The theory of the electric fluid, as it is called, is to be sought for in philosophical treatises, our province being to notice its distribution, phenomena, and effects. That subtle principle which the Greeks denominated electricity, from $\eta \lambda \varepsilon x \tau \rho o v$, amber, because the property was first noticed in that substance, appears to be a universally diffused agent, its presence having been detected in connection with the clouds, with hail, rain, and snow, with regetation, animals, and the interior strata of the earth. But undue accumulation transpires - the electrical equilibrium is disturbed; and the resulting phenomena of equalisation are lightning and thunder. 'Thus two clouds, or a cloud and the earth, unequally electrified, tend to return to a condition of equality through a conducting medium, a metallic or moist body having the preference as a conductor, the discharge of electricity appearing in the form of a spark or flash, accompanied by a loud detonation according to its violence, the peal rebounding in echoes from cloud to cloud, and from hill to hill. Some regions of the globe are peculiarly subject to accumulations of electricity. Mr. Hamilton, in his work on Asia Minor, observes : - "One of the most remarkable phenomena which I observed in Angora, was the great degree of electricity which seemed to pervade everything. I observed it particularly in silk handkerchiefs, linen and woollen stuffs. At times, when I went to bed in the dark, the sparks which were emitted from the blanket gave it the appearance of a sheet of fire; when I took up a silk handkerchief, the crackling noise would resemble that of breaking a handful of dried leaves or grass; and on one or two occasions I clearly felt my hands and fingers tingle from the electric fluid. I could only attribute it to the extreme dryness of the atmosphere, and momentary friction. - I did not observe that it was at all influenced by wind ; the phenomena were the same, whether by night or by day, in wind or calm. Not a cloud was visible during the whole of my stay." Similar striking indications of the prevalence of electric action have frequently been observed by travellers when near the summits of high mountains, as by Sir W. J. Hooker on Ben Nevis, Saussure on Mont Blanc, and Tupper on Mount Etna. The latter, descending a field of snow, a good conductor, felt a slight shock upon entering a cloud which seemed electric, with a sensation of pain in the back. The hair of his head stood erect, and upon moving the hand near the head, a humming sound proceeded from it, which arose from a succession of sparks. Though a situation of great danger, yet we have several instances of such clouds having been traversed with impunity, when in the act of electrical explosion. The Abbé Richard, in August 1778, passed through a thundercloud on the small mountain called Boyer, between Chalons and Tournus. Before he entered the cloud, the thunder sounded, as it is wont to do, with a prolonged reverberation; but when enveloped in it, only single peals were heard, with intervals of silence, without any roll; and after he had passed above the cloud, it reverberated as before, and the lightning flashed. The sister of M. Arago was a party to a similar occurrence between Estagel and Limoux, and some officers of engineers likewise, during a trigonometrical survey on the Pyrenees.

The energy of atmospheric electricity appears to decrease as we recede from the equator to the poles, thus sympathizing with light and heat; for it is in tropical countries that the most terrific flashes of lightning and the loudest bursts of hearen's artillery 
occur. Awful as these manifestations are occasionally in our temperate climate, they are but as a skirmishing of outposts to the general engagement of armies, when compared with inter-tropical displays. In Hindûstan, in the Indian Ocean, along the African coast off Cape St. Verde, and in Central America, there is often a scene exhibited, which seems a rehearsal of the day "when the heavens being on fire shall pass away with a great noise." Humboldt, during his residence at Cumana, witnessed a coincident development of electrical action, peculiar atmospheric phenomena, and terrestrial disturbance, during what is called the winter of that region. From the 10th of October to the 3rd of November, a reddish vapour rose in the evening, and in a few minutes covered the sky. The hygrometer gave no indication of humidity; the diurnal heat was from $82 \cdot 4^{\circ}$ to $89 \cdot 6^{\circ}$. The vapour disappeared occasionally in the middle of the night, when brilliantly white clouds formed in the zenith, extending towards the horizon. They were sometimes so transparent, that they did not conceal stars even of the fourth magnitude, and the lunar spots were clearly distinguishable through the veil. The clouds were arranged in masses at equal distances, and seemed to be at a prodigious elevation. From the 28th of October to the 3rd of November, the fog was thicker than it had been before; and the heat at night was stifling, though the thermometer indicated only $78.8^{\circ}$. There was no evening breeze. The sky appeared as if on fire, and the ground was everywhere cracked and dusty. About two o'clock in the afternoon of November 4th, large clouds of extraordinary blackness enveloped the mountains of the Brigantine and 'Tataraqual, extending gradually to the zenith. About four, thunder was heard overhead, but at an immense height, and with a dull and often interrupted sound. At the moment of the strongest electric explosion, two shocks of an earthquake, separated by an interval of fifteen seconds, were felt. The people in the streets filled the air with their cries. Bonpland, who was examining plants, was nearly thrown upon the floor, and Humboldt, who was lying in his hammock, felt the concussion strongly. A few minutes before the first, there was a violent gust of wind followed by large drops of rain. The sky remained cloudy, and the blast was succeeded by a dead calm, which continued all night. The sunset was a scene of great magnificence. The dark atmospheric shroud was rent asunder close to the horizon, and the sun appeared at $12^{\circ}$ of altitude on an indigo ground, his disc enormously enlarged and distorted. The clouds were gilded on the edges, and bundles of rays reflecting the most brilliant prismatic colours extended over the heavens. About nine in the evening, there was a third shock, which, though much slighter, was evidently attended with a subterranean noise. In the night between the 3 rd and 4 th of November, the red vapour before mentioned had been so thick, that the place of the moon could only be distinguished by a beautiful halo, $20^{\circ}$ in diameter. The vapour ceased to appeur on the 7 th; the atmosphere then assumed its former purity; and the night of the 11th was cool and extremely lovely. This account, with similar details from other observers, seems to indicate a more intimate relation than is generally admitted between the interior of the earth, and its external atmosphere.

Among the regions peculiarly subject to electric phenomena is the country around the estuary of the Rio Plata. In the year 1793, one of the most destructive thunder-storms perhaps on record, happened at Buenos Ayres, when thirty-seven places in the city were struck by the lightning, and nineteen of the inhabitants killed. It is an observation of Mr. Darwin, founded on statements in books of travels, that thunder-storms are very common near the mouths of great rivers ; and he conjectures that this may arise from the mixture of large bodies of fresh and salt water disturbing the electrical equilibrium. "Even," he remarks, "during our occasional visit to this part of South America, we heard of a slip, two churches', and a house, having been struck. Both the church and the house I saw shortly afterwards. Some of the effects were curious: the paper, for nearly a foot on 
each side of the line where the bell-wires had run, was blackened. The metal had been fused, and although the room was about fifteen feet high, the globules, dropping on the chairs and furniture, had drilled in them a chain of minute holes. A part of the wall was shattered as if by gunpowder, and the fragments had been blown off with force sufficient to indent the wall on the opposite side of the room. The frame of a looking-glass was blackened; the gilding must have been volatilized, for a smelling-bottle, which stood on the chimney-piece, was coated with bright metallic particles, which adhered as firmly as if they had been enamelled." Near the shores of the Rio Plata, in a broad band of sand hillocks, he found those singular specimens of electric architecture, fulgurites, or vitrified siliceous tubes, formed by the lightning striking into loose sand. These tubes had a glossy surface, and were about two inches in eircumference, the thickness of the wall of each tube varying from the twentieth to the thirtieth part of an inch. Four sets were noticed, probably not produced by successive distinct discharges, but by the lightning dividing itself into separate branches before entering the ground. Similar cylindrical formations have been noticed in other places. Dr. Priestley has described, in the Philosophical Transactions, some siliceous tubes, which were found in digging into the ground, under a tree, where a man had been killed by lightning; and at Drigg in Cumberland, three were observed, within an area of fifteen yards, one of which was traced to a depth of not less than thirty feet. In the temperate climates, electrical phenomena are most common and usually most energetic in the summer season, and the displays are grander and more formidable in mountainous than in level countries. As we approach the poles, they become less striking; thunder is rarely heard in high northern latitudes, and only as a feeble detonation; and though lightning is more common, it is seldom destructive. In Iceland, in the winter, it often plays in the impressive but harmless manner which the natives call laptelltur. This is a fluctuating appearance of the whole sky, as if on fire, accompanied by a strong wind and drifting snow, but inflicting no further damage than that arising from the terrified cattle falling over the rocks in their efforts to escape from the phenomenon. At Reikiavik, the capital of the island, thunder was only heard once in the interval between September 21, 1833, and the end of August 1835. It is stated by Gisecke, that during a residence of six years in Greenland, in lat. $70^{\circ}$, he only heard it thunder once.

Discharges of lightning of three kinds are discriminated by Arago, zigzag, sheet, and globular. The first variety indicates itself by a long streak of light, very thin, and well defined at the edges, of a white, violet, or purple hue, moving in a straight line, or deviating into a zigzag track, frequently dividing into two or more streams in striking terrestrial objects, but invariably proceeding from a single point. The second kind are expanded flashes spreading over a vast surface without having any apparent depth, of a red, blue, or violet colour, not so active as the former class, and generally confined to the edges of the clouds from which they appear to proceed. The third class are concentrated masses of light, known as ball or globular lightning, which seem to occupy time, to endure for several seconds, and to have a progressive motion. Mr Hearder of Plymouth describes a discharge of lightning of this kind, on the Dartmouth hills, very near to him. Several vivid flashes had occurred before the mass of clouds approached the hill on which he was standing; and before he had time to retreat from his dangerous position, a tremendous crash and explosion burst close to him. The spark had the appearance of a nucleus of intensely ignited matter, followed by a flood of light. It struck the path near him, and dashed with fearful brilliancy down its whole length to a rivulet at the foot of the hill, where it terminated. Analogous to the discharges described as globular lightning are the fireballs so often noticed, about which there has been no little scepticism; but the evidence cannot reasonably be doubted, that displays of electrical light have repeatedly 
occurred, conveying the impression of balls of fire to the observer. An instance is given by Mr. Chalmers while on board the Montague, of seventy-four guns, bearing the flag of Admiral Chambers. In the account read to the Royal Society, he states, that "on November 4th, 1749, while taking an observation on the quarter-deck, one of the quartermasters requested him to look to windward, upon which he observed a large ball of blue fire rolling along on the surface of the water, as large as a mill-stone, at about three miles distance. Before they could raise the main tack, the ball had reached within forty yards of the main-chains, when it rose perpendicularly with a fearful explosion, and shattered the main-topmast to pieces." In an account of the fatal effects of lightning in June 1826, on the Malvern Hills, when two ladies were struck dead, it is stated, that the electric discharge appeared as a mass of fire rolling along the hill towards the building in which the party had taken shelter. Sir W. Snow Harris remarks upon the difficulty of explaining these appearances. The amazing rapidity of the ordinary electric spark, and the momentary duration of the light, render it impossible that they should be identical with it; but he conjectures that there may be a "glow discharge" preceding the main shock, some of the atmospheric particles yielding up their electricity by a gradual process before a discharge of the whole system takes place. In this view, the distinct balls of fire of sensible duration which have been perceived, are produced in a given point or points of a charged system previously to the more general and rapid union of the electrical forces.

The remarkable electrical meteor called the Mariners' Lights, or St Elmo's Fire, has frequently been observed during storms at sea. Pliny mentions lights noticed by the Roman mariners during tempests, flickering about their vessels, to which Seneca likewise makes allusion. By the superstition of modern times they have been converted into indications of the guardian presence of St. Elmo, the patron saint of the sailor, lience called cuerpo sante by the Spanish mariners. During the second voynge of Columbus among the West India islands, a sudden gust of heavy wind came on in the night, and his crew considered themselves in great peril, until they beheld several of these lambent flames playing about the tops of the masts, and gliding along the rigging, which they hailed as an assurance of their supernatural protector being near. Fernando Columbus records the circumstance in a manner strongly characteristic of the age in which he lived. "On the same Saturday, in the night, was seen St. Elmo, with seven lighted tapers, at the topmast. There was much rain and great thunder. I mean to say that those lights were seen which mariners affirm to be the body of St. Elmo, on beholding which they chanted many litanies and orisons, holding it for certain, that in the tempest in which he appears, no one is in danger." A similar mention is made of this nautical superstition in the voyage of Magellan. There is on such occasions a strong charge of electricity in the air, which becomes visible in the form of pale-coloured flames, as it is gradually relieved. These harmless fires usually appear quivering on the extremities of bodies, as the topmasts and yard-arms of ships, the points of spears and military weapons, with other projecting and exposed objects. In showers of rain and snow, the drops and flakes have been observed to be luminous.

It is a striking instance of the triumph of mind, that by the introduction of lightning conductors into different civilised states, the power of this most energetic agent of nature is controlled, and comparative security provided for life and property, otherwise in imminent jeopardy, when a severe thunder-storm occurs. Experience has taught the prime importance of furnishing exposed or elevated structures with a conducting apparatus, and has sufficiently shown that the immunity from danger enjoyed by many an unprotected building has been merely accidental; for when the teeming thunder-cloud has been wafted within reach of the edifice hitherto unscathed, the delusion has vanished, that man may carelessly and with impunity, thrust up his handiwork into the region of storms, as if 
daring the fury of the tempest, and inviting down its vengeance. The fine tower of St. Mark's at Venice, rising to the height of 360 feet, terminates in a pyramid which was severely injured in 1388. In 1417 the pyramid was again struck, and set on fire, having been constructed of wood. The same event happened in 1489, when it was entirely

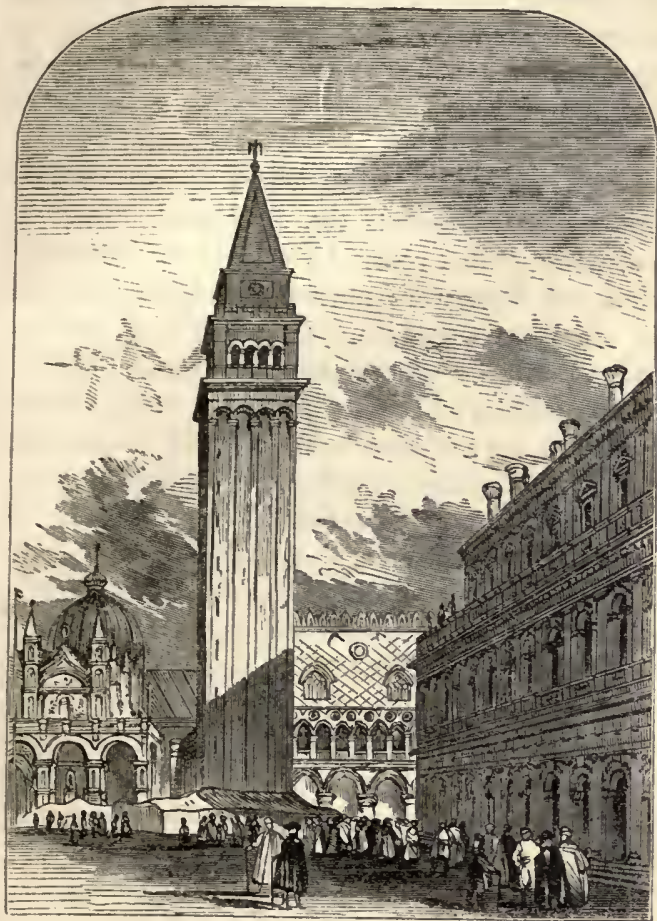

Tower of St. Mark's, Venice. consumed. After being rebuilt of stone, the fell lightning renewed its destructive stroke in 1548, 1565, 1653, and 1745 ; and on the last occasion the whole tower was rent in thirty-seven places, and almost destroyed. It was again ravaged in 1761 and 1762 , but in 1766 a lightning rod was put up, which has since protected it from damage. At Glogau, in Silesia, an interesting example of the value of conductors occurred in the year 1782. On the 8th of May, about eight o'clock in the evening, a thunder-storm from the west approached the powder magazine established in the Galgnuburg. An intensely vivid flash of lightning took place, accompanied instantly with such a tremendous peal of thunder, that the sentinel on duty was stupified, and remained for awhile senseless, but no disaster occurred. Some labourers at a short distance from the magazine saw the lightning issue from the cloud, and strike the point of the conductor, which conveyed it in safety by the combustible material. A different result took place with reference to a large quantity of unprotected ammunition, belonging to the republic of Venice, deposited in the vaults of the church of St. Nazaire, at Brescia. The church was struck with lightning in the month of August, 1767, and the electric fluid, descending to the vaults, exploded upwards of $207,600 \mathrm{lbs}$. of powder, reducing nearly one-sixth of the fine city to ruins, and destroying about 3000 of the inhabitants. Pointed hills, projecting rocks, elevated buildings, and tall trees, especially if they are isolated, are particularly liable to be struck, and hence it is a good general maxim in a thunder-storm, not to take a position either under a tree or close to a lofty edifice, but to keep as much as possible in the open country. The inhabitants of Switzerland and other mountainous countries, know by experience that they have nothing to fear from thunder-storms, while in the deep and close valleys. The clouds never descend to their bottom; and the lightning alone strikes the hills, or objects upon them.

For ages the inhabitants of the globe have seen the lightning flash, and heard the thunder rattle; and some writers upon the occult sciences of the ancients, as Salverte, have supposed that, tutored by experience, without any understanding of the theory of the subject, they possessed the secret of warding off from their buildings the thunderbolt, by a conducting apparatus. It is certain that extraordinary intimations to this effect may be culled from their writings. Pliny states that Tullus Hostilius, practising Numa's art of bringing down fire from heaven, and performing it incorrectly, was struck with 
lightning - a fate which Professor Richman of St.Petersburg experienced, while performing incautiously the sublime experiment of Franklin, measuring the strength of the electricity brought down by a metallic rod in a thunder-storm, being instantly killed. Pliny likewise mentions the laurel as the only earthly production which lightning does not strike; hence, as a protection, these trees were planted around the temple of Apollo. Columella, however, mentions white vines surrounding the house of Tarchon, the Etruscan, for the same purpose. These expedients may provoke a smile without deserving one; for there can be no doubt that trees sufficiently high around a temple, or succulent plants covering a dwelling, will exercise to some extent a protective power, and act as a regular system of conductors. Salverte mentions several medals which appear to have reference to this subject, particularly one which represents the temple of Juno, the goddess of the air, the roof of which is armed with pointed rods. He quotes also Michaelis, upon the temple of Jerusalem, to show that the Jews were not unacquainted with the art of protecting their public buildings - a position grounded upon the following facts :" 1 . That there is nothing to indicate that the lightning ever struck the temple of Jerusalem during the lapse of a thousand years." This, of course, does not make the fact certain; but when, as M. Arago justly remarks, we consider how carefully the ancient authors recorded the cases in which their public buildings were injured by lightning, we may accept the silence observed respecting the temple of Jerusalem, as proof that it was never struck. For three centuries the cathedral of Geneva, the most elevated in the city, has enjoyed a similar immunity, although inferior buildings have been repeatedly damaged. Saussure discovered the reason of this, in the tower being entirely covered with tinned iron plates, connected with different masses of metal on the roof, and again communicating with the ground by means of metallic pipes. " 2 . That according to the account of Josephus, a forest of spikes with golden or gilt points, and very sharp, covered the roof of this temple; a remarkable feature of resemblance with the temple of Juno represented on the Roman medals. 3. That this roof communicated with the caverns in the hill of the temple, by means of metallic tubes, placed in connection with the thick gilding that covered the whole exterior of the building; the points of the spikes there necessarily producing the effect of lightning rods. How are we to suppose that it was only by chance they discharged so important a function; that the advantage received from it had not been calculated; that the spikes were erected in such great numbers only to prevent the birds from lodging upon and defiling the roof of the temple? Yet this is the sole utility which the historian Josephus attributes to them." Curious as are these facts, they will by no means justify the conclusion that the ancient world had any acquaintance with the art of guiding the electric fluid from the bosom of the clouds, conducting it in a prescribed course, and thus disarming it of its terrors.

The subject of electrical agency is intimately connected with that of magnetism, to which this is the fittest place to glance, -one of the most recondite points of physical science. The two forces were long supposed to be related, from the fact that lightning often renders steel magnetic, and disturbs the magnetic needle. But they are now known to be identical, or rather, different forms under which the same power manifests itself. The magnetic agency, like electricity, has a general distribution over the earth, but the phenomena differ in different parts of the world, and are subject to periodical differences in the same place, the cause of which is very little understood. Every one is acquainted with the polarity of a freely suspended magnetic needle, or its tendency to lie parallel with the earth's axis, pointing nearly north and south in every region of the globe. What is called the dip or inclination of the needle is its divergence from a perfectly horizontal position. Thus the north pole of the needle inclines downwards in the latitude of London at an angle of $70^{\circ}$, but conveyed towards the equator, the dip diminishes, till no inclina- 
tion at all appears. Transported farther towards the south, the dip again discovers itself, but in an opposite direction, the south pole of the needle inclining downwards. "To understand the reason of this dip of the magnetic needle, and of its general direction, we have only to consider that the earth itself operates as a great magnet, the poles of which are situated beneath its surface. The directive property of the needle is owing to these poles; and when the needle is on the north side of the equator, the north pole of the earth having the greatest effect, the needle is attracted downwards towards the north pole; hence exactly over the magnetic pole the needle would be vertical. Similar phenomena occur in the southern hemisphere; but here the south pole predominates, and of course depresses the corresponding pole of the needle; while at the magnetic equator, from the equal action of both poles, the needle will assume an exactly horizontal position."

But neither the magnetic equator nor the magnetic poles coincide precisely with the geographical equator and poles, and this difference constitutes what is termed the variation of the needle. From calculation, the north magnetic pole had been fixed in latitude $70^{\circ}$, and longitude $98^{\circ} 30^{\prime}$ west, a spot which Sir James C. Ross approached within the distance of ten miles, in the year 1830, but was unable to verify the site, for want of the requisite instruments. Upon going through a long series of calculations afterwards himself, he concluded the above position to have been erroneously assigned, and that the real point lay in latitude $70^{\circ} 5^{\prime} 17^{\prime \prime}$ north, and longitude $96^{\circ} 46^{\prime} 45^{\prime \prime}$ west, a spot on the western coast of Boothia, which he prepared to reach. On the 1st of June 1831, at eight o'clock in the morning, he arrived at the site to which his calculations pointed, and found the same day the amount of the dip to be $89^{\circ} 59^{\prime}$, only one minute less than $90^{\circ}$, the vertical position, which would have precisely indicated the polar station; and the horizontal needles, suspended in the most delicate manner possible, did not betray the slightest movement. The spot was an unattractive level site along the coast, rising into ridges from fifty to sixty feet high, about a mile inland. The wish expressed by the discoverer was natural, that a place so important had possessed more of mark or note, but Nature had erected no monument to denote the spot which she had chosen as the centre of one of her "great and dark powers." A cairn of some magnitude was constructed by the adventurers, upon which the British flag was planted, and underneath, a canister was buried, containing a record of the interesting enterprise.

The magnetic needle has frequently exhibited violent disturbance when the Aurora Borealis has appeared. This has led to the surmise that these brilliant lights are connected with the electric and magnetic properties of the earth, though in a manner which we cannot explain. It has been remarked that during the appearance of the aurora the electric fluid may often be readily collected from the air. If a current of electricity also be passed through an exhausted receiver, a very correct imitation of the auroral light will be produced, displaying the same variety of colour and intensity, and the same undulating motions. It is highly probable, therefore, that the beautiful and fantastic meteoric display is connected with electricity; but great obscurity rests upon this department of meteorology.

Of all optical phenomena, the Aurora Borealis, or the northern day-break, is one of the most striking, especially in the regions where its full glory is revealed. The site of the appearance, in the north part of the hearens, and its close resemblance to the aspect of the sky before sunrise, have originated the name. The "Derwentwater Lights" was long the appellation common in the north of England, owing to their display on the night after the execution of the unfortunate earl of that name. The scene in the illustration is a picture of the auroral light, as observed from the neighbourhood of Loch Leven a scene in itself admirably calculated to exhibit the phenomenon; and to convey any 


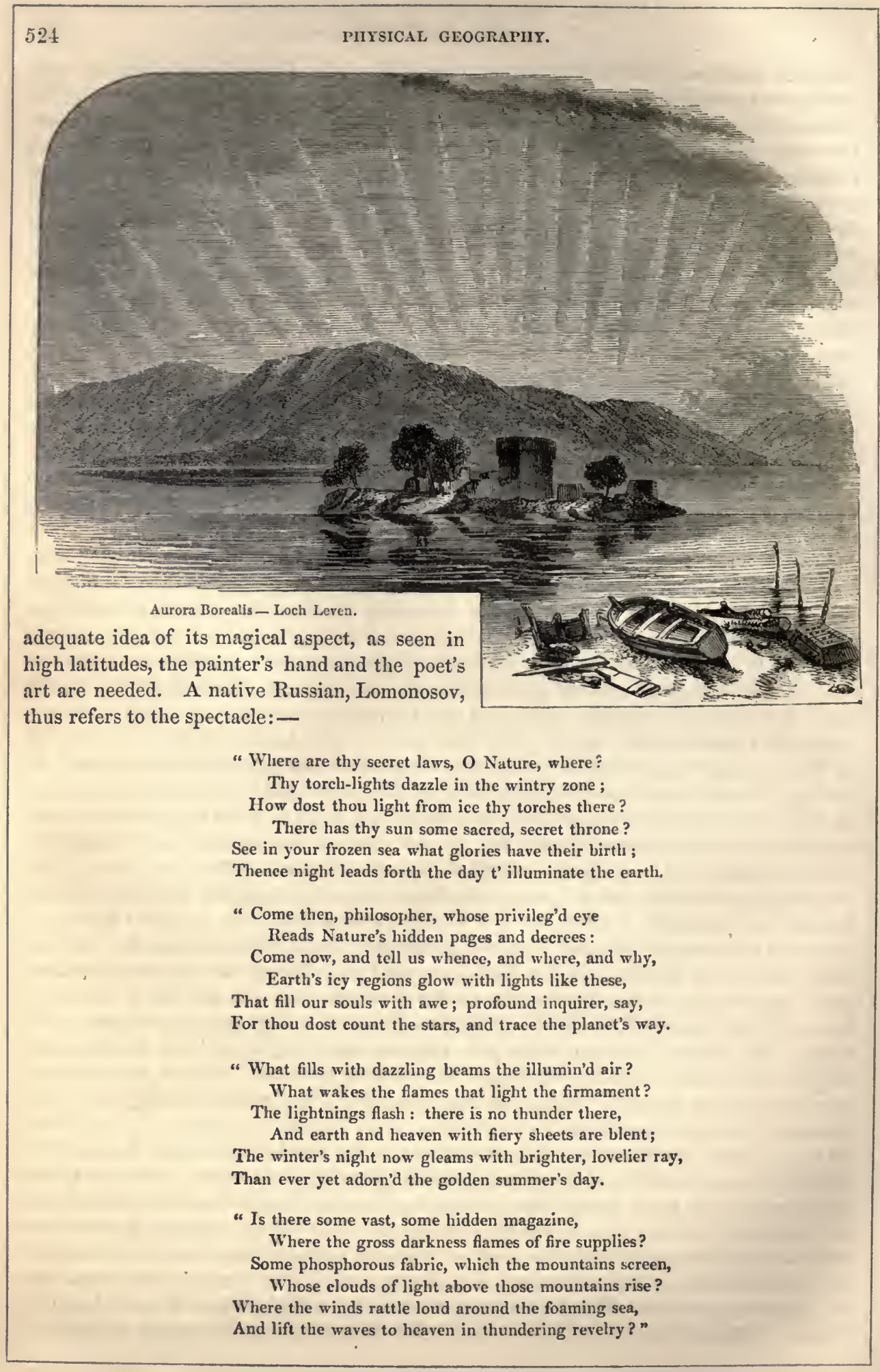


The appearances exlibited by the aurora are so various as to render it impossible to comprehend every particular in a description that must be necessarily brief and general. A cloud, or haze, is commonly seen in the northern region of the heavens, but often bearing towards the east or west, assuming the form of an arc, seldom attaining a greater altitude than $40^{\circ}$, but varying in extent from $5^{\circ}$ to $100^{\circ}$. The upper edge of the cloud is luminous, sometimes brilliant, and irregular. The lower part is frequently dark and thick, with the clear sky appearing between it and the horizon. Streams of light shoot up in columnar forms from the upper part of the cloud, now extending but a few degrees, then as far as the zenith, and even beyond it. Instances occur in which the whole hemisphere is covered with these coruscations; but the brilliancy is the greatest, and the light the strongest, in the north, near the main body of the meteor. The streamers have in general a tremulous motion, and when close together present the appearance of waves, or sheets of light, following each other in rapid succession. But no rule obtains with reference to these streaks, which have acquired the name of "the merry dancers," from their volatility, becoming more quick in their motions in stormy weather, as if sympathising with the wildness of the blast. Such is the extrnordinary aspect they present, that it is not surprising the rude Indians should gaze upon them as the spirits of their fathers roaming through the land of souls. They are variously white, pale red, or of a deep blood colour, and sometimes the appearance of the whole rainbow as to hue is presented. When several streamers emerging from different points unite at the zenith, a small and dense meteor is formed, which seems to burn with greater violence than the separate parts, and glows with a green, blue, or purple light. The display is over sometimes in a few minutes, or continues for hours, or through the whole night, and appears for several nights in succession. Captain Beechey remarked a sudden illumination to occur at one extremity of the auroral arch, the light passing along the belt with a tremulous hesitating movement towards the opposite end, exhibiting the colours of the rainbow; and as an illustration of this appearance, he refers to that presented by the rays of some molluscous animals in motion. Captain Parry notices the same effect as a common one with the aurora, and compares it, as far as its motion is concerned, to a person holding a long riband by one end, and giving it an undulatory movement through its whole length. though its general position remains the same. Captain Sabine likewise speaks of the arch being. bent into convolutions, resembling those of a snake in motion. Both Parry, Franklin, and Beechey agree in the observation that no streamers were ever noticed shooting downwards from the arch.

The preceding statement refers to aurora in high northern latitudes, where the full magnificence of the phenomenon is displayed. It forms a fine compensation for the long and dreary night to which these regions are subject, the gay and varying aspect of the heavens contrasting refreshingly with the repelling and monotonous appearance of the earth. We have already stated that the direction in which the aurora generally makes its first appearance, or the quarter in which the arch formed by this meteor is usually seen, is to the northward. But this does not hold good of very high latitudes, for by the expeditions which have wintered in the ice, it was almost always seen to the southward; while by Captain Beechey, in the Blossom, in Kotzebue Sound, 250 miles to the southward of the ice, it was always observed in a northern direction. It would appear, therefore, from this fact, that the margin of the region of packed ice is most favourable to the production of the meteor. The reports of the Greenland ships confirm this idea; for, according to their concurrent testimony, the meteoric display has a more brilliant aspect to vessels passing near the situation of the compact ice, than to others entered far within it. Instances, however, are not wanting, of the aurora appearing to the south of the zenith in comparatively low latitudes. Lieutenant Chappell, in his voyage to Hudson's 


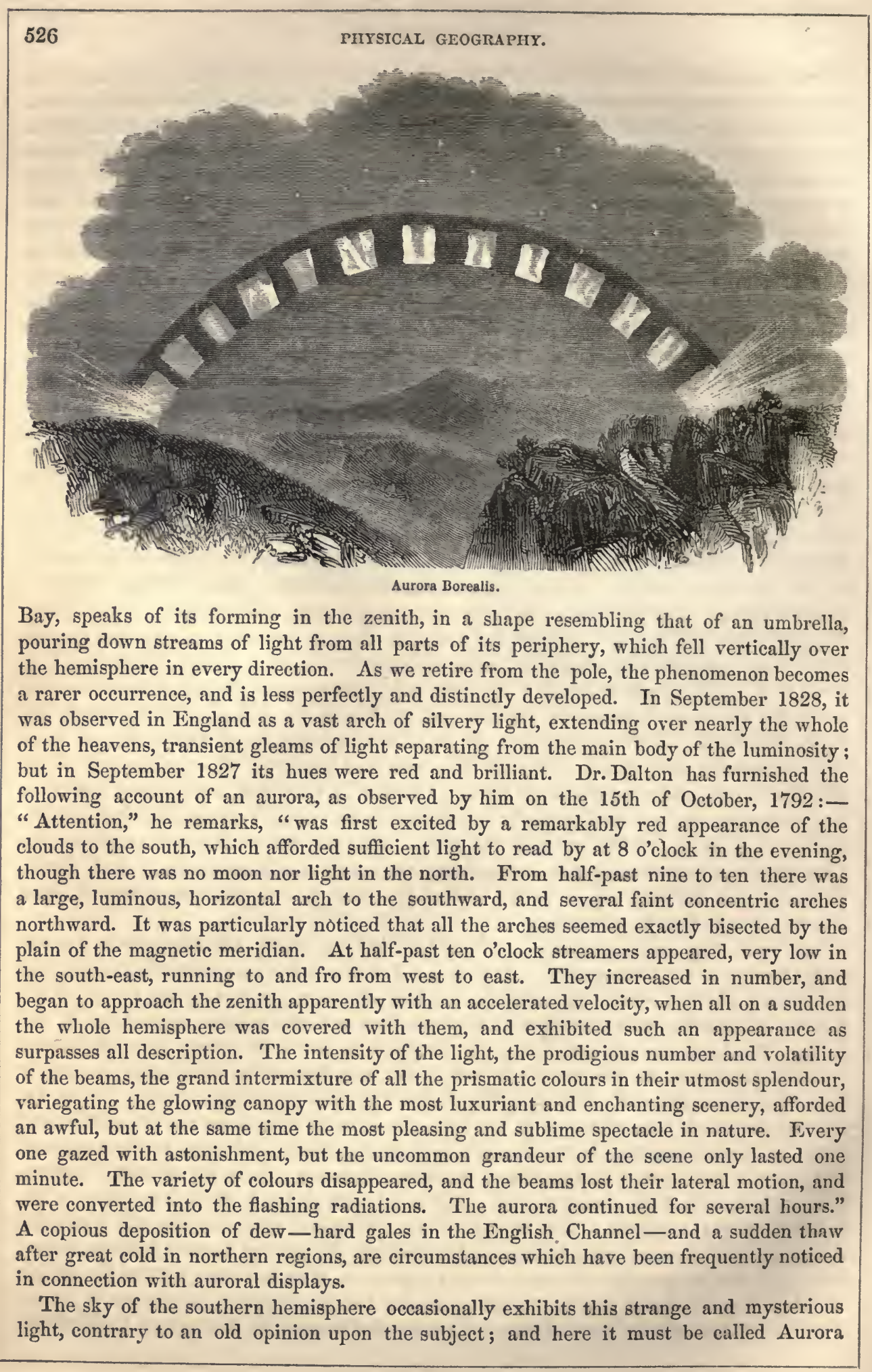


Australis, the southern day-break. Its appearance, however, is far from being so common as in the northern zone, and is much less imposing. Don Antonio Ulloa, off Cape Horn, in the year 1745, witnessed the first appearance of the kind upon record in this region. Upon the clearing off of a thick mist, a light was observed in the southern horizon, extending to an clevation of about thirty degrees, sometimes of a reddish colour, and sometimes like the light which precedes the rise of the moon, but occasionally more brilliant. Captain Cook, in the same latitudes, had more distinct views of the luminous streamers adorning the night-sky of the south. In the course of his second voyage he remarks, that on February the 17 th, 1773 , "a beautiful phenomenon was observed in the heavens. It consisted of long colours of a clear white light, shooting up from the horizon to the eastward, almost to the zenith, and spreading gradually over the whole southern part of the sky. These columns sometimes bent sideways at their upper extremity; and though in most respects similar to the northern lights, yet differed from them in being always of a whitish colour, whereas ours assume various tints, especially those of a purple and fiery hue. The stars were sometimes hid by, and sometimes faintly to be seen through, the substance of these southern lights, Aurora Australis." The sky was generally clear when they appeared, and the air sharp and cold, the thermometer standing at the freezing point, the ship being in latitude $58^{\circ}$ south.

The history of auroral phenomena goes back to the time of Aristotle, who undoubtedly refers to the exhibition in his work on Meteors, describing it as occurring on calm nights, having a resemblance to flame mingled with smoke, or to a distant view of burning stubble, purple, bright red, and blood-colour, being the predominant hues. Notices of it are likewise found in many of the classical writers; and the accounts which occur in the chronicles of the middle ages, of surprising lights in the air, converted by the imagination of the vulgar into swords -gleaming and armies fighting, are allusions to the play of the northern lights. There is strong reason to believe, though the fact is perfectly inscrutable, that the aurora has been much more common in the European region of the northern zone, during the last century and a half, than in former periods. A very brilliant appearance took place on the 6th of March 1716, which forms the subject of a paper by Halley, who remarks, that nothing of the kind had occurred in England for more than eighty years, nor of the same magnitude since 1574, or about 140 years previous, in the reign of Queen Elizabeth, when Camden and Stow were eye-witnesses of it. The latter states in his Annals, that on November 14th, "were seen in the air strange impressions of fire and smoke to proceed forth from a black cloud in the north towards the south that the next night the heavens from all parts did seem to burn marvellous ragingly, and over our heads the flames from the horizon round about rising did meet, and there double and roll one in another, as if it had been in a clear furnace." The year following, 1575, it was twice repeated in Holland, but not observed in this country; and as a specimen of the tone of thought respecting the aurora, the description of Cornelius Gemma, a professor in the university of Louvain, may be given. Referring to the second instance of the year, and speaking in the language of the times, he remarks:- "The form of the Chasma of the 28th of September following, immediately after sunset, was indeed less dreadful, but still more confused and various; for in it were seen a great many bright arches, out of which gradually issued spears, cities with towers and men in battle array; after that, there were excursions of rays every way, waves of clouds and battles mutually pursued and fled, and wheeling round in a surprising manner." This phenomenon was repeatedly observed in the last century in Sweden, as at present; but prior to the year 1716, the inhabitants of Upsal considered it as a great rarity. Nothing is more common now in Iceland than the northern lights, exhibited during the winter with imposing grandeur and brilliance : but Torfæus, the historian of Denmark, an Icelander, who 
wrote in 1706 , records his remembrance of the time when the meteor was an object of terror in his native island. It deserves remark, that its more frequent occurrence in the Atlantic regions has been accompanied by its diminution in the eastern parts of Asia, as Baron Von Wrangel was assured by the natives there, who added that formerly it was brighter than at present, and frequently coloured like the rainbow. A work by M.de Mairan, entitled, Traité Physique et Historique de l'Aurore Boreale, published in 1754, records all the observations of aurora from the sixth century down to that date, as far as they appear upon the page of history. From this work, the singular view of an auroral appearance just given is copied, which was observed for a few minutes at Breuillepont, in Normandy, on the 19th of October, 1726. The gross number of distinct phenomena enumerated by M. Mairan, amounts to 1441, distributed as follows :-

\begin{tabular}{rrrrr} 
& & \multicolumn{2}{c}{ Number obserred. } \\
1954 & & A. D. 1354 & - & - \\
1560 & 1560 & - & - & 34 \\
1592 & 1592 & - & - & 69 \\
1633 & 1633 & - & - & 70 \\
1684 & 1684 & - & - & 34 \\
1721 & 1721 & - & - & 219 \\
1745 & 1745 & - & - & 961 \\
& 1751 & - & - & 28
\end{tabular}

Of course, during the earlier periods, we must suppose that a great many instances occurred which found no record; but the ligh numbers which appear after the close of the seventeenth century, may be considered as confirming the presumption of auroral exhibitions having become more common in European localities. Distributed according to the different months in which the aurora appeared, the numbers to be assigned to each are -

\begin{tabular}{|c|c|c|c|c|}
\hline January & . & - & - & - \\
\hline February & - & - & - & - \\
\hline Mareh & - & - & - & - \\
\hline April - & - & - & - & - \\
\hline May - & - & - & - & - \\
\hline June - & - & - & - & - \\
\hline
\end{tabular}

\begin{tabular}{|c|c|c|c|c|}
\hline July - & - & - & 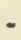 & - \\
\hline August & - & - & - & - \\
\hline September & - & - & - & - \\
\hline October & - & - & - & - \\
\hline November & - & - & - & - \\
\hline December & - & - & - & - \\
\hline
\end{tabular}

The instances in the winter balf-year amount to 972 , and those in the summer to 469 , being nearly in the proportion of 2 to 1 in favour of the former.

It has been repeatedly affirmed, that auroral displays are attended with sound, variously described as a hissing, murmuring, and crackling noise. Blagden and Gmelin offer several testimonies of a rustling noise having been occasionally heard; Nairne, Cavallo, and others speak of a hissing sound; and Henderson remarks, that in Iceland, when the coruscations are particularly quick and vivid, a crackling noise is heard, resembling that which attends the escape of the sparks from an electric machine. Captain Lyon observes, that the sudden glare and rapid bursts of those wondrous showers of fire that appear in the sky make it difficult to fancy their movements wholly without sound, but nothing was ever heard by him, or by his companion Captain Parry. The latter states, that it was too cold to admit of the ears being long uncovered; but Lyon declares, that he stood for hours on the ice listening, and at a distance from every sounding body, without catching the faintest noise. But the counter testimonies are so numerous, that this point must be deemed at present an open question. Dr. Richardson was an attentive student of the aurora during the arctic land expedition of Sir John Franklin; and though he never heard any sound that could be unequivocally considered as originating with the meteor, yet the united testimony of the natives, both Crees, Copper Indians, and Esquimaux, and 
of all the older residents at the European ports, induced him to believe that its motions are sometimes audible. It has also been debated, what effect the auroral light produced upon the stars in its path, respecting which, Parry states: - "Of its dimming the stars there cannot be a doubt; we remarked it to be in this respect like drawing a gauze veil over the heavens in that part, the veil being the thickest when two of the luminous sheets met and overlapped."

Various results of calculation have been given as to the elevation of auroral phenomena. They clearly oceur within the limits of our atmosphere, from the fact of the earth's diurnal motion having no effect upon the apparent position of the meteor. MI. de Mairan assigns to it a mean height of 175 Frencl leagues, equal to 464 English miles; Dr. Dalton concludes the average elevation to be about 100 English miles; but according to Parry, the auroral appearances seemed to be full as near as many of the clouds commonly seen. In one instance, the aurora appeared to be connected with a very remarkable cloud of a light brown colour, resenibling an immense volume of smoke, or a powder magazine in a state of explosion, (the comparison of the gunner, for upon the breaking up of the cloud the phenomenon was seen in the same part of the heavens. The experience of Beechy is in favour of a comparatively low elevation. "We frequently observed," he states, "the aurora attended by a thin, fleecy, cloud-like substance, which, if not part of the meteor, furnishes a proof of the displays having taken place within the region of our atmosphere, as the light was decidedly seen between it and the earth. This was particularly noticed on the 28th of September, 1827. The aurora on that night began by forming two arches from W. by N. northward to E. by N., and about eleven o'clock threw out brilliant coruscations. Shortly after the zenith was obscured by a lucid haze, which soon condensed into a canopy of light clouds. We could detect the aurora above this canopy by several bright arches being refracted, and by brilliant colours being apparent in the interstices. Shortly afterwards the meteor descended, and exhibited a splendid appearance, without any interruption from clouds, and then retired, leaving the fleecy stratum only visible at first. This occurred several times, and left no doubt in my own mind of the aurora being at one time above, but at another below, the canopy formed about our zenith. 'The supposition of the light being at no great elevation, is strengthened by the different appearances exhibited by the aurora at the same times, to observers not more than from ten to thirty miles apart; and also by its being visible to persons on board the ship at Chamisso Island after it had vanished in Escholtz Bay, only ten miles distant, as well as by the aurora being seen by the barge detached from the Blossom several days before it was visible to persons on board the ship, about two hundred miles to the southward of her. Captain Franklin has mentioned a similar eircumstance in his notices on the Aurora Borealis in his first expedition, when Dr. Richardson and Mr. Kendall were watching for the appearance of the meteor by agreement, and when it was seen by the former actively sweeping across the heavens and exhibiting prismatic colours, without any appearance of the kind being witnessed by the latter, then only twenty miles distant from his companion. Captain Parry also, in his third voyage, describes the aurora as being seen even between the hills and the ship anchored at Port Bowen." Still, it is unquestionable, that the aurora occasionally occurs in the lighest regions of the atmosphere, as in the grand example of 1716 , which was simultaneously observed in places very remote from each other, and ascertained to be visible from latitude $50^{\circ}$ north, all over Europe, between the confines of Russia on the east and Ireland on the west, a sufficient evidence of its very great altitude.

From optical phenomena belonging to the electric class, or which are supposed to have electrical connections, we proceed to consider the appearanees which simply result from peculiar atmospheric conditions. 
1. Halos. The simplest form of the halo is that of a white concentric ring surrounding the sun or moon, a very common appearance in our climate in relation to the moon, oceasioned by very thin vapour, or minute particles of ice and snow, diffused through the atmosphere, deflecting the rays of light. Double rings are occasionally seen, displaying the brightest hues of the rainbow. The coloured ring is produced by globules of visible vapour, the resulting halo exhibiting a character of density, and appearing contiguous to the luminous body, according as the atmosphere is surcharged with humidity. Hence a dense halo close to the moon is universally and justly regarded as an indication of coming rain. It has been stated as an approximation, that the globules which occasion the appearance of coloured circles vary from the 5000th to the 50,000th part of an inch in diaineter. Though seldom apparent around the sun in our climate, yet it is only necessary to remore that glare of light which makes delicate colours appear white, to perceive segments of beautifully tinted halos on most days when light fleecy clouds are present. The illustration shows a nearly complete and slightly elliptical ring around the sun, the lower portion hidden by the horizon, which was distinetly observed during the summer of 1845 in the neighbourhood of Ipswich, of an extremely pale pink and blue tint. When Humboldt was at Cumana, a large double halo around the moon fixed the attention of the inhabitants, who considered it as the presage of a violent earthquake. The hygrometer denoted great liumidity, yet the vapours appeared so perfectly in solution, or rather so clastic and uniformly disseminated, that they did not alter the transparency of the atmosphere. The moon arose after a storm of rain behind the Castle of St. Antonio. As soon as she appeared on the horizon, two circles were distinguished, one large and whitish, $44^{\circ}$ in diameter, the other sinaller, displaying all the colours of the rainbow. The space between the two circles was of the deepest azure. At the altitude of $4^{\circ}$ they disappeared, while the meteorological instruments indicated not the slightest cliange in the lower regions of the air. The phenomenon was chiefly remarkable for the great brilliancy of its colours, and for the circumstance that, according to the measures taken with Ramsden's sextant, the lunar disc was not exactly in the centre of the halos. Humboldt mentions likewise having seen at Mexico, in extremely fine weather, large bands spread along the vault of the sky, converging towards the lunar disc, displaying beautiful prismatic colours; and he remarks, that within the torrid zone, similar appearances are the common phenomena of the night, sometimes vanishing and returning in the space of a few minutes, which he assigns to the superior currents of air changing the state of the floating vapours, by which the light is refracted. Between latitude $15^{\circ}$ of the equator, he records having observed small tinted halos around the planet Venus, the purple, orange, and violet being distinctly perceptible, which was never the case with Sirius, Canopus, or Acherner. In the northern regions solar and lunar halos are very common appearances, owing to the abundance of minute and highly crystallised spicula of ice floating in the atmosphere. The arctic adventurers frequently mention the fall of icy particles during a clear sky and a bright sun, so small as scarcely to be visible to the naked eye, and most readily detected by their melting upon the skin.

2. Parhelia. Mock suns, in the vicinity of the real orb, are due to the same cause as halos, which appear in connection with them. Luminous circles, or segments, crossing one another, produce conspicuous masses of light by their united intensities, and the points of intersection appear studded with the solar image. This is a meteorological rarity in our latitude, but a very frequent spectacle in the arctic climes. In Iceland, during the severe winter of 1615 , it is related that the sun, when seen, was always accompanied by two, four, five, and even nine of these illusions. Captain Parry describes a remarkably gorgeous appearance, during his winter sojourn at Melville Island, which continued from noon until six o'clock in the evening. It consisted of one complete halo, 


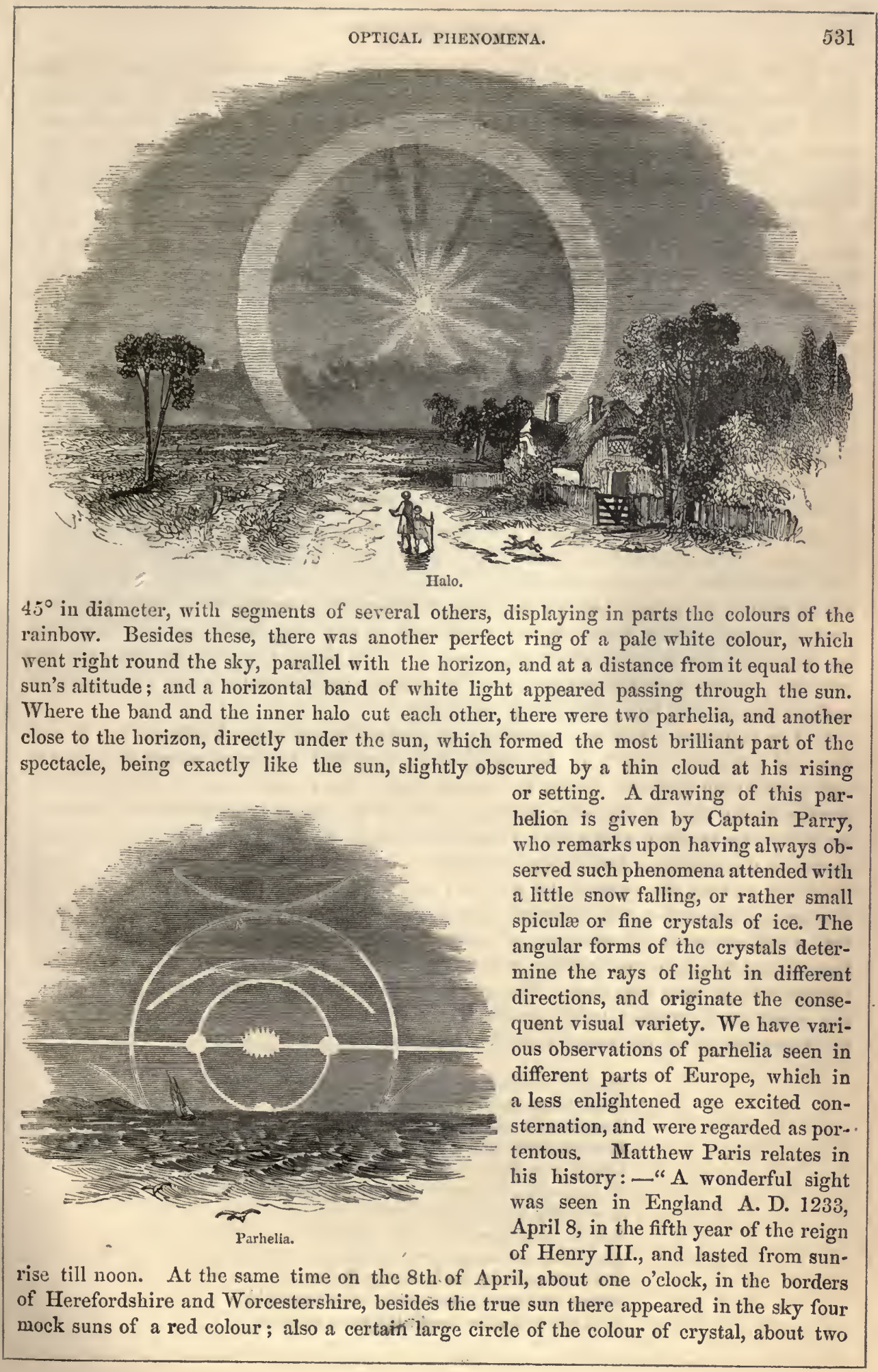


feet broad, which encompassed all England as it were. There went out semicireles from the side of it, at whose intersection the four mock suns wcre situated, the true sun bcing in the east, and the air very clear. And becausc this monstrous prodigy cannot be described by words, I have represented it by a scheme, which shows immediately how the heavens were circled. The appearance was painted in this manner by many pcople, for the wonderful novelty of it."

3. Paraselena. Mock moons, depending upon the causes which produce the solar image, or screral examples of it, as frequently adorn the arctic sky. On the 1 st of December 1819, in the evening, while Parry's expedition was in Winter Harbour, four paraselenr were obscrved, each at the distance of $21 \frac{1}{2}^{\circ}$ from the truc moon. One was close to tho horizon, the other perpendicular above it, and the other two in a line parallel to the horizon. Their shape was like that of a comet, the tail being from the moon, the side of each towards the real orb being of a light orange colour. During the existence of thesc paraselenx, a halo appeared in a concentric circle round the moon, passing through each image. On the evening of March 30, 1820, about ten o'clock, the attention of Dr. Trail at Liverpool was directed by a friend to an unusual appearance in tle sky, which proved to be a beautiful display of paraselena. The moon was then $35^{\circ}$ above the southern horizon. The atmosphere was nearly calm, but rather cloudy, and obscured by a slight haze. A wide halo, faintly exhibiting the prismatic colours, was described round the moon as a centre, and had a small portion of its circumference cut off by the horizon. The circular band was intersected by two small segments of a larger circle, which if completed would have passed through the moon, and parallel to the horizon. 'These segments were of a paler colour than the first mentioned circle. At the points of intersection appeared two pretty well defined luminous dises, equalling the moon in size, but less brilliant. 'The western paraselene had a tail or coma, whicl was directed from the moon, and the eastern also, but mueh less clearly defined.

4. The Rainbow. The most glorious vision depending upon the decomposition, refraction, and reflection of light, by the vapour of the atmosphere reduced to fluid drops, is the well-known arch projected during a shower of rain upon a cloud opposite to the sun, displaying all the tints of the solar spectrum. The first marked approximation to the true theory of the rainbow occurs in a volume entitled De Radiis Visus et Lucis, written by Antonius de Dominis, Archbishop of Spalatro, published in the year 1611 at Venice. Descartes pursued the subject, and correctly explained some of the phenomena ; but upon Newton's discovery of the different degrees of refrangibility in the different coloured rays which compose the sunbeam, a pencil of white or compounded light, the cause of the coloured bands in the rainbow, of the order of their position, and of the breadth they occupy, was at once apparent. The bow is common to all countrics, and is the sign of the covenant of promise to all people, that there sliall no more be such a wide-spread deluge as that which the sacred narrative records.

\footnotetext{
"But say, what mean those coloured streaks in liearen Distended, as the brow of God appeased?

Or serve they, as a flowery verge to bind

The fiuid skirts of that same watery cloud,

Lest it again dissolre, and sliower the earth?

To whom the Arelsangel: Dexterously thou aim'st;

So willingly dotlı God remit his ire -

That he relents, not to blot out mankind;

And makes a covenant never to destroy

The earth again by flood; nor let the sea

Surpass its bounds; nor rain to drown the world,

With mau therein, or beast; but when he brings
} 
O'er the earth a cloud, will therein sct

Ilis triple-coloured bow, whereon to look,

And eall to mind his covenant."

It is happily remarked by Mr. Prout, in his Bridgewater treatise, that no pledge could have been more felicitous or satisfactory; for, in order that the rainbow may appear, the

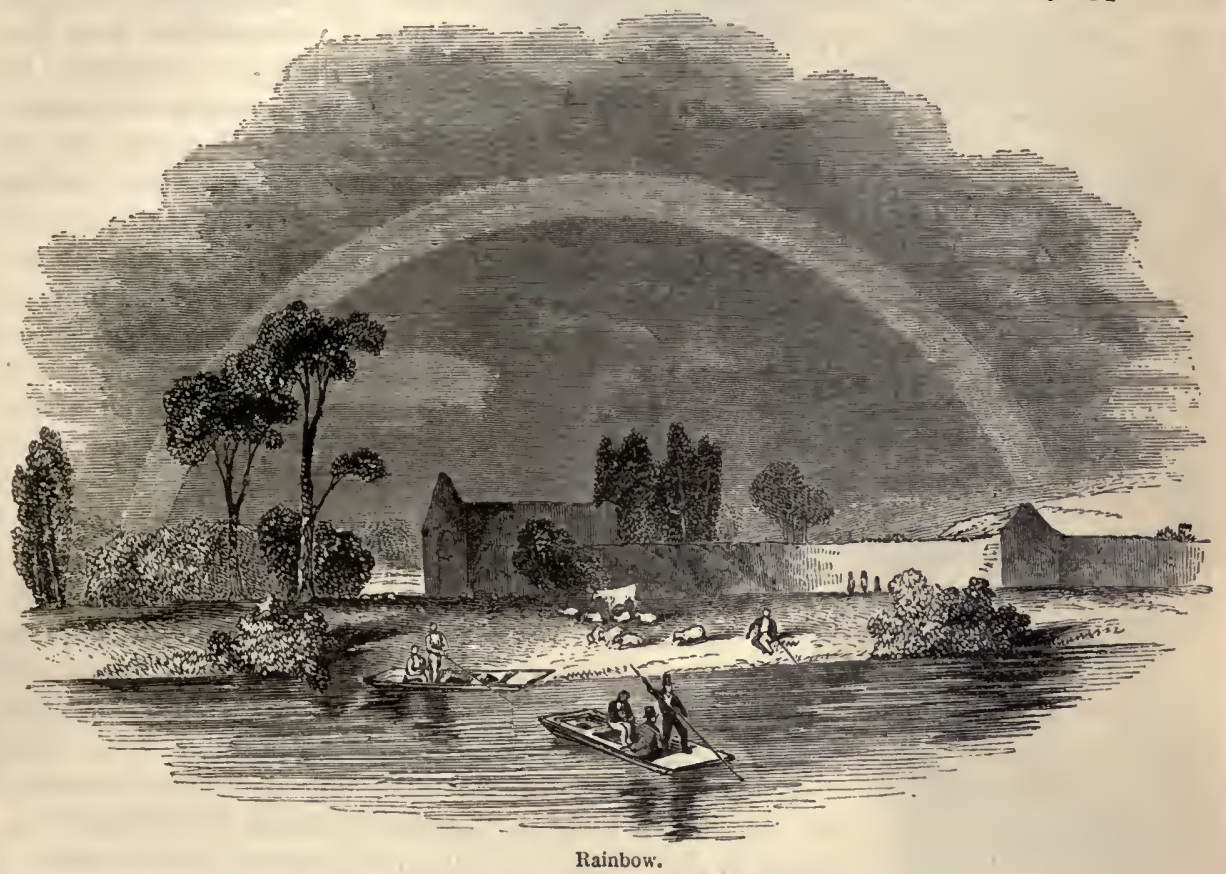

clouds must be partial, and hence its existence is absolutely incompatible with universal deluge from above. So long, therefore, as "He doth . set his bow in the clouds," so long have we full assurance that these clouds must continue to shower down good, and not evil, to the earth.

When rain is falling, and the sun is on the horizon, the bow appears a complete semicircle, if the raiu-cloud is sufficiently extensive to display it. Its extent diminishes as the solar altitude increases, because the coloured arch is a portion of a circle whose centre is a point in the sky directly opposite to the sun. Above the height of $45^{\circ}$ the primary bow is invisible, and hence, in our climatc, the rainbow is not seen in summcr about the middle of the day. In peculiar positions, as when the spectator is on a mountain and the shower is in a valley, or whell we chance to view the shower from any lofty pinnacle, nearly the whole circumference may sometimes be embraced. Ulloa and Bouguer describe circular rainbows, frequently seen on the mountains, which rise above the tableland of Quito. When rain is abundant, there is a secondary bow distinctly seen, produced by a double reflection. This is exterior to the primary one, and the intervening space has been observed to be occupied by an arch of coloured light. The secondary bow differs from the other, in exhibiting the same series of colours in an inverted order. Thus the red is the uppermost colour in the interior bow, and the violet in the exterior. A ternary bow may exist, but it is so exceedingly faint from the repeated reflections, as to be scarcely ever perceptible. The same lovely spectacle may be seen when the solar splendour falls upon the spray of the cataract and the waves, the shower of an artificial 
fountain, and the dew upon the grass. There is hardly any other object of nature more

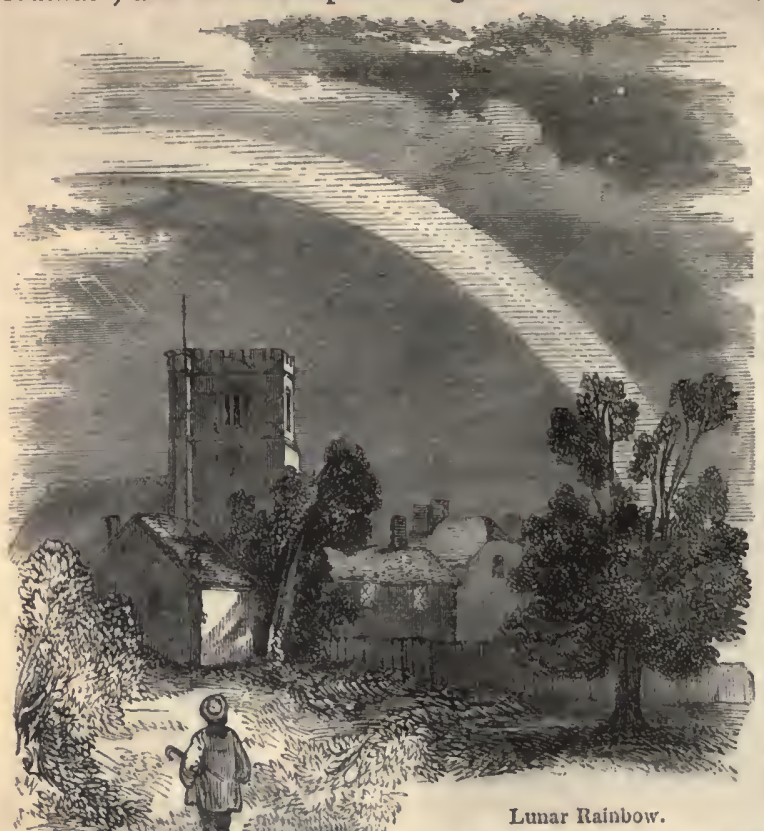
pleasing to the eyc, or soothing to the mind, than the rainbow, when distinctly developed - a familiar sight in all regions, but most common in mountainous distriets, where the showers are most frequent. Poetry has celebrated its beauty, and to convey an adequatc representation of its soft and rariegated tints, is the liighest achicvement of the painter's art. While the Hobrews ealled it the Bow of God, on account of its association with a divine promise, and the Greeks the Daughter of Wonder, the rude inhabitants of the North gave expression to a fancy which its peculiar aspect might well crente, styling it the Bridge of the Gods, a passage connecting liearen and earth.

The principles which account for the formation of the rainbow explain the appearance of beautiful irridescent arches which have occasionally been observed during the prevalence of mist and sunshine. Mr. Cochin describes a spectacle of this kind, noticed from an eminence that overlooked some low meadow grounds, in a direction opposite to that of the sun, which was shining very brightly, a thick mist resting upon the landscape in front. At about the distance of half a mile from each other, and incurvated, like the lower extremities of the common rainbow, two places of peculiar brightness were seen in the mist. They seemed to rest on the ground, were continued as high as the fog extended, the breadth being nearly half as much more as that of the rainbow. In the middle, between these two places, and on the same horizontal line, there was a coloured appearance, whose base subtended an angle of about $12^{\circ}$, and whose interior parts were thus variegated. The centre was dark, as if made by the shadow of some object resembling in size and shape an ordinary sheaf of corn. Next this centre there was a curved space of a yellow flame colour. To this succeeded another curved space of nearly the same dark cast as the centre, very evenly bounded on each side, and tinged with a faint blue green. The exterior exhibited a rainbow circlet, only its tints were less vivid, their boundaries were not so well defined, and the whole, instead of forming part of a perfect circle, appeared like the end of a concentric ellipsis, whose transverse axis was perpendicular to the horizon. The mist lay thick upon the surface of the meadows ; the observer was standing near its margin, and gradually the scene became fainter, and faded away, as he entered into it. A similar fog-bow was seen by Captain Parry during his attempt to reach the North Pole by means of boats and sledges, with five arches formed within the main one, and all beautifully coloured.

The iris lunaris, or lunar rainbow, is a much rarer object than the solar one. It 
frequently consists of a uniformly white arch, but it has often been seen tinted, the colours differing only in intensity from those caused by the direct solar illuminations. Aristatle states that he was the first observer of this interesting spectacle, and that he only saw two in the course of fifty years; but it must have been repeatedly witnessed, without a record having been made of the fact. Thoresby relates an account received from a friend, of an observation of the bow fixed by the moon in the clouds, while travelling in the Peak of Derbyshirc. She had then passed the full about twenty-four hours. The evening had been rainy, but the clouds had dispersed, and the moon was shining very clearly. This lunar iris was more remarkable than that observed by Dr. Plot, of which there is an account in his History of Oxford, that being only of a white colour, but this had all the hues of the solar rainbow, beautiful and distinct, but fainter. Mr. Bucke remarks upon having had the good fortune to witness several, two of which were perhaps as fine as were ever witnessed in any country. The first formed an arch over the vale of Usk. The moon hung over the Blorenge; a dark cloud was suspended over Myarth; the river murmured over beds of stones, and a bow, illumined by the moon, stretched from one side of the vale to another. The second was seen from the castle overlooking the Bay of Carmarthen, forming a regular semicircle over the river Towy. It was in a moment of vicissitude; and the fancy of the observer willingly reverted to the various soothing associations under which sacred authority unfolds the emblem and sign of a merciful covenant.

5. Aerial Illusions. - $\mathbf{A}$ series of curious and interesting phenomena, involving the apparent elevation and approach of distant objects, the production of aerial images of terrestrial forms, of double images, their inversion, and distortion into an endless variety of grotesque shapes, together with the deceptive aspect given to the desert-landscape, are comprehended in the class of optical illusions. Different varieties of this singular visual effect constitute the mirage of the French, the fata morgana of the Italians, the looming of our seamen, and the glamour of the Highlanders. It is not peculiar to any particular country, though more common in some than others, and most frequently observed near the margin of lakes and rivers, by the sea-shore, in mountain districts and on level plains. These phantoms are perfectly explicable upon optical principles, and though influenced by local combinations, they are mainly referable to one common cause, the refractive and reflective properties of the atmosphere, and inequalities of refraction arising from the intermixture of strata of air of different temperatures and densities. But such appearances in former times were readily converted by the imagination of the vulgar into supernatural realities; and hence many of the goblin stories with which the world has been rife, not yet banished from the discipline to which childhood is subject, -

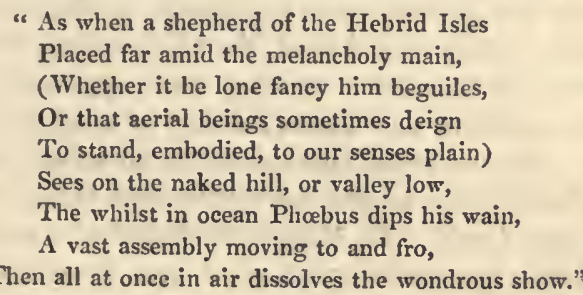

Pliny mentions the Scythian regions within Mount Imaus, and Pomponius Mela those of Mauritania, behind Mount Atlas, as peculiarly subject to these spectral appearances. Diodorus Siculus likewise refers to the regions of Africa, situated in the neighbourhood of Cyrene, as another chosen site:- "Even," says he, "in the severest weather, there are sometimes seen in the air certain condensed exhalations that represent the figures of all 
kinds of animals; occasionally they seem to be motionless, and in perfect quietude; and occasionally to be flying; while immediately afterwards they themselves appear to be the pursuers, and to make other objects fly before them." Milton might lave had this passage in his eye when he penned the allusion to the same apparitions:-

"As when, to warn proud cities, war appears

Waged in the troubled sky, and armies rush

To battle in the clouds; before eacli van

Prick forth the airy knights, and couch their spears,

Till thickest legions close; with feats of arms

From either side of heaven the wclkin rings."

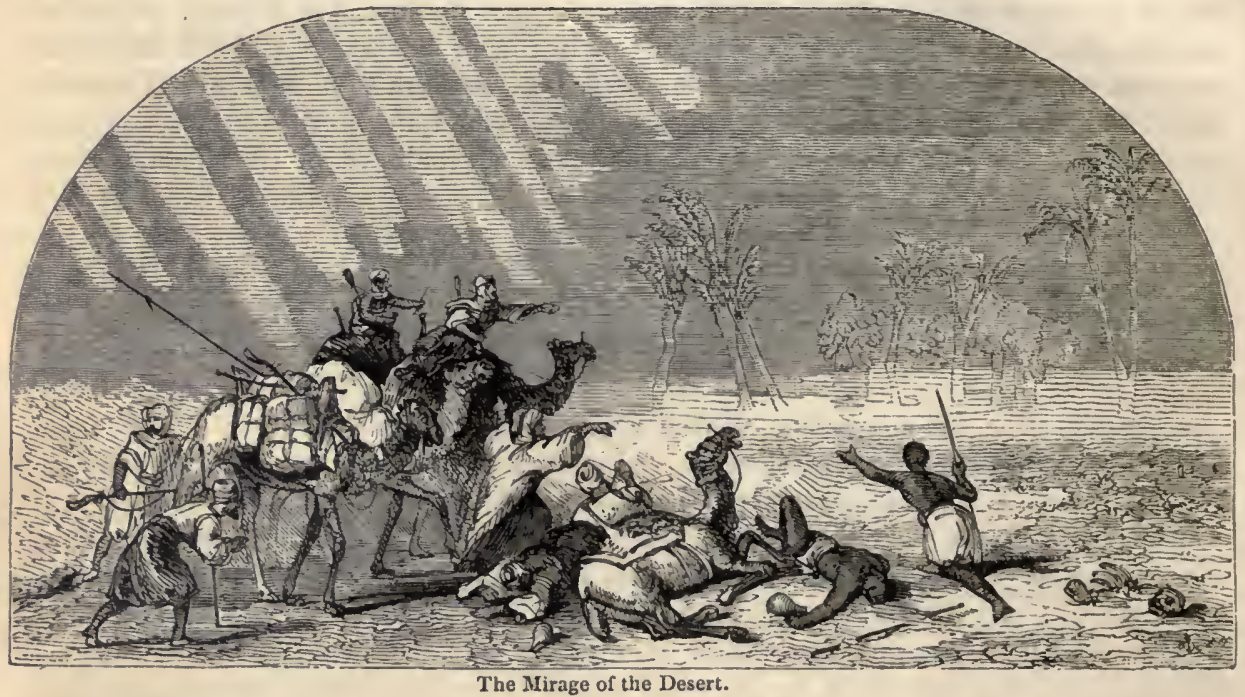

The Mirage of the Desert.

The mirage, adverted to in noticing the sandy deserts of the globe, is the most familiar form of optical illusion. M. Monge, one of the French savans, who accompanied Buonaparte in his expedition to Egypt, witnessed a remarkable example. In the desert between Alexandria and Cairo, in all directions green islands appeared, surrounded by extensive lakes of pure, transparent water. Nothing could be conceived more lovely or picturesque than the landscape. In the tranquil surface of the lakes the trees and houses with which the islands were covered were strongly reflected with vivid and varied hues, and the party hastened forward to enjoy the refreshments apparently proffered them. But when they arrived, the lake on whose bosom they floated, the trees among whose foliage they arose, and the people who stood on the shore inviting their approach, had all vanished; and nothing remained but the uniform and irksome desert of sand and sky, with a few naked huts and ragged Arabs. But for being undeceived by an actual progress to the spot, one and all would have remained firm in the conviction that these visionary trees and lakes had a real existence in the desert. M. Monge attributed the liquid expanse, tantalising the eye with an unfaithful representation of what was earnestly desired, to an inverted image of the cerulean sky, intermixed with the ground scenery. This kind of mirage is known in Persia and Arabia by the name of Serab or miraculous water, and in the western deserts of India by that of Tchittram, a picture. It occurs as a common emblem of disappointment in the poetry of the orientals.

In the Philosophical Transactions for the year 1798, an account is given by W. Latham, Esq., F.R.S., of an instance of unusual refraction observed by him, by which the 
coast of Picardy was rendered distinctly visible, and was apparently brought near to that of Hastings. On July the 26th, about five in the afternoon, while sitting in his diningroom, near the sea-shore, attention was excited by a crowd of people ruming dowu to the beach. Upon inquiring the reason, it appeared that the coast of France was plainly to be distinguished with the naked eye. Upon proceeding to the shore, he found that he could see the cliffs across the Channel, which are fifty miles distant, and are actually hid by the convexity of the earth, that is, a straight line drawn from Hastings to the French caast would pass through the sea. They appeared to be only a few miles off, and seemed to extend for some leagues along the coast. At first the sailors and fishermen could not be persuaded of the reality of the appearance, but they soon became thoroughly convinced, by the cliffs gradually appearing more elevated, and seeming to approach nearer, so that they were able to point out the different places they had been accustomed to risit, such as the Bay, the Old Head, and the Windmill at Boulogne, St. Vallery, and several other spots. Their remark was, that these places

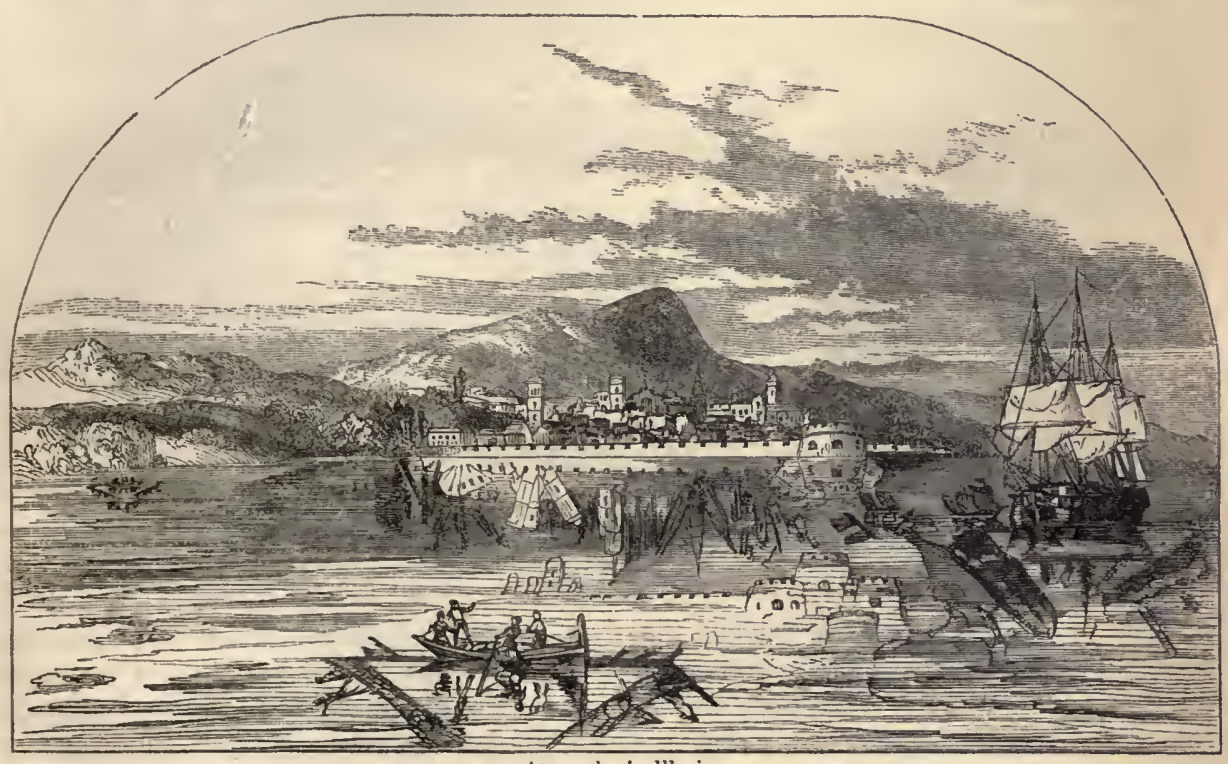

Atmospheric lllusion.

appeared as near as if they were sailing at a small distance into the harbour. The apparition of the opposite cliffs varied in distinctness and apparent contiguity for nearly an hour, but it was never out of sight, and upon leaving the beach for a hill of some considerable height, Mr. Latham could at once see Dungeness and Dover cliffs on each side, and before him the French coast from Calais to near Dieppe. By the telescope the French fishing boats were clearly seen at anchor, and the different colours of the land on the heights, with the buildings, were perfectly discernible. The spectacle continued in the highest splendour until past eight o'clock, though a black cloud obscured the face of the sun for some time, when it gradually faded away. This was the first time within the memory of the oldest inhabitants, that they had ever caught sight of the opposite shore. The day had been extremely hot, and not a breath of wind had stirred since the morning, when the small pennons at the mast-heads of the fishing-boats in the harbour had been at all points of the compass. Professor Vince witnessed a similar apparent elevation of the coast of France as seen from Ramsgate, for at the very edge of the water he discerned the Calais cliffs a very 
considerable height above the horizon, whereas they are frequently not to be seen in clear weather from the high lands above the town. A much greater breadth of coast also appeared than is usually observed under the most farourable circumstances. The ordinary refractive power of the atmosphere is thus liable to be strikingly altered by a change of temperature and humidity, so that a hill which at one time appears low, may at another be seen towering aloft; and a city in a neighbouring valley, may from a certain station be entirely invisible, or it may show the tops of its buildings, just as if its foundations had been raised, according to the condition of the acrial medium between it and the spectator.

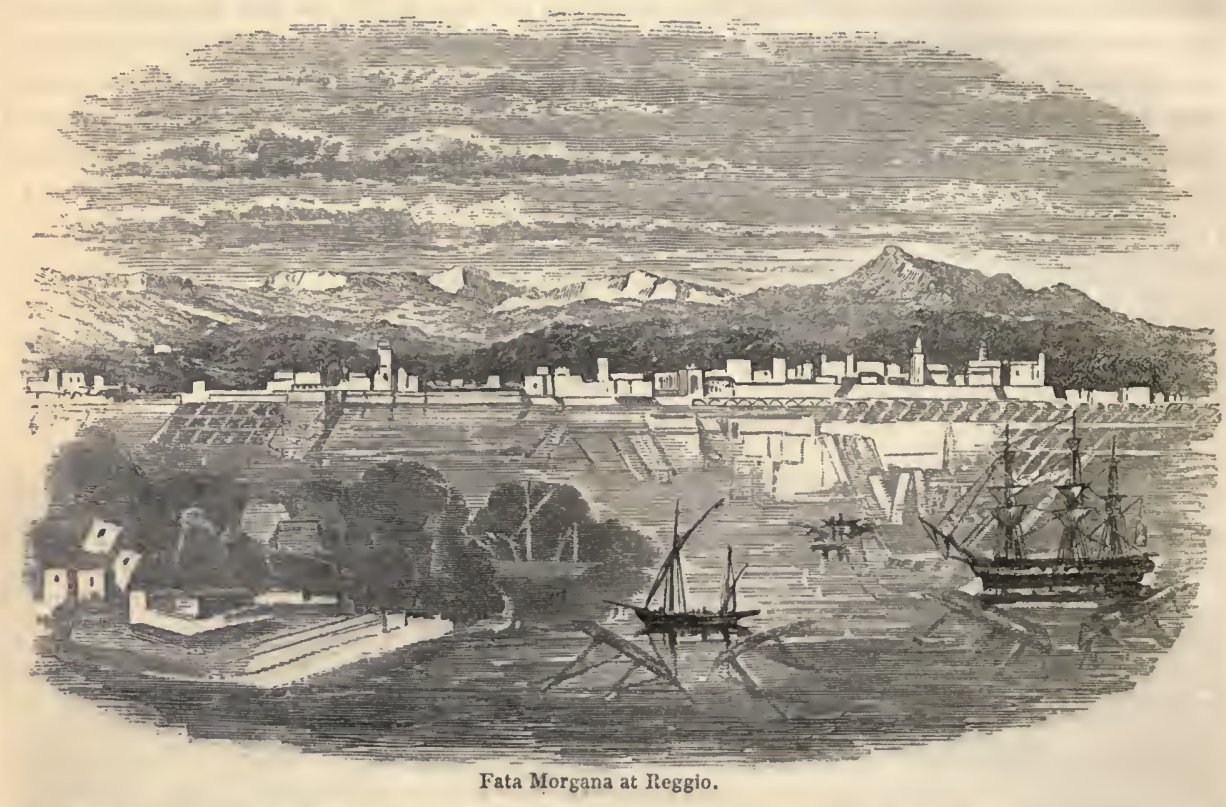

Of all instances of spectral illusion, the fata morgana, familiar to the inhabitants of Sicily, is the most curious and striking: It occurs off the Pharo of Messina, in the strait which separates Sicily from Calabria, and has been variously described by different observers, owing, doubtless, to the different conditions of the atmosphere at the respective times of observation. The spectacle consists in the images of men, cattle, houses, rocks, and trees, pictured upon the surface of the water, and in the air immediately over the water, as if called into existence by an enchanter's wand, the same object having frequently two images, one in the natural and the other in an inverted position. A combination of circumstances must concur to produce this novel panorama. The spectator, standing with his back to the east on an elevated place, commands a view of the strait. No wind must be abroad to ruffle the surface of the sea; and the waters must be pressed up by currents, which is occasionally the case, to a considerable height, in the middle of the strait, so that they may present a slight convex surface. When these conditions are fulfilled, and the sun has risen over the Calabrian heights so as to make an angle of $45^{\circ}$ with the horizon, the various objects on the shore at Reggio, opposite to Messina, are transferred to the middle of the strait, forming an immovable landscape of rocks, trees, and houses, and a movable one of men, horses, and cattle, upon the surface of the water. If the atmosphere, at the same time, is highly charged with rapour, the phenomena apparent on the water will also be visible in the air, occupying a space which extends 
from the surface to the height of about twenty-five feet. Two kinds of morgana may therefore be discriminated: the first, at the surface of the sea, or the marine morgana; the second, in the air, or the aerial. The term applied to this strange exhibition is of uncertain derivation, but supposed by some to refer to the vilgar presumption of the spectacle being produced by a fairy or magician. The populace are said to hail the vision with great exultation, calling every one abroad to partake of the sight, with the cry of "Morgana, morgana!"

Father Angelucci, an eyc-witness, describes the scene in the following terms:- "On the 15th of August, 1643, as I stood at my window, I was surprised with a most wonderful, delectable vision. The sea that washes the Sicilian shore swelled up, and became, for ten miles in lengtli, like a chain of dark mountains; while the waters near our Calabrian coast grew quite smooth, and in an instant appeared as one clear polished mirror, reclining against the aforesaid ridge. On this glass was depicted, in chiaro scuro, a string of several thousands of pilasters, all equal in altitude, distance, and degree of light and shade. In a moment they lost half their height, and bent into arcades, like Roman aqueducts. A long cornice was next formed on the top, and above it rose castles innumerable, all perfectly alike. These soon split into towers, which were shortly after lost in colonnades, then windows, and at last onded in pines, cypresses, and other trees, even and similar. This was the Fata Morgana, which, for twenty-six years, I had thought a mere fable."

Brydone, writing from Messina, evidently in a dubious vein, states:- "Do you know, tlie most extraordinary plienomenon in the world is often observed near to this place? I laughed at it at first, as you will do, but I am now convinced of its reality, and am persuaded, too, that if ever it had been thoroughly examined by a philosophical eye, the natural eause must long ago have been assigned. It has often been remarked, both by the ancients and moderns, that in the heat of summer, after the sea and air have been much agitated by winds, and a perfect calm succeeds, there appears, about the time of dawn, in that part of the heavens over the straits, a great variety of singular forms, some at rest, and some moving about with great velocity. These forms, in proportion as the light increases, seem to become more acrial, till at last some time before sunrise they entirely disappear. The Sicilians represent this as the most beautiful sight in nature. Leanti, one of their latest and best writers, came here on purpose to see it. He says the heavens appeared crowded with a variety of objects : he mentions palaces, woods, gardens, \&c., besides the figures of men and other animals, that appear in motion amongst them. No doubt the imagination must be greatly aiding in forming this aerial creation; but as so many of their authors, both ancient and modern, agree in the fact, and give an account of it from their own observation, there certainly must be some foundation for the story. There is one Giardini, a Jesuit, who has lately written a treatise upon this phenomenon, but $I$ have not been able to find it. The celebrated Messinese Gallo has likewise published something on this singular subject. The common people, according to custom, give the whole merit to the devil; and indeed it is by much the shortest and easiest way of accounting for it. Those who pretend to be philosophers, and refuse him this honour, are greatly puzzled what to make of it. They think it may be owing to some uncommon refraction or reflection of the rays, from the water of the straits, which, as it is at that time carried about in a variety of eddies and vortices, must consequently, say they, make a variety of appearances on any medium where it is reflected. This, I think, is nonsense, or at least very near it. I suspect it is something of the nature of our aurora borealis, and, like many of the great phenomena of nature, depends upon electrical causes; which, in future ages, I have little doubt, will be found to be as powerful an agent in regulating the universe as gravity is in this age, or as the subtle fluid was in the last. The electrical 
fluid in this country of voleanoes, is probaluly produced in a much greater quantity than in any other. 'The air, strongly impregnated with this matter, and confined betwixt two ridges of mountains - at the same time exceedingly agitated from below by the violence of the current, and the impetuous whirling of the waters-may it not be supposed to produce a variety of appearances? And may not the lively Sicilian imaginations, animated by a belief in demons, and all the wild offspring of superstition, give these appearances as great a variety of forms? Remember, I do not say it is so; and hope yet to have it in my power to give you a better account of this matter."

Ingenious as Brydone was, he here indulges a most unfortunate speeulation, which, had he enjoyed the good fortune of personally observing the phenomenon, most likely, he would not have proposed. It is to be accounted for upon optical principles, which MI. Biot, in his Astronomie Physique, thus applies, from Minasi's dissertation upon the subject:- "When the rising sun shines from that point whence its incident ray forms an angle of forty-five degrees, on the sea of Reggio, and the bright surface of the water in the bay is not disturbed either by wind or current - when the tide is at its height, and the waters are pressed up by the currents to a great elevation in the middle of the channel; the spectator being placed on an eminenee, with his back to the sun and his face to the sea, the mountains of Messina rising like a wall behind it, and forming the background of the picture - on a sudden there appear in the water, as in a catoptric theatre, various multiplied objects - numberless series of pilasters, arches, castles, welldelineated regular columns, lofty towers, superb palaces, with balconies and windows, extended alleys of trees, delightful plains, with herds and flocks, armies of men on foot, on horseback, and many other things, in their natural colours and proper actions, passing rapidly in succession along the surface of the sea, during the whole of the short period of time while the above-mentioned eauses remain. The objects are proved, by accurate observations of the coast of Reggio, to be derived from objects on shore. If, in addition to the circumstances already described, the atmosphere be highly impregnated with vapour and dense exhalations, not previously dispersed by the action of the wind and waves, or rarefied by the sun, it then happens that, in this vapour, as in a curtain extended along the channel to the height of above forty palms, and nearly down to the sea, the observer will behold the scene of the same objects not only reflected on the surface of the sea, but likewise in the air, though not so distinctly or well defined. Lastly, if the air be slightly hazy and opaque, and at the same time dewy, and adapted to form the iris, then the above-mentioned objects will appear only at the surface of the sea, as in the first case, but all vividly coloured or fringed with red, green, blue, or other prismatic colours."

Aerial images of terrestrial objects are frequently produced as the simple effect of reflection. Dr. Buchan mentions the following oecurrence:- "Walking on the cliff about a mile to the east of Brighton, on the morning of the 18th of November. 1804, while watching the rising of the sun, I turned my eyes directly to the sea, just as the solar disc emerged from the surface of the water, and saw the face of the cliff on which $I$ was standing represented precisely opposite to me, at some distance from the ocean. Calling the attention of my companion to this appearance, we soon also discovered our own figures standing on the summit of the opposite apparent cliff, as well as the representation of a windmill near at hand. The reflected images were most distinct precisely opposite to where we stood; and the false cliff seemed to fade away, and to draw near to the real onc, in proportion as it receded towards the west. 'This phenomenon lasted about ten minutes, till the sun had risen nearly his own diameter above the sea. The whole then seemed to be elevated into the air, and successively disappeared. The surface of the sea was covered with a dense fog of many yards in height, and which gradually receded 


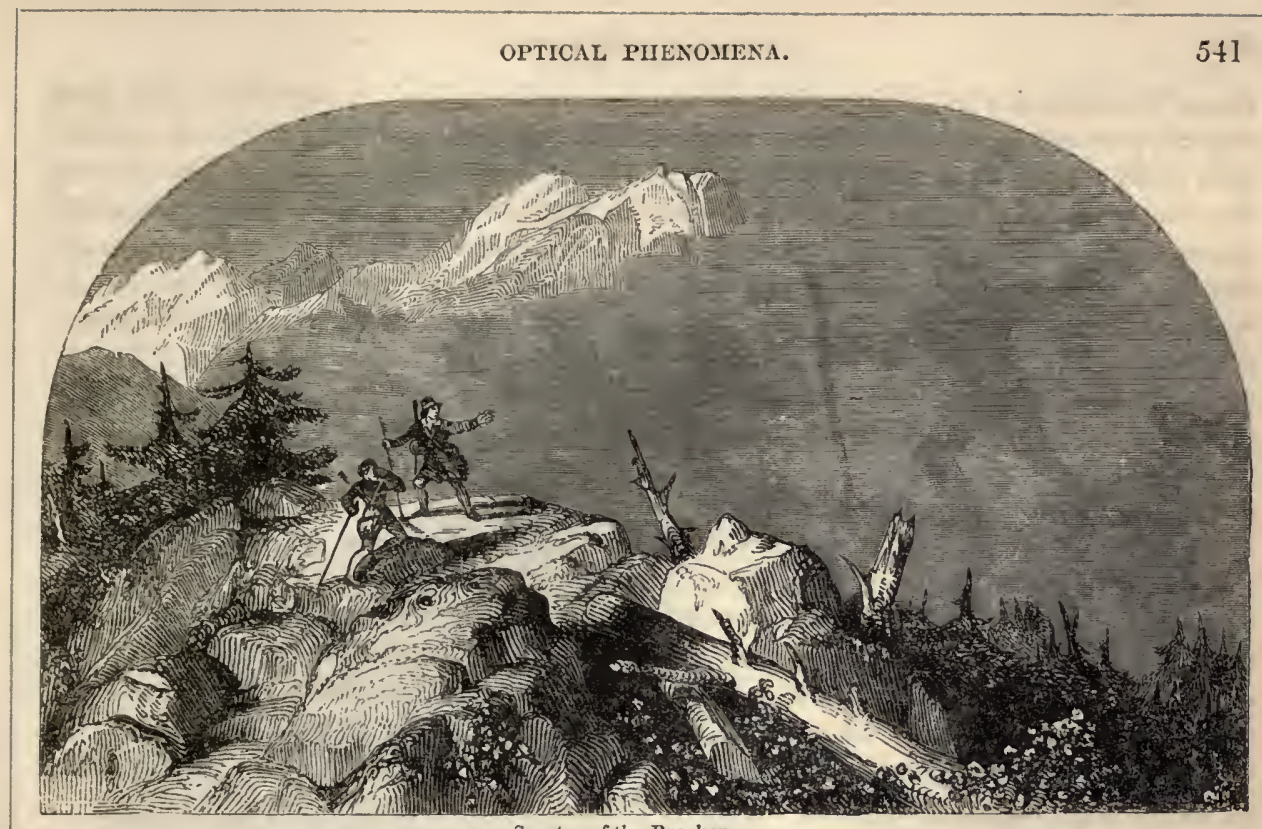

Spectre of the Brocken.

before the rays of the sun." In December 1826 a similar circumstance excited some consternation among the parishioners of Miqué, in the neighbourhood of Poitiers, in France. They were engaged in the exercises of the jubilee which preceded the festival of Christmas, and about three thousand persons from the surrounding parishes were assembled. At fire o'clock in the evening, when one of the clergy was addressing the multitude, and reminding them of the cross which appeared in the sky to Constantine and his army, suddenly a similar cross appeared in the heavens, just before the porch of the chureh, about two hundred feet above the horizon, and a hundred and forty feet in length, of a bright silver colour tinged with red, and perfectly well defined. Such was the effect of this vision, that the people immediately threw themselves upon their knees, and united together in one of their canticles. The fact was, that a large wooden cross, twenty-five feet high, had been erected beside the chureh as a part of the ceremony, the figure of which was formed in the air, and reflected back to the eyes of the spectators, retaining exactly the same shape and proportions, but changed in position and dilated in size. Its red tinge was also the colour of the object of which it was the reflected image. When the rays of the sun were withdrawn, the figure vanished.

The peasantry in the neighbourhood of the Harz Mountains formerly stood in no little awe of the gigantic spectre of the Brocken - the figure of a man observed to walk the clouds over the ridge at sunrise. This apparition has long been resolved into an exaggerated reflection, which makes the traveller's shadow, pictured upon the clouds; appear a colossal figure of immense dimensions. A French savant, attended by a friend, went to watch this spectral shape, but for many mornings they traversed an opposite ridge in vain. At length, however, it was discovered, having also a companion, and both figures were found imitating all the motions of the philosopher and his friend. The ancient classical fable of Niobe on Mount Sipylus belongs to the same category of atmospheric deceptions; and the tales, common in mountainous countries, of troops of horse and armies marching and countermarching in the air, have been only the reflection of horses pasturing upon an opposite lieight, or of the forms of travellers pursuing their journey. On the 19th of August 1820, Mr. Menzies, a surgeon of Glasgow, and Mr. Macgregor 
began to aseend the mountain of Ben Lomond, about fire o'clock in the afternoon. They had not proceeded far before they were overtaken by a smart shower; but as it appeared only to be partial, they continued their journey, and by the time they were half way up, the cloud passed away, and most delightful weather succeeled. Thin, transparent rapours, which appeared to have risen from Loch Lomond beneath, were occasionally seen floating before a gentle and refreshing breeze; in other respects, as far as the cye could trace, the sky was clear, and the atmosphere serene. They reached the summit about half-past seven o'clock, in time to see the sun sinking beneatlı the western hills. Its parting beams had gilded the mountain tops with a warm glowing colour ; antl the surface of the lake, gently rippling with the breeze, was tinged with a yellow Itistre. While admiring the adjacent mountains, hills, and valleys, and the expanse of water beneath, interspersed with numerous wooded islands, the attention of one of the party was attracted by a cloud in the east, partly of a dark red colour, apparently at the distance of two miles and a half, in which he distinctly observed two gigantic figures, standing, as it were, on a majestic pedestal. He immediately pointed out the phenomenon to his companion; aind they distinctly perceived one of the gigantic figtires; in imitation, strike the other on the slioulder; and point towarls them. They then inade their obeisance to the airy phantoms, which was instantly returned. They waved their hats and umbrellas, and the shadowy figures did the same. Like otlier travellers, they had carried with thein a bottle of usquebaugh, and amused themselres in drinking to the figures, which was of eourse duly returned. In short, every movement which they made, they could observe distinetly repeated by the figures in the cloud. The appearance continued about a quarter of an hour. A gentle breeze from the north carried the cloud slowly away; the figures became less and less distinet, and at last vanished. North of the village of Comrie, in Perthshire, there is a bold hill called Dunmore, with n pillar of seventy or eighty feet in height built on its summit in memory of the late Lord Melville. At about eight o'clock of the evening of the 21st of August of the present year, a perfect image of this well-known hill and obelisk, as exact as the shadow usually represents the substance, was distinctly observed projected on the northern sky, at least two miles beyond the original, which, owing to an intervening eminenee, was not itself at all in view from the station where the aerial picture was observed. The figure continued visible for about ten minutes after it was first seen, and was minutely examined by three individuals. One of these fancied that there was a projection at the base of the monument, as represented in the air, which was not in the original; but, upon examining the latter the next morning, the image was found to have been more faithful than his memory; for there stood the prototype of the projection, in the shape of a clump of trees, at the base of the real obelisk.

In northern latitudes the effects of atmospleric reflection and refraction are very familiar to the natives. By the term of uphillanger the Icelanders denote the elevation of distant objects, which is regarded as a presage of fine weather. Not only is there an increase in the vertical dimensions of the objects affected, so that low coasts frequently assume a bold and precipitous outline, but objects sunk below the horizon are brought into view, with their natural position changed and distorted. In 1818, Captain Scoresby relates that, when in the polar sea, his ship had been separated for some time from that of his father, which he liad been looking out for with great anxiety. At length, one evening, to his astonishment, he beheld the vessel suspended in the air in an inverted position, with the most distinet and perfect representation. Sailing in the direction of this visionary appearance, he met with the real ship by this indication. It was found that the vessel had been thirty miles distant, and seventeen beyond the horizon, when her spectrum was thus elevated into the air by this extraordinary refraction. Sometimes two images of a vessel are seen, the one erect and the other inverted, with their topmasts or 


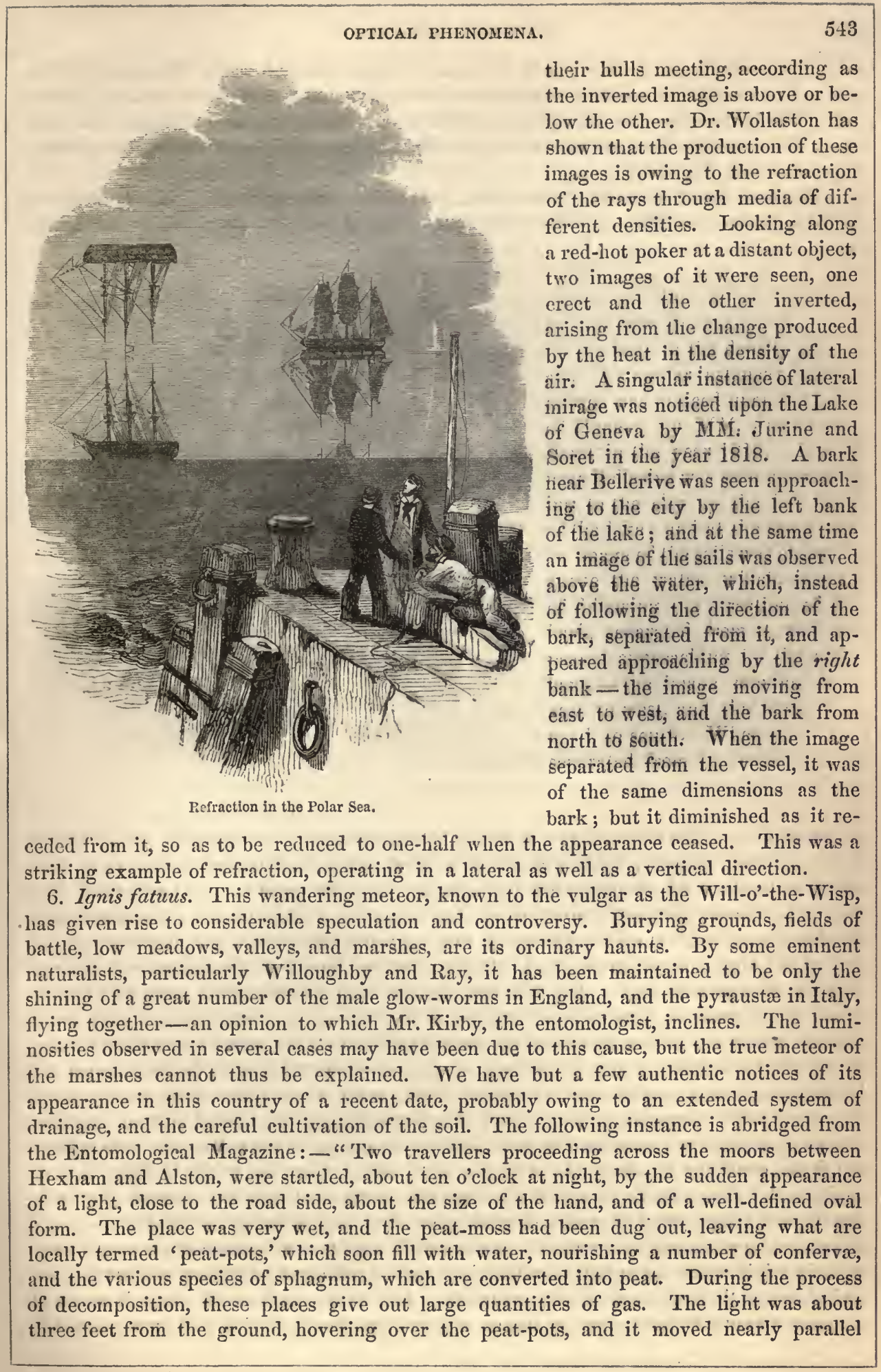


with the road for about fifty yards, when it vanished, probally from the failure of the gas. 'The manner in which it disappeared was similar to that of a candle being blown out." The ignis fatuus lias not become so strange in various continental districts as with us. We have the best account of it from Mr. Blesson, who examined it abroad with great care and diligence.

"The first time," he states, "I saw the ignis fatuus, was in a valley, in the forest of Gorbitz, in the New Mark. This valley cuts deeply in compact loam, and is marshy on

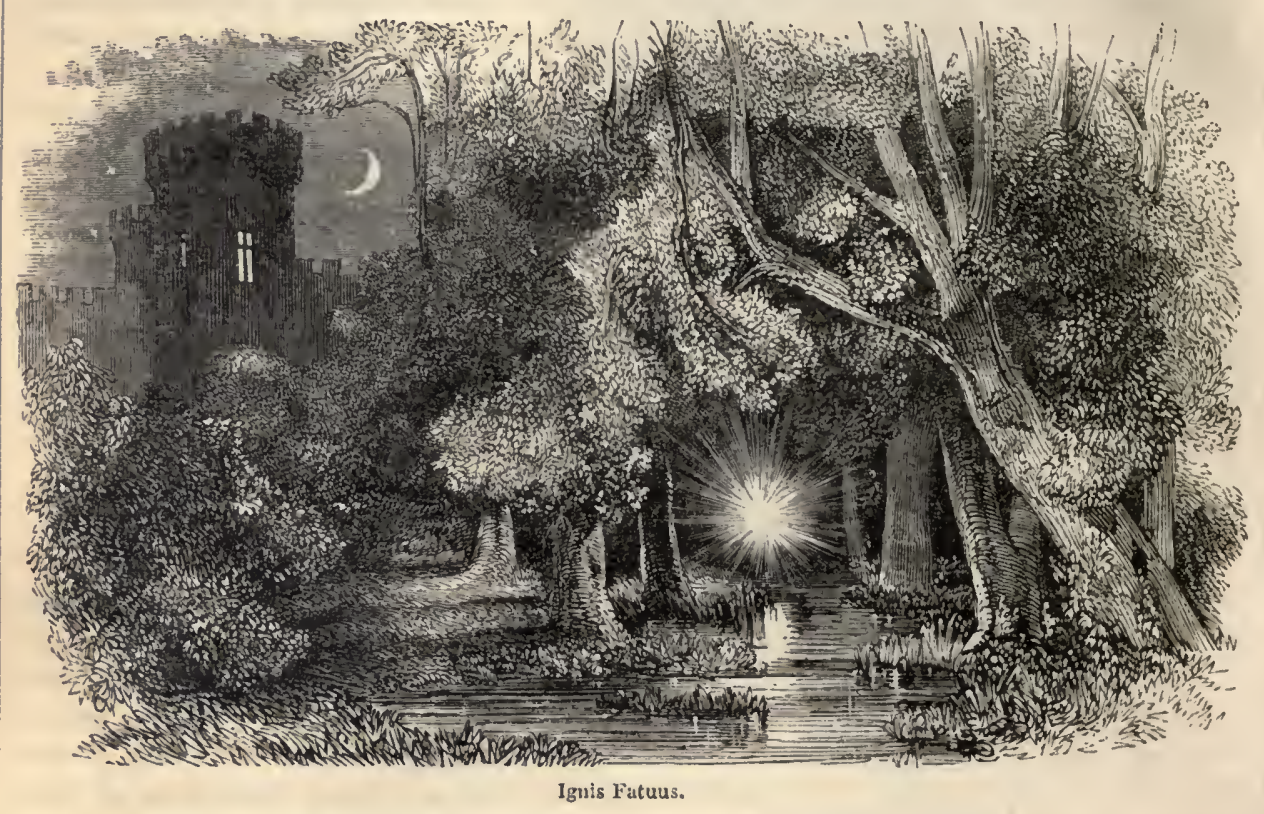

its lower part. The water of the marsh is ferruginous, and eovered with an iridescent crust. During the day, bubbles of air were secn rising from it, and in the night blue flames were observed shooting from and playing over its surface. As I suspected that there was some connection between these flames and the bublules of air, I marked during the day-time the place where the latter rose up most abundantly, and repaired thither during the night ; to my great joy I actually observed bluish-purple flames, and did not hesitate to approach them. On reaching the spot they retired, and I pursued them in vain; all attempts to examine them elosely were ineffectual. Some days of very rainy weather prevented farther investigation, but afforded leisure for reflecting on their nature. I conjectured that the motion of the air, on my approaching the spot, forced forward the burning gas, and remarked that the flame burned darker when it was blown aside; hence I concluded that a continuous thin stream of inflammable air was formed by these bubbles, which, once inflamed, continued to burn, but which, owing to the paleness of the light of the flame, could not be observed during the day. On another day, in the twiliglit, I went again to the place, where I awaited the approach of night: the flames beeame gradually visible, but redder than formerly, thus showing that they burnt also during the day: I approached nearer, and they retired. Convineed that they would return again to the place of their origin when the agitation of the air ceased, I remained stationary and motionless, and observed them again gradually approach. As I could casily reach them, it occurred to me to attempt to light paper by means of them; but for some time $\mathrm{I}$ did not succeed in 
this experiment, which I found was owing to my breathing. I therefore held my face from the flame, and also held a piece of cloth as a screen; on doing which I was able to singe paper, which became brown-coloured, and covered with a viscous moisture. I next used a narrow slip of paper, and enjoyed the pleasure of seeing it take fire. The gas was evidently inflammable, and not a phosphorescent luminous one, as some have maintained. But how do these lights originate? After some reflection, I resolved to make the experiment of extinguishing them. I followed the flame; I brought it so far from the marsh that probably the thread of connection, if I may so express myself, was broken, and it was extinguished. But scarcely a few minutes had elapsed when it was again renewed at its source (over the air-bubbles), without my being able to observe any transition from the neighbouring flames, many of which were burning in the valley. I repeated the experiment frequently, and always with success. The dawn approached, and the flames, which to me appeared to approach nearer to the earth, gradually disappeared. On the following evening I went to the spot and kindled a fire on the side of the valley, in order to have an opportunity of trying to inflame the gas. As on the evening beforc, I first extinguished the flame, and then hastened with a torch to the spot from which the gas bubbled up, when instantaneously a kind of explosion was heard, and a red light was scen over eight or nine square feet of the marsh, which diminished to a small blue flame, from two and a half to three feet in height, that continued to burn with an unsteady motion. It was therefore no longer doubtful that this ignis fatuus was caused by the evolution of inflammable gas from the marsh."

The ignis fatuus of the churchyard and the battle-field we may conclude to arise from the phosphuretted hydrogen emitted by animal matter in a state of putrefaction, which always spontaneously inflames upon contact with the oxygen of the atmosphere; and the flickering meteor of the marsh may be referred to the carburetted hydrogen, formed by the decomposition of regetable matter in stagnant water, ignited by a discharge of the electric fluid, or by contact with some substance in a state of combustion. This wandering light has often been a source of terror to the ignorant, and has frequently seduced the benighted traveller into dangerous bogs and quagmires, under the impression that it proceeded from some human habitation.

\footnotetext{
"Drear is the state of the benighted wretch, Who then, bewilder'd, wanders through the dark, Full of pale fancies, and chimeras huge ; Nor visited by one directive ray, From cottage streaming, or from airy hall. Perhaps impatient as he stumbles on, Struck from the root of slimy rushes, blue, The uild-fire scatters round, or gather'd trails, $A$ length of flame deceitful o'er the moss: Whither decoy'd by the fantastic blaze, Now lost and now renew'd, he sinks absorb'd, Rider and horse, amid the miry gulf:

While still, from day to day, his pining wife And plaintive children his return await, In wild conjeeture lost."
}

The production of inflammable gases is one of the processes in constant action in the great laboratory of nature, and extraordinary disengagements of combustible elements occur, though we are quite ignorant of the cause. In the middle of the last century the snow on the summit of the Apennines appeared enveloped in sheets of flame; and in the winter of 1693 hay-ricks in Wales were set on fire by burning gaseous exhalations. 


\section{CHAPTER XVII.}

\section{GEOGRAPHICAL DISTRIBUTION OF PLANTS.}

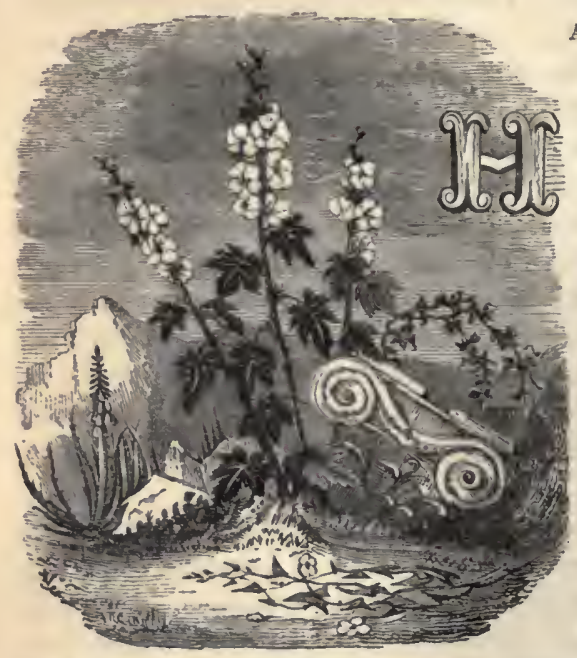

Avixg reviewed the arrangements and plienomena of inanimate nature, we proceed to consider the globe as the habitation of innumerable organised beings, beginning with the lowest division in the world of living existence, the diversified vegetable forms which clothe the surface of the carth, adoln its scenery, and contribute to the sustenance of its animal and liuman races. The productions of the regetable kingdom are among the most useful and interesting objects we contemplate. They are associated with the earliest and some of the purest pleasures of mankind; for crery one will vividly recollect the delight experienced in his childhood by the appearance of the harbingers of the vernal season - the flowers of the snowdrop, crocus, primrose, and violet, pecping up above the greensward, or from the hedgerows, proelaiming, in an obvious and impressive manner, "Lo, the winter is past, the rain is over and gone, the flowers appear upon the earth, the time of the singing of birds is come." The cultivated flora of the garden, and the wild flora of the field, are among our first and best instructors, conveying, by their external configuration, lessons of purity and of grace to the mind in the age of its awakening susceptibilities. This is a moral and intellectual discipline, silent and unostentatious in its process, but of great importance in its effect as a source of valuable directive influence to the thoughts and feelings. But to man, in mature life, the larger plants and timber trees are essential. His existence and civilisation depend upon them. 'They furnish, with unbounded prodigality, the food which satiates his hunger and gratifies his taste; supply many of the medicines that allay his sickness; afford him materials for an habitation; yicld the means of transporting limself and his property across the land, and of accomplishing the passage of the ocean; besides being the chief ornament of his walks during the period of their growth.

It belongs to Botany, Physiology, and Agricultural Chemistry, to investigate the structure of plants; to unfold the riches of the regetable kingdom with its different organisations, and the means by which their derelopment and fructification are secured. The department of the physical geographer is simply to notice the general disposition of the vegetable tribes, and the circumstances which seem to regulate their distribution.

We have no more striking evidence of contrivance than in the wide dispersion of vegetable life, and in the different conditions under which it exists, at the extremes of terrestrial elevation and depression, of cold and heat, of light and shade, of solidity and solution. Forests of beech wave in the Himalaya at a greater height than that reached by the Finsterhorn of the Alps, or more than fourteen thousand feet; and there also shrubs flourish upon sites which are above the altitude of the hoary-headed Mont Blanc, the monarch of 
the European mountains. On the otlier hand, the bottom of the sea is clothed with an

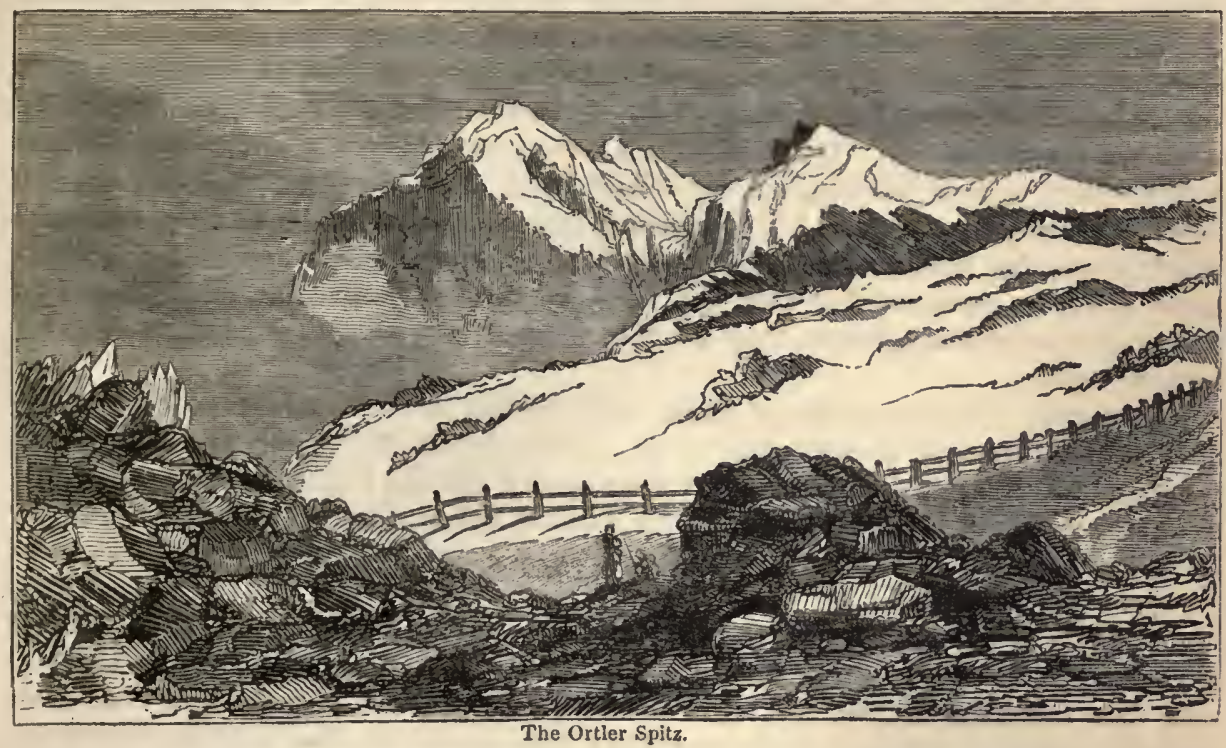

endless varicty of green, red, and purple algæ; and, in the dark caverns of the ocean, the vine-leaved fucus produces its enormous fronds, with a hue as green as that of grass. Melville Island, with its long dreary night, and nine or ten months of rigid winter, has in various places an abundance of moss, lichen, grass, saxifrage, the dwarf-willow, poppy, and sorrel; and Captain Parry found a ranunculus in full flower, in a sheltered spot, during the second week of June. In a diametrically opposite condition, some plants of the confervæ tribe thrive, living in hot springs, where the temperature is that of boiling water ; and, at the commencement of the seventeenth century, a shrubbery flourished in the crater of the Vesuvian furnace. The rich black loam of the plains sustains luxuriantly an appropriate vegetation; while creeping plants derive sustenance from the hardest rocks, and alternate beautifully with the naked projections of mountain masses. Within the tropics magnificent trees grow up under the direct action of the solar beams; and in dens and caves of the earth, which have never been visited with the light of day, vegetable life defies the perpetual darkness. In the great cavern of the Guacharo, to the south-east of Cumana, Humboldt beheld with astonishment the progress of subterranean vegetation, after having passed a considerable distance beyond the point to which the daylight penetrates. The seeds which the birds carry into the cave to feed their young, spring up wherever they fix in the mould that covers the calcareous incrustations; and blanclied stalks were noticed, which had risen to the height of two feet, with some halfformed leaves. During the visit of the traveller, these traces of organisation amid darkness forcibly excited the curiosity of the native Indians, who examined them with the aid of their torches in silent meditation and fear, as if the subterraneous vegetables, pale and disfigured, had been phantoms banished from the face of the earth. To Humboldt, the scene recalled one of the happiest periods of his earliest youth - a long abode in the mines of Freiburg, where he had found plants growing in the complete darkness, green as well as blanched. The entire failure of moisture seems to be the only insurmountable obstacle to the growth of plants; for the sandy desert will "rejoice and blossom as the rose" wherever a very scanty supply of humidity gains access to it. De Candolle makes 
an interesting statement respecting the plant vulgarly known by the name of the rose of Jericho, Anastatica Hierochuntina, growing in the arid wastes of Arabia and Palestinc. By the time it dies, owing to the great drought, its tissuc has become almost woody; its branches fold over each other till the whole mass assumes the form of a ball; its seedvessels have their valves tightly shut; and the plant remains adhering to the ground by a solitary branchless root. The wind, which always acts powerfully along the surface of a sandy plain, uproots this dry ball, and rolls it along. If it chance to meet with a splash of water during its constrained but necessary journey, it speedily imbibes the moisture, which causes the branches to unfold, and the pericarps to burst; and the seeds which could not have germinated if they had fallen on the dry ground, now sow themselves naturally in a moist soil, where they are able to grow, and where the young plant may support itself.

The number of known species of plants on the surface of the earth, mentioned by botanists from the time of Theophrastus to the present day, is thus given, in a menoir on geographical botany by Mr. Hinds, who accompanied the late expedition of the Sulphur round the world, under the command of Sir Edward Belcher:-

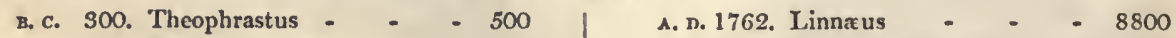

$$
\begin{aligned}
& \text { A. D. 70. Pliny - - - }-1000 \quad \text { 1806. Persoon - } \quad-27,000 \\
& \text { 1683. Baubin - - - } 6000 \text { 1820. De Candolle - - } 56,000
\end{aligned}
$$

Lindley, in 1835, gave the number at 86,000 ; but, according to Mr. Hinds, at the present time there are 89,000 species of plants described; and computing for countries scareely examined, or as yet wholly unexplored, he supposes the total aggregate of species which regetate on the earth to amount to about 133,000 . This is an estimate which only gocs a little beyond a similar ealculation of De Candolle; and when we reflect that the interior of Africa, of Australia, and of the great islands of Oceanica, have not been visited by the geographer and the naturalist, the estimate will not be deemed extravagant. It illustrates the variety which marks the regetable kingdom, and the work which still remains to be accomplished in the department of botanical discovery and description. Plants divided according to their station, or the physical nature of the locality to which they are adapted, are ranged by De Candolle in fifteen classes, to which two others have been added by M. Bory de Saint Vineent.

1. Maritime or saline plants. These are terrestrial plants which grow on the borders of the sea, or of salt lakes; as salicornia, or saltwort, salsola, or glasswort, which abound on the shores of the Mediterranean, and are there generally burnt for soda, used in the manufacture of glass, especially at Marseilles.

2. Marine plants, as the fuci and many of the alga, which are plentiful in the seas that wash the coasts of Great Britain, and are often attached to stones and rocks near the shore. They are either buried in the ocean, or, situated above low-water mark, are alternately immersed and exposed to the action of the atmosphere; but none of them can be made to regetate apart from its waters.

3. Aquatic plants, growing in fresh water; as sagittaria, or arrowhead, potamogeton, or pond-weed, nymphae, or white water-lily. They oecupy the beds of rivers, and vegetate in the midst of the running stream or in stagnant pools, being for the most part

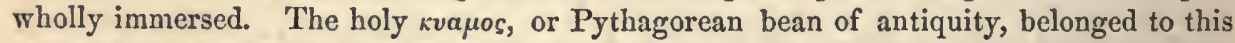
genus, and is probably identical with the produce of the Nelumbium, a stately aquatic, common in various parts of the east, especially in China, where the ponds are literally mantled with its leaves and flowers.

4. Marsh or swamp plants, living in ground which is generally submerged, but occasionally dry; as ranunculus aquatilis and sceleratus, or water and celery-leaved crowfoot, polygonum amphibium, or amphibious persicaria. 
5. Meadow and pasture plants, as a great number of grasses and trefoils.

6. Plants found in cultivated fields. In this division many plants are included which have bcen introduced by man along with grain; as centaurea cyanus, corn blue-bottle, sinapis arvensis, or common wild mustard, agrostemma, corn-cockle, several species of veronica, or speedwell, and euphorbia, or spurge.

7. Rock or wall plants; as saxifrages, wall-flower, some species of sisymbrium, or hedge-mustard, bromus, or brome-grass, linaria cymbalaria, or ivy-leaved toadflax.

8. Sand plants, as carex arenaria, or sea-carex, calamagrostis arenaria, or small sandreed, and plantago arenaria, or sand plantain. By the cultivation of these plants, large districts have been reclaimed from utter barrenness, and clothed with stately forests; and countries subject to a periodical invasion of sand, blown over them by the prevalence of certain winds, have been rescued from that calamity - one of the most useful agricultural enterprises of modern times. The plan was first adopted by an engineer of the name of Bremontier, on the coast of Gascony. He sowed, in the driest and most shifting sand, the seeds of the broom, genista scoparia, mixed with those of the sea-pine, pinus maritima, and then covered over the spaces that were sown with branches from the nearest pine forests, by which means the sand was to a certain extent prevented from shifting. The broom, which springs up first, serves the double purpose of further restraining the sand, and of nursing the young pines; and the foliage of the latter, after a growth of seven or eight years under shelter of the broom, becoming annually mingled with the sand, tends to fertilise it. After this period the pine overtops the broom, and frequently entirely kills it with its shade. In ten or twelve years the rising forest is thinned for the manufacture of tar, and for procuring branches to cover the newly-sown districts. After twenty years have passed, a fall of the trees commences for the manufacture of resin. Thus these forests, placed on the dunes or drifting sand-hills between the mouths of the Adour and the Garonne, shelter the whole country behind them from the inroads of the element from the sea, and yield themselves a supply of an important article of commerce.

9. Plants found on rubbish, or those which select the habitations of man and animals, on account of the salts and azotised substances which enter into their composition, as pellitory of the wall, nettles, and some mushrooms.

10. Forest plants, including trees which live in society, as the oak, beech, elm, and fir, and the plants which grow. under their shelter, as the greater part of the European orchises. 'Some of the former attain to enormous dimensions, and survive to a hoar antiquity. Four celebrated yew trees in Great Britain, whose dimensions are on record, appear, from the number of concentric zones observable in a transverse section of their stems, to have lived respectively $1214,1287,2558$, and 2880 years. In relation to the first of these examples, we have the testimony of history, that this tree was in existence, and must have been of considerable size in the year 1133, it being recorded that the monks took shelter under it during the building of Fountains' Abbey. De Candolle gives the following ages, but is supposed to have overrated them one-third:-

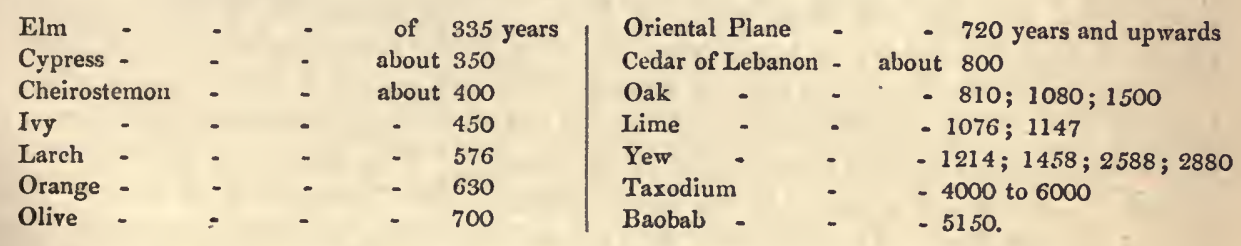

The majestic forests of the equatorial zone contain trees of a most gigantic size. On the banks of the Atabapo, a bombax caiba was measured by Humboldt, more than 120 feet high, and 15 feet in diameter; and near the village of Turmero, to the south-west 
of the city of Cumana, he found the famous Zamang del Guayre, a species of mimosa, with its trunk nearly ten feet thick, and its hemispherical head more than 600 feet in circumference, the branches bending towards the ground in the form of an immense umbrella. The baobabs of Senegal, and of the Cape Vcrde Islands, exhibit still greater dimensions, several having been noticed with trunks varying from 50 to 100 feet in circumference.

11. Plants of the thickets or hedges, comprehending the small shrubs which form the hedge or thicket, as the hawthorn and sweet brier; the herbaceous plants which grow at the foot of these shrubs, as tuberous moschatel, wood sorrel, and violets; and those which climb among their numerous branches, as bryony, black bryony, and some spccies of everlasting pea.

12. Subterranean plants, or those which live in mines and caves, entirely excluded from the light, as byssus, truffles, and some other cryptogamic plants.

13. Plants of the mountains, which De Candolle proposes to divide into two sections: 1. Those which grow on alpine mountains, the summits of which are covered with perpetual snow, and where, during the heat of summer, there is a continued and abundant flow of moisture, as numerous saxifrages, gentians, primroses, and rhododendrons. 2. Those inhabiting mountains on which the snow disappears during summer, as several species of snap-dragon, umbelliferous plants chiefly belonging to the genus seseli, or meadow-saxifrage, and labiate plants.

14. Parasitic plants, which derive their nourishment from other vegetables, and which, consequently, may be found in all the preceding situations, as the misletoe, brown-rapc, dodder, and a number of lichens, mushrooms, and mosses.

15. Pseudo-parasitic plants, which live upon dead vegetables, or upon the bark of living vegetables, but do not derive their nourishment from them, as epidendron, lichens, and mosses.

16. Plants which vegetate in hot springs, the temperature of which ranges from $80^{\circ}$ to $150^{\circ}$ of Fahrenheit, as vitex agnus castus, the chaste-tree of the ancients, a species of osier, sevcral cryptogamous plants, and ulva thermalis, the hot-spring laver.

17. Plants which are developed in artificial infusions or liquors, as the mould found in Madeira wine, a species of conferva.

This is an arrangement of vegetable tribes, according to the physical nature of the station they occupy, but very different species are found upon similar sites in different parts of the world, a diversity partially referable to a diversity of climate, which we have seen to depend upon elevation and latitude. There are some general laws respecting the distribution of plants, which it is not likely that any subsequent observation will modify. The proportion of the cryptogamic to the phænogamic species, or those which never bear flowers, as mosses and lichens, to the common flowering plants, increases as we recede from the equator. The cryptogamous plants are to the phænogamic, in equatorial countries, as 1 to 5 ; in Australia, as 2 to 11 ; in France, as 1 to 2, in several countries licarly equal, and over the whole globe as 1 to 7 . The proportion of dicotyledonous plants, or those which have two seed-lobes, like most of the European trees, to the monocotyledonous, which have only one, as grasses, lilies, and palms, increases as we recede from the poles. The absolute number of species, and also the proportion of woody specics to the herbaceous, increases as we approach the equator. The number of species, either annual or biennial, is greatest in temperate regions, and diminishes both towards the equator and the poles. The following table gives the relative proportions which several well-defined orders, or families of plants, bear to the whole mass of vegetation in the zones mentioned, and shows the zone in which they occur in the greatest relative abundance. 


\begin{tabular}{|c|c|c|c|c|c|}
\hline Orders. & Examples. & $\begin{array}{l}\text { Equatorial Zone, } \\
\text { Lat. } 00^{\circ} 10^{\circ} \text {. }\end{array}$ & $\begin{array}{c}\text { Temperate Zone, } \\
\text { Lat. } 45^{\circ} 5 \mathcal{Z}^{\prime} \text {. }\end{array}$ & $\begin{array}{l}\text { Frigid Zone, } \\
\text { Lat. } 67^{\circ} 72^{\prime} \text {. }\end{array}$ & $\underset{\text { in }}{\text { Maximum Ratio }}$ \\
\hline Agama & $\begin{array}{l}\text { Ferns, Lichens, } \\
\text { Mosses, Fungi }\end{array}$ & $\begin{array}{l}\left\{\begin{array}{l}\text { Plains } \\
\text { Mountains }\end{array}\right. \\
\text { Countries nearly }\end{array}$ & $\frac{1}{2}$ & $t$ & Frigid. \\
\hline Ferns alone & - & $\left\{\begin{array}{l}\text { flat } \\
\text { Countries very } \\
\text { mountainous } \frac{1}{3} \text { to } \frac{1}{8}\end{array}\right.$ & $\frac{1}{10}$ & $\frac{1}{23}$ & Equatorial. \\
\hline Monocotyledones & - $\quad-$ & $\left\{\begin{array}{l}\text { Old Contiuent } \frac{1}{5} \\
\text { New Contisent }\end{array}\right.$ & $\frac{1}{4}$ & $\frac{1}{3}$ & Frigid. \\
\hline Glumaceæ & $\begin{array}{c}\text { Rushes, Sedges, } \\
\text { Grasses }\end{array}$ & \}$-\frac{1}{n}$ & $\frac{1}{8}$ & 1 & Frigid. \\
\hline Juncex alone & Rushes & $-x^{3}-\frac{1}{400}$ & $\frac{1}{30}$ & $\frac{1}{25}$ & Frigid. \\
\hline Cyperacea alone & Sedges & $\left\{\begin{array}{l}\text { Old Continent } \frac{1}{2 \frac{1}{2}} \\
\text { New Continent } \frac{1}{60}\end{array}\right.$ & $\frac{1}{20}$ & $\frac{1}{9}$ & Frigid. \\
\hline Graminex alone & Grasses & $-\quad-\frac{1}{11}$ & $\frac{1}{2}$ & $t_{0}$ & Frigid. \\
\hline Compositæ & $\begin{array}{l}\text { and many culi- } \\
\text { nary and orna- } \\
\text { mental plants }\end{array}$ & $\left\{\begin{array}{l}\text { Old Continent } \frac{1}{18} \\
\text { New Continent } \frac{1}{18}\end{array}\right.$ & $\frac{1}{8}$ & $\frac{1}{13}$ & Temperate. \\
\hline Leguminose & $\begin{array}{l}\text { Various kinds of } \\
\text { Pulse }\end{array}$ & $=-\frac{1}{10}$ & $\frac{1}{16}$ & $\frac{1}{35}$ & Equatorial. \\
\hline Rubiacæ & $\begin{array}{l}\text { Madder, Coffee, } \\
\text { \&c. }\end{array}$ & $\left\{\begin{array}{l}\text { Old Coutinent } \frac{1}{14} \\
\text { New Continent } \frac{1}{23}\end{array}\right.$ & $\frac{1}{60}$ & $\frac{1}{80}$ & Equatorial. \\
\hline Euplıorbiasee $x$ & $\begin{array}{l}\text { Spurge, Castor } \\
\text { and Croton oil } \\
\text { plants }\end{array}$ & $\frac{1}{38}$ & $\frac{1}{80}$ & $\frac{1}{300}$ & Equatorial. \\
\hline Labiaceæ & $\begin{array}{l}\text { Sage, Lavender, } \\
\text { Mint, Thyme, } \\
\text { \&c. }\end{array}$ & $\frac{1}{30}$ & $\begin{cases}\text { America } & \frac{1}{26} \\
\text { Europe } & 1 \\
25\end{cases}$ & $\frac{1}{70}$ & Temperate. \\
\hline Malvaceæ. & $\begin{array}{l}\text { Mallow tribe, } \\
\text { Hollyhocks }\end{array}$ & $-\quad-\frac{1}{35}$ & $\frac{1}{200}$ & $\frac{0}{0}$ & Equatorial. \\
\hline Ericaceæ & $\begin{array}{c}\text { Heaths, Arbu- } \\
\text { tuses, Azalias, } \\
\text { Rhododendrons }\end{array}$ & $=\frac{1}{130}$ & $\left\{\begin{array}{lc}\text { Europe } & \frac{1}{100} \\
\text { America } & \frac{1}{36}\end{array}\right.$ & $\frac{1}{25}$ & Frigid. \\
\hline Amentaces & Most European & $-\frac{1}{800}$ & $\begin{cases}\text { Europe } & \frac{1}{43} \\
\text { America } & \frac{1}{25}\end{cases}$ & $\frac{1}{20}$ & Frigid. \\
\hline Umbelliferæ & $\begin{array}{l}\text { Ifemlock, Parsley, } \\
\text { Carrot }\end{array}$ & $-\quad-\quad 3 \frac{1}{30}$ & $\frac{1}{40}$ & $\frac{1}{60}$ & Temperate. \\
\hline Cruciferæ & $\begin{array}{l}\text { Wall-flower, } \\
\text { Cresses. }\end{array}$ & - $\frac{1}{800}$ & $\begin{cases}\text { Europe } & \frac{1}{18} \\
\text { America } & \frac{1}{60}\end{cases}$ & $\frac{1}{21}$ & Temperate. \\
\hline
\end{tabular}

Thus the group of ferns, mosses, lichens, and fungi in the equatorial zone constitutes $\frac{1}{15}$ th of the vegetation on the plains, and $\frac{1}{5}$ th of that on the mountains, while in the temperate zone it forms one half of the whole number of plants, and in the frigid zone almost the entire regetation belongs to this family. The group of grasses constitutes, in the equatorial zone, $\frac{1}{14}$ th of the whole number of plants that exist in it, in the temperate zone $\frac{1}{12}$ th, and in the frigid zone $\frac{1}{10}$ th, the maximum ratio being attained in the latter. The social plants, or those which live together, covering large tracts of country, like the common heath which is spread over the sand-hills of Jutland, Holstein, Hanover, Westphalia, and Holland, are comparatively rare within the tropics, and are only found on the sea coasts and upon elevated plains.

In the cold and inhospitable climate of high northern latitudes, where the ground is frozen hard during nine months in the year, and covered with snow several feet deep, the vegetable tribes are few in number, stunted in their appearance, and of analogous species in the polar regions of Europe, Asia, and America, the continents there being nearly united. Mosses and lichens - the cryptogamia of Linnæus, and acotyledones of Jussieu - form one of the chief botanical features of the arctic zone, and extend in small and isolated tufts as far as travellers have been able to penetrate to the north. One species occurs in great abundance on the southern confines of this zone-the reindeer moss- 
covering of itself a large extent of country, and constituting the principal support of the aninal after which it is called, and upon that animal the Laplander entirely depends for his own subsistence. The scurvy grass and sorrel, so valuable for their antiscorbutic qualities, flourish likewise under the almost perpetual snows; and during the short summer which the aretic fields enjoy, some low flowering herbs, the saxifrage, primrose, ranunculus, anemone, and yellow poppy, display their tints upon the sites which have a southern aspect. In receding from the pole, the first specimens of the higher classes of vegetation encountered are a few shrubs of wild thyme, and a species of willow expanding itself laterally to the extent of several feet, yet never rising more than two or three inches from the ground, showing the ungenial influence of the climate. Next comes tlie "lady of the woods," the birch, but shorn of her fair proportions - a mere dwarf - along with various kinds of bushes yielding edible fruit of delicious flavour, as the cloud-berry and arctic bramble. The latter grows in the svildest and most exposed districts of Lapland. It sometimes offered to Linnæus the only food he could obtain during his perilous journey in that dreary region; and hence the reference made to it in his work:- "I should be ungrateful towards this beneficent plant, which often, when I was almost prostrate with hunger and fatigue, restored me with the vinous nectar of its berries, did I not bestow on it a full description." At the island of Hammerfest, near the North Cape of Europe, in latitude $70^{\circ} 40^{\prime}$, the birch grows in sheltered hollows between the mountains, attaining to about the human height; and in the low branches which creep along the ground the ptarmigan finds a summer retreat, and breeds in security. The only other trees of any importance, that can maintain an existence within the arctic circle, are some of the pine species, the Scotch and spruce fir, which in Norway pass a short distance beyond its confine, but chiefly the former. Barley is cultivated in this zone as high as latitude $70^{\circ}$; but it requires a favourable aspect and season in order to be ripened, for there is little more than three months between the loosening of the frozen ground and its being again bound up. Wahlenberg states, that the cultivation of this grain succeeds wherever the mean temperature during ninety days rises to $48^{\circ}$. At Enontekeis, in Lapland, barley and turnips yielded nine good crops in the thirty years between 1800 and 1830 . The preceding remarks apply to the arctic regions of Europe, which have a less severe climate than those of $\Lambda$ sia and America, and, consequently, a more copious vegetation, scanty as it is.

Referring to the temperate zone, we find the pine tribe luxuriant at its northern confine, forming the magnificent forests of Scandinavia, where the spruce fir grows perfectly straight, sometimes to the height of two hundred feet. Hence the Germanic name of this tribe, nadel-holz - needle-wood ; and Milton's illustration in the splendid description of Satan, -

\footnotetext{
"His spear, to equal which the tallest pine

Hewn on Norwegian hills, to be the mast

Of some great ammiral, were but a wand."
}

The pines occur in much more extensive forests, and with less admixture, than any other genus of timber-trees, immense districts in North America being covered with them; but they do not reach to such ligh parallels of latitude there, or in Asia, as in Europe. The Norwegian pine is, however, far exceeded by a transatlantic species, Pinus Lambertiana, growing singly on the plains to the west of the Rocky Mountains. Several have been measured, and found to be 250 feet high, 60 feet in circumference at the base, $4 \frac{1}{2}$ feet in circumference at the height of 190 feet, yielding cones 11 inches round, and from one foot to 16 inches long, a transverse section of the trunk showing 900 annual rings. In descending into the temperate zone, we meet with the alder, aspen, and mountain ash. We then come to the extreme northern boundary of the oak, in latitude $63^{\circ}$, 


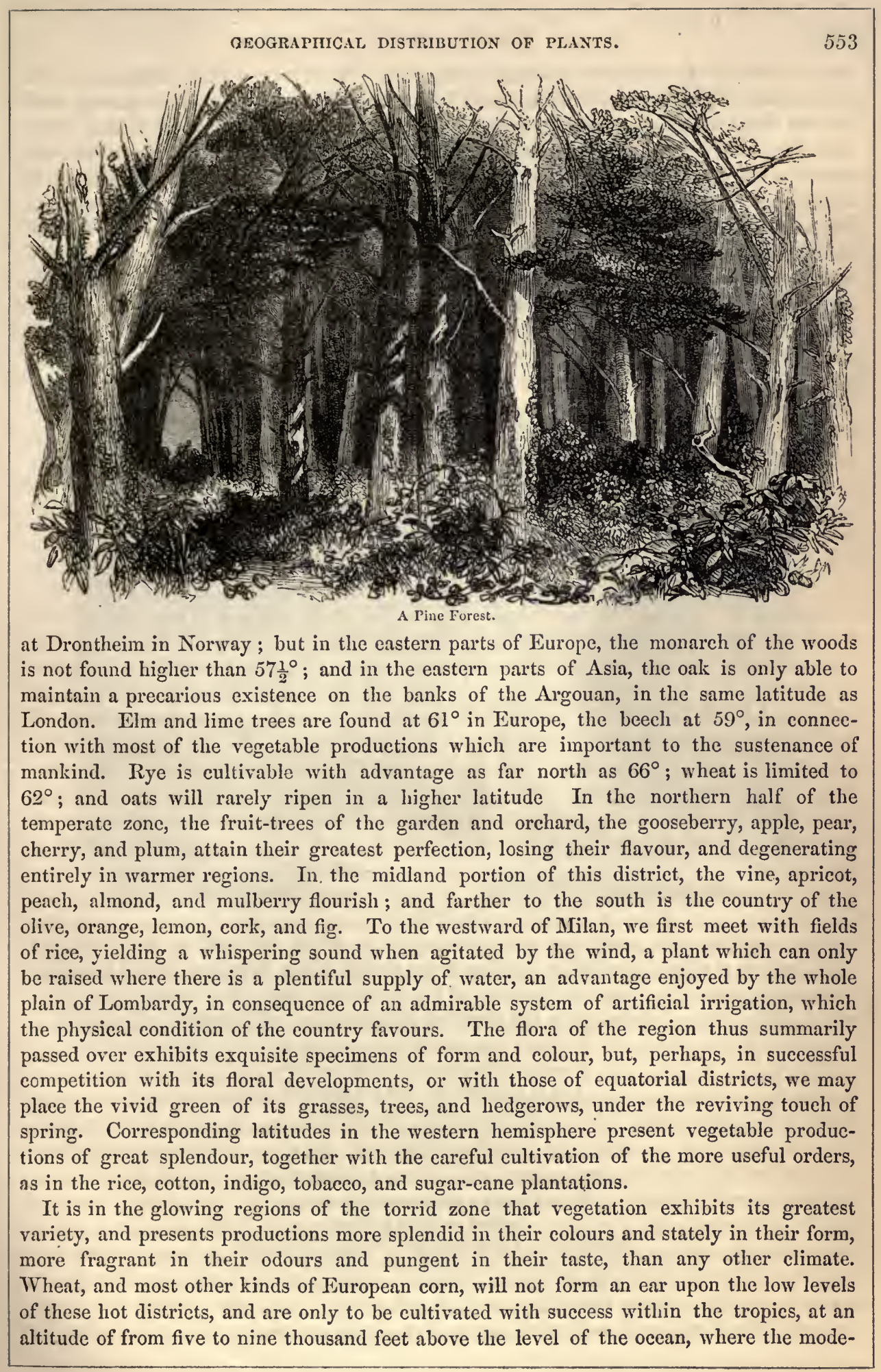


rate warmth of the temperate latitudes is enjoyed. There are several exceptions to this rule, created by local peculiarities, for at $10 \frac{1}{2}^{\circ}$ north of the equator, in Venezucla, fields of corn blend with plantations of sugar-cane, coffee, and plantains, at no greater elevation than 1900 feet above the sea-level, while in the interior of the island of Cuba fine harvests are raised at but a small height above the ocean. Various other kinds of grain, however, flourish abundantly upon the plains, as millet, maize or Indian wheat, and rice, the latter being the chief food of perhaps a third of the human race, wlile valuable substitutes for grain are found in the bread-fruit and plantain, the cassava and manioc roots of America, the taro-root and yam of Polynesia. In the central parts of the torrid region, we find the plants which yield the most powerful aromatics - the vanilla, the cinnamon, the nutmeg, the pepper, the clove, and the camphor; but it is especially remarkable for the abundance and grandeur of its flora and timber-trees, whether growing singly or in forests. In Hindùstan and Cochin China, the banyan or pagod-tree, Ficus

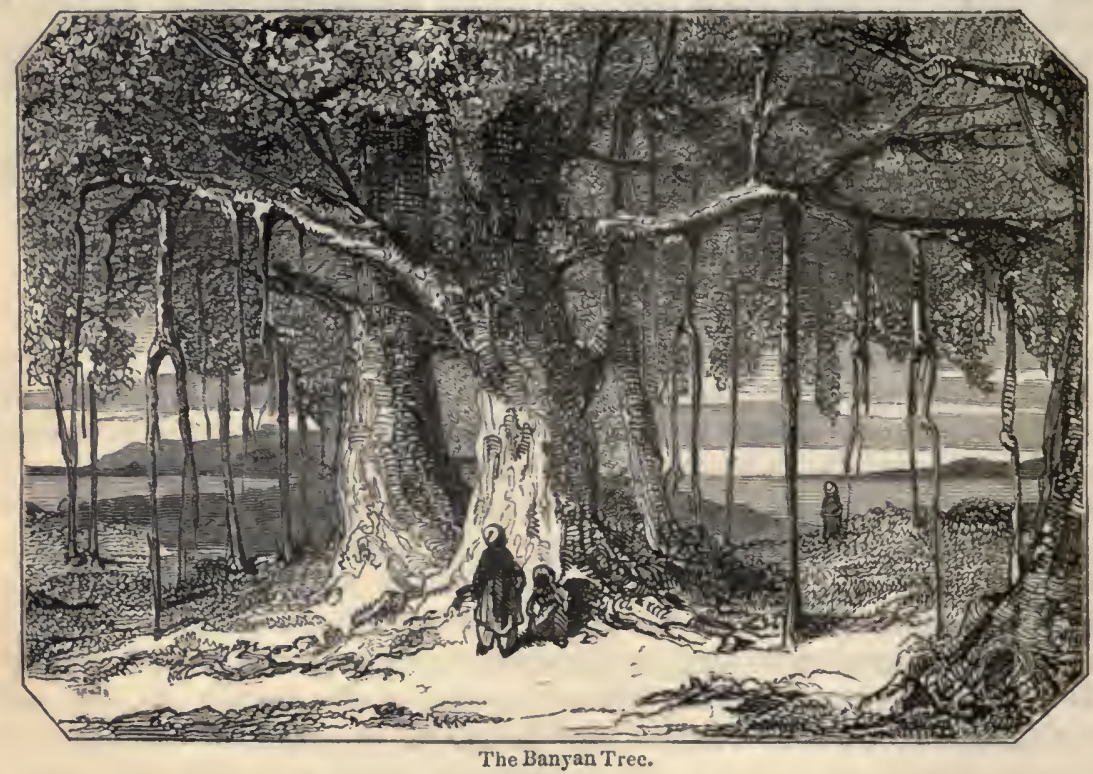

Indica, exhibits that vast size and peculiar form, which rendered it the wonder of the ancients, the lateral branches sending down shoots which take root in the earth, and compose a grove, in process of time, out of the individual, sometimes covering an area of 1700 square yards. Southey, in the Curse of Kehama, has well described this object:-

"'Twas a fair scene wherein they stood, A green and sunny glade amid the wood, And in the midst an aged banyan grew. It was a goodly sight to see

That venerable tree,

For o'er the lawn, irregularly spread,

Fifty straight columns propp'd its lofty head;

And many a long depending shoot Seeking to strike its root,

Straight, like a plummet, grew towards the ground.

Some on the lower boughs, which eross'd their way,

Fixing their bearded fibres, round and round,

With many a ring and wild contortion wound;

Some to the passing wind, at times with sway 
Of gentle motion swung;

Others of younger growth, unmoved, were hung

Like stone-drops from the eavern's fretted height.

Beneath was smooth and fair to sight,

Nor weeds nor briers deform'd the natural floor;

And through the leafy cope which bower'd it o'er

Came gleams of ehequer'd light.

So like a temple did it seem, that there

A pious heart's first impulse would be prayer."

The same tribes which are the slender and humble plants of northern regions, become lofty trees within the tropics, as several of the grasses, the bamboo rising to the height of sixty feet; the hollow stalk of which is capable of being constructed into capacious household vessels. Some of the family of leguminosa are hardy-flowering trees, and contribute greatly to the beauty of the gardens of northern climes, as the Robinia and the Labernum, but they give way before the splendour and elegance of their tropical brethren. The flower's of the Erethrina, or coral tree, are of the deepest and most brilliant crimson, and appear in profusion upon some of the loftiest trees of the forest, while the Bauhinias, with their snake-like stems, and twin leaves, hang in festoons from branch to branch of other trees, and are only rivalled by the less vigorous but more richly coloured blossoms of the Carpopogons. But from these the Mimosa bears away the palm, with its rugged trunk, airy foliage, and golden flowers, which cast a charm over even the sterile wastes of burning Africa.

All naturalists, who have visited equinoctial America, hare found it impossible to convey any adequate idea of the impression produced upon the mind by its forests, consisting of noble trees, thickly planted by the hand of nature, the trunks of which are not covered with moss and lichen as in our climate, but with creeping plants ascending from the ground to the very summit of the trees, binding the whole together into a closely united mass of vegetation, and adorning it with brilliant flowers. "When a traveller," says Humboldt, "newly arrived from Europe, penetrates for the first time into the forests of South America, if he is strongly susceptible of the beauty of picturesque scenery, he can scarcely define the various emotions which crowd upon his mind; he can scarcely distinguish what most excites his admiration - the deep silence of these solitudes, the individual beauty and contrast of forms, or that vigour and freshness of vegetable life which characterise the climate of the tropics. It might be said that the earth, overloaded with plants, does not allow them space to unfold themselves. - So thick and uninterrupted are the forests which cover the plains of South America between the Orinoco and the Amazon, that, were it not for intervening rivers, the monkeys, almost the only inhabitants of these regions, might pass along the tops of the trees for several hundred miles together without touching the earth." Towards the junction of the Cassiquiaire with the Orinoco, "the Iuxuriousness of the vegetation increases in a manner of which it is difficult, even for those who are accustomed to the aspect of the forests between the tropics, to form an idea. There is no longer a beach; a palisade of tufted trees forms the bank of the river. You see a canal 200 toises (426 yards) broad, bordered by two enormous walls, clothed with lianas and foliage. We often tried to land, but without being able to step out of the boat. Towards sunset we sailed along the bank for an hour, to discover, not an opening, since none exists, but a spot less wooded, where our Indians, by means of the hatchet and manual labour, could gain space enough for a resting-place for twelve or thirteen persons." Mr. Darwin records similar facts and impressions:- "During the second day's journey, we found the road so shut up, that it was necessary that a man should go abroad with a sword to cut away the creepers. The woody creepers, themselves covered by others, were of great thickness; 
some which I measured were two feet in circumference. Many of the older trees presented a very curious appearance from the tresses of a liana hanging from their boughs, and resembling bundles of hay. If the eye was turned from the world of foliage above, to the ground beneath, it was attracted by the extreme elegance of the leaves of the ferns and mimose. It is easy to specify the individual objects of admiration in these grand scenes; but it is not possible to give an adequate idea of the ligher feelings of wonder, astonishment, and devotion, which fill and elevate the mind. Among the scenes which are deeply impressed upon my mind, none exceed in sublimity the primeval forests undefaced by the hand of man; whether those of Brazil, where the powers of Life are predominant, or those of 'Tierra del Fuego, where Death and Decay prevail. Both are temples filled with the varied productions of the God of nature; - no one can stand in these solitudes unmoved, and not feel that there is more in man than the mere breath of his body."

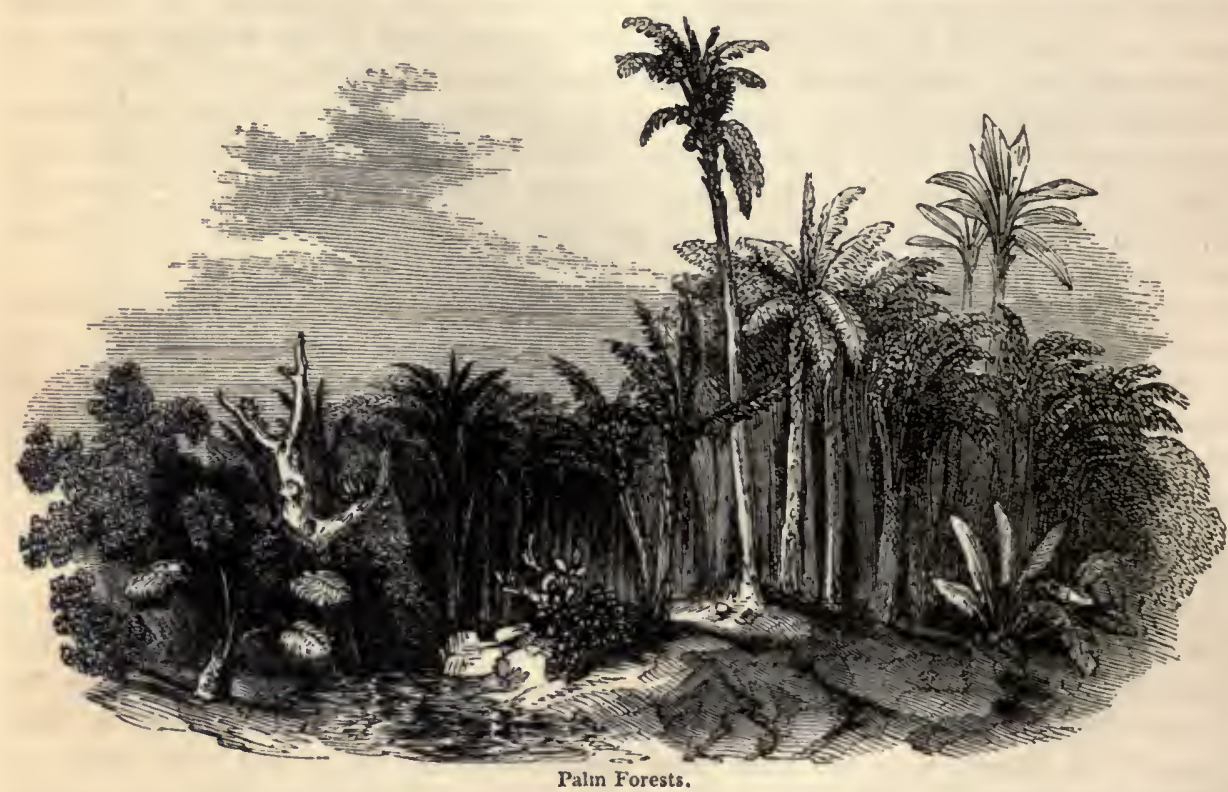

For utility and majestic port, the order Palme, the princes of the vegetable world, to use the appropriate phrase of Linnæus, constitute the chief vegetable glory of intertropical localities, though found in reduced dimensions in Spain, the neighbourhood of Genoa, around Naples, and in Sicily. The date-palm, with its cylindrical columnar stem, and crown of leaves, is a singularly graceful object in the deserts of the Old World :-

" Those groups of lovely date trees bending

Languidly their leaf-erown'd heads,

Like youthful maids, when sleep descending

Warns them to their silken beds."

But in equinoctial South America the palm tribes appear in their greatest magnificence, fascinating and imposing to the eye of the traveller, as he beholds them on the granite rocks at the cataracts of Atures and Maypures, on the Orinoco, the light green of the leaves, waving in the breeze, strikingly contrasting with the darker surrounding vegetation. On the plains, which are subject to floods, the European is sometimes startled by seeing the tops of these trees lighted with fires. They are kindled by the Guanacas, a people who have remained for ages in these marshy districts, secured from the floods by 
living in the palms, where, with mats coated with clay, they construet hearths for the fires which are essential to their comfort. In other districts the palm-groves, says Desfontaines, "being impervious to the sun's rays, afford a hospitable shade, both to man and other animals, in a region which would otherwise be intolerable from the heat. Under this natural shelter the orange, the lemon, the pomegranate, the olive, the almond, and the vine, grow in wild luxuriance, producing, notwithstanding they are so shaded, the most delicious fruit. And here, while the eyes are fed with the endless variety of flowers which deck these sylvan scenes, the ears are at the same time ravished with the melodious notes of numerous birds, which are attracted to these groves by the shade, and the cool springs, and the food which they there find." The date, the cocoa-nut, and the sago palm, are of vast importance to mankind, for the nourishing farinaceous food they supply, and their extraordinary fecundity, which led to the assertion of Linnæus, that the region of palms was the first country of the human race, and that man is essentially palnivorous. The cocoa palm produces annually, during the greater part of a century, 100 of its large nuts, but the Seje palm of the Orinoco yields 8000 fruits at a crop. A single spatha of the date palm, the broad sheathing leaf which incloses the flowers, contains 12,000, while each spatha of another species, the Alfonsia Amygdalina, has 207,000 flowers, and the individual plant 600,000. The produce of the banana, or plantain, another inhabitant of tropical climes, is still more enormous; a plant which requires but little cultivation, and is to immense numbers of the human race, what rice is to the Hindoos, and wheat to the Europeans. According to a calculation of Humboldt, upon the same space of ground, the weight of the yield in the case of bananas will be 44 times that of potatoes, and 133 times that of wheat!

In thus proceeding through the vegetable kingdom from the pole to the equator, we come to different productions as we descend from the frozen to the cold, the tempcrate, the warm, and the hot regions; but as a cliange of elevation has the same effect upon climate as a change of latitude, the plants that are characteristic of the high latitudes appear in succession upon the lofty mountains of those that are much lower. Tournefort found the plants that are peculiar to Armenia at the foot of Mount Ararat; above these he met with those that are common in France; at a still greater height he came to those that grow in Sweden; and towards the summit the vegetation of the polar regions appeared. The Alps, Pyrenees, and Andes exhibit the same feature; and hence it may be regarded as a botanical axiom, that the flora of a mountainous country will be richer than that of another of less dirersified aspect in the same latitude. The table states some interesting facts respecting vegetation on some of the mountains of the torrid and temperate zones. The fathom is equal to 6.39453 English feet.

\begin{tabular}{|c|c|c|c|c|c|}
\hline & $\begin{array}{l}\text { Andes of Quito, } \\
\text { Lat. } 0^{\circ} \text {. }\end{array}$ & $\begin{array}{l}\text { Mountains of } \\
\text { Mexico, } \\
\text { Lat. } 20 \% \text {. }\end{array}$ & 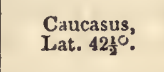 & 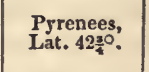 & $\begin{array}{l}\text { Alps, } \\
\text { Lat. } 45 \frac{1}{3}{ }^{\circ} \text { to } 46^{\circ} .\end{array}$ \\
\hline $\left.\begin{array}{c}\text { Distance between trees and } \\
\text { the line of perpetual snow }\end{array}\right\}$ & 600 fathoms & S50 fathoms & 650 fathoms & 230 fathoms & 450 fathoms \\
\hline Upper limit of trces. & 1800 fathoms & 2000 fathoms & 1000 fathoms & 1170 faths. & 920 fathoms \\
\hline $\begin{array}{l}\text { Last species of trees towards } \\
\text { the snow }\end{array}$ & $\begin{array}{l}\text { Escalonia } \\
\text { Alstonia. }\end{array}$ & $\begin{array}{l}\text { Pinus occident. } \\
\text { The occidental } \\
\text { pine covers the } \\
\text { Nevado of } \\
\text { Toluca. }\end{array}$ & $\begin{array}{l}\text { Betula alba. } \\
\text { The common } \\
\text { Birch. }\end{array}$ & $\begin{array}{l}\text { Pinus rubra. } \\
\text { Pinus uncin. }\end{array}$ & Abies excelsa. \\
\hline $\left.\begin{array}{l}\text { Distance between the snow } \\
\text { and corn }\end{array}\right\}$ & 800 fathoms & - & 630 fathoms & - & 700 fathoms \\
\hline
\end{tabular}


Marine botany exhibits a similar diversity of species in different temperatures and localities of the ocenn. The Polar Atlantic, the West Indian sens, the Indian Ocean and its gulfs, the eastern shores of South America, the coasts of Australasia, the Mediterranean and Red seas, have each peculiar kinds of algx, or sea-weed, belonging to them, though some marine productions take a very wide range, and appear to be universally diffused. The genus fucus, which grows up to tlie surface from deeply sunk rocks, forming immense beds, which act as natural breakwaters, and appear like extensirely inundated meadows, through which ships with difficulty can make their way, is found from the extreme southern islets near Cape Horn, along the whole western coast of South Ameriea, and in the tropical Atlantic Ocean. It is abundant in the northerly regions of the deep. This plant has already been mentioned as remarkable for the enornous length of its stems, in some eases reaching to three liundred and sixty feet. It is a striking example, also, of rapid growth. Mr. Stephenson found that a rock uncovered only at spring-tides, which had been chiselled smooth in November, was thickly covered with fucus digitatus two feet in length, and fucus esculentus six feet, in the following May, within six months afterwards. Some terrestrial plants, likewise, are extensively diffused, and adapt themselves to every variety of climate. The Samolus valerandi, a flowering marsh plant, occurs all over the globe, associated witl the birches of the frozen north, and with the palms of the burning tropies.

But climate only suffices very partially to explain the phenomena of regetable distribution; for under the same, or corresponding parallels of latitude, at the same elevations above the level of the sea, and upon kindred soils, we find totally distinct genera, and different species. 'The genus erica, or the common heath, seems to be exclusively confined to one side of our planet. It is chiefly to be found in a narrow longitudinal zone, extending from the northern parts of Europe to the Cape of Good Hope; for it rarely occurs in Asia, and of the 300 known species only one belongs to America. "Large commons without heaths," says Sir C. Lyell, speaking of his first transatlantic impressions, in the neighbourhood of Boston, "reminded me of the singular fact that no species of heath is indigenous on the American continent." On the other hand, the cactus family belongs as exclusively to the New World as the heaths to the Old. The beautiful and fragrant rose-tree appears to be entirely wanting as a native plant in South America. and throughout the southern hemisphere; and in general, comparing the vegetation of the two continents, where the same genera recur, the species are not identical. Humboldt found upon the lofty mountains of equinoctial America, where the climate corresponds with that of the temperate zone, plantains, ralerians, arenarias, ranunculuses, medlars, oaks, and pines, which, from their physiognomy, might be confounded with those of Europe, but they were all specifically different. 'The plants of Australasia, with rery few exceptions, are different to those of the rest of the world; and of sixty-one native species, in the little island of St. Helena, only two or three are to be found in any other part of the globe. In some instances, upon travelling across a ridge of mountains, without: any change of latitude, the vegetation is found quite different on the one side from the other. Nothing can be more striking than the contrast between the vegetation of the eastern and western sides of the chain of the Rocky Mountains. On the castern side azaleas, rhododendrons, magnolias, with a variety of oaks and elms, form the principal features of the landseape; but beyond the ridge, most of these genera entirely disappear, and the giant pine becomes the chief object in view. Starting in an easterly direction through the northern parts of the Old World, we gradually lose the oak, the wild-nut, and the appletree, so common in Europe, upon crossing the Uralian mountains, and they cense to be met with beyond the banks of the Tobol; but in the eastern parts of Asia, on the banks of the Argouan, the two former occur anew, and the last re-appears in the Aleutian isles. 



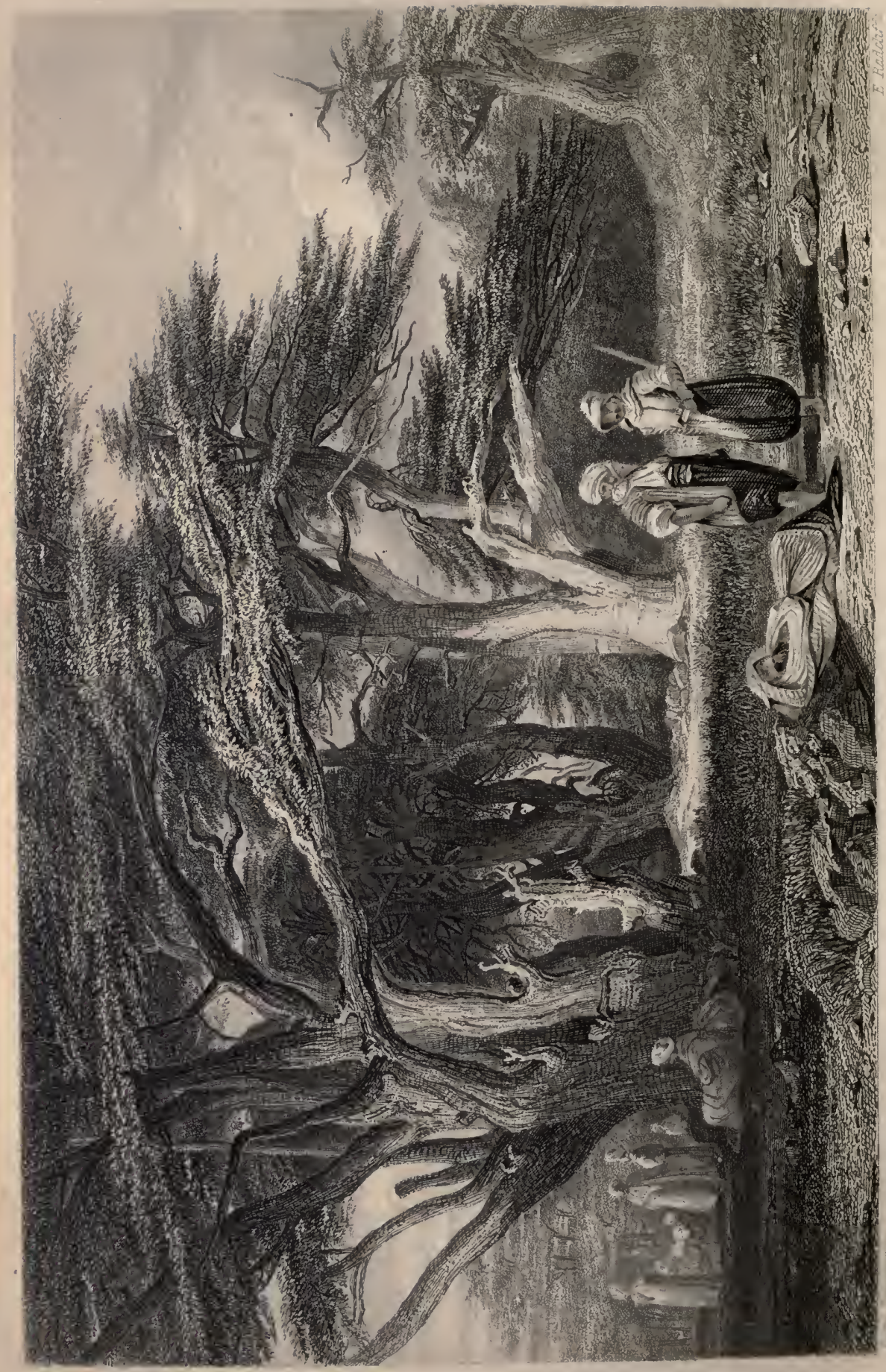


There are multitudes of plants of a completely insulated growth flourishing spontaneously in a particular spot, and nowhere else. Examples occur. upon the volcano of Guadaloupe, the Table Mountain of the Cape, and upon some sites of New Zealand; but the most remarkable case of this kind is that of the cedar of Lebanon, which has never been found indigenous in any other locality. From the earliest times the cedars of Lebanon have been celebrated. Their timber was largely used in some of the most famous structures of the ancients, and was highly prized on account of its durability; for though not equal to the oak in absolute wear, it is so bitter that no inseet will touch it. When Solomon built his temple, he sent to Hiram, the lord-paramount of Lebanon, to procure the necessary quantity of cedar-wood for the structure; and the thirty thousand axes of the King of Israel must have deprived the heights of some of their noblest trecs. Very few of the ancieut stock now exisi - whether owing to similar ravages, or to some change in the climate, it is impossible to determine. When Ballonius visited them in the year

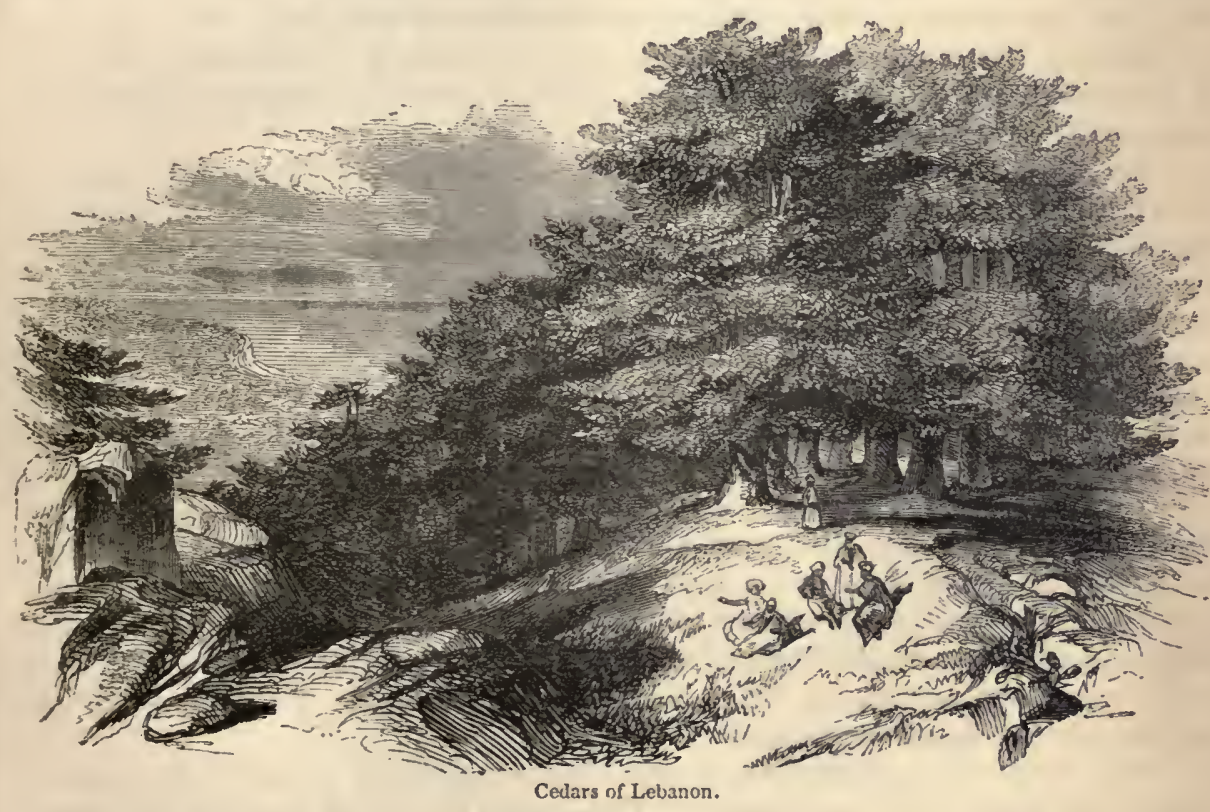

1550 , there were twenty-eight of the old race remaining. In 1575 Rauwolf found twenty-four; in 1680 Dandini found twenty-three; in 1738 Pococke counted fifteen; in 1811 Burckhardt could only number eleven; Dr. Richardson in 1828, and Lamartine in 1832 , speak of only seven. The age of these patriarchs of the forest has been variously estimated. The inhabitants firmly believe them to be the remains of that identical forest which flourished in the time of Solomon. Lamartine supposes it a fair presumption, from their size and appearance, that they go back to biblical times. It is certain that they were regarded as very ancient several centuries ago; nor is it unlikely that they are the surviving relies of a second generation since the time of the Jewish king. The cedar, full grown, with its upward inclining branches, is one of the most majestic and beautiful of the productions of the vegetable kingdom. The Arabs regard this inclination as a sign of intelligence, answering to instinct in animals, and reason in man; and it is asserted that this upward turning of the branch is always greater previous to the descent of the snow, as if the tree anticipated, and prepared to receive, the coming burden. 
"It was a cedar tree

That woke him from the deadly drowsiness;

The broad round-spreading branches, when they felt

The snow, rose upward in a point to heaven,

And, standing in their strength erect,

Defied the bafled storm."

Various magnificent specimens of the cedar of Lebanon have been reared in England, but it has never been found growing wild apart from the Syrian mountains.

Owing to the exclusire confinement of individual families of plants to particular localities, or their predominance there, the globe has been divided into a series of botanieal habitations, regions, or provinees, which are named after the most remarkable feature of their vegetation, or charaeterised by the geographical terms conmonly applied to the districts. In the arrangement of Professor Schouw both methods are adopted, but the latter only where a distinet botanical province is surmised, without a sufficient acquaintance with its productions being possessed to denominate it after those which are most predominant. There are about fifty botanical regions noticed by De Candolle; forty-eight by Mr. Hinds; and twenty-tro by Professor Schouw. From the latter the following arrangement is derived:-

1. The region of saxifrages and mosses, or the alpine arctic flora. This region is characterised by the abundanee of mosses and liehens; by the presence of the saxifrages, and gentians, chickweed tribe, sedges, willows ; by the total absence of tropical families, and a marked decrease of the forns peculiar to the temperate zone, of the forests of firs and birches, and an absence of other forests. It is also distinguished by the small number of annual plants, the prevalence of perennial species, and by a greater livcliness in their simple colours. The region is divided into two provinces: 1 . The province of the Carices, or the Aretie Flora, which comprehends all the countries within the polar circle, with some parts of Ameriea, Europe, and Asia, which are to the south of it; more especially Lapland, the north of Russia, Siberia, Kamsehatka, New Britain, Canada, Labrador, Greenland, and the mountains of Scotland and Scandinavia. The Laplander combs and dresses some species of carex, as we do flax, and in winter stuffs his shoes and gloves with it, as a protection against the extreme cold of the elimate. 2. The provinee of Primroses and Rampions, or the Alpine Flora of the south of Europe, which embraees the flora of the Pyrenees, Switzerland, the Tyrol, Savoy, the Apennines, the mountains of Greece, and probably the Spanish mountains.

2. 'The region of the umbelliferous and cruciferous plants, to which the hemlock, parsley, wall-flower, and cresses belong. These tribes are here in much greater number than in any other region. Roses, crowfoots, amentaeeous and coniferous plants are also very numerous. The abundanee of carices, and the fall of the leaves of almost all the trees during winter, form, also, ehief features of this division. It may be separated into two distinct provinees:- 1 . The province of the cichoracea, including the sowthistle, dandelion, and lettuce, which embraces all the north of Europe, not comprehended in the preceding region, namely, Britain, the north of France, the Netherlands, Germany, Denmark, Poland, Hungary, and the greater part of European Russia. 2. The province of the astragali, and cynarocephala, to whieh the milkreteh, burdock, and thistle belong, which includes a part of Asiatic Russia, and the countries about the Caueasian mountains.

3. The region of the labiute, and caryophille, to which the pink, catch-fly, and sandworts belong, or the Mediterranean flora. It is distinguished by the abundance of the plants belonging to these two orders. Some tropieal families are also met with, such as palms, laurels, arums, plants yielding balsam and turpentine, grasses belonging to the 
genus Panicum, or millet, and the true Cyperacea, or sedges. The forests are composed chiefly of the amentaceous and coniferous tribes, as birches, willows, and oaks; the copses of Ericince, or heath tribe, and Terebinthacea, as the mastic; and we meet with a great number of evergreen trees. Vegetation never ceases entirely, but verdant meadows are more rare. The region is divided into five provinces:- 1 . The province of the cistuses, or rock-roses, including Spain and Portugal. 2. The province of the sage and scabious, including the south of France, Italy, and Sicily. 3. The province of the shrubby I.abiata or the Levant, Greece, Asia Minor, and the southern part of the Caucasian mountains. 4. The Atlantic province, including the north of Africa, of which Professorschouw has ascertained no distinctive character. 5. The province of the houseleeks, or the Canary Isles, and probably also the Azores, Madeira, and the north-west coast of Africa. Many houseleeks, and some spurges, with naked and spiny stems, particularly characterise this province.

4. The region of the Rhamni and Caprifoliacere, to which the buckthorn and honeysuckle belong; or the Japanese region. It embraces the eastern temperate part of the old continent; namely, Japan, the north of China, and Chinese Tartary. The vegetation is indifferently known; but the mass appears to be temperate, yet singularly mixed with tropical forms. There are no large masses of oaks and fir, though these trees are common. The fruit trees of southern Europe are abundant and productire; some spice plants appear; and cotton and tobacco are grown in considerable quantities. The tea shrub is cultivated in extensive plantations. The hedges of some of the farms also consist of it, and supply the drink of the labourers.

5. The region of Asters and Solidagos, Mlichaelmas daisies and golden rods. This is marked by the great number of species belonging to these two genera; by the great variety of oaks and firs; the small number of umbelliferous and cruciferous plants; the total absence of the heath; and the presence of more numerous species of whortleberry than are to be met with in Europe. It comprehends the whole of the eastern part of North America, with the exception of what belongs to the first region. It has been divided into two provinces:-1. that of the south, which embraces the Floridas, Alabama, Mississippi, Louisiana, Georgia, and the Carolinas; 2. that of the north, which includes the other states of North America, such as Virginia, Pennsylvania, and New York.

6. The region of Magnolias, chiefly large trees, with large leaves and highly-odorous flowers, the perfume of which may be discovered at a great distance if the wind be farourable. It comprises the most southern parts of North America. The tropical forms, which show themselves more frequently than on a similar parallel of the old continent, are the chief features of the vegetation.

7. The region of Cactuses, Peppers, and Melastomas. These families are here predominant, both as it regards the number of the species, and of the individual plants. It is divided into three provinees:-1. the province of the Ferns and Orchises, comprehending the West India islands; 2. the province of the Palms, including the lower parts of Mexico, New Granada, New Guiana, and Peru; 3. Brazil also seems to form a provinee, and may perhaps constitute a region of itself.

8. The region of Cinchonce, or medicinal barks, comprising a part of the elevated regions of South America, from twelve hundred to five thousand feet above the level of the sea, included in the torrid zone. The Cinchona belongs exclusively to this region, and forms its principal feature, from which we have the well-known and lighly-valued Peruvian bark of medicine.

9. The region of Escallonias, Whortleberries, and Winter's Barks. It embraces the highest parts of South America. We also meet with Alpine plants; as saxifrages, whit- 
low-grass, sandworts, sedges, and gentians. Perhaps, also, the mountains of Mexico belong to this region, although they may form a separate province-that of the oaks and firs.

10. The Chilian region. The flora of Chili differs essentially from those of New Holland, the Cape of Good Hope, and New Zealand, although an approach to them is observable in the genera Goodenia, Araucaria, or Chilian pine, Protea, Gunnera, and Ancistrum. In a few favoured valleys the ground is quite yellow with the multitudes of flowers of Pancratium Amancaes - a beautiful and rare specimen of the genus-whose expanding flowers are the signal for the commencement of the revels bearing its name.

11. The region of Arborescent Composita, or arborescent plants, with flowers like the dandelion and daisy. The great number of syngenesious plants, more particularly of the family of Boopidea, forms the chief feature of this flora, which approaches in a remarkable manner to that of Europe, while it differs entirely from those of Chili, the Cape, and New Holland. This region comprehends the lower part of the basin of the Rio Plata, and the plains which extend to the west of Bucnos Ayres.

12. The Antarctic region, formed by the countries near the Straits of Magellan. The vegetation here has a considerable affinity with what is seen in the north temperate zone. Polar forms, however, display themselves in the species of saxifrage, gentian, arbutus, and primrose. There is also a resemblance between the flora of this region and those of the mountains of South America, of Chili, and the Cape.

13. The region of New Zealand. This flora, besides the plants peculiar to these islands, comprehends several others which belong to the extremities of America, Africa, and Australia. The Phormium tenax is here indigenous, whose numerous leaves the natives manufacture into matting; or a coarse thread is separated from them, and made into cordage and coarse linen, as is done from different species of aloe and agave in the Levant and southern Europe.

14. The region of Epacrides and Eucalypti, comprehending the temperate parts of Australia and Van Diemen's Land. The former are ornamental plants growing upon high situations; the latter are lofty timber trees. Besides these two families, from which the region derives its name, it is characterised by the presence of a great number of Proteacea, Stylidea, Restiacea, Diosmea, myrtles, and acacias.

15. The region of Mesembryanthema, Fig-Marigolds, and Stapclias. These two genera, as well as the heatls, are very abundant here. It embraces the southern extremity of Africa, where the family of heaths is found in greater quantity than anywhere else. But three or four humble British shrubs, with the heath of Spain, Erica Mediterranea, were known previous to the conquest of the Cape of Good Hope. Several hundreds of species were then brought to light, many of very elegant, and some of splendid appearance.

16. The region of Western Africa. We are only acquainted witll Guinea and Congo, the vegetation of which is a mixture of the floras of Asia and America, bearing most resemblance to the former. A considerable number of grasses and sedges characterise this region, and the peculiar genus Adansonia, the baobab-the largest known tree in the world. The name is derived from the French botanist Adanson, who first observed the tree upon bis voyage to Senegal. He measured the trunks of several from sixty-five to seventy-eight feet in circumference, the single branches of which would be equal to monstrous trees: and where the water of a river had washed away the earth, so as to leave the roots of one partially bare and open to the sight, they measured 110 feet long.

17. The region of Eastern Africa, of the vegetation of which no definite knowledge is yet possessed.

18. The region of the Scitaminea, the turmeric, cardanom, and Indian shot, or the 
Indian flora. The Scitaminece are here much more numerous than in America, as well as the Leguminosa, such as pease and broom. The Cucurbitacea, or the cucumber tribe, and Tiliacece, or the lime-tree tribe, are also abundant, but in a less degree. The region comprehends India east and west of the Ganges; the islands of Madagascar, Bourbon, and Mauritius; those between India and New Holland; and perhaps the tropical part of this last continent.

19. The mountains of India form one or two regions, the vegetation of which differs from that of the plains. These countries perhaps constitute one region with nearly the whole of Central Asia.

20. The floras of Cochin China, Tonquin, and the south of China, notwithstanding their resemblance to that of India, present a sufficient number of peculiar indigenous plants to constitute a distinct region.

21. The flora of Arabia, Persia, differing from that of India and the Mediterranean, forms a particular botanical region, characterised by the numerous species of Cassia and Mimosa. Of the latter family, there is the beautiful acacia described in Lalla Rookh :-

\footnotetext{
"Our rocks are rough; but smiling there

Th' acacia waves her yellow hair,

Lonely and sweet, nor lov'd the less

For flow'ring in a wilderness."
}

It is probable that Nubia and part of Central Asia belong to the same region; and Abyssinia, the elevated parts of which possess such a different climate, may form one of the great subdivisions, or even a totally distinct region.

22. The islands of the Soutl Sea, which lie within the tropics, form a separate region, but with a slender degree of peculiarity. Among 214 genera, 173 are found in India, and most of the remainder are in common with America. The bread-fruit tree is among the characteristics of these islands, although it is not confined to them.

To the preceding enumeration there should be added those islands which have a distinct regetation, as Kerguelen's Land, or the Island of Desolation, the whole flora of which, when visited by Captain Cook, consisted of sixteen or eighteen species, all of which were considered to be peculiar to it. St. Helena is another example, characterised by an indigenous vegetation, not a single species of which is found on the continent of Africa, while not more than two or three of its species occurs on the continent of America.

It thus appears, upon examining different and distant localities, that each has a vegetation peculiar to itself, while a common analogy prevails among them, where the physical conditions of soil, temperature, and local circumstances are the same. Plants of the simplest structure, or the cryptogamic tribes - the lowest orders in the vegetable creation - are the most extensively diffused, the same species existing in far remote countries. Of the lichens observed in Australia, two-thirds are also natives of Europe; and of the one hundred species of ferns discovered there, twenty-eight are common to other countries. It is very different with plants of the more perfect kind, or the dicotyledonous tribes, the aggregate number of which, known to Mr Brown, in Australia, amounts to 2100 species, of which only fifteen, or about the one hundred and ninety-third part, are found in Europe. Of the plants belonging to an intermediate class, or the monocotyledonous tribes, amounting to 860 species, there are thirty, or about the one twenty-ninth part, chiefly grasses, that are native to Europe. "If the animal kingdom in New Holland," says M. Leschenault, "offers remarkable peculiarities which isolate it from all other parts of the world, the vegetable kingdom has a character no less distinctive. This character relates not only to botanical differences, but likewise to a natural physiognomy which would be remarked by the most careless observers. The vegetation only of the 
southern parts of $\Lambda$ frica can be compared to that of New Holland. In the same latitudes we find innumerable legions of heaths and Protec, which include many shrubs remarkable for their graceful and delicate forms, adorning the otherwise barren soil of either climate. But in all the places we have visited, and above all on the western side of New Holland, we do not find, in the great masses of vegetation, either the majesty of the virgin forests of the New World, or the variety and elegance of those of Asia, or the delicacy and freshness of the woods of our temperate countries of Europe. The vegetation is generally gloomy and sad. It has the aspect of our evergreens or heatis. The plants are for the most part woody: the leaves of nearly all are linear, lanceolated, small, coriaccous, and spineseent. This contexture of vegetable productions is the effect of the aridity of the soil and the dryness of the climate. It is without doubt to these same causes that the rarity of eryptogamous and herbaceous plants is owing. The grasses, which elsewhere are generally soft and flexible, participate in the stiffness of the other vegetables. The greater part of the plants of New Holland belong to new genera; and those ineluded in the genera already known are of new species." Analogy, with still stronger diversity, marks the vegetation of most contrasted distriets at some considerable distance from each other; but the analogy is striking between the flora of contiguous countries, not divided by arid deserts or high mountain chains. Thus England does not possess fifty species of plants which are not found in France; and the opposite shores of the Mediterranean have a kindred flora. On the other hand, there are scarcely any species to be met with in Senegal that are common to the north const of Africa, the Great Desert dividing the two regions; and Mr. Darwin, upon crossing the Andes of Chili, was struek with the marked difference of the regetation in the valleys on each side, though the cliniate, as well as the kind of soil, was nearly the same, and the difference of longitude very trifling.

The preceding facts are obviously fatal to the Linnæan hypothesis respecting vegetable distribution - that the originals of all the species of plants had their primary habitation in one spot, from which central region they have been diffused by natural agencies orer the face of the globe. In order to provide that diversity of climate necessary to support in the same place aretic and tropical forms, Linnæus imagined the common birthplace of plants to have been a high mountain tract in a warm region, the various necessary temperatures being found at different heights from the base to the summit. This has been justly called a seheme more allied to poetry or fiction than to a serious investigation of the phenomena of nature. The ascertained condition of the vegetable kingdom is utterly irreconcilable with it. A second theory rejeets the idea of a local centre, and places the original distribution of plants under the government of soil and climate: but this is scarcely more tenable than the former hypothesis, on account of totally different genera and species occurring under the same physical conditions. A third theory is an expansion of the Linnæan. It recognises every species or tribe as emanating from a primitive centre, each centre being the seat of a certain number of species, these primary habitations being in different parts of the earth. This hypothesis is most in harmony with facts. It accounts for the different botanical regions into which the surface of the carth may be mapped out; for the diversities of species under the same parallels of latitude; while the natural transporting agencies of Linnæus remain in full force, to disperse each species to a distance from its primal seat, and to intermingle the floras of different districts, not separated by insurmountable physical barriers to migration. Dr. Prichard, after examining the subject with great research and care, thus states the conclusion:"It appears, then, that the phenomena connected with the distribution of plants are only reconcilable with one hypothesis, or rather they lead us clearly to one inference, namely, that the vegetable creation was originally divided into a limited number of provinces. Eaeh country had its particular tribes, which at first existed not elsewhere. 'This conclu- 
sion results most distinctly from the general difference in the species belonging to each of the great continents - $a$ difference never called in question in respect to the principal masses of vegetation - and the great aggregate number of plants which, by their situation at a distance from sea-coasts, and by the nature of their seeds, are removed from the chances of transportation; and secondly, from the arrangement of gregarious plants round some particular foci, the individual species being spread out in various directions with reference to the central points."

In relation to the plants which are diffused through different botanical regions, we shall perhaps see reason to believe that they are not indigenous in all of them, but that each has been dispersed from its original seat, by briefly adverting to the natural provision made to effect the diffusion. 'This includes the agency of air, water, animals, and man.

The seeds of many plants are furnished with downy appendages or winglets, by which, under the control of the winds, they are borne to a distance from their birth-place; and where the breezes are permanent in one direction, as in the case of the trade-winds, their. transportation to a far remote site may obviously transpire. The minute and almost impalpable sporules of the cryptogamic species, light as the fincst powder, answering to the seeds of other plants, are most completely susceptible of atmospleric impulsion; and it is exactly this species that we find most extensively spread. De Candolle found two species of lichen on the south-west const of Bretagne, which had never been met with in France before - the Sticta crocatu and the Physcia favicans of Jamaica, which he supposed had been brouglit from that island by the south-west winds. Linnæus records the striking case of the Erigeron canadense, or flea-bane, which, after being brought from Canada, and introduced into the botanical gardens at Paris in the course of a century spread itself over all France, Italy, Sicily, Belgiun, and Germany, the wind scattering the seeds. "The brown linnet, when feeding on thistle-seed, perches on the top of the weeds, and tears the downy head asunder, in order to reach the seeds which are attached to the receptacle. During this act, many of the grains, being loosened, are borne away on their downy wings by the breeze to places fur distant from the parent stem - the bird being in this case the indirect disseminator of the thistle. Were the head not torn asunder in this manner, ten to one but it would become soaked with the rains of winter, and fall down only a few inclies from the original stalk, instead of being transported, as it often is, across many miles of country. What is here mentioned of the linnet may be witnessed in any thistlery, during some fine day in September, when the birds are feeding in flocks, and scattering the down in every direction. The greater part of the seeds is no doubt devoured by them, but a number also escape, a fact which the bird is well aware of, as it frequently gives cliase to the stray ones as they are borne away by the wind." Even seeds which are comparatively heavy, and not furnished with wings, or downy appendages, are easily uplifted by the stronger aerial currents, and compelled to take a journey of several leagues by the rush of the tempest. Such storms as the hurricanes that are common in tropical regions, which move at the rate of from fifty to a hundred miles an hour, overturning buildings, and wrenching up the largest trees, and conveying heavy fragments to a considerable distance, are potent agents in the dispersion of plants, introducing the seeds of those that are peculiar to one island into another, bearing them across wide arms of the sea, and assimilating the regetation of opposite shores.

The agency of water is another active and influential cause in the dissemination of plants. "The mountain stream or torrent," observes Keith, an able writer on botany, "washes down to the valley the seeds which may accidentally fall into it, or which it may happen to sweep from its banks when it suddenly overflows them. The broad and majestic river, winding along the extensive plain, and traversing the continents of the world, conveys to the distance of many liundreds of miles the seeds that may have rege- 
tated at its source. Thus the southern shores of the Baltic are visited by seeds which grew in the interior of Germany, and the western shores of the Atlantic by seeds that have been genernted in the interior of America." The seeds of several terrestrial species are enveloped with a mucous matter, by which they are preserved for a long time from the injurious influence of the ocean, or some other peculiarity of structure or accidental circumstance affords protection, so that they are capable of germinating after a lengthened immersion in the briny deep. The fruit of the casliew-nut, Anacardium occidentale, which grows in Jamaica, has been drifted by the gulf stream across the Atlantic to the western coast of Scotland, in such a condition as to hare been capable of re-production in a favourable soil and climate. By the same current the Lenticula marina, or sargasso, a bean common to the same locality, arrives at the Orkney Islands and the coast of Ireland; and an instance is recorded of the Guilandina Bonduc, or nicker tree, one of the tribe of Leguminose, having been raised from a seed which had accomplished the $\Lambda$ tlantic passage. In a collection of plants gathered from the neighbourhood of the river Zairc, on the west const of Africa, about $6^{\circ}$ south latitude, Mr. Brown found thirtecn species that are met with on the opposite shores of Guiana and Brazil. These species were only found towards the lower part of the river, where they bear but a small proportion to the whole regetation; and, as they were chiefly such as produce seeds capable of retaining their vitality during a long immersion in the waters of the ocean, it was inferred from these circumstances, that they had been drifted in the intertropical seas from a TransAtlantic to an African site.

Animals, of various tribes, contribute to the dissemination of vegetable productions. Nature has expressly provided the seeds of several kinds of plants with an apparatus of barbs and hooks for eatching hold of the wool and hair of quadrupeds, and the feathers of birds, in whose locomotion they participate. Fifty genera thus constituted are enumerated by Linnæus, among which the burdock, teasel, and woodruff are obvious examples; and such seeds are widely dispersed by animals of the sheep and goat kinds, with the ox, horse, camel, deer, and buffalo, which at certain seasons are prone to rub themselves against the trees and shrubs. "A deer," observes Sir C. Lyell, "has strnyed from the herd when browsing on some rich pasture, when he is suddenly alarmed by the approach of his foe. He instantly plunges through many a thicket, and swims through many a river and lake. The seeds of the herbs and shrubs adhere to his smoking flanks, and are washed off again by the streams. The thorny spray is torn off, and fixes itself in lis hairy coat, until brushed off again in other thickets and copses. Fven on the spot where the victim is deroured, many of the seeds which he had swallowed immediately before the pursuit may be left on the ground uninjured." Some naturalists have deemed the latter statement questionable, supposing that seeds and fruit cannot escape being comminuted and destroyed in their passage through the stomach; but a variety of well-attested facts proves the contrary, of which the sagacious rook is aware, and hence haunts the exuvix of animals. Linnæus observes, that to many it seems extraordinary, and something of a prodigy, that when a field is well tilled, and sown with the best wheat, it frequently produces darnel, or the wild oat, especially if it be manured with new dung: they lo not consider that the fertility of the smaller seeds is not destroyed in the ventricles of animals. Birds especially, as the linnet, blackbird, and thrush, after feeding too rapaciously upon berries, are known to part with them in an undigested state. It is not for the kerncl or seed that birds swallow the haw and the elderberry, but for their pulp; and many have their organs so constructed that the stone is ejected without injury. The seeds of the misletoe and juniper, it is well known, are thus dispersed and planted by birds; and acorns taken from the stomach of wood-pigeons have so far preserved their vitality as to spring up into healthy saplings, upon being sown, equal to the oaks grown in the usual 
way. The soft covering of the nutmeg, known to us by the name of mace, affords a favourite repast at certain seasons to some species of the arboreal pigeons of the Indian archipelago. The nutmeg itself, which is generally swallowed with the whole of its pulpy covering, passes uninjured through the digestive organs of the bird, and is thus dispersed throughout the group of the Moluccas, and the adjacent islands. An example of a different way in which animals contribute to the dispersion of plants, may be taken from the habits of the common squirrel, led by instinct to lay up a store of food for the winter, as is the case with several other species. In the woods belonging to the Duke of Beaufort, near Troy House, Monmouthshire, a squirrel was observed sitting very composedly upon the ground. In a few seconds he darted like an arrow to the top of a tree, and brought down an acorn, which was carefully deposited in the ground. The same process was repeated several times, the different acorns being laid up in different holes. We may suppose the place of deposition, in the case of some, to escape the memory of the little animal, upon the return of winter, which germinate, and ultimately supply the place of the parent tree.

The three agencies noticed compose a machinery competent to effect the wide dissemination of plants, nor is it extravagant to suppose their combined action resulting in an intermingling of the productions of far distant botanical habitations. Tracing the operation of the causes in connection, Mr. Lyell imagines a tempestuous wind, after bearing the secls of a plant many miles through the air, delivering them up to the ocean. Its currents then may drift them to the shore of some remote continent, where, upon the fall of the tide, they are deposited; and finally, some of the land-birds may thence convey them over hill and dale to their retreat, where, from their exuviæ they germinate, and clothe the spot with a new regetation. To the preceding causes of dispersion we have now to add the agency of man, who by design, and involuntarily, has largely contributed to the diffusion of vegetable productions.

For the purposes of food, luxury, ornament, and use in the arts of life, an immense number of plants have been transported by the human race in their migration to climates, soils, and situations, where they are not indigenous. The cereal vegetables, so important to our sustenance, are importations into Europe, and have from thence been taken by its inhabitants to various parts of the globe which they have colonised. The native country of these grasses has escaped remembrance, and can never now be ascertained, though Bruce states that he found the oat wild in Abyssinia, while other travellers have mentioned barley as growing wild on the banks of the Semara in Tartary, and wheat in hilly situations in the Last Indies. But whether these valuable grains came originally from those countries, and when and how they migrated, are points equally unknown. The New World received them from the Old at the hands of the Spaniards. One of the scrvants of Cortes found among the rice which served to support his troops three or four grains of wheat, which were sown in Mexico, probably, about the year 1530. The name of the person who carried the first grains to Lima has been preserved-a Spanish lady, Maria d' Escobar. Upon being sown, their produce was distributed for three years among the colonists, each receiving twenty or thirty seeds. At Quito, the first European corn was sown near the convent of St. Francis, by Father Jose Rixi, a native of Flanders ; and the monks still show, as a precious relic, the earthen vessel in which the original wheat came there. "Why," asks Humboldt, "have not men preserved everywhere the names of those who, in place of ravaging the earth, have enriched it with plants useful to the human race?" In return, the Old World has received the potato from the New, which found its way to England from North America; but previously it had been brought to Spain from the southern part of the continent, where Humboldt searched in vain to discover it in a wild condition, and declares its native country to be unknown. The 
edible potato has, however, since his researches, been found wild in the neighlourhood of Valparaiso, and Mr. Darwin met with it on the islands of the Clionos Archipelago, off the coast of Chili. "The tallest plant," he remarks, "was four feet in height. 'The tubers were gencrally small, but I found one, of an oval shape, two inches in diameter; they resembled in every respect, and had the same smell as English potatoes; but when boiled they shrunk much, and were watery and insipid, but without any bitter taste. They are undoubtedly here indigenous; they grow as far south, according to Mr. Low, as lat. $50^{\circ}$, and are called Aquinas by the wild Indians of that part; the Chilotan Indiaus have a different name for them. Professor Henslow, who has examined the dried specimens which I brought home, says that they are the same with those described by Mr. Sabine from Valparaiso, but that they form a variety which by some botanists has been considered as specifically distinct. It is remarkable that the same plant should be found on the sterile mountains of central Chili, where a drop of rain does not fall for more than six months, and within the damp forests of these southern islands." The vine, Vitis vinifera, now naturalised in Europe, does not belong to it, but occurs in a wild state on the coasts of the Caspian Sea, in Armenia, and in Caramania. 'The Greeks received it from Asia, the Romans fiom the Greeks, who planted it upon the banks of the Rhine, and introduced it into England. Previous to the Roman Conquest, it is probable that the native Britons possessed no other fiuits than the crab, the sloe, the hazel-nut, and the acorn; but the vegetable productions with which that people were enriched by their Asiatic conquests, gradually found their way into Western and Northern Europe, with the extension of the Roman Empire.

The plains of Spain and the south of France received the olive from Tuscany, to which it came from Greece, where it grows spontaneously, covering the beautiful plain of Athens as seen from Mount Hymettus, but its parent spot is farther eastward. According to Sickler, a laborious writer on the history of cultivated regetables, the Romans derived the fig from Syria, the orange from Media, the peach from Persia, the apricot from Epirus, the pomegranate from Africa, the plum, the cherry, the apple, and the pear from Armenia ; but Epirus received the apricot from Persia, where it bears the figurative name of "the seed of the sun;" and probably it came thither from a southern region. A cherry-tree laden with fruit adorned the triumph of Lucullus, who brought it to Rome as a memorial of his triumpl over Mithridates, in whose province of Pontus he had found the tree; and Pliny states, that "in less than one hundred and twenty years afterwards, other lands had cherries, even as far as Britain beyond the ocean." There is, however, a species of wild cherry, supposed to be indigenous to France and other parts of Europe. In all probability, most of our common fruits are standing memorials of Roman domination in the island. In like manner, the mad enterprise of the crusades contributed to the transport westward of the eastern vegetable treasures, the monks and ecclesiastics being diligent patrons of horticulture in the middle ages. Thus a variety of the plum, the damson, or damascene, as its name imports, was brought from Damascus during the crusades. The damask rose came likewise from the same place, along with the narrowleaved elm from the Holy Iand. The conquests of the caliphs also were attended with the same result, the lemon migrating after them to the foot of the Pyrenees, though originally confined to India beyond the Ganges, where it now grows naturally. Culture has exerted a marked influence upon many of these plants, for which it is impossible to account, changing to some extent the form of their leaves, the habits of the trees, and the qualities of their fruits. The cultivated peach becomes one of the most delicions of fruits, but in its wild state in Medina it is poisonous, so that the Persians are said to have sent it into Egypt with the design of poisoning the inhabitants. There is a species of apricot in Barbary, called Matza Franca, or the killer of Christians, which becomes 
innocuous when tended by the skill and industry of man. Upon herbaceous and flowering plants, the influence of cultivation is not less conspicuous. Different kinds of cabbage - saroy, broccoli, and cauliflower, - are supposed to be derived from a plant whieh is sometimes found growing wild on our coasts, the Brassica oleracea; the clove, pink, and the carnation, are varieties of a flower found among the ruins of some of our old eastles, the Dianthus Caryophyllus; and the polyanthus is probably a derivation from the wild primrose. It is observed, however, that the primitive structure of plants never changes, however cultivated and far transported. The potato grown in Chili at the height of twelve thousand feet above the level of the sea is identical with the potato of Siberia.

Involuntarily, man contributes largely to the propagation and dispersion of plants, some of which are useless to him, or positively noxious. Their seeds become mixed with the bales of merchandise which he transports, and with the ballast of ships, and are thus conveyed to a distance from their place of growth, accidental eircumstances leading to their germination. De Candolle states, that at the gate of Montpellier there is a meadow set apart for the purpose of drying foreign wool after it has been washed; and that scarcely a year passes without some foreign plants being found naturalised in this drying ground, as Centaurea parviflora, Psoralea palastina, and Hypericum crispum. There is a remaikible instance in South America of a European plant, which was probably introduced by accident, soon after the first colonists of La Plata landed in the year 1535, which lias now taken such entire possession of a large district, as to have obliterated nearly the whole of the spontaneous vegetation. 'This is a species of thistle, Cynara Cardunculus, or cardoon, of the artichoke kind. In the Banda Oriental, remarks Mr. Darwin, "very many, probably sercral liundred square miles, are covered by one mass of these prickly plants, and are impenetrable by man or beast. Over the undulating plains, where these great beds occur, notling else can now live. Before their introduction, however, the surface must have supported, as in other parts, a rank herbage. I doubt whether there is any case on record of an invasion on so grand a scale of one plant over the aborigines." Mr. Hinds is tempted to inquire, from its rifeness and luxuriance, whether plants may not find a situation more favourable to their existence than that in which Nature has placed them, - a question which the excessive development of this stranger, as well as that of Psidium pyriferum at 'Tahiti, a species of exotic guava, would seem to require an affirmative answer. The cardoon must not be confounded with the giant thistle of the Pampas, so vividly described by Captain Head, from which it is essentially different. Fennel, another importation from Europe, has widely spread itself in the same region, covering the banks of the ditches in the neighbourhood of Buenos Ayres and Monte Video. In like manner, the common English nettle speedily grew up in New England after the first colonists settled in the district.

When we consider the condition of the vegetable kingdom, and the operation of the preceding agencies, it is impossible to resist the conclusion, that different species of plants were originally planted by the Creator at several foci on the surface of the earth, many of which have been subsequently widely diffused by the causes enumerated. It lias, indeed, been thought, that the occurrence of cryptogamous plants in mines and deep excavations of the earth, presents a case which cannot be explained by any known method of dispersion, and which seems to favour the doctrine of equirocal production. But some striking facts deserve notice, which are calculated to remove the difficulty, by establishing an extensive diffusion of seeds through the soil of the earth, in some instances at a considerable deptl, which past geological catastrophes have imbedded, and which preserve their vitality, so as to germinate upon any accidental exposure to the action of the atmosphere. Dr. Prichard gives the following example, upon the authority 
of Professor Graham, of the University of Edinburgh. Previous to the year 1715, no broom grew in the king's park at Stirling; but in that year a camp was formed there, and the surface of the ground consequently was broken in many places. Wherever it was broken, broom sprang up. The plant was subsequently destroyed; but in 1745 , a similar growth appeared after the ground had been again broken for a like purpose. Some time afterwards the park was ploughed up, and the broom became generally spread over it. Some year's ago a gentleman planted a garden in Stirlingshire, and as he was about to make a bleaching ground in the neighbourhood, he took from six to nine inches of soil off the surface of the field intended for the purpose, and carried it into his garden, afterwards sowing the ficld with grass seeds. In the field thus uncovered, seedling broom appeared as thick as the grass which had been sown. Professor Graham concludes, that the seeds could not in either case have been supplied by the wind: first, because they arc hcavy, round, and without wings; and, secondly, because all the broom seed in the district could not have produced such crops as sprung up. The form of the ground is also such, that no stream of water could have transported them. The seeds must have been in the soil, how long and how imbedded cannot be conjectured. 'The case is still more striking in the United States, of soil turned up from the depth of many feet immediately yielding a crop of white clover. The occurrence of seeds thus buricd in the soil of the earth, may explain the appearance of cryptogamous plants in mines in situations peculiarly inaccessible to the ordinary agents of dispersion; while the growth of wheat from grains found in the sepulchres of the Egyptian kings, after an entombment certainly of from three to four thousand years, sufficiently attests the tenacity with which enclosed seeds retain their vitality.

The adaptation of external nature to the wants of man is finely displayed by the regetable tribes with which the earth is replenished, which minister in a thousand ways to his cxistence, health, convenience, and refinement. The reproductive power of some species, cspecially of the more useful kind, is an obvious instance of bountiful design : but, notwithstanding the evidence of it which the experience of the human race has already acquired, we are far from having had the limit of the prolific quality developed. The orange displays an extraordinary fecundity. A single tree at St. Michael's has been known to bear 20,000 oranges in a season fit for exportation, those damaged and defective amounting to at least one third more. The ten, sugar, and potato plants, yielding products which are necessaries of life to the cultivated nations, are additional examples, with the common grasses which clothe the hills and valleys with their refreshing green, forming the pastures upon which innumerable flocks and herds graze by day and repose at night. A single potato from the crop of 1844 was cut into twenty-eight sets, and planted, yielding a produce of sixty-eight pounds' weight during the next season. In the harvest of 1840, a Cambridge agriculturist gathered from one of his fields some very fine cars of wheat, the proceeds of which filled a common wine glass. This was planted the following autumn, and produced a peck of grain, which was again planted November 3. 1841, and yielded rather more than seven bushels. Upon this being sown November 3. 1842, the yield amounted to upwards of 108 bushels, which, being returned to the soil in the autumn of 1843 , produced 1868 bushels. In some of the more fertile parts of the tableland of Mexico the common return of the wheat harvest is from thirty-five to forty grains for one, and it frequently exceeds from seventy to eighty for one. It is not undeserving of notice, that the vegetable productions upon which the sustenance of nan mainly depends, have the flavour of their fruits accommodated to his taste, being apart fiom the pungent and the insipid, so that a sufficient quantity may be consumed without annoyance or disgust. Yet, as if to accomplish the law of Providence to the human creature, "In the sweat of thy brow shalt thou eat bread,"- the cercal and leguminous tribes, 
which furnish him with the staff of life, demand cultivation in order to be prolific and nutritive; while the chief vegetable support of animals - the permanently green grasses - flourish without industry or skill.

\section{CHAPTER XVIII.}

\section{THE DISTRIDUTION OF ANIMARS,}

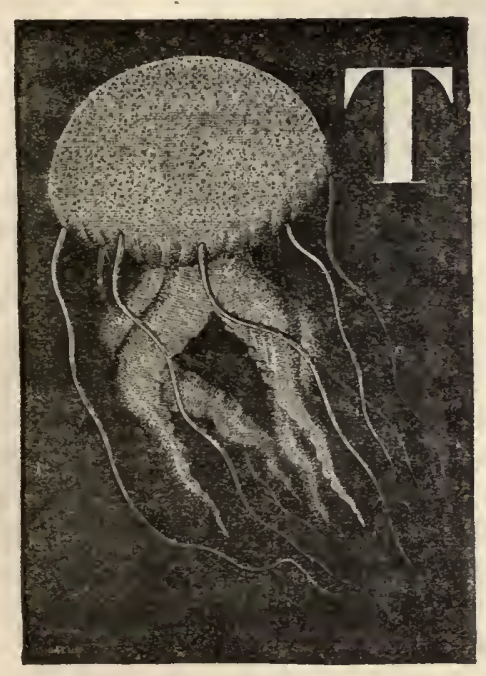

HAT department of animated nature upon a vicw of which we now enter, presents to our attention the same wide diffusion of its objects, variety of organisms, and gradual advance from the most simple to the more perfect and majestic forms, together with a precise adaptation to different external circumstances, which characterises the productions of the vegetable world, The high ice-clad mountains, the level and parched deserts, together with the "deep unfathomed caves of ocean," have their respective animal tribes; while the bowels of the earth are not devoid of locomotive tenants, as in the case of the carerns of Carniola, where the Proteus anguinus sustains existence in the perpetual darkness, writhing and languishing upon any transition to the realms of day without some protection from the light. The study of animals, as evidenced by the extant records of observation, commenced with Aristotle, although it formed an accomplishment of the wise Jewish king to speak not only "of the trees, from the cedar of Lebanon even to the lyyssop which springeth out of the wall,"but also "of beasts, and of fowl, and of creeping things, and of fishes." But from the time of the celebrated Greek, the science of zoology made little progress, till our countryman Ray addressed himself to a methodical arrangement of animals, founded upon their difference of structure, and originated a system which Linnæus expanded and improved, and left for Cuvier to re-arrange and perfect. The more recent results obtained, have chiefly been an extension of the sphere of vitality by Ehrenberg's brilliant discoveries on the occurrence of minute life in the ocean, which have opened to our knowledge a thickly-pcopled world of microscopical living atoms in the oceanic abyss, some of which have but the estimated diameter of one three-thousandth of a line. It is difficult for a thoughtful mind to decide, whether admiration is more descrvedly challenged by the vast or the minute forms of living existence around us; but the adaptation of both to fulfil the purposes of their being, and the varieties which intervene between the two extremes, cannot be carefully observed, without a conception the most exalted of the fertility of the Creating Mind, and the richness of the Creation. Evident as was the fact to Lucretius, it is still more open to our own observation:-

"Thus nature varies: man, and brutal beast,

And herbage gay, and scaly fishes mute,

And all the tribes of heaven, o'er many a sea,

Through many a grove that wing, or urge their song 
Near many a bank or fountain, lake or rill ;

Search where thou wilt, each differs in his kind, In form, in figure, differs."

In cursorily surveying the distinctive characters of the animal races, it is usual to follow the series ascending from the lower to the higher organisations.

The class of Zoophytes, or plant animals, may be regarded as forming the first link in the ehain of animal life. It includes several families whose members in general are

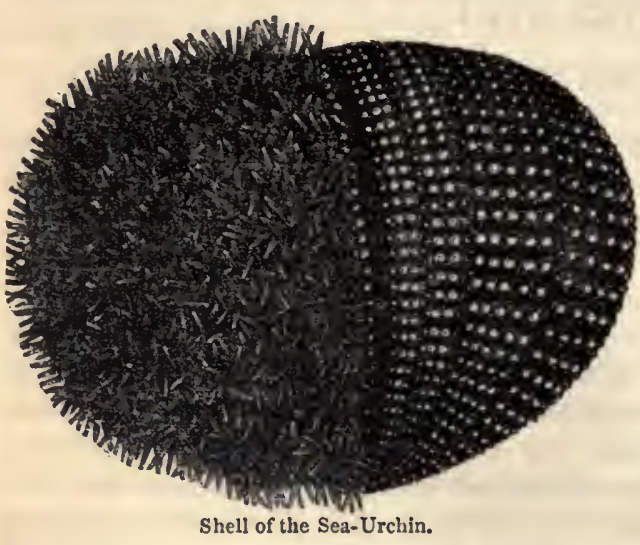
aggregated in a common living mass, as the buds of a dicotyledonous trec are united to the stems. 'This is the case witli the tribes of polypi, which have their special habitation in the equatorial seas, and there construct the coral reefs and islands. In the Infusoria, or animaleula, chiefly found in stagnant fresh water filled with vegetable matter, and in common sea-water, a real individual existence is developed, but so exceedingly minute as to be seldom capable of being traced except with the aid of a microscope. The brown-coloured fine dust, so often noticed in the Atlantic, which has fallen in such quantities upon ressels as to soil every thing on board, and even cause them to run ashore through the obscurity of the atmosphere, consists principally of Infusoria. Some of the species multiply at a prodigious rate; for Ehrenberg calculated that, in twenty days, a single individual may increase to a million. In the ciass of Mollusca, whether naked or testaceous, that is, furnished with a shelly covering more or less thick and entire - as in the case of the oyster, lobster, and crab - a well-defined individual existence appears. 'This order is very extensively diffused; but several species are exclusively confined to particular seas, the pearl-oyster only arriving at perfection in the equatorial ocean. The Indian and the Mediterranean seas are the chosen haunts of the Pinna marina, whose filaments rival in appearunce the most glossy silks. Different kinds of shells are found on the shores of South America and Australasia; also in each of these districts with a change of latitude; and the tropical forms are distinct from those of extra-tropical situations. The natural distribution has, however, been interfered with by accidental causes; for many mollusc , adhering to the bottoms of ships, have been transported to foreign parts of the ocean, which liave become peopled with new species. Tlus the shelly shipworm, Teredo navalis, so peculiarly destructive to vessels, boring with ease and rapidity into the stoutest oak planks, has in this way been conveyed to the waters of Australia. Some unknown cause brought greąt numbers in the years 1731 and 1732 to the banks of Zealand, and excited the fears of the Dutch for their piles; but they departed without doing much mischief, probably to seek a warmer temperature.

A further adrance in ascending the scale of animal existence brings us to the Insect tribes, some of which are extensively disseminated; as gnats, bees, and flies. The thistlebutterfly, la belle dame, is common in Sweden, throughout midland and southern Europe, and found also at the Cape of Good Hope. Others, as Prichard observes, are especially limited in the sphere of their existence by the presence of particular plants, which afford them habitation and sustenance; and in general, where countries are separated by great distances, though their temperature and soil are the same, the insects inhabiting them are 
of different species. Those occupying the eastern parts of $\Lambda$ sia are distinet from these met with in Europe and $\Lambda$ friea under the same parallels of latitude; and a similar difference is observable upon comparing the entomology of the old and the new continents, though both have species in common, while Australia presents forms peculiar to itself. It is in the torrid zone of the earth, where the air is humid and the vegetation rank, that we have the most intense, splendid, and at the same time annoying, development of insect life. By day, in countless numbers, and adorned with the richest colours, butterflies sport in the sunbeams; and by night the tropical forests are illuminated by the green light of myriads of fire-flies - a family which includes the glow-worm of our climate, most brilliant when disturbed and irritated-which give to the woods the appearance of a natural Vauxhall. "It is snowing butterflies!" was the remark of a seaman of the Beagle when off the coast of South America ; for flocks consisting of many myriads extended as far as the eye could range; nor, with the help of a telescope, could a space be discorered free from their presence. As the atmosphere was perfectly calm, they had evidently left the shore upon a voluntary exeursion. But in these countries several of the insect races are a source of severe suffering to the human inhabitants, on account of their venomous qualities, their immense swarms, the pertinacity with which they assail the person of man, or their rapacity in consuming the fruits of the eartl. The spider of Guiana will even singly attack birds with success: and the termites, or white ants of India and Africa, will penetrate the beams of houses; destroy timbers, chests, books, and clothing in a few hours; or, by excavating beneath the dwellings of the inhabitants, render them insecure. 'Though only about a quarter of an inch in length, they erect pyramids to the height of ten or twelve feet, sufficiently compact to sustain the weight of several men, dividing them into numerous apartments - far more wonderful works, in proportion to the size of the animal architect, than the pyramids of Egypt. The musquitoes by day, succeeded a little before sunset by the tempraneroes, and the zancudoes by night, are, howerer, the most painful and unceasing scourge of man in the torrid zone of America. They are rarely found on the elevated table-lands, but in the valleys, as well as in most places along the coasts, the lower stratum of the atmosphere is frequently so completely occupied by them to the height of twenty feet, as to assume the appearance of a dense cloud of vapour. It is a remarkable feature of their distribution, that while they aroid dry and unwooded situations, and cliefly haunt the banks of rivers, they shun those streams which have what the Spaniards call black waters, aguas negras, or water of a yellowish-brown colour. Insect life is also rife in high latitudes, the heat of the short polar summer calling forth in the aretic region of Greenland and Lapland an army as innumerable as the heat of the equator, and of an analogous annoying species.

Several of the insect races are eminently gregarious, associate in numbers utterly inappreciable, and unitedly migrate under the influence of some casual pressure, the quest of food. Hence the vast armics of the eastern loeust, Gryllus migratorius, which from time immemorial have been regarded as an avenging seourge, stripping large territories of every particle of verdure, and passing on in a dark and overwhelming cloud to blast the expectations of the husbandman, whose fields are preparing for the harvest. A Jewish imagination illustrates the havoc to be apprehended from the advance of a reckless oriental conqueror, by a reference to the disasters consequent upon an invasion of this insect tribe:-

"For a nation hath gone up on my land,

Who are strong and without number;

They have destroyed my vine, and liave inade my fig-tree a broken branch,

'They bave made it quite bare, and cast it away; the branches thereof are made white.

The field is laid waste; the ground, the ground moumeth! 
Now do the beasts groan!

The herds of cattle are perplexed, because they have no pasture!

The land is as the garden of Eden before them, and behind them a desolate wilderness!"

Instances are numerous of extensive and dreadful devastations occasioned by the multiplication and migration of the individually feeble locust. St. Augustine mentions a famine in Africa, produced by the consumption of every green thing, during which upwards of half a million of luman beings were cut off in the kingdom of Massanissa alone. In 677 Syria and Mesopotamia were overrun by these inseets. In 852 immense swarms took their flight from the eastern regions into the west. They destroyed all vegetables, not sparing the bark of trees, or the thatch of houses, devouring the corn so rapidly, that, upon computation, a hundred and forty acres in a day perished. Their daily marches or distances of flight were regulated by leaders, who flew first, and settled on the spot which was to be visited afterwards by the whole legion. At length, the locusts were driven out to sea by the force of the wind, and died in its waters; but being thrown back by the tide upon the shores, a pestilence was caused by the offensive smell from their remains. In 1271 all the corn-fields of Milan were destroyed; and in 1339, all those of Lombardy. In 1541, an incredible host afflicted Poland, Wallachia, and the adjoining countries, darkening the sky with their numbers, and ravaging all the fruits of the earth. A species of locust, closely resembling the Gryllies inigratorius of the East, appears in South America, under analogous circumstances. "We observed," says Mr. Darwin, speaking of the passage of the Cordillera of Chili, "to the south a ragged cloud of a dark reddish-brown colour. At first, we thought that it was smoke from some great fire on the plains; but we soon found that it was a swarm of locusts. They were flying northward; and with the aid of a light breeze, they overtook us at a rate of ten or fifteen miles an hour. The main body filled the air from a height of twenty feet, to that, as it appeared, of two or three thousand above the ground; 'and the sound of their wings was as the sound of chariots of many horses running to battle;' or rather I should say, like a strong breeze passing through the rigging of a ship. The sky, seen through the advaneed guard, appeared like a mezzotinto engraving, but the main body was impervious to sight; they were not, however, so thick together, but that they could eseape a stick wared backwards and forwards. When they alighted they were more numerous than the leares in the field, and the surface became reddish instead of being green; the swarm having once alighted, the individuals flew from side to side in all directions. Locusts are not an uncommon pest in this country; already, cluring this season, several smaller swarms had come up from the south, where, as apparently in all other parts of the world, they are bred in the deserts. The poor cottagers in vain attempted, by lighting fires, by shouts, and by waving branches, to arert the attack." The force of the wind frequently occasions the involuntary migration of inseets. When a strong gale blows towards the sea, and the shore is unprotected by trees, vast numbers are driven to a distance from their home, either to perish in the ocean, or to gain a settlement in some contiguous island or continental region. In this way, the dissemination of the insect races has, no doubt, been largely promoted. When the Creole frigate was lying in the outer roads of Buenos Ayres, in 1819, her decks and rigging were suddenly covered with myriads of flies and grains of sand, which the breeze had borne from the coast, and so disfigured were the newly painted sides of the vessel by the multitudes adhering to them, as to require a fresh coating. A remarkable instance of an insect at a distance from land was observed by the crew of the Beagle, off the coast of Africa, when a large grasshopper, Acrydium, flew on board, the nearest point of land being nearly four hundred miles distant.

The class of Fishes offers many remarkable peculiarities to our notice; and, perhaps, 
this department of the animal kingdom presents greater variety of form, from the beautiful to the grotesque and monstrous, than any other. Some species, as the common pike of our rivers, attain an age surpassing that of the longest-lived land animals. The individual taken at Kaiserslautern in 1754, which was nineteen feet in length, had been put into the pond of that castle by order of Frederick the Second, with a ring fastened to the gill-covers, bearing the date of 1487 , so that the fish was more than two centuries and a half old, at the time of the capture. Though low in the scale of existence, several varieties show a capacity for instruction, and have been trained to recognise their names, making their appearance when summoned by them. Lacépède mentions this fact, in relation to some fish, which, for more than a century, had been kept in the basin of the 'Tuilleries; and in some parts of Germany, trout, carp, and tench have been taught to come for their food by the ringing of a bell. While some tribes are sluggish, and appear to love repose, leading a meditative life in the waters, the herring rivals the swallow in activity and speed, rushing through the deep at the rate of sixteen miles an hour. While many also seem perfectly defenceless, there are several species armed with formidable weapons, which are wielded with tremendous power, as the teeth of the shark, and the snout of the Xiphias or sword-fish. This latter inhabitant of tlie ocean is well known to have endangered an East Indiaman, by driving his long serrated snout through the hulk of the vessel, which might have foundered, but for the sword being driven with such force into the timbers of the ship that the fish could not extricate it, so that no leak of any consequence ensued. A piece of the hulk, with a part of the fish's sword imbedded in it, is now among the curiosities of the British Museum. Other tenants of the deep have the same singular property of emitting light while alive, which belongs to the torn and irregular particles of gelatinous matter with which the ocean is charged, their dead and dismembered relics, the common eause of the phosphorescence of the sea. Besides the bright green sparks with which the waves are observed to scintillate, which are duc to decomposing organic particles, or to minute living crustacea, circular and oval patches, from two to four yards in diameter, with defined outlines, shining with a steady and pale light, are often remarked in certain oceanic localities, indicating the presence of the sun or the moon-fish, which is so called from the object resembling a reflection of either of these luminaries in the water, though neither may be seen in the heavens. Some fishes display the curious power of shooting at the insects upon which they prey with a drop of water, thereby encumbering their wings, and bringing them within reach. The Chatodon rostratus performs this feat with surprising accuracy, striking a fly winging its flight over the surface of the sea, or resting upon an aquatic plant at the distance of from three to six feet. But among the most striking of the finny tribe is the Exoccetus, or flying-fish, which has the power of raising itself out of the water, and continuing suspended for a season in the air, beyond the reach of the pursuing dolphin, presenting one of the most interesting and novel spectacles which the tropies unfold to the eye of a stranger.

No property of the inhabitants of the waters is more extraordinary, than that possessed by various species, of inflicting an electrical shock so severe, as to produce exhaustion and numbness of the nerves exposed to its action. The torpedo of the Mediterranean exhibits this wonderful power, which was well known to the ancients, and is often referred to in their writings. Thus Appian tclls us, that the animal, conscious of his latent faculty, when caught by a hook, exerts it in sucl a manner, that passing along the line and rod, it benumbs the astonished fisherman, and suddenly reduces him to a state of helpless stupefaction :-

" The hook'd torpedo, with instinctive force,

Calls all his magic from its secret source; 
Quick through the slender line and polish'd wand

It darts; and tingles in th' oflending hand.

The palsied fisherman, in dumb surprise,

Feels through his frame the chilling vapours rise:

Drops the lost rod, and secms, in stiffening pain,

Some frost-fix'd wanderer on the polar plain,"

Though this is an exaggerated picture, it is still true that an electric shock is equally inflicted by the torpedo, whether the fish is touched by the naked hand or by the medium of a stick. 'The trembler, or the Silurus clcetricus of the African rivers, displays the same property, and yet more remarkably, the Gymnotus clectricus, found in the basins of stagnant water on the llanos of Sonth Ameriea, and in the confluents of the Orinoco. Placing his two feet upon one of the gymnoti, or electrical eels, just taken out of the water, Humboldt received a shock mcre violent and alarming than he ever experienced from the discharge of a large Leyden jar; and for the rest of the day he felt an acute pain in lis knees, and almost all his joints. He gives a spirited account of the manner in which the animal is taken. On the 19th of March, at an early hour, he set off with Bonpland for the village of Rastro de Abaxo, whence they were conducted by the natives to a stream, which in the dry season forms a pool of muddy water, surrounded by trees. It being rery difficult to eatch the gymnoti with nets, on account of their extreme agility, it was resolved to procure some by intoxicating or benumbing them with the roots of certain plants, which when thrown into the water produce that effect. At this juncture the Indians informed them that they would fish with horses, and soon brought from the savannal about thirty of these animals, which they drove into the pool. The result may be given in the words of the traveller:-

" 'The extraordinary noise caused by the horses' hoofs makes the fishes issue from the mud, and excites them to combat. 'These yellowish and livid eels, resembling large aquatic snakes, swim at the surface of the water, and crowd under the bellies of the horses and mules. The struggle between animals of so different an organisation afforis a very interesting sight. The Indians, furnished with harpoons and long slender reeds, closely surround the pool. Some of them climb the trees, whose branches stretch horizontally over the water. By their wild eries and their long reeds, they prevent the horses from coming to the edge of the basin. The eels, stunned by the noise, defend themselves by repeated discharges of their electrical batteries, and for a long time seem likely to obtain the victory. Several horses sink under the violence of the invisible blows which they receive in the organs most essential to life, and, benumbed by the force and frequency of the shocks, disappear beneath the surface. Others, panting, with erect mane and haggard eyes expressive of anguish, raise themselves, and endeavour to escape from the storm which overtakes them, but are driven back by the Indians. A few, howerer, succeed in eluding the active vigilance of the fishers; they gain the shore, stumble at every step, and stretch themselves out on the sand, exhausted with fatiguc, and having their limbs benumbed by the electric shocks of the gymnoti. In less than five minutes two horses were killed. The eel, which is five feet long, presses itself against the belly of the horse, and makes a discharge along the whole extent of its electric organ. It attacks at once the heart, the viscera, and the cocliac plexus of the abdominal nerves. It is natural that the effect which a horse experiences should be more powerful than that produced by the same fish on man, when he touches it only by one of the cxtremities. The horses are probably not killed, but only stunned; they are drowned from the impossibility of rising amid the prolonged struggle between the other horses and eels.". Some of the gymnoti, having expended their energy, were afterwards secured, and were found to be from five to six feet in length, of a fine olive-green colour. They are objects of dread to the natires, and 
their presence is considered to be the principal cause of the absence of fish in the pools of the Llanos. All the inhabitants of the waters avoid them, and it became necessary to change the direction of a road near Uritico, in consequence of the number of mules lost in fording a river in which they were rery numerous. It is supposed that they can communicate their electric shock through a thick mass of water, and kill from a distance the prey they are anxious to devour.

From the facts gathered with reference to fishes, it appears that particular districts ol basins of the ocean have tribes peculiar to them, distinct from those which inhabit even contiguous seas. Thus the speciez common to the Arabian Gulf are said to differ entirely from those of the Mediterranean, and according to MM. Séron and Leseur, there is not a single animal of the southern regions which is not distinguished by essential characters from the analogous species in the northern seas. The flying-fish are chiefly intertropical, or, at the farthest, they are never found beyond the fortieth parallel of latitude, while the Atlantic species differ from those of the Pacific. The cod-fish, diffused throughout the whole of the northern ocean between Europe and America, chiefly haunt the great banks of sand to the south-east of Newfoundland, where they exist in undiminished numbers owing to their astonishing fecundity, which makes up for the havoc occasioned by the extensive fisheries. Leeuwenhoek counted more than nine millions of eggs in the ovary of a cod-fish of the middle size. While many species of fish appear never to depart from the site of their birth, but live and die in the same spot, others periodically migrate to a rast distance for various purposes, and become the food of nations to whose shores they are led by unfailing instinct. This is the case with the tunny which enters the Mediterranean regularly from the Atlantic, the pilchard, and the herring. The latter, so eminently important in a commercial point of view, derives its name from the German heer, an army, in allusion to the countless swarms that annually come up from the depths of the open sea, and proceed to the western shores of Europe, Great Britain, the United States, as well as to those of Kamtschatka, and the neighbouring islands. The herrings migrate to find food, and to deposit their spawn, forming shoals consisting of millions upon millions, several miles in length and width, and many fathoms in thickness. The water ripples before them as they advance. The sea-birds hover over

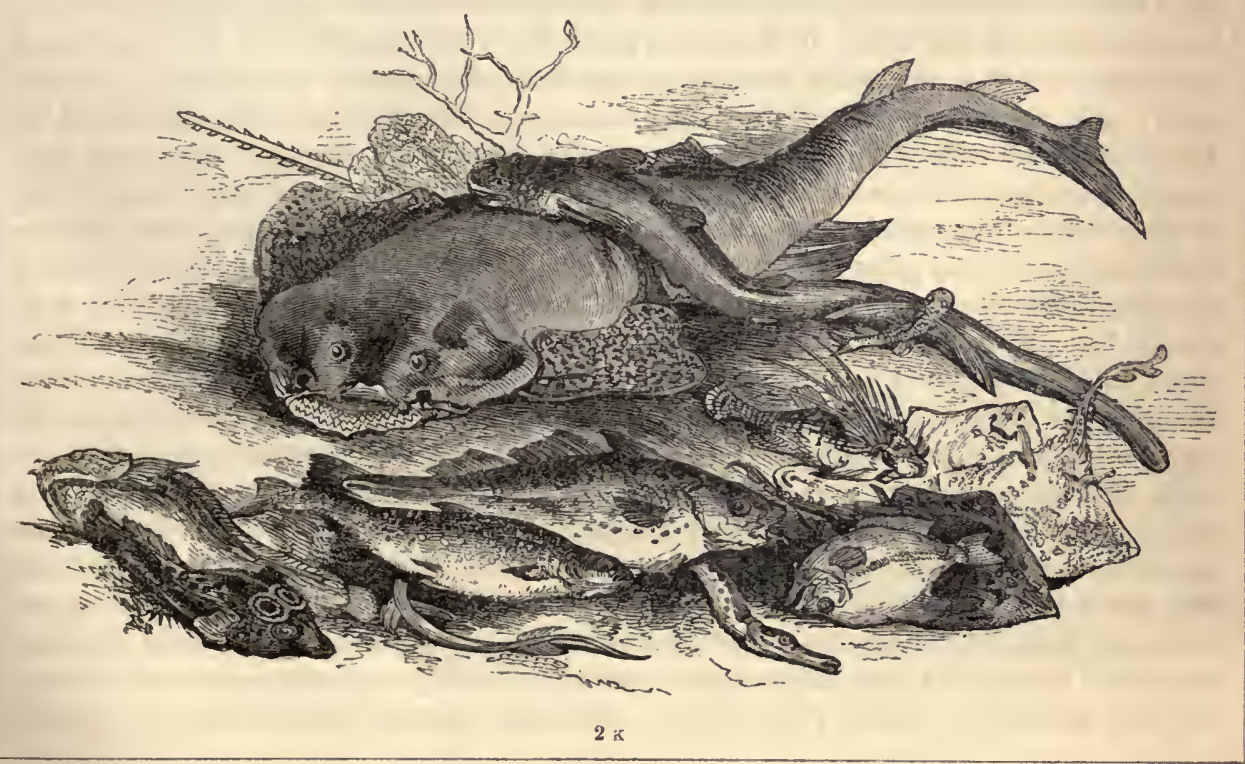


them. A rariety of splendid colours in bright weather indicates their presence at the surface of the sea, and a pale phosphoric light denotes the same in calm dark nights. This is caused by the oily substance thrown off by the fish, which is spread over their columns, and seems as if a dimly white napkin lay upon the deep. Some idea may be formed of the number of individuals in the herring shoals, from the fact mentioned by Lacepede, that the Norway fishermen capture four hundred millions in most years, and that at Gottenburgh and its vicinity seven hundred millions are annually taken; but both these sums together are insignificant when compared with the gross amount captured by the other European nations. The migrations of several kinds of fish lead them out of their native element to wander over the land in quest of food, or of a more convenient habitation. Thus the common eel at night will forsake the water to traverse the meadows, feeding on the snails it finds in its passage; and when the pools become dry in seasons of drought, some of the Siluridan family quit their old residence, in search of another, from which the water has not been evaporated. Upon the coast of Coromandel, a kind of perch, Perca scandens, leaves its liquid home for the shore, and even climbs up the palm-trees in pursuit of the small crustaceans upon which it feeds-an enterprise to which its organisation is expressly adapted. In the West Indies and South America, the land crahs quit the mountains regularly once a year, march down to the sca-side in a body of some millions at a time, directing their march with the right-lined precision of the geometer, travelling chiefly in the night, the object to be attained being the deposition of their spawn in the ocean.

It may be allowed here to notice those animals which are classed with the warm-blooded mammalia, yet whose residence is usually or exclusively marine, and whose forms are as characteristic of the fish as of the quadruped. Of these, the whale tribes, the narwal or seaunicorn, the sea-horse, the phoca or sea-calf, and the dolphin, are the principal examples. The former gigantic animals occupy the high latitudes of the ocean, and are characteristically different in the north polar seas from their brethren in antarctic regions. Incessantly pursued by man, as affording materials that arc of high ralue in the arts of life, the common whales have deserted their old haunts, and retired farther north, under the pressure of danger, to the protection afforded by the perpetual ice. Notwithstanding their vast size, these leviathans of the deep dive with prodigious rapidity to the bottom of the soundless sea, and often in frolicsome gambols elevate the whole of their enormous mass entirely out of the water with the exception of the tail-fins, falling down sideways with a noise resembling that of a distant broadside. The seals, and other animals of the Phoce tribe, are widely diffused, but those which inhabit the waters of the north differ from the members of the same family which have their station in the southern seas, and vary in their habits from those found within the tropics, the tropical species being solitary individuals, while the polar associate in herds consisting of many thousands. It has been thought a difficulty by naturalists, that inland seas, like the Caspian and the Lake Aral, should have marine mammalia, the Phoce vituline or sea-calves, identical with those found in the Euxine and the Mediterranean; and to account for their appearance in those localities, the assistance of subterranean channels of communication between them has been conjectured. But Mr. Lyell justly remarks, that as the occurrence of wolves and other noxious animals on both sides of the British channel was adduced by Desmarest as one of many arguments to prove that England and France were once united, so the correspondence of the aquatic species of the inland seas of Asia with those of the Black Sea tends to confirm the hypothesis, for which there are abundance of independent geological data, that those seas were connected together by straits at no remote period of the earth's history. To the same order of animals, the Manatus americanus and Halicore Dugong, or sea-cow, belong; the former abounding in the Orinoco, and the latter in 
shallow inlets of the sea on the Malacca coast. Both species attain the length of ten or twelve feet, and are herbivorous, browsing on the fuci and algæ found at the bottom of the waters, in much the same manner as the cow does upon the grass of the field.

Among tellurian animals the class of Reptiles is the lowest grade. It includes some of the most dangerous members of the animal kingdom, as well as the most revolting in their appearance. The tortoise, one of this family, occurs in abundance in tropical situations, and sometimes strays into higher latitudes, either voluntarily, attracted by a supply of food, or driven by the force of the tempest. 'Two instances are recorded of its appearance on the coast of Cornwall in the year 1756, and one was taken from the Severn in 1774. In the lizard division of this class, the crocodile of the Nile, the cayman of South America, and the gavial of the Ganges, are the giants, specifically distinct, and differing also in their size and powers of destruction. The Nilotic crocodile is the largest, sometimes attaining, when full grown, the length of thirty feet. These saurians liave their home in the tropical pools and rivers, occasionally visiting the shore in search of prey, or to bask in the sunbeams; but the South American species, in calm

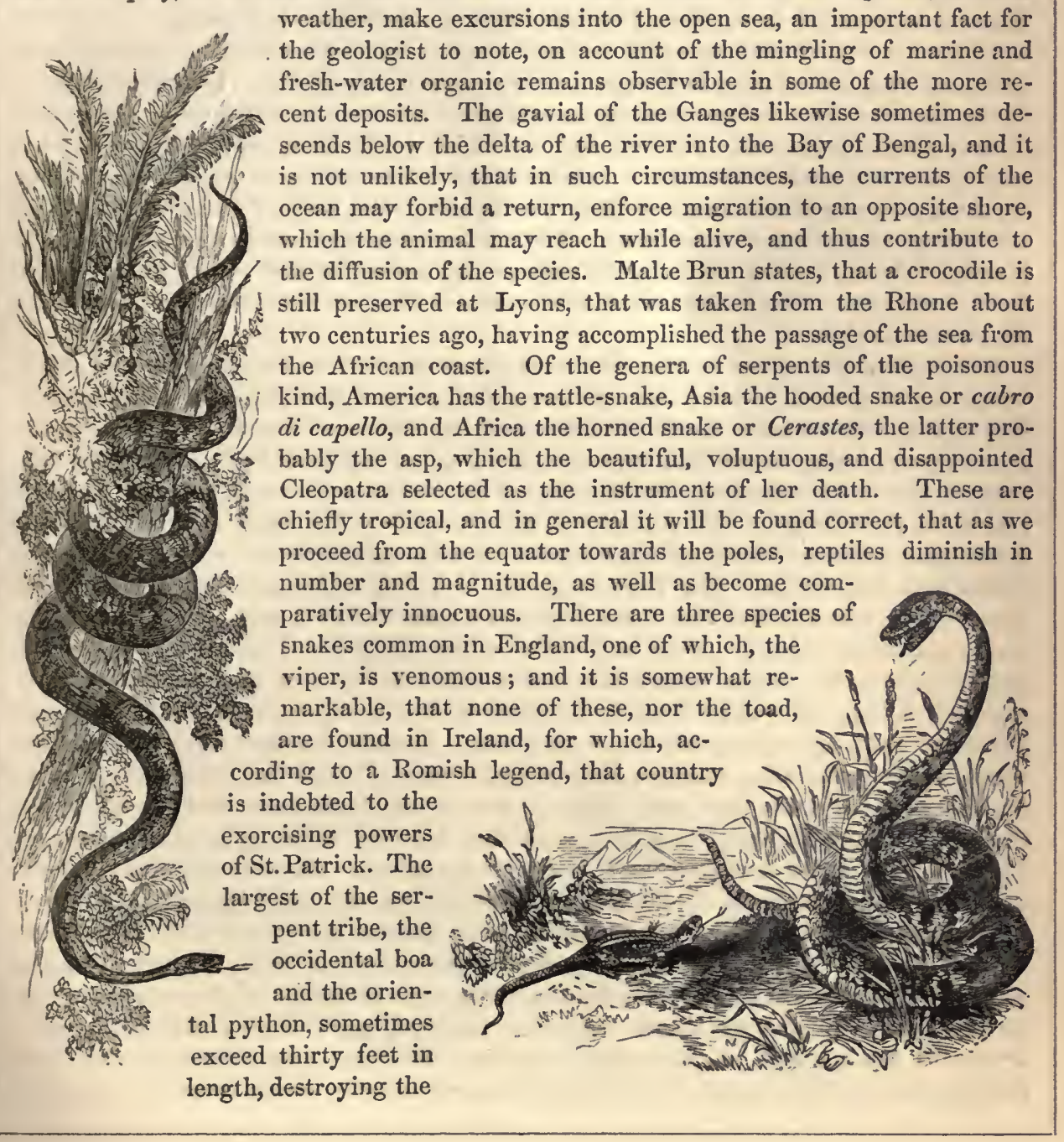


great quadrupeds by the force with which they coil around their bodies. A singular circumstance is recorded of the transportation of one of these monstrous creatures alive to the island of St. Vincent, which illustrates the occasional influence of the oceanic currents in disseminating the animal tribes. "A noble specimen," says the Rev. L. Guilding, "of the boa constrictor was lately conveyed to us by the currents, twisted round the trunk of a large sound cedar tree, which had probably been washed out of the bank by the floods of some great South American river, while its huge folds hung on the branches, as it waited for its prey. The monster was fortunately destroyed after killing a few sheep, and his skcleton now hangs before me in my study, putting me in mind how much reason I might have had to fear in my future rambles through the forests of St. Vincent, had this formidable reptile been a pregnant female, and escaped to a safe retreat." Upon several of the reptile race, the dry season near the equator has the same effect as the winter of northern latitudes, inducing a state of lethargy, during which the great saurians and the serpent tribe are dead to the surrounding world. While the alligators of North America, become torpid through excess of cold, their congeners, the caymans of South America are reduced to the same condition through a deficiency of moisture. Humboldt was shown a hut or shed in which a singular scene had bcen witnessed by his host of Calabazo, who, having slept in it upon a bench covered with leather, was awakened early in the morning by a violent shaking, accompanied with a horrible noise. Presently a cayman issued from under the bed, and darted at a dog lying on the threshold; but missing him, ran towards the river. When the spot where the bench stood was examined, the dried mud was found turned up to a considerable depth, where the animal had lain in its state of torpidity or summer sleep. The hut being situated on the edge of a pool, and inundated during part of the year, the cayman had entered at that period, and concealed itself in the mire. The Indians often find enormous boas, or water-serpents, in the same lethargic condition.

The highest department of the animal kingdom commenecs with the class of Birds, which may be naturally divided into the three great orders of aerial, terrestrial, and aquatic. Aggregation into immense flocks is a distinguishing feature of several species, especially of the aquatic order, which form separate colonies, building their nests in the same site, though other spots apparently equally adapted for the purpose are at no great distance. Hence the Vogel-bergs, or bird-rocks of the northern seas, one of which at Westmannsliarn in the Faroe group of islands, seldom intruded upon by man, presents a most extraordinary spectacle to the visitor. The Vogel-berg lies in a frightful chasm in the precipitous shores of the island, which rise to the height of a thousand feet, only accessible from the sea by a narrow passage. Herc congregate a host of birds. Thousands of guillemots and auks swim in groups around the boat which conveys man to their donain, look curiously at him, and vanish beneath the water to rise in his immediate neighbourhood. The black guillemot comes close to the very oars. 'The seal stretches his head above the wares, not comprehending what has disturbed the repose of his asylum, while the rapacious skua pursues the puffin and gull. High in the air the birds seem like bees clustcring about the rocks, whilst lower they fly past so close that they might be knocked down with a stick. But not less strange is the domicile of this colony. On some low rocks scarcely projecting above the water sit the glossy cormorants, turning their long necks on every side. Next are the skua gulls, regarded with an anxious eje by the kittiwakes above. Nest follows nest in crowded rows along the whole breadth of the rock, and nothing is visible but the heads of the mothers and the white rocks between. A little higher on the narrow shelves sit the guillemots and auks, arranged as on parade, with their white breasts to the sea, and so close that a hailstone could not pass between them. The puffins take the highest station, and, though scarcely visible, betray themselves by their 
flying backwards and forwards. The noise of such a multitude of birds is confounding, and in vain a person asks a question of his nearest neighbour. The harsh tones of the kittiwake are heard above the whole, the intervals being filled with the monotonous note of the auk, and the softer voice of the guillemot. When Graba, from whose travels this description is principally drawn, visited the Vogel-berg, he was tempted by the sight of a crested cormorant to fire a gun, but what became of it, he remarks, it was impossible to ascertain. The air was darkened by the birds roused from their repose. Thousands hastened out of the chasm with a frightful noise, and spread themselves in troops over the ocean. 'The puffins came wandering from their holes, and regarded the universal confusion with comic gestures. The kittiwakes remained composedly in their nests; whilst the cormorants tumbled headlong into the sea. Similar great congregations of the feathered race appear where the shores are rocky, high, and precipitous, but this is strik. ingly the case, where

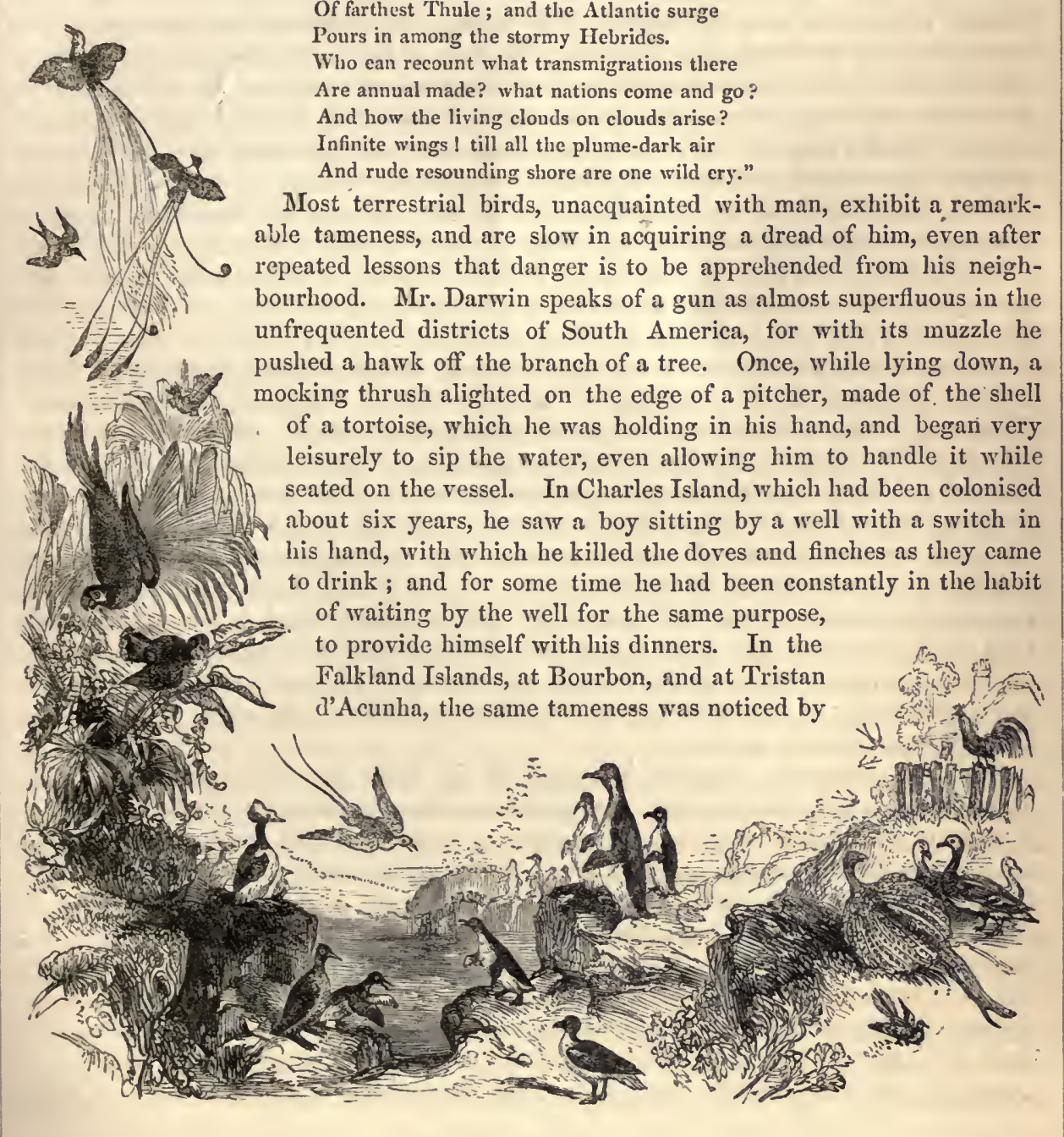

\begin{abstract}
"The northern ocean, in vast whirls,
Boils round the naked melancholy isles

Of farthest Thule; and the Atlantic surge

Pours in among the stormy Hebrides.

And rude resounding shore are one wild ery."
\end{abstract}

st terrestrial birds, unacquainted with peated lessons that danger is to be apprehended pushed a hawk off the branch of a tree. Once, while lying down, a mocking thrush alighted on the edge of a pitcher, made of the shell of a tortoise, which he was holding in his hand, and began very leisurely to sip the water, even allowing him to handle it while seated on the vessel. In Charles Island, which had been colonised about six years, he saw a boy sitting by a well with a switch in his hand, with which he killed tlie doves and finches as they carne o drink; and for some time he had been constantly in the habit of waiting by the well for the same purpose, to provide himself with his dinners. In the Falkland Islands, at Bourbon, and at Tristan d'Acunha, the same tameness was noticed by 
the early visitors. On the other hand, the small birds in the arctic regions of America, which have never been persecuted, exhibit the anomalous fact of great wildness. From a review of various facts, Mr. Darwin concludes, "first, that the wildness of birds with regard to man is a particular instinct directed against him, and not dependent on any general degree of caution arising from other sources of danger; secondly, that it is not acquired by individual birds in a short time, even when much persecuted; but that in the course of successive generations it becomes hereditary. Comparatively few young birds in any one year have been injured by man in England, yet almost all, even nestlings, are afraid of him ; many individuals, however, both at the Galapagos and at the Falklands, have been pursued and injured by man, but yet have not learned a salutary dread of him."

Numerous species of birds may be regarded as the favourites of nature, on account of the graeefulness given to their shape, and the richly coloured plumage with which they are adorned, as evideneed in the gaudy liveries of many of the parrot tribe, and the form and hues of the birds of paradise. But they are especially interesting to man for the faculty of song with which they are endowed ; in some, "most musical, most melancholy," in others, sprightly and animating, inspiriting the sons of toil under the burdens peculiar to their station. It deserves to be remarked, as an instance of compensation and adjustment, that while the birds of the temperate zone are far inferior to those of tropical climes in point of beauty, they have far more melodious notes in connection with their less attractive appearance. Our best songster, the nightingale, a summer visitor, has only a limited distribution in the kingdom. It does not frequent the south-west angle of England, or usually range westerly and northerly, beyond a wavy line drawn from the Bristol Channel, through the midland counties, by York, to the south of Flamborough Head. It is consequently absent from Cornwall and West Devon, Wales, Scotland, and Ireland. The blackcap, the rival of the nightingale, also a visitor, has not been noticed in many parts of Scotland, and only once or twice in any part of Ireland, though general in England and Wales.

Birds are ranged in the following six orders:-Rapaces-Birds of Prey; ScansoresClimbers; Oscines-Songsters; Gallinacea-Gallinaceous birds; Grallatores-Waders; Natatores-Swimmers. The total number of species now known amounts to about 8000 . Tropical and warm countries have the greatest number of species and individuals, with one exception, that of the Swimmers, which are most abundant in and near the arctic zone. The most peculiar specimen of ornithology at present existing is found in New Zealand, apparently the last remnant of departed races. This is a small bird, absolutely wingless, and covered with hair, called the apteryx, the largest animal found in the island at the time of its discovery. But in the gravel, fossil bones are met with nearly as large as the thigh-bone of an ox, which are the remains of a series of birds of various sizes, more or less corresponding to the surviving species, all being wingless, and some of them much more gigantic than any ostrich.

Omitting accidental stragglers belonging to the fauna of other countries, with the domesticated breeds, but including the periodical migrants whose journeying to and fro is a part of their natural economy, the number of species of birds in Great Britain and the adjacent islands amounts to about 300. The stragglers include the Egyptian vulture, shot in Somersetshire in 1825; the griffon vulture, from the Alps and Pyrenees, taken in Ireland in 1843; the red-winged starling of America, caught near London in 1844; and the Bonapartian gull, from the fur countries of North America, captured in Ireland, the only individual of the species known to have visited Europe.

From the powerful means of locomotion possessed by several of the bird tribe, and their great specific levity, air being admitted to the whole organisation as water to a sponge, it might be inferred, that the entire atmosphere was intended to be their 
domain, so that no species would be limited to a particular region. The common crow flies at the rate of twenty-five miles an hour; the rapidity of the eider-duck, Anns mollissima, is equal to ninety miles an hour; while the swifts and hawks travel at the astonishing speed of a hundred and fifty miles in the same time. It is true that some species have a very extensive range, as the nightingale, the common wild goose, and several of the vulture tribe. The same kind of osprey or fishing-eagle that wanders along the Scottish shores appears upon those of the south of Europe, and of Australia. The lammergeyer haunts the heights of the Pyrenees, the mountains of Abyssinia, and the Mongolian steppes ; and the penguin falcon occurs in Greenland, Europe, America, and Australia. In general, however, like plants and terrestrial quadrupeds, the birds are subject to geographical laws, definite limits circumscribing particular groups. 'The common grouse of our own country affords a striking exemplification of this arrangement, as it is no where met with out of Great Britain; and other examples occur of a very scanty area containing a species not to be found in any other region. The celebrated birds of paradise are exclusively confined to a small part of the torrid zone, embracing New Guinea and the contiguous islands; and the beautiful Lories are inhabitants of the same districts, being quite unknown in the New World. Parroquets are chiefly occupants of a zone extending a few degrees beyond each tropic, but the American group is quite distinct from the African, and neither of these have one in common with the parrots of India. The great eagle is limited to the highest summits of the Alps; and the condor, which soars above the peak of the loftiest of the Andes, never quits that chain. Humming-birds are entirely limited to the western hemisphere, where a particular species is sometimes bounded by the range of an island, while others are more extensively spread, the Trochilus flammifrons, common to Lima, being observed by Captain King upon the coasts of the Straits of Magellan, in the depth of winter, sucking the flowers of a large fuchsia, then in bloom in the midst of a shower of snow. Among the birds incapable of flight, which rival the quadrupeds in their size, the intertropical countries of the globe have their distinct species, presenting similar general features of organisation, as the ostrich of Africa and Arabia, the cassowary of Java and Australia, and the touyou of Brazil. In the arctic regions, we meet with species peculiar to them, the Strix lapponicus or Lapland owl, and the eider-duck, an inhabitant of the shores, from whose nests the eider-down is obtained. Several families of maritime birds are likewise limited to particular oceanic localities. Approaching the fortieth parallel of latitude, the albatross is seen flitting along the surface of the waves, and soon afterwards, the frigate and other tropical birds appear, which never wander far beyond the limits of the torrid zone. It thus appears, that notwithstanding the great locomotive powers of birds, particular groups have had certain regions assigned to them as their sphere of existence, which they are adapted to occupy, and to which they adhere in the main, though it is easy to conceive of natural causes occasionally constraining to a migration into new and even distant territories. Admiral Smyth informed Sir C. Lyell, that when engaged in his survey of the Mediterranean, he encountered a gale in the Gulf of Lyons, at the distance of between twenty and thirty leagues from the coast of France, which bore along many land-birds of various species, some of which alighted on the ship, while others were thrown with violence against the sails. In this manner, many an islet in the deep, after ages of solitude and silence, uninterrupted except by the wave's wild dash, and the wind's fierce howl, may have received the song of birds, forced by the tempest from their home, and compelled to seck a new one under its direction.

There is no feature more remarkable in the economy of birds than the periodical migrations, so systematically conducted, in which five sixths of the whole feathered population engage. In the case of North America, according to an estimate by Dr. Richard- 
son, the passenger pigeons forming themselves into rast flocks for the journey, one of which has been calculated to include $2,230,000,000$ individuals. We are familiar with the cuckoo as our visitor in spring, and with the house-swallow as our guest through the summer, the latter usually departing in October to the warmer regions of the south, wintering in Africa, returning again when a more genial season revives its insect food. By cutting off two claws from the feet of a certain number of swallows, Dr. Jenner ascertained the fact, of the same individuals reappearing in their old haunts in the following year, and one was met with even after the lapse of seven years. The aretic birds migrate farther south, when the seas, lakes, and rivers, become covered with unbroken sheets of ice; the swans, geese, ducks, divers, and coots flying off in regular plaalanxes to regions where a less rigorous winter allows of access to the means of life. Hence, soon after we lose the swallows, we gain the snipes and other waders, which have fled from the hard frozen north to our partially frozen morasses, where their ordinary nutriment may still be obtained. The equinoctial zone, where the seasonal change is that of humidity and drought, furnishes an example of the same phenomenon. As soon as the Orinoco is swollen by the rains, overflows its banks, and inundates the country on either side, an innumerable quantity of aquaties leave its course for the West India islands on the north, and the valley of the Amazon on the south, the increased depth of the river, and the flooded state of the shores, depriving them of the usual supply of fish and insects. Upon the stream decreasing, and retiring within its bed, the birds return.

The class of Quadrupeds brings us to the most perfeetly organised members of the animal kingdom, as well as to the largest, most powerful, and ferocious ; of which the lion, tiger, elephant, rhinoceros, lippopotamus, panther, leopard, hyæna, bear, and giraffe are familiar examples. The weight of some of these animals, which may be taken as an indication of their comparative size, has been computed to be-a ton for the giraffe, three tons for the rhinoceros, three tons and a half for a hippopotamus sent to England cut up into pieces, while the elephant that was killed at Exeter Change was estimated to weigh five tons and a half. The class embraces a number of animals remarkable for their beauty, as the striped zebra and the bounding antelope, particularly the gazelle species, whose light forms, brilliant and expressive eyes, have from remote antiquity been the favourite themes of eastern song. It includes also various quadrupeds, readily capable of domestication, which largely minister to the welfare of the human race, as the horse, ox, camel, and deer. In examining the distribution of the wild quadrupeds, the hot regions, extending from the equator to a few degrees beyond the tropies, are found to yield the greatest number of tribes and individuals, as well as of those animals which are distinguished by their bulk, strength, and ferocity. It has been commonly assumed, but without sufficient authority, that we have here, an excessive development of animal life, as an instance of intentional adjustment to a luxuriant vegetation. Thus $\mathrm{Mr}_{\mathrm{r}}$. Prout remarks, in his Bridgewater Treatise, that "in tropical climates, the qualities of animals, as well as those of regetables, are developed to the utmost; and hence arises that harmonious adaptation of all the works of nature, conspicuous indeed in all climates, but in tropical climates more especially: for where else than amidst the profuse exuberance of the vegetation within the tropics could the elephant, the rhinoceros, the giraffe, and other large quadrupeds find subsistence? Where else could we expect to see such birds as the ostrich and the cassowary-such reptiles as the crocodile-such serpents as the boa?" It need only be remarked, to show the fallacy of this statement, that, upon the principle laid down, intertropical America ought to be well stocked with the animal tribes of the largest class, whereas it is remarkably deficient in them; while in Africa the same tribes should be rare, whereas that is precisely the region where they are most abundant.

The incorrectness of the opinion advanced by $\mathrm{Mr}$. Prout, in common with other 
writers, is clearly shown by $\mathrm{Mr}$. Darwin, in a passage of great interest and value: "That large animals require a luxuriant vegetation, has been a general assumption, which has passed froin one work to another ; but I do not hesitate to say that it is completely false, and that it has vitiated the reasonings of geologists on some points of great interest in the ancient history of the world. The prejudice has probably been derived from India, and the Indian islands, where troops of elephants, noble forests, and impenetrable jungles are associated together in every one's mind. If, however, we refer to any work of travels through the southern parts of Africa, we shall find allusions, in almost every page, either to the desert character of the country, or to the numbers of large animals inhabiting it. On the southern and south-eastern coasts there are some fine forests; but, with these exceptions, the traveller may pass for days together through open plains, covered by a poor and scanty vegetation. It is difficult to convey any accurate idea of degrees of comparative fertility; but it may be safely said that the amount of regetation supported at any one time $\mathrm{by}^{\prime}$ Great Britain exceeds, perhaps eren tenfold, the quantity on an equal area in the interior parts of Southern Africa. The fact that bullock-waggons can travel in any direction, excepting near the coast, without more than occasionally half an hour's delay in cutting down bushes, gives perhaps a more definite notion of the scantiness of the vegetation. Now if we look to the animals inhabiting those wide plains, we shall find their numbers extraordinarily great, and their bulk immense. We must enumerate the elephant, three species of rhinoceros, and probably two others, the hippopotamus, the giraffe, the bos caffer (as large as a full-grown bull), and the elan (but little less), two zebras, and the quaccha, two gnus, and several antelopes, even larger than these latter animals. It may be supposed, that although the species are numerous, the individuals of each kind are few. By the kindness of Dr. Andrew Smith, I am enabled to slow that the case is very different. He informs me, that in lat. $24^{\circ}$, in one day's march with the bullock-waggons, he saw, without wandering to any great distance on either side, between one hundred and one hundred and fifty rhi-

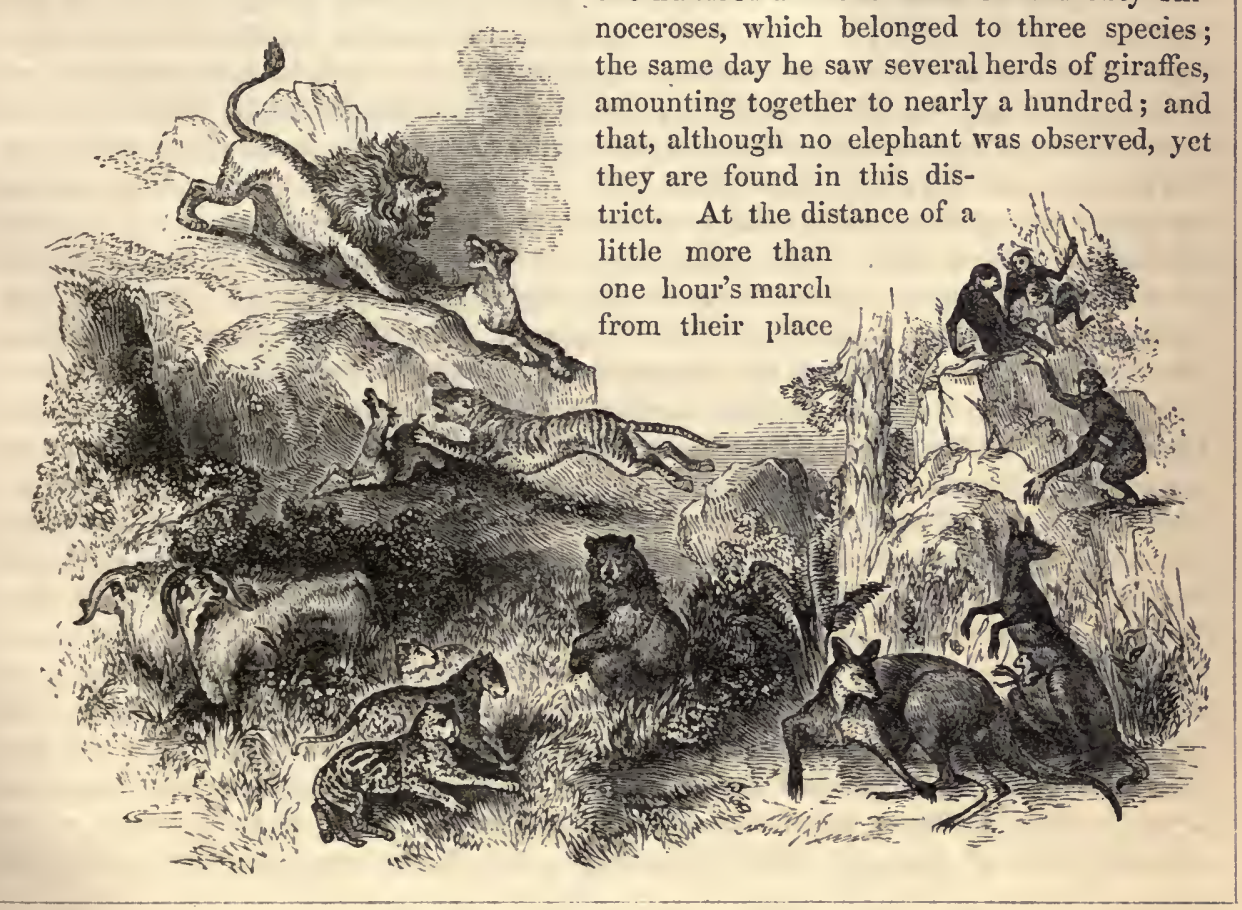


of encampment on the previous night, his party actually killed at one spot eight hippopotamuses, and saw many more. In the same river there were likewise crocodiles. Of course it was a case quite extraordinary to ses so many great animals crowded together; but it evidently proves that they must exist in great numbers. Dr. Smith describes the country passed through that day as being thinly covered with grass, and bushes about four feet high, and still more thinly with mimosa trees. 'The waggons were not prevented travelling in a nearly straight line."

Nothing can be more striking than the contrast between the South African and the South American vegetation; the former meagre, the latter exuberant to excess: yet, comparing together the weight of two of the largest species of herbivorous animals in each, the ratio of the scantily pastured African, to the richly pastured American quadrupeds, is as twenty-four to one. It is abundantly evident, therefore, that there is no close relation between the bulk of animals and the amount of vegetation in the countries which they inhabit ; and that common ideas, respecting the quantity of food which a large quadruped requires for its support, are greatly exaggerated. 'The mention of the camel, an animal of the larger class, instantly brings the desert to our remembrance, his native region. This fact has an important bearing upon geological points; for it shows that the remains of large mammalia in the European tertiary strata, with those of the Rhinoceroses discorered in the Siberian steppes, do not necessarily require the supposition that a vegetation bearing the character of tropical luxuriance was coincident with their living existence, and that a change of climate, from heat to cold, occasioned by violent catastrophes has occurred, accounting for the comparatively waste and sterile aspect of sites presumed to have been elothed with vegetable richness at a former epoch. There may have, and no doubt there has, been a great change of climate in the northern region of the globe ; but it is fallacious to argue it on the ground of a tropical vegetation being required to sustain the mighty quadrupeds that once occupied the district.

A comparison between the quadrupeds of the Old and New Worlds is in every point strikingly in favour of the former. Not only has the western continent no animals of such giant bulk as those of the eastern, but no examples of such high organisation, such power and courage, as the African lion and the Asiatic tiger display. Buffon's remark must indeed be considerably modified, respecting the cowardice of the American feline race; for the jaguar of the woods about the Amazon, when attacked by man, will not hesitate to accept his challenge, will even become the assailant, nor shrink from an encounter against the greatest odds. The following passages from the writings of Humboldt show that this Transatlantic animal is not to be despised :- "The night was gloomy; the Devil's Wall and its denticulated rocks appeared from time to time at a distance, illuminated by the burning of the savannahs, or wrapped in ruddy smoke. At the spot where the bushes were the thickest, our horses were frightened by the yell of an animal that seemed to follow us closely. It was a large jaguar, that had roamed for three year's among these mountains. He had constantly escaped the pursuit of the boldest hunters, and had carried off horses and mules from the midst of enclosures; but, having no want of food, had not yet attacked men. The negro who conducted us uttered wild cries. He thought he should frighten the jaguar; but these means were of course without effect. The jaguar, like the wolf of Europe, follows travellers even when he will not attack them; the wolf in the open fields and in unsheltered places, the jaguar skirting the road, and appearing only at intervals between the bushes." The same illustrious observer also remarks, - "Near the Joval, nature assumes an awful and savage aspect. We there saw the largest jaguar we had ever met with. The natives themselves were astonished at its prodigious length, which surpassed that of all the tigerg of India I had seen in the collections of Europe." Still, these were extraordinary specimens of the race, and 
leave the fact undoubted, that the most formidable of the western Ferœ has no pretensions to an equality with his congener the tyrant of the jungles of Bengal.

In vain also we look among the tribes of America for a rival in outward appearance to the giraffe, so remarkable for its height, its swan-like neck, gentle habits, and soft expressive eye; while of the animals most serviceable to mankind-the horse, the ox, the ass, the goat and the hog, - not a living example of either was known there before its occupancy by the Europeans. But however inferior the animal races of the New may be as compared to those of the Old World, the balance between the two appears to have been pretty equal in remote ages, - geological discovery has disproved the assertion of Buffon, that the creative force in America in relation to quadrupeds never possessed great vigour, and has established the fact, that it is only the more recent specimens of its energy that are upon an inferior scale. The relics of the unwieldy megatherium, of the gigantic sloth, and armadillo-like animals, discovered in great abundance imbedded in its soil, prove that at a former period it swarmed with monsters of equal bulk with those that now roam in the midst of Africa and Asia. The estuary deposit that forms the plains westward of Buenos Ayres, and covers the granitic rocks of the Banda Oriental, appears to be the grave of extinct gigantic quadrupeds.

There are various animals which are very widely dispersed, enduring the extremes of tropical heat and of polar cold, which are either in a wild condition or in a state of domestication. Wild races, considered to be varieties of the domestic dog, oecur in India, Sumatra, Australia, Beloochistan, Natolia, Nubia, various parts of Africa, and both the Americas ; while in subjection to man, the dog is his faithful companion, and has followed his steps into every diversity of climate and of situation to which he has wandered. The north temperate zone of the Old Continent appears to be the native region of the ox, which passes in Lapland within the arctic circle, and has been spread over South America since its first introduction by the Spaniards. The horse, originally an inhabitant of the temperate parts of the Old World, has shared in a similar dispersion, and now exists in the ligh latitude of Iceland, in the desolate regions of Patagonia, and roams wild in immense herds over the Llanos of the Orinoco, leading a painful and restless life in the burning climate of the tropics. Humboldt draws a striking picture of the sufferings of these gifts of the Old World to the New, returned to a savage state in their western location: "In the rainy season, the horses that wander in the savannah, and hare not time to reach the rising grounds of the Llanos, perish by hundreds amidst the overflowings of the rivers. The mares are seen, followed by their colts, swimming, during a part of the day, to feed upon the grass, the tops of which alone wave above the waters. In this state they are pursued by the crocodiles; and it is by no means uncommon to find the prints of the teeth of these carnivorous reptiles on their thighs. Pressed alternately by excess of drought and of humidity, they sometimes seek a pool, in the midst of a bare and dusty soil, to quench their thirst; and at other times flee from water and the overflowing rivers, as menaced by an enemy that encounters them in every direction. Harassed during the day by gad-flies and musquitoes, the horses, mules, and cows find themselves attacked at night by enormous bats, that fasten on their backs, and cause wounds which become dangerous, because they are filled with acaridæ and other hurtful insects. In the time of great drought, the mules gnaw even the thorny melocactus (melon-thistle), in order to drink its cooling juice, and draw it forth as from a vegetable fountain. During the great inundations, these same animals lead an amphibious life, surrounded by crocodiles, waterserpents, and manatees. Yet, such are the immutable laws of nature, their races are preserved in the struggle with the elements, and amid so many sufferings and dangers. When the waters retire, and the rivers return into their beds, the savannah is spread over with a fine odoriferous grass; and the animals of old Europe and Upper Asia seem to 
cnjoy, as in their native elimate, the renewed vegetation of spring." The first colonists of La Plata landed with seventy-two horses, in the year 1535 , when, owing to a temporary desertion of the colony, the animal ran wild; and in 1580, only forty-five years afterwards, it lad reached the Straits of Magellan. 'The ass has a more restricted range than the horse, not being capable of enduring so great a degree of cold, though usually far from being considered a delicate animal. To the warmer parts of the temperate zone, between the 20th and the 40th parallels of latitude, the ass seems best adapted, not propagating much beyond the 60th, and only occurring in a state of degeneration beyond the 52nd. The sheep and goat tribe are widely spread, equally supporting the extremes of temperature. According to Zimmerman, the Argali or Mouflon, the original race of sheep, still exists on all the great mountains of the two continents; and the Capricorn and 1bex, the ancestors of the common goat, inhabit the high European elevations. From the 64th degree of north latitude, the hog is met with all orer the Old Continent, and also in the islands of the Indian Ocean peopled by the Malay race; and since its introduction into the New World, it has diffused itself orer it, from the 50th parallel north as far as Patagonia. Originally the cat was not known in America, nor in any part of Oceanica; but it has now spread into almost every country of the globe. Among animals entirely wild, the most extensively diffused are, the fox, hare, squirrel, and crmine; but the species are different in every region of the world; nor is there perhaps one example to be found of a species perfectly identical naturally existing in distant localities of the earth.

Confining our attention chiefly to the wild quadrupeds, and to those of the largest class, the earth may be divided into several great zoological provinces, in each of which we find distinct groups of animals.

1. The Arctic Region. The northern parts of both continents have the same animals in common; for north-eastern Asia is only separated from nortll-western America by a narrow strait, across which the communication, in the winter season, is not diffieult, by means of the ice and intervening islands. Throughout this district the white or polar fox is diffused, sometimes called the isatis, an animal different from the common species, occurring in great numbers in Nova Zembla, inhabiting Kamtschatka and the Aleutian Isles on the one side, and Iceland and Lapland on the other. Here also is the range of the rein-deer, of all large land animals, the one that advances nearest to the pole. It is found on all the coasts of the Frozen Ocean, and is so impatient of warmth, that in Scandinavia it can scarcely exist south of $65^{\circ}$, descending in Russia to $63^{\circ}$, where the climate is colder, and to $50^{\circ}$ in Asia, roving into Chinese 'Tartary among the Tongouses, where a still more rigorous temperature prevails. In America; the rein-deer, or karibou, which is identically the same animal, descends as low as $45^{\circ}$. It is indigenous in the island of Spitzbergen, and is found also in Iceland, but not as a native, having been brought there by man so late as the year 1770 , when three were introduced from Norway, and turned adrift, which have since multiplied into considerable herds, not unfrequently seen in the mountainous districts. In the white or polar bear we have the monarch of quadrupeds in the arctic region, a maritime species, the Ursus maritimus of naturalists, totally different from the common bear of the land. This ferocious and formidable animal never quits the "regions of thick-ribbed ice," nor travels far from the ocean; but haunts the shores, sometimes putting out to sen upon the drifting ice, and making distant excursions by this means, and by his own locomotive energies, being a strong and perserering swimmer. Henee, he is well known in the islands, as well as the continental parts of the frozen zone, twelve or thirteen in a season occasionally finding their way from West Greenland across the strait to Iceland. It has been observed by Scoresby, that they have been seen on the ice in such quantities as to be comparable to flocks of sheep on a common, and that they are often found on field-ice, above two hundred miles from the shore. Captain Parry, 
upon one of his royages through Barrow's Strait, met with a bear swimming in the water about midway between the shores, which were forty miles apart, and where no ice was in sight. These facts sufficiently account for the extensive occupancy of the aretic region by the polar bear, and for his appearance on islands separated from the continents by a broad oceanic expanse. As an instance of adaptation to external circumstances, the capital clothing of the animals of this zone may be mentioned, which supplies us with the choicest furs; as well as their prevailing white colour, of which we have examples in the bear, the fox, and the white hare of Greenland, - the colour which reflects most heat and light.

2. North Temperate Region. This district comprises two departments, separated from encll other by a wide extent of ocean, impassable to the land animals by ordinary means, the one extending through Europe and Asia, and the other through North America, between which the billows of the Atlantic and Pacific roll. Here we have two distinct zoological prorinces. The common bear, which occurs in Europe and in the north of Asia, does not exist in America; nor the stag, which inhabits the European part of the Old Continent to the 64th parallel, and the Asian to the 55th. On the other hand, the corresponding tract in America is the abode of races peculiar to itself, among which we may enumerate the wapiti, the grizzly bear, and the bison. This latter animal once occupied nearly the whole of the temperate regions of the New World, but has retreated within narrower limits before the advancing influence of civilisation. It inhabited the Carolinas at the period of the earliest colonisation, and formerly extended over all the United States favourable to its existence, but it has not been seen in Kentucky since the ycar 1766, and now haunts chiefly the great prairies bordering on the Missouri, occasionally extending southward to the 35 th, and northward to the 62nd parallels. The bisons associate in vast herds, and, being herbirorous, are compelled to wander far, in order to find the requisite supply of vegetable food. The surface of the prairies is sometimes blackened by their numbers. "It is no exaggeration," says Mr. James, " to assert, that in one place, on the banks of the Platte, at least ten thousand burst on our sight in an instant. In the morning we again sought the living picture; but upon all the plain, which last evening was so teeming with polar animals, not one remained." Till a recent date, the Rocky Mountains formed an impassable barrier to their westward progress; but of late years they are said to have discovered a passage across the range, near the sources of the Saskatchawaw, and now roam upon the banks of the Columbia. The same causes which have affected the range of these quadrupeds in North America, have operated to produce a similar effect, in various parts of the globe, in the case of other animals. The republican establishments of the beaver have vanished from the banks of the Rhone and the Danube; the bear, wild boar, and wolf have disappeared from our own country; and the lion, which, in former times, must have shook the hoar-frost from his mane, as a dweller in Thrace and Macedonia, lias retired entirely from Europe.

3. Region of Intertropical and South America. In this extensive tract, eapable of subdivision into several distinct zoological provinces, we have, besides the jaguar, formerly mentioned, - the puma, or lion of the New World, but a very feeble representative of its eastern namesake; the llama, improperly styled the camel of the western continent, inhabiting Peru and Chili ; the tapir of Brazil; and the didelphis, or American opossum, one of the marsupial family, which comprise those animals which produce their young in an immature state, and keep them for a time attached to their bodies, chiefly in abdominal bags or pouches, of which several gencra occur in Australia. The conformation of the American opossum differs from that of the Australian in several respects, but chiefly in having a long prehensile or muscular tail, constituting a fifth limb, a furniture designed to accommodate the animal to the vast and lofty forests of Guiana, which are its abode. 
The monkey races here are similarly furnished, and essentially differ from the apes of Africa and Asia, which have no such peculiarity. It has been remarked, that America is deficient in the large and powerful animals which are found on the ancient continent; but in their place, some singular tribes appear, in the formation of which the ordinary rules of nature seem to have been abandoned. Such are the tribes which Linnzus referred to his order of Bruta, and which Cuvier has called Edentes, quadrupeds which are partially or wholly deficient in the organs of mastication, as the sloths, the ant-eaters, and the armadilloes, the former of which especially are the defective monsters of Buffon, rude and imperfect attempts of nature. With his usual felicity, Cuvier remarks of the sloths, "that we find in them so little relation to ordinary animals; the general laws of organisation prevailing among the species at present existing, apply so little to them; the different parts of their bodies appear to be so much in contradiction to the laws of co-existence which we find established through almost the whole animal kingdom, - that we might really suspect them to be the remains of another order of things - the living relics of that precxisting nature, the ruins of which are elsewhere discovered only in the interior of the earth; and we might conjecture that these creatures have escaped by some miracle the catastrophes which have destroyed the other species that were their contemporaries." The organic remains of nearly-allied animals to the sloth are common in South Americathe megatherium, megalonyx, scelidotherium, and mylodon, - in dimensions and power the rhinoceroses and elephants of a former world.

4. Region of Intertropical and South Africa. In the northern part of this district, where those desert plains commence which traverse the whole of the Old Continent, we find the one-humped camel, of which the dromedary is a fleet species, without which the Sahara could not be crossed by the caravans. In all the great rivers of this quarter of the globe, except the lower part of the Nile, the hippopotamus occurs, but more abundantly in the southern districts. The giraffe is peculiar to a tract of country extending from Cape Guardafui to the Cape of Good Hope, probably including the mountainous plains of Central Africa. This is the location likewise of the beautiful zebra and quagga, analogous animals to the horse and ass of the northern hemisphere, as well as of a variety of remarkable antelopes. No genuine tigers are found in this region; but the leopard and the panther supply their place-two species of the feline tribe that are outwardly distinguished only by their spots, those of the leopard being more regular and beautifully defined, a tenant chiefly of Guinea and Senegambia. One species of rhinoceros, that with two horns, is peculiar to South Africa, where it is very commonly met with, along with a race of elephants, distinct from the Asiatic, which are every where found in great numbers, from the Cape of Good Hope to the 20th parallel. 'While the king of quadrupeds has an extensive range in Asia, it is in Africa that the lion is most perfectly developed, exhibiting that majestic mien, that strength and courage, which have won for him his title. His home here extends from the southern roots of Mount Atlas to the Cape.

5. Region of Continental India and the Indian Archipelago. This is specially the country of the tiger, which, though found in Eastern Persia and in China, attains his maximum size, and displays the greatest ferocity, in the jungles of Hindùstan, Ceylon, and Sumatra. A variety of the elephant occupies the continent as far as the 30th parallel, and occurs in some of the islands, which is the range also of the one-horned rhinoceros. But several of the islands of the archipelago contain species and genera which are not found on the continent; and hence they are sometimes considered as forming a separate zoological province. Thus the hippopotamus, which does not exist in any of the Asian rivers, is said to inhabit the Sunda isles; and in other islands we have the crocodile proper, a distinct animal from the gavial of the Ganges. The tapir also, which was once 
considered as peculiar to South America, is found in Sumatra; and the dugong, not known in any other part of the globe, the existence of which was long treated with incredulity. Among flying quadrupeds, or those mammifers which can imitate the flight of birds, supporting themselves for a short time in the air, nearly the whole race, with the exception of bats, are confined to the islands of South-eastern Asia. Three species of the flying Lemurs occupy the Sunda, Molucca, and Pelew islands; and sereral species of the flying nocturnal squirrels inhabit Java and the neighbouring parts of the archipelago. It is a conjecture of M. Lesson, that the islands stretching from Asia to Australia once formed part of a great continent; an opinion founded on the fact, that these islands contain great living species of quadrupeds which are in some instances common to several different isles, and that the channels by which they are separated are shallow, and intersected by banks apparently the remains of ground submerged. Dr. Prichard remarks upon this idea, "that the momentum with which the waters of the equatorial ocean are borne against the eastern side of America, though it has hollowed out the Gulf of Mexico, has not been sufficient to break through the ridge of the Cordilleras. In the Eastern Seas no similar mountain-chain existed to support the connection between Asia and Terra Australis. A comparison of the geographical facts which discover themselves in other equatorial regions, gøes far to confirm the opinion of M. Lesson."

6. Region of Australia. One of the most remarkable provinces of the animal kingdom, hitherto but imperfectly explored, is formed by Australia and the adjacent islands to the southward. We here meet with several entire genera of quadrupeds, which, though different in many respects from each other, have some common features of organisation, yet distinct from those which generally characterise the animal races in other parts of the globe. This great region has therefore been styled, and without any exaggeration, the cradie of a new creation, in which animal life has been arranged upon a peculiar plan, apart from those laws which are its universal conditions in other districts. The warmblooded quadrupeds were assumed by Linnæus to be, without any exception, viviparous and mammiferous; the former term denoting the production of their offspring in a living and perfect state, and the latter term expressing the furniture of the parents with organs for suckling their young. Such animals therefore, on the last account, were constituted into the great class of Mammalia. The Australian tribe of monotremes is, however, an exception to the assumption of Linnæus, for these are warm-blooded quadrupeds that are oviparous, producing eggs from which the young are hatched, and being consequently unprovided with mammiferous organs. This tribe is probably unique. Another remarkable fenture of this zoological province is the prevalence of marsupial animals, whose peculiar structure has been previously noticed, in the instance of the American opossum. Besides this example of marsupiality, a few more are found, chiefly in the Malay islands; but in Australia it occurs as a zoological law, applying to all the carnivorous animals, with only about the three exceptions of the bat, the phoca, and the dog, and distinguishing several of the herbivorous tribes. The wombat, the koala, and the kangaroo are lierbivorous marsupials; the phalangers are partly so, and insectivorous; the opossums and the dazyures are carnivorous, the latter corresponding to the civets and weasels of the Old World. We naturally inquire why this part of the globe should be distinguished from all other regions by the prevalence of a peculiar structure among its animal races; or, in other words, why the young of the warm-blooded quadrupeds of Australia should leave the matrix of the mother at an earlier period than those of other districts, and thus have a premature birth, so as to require an express provision for the preservation of the diminutive embryo? No reasonable conjecture can as yet be advanced upon the subject; though no doubt it stands in intimate connection with peculiar physical circumstances, the elucidation of which may one day further develop the story of the animal kingdom. 
In thus glancing at the zoology of the three great land divisions of the globe-those of the western continent, of the eastern, and of Australia-we perceive instances of different genera peculiar to each; and even where the same genus occurs in these far separated localities, the climates corresponding, the species are not identical. The animals of the ape tribe; of the canine and feline races, embracing wolves, foxes, hymenas, lions, and tigers ; of pachydermata, or the thick-skinned order, ineluding elepliants, tapirs, rhinoceroses, hogs ; of saurians and serpents ; of birds, aquatic, aerial, and terrene; and of other kinds, - are all variously organised in the three great continents, as well as in different elimates of the same hemisphere. If we look to the zoology of small islands, situated at no great distance from continents, like Great Britain, the Mediterranean isles, and Madagascar, we find their animal races generally the same as those on the adjoining mainlands; and with reference to those that are isolated, and far from any continent, they liave commonly no land quadrupeds at all, except those that have been transported to them by man, or have found their way thither by accidental means. Some of the islets of the Keeling or Cocoo group, situated in the Indian Ocean, about six hundred miles from the coast of Sumatra, are inhabited by rats, identical with the English species, whielı were brought in a ship from the Mauritius, wrecked upon the shores. By the European vessels, these troublesome parasites of the Old World, the rats and mice, have been conveyed to remote islets, bearing with as much impunity the heat of the equator as the cold of the north. The great groups of the Pacific, upon their first discovery, presented no warm-blooded animals, except a few tribes which liad accidentally migrated or been conveyed by the natives, probably colonists from the Malayan archipelago.

The conclusion to which we are led by the preceding facts with reference to animal distribution, is clearly the theory adopted in relation to the dispersion of plants, namely, in the words of Prichard, that various tribes of organised beings were originally placed by the Creator in certain regions, to which they are by their nature peculiarly adapted, probably a single pair of each species, from which their offspring lave dispersed themselves to as remote a distance from the original centre of their existence as their own powers of locomotion, their eapacity to endure change of climate, and the absence of physical obstacles of migration, have enabled them to wander. In the case of birds and insects, the agency of the winds has been a potent cause of dispersion, and some wellknown circumstances illustrate the mode by which animals of considerable size may be conveyed to shores distant from their original location, and become the occupants of islands to which, apparently, the ocean forbids the advance of animal life from without, unless transported thither by man. The common brown fox is found in Greenland and in Iceland, and has been borne from the former to the latter by the drifting ice, a mode of conveyance which has been observed in operation, for Olafsen mentions, that on one occasion he saw no fewer than four on one piece, sailing away on some such royage of discovery. The animals perish if the ise makes no land, as is the case with immense fields which reach the heart of the Atlantic, and melt in the warm water of the gulfstream; but should it gain a shore, the living cargo may be disembarked, introducing a new species to the district, or multiplying one previously brought there in the same way. It is not uncommon for the northern voyager to hear the wolves fearfully howling as they die by famine, having taken to the ice in the pursuit of seals, and been set afloat, hunger overtaking them in the open sea. Several animals, as the rat, dog, and bear, can accomplish considerable distances by their own powers of swimming; and the recent occurrences of the Moray floods show, contrary to a popular sentiment, that the common swine is adequate to the same performance. Three members of the same litter compassed the distance of five miles; and one, after being carried down to the mouth of the Spey, swam four miles, and landed safe. Sir C. Lycll remarks, that " in an adult and wild state, 
these animals would doubtless have been more strong and active, and might, when hard pressed, have performed a much longer voyage. Hence islands remote from the continent may obtain inhabitants by casualties which, like the late storms in Morayshire, may only occur once in many centuries, or thousands of years, under all the same circumstances." The isles of the Pacific have no quadrupeds, but some of those just mentioned-hogs, dogs, and rats, with the exception of a few bats; and only rats are found in Easter Island, the most remotely seated in the Pacific.

'There is another method of transport, which, though very rarely in action, may extensively diffuse both vegetable and animal tribes. In a former chapter of this work, the occurrence of floating islands in lakes has been noticed; and in addition to the instances there referred to, Mr. Darwin describes some on the Lake of Tagua-cagua, in Chili, which deserve attention. "They are composed of the stalks of various dead plants intertwined together, and on the surface of which other living ones take root. Their form is generally circular, and their thickness from four to six feet, of which the greater part is immersed in the water. As the wind blows they pass from one side of the lake to the other, and often carry cattle and horses as passengers." 'Towards the mouths of the great rivers, the Mississippi, Amazon, Orinoco, Congo, and Ganges, similar islands are formed, where any costacle occurs to the further progress of the wood and regetation drifted down by the currents from the interior countries, and sometimes these islands are driven from their moorings by a flood or a storm, and then float away, either entire or in piecemeal, into the open sea. They have been several times met with in the Indian Ocean, after the typhoon has raged, covered with mangrove-trees interwoven with underwood, and ships have sometimes been in peril, in consequence of mistaking them for firm ground. "It is highly interesting to trace, in imagination, the effects of the passage of these rafts from the mouth of a large river to some archipelago, such as those in the South Pacific, raised from the deep, in comparatively modern times, by the opcrations of the volcano and the earthquake, and the joint labours of coral animals and testacea. If a storm arise, and the frail vessel be wrecked, still many a bird and insect may succeed in gaining by flight some island of the newly formed group, while the seeds and berries of herbs and shrubs, which fall into the waves, may be thrown upon the strand. But if the surface of the deep be calm, and the rafts are carried along by a current, or wafted by some slight breath of air fanning the foliage of the green trees, it may arrive, after a passage of several weeks, at the bay of an island, into which its plants and animals may be poured out as from an ark, and thus a colony of several hundred new species may at once be naturalised." Extremely rare as is the occurrence of such a wandering Delos, it unquestionably belongs to the class of facts, romantic as it appears; nor do the effects attributed to it at all trespass beyond the sobrieties of calculation. If the West India islands had no samples of animal nor vegetable life common to the continent of North America, their reception of both might be presumed, whenerer the great raft of the Atcliafalaya (an arm of the Mississippi, ten miles long, and two hundred yards broad, is broken up, as it is almost certain to be, - sending down a hundred islets to float in the waters of the Gulf of Mexico.

The theory embraced with reference to animal distribution may appear to some readers at variance with the authority of Revelation, which, according to popular interpretation, teaches the collection of types of all living races into the Noachian ark, the occurrence of a universal deluge destroying the other members of each family, and the subsequent dispersion of the preserved stock from one common centre, the mountains of Ararat, to repopulate the world. With this theory of Linnæus and Pennant it is impossible to reconcile zoological facts, without supposing a series of the most astounding and useless miracles, concerning which a total silence is preserved in the Scripture narrative. 
We know that the kangaroos and emus of Australia, the llamas of Peru, the sloths, armadilloes, and ant-eaters of Paraguay, to mention no other instances, never could have accomplished the passage from the places of their location to any central part of the Old World, and back again, from the scene where the ark of Noah was set afloat, by natural means. Neither can the polar bear and the hippopotamus, the ostrich and the eider fowl, the reindeer and the giraffe, to refer to no more examples, exist together in a state of nature, requiring a great diversity of climate; and supposing them aggregated by the Divine Power, and sustained in a common temperature, the difficulty of conceiving a building capable of accommodating a tenth of the single parent pairs of all the species, is prodigious. The difficulty increases when we consider the vast number of freshwater fish, and reptiles of the rivers, to be provided for. To supernatural agency, indeed, all things are possible; but when nothing is said of its action in the record-when the object, imagined to have been effeeted by it, must have been to a great extent useless - and when the congregation of the animals is represented as in the main the work of Noah, we may surmise that a transaction local in its nature, and comparatively limited in its extent, is the subject of the relation. This opinion, which zoological considerations favour, is not opposed to the narrative, expounded in harmony with Oriental forms of speech, and with the genius of Scripture diction when treating of physical events; for it is consonant with both to employ universal terms with reference to local circumstances, and to express in descriptions of physical phenomena the optical appearance, and not the philosophic reality. In fact, the universa terra, or the whole earth, of the book of Genesis, which was sub-

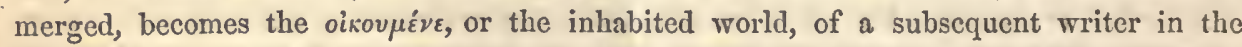
sacred volume; and if this were the place to handle the question, it might readily be shown, that at the diluvian era there had been no great multiplication of the human race, and consequently no wide dispersion of them. The fact of their circumscribed limits furnishes a presumption in favour of a partial deluge; for, to accomplish the "judgment of ungodly men," confined to a small part of the earth's superficies, by bringing a flood of waters upon the existing continents, and at the same time suspending the ordinary laws of nature, in collecting from distant lands, and sustaining at a common focus, live pairs of the animal races accustomed to different climates, and addicted to discordant habits this would be, to say the least, a vast superfluity, and to a great extent an unmeaning catastrophe. When no recognised principle of interpretation is violated by a contrary hypothesis, which accords with zoological conclusions, we may reasonably believe the Noachian deluge to have been limited to the world of man-probably the western region of Central Asia - the native seat of most of the domesticated animals and the cereal grasses, upon which the food, clothing, and convenience of mankind depend, reproductive examples being preserved, to minister to the wants of the patriarchal family, and to multiply and migrate, in the train of thcir posterity, to the far-distant regions to which they have wandered.

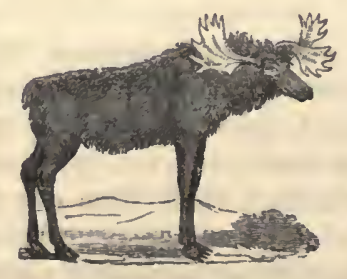




\section{CHAPTER XIX.}

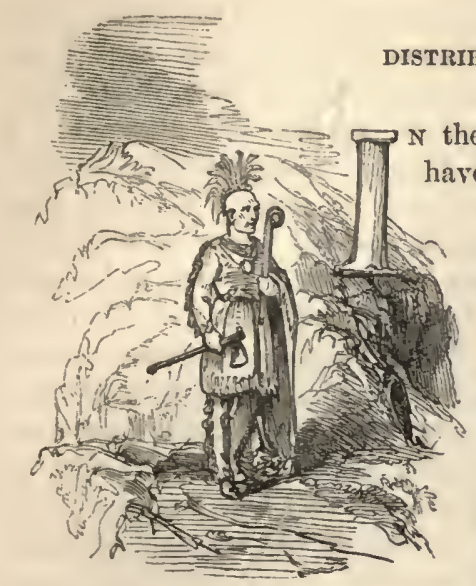

ISTRIBUTION OF THE HUMAN RACE.

the great scheme of creation immediately around us, we have viewed unorganised matter destitute of life, and matter organised, as in the grass of the field, with life, but destitute of sensation, and in the inferior animals, with life, sensation, and a portion of knowledge; but in man the scale of being rises above mere animal life and sensation, however delicate and varied, and beyond mere instinct, whatever that mysterious faculty may be, to rational existence, which constitutes him "the minister and interpreter of nature." The most sagacious and instinctive of the brute creation live and die without the least comprehension of the vast system of which they form a part; but man is capable of surveying the whole with thought and reflection, of understanding its economy and purpose, of tracing the Author of the work, and marking the display of his perfections, of yielding to Him adoration and homage, and sanctifying the varied scene to moral uses. Sometimes, in the spirit of lurking infidelity to the announcements of Scripture respecting the attention paid to our race by Divine Providence, philosophy has paraded before us its demonstrations concerning the plan of the universe, and called upon us to contemplate its stately forms and vast dimensions. We may obey its summons, and return from the contemplation with renewed ability to "vindicate the ways of God to man." For what knows the sun of his own brightness, or the lightnings of their force, or the planets of their velocity, or the ten thousand stars of their mighty proportions? The universe of material things can neither think nor feel, but is perfectly unconscious of itself; whereas man can appreciate to a certain extent its design, derive enjoyment from its objects, track their course, comprehend their laws, gather from them an intellectual apprehension of the wondrous Artificer, make them subservient to morals and devotion; and thus the grandeur of nature illustrates the greatness of man.

Linnæus placed man in the order of Quadrumana, or four-handed, in fellowship with the monkey tribe, and even considered the genus Homo as consisting of two species, the ouran-outang being the second, the congener of the human being. Cuvier, with an obvious propriety, has departed from this classification, and placed man in an order by himself, that of Bimana, or two-handed, in allusion to the prehensory organs with which he is furnished. They are instruments of essential moment to their possessor, and form a characteristic mark of his nobility, for, strictly speaking, he is the only bimane. In several physical respects, man is far inferior to many of the lower animals. The elephant is his superior in bulk and power, the hawk in sight, the antelope in swiftness, the hound in scent, and the squirrel in agility. No animal, in the infancy of existence, continues for so long a period in a state of helplessness and dependence, or suffers for an equal interval infirmity in age. To every other animal nature supplies an appropriate clothing, for which they "toil not, neither do they spin" the office of man; without which, he would live and die in the nakedness of his birth. No parallel to his case can be found in the animal kingdom, in relation to the slowness of 
his growth, the variety of his wants, and the numerous diseases to which he is exposed; and while animals directly adapt to their support the food that is suited to them - the lion his flesh, and the ox his grasses - the greater part of the human aliment, according to the practice of all nations, is subject to preparing proeesses, more or less rude or perfect, in order to be rendered agreeable and nutritious. 'These are apparently the hardships of the human condition : but a regard to their moral and intellectual effect will strip them of the character of disadvantages. If endowed with a high degree of physical force, if free from the necessity of culinary preparation, if naturally arrayed against the exigencies of climate, and thus constituted with a greater amount of personal independence, - it may reasonably be inferred, that civilisation would not have made its present advances, that mental capacity would have remained largely undeveloped, and the career of man have exhibited a succession of melancholy oscillation, between intemperate ferocity and selfish indolence. The sense of his weakness and the pressure of his wants have contributed to call forth his resources, to stir up "the gift and faculty divine," to rouse inventive powers to action, which would otherwise have continued dormant, and to excite benevolent affections, by the demand he is compelled to make for the society of his kind; and thus the very disabilities of his mere animal being tend to evoke his higher nature, and to accomplish one of the designed ends of his creation by sheer intellectual power, that of having "dominion over the fowl of the air, and over the fish of the sea, and over the cattle, and over every creeping thing that creepeth on the earth."

The aggregate number of individuals belonging to the human family has been very variously estimated by geographers. Berghaus, the most recent authority, has carried it higher than any of his predecessors. His estimate is as follows:-

\begin{tabular}{|c|c|c|c|c|}
\hline & $\begin{array}{l}\text { Area. } \\
\text { Square Miles. }\end{array}$ & Total Population. & $\begin{array}{l}\text { No. of Souls to } \\
\text { One Sq. Mile. }\end{array}$ & $\begin{array}{l}\text { No. of Acres to } \\
\text { One Individual. }\end{array}$ \\
\hline $\begin{array}{l}\text { Europe, } \\
\text { Asia, } \\
\text { Africa, } \\
\text { America, . } \\
\text { Australasia and Polynesia, }\end{array}$ & $\begin{array}{r}3,673,880 \\
14,190,000 \\
11,580,000 \\
18,760,000 \\
3,400,000\end{array}$ & $\begin{array}{r}296,000,000 \\
652,000,000 \\
275,000,000 \\
47,000,000 \\
2,000,000\end{array}$ & $\begin{array}{c}81 \\
46 \\
24 \\
21 \\
0 \frac{2}{3}\end{array}$ & $\begin{array}{r}8 \\
14 \\
27 \\
255 \\
1088\end{array}$ \\
\hline Whole Globe, & $51,603,880$ & $1,272,000,000$ & 25 & 26 \\
\hline
\end{tabular}

Of the total population, 83 per cent., or $1,056,000,000$, are supposed to be agricultural nations; 16 per cent., or $203,000,000$ are nomadic; and 1 per cent., or $13,000,000$, are fishers or hunters.

But however uncertain the numbers of the human race, maritime and inland discovery show the wide dispersion of the species, to the extreme bounds of regetable life; and the extraordinary facility of the human frame in accommodating itself to diverse circumstances. There are but few tracts of land which have not within their limits an indigenous human population. The antarctic continent, the Falkland Isles, and Kerguelen's Land, with Nova Zembla and Spitzbergen in the northern zone, are the principal exceptions. St. Helena is also another; for when that island was discovered, in 1501, it was only occupied by seafowl, occasionally visited by seals and turtles, and covered with forest-trees and shrubs. However small the coral islands of the Pacific, and remote from continents, they have in general their families of men. The New World, though very scantily peopled, has the Esquimaux at its northern extremity, within ten degrees of the pole, and the Fuegians at its southern end, perhaps in the lowest condition in which humanity exists upon the face of the globe. In the Ancient World, we every where meet with traces of man and of his works, except in the zone of deserts; and even here he has planted his race in the oases, the verdant islets of the great ocean of sand. In situations, high and low, dry and moist, cold and hot, we find members of the family to whieh we belong, enduring the extremes 
of temperature, a degree of heat which on the banks of the Senegal eauses spirits of wine to boil, and of cold in the north-east of Asia which freezes brandy and mereury.

This wide diffusion of the specics, occupying every variety of climate, soil, and situation, necessarily involves the fact of man being omnivorous, or able to derive support from all kinds of aliment; for otherwise, if his nourishment depended exclusively upon animal or vegetable food, various regions where the race exists and multiplies would be ineompatible with the easy maintenance of human life. In the eold and frozen north, beyond the range of the cereal plants, where excessive poverty marks the only vegetation that appears, the tribes of Esquimaux draw their support entirely from the land and marine animals, principally from fish and seals; and this is also the case with the miserable

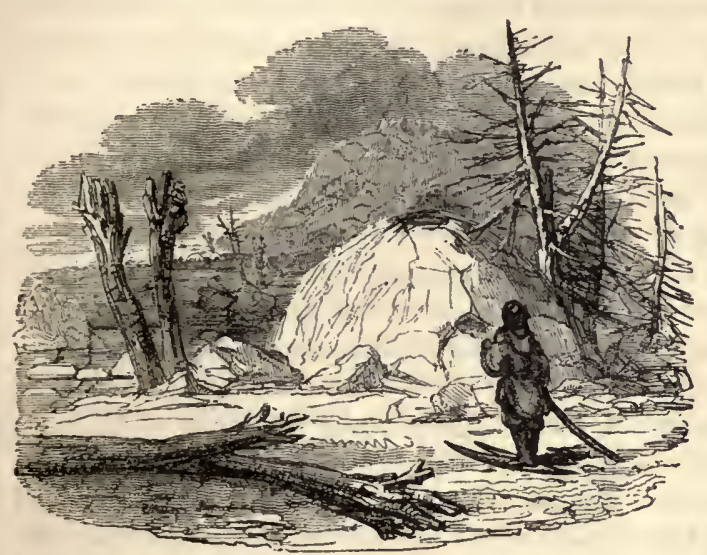

Esquimaux Hut. Petcheres, inhabiting a corresponding district in the southern hemisphere, the chill and barren shores of Tierra del Fuego. On the other hand; the eondition of many.interior tropical countries is not propitious to the subsistence of an extended population of the domestic animals and the common cerealia, owing to the number of the beasts of prey and the interchange of a flooded and a parehing soil ; and there we find large families of men chiefly sustained by a peculiar farinaceous diet, the fruits of the plantain and the palm. In the temperate zone; a plentiful supply of both animal and vegetable food is met with, which mingle in the aliment of the inhabitants. Thus, as we approach the poles, man does not live by bread at all, the Esquimaux being unacquainted with it : while approaching the equator he is mainly suppoited by vegetable nutriment; and intermediate between them, he is strikingly omnivorous, various kinds of grain and flesh composing the staff of life. Some naturalists have proposed a elassifieation of mankind, aecording to the species of food by the use of which they are distinguished. Thus we have Carnivorous, or flesh-eaters; Ichthyophagists, or fish-eaters; Frugivorous, or fruit and corn-eaters; Acridophagists, or locust-eaters; Geophagists, or earth-eaters; Anthropophagists, or man-eaters; and Omnivorous, or devourers of everything. 'But we have no tribes of men that exelusively belong to any one of these classes. The only clear division that ean be made of the luman race, taking their food as a characteristic, is the very general one already stated, between the inhabitants of polar, temperate, and tropical regions; and growing intercommunication is eonstantly lessening the amount of difference even here, by transporting the aliment yielded in abundance in one district to another naturally destitute of it. The locust-eaters include some of the wandering Arabs of northern Afriea and western Asia, where the erested locust, one of the largest species of the tribe, is made use of for food, both fresh and salted; in which last state it is sold in some of the markets of the Levant. Morier, in his Second Journey to Persia, observes, that loeusts are sold at Bushire as food, to the lowest of the peasantry, when dried; and he adds, that " the locists and wild honey, which St. John ate in the wilderness, are perhaps particularly mentioned to show, that he fared as the poorest of men." The Otomacs, one of the rudest of the American tribes, living on the banks of the Orinoco and its tributaries, are geophagists, or earth-eaters. When the waters are low, they live on fish and turtles; but when the rivers swell, and it becomes difficult to procure that food, they eat daily a large portion of 
clay, for the purpose of allaying hunger. Humboldt found in their huts heaps of it in the form of balls, piled up in pyramids three or four feet high. The substance is fine and unctuous, of a yellowish-grey colour, containing silica and alunina, with three or four per cent. of lime.

In considering the distribution of mankind, it is an obvious reflection that, to secure the general diffusion of human life, the same necessity did not exist, as in the case of plants and animals, for parent stocks to be originally planted in different regions of the globe. It has been correctly remarked, that had an individual of each tribe of plants, and a pair of each tribe of animals, been called into being in one and the same spot, the Linnæan lyypothesis, large regions, separated by wide seas and lofty chains of mountains from the country containing that single spot, would for ever have remained almost, if not entirely, destitute of plants and animals, unless at the same time means had been provided for their dispersion far more effectual than any which we behold in operation, and a constitution more accommodated to diverse climates had been given to them. To accomplish the dissemination of animal and vegetable life, to an extent commensurate with the capacity of the globe, separate regions were supplied with distinct stocks of plants and animals. But the case of man required no such arrangement to secure a large occupancy of the earth with his species. Endued with a constitution capable of accommodating itself to extreme diversities of climate, and with intelligence to invent methods of protection against atmospheric influences; enabled also by the same intelligence to devise means of transport over the most extensive seas, and across the most formidable ranges of mountains, it is clear, that, possessed of these capabilities, the whole habitable earth might be replenished with his race from the location of a single pair. This is the doctrine of the Mosaic history, and also of another part of the sacred record, which declares that God " hath made of one blood all nations of men for to dwell on all the face of the carth ;" and notwithstanding numerous and important diversities, the conclusions of philosophical inquiry are clearly in harmony with it, establishing the unity of mankind.

Before touching upon the question of the common nature and origin of the human race, a necessary preliminary to the question of their diffusion, it may be requisite to state the sense of certain terms of common occurrence in natural history, as species, genus, and varieties. A race of animals, or plants, which constantly transmit from one generation to another the same peculiar organisation, constitute what is technically called a species; and two races are held to be specifically distinct, where a marked difference of organisation exists, which is unvaryingly transmitted. A species therefore includes those animals and plants which may be presumed to have sprung from the same parent stock. "We unite," says De Candolle, "under the designation of a species, all those individuals who mutually bear to each other so close a resemblance as to allow of our supposing that they may have proceeded originally from a single being, or a single pair." The term genus has a more comprehensive signification. It is applied to a group of animals or plants, the several tribes of which seem constructed after a common general model, each being distinguished from the rest by a peculiarity of organisation, for which we cannot account but by supposing them to have proceeded from originally different individuals. Animals of the horse kind, which includes the ass and the zebra, furnish an example of genus. They display the phenomena of general resemblance, but with such marked differences, which are regularly transmitted, that we cannot suppose them the common offspring of the same individuals, but to have descended from originally different pairs. Animals of the feline race, as the cat and the tiger, and of the bovine kind, as the ox, buffalo, and bison, are similar instances of genera. A genus therefore embraces several species. But within the limits of a species varieties occur, or deviations from the type exhibited by the parent stock, which are due to external causes, elimate, soil, food, and other agencies, 
which have an obvious and marked effect upon animal and vegetable forms, however little their operation is understood. Some of these varieties are transient, but others become fixed and permanent in the race, and are so optically striking, as in several cases to suggest the idea of a specific difference, where the species is identical. Now, the question to be considered in relation to man is, whether the diversities which he exhibits in different parts of the globe are compatible with his race coming under the denomination of a species, having a common ancestry; or whether it forms a genus including several tribes, having a general resemblance, but so characteristically different as to lead the philosophical investigator to the verdict, that the diverging streams of humanity have originated independent of each other, and have not proceeded from the same fountainhead.

In prosecuting this inquiry, one method to be adopted is to review the principal external differences observable among mankind, as to complexion, structure, and stature; and examine, whether analogous diversities appear among the lower animals within the limits of the same species. If it is ascertained that corresponding phenomena to the lumau variations occur in the case of animals belonging to an identical species, the chief objection is obviated to the unity and common origin of the human kind.

1. The most obvious distinction displayed by mankind is that of colour, in relation to the skin, hair, and eyes, which, with few exceptions, are well known to have a certain correspondence, intimating their dependence on a common cause. Thus light-coloured hair is very generally in alliance with light blue or grey eyes; but a relation of the complexion of the skin to the hue of the hair is still more invariable. Persons of light hair have a fair and transparent skin, which assumes a ruddy tint by exposure to the light and heat of the sun, while the complexion of black-haired individuals is of a darker cast, and acquires a bronze shade in proportion to the intensity of the solar influence admitted to it. The dark-haired women of Syria and Barbary are indeed frequently very white; but this is owing to the careful avoidance of exposure to the effect of climate, which Prichard calls, a being "bleached by artificial protection from light, or at least from the solar rays." He discriminates three principal varieties of mankind, taking the colour of the hair as the leading character, which he styles the melanic, the xanthous, and the leucous. The melanic or black variety includes all individuals or races who have black or very dark hair; the xanthous or fair class embraces those who have either brown, auburn, yellow, flaxen, or red hair; and the leucous or white variety comprises those who are commonly called albinos, whose hair is either pure white or cream-coloured.

The great majority of the human race belong to the melanic or black-haired variety, the corresponding hue of the skin being pronounced by Prichard the natural and original complexion of the human species. This hue varies from the deepest black to a copper and olive colour, and to a much lighter shade. The Senegal Negros are jet black, and the natives of Malabar, with other nations of India, are nearly so. In some races, the black combines with red, and in others with yellow, as in the instance of the copper and olive coloured tribes of America, Africa, and Asia; and the same indigenous population furnishes examples of great discrepancy as to the character of the tint. "The great difference of colour," says Bishop Heber, of the Hindoos, "between different natives struck me much. Of the crowd by whom we were surrounded, some were black as Negros, other's merely copper-coloured, and others little darker than the Tunisines, whom I have seen at Liverpool. It is not merely the differences of exposure, since this variety of tint is visible in the fishermen who are naked all alike. Nor does it depend on caste, since very high caste Brahmins are sometimes black, while Pariahs are comparatively fair. It seems, therefore, to be an accidental difference, like that of light and dark complexions in Europe; though where so much of the body is exposed to sight, it becomes more 
striking here than in our own eountry. Two observations," he elsewhere observes, "struck me forcibly; first, that the deep bronze is more naturally agreeable to the human eye than the fair skins of Europe, sinee we are not displeased with it even in the first instance, while it is well-known that to them a fair complexion gives the idea of ill health, and of that sort of deformity which, in our eyes, belongs to an albino." The same class includes the swarthy Spaniards, and the inhabitants of southern Europe in general, who have dark hair, with the melanic complexion only strongly dilute, which characterises the olive, copper coloured, and negro nations. In the xanthous or light-haired variety, who have commonly grey or azure blue eyes, combined with a fair eomplexion, which aequires a ruddy instead of a bronze tinge on exposure to heat, some whole tribes in the temperately cold regions of Europe and Asia are included. Red or yellow hair and blue eyes peeuliarly eharacterised the old Gothic races according to the testimony of Tacitus, and are prevalent among their descendants at present. But examples of the xanthous variety present themselves in every dark-haired race, and we gather from Homer, that it was not uncommon among the Greeks of his time to find a melanic family. "The Jews, like the Arabs," says Prichard, "are generally a black-haired race; but I have seen many Jews with light hair and beards, and blue eyes; and in some parts of Germany, the Jews are remarkable for red bushy beards. Many of the Russians are light-haired, though the mass of the Slavonian race is of the melanous variety. 'The Laplanders are generally of a dark complexion, but the Finns, Mordouines, and Votiaks, who are allied to them in race, are xanthous. Many of the northern Tungusians, or Mantschu Tartars, are of the xanthous variety, though the majority of this nation are black-haired." Even among the more swarthy races of the melanie class, as the Negros of Senegal, examples of fairhaired individuals, with the corresponding complexions, occur; and the native stock of Egypt supplies similar instances, as appears from the light brown hair of some of the mummies. The leueous or white variety includes no entire race of people; but occasionally albinos, with perfectly white hair and skin, and red or pink eyes, appear in all countries;-among the xanthous tribes of Europe, the eopper-coloured nations of Ameriea, and the pure blacks of Africa. The phrase, white Negros, though a literal contradiction, exaetly expresses the physical fact - a white individual of a black stock. In some instanees, pure white and black ehildren have mingled in the same family, the offspring of black parents.

The springing up of individuals, distinguished from their parents, and from the partieular race in general to which they belong by a different eomplexion, evidenced by the oceurrence of albinos, and the more frequent grafting of a xanthous variety upon a melanie stock, or the reverse, renders the presumption strong, that those diversities of colour which discriminate nations from each other, are mere varieties of a species, due to loeal eauses, which, though they evade our serutiny, eertainly operate to an inferior extent, and yet with an analogieal effeet in families at present. The differenee in the cases is chiefly one of degree and of duration; but this presents no diffieulty when we consider, that strongly marked varieties of colour have been introduced among animals of the same speeies, and have become permanent from which a similar phenomenon may reasonably be inferred, in relation to the human race. "In the Mysore there are three varieties of colour in the sheep; they are red, black, and white, and these are not distinet breeds. The ass of the Carnatic presents singular varieties of colour; some are of the usual ashcolour, while others are almost blaek, in which ease the eross on the shoulders disappears. Milk-white asses are also to be found, but they are rare. These are not distinet species, for black individuals have sometimes ash-eoloured eolts, and vice versâ. Some remarkable facts are mentioned by Azara with reference to the colour of horses and oxen in Paraguay. It is well known that both these races have run wild in South America, and the climate 
being congenial to them, have multiplied prodigiously in the fertile plains in the neighbourhood of the river de la Plata. Azara says that all the wild horses are of a chestnut or bay-brown colour, while the tame horses are of all colours, as in other countries. Hence he conjectures this to be the original colour of the race. He makes a parallel observation respecting the ox. Varieties in the colour's of animals sometimes spring up casually and sporadically; in other instances they are generally prevalent in particular breeds. In the different parts of England, Wales, and Scotland there are different breeds of cattle and of horses. In some districts, the oxen are always black; in others, brown or spotted. The cattle of particular countries are immediately recognised by their colour. Blumenbach has noticed many examples of the same kind. He remarks that all the swine of Piedmont are black; those of Normandy, white; and those of Bavaria, of a reddish brown colour. 'The same author observes that the oxen of Hungary are of a greyish white; in Franconia, they are red. Horses and dogs are spotted in Corsica; the turkeys of Normandy are black; those of Hanover almost all white. In Guinea, the dogs and the gallinaceous fowls are as black as the human inhabitants of the same country."

The cause of the introduction of these varieties of colour among the inferior animals of the same species, which have become permanent, is involved in great obscurity; but we lave good reason to suppose that differences of climate, situation, food, and habits are some of the influential agencies in their production, chiefly perhaps the former, which appears to operate to a considerable extent in the various colouring of the human race. Both the plants and animals of hot regions display the deepest colours with which we are acquainted, while lighter shades are characteristic of those that are situated in cold countries. Within the tropies, the birds, beasts, flowers, and even fishes have the respective hues of their feathers, hairs, petals, and scales uniformly very deeply tinctured ; while, as we recede from the equator, the colour of the animal races progressively becomes of a lighter cast, till, approaching the poles, white is their common livery. The same remark is true very generally of the complexion of mankind. The black, dark-brown, and copper colours prevail in equatorial districts; the lighter olive is distinetive of the nations immediately north of the tropic of Cancer; and still lighter shades become more universal in the higher latitudes. The Abyssinians are much less dark than the Negro races, for though their geographical climate is the same, their physical climate is very different, the high table-land of the courtry placing them in a lower temperature. Shut up within the walls of their seraglios, and secluded from the sun, the Asiatic and African women are frequently as white as the Europeans; while, in our own country, exposure to the sun is well-known to produce a deeper complexion, and artificial protection from its influence is adopted to preserve a fair and unfreckled skin. The larvæ of many insects deposited in dark situations are white, and acquire a brownish lue upon being confined under glasses that admit the influence of the solar rays. Facts of this kind indicate the powerful operation of diverse climates in the various colouring of the human skin, and are sufficient to show, that the different complexions of mankind are mere varieties of species, introduced and rendered permanent by the continued action of local causes.

2. The next most obvious and important of the human differences involves variety of structure, especially in the shape of the skull. Taking this as the basis of a classification, Professor Blumenbach proposed a division of mankind into five grand classes - the Caucasian, Mongolian, Ethiopic, American, and Malay, which has been very generally adopted. 'The principal descriptive particulars of each, as given by that distinguished naturalist, are the following:

In the Caucasian race, the head is of the most symmetrical shape, almost round; the forebead of moderate extent; the cheek-bones rather narrow, without any projection; the face straight and oval with the features tolerably distinct; the nose narrow, and slightly 
arched; the mouth small, with the lips a little turned out, especially the lower one; and the chin full and rounded. This form, and the most perfect exof Western Asia, bordering on the vast chain of derives its name, posed to be the
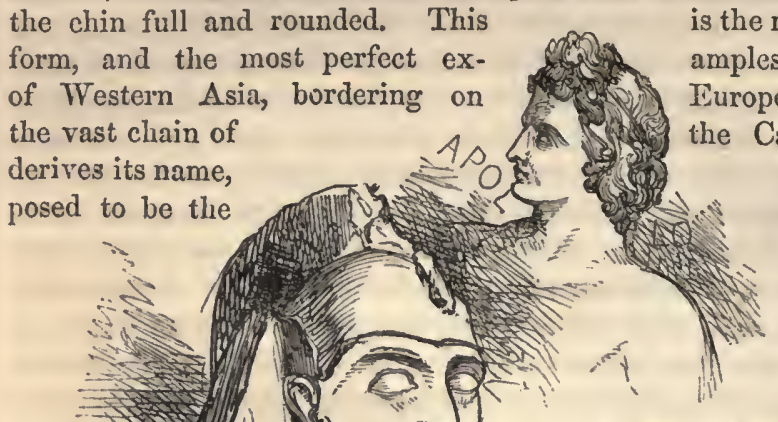
is the most elegant variety of the human amples of it are found in the regions Europe, which skirt the southern foot of Caucasus, from whence the class and which is near what is supparent spot of the human race. Here are the Circassians and Georgians, the most exquisite models of female beauty. But the Caucasian class includes nations very dissimilar apart from the form of the head. Its members are of all complexions, from the Hindoos and Arabs, some of whom are as black as the Negros, to the Danes, Swedes, and Norsemen, who are fair, with flaxen lair and light blue eyes. The class comprises the ancient and modern inhabitants of Europe, except the Laplanders and Finns, the Turks and Magyars. It comprises also the

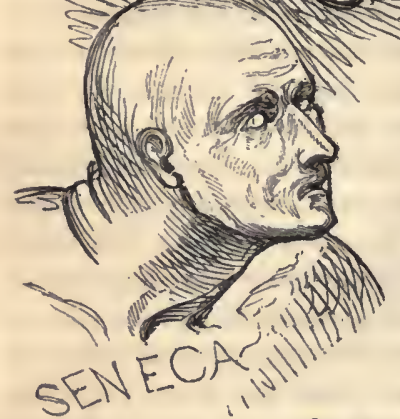
ancient and modern inhabitants of Western $\Lambda$ sia, as far as the Oxus, the Belurtagh, and the Ganges such as the Assyrians, Babyloninns, Medes and Persinns, Sarmatians, Scythians, Parthians, Jews, Arabs, and Syrians, the tribes of Caucasus, the Armenians, Affghans, and Hindoos. It includes likewise the Africans who live on the shores of the Mediterranean, and throughout the Sahara, the Egyptians and Copts, the Abyssinians, and the Guanches, or ancient inhabitants of the Canary Islands, with those Europeans who have colonised America and other parts of the world. The colour of the Caucasian class seems mainly to depend on climate, on the degree of solar heat to which there is exposure, for they are all born with light complexions, and become dark only as they grow up, and are more freely acted on by the sun. Their hue is found to deepen by a regular gradation from the farthest north, where the members of this class are very fair, through the olive coloured inhabitants of Southern Europe, and the swarthy Moors of Northern Africa, till the gradation ends with the deep black natives of the African and Arabian deserts, and of inter-tropical India. The lighter shades of colour, however, prevail among the Caucasians, and hence they are correctly styled the white race, though some of them are jet black. Their hair is variously melanic and xanthous, always long, and never woolly like that of the Negros.

In the Mongolian class, that of the brown man of Gmelin, the head, instead of being round, is almost square; the face is broad and flat, with the parts imperfectly distinguished; the arches of the eye-brows are scarcely to be perceived. The complexion is generally olive, sometimes very slight, and approaching to yellow; but none of this class are known to be fair. The eyes are small and black; the hair, dark and strong, but seldom curled, or in great abundance; and there is little or no beard. This division embraces the tribes that occupy the central, east, north, and south-east parts of Asia; the people of China and Japan, of 'Thibet, Bootan, and Indo-China, the Finns and Laplanders of Northern Europe, and the Esquimaux on the shores of the Aretic ocean. Climate influences the colour of many of this class, those parts of the body protected from the sun 
being much lighter than those that are uneovered. Dr. Abeel mentions, that when he saw the Chi- 8 nese boatmen throw off thcir clothes, for the purpose of entering saw the Chi- 8 nese woater to push along the boats, they appeared,

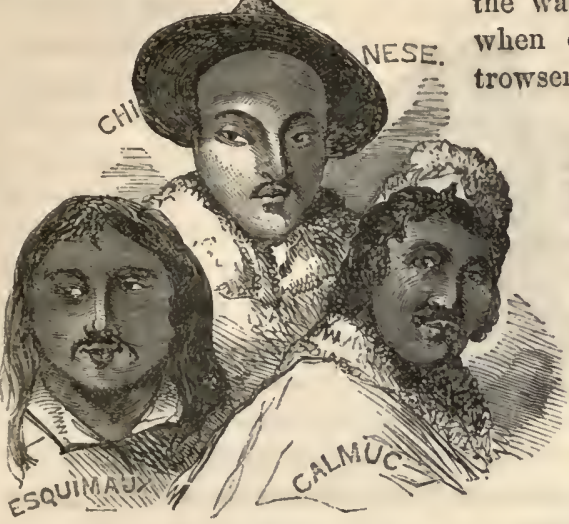

In the Ethiopic division, that of the black man of Gmelin, the head is narrow and compressed at the sides; the forehead very convex and vaulted; the cheek-bones project forwards ; the nostrils are wide, the nose sprend, and is almost confounded with the cheeks; the lips are thick, particularly the upper one; the lower part of the face projects considerably; and the skull is in general thick and heavy. The iris of the eye, which is deep-seated, and the skin of this class, are black, as well as the hair, which is generally woolly. These characteristics of the Negros vary less than those of the two former classes, because they are chiefly confined to one climate within the tropics, whereas the Mongolians and Caucasians are spread through every variety of temperature, from the equator to the polar circle. The division comprises the native Africans to the south of the Sahara and Abyssinia, and of course those who have been transported to the West Indies and America, the natives of New Holland and various tribes scattered through the Islands of the Pacific Ocean and the Indian Archipelago. Though, for the reason stated, this class exhibits a great general uniformity, examples are notwanting of beauty of feature, and fine stature and proportions, in several races belonging to this
department of mankind.

'The American variety, that of the red man of Gmelin, approaches to the Mongolian, but the head is less square; the cheek-bones are prominent, yet not so angular as in the Mongol; the forchead is low, the eyes deep-seated, and the features, riewed in profile, are strongly marked. The skin is red, or of an obscure orange, rusty iron, and copper colour, sometimes ncarly black, according to climate and circumstances. chtsinm The native American tribes and nations, excepting the Esquimaux, and the descendants of African and European colonists, belong to this class.

In the Malay class, that of the tawny man of Gmelin, the top of the head is slightly narrowed; the face is less narrow than that of the Negro; the features are generally more prominent; the hair is black, soft, curled, and abundant; the colour of the skin is tawny, but sometimes approaching to that of mahogany. The division embraces the principal tribes of the Indian arelipelago, and all the islanders of the Pacific, excepting those which belong to the Ethiopic variety.

The preceding five great divisions of Blumenbaeh are reduced by some naturalists to three, who consider the Malay class to be only a sub-variety of the Caucasian, and the American a sub-variety of the Mongolian. Cuvier gives only three distinct well-marked 
divisions, the white or Caucasian, the yellow or Mongolian, and the Negro or Ethiopic;

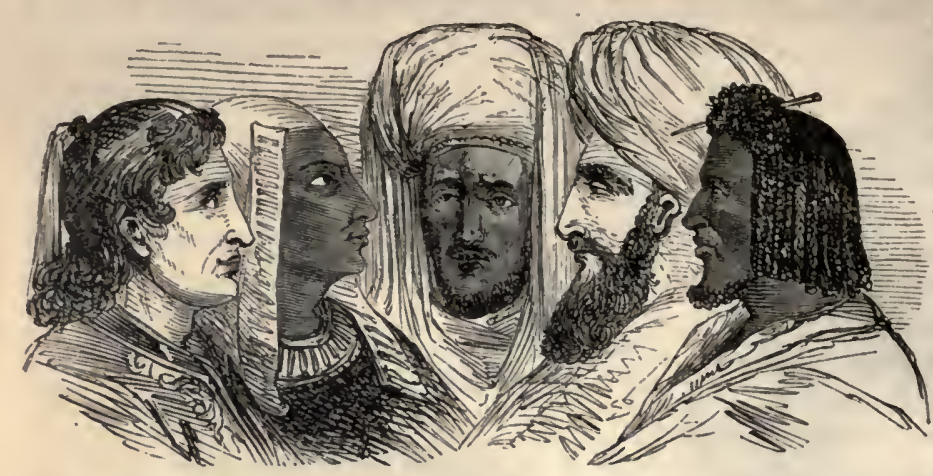
at the same time stating that several tribes diverge so remarkably, that they can scarcely be referred to any one of these varieties. In reality, the more ex. tended arrangement of Blumenbach is but a very imperfect classification of mankind, for not only individuals but whole tribes, incorporated in each particular division, lave distinctive characters which separate them from the rest of the class, and some peculiarities of one division are frequently traceable in the others.

Dr. Prichard distinguishes seven principal groups :

The Iranian or Indo-Atlantic nations, including almost all the Europeans, all the North Africans, and the Asiatics within a line passing from the Euxine along the chain of the Caucasus, cutting the Caspian, following the Oxus nearly to the source of that rirer, thence turning mountain range Caucasian of from the ancicnt

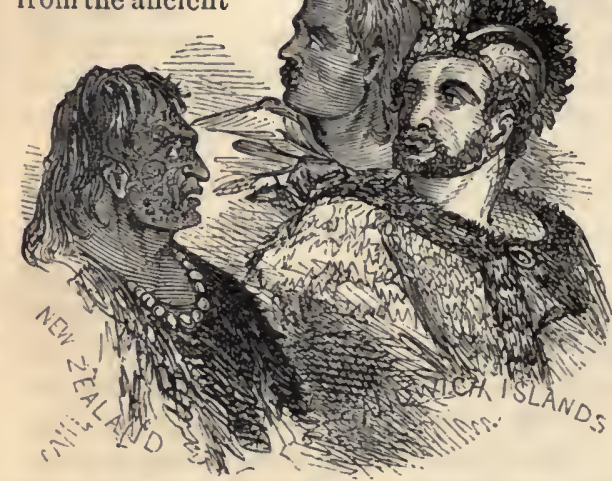
to the south-east, and proceeding along the Himalaya to the Gulf of Bengal. This class corresponds to the

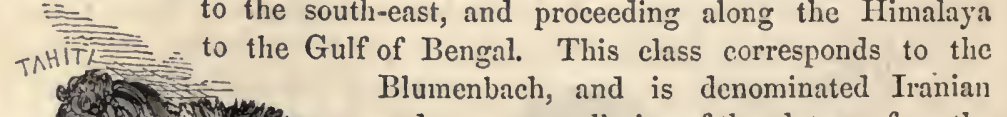
and proper appellation of the plateau of southwestern Asia, and Indo- $\Lambda$ tlantic, because stretching from India to the Atlantic on both sides of the Mediterranean.

The Turanian nations form the next division, comprehending all the Asiatics beyond the Oxus and Himalaya, denominated from 'Turan, the Persian name applied to all Asia apart from the table-land of Iran. The Malayo-Polynesians are included in this group, with the Finns, Lapps, Turks, and Magyars in Europe, and the Esquimaux in Amcrica.

The aborigines of America, or those nations whose abode in that continent dates from a period antecedent to history, excluding the Esquimaux, form the third class, a well-marked division of the human family.

The Negros, extending from the Saharn to the borders of the Cape Colony, with their transatlantic brethren, comprise the fourth class.

The Hottentots and Bushmen compose the fifth group, occupying part of Southern Africa, most resembling the North Asiatics.

The Papuas, or woolly-haired nations of the isles in the Malayan seas, frequently styled Oceanic Negros, are the sixth division.

The last group includes the Alfourous mountaineers of New Guinea, and the natire tribes of Australia.

Attending exclusively to the form of the human skull, Dr. Prichard discriminates three leading varieties:- The symmetrical or oval form, which is that of the Europcan and western Asiatic nations; the narrow and elongated skull, of which the most strongly marked example is perhaps the cranium of the Negro of the Gold Coast; the broad and 
square-faced skull, of which the Mongols afford a fair specimen, and the Esquimaux an exaggerated one.

The inquiry now recurs, whether these rarieties are compatible with a view of the luman race as a species, the offspring of a common stock ; and observing what transpires in the ease of the lower animals, especially of the domesticated kind, the reply will bc clearly in the affirmative. In fact, the direrse structure which arises in the same animal species is far greater than that apparent between one nation of men and another. The horse, ox, dog, sheep, and hog kind furnish indubitable examples of the truth of the assertion. "What a difference," says Blumenbach, "is there between the horses of Arabia and Syria and those of northern Germany; between the long-legged oxen of the Cape of Good Hope, and the short-legged breeds of England;" and he asserts that "there is less difference in the form of the skull in the most dissimilar of mankind, than between the elongated heads of the Neapolitan horse and the skull of the Hungarian breed, which is remarkable for its shortness and the extent of the lower jaw." Professor Palins remarks, that a series of skulls, from the large head of the wild horse, to the short head of the Hungarian breed, or the slender head of an English racer, would display more remarkable deviations than any that can be found in the crania of the human races. Blumenbach states of the hog tribe:- "No naturalist has earried his scepticism so far as to doubt the descent of the domestic swine from the wild boar. It is certain that before the discovery of America by the Spaniards, swine were unknown in that quarter of the world, and that they were first carried thither by Europeans. Yet, notwithstanding the comparative shortness of the interval, they have in that country degenerated into breeds wonderfully different from each other and from the original stock. These instanees of diversity, and those of the hog tribe in general, may therefore be taken as clear and safe examples of the variations which may be expected to arise in the descendants of one stock. The whole difference between the cranium of a Negro and that of a European is by no means greater than that equally striking difference between the cranium of the wild boar and that of the domestic swine. Those who have not observed this in the animals themselves, need only to east their eyes on the figure which Daubenton has given of both." Similar instances of variation of structure arising in species, in the case of the inferior animals, might readily be adduced in abundance, and must be accepted as evidence that diversity of structure in the human race is consistent with the doctrine of its unity.

3. The other principal physical variations observable between different nations refer to the proportion of the limbs, to stature, to the texture of the skin, and to the character of the hair. Large hands and broad and flat feet are among the peculiarities of the Negro; and in general, the arm below the elbow is more elongated in proportion to the length of the upper arm and the height of the person, than in the case of Europeans. But among the latter, individual examples of the same construetions occur, while among the former, instances of structure after the European type may be found. As it respects stature, the variations are not remarkable in relation to the majority of mankind, but a striking discrepancy appears upon comparing a few isolated tribes. America exhibits the extremes of stature, in the Esquimaux who are generally below five feet, and in the Patagonians who are usually more than six, and frequently as much as seren; but individual specimens of both extremes are observed among the inhabitants of almost every country. Europe has often presented the human form developed in gigantic and dwarfish proportions. The contrasts are striking with reference to the texture of the skin, that of the Negros and some of the South Sea islanders being always cooler, more soft, and velvety than that of the Europeans. Connected probably witl rarieties of the skin in texture are the various odours which it is well-known belong to different races. "The 
Perurian Indians," says Humboldt, "who in the middle of the night distinguish the different races by their quick sense of smell, have formed three words to express the

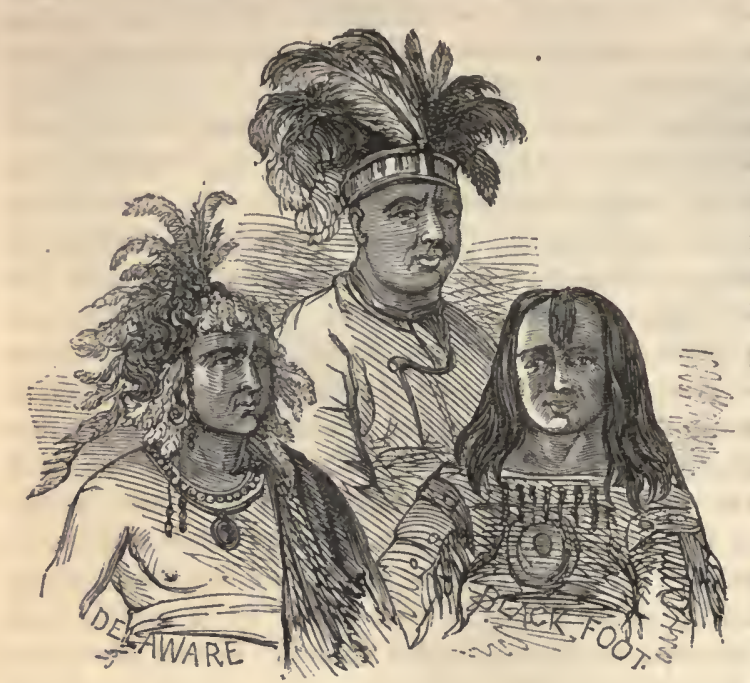
odour of the Europeans, the Indian Amerieans, and the Negro." The diversities are great and obvious in the charaeter of the hair, from that of the Negro, which is short and crisp, and has acquired the name of wool, to the long, flowing, and glossy locks of the Esquimaux, between which there are many gradations.

Preeisely parallel varieties are ascertained to arise in the same race of animals. Those of the domestic kind "vary from each other in size much more than individuals the most different in stature among mankind. The small Welsh cattle, compared with the large flocks of the southern counties in England, or the Shetland ponies with the tall-backed mares of Flanders; the bantam breed with the large English fowls, are well-known examples. More striking instances are mentioned by naturalists. In the isles of the Celebes, a race of buffaloes is said to exist, which is of the size of a common slicep ; and Pennant has described a variety of the horse in Ceylon not more than thirty inches in height." The swine of Cuba, imported into that island from Europe, have become double the height and magnitude of the stock from which they were derived. The disproportionate arm of the Negro and leg of the Hindoo meet an exact parallel in the swine of Normandy, the hind-quarters of which are so out of keeping with the fore, that the back forms an inclined plane to the head; and as the head itself partakes of the same direction, the snout is but a little removed from the ground. Among domesticated animals, no species afford more striking specimens of modification in structure than the hog tribe. The external forms which the race has assumed surpass in monstrosity the most extraordinary diversities of the human frame. "Swine," observes Blumenbach, "in some countries have degenerated into races which, in singularity, far exceed every thing that has been found strange in bodily variety among the human race. Swine with solid hoofs were known to the ancients, and large breeds of them are found in Hungary and Sweden. In like manner the European swine first carried by the Spaniards in 1509 to the island of Cuba, at that time celebrated for its pearl-fishery, degenerated into a monstrous race, with toes that were half a span in length." The texture of the skin of several species of animals is different in a wild and in a domestieated condition; and the character of the hair exhibits analogous variations to that of the tribes of mankind. In the instance of a neglected flock of sheep, the fine wool is soon succeeded by a coarser kind, and the breed approximates to the argali, or wild sheep of Siberia, the original stock, which are covered with hair. The covering of the goat and dog displays the same variety. Thus, the several external distinctions from each other which the nations of men develop, must be admitted to be plainly compatible with their forming a single species, when distinctions of a parallel nature, but more numerous and singular, have arisen within the limits of a species in the inferior animal creation. It may be diffieult, nay impossible, to explain the phe- 
nomena of external variation; but surely it would be a matter of surprise if it did not exist, considering the variation of external circumstances - arctic cold and tropical heat - flowery savannahs and arid deserts - civilisation and barbarism - liberty and oppression - scantiness of food and an abundant supply - nutritious diet and a feebly supporting fare - the feeling of security and the sense of danger.

If the existence of varieties of structure and complexion offers no argument against the common nature and origin of the millions of mankind in the slightest degree valid, their identity as a species is strongly supported by adverting to the general laws of their animal economy. These have reference to the manner of their birth, the period of gestation, the duration of life, and the casualties in the form of diseases to which they are subject; and, in all these respects, a general coincidence proclaims the unity of the human population of the globe. As to longevity, it is the case indeed that the barbarian tribes are shorter-lived than the cultivated races; but this is owing to the physical hardships under which they suffer, and to ignorance of the appropriate remedies to use under the assailments of sickness, freedom from the former and the knowledge of the latter being possessed by all civilised nations. Facts prove that, in circumstances favourable to extreme longevity, the Europeans, the most polished communities, have no pre-eminence over the tribes of Africa, among the least advanced in the social scale. Mr. Easton of Salisbury gives the following instances of advanced age from the Europeans and Asiatics :-

\begin{tabular}{|c|c|c|c|c|c|c|c|c|c|}
\hline & & & & In $\mathbf{A} . \mathbf{D}$. & Aged & & & In A. D. & Aged \\
\hline Apollonius of $\mathrm{Ty}$ & ana & - & - & 99 & 130 & Henry Jenkins & - & 1670 & 169 \\
\hline St. Patrick & - & - & & 491 & 122 & Countess of Desmond & - & 1612 & 145 \\
\hline Attila - & - & - & - & 500 & 124 & Thomas Damine & - & 1648 & 154 \\
\hline Leywareh İêw & - & - & . & 500 & 150 & Peter Torton - & - & 1724 & 185 \\
\hline St. Coemgene & - & - & - & 618 & 120 & Margaret Patters & - & 1739 & 137 \\
\hline Piastus, King of & Poland & - & - & 861 & 120 & John Rovin and Wife & - & 1741 & 172 and 164 \\
\hline Thomas Parr & - & - & - & 1635 & 152 & St. Mongah or Kentig & gern & 1781 & 185 \\
\hline
\end{tabular}

In juxtaposition with this list, we may place the following observation of Humboldt relating to the native Americans : "It is by no means uncommon," he remarks, " to see at Mexico, in the temperate zone, half-way up the Cordillera, natives, and especially women, reach a hundred years of age. This old age is generally comfortable; for the Mexicans and Peruvian Indians preserve their strength to the last. While $I$ was at Lima, the Indian, Hilario Sari, died at the village of Chiguata, four leagues distant from the town of Arequipa, at the age of one hundred and forty-three. She had been united in marriage for ninety years to an Indian of the name of Andrea Alea Zar, who attained the age of one hundred and seventeen. This old Peruvian went, at the age of one hundred and thirty, a distance of from three to four leagues daily on foot." Dr. Prichard, from various sources, collected a variety of remarkable instances of Negro longevity, of which the two following are samples:-

December 5th, 1830, died at St. Andrew's, Jamaica, the property of Sir Edward Hyde East, Robert Lynch, a negro slave in comfortable circumstances, who perfectly recollected the great earthquake in 1692, and further recollected the person and equipages of the Lieutenant-governor Sir Henry Morgan, whose third and last governorship commenced in 1680, viz. one hundred and fifty years before. Allowing for this early recollection the age of ten years, this negro must have died at the age of one hundred and sixty.

Died, Feb. 17th, 1823, in the bay of St. John's, Antigua, a black woman named Statira. She was a slave, and was hired as a day-labourer during the building of the gaol, and was present at the laying of the corner-stone, which ceremony took place one hundred and sixteen years ago. She also stated, that she was a young woman grown 
when the President Sharp assumed the administration of the island, which was in 1706 . Allowing her to be fourteen years old at that time, we must conclude her age to be upwards of one hundred and thirty years.

The same authority received from a physician at St. Vincent's, as an answer to his query, the statement :- “ I have known a great many very old Negros whose exact ages could not be ascertained. At the time of the hurricane in 1831, I had a record of the mortality in the whole of my practice from the year 1813, and in every year there were deaths of Negros computed to be sixty, seventy, or eighty years of age, and upwards. My father will be eighty-four years old in May next, and the Negro woman who carried him about as a child is still living, and at the age of ninety-six enjoying good health, upright in figure, and capable of walking several miles." It may be true that the Negros regarded in mass exhibit a shorter term of life than the European average; but this is sufficiently explained by the privations of their lot in the colonies to which they hare been transported, and by an unfavourable climatic influence and geographical site in their native country. The preceding facts show, that there is no law forbidding the Negro to attain a longevity equal to that of the European in circumstances friendly to it; while placing the European in subjection to the same amount of toil in the West Indies, or planting him amid the swamps, the luxuriant vegetation, the inundations, and heat of Western Africa, and his term of life in general would not come up to the Negro standard. It appears from the researches of Major Tulloch, as embodied in statistical reports printed by the House of Commons, that neither the Saxon, nor Celtic, nor mixed race, composing the troops of Great Britain, can withstand, even under the most favourable circumstances, the deleterious influence of a tropical climate. It is shown, also, that this result is not to be attributed to intemperance, the besetting vice of all soldiers; for though temperance diminislies the effects of climate, and adds to the chances of the European, it is by no means a permanent security. So far as regards the vast regions of the earth, the most fertile, the richest, the question as to their permanent occupancy by the Saxon and Celt, as Britain, or France, or any other country, is now occupied by its native inhabitants, appears, from these reports, to be answered in the negativc. "The AngloSaxon is now pushing himself towards the tropical countries; but can the Saxon maintain himself in these countries? It is to be feared not. Experience seems to indicate that neither the Suxon nor Celtic races can maintain themselves, in the strict sense of the word, within tropical countries. To enable them to do so, they require a slave population of native labourers, or of coloured men at least, and, in addition, a constant draught from the parent country. The instances of Cuba, Brazil, Mexico, and Columbia, where the Spanish and Portuguese seem to be able to maintain their ground, do not bear so dircetly on the question as many may suppose; for, in the first place, we know not precisely the extent to which these have mingled with the dark and native races; and secondly, the emigrants from Spain and Portugal partook, in all probability, more of the Moor, Pelasgic, and even Arab blood, than of the Celt, or Saxon."

A careful comparison of different tribes leads to the conclusion, that the general phenomena of human life, or those processes which are termed the natural functions, the laws of the animal economy, are remarkably uniform, making allowance for the influence of climates, of modes of living, of localities, and of the accidents which interrupt the natural course. The age of puberty announces itsclf by corresponding symptoms, and that of advanced life by analogous signs of decrepitude, the decrease of the humours, the loss or decay of sight and of the other senses, and a change in the colour of the hair. All communities of men appear open to the attack of all kinds of disease, though a few haunt particular districts, and of course only prey upon those who arc exposed to their invasion. In some cases, it is only the old inhabitants of these neighbourhoods that are attacked, as 
in the instance of the plica polonica, which afflicts the Sarmatic race on and near the banks of the Vistula, from which the German residents are in a great measure free. But this proves no specific difference between the two, but only shows, that, to acquire a predisposition to certain local complaints is a work of time, and will probably appear in new settlers after the lapse of centuries. There is a well-marked variety in the constitution of nations, and in their liability to certain given disorders; but the difference between the torpid American and the irritable European is not greater than the common varieties of constitution which meet us within the bounds of the same family, and which render its different members peculiarly subject to different complaints. The conclusion to which these considerations point - that of the identity of mankind as a species - is strongly supported by the fecundity of the offspring of parents of different races. Hunter and other naturalists have advanced it as a law, that if the offspring of two individual animals belonging to different breeds is found to be capable of procreation, the parent animals, thougl differing from each other in some particulars, are of the same species; and if the offspring so engendered is sterile, then the races from which it descended are originally distinct. This is a position to which there are many exceptions; but it is undoubtedly true, that the energy of propagation is very defective in the product of a union of different species. Tried by this test, the inference is in favour of a common nature belonging to all mankind; for the mixture of originally far-separated human races has repeatedly resulted in a numerous population, physically equal, and in many instances superior, to either branch of the ancestral stock.

It has suited the views of some interested parties in time past, who have their representatives at present, to pronounce certain tribes of men to be distinct species from the whites, constituted upon a type physically and mentally inferior to that of the Caucasian nations. This assumption has been embraced in order to exeuse the aggressions of the latter upon the persons and property of the former. Especially has the negro been subject to this treatment; and mental incapacity has been inferred from his retreating forehead and depressed vertex. But this favourite doctrine of the slave-owner has been amply refuted by the heroes, politicians, and legislators among the emancipated black population of Hayti, - by members of the same race, in other districts, when under cultivation, displaying a power of intellect, and loftiness of moral character, which would reflect honour upon any of the whites, - and by the testimony of travellers, that, apart from cultivation in his native wilds, the negro is capable of all the benevolent and social feelings of our nature, and merely developes the effect of unfavourable circumstances. The latter varying in nature and degree, will account satisfactorily for every case of physical and mental deterioration presented by the human races-the Australians, Fuegians, and Bosjesmans; for many an example has occurred of Europeans, brought under their influence, undergoing a marked degeneration.

A variety of evidence, psychical and moral, physical and philological, rebukes the ancient boast of Attica, that the Greeks descended from no other stock of men, the first occupants of the country springing out of the soil, -an opinion held by the populace, but not the creed of the philosophers. One of the most distinguished anatomists of his day, who cannot be suspected of any prejudice upon the question, Mr. Lawrence, draws this induction from an extensive series of facts and reasonings-" "that the human species, like that of the cow, sheep, horse, and pig, and others, is single; and that all the differences which it exhibits, are to be regarded merely as varieties." In what particular spot the location of the primal pair was situated, and what race now makes the nearest approximation to the original type, are points of some interest, but of no importance, and are now involved in an obscurity which it is impossible to remove. That the primitive man occupied some part of the country traversed by the Tigris and Euphrates, 
appears to be the best supported opinion, as it is the most general; and from thence there is no difficulty in conceiving the diffusion of the race to the remotest habitable districts, in the course of ages. In the infancy of society, an increasing population would specdily outstrip the means of subsistenee to be found in a limited district, inducing the necessity of emigration to an unoccupied territory $-a$ proceeding which the natural love of adventure, with the spirit of euriosity and acquisition, so influential in later ages, could not fail to facilitate. Considering the connection of Asia, Africa, and Europe, the approximation of the northern parts of the two great continents, with the contiguity of the islands of Asia to it, we cannot marvel, that the races spreading out to these points should devise means to eross rivers, seale mountains, penetrate into deserts, and navigate the sea. The spur of necessity, the excitement of enterprise, the stimulus of ambition, the occurrenee of accident, and sometimes the influence of fear, created by the commission of crime, have all contributed to this result; but perhaps man has more frequently than otherwise become the involuntary occupant of isolated and distant islets. Three inhabitants of Tahiti had their canoe drifted to the island Wateoo, a distance of five hundred and fifty miles; and Malte Brun relates, that, in 1696, two canoes containing thirty persons were thrown by storms and contrary winds upon one of the Philippines, eight hundred miles from their own islands. Kotzebue also states, that in one of the Caroline isles he became acquainted with Kadu, a native of Ulea. Kadu, with three of his countrymen, left Ulea in a sailing-boat for a day's excursion, when a violent storm arose, and drove them out of their course. For eight months they drifted about in the open sea, according to their reckoning by the moon, making a knot on a cord at every new moon. Being expert fishermen, they were able to maintain themselves by the produce of the sea, and caught the falling rain in some vessels that were on board. Kadu, being a diver, frequently went down to the bottom, where it is well known that the water is not so salt, taking a cocoa-nut shell with only a small opening to receive a supply. When these castaways at last drew near to land, every hope and almost every feeling had died within them; but by the care of the islanders of Aur, they were soon restored to perfect health. Their distance from home, in a direct line, was one thousand five hundred miles.

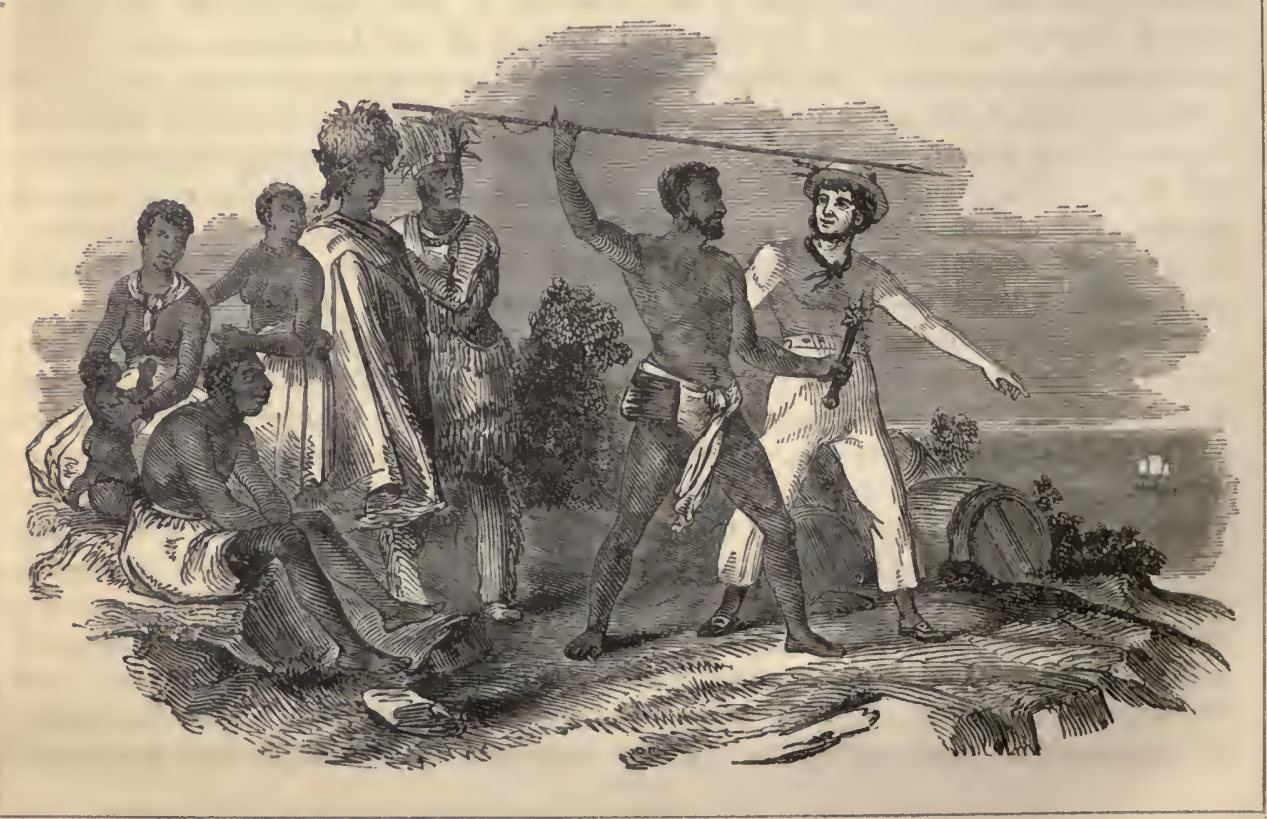




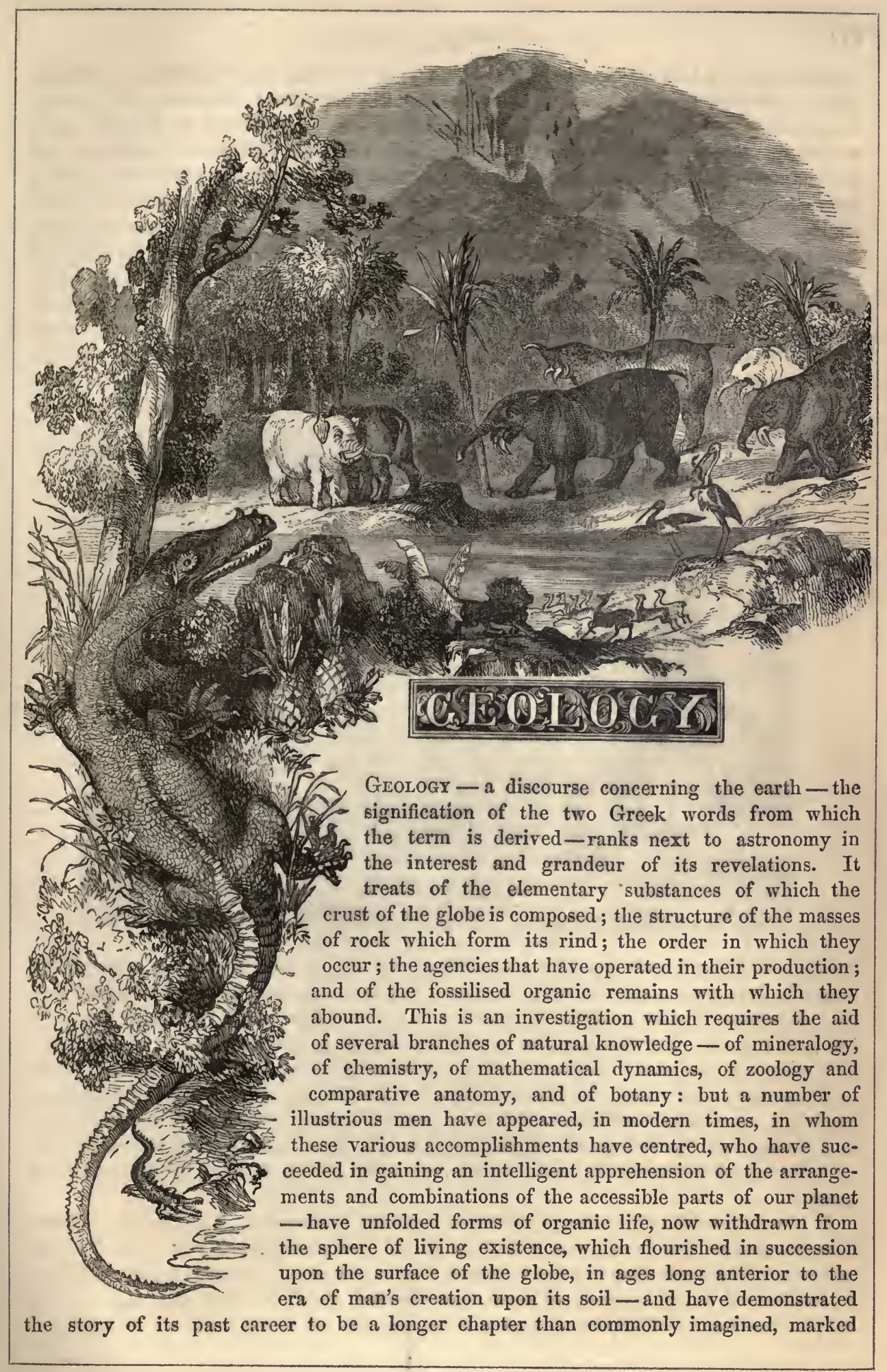


by revolutions which have repeatedly submerged, elevated, and dislocated its framework. Disclosures of this nature - surpassing the marvellous fancies of an oriental imagination - so novel to the great crowd of men-so contradictory to the prevailing sentiments in which they are educated - have been received with no little distrust, and have exposed the geologist to no small amount of obloquy, from the parties who prefer clearing to the tradition received from their fathers, and to the more obvious optical impressions, than to engage in any laborious exercise of the reflective faculties upon the phenomena of nature. In fact, geology has had to encounter the precise difficulty with which astronomy had to contend in its early stages - that of being antagonistic in its decisions to habitual ideas, and to the first blush of sensible evidence: for as the eye recognises the revolution of the sun, and the fixedness of the earth, while science teaches the stability of the former, and the rotation of the latter, - so the idea conveyed to the mind by the Cyclopean masonry of the limestone mountains, mass piled on mass, till the height of the clouds is scaled, is that of a hard and refractory sub-

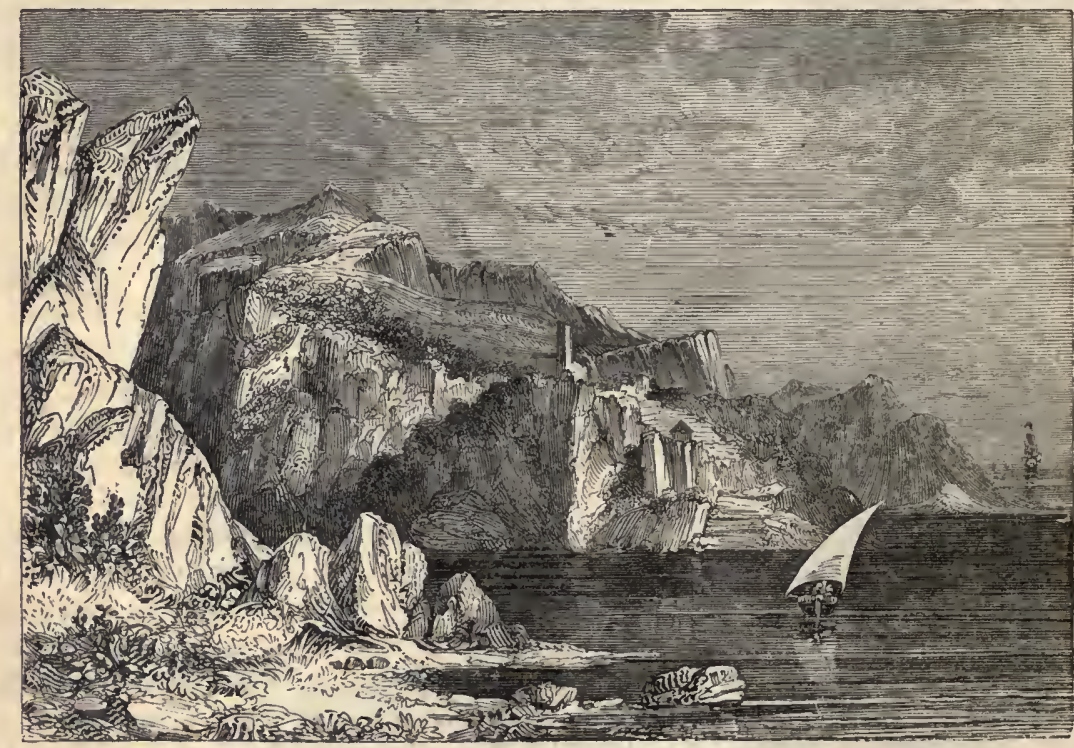

Limestone liocks in the Gull of Corinth.

stance, which has sternly stood its ground from the era of primeval time; whereas the scientific investigator teaches, that its materials were once held in aqueous suspension, and its substance as susceptible of impression as the sand from which the tide of the ocean has just retired. Yet the proof is equally irresistible in the one case as in the other. 'The minute organisations which cnter into the constitution of many of the towering cliffs which proudly throw back the impetuous dash of the billows, and the exquisitely delicate markings by organic structures which they present - the impressions of plants, learcs, and shells, and the foot-prints of birds - proclaim with undeniable evidence the fact of a former soluble condition, and of great vicissitude having stamped its character upon them.

It is a distasteful task to the generality of mankind to unlearn. They do not willingly abandon notions that have grown with their growth, and strengthened with their strength, and struck their roots deep and fast into their " heart of hearts." Besides being mortifying to intellectual vanity to admit an error, they disrelish the mental disturbance occasioned by the breaking up of old associations of ideas, and the toil which a correct conception cf 
truth may require. Much of the suspicion with which the scientific have been visited, may be referred to prejudices in favour of early imbibed opinions, to which the demonstrations of science have been opposed - prejudices which are known in the pages of Lord Bacen as idola specus, the individual mind being the den to which that sagacious observer of human nature alludes; and repugnant as it is to the owner and guardian of the mental cavern to have its chambers of imagery searched, and the occupant of any niche ejected, men have been compelled repeatedly to submit to the process, however they may have resisted the attempt. A country schoolmaster may still discourse of the four elements - fire, air, earth, and water; and his boys may look up to him as a prodigy of erudition; but chemical analysis teaches us to smile at the enumeration, though old as the days of the Greek philosophers. So the antiquated notion of the earth being an extended plane, like a table, - as motionless as that lousehold instrument, the sun coming to take his daily peep at it, like a careful watchman on his rounds, - has vanished from the face of civilised socicty, though supported by the impression of the senses, once deemed essential to religious faith, and defended by ecclesiastical law. It bccomes us therefore, when the decisions of science are contrary to our familiar ideas, to inquire into the soundness of both, and willingly to surrender our preconceived opinions to the force of truth, and not to array prejudice against knowledge. Even did the revelations of geological inquiry not admit of common minds cntertaining the evidence upon which they rest, the decisions of the actual experimentalists invite regard, on account of their number, science, sagacity, moral character, means of information, and unwearied industry in employing them. But however at variance several of its conclusions may be with the convictions gathered from the ordinary ocular view of nature, it requires but a little attentive inspection of the face of a country - its sea-cliffs, beaches, mountain sides, rocky precipices, land-slips, and ravines, connected with a very

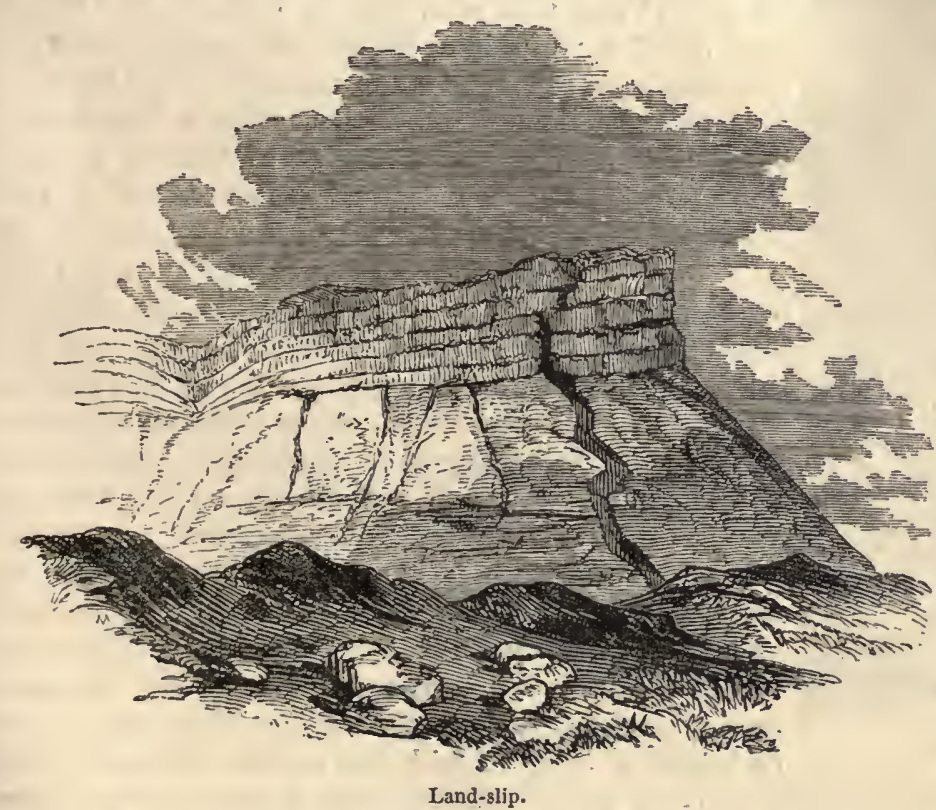
slight reflection, to apprehend the solid foundation upon. which the geologist grounds his doctrines, of changes and catastrophes in the constitution of the superficies, as well as the rast epochs of time required for the aggregation of strata: and to one who has read the record of mutation so clearly inscribed upon the surface of the globe, and has recognised its hoar antiquity as a legitimate deduction from the existing monuments of its fluctuations, the wonder is, that with the same powers of observation, the great mass in enlightened communities, until a recent period, should have remained so ignorant of the history of their terrestrial home. 
The time is happily going by, for aspersions to be cast upon the geologist, as if he were pursuing an unprofitable employment, or

" Had learned the art that none might name,

In Padua, far beyond the sea."

A fair comparison between the objects of his attention, and many of those which occupy their busy thought by day, and ferered dreams by night, who have pronounced his wisdom folly, would turn the tables upon his censors, and prove that folly must be assigned to them; while an enlightened use of his mental faculties, and means of knowledge, must bo attributed to him. 'To visit a bed of chalk, a sandstone quarry, an erratic block, or' an ossiferous cavern - to pick up shells, pore over a fossil, chip off portions of rocks, and store away the ungainly fragments in a cabinet - to examine the structure of strata, their dislocations, dip, and organic remains - to ascertain the aqueous or igneous origin of the vast mineral masses overlying the globe - to detect the substances which inhere in the composition of the earth's surface, simple or combined, and become familiar with gneiss, hornblende, felspar, quartz, mica-schist, and the carbonate of lime, which gives marble to

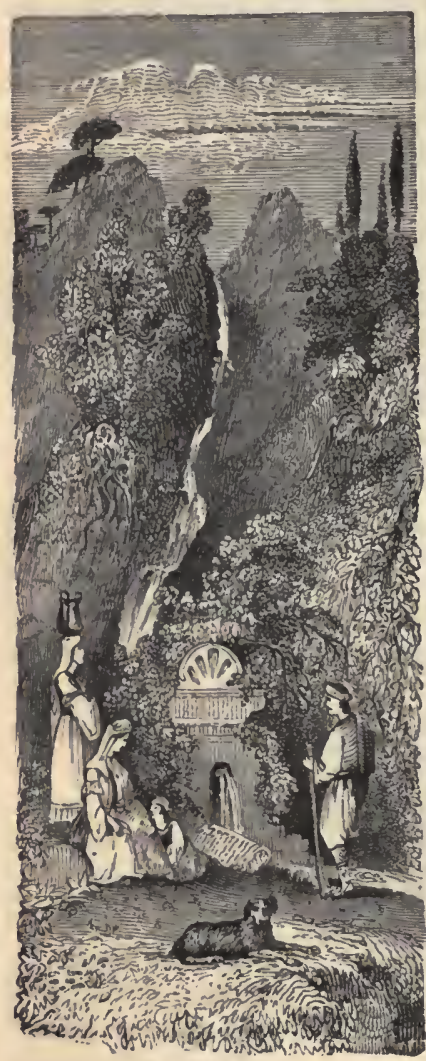

Castalian Spring. the statuary - these may seem, to the superficial observer, occupations barren alike of interest and profit, yielding only insipidity and toil to those who engage in them. But, in reality, they have relations which bring the inquirer into immediate contact with some of the grandest movements of Providence in this lower world: they may lead him, by a strict process of ratiocination, to results which will proclaim to his inward consciousness, that a wise and mighty Potentate "sits upon the circle of the earth," and that man, who is capable of "feeling after Him," is " of subtler essence than the trodden clod :" they may be so conducted as to minister to the repose of his mind upon Him whose workmanship is investigated, and impress it with those sentiments of humility and awe which are so beneficial in their influence, yet so soon effaced amid the bustle of this life's customary labours. It is assuming what remains to be proved, to say - that it is in the vagueness of mere curiosity, or in the vanity of human nature, that the geologist looks abroad upon terrestrial phenomena, recurring to periods in the past far removed from the present era, and to events which appear to have no direct bearing upon our existing condition and wants. He is a part of the vast scheme of being which he seeks to explore. He indulges intellectual appetencies, which have been given him by the Father of spirits: he takes tho faculty to observe, admire, and partially comprehend, into a fleld furnished with impressive evidences of Divine power, intelligence, and goodness; and the spectacle presented to his attention is a sublime one, and has its lessons of religious faith and practice to teach. The rudest stocks and stones that peep out of the greensward with which the soil is covered-the remains of organic life that have been buried from the light of heaven for countless ages, form the colossal megatherium to the microscopic infusoria - from delicate mosses to stately coniferæ - bear witness to a Creator, and to animal and vegetable tribes witl marvellous 
organisations, flourishing upon the earth beforc the present races appeared, the monuments of His skill; and while $\mathrm{He}$ is to be praised, for enabling man, with limited capacities, and inhabiting a spot so comparatively small, to acquaint himself with forms that have been blotted from the book of life, it is man's obvious duty, and as much to his advantage, to contemplate these works of His hands, and demonstrations of His attributes.

The acquirement of correct views respecting the condition of the crust of the earth, and the fluctuations it has undergone, is of very recent date; though several of the ancient Greek and Roman writers possessed no inconsiderable amount of geological knowledge. Strabo discussed the question of the occurrence of marine shells at a distance from the shore, and at great elcvations, and offered the theory of an upheaving cause in explanation, substantially the same as that adopted in modern times. The following passage from the philosophical geographer, written more than two thousand years ago, expresses the identical proposition which forms the basis of Sir C. Lyell's introductory volume on the Principles of Geology: "It is proper," he observed, "to derive our explanations from things which are obvious, and in some measure of daily occurrence, such as deluges, earthquakes, volcanic eruptions, and sudden swellings of the land beneath the sea; for the last raise up the sea also; and when the same lands subside again, they occasion the sea to be let down. It is not merely th:e small, but the large islands, and not merely the islands, but the continents, which can be lifted up, together with the sea; and both large and small tracts may subside, - for habitations, and cities, like Bure, Bizona, and many others, have been engulfed by earthquakes." In Lucretius, we have a description of monstrous quadrupeds, recognised as existing previous to man and the present race of animals, which might almost warrant the belief that some fossil gigantic skeleton had met his eye :-

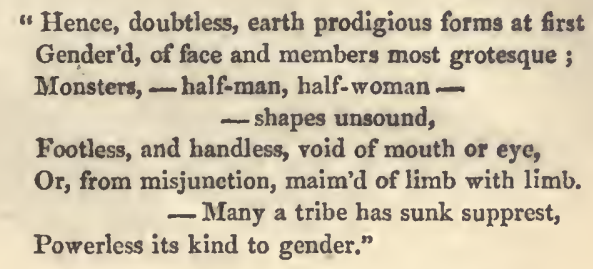

In the fifteenth book of the "Metamorphoses" of Ovid, the poet, when detailing the Pythagorean doctrines, adduces a series of examples of that process of change, attributed by the philosopher of Samos to nature, which sufficiently separate him from the class of speculatists, and entitle him to rank with physical inquirers. The chief instances of variation enumerated are -

The conversion of the sea into dry land, and the dry land into sea.

The occurrence of marine shells at a distance from the shores, and of anchors fixed on the summits of the hills.

The reduction of hills to plains, and the scooping out of valleys in the plains by the action of floods, with the transportation of their detritus to the sea.

The change of bogs into solid ground, and the formation of stagnant pools in dry places.

The opening of springs, and the damming up of rivers, as the effect of earthquakes, compelling them to pursue a new course; of which last phenomenon, the Erasimus in Greece, the Lycus and Mysus in Asia Minor, are the given instances.

The conversion of the waters of certain rivers from sweet to brackish, as those of Anigris and Hypanis.

The increase of continents, by the junction of islands, through the growth of deltas and 
deposition from the sea, as in the ease of Pharos joined to Egypt, and Tyre to Syria, with the analogous instance of Antissa to Lesbos.

The formation of islands, by the ocean eutting its way through peninsulas, as Leucadia and Sicily, the latter recognised by tradition as Laving once been a portion of Italy.

The subsidenee of land during earthquakes, letting in the sea, or gradually forming lakes, submerging the cities that once oceupied those sites, as Buris and Helice in Greece.

The upheaving of plains, and the dirersions of level ground into mountains, as at Trozene in the Peloponnesus.

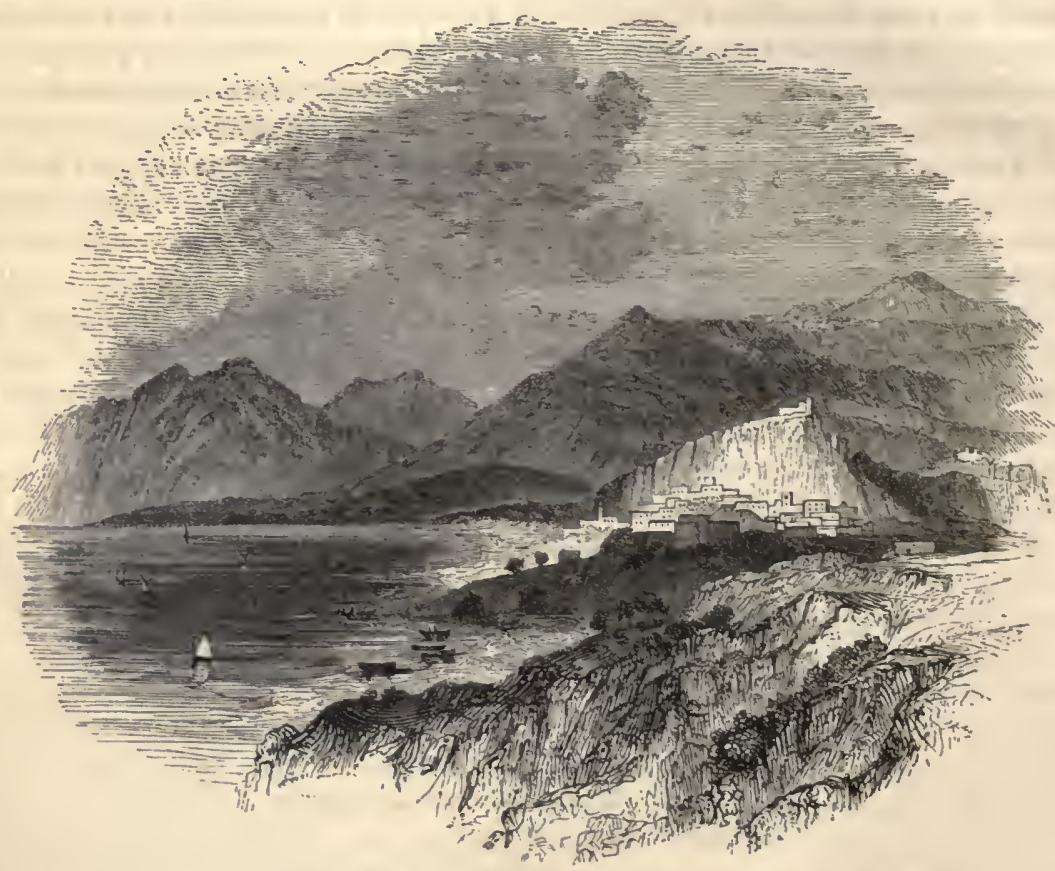

Limestone Mountains on the Coast of Arcadia.

The displacement and limited duration of volcanic vents. "There was a time," says Ovid, as the exponent of Pythagoras, "when Etna was not a burning mountain; and a time will arrire when it will cease to burn."

It must be acknowledged that the philosopher who noted such events as these, had acquired just views of the physical mutations to which our globe is subject, and of the complicated powers that operate in varying its condition. The path marked out in bygone days has been ably followed by Sir C. Lyell ; and it scarcely admits of a doubt, that all geological phenomena are the effects of physical forces now in action, however questionable his general proposition respecting the perfect equality of their intensity in ancient and in modern times. The changes wrought by these natural agencies in the sweep of ages, acting with varying vigour, - of which any one who has eyes, and will use them, may see the evidence,- - were never better illustrated than by an Arab fable, beautiful for its simplicity, and striking for its trutl. It occurs in a manuscript of the thirteenth century, in the following narrative from an allegorical personage:-

"I passed one day by a very ancient and populous city, and I asked one of its inhabitants how long it had been founded? 'It is indeed a mighty city', replied he ; 'we 
know not how long it has existed; and our ancestors were on this subject as ignorant as ourselves.' Some centuries afterwards, as I passed by the same place, I could not perceive the slightest vestige of the city. I demanded of a peasant, who was gathering herbs upon its former site, how long it had been destroyed? 'In sooth, a strange question,' replied he; 'the ground here has never been different from what you now behold it.' 'Was there not,' said I, 'of old, a splendid city here ?' 'Never,' answered he, 'so far as we know ; and never did our fathers speak to us of any such.'

"On my return there again, after the lapse of other centuries, $I$ found the sea in the same place, and on its shores were a party of fishermen, of whom I inquired how long the land had been covered by the waters? 'Is this a question,' said they, ' for a man like you? 'This spot has always been what it is now.'

"I again returned ages afterward, and the sea had disappeared. I inquired of a man who stood alone upon the ground, how long ago the change had taken place? and he gave me the same answer that $I$ had received before.

"Lastly, on coming back again, after an equal lapse of time, I found there a flourishing city, more populous and more rich in buildings than the city $I$ had seen the first time; and when I would fain have informed myself regarding its origin, the inhabitants answered me, - 'Its rise is lost in remote antiquity ; we are ignorant how long it has existed; and our fathers were on this subject no wiser than ourselves."

With the exception of this myth, which presents us with a graphic picture of the physical history of the earth, there is nothing of interest, in a geological point of view, in the interval between the loss of the ancient civilisation, and the dawn of true inductive science. Dreamers resolved fossil shells and fishes into lusus nature, and attributed them to "a plastic virtue latent in the earth," or to "the tumultuous movements of terrestrial exhalations," or to the influence of the heavenly bodies. Scott, in his "Marmion," refers to a legend once prevalent in the neighbourhood of Whitby, that the ammonite shells, which are common in that vicinity, had formerly been snakes, which the foundress of the abbey, St. Hilda, succeeded in decapitating by her prayers, and then converting into stone :-

\footnotetext{
" And how the nuns of Whitby told, How of countless snakes, each one Was changed into a coil of stoneWhen holy Hilda pray'd. Themselves within their sacred bound Their stony folds had often found."
}

It was not until the end of the seventeenth century that the animal origin of fossil remains was generally admitted; and the eighteenth was drawing to its close before an extended and enlightened prosecution of geological pursuits commenced. No individual contributed more to enlist rotaries in this service than Werner did, by the charm of his eloquence, however unfortunate in the theory he advanced, which referred the formation of all rocks to chemical precipitation from water. Abraham Gottlob Werner was born in the year 1750, at Welslau on the Queiss, in Upper Lausitz, where his father had the superintendence of a foundery. He gave the child minerals for playthings, who thus became acquainted with their names and characters in his tender years, and imbibed that love for mineralogy which distinguished his advanced life. Appointed, in his twenty-fifth year, professor of that science in the School of Mines at Freiberg, and subsequently Chancellor of the mines of Saxony, he deroted himself to mineralogy, and to advance views of the structure of the earth; soon attracting round him, by his captivating mode of lecturing, a number of admiring students, among whom the names of Alexander Humboldt, Von Bûch, D'Aubuisson, Jameson, Englehart, and Emmerling occur. It was maintained, in the Wernerian system, that volcanic action is of recent date, and was inoperative in the early 
history of the globe; that all rocks - basaltic, trap, and granite - as well as the secondary and tertiary beds - had been produced by a series of depositions formed in succession from water; and hence the followers of Werner took the name of Neptunists, in the controversy which ensued with the disciples of Hutton, who were called Vulcanists, as the adrocates of igneous action. Werner proceeded to generalise upon few and insufficient data, taking Saxony as a miniature picture of the earth; though even here many appearances were overlooked or misinterpreted. 'The fallacy of his doctrine respecting the aqueous origin of all rocks is now universally admitted; but the faults of his system should not blind us to the merits of the man, who was one of the first to recognise the existence of natural groups of strata in a certain order of superposition, and who succeeded in enthusiastically attaching some of the finest minds of the day to geological inquiry -in several instances, to aid in overthrowing the theory of the teacher.

A contemporary of the Freiberg professor, in Scotland - Dr. James Hutton - proposed views concerning the formation of the mineral masses, founded upon the phenomena of universal nature, which, though little appreciated in his lifetime, at last completely exploded the theory of the Neptunists, and now rank among well-established geological doctrines. The object of Hutton was not to explain the origin of things, but to elucidate their existing state, by the agency of known causes. The following propositions are the leading features of his system:-

1. That a great portion of the crust of the globe is formed out of more ancient mate. rials; that all the stratified rocks consist of the remains of other strata, more ancient than themselves.

2. That the greater part of the present continents, having once existed in a sedimentary state at the bottom of the sea, must have been consolidated by some powerful agent; that this agent is subterraneous heat, which is freed from the objections urged against it, by the principle of compression restraining the volatility of many substances, which cannot exist upon the surface except in the form of gas, and compelling them to remain in combinations impossible under the pressure of the atmosphere alone.

3. That the stratified rocks, instead of having a horizontal position, being actually inclined at various angles, or even vertical, - being inflected, broken, and the portions often detached from each other, beds of the same character occurring at various elevations, and sometimes at the greatest heights above the sea, - they have been raised, therefore, by some expansive force acting from beneath, which approximates closely to the cause of the volcano and the earthquake: this force is heat.

4. That veins, whether metalliferous or composed of stony substances, are of posterior formation to the strata which they intersect; that their materials have generally been melted, and ejected from below; and that this condition extends to the masses of whinstone, granite, and other unstratified rocks, which are sometimes interposed among the sedimentary strata, and which have been forced up through or injected among them, heat being the cause of the propulsion. Hutton appears to have arrived at these views by a course of independent investigation, though anticipated in a few points by some Italian writers; and all modern observation has tended, while slightly modifying his principles, to confirm and extend them in the main. There are no geologists of note who do not agree in the following doctrines: that the granitic, trappean, and basaltic masses are the result of simple fusion; that the rocks of igneous origin have been violently injected among the stratified deposits, by an upheaving force, elevating and indurating them, at various epochs; and that this mighty power from within, is the expanding property of internal heat, whatever be its nature or its cause.

The igneous theory, during the life of its author, and for some years after his death, encountered general neglect, and, from various quarters, virulent opposition. Some 
unguarded expressions alarmed the religious world; and the odium of infidelity becoming attached to his name, the current of public opinion set in strongly against his views. On the other hand, Werner had obtained the adherence of the scientific, by his zeal and eloquence; and his system being supposed to be valuable evidence in favour of the diluvian catastrophe in the sacred records, it received the homage of the public mind. The continental geologists especially were steady Wernerians long after the doctrines of Hutton had become the established faith of the English philosophers. Cuvier, in his éloge of De Saussure, read in the year 1810, remarked, that "he overthrew the doctrine of central fire - of a source of heat placed in the interior of the globe," and continued to the last " a believer in the aqueous origin of granite." Eight years afterwards, in 1818, in pronouncing his éloge of Desmarest, Cuvier speaks of a "new sect, to which the name of Plutonians had been assigned, because they went so far as to attribute to the action of fire, rocks, even the most universally expanded over the surface of the globe, and which no person till then had cver dreamed of withdrawing from the domain of water!" Again, in the same éloge, alluding to Von Bûch's researches in Auvergne, Cuvier observes, with surprise: "In his enthusiasm, from having been a zealous Neptunian, he became almost Plutonian. It is not basalt alone that he ascribes to volcanic action: porphyry itself, which forms a protuberance of more than sixteen leagues in diameter, of which Mont D'Or is the centre, has been, if not thrown out, uplifted by volcanic power!" It is evident, that down to the period referred to, the illustrious Frenchman was a disciple of the Werncrian school; and this was the case also with most of the continental physical inquirers, when the igneous theory, having emerged from obscurity in England, had conquered opposition, and won the assent of Jameson, Macculloch, Buckland, and Conybeare.

In a sketch of the progress of knowledge relative to the economy of the underlying masses which observation can reach, it is impossible to omit the name of William Smith, - commonly, and justly, called the father of English geology, - who, without the furniture of high education, or the advantages of wealth and patronage, conducted a series of laborious examinations of the stratified formations, chiefly in the midland and southern counties of his native country, and arrived at the discovery of a fact, which Sedgwick has styled "the master-principle of our science." Commencing his career as a humble surveyor, his mind soon became impressed with a deep conviction of the regular succession and continuity of strata; and by a minute analysis of them, he grasped the truth, that the organic remains of animal and vegetable life in the earth were definitely distributed. By a course of patient investigation, he reached the sublime conclusion, that each stratum, wherever it occurred, in detached masses, and in distant localities, presented its own peculiar species of fossils, and might be identified by this characteristic mark; so that, exhibiting a particular fossil, it might instantly be declared from what rock, and even bed of stone or clay, the specimen had been derived. The important doctrine was thus established, that there had been a systematic succession of life in the ancient earth ; that, during the formation of its stratified crust, different races of animals and plants had appeared and vanished; each stratified rock being thus a kind of museum, preserving specimens of the organic life existing during the period of its deposition. The coming in of new organic forms, and the extinction of those that pre-existed on the earth, realises the sentiment expressed in a line of Ariosto, "Natura il fece, e poi ruppe la stampa," "Nature made it, and then broke the die." Besides developing this important doctrine, "Stratum Smith," as he was familiarly called, took the lead in constructing a geological map of England, which, though superseded by the labours of Mr. Greenough, was worthy of his name, and gave the hint for making those surveys, by the practical illustration of their advantages, which Macculloch, Von Bûch, and others followed in their respective 
countries. Of this work, D'Aubuisson observed, "that what many celcbrated mineralogists had only accomplished for a small part of Germany, during half a eentury, had been effected by a single individual for the whole of England." Upon the importance and interest of geological investigations becoming more extensively appreciated, societies were organised at home and abroad for the purpose of facilitating such inquiries, whose published transactions are monuments of the admirable energy and strict philosophical spirit with which the object has been pursued; nor is it too much to say, that no indiriduals, in any age of the world, have established a stronger claim to confidence than the members of the Geological Society of London by their personal labours, to arrive at a just knowledge of facts. It has been the grand maxim of that institute to multiply and record accurate observations, leaving theory in abeyance until sufficient materials for generalisation have been gathered; a principle which has been faithfully kept in view, and which has equally distinguished the researches of the leading geologists of the Continent.

To this department of science, many of the arts of life are indebted for their rapid advance in modern times; and its cultivation may justly be regarded as one of the elements of our social prosperity. An improved agriculture has resulted from the knowledge of the nature of soils, and of the due admixture of those ingredients - clay, flint, and limewhich constitute the most fertile and the least exhaustible land; while the operations of draining, and of conducting moisture to dry and friable soils, lias been facilitated by an acquaintance with the strata of districts, their disturbances, and lines of dislocation. 'The civil engineer, who has to construct a railroad or a canal, geology directs in the route to be pursued through those deposits which are workable at the least expense, or whose masonry and mineral contents will yield the best return to the promoters of the enterprise ; and, from the same source, the architect receives valuable aid in the selection of building materials. Oxford and Bath furnish many examples of crumbling edifices, of which also the Capitol at Washington is an instance, having been constructed of a stone that readily yields to the action of the atmosphere; and hence the British senate, in erecting new Houses of Parliament, referred the selection of the material to a commission of geologists, by whom one of the durable magnesian limestones was chosen. Some of the finest works of art have become disfigured or entirely ruined in the lapse of time, in consequence of the ignorant selection, by the sculptor, of stone liable to chip and decompose, or impregnated with the metallic oxides. But it is especially in the conduct of mining operations that geology has displayed its practical utility. A knowledge of the position occupied by the coal or ironstone strata, and of the rocks usually associated with them, has guided the capitalist to the spot where lie might engage in the search for these products with the least chance of disappointment ; and had the directions of science been sought in many instances, and followed, vast sums would have been saved to the community, that have been expended upon a useless quest. Deceived by appearances, or misled by designing individuals, coal has been sought by public companies at a great expenditure, in the wealden formation of Sussex, the oolites of Oxfordshire and Northamptonshire, and the silurians of Radnorshire; whereas an attention to the simplest principles of geology would have shown the folly of such schemes. Because Pennsylvania is rich in coal, it was imagined in the neighbouring state of New York that the precious gift might be found there also; and the resemblance of certain silurian rocks on the banks of the Hudson river to the bituminous shales of the true coal formation, appeared to sanction the surmise. Accordingly mining adventurers squandered away a large amount of capital in sinking shafts there, below the carboniferous series, until geology, at the invitation of the legislature, authoritatively declared the futility of such attempts.

Besides its economical value, geological science possesses a thrilling dramatic interest, which invests it with peculiar fascinations. It unfolds the successive conditions of the 
world at far distant epochs of time, and the various forms of organic life that were coincident with them, with the action of mighty forces that have repeatedly changed its surface, sweeping numerous tribes of plants and animals from the catalogue of the earth's inhabitants, and involving them in the oblivion of ages, till the discovery of their remains in the fossiliferous rocks. "We learn," says Sedgwick, "that the manifestations of God's power on the earth have not been limited to the few thousand years of man's existence. The geologist tells us, by the clearest interpretation of the phenomena which his labours have biought to light, that our globe has been subject to vast physical revolutions. He counts his time, not by celestial cycles, but by an index he has found in the solid framework of the globe itself. He sees a long succession of monuments, each of which may have required a thousand ages for its elaboration. He arranges them in chronological order, observes in them the marks of skill and wisdom, and finds within them the tombs of the ancient inhabitants of the earth. He finds strange and unlooked-for changes in the forms and fashions of organic life, during each of the long periods he thus contemplates. He traces these changes backwards, through each successive era, till he reaches a time when the monuments lose all symmetry, and the types of organic life are no longer seen. He has then entered on the dark age of Nature's history ; and he closes the old chapter of her records." These are revelations calculated to stimulate intellectual action, and to apply a wholesome discipline to the mind, while expanding it by an obvious moral lesson. However the phenomena in detail may be interpreted, there can be no question about the general explanation; and clear enough is the fact, that through the revolution of centuries mankind were completely in the dark respecting both the mechanism of the heavens and the economy of the earth. Even now, though the threshold of the temple of knowledge has been passed, how little can man explain the realities that hare dawned upon his apprehension! Both facts give an impressive rebuke to human intolerance and pride; and especially teach us to aroid an air of censoriousness towards those who differ from us in judgment, because of the manifest fallibility of the nature which we inherit.

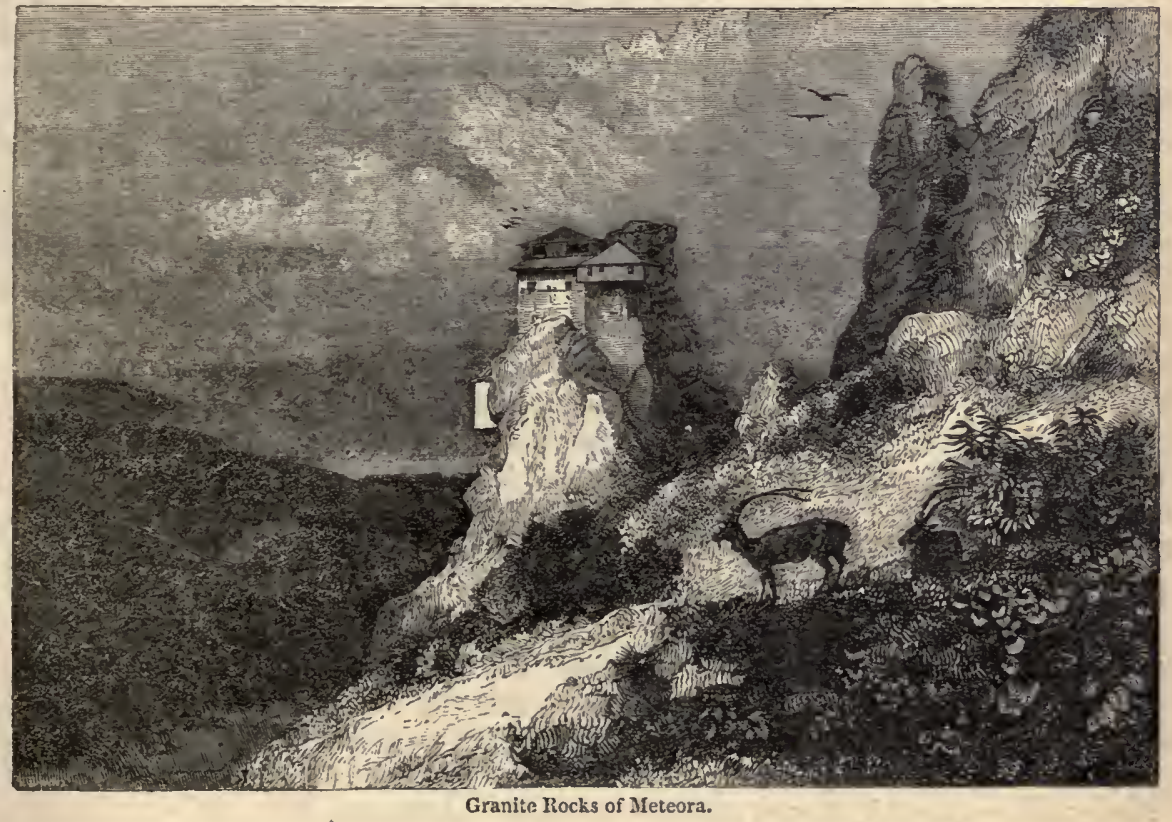




\section{CHAP'TER I.}

THE STRUCTURE AND CLASSIFICATION OF ROCKS.

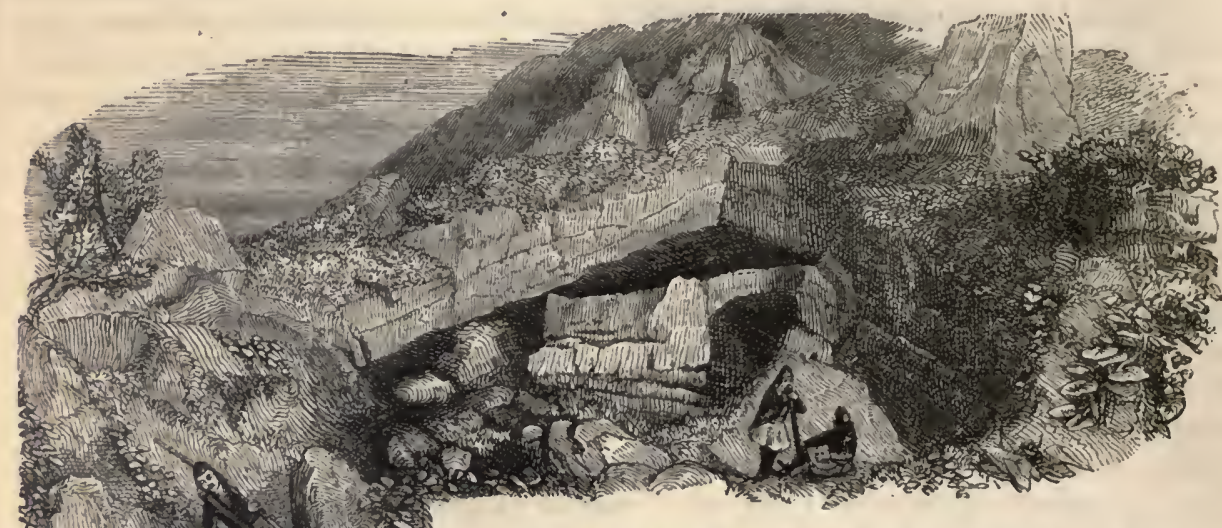

N popular language, the word rock instantly suggests the idea of a huge, compact, and hard substance. This is not the geological signification of the term. It is applied to every kind of formation which constitutes the erust of the globe, from the loose sand and gravel of our pathway, and the soft clays that lic beneatl the surface soil, to the elose-grained, heavy, and majestic masses of granite that form the highest Alps, or of porphyry that crown the summits of the Andes. These materials, so various in texture and diverse in form, are found upon analysis to be compounded of a very few elementary substanees. Chemistry, which, like all science, takes us back from the most complex results to the most simple causes, has been brought sufficiently to bear upon the matter of the globe to show, that but a scanty number of elements enter into its composition. Simplieity in the causation, and amplitude in the result, is one of the laws of the all-potent Creator, which may well exeite our admiration. It meets us in every department of nature, and is very strikingly developed by chemical analysis of the ponderous mass upon which we tread, and the magnificent elevations whose tops are screened from our notice by the elouds of heaven; for nearly the whole of the matter yet known to enter into the composition of our terrestrial sphcroid - the phenomena of every mountain that rises, and every valley that sweeps-every forest that waves and cvery occan that roars - may be referred to about sixteen simple substances variously combined. The difference between the simple and compound state of these elements is often most remarkable. It is a curious result of chemical science, that while oxygen and nitrogen compose the principal part of the atmosphere, and oxygen and hydrogen constitute water, a largely diffused fluid, - oxygen, whieh is a light and invisible gas in its simple state, enters largely into combination with the earths and metals, and is supposed to compose fully one balf of the solid contents of the globe. The number of simple substances, or those out of which nothing different from themselves can bo obtained, amounted in the year 1787 to seventeen, in 1802 to twentyeight; but the number at present known amounts to upwards of sixty. They are:

Five gases-oxygen, hydrogen, nitrogen, chlorine, and fluorine. 
Eight non-metallic liquids and solids-sulphur, phosphorus, selenium, iodine, bromine, boron, carbon, and silicon.

Three metallic bases of the alkalies-potassium, sodium, and lithium.

Four metallic bases of the alkaline earths - barium, strontium, calcium, and magnesium.

Five metallic bases of the earths - aluminium, yttrium, glucinum, thorium, and zirconium.

Thirty metals, whose combinations with oxygen produce neither alkalies nor earths, and which are all solid but mercury-manganese, zinc, iron, tin, cadmium, arsenic, antimony; copper, molybdenum, chromium, tungstenum, uranium, columbium, nickel, cobalt, ceranium, titanium, bismuth, tellurium, lead, mercury, silver, gold, platinum, palladium, rhodium, osmium, iridium, vanadium, ruthenium, with eight others obscurely known.

The most important of these elementary substances, on account of their prevalence in the constitution of the globe, are-oxygen, carbon, sulphur, aluminium, silicon, potassium, sodium, calcium, magnesium, and iron, a specific description of which may be found in any chemical treatise. 'The preceding ingredients, either singly or combined, compose the simple minerals, differing from each other in shape, colour, lustre, and hardness; and all rocks are either mineral aggregations, or formations of only one mineral. The leading mineral substances of which rocks are composed are the following:-

Quartz, or siliceous earth. This is one of the hardest and most abundant substances in nature. It forms independent mountainous masses; occurs in veins intersecting mountains; is a constituent part of flint, chalcedony, rock-crystal, sandstone, and granite ; and is found in some regetable productions, as the stalks of reeds, and the outer coating of the bamboo, which will strike fire with steel. The white crystals of granite, and the white grains of sandstone, are of quartz.

Felspar, a compound of siliceous and clay earths, with a portion of potassia, lime, and oxide of iron, is also an abundant mineral, but less hard than quartz. The soft gray crystals of granite, which can easily be scratched, are of felspar. It is sometimes white, cream coloured, or red, passing through various shades, according to the quantity of the oxide of iron. Containing a large proportion of aluminum or clay earth; felspar is employed in the manufacture of pottery ware, Cornwall furnishing the principal part of that used in England. The Pentland Hills are almost entirely composed of it ; but it is there too much tinged with the metallic oxide to be serviceable in the arts.

Mica, a term derived from the Latin micans, glittering, is a compound of alumina, silica, magnesia, and oxide of iron, and is so called from its lustrous appearance. The transparent portions of granite are of mica, and it occurs in many sandstones, giving them a silvery aspect.

Talc, a substance closely resembling mica, is distinguishable from it by being softer and more brittle and inflexible.

Chlorite, nearly allied to talc, differs from it in colour, deriving its name from the Greek chloros, green. In the composition of many of the Alpine granite rocks, talc and chlorite take the place of mica.

Hornblende, a combination of silica, alumina, magnesia, lime, oxide of iron, and manganese, is of a deep green colour, and sometimes black. It is a prevalent ingredient in many igneous masses, occurring in beds, veins, and granular pieces in compound rocks, and forming entire mountains, the trap rocks consisting of it. Of a similar composition are the greenish minerals augite and actynolite. Serpentine contains the same ingredients as hornblende, but in different proportions, having more magnesia and less iron. It derives its name from its spotted colours, resembling those of the serpent's skin.

Carbonate of lime, the constituents of which are lime and carbonic acid, enters largely 
into the composition of aninal bodies, forming the solid parts of the bones and teeth, and the shells of many molluses. It enters also into the composition of regetables, is diffiused in the ocean in the form of muriate of lime, forms marble, chalk, and limestone, of various degrees of lardness, and is supposed to constitute one seventh of the crust of the globe. It exists in great purity in calcareous spar, and in the Carrara marble used in statuary; but limestone often occurs intermixed with other ingredients, as magnesia, alumina, silica, or iron.

Iron, in some combination, as an oxide, sulphuret, or carburet, occurs abundantly, and is supposed to constitute at least three per cent. of all known rocks. Rust is an oxide of iron; pyrites, or the small yellow cubes found in roofing slate, a sulphuret; and graphite, a carburet, also known under the names of plumbago and black lead, is found in great purity in Borrowdale in Cumberland.

These are the simple minerals which form the great mass of rocks, though others compose large independent beds, or occur extensively in connection with those enumerated, modifying the character of their respective structures; as sulphate of lime, or gypsum, the plaster-stone of commerce ; chloride of sodium, or common salt, found in sea-water, and in masses constituting rock-salt ; bitumen, found liquid in petroleum or rock-oil, solid in asphalte, and mixed in common coal; garnet, schorl, and steatite. Rocks are eitlier simple, formed by a single mineral, or compound, several uniting in their composition,-in general from two to four. 'Thus quartz, limestone, and common salt exist by themselves in large masses; while granite is a compound of the crystals of quartz, felspar, and mica. Some rocks appear simple, which are in reality compounds, owing to the different materials of which they consist having been so much ground down, previous to consolidation, as to make the formation appear homogeneous, as in several varieties of shale and slate. Among the compound rocks, the granitic have their grains or crystals united together without a cement; in the porphyritic, distinct crystalline masses, of a different composition from the base of the rock, are imbedded in it, as in a kind of paste; in the amygdaloidal, there are round or kernel-shaped cavities, filled with mineral matter, distinct from that which forms the basis. Angular fragments of rock, of the same or different kinds, cemented together by iron or carbonate of lime, infiltrated through the mass in a state of solution, constitute a breccia; and large fragments of stone, whether angular or rounded, imbedded in strata of hardened clay or sand, form a conglomerate.

From the composition of rocks, which includes their chemical and mineral character, we proceed to notice their mechanical structure, or the internal and external appearances which they present.

The Internal Structure of rocks refers to the manner in which the constituents of each particular species are arranged, the leading varieties of which are the granular, the fibrous, the porous, and the laminar. The texture of the granular exlibits distinct grains of different sizes, as granite, which frequently assume a regular and well-defined crystalline form, the several crystals being confusedly mixed and compacted together, at all points interfering with each other, exhibiting the appearance of a simultaneous formation. The fibrous texture is a compost of long and minute fibres, as in asbestos, which is called acicular when the fibres have a distinct needle-shaped appearance. Pumice-stone is an example of the porous texture, being penetrated by pores, which is styled cellular, or vesicular, when the pores swell into rounded cavities resembling cells or vesicles. The laminar texture - also called slaty, fissile, and schistose-is an arrangement of the substance of rocks in thin plates or divisions. It appears in gneiss, felspar, and mica-schist. Mica is readily split into thin, flexible, and transparent plates, which before the general introduction of glass were frequently used to form window-panes, and 
are said to be so used at present in some remote parts of Russia. These laminæ, however, often give an appearance of fissility to a rock which is deceptive, the layers separating with great difficulty. Though in general parallel to the greater lines of stratification, the lamination is frequently inclined and wavy. Fig. 1 shows several varietics. Occasionally the lamination is highly undulating, tortuous, and angular. Fig. 2 is an instance of rery contorted lamination, from a loose block of gneiss, two or three fect thick, in Colebrook in

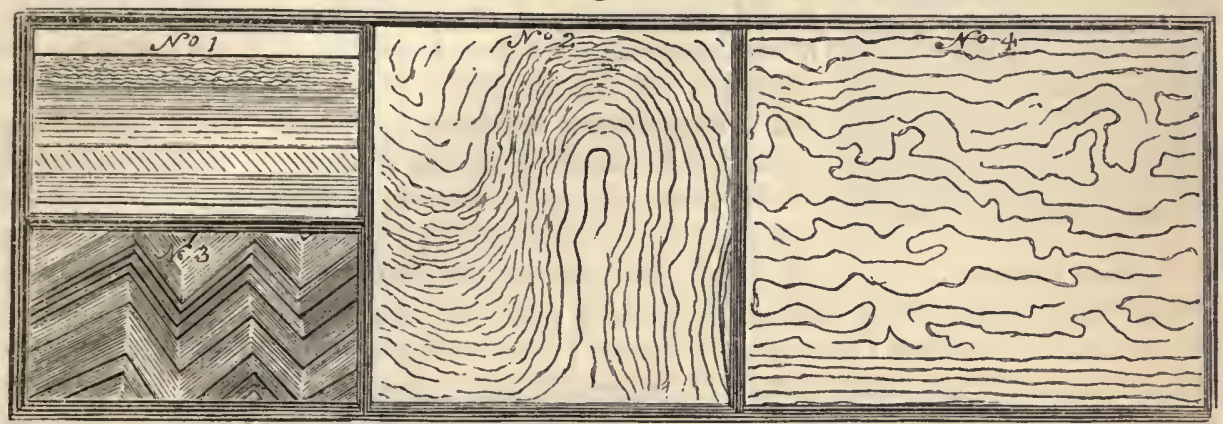

Connecticut. Fig. 3 is a specinen of zigzag or angular lamination, from the coal. In a bed of diluvial clay, in Deerfield in Massachusetts, disturbed layers of clay appear intervening between others, which are horizontal and undisturbed, as in Fig. 4. 'The disturbed lamina here must have received their flexure subsequent to deposition by some operation acting upon them alone. The laminar structure is almost entirely confined to rocks which have been originally produced by deposition in water, and its varieties are the result of the different circumstances under which deposition has taken place, together with pressure acting upon the mass while yet in a plastic statc. Thus the horizontal parallel lamina result from quiet deposition in still waters upon a level surface. The waved laminæ bear witness to deposition in shallow water, and show what is commonly called the ripple-mark, which we may every day observe upon our own shores, for, when the tide has ebbed, there is the impression of its retreating ripples on the sand. The inclined lamina may have been caused by deposition on a variously inclined shore: and the highly contorted and zigzag laminations have probably resulted from lateral or vertical pressure operating after deposition, before the strata had become indurated. It will be seen that the laminar structure of a stratum bears the same relation to it, as its own stratification does to a whole series of beds.

The extcrnal structure of rocks may be conveniently considered under the two grand classes, of the stratified and unstratified, which include every kind of formation. The unstratified rocks are those of igneous origin, as granite, porphyry, and serpentine, which show no

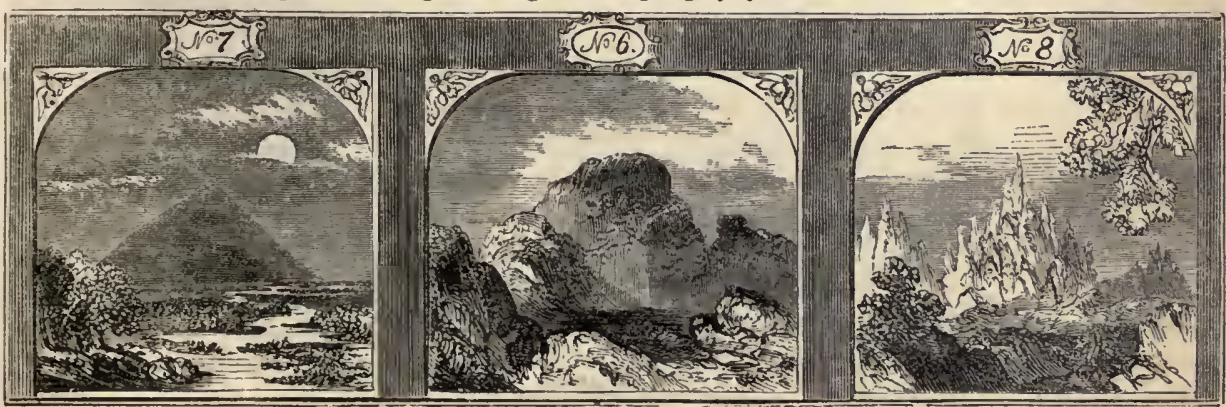

regular divisional structure resembling a series of beds, but occur in enormous masses, only broken by irregular fissures in different directions. Their aspect to the eye is variously 
globular, pointed, or indeterminate, as in figs. $6,7,8$. The appearanee of stratification is sometimes presented, but the deception is readily detected, not only by the nature of the rock, but by the lines which seem to indicate it, running into each other, and extending only short distances, as in fig. 9. But the phrase, indeterminate structure, cannot in the

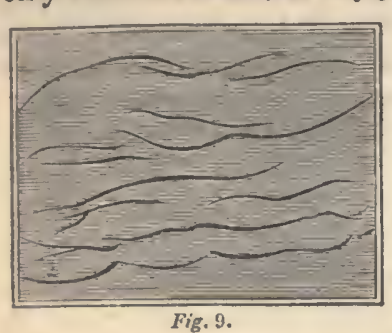
strictest sense be applied to several igneous rocks, which, without stratification, assume beautiful and distinct forms, caused by the particular eircumstances under which they were produced. The most important of these forms is tho columnar, a structure which particularly characterises basalt, and is occasionally exhibited by porphyry and greenstone. Masses of basalt, divided into columns or prisms, occur at Staffa, at the Giants' Causeway in Ireland, and in various volcanic districts, which have more the appearance of works of art than of nature, and constitute some of the most striking scenery of the globe. The columns have three, four, five, six, and eight sides, but are commonly pentagonal, and are so closely compacted together, that though perfectly separable, there is no perceptible space between them. Figs. 10 and 11 represent these ranges, vertical and inclined. $\Lambda$

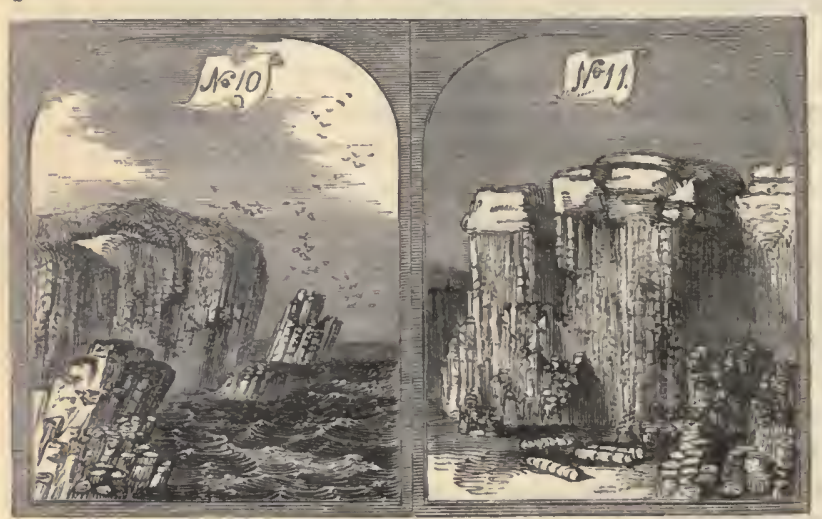
remarkably fine example of columnar basalt occurs upon the banks of the little river Volant in France, a view of which is given. Sometimes the basaltic columns are not continuous, but consist of a number of short pieces placed upon one another. In North America, the columnar arrangement is very commonly assumed by greenstone, the rock which forms the Salisbury Crags, near Edinburgl. A spot on Mount Holyoke in Massachusetts, which has been called 'Titan's Piazza, exhibits a group of greenstone columns, which hang over the observer's head, the pro-

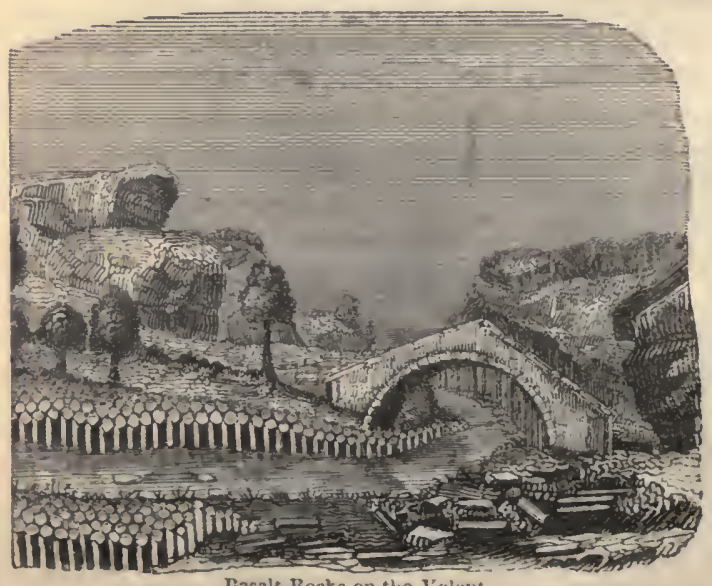

Casalt Rocks on the Volant.

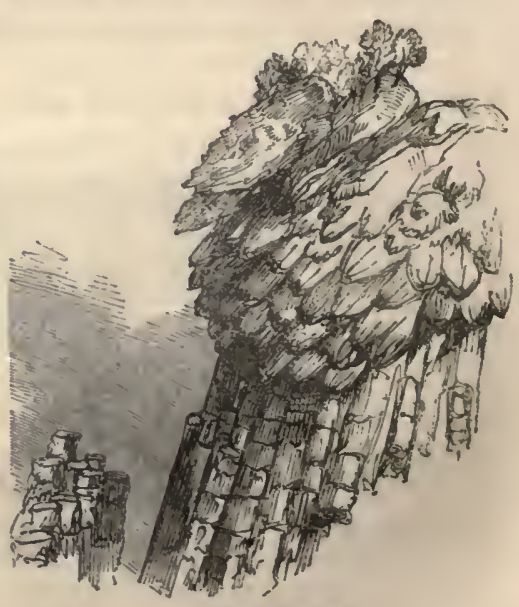

Titau's l'iazza. 
jecting ends being exfoliated in such a manner as to present a convex surface downwards. The Palisadoes, on the banks of the river Hudson, are another example; but the most extensive formations of this kind, perhaps, upon the face of the globe, which appear to throw our Giants' Causeway into insignificance, are in the country west of the Rocky Mountains. There the Columbia river passes through mountains of the trap family, not improbably basalt, which range from 400 to 1000 feet high, the walls consisting of successive rows of columns, superimposed upon one another, separated by a few feet of amygdaloid, conglomerate, or breccia. In Wales, the columnar structure is developed in the porphyritic trap on the northern side of Cader Idris; and in England, though obscurely, in some of the basaltic hills near Dudley. 'This peculiar construction, which distinguishes rocks of the trap family, is supposed to result from a kind of crystallisation while they were cooling down under pressure from a melted state. Mr. Gregory Watt fused seven hundred pounds weight of the Dudley basalt, and caused it to cool slowly, when globular masses were formed, which enlarged and pressed against each other until regular columns were the result. Recent lavas exhibit precisely similar columns.

'The stratifled rocks, which are all of aqueous origin, show a regular divisional structure of layers or beds, to which the Latin word strata is applied, and which have resulted from successive sedimentary processes at the bottom of lakes and seas. They vary in thickness from that of paper to many yards, and are sometimes divided by a thin layer of soft earthy matter, called a scam; but at other times, the surfaces of the upper and lower stratum are so closely joined, that it requires a considerable force to separate them. If the depositions which constitute this class of rocks went on always in quiet waters, and if there were no disturbing forces in operation, the position of strata would be uniformly horizontal; but these two conditions have not existed, and consequently the strata are generally found to dip down to some point of the horizon, and of course to rise towards the opposite point. A line drawn through these two points is called the line of their dip; and another line, drawn at right angles to this, marks Fig. 16.

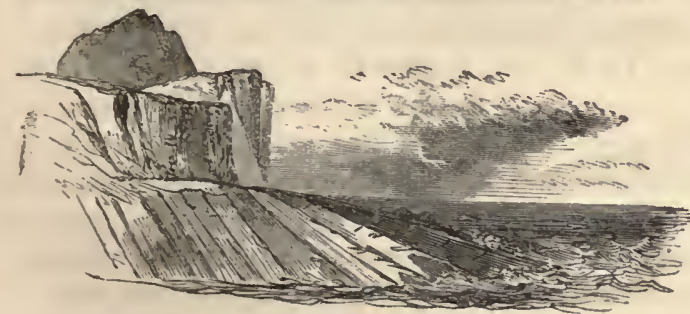

the course along which the strata stretch out to the greatest extent, which is the line of their bearing. Figs. 16 and 17 are examples of horizontal and inclined stratification, showing that an elevating cause has acted upon the latter subsequent to deposition, to which the former has Inclined Stratification. not been subject. With such intensity has this elevating power operated in some instances, as to lift the strata into a ver-

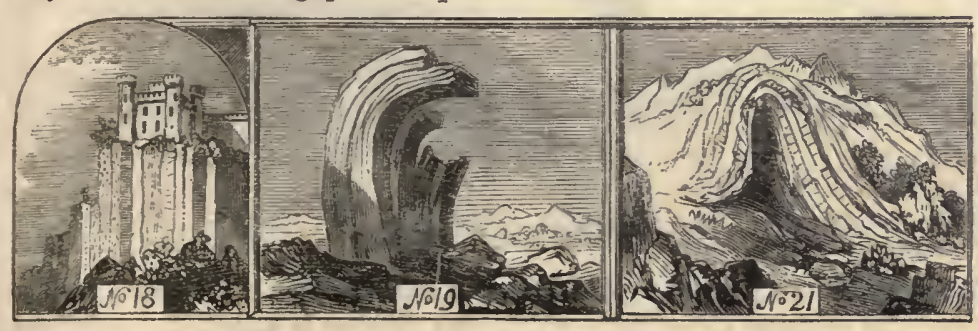
tical position. An interesting example of this arrangement is given in $f g .18$ by Sir $\mathrm{R}$. Murchison from the rock on which Powis Castle is built. The strata, consisting of calcareous red grit, highly charged with portions of encrinital stems, are vertical, or highly inclined at angles of $70^{\circ}$ or $80^{\circ}$ to the horizon, and appear like massive buttresses erected for the purpose of supporting the noble structure placed upon them, 
and continuations of it. Curved, arched, and contorted stratifications liave resulted from the action of the same upheaving cause. Fig. 19 represents an instance of curred strata, as delineated by Dr. Maceulloch, occurring in gneiss, at Oreby in the Isle of Lewis, one of the western islands of Scotland. Of the arched form of strata, there are striking examples at Crich-cliff in Derbyshire, at Alum Bay in the Isle of Wight, and in the

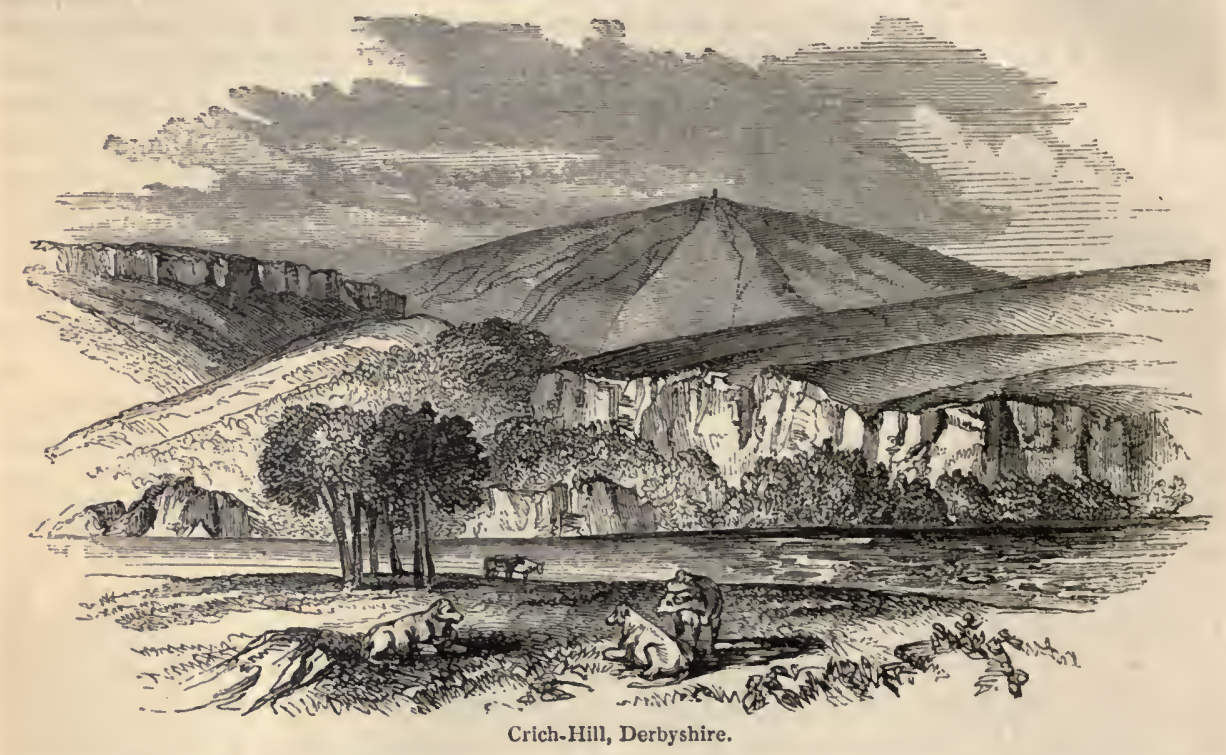

Malvern Hills. Fig. 21 exhibits the appearance of contorted strata, as remarked by Murchison on the banks of the Wye. The stratification is said to be unconformable, or discordant, when the planes of the strata in different formations are not parallel to one another, which is usually the case. In fig. 22 horizontal strata appear divided

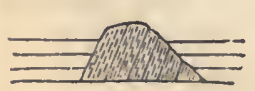

Fig. 22.

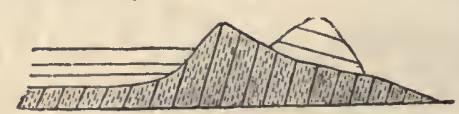

Fig. 23.

by the inclined, which latter were plainly elevated before the deposition of the former. This is likewise shown in fig. 23, where, upon a base of liiglily inclined strata, horizontal beds rest, and a series inclined in a different direction. When strata dip in opposite directions, as at $a$ in fig. 24, they are said to

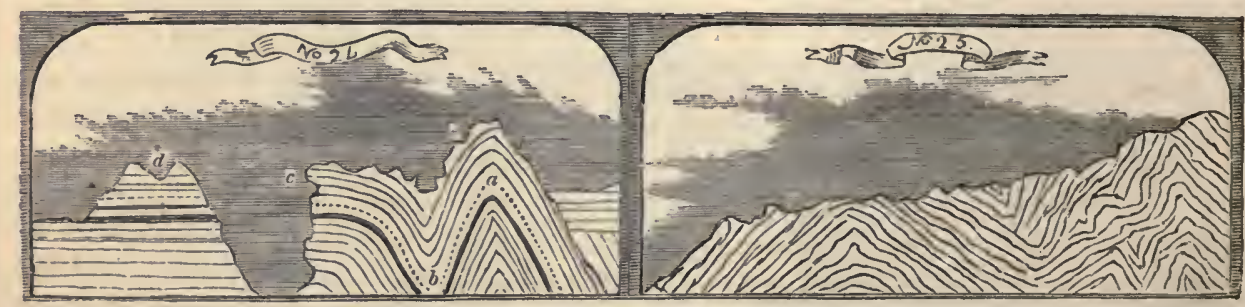

form a saddle-back, or anticline; a word derived from the Greek anti, on oppositc sides, and clino, $\mathrm{I}$ bend; and the common ridge from which they diverge is called the anticlinal axis. The hollow formed at $b$ is termed a trough or basin; the abrupt termination of a series at $c$ is designated an escarpment, bluff, or headland; a series separated from the main beds to which they belong, as at $d$, are outliers; and where a stratum exposes itself 
and terminates at the surface, it is said, in the language of miners, to crop out. Sometimes several of the diversities in the structure of strata noticed, appear associated together, as in fig. 25, an appearance very common in the slate rocks on the north coast of Devon. It is obvious that the disturbances which have originated these constructions, have rendered an essential service to mankind, hare largely opened the surface of the earth to their knowledge, and brought the mineral riches of different strata, which lic low in the series, within reach; for had they remained in an undisturbed horizontal position, piled one upon another, man could never have penetrated to those which are most important to the arts of life, and would for ever have been ignorant of their existence.

The operation of an elerating cause, to which various stratified formations have been subject, has frequently interrupted their continuity, produced cracks and fissures, filled with fragments of rocks from above, or with igneous injections from below, extending in breadth from a few inches to twenty or thirty feet, and even yards. These are termed faults, slips, notches, or dykes. The shock which has produced this dislocation of a stratum, besides interrupting its continuity, has commonly also caused a change of level

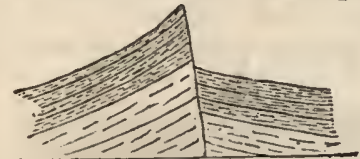

Fig. 26.

in the divided parts. Fig. 26 is an example of a fault, where beds that were once united appear broken, the separated portions being displaced, one rising above the other, which is, in mining language, termed the up-throw or down-throw of a bed. The occurrence of faults, which are very common in the coal formation, is a source of great inconvenience to the miners, not only interrupting their labours, but involving them in perplexity, as to whether the continuation of the mineral is to be sought upon the same level, or whether it lies above or below it. Several faults occurring in a stratum, where the divided portions are variously altered in their level, often engender the hope of great mineral riches in a district, which is deceptive. Thus

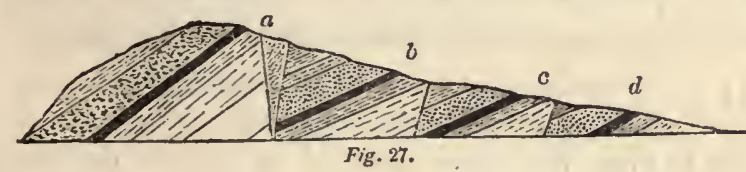

Fig. 27.

fig. 27 shows dislocation, giving to the same series of beds the appearance of many. It might be imagined by a sanguine speculator, observing these beds crop out at the surface at $a, b, c$, and $d$, that here were four distinct seams of coal, whereas he would find, upon working them, that his calculation was false as to the wealth of his land, for there is but a single seam, which has been dislocated and variously disturbed.

It will be at once perceived, that the upheaving cause which has given rise to faults in strata, has operated to produce the fractured appearance of the surface of the earth, which is the aspect of many valleys, subsequently modified and rendered beautiful and arable by atmospheric and aqueous agencies. In the carly stages of geological inquiry, the formation of all valleys was referred to the erosion of river currents: but this is plainly an inadmissible theory; for an immense number of valleys are found at high elevations, where there are no streams, and never could have been any, of sufficient power to scoop them out. Some of those in low countries may have been produced by this cause; but eren the valleys of denudation, as they are termed, appear to be original hollows in the superficies, which the rains and rivers have contributed to modify and enlarge. The longitudinal hollow spaces between two ranges of mountains, and the transverse breaks which interrupt the continuity of the same chain of hills, often constituting mere gorges and ravines, exhibit in most cases such similarity of strata on the opposite sides, and appear so capable of interlocking, if brought together, as to leave no doubt of their formation resulting from the breakagc of the general mass during its upheaval. The sides of such valleys, ravines, or gorges are commonly excessively steep and rugged; 
for the atmospheric and aqueous agencies, which have subsequently operated, so far from

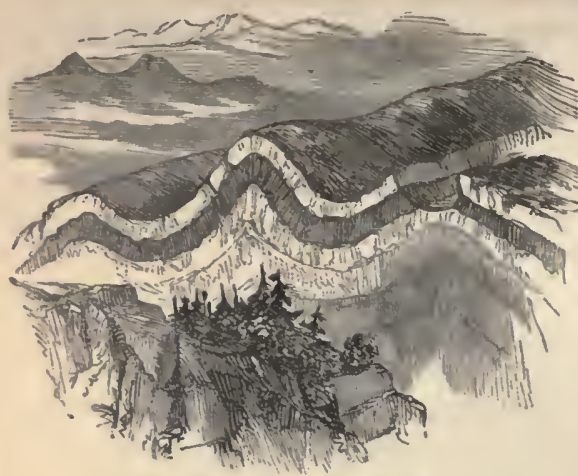

Section of the Jura Mountains. giving them a smoother outline, wear away the surface unequally, producing furrows and projections. It often appears, that the pressure from below, acting with inferior intensity, has lifted up strata without any consequent fracture, and has put forth greater power at two neighbouring points than in the intermediate space. This has given rise to valleys of Undulation, of which the accompanying scction is an example from the Jura mountains. In what are termed valleys of elevation, there has been fracture, with an upward movement of the fractured part, the strata dipping from the valley on eacli side; to the formation of which, denudation has subsequently contributed. Dr. Buckland noticed a vallcy of this kind, of which fig. 29 is a section: v, valley of Kingsclere, near Shaftesbury;

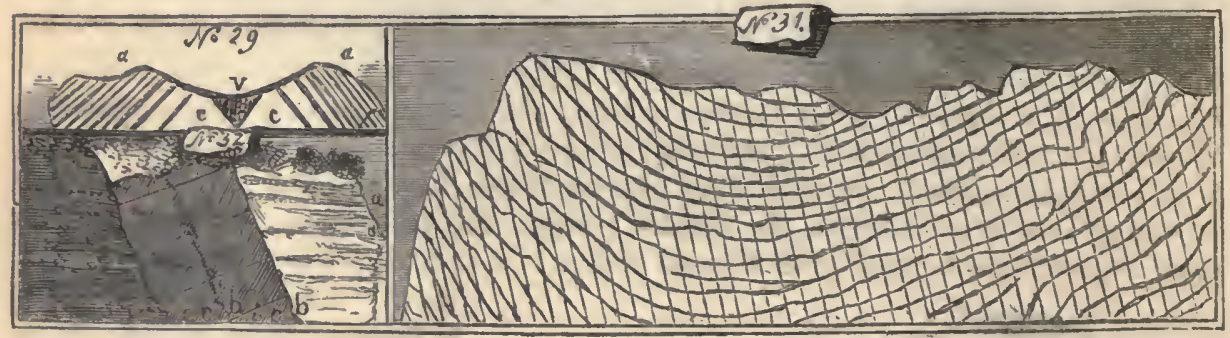

$a$, chalk, with and without flints; $c c$, green-sand, - strata which evidently were once continuous. There is little difference between valleys of elevation and dislocation; but the former term is generally applied to those which are bounded by hills of moderate height.

Both the stratified and unstratified rocks exhibit a peculiarity of structure, to which the term joints is applied: but this is more especially true of the sedimentary deposits, each stratum being divisible into masses of determinate shapes, generally approaching to the cubical or rhomboidal form; and by these separations, or tendency to separate, the quarrying of a rock is materially facilitated. Some rocks also are divided by a set of parallel planes, coincident neither with the stratification, the lamination, nor the joints, to which the name of cleavage has been given. These cleavage planes are most perfectly exhibited by the argillaceous slates, and in those of the finest grain. They are remarkable for maintaining an almost exact parallelism while ranging over many square miles of country, and for preserving this parallelism across wavy and contorted strata. In fig. 32 the planes of stratification, $a a$, are exhibited; the joints, $b b$, and the slaty cleavage, c $c$; but the cleavage structure is more distinctly displayed in fig. 31 , from the slate rocks of Wales. Professor Sedgwick, who has paid the most attention to this subject, remarks, in elucidation of it : - "A rugged country, more than thirty miles in length, and eight or ten miles in breadth, stretching from the gorge of the Wye, above Rhaiada in North Wales, to the upper gorges of the Elan, exhibits, on a magnificent seale, thousands of examples like that represented above. The whole region is made up of contorted strata, and of the true bedding there is not the sliadow of a doubt. Many parts are of a coarse mechanical structure; but subordinate to them are fine crystalline chloritic slates. But 
the coarser beds and the finer, the twisted and the straight, have all been subjected to one change. Crystalline forces have re-arranged whole masses of them, producing a beautiful crystalline cleavage, passing alike through all the strata. And again, through all this region, whatever be the contortions of the rocks, the planes of cleavage pass on generally without deviation, running in parallel lines from one end to the other, and inclining, at a great angle, to a point only a few degrees west of the magnetic north. Without considering the crystalline flakes along the planes of cleavage, which prove that crystalline action has inodified the whole mass, we may affirm that no retreat of parts, no contraction of dimensions, in passing to a solid state, can explain phenomena such as these. They appear to me only resolvable, on the supposition that crystalline or polar forces acted on the whole mass simultaneously, in given directions, and with adequate power. It is not, however, necessary to suppose that these effects were produced in a short lapse of time. In speculating on the time required for the completion of these phenomena, we are free from any unnecessary limitation." Whether this points to the true solution of an obscure problem, or not, it is evident that the structures indicated by joints and cleavage were impressed upon the rocks they characterise by agencies acting after their deposition; for, in several newer fossiliferous strata, symmetrical joints pass through the organic remains imbedded in them.

The manner in which the two great classes of rocks, the stratified and the unstratified, are disposed in relation to each other, now requires a notice. It is very clear that they have been formed under the operation of totally distinct causes. The parallel arrangement of the strata, the pebbles of pre-existing rocks and organic remains imbedded in them, together with the ripple-mark, the footprints and other traces of animals which they exlibit, demonstrate their deposition in water; while the clear marks of having crystallised in cooling from a state of fusion borne by the unstratified rocks, the close analogy of their composition to modern lavas, and often complete identity, plainly prove their igneous origin. In considering the association of the two classes, the most decisive evidence appears, that while the unstratified masses are uniformly found beneath the stratified, they have been violently propelled among the strata in a melted state, by the expansive property of an immensely high temperature acting under pressure, occasioning the different inclinations, contortions, and fractures previously described. It is obvious that the materials of the sedimentary rocks must have been deposited horizontally; yet nothing is more common than to see beds of sandstone and conglomerate in a vertical position. The leaves of ferns in the shale of coal countries, which are often spread out as regularly as dried plants between the sheets of paper in the herbarium of a botanist, are also frequently found highly inclined, and sometimes vertical, though they must have been horizontally disposed when deposited. Fig. 33 represents a common instance of the

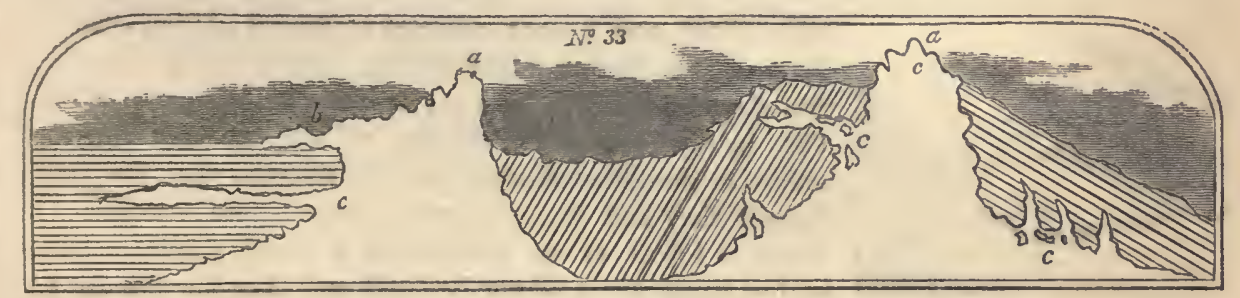

manner in which the unstratified and stratified rocks are associated, in which strata of limestone appear lying upon mountainous masses of granite. At $a a$ the granite has burst through the limestone; at $b$ it overlies it, as if it had flowed over; at $c$ it interstratifies it, having introduced itself in a rent or fissure produced by the catastrophe of 
its ejection from beneath. As a penetrated body must have an existence prior to its penetration, nothing can be plainer than that the limestone was formed prior to the invasion of the granite; while it is cqually clear, that, by thus overlying and interstratifying the limestone, and forming veins as at $c c$, the granite must have been erupted in a melted condition. A remarkable change is often observed in the character of the sedimentary strata in immediate contact with the granite or any other igneous rock, arising fiom exposure to the action of the heated mass. Thus the celebrated Carrara marble, used in sculpture, once supposed, from the absence of fossils, and its crystalline texture, to be a primitive rock, is only a limestone of a comparatively modern period, whose characteristic fossils have been obscured or destroyed, and the whole fused into a uniform rock, by plutonic action. Clay and sandstone also have been converted into substances as liard as flint, and coal into coke, by the invasion and interjection of the igneous rocks - changes analogous to what may now be produced in those materials by artificial means of a similar nature.

Thus the unstratified rocks, of which granite only has been mentioned, as the most important example, occur in irregular masses beneatl the stratified; in disrupting masses, which have broken asunder the strata, and inclined and contorted them in an endless variety of ways, forming some of the lighliest mountains of the globe; in incumbent masses, having flowed over the surface of strata, while in a state of fusion; as interposing masses, filling cracks or fissures in strata produced by the disturbing force which has acted upon them; and as veins, which are similar insinuations of the melted mineral matter, but with many slender ramifications or branches, often containing angular fragments, broken from the invaded rock.

When Hutton was groping his way to the doctrine which lie was the first to propound, that granite was the result of igneous fusion,- or, to employ his own language, a body transfused from the subterraneous region, and made to break and invade the strata, - he rightly regarded this as a question only to be determined upon the spot where it is found in immediate contact with those bodies which are evidently stratified. "I wanted to see," he remarks, "whether the granite mass, in point of time, had been prior or posterior to those water-formed bodies, the Alpine strata, or primary schists (transition slates); and, as to the manner of operation, I particularly desired to know if the granite had been made to flow, in that state of fusion, among the broken and dislocated strata. Having suspended my opinion till I should find some decisive appearance by which this important question might be determined, I considered where I might be most likely to find the junction of the granite country with the Alpine strata; and having an engagement with Mr. Clerk, of Eldin, to visit the Duke of Athol at Blair, I concluded that from that place it could not be far before the great mass of granite, which runs south-west of Aberdeen, would be net with in the river Tilt, or some of its branches. But," he adds,

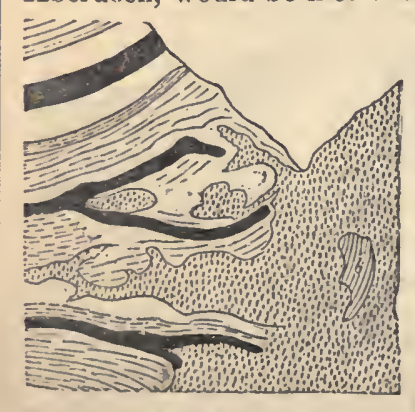

"Mr. Clerk and I were resolved to find it out, to whatever distance the pursuit might lead us among the mountains of this elevated tract." The result was the discovery in Glen Tilt, in the bed of the stream, of the expected junction, which so delighted Hutton and his friends, that the guides thought they had detceted some mine of gold. "Here," he states, "I had every satisfaction I could possibly desire, having found the most perfect evidence that the granite had been made to break the Alpine strata, and invade that country in a fluid state." The actual appearance of the junction in Glen Tilt is represented in fig. 34, which shows the undulating outline of the granite forming veins, intruding itself into the beds of clay 
slate and limestone, from which it differs remarkably in composition. Dr. Macculloch has noticed here the metamorphic change, to which reference has been made, produced in the sedimentary strata in immediate contact with the igneous rocks, by their high temperature when obtruded; for the limestone is changed in character by the proximity of the granitic mass or its veins, and acquires a more compact texture, like that of hornstone, or chert, with a splintery fracture. Besides intruding into the stratified rocks in the form of veins, the granite and other igneous masses are frequently traversed themselves by reins, which show successive epochs in which the fiery fluid from beneath has been erupted, the rock itself thus veined having of course been ejected at the earliest epoch. In one remarkable example of veins of different kinds, near Salem in Miassachusetts, where the basis rock is syenitic greenstone, Professor Hitcheock has been able to trace eleven epochs of eruption. Dykes, from the Scottish dyke, a wall or fence, are analogous to veins, being generally composed of igneous matter ejected from below into fissures of the strata, which are usually straight, and often form thick divisional walls.

It is impossible to account for aH veins upon the principle of injection, as in such examples as are shown in the following figures:-

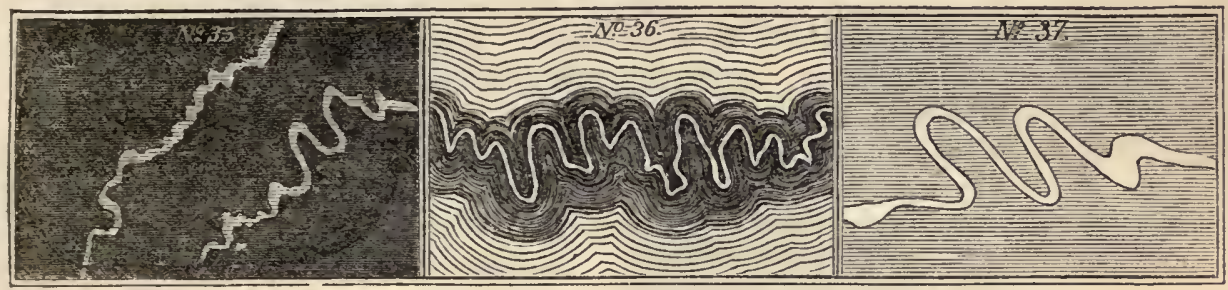

Fig. 35 represents two small but very distinct granitic veins, occurring in lomogeneous micaceous limestone, which pursue a very tortuous course. Fig. 36 shows a granitic vein, equally tortuous, and only one-eighth of an inch thick, conforming to the flexures of mica schist. Fig. 37 exhibits a tortuous granitic vein, occurring in talcose slate, which does not conform to the laminæ of the slate. Veins of this description are supposed by Professor Sedgwick to have been produced by chemical segregation from the rock in which they occur, while that was in a yielding state, just as the nodules of flint were segregated from chalk, or crystals of simple minerals from the rocks in which they are now found imbedded. This opinion is supported by the fact, that sometimes these veins pass by insensible gradations into the intruding rock, thus showing that they are of a contemporaneous origin with the rock, while both were in a fluid state. The metalliferous reins are of both kinds, fissures that have been subsequently filled with metallic matter, and segregations of metallic particles from the surrounding mass by elective affinity.

The phenomena of the metallic veins constitute one of the most difficult problems of geology; but their contents are so important to human improvement and happiness, and form so marked a feature of the erust of the earth, as to demand a general notice. It is always the case, that the metalliferous veins, like other mineral veins, are occupied with matter different from the rocks they traverse; but it rarely occurs that the metallic matter, or the ore, fills the whole of the vein, but is more or less abundantly disseminated through the quartz, sulphate of baryta, or granite, which constitutes the matrix or veinstone. The veins vary greatly in width, from a line to several hundred feet, those of Cornwall being from an inch wide to upwards of thirty feet. They vary also in their direction, and are of unknown depth, for scarcely ever have they been exhausted downwards. 'The metalliferous contents likewise vary in the same veins, at different distances from the surface, owing to their passage through different rocks, copper following zine 
in several of the Cornish mines; while mines in the south of France have conducted first to iron, next to silver, and lastly to copper. 'The metallic veins are ehiefly found in rocks of the primary and transition series, none being worked in Great Britain above the new red sandstone, nor any of much importance above the carboniferous limestone. That variety of iron ore, however, called by mineralogists hamatite, from the Greek word signifying "blood," and also termed blood-stone, occurs in the lias and chalk of the Pyrenees; and in the Andes of Chili, the tertiary strata, which have become metamorphic by proximity to granite, are traversed by true metallic veins of iron, copper, arsenic, silver, and gold, which proceed from the underlying granite. The great deposits of copper are found in the older sedimentary and the unstratified rocks, of which the county of Cornwall is composed; which produces more of this metal than all the other European mines collectively. Scarcely an cxample occurs in which a vein has been cut out, or its termination been reached; for when abandoned, it is generally owing to its having become poor, or to the expense of going deeper being greater than what the probable produce would yield. So extensively are some of the mining operations for copper carried on, that in the Consolidated Mines of the parish of Gwennap, near Redruth, the engine-power employed, if exerted to its full extent, is equal to the work of from seven to eight thousand horses. Lead is found most abundantly in the carboniferous limestone, in considerable quantity also in the lower stratified rocks, likewise in granite and in the coal measures, but not in any of the strata above the coal. The veins in the limestone are the largest and the richest in ore; and the same vein

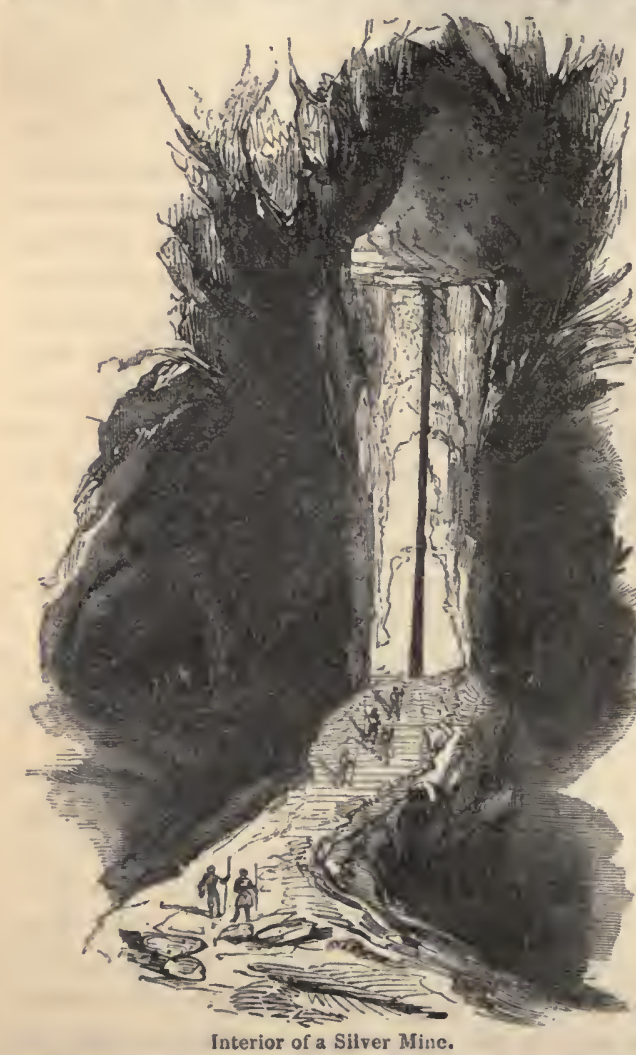
which in a limestone stratum may have a width of seventeen feet, has been found to contract to three in the sandstone below. Silver is met with chiefly in primary strata, and also in unstratified rocks. The rich mine of Potosi in South America, discovered in 1545 , which yielded in the space of eighty-three years from its discovery four hundred millions of ounces, is situated in primary slate.

Besides occurring in veins, silver has been found in large insulated masses, as in one of the Peruvian mines, in which a lump was discovered weighing eight hundred pounds. At Konigsberg, in Norway, a mass of upwards of five hundred pounds' weight was found; and masses of a hundred pounds have frequently been yielded by the mines of Freiberg in Saxony. Gold also occurs in veins in the older sedimentary strata, the gneiss and mica-slate in Mexico, as well as in the unstratified rocks. It has been found in masses likewise, varying from eighteen to forty-five pounds' weight, in the Ural mountains, in Columbia, and in Peru. The subject of the occurrence of the metals in veins and masses is most obscure; but the general fact, that they are most abundantly situated near the junction of stratified 
and unstratified rocks, indicates their connection with an igneous cause; and, in common with other veins, the two principles of simple injection and chemical segregation have doubtless operated in their production.

The preceding division of rocks into two classes-the stratified and the unstratified - was first made by Leibnitz, in the year 1680. Optically, the stratified immensely preponderate over the unstratified, the latter being supposed to occupy not a tenth part of the earth's surface. The proportion of each varies remarkably in different countries; the unstratified masses in Great Britain, according to Macculloch, not covering a thousandth part of the superficies of the island, while in Massachusetts they occupy nearly a quarter of the surface. But it must be remembered, that what meets the eye, in this case, is no criterion of the relative magnitude of these two parts of the crust of the globe; for the whole of the interior shell, to a great depth, is probably constituted of masses of unstratified rock, kindred to those which in former ages, in an ebullient state, have disrupted the strata, and are now open to our inspection.

The subject we are now considering - the structure of the exterior mass of the earthnecessarily requires a division of rocks into two more grand classes - the fossiliferous and the non-fossiliferous, or those formations which contain animal and vegetable remains, and those in which no organic remains have been discovered. The non-fossiliferous include all the unstratified rocks, with the earliest three groups of strata-the gneiss, micaschist, and clay-slate systems. But it by no means follows, that because the latter sedimentary strata éxhibit no organic remains, therefore organised nature, animal or vegetable, was not coincident with their deposition; for all vestiges would be destroyed by the igneous action with which they have been in immediate contact, and which has given them a metamorphic character. The fossiliferous class embraces all the stratified formations excepting those just mentioned, the remains of animal life vastly preponderating over the remains of vegetables in the older strata, except in the beds connected with the coal -a fact which may be sufficiently explained by the easy destructibility of vegetable fibres. In the Alps, the fossiliferous rocks are found at the height of from 6000 to 8000 feet above the level of the sea; in the Pyrenees, nearly as high; and in the Andes, at the height of from 16,000 to 18,000 feet. In examining a formation of very limited extent, the same specific organic remains may be found universally diffused through it ; but if the formation has a larger area, extending into different countries or hemispheres, the specific resemblance between the organic contents will be found to diminish according to the distance; and excepting in a few particular instances, no wide diffusion of species will be found in contemporaneous rocks. This is a highly interesting fact, since it manifests the coincidence between the laws of the animal and vegetable kingdoms, in immeasurably distant ages and at the present epoch ; groups of species being confined to distinct botanical and zoological provinces. In the more recent formations, examples of the remains of species identical with those which mark the existing condition of nature occur, but the proportionate number of these and extinct species becomes less as we descend through the six or seven tertiary beds, till we arrive at the chalk, in and below which no species are observed which can be identified with any now living, though, according to Koferstein, a German writer in 1834, the species of organic remains described in rocks below the tertiary strata amount to upwards of 9000 .

It is an extraordinary fact, that whole masses of the solid materials of the globe appear to be composed almost entirely of the remains of animals or plants. Ehrenberg, the Prussian naturalist, mentions a bed in Germany, fourteen feet thick, made up of the shields of animalcula, so small, that it would require $41,000,000,000$ of them to form a cubic inch. But mountains, hundreds and even thousands of feet. ligh, are essentially constituted of organic matter; and some idea of the enormous amount entering into the 
composition of the lifeless and rigid masses around us, may be formed from the following list of strata by Dr. Mantell, which are wholly, or in great part, composed of animal remains :-

Strata.

Trilobite schist

Dudley limestone -

Shelly limestone -

\section{Mountain limestone}

Encrinital marble -

Muscle-band

Ironstone nodules -

Lias shales and clays

Limestone -

Lias conglomerates -

Gryphite limestone -

Limestone

Stonesfield slate

Pappenheim schist -

Batlı stone

Limestone

Coral-rag

Iradford limestone -

Portland oolite

Purbeck and Sussex marble

Wealden limestone -

Tilgate grit (some beds)

Farringdon gravel -

Jasper and chert -

Green-sand

Chalk

Maestricht limestone

Hippurite limestone

Hard clialk (some beds)

Flints

Limestone

Nummulite rock

Septaria

Calcaire grossier -

Gypseous limestone

Siliceous limestone

Lacustrine marls -

Monte Bolce limestone

Bone-breccia

Sub-Himalaya sandstone

Tripol

Richmond -

Semiopal

Mountain mar

Guadaloupe limestone

Bermuda limestone

Bermuda chalk

Bog iron ochre

-

$-$

Prevailing Fossils.

Trilobites and shells

Corals, crinoidea, shells, and trilobites

Productæ, spiriferæ, \&c.

\section{Corals and shells}

- Lily-shaped animals and shells

- Fresh-water muscles

- Trilobites, insects, aud sliells

- I'entacrinites, reptiles, fishes

- Terebratulæ and other shells

- Fishes, shells, corals

- Shells, priucipally gryphites

- Terebratulæ, and otlier shells

- Shells, reptiles, fishes, insects

- Crustacea, reptiles, fishes, insects

- Shells, corals, crinoidea, reptiles, fishes

- Cephalopoda, principally ammonites

- Corals, shells, echini, ammonites

- Crinoidea, shells, coral cephalopoda

- Ammonites, trigonix, and other shells

Fresh-water slıells, crustacea, reptiles, fishes

- $\left\{\begin{array}{l}\text { Cyclades, and other fresh-water shells, } \\ \text { crustacea, reptiles, fishes. }\end{array}\right\}$

Reptiles, fishes, fresh-water shells

- Sponges, corals, echini, and shells -

- Shells, sponges, and animalcules

Fibrous zoophytes -

Corals, infusoria, echini, sliells, fisles

- $\left\{\begin{array}{c}\text { Corals, shells, ammonites, belemuites, and } \\ \text { other ceplialopoda - reptiles. }\end{array}\right\}$

- Shells, principally hippurites

- Echini and belemnites

- $\left\{\begin{array}{l}\text { Sponges and other fibrous zoopliytes, in- } \\ \text { fusoria, and spines of zoophytes, shells, } \\ \text { corals, crinoidea. }\end{array}\right.$ corals, crinoidea.

- Fresh-water shells

\section{- Nummulites}

- Nautili, turritellæ, and other shells

- Shells and corals

- Mammalia,palæotheria,\&c.birds,reptiles,fishes

- Shells

- Cyprides, phryganex, fresh-water shells -

$-$

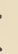$$
\text { - }
$$ 
In addition to this amount of animal mattcr, the vegetable kingdom has contributed, in an inferior degree, yet in no unimportant manner, to the composition of strata, as the anthracite, coal, and lignite formations attest, which occupy extensive areas of country.

The thickness of the fossiliferous rocks in Great Britain is thus given by Professor Phillips :-

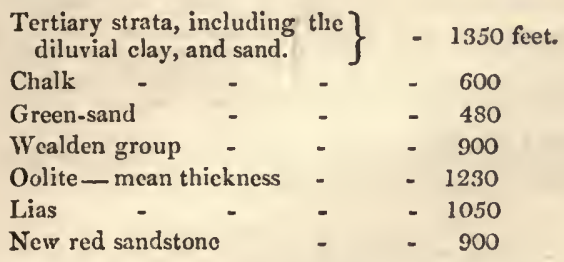

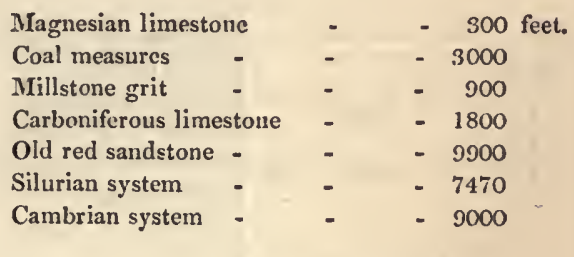

The total, according to this estimate, is 34,080 feet, or about 6.5 miles : but it appears from more recent investigations, that the Cambrian group and Silurian system far exceed in thickness the entire aggregate of the other strata.

The division of rocks into fossiliferous and non-fossiliferous, into stratified and unstratified, is founded upon obvious and important nat ural characters, and accordingly all geologists are here agreed. Nor is there any difference of opinion as to the order of succession and relative age of the larger formations, however, in the details of classification, the grouping of strata, and the distinctive terms employed, some diversity prevails, perplexing to the student. The first arrangement was made by Lehman, who divided all rocks into -

Primitive. - Those of hard and slaty structure, containing no fossil organic remains.

Secondary. - Rocks of comminuted fragments, and containing organic renains.

Local. - Those of partial occurrence in different districts.

Werner introduced another class between the primary and secondary, to which he applied the term Transition, from the indications they exhibited of a transition state from the one to the other as to mineral structure, and of having been formed when the world was passing from an uninhabitable to a habitable condition. Afterwards the word Local gave place to Tertiary, which became the generic title of all regularly stratified beds above the chalk up to the superficial formations; and the transition class was incorporated with the secondary. But as geology advanced, this arrangement was soon found to be far too general. Each of these grand divisions has since been subdivided into systems and groups of strata, which are so distinguished from each other by mineral or fossil peculiarities, as to justify the idea that they were formed independently, under different conditions, during successive epochs. Thus, beginning at the surface, we have, in descending order, the following systems, distributed into great life periods, according to natural history distinctions :-

CLASSIFICATION OF STRATIFied ROCKS.

Cainozoic Period $\{$ 1. Post-Tertiary System.

(Recent Life.) \{ 2. Tertiary System.

Mesozoic Period $\left\{\begin{array}{l}\text { 3. Cretaceous, or Chalk System. } \\ \text { 4. Oolitic System. }\end{array}\right.$

(Middle Life.) $\left\{\begin{array}{l}\text { 4. Oolitic System. } \\ \text { 5. Upper New Red }\end{array}\right.$

6.

Palmo (6. Lower New Red Sandstone, or Permian System.

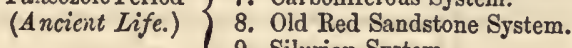

9. Silurian System.

Azoic Period $\{$ 10. Clay-Slate System.

(Void of Life.) $\left\{\begin{array}{l}\text { 11. Mica-Schist System. } \\ \text { 12. Gneiss System. }\end{array}\right.$

This arrangement is more clearly exhibited on the next page. 


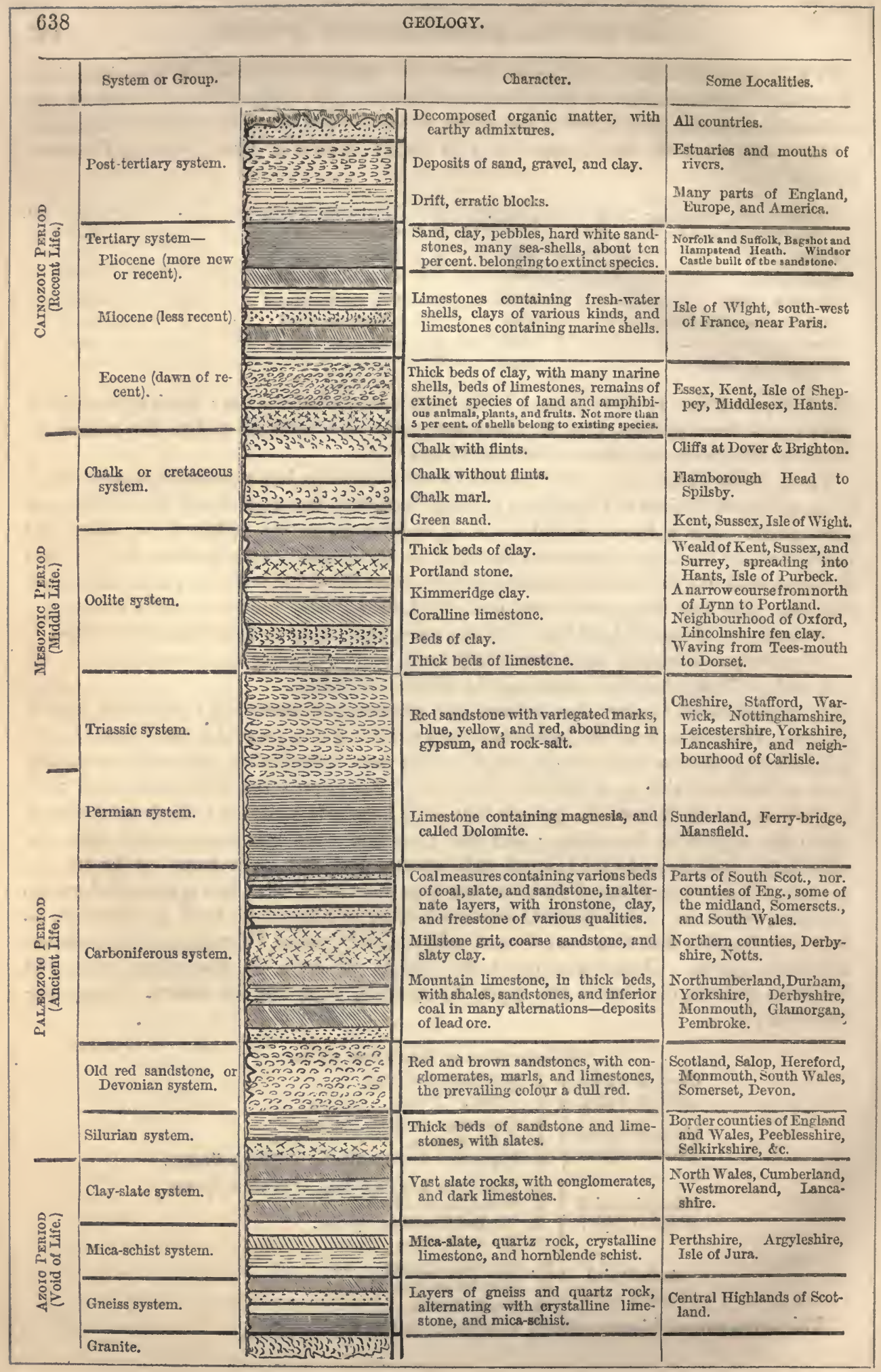


This synopsis exhibits a view of the succession of strata as developed in Great Britain, and, excepting some circumscribed continental tertiaries, we have, within our own island, the representative or the equivalent of almost every formation whose existence has been ascertained. This order of succession is invariably maintained; for though many members of a group may be wanting, and also many groups, those that occur are found universally to occupy the same relative position. We may suppose the series to occur,

\begin{tabular}{|c|c|c|c|c|c|}
\hline $\boldsymbol{\Lambda}$ & $\mathbf{A}$ & A & A & c & \\
\hline B & B & B & D & B & \\
\hline c & c & 一 & 一 & - & \\
\hline D or as & - or as & - but it never occurs as & $\mathrm{B}$ or as & $\mathbf{F}$ & or in any such inverted order. \\
\hline $\boldsymbol{\Sigma}$ & $\mathbf{E}$ & 一 & 一 & D & \\
\hline $\mathbf{F}$ & - & c & , & 一 & \\
\hline G & G & G & $\mathbf{F}$ & $E$ & \\
\hline
\end{tabular}

Thus, a system low in the diagram may be found immediately under the surface soil of a district, or quite naked to inspection, all the intermediate groups being absent; as the magnesian limestone in Durham, the coal in Fifeshire, the old red sandstone in Herefordshire, and the slate in North Wales; but if these lower groups in the diagram appear at the surface, then, however deeply we might pierce the strata there, we should never come to any of the systems higher in the scale. It would be vain to sink a shaft in search for chalk in Durham, or for magnesian limestone in Fife, or for coal in Hereford, or for the old red sandstone in the neighbourhood of Plinlimmon, because the formations sought are superior in the series to those which occupy the surface in the localities named. Hence a practical knowledge of the succession of strata would have prevented the expenditure of thousands in the search for coal, in situations geologically beneath it, or so far overlying it as not to be accessible. The absence of groups of strata, to which we have referred, may have arisen from the action of water, subsequent to deposition, denuding and washing them away, diffusing their materials upon the floor of the ocean, or entering into fresh formations; or other modifying circumstances may have prevented their deposition altogether in such sites.

The first nine of the systems named contain, in a varying degree, the remains of plants and animals. The other three exhibit no traces of them, except the upper part of the clay-slate system, in which they are occasionally found. Upon comparing the remains exhibited by formations of different ages together, decisive evidence appears of the progressive development of organic life, from the more simple and imperfect structures that obtain in the older strata, to the higher organisations that are found in those depositions which belong to æras immediately antecedent to the existing epoch. In the course of our planet's history, the less complex tribes of animals and plants were the first to appear, the more perfect spccies beconing more and more numerous up to the creation of the present races. This is not generally held by geologists, as inferring a gradual perfectionnement of species. It is true that fishes, which of all vertebrata rank the lowest, appear first in geological history; but then they are not imperfect formations-they have no mark of inferior organisation, but occur in their highest state of approximation to the reptile, and not in their lowest condition of affinity to the worm. It is also true, that reptiles precede mammalia, but they are reptiles belonging to the higher grades of that class. The earliest zoophytes and mollusca likewise display no inferiority in their organisation when compared with their living representatives. Hence it is concluded, that while there has been a progressive development of organic life upon the face of the globe, it has not been by an improvement of species, but by an addition of fresh organisations, a new dramatis persona, to meet new physical conditions of the earth. 
The dawn of organic life-the moming twilight of the ern of living bcings-appears in certain slaty rocks of North Wales, which are variously regarded as upper beds of the clay-slate system, as lower Silurian, and as a distinct formation under the name of Cambrian. Zoophytes, molluscs, and traces of ammelidans, are occasionally detected. In the following table, the more important remains of animal and vegetable life, characteristic of great geological eras, are indicated :-

SILURIAN PERIOD.

Fossils eminently marine. Zoophytes in great abundance and of many species, among which the chain-pore coral (Catenipora escharoides), is a beautiful example ; encrinites of several varieties; crustaceans, particularly trilobites; and molluses in great numbers. True vertebrated fishes, towards the close of the period. Sea-weeds and aquatic plants.

OLD RED SANDSTONE PERIOD.

Remarkably uncouth fishes common, many covered with bony plates. First trace of reptiles, apparently allied to the lizards. Land-plants appear akin to the tree-ferns, and Catenipora escharoides. other vegetation of the succeeding period.

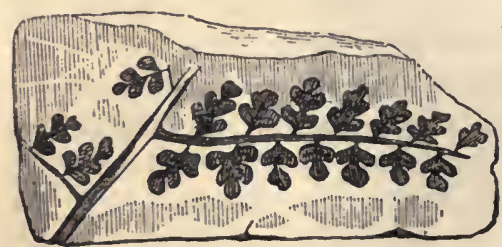

Sphænopteris Hæninghausi.

CARBCXIFEROUS SERIOT.

Marine life exuberant. Fishes of large size and of sauroid character. Fragments of land-shells, and skeletons of minuto reptiles of the frog-kind, indicate a terrestrial fauna. An abundant and gigantic flora forms the grand feature of the period, consisting of araucarian-like pines, palms, tree-ferns, enormous reeds, equisetums, club-mosses, and other kindred plants.

LOWER NEW RED SINDSTONF, OR PERMIAN PERIOD.

Land-plants allied more or less to those of the preceding era. True air-breathing, land-inhabiting ereatures more distinetly indieated, of the frog and lizard families-the Palceosaurus (ancient saurian), Protorosaurus (first saurian), Thecodontosaurus (sheath-tooth saurian), the latter allied to the living monitor.

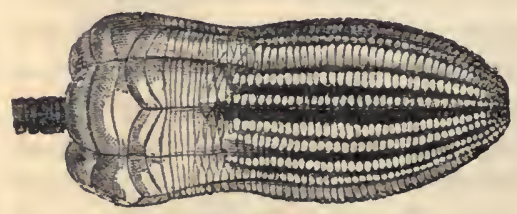

Encrinites Monlifformis.

UPFER NEW RED SANDSTONE, OR TRIASSIC PERIOD,

A limited flora indicated, both as to species and individuals, but more allied to that of the present era than of the preceding epochs. Frog-like reptiles, of huge size, appear, and new families of saurians. Ichnolites (foot-prints on stone), those of reptiles; and Ornithichnites (stony bird tracks), the imprints of birds, some of gigantic size, are characteristic memorials of the period.

DOLITIC PERIOD.

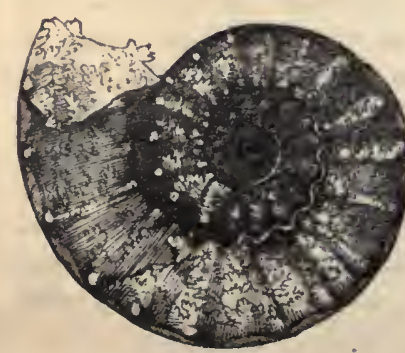

Ammonite Catena.

Organic remains extremely numerous and well-preserred. The most remarkable are reptiles, many of enormous size, as the Ichthyosaurus (fish-like saurian), Plesiosaurus (akin to the saurian), and the intermediate Pliosaurus, inhabitants of the ocean; the Pterodactyle (wing-fingered reptile), a flying saurian; the Hylceosaurus (forest-saurian); the Megalosaurus (great saurian), a gigantic carnivorous terrestrial reptile; and the Iguanodon, a huge herbivorous reptile, allied to the existing iguana. Among molluses, Ammonitcs occur in prodigious numbers, of many species, and varying size. Insects also appear, beetle-like and dragon-fiy-like; and a specimen or so of birds. Fragments of small marsupial animals proclaim the existence of warm-blooded terrestrial mammalia. 


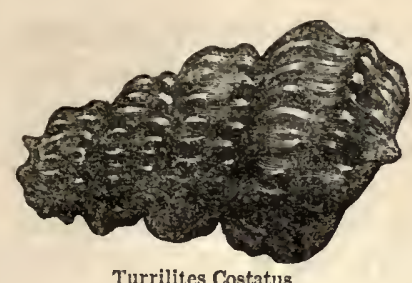

Turrilites Costatus.
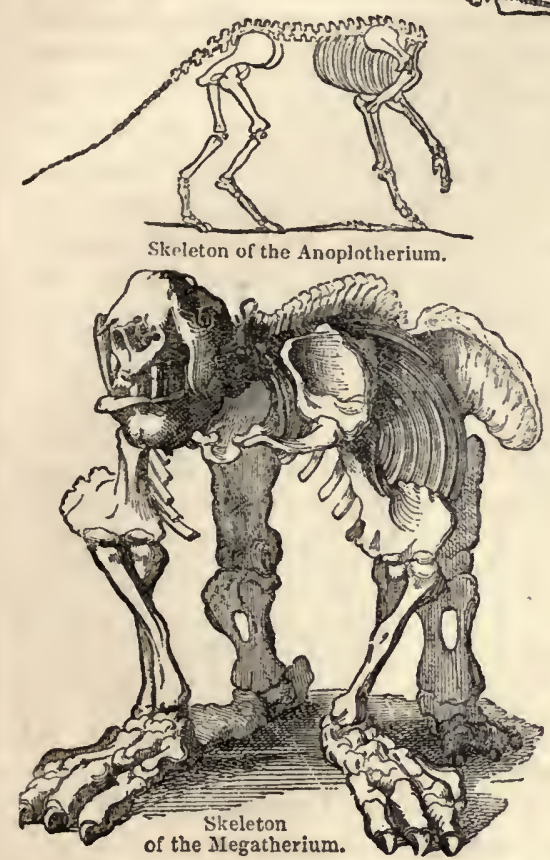

CRETACEOUS PERIOD.

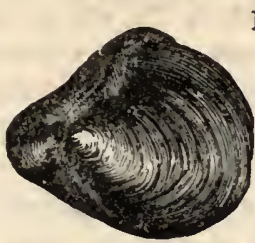

Mocesamus Concentricus.

Few examples of land organisms. Plants rare, and nearly all referrible to marine types. Snonges, zoophytes, star-fishes, echinites, and molluses abundant. Fishes of the ctenoid and cycloid orders, to which the perch, herring, and nearly all existing fishes belong, for the first time appear. Reptiles common, identical with, or closely allied to, those of the preceding era. Birds and monkeys indicated.

TERTIARY PERIOD.

The prevalence of mammalian life is the grand distinguish. ing feature of this epoch. All the existing orders are represented, except man, though by extinct species, many of which did not appear till towards the close of the era. The most remarkable are of the order of toothless animals, as the Megatherium (great wild beast), the Megalonyx (great claw), and the Glyptodon (sculptured tooth), gigantic analogues of the sloth, armadillo, and ant-eater. The thick-skinned order is represented by the Palceotherium (ancient wild beast), the Anoplotherium (defenceless wild beast), the Deinotherium (terrible wild beast), uncouth, tapir-like forms; and by allies of the rhinoceros and hippopotamus, with true elephantoid genera, as the Mastodon and Mammoth.

POST-TERTIARY PERION.

Remains of plants and animals belonging to species now existing, more or less fossilised.

The manner in which organic remains have been preserved varies with the nature of the deposit in which they are embedded. In the more recent rocks, the entire skeletons of animals have been found, which have scarcely undergone any alteration, but more frequently the harder parts alone occur, and with these the teeth are met with most abundantly, still retaining their sharp edges and enamel. Shells also are common in strata of very high antiquity, as perfect in form as if newly picked up on the shore of the ocean; and microscopic animals, which the slightest disturbance must have crushed, appear uninjured, which proves that they must have lived and died on or near the spot where they are found, have been deposited at the bottom of very quiet waters, and that the consolidation of the strata was a very gradual and uninterrupted process. Dr. Mantell remarks, that in his early researches he fell into the error of supposing that all fossils must necessarily be petrifactions, and threw away many beautiful shells that were associated with ammonites in the marl at Hornsey, supposing, from their perfect state, that they had been accidentally imbedded, and were not genuine fossils. " But the state of preservation," he adds, "and the degree of change which an organic body has undergone in the mineral kingdom, have no necessary relation to its antiquity. The shells in some of the ancient secondary strata are frequently as perfect as those of modern tertiary.deposits. . I have collected, in the lowermost clays of the TVealden, fresh-water shells having traces of the 
epidermis, and of the ligament by which the valves were held together; and bones of reptiles in Tilgate Forest, as light and porous as those of the bear and hyena from the caverns of Germany. On the other hand, fossil remains from the newest tertiary formations are often completely petrified, that is, permeated by, or transmuted into stone."

In animal remains the harder parts are sometimes partially impregnated with mineral matter, while the animal matter is still obvious to inspection; but far more frequently, the animal matter appears to be almost entirely replaced by the mineral, constituting a genuine petrifaction. Parkinson, however, observes, that probably, in every case, a chemical process would show the presence of considerable organic matter. The mineralising agent is most commonly carbonate of lime, but often silica, or clay, or oxide of iron, and sometimes the ores of metals. Vegetable remains occur, in a similar manner, completely permeated by mineral matter, yet without any destruction of their cxternal character or internal structure, so that the most delicate tissues of plants, their leaves and seed-vessels, and even their pollen, are quite distinct. But large masses of vegetation have entirely lost all organic structure, having been bituminised, through that peculiar chemical process which vegetable substances undergo when excluded from the air, and subject to great pressure. Of this process, coal, lignite, amber, and asphalte are cxamples. There are productions in course of formation at present, strikingly analogous, if not identical, with those changes which the mass of fossil organic remains has experienced. Thus rivers and springs hold in solution a large proportion of lime, silex, and iron, which various causes precipitate, and substances exposed to their action for some time become incrusted and premeated with the siliceous and calcarcous earths, and the metallic oxides. A bone buried in clay containing sulphate of iron, will, in a few years, or even months, have undergone a perceptible change towards petrifaction; and by an experiment of $\mathbf{M}$. Goppert, it appears that fern leaves placed carefully in clay exposed to a red heat, will be made to resemble the petrified plants found in the rocks.

Travelling from the metropolis across our own island in a north-west dircction, we successively meet at the surface with the several groups of strata which appear in the synopsis. Around London we find the tertiary deposits, which spread from thence over nearly the whole of the eastern coast of England to beyond the Humber, covered with various superficial accumulations. The chalk is encountered in the counties of Hertford, Bedford, or Buckingham; the oolite in Northamptonshire; the new red sandstone and carboniferous systems in Leicestershire and Staffordshire; the old red sandstones and Silurians in Salop; and lastly, the clay-slate, mica-schist, and gneiss groups occur in the alpine or mountainous districts of Great Britain, which extend, with some interruptions, along its western side. In describing the several systems of strata, some writers traverse the series descendingly, commencing with the uppermost or most recent deposits; but the more natural plan is to proceed ascendingly, beginning with the lowest formations, the earliest in point of time, and the storehouse whose matcrials have contributed to the production of the rest. The first step in an arrangement of this kind involves a reference to formations of more ancient date than the oldest of the strata-the unstratified foundation rock-the granitic platform, upon which all the other deposits arc based, sinking to depths which the eye of man can never explore, and rising in mountain walls and pinnacles to heights which only a few of his race have reached. This will form the subject of the following Chapter, in connection with the other igneous masses in general, except those which have been formed during the age of man, which will hereafter be noticed. 


\section{CHAPTER II.}

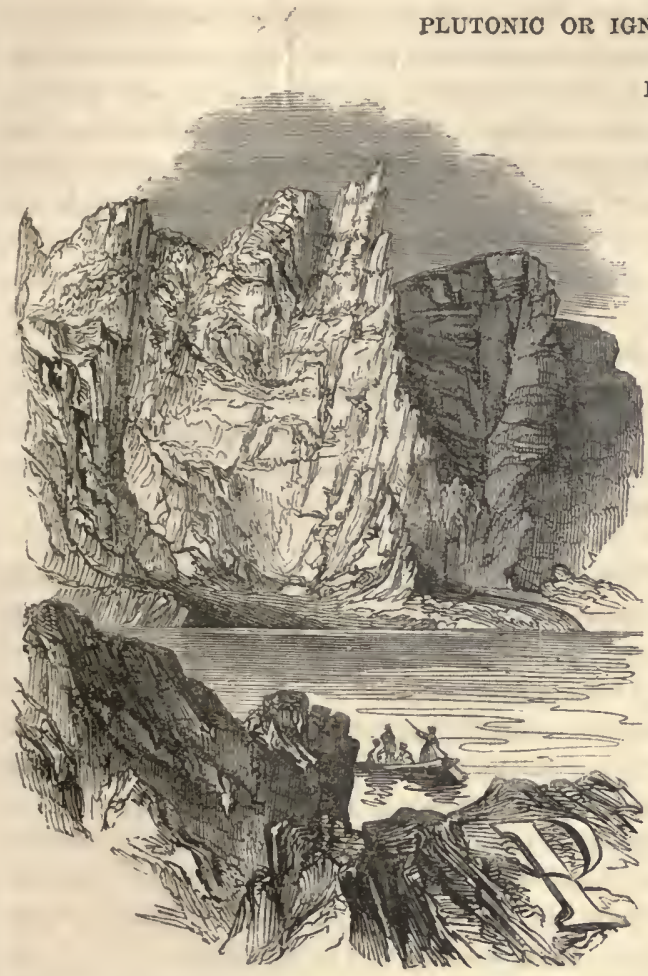

LETO, presiding over fire, was early introduced into the nomenclature of geology, to supply a generic title for those vast masses which consist of melted mineral matter cooled down, which have been driven up from the interior deepseated regions of the globe, from whence the lavas, scorix, and ashes of the modern epoch are erupted through the volcanic vents. Recurring to former pages of this work, some of the evidence will be found recorded in favour of the doctrine, that the interior shell of the solid crust upon which we tread is in contact with an immensely high temperature, which permeates through it, gradually diminishing with the distance from the focus of heat; and that at a certain extent below the surface of the earth, perhaps not more than thirty miles, matter exists in a state of fusion. According to some eminent geologists, the volcanic action that marks the present history of our planet, is the comparatively feebler play of identically the same causes, which, in the earlier part of its story, operated with inconceivable energy in the structure and configuration of its frame-work. It must be admitted, that nothing analogous to the productions of ancient time - the granites and porphyries - can now be seen in the course of formation upon the actual surface of the globe; yet we can only be acquainted with part of the workmanship of the volcano - with the products ejected whose diverse character is no proof that granite is not elaborated in the depths of the furnace. Be this as it may, the evidence is irresistible of the intense action of heat in the construction and elevation of those rocks to which the term Plutonic or igneous has been attached, and in the transformation or metamorphic change of the primary strata.

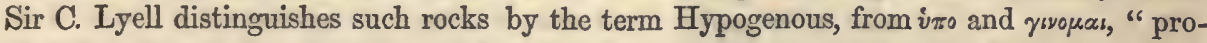
duced under," or "nether-formed;" but such an appellation is scarcely distinctive, for it will equally apply to the sedimentary strata, constructed and consolidated beneath the waters of the ocean. There is no ralid reason in this case for changing a well-known nomenclature, which, in every science, should be as little disturbed as possible.

The igneous rocks have been variously classified by Dr. Macculloch, M. Brongniart, and Mr. Scrope, according to their mineralogical composition; but a more general, though less scientific, arrangement is prevalent. This refers to the different aspects of igneous products, which have resulted more from the varying circumstances under which cooling down and solidification have taken place, than from any original and real difference of 
nature. Hence we have the Granitic, Trappean, and Volcanic roeks - the popular distribution - from which there is no necessity here to deviate.

Granitic Rocks. - Pliny uses the word geranites to denote a particular kind of stone, to which some writers refer the word granite, but more probably the granular structure of the rock itself originated the term. Its essential ingredients are quartz, felspar, and mica; the felspar in general predominating, and the mica occurring in the smallest proportion. These constituents vary considerably in size, being sometimes very coarse, and in other cases so fine as to be scarcely visible to the naked eye; and between these extremes there exists an almost infinite variety. The fine-grained varieties are the best adapted for economical purposes; but the coarser abound most in interesting simple minerals. The ingredients of granite vary also as to colour, and that in the same ingredient. Felspar occurs usually dark-red or white; quartz, white or grey; and mica, black, brown, or white, and in various degrees to silvery. Hence the different hue exhibited by the rock, from the flesh-coloured granite of Scotland to the white of Cornwall. The coping-stones of Waterloo Bridge show the red, and the balustrades the white variety. The preceding ingredients enter into the composition of all true granite, but frequently one is unusually predominant, or entirely wanting and without a representative; or talc, hornblende, or hypersthene supply its place; or one of these is added to the three constituents, and hence the following varieties:-

\section{Granite of Two Ingredients.}

Felspar and mica; quartz and mica, either uniformly mixed, as in Muncaster Fell, Cumberland, or in segregated portions, constituting graphic granite; quartz and lornblende; felspar and hornblende, common in Aberdeenshire.

\section{Granite of Three Ingredicnts.}

Quartz, felspar, and mica, uniformly blended, constituting the true specimen, or with distinet additional crystals of felspar, composing porphyritic granite, a fine example of which occurs near. Shap in Westmoreland; quartz, felspar, and mica, the quartz and mica very rare, and the felspar predominant, forming felspathic granite, the whitestone of Werner, eurite of the French, and compact felspar of English geologists; quartz, felspar, and talc or chlorite, the composition of the granite of Mont Blane; quartz, felspar, and hornblende, the Sienitic granite; mica, quartz, and hypersthene.

\section{Granite of Four Ingredients.}

Quartz, felspar, miea, and hornblende, or actinolite; quartz, felspar, mica, and compact felspar, or porcelain clay; quartz, felspar, horn-

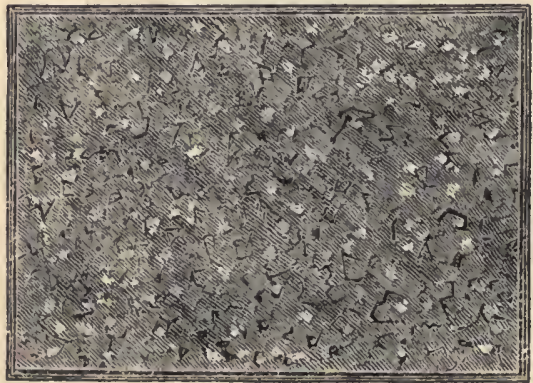

blende, and chlorite, or steatite.

Graphic granite, a binary composition, is so called from an arrangement of the quart $z$ and the felspar, which gives to the surface of the rock, upon being polished, the appearance of an inseription with Arabic or Oriental characters. The aecompanying cut represents an exanple from the northern United States. It is only found in veins. One of its best-known localities in our own country is Portsoy, on the coast of Banffshire, where a vein occurs in mica-slate.

Sienitic granite, a ternary compound, in which hornblende, either wholly or partially, supplies the place of mica, giving a darker hue to the mass, has received its name from Syene, in Upper Egypt, where it is found in great abundance, and is the common material of the ancient monuments in that country, the Pyramids and Pompey's Pillar. When it was ascertained that Mount Sinai, in Arabia, was composed of it, one of the French 
geologists proposed the substitution of Sinaite for Sienite, but the suggestion has not been adopted. In the Malvern Hills, and those of Charnwood Forest in Leicestershire, common granite is found frequently passing into the sienitic variety, in the same bed.

Diorite or greenstone is but little different from the sienite, containing a larger proportion of hornblende or augite; the latter an earthy mineral, usually of a greenish hue. It might therefore be called dioritic granite. The block out of which the head of Memnon (in the British Museum) has been hewn, exhibits an instance of sienite passing into greenstone in the same mass.

Hypersthenic granite is another variety, formed by scattered crystals of mica in an admixture of quartz and bypersthene, an earthy mineral, so denominated from the Greek, in allusion to its difficult frangibility.

Granite forms what may be called the skeleton of the solid crust of the earth, of which the various systems of strata are the clothing; for wherever these are seen to their very base, they are invariably found in all parts of the world to rest on true granite, or some of its varieties. It follows, that any idea formēd of its diffusion from what meets the eye is fallacious, for the superincumbent strata, in layers of enormous thickness, shroud it from the observation of man. It may be regarded as a universally diffused rock, entering into the composition of the whole lower portion of the solid shell of the globe. But in various parts of the world it appears at the surface, rising in lofty mountains above it. The chief localities are:-

Great Britain-Cornwall, Devon, North Wales, Malvern Hills, Charnwood Forest, Cumberland, the Highlands of Scotland, Isle of Arran, the Wicklow Mountains in Ireland.

Europe-Finland, the Dofrafield Mountains, the Hartz, the Black Forest, the Alps, the Pyrenees, the Carpathians, and Central France.

Asia-Siberia, the Caucasian, Uralian, Altai, and Himmalayan ranges.

Africa-Mountains of Upper Egypt, the Atlas Mountains, at the Cape of Good Hope, where it forms the base of the Table Mountain.

America - Cape Horn, the Andes, sides of the Orinoco, Venezuela, Mexico, New York, Pennsylvania and Virginia, Greenland, Melville Island.

In the ligher mountains of the Swiss Alps, granite is usually confined to the base, the summits consisting of sedimentary strata; but in those of Savoy, protogine, a granitic variety, in which there is little or no mica, but talc or chlorite, or steatite in its place, appears at their very crests, forming the top of Mont Blanc, which rises to the height of upwards of fifteen thousand fect above the level of the sea. The Himmalaya runge ascends to a far greater altitude, but the uppermost ridges appear to be composed of stratified rocks; and the summits of Chimborazo, Antisana, and Pichincha, in the Andean chain, consist of vast masses of porphyry, basalt, and modern volcanic matter, the granite only appearing at the height of between eleven and twelve thousand feet. When Humboldt was exploring the Andes, he found the granite so covered over with other rocks, that he thought a person might travel for years through the mountain districts of Peru, without even suspecting its existence there. Probably, therefore, in the instance of Mont Blanc, granite occurs at its greatest elevation upon the face of the globe. Saussure reached its crest in the year 1787, after eighteen hours' hard and incessant labour, besides several spent in repose and refreshment. At four o'clock in the afternoon of the second day occupied in the journey, he pitched his tent on the second of the three great plains of snow intervening between Chamouni and the top, nine thousand three hundred feet above the level of the sea. The next day the summit was gained at eleven o'clock, where he remained five hours, and made many observations. "From this elevated observatory," he states, "I could take in at one view, without changing my place, the whole of the grand phenomenon of these mountains; namely, the position and arrangement of the beds of which they are 


\section{6}

GEOLOGY.

composed. Wherever I turned my eyes, the beds of rock in the chains of secondary mountains, and even in the primary mountains of the second order, rise toward Mont Blanc and the lofty summits in its neighbourhood. The escarpments of these beds of rock were all facing Mont Blanc; but beyond these chains were others, whose escarpments were turned in a contrary direction. Notwithstanding the irregularity in the forms and distribution of the great masses that surround Mont Blanc, and those which constitute the mountain itself, I could trace some features of resemblance not less certain than important. All the masses that I could see were composed of vertical plates, and the greater part of these plates were ranged in the same direction - from north-east to southwest. I had particular pleasure in observing the same structure in the lofty peak of granite called the Col du Midi, which I had formerly endeavoured, but in vain, to approach, being prevented by inaccessible walls of granite. After the second day's ascent, this lofty pinnacle was beneath me; and I fully convinced myself that it is entirely composed of magnificent plates of granite, perpendicular to the horizon, and ranging from east to west. I had formerly been induced to believe that these plates were folded round the peak, like the leaves of an artichoke; but this was an optical illusion, when seen imperfectly from below. Here, where the eye could as it were dart clown into the interior structure of the mountains, the plates of rock appeared regularly parallel in a direct line. I was also particularly desirous of ascertaining, whether the vertical beds were composed of the same substances at their summits as at their bases, where I had so frequently inspected them; and I am perfectly satisfied, from actual examination, that they preserve the same nature through their whole extent, and are the same at the summit as below." The vertical position of the beds of granite conposing the chief part of Mont Blanc, and the Col du Midi, together with the same arrangement of adjoining stratified formations, and their general direction towards the point of highest elevation, profoundly impressed the mind of Saussure with the conviction, that this configuration had been produced by forces acting from beneath. Viewing, however, the Alps in the mass, we do not contemplate the effect of a single operation of nature, as was formerly imagined, but the result of successive elevations taking place after great and unequal intervals.

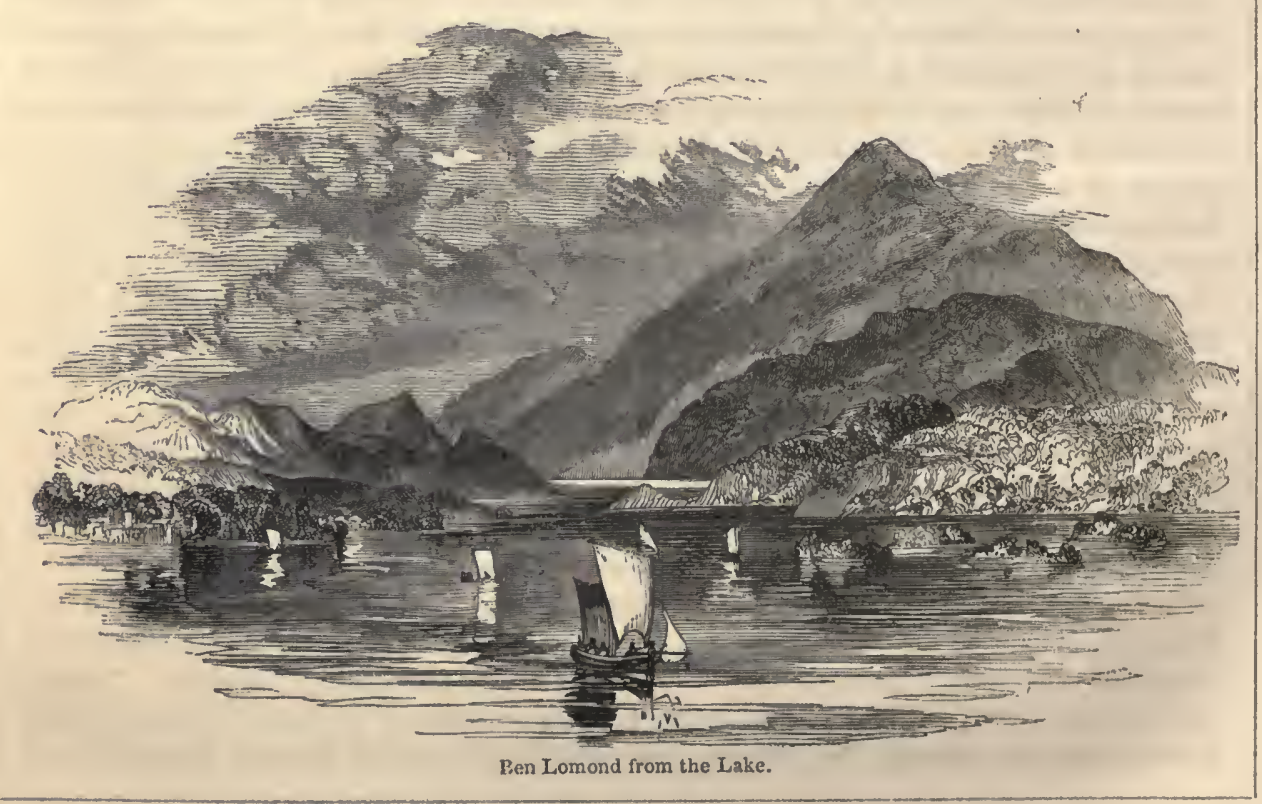




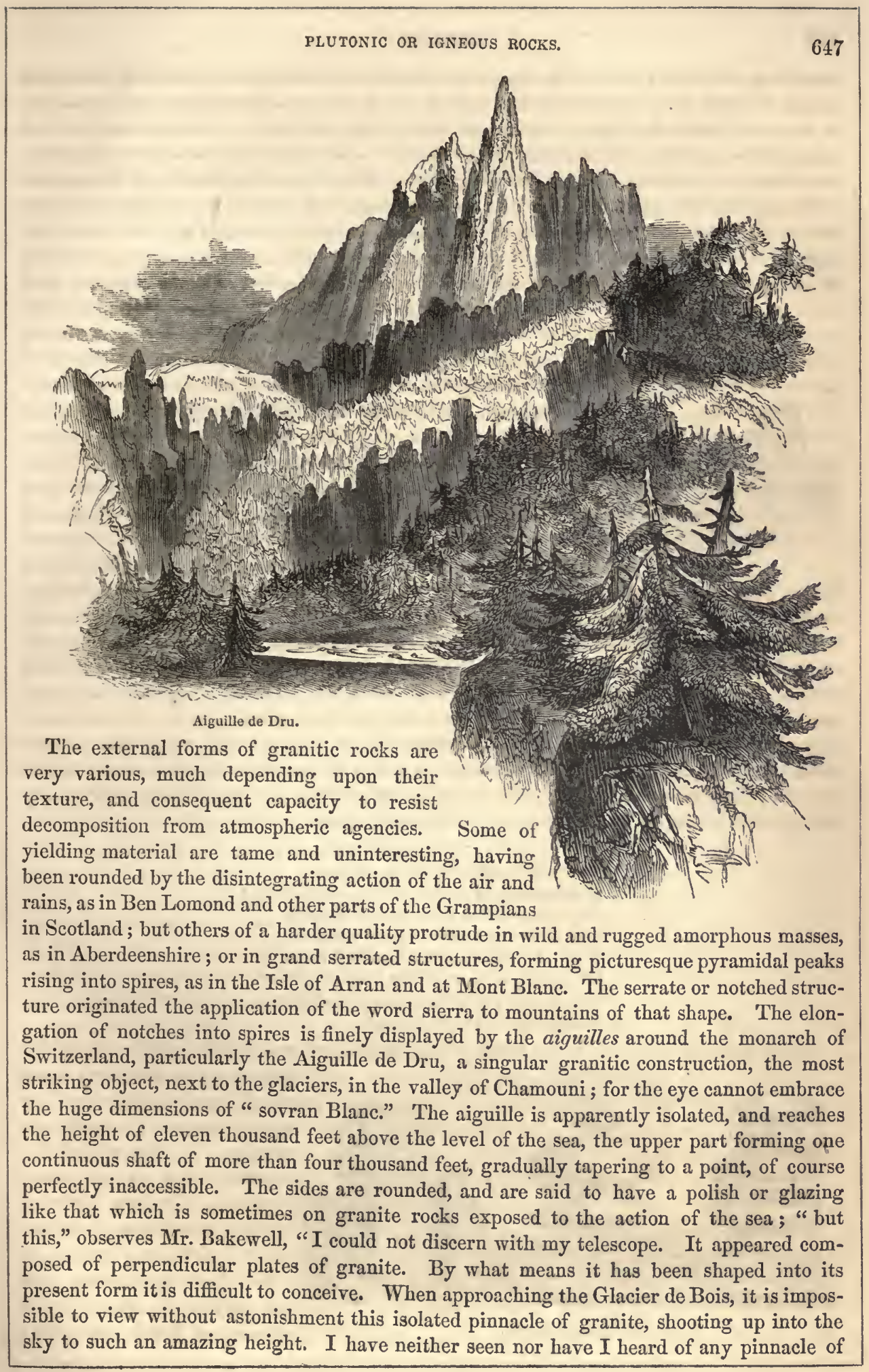


granite in the Alps that can be compared with it for the elegance of its form, or for the length of its shaft. The Geant, it is true, is nearly equal to Mont Blane in height, but it does not rise so far above its base as the Aiguille de Dru." The view exhibits this extraordinary shaft - the Aiguille Verte behind it - the Glacier de Bois descending into the valley, a continuation of the Mer de Glace - and the Arveiron flowing at the bottom.

Though several specimens of ancient art are composed of granite, and, as the monuments of Egypt bear witness, are of extreme durability, having stood the wear and tear of thousands of years without much injury, - the existing state of granitic rocks of the hardest texture significantly intimates the destructive effect of agencies acting upon

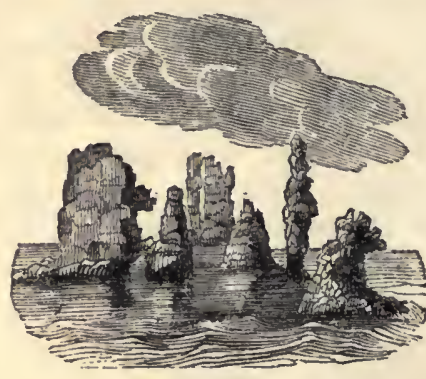
them through longer intervals of time. A great number of examples occur around the islands of Seotland, of huge masses of granite having been worn away, and separated into fragments, by the action of the sea, as here represented: while to the north of Aberdeen, the bold granite coast has been singularly hollowed out, by the play of the waves, into arches and caves - the Bullers of Buchan, so called from the peculiar noise produced in them by the stormy ocean; and the summit of Mount Bennachie supplies an example of the manner in which granite yields to the decomposing power of the atmosphere, having been separated into luuge masses or blocks, irregularly piled, by the mouldering away of the base or paste. 'The felspar' constituent is the first to decay, and that rapidily, if it contains soda or potash in cxcess, crumbling into sand and dust, which the rains carry down into the valleys, and accumulate in beds of clay, in which state the Chinese employ it in the manufacture of their finest porcelain. The celebrated Logan stone near the Land's End in Cornwall-an enormous mass of granite, said to weigh more than sixty tons - wlich is so delicately poised on the top of other rocks, that a slight foree, the strength of one man, is sufficient to set it in motion - is an instance of this process. Tradition, indeed, regards it as a contrivance of the Druids, which they employed as an engine of superstition - a kind of ordeal.

$$
\text { "Behold yon huge }
$$

And unhewn sphere of living adamant,

Which, poised by magic, rests its central weight

On yonder pointed rcek : firm as it seems,

Such is its strange and virtuous property,

It moves obsequious to the gentlest touch

Of him whose breast is pure; but to a traitor,

Though e'en a giant's prowess nerved his arm,

It stands as fixed as Snowdon."

The position of the stone is the result of the natural process of disintegration, by which

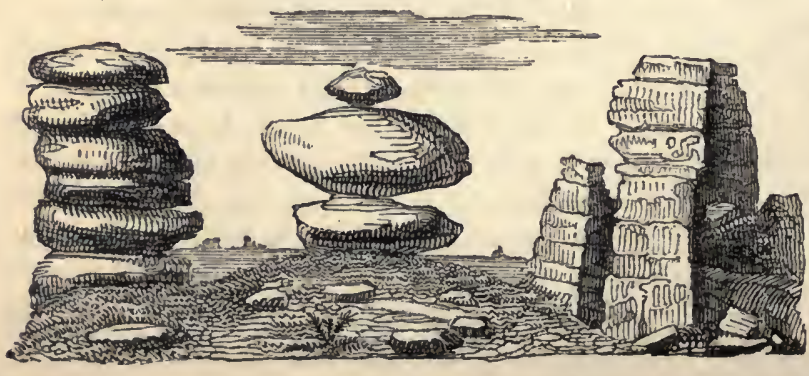
granite rocks are often separated into rhomboidal or square masses, gradually assuming a spheroidal or rounded form as the decay proceeds. De Luc observed in the mountains of Silesia several of these spheroids, so piled upon each other, that he compared them to a Disintegrated Granite. number of Dutcli cheeses, as 
represented in the preceding figure. D'Aubuisson mentions, that in a hollow way which had been only six years blasted through granite, the rock was entirely decomposed to the depth of three inches. He also states, that the granite country of Auvergne - the Vivarais and the eastern Pyrenees - is frequently so.much decomposed, that the traveller may imagine himself on large tracts of gravel. But this is owing to a cause peculiar to the district, the large development of carbonic acid gas, which produces the granite-rot, styled by Dolomieu la maladie du granite, the rock subjected to its action crumbling to pieces in the liand. Nevertheless, great durability is the prevailing characteristic of granite, and hence its extensive employment in the construction of our docks and bridges, where that quality is of the first importance.

Various minerals occur in granite besides those which enter into the composition of the rock, either traversing it in veins, or imbedded in it as crystals - as tourmaline,

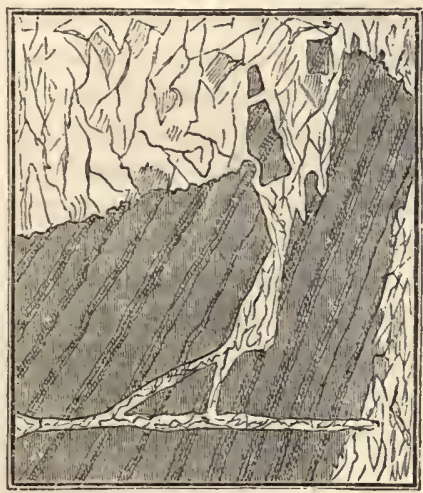

Granite Vein in Grauwacke. emerald, berge, topaz, garnet, and fluor-spar. Large curved crystalline prisms of tourmaline are found in the granite at Portsoy in Banffshire, in Norway, the Tyrol, and Saxony; a village in the latter country, where it is met with, giving to the mineral its other name of schorl. The Mourne granite mountains in Ireland contain topaz, associated with berge; and large and magnificent crystals of the former are furnished by the district of Cairngorm in Aberdeenshire. They are common also with emerald in the Uralian and Altai ranges. Among the metalliferous minerals, tin chiefly occurs in Cornwall and Saxony, but iron is found in the Piedmontese Alps and the Pyrenees, and occasionally silver.

The fact of granite traversing the stratified formations in veins of fantastic description has already been noticed. 'This is a proof of the fused and melted condition of the rock when erupted, in which state it flowed into cracks and fissures of the superincumbent strata. Above is a striking example, given by Sir

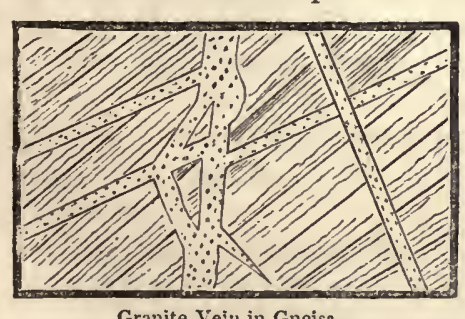

Granite Vein in Gneiss.

James Hall, of the Loch Dee granite, in Wigtonshire, invading the grauwacke, near the top of the hill of Lauren. Several other junctions occur in the same neighbourhood, the granite meeting the nearly vertical strata at various angles, sometimes in reins nearly a hundred yards wide, but gradually thinning out. An instance, from the upper basin of the Spey, of granite veins penetrating the gneiss in a direction parallel to the strata, and joining together, producing apparent alternations of the two rocks, is here given. In such cases the posterior formation of the granite to the invaded strata is very evident; and in fact, whilst the granite goes

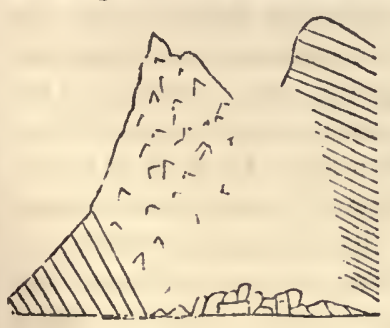
back to the earliest stage of the earth's history of which we can catch a glimpse, - the oldest stratified rocks, the gneiss, and mica schist systems having been formed out of its disintegrated material, - we have numerous examples of its having erupted at a comparatively modern date, -instances of granite formations in every subsequent geological epoch, down to the tertiary period, being found.

In this cut, an example is presented from the Alps, of beds belonging to the upper secondary strata, - kindred to our magnesian limestone, lias, and oolite, - uplifted and turned back by the intruding 
granite; but in Charnwood Forest, in our own country, beds belonging to the same

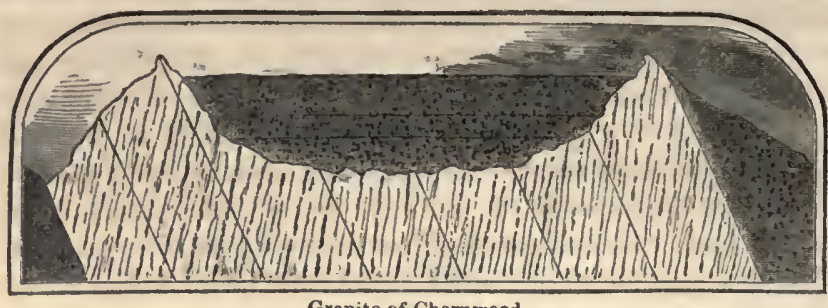
series lie horizontally upon the abrupted granite, here shown. It follows that the granite of Charnwood was clevated before the deposition of the strata, and the granite of the Alps subsequent to it; and as simiGranite of Charnwood. lar calcareous formations, containing similar organic remains, must be regarded as of contemporaneous origin, we are here presented with an instance of granites of different ages, the English older than the Alpine. Nothing can be more conclusive upon this point than the circumstance of granitic veins traversing granite, an example of which is given, from the vicinity

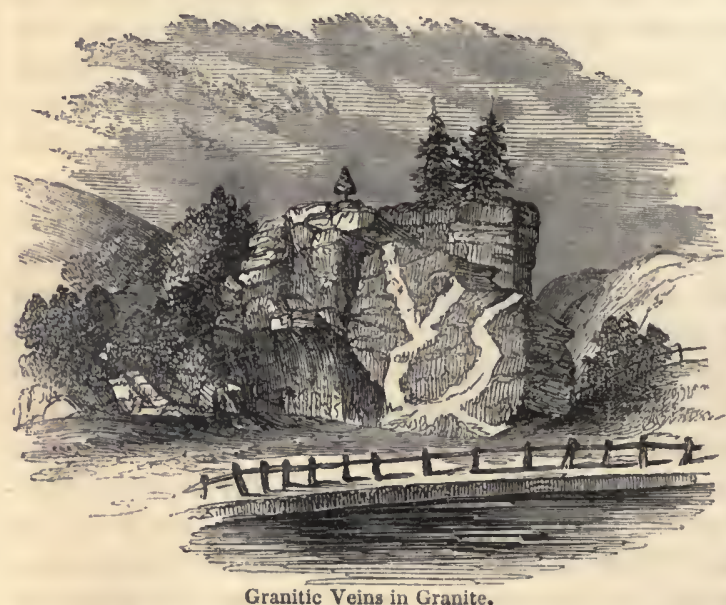

Granitic Veins in Granite. of Carlsbad in Germany, decisively proclaiming the two eras of the formation of the mass. In the Pyrenees, according to $M$. Dufrénoy, granite veins occur in limestones referable to the upper secondary strata; at Weinbohla in Saxony, and in the county of Antrim in Ireland, the chalk belonging to the same scries is overlaid by the granite, which shows its production at the epoch of the chalk; and M. Von Bûch, De Beaumont, and De Luc refer the elevation of the granite of the western Alps, extending from the Mediterranean to Mont Blanc, to the still more recent tertiary era, and the eastern range is supposed not to have been upreared until after the deposition of all the tertiary strata. Mr. Darwin, also, has advanced the opinion that the granite of the South American Cordilleras is of the same comparatively modern date, and has entered and contorted beds belonging to the tertiary series.

There are several igneous rocks, which, though not mineralogically granitic, are commonly classed with the granite group, as primitive porplyry, whose base is felspar; diallage-rock, a compound of diallage and felspar; and serpentine, which forms large masses in its simple mineral state, but is more frequently combined with diallage.

Diallage - the saussurite of some French writers, from its being first noticed by Saussure scattered in loose blocks over a valley near the Lake of Geneva, and the gabbro of Von Bûch - is generally of a greenish colour, and sometimes so unconquerably hard as to defy all attempts to remove it by blasting. It occurs in the valley of Saas in the Haut Valois, enormous blocks being brought down by the glaciers which descend from Mont Rosa. It is found there also in beds, and on the Italian side of the Alps, in the Apennines, in Norway, at the North Cape, and in other districts. Diallage was known to artists long before it attracted the attention of geologists. The Grand Duke Ferdinand de Medicis caused numerous blocks of it to be transported from Corsica to Florence in 1604, where, under various forms, it ornaments the Laurentine chapel. On account of its great hardness and peculiar tenacity, it is used in Vienna as the ordinary paving-stone. 
Serpentine-often in alliance with diallage-exhibits shades of light and dark green with red varieties, has an unctuous feel, and a strongly argillaceous odour. It is found in

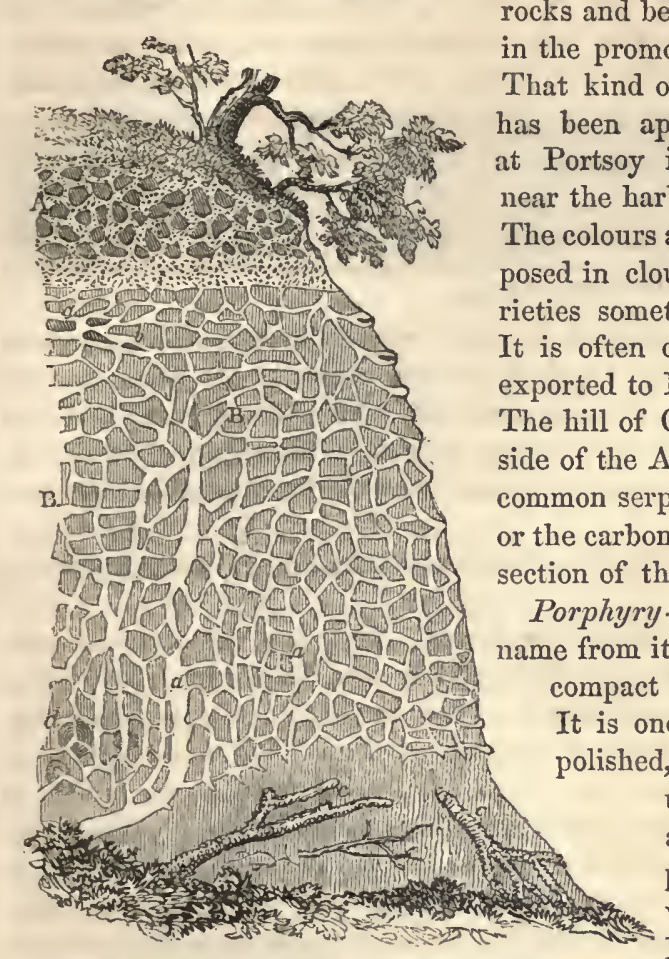

$A$, diluvium or alluvium, composed of rolled pebbles and reddisl sand. $B E$, mass of pale green disintegrated serpentine, in which reins of magnesite wind and osculate. $a \boldsymbol{a} a$, veins of magnesite. $b$, chalcedony ln mammillated plates, in the midst of some of these veins. $c c$, veins of green concretioned hornstone, d, nodules of
brownish-green felspathic serpentine in concentric layers.

superimposed upon a plateau of granite. irregular four-sided prism of primitive porphyry, of a dark grey or black colour, denote any particular kind of rock, but only a certain structure of rock, which will be noticed under the next group.

Trappean Rocks. - We derive the word trap from the Swedish Trappa, a stair, applied to certain unstratified rocks, because of their frequent arrangement in the form of a series of steps. The term is somewhat loosely employed; but the rocks included in the class it designates consist essentially of felspar, in combination with hornblende or augite, or with both. It embraces several species, which are very generally diffused over the globe, and furnish indisputable evidence of having been protruded from below in a state of fusion, disturbing the sedimentary strata by their irruption, and becoming associated with them in overlying masses, or injected into fissures produced by the disturbance, forming dykes and interstratifications. They belong, apparently, to all ages, from the time of the older granites to recent epochs; and while in many instances they are similar to the products of active volcanoes, in other cases they so much resemble the granite and its kindred rocks, that, taken metaphorically, their generic title, as Mr. Bakewell observes, becomes extremely appropriate, as these rocks offer a series of gradations, or steps, by which the geologist may pass from the lava of Etna to the most ancient terrestrial formations. The igneous origin of the members of the trap family is very clearly shown by a 
common appearance exhibited in the carboniferous system, that of the coal being reduced to a cinder, and eonverted into coke, in contact with the trap dykes, which intersect the strata. In general, also, strata of every kind require a greater degree of induration in contiguity with trap rocks, loose grits passing into compact quartz, and shales into flinty slates, evidencing the action of a high temperature upon them. The engraving represents

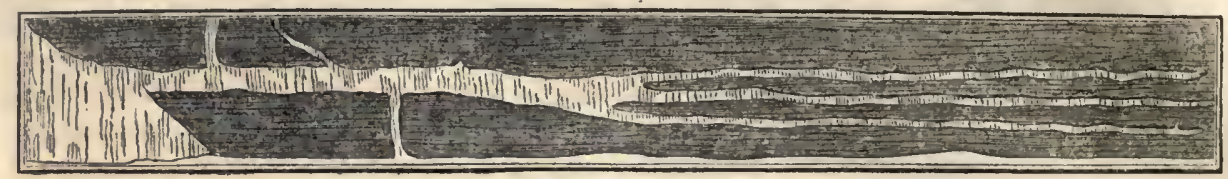

Thrèe Positions of Trap.

a section of the sandstone strata, in the cliffs on the east coast of the Isle of Skye, which exhibits all the three modes of position assumed by the trap rocks, in the same mass of trap. To the left a large mass appears overlying the strata; from this a horizontal bed runs conformably through the midst of the strata, ultimately beeoming divided into beds, three smaller interstratifying the sandstone; and from the horizontal bed the trap diverges in dykes, or walls.

The following principal members of the trap family are selected for description and remark.

Greenstones. - These are popularly called whinstones. They are the most common speeies of trap, and are ordinarily composed of hornblende and felspar in nearly equal proportions, and less commonly of augite and felspar. When the hornblende preponderates, the rock so formed usually receives the name of hornblende rock. When the grains of felspar and hornblende are quite coarse, the result is sienitic greenstone, which is frequently found in combination with quartz, and then passes into sienitic granite. But the varieties are numerous, and are differently distinguished in the geological nomenelature. The columnar or prismatic strueture is not unfrequently displayed by greenstone, sometimes rudely, as at Corygills in the Isle of Arran, but in other cases, in a very definite and magnificent manner. It is found in almost every region of the globe, and is abundantly distributed through the coal strata of Great Britain. In the Corstorphine Hill, near Edinburgh, the sandstone is capped with greenstone, a liundred and fifty feet thick, composed of felspar and hornblende, disposed in beautiful stellar concretions, of a yellowish-green live. It oceurs, in the same locality, in the Salisbury Crags, and in Arthur's Seat.

Basalts.--This variety of that mass of melted rock which has been ejected at different periods from the interior regions of the globe is substantially identical with greenstone in mineral composition, consisting of hornblende and felspar, or augite and felspar ; but these ingredients are more intimately combined and finely granular. A considerable per-centage of oxide of iron is also found in basalt, and distinct grains of olivine, a variety of chrysolite. The rock has a compact and uniform texture, and a grecnish or iron-grey colour, approaching to black. It occurs in very extensive masses, constituting many thousand square miles of the surfaee of the Deccan in India. Basalt forms dykes and horizontal beds, in both of which it very frequently displays the columnar and prismatic structure, which has rendered it an object of great popular interest. Viewed from above, the tops of a number of basaltic columns appear like a pavement artificially composed of hexagonal or polygonal pieces of stone, nicely fitted into each other, as in fig. 1. Viewed laterally from a distance, a range may readily be mistaken for a pile of buildings - the frequent appearance of the basalt which rises up suddenly from the plains of the Decean. Viewed in the same direction, in situations where the columns are jointed, and have been exposed to the destructive action of the ocean, the mass resembles a building in ruins, as 
in fig. 2. Fig. 3 represents a specimen of horizontal basalt. Two beautiful examples of basaltic columns are at Staffa, one of the Hebrides, and in the county of Antrim on the

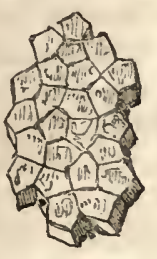

Fig. 1.

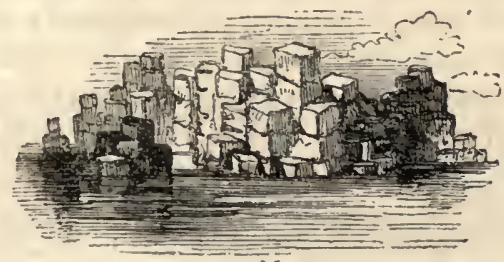

Fig. 2.

north coast of Ireland, where they form the celebrated Giant's Causeway. The latter is a platform running out

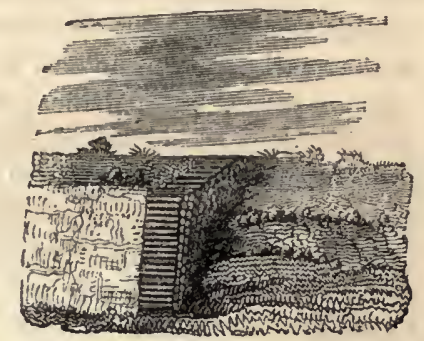

Fig. 3.

into the sea, composed of the most compact and homogeneous rariety of basalt, whicl is more or less sonorous when struck with a hard substance. The columns forming the causeway rarely exceed a foot in breadth, and thirty feet in height. They are chiefly liexagonal, but polygons, of five, seven, and eight sides, are of frequent occurrence; and there is one example of a triangular prisn. It is not, however, at the Causeway that the largest-sized columns are found. Fair-head, the highest promontory on the coast, rising five hundred and fifty feet above the level of the sea, is entirely composed of them, some of which, according to the accurate measurement made during the recent Ordnance trigo-

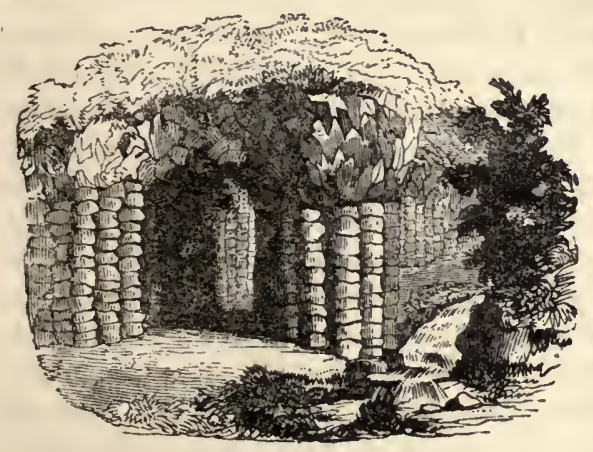

Grotte des Fromages. nometrical survey of Ireland, are 317 feet in height, the sides of these enormous prisms occasionally measuring five feet. The vicinity of the Causeway affords numerous proofs of the basalt having been erupted in a state of fusion from lieat, in the effect produced upon the secondary strata in contact with it, the old red sandstone being changed into hornstone, the clay-slate into flinty slate, the coal into coke, and the chalk into granular marble. The accompanying illustration represents the basalt rocks at Bertrich-Baden, called the "Grotte des Fromages," from its resemblance to a pile of cheeses.

Wacke and claystone are soft varieties of basalt, having an carthy admixture under different degrees of induration. Clinkstone is a basalt in which the felspar greatly predominates, and the texture becomes very compact and hard, so as not to be easily scratched with a knife. 'The rock is of a massive structure, not crystallised, and of a greenish or iron-grey colour. It derives its name from yielding a metallic sound upon being struck, and closely resembles the basalt of the Causeway, sometimes exhibiting the same columnar structure, as in Swarthfell in Cumberland, where it is defined upon a magnificent scale. Pitchstone, another basalt, containing a portion of bitumen, is of a glassy green colour, resembling obsidian or volcanic glass. It occurs in veins in the Isle of Arran, and in the county Down in Ireland; and is found extensively in the hills around the valleys of Tribioch near Messein in Saxony. The lofty promontory called the Scuir of Egg, in the island of that name, one of the Hebrides, is a gigantic pitchstone vein, which seems to have been left in the destruction of the surrounding rocks. 'The promontory rises 1339 feet above the sea; and the pitchstone, which is intensely black, with crystals of glassy felspar, forming a substance of great beauty, is arranged in columns, 
which exceed in grandeur, and in picturesque effect those of Staffa. "The promontory," says Dr. Macculloch, "rests on a bed of compact grey limestone, approaching to a stone marl. This bed, which is three or four feet thick, rests on a still lower bed, of hard reddish stone. Masses of bitumenised wood, penetrated with carbonate of lime, are found in the marl stratum, not at all flattened. Portions of trunks of trees, retaining their original shape, but petrified, are found in the same stratum; the rifts are filled with chalcedony, approaching in aspect to semi-opal. The columns on this island are both perpendicular and inclined, and some of them are bent or curved." They vary from two feet to a few inches in diameter.

The varieties of basalt are frequently associated with and pass into each other. Where the columnar structure is not distinctly defined, there is often a tendency to it plainly developed, as in the basaltic hills near Dudley; while many basalts, which are non-

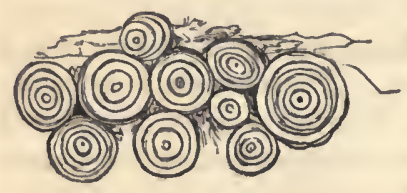

Fig. 4. columnar, upon a section being made, or decomposition taking place, exhibit a globular construction, as in fig. 4, similar to that of a number of hard balls imbedded in a softer cementing mass. The most important example of the occurrence of basalt in dykes is the great Cleveland basaltic wall, which cuts through various strata - the coal measures, red sandstone, and lias - in its course of from fifty to sixty miles, extending from the west side of the county of Durham, across the Tees, and through the Cleveland Hills in the East Riding of Yorkshire, to the sea between Scarborough and Whitby, probably entering the bed of the German Ocean. "The effects of this basaltic dyke on the different rocks through which it passes are truly deserving notice. When it comes in contact with limestone, the limestone is often found granular and crystalline. When it crosses the coal strata, and comes in contact with seams of coal, the substance of the coal is for several feet converted into soot. At a greater distance from the basalt the coal is reduced to coke or cinder, which burns without smoke, and with a clear and durable heat. At the distance of fifty feet from the dyke, the coal is found in its natural unaltered state. The formation of basaltic dykes is sufficiently explained by what takes place in the vicinity of volcanoes. Before the confined vapour that afterwards issues through the crater finds a vent there, the surface of the ground in the vicinity of the volcano is frequently upleaved, and fissures of great extent are made, into which melted lava is sometimes forced, which, on crossing, forms a wall or dyke, in every respect similar to a basaltic dyke. During an eruption of Vesuvius that took place in 1794, a vent of this kind was formed near the bottom of the mountain, 2375 feet in length and 237 feet in breadth, which became filled with compact lava. Rents or fissures, of some miles in length, have been opened on the sides of Etna."

Porphyries. - It has been previously observed that the term porphyry is not now employed to designate any particular kind of rock, but to denote all rocks which have a homogeneous, compact, or earthy base, through which are disseminated crystalline masses of some other mineral of contemporaneous origin with the base. It refers, therefore, to a distinctive mechanical structure, and not to any peculiar mineralogical composition. The substance that forms the base of the rock gives the name to the porphyry. Hence we may have-

Felspar porphyry - base of felspar, with crystals of quartz, or mica.

Greenstone porphyry - base of greenstone, with crystals of felspar, quartz, or calcareous spar.

Claystone porphyry - base of claystone, with crystals of felspar.

Pitchstone porphyry - base of pitchstone, with crystals of felspar.

Porphyry, in its several varieties, occurs in amorphous masses and in veins; and frequently 
presents that stair-like appearance which has originated the use of the word trap. Fig. 5 is an example of this arrangement, from the neighbourhood of Kirkcudbright in Scotland,

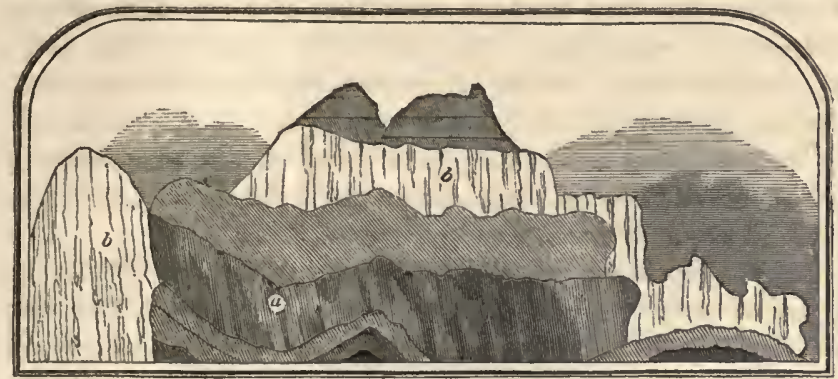

Fig. 5. $a$, Grauwacke. b, Porphyry. which shows the outcrop of the porphyry on one side, forming steps, and on the other side, a projecting vertical mass. Strictly speaking, the former alone is trap-porphyry. The porphyries are frequently associated with primary strata, and with granite. They are in general of more ancient date than the basalts, which are commonly in conjunction with secondary rocks. The tops of the Andes are enormous porphyritic piles, so arranged, according to Humboldt, as to strike the eye of the traveller like immense castles lifted into the sky.

Amygdaloids. - This is also a term denoting a structure occasionally assumed by all the members of the trap family. It indicates generally a base of fine-grained basalt, of a loose earthy texture, in which pores or rounded cavities occur, which have been subsequently filled up with fluid solutions of various mineral substances, and become consolidated into nodules of calcareous spar or green earth, and more rarely of chalcedony and zeolite. Hence such rocks often present the appearance of a paste studded with almonds, which has originated their generic title of amygdaloids, from amygdalea, an almond. The rock familiarly called toadstone in Derbyshire is an amygdaloidal trap, consisting of a finegrained basalt paste of an iron colour, containing nodules of whitish calcareous spar and green earth, varying in size from small spots to that of hazel-nuts. Where the decomposition of these nodules has been effected, the toadstone assumes a vesicular and lava-like character.

There is no part of Great Britain, and but few places on the globe, which present so great a variety of the igneous products noticed, within such narrow bounds, as the island of Arran, off the coast of Scotland, lying in the bay formed by the peninsula of Cantire and the Ayrshire shore. It is about twenty miles long by half that number broad. The northern part of it consists of a great central mass of granite, which protrudes the stratified formations of mica-schist and sandstone in a group of grand picturesque serrated mountains, distinguished by their spiry forms, stupendous precipices, and general destitution of vegetation. Goatfell, or, according to the Gaelic, Gaodl Bhein, the "Mountain of Winds," the highest of them, rising to the height of 2875 feet, as estimated by a trigonometrical observation of Macculloch's, has an obtuse pyramid of granite for its summit, consisting of large blocks, completely barren, with the exception of a few lichens. In other parts of the island, the granite is often prismatic or cuboidal, forming immense tabular masses, giving it the aspect of stratification. In the southern district the red sandstone is the predominating rock. This is peretrated by numerous trap veins, consisting of dark porphyry with metallic diallage, black porphyritic greenstone, earthy greenstone, and claystone with nodules of green earth, all of which at several points are closely aggregated; and pitchstone has here one of its chief repositories, of which Macculloch has enumerated twenty-six varieties.

Volcavic Rocks. - We include in this class those ancient lavas and trachytic mountains, the formation of which took place in geological epochs antecedent to the existing arrangement of the earth, though of recent date, and clearly, from their nature, of volcanic origin. The principal ingredients of trachytic rock are glassy felspar, with some horn- 
blencle, mica, titaniferous iron, and occasionally augite. The name is derived from rpa$\chi v \varsigma$, rough, and expresses the harshness of the substance to the touch. 'Trachyte is of a whitish or grey eolour, and appears to have been an abundant product of voleanoes during the tertiary period, which have continued to the present to erupt trachytic lava. It oceurs largely in Hungary and Auvergne, and in vast quantities in South America, some of the loftiest heights of the Cordilleras being composed of it. 'The products of extinct volcanoes are entirely identical with those that are now active, and so strikingly resemble the older basalts and the other Plutonic rocks in general, that the common origin of the whole, modified by different circumstances, may be inferred.

There are no examples of igneous formation in process now within the bounds of our own island; but the granitic and trappean groups are abundantly disseminated, and bear witness to the fiery activity of former periods. Playfair estimated the granite in Scotland to occupy an area of 940 geographical square miles, equal to 1250 English miles, or about a twenty-fifth of the country; but a more recent estimate gives to the granite of North Britain an area of 1760 miles. In England it is supposed to be under 300 miles, or 2000 in all; while the trap in both parts of the kingdom is not less than 3000 square miles, making the whole extent of the igneous formations in Great Britain amount to 5000 miles; about one seventeenth of the whole surface, the larger proportion of which belongs to Scotland. We must look for the origin of the Plutonic rocks to those interior regions of the globe from whence the igneous products of the present era are erupted; but while the formation of the different groups has transpired from similar eauses, it has taken place under different circumstances. The granites, excepting the most ancient, have been erupted, cooled, and solidified, under the pressure of superincumbent strata; the traps have undergone the same process, under the depth and pressure of the ocean; and the voleanic rocks have refrigerated and become solid masses at or near the surface, in contact with the atmosphere. These diverse conditions will explain many diversities of strueture in these productions of the interior fires; and, as involving a different rate of cooling, they may account for the remarkable distinction between granitic veins and porphyritic and basaltic dykes, which has given rise to so much speculation. Granite and its varieties are found intruding into the minute fissures of the stratified masses, producing small diverging branches; while the trappean rocks generally pass through them without these ramifications. It seems likely that the circumstances under which the trap erupted admitted of a more rapid cooling and reduction to solidity than what obtained in the case of the granite. The latter retaining its fluidity longer, penetrated into the smail rents of the strata, which the former, for the reason assigned, had not the capacity to do.

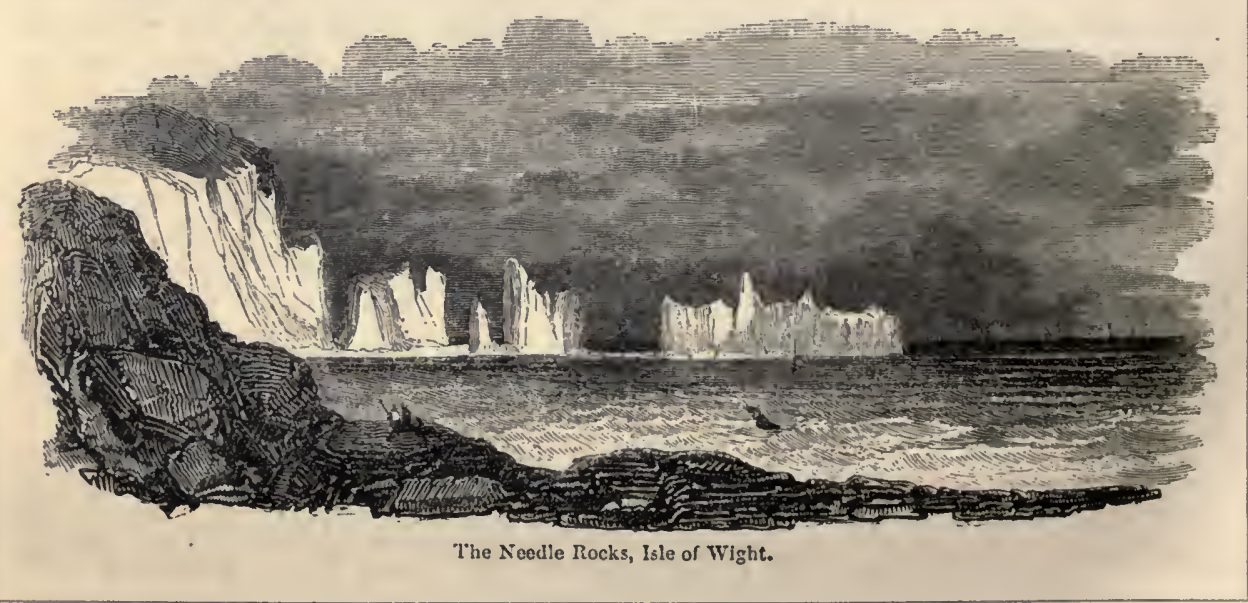




\section{CHAPTER III.}

\section{GNEISS, MICA SCHIST, AND CLAY SLATE SYSTEJIS.}

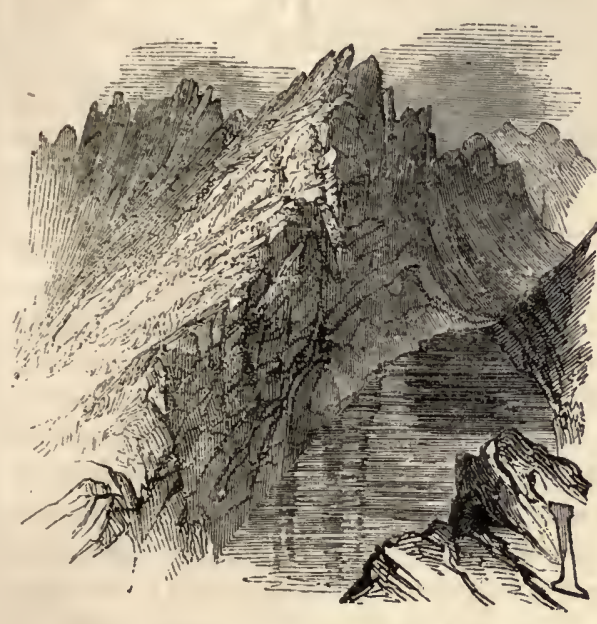

$T$ is an opinion sustained by the force of geological evidence, that a time has been, in the history of the earth, when it was in an incandescent condition - a molten mass of matter; but whether this was its first estate - the commencement of that cycle of change it has undergone - or merely another change from anterior solidity, is a point upon which geology can pronounce no verdict. The proof of the first hypothesis appears in the universal diffusion and igneous character of the granitic rocks, which, as we have had occasion to remark, while constituting some of the loftiest eminences of the globe, we are warranted in regarding as a vast crystalline floor, upon which all the stratified formations repose. The reader will bear in mind the fact, that at various eras subsequent to the first deposition of strata, the granite parement has undergone fusion, and becn protruded in a fluid state among the sedimentary formations. The production of a solid crust would be the result of this incandescent igneous mass losing its heat by radiation into surrounding space, and this crust would exhibit a surface diversified with inequalities, marked with projections and depressions, which may be called mountains, valleys, rents, and ravines, according as the various parts of the surface might radiate heat in an unequal manner. A strictly analogous case is the cooling down of a mass of metal after fusion in a furnace, upon which blisters and scoriæ are formed, presenting a similar proportion to the quantity of metal, as our highest mountains at present do to the mass of the planet. Upon the ordinary atmospheric and aqueous agencies, - the decomposing energy of the air, the fall and percolation of rains, - and the flow of streams coming into play on a solid rind thus diversified - a consequent disintegration must have taken place, and the carrying away of the abraded material held in suspension or solution by the rivers, with its ultimate deposition at the bottom of those basins into which they discharged their waters, would be the result. In this manner we have strong grounds to believe that the first stratified rocks were produced-the gneiss and mica-schist systems-as well as all subsequent deposits; for it is in harmony with operations that are clearly traceable as in progress in the existing constitution of the earth.

The gneiss and mica-schist with part of the slate systems form the primary strata of the improved Wernerian classification; the inferior order of Mr. Conybeare; the inferior stratified, non-fossiliferous group of Sir H. De la Beche; the metamorphic rocks of Sir C. Lyell ; and the Agalysian rocks of Alexander Brongniart.

Gneiss System. - The essential ingredients of gneiss are the same as granite-quartz, felspar and mica, or hornblende - but sometimes one or more of these minerals are absent, and other substances supply their place, which contributes to vary the general 
compound. The elements of gneiss, however, show decided symptoms of being less entire than in granite, having lost their asperity, had the sharp angles rounded or broken off, as if water-worn, and display, more or less, a laminated and stratified structure. These circumstances mark the aqueous origin of the rock, which, though obscure in some cases, so as to render it difficult to distinguish it from granite, are in general very well developed. Three principal varieties have been noticed :-

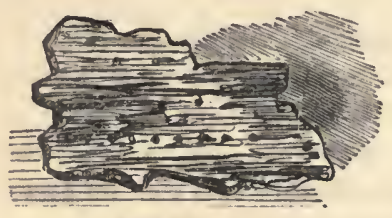

Mica Schist.

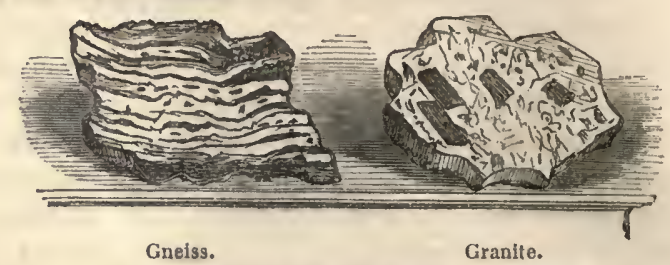

Gneiss.

Granite.

The granitic, closely resembling granite, the crystalline grain being large and distinct.

The schistose, having a slaty appearance, and easily splitting into layers.

The laminar, having the various minerals disposed in distinct alternating laminæ,

which give a striped appearance to the rock.

The last variety is represented above in contrast with granite. The lamina are frequently undulating and contorted in a very high degree, indicating " a troubled condition of the water from which the ingredients fell; or a source of agitation in the still yielding sediment, which seems scarcely ever to have occurred among the secondary and later strata. The only plausible explanation of this remarkable circumstance which has occurred to us," says Mr. Phillips, "is the agitation of the sea or the soft sediment on its bed by heat; exactly as in the bottoms of steam-boilers, the calcareous sediment is formed in irregular undulating laminx, which appear on a cross section very similar to the flexures in the laminæ of gneiss." Except in the variety which closely resembles granite, gneiss is very distinctly stratified, as in the beds about Loch Sunart in Argyleshire, the strata exhibiting considerable contortions and convolutions. The colour is usually of a greyish or reddish white, but has a darker tinge when hornblende instead of mica enters into its composition. Almost all the metals are met with in gneiss; the Saxon, Bohemian, and Saltzburg mines are worked in this rock; but in Great Britain the metallic ores are not rich in such situations. At Strontian in the Scotch highlands, a lead vein, occurring at the junction of the gneiss and the granite, was formerly celebrated.

Gneiss has a very wide geographical range, for hardly any considerable range of mountains occurs without it. In England and Wales it is scarcely known at all, but in Scotland it occupies an estimated area of 9600 square miles. The external aspect of the country in which it predominates has been thus described:- "Occupying large tracts of the central highlands, the characters which gneiss impresses on the scenery are very distinctly seen. It is the least picturesque and most monotonous of the primary rocks, the hills being flat and shapeless, and their sides embossed with small round protuberances, between which the water stagnates and moss accumulates. Most gneiss districts seem but a repetition of these features on a great scale, the hills being seldom serrated in outline, or broken into rocky cliffs; whilst the valleys or straths are wide and flat, full of small lakes or pools, and disfigured by brown heaths and dark morasses. It has altogether the aspect of a land newly raised from the ocean, in which the rivers have not had time to hollow out channels for themselves, or to complcte its drainage. In a word, all who are in quest of the picturesque should avoid the pure gneiss districts, as the few spots worthy of notice will be found separated by long dreary uninteresting tracks." One of these excepted spots, we may suppose to be Cape Wrath, the north- 
western point of Scotland. This is a lofty headland of gneiss, interstratified with hornblende, and intersected with granite veins. It projects far out into the rough Atlantic. The waves driven by the northern storms have cut deep fissures and caverns in the promontory; the pinnacles around it, and the rocks at its base starting up from the bottom of the ocean, striking the imagination as so many guards against the further invasion of the Cape.

Mica-schist System. The mica-schist is a compound essentially of quartz and mica, and thus differs from granite and gneiss by the absence of felspar as a constituent. Sometimes the mica predominates, or the quartz, and occasionally felspar occurs with other substances, as hornblende, chlorite, and talc, producing hornblende, chlorite, and talcose schists. Common garnet, also, and staulorite, are often so abundant as to become constituents, and originate the varietics of garnetiferous and staurolitiferous mica-schist. In some varieties, it exhibits a fine and regular laminar structure, which gives to the rock a fibrous aspect, as on the preceding page. In talcose and chlorite schist, the distinctive elements take the place of mica, quartz forming the other ingredient. They are usually found associated together, but the chlorite is more abundant than the talc, and easily distinguishable by the green colour, flexible structure, and soapy feel of its characteristic mineral. Hornblende-schist has a dark-green colour approaching to black, but it is of rare occurrence in an independent form, Ben Lair in Ross-shire being the principal mass in Great Britain. Mica-schist, on the contrary, is often silvery or pearly white with intermingling shades of grey. The same able Scotch geologist, whose description of the gneiss districts of his native country has been given, thus speaks of the associate system:- "Mica slate has but little economical value, though in exposed situations forming a useful substitute for roofing slate. Either alone or mixed with other beds, it forms extensive districts, whose scenery assumes various features, according to the power of the rock to resist decomposition. Where soft and easily destroyed, the mountain districts to which it is mostly confined are low, tame, undulating, and seldom broken by precipices or projecting cliffs; where it is hard and quartzose, they have.a more picturesque character, the hills rising to 4000 feet or upwards, and running out in long serrated edges, with peaked or dome-shaped summits, abrupt precipices, and deep craggy ravines, overhung with birch, or partially covered with vegetation. As illustrations of these, it is enough to mention Killicrankie, Loch Katterin, and the Trosachs, the fantastic ridges of Glencroe, or the bold, rugged, and sterile mountains on the west coast."

The annexed sketch exhibits the two great formations in their order of succession

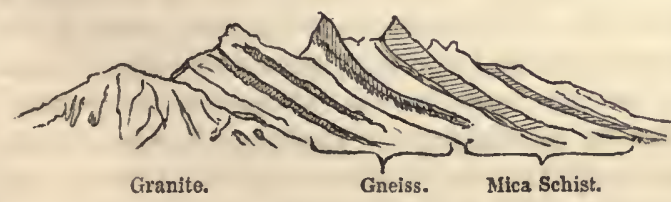

UPPER SERIES. Chlorite slates, apparently uniting the clay-slate and mica-slate deposits. No organic remains. It ranges on the whole south-east border of the Grampians, from near Aberdeen to Argyleshire.

Mtdple Series. Mica-schists, primary limestone, quartz-rock, in various combinations, the former by far the most predominant, the others only locally important; the limestone occurs in different parts of the series. That of Loch Earn, Inverary, and Balahulish, is in the upper part, approaching to chlorite-slate; that of Glen Tilt, and of the vale of Loch Tay, is in the lower part. No organic remains. This occupies a great part of the eastern and southern Highlands, the north-west of Ireland. 


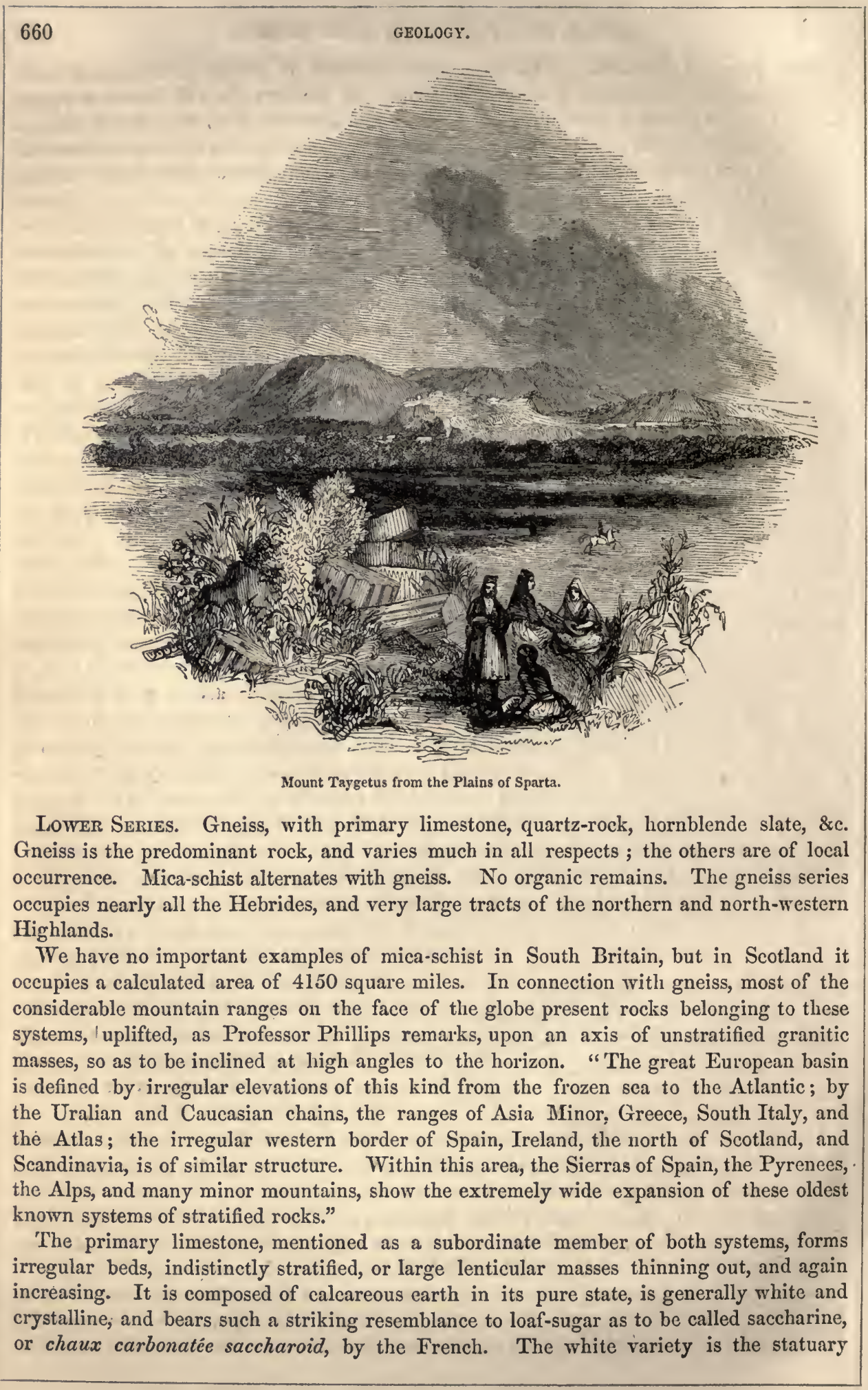


marble of Greece and Italy, but lead-grey, pink, green, and yellow varieties occur, and sometimes two or more varieties of these colours are united in stripes, spots, or veins. The texture is variously fine and large-grained, the latter distinguishing the marble of which the celebrated Duomo of Milan is constructed, which was taken from the micaschist of the lake of Como. The white crystalline limestone used in the arts is found abundantly in the Grecian Archipelago, the isle of Paros and the promontory of Athos being composed of it. It occurs also in the Apennines, Alps, and Pyrenees, and of inferior quality in different parts of Scotland, particularly in the isle of Skye. Another subordinate member of the gneiss and mica-schist systems - quartz-rock - is essentially composed of that mineral. The texture of the rock is either granular, the grains being large and distinct, or arenaceous, the grains fine and apparently in imperfect contact. 'The intermixture of other minerals gives rise to varieties, but in all its forms a distinct stratification may be traced, and when micaceous it divides even into thin flags. Quartz occupies very extensive tracts of country, either alone or in union with other strata, the beds varying in thickness from a few inches to one or two thousand feet. In Sutherlandshire, between Lochs Eribol and Assynt, and in the isles of Islay and Jura, large continuous tracts occur, which have a thickness of 2200 feet in the latter island. These regions have a very peculiar aspect, "the hills being in general conoidal, with a smooth flowing outline and few asperities, though with numerous scattered fragments. The soil that covers them is remarkable for sterility even in this land of barrenness; whilst their summits and declivities, refusing nourishment to the humblest moss, shine with dazzling whiteness. Of this kind is the conical Stack Balloch-nan-fey, the last remarkable unountain on the west coast, whose naked ridge of bright quartz shines in the sun like snow, and which was described by Pennant as marble."

It is impossible to make an accurate approximation to the thickness of these groups of strata, for the overlying masses prevent their being adequately explored, and cause our surveys to fall short of the full amount as to magnitude. But sufficient evidence is attainable to vindicate an estimate of several thousand yards, nay, even. several miles, from the charge of exaggeration, when applied to the thickness of these systems. An enormous demand is made upon time for the production of these immense beds, the sedimentary origin of which is proved by the water-worn aspect of their component ingredients, their leaf-like arrangement, and lines of stratification. To disintegrate to any considerable extent a solid rock - to transfer the material by a river-current to any oceanic site - to deposit it, and consolidate the deposition, are excessively slow operations, requiring the lapse of centuries to accomplish the formation of a thin stratum. We are certain, therefore, that the building up of the gneissic and mica-schist systems, by the abrasion of the granite, and the gradual deposition of the detached matter at the bottom of the ocean, must have required a period, with the vastness of which the mind can hardly grapple, though perfectly insignificant in His view, to whom "one day is as a thousand years, and a thousand years are as one day." Of these two groups, Dr. Macculloch remarks, "The thickness of these strata we know to be enormous, their depths are discovered by geological observations and inferences:- that they extend to many miles was also proved. - We have every reason to know, from what is now taking place on our own earth, that the accumulation of materials at the bottom of the ocean, is a work infinitely slow. We are sure that such an accumulation as should produce the primary strata as we now see them, must have occupied a space, from the contemplation of which the mind shrinks."

The gneiss and nica-schist systems, with a subsequent formation, belong to Sir C. Lyell's class of metamorphic rocks, or strata which have undergone various metamorphoses by proximity to great plutonic masses in a state of fusion. Besides the protrusion of melted 
granite in veins and beds among these strata, they have been invaded from below by other igneous rocks, the porphyries, greenstones, and basalts, which are found intermingled with them, forming dykes and disrupting masses peering up above them. Examples of this are of common occurrence in the Hebrides, and several parts of the Highlands. Reference has been made to the conversion of coal into colse in the neighbourhood of a trap dyke-a metamorphic change-and analogously, the gneiss and mica-schist strata, subjected to a high temperature by the invasion and interjection of heated masses forced up from below, have had much of their original character defaced, and have become in part crystalline, without entirely obliterating those traces of laminar and stratified arrangement which proclaim their origin. In those instances, where such traces are obscure in the gneiss and mica-slate, and they exhibit a pseudo-crystalline texture, presenting such a striking resemblance to granite as to render their identification difficult, the reason is, that besides being composed of granitic detritus, they have experienced metamorphic change, by the action of heat, through contact with masses protruded among them in a state of igneous fusion. In a similar manner, by the application of heat and pressure, the chemist may convert sandstone into quartz-rock, and carbonate of lime into crystallised limestone. From the contiguity of primary strata to granite, and the extensive prevalence of other igneous rocks by which they have been invaded, it is obvious that the absence of organic remains in them is not positive proof of a desolate world being contemporaneous with their deposition. It is certainly possible that the same cause which has rendered them metamorphic may have destroyed fossils imbedded in them, with all traces of their presence, so that we are not in circumstances to say, upon arriving at the era of extant remains, that here commences the chain of organic life, and that the globe, in antecedent ages, was a habitation without an inhabitant.

Clay Slate System.-This is the lower greywacke, a German miner's term for grey rock, also called the clay-slate or Cambrian and Cumbrian group. The latter denomination is that of Professor Sedgwick, from Cambria, the ancient name of Wales, and the county of Cumberland, localities where the formation indicated is largely developed. There is a grand general distinction in mineral composition between the two former systems noticed, which are eminently siliceous compounds, and the present, which is as eminently argillaceous, consisting of clays under different degrees of induration, having a fissile structure. It varies, however, from the finest clay-slates to conglomerates, which are fragments of quartz, felspar, and mica, united by an argillaceous cement. These conglomerates, especially in the upper part of the system, are interstratified with slates. Observing the order of superposition, Professor Phillips divides and arranges the system in the following manner :-

\section{UPPER OR CAMIBRIAN GROUP.}

Plynlymmon Rocks. - Hard, fine, sandy, or coarse grauwacke, and grauwacke-slate, without organic remains, which is locally productive of roofing slates, and generally traversed by an extraordinary abundance of symmetrical fissures. Wales, Cumberland, and Westmoreland, the Lammermuir Mountains, Donegal Range, borders of Dartmoor, North Devon, Charnwood Forest. Thickness, in the Cumberland tract, 3000 feet at least.

Bala Limestone. - Dark, slaty, calcareous rock, variously associated with the slate, and locally rich in organic remains, both in Wales and Westmoreland. Limestone of Ilfracombe and North Devon; of the Hartz, Norway, Brittany, \&cc. Thickness, in Westmoreland, 100 feet.

Snowdon Rocks. - In this division are rocks of various colours, green, blue, purple, \&c., and fine or coarse grain. Good roofing slate abounds, and the peculiar fissility, called 
cleavage, on which it depends, is very general in all the mass of rocks, which are some thousand fect thick, both in Wales and Cumberland. In both districts also the sedimentary rocks are much intermixed with porphyry and greenstone, both in seeming beds and dykes, and many parts of the slaty rocks themselves are really amygdaloidal, or else composed of fragments of porphyry and other igneous rocks. No organic remains have been found in the Cumbrian district, but they occur in Snowdon. Thickness, in Cumberland, 6000 feet at least.

\section{LOWER OR CUMBRIAN GROUP.}

Clay-slate. - This is a singular uniform mass of laminated argillaceous rock, of a dark colour and smooth texture, with vertical cleavage and symmetrical joints. It is devoid of organic remains.

Chiastolite-slate differs hardly at all from the preceding, except by including crystals of chiastolite and hornblende.

Hornblende-slate. - This is very different from the rock so named in Glen Tilt, for its basis is clay-slate, with intermixed crystals of hornblende or actinolite.

These three divisions may be about 3000 feet thick in Cumberland.

Passing through the series ascendingly, there is little occasion for remark in relation to the lower division. The actinolite is only a variety of the hornblende, which forms the slate called after it, a mineral which occasionally presents fine radiating fibres, and has hence been named after its resemblance to the sun's rays. The chiastolite imbedded in clay-slate, and comprising one of its varieties, is so called from the form of an $\mathbf{X}$, in dark lines, visible on the summits of the crystals. The chiastolite-slate, a soft, dark kind, occurs near Bareges in the Pyrenees; at St. Jago di Compostella in Spain, and in the Sierra Morena; at Agnavanagh in Wicklow; and constitutes in connection with other varieties the great mass of Saddleback, 2787 feet high, and of Skiddaw, 3022 feet, in Cumberland.

Snowdonia, a range of variously coloured and indurated argillaceous slates, the lower division of the Cambrian group, is of peculiar interest to the geologist; for bere we meet

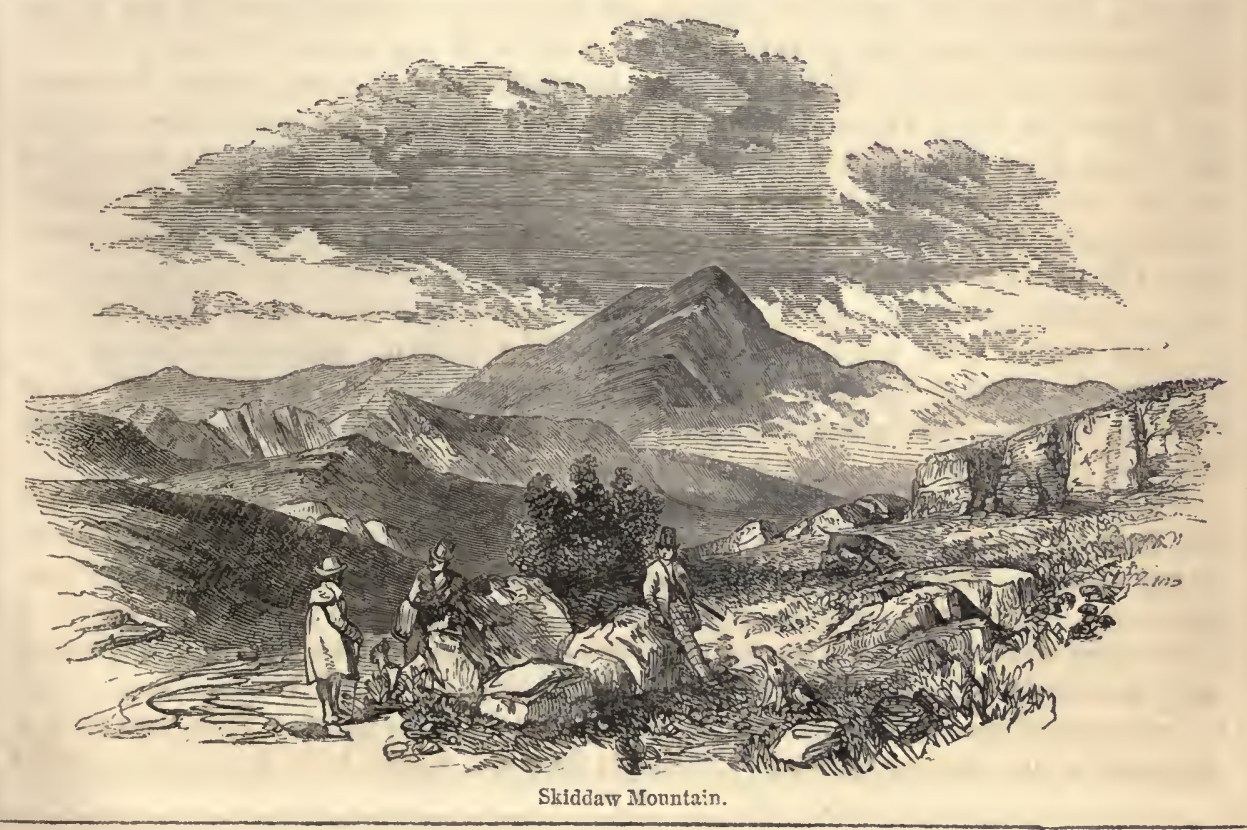


with the first extant monuments of organic life, which have not hitherto been discovered in the Cumbrian district, though the same strata are there extensively developed. The division includes the high mountains of Carnarvonshire and Merionethshire, where the slates are abundantly interstratified with masses of porphyry; and where south Britain has its loftiest elevation, Snowdon rising to the height of 3571 feet. In this series of strata, both in Wales and Cumberland, the richest metalliferous veins oceur, excepting the lead and iron ores of the carboniferous system. Greenwich Hospital receives a large revenue from the estates of the unfortunate Earl of Derwentwater, transferred to that establishment upon their forfeiture to the crown, and which abound in productive lead ore. Corresponding strata in Brittany and the Hartz are also highly metalliferous. The upper components of the system, the Bala limestone, consisting of a vast thickness of dark laminated beds in Wales, present many fossil remains of a few species, but none have been found in those patches of the strata which occur in Westmoreland. The Plynlymmon Rocks, hard, slaty, fine or coarse-grained, occupy the greatest part of the chain of the Berwyns, of which Plynlymmon is the central mass. They have few metallic riches, and appear to be nonfossiliferous.

The whole region of the slates exhibits a magnificent physiognomy, having been largely invaded by the igneous rocks, which have variously elevated the strata, and burst through them in great masses, or flowed into them, forming inter-stratifying layers and dykes. "Supported by granite," says Phillips, "and mixed with igneous masses, the slaty rocks of the English lakes rise to more than 3000 fect in height, and present a variety of outline and intricacy of combination which, in connexion with clear lakes and considerable waterfalls, leave to Switzerland little superiority." At Borrowdale, Scawfell, Patterdale, and Helvellyn, the slate is associated with greenstone, amygdaloid, and argillaceous porphyry, which constitute the towering crags and lofty precipices of those districts, and form the rocks over which the cataracts fall. The contour of Snowdonia exhibits a similar style of landscape, and indicates the amazing energy with which disturbing causes have acted upon it, the intruding porphyries here, as in Brittany, Cornwall, and in the Lammermuir Hills on the southern boundary of the plain of the Lothians, having been subject to subsequent disturbance equal to that of the strata. "We began a toilsome march," says Pennant, speaking of his ascent of Snowdon, "clambering among the rocks. On the left were the precipices over Cwm (valley) Brwynog, with Llyn (the pool) $d u y r A r d d w y$ at their foot; on our right were those over the small lakes Llyn Glas, Llyn y Nadroedd, and Llyn Coch. The last is the lighest on this side of the mountain, on whose margin we were told that, in fairy days, those diminutive gentry kept their revels. This space between precipice and precipice forms a short and no very agreeable isthmus, till we reachcd a verdant expanse, which gave us some respite before we laboured up another series of broken crags; after these is a second smooth tract, which reaches almost to the summit, whicll, by way of prceminence, is styled $y W y d d j a$, or the conspicuous. It rises almost to a point, or, at least, there is but room for a circular wall of loose stones, within which travellers usually take their repast.

"The mountain from hence seems propped by four vast buttresses, between which are four deep cwms, or hollows : each, excepting one, had one or more lakes lodged in its distant bottom. The nearest was Ffynnon Llas, or the green well, lying immediately below us. One of the company had the curiosity to descend a very bad way to a jutting rock that impended over the monstrous precipice, and he seemed like Mercury ready to take his flight from the summit of Atlas. The waters of Ffynnon Llas from this height appeared black and unfathomable, and the edges quite green. From thenee is a succession of bottoms, surrounded by the most lofty and rugged hills, the greatest part of 
whose sides are quite nural, and form the most magnificent amplitlieatre in nature. The Wyddfa is on one side ; Crib y Distill, with its serrated tops, on another; Crib Coch, a ridge of fiery redness, appears beneath the preeding; and opposite to it is the boundary ealled Lliwedd. Another very singular support to this mountain is $Y$ Clawdd Coch, rising into a sharp ridge, so narrow as not to afford breadth even for a path."

Pennant proceeds to remark:- "The view from this exalted scene is unbounded. In a former tour I saw from it the county of Chester, the high hills of Yorkshire, part of the north of England, Scotland, and Ireland; a plain view of the Isle of Man; and that of Anglesey lay extended like a map beneath us, with every rill visible. I took much pains to see this prospect to advantage; sat up at a farm on the west till about twelve, and walked up the whole way. The night was remarkably fine and starry; towards morn the stars faded away, and left a short interval of darkness, which was soon dispersed by the dawn of day. The body of the sun appeared most distinct, with the rotundity of the moon, before it rose high enough to render its beams too brilliant for our sight. The sea, which bounded the western part, was gilded by its beams, first in slender streaks, at length glowing with redness. The prospect was disclosed to us like the gradual drawing up of a curtain in an amplitheatre. We siw more and more, till the heat became so powerful as to attract the mists from the various lakes, which in a slight degree obscured the prospect. The shadow of the mountain was flung many miles, and showed its bi-capitated form; the Wyddfa making one, Crib y Distill the other. I counted this time between twenty and thirty lakes, either in this county, or Meirionydd (Merioneth) shire. 'The day proved so excessively hot, that my journey cost me the skin of the lower part of my face before I reached the resting-plaee, after the fatigue of the morning.

"On this day the sky was obscured very soon after I got up. A vast mist enveloped the whole circuit of the mountain. The prospect down was horrible. It gave the idea of a number of abysses, concealed by a thiek smoke, furiously circulating around us. Very often a gust of wind formed an opening in the clouds, which gave a fine and distinct vista of lake and valley. Sometimes they opened only in one place; at others in many at once, exhibiting a most strange and perplexing sight of water, fields, rocks, or chasms in fifty different places. They then closed at once, and left us involved in darkness; in a small

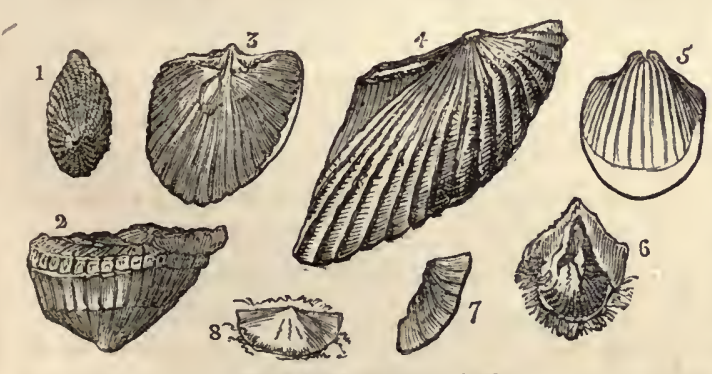

Fig. 1. Crathophyllum.

2. Cyathophyllum, the same as found in the Silurian system.

3. Terebratula distinct from T. prisca.

4. Spirlfera with knotted ridges.

5. Producta (or

7. Spirifera with fine radiating striæ.

8. Leptæna $\mathrm{L}$. lata of the Silurian rocks. space they would separate again, and fly in wild eddies round the middle of the mountains, and expose, in parts, both tops and bases clear to our view."

But Snowdon - the Saxon translation of the Welsh for snow-mountain - with the ranges in connexion with it, acquires peculiar interest, from its presenting us with the dawn of organie life in the world which we inhabit, as far as extant monuments serve to unfold it - the morning twilight of the era of living beings, which broke immeasurable ages before the present epoch. Professor Phillips speaks of having found, himself, in the slates of Snowdon, Zoophyta (lamelliferous corals) and Brachiopodous (arm-feet) bivalves. The latter are mollusea, so ealled from having two long, spiral, fleshy arms, or brachia. The above specimens he obtained from Snowdon in the year 1836.

"It may surprise," he observes, "the speculators in cosmogony to hear that these, the 
most ancient forms of life known to us, should be, not plants, but animals; not merely zoophyta, but conchifera; not the lowest grades of their respective classes, but perfectly developed lamelliferous zoophyta, and brachiopodous mollusea." These mollusca, now extinct, lived in the ocean attached to other bodies. They prevail through the older fossiliferous rocks, in connection with a large increase of species, gradually disappear from the sphere of existence in newer formations, and finally vanish in the lias, where only

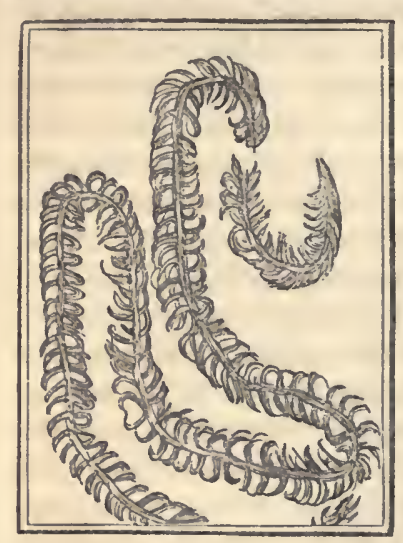
one species occurs. In addition to these fossil examples of ancient organisms, traces of Annelidans, the first class in Cuvier's arrangement of articulated animals, have been recognised. These are worms with red blood, formed of rings, or annular segments, like the leech and common earthworm, some of which are naked, while others have a shelly covering, or are protected by a kind of cont formed of agglutinated sand. Their remains are abundant in more recent deposits, but in several instances, upon the older rocks, their traces only are discernible. "Singular convoluted impressions," Sir R. Murchison remarks, " had been observed by the Rev. A. Oliphant, of Llampeter College, on the surface of the building-stone of that place; and upon submitting some specimens to the examination of Mr. W. Macleay, that profound naturalist pronounced them to liave been formed by sea-worms." The engraving represents the instance in question, Nereites Cambrensis, from Llampeter in North Wales, from which the body appears to have bcen composed of about one hundred and twenty segments. A greater number of segments appears to have distinguished a more slender species, named after the founder of the Cambrian group, Nereites Sedgwickii.

Such were the creatures that appear to have first crawled upon the stage of life, opening that drama of being in which we are now actors, and in which man, as poet, warrior, and sage, has for some thousands of years played a conspicuous part. Wandering upon our sandy shores, we often in listlessness or idle curiosity overturn the stones in our pathway, and observe existing Nereidina_slender worms wriggling in the water and mud-and these insignificant animals are the analogues of those forms in which we have reason to believe sensitive life first appeared in our world. "From this origin of organic life, there is no break in the chain of organic development, till we reach the existing order of things; no one geological period, long or short-no one series of stratified rocks is every where devoid of traces of life. The world once inhabited has apparently never, for any ascertainable period, been totally despoiled of its living wonders. But these have many changes in the individual forms; great alterations in the generic assemblages: entire revolutions in the relative number and development of the several classes. Thus the systems of life have been varied from time to time, to suit the altered condition of the planet, but never extinguished. The eartl, once fieed from its early inadequacy to support life, according to the appointed laws, has since been prolific of regetable and animal existence." It should be remarked, that these beds in which the traces of life are occasionally detected, the oldest of the fossiliferous rocks, are by some geologists regarded as forming a distinct and independent system, while others associate them with the ensuing Silurians, as the basis or bottom-rocks of that series. 


\section{CHAPTER IV.}

THE SILURIAN SYSTEM.

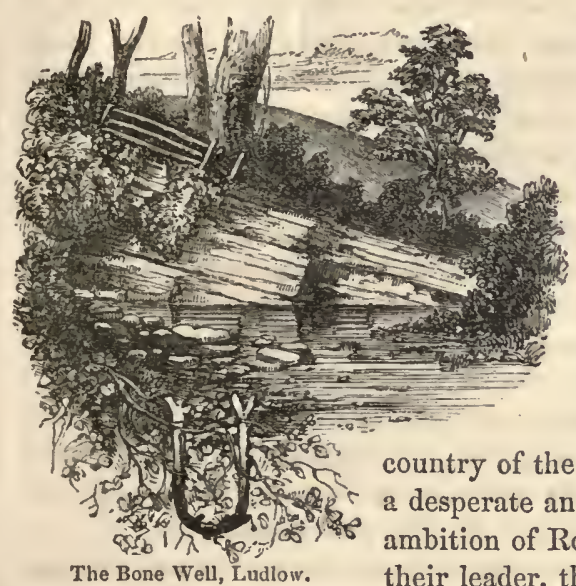

NDER this title a great scheme of deposits is classed, lying upon the sloping sides of the slates of Wales, formerly included in the ill-defined grauwacke group, and constituting the middle division of that series. By the careful researches of Sir R. Murchison these rocks have been firmly established as an independent system, having distinct physical features, lithological structure, and organic remains. The name is derived from the native denomination of the British region, where the "system is developed in remarkable perfection. In the tacus of history, whose unbroken spirit and noble demeanour in adversity commanded the admiration of the Emperor Claudius, they rallied again to conquer, and were not finally vanquished until the reign of Vespasian.

\section{"In ancient days,}

The Roman legions, and great Casar found Our fathers no mean foes."

Their territory embraced a considerable portion of South Wales, with parts of the border counties of England, though its exact limits cannot now be defined. It had within its bounds the counties of Radnor, Brecon, Hereford, and Monmouth, and probably ex-

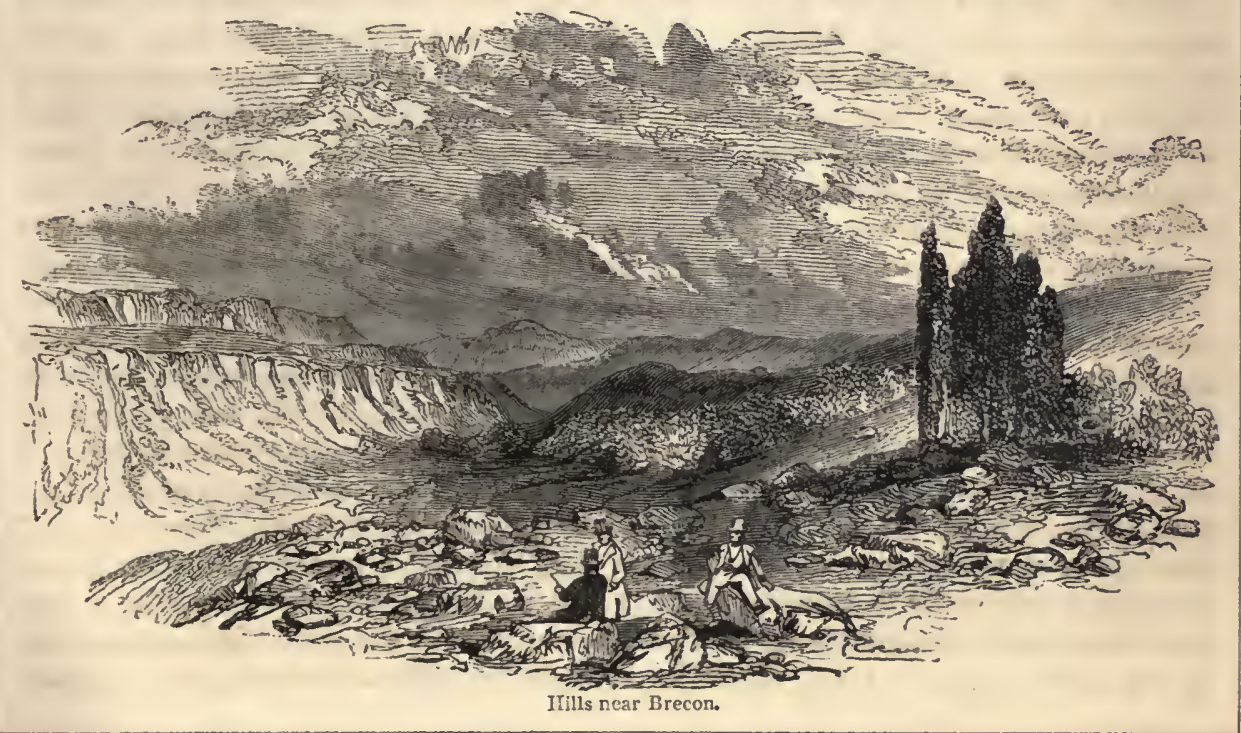


tended beyond the Malvern hills to the banks of the Severn, thus including the northwest of Worcestershire and the sonthern half of Salop. Here, memorials of the former inhabitants still survive. Siluria is marked in the Ordnance maps as the name of a farm near the centre of the district, not far from the town of New Radnor; and the Caradoc hills in South Salop commemorate the gallant chieftain who resisted the Roman arms in thcir neighbourhood.

It must not be understood that the geological Siluria, as developed on the fronticrs of England and Wales, is connected with the limits of the geographical; but the two are so far coincident as to justify the application of the term to the formations indicated by it. The general form of the Silurian region is that of a crescent, running out from beneath the old red sandstone of Herefordshire, extending northward by Llangollen to the beautiful vale of Clwydd. It is intersected by the Severn at nearly the widest part, which is about twenty-five miles. The river runs obliquely through it from Newtown in Montgomeryshire to the plain of Shrewsbury. 'The southern extremity is a very narrow strip, scarcely four miles across where it is widest, and in some places less than one. It extends from the valley of the Wye at Builth, through the wildest tracks of Brecknockshire, to the vale of the Towy, along which it proceeds to Caermarthen, and thence in a direction nearly west by Haverfordwest to the extremity of Pembrokeshire, terminating at St. Bride's Bay. Besides this continuous tract, there are Silurian outliers obtruded through incumbent groups of strata, through the old red sandstone of Monmouth and Herefordshire, and through the carboniferous series at Dudley and Walsall.

Since the establishment of the Silurian rocks of South Wales and the border counties as a separate system, it has been discovered, as might have been inferred from analogy, that the same series of strata is very widely distributed, and appears in very distant regions of the globe. Formations belonging to the same class are recognised, and of considerable dimensions, between Kondal in Westmoreland, where they repose upon the Cambrian rocks, and Kirkby Lonsdale in Yorkshire, where they dip under the old red sandstome of the valley of the Lune. They occur also in the south of Scotland and Ireland, in Bohemia and Silesia, on the southern frontier of the Ardennes in France, in Servia and the adjacent parts of Turkey in Europe, in the neighbourhood of Smyrna and the Cape of Good Hope, in the Hartz mountains and Norway, and in various parts of America. It has been stated by Mr. Conrad, of the New York Geological Survey, that he can not only identify the Silurian system generally with rocks in that state, but also the subdivisions; and that the strata are more fully developed in that country than in England, particularly about the borders of the great lakes Huron and Superior. From the Falkland Islands, Mr. Darwin brought home masses of rock charged with fossils, very nearly related to, if not identical with, those of our Caradoc sandstones. The discovery of this wide diffusion of the strata has produced the reflection, that the generic appellation, although perfectly appropriate with reference to British geology, is inadmissible beyond this boundary; that to classify rocks of the same lithological character, occurring in remote situations, under a title belonging to a particular locality, is invidious and incorrect. Hence, a transatlantic geologist, after stating that particular rocks of his district range with Sir R. Murchison's Silurian group, remarks :- "We do not, however, see any propriety in applying a local term to a class of rocks abundant in every quarter of the globe; we have the same right to our Nerepsis, Mispek, and Quaco rocks, as our contemporaries across the Atlantic have to their Ludlow, Wenlock, and Caradoc rocks," subdivisions of the Silurian system. But it may be replied to this somewhat jealous observation, that as Sir R. Murchison led the way in demonstrating and describing a complete succession of fossiliferous deposits interpolated between the oldest slaty rocks and the old red sandstones, to him it of course belonged to denominate the scries by a collectivc 
name, and to designate its subdivisions; that nothing could be more natural than to describe the system and its components, till then untraced in other quarters by the geographical names of the localities where they were most conspicuously developed; and that so widely has the nomenclature been adopted by the geologists of Europe, as to render it desirable that the term Silurian, which involves no theory, should be retained as a generic appellative.

In composition, the Silurian rocks are arenaceous, argillaceous, and calcareous, showing in all cases evidence of a sedimentary origin, and in general of a regular and tranquil deposition, the original lamination of the beds being quite obvious. The system is divided naturally into two principal groups, now called the Upper and Lower Silurians, each of them supposed to be about 4000 feet in thickness. 'The upper group consists of soft, greenish, or drab-coloured, shaly sandstone, locally called "mudstone," from having been completely broken down and softened by exposure. The second division contains hard slaty sandstones, with beds of limestone, having a concretionary sub-crystalline texture, the lower members consisting of dark-coloured flags, rescmbling the Cambrian slates

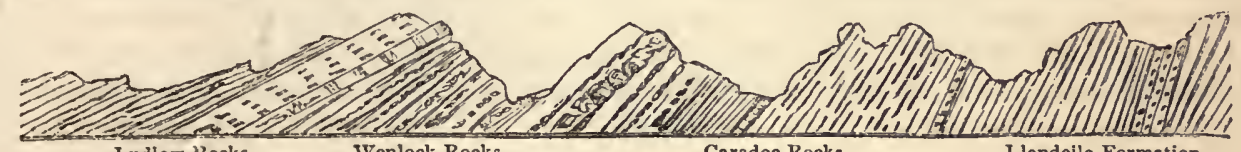

Ludiow Rocks.

Wenlock Rocks.

Caradoc Rocks.

Llandeilo Formation.

below and in many cases passing into them. The annexcd is Sir R. Murchison's section of the series, and his summary, with some additions from other sources : -

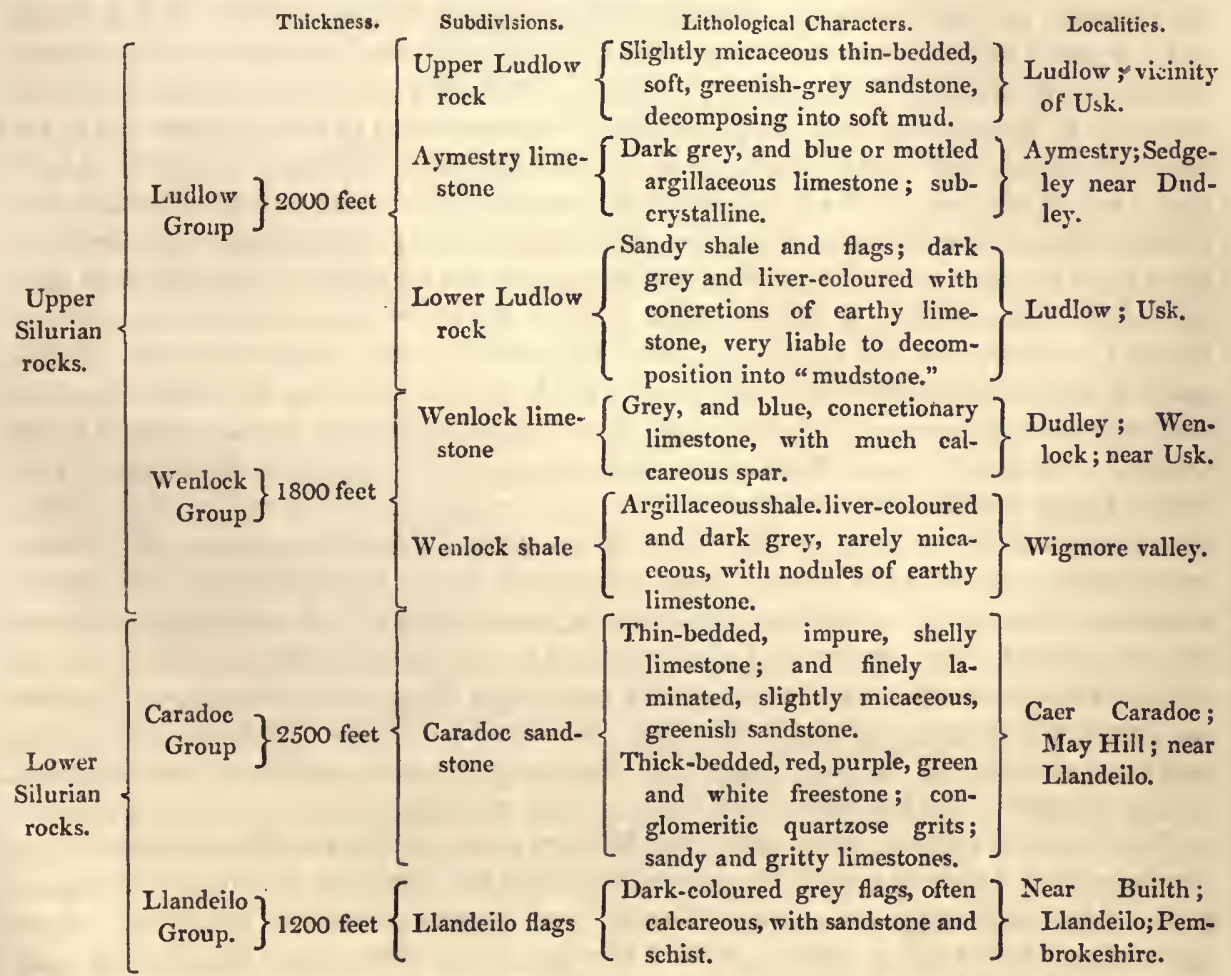

The whole of these groups are crowded with organic remains, and include some beds almost entirely composed of them. 
Of these forms of ancient life, the folloring genera and species have been well ascertained : -

\begin{tabular}{|c|c|c|c|c|c|c|c|c|}
\hline Pisces, true & verteb & rated fishes & - & - & - & - & $\begin{array}{l}\text { Number } \\
\text { of Gedera. } \\
-\quad 15\end{array}$ & $\begin{array}{l}\text { Number } \\
\text { of Species. } \\
24\end{array}$ \\
\hline Crustacea & & - $\quad-$ & - & - & 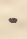 & - & -10 & 37 \\
\hline Annelida - & 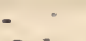 & - & - & - & - & - & -5 & 6 \\
\hline \multirow[t]{3}{*}{ Mollusca. } & Order & Heteropoda & - & - & - & - & - & 11 \\
\hline & & Cephalopoda & - & - & - & - & -6 & 41 \\
\hline & & Gasteropoda & - & - & - & - & - 13 & 34 \\
\hline \multirow[t]{3}{*}{ Conchifera } & & Brachiopoda & $\alpha$ & - & - & - & -8 & 107 \\
\hline & & Monomyaria & - & - & - & - & -1 & 6 \\
\hline & & Dimyaria & - & - & - & - & -10 & 21 \\
\hline Crinoides & - & - $\quad-$ & - & - & - & - & -5 & 14 \\
\hline Polyparia & & - & - & - & - & - & - $\quad 85$ & 65 \\
\hline \multirow[t]{2}{*}{ Sedis incert } & & - & - & - & - & - & -6 & 9 \\
\hline & & & & & & & 115 & 375 \\
\hline
\end{tabular}

The great majority of these bodies are essentially distinct from the numerous and welldefined fossils of the carboniferous system, and also from those of the old red sandstone, which intervenes between the two systems. Sir R. Murchison queries as follows:"Beginning with the vertebrata, are not the fishes of the old red sandstone as distinct from those of the carboniferous system, on the one hand, as from those of the silurian on the other? Mr. Agassiz has pronounced that they are so. Are any of the crustaceans so numerous and well-defined throughout the Silurian rocks, found also in the carboniferous strata? I venture to reply, not one. Are not the remarkable cephalopodous mollusca, the Phragmoceras, and certain forms of Lituites, peculiar to the older (Silurian) system? Is there one species of the crinoidea figured, known in the carboniferous strata? Has the Serpuloides longissimum, or have those singular bodies the Graptolites, or, in short, any zoophytes of the silurian system been detected in the well-examined carboniferous rocks? And in regard to the corals, which are so abundant that they absolutely form large reefs, is not Mr. Lonsdale, who has assiduously compared multitudes of specimens from both systems, of opinion, that there is not more than one species common to the two epochs?" A few species of shell-fish, obviously capable by their rery nature of enduring great vicissitudes, survired through the interval between the formation of the Silurian rocks and the accumulation of the carboniferous limestone, but the mass of animal existence in the waters at the former period appears to have been obliterated by the changes that subsequently modified the aspect of the globe; and as we may beliere, through submarine volcanic outbursts, which are now traceable in the Silurian district, introducing a material to the ocean, poisonous to the life of its inhabitants. In addition to animal remains, a few marine plants hare been described as occurring in Silurian deposits, chiefly alga (sea-weeds) of four species; equisetacea (answering to the horse-tails. of our swamps and ditches) of two species; and filices (ferns) of five species. The algre are principally from Christiana in Norway; the rest from the Rhine-ralley; but there is still some doubt as to the true geological place of the strata containing these regetable relics, whether in the Silurian or the carboniferous systems.

The Llandeilo group. The base of the Silurian series is not seen where the superior members of the system are conspicuously developed in Salop, but it appears extensively in the neighbourhood of the town of Llandeilo in Caermarthenshire, after which it has been named. The group consists of hard flagstones, from two to four inches thick, of a dark grey or indigo colour when extracted, which lightens to an ashy hue upon exposure to the weather, and interspersed among them, there are veins of white crystallised 


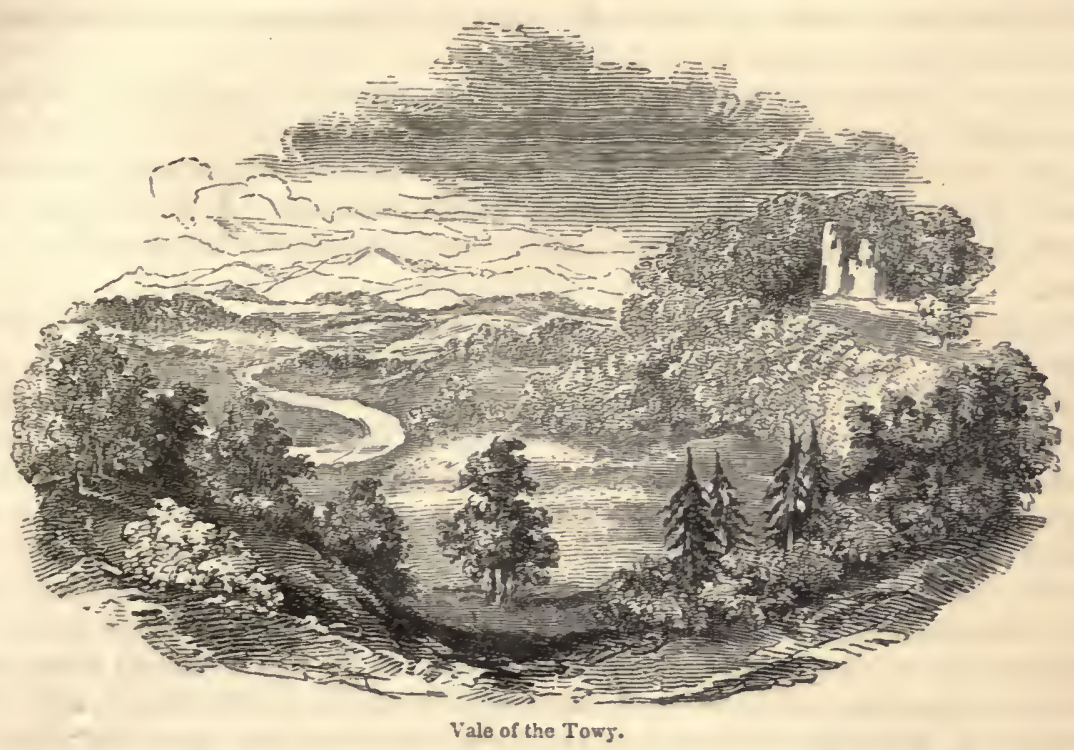

carbonate of lime passing occasionally into an impure limestone. The flags are seen in broken and detached masses on the right bank of the river Towy from Llandeilo to Caermarthen, a distance of fifteen miles; often in a highly inclined, vertical, and contorted position, and reversing their direction repeatedly in a very short space, a memorial of the powerful convulsions with which the strata have been agitated. These commotions of the past have contributed to endow the surface with great beauty, throwing it into knolls, which, in the vale of the Towy, are richly covered with woods, in some instances apparently going back to the time of the Silures. The annexed sketch of the scenery of this valley represents part of the domestic domain of Dinas-fawr, the residence of the ancient princes of South Walez, now the property of Lord Dynevor.

The most common or remarkable fossils of the Llandeilo flags, besides a few shells, are the mol-

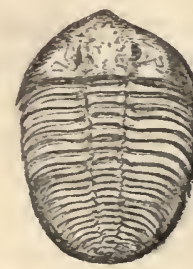

Asaphus de Buchii.

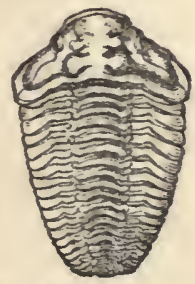

Calymene Birmentachil. lusca, one of which has a diameter of nearly two inches, and occurs near Llandorery in black schistose beds of passage from the Silurian into the Cambrian rocks; and the chain-coral catenipora escharoides, a species which sometimes forms hemispherical masses more than $n$ foot in diameter.

But the characteristic fossils are the trilobites (three-lobed), a name referring to their structure, consisting of an oblong body, divided transversely into three principal parts, and longitudinally into three lobes. These fossil bodies have long been known under the provincial title of Dudley insects, or locusts, a district where they abound; and the characteristic terms of species display the perplexity of naturalists respecting them;

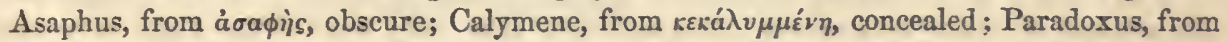

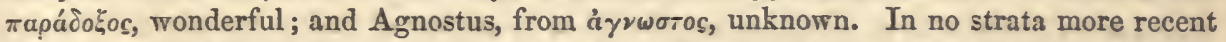
than the carboniferous has any trilobite yet been discovered; but a few genera and species occur in that system. The Silurian rocks hare been styled the "great trilobitic series," the "grand mausoleum of these ancient beings," from their prevalence, some of which 
literally teem with them. Though long supposed to be insects, the trilobites are now known to be true crustaceans; and, though the entire family is without any living representative, liaving been annihilated with the accumulation of the carboniferous deposits, we can make as near an approximation to their habits as we can to those of many of the inhabitants of the existing seas. The existing crustacean which most resembles the extinct trilobite appears to be the Bopyrus, a small parasitical animal attaching itself to prawns, and causing a large swelling on their bodies, one parasite fastening itself on each prawn.

The trilobites are usually found from one to six inches long; but a specimen discovered in the state of Ohio, and described by Professor Locke, was nearly two feet in length. These animals had a protecting crustaceous shell, or case, composed of numerous segments, folding over one another like those of a lobster's tail. This shield they appear to have had the power of contracting at pleasure, like the wood-louse and armadillo, as some are found variously expanded or coiled up. No certain traces of antennæ and legs have been discovered; from which a sedentary habit is inferred, the animals adhering, with a soft articulated underside, either to rocks and fuci, or in masses to one another, hence forming those conglomerations of individuals which are so remarkable in various rocks. Some naturalists, however, suppose a power of locomotion in the water, either by soft paddles, which have perished, or by sculling forward with the aid of a flexible extremity.

From a peculiarity of the mouth, it has been concluded that they were carnivorous, preying on naked molluscs, or on the annelides, with which their remains are associated.

The most curious fact respecting the trilobites is the compound organisation of the eyc in several species, many specimens of which have been found in a perfect state of preservation, and unfold a structure of which we have various living examples. It is well known that the eyes of crustaceous animals, like those of insects, are composed of a vast number of minute facets or lenses, placed at the end of tubes, which are arranged side by side, so as to produce a radiating mass of eyes, which being generally of a hemispherical or conical form, and sometimes elevated from the head on a stem, enable the animal to see in every direction. In some insects the number of these lenses in both eyes, as in the

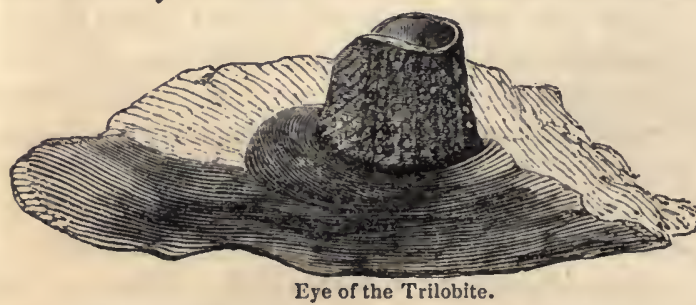
house-fly, is 14,000 ; in other cases, the dragon-fly, 25,000; in others, the butterfly, 35,000; in others, the Mordella, 50,000. The visual organ of several of the trilobites is formed upon the same principle, each eye, according to fossil anatomists, containing at least 400 spherical lenses, fixed in separate compartments on the surface of a cornea projecting conically upwards. The engraving is a representation of this structure.

The preceding facts lead us to results of singular interest and importance. They establish the conclusion, that at that remote epoch when the trilobites flourished, countless ages ago, the condition of the atmosphere and of the waters of the sea, with the adaptation of light to the eye, and of the eye to light, were much the same as at the present era. "With respect to the waters," says Dr. Buckland, in his luminous commentary upon the phenomena of these crustaceans, "we conclude that they must have been pure and transparent enough to allow the passage of light to organs of vision, the nature of which is so fully disclosed by the state of perfection in which they are preserved. With regard to the atmosphere, also, we infer, that, had it differed materially from its actual condition, it might have so far affected the rays of light, that a corresponding difference from the 
eyes of existing crustaceans would have been found in the organs on which the impressions of such rays were then received. Regarding light itself, also, we learn, from the resemblance of these most ancient organisations to existing eyes, that the mutual relations of light to the eye, and of the eye to light, were the same at the time when crustaceans, endowed with the faculty of vision, were first placed at the bottom of the primeval seas, as at the present moment. Thus we find among the earliest organic remains, an optical instrument of most curious construction, adapted to produce vision of a peculiar kind in the then existing representatives of one grcat class in the articulated division of the animal kingdom. We do not find this instrument passing onwards, as it were, through a series of experimental changes, from more simple into more complex forms: it was created, at the very first, in the fulness of perfect adaptation to the use and condition of the class of creatures to which this kind of eye has ever been, and is still, appropriate. If we should discover a microscope, or telescope, in the hand of an Egyptian mummy, or beneath the ruins of Herculaneum, it would be impossible to deny, that a knowledge of the principles of optics existed in the mind by which such an instrument had been contrived. The same inference follows, but with cumulative force, when we see nearly four hundred microscopic lenses set side by side in the compound eye of a fossil trilobite; and the weight of the argument is multiplied a thousand fold, when we look to the infinite variety of adaptations by which similar instruments have been modified, through endless genera and species, from the long-lost trilobites of the transition strata, through the extinct crustaceans of the secondary and tertiary formations, and thence onwards throughout existing crustaceans, and the countless hosts of living insects. It appears impossible to resist the conclusions as to unity of design in a common Author, which are thus attested by such cumulative evidences of Creative Intelligence

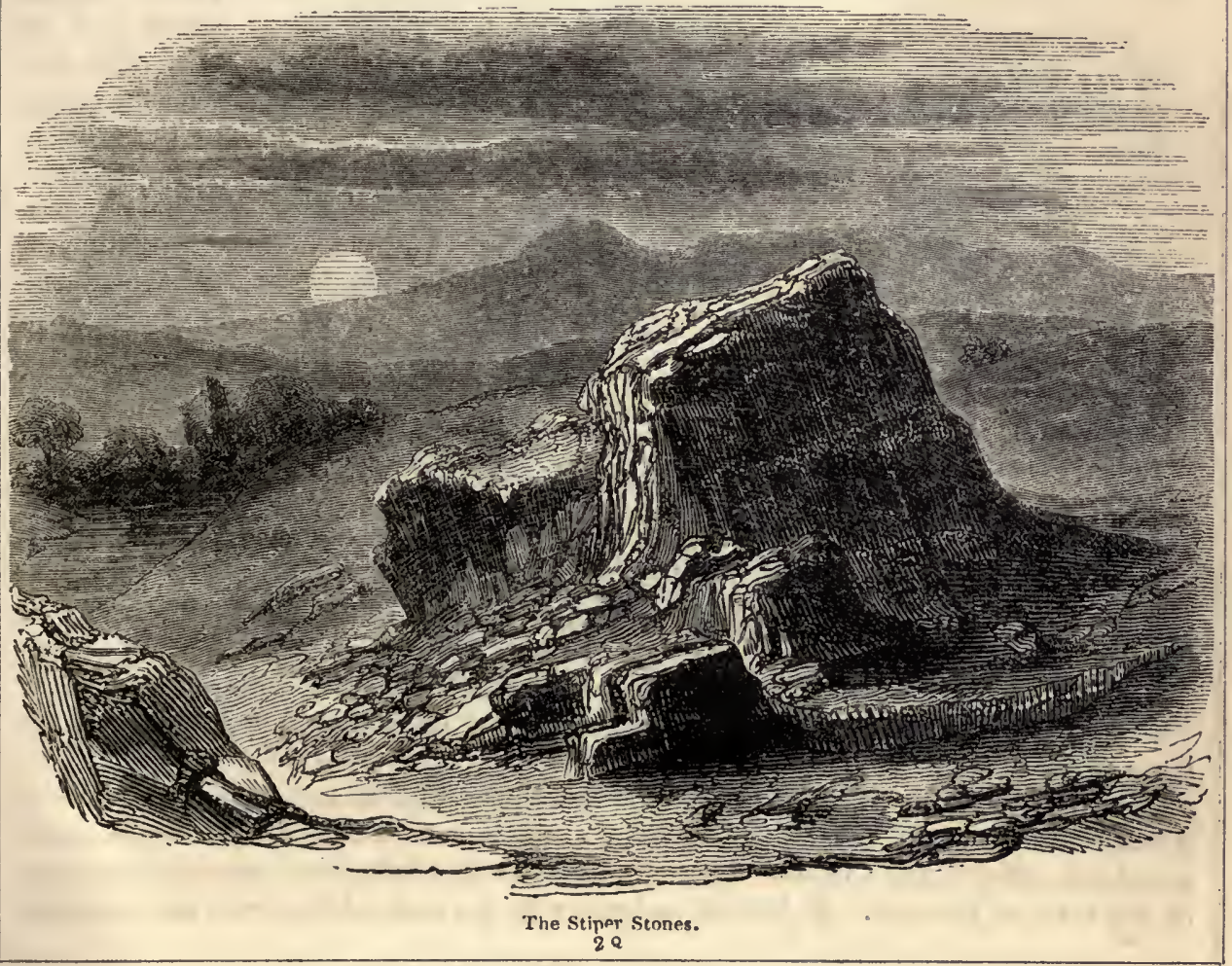


and Power; both as infinitely surpassing the most exalted faculties of the human mind as the mechanisms of the natural world, when magnified by the highest microscopes, are found to transcend the most perfect productions of human art."

The Caradoc group. - The second member of the Silurian series of deposits, following the ascending order, comprises sandstones of different colours, with occasional subordinate courses of calcareous matter. The strata constitute ranges of eminences, abutting against the trappean chain of the Caradoc hills in Shropshire. They are largely developed also in Montgomeryshire and Denbighshire, forming mountainous masses and picturesque knolls, upon one of which Powis Castle is built. Beds of quartz occur frequently where trappean rocks have cut through the sandstones; which are, no doubt, the ordinary strata of the district altered by the action of heat. A remarkable ridge on the east of the Caradoc, called Hoar Edge, is a quartzose mass of this description, consisting of sandstones fused by the great plutonic outburst of the Caradoc itself: and the extraordinary Stiper Stones supply another example of metamorphic sandstone, thrown into irregular serrated piles, like rugged cyclopean ruins, protruding from elevated moorlands in immediate contiguity to unaltered strata, exhibiting fine woodland scenery. Among the organic remains of the sandstone, trilobites of several species are abundant; a woody ravine, upon the property of Lord Clive near Welch Pool, so abounding with them, and with beautiful casts, that Sir R. Murchison honoured the nameless site by calling it the "Trilobite Dingle." Several species of shells belonging to the genus Terebratula (bored, alluding to the perforated beak, are of common occurrence. Shells of this kind form a numerous family, and have been denominated the Fossil Aristocracy, from the incalculable antiquity of their lineage. They are found in great numbers in the chalk, but of different

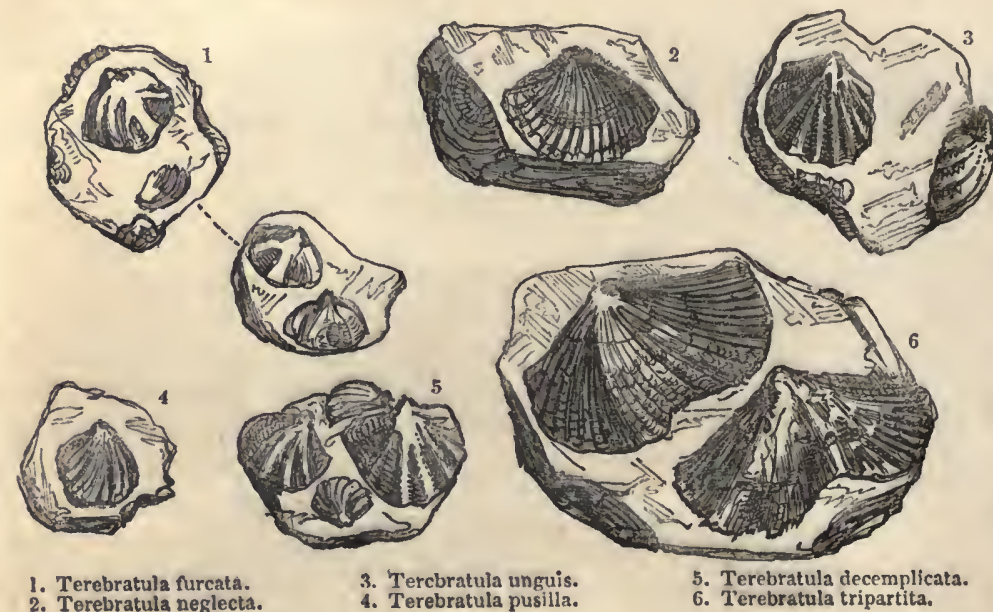
species to those in the Silurian strata. Of corals, the chief remains belong to the tribe of Favosites, zoophytal organisationsthatappear to have swarmed in the $\mathrm{Si}$ lurian seas, the formations consisting of a congeries of diverging or ascending 2. Terebratula neglecta. 4. Terebratula pusilla.

6. Terebratula tripartita.

parallel, prismatic, and porous tubes. An example of two species is given, the tubes of which vary considerably in size. Beautiful specimens have been figured from Eifël and Groningen, and from the Silurian strata of the Olio arid Niagara, where the cells are filled up with caleareous spar. Varieties of the genus Cyathophyllum also oceur, but more plentifully, in the superior rocks of the system.

The Wenlock group. - We now come to the Upper Silurians, the lower members of which consist of shale and limestone. The shale is a dull, argillaceous deposit, witl occasional concretions of impure limestone, extensively developed in the neighbourhood of the town of Wenlock. It has its equivalent in the shale of Dudley. In the former 
locality it appears continuously in the longitudinal valley reaching from the Severn to the Onny, running in a line parallel to the ridge called Wenlock Edge, and intermediate between it and the Caradoc hills. The lower part of the shale contains concretions, which exhibit, upon being broken, an internal structure similar to the "cone-in-cone," common to the shale of the lias, the cones consisting of dark-coloured crystalline card bonate of lime in an argillaceous paste. The upper part, where exposed to the action of the atmosphere, has been deeply denuded. The Wenlock limestone is seen conspicuously in the Edge, which extends a course of about twenty miles, and forms one of the most remarkable features of the physical geography of Shropshire. The lime-

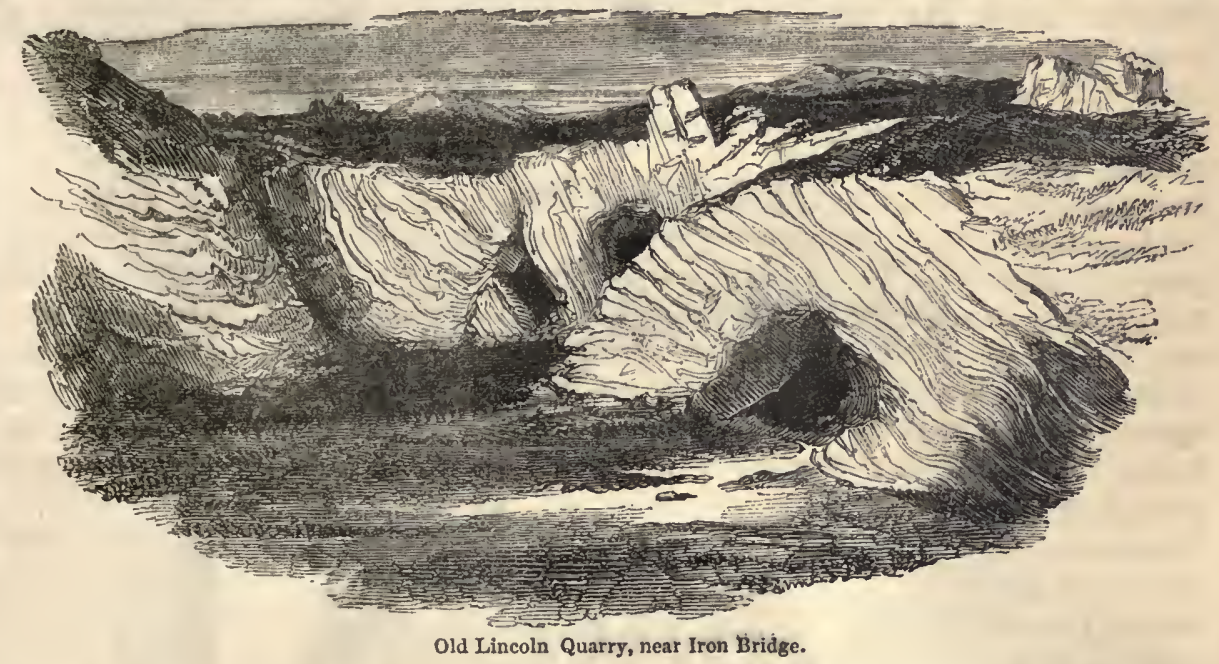

stone is disposed in two forms. It occurs in regular beds, termed "measures," of varying thickness, dull grey colour, more or less impure through the presence of argillaceous matter, the strata being often wavy and contorted. It occurs, also, in large
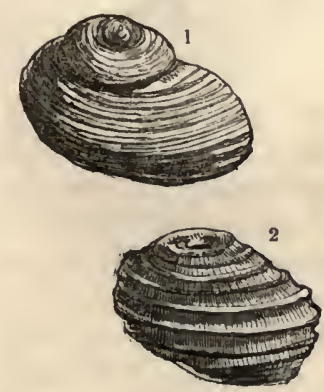

1. Euomphalus sculptus. 2. Euomphalus funatus.
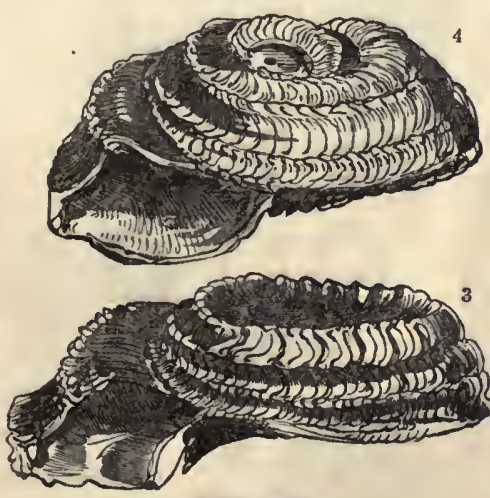

2. Euomphalus rugosus. concretional masses, where it is purer and more crystalline, (locally, they are called ball-stones, which are sometimes dark blue, occasionally pink, freckled with veins and strings of white crystalline carbonate of lime. The ball-stones are frequently of immense size, having a diameter of thirty feet, and, in one case, a single mass has been quarried to the depth of eighty feet without its dimensions being ascertained. The annexed view of one of the quarries near Iron Bridge, shows the undulated and contorted beds of impure limestone, and the places from whence the crystalline variety, the concretions or ball-stones, have been extracted. The Wenlock shale, as a bed of passage, between the Upper and Lower Silurians, contains shells, corals, and trilobites, common to both; but the limestone is 


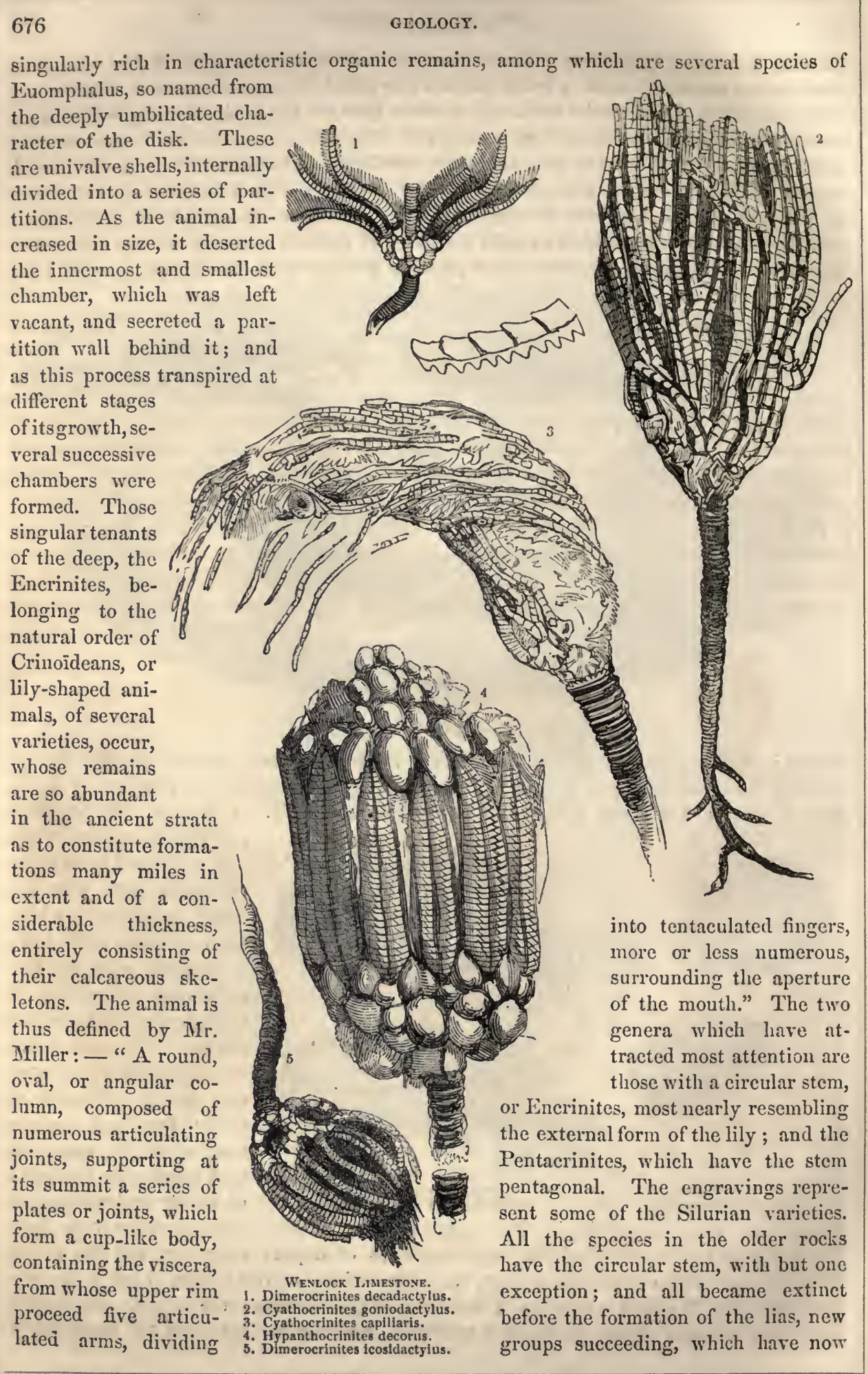


dwindled down to tivo analogues, which inhabit our existing seas. The animal occupied a fixed position at the bottom of the ocean, like its modern representatives, or was attached to floating pieces of wood, merely moving itself as far as it could reach by bending its very flexible column, which was admirably adapted for this purpose. This stem, which may be called the vertebral column, although the Encrinites are invertebrated, consists of a vast number of ossicula, little bones or joints, with a central perforation, so as to admit of being strung together when found detached. They commonly occur singly in the northern counties, passing under the denominations of "wheel-stones," and "St. Cuthbert's beads," from having been strung as beads, and formerly used as rosaries. Hence the lines in Marmion :-

\author{
"On a rock by Lindisfern \\ St. Cuthbert sits, and toils to frame \\ The sea-born beads that bear his name."
}

Dr. Mantell states that he has found these circular perforated ossicula, which had been worn as ornaments, in tumuli of the ancient Britons; and also, that the "channel formed by the united ossicula of the column, has given rise to the curious fossils called in Derbyshire screwo, or pulley stones, which are flint casts of these cavities. They occur in the beds of chert which are interstratified with the mountain limestone; the siliceous matter, when fluid, filled up the channels, and invested the stems: the calcareous substance has since been dissolved and removed, and solid cylinders of flint, resembling a pulley, remain. In the quarries on Middleton Moor, near Cromford, where extensive beds of

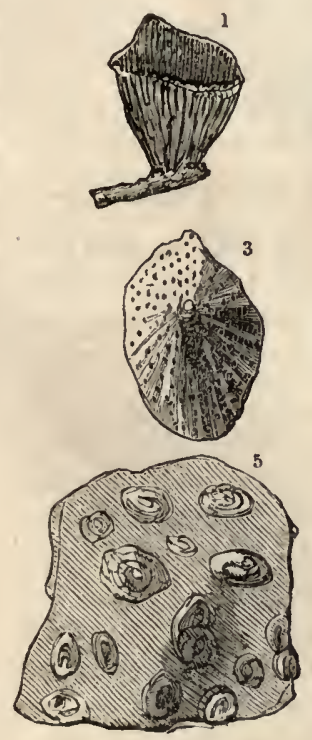
1. Fenestilla prisca. 3. Fetepora infundibulum.

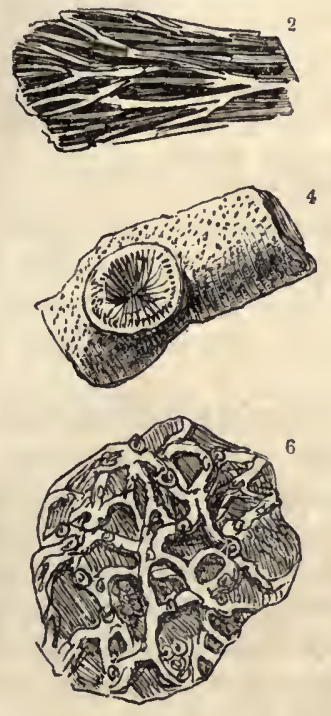

Ludzow Corals.

4. Heteropora crassa. 5. Stromatopora nummulitlsimilis.

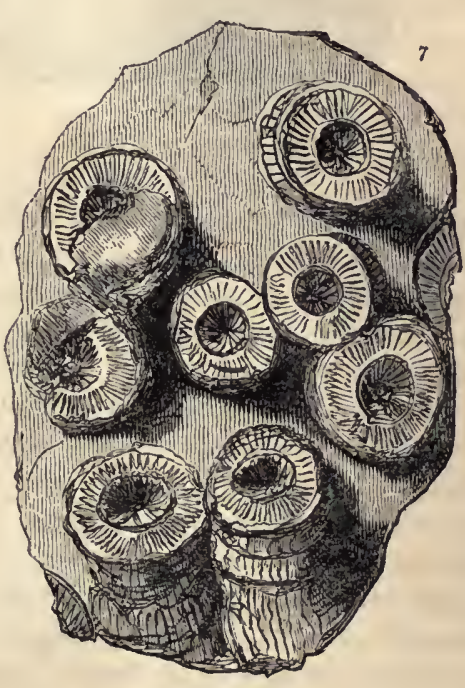

6. Aulopora serpens. 7. Cyathophyllum dianthus.

limestone, composed of crinoideal remains, are worked for chimney-pieces and other ornamental purposes, beautiful examples of these fossils may be obtained. The cavities of the column and ossicula are often filled with white calcareous spar; while the ground of the marble is of a dark reddish-brown colour." Man now erects his mansion, and has its apartments adorned with variegated slabs, little imagining that the component parts 
of the material employed were once instinct with life and animation, immeasurable ages before the creation of his race. A very rare crinoideal animal, the Pentacrinus CaputMedusce, fixed at the bottom of the seas of the Antilles, having a column formed of numerous pentangular joints, is now the chief living representative of those mighty swarms that were among the first inhabitants of the ocean, whose petrified bones form a vast extent of strata in northern Europe and America, as essentially as a hayrick is composed of grassy fibres.

But among the organic remains of the Wenlock limestone, the corals are the most numerous, and form the most striking characteristic of the stratum. They belong to

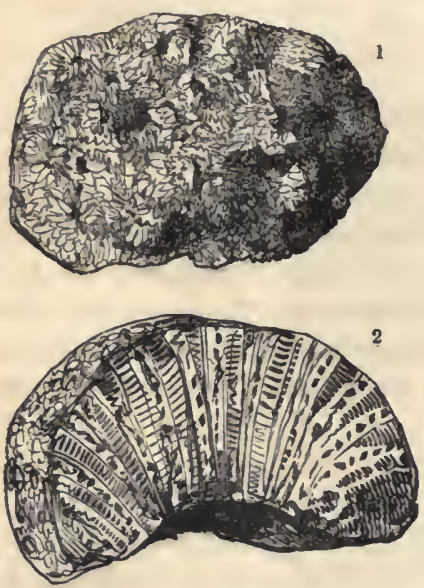

1. Porites discoldea.
Wenlock Corals.

2. Porites petalliformis.

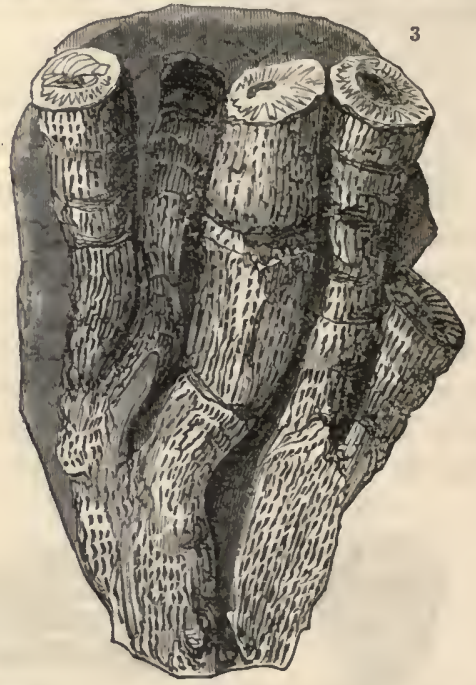

3. Cyathophyllum capitosum.

upwards of fifty species, and exhibit structures of great beauty, as may be seen from the accompanying engravings. It may here be observed, that there is a loose and inaccurate mode of speaking of corals, as if they were formations apart from the coral animals; whereas the relation between the two is analogous to that of the bones and flesh in the human frame.

The Ludlow group. This division comprises the uppermost series of Silurians, of which three subdivisions are made, - the Aymestry limestone, interrening between the Upper and Lower Ludlow rocks. The latter is a great argillaceous mass, varying in colour from dark grey to black, forming the popular "mudstone" of the district; in other places called "waterstone," from its tendency to decomposition. Some of the beds contain spheroidal concretions of compact earthy limestone formed around organic remains. Sir R. Murchison counted thirty fragments of the trilobite Asaphus caudatus in a single nodule. The Aymestry limestone is sub-crystalline and argillaceous, yielding a valuable lime for cement under water, named after the beautiful village where it is most distinctly seen. It appears at various places apart from this particular locality, as on the east of Hereford, where the Silurian strata protrude through the old red sandstone; and at Sedgeley, in Staffordshire, the rock presents itself through the carboniferous formation in a highly calcareous form. It is every where charged with shells. One species, with a peculiar organisation, and almost exclusively confined to this calcareous zone, has been named after a distinguished naturalist, T. A. Knight, F. R. S., in whose domain at Downton Castle it is very abundant. The Upper Ludlow 
rock, upon which the town of that name is built, the highest member of the Silurian system, consists of sandstone of various qualities, the grey strata of which are seen coming out from beneath the old red sandstone, along a zone extending through a hundred and fifty miles, from the hills near Ludlow on the north-east to the sea-cliffs of Pembroke on the south-west. At a shortdistance below the junction of the two systems, at Ludford, in thie vicinity of Ludlow, upon laying
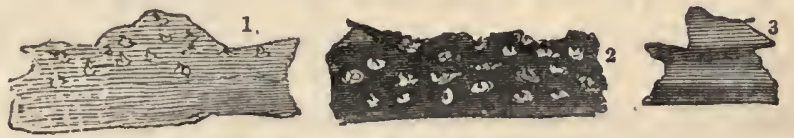
open the rock for the foundation of a house, a stratum was discovered, abounding in the confused remains of fishes, which have also been found in various parts of the same deposit. The remains consisted of a matted mass of scales, teeth, and jaws; and as no fossil relics of fishes had previously been detected in strata so ancient as the Silurian, or imagined to exist, the discovery of this bone-bed became of singular interest and importance. The engraving represents a few of these remains. According to M. Agassiz, 1, 2, 3 are probably fragments of the shagreen or skin of the same animal to which the tooth 4 belonged. This, he remarks, "constitutes a new generic type, which may bedesignated by the name of Sphagodus, slaughtering or murderous tooth." Of the other teeth, he states, that "they cannot be referred to any species already known, and constitute a genus, the fishes of which were without doubt the pirates of the sea of that period." In association with the fish-bones, there was a "fucoid bed," according to the analysis of Dr.Prout, almost entirely made up of a multitude of small, wavy, rounded, stem-like forms, so completely resembling entangled sea-weed, as to induce the conjecture that they must be the impressions of such vegetables.

In modern times, the Upper Silurians have in various spots suffered considerable displacement through subsidences of strata, or landslips. The ancient chroniclers have made the most of such events. "Near to the confluence of the Wye and the Lugg, to the east," Camden relates, "a hill called Marley Hill, in the year 1575, rose as it were from sleep, and for three days moved on its vast body, with a horrible noise, driving every thing before to a higher ground, to the great astonishment of the beholders." But a much more exaggerated statement occurs in Baker's Chronicle:- "In the 13th Queen Elizabeth, a prodigious earthquake happened in the east part of Herefordshire, at a little town called Kinaston. On the 17th of February, at six in the evening, the earth began to open, and a hill with a rock under it, making at first a great bellowing noise, which was heard a great way off, lifted itself up and began to travel, bearing along with it the trees that grew upon it, the sheepfolds and flocks of sheep abiding there at the same time. In the place from whence it was first moved, it left a gaping distance, forty feet broad and four-score ells long, the which field was about twenty acres. Passing along, it overthrew a chapel standing in the way, removed a yew-tree, standing in the church-yard, from the west to the east. With the like force, it thrust before it highways, sheepfolds, and trees, made tilled ground pasture, and again turned pasture into tillage. Having walked in this sort from Saturday evening till Monday noon, it then stood still." Drayton, in his Polyolbion, refers to this movement of Marley Hill :-

" Inrag'd and mad with griefe, himself in two did rive;

The trees and hedges neere, before him up doth drive,

And dropping headlong downe three daies together fall;

Which, bellowing as he went, the rocks did so aphall,

That they him passage make, who cotes and chappels crusht,

So violentlie he into his valley rusht." 
The evidence of the landslip appears on the spot, which still retains the name of "The Wonder." A similar event, more ancient, and unrecorded, is clearly traceable in the neighbourhood of Ludlow, at the Palmer's Cairns, where strata of Aymestry limestone have slid down from the crest of a hill, exposing the unctuous and argillaceous Lower Ludlow rock.

But these modern catastrophes are insignifieant to the disruptions which, in epochs of unknown remoteness, the Silurian strata have undergone, from the great plutonic masses which protrude through and intermingle with them. The principal igneous rocks associated with these strata appear in the Caer Caradoc, the culminating point of which rises to the height of 1200 feet above the level of the sea; in the Wrekin, 1330 feet above the sea, and its associate hills, which the traveller discerns from the heart of Staffordshire looming above the southern horizon; in the Breiddin group; and in the Malvern Hills, all of which have hard, compact felspar for the predominating material, producing, in different combinations, varieties of pink and dark-red syenite. The intrusion of these fiery products has variously dislocated and inclined the strata lying along their flanks, forced them up, and in some instances even folded them back, so as to make the newer deposits underlie the older; marked alterations in the character of the stratified formations appearing at the points of contact-limestone crystallised, shale indurated, and sandstone rendered quartzose, with the production of copper ore, iron pyrites, and bad serpentine. According to Sir R. Murchison, the district furnishes evidence of the play of rolcanic action during the deposition of the Lower Silurian strata at the bottom of the sea; of its repose while the upper members of the series wcre consolidating; of vast outbursts of intrusive trap subsequently taking place; and of some of the most violent disturbances transpiring after the accumulation of the old red sandstone and carboniferous systems. Hence the perforations of both with Silurian rocks at Malvern and at Dudley.

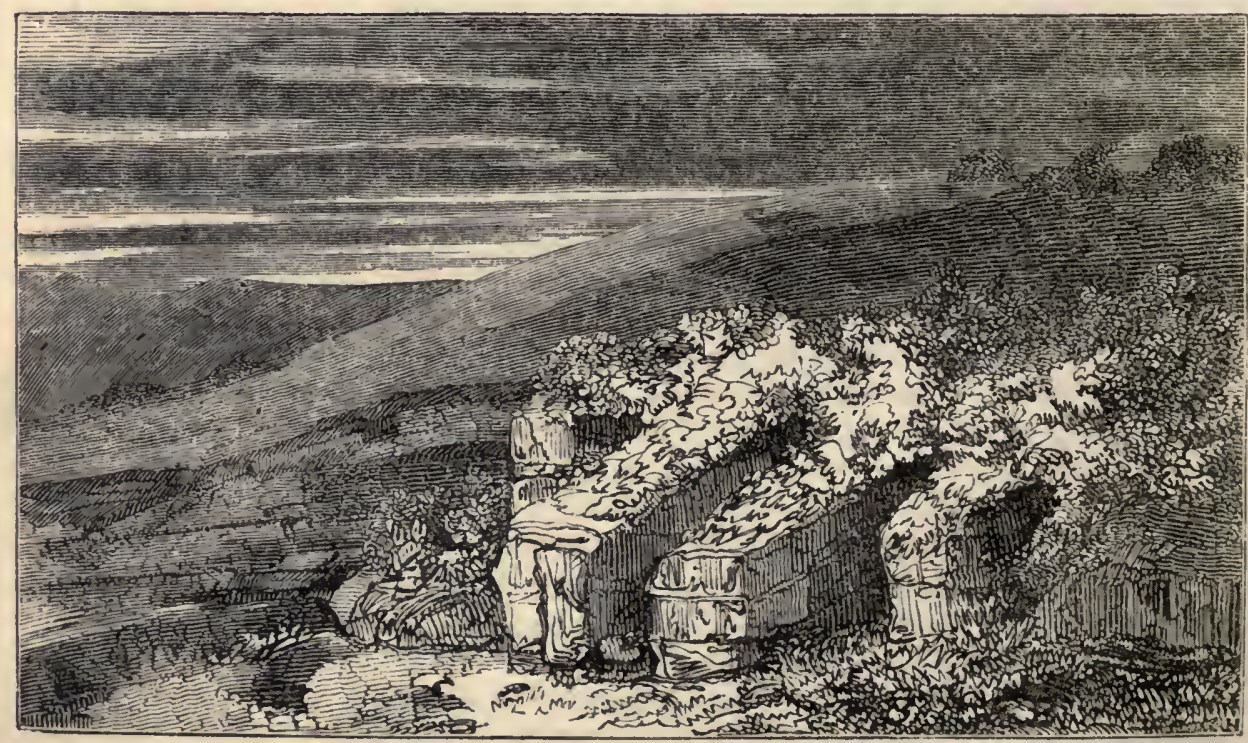

Palmer's Cairns, Ludlow. 


\section{CHAPTER V.}

\section{THE OLD RED SANDSTONE SYSTEM.}

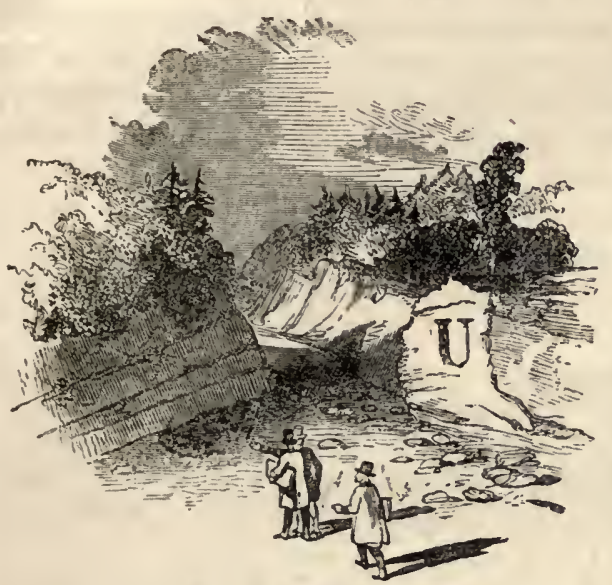

Trap Dyke, Brockhill, Worcester.

NTIL a comparatively recent date, it has been usual to distribute the members of this system among its neighbours, the subjacent Silurian and the overlying carboniferous systems, the principal part being incorporated with the latter. 'This is the plan adopted by Dr. Buckland and Professor Phillips; but Sir R. Murchison has clearly shown its right to an independent status, having distinct lithological characters and zoological contents. "You must inevitably give up the old red sandstone," said a distinguished foreigner to the latter, who was well acquainted with the ancient formations; " it is a mere local deposit, a doubtful accumulation huddled up in a corner, and has no type or representative abroad." "I would willingly give it up if Nature would," was the reply; "but it assuredly exists, and I cannot." It is now universally admitted that the English geologist was correct in classifying the strata in question as a separate system, one of the best defined groups of rocks in Great Britain, though ill developed in France and Germany, and lence the hesitation of the continental geologists to consider it entitled to that rank. It has however been recognised in Germany and Poland ; it occupies vast areas in southern Russia, Siberia, and 'Tartary ; it forms the southern flanks of the Himmalaya mountains; oceurs in Africa, and in various parts of the western world. In Scotland, the old red sandstone is exhibited upon an immense scale, extending in a broad unbroken bar across the kingdom, along the line of the Grampians from the east coast at Stonehaven to the Firth of Clyde. Two large bands also appear on each side of the Moray Firtlı, stretching far into the interior of the great Caledonian valley. It occupies the northern const of Caithness, the neighbourhood of Cape Wrath in Sutlerlandshire, and is found in large detached masses alonir a considerable part of the western coast. Mr. Miller supposes that at some early period these beds were continuous, forming a girdle round the entire coast of the north of Scotland; and from the occurrence of island-like patclies in the interior, he conjectures that, at some still earlier period, this girdle formed a mantle, which covered the enclosed tract, consisting of the entire Highlands. Porphyries, granites, gneisses, and micaceous schists now compose the central region, surrounded by a broken sandstone frame, the remains of the mantle, which was rent, and in great part swept away, when upheaving fires below and ccean currents above contended in sublime antagonism. An attentive examination of the physical aspect of the district, where igneous action is so extensively displayed, and evidence of vast denudation appears, suggested the idea now stated to the author of the "Old Red Sandstone, or New Walks in an Old Field,"- a volume which could only have been produced by the very highest genius, combining as it does the fascination of romance with the acquirements of science. 
In England, the old red sandstone occupies the greater part of Herefordshire; it spreads over wide tracts of Monmouthshire, Shropshire, and Worcestershire; surrounds the coal-field of the Forest of Dean and the great coal-basin of South Wales; and forms the lofty mountains of Brecknock, called the Brecon and Caermarthen Fans, or summits, which rise 2500 feet above the sea, and are the highest in our southern districts. It appears largely also in Devon, and hence the system has been called the Devonian; but the title which so eminently describes its composition is preferable. For a considerable time, it was regarded as a doubtful point, whether the sandstone formation of Devon was identical with that of Herefordshire, from the former presenting shells which are not found in the latter, and the latter containing fossil fish not discoverable in the former. All doubt upon the subject has however been removed, since Mr. Murchison observed, in the Russian deposits of sandstone, the fish of Hereford and the shells of Devon in the same beds.

An enormous thickness belongs to the system, equal in various localities to the height of Etna above the level of the sea, and probably averaging 10,000 feet. The following triple subdivision of this vast mass has been made by Mr. Conybeare and Dr. Buckland, as developed on the north of the Bristol Channel :-

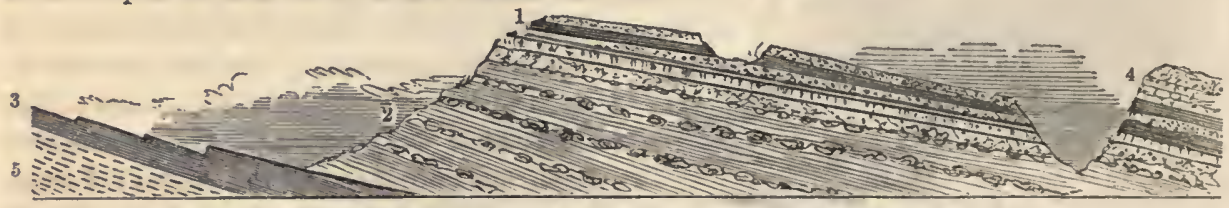

1. Upper - A quartzose conglomerate passing downwards into chocolate, red, and green sandstone and marl.
2. Central - Cornstone and mar) (red and green argillaceous spotted marls) with irregular courses of Impure concretionary limestone, provincially called cornstone, mottled, red, and green, containing remains of fishes.

3. Lower - Tilestones, finely laminated hard reddish or green micaceous or quartzose sandstones, which split into tiles, con-

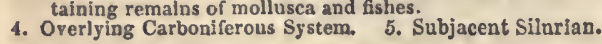

The section exhibits the triple group which constitutes the old red sandstone, with the subjacent Silurian and the overlying carboniferous systems. It will be seen that the lower member of the series, the tilestone division, is by far the smallest. This fissile formation appears at Pont-ar-Lleche, the "Bridge on the Tiles," in Caermarthenshire, occupying lofty heights, where the strata have been extensively quarried; and junctions with the Upper Silurians are well seen in the gorge of the Teme, and in the vicinity of Ludlow. The provincial cornstones in the central member of the system, consisting of concretions of very impure calcareous matter, vary in diameter from half an inch to three or four inches, and are quarried for the repair of the roads. The " conglomerate," composing the superior division of the series, comprises pink and white pebbles of quartz, from the size of a hazel-nut to that of a cannon ball, and is well developed in great masses on the right bank of the Wye, to the north of Tintern Abbey. The entire system is eminently arenaceous, and hence its name, the term "old" distinguishing it from another series, above the coal measures, called the new red sandstones, and the term "red" referring to the predominant colour of the strata. This colour, which exhibits various shades, from a dark brick-red to a cream-yellow, arises from iron oxide, the different hues depending upon the amount of iron in the rock, and its state of oxidation, though in several places in Scotland the tint seems to be occasioned by copper. The origin of the metallic oxide is usually referred to the play of volcanic agency during the deposition of the sandstone, the infusion of the mineral matter rendering the waters uninhabitable by organic life. It has been thought a curious corroboration of this fact, that fossil fishes are most abundantly found in the lightest coloured and least impregnated strata.

The physiognomy of the old red sandstone districts is not so striking as that exhibited by the more ancient systems, but presents bolder developments than are common to the subsequent formations. The scenery consists of extensive undulating plains, where the 
strata lie flat or nearly so, not having been invaded by igneous rocks. In proximity to the latter, the sandstone forms considerable and precipitous hills, with rounded dome-like summits, in connection. with lower bluffs, which affect the mural form, and display a tendency to separate into huge quadrangular masses. 'The Brecon and Caermarthen fans, and the Ochills in Scotland, are some of its most imposing appearances, Ben Clach, in the latter chain, being 2182 , and the King's Seat 2100 feet high. "We find the upper formation," says the historian of the deposit, Mr. Miller, " associated with scenery of great though often wild beauty; and nowhere is this more strikingly the case than in the province of Moray, where it leans against the granitic gneiss of the uplands, and slopes towards the sea in long plains of various fertility - deep and rich, as in the neighbourhood of Elgin, or singularly bleak and unproductive, as in the far-famed heath near Forres. Let us select the scene where the Findhorn, after hurrying over ridge and shallow, amid combinations of rock and wood, wildly picturesque as any the kingdom affords, enters on the lower country, with a course less headlong, through a vast trench scooped in the pale red sandstone of the upper formation. For miles above the junction of the newer and older rocks, the river has been toiling in a narrow and uneven channel, between two upright walls of hard grey gneiss, thickly traversed, in every complexity of pattern, by veins of a light red, large-grained granitc. The gneiss abruptly terminates, but not so the wall of precipices. A lofty front of gneiss is joined to a lofty front of sandstone, like the front walls of two adjoining houses; and the broken and uptilted strata of the softer stone show that the older and harder rocks must have invaded it from below.-We stand on a wooded eminence, that sinks perpendicularly into the river on the left, in a mural precipice, and descends with a billowy swell into the broad fertile plain in front, as if the uplands were breaking in one vast wave upon the low country. The river travels along under pale red cliffs, wooded atop. It is through a vast burial yard that it has cut its way-a field of the dead so ancient, that the sepulchres of Thebes and Luxor are but of the present day in comparison - resting-places for the recently departed, whose funerals are but just over. These mouldering strata are charged with remains, scattered and detached as those of a churchyard, but not less entire in their parts - occipital bones, jaws, teeth, spines, scales - the dust and rubbish of a departed creation."

Every where the sandstone presents evidence of being a littoral deposit, frequently showing the tidal ripple-mark as plainly as the sands of our present shores; but the different members of the series appear to have been deposited under different circumstances. The lower tilestone formation seems an accumulation of sediment in calm water, while the upper conglomerate is a compost of water-worn boulders, which show considerable attrition, and proclaim the action of strong oceanic currents. In various localities the sandstone exhibits a countless profusion of singular depressions, in the form of rings, horse-shoes, or almonds, small in the English districts, but often nearly a foot in diameter in Scotland, easily perceptible by their pale yellow colours, contrasting with the dark red of the surrounding rock. These impressions point to the marking of the surface of the strata with blotches, the origin of which is obscure, but consisting of a softer material than the mass they distinguish, which the subsequent action of water or of the atmosphere has partially or entirely worn away. In former times superstition converted these appearances into supernatural phenomena. According to the tradition of the English borders, a mare and her foal, belonging to the chapelry of Sapey, having been stolen by a woman, who led them down the bed of a stream, to avoid the discovery of their traces, the patron, St. Margaret of Audley, interposed, and ineffaceably imprinted upon the rock the foot-prints of the animals and those of the woman's pattens, as a memorial of the sacrilegious crime.

It was at one time imagined, that the old red sandstone system contained few or no 
fossils; but upon a more careful attention being paid to it, they were discovercd in abundance, and of singularly interesting and important forms. The remains of vegetables, though numerous, are yet very indistinct and much broken, as if they had been drifted by powerful currents from a considerable distance. Descending into the quarries of the parish of Carmylie in Scotland, in the cornstone formation of the system, Mr. Miller found almost every layer of the strata covered with carbonaceous markings -irregularly grooved stems, branching out into boughs at acute angles, seeming miniature semblances of the trunks of gnarled oaks and elms; also oblong leaf-like impressions, with impressions of more slender form, like the narrow parallel-edged leaves of the sea-grass weed; and a large bunch of riband-like leaflets converging into a short stem, the whole resembling a scourge of cords. The engraving shows some examples. In the same

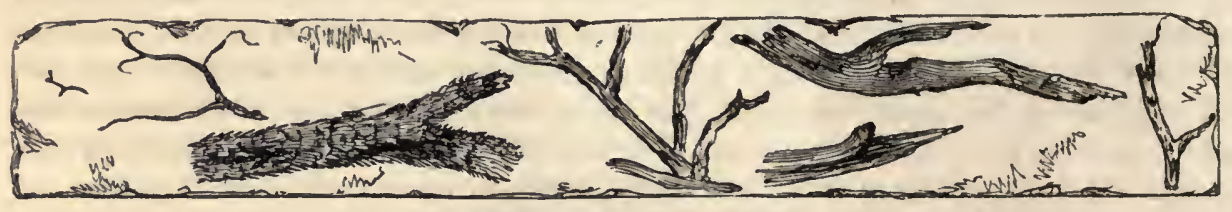

Vegetable Remains in Old Red Sandstone.

locality the same observer found irregularly-shaped patches, reticulated into the resemblance of polygonal meshes, like pieces of ill-woven lace, familiarly called by the workmen "puddock spawn," from their similarity to the eggs of the frog. These patches are supposed by Sir C. Lyell to be formed of remains of the eggs of some gasteropodous molluse of the period. Shells are abundant in the lower part of the system in England, several of which have been carefully figured by Sir R. Murchison, and in Scotland the traces or remains of gigantic crustaceans are of common occurrence. The labourers in the sandstone of Forfarshire hare long remarked appearances in the strata, denominated by them "petrified seraphims," from an imaginary resemblance to the representations of those angelic beings upon the gravestones in country churchyards. A number of detached fragments having been discovered at Bulruddery, were submitted to the inspection of M. Agassiz in Edinburgh, in the presence of other geologists, whom they had completely puzzled. "I will tell you," he observed, after a short examination, - " $I$ will tell you what these are-the remains of a large lobster." The distinguished ichthyologist then took fragment after fragment from the group, arranged the parts, exhibited the animal to the company - a huge lobster, indicating a total length of four fect.

Ichthyolites, or fossil fishes, belonging to the vertebrated order, are, however, the characteristic fossils of the system, some of which appear to be organisations but a little removed from the humbler crustaceans, while others display an advanced structure. Having now arrived at an era in the history of the globe which furnishes decisive and abundant evidence of the prevalence of high organic life in the waters, the state of ichthyology, which has undergone a complete revolution in our own day, and of fossil ichtlyyology, requires a notice. The number of living species of fishes at present known amounts to somewhat more than 8000 . It was formerly usual to classify fishes according to the nature of the skeleton, into the two great groups of osseous or bony, and cartilaginous. The osseous class embraces those whose skeletons are the most durable, being composed of calcareous earth pervading an organic base : the cartilaginous, on the contrary, contain little of this earth, the skeleton consisting of elastic, semi-transparent, indurated animal matter, speedily yielding to decay. But Agassiz, departing from this arrangement of Cuvier, distinguishes four great orders of fishes, characterised by essential differences in the form and structure of the scales, or the dermal (skin) system, 
with which other important distinctions are found to coincide, in the same manner as the varieties in the hair of mammalia, the feathers of birds, and the naked or plated skin of reptiles, are connected with structural and functional differences, and are a natural index to them. The value of this discovery is apparent from the fact, that the scales are precisely those remains of the finny races that are most abundant in a fossil state, so that a single scale becomes a clue to the order and habitat of the animal to which it belonged. The divisions proposed by Agassiz are-

\section{SCALES ENAMELLED.}

1. Placoidians - from $\pi \lambda a \xi$, a broad plate. The fishes of this order are irregularly covered with large or small plates of enamel, sometimes reduced to mere points, like the

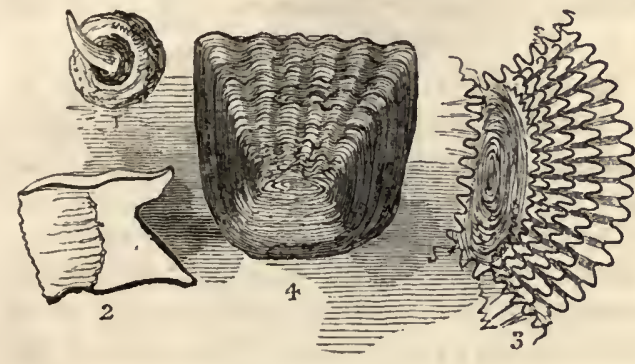
shagreen on the skin of the shark, and the prickly tooth-like tubercles of the skin of the ray. It comprehends all the cartilaginous fishes of Cuvier except the sturgeon.

2. Ganoidians-from ravos, splendour, referring to the brilliant surface of their enamel. Angular scales charac. terise the families of this order, composed internally of bone, and externally of enamel, generally bright and smooth. The bony pike of the North American lakes and sturgeons are of this order. Upwards of sixty genera have been noticed, of which fifty belong to the fossil kingdom.

\section{SCALES NOT EXAMEILED.}

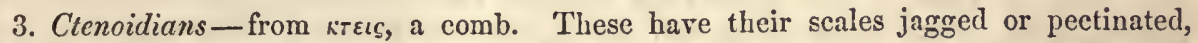
like the teeth of a comb, on their posterior margin, of which the perch affords a familiar example.

4. Cyeloidians - from $x$ ukios, a circle. Fishes of this order have their scales smooth and entire at their posterior margin, composed of horn or bone, of which the herring, salmon, and carp are instances.

Both osseous and cartilaginous fishes are included in each of these orders; but only those of the first and sccond grand divisions, with enamelled scales, Placoidians and Ganoidians, existed in the ancient strata antecedent to the chalk. 'The third and fourth orders, Ctenoidians and Cycloidians, to which three fourths of the existing species of fishes belong, make their appearance in that formation, when all the preceding fossil genera had become extinct. The following table exhibits the geological distribution of these orders :-

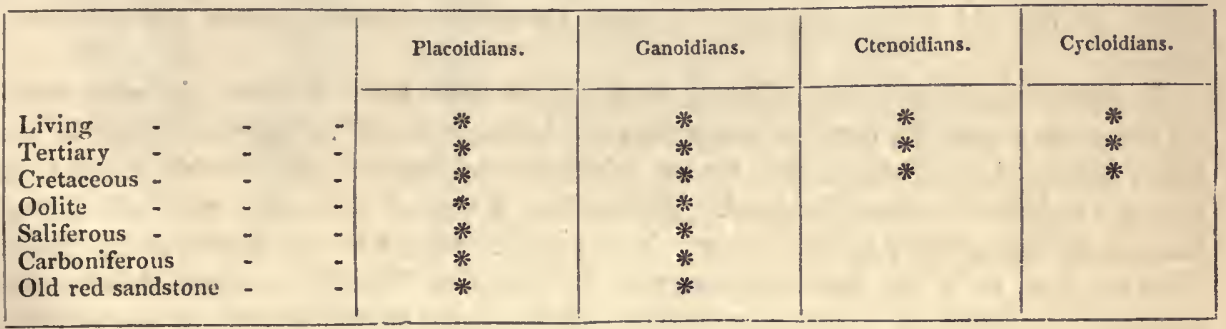


Another remarkable circumstance pointed out by Agassiz refers to the diverse form of the tails of fishes, as in the engraving, which represents - 1 . the homocercal, or eren-tail, as in the trout; 2 . the single and rounded, as in the wrasse; and, 3 . the heterocercal, or unequal tail, as in the shark. Now it is a singular fact, that nearly all the fossil fishes

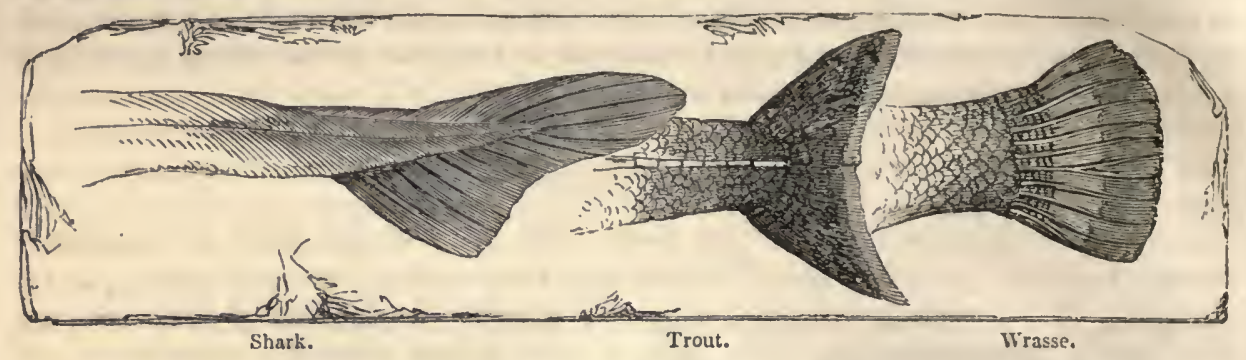

that occur in the ancient strata, or below the magnesian limestone, are distinguished by their heterocercal or unsymmetrical tails; while this form is rarely found in the oolitic and superior systems, and among living species. The heterocercal structure in the case of the living shark is an arrangement to meet the position of the mouth, which is placed downwards beneath the head, so that the body of the animal requires to be turned, in order to bring the mouth in contact with its prey - a movement to which the peculiar form of the tail is adapted. As the heterocercal tail is formed by a prolongation of the vertebral column, it seems an advance of organisation in fishes torvards the class of reptiles, in which the same structure is fully developed.

When death closed the labours of Cuvier, and arrested the progress of his great work, Ossemens Fossiles, he had only just commenced the difficult task of examining and arranging the fossil remains of fishes, naming and describing but ninety-two distinct species. Committing the materials he had collected to Agassiz, the number of species was raised to 1600 in little more than fourteen years, and it is now rapidly verging towards 2000. Some, the most strange and singular conformations, are encountered in the old red sandstone, - " creatures whose very type is lost-fantastic and uncouth, and which puzzle the naturalist to assign them even their class: boat-like animals, furnished with oars and a rudder; fish plated over, like the tortoise, abore and below, with a strong armour of bone, and furnished with but one solitary rudder-like fin; other fish, less equivocal in their form, but with the membranes of their fins thickly covered with scales, creatures bristling over with thorns; others glistening in an enamelled coat, as if beautifully japanned: the tail, in every instance among the lcss equivocal shapes, formed not equally, as in existing fish, on each side of the central vertebral bone, but chiefly on the lower side, the bone sending out its diminished vertebrx to the extreme termination of the fin. All the forms testify of a remote antiquity - of a period whose fashions have passed away. The figures on a Chinese vase or an Egyptian obelisk are scarcely more unlike what now exists in nature than the fossils of the old red sandstone." Among these remarkable objects, the following occur :-

Cephalaspis.-This genus, of which four species have been described, is remarkable for the great size of the head in proportion to the body, equal to fully one-third of the entire length of the creature, and for its shield-like appearance, after which it has been named, Cephalaspis - buckler-head. The outline is that of a crescent, with the lateral horns inclining slightly to each other. The eyes are placed in the middle of the shield, close together, as is the case with many of the flat fish. Scales variously circular and angular, bony, with an exterior enamelled surface, each having a convex centre, from 
which furrows diverge, cover the head. The thin angular body is apparently, though not really, composed of joints like the trilobites, to which family the creature was at first referred; and, in fact, it seems a link between the crustaceans and fishes.

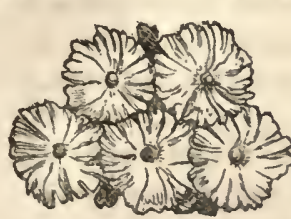

The scales of the head magnified are represented in the engraving. "Has the reader ever seen a saddler's cutting-knife-a tool with a crescent-shaped blade, and the handle fixed transversely in the centre of its concave side? In general outline the Cephalaspis resembled this tool; the crescent-shaped blade representing the head, the transverse handle the body." It seems to have been well prepared for defence, encased in armour of great strength, for its remains

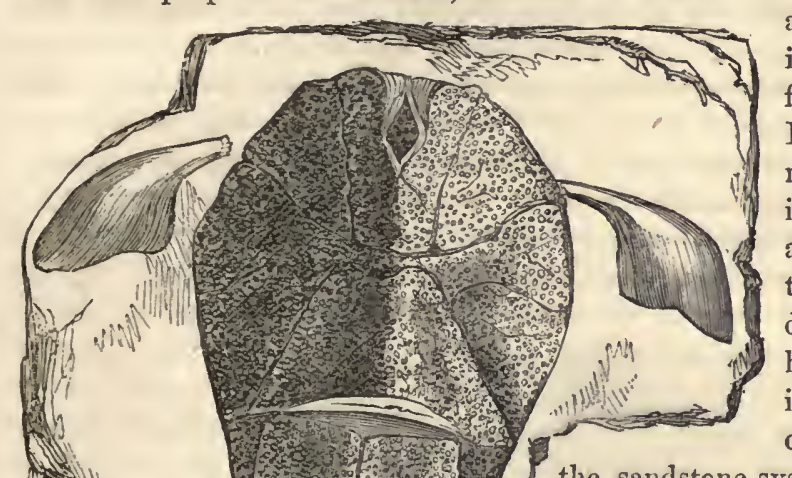
are found very perfect in strata impregnated with iron, in which few fossils could have survived. It would have been likewise a formidable animal for attack, could it have commanded any considerable impetus, like the sword-fish, the sharp margin of the shield doing the work of a vigorously hurled javelin. This singular ichthyolite is the characteristic organism of the cornstone part of

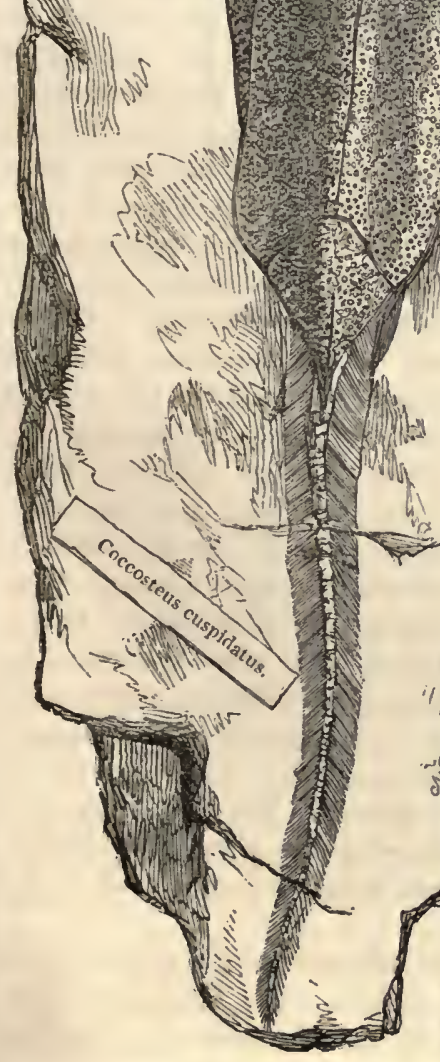
the sandstone system, both in England and Scotland. The several species which occur in the border English countics, says Sir R. Murchison, " seem not to have been suddenly killed and entombed, but to have been long exposed to destructive submarine agencies, such as the attacks of animals, currents, and concretionary action, by which they were dismembered." Though hundreds of fragments have been found in England, it is remarkable, that no example of an entire fish has yet bcen discovered. This is not the case with Scotland, where the species Cephalaspis Lyellii was found entire in Forfarshire, and named by Agassiz after the distinguished geologist born in that county.

Coccosteus.-This has been styled a Cephalaspis a stage further on, more of a fish, having the horns of the crescent-shaped head cut off, and the angular body terminated by a long vertebrated tail. The name, bone-berry, refers to berry-like tubercles, with which the plates composing its bony casement are dotted. The creature has been aptly compared to a boy's kite, varying in length from one to two feet. Four species have been described, of one of which this is a representation. Their fragments are frequently of a brilliant blue or purple colour, and are easily recognised from the contrast with the dull red tint of the sandstone rock. Sir R. Murchison supposes the 
colour to be owing to the presence of phosphate of iron, which has communicated a simila. tint to the fishes of the Caithuess schist. The tecth of Coccosteus, instead of being fixed in sockets, are integral portions of the bone, like the teeth of a comb; and the mouth is supposed to have been placed vertically, which, if proved to be correct, is an anomalous construction. The mouths of crustacea, as the crab and lobster, open rertically; but naturalists have hitherto found it an invariable condition of vertebrata, that the position of the jaws is horizontal.

Pterichthys. - The first individual of this genus - winged-fish - which embraces several species, was discovered by Mr. Millcr, who remarks, upon finding the prize - "I fain wish I could communicate the fecling with which I contemplated my first-found specimen. It opened with a single blow of the hammer; and there, on a ground of lightcoloured limestone, lay the effigy of a creature fashioned apparently out of jet, with a body covered with plates, two powerful-looking arms articulated at the shoulders, a head as entirely lost in the trunk as that of the ray or the sun-fish, and a long angular tail. My first-formed idea regarding it was, that I had discovered a connecting link between the tortoise and the fish; the body much resembles that of a small turtle; and why, I asked, if one formation give us sauroid fishes, and another give us chelonian ones, - or if in the lias we find the body of the lizard mounted on the paddles of the whale, why not find in the old red sandstone the body of the tortoise mounted in a somewhat similar manner? The in error, but as which not many have corrected may be deemed

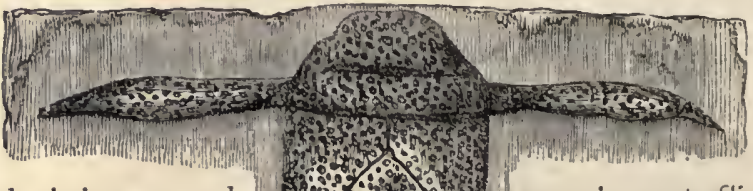
idea originated it was an errol naturalists could at the time, it an excusable one." Upon submitting several wrote in reply: - "As to your here (London), except that they rements of some of the Caitliness can be referable to any reptile; for approach to crustaceans than to any that Agassiz will pronounce them the curious genus Cephalaspis of connecting links between crustaanticipated from the Swiss him. The form of Piterichthys, a rougli resemblance to that of extended, the body narrowing, and the centre of the trunk, gradually species of the genus found in this

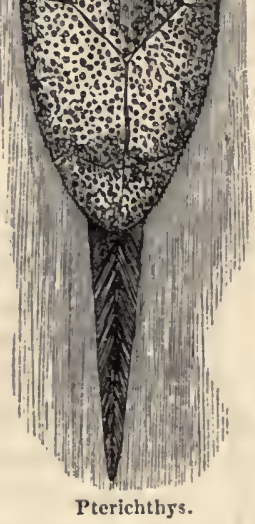

specimens to Sir R. Murchison, he fossils, we know nothing of them mind me of the occipital fragfishes. I do not conceive they if not fishes, they more closely other class. I conceive, however, to be fishes, which, together with the old red sandstone, form the ceans and fishes." The verdict naturalist was pronounced by which is here restored, bears a headless man, with his arms terminating in one leg fixed in tapering down to a point. The country are all small, not longer than eight or ten inches; but examples of the lateral spines have been discovered in Russia, exceeding a foot in length, which must lave belonged to enormous individuals. These spines were not intended for locomotion but defence, lying close by the creature's side when in a state of security, and erected upon the intimation of danger, as in the case of the common river bull-head, which has similar spines. The Pterichthys are lowerer commonly found with the spines extended, proclaiming the alarm under which existence terminated, and the instinct of self-preservation, whicls now marks all living organisms, then in action, but exerted in vain.

Holoptychius. - This genus has been so named from the character of the seales, which present undulating folds or furrows upon an enamelled surface. The scales have been found exceeding three inches in length by two and a half in breadtb, indicating the great 
magnitude of the fish. One specimen, which measured two feet four inches by one foot, was found at Clashbinnie, near Perth, by the Rev. James Noble, and called Nobilissimus, after the discoverer. The organs of locomotion, the tail and fins, are well developed. The characteristic features are, the small size of the head in proportion to the body, and the far removal of the fins towards the tail. This fish occurs in Scotland and in Russia, in the upper part of the old red sandstone system - the quartzose conglomerate which is highly fossiliferous in those countries, while in England and Wales it presents but few organic remains.

Osteolepis. - However an unscientific eje might fail to recognise the preceding forms as belonging to the class of fishes, the most rustic mind would immediately identify this genus with the ordinary inhabitants of the waters. The generic name-bony-scalebelonging to the days of Cuvier, was first given to the fossil fishes of Caithness, and has been continued, though subsequent discovery has shown that the same descriptive title would apply equally as well to fishes of other families. The particular kind, thus indicated, exhibits the form of a perfect fish, with pectoral, abdominal, and caudal fins, the bony scales being arranged side by, side like so many bricks in a wall. The tail was heterocercal, the vertebral column running on nearly to the extremity of the caudal fin. The length of the fish varies from under six inches to somewhat more than a foot. Equally recognisable is another family of fishes, the Dipterus, or double winged, first brought into notice by Sir R. Murchison and Professor Sedgwick. This fish chiefly differs from the former in the fins being opposite each other, instead of alternating.

Such are some of the forms which the ichthyology of the old red sandstone system comprises. During its formation - which necessitates a large draught upon time to account for the accumulation of strata ten thousand feet thick-the only dry land consisted of the older granites, with a portion of the stratified systems formed from their disintegration-mere islands, in a vast oceanic expanse; and the waters appcar to have been in very discordant circumstances - calm as the unrippled lake, when the finely laminated tilestones of England were laid down, and swept by powerful currents while the quartzose conglomerates were depositing. The evidence is clear of the existence of terrestrial vegetation, and for the first time memorials are met with of an air-breathing animal, a reptile apparently allied to the lizards. The proof is also ample of the ocean having abounded with organic life, as much so as now that its vast armies of herrings appear along our coasts. "I have seen," says the authority already quoted, the best that can be cited, whose graphic chronicle of the phenomena of the system is beyond all praise, "I have seen the ichthyolite beds as thickly covered with oblong spindle-shaped nodules, as I have ever seen a fishing-bank covered with herrings; and have ascertained that every individual nodule had its nucleus of animal matter - that it was a stone coffin in miniature, holding enclosed its organic mass of bitumen or bone - its winged, or enamelled, or thorn-corered ichthyolite." These beds, involving an area of many thousand square miles, now form a vast mausoleum, containing the remains of countless swarms of oceandwellers, which once, gay with life, sported in the waters; and, what is most remarkable, these myriads appear to have perished by violence at the same moment, and in a calm sea! Their contorted frames - their tails in many instances twisted towards the headtheir spines stuck out, and fins spread to the full - their arms, in the case of the Pterichthys, stretched abroad at their acutest angle-attitudes proclaiming alarm and painpoint to some tremendous and instant catastrophe - while their scales, retaining the enamel, a fine edge, and only scattered as if by a ripple, point to the disaster occurring when the tempest slept and the bosom of the deep was unagitated! Strange as this appears, the history of oceanic and terrestrial life during the present epoch supplies precisely parallel examples. The "pestilence that walketh in darkness, and the destruction 
that wasteth at noon-day," has repeatedly visited the globe in modern eras, making havoc with the animal races, like the fatal murrain which Virgil describes as depopulating the Alps. But a case more in point has presented itself to the eye of the sailor, in shoals of the finny tribes - haddock, cod, ling, and whiting - floating dead upon the surface of the sea, apparently smitten at the same moment by some inexplicable destroying agent. "On Friday, the 4th of December, 1789, the ship Brothers, Captain Stewart, arrived at Leith from Archangel, who reported, that on the coast of Lapland and Norway, he sailed many leagues through immense quantities of dead haddocks. He spoke several English ships, who reported the same fact. It is certain that haddock, which was the fish in greatest abundance in the Edinburgh market, has scarcely been seen there these three years." This statement occurs in one of the letters addressed to Sir John Sinclair, and it records an example of death, and of the deposition of organic forms at the bottom of the existing seas, upon as broad a scale, and in an analogous manner, to that which the long dry and elevated rock formations in question disclose.

\section{CHAPTER VI.}

\section{THE CARBONIFEROUS SYSTEM.}

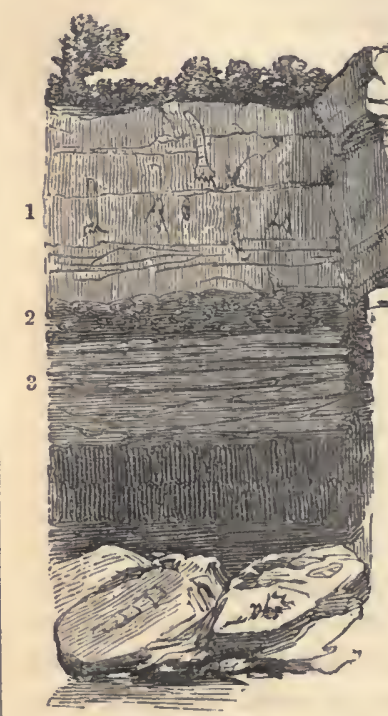

1. Stems of vegetables,

2. Compact carbonate of iron.

3. Coal Seam.

a $\mathrm{N}$ the history of the earth, as inscribed in its various rock-formations - a "scroll written within and without," - the scene repeatedly shifts in a very striking manner, and a new aspect is given, as we advance, to the condition of terrestrial nature. Nowhere is this revelation of fresh existence more apparent than in passing from the old red sandstone to the carboniferous system.

The former discloses to us a vast ocean swarming with organic life - with vertebrated fishes, mollusca, and seaweed, - the waters alternately reposing and flowing in strong currents; but extensive tracts of fertile soil, covered with a regetation as luxuriant as that now found along the banks of the South American rivers, in connection with an abundance of oceanic organisms, is the state of our planet unfolded by the great coal deposits, - the most important, and among the most interesting, contents of its crust. There is no ancient condition of the earth that is now contributing so essentially to human happiness and national wealth; for when we have enumerated a supply of zinc and copper, roofing-slates, and building or paving stones, we have mentioned the chief direct obligations we owe to the older formations. It is from the carboniferous system that we derive the most valuable metals of commerce-lead and iron, with the vegetable matter that enlivens our hearths, aids in preparing our food, yields the gas that lights our streets, and is an essential agent in the production of that steampower, upon which manufactures, and locomotion by land and sea, to a large extent 
depend. It is impossible to conceive of a greater and more disastrous change than that which an exhaustion of coal would produce. The native-grown timber would furnish no supply of fuel equal to the demand, or would be out of the reach of the mass, from its price. This would speedily be true, likewise, of an imported article; and just in proportion as the former forests of our island were revived to meet the emergency, would the domain of the cereal grasses be invaded, equally necessary to the sustenance of a numerous population. While the people consisted of a mere handful, scattered over an ample territory, abounding with large tracts of unenclosed timber-ground, they could afford to be ignorant of the ignitable deposits in the bowels of the earth: and it deserves notice, that the discovery of these precious stores has not taken place until a very recent date, as if it were an intentional arrangement, to secure from needless waste a material so vital to the maintenance of civilisation in a land replenished with inhabitants. The Greeks and Romans seem to have been quite unacquainted with coal. The earliest mention of it in our own history occurs in a charter granted to the inhabitants of Newcastle, in the year 1234, by Henry III. ; but it was not until the reign of Charles $\mathrm{I}$. that it was in common use in the southern part of the kingdom.

Besides the carboniferous beds, the coal-bearing system comprehends other strata, occurring in the following order of succession:-

Coal Measures-Layers of sandstone, shale, ironstone, and clay, alternating with coal, and more rarely with thin layers of limestone: the estimated thickness of the whole mass, 1000 yards.

Millstone Grit-A series of sandstones, composed of sandy and quartzose pebbles, sometimes fine-grained, but generally very coarse. Grit is a provincial name for coarse sandstone, and millstones are obtained from some parts of it. In some localities shale and thin seams of bad coal, with plants of the coal measures, accompany the grit. The estimated thickness is from 500 to 650 feet.

Mountain Limestone- A mass of calcareous rocks, with nodules of chert, several varieties of variegated marbles, layers of red oxide of iron, ores of lead, zinc, and copper, and innumerable remains of crinoidea and marine shells.

The section exhibits the old red sandstone, 0 , on the left, the base of the carbon-

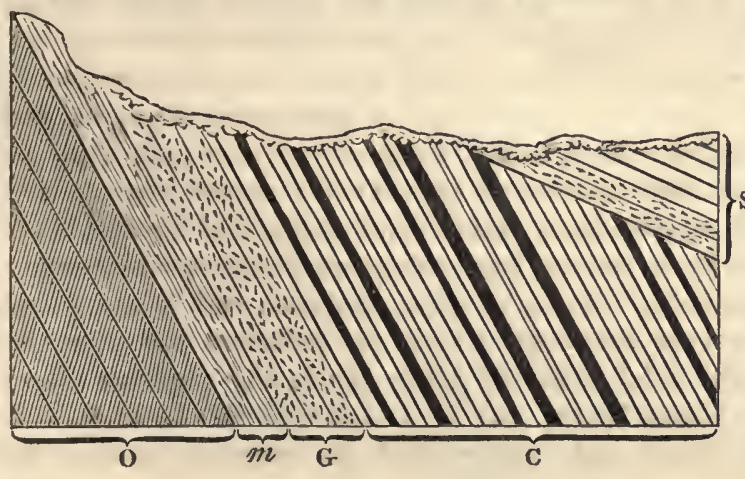
iferous system; $m$ the mountain limestone, next occurring; $\mathrm{G}$ the millstone grit; $\mathrm{c}$ the coal measures; and $s$ the strata of the overlying saliferous system, which cover $S$ them in unconformable stratification. The coal-fields of England usually present the arrangement in the preceding section, the coal lying all above the millstone grit; but in the north-western parts of Yorkshire the carboniferous system is complicated and varied, the coal-measures being interstratified both by the millstone grit and the mountain limestone. The great coal-field of Dudley is also another deviation, for there the old red sandstone is entirely wanting, and the coal rests upon the upper Silurian rocks.

Mountain Limestone. - This formation, a prominent feature of the superficies in England, the north of France, and Belgium, is so called from its mineral character, and frequent development in bold hilly masses, many of which are of considerable magnitude, though it often appears in valleys and flat lands. It is not uniformly calcareous, but has 
alternating beds of a different composition, layers of chert, or nodules of a hard siliceous nature, corresponding to those of flint, which so commonly occur in the chalk cliffs. The limestone, however, sufficiently predominates to become characteristic. It yields the lime of agriculture upon being burnt, and that used for mortar, the action of heat changing its colour to a pure white, by destroying the animal and vegetable remains which impart to the rock its various shades of light and dark grey. The black variety also, frequently used for chimney-pieces, has its colour, probably arising from bitumen, completely expelled by burning. The limestone exhibits a well-defined stratification, a compact structure, and forms marbles of great beauty upon being polished. The romantic rocks of Cheddar flanking the chain of the Mendip Hills in Somersetshire, the heights on each side of the Avon at Clifton, the picturesque cliffs on the banks of the Wye, the bold tors of Derbyshire, and the high mural precipices laved by the Meuse below Namur, are examples of the mountain limestone, which, for scenic effect, upon a limited scale,

\section{"So wondrous wild, the whole might seem \\ The scenery of a fairy dream,"}

stands at the head of the rock-formations of the globe. This part of the carboniferous system presents numerous fissures and caverns, almost all the grand examples of these structures being found in it. They have either arisen from irregular beds of sand and clay deposited with the limestone, and subsequently washed away by the agency of water, or from small fissures in the rock, formed by the elevating forces that have acted upon it, which, in the course of ages, the constant percolation of water has enlarged into the chasms that now yawn in the rocky fabric. The stream that issues from the mouth of the cavern at Castleton - the general attendant of such excavationspoints to one part of the machinery that has operated in their construction; and the disturbance of the strata by the protrusion of igneous rocks is clearly indicated in other localities. We have previously given a view of the insulated dome-shaped hill at

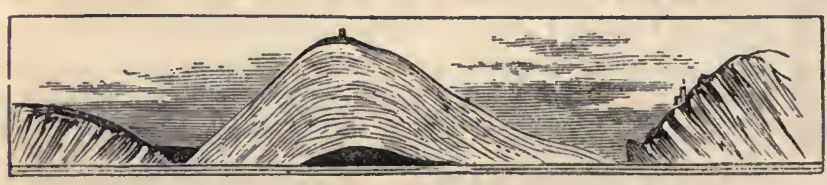

Section of the Crich-hill. Crich in Derbyshire, which supplies an example of the arched arrangement of strata; and the cut represents a section of this protuberance, a remarkable object in the

district, - showing, in the dark shaded centre, a protrusion of compact trap, reached upon striking a shaft in search of lead ore, which explains the curved form of the overlying limestone mass. The hill supplies many instances of cracks and fissures, filled with metallic ores and spars, formed by an intense heat acting under immense pressure.

The mountain limestone is remarkably rich in metallic products; and hence it las been sometimes called the metalliferous limestone. It is the principal depository of the lead found in Great Britain, the chief mines of which are in the northern counties of England, in Derbyshire, in North Wales, and in Devonshire on the borders of Cornwall. These mines, with the Scotch and Irish, yielded the following produce in the year 1855 :-

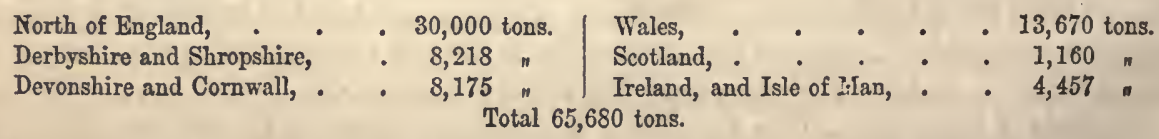

The Derbyshire lead-mines, among the most ancient in the kingdom, are in the north-west part of the county, extending as far south as the neighbourhood of Matlock, 
where the carboniferous limestone occurs in great force, overlain by the millstone grit; the strata exhibiting great disturbance from the intrusion of igneous rocks which appear in intersecting beds and dykes. They were worked as early as the year 835 , at which time a grant was made by the abbess of Repton, of her estate at Wirksworth, on condition of an annual stipend of lead being paid, for certain religious uses; but a still greater antiquity belongs to them, as evidenced by the discovery of some Roman remains. A block of lead was discovered on Cromford moor, in the year 1777, with the following inscription,-_"'The Emperor Cæsar Hadrianus Augustus, from the mines at Lutudarum," a station in that locality; and another block was met with near Matlock in 1783, inscribed, "Lucius Aruconius Verecundus, from the mines of Lutudarum." All affairs with reference to these mines are regulated by a peculiar court, legally constituted, the laws of which are administered by an officcr called the barmaster, whose mode of proceeding is extremely simple and summary. When a person has found, or imagines lie has found, a vein of ore in any part of the "King's field," which, with few exceptions, includes the whole of the mineral districts of Derbyshire, he may claim it as his own merely by fixing down a few sticks, put together in a peculiar way, and notifying the same to the appointed officer, who immediately confirms him in the possession of his newly-acquired property. The officer, attended by two jurymen, proceeds to the spot, marks out a plot of ground about fourteen yards square, takes it from the former proprietor, whether it be freehold or not, and gives it to the fortunate discoverer. $\mathrm{He}$ then, with his attendants, their arms extended and finger-ends touching, proceeds to the nearest highway, the line of route becoming a carriage way in perpetuity to the miner, whereon he may cart his minerals. Neither standing corn, nor any other description of property, with the exception of " a dwelling house, a high road, a garden or an orchard," is, or can be, exempt from this fundamental law of the miners.

So numerous are the organic remains in this formation, that it has received the name of the Encrinal Limestone, from the abundance and variety of encrinite exuvix found in

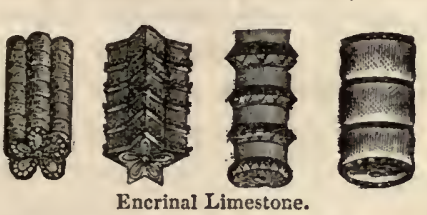
it, whole masses of the rock being almost entirely composed of them. Various articulations of the stems of these interesting lily-shaped animals are here shown. Some of this limestone, when sufficiently hard and close to be susceptible of a polish, is formed into the splendid variegated slabs which adorn the mansions of wealth, fully equal to the marbles imported from Italy to gratify a taste for foreign productions. The seas, during the deposition of the mountain limestone, must literally have swarmed with members of the encrinite family, since they enter into the composition of various masses as largely as coral-animals into a now growing coral-reef. Shell-fish were also abundant, belonging to all orders, of which the engraving affords some examples. 1. Orthoceras lateralis, a straight shell divided by transverse septa into chambers, of which

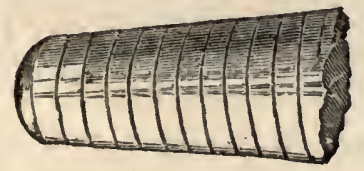

1.

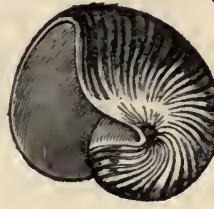

2. nearly seventy have sometimes been counted. Orthoceratites have been found a yard in length, sometimes more, and half a foot in diameter, forming a float which would have accommodated an animal far larger than any existing cephalopod. 2. Bellerophon costatus, a small-sized unchambered shell, analogous to the recent Argonaut, or Paper Nautilus, an inhabitant of the Mediterranean. The gigantic scale of some of these shells is supposed to indicate a very warm climate favouring their development in the northern seas, and an ocean highly charged with calcareous matter supplying the material for their construction. Many remains of icthyolites, either as entire fishes, or detached scales and 
teeth, with coprolites, their fossil excrement, are scattered through the limestone strata, some of which were of great magnitude, and evidently voracious, from the formidable weapons with which they are armed. 1. represents, a tooth belonging to the tribe
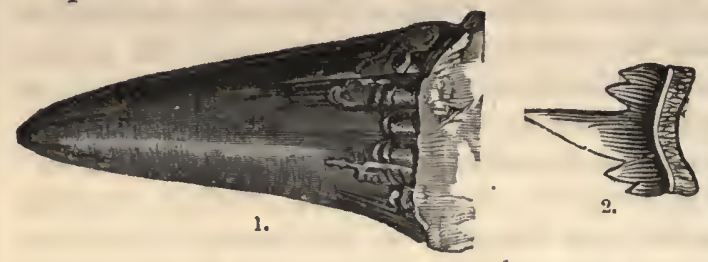
of Hybodants, a family of sharks analogous to the living genus, the Port Jackson shark: and, 2. a tooth of the Megalichthys, a gigantic sauroid fish, from the limestone of Burdie-house near Edinburgh. Sir R. Murchison found in Russia the scales of this creature, which belongs to the car-

boniferous system, in an upper bed of the old red sandstone, mingled with those of the Holoptychius, noticed in the last chapter, which belongs to the sandstone formation; and in the strata at Burdie-house, forming the lower part of the coal series, the scales of both are intermingled. "Both ichthyolites cross, as it were, the borders of their respective formations. The one witnessed the closing twilight of the more ancient system, the other the dawn of the system which succeeded it. They were cotemporaries for a time, somewhat in the manner that Shem was cotemporary with Isaac."

Millstone Grit.-The coarse sandstones which form the principal part of this deposit are chiefly distinguished by their great induration; and the evidence afforded of mechanical formation from the detritus of pre-existing masses. Quartzose particles of various sizes, with rounded particles of felspar occasionally, agglutinated by an argillaceous cement, compose the grit, in which beds of shale are interspersed, and impure bituminous limestone, with thin seams of coal of an inferior quality. It forms the surface of elevated moorlands, covered with a vegetation of brown or purple heath, mosses, and groups of pines, and in several instances the grit occurs as a kind of cap to insulated mountains of shale. Kinder-Scout, the loftiest eminence in the Peak of Derbyshire, the subject of the local adage, indicating the long reign of winter upon its brow, -

"If there be snow without; it will lie on Kinderscout," -

is a huge mass of shale with a cap of millstone grit. It is extensively developed in northern and central England, and forms an important component of the wild scenery in the neighbourhood of Matlock, capping the High Tor at the entrance of the valley, and composing the remarkably bold escarpment of Stonnis, the strata at various points exhibiting great disturbance, being split and shattered in every direction, and abruptly projecting from the general mass in a highly inclined position. "I stood," says a tourist, "on the top of Stonnis (Stone-house) - huge masses of rock (millstone grit) lay scattered at my feet-a grove of pines waved their dark branches over my head. I have scaled the highest eminences in the mountainous districts of Derbyshire - seen from their summits the sweet dales that repose in tranquil beauty at their base-marked the multitude of hills included within the wide horizon they command; but not an eminence that I ever before ascended - not a prospect, however rich and varied, which I thence descried - was at all comparable with the view from Stonnis."

Marine shells occur in the millstone grit, and vegetable impressions in the shales, analogous to those which are so abundant in the superjacent strata, to which we proceed.

Coal Measures. - Alternations of layers of variable nature and thickness compose this important formation, the chief of which consist of sandstone, shale, ironstone, and coal, which gives its name to the entire series. The two latter may be styled new products in the economy of the globe, for though iron exists in veins in the older rocks, and is diffused through some of them as a colouring matter, layers of clay-ironstone first appear in the 


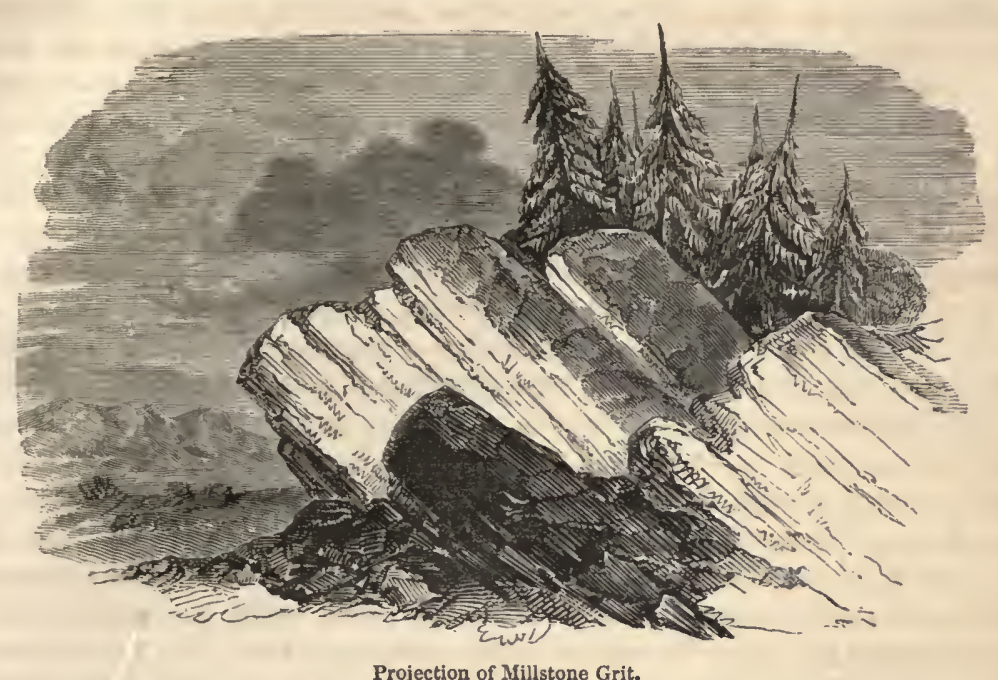

Projection of Millstone Grit.

coal-measures; and though thin seams of coal occur in the mountain limestone, the workable and useful article is only met with in the upper part of the carboniferous system. The argillaceous, or clay-ironstone, is of a grey, brown, or bluish-grey colour, and is scarcely to be discriminated from any ordinary stone except by its greater weight. There are in general several detached strata of it in the same tract of country, each varying in thickness from half an inch to upwards of a foot, and presenting some differences of chemical composition. It occurs also in the form of nodules imbedded in strata of clay or shale, having an oval or conical shape, and composing continuous bands like the flints in chalk. These nodules differ greatly in size, from that of a bean to several feet in diameter, and in weight from an ounce to upwards of a ton. They are often aggregations around shells, or fern branches. To separate the metal from the other ingredients which enter into the composition of the ironstone, coal and limestone are essential; and it has been properly remarked to be one of the beneficent arrangements of Providence in distributing the rude materials of the earth, that iron, the most useful of all metals, so indispensable to all the arts which bring comfort to man, should be found in immediate connection with the fuel required to melt the ore, and with the limestone, which subjects the argillaceous matter in it, by itself infusible, to the action of fire.

The existence of the iron manufacture in any locality is thus determined by the readiness with which the ironstone as well as the fuel and limestone necessary for its reduction can be procured, and by the facilities afforded in the district for the transport of the heavy products to the best markets. The forest of Dean was one of the earliest seats of the manufacture, wood being used as fuel ; but apprehending a scarcity of timber for ship-building, its further employment was restricted by several acts of Queen Elizabeth. Various unsuccessful attempts were soon afterwards made to smelt iron with pit-coal, one of which is detailed in a curious volume entitled Metallum Martis, by Dudley, the founder of the noble family of Dudley and Ward, published in the reign of Charles II. He made the experiment himself, and states: "The author erected a new large furnace on purpose, twenty-seven feet square, all of stone, for his new invention, at a place called Hascobridge, in the parish of Sedgeley and county of Stafford; the bellows of which furnace were larger than ordinary bellows are; in which work he made seven tons of iron per week, the greatest quantity of pit-coal iron that ever yet was made in 
Great Britain. Near which furnace the author discovered many new coal-mines, ten yards thick, and iron-mines underneath, which coal-works being brought into perfection, the author was by force thrown out of them, and the bellows of his new furnacc and invention by riotous persons cut in pieces, to his no small prejudice, and loss of his invention of making iron with pit-coal." He informs us, further on, that this had been "of late a mighty woodland country;" and proceeds, "Now if the coals and ironstone so abounding were made right use of, we nced not want iron as we do, for very many measures of ironstone are placed together under the great ten yards' thickness of coal, and upon another thickness of coal two yards thick, not yet mentioned, called the bottom coal or heathern coal, as if God had decreed the time when and how these smiths should be supplied, and this island also, with iron; and most especially that this coal and ironstone should give the first and last occasion for the invention of making iron with pit-coal, no place being so fit for the invention to be perfected in as this country for the general good, whose lands did formerly abound in forests, chases, parks, and woods, but exhausted in these parts." Many subsequent attempts with furnaces supplied with air from leathern bellows, worked by oxen, horses, or human labour, were failures, for additional resources from mechanical powers were needed before the blast could be rendered sufficiently powerful to enable pit-coal to be applied to the smelting of iron. The required assistance was at length provided in the stenm engine, improved and perfected within a few miles of one of the great coal and ironstone districts.

The beds of coal in a coal-field, though of a considerable number, are far less numerous than the alternating strata of sandstone, and shale, called rock measures, and far less in the aggregate thickness. At Anzin, near Valcnciennes, a pit less than 100 yards deep passes through 50 layers of coal, small and great; at Liege 61 have been ascertained; the single mountain of Duttweiber, near Saarbruck, includes 32 ; at Newcastle the Killing worth pit, within 230 yards, traverses 25. The total "thickness of the coal in the English and Scottish fields is stated to be from 50 to 60 feet, divided into 20 or more beds, which vary in thickness from a few inches to six feet, and alternate with from 20 to 100 times as great a quantity of rock measures. Mr. W. Forster, in the following table, represents the alternations of the coal and rock measures in the Newcastle district, with the thickness of each :$y d s . f t$ in. yds, ft. in.

Brown post, or grindstone sill $24 \quad 0 \quad 0$

Coal

Rock measures -

Coal

Rock measures

Coal

Rock measures

Coal

Rock mcasures

Coal

Rock measures

Coal

Rock measures

Coal

Rock measures

Coal

Rock measures

Coal (High Main)

Rock measures

Coal (metal coal)

Rock measures

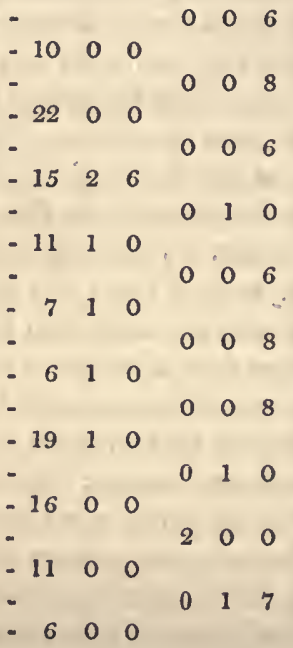

Rock measures

Coal (stone coal) -

Rock measures -

Coal (yard coal) -

Rock measures -

Coal

Rock measures -

Coal (Bensham) -

Rock measures -

Coal

Rock measures -

Coal

Rock measures -

Coal

Rock measures -

Coal (Low Main) -

Rock measures -

Coal

Rock measures -

Coal

Rock measures yds. ft. in. yds. ft. in. - 1012

$.190 \quad 7$

-

$-713$

$\begin{array}{llllll}-18 & 0 & 11 & & 0 & \end{array}$

$\begin{array}{lllllll}-18 & 0 & 11 & & & \\ - & & & 1 & 0 & 3\end{array}$

$\begin{array}{lll}-26 & 0 & 6\end{array}$

- 106

- 9110

- 102

$-110$

- 009

- 929

$\begin{array}{llll}2 & 0 & 6\end{array}$

$-2700$

-

$-1500$

$-$

$-1200$ 


\begin{tabular}{|c|c|c|c|c|c|c|c|c|c|c|c|c|c|c|}
\hline Coal & - & - & - & 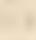 & & 0 & 0 & 2 & Coal (Whickam St.) & - & & & 2 & 0 \\
\hline \multicolumn{2}{|c|}{ Rock measures } & - & -10 & 0 & 0 & & & & Rock measures - & -10 & 0 & 0 & & \\
\hline Cual & - & - & - & & & 0 & 0 & 6 & Coal (Brockwell) - & - & . & & 1 & 0 \\
\hline \multicolumn{2}{|c|}{ Rock measures } & - & - & 0 & 0 & & & & Various rock measures & -50 & 2 & 0 & & 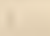 \\
\hline Coal & - & - & - & & & 0 & 0 & 6 & Millstone grit. & & & & & \\
\hline
\end{tabular}

Total th. ft. in.

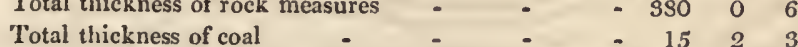

Mr. N. J. Winch gives the following enumeration of the different strata passed through in Bigge's Main Colliery in the Newcastle coal-field, which shows the relative preponderance of the rock measures over the seams of coal in thickness :-

3. They then came upon the first seam of coal, but whicl had only a thickness of

4. From this scam to the thick bed called the High Main coal of the Tyne, they sunk through 29 different beds of sandstone and shale, varying in thickness from 40 inches to 31 feet, interstratified with 8 seams of coal from 5 to 18 inches thick, amounting together to

5. The High Main coal of the Tyne had here a thickness of -

6. From this seam they sunk further through 52 beds of sandstone and shale, varying from 5 inches to 84 feet in thickness, interstratified with 19 different seams of coal from 2 to 37 inches thick, and amounting together to -

7. They now came upon the seam of coal called the Low Main coal of the Tyne, which had in this pit a thickness of

8. And they sank beneath this through 10 different beds of stone, from 12 inches to 12 feet thick, and two seams of coal of 4 and 12 inches, making together

And giving a total depth of

$$
\text { - }
$$$$
\frac{-820}{-115711}
$$

Thus 125 different strata were passed through, only 32 of which were seams of coal, and only 19 of these were capable of being profitably worked. 'The thickest bed of coal in the Newcastle district, the High Main of the Tyne, does not exceed 6 feet; this is exceeded by a bed in the Yorkshire coal-field, near Barnsley, which is 10 feet; but this is again far surpassed by the south Staffordshire or Dudley coal-field, which contains seams from 30 to 45 feet in thickness. In this latter case, however, the enormous thickness seems to be rather made up of a number of beds divided by thin layers of clay slate, than one continuous stratum. In general, except near to the surface, $a$ seam of coal will not pay the expense of working under a thickness of two feet.

The position of the coal measures is occasionally very highly inclined, but commonly they lie at a less angle, and often, as a whole, exhibit the appearance of a huge trough, or basin. The next engraving represents this construction, a section of the Bristol coal-field, extending from the Mendip Hills to the north-west of Bath, a distance of about twenty miles. The regular basin-shape given to the strata in the section is not indeed that which a perpendicular cutting into the ground of the district would expose, for many dislocations and disturbances would appear; but the general arrangement of the coal measures of that locality, and in other places, shows the concave bendings indicated. This dispoeition is not peculiar to the coal series, but belongs more or less to all formations where underlying strata or igneous rocks project in hills and mountains, though it has been more particularly remarked in the carboniferous system, from that having been more attentively searched for its important product. It is obviously due to an upliearing subterranean agency, to the action of which the series of coal seams has been variously 
exposed, tilted up on the sides by the obtrusion of subjacent masses. This basin-shape is of immense utility, since it has brought all the layers of the formation near to the

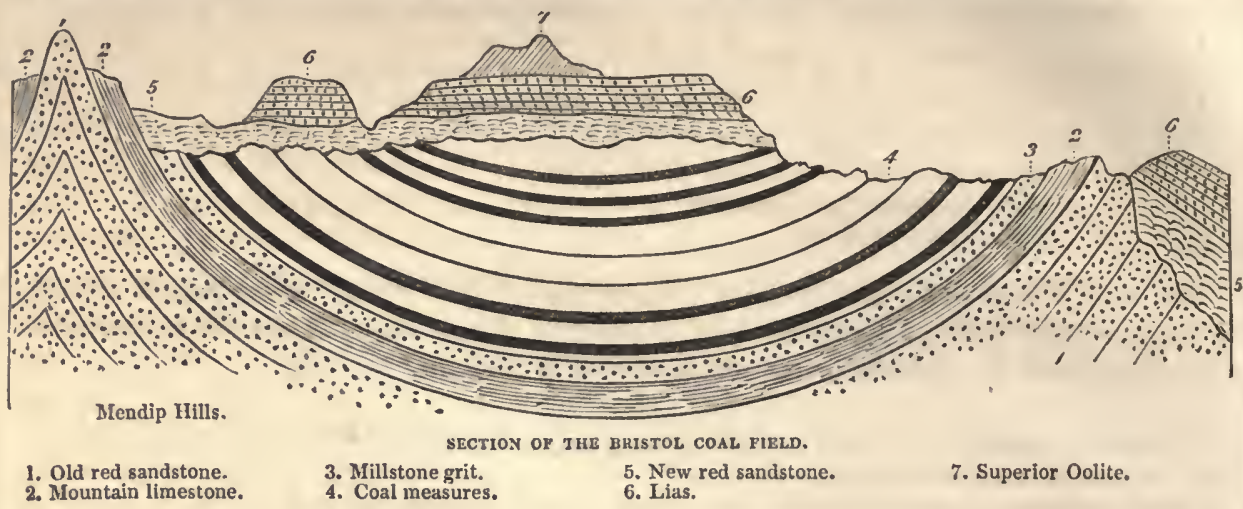

surface, and thus placed them within reach; for had they followed a uniformly inclined course without interruption, the lower seams would have sunk to depths inaccessible to the art of man. The preceding section very clearly points to the cause of the concave form of the coal-beds. It shows also that the carboniferous deposit must have been laid down before the elevation of the Mendip Hills, and that the horizontal strata overlying the coal, belonging to the saliferous and oolitic systems, must have been formed after the disturbance took place, since they exhibit no symptoms of participation in it.

Besides the proof of disturbance afforded by the concave form of the coal strata, they

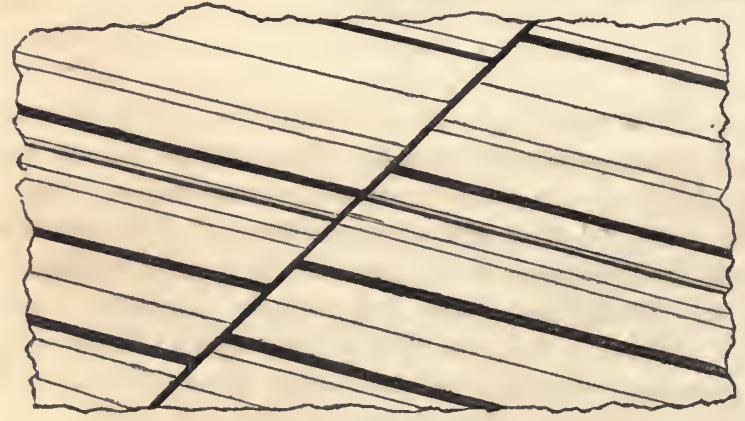

Fault in Coal-field. have been splintered and broken in various directions, by the same tremendous power to which their general contour is due, and hence the slips, faults, and dykes which the miner encounters in traversing a single stratum. The simplest form of a fault, or dyke, is shown in the engraving, the corresponding beds on each side being slightly thrown out of their level, the fault itself having no great breadth. In many cases, however, faults have a considerable width, one of 22 yards occurring in Montagu colliery in the Neweastle coal-field ; and instead of the beds thus broken presenting only a trifling change of level, the difference is often enormous. In the Newcastle coal-field a fault occurs termed the "ninety fathom hitch," the strata on the opposite sides deviating from a common line to that extent. A fault at Sheriff-hall, in the vale of the Esk, in Mid Lothian, throws the strata out of the line of stratification no less than 500 feet, and in that locality 120 ascertained dislocations occur. They abound also in the coal-fields of Fife and Clackmannan, causing divergences to the extent of from between 500 and 1200 feet. The extraordinary energy of the dislocating power is sufficiently proclaimed by the fact of massy beds being fractured, and the broken parts separated from each other, by such intervals as these, either through the elevation of the one or the subsidence of the other, for it is impossible to say which has happened. Faults are sometimes repeated several times within a very short distance, each involving the displacement of strata. However 
Beriously these derangements interrupt for a time the work of the miner, they are not without their use, acting sometimes as valves by which the water of a mine is drained off, or when filled up with compact matter, they serve as floodgates arresting its course, and preventing its access to deposits which it might otherwise inundate.

The coal-beds exhibit immense disturbances from the eruption of igneous rocks, the members of the trap family - greenstones, clinkstones, and basalts - which are associated with them in disrupting, overlying, and interstratifying masses, charring the coal in their neighbourhood, and variously converting it into coke, anthracite, and plumbago. The South Staffordshire coal-field is invaded by a picturesque range of basaltic hills between Dudley and Rowley Regis, and by other eruptions of trap which fill up dykes and faults occurring in the strata. The manner in which the beds of coal have here been disturbed and broken through by protruding plutonic masses, is illustrated in the two sections from

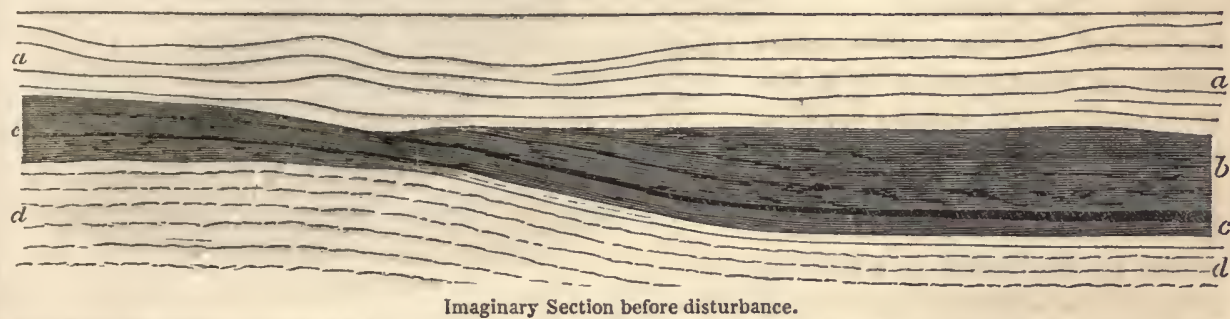

$a$, Lower new sandstone; $b$, thick coal seams; $c$, thin seams spreading out beneath the seams; $d$, silurian rocks on which they rest.

Sir R. Murchison; the one an imaginary sketch of its appearance while a depositary undisturbed by the subterranean forces; the other exhibiting its present shattered aspect as the result of their action. Analogous disruption and dislocations of the coal by trap rocks appear in almost every field.

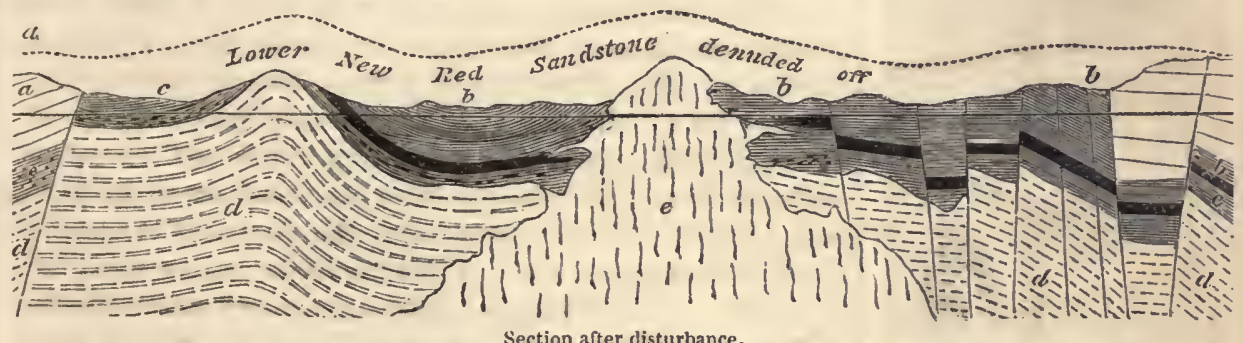

$a$, Lower new red sandstone ; $b, b$, coal measures ; $c$, thin coal and ironstone; $d$, silurian rocks ; $e$, trap rock.

The working of the coal measures is one of the most severe and dangerous departments of human labour, even when under the most enlightened and humane superintendence, and with capital sufficient to command the application of steam-power as extensively as it can be employed; but when under the management of a needy or grasping owner, a colliery is equally degrading to humanity and perilous to life. In coal mines of this latter description females were employed at the windlass and at labours still more revolting - a spectacle which legislation has in the present age laudably abolished. The master difficulty, however, of many coal-mines, which no law can touch, and which defies the power of capital and the contrivances of humanity, arises from the thinness of the coal-seams, which become the subterranean roadways after the mineral has been extracted, and the distances to which these lateral passages extend from the main shaft, together with the depth below its bottom to which excavation leads. They cannot be traversed except in an unnatural and constrained posture, nor could their capacity be enlarged without an 


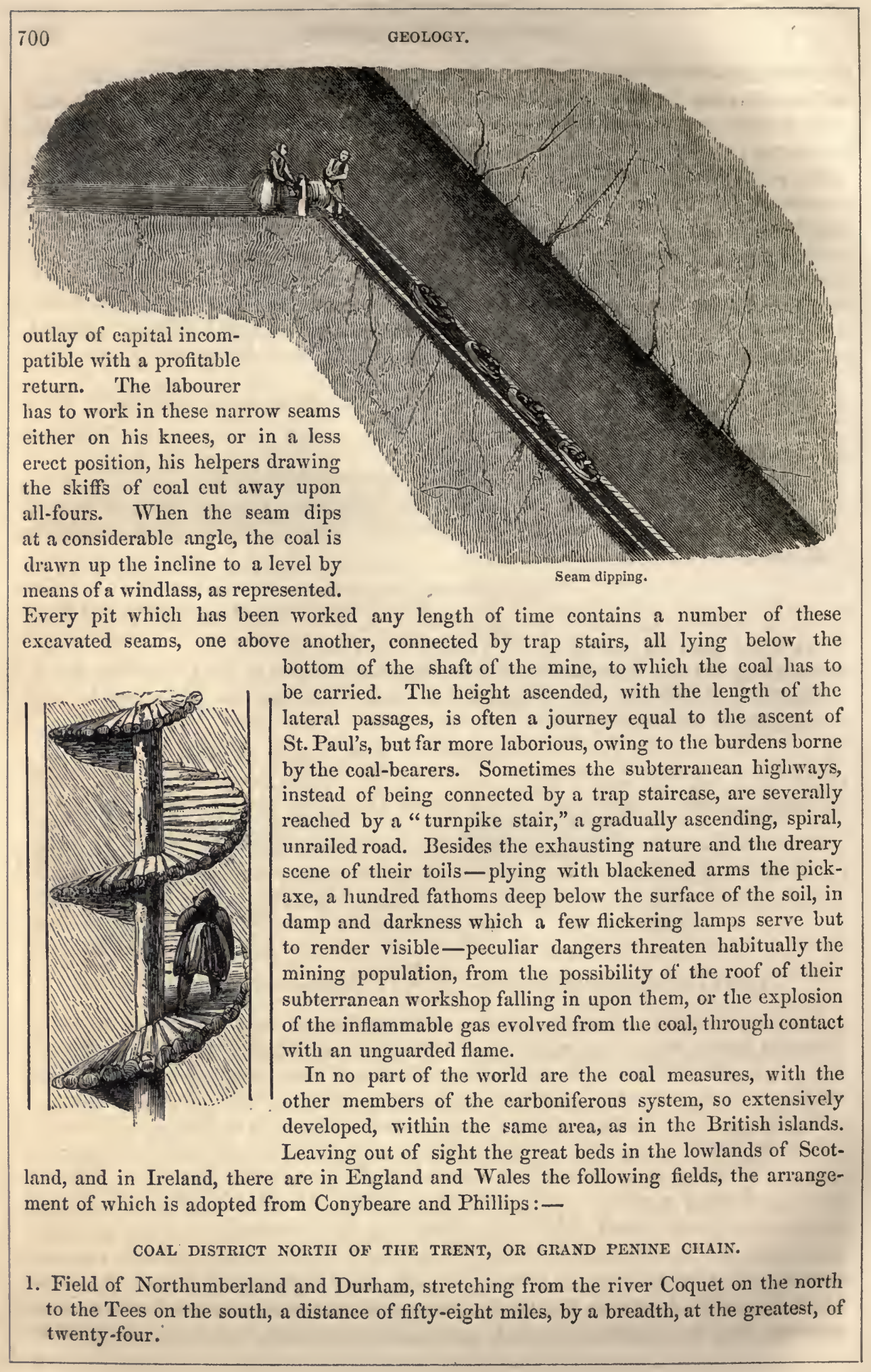


2. Fields detached in north Yorkshire, of very limited extent.

3. Field of south Yorkshire, Nottingham, and Derbyshire, extending from the north-east of Leeds to the north of Derby, a length of sixty-five miles, by a width, at the greatest, of twenty-three.

4. Fields of north Staffordshire - two detached - one at Newcastle under Lyme, the most important, and the other at Cheadle, of small consequence.

5. Field of south Lancashire, or Manchester, extending from the north-west of Derbyshire nearly due north to Rochdale, and from thence westward to Preston, having a general crescent-shape.

6. Field of north Lancashire, between Lancaster and Ingleton.

7. Field of Whitehaven, on the west coast of Cumberland.

\section{CENTRAL COAL DISTRICT.}

8. Field of Ashby de la Zouch, occupying an irregular area, the longel diameter of which is about ten miles, and the shorter eight.

9. Field of Warwickshire, reaching from the neighbourhood of Coventry to that of Tamworth, sixteen miles in length, by an average breadth of three.

10. Field of South Staffordshire, or Dudley, extending from Brereton near Rugeley to near Stourbridge, about twenty miles, having its greatest breadth, from Walsall to Wolverhampton, about seven miles.

\section{WESTERN COAL DISTRICT.}

11. Field of Isle of Anglesea, a valley traversing the whole island, at various points of which coal has been worked.

12. Field of Flintshire, extending from the western cape of the estuary of the Dee to near Oswestry in Shropshire, a distance of thirty miles, but far from being worked throughout.

13. Field of Coal-brook Dale, on the Severn, six miles long, by two broad.

14. Field of the Plain of Shrewsbury, east of the Wrekin chain, consisting of small, detached patches of coal-strata, of very limited extent.

\section{GREAT SOUTH-WESTERN COAL DISTRICT.}

15. Field of South Wales, extending from Pontypool on the east, to St. Bride's bay in Pembrokeshire, on the west, upwards of a hundred miles in length, with a breadth varying from four to twenty.

16. Field of Somerset and south Gloucester, an irregular area, bounded by Bath on the east, and Bristol on the west, about eleven miles, the Mendip Hills on the south, and Coleford on the north, about trwenty-five miles.

17. Field of the Forest of Dean, an irregular elliptical area, bounded by the Wye, the Severn, and the road from Gloucester to Ross, the longer diameter ten miles, and the shorter six.

The more important of these fields are those numbered 1.3.5. 10.15, and 16, yielding coal, of which there are three principal varieties. 1. Stone-coal, containing little or no bitumen, but much earthy matter, producing a large quantity of ashes, the prevailing kind furnished by the Staffordshire pits. 2. Caking-coal, containing about forty per cent. of bitumen, the kind found in Durham and Northumberland. 3. Cannel coal, containing about twenty per cent. of bitumen, occurring in Lancashire. All these varieties are sometimes obtained from the same pit. The quantity raised in the United Kingdom in the year 1855 amounted, in round numbers, to $64,000,000$ tons, of which somewhat less than onefourth was obtained from the Durham and Northumberland field. The next largest amount was little more than half this quantity, produced in Lancashire, and was nearly equalled 
by South Wales. The abstraction of this enormous mass from the bowels of the land, increasing every year with an augmented population, has created immense vacuities beneath the surface soil, which not unfrequently proclaims their existence by its subsidence. The south Staffordshire coal district has been aptly compared to a rabbit warren, so completely has the country been bored into and burrowed under. Houses and rows of buildings, swerving from the perpendicular, with large cracks in the walls, caused by the sinking of the ground into old workings, form a common spectacle in that locality; and many have long remained tenantless, owing to the danger involved in occupying them. There is an instance in the parish of Sedgeley of a church and parsonage house, recently erected, composed of wooden frame-work, which will admit of their being screwed up again into the perpendicular, when thrown out of it.

The foreign localities of coal are far too numerous to be mentioned. It occurs in Spain, Sweden, France, Belgium, and largely in various parts of Germany and Russia; in the Indian and Birman empires, in China, Australia, and around the Persian gulf; in Melville island, within the polar circle; and of the northern part of the western continent, generally, Professor Hitchcock remarks, that its " coal deposits are among the largest in the world. The anthracite deposit of Pottsville is sixty miles long and about five broad; that of Shamokin, commencing near Lehigh, is of the same length and width; and that of Wilkesbarre is forty miles long and two broad. In some instances a single seam of coal in these strata is sixty feet thick; and near the middle of the valley, between the Sharp and Broad mountains no less than 65 seams have been counted. The bituminous coal-field, embracing the western part of Pennsylvania, and a part of Ohio, extends over an area of twenty-four thousand square miles; the largest accumulation of carbonaceous matter probably in the world. In fact, the bituminous coal measures can perhaps be traced almost continuously from Pennsylvania to the Mississippi, and even into Missouri, two hundred miles west of that river. Indeed, coal exists on the eastern slope of the Rocky Mountains; and it would not be strange if this should be found to be the western outcrop of coal-bearing strata, whose eastern extremity is in Pennsylvania. At any rate, it is certain that extensive seams of bituminous coal exist in Pennsylvania, Virginia, Ohio, Indiana, Illinois, Michigan, Tennessee, Alabama, and Missouri."

The regetable origin of this important product is established by the most irrefragable evidence, and is now universally admitted. Mr. Hutton states, that if any of the three varieties of coal found near Newcastle be cut into very thin slices, and submitted to a microscope, more or less of vegetable structure can be recognised; and Dr. Macculloch solved the problem of this substance by a series of interesting experiments, successfully tracing the transition of regetable matter from peat-wood, brown-coal, lignite, and jet, to coal, anthracite, graphite, and plumbago. The imbedding of regetable matter in the earth-the exclusion of the atmospheric air-and the confinement of the gaseous elements evolved, are the three necessary conditions of the process of change, and according to the completeness in which they have co-existed, have we a perfectly formed coal, which requires the microscope to detect the traces of vegetable structure, or a mass only partially carbonised, the nature of which is at once proclaimed by a clear development of vegetable forms. In many coal-fields, the remains of vegetables are found, retaining in wonderful perfection and beauty their original contour, even the most delicate parts, and exhibiting little change at all excepting that of colour. Dr. Buckland remarks of the Bohemian coal mines :- "The most elaborate imitations of living foliage upon the painted ceilings of Italian palaces, bear no comparison with the beauteous profusion of extinct vegetable forms, with which the galleries of these instructive coal mines are overhung. The roof is covered as with a canopy of gorgeous tapestry, enriched with festoons of most graceful foliage, flung in wild, irregular profusion orer 
every portion of its surface. The effect is heightened by the contrast of the coal-black colour of these vegetables, with the light ground-work of the rock to which they are attached. The spectator feels himself transported, as if by enchantment, into the forests of another world; he beholds trees of forms and characters now unknown upon the surface of the earth, presented to his senses almost in the beauty and vigour of their primeval life; their scaly stems, and bending branches, with their delicate apparatus of foliage, are all spread forth before him; little impaired by the lapse of countless ages, and bearing faithful records of extinct systems of regetation, which began and terminated in times of which these relics are the infallible historians." It is not in the coal itself that the distinct forms of vegetable matter are most numerous, but in the layers of shale, aandstone, and ironstone which intervene between its seams; and besides plants, the conl formation contains the organic remains of marine fishes, with molluscous and crustaceous reliquiæ, supposed to be of fresh-water or estuary origin-the latter, a new feature in the earth's story of organic life.

The following are some of the most common and interesting vegetable remains in the coal measures.

Ferns.-Of these flowerless plants there are now existing about fifteen hundred species.

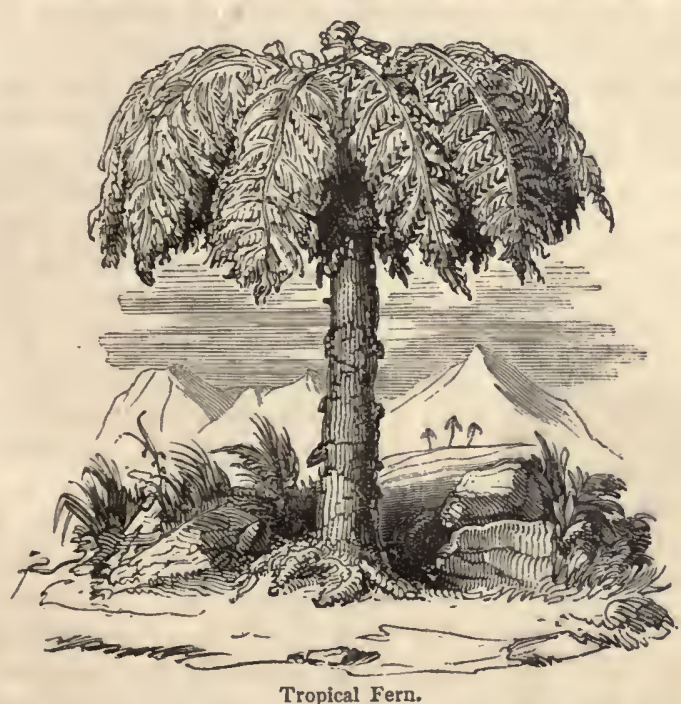

They are often subterraneous and creeping, but become arborescent and leafy above the ground, especially within the tropics, to which zone the arborescent ferns are now confined, with the exception of some in the islands of the southern hemisphere. Those of Europe are of diminutive size, but towards the equatorial regions they often attain the height of forty or fifty feet, the magnitude of trees, as in the adjoining figure. On the staircase of the British Museum there is an example of a Bengal species fortyfive feet high. The fossil ferns of the coal formation, amounting to one hundred and twenty species and upwards, include nearly half of its flora, and almost all of them belong to the arborescent tribe, from which Brongniart in-

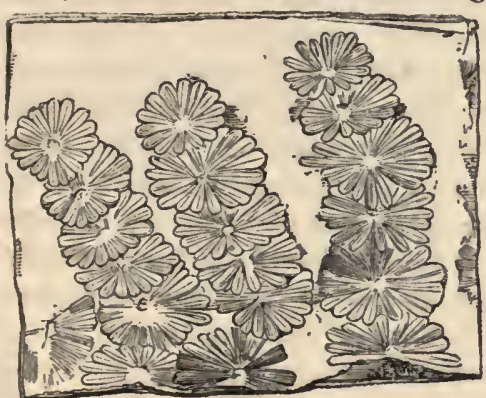

Annularia brevifolia. fers that the conditions of heat and humidity, which now farour their growth, more especially obtained, and that in high northern latitudes, during the

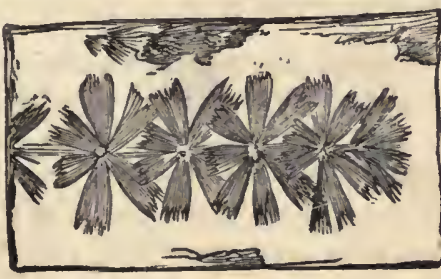

Sphenophyllum dentatum. carboniferous period. They are arranged in genera, according to the shape of the leaves, their mode of attachment to the stem, and the manner in which the veins of the leaves are distributed. While the foliage of these ancient ferns occurs 
abundantly in the coal series, their stems are but rarely encountered. It is uncertain to what tribe of plants the annexed specimens belong, denominated from the wedge and ring-shape of their leaves, very abundant in many localities.

Sigillarix. - This is a class of trees, of which many species are enumerated, formerly supposed to be monocotyledonous plants, allied to the arborescent ferns, but now considered to belong to the dicotyledonous tribe, differing from any now existing upon the face of the globe. The name is derived from sigillum, a seal, and refers to the im-

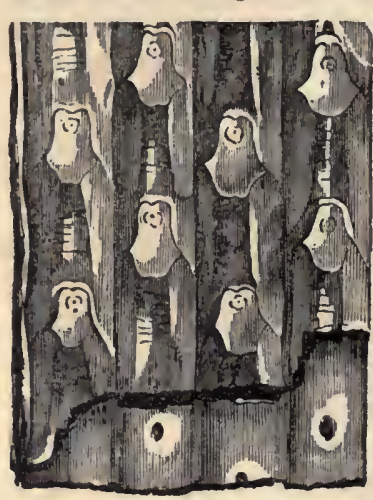
prints upon the surface of the stem or trunk, as in the figure, which are scars left by the separation of the stalks from it. Longitudinal ribs or flutings marked the stem, a structure exhibited by some living dicotyledonous trees in New Zealand. Sigillaria are often found crushed into slabs, by the weight of the superincumbent strata, but vertical or highly inclined trunks of these fossil trees have been repeatedly discovered, standing apparently in the place where they grew, the bark being converted into coal, with the interior now filled up with sand or clay; and it is no uncommon occurrence at present, in tropical countries, for the interior of hard-wood trees to be entircly eaten away by insects, the bark being left intact, and the tree to all appearance sound. Brongniart long ago described a remarkable example in the Treuil coal-mine near Etienne, in the department of the Loire, of which the figure is a view. 'The coal formation in this place offers a circumstance favourable for

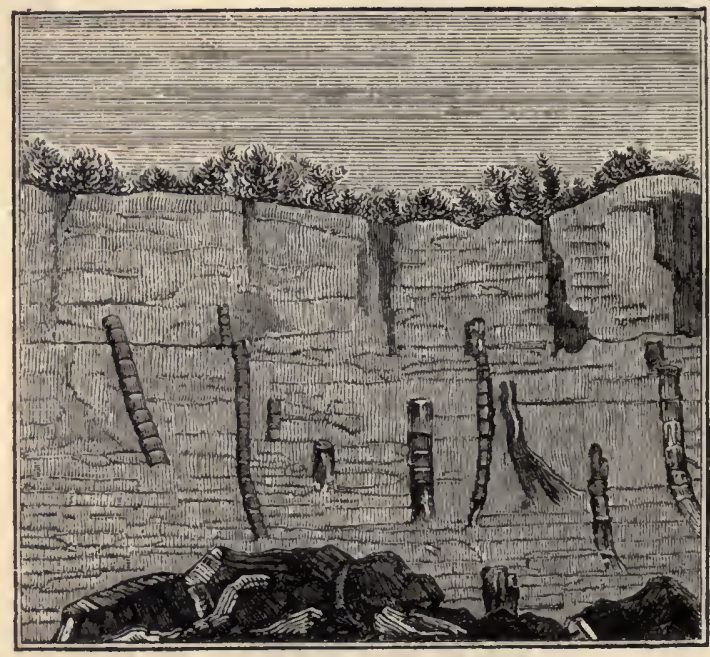

Section of a Coal-mine near Etienne. observation, being situated in sucl a manner that it can be worked in open day as a quarry, of which we have no instance in England. The mine presents a series of alternating beds of schistose clay, ironstone, coal, and micaceous sandstone, in which numerous stems occur, placed vertically, traversing all the strata, of which the view annexed shows only a very small proportion. It is a true fossil forest, as it were petrified in place. The stems, for the most part, were obscrved to be cylindrical, articulated, and striated, the interior showing no organic texture, but filled with a rock of the same nature as that composing the beds traversed. The occurrence of similar fossil trunks in the coal measures has been often noticed, some of which must have been of gigantic size, the diameter of the remains varying from half a foot to three feet, and the length extending to sixty feet and more. Our recent railway operations have brought to light a considerable number of instances. In the construction of the Claycross tunnel, which runs through strata lying in the middle of the Derbyshire coal measures, a group of between thirty and forty trees was discovered, standing close together, at right angles to the plane of the strata; and in forming the Manchester and Bolton railway, five trunks were found, of which an excellent memoir has been given by Mr. Hawkshaw, from 
the drawing of which this engraving is taken. These trunks were coated with a thin layer of coal, their carbonised bark, the interior consisting of the shale in which they were discovered.

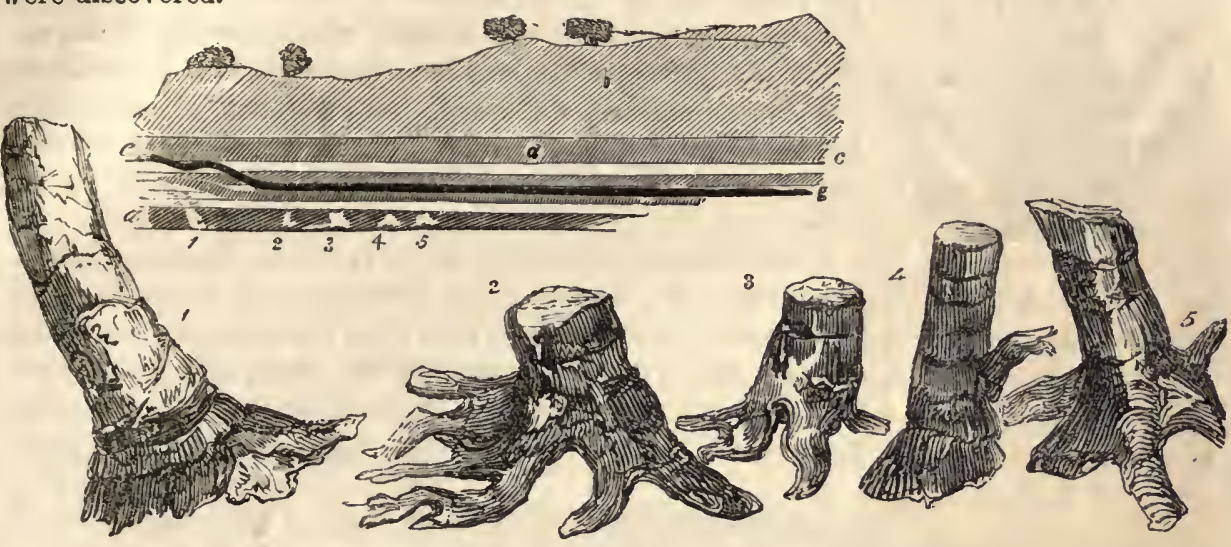

Fossıl Trees on the Bolton and Manchester Railway:- $a$, the trees; $b$, stratification above the fossils; $c, d, e$, thin beds of shale; $g$, a seam of coal two feet thick.

Stigmarix. - These extraordinary regetable fossils are so called from their spotted stems,

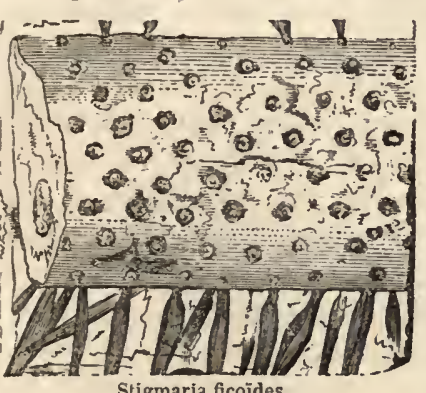

Stigmaría ficoides. as in the cut. They are known in almost every coalmine, fragments occurring in almost every heap of shale thrown out. A cylindrical stem, the surface marked with tubercles or spots, with many horizontal branches or leaves springing from it, the interior probably of a yielding fleshy substance, characterise this tribe of extinct plants, which have now no living analogues. They are supposed to have been aquatics, occupying swamps or shallow lakes, attaining a considerable magnitude, the stems varying in diameter from a few inches to several feet.

Lepidodendra. - This name, signifying scaly-tree, refers to the scaly appearance of the

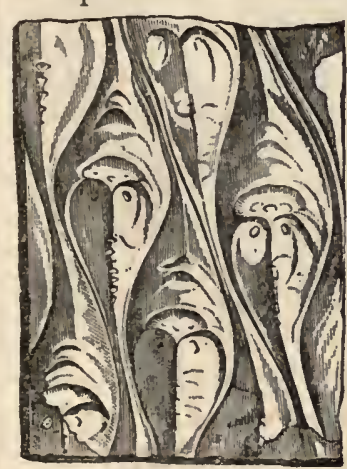

Lepidodendron crenatum. plants thus indicated, which are among the common constituents of the coal measures. 'The cut represents a portion of the stem of one species; but stems occur, of other species, invested with leaves of simple structure and lanceolate shape. By some they are viewed as analogous to the existing lycopodiaceous genus, or tribe of club-mosses, but we have no living examples of this tribe which attain a greater height than three feet, and they are principally weak, diminutive plants, trailing on the ground, while these fossil specimens exhibit an enormous size, rivalling forest-trees in magnitude. In the Jarrow colliery, a specimen was discovered, the stem of which was forty feet in length, and thirteen feet in diameter at the base, dividing towards the summit into fifteen or twenty branches.

Calamites.-These plants, characterised by a reedy structure, cylindrical, articulated stems, constituted an important feature of the vegetation of the carboniferous era, as shown by the abundance of their remains, and are usually considered to have formed the earliest terrcstrial flora, some obscure traces of them being found in the more ancient strata. They are thought to be allied to the existing order of Equisetacece, or horse-tails, a 
rery common tribe in our swamps and ditches, whose geographical range extends from

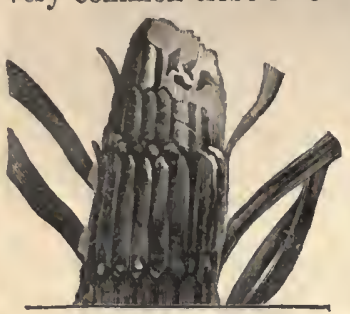

Calamites cannæformis. the polar circle to the torrid zone. But the difference between the living and the extinct families is immense as to dimensions. The horse-tails are elegant, slender, weak-stemmed plants, not exceeding in tropical regions the height of five feet, and the diameter of an inch, while some of the Calamites attained a height of from thirty to forty feet, and a diameter of from one to three feet. The figure exhibits the fragment of a Calamite.

Coniferæ. - Cone-bearing trees, as the fir, larch, and Araucaria, or Norfolk Island pine, constitute a large and important part of the existing vegetation of all climates, and they occur in rocks of all ages from the carboniferous system to the superficial accumulations. Mr. Witham has figured the trunk of an Araucaria, large and branchless, found in Cragleith quarry, near Edinburgh, in strata belonging to the coal-field of Mid Lothian. It was forty-seven feet long, the greatest diameter

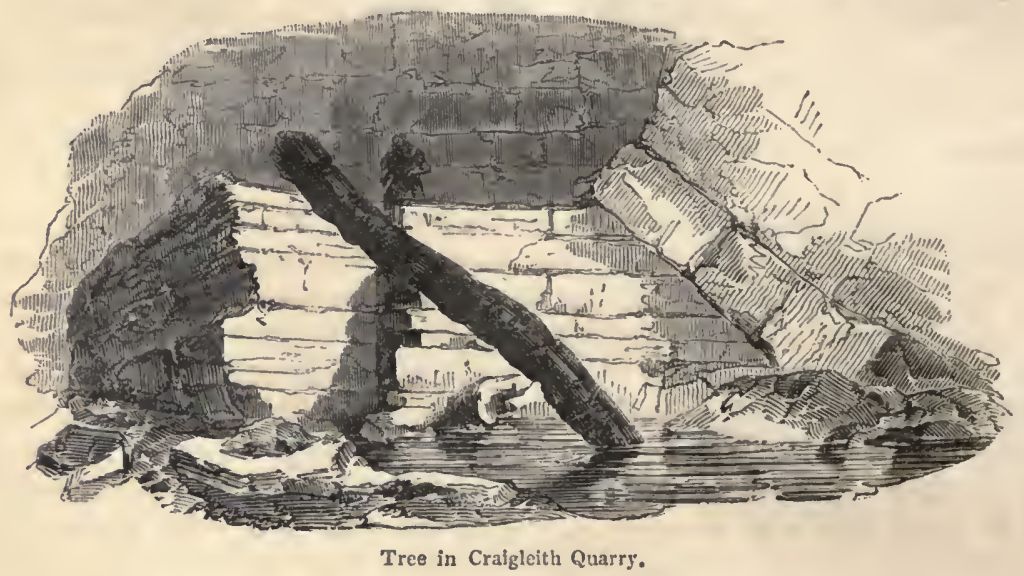

being five feet, the smallest nineteen inches. The trunk was very much flattened in some parts, lying under 136 feet of strata, in an inclined position, as ropresented in the sketch. The bark was converted into coal, but internally the woody texture of the tree was in many places perfectly preserved. Araucarias have been alone found fossil in Great Britain; but genuine pines occur in the coal formations of Nova Scotia and New Holland.

Such are some of the vegetable forms extant in the coal measures, the greater proportion of which are ferns; but, from a celebrated experiment of Dr. Lindley, it appears that the preserved specimens of plants are no index to the entire constitution of the carbonaceous matter, or to the whole flora of the globe at the carboniferous cra. He immersed in a tank of fresh water 177 species of living plants for more than two years, and arrived at the following conclusions:-1. That the leaves and bark of most dicotyledonous plants are wholly decomposed in two years; and that of those that do resist it, the greater part are Coniferæ and Cycadex. 2. That monocotyledons are more capable of resisting the action of water, particularly Palms and Scitamineous plants, but that grasses and sedges perish. 3. That Fungi, Mosses, and all the lowest forms of regetation, disappear. 4. That Ferns have a great power of resisting water, if in a green state; not one of those submitted to the experiment having disappeared, but that their fructification perished. Thus those plants (the ferns) were found, by this experiment, most enduring 
in water, which we find most abundant in a fossil state; while the dicotyledonous tribes had little capacity to resist its action, and their organic remains are comparatively rare. The chief objection that can be made to the experiment is adranced by Count Sternberg, that pure water, used by Dr. Lindley, may not have produced precisely the same chemical effects upon the regetation, as in the case of the coal-plants, which were immersed in waters so impure and admixed as to have deposited the shale in which they are imbedded. It follows, however, as a general conclusion, that a large mass of vegetable organisation has probably perished, which was contemporaneous with the forms that are still extant, and diverse from them; so that the structures traceable must be regarded as a few specimens only of the ancient flora of the earth, which have survived the catastrophe of submergence. Yet nothing can be clearer, from the vast accumulations of carbonaceous matter, and the gigantic size of its fossil plants, than the existence of landscapes, in far remote ages, clothed with a vigorous and abundant vegetation, - forests waving in the breeze, as ample as those that now distinguish our humid equatorial districts. Still, as far as evidence extends, there was as yet no song of birds - no voice of any vertebrate animal - to enliven the scene; and the aspect of terrestrial nature, though imposing, was sombre, better adapted to prepare fuel for man, than to constitute his happy dwelling.

\section{CHAPTER VII.}

\section{THE PERMIAN AND TRIASSIC SYSTEMS.-LOWER AND UPPER NEW RED SANDSTONE.}

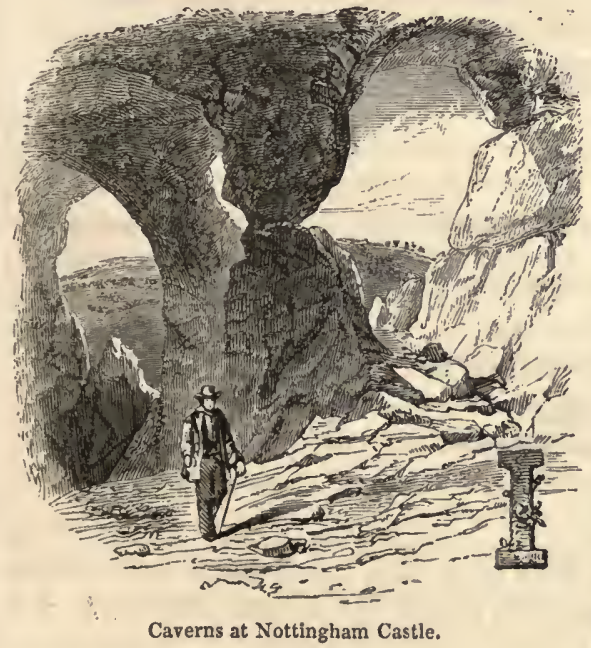
superficies remarkably different to that which, during the formation of the coalmeasures, was crowded with the stately forms of a vigorous vegetation. In another respect, its strata strikingly and pleasingly contrast with the coal series; for, instead of the dark shales and black seams of the latter, we have variegated marls, red, green, and blue ; sandstones, red and white; and grits, brown, yellow, and cream-coloured. From

$T$ is common with the travellers of modern times, in various regions of the globe, after passing through extensive tracts of dense and noble forests, almost impenetrable through an accumulation of brushwood and interlacing creepers, to enter upon an open country, bare of vegetation, and presenting upon its sandy plains few of the forms of organic life. A similar change in the aspect of terrestrial nature is encountered upon an advance from the carboniferous to the overlying strata in the grand series of formations. During the deposition of the New Red Sandstone, the condition of the earth appears to have been unfavourable to organised existence, from the paucity of the remains contained in it. These are chiefly marine, with few traces of land plants, indicating a state of the exposed solid 
the diffcrent tints of the marls, the groups have been ealled Poikilitic by Mr. Conybeare, signifying mottled or varied; and Saliferous-salt-bearing-by others, from the immense deposits of rock-salt. But the New Red Sandstone is the appellation in most common use, denoting the arenaceous composition of the predominant rocks, the colour prevailing in the suite, and its more recent date than the Old Red Sandstone, which underlies the carboniferous system. Argillaceous, calcareous, magnesian, and saline strata-marls, limestone, magnesian limestone, and rock-salt, are variously associated with the sandstone.

Where the series is completely exhibited in England, it presents the following succession of beds :-

Upper, or $\begin{gathered}\text { Variegated marls. - Red, with bluish, greenish, and whitish laminated clays or marls, holding } \\ \text { gypsum generally, and rock-salt partially, as in Chcshire. Included in these marls are } \\ \text { eertain white and grey sandstones. } \\ \text { Triassic } \\ \text { System. } \\ \text { Variegated sandstones. - Red sandstones, with some white and mottled portions, the lower } \\ \text { parts in some districts (Nottinghamshire) pebbly. } \\ \text { Permian } \\ \text { System. }\end{gathered}\left\{\begin{array}{c}\text { Laminated limestones of Knottingley, Doncaster, \&c., with layers of coloured marls, } 30 \text { or } 40 \\ \text { feet. } \\ \text { Gypseous marls - Red, bluish, and mottled. } \\ \text { Magnesian limestone, yellow and white, of various texture and structure, some parts full of } \\ \text { fragmentary masses. } \\ \text { Marl slates. - Laminated, impure, calcareous rocks, of a soft argillaceous or sandy nature. } \\ \text { Red sandstone, with red and purple marls and inicaceous beds.-The grits are sometimes } \\ \text { white or yellow, and pebbly. When conformable, this sandstone occasionally passes into } \\ \text { the coal-measures on which it rests. }\end{array}\right.$

It is only in a few places in the north of England that the above beds are found entire. In other parts of the kingdom, as well as on the continent, several members are wanting, and sometimes the whole series is almost exclusively represented by the gypseous marls, or the magnesian limestone, or the red mottled sandstone. The following table exhibits the eomplete German, English, and French series :-

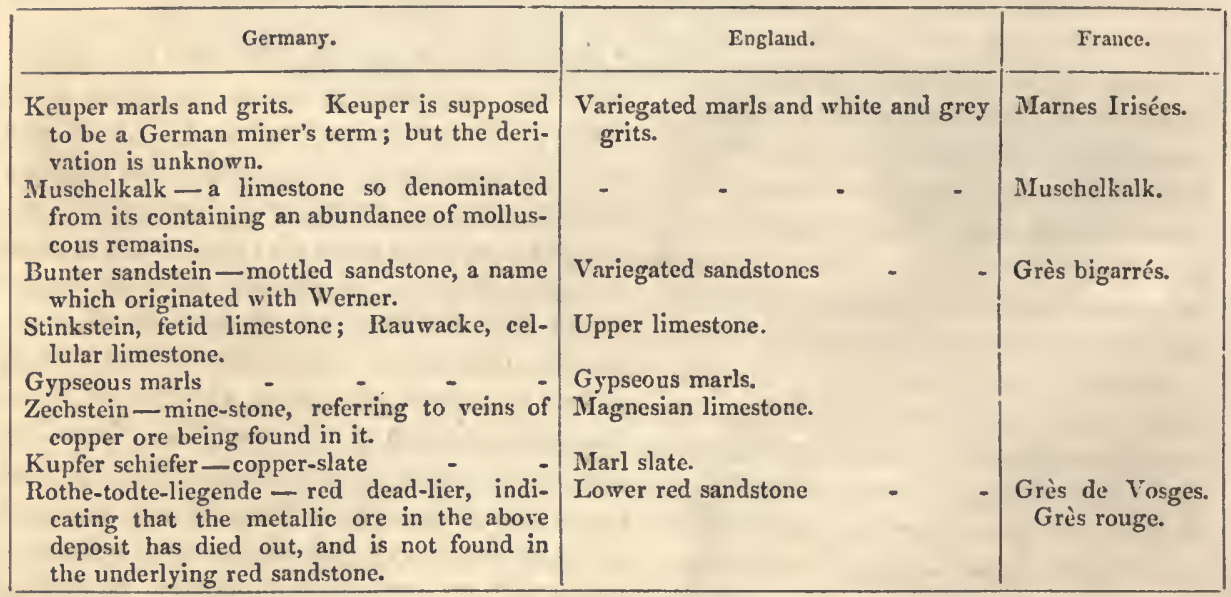

It will be seen from a comparison of the above table, that the German series differs from the English in the addition of the muschelkalk; while the French contains it, and differs from that of the other two countries in the absence of various beds. It lias, therefore, been remarked, as an important fact for the student to bear in mind, that it is by a general analogy in the type, and not by any conventional series of strata, that systems are to be identified in different countries. In France, the chain of the Vosges - a ridge which separates the ancient province of Alsace from that of Lorraine, and stretches northwards into the Bavarian cirele of the Rhine - consists of granite and primary strata. 
At the foot of these mountains coal-measures are found, above which are unconformable strata of the Lower New Red sandstone, grès rouge and grès de Vosges. The latter is covered by the grès bigarrés, or variegated sandstone, the intermediate beds, which are wanting, having probably been denuded off, as the surface of the grès de Vosges exhibits considerable degradation. This is overlain by the smoke-grey limestone, or muschelkalk, and then the marls occur, called marnes irisees, from their varied hues. But both in France and Germany the upper part of the series constitutes a separate system, under the name of terrain keuprique, or trias, from being readily divisible into three principal groups, those named at the head of the table, - which contain many remains of terrestrial plants,

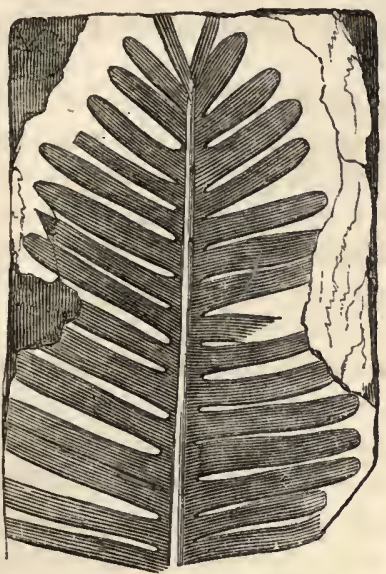

Phterophyllum Pieiningerii.

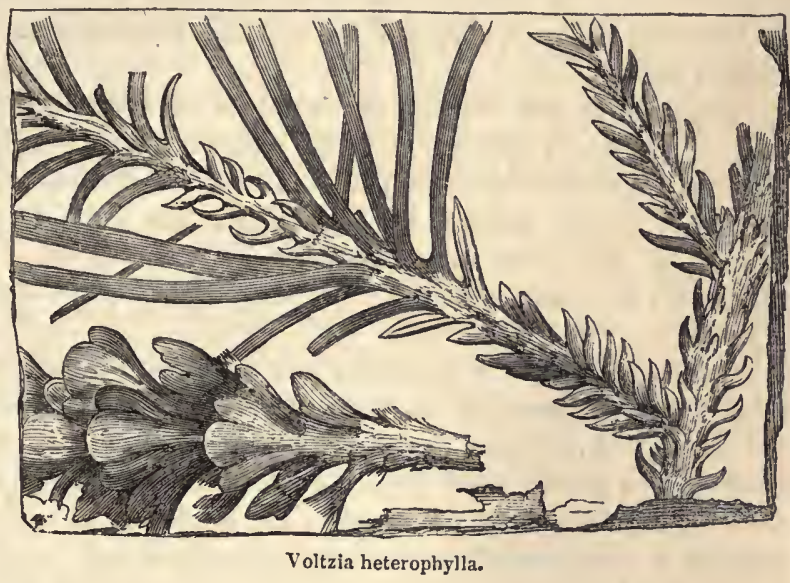

Coniferæ and Cycadex, represented in the cut. This arrangement is now adopted by English geologists, who divide the series into two independent systems, the Permian and Triassic. The former embraces the lower members, and has its name from the government of Perm in Russia, where Sir R. Murchison, in 1841, found them extensively developed, occupying an area twice the size of France. The latter includes the upper members, and derives its name from the well-marked triple group, exhibited in Germany and France. This division has been made in consequence of the respective fossils indicating connection with distinct epochs of life. Thus the Permian fossils are allied to those of the coal-measures below, and therefore belong to the Palrozoic (ancient life) period, while the Triassic fossils are allied to the oolitic above, and hence belong to the Mesozoic (middle life) period.

It will be sufficient simply to mention this new arrangement. In a popular description of the strata, it may be disregarded, and both systems be referred to as the New Red sandstone series. It occupies a vast extent of the area of England, stretching in a belt from south Devon to the midland counties, where it expands and bifurcates, the east branch passing up the valley of the Trent, through Yorkshire, into Durham, and the west branch running up from Cheshire in a narrow devious course to the north of Lancashire. Mr. Conybeare notices the prevailing red colour of the soil of this district as having given to many places their local names; -in Exeter, to Rougemont Castle, now a prison; in Somersetshire, to Radford, Red-hill, and Redcliff; in Gloucestershire, to Redbrook; in Worcestershire, to Red Marley; in Nottinghamshire, to Retford, Radford, Ratcliffe, and Red-hill, at the junction of the Trent and Soar; in Yorkshire, to Red Mire, Red Ho, and Red Bar Rocks, which appear on the seacoast between Guisborough and Hartlepool. 'The general aspect of the district exhibits a series of levels, with gently undulating ridges, but without any considerable 
eminences. This circumstance, Mr. Phillips states, " is probably not explicable by the mere wasting of these soft rocks by floods of water, but due to some law of physical geology yet unexplained. We can only conjecture that it is connected with the repose of subterranean forces, which prevailed after the violent commotions of the coal strata over nearly all Europe, till the tertiary epoch." A few elevations occur at the height of 800 feet above the level of the sea,-Ashley Heath, Brandon Mount, and Barr Beacon; but the average altitude of the hills is much lower. Some of the finest pastures in the kingdom are included within the range of this formation. The cereal grasses and leguminous plants flourish luxuriantly upon the red marls, while the soil formed by the magnesian limestone, though usually considered unfertile, is favourable to the growth of various timber-trees, the oak, elm, and walnut, and especially suits the yellow rose and sweetscented violet.

The series is but scantily developed in Scotland, except on the borders of the Solway Firth, where it occurs in force, occupying also a considerable area in the north of Ireland. It comprises an immense extent of the continent of Europe, appears conspicuously in the countries watered by the Rhine, the Danube, and the Volga, and composes many of the river valleys of the United States. Without going through the successive beds consecutively, a few prominent or peculiar rocks are selected for a general notice.

Sandstone. - This is occasionally a fine-grained quartzose rock, forming a hard grit, of sufficient cohesion to be useful for architectural purposes. The grains seem covered externally and cemented together by the red oxide of iron, as if they were the ruins of a mass of pure quartz, much ground down, and deposited in waters, having a strong ferruginous impregnation. But frequently the sandstone is a coarse conglomerate, composed of pebbles of various kinds, very slightly cemented, and hence easily excavated into artificial caverns, and of little value as a building stone. This is the case with the sand rock of the town and castle of Nottingham, consisting of rounded pebbles of quartz, granite,

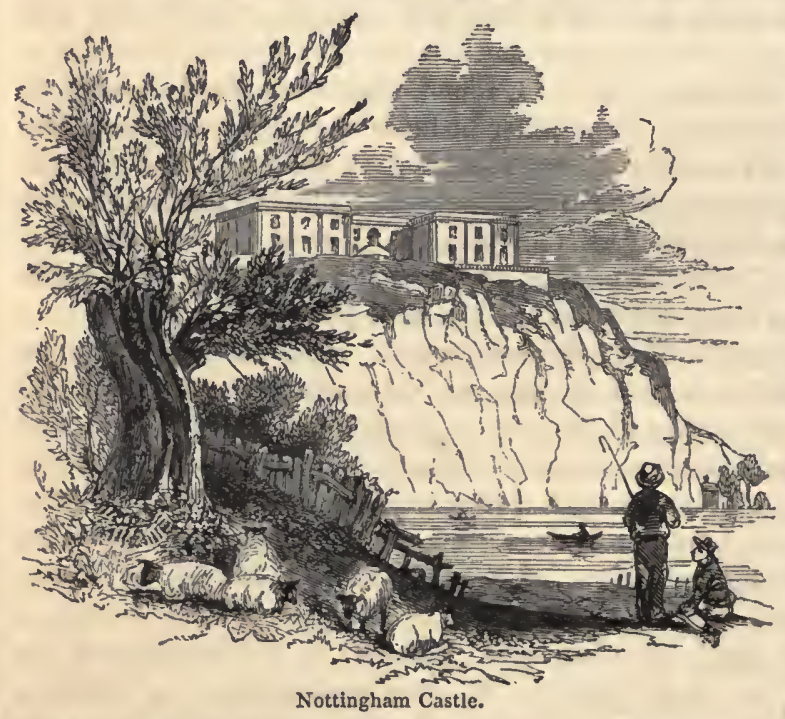
porphyry, and slate, which have either been derived from the Charnwood Forest Hills, or from identical rocks connected with that range, which have been completely worn away. The arrangement of these pebbles in the castle-rock indicates the state of commotion in which they were aggregated. The sandstone of this locality is remarkable for its numerous caverns, which are all probably artificial, or, if natural, have been enlarged, and received their present shape from human labour, the soft and friable nature of the rock admitting of an easy excavation. This circumstance, according to some etymo* logists, has given its name to the town, and through it to the county, a derivation from the Saxon snodengaham, signifying "the house of caverns." Similar caverns occur in the same strata, but upon a smaller scale, at Guy's Cliff, near Warwick, and at Knaresborough in Yorkshire. 
Magnesian limestone.-This characteristic rock is well developed in a continuous band, extending from the Tyne southwards through Yorkshire, and descending into the counties of Derby and Nottingham. Towards the northern and southern extremities the strata rise into a series of round-topped hills; but the centre sinks to the general level of the country. The appearance of stratification is very distinct, and several varieties of structure occur-some beds being granular, others imperfectly crystalline, and others cellular. In the latter variety, abundant in the county of Durham, where it bears the name of the honeycomb limestone, the cells are lined with crystallised carbonate of lime. The rock, as its name imports, is a compound of the carbonate of lime and the carbonate of magnesia, in various proportions; but calcareous beds are common, in which there is little or no admixture of magnesia with the lime. It forms one of our most durable building stones, and has been largely used in the construction of some of our finest edifices, as York Minster and Westminster Hall, which have admirably withstood the wear and tear of the atmosphere. It is now employed in the erection of the new houses of Parliament, derived from the Bolsover quarries in Derbyshire. An analysis of the stone of York Minster gives-

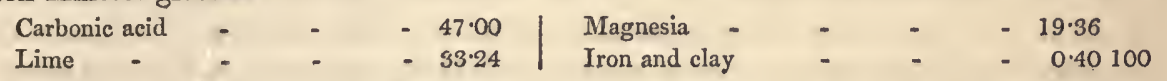

The stone of Westminster Hall contains about 2 per cent. less of magnesia, but the proportion is often far greater, amounting to more than 50 per cent. Magnesia in minute quantities is very extensively distributed; it occurs more largely in the mountain limestone, oolites, and chalk; but is only found in such abundance in the limestone of this system as to become a characteristic. The two constituents of the rock, the carbonates of lime and magnesia, some suppose to have been deposited contemporaneously; but Von Bûch considers the magnesian limestone to be a metamorphic change of common limestone, effected by the disengagement of vapours containing magnesia from plutonic masses. But it has been justly remarked, that, according to this theory, we ought to expect all limestones to become magnesian in the neighbourhood of igneous rocks, which is far from being the case.

Gypsum. - This sulphate of lime, one species of which is commonly known under the name of alabaster, frequently appears in association with the red marls and sandstones of the upper part of the series. It occurs in detached nodules of fibrous structure, in horizontal seams equally fibrous, varying from one to three inches in thickness, and in amorphous granular masses capable of being worked into columns. The red marly banks of the Trent exhibit beautifully white and translucent seams of gypsum; and at Chellaston, not far from the borders of the river, it appears in a granular mass, from which the beautiful pillars at Kedleston Hall, near Derby, were wrought. Its origin has been referred by some to segregation from the surrounding sedimentary matter; but its common connection with rock-salt, wherever the latter mineral is found, is considered by others as indicating its formation from the same cause.

Rock-salt. - The mineral, chloride of sodium, is not peculiar to the series of deposits under notice, for salt springs occur in the coal-measures, and in strata belonging to the modern volcanic period; and salt is procured from the chalk and oolite systems. Former writers, therefore, were too hasty in referring the production of all the saliferous deposits upon the face of the globe to the geological era of the new red sandstone. Still, saline strata - clear, white cubically crystallised masses of salt, and brine springs issuing from such rocks-are so remarkable and frequent in it, as to be justly regarded as one of its distinguishing features, and hence the common application of the term saliferous to the entire series. By far the finest example of rock-salt in Europe, on account of its position at the surface, is at Cardona, a small town in the interior of Catalonia, sixteen leagues 
from Barcelona, and seren from the central ridge of the Pyrenean chain. The formation in this locality includes the hill on which the town is situated, and the environs to a considerable extent, which are diversified by various eminences composed of the mineral, but one in particular, called the mountain of red salt, from that colour predominating, is most prominent, from its insular character, its great mass, its sharp forms, and the red and white hues, the vivacity of which contrasts with the grey and sallow tints of some surrounding rocks. It has been well described by M. Cordier, in the Annales des Mines for 1817, and by Count A. Laborde, in his Travels in Spain. "The colours," says the latter, "vary with the altitude of the sun, and the greater or less quantity of rain. At the foot of the mountain a spring of water issues, which comes through a fissure we perceive on the summit. The rivulet runs all along the valley from the east, but passes under ground in part of its course, particularly under the hill where the rock-salt is mined; it rises again to the surface at a little distance, and, after running along the plains, discharges itself into the river Cardona. This brook in rainy seasons swells the waters of the river, which then become salt, and destroy the fish ; but at three leagues lower, the water has no perceptible taste of salt. All the salt mountains are intersected by crevices and chasms, and have also spacious grottoes, where are found stalactites of salt, shaped like bunches of grapes, and of various colours; - nothing can compare with the magnificence of the spectacle which the mountain of Cardona exhibits at sunrise. Besides the beautiful forms which it presents, it appears to rise above the river like a mountain of precious gems, displaying the various colours produced by the refraction of the solar rays through a prism."

Saliferous strata occur upon an immense scale in Hungary and Poland, and in Western Asia, referable to various geological eras; but the extensive beds of rock-salt and gypsum near Bex in Switzerland, so long considered as a decided example of such rocks occurring in the more ancient deposits, have been shown by Dr. Buckland to belong to the new red sandstone formations. The chief site of the mineral in England is in the marl of Cheshire, where, with a few exceptions, it is found in the valleys of the Weaver and its tributary streams, in some places manifesting its presence by springs impregnated with salt; in others, being known by mines earried down through the substance of the strata. At Northwich the brine springs are very abundant, formed by the penetration of spring or rain waters to the upper surface of the rock-salt, in passing over which they acquire a degree of strength, modified by various circumstances, in some instances approaching to the point of perfect saturation of the brine. Here, also, many mines have been sunk for the purpose of working out the fossil salt, which was first discovered in the year 1670 in searching for coal. It forms two great strata or beds, lying nearly horizontal, but on different levels, the superincumbent being separated from the subjacent stratum by several layers of indurated clay or argillaceous stone, irregularly penetrated by veins of salt. The upper stratum is found from 28 to 48 yards below the surface of the earth, the superior soil consisting of white clay and gypsum, the latter appearing in connection with the salt of Hungary, Poland, and Transylvania. This bed, varying in thickness from twenty to thirty yards, has a reddish-brown colour, not much unlike sugar-candy, and consists of muriate of soda, mixed with a small portion of oxide of iron, which gives it its tint. The lower stratum, which has never been entirely perforated, is remarkably different from the upper in appearance, consisting of almost pure muriate of soda, generally perfectly white and clear as crystal. The quantity carried down the river Weaver from April 5, 1855, to April 5, 1856, amounted to 53,256 tons of rock-salt, and 708,358 tons of white salt, manufactured from brine.

The formation of rock-salt and gypsum is in general referred to deposition from the waters of the sea $\mathrm{Dr}$ Holland, from the appearance of the plain constituting the salt 
district of Cheshire, supposes that the sea once flowed up the valley of the Weaver, and was cut off from it by the growth of a bar, again making its appearance by bursting through the barrier, and again the communication ceasing from the same cause. He conceives, therefore, the two beds of rock-salt to have arisen from the two salt lakes thus suecessively formed, whose waters were dissipated by the natural process of evaporation, and their salt deposited, the intervening and superior strata of indurated clay proceeding from earthy sediments ir the lakes, deposited after the precipitation of the salt. 'This hypothesis is supported by the phenomena of many salt lakes in the present day, whose waters are lowering through the supply from springs not keeping up with the expenditure through evaporation, and whose beds consist of layers of salt, deposited by the overcharged water. There can be little doubt that this is the principle upon which the saliferous deposits have been formed, accelerated in its action by a higher atmospheric temperature, and the frequent play of igneous forces, in earlier ages. But the detail of the theory in the case of the Cheshire salt deposits is open to the objeetion, that it " employs data drawn from the present relations of land and sea to elucidate the phenomena of a period long gone by, and when from unquestionable evidence it is certain that their relations were generally very different." At the same time, it is quite possible, that in the district in question these relations may have been much the same then as at the present.

It has been observed, that the new red sandstone series, taken as a whole, is remarkably deficient in the traces of organic life, though, locally, some of its members, as the muschelkalk of Germany, are rich in fossils. The vegetable luxuriance of the carboniferous epoch appears to have died away, though it is true, the paucity of life may be more apparent than real, for it may have arisen from the unfitness of the new red sediments to preserve organic remains in the fossil state. The most numerous relics are those of marine life, which present a new phase in the instance of fishes. Agassiz established the curious generalisation, that the heterocercal tail is universal in the magnesian limestone, and all the older formations; while in all strata above the magnesian limestone, the homocereal tail predominates, as at present. Reptiles seem to have been on the increase. In the year 1834, two species were discovered on Durdham-down, near Bristol, in strata belonging to the magnesian limestone-the Palæosaurus and The-

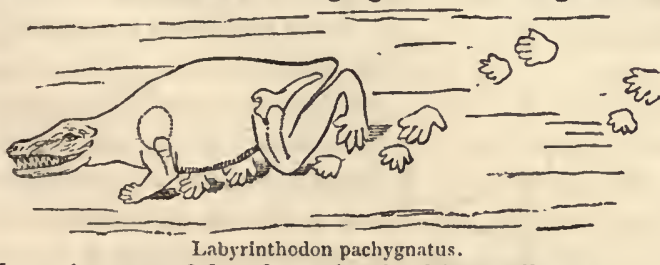
codontosaurus. Relics of a very singular reptile of the lizard tribe were found by Dr. Ward in quarries of the new red sandstone at Grinsill, near Shrewsbury - the Rhynchosaurus with foot-prints upon the layers of stone in the quarries, supposed to have been impressed by the animal while walking over the surface of the strata, when in a soft state. Parts of the skeletons of Batrachian reptiles,-the Greek name for the frog,but of a gigantic size, have been taken from the sandstones of Guy's Cliff, near Warwick and Leamington, of which the cut exhibits a restoration of one species by Professor Owell. The generic name, Labyrinthodon, refers to the labyrinthine inflections of the teeth. In the upper part of the series on the continent, the remains of reptiles multiply; and here, in the muschelkalk, occur the bones of some large animals of that class-the Protosaurus and Phytosaurus. But the most striking peculiarity yet observed is the repeated occurrence of fossil footsteps, or tracks on the sandstone, affording evidence of the existence, at the era of its deposition, of birds belonging to the tribe of Waders, the first indications we have of that highly organised class of vertebrated animals, as tenants of the globe. Ichnites, traces or foot-prints, are characteristic of the new red sandstones, 
and appear to have been impressed generally by reptiles and birds. It was long suspected that such impressions were of organic origin; but geologists hesitated to admit this opinion till the evidence was complete, preferring to consider them as the effects of disintegration or aqueous action, by which the softer parts of a rock are worn away before the harder yield. We may notice such impressions under two general divisions.

Ichnolites, foot-prints on stone.-In the year 1828, Dr. Duncan gave an account, with drawings, to the Royal Society of Edinburgh, of the tracks of an animal on new red sandstone, in the quarry of Corn Cockle Muir, in Dumfriesshire. The tracks were found there in great abundance, on many successive layers of stone, to the depth of forty-five feet, or as low as the quarry had been opened. After removing a large slab which

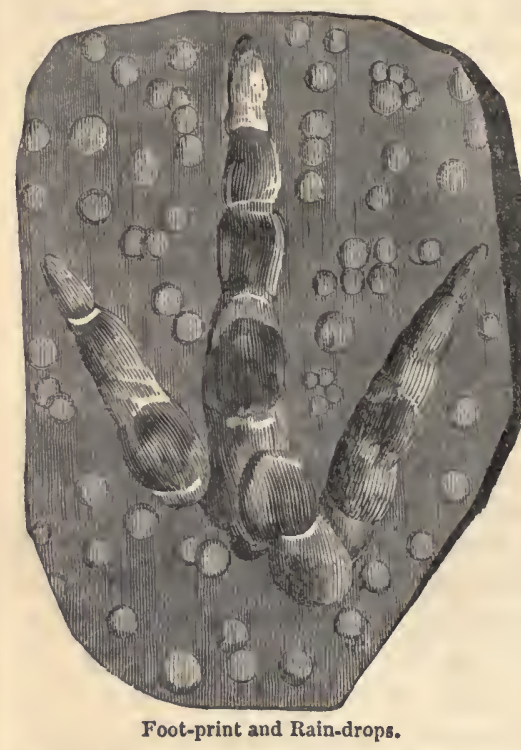
presented foot-prints, perlaps the very next stratum, at the distance of a few feet or inches, exhibited the same phenomenon. Hence the process by which the impressions were made on the sand, and subsequently buried, must have been repeated at successive intervals. In another quarry in similar strata, near the town of Dumfries, the same marks were discovered, and in one instance a track extended from twenty to thirty feet in length. Dr. Buckland refers these impressions to land tortoises. In 1834, an account was published of some remarkable fossil footsteps in the new red sandstone at Hesseburg, near Hildberghausen in Saxony. The largest track appears to have been made by an animal whose hind foot was eight inches long. It has received, from Professor Kaup, the name of Chirotherium, founded on the resemblance of its impressions to the shape of the human hand; but some of the tracks appear to have been made by tortoises, and M. Link suggests, that others are to be referred to gigantic batrachians, or frogs and salamanders. The annexed cut shows a few tracks of the Chirotherium on a sandstone slab from Hesseburg. In the summer of 1838 , a va-

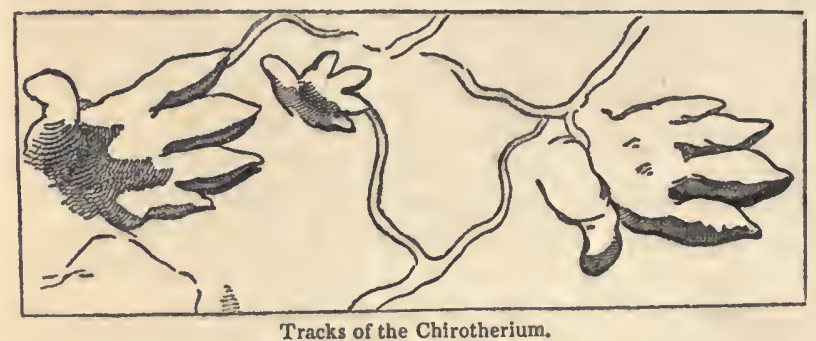
riety of tracks, referred to the Chirotherium, tortoises, and saurian reptiles, were discovered in the new red sandstone at the quarries of Storeton Hill, in the neighbourhood of Liverpool. The largest foot-print was nine inches long, and six inches broad, the length of the step approaching to two feet. Professor Hitchcock notices twentyseven species of tracks, occurring in fifteen quarries, along the banks of the Connecticut river, some of which he called Sauroidichnites, from their resemblance to the tracks of saurians; and Mr. Scrope found abundant foot-prints, along with ripple-marks, on layers of the forest marble, to the north of Bath. These are conjectured to have been made by crustacea, crawling along the bottom of an estuary, for between the rows of the foot-marks the impression of the stomach, or the trail of the tail, is sometimes visible.

Ornithichnites, stomy bird tracks. - A communication made to the American Journal 
of Science, in January, 1836, by Professor Hitchcock, brought before the attention of European savans some very distinct tracks in the red sandstone of the Connecticut valley, first observed by Dr. Deane of Greenfield, who immediately noticed their similarity to the impressions left on the muddy banks of the river by the living aquatic birds common to the locality. Subsequent examinations discovered similar foot-marks in several quarries in the same valley, and other parts of Massachusetts, and several specimens are now in the British Museum, the most remarkable of which is a slab, eight feet by six, which exhibits traces of various sizes, belonging to different individuals. Subjoined is a representation of this slab-that which arrested the attention of Dr. Deane, at Turner's Falls, Massachusetts.

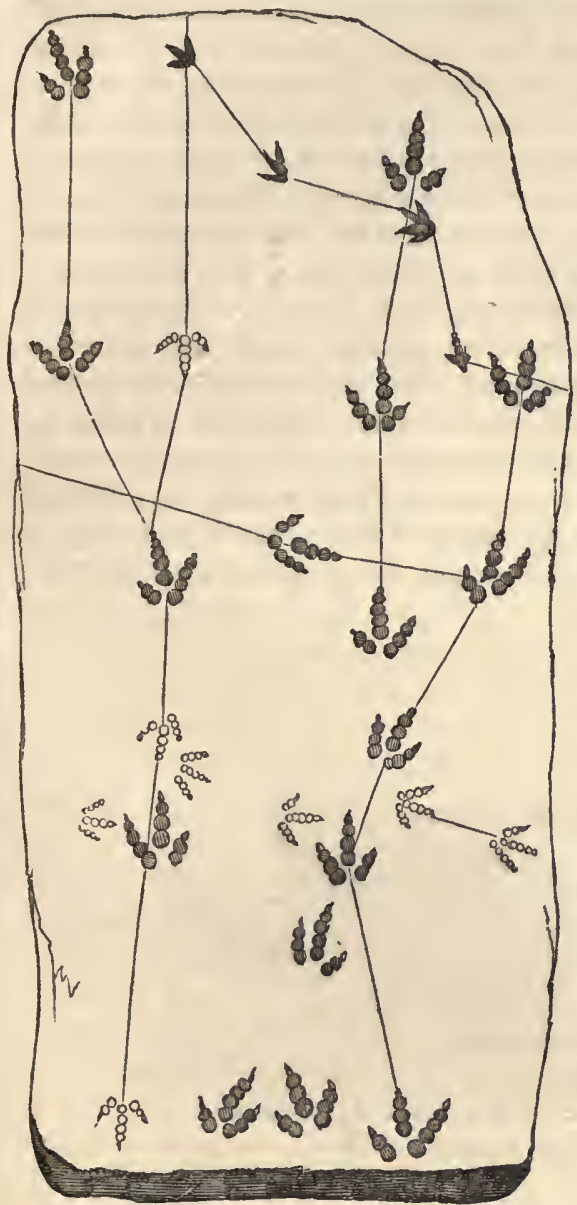

Portion of a slab of new red sandstone from Turner's Falls, Massachusetts, with imprints of the footsteps of a large bird.

All these footmarks are referred to that class of birds called Waders; and while some are very small, others are of enormous size, indicating proportions equal nearly to twice the magnitude of the ostrich. In one species, Ornithichnites giganteus, the imprint of the foot measures fifteen inches in length, and ten inches in width, excluding the hind claw, which is two inches long. The distance of the impressions from each other vary from four to six feet. The former may be taken as the length of the stride of the bird when walking at an ordinary pace, and the latter when proceeding more swiftly. These dimensions, so far surpassing those belonging to any known birds, led many geologists to conceive that some mistake had been made respecting the nature of the impressions, till convinced by an actual inspection of the specimens transmitted to Europe, and by the discovery of the bones of the Dinornis, fearfully great bird, in New Zealand, an individual much larger than the existing ostrich.

But a still more remarkable feature of the new red sandstone formations is the preservation, in connection with foot-prints, of very distinct impressions of rain drops upon the strata, as represented upon the preceding page. Dr. Deane discovered a stratum containing, in all, more than one hundred marks of the feet of four or five species of birds, the whole surface having also been pitted with the marks of a shower of rain. The same observation has been made in the Storeton quarry, near Liverpool, where tracks of the Chirotherium are found. "The under surface of two strata, at the depth of thirty-two or thirty-five feet from the top of the quarry, presents a remarkably blistered or watery appearance, being densely covered by minute hemispheres of the same substance as the sandstone. These projections are casts in relief of indentations in the upper surface of a thin subjacent bed of clay, and owing, in Mr. Cunningham's opinion, to drops of rain." The impressions are sometimes perfect hemispheres, indicating a vertical fall of rain; but in 
other cases they are irregular and elongated in a particular direction, as if the drops had struck the surface obliquely, indicating a wind accompanying the rain. The same appearances occur in the formation near Shrewsbury. Professor Hitchcock mentions specimens of sandstone in his possession, obtained from various parts of the United States, which show footprints, ripple-marks, and rain-drops, the latter evincing, by a uniform elongation of shape, the direction of the wind when the rain fell.

Walking along our shores in the present day, we observe a well-definerl cast of our own footstep left in the sand still wet from the retreating tide, and similar distinct impressions made by the passage of animals and birds across it, and by the descent of a violent shower of rain upon it. In the same manner it is probable that the tracks which the new red sandstones present, were formed on the shores of an estuary, or a tidal river, between high and low water mark-then dried and hardened by the action of the sun and air during the recession of the waters-the returning waves washing up silt to cover up the impressions, the two layers uniting, to exhibit, if ever separated, the one a mould and the other a cast from it, of the forms that have been there. The observation of phenomena now, similar to that unfolded by the old rock-systems, is of no mean importance and interest to mankind, in every condition of society. Many a depredator has been detected by the correspondence of his foot to its imprint in the snow or loose earth near the place of his crime. The North American Indian finds his enemy by his trail, and can not only distinguish between the elk and the buffalo by the marks of their hoofs, but determine with great exactness the space of time that has elapsed since the animals have passed. In the deserts of Africa the track of the camels proclaims to the Arab whether a heavily or lightly laden caravan has crossed the sands. But from the simple imprints presented by these ancient formations, we gather information relating to thousands, nay, tens of thousands of years ago-catch a glimpse of the animals that then existed, no vestige of whose actual forms remains-and have even the pattering of the shower and the direction of the wind indicated to us.

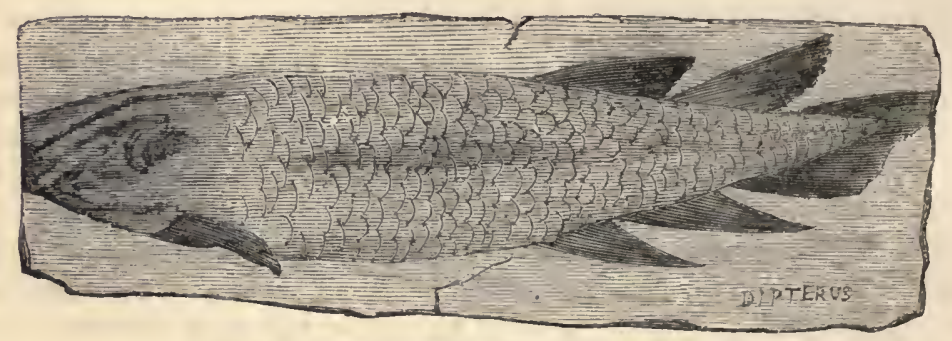

Dipterns, from the Old Red Sandstone, described at p. 689. 
Limestone Ridges at Leuctra.

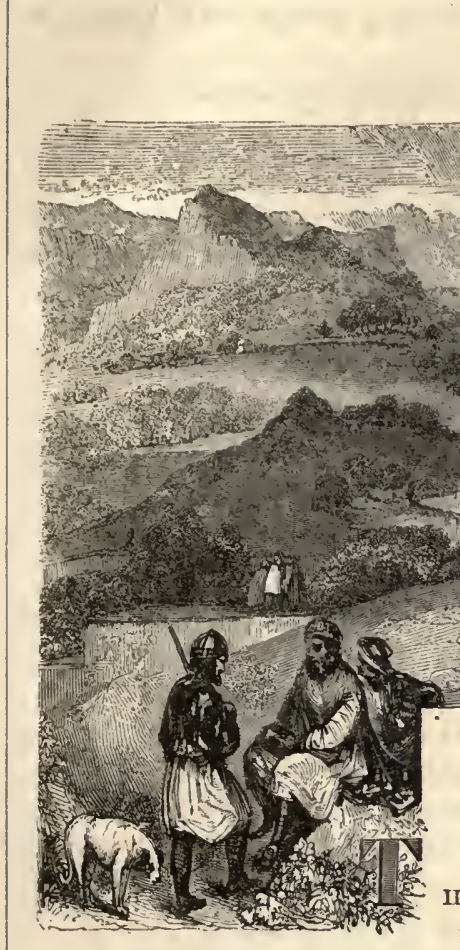

unfolded to our rier. of the beds, and in the numerous and unique organisms

\section{CHAP'TER VIII.}

\section{THE OOLITIC SYSTEM.}

IIE strata of the present system are eminently distinct from those just noticed, both in the composition and colour We are presented indeed with much the same general compounds - argillaceous, arenaceous, and calcareous deposits - clays, sandstone and limestone rocks - but they are very readily distinguishable from those of older date by their texture and hues. The clays have commonly a deep blue tinge. The sandstones, chiefly calcareous, through an admixture of carbonate of lime, have a cream-yellow tint, derived from the oxide of iron, in a different state of oxidation to that which the decided red of the preceding formations indicates. The limestones are of rarious shades, but remarkably characterised by a concretionary or shelly structure, which is due to the collection of particles of lime by molecular attraction around shells, corals, or grains of sand. In order to produce this diverse series of strata, we must supposc some great change to have transpired in the condition of terrestrial nature, from that during which the magnesian rocks, red sandstones, and saliferous marls were deposited. The upheaval of these latter formations from the floor of the existing oceanic basins, creating new land to be disintegrated, and submerging portions of dry ground, thus forming a coast-line of fresh strata, to be abraded by the tides and currents of the sea-this is the physical revolution which is suggested. Though we can never know the precise alterations made by the event, in the relations of land and sea, yet it renders quite intelligible to us the building up of the oolitic rocks beneath the waters of the deep, from the sediments introduced to them from the changed terrestrial superficies. But, especially, these deposits most strikingly contrast with those of previous origin, by their organic remains, those of saurian animals, which in great numbers and gigantic size inhabited the rivers and estuaries, and also occupied their banks, during the period of their formation. From this circumstance, that interval, embracing a long series of ages, has been styled "the age of reptiles." 
The system, as developed in England, presents the following groups, each having its subordinate divisions :-

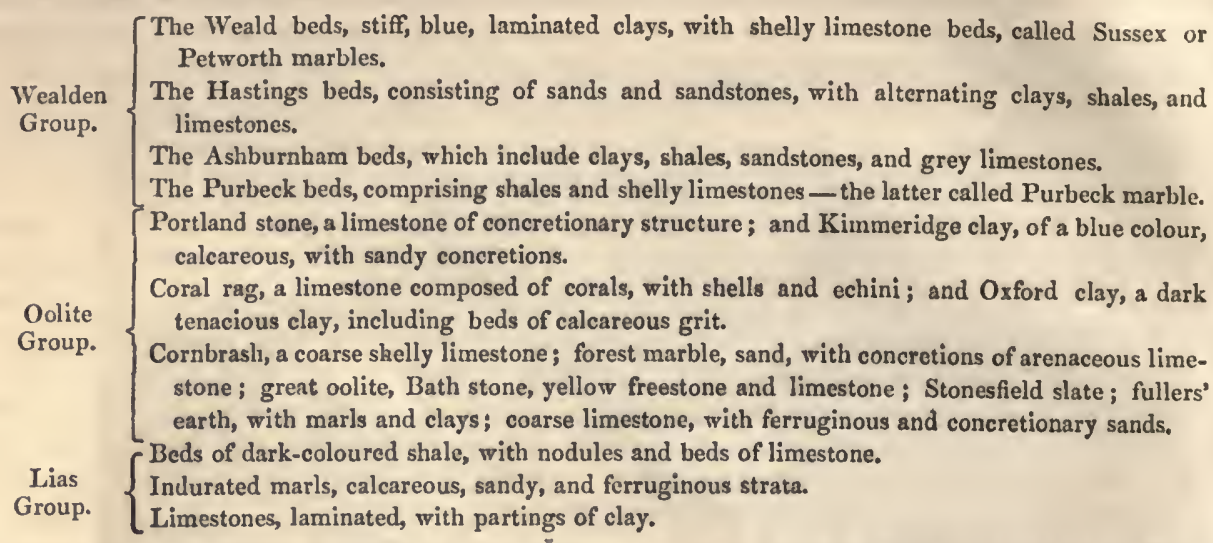

With the exception of the Wealden group - a local deposit, lying principally in Kent and Sussex - the system occupies an extent of country, reaching, in a wavy course and almost uninterrupted line, from the north-east coast of Yorkshire, above Whitby, to the cliffs of Lyme Regis, in Dorsetshire. It runs parallel to the new red sandstone, with many minute flexures and irregularities, acquires a considerable breadth in Yorkshire, narrows to a point before leaving that county towards the confluence of the Humber and the Trent, re-appears immediately on the south of the former river, proceeds through the midland counties, where it attains its greatest expansion, again contracting and becoming exceedingly involved and intricate as it approaches the southern coast. Among the principal places included within its range are Newark, Grantham, Leicester, Northampton, Banbury, Cheltenham, Oxford, and Bath. On its eastern edge are Lincoln, Peterborough, Huntingdon, and Shaftesbury, and, on its western, Wells and Gloucester. There is a remarkably insulated outlying patch of the lias part of the system between Whitchurch and Wem in Shropshire; another occurs in South Wales; and several, less considerable and not so insulated, appear on its south-western border. Identical rocks are very abundant in France, intersecting that kingdom in bands, extending north and south from the coast of Normandy to near the borders of the Mediterranean, and from the west coast near Rochelle to the banks of the Rhine. The French and Swiss Jura mountains consist of harder limestones of this formation, and hence the title terrain Jurassique applied to it. The system is developed north of the Alps from the Rhine to Vienna, and, on the south, many of the beautiful Italian lakes are embosomed in it. The limestone ridges of Illyria, Dalmatia, Albania, and Greece belong to it; it appears in the range of the Atlas; and the southern slopes of the Himalaya are argillaceous rocks corresponding to the English lias.

Lias group. - The base of the oolitic system is its most extensive member, and the most remarkable in its organic contents. It consists of thin strata of argillaceous limestones associated with clays, forming a thick bed of a blue or white colour. The blue lias contains a large proportion of lime, which hardens into a strong cement when under water, for which reason it was used in the construction of the Eddystone Lighthouse. The white variety takes a high polish, and is the stone sometimes employed in lithography. The clays of the lias occur in the form of soft shales, impregnated with bitumen and iron pyrites. They are susceptible of slow combustion, which has taken place spontaneously when in contact with a sufficient supply of moisture. About the middle of the last century the cliffs of lias clay near Lyme in Dorsetshire ignited after heavy 
rains, and continued burning for a considerable time. This has, more recently, been the case with a hill near Weymouth, composed of bituminous clay with pyrites; and, upon a part of the cliff at Whitby falling, so as to become exposed to the action of the tide, it took fire spontaneously, and continued to burn for two or three years. The external aspect of lias districts in England exhibits plains diversified with low ridges and broad river valleys, though it sometimes forms cliffs and steep escarpments, but of no great elevation. The term is supposed to be a corruption of the word layers, alluding to the unequivocal stratification displayed; but in the annals of French geology it bears also the name of calcaire à gryphée arquée, from a deeply incurved bivalve shell which abounds in it, and is frequently met with in the English lias. The shells of this deposit are very numerous, and present a variety of interesting and beautiful forms, of which the following are cxamples.

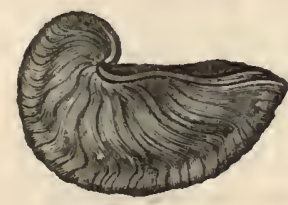

Gryphæa arcuata.

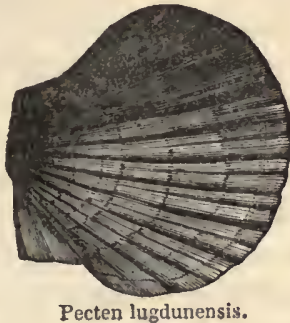

Pecten lugdunensis.

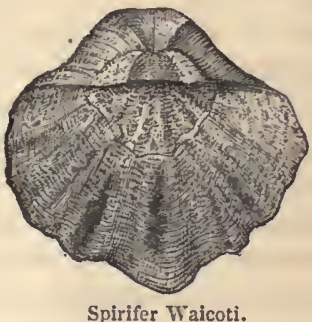

Spirifer Waicoti.

Among the organic remains of the lias we have molluscous animals, Ammonites and Belemnites, of common occurrence, and of various species.

The large family of Ammonites runs through all the fossiliferous formations, from the Silurian to the chalk. With the latter the race became extinct. A notice of the genus has been deferred to this place because the number of species is by far the most abund-

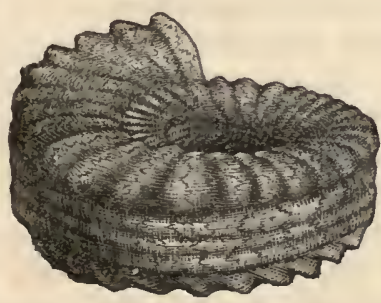

Ammonites Bucklandi.

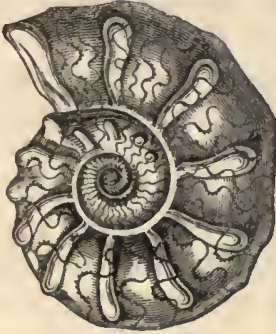

A. nudosus.

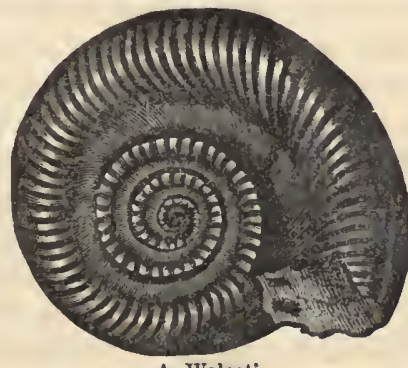

A. Walcoti.

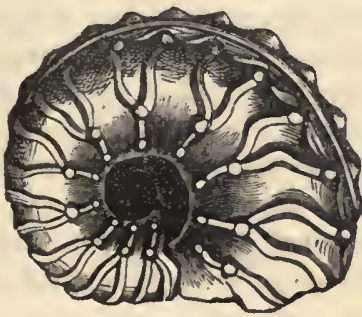

A. varians. ant in rocks of the oolitic system. Of 223 species, according to Phillips, 17 belong to the oldest fossiliferous rocks, 7 to the carboniferous system, 15 to the new red sandstone, 137 to the oolite, and 47 to the chall. The name is derived from a fancied resemblance of the shell to the sculptured horn on the head of Jupiter Ammon. The shells are of various sizes, from the diameter of half an inch to that of four feet. Two species common to the lias, Ammonites Bucklandi, Ammonites Wal. coti, are represented above, with one, Ammonites nudosus, belonging to a limestone in France of the new red sandstone era, and another, Ammonites varians, from the chalk. The Ammonites Walcoti 
found in the lias at Whitby and Lyme Regis have been met with at a great elevation in the maritime Alps, and also at the height of 16,000 feet in the Himalaya mountains. These molluscous animals appear to have preyed upon humbler molluses, crustaceans, and perhaps fishes, thus keeping the races within bounds. They were adapted, by the organisation of their shells, equally to float at the surface of the sea and to visit its profound depths at pleasure. A thin and light shell, with suceessive air chambers, qualified them for the former purpose, while a general arch-like form, strengthened by a series of ribs or transverse arches, enabled the shell to resist the great pressure of the superincumbent water when at the bottom of the sea. This is another of the ten thousand instances exhibited by the various departments of nature, of ingenious contrivance to meet peculiar circumstances, which as elearly demonstrates the existence of a wisely-designing First Cause, as the arch of a bridge, or the groined roof of a Gothic cathedral, attests the action of an intelligent artificer. Nothing better displays the advantage of knowledge than the information we now have respecting the economy of the Ammonites, and the inferences deducible therefrom, contrasted with the views current in former ages of these organic remains. They were the lusus naturce of the learned, the petrified ram's horns of the vulgar, and the snakes decapitated and turned into stone by the prayers of St. Hilda, of the superstitious. A similar legend to that of the north of England belongs to a locality in the south, which recognises St. Keyna surrounded by serpents in a wood at Keynsham, between Bath and Bristol, changing them into headless stones by the fervour of her devotions.

Belemnites, another extensive extinet family of molluses, belonging to the same division as the Ammonites, termed cephalopodous, from their organs of motion being arranged around the head, make their first appearance in England in the lias, and prevail through the oolite and chalk, but on the Continent they oceur in strata of the subjacent system. These fossil bodies are the thunderstones of the populace, for before their organic animal origin was suspected, they were supposed to be concretions produced by electricity. By the ancients they were called Idai dactyli or petrified fingers, from being found on Mount Ida, and from their supposed resemblance to those organs; while to the northern nations, whose imagination was of a gloomy cast, they were known as the devil's fingers, and as spectre candles. The Belemnites, of which there are millions of individuals, belonging to between eighty and ninety species, derive their scientific name from their similarity to the head of a dart or javelin. They generally occur as cylindrical stones, pointed at one extremity, with a cavity at the other end, which is either filled up with a chambered shell, or with the material of the stratum in

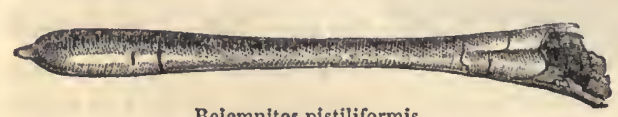
which the fossil lias been imbedded. They vary from a very small size to several inches in circumference, and nearly a foot in length. An example of one species is here given, but it presents only a subordinate part of the original structure of the animal, called the osselet, which performs the office of a guard or sheath. Recent discovery has proved that the ancient Belemnite corresponded to the Sepia, or cuttle-fish, in being furnished with an ink-bag, ejecting the fluid at pleasure, as a means of defence against enemies, or by way of covering its retreat from them. It is a remarkably curious fact, that a substance so easily destroyed as the ink-bag and its contents should have been found perfectly preserved in the lias limestone of Lyme Regis. Dr. Buckland infers from this circumstance that the animals must have died suddenly, for their living analogues eject the inky fluid upon the least approach of danger. It is very rare to find a specimen complete in all its parts, probably owing to the imbedding stratum which is favourable to the preservation of one portion being unfavourable to that of another. But a few perfect examples 
have been discovered - in one instance, by the Marquis of Northampton, in the oolite near Chippenham - which have contributed to unfold the organisation of these interesting animals.

Among radiated animals, or those whose parts are arranged around a common centre, several specics of asterias, or star-fishes, a family which began its existence with the oldest silurian deposits, appear in the lias. Examples from the strata in Germany have been found, and very perfect specimens occur in our own country, through the different members of the oolitic system, and in the chalk formation. Echinites, or sea-urchins, belonging to the same division of animated nature, which make their appearance in the carboniferous system, begin to be largely developed with the dawn of the oolitic, prevailing through the chalk, and presenting a great number of species, now extinct. The echinus of the existing seas is an animal of a globular form, covered with a kind of shell or crust,

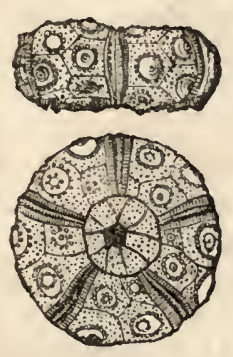

Cidaris coronata.

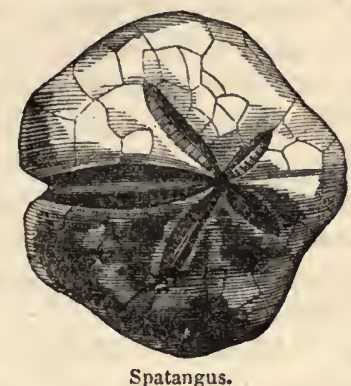

Spatangus. generally thin, beset with rows of spines, and marked with rows of pores, disposed in avenues. It seems a star-fish with the rays coalesced and united together into a spherical case. It has a flat base, often somewhat concave, in which the mouth is always situated. The figure represents a fossil species, cidaris coronata, or turban echinus, found in France and England, exhibiting the base and profile, with two varieties of the same genus from the Yorkshire oolite, and a specimen of another class, spatangus cor-anguinum, snake-heart echinus, from the Pyrenees.

'The organic remains of the lias include crustacea, zoophyta, fishes, marine and terrestrial plants, but it peculiarly commands attention, on account of the abundant relics of saurians, of immense size, which appear to have swarmed in the seas of the liassic period. Sir Everard Home was the first who called public notice to the skeletons of these animals, publishing an account in the year 1814 of some bones found on the coast, between Lyme and Charmouth, in a rock thirty or forty feet above the level of the sea. But the remains examined were incomplete, and the nature and habitat of the animal to which they belonged baffled all inquiry, until the discovery of more perfect skeletons, and the application to them of the great genius of Cuvier, Mr. Conybeare, De la Beche, and others, unfolded a race of water saurians, which received the name of Ichthyosaurus, or fish-lizard, from Mr. König, of the British Museum. This strange creature, ranging from five to more than thirty feet in length, of which ten species are enumerated, had the snout of a porpoise, the head of a lizard, the teeth of a crocodile, the vertebræ of a fish, the sternum of an ornithorhyncus, and the paddles of a whale, thus uniting in itself a combination of mechanical contrivances which are now found distributed among three distinct classes of the animal kingdom. "Persons," says Dr. Buckland, "to whom this subject may now be presented for the first time, will receive with much surprise, perhaps almost with incredulity, such statements as are here advanced. It must be admitted that they at first seem much more like the dreams of fiction and romance, than the sober results of calm and deliberate investigation; but to those who will examine the evidence of facts upon which our conclusions rest, there can remain no more reasonable doubt of the former existence of these strange and curious creatures, in the times and places we assign to them, than is felt by the antiquary, who, finding the catacombs of Egypt stored with the mummies of men, and apes, and crocodiles, concludes them to be the remains of mammalia and reptiles, that have formed part of an ancient population on the banks of the 
Nile." The teeth of the ichthyosaurus, in some instances amounting to 180 , and the length of the jaws to more than six feet, qualified it for predacious habits, its food being fishes and the young of its own species. A single paddle of the four with which the animal was furnished sometimes contains more than a hundred bones, giving it great elasticity and power, and enabling it to proceed at a rapid rate through the water. The eye was enormously large, the orbital cavity, in one species, being fourteen inches in its longest direction. The eye also had a peculiar construction, to make it operate both like a telescope and a microscope, so that the animal could descry its prey by night as well as day, and at great depths in the water. This fish-like lizard in some degree answers to the words of Milton, -

“ With head uplift above the waves, and eyes

That sparkling blazed, his other parts besides,

Prone on the flood, extended long and large,

Lay floating many a rood, in bulk as huge

As whom the fables name of monstrous size,

Titanian, or earth-born, that warred on Jove ;

Briareus, or Typhon, whom the den

By ancient Tarsus held; or that sea beast

Leviathan, which God of all his works

Created hugest that swim the ocean stream."

The ichthyosaurus was an air-breathing, cold-blooded, and carnivorous inhabitant of the ocean, probably haunting principally its creeks and estuaries, fitted by its formidable jaws and teeth, its rapid motion and power of vision, to be the scourge and tyrant of the existing seas of its era, keeping the multiplication of the species of other animals within proper limits. Though essentially marine, and admirably adapted by its organisation to cut the waves, certain peculiarities of structure have induced the opinion that the anterior paddles might be subservient to locomotion not only in the water, but on land. Professor Owen thinks it very conceivable that the ichthyosauri, like the existing crocodiles, may have come ashore to sleep, or resorted thither to deposit their eggs, supposing them to have been oviparous, as the sum of the analogies deducible from their osseous texture would indicate. The remains of these animals are found through the oolite, and in the lower beds of the chalk, but the lias is especially their sepulchre. They occur in great abundance in England, at Barrow-on-Soar, in Leicestershire, in the valley of the Aron, between Bath and Bristol, and on the coast of Dorsetshire, where the cliffs appear to be inexhaustible quarries of them.

Another marine reptile appears in the lias, which received its name of Plesiosaurus, from Mr. Conybeare, signifying akin to the lizard, from its more closely resembling animals of this genus than fishes, especially in the character of the vertebræ. A similar remarkable combination of forms appears in this animal to that which distinguishes its preceding congener, the head of a lizard, the teeth of a crocodile, a neck resembling the body of a serpent, the trunk and tail of an ordinary quadruped, the ribs of a chameleon, and the paddles of a whale. Its most striking feature is the great length of the neck, which has from 30 to 40 vertebræ, a larger number than in any other known animal, those of living reptiles varying from 3 to 6 , and those of birds from 9 to 23 . It has been therefore correctly compared to a serpent, threaded through the body of a turtle. "That it was aquatic," remarks Mr. Conybeare, "is evident from the form of its paddles ; that it was marine is almost equally so, from the remains with which it is universally associated; that it may have occasionally visited the shore, the resemblance of its extremities to those of the turtle may lead us to conjecture; its motion, however, must have been very awkward on land; its long neck must have impeded its progress through the water, 
presenting a striking contrast to the organisation of the ichthyosaurus, which so admirably fitted it for that purpose. May it not therefore be concluded (since, in addition to these circumstances, its respiration must have required frequent access of air) that it swam upon or near the surface, arching back its long neck like the swan, and occasionally darting it down at the fish which happened to float within its reach? It may perhaps have lurked in shoal water along the coast, concealed among the sea-weed, and raising its nostrils to the surface from a considerable depth, may have found a secure retreat from the assaults of dangerous enemies; while the length and flexibility of its neck may have compensated for the want of strength in its jaws, and its incapacity for swift motion through the water, by the suddenness and agility of the attack which they enabled it to make on every animal fitted for its prey." These remarks are in harmony with the appearance of the animal, which is far less formidable than that of the ichthyosaurus, more adapted to occupy the tranquil waters of sheltered creeks and bays, than to brave the rough breakers of the deep, with which its congener might contend. The first almost entire skeleton of plesiosaurus was obtained in January 1824, from the cliffs of Dorset, by Miss Mary Anning; and soon afterwards Cuvier demonstrated its existence on the opposite side of the Channel, from an examination of some vertebræ and other bones which had been collected at Honfleur, near the mouth of the Seine. Subsequently sixteen species have been established, ranging from the lias to the chalk. From the connected and almost perfect state of the skeletons of ichthyosauri and plesiosauri, as if prepared by an anatomist, these animals appear to have been suddenly destroyed and immediately imbedded; a circumstance which we have had occasion to remark, from the condition of other organic remains.

In addition to these animals of the liassic period, marine, fresh-water, and terrestrial tortoises flourished, with crocodilians of extinct species, but approaching in structure to the existing gavial of the Ganges, and the Pterodactyle, or wing-fingered reptile, perhaps the most singular and monstrous creature of the ancient world, the type of which appears in no living genus. Naturalists pored over its remains, and were unable to refer it to its true place in the animal kingdom, some pronouncing it a bird, others a reptile, and others a bat, till Cuvier took its skeleton in hand. "Behold," he observes, "an animal, which, in its osteology, from its teeth to the end of its,claws, offers all the characters of the saurians; nor can we doubt that those characters existed in its integuments and soft parts -in its scales, its circulation, its generative organs. But it was, at the same time, an animal provided with the means of flight, which, when stationary, could not have made much use of its anterior extremities, even if it did not keep them always folded as birds keep their wings; which, nevertheless, might use its small anterior fingers to suspend itself from the branches of trees, but when at rest must have been ordinarily on its hind feet, like the birds, again; and also, like them, must have carried its neck sub-erect, and curved backwards, so that its enormous head should not interrupt its equilibrium." Pterodactyles had the head and neck of a bird, the mouth and teeth of a reptile, the wings of a bat, the body and tail of a mammifer. Their eyes were enormously large, so that they could seek their prey in the night. They could not only fly, but Dr. Buckland supposes that, like the existing vampire-bat, they had the power of swimming. "Thus," says he, "like Milton's fiend, all-qualified for all services, and all elements, the Pterodactyle was a fit companion for the kindred reptiles that swarmed in the seas, or crawled on the shores of a turbulent planet:-

"The Fiend,

O'er bog, or steep, through strait, rough, dense, or rare,

With head, hands, wings, or feet pursues his way,

And swims, or sinks, or wades, or creeps, or flies." 


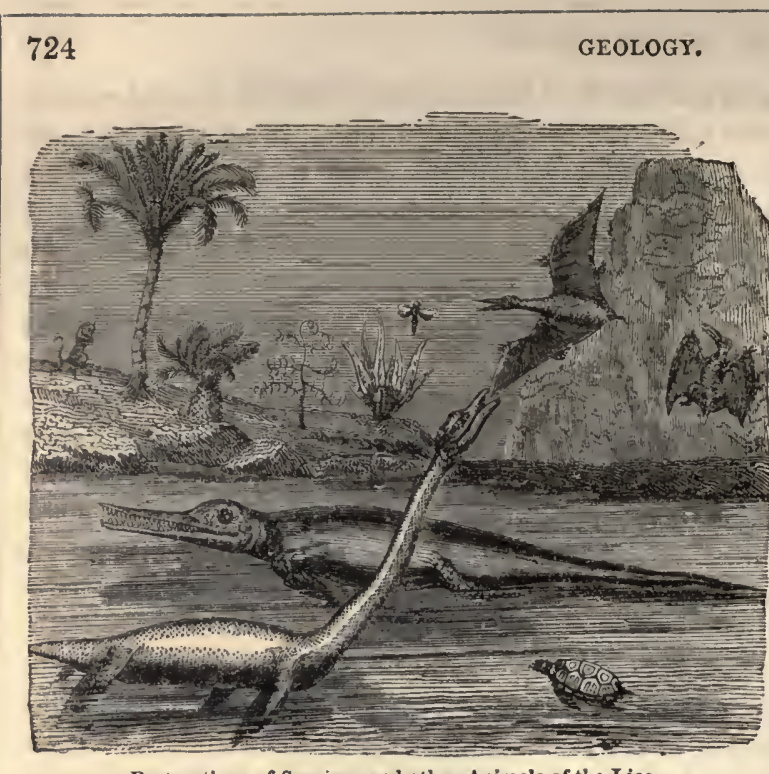

Restorations of Saurians and other Animals of the Lias.

Cuvier, in lis great work, pronounces these flying reptiles the most extraordinary of all the beings whose ancient existence is revealed to us; and those which, if alive, would seem most at variance with living forms. Eight species liave bcen determined, from the size of a snipe to that of a cormorant, occurring in the lias of Lyme Regis, the oolite of Stonesfield, the grit of the Wealden, and on the continent at Pappenheim and Solenhofen. The annexed cut exhibits the chief reptiles of the liassic age, the ichthyosaurus and plesiosaurus, the latter in the act of catching a pterodactyle.

Oolitic Group. - The series of rocks which pass under this denomination have small globules imbedded in them, resembling minute eggs or the roe of a fish, and hence the generic name-roestone or oolite, the latter term being a compound of the Greek wor, an egg, and $\lambda_{\iota} \theta_{o s}$, a stone. But this structure does not prevail through the entire formation, nor is it exclusively confined to it, though sufficiently prominent to become characteristic. Upon microscopic examination, the egg-like grains of these rocks are found to consist either entirely of lime, or of calcareous accretions around some organic substance as a nucleus, generally the fragment of a coral or a shell. The group comprehends, beside the proper oolites, various alternating clays, sandstones, marls, and limestones, and may be subdivided as follows :-

\begin{tabular}{llll}
\multicolumn{1}{c}{ Upper. } & Middle. & \multicolumn{1}{c}{ Lower. } & Fuller's earth. \\
Portland stone. & Coral rag. & Cornbrash and forest marble. & Fur. \\
Kimmeridge clay. & Oxford clay. & Great oolite and Stonesfield slate. & Inferior oolite.
\end{tabular}

The rogenstein or roestone of the Germans, the terrain jurassique of the French, constituting the great mass of the Jura Mountains, and various other continental deposits, answer to the members of the series as developed in England. The oolitic group is remarkable for the vast amount of calcareous matter which it contains, for its limestones extensively employed in architecture, and for the great number and variety of its organic remains. The strata have variously a brown, light yellow, or grey tinge, derived from the oxide of iron, according to the proportion in which it has been dispersed through the mass.

In the lower division of the group we have six members enumerated. The cornbrash is a thin bed of coarse loose limestone, so called in Wiltshire, probably from the facility with which the superincumbent red soil yields to the plough. The forest marble is a fissile arenaceous limestone, frequently a congeries of dark-coloured shells, capable of being polished, and hence occasionally worked as a marble, deriving its name from that circumstance, and from its occurrence in Whichwood Forest, Oxfordshire, appearing also in other localities. The great oolite, the most important member of the wholc series for thickness and utility, is a stratified calcareous mass, furnishing an excellent freestone, the naterial of many public edifices, especially of our fine old churches. It 
appears conspicuously in the Cotteswold Hills in Gloucestershire, in the beautiful hills near Bath, and is represented in the north of France by the well-known Caen stone of Normandy. In the neighbourhood of Bath the great oolite, or Bath stone, is accompanied with thick layers of fuller's earth, a soft aluminous marl, composed of silica, alumina, and 24 per cent. of water. This soil is remarkable for its property of absorbing oily matter, and was once largely employed in the woollen manufacture for cleansing woollen cloth from its impurities, but it is now generally superseded by the use of soap. The Stonesfield slate, celebrated for its organic remains, is a calcareous slaty rock, which has long been quarried at the village of that name, near the town of Woodstock. The inferior oolite, a coarse limestone, with ferruginous sand and sandstone, is distinguished from the great oolite by its less economic value and darker hue, derived from the greater quantity of oxide of iron disseminated through the mass. Dundry Hill, near Bristol, is an interesting outlier of inferior oolite resting on a bed of lias, in the quarries of which many remains of marine crustacea have been found.

Among the preceding members of the lower division of the oolitic rocks, the Stonesfield slate, in Oxfordshire, is of singular interest, on account of its numerous and varied fossils. The village is situated in a valley, the hill-sides of which have been perforated with horizontal galleries to obtain the slate, which divides into thin plates on exposure to frost, and is used for roofing. Here occur vegetable remains, consisting of drifted fragments of coniferous wood, leaves and fruits of cycadeæ, marine plants referable to fuci, associated with shells, the relics of fishes, birds, and insects, the bones of reptiles and mammalia, the lutter, the first instance of mammalian relics that occurs in the history of the globe, and the only instance that has yet been discovered in rocks of older date than the tertiary strata. Among the animal exuvix, Dr. Buckland found those which enabled him to establish a new genus of reptiles, described under the name of Megalosaurus, a lizard of great size, as the name imports, allied to the living monitor, a species of lizard which has been thus styled from the groundless supposition that it gives warning of the approach of the crocodile by a hissing noise. The remains of this reptile have also been met with in the oolite near Besançon, in France. Though no entire skeleton has been discovered, yet, from the perfect state of many of the bones and teeth, their size and proportions, the naturalist can approximate closely to the form and dimensions of the animal. It was asserted by Cuvier of another reptile, that before even he had seen a single rertebra or a bone of its extremities, he was able to announce the character of the entire skeleton, from an examination of the jaws and teeth alone, or from a single tooth; a result, as Dr. Buckland observes, of those magnificent laws of co-existence, which form the basis of the science of comparative anatomy, and which give the highest interest to its discoveries. According to Cuvier, the megalosaurus must lave measured from forty to fifty feet in length. This enormous reptile was carnivorous. In the structure of its teeth are combined the knife, the saw, and the sabre. Its food probably consisted of crocodiles and tortoises. The thigh and leg bones are not solid throughout, like those of aquatic quadrupeds, but hollow at the centre for the reception of medullary substance, like the bones of terrestrial animals, and from hence it is inferred that the megalosaurus was an inhabitant of the land. Its remains are not peculiar to the oolite, but occur in the strata of the Weald.

But the most interesting animal reliquir of the Stonesfield slate are several mutilated lower jaws with teeth, belonging to marsupial mammalia, quadrupeds that carry their young in a pouch (marsupium), as the existing kangaroo. The figure is a specimen double the natural size, with seven molar teeth, one canine, and three incisors. This jaw, that of a very small animal, upon being submitted to Cuvier, was pronounced to be that of a marsupial quadruped allied to the opossum, a decision which has been ratified by several 
naturalists from the inspection of other remains. It has been called Phascolotherium (phaskolos, a pouch.) At a more recent period, the Purbeck beds of the Upper Oolite have

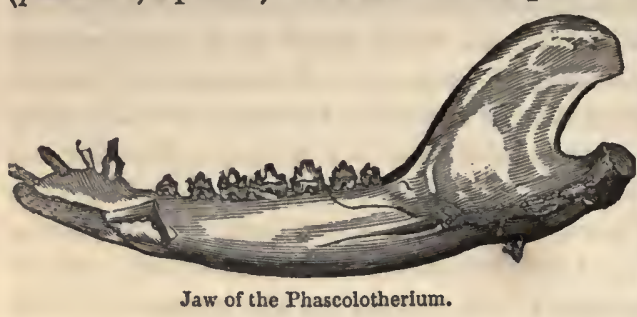
yielded a great variety of similar remains. The discovery of these marsupial relics in the Stonesfield slate, is a proof, as Dr. Buckland observes, that this order, instead of being, as was once supposed, of more recent introduction than other orders of mammalia, is in reality the first and most ancient condition under which animals of this class appeared upon our planet. According to the data at present obtained, it was the only type of mammalian organisation before the tertiary era; and once existed in Europe at a high northern latitude, though now restricted to the tropical parts of North and South America, to New Holland, and the adjacent islands. At Solenhofen, in Germany, in strata corresponding with the Stonesfield slate, similar organic remains are found.

The middle division of the oolite includes the Oxford clay and the coral rag. The former, a dark blue tenacious clay, has underlying subordinate beds of limestone, called Kelloway rock, from being exposed near Kelloway Bridge, in Wiltshire. The clay extends over a considerable portion of France, including the Jura, into Germany; and in England it ranges along the valley of the Isis in Oxfordshire, the Ouse in Huntingdonshire, and the Witham in Lincolnshire. In the latter locality, where it is known as the fen clay, it has a considerable expansion and great thickness; for in sinking for water at Boston the stratum has been penetrated to the extent of 478 feet, at which depth a thin bed of stone, perhaps the Kelloway rock, was met with. Shells are numerous through this formation, and bones of the ichthyosaurus occur, though rarely, and of a different species from those found in the lias. The coral rag, the groupe coralien of French authors, is a limestone composed, in certain situations, chiefly of corals, as its name indicates; but, besides this, the formation includes subjacent beds of sand or gritstone, resting on the Oxford clay, and a calcareous freestone overlying the coral rag. This freestone, largely composed of the comminuted fragments of shells, is the material of many of the noble buildings of Oxford, whose appearance now attests its easy destructibility, being liable to scale off in large flakes after a few years' exposure to the weather. Vertebræ of the ichthyosaurus, several beautiful echinites, and various shells, such as astarte elegans, occur in this part of the oolitic series.

The upper division of the oolite includes the Kimmeridge clay and Portand stone.

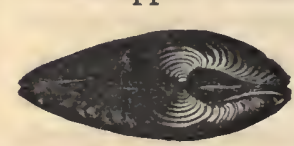
The former, a stratum lying over the superior beds of the coral rag, varies in its composition from a greyish tenacious soil containing selenite, covered with oak-woods, in Wiltshire, where it is called the oak-tree clay, to highly bituminous shales, which are burnt for fuel, near Kimmeridge, on the coast of Dorsetshire, which gives its name to the whole deposit. The remains of crocodilians have been found in the Kimmeridge clay of Honfleur in France, and that of Oxfordshire has yielded the jaws, teeth, vertebræ, and bones of the extremities, of a large marine reptile allied to the plesiosaurus, described and named by Professor Owen the Pliosaurus. The Portland stone consists of a series of beds of cal-

Astarte elegans. careous and siliceous freestone, of no great thickness or extent, being chiefly confined to the county of Dorset, but highly valuable for architectural purposes, having yielded the material of Somerset House, and of many of the public edifices of the 
metropolis. The isle of Portland, where this stone is obtained chiefly, is, properly speaking, a bold promontory off Weymouth, about four miles and a half in length, and two in breadth. Its base consists of Kimmeridge clay and the series of building-stone, upon which the remarkable "dirt-bed" presents itself. This is a bed of black mould, dark argillaceous mud, in which there exist large erect stumps of cycadeæ, or tropical trees, which must have grown on the spot where the stumps now stand, broken as if by a hurricane. 'The following conclusions respecting alternate elevations and subsidences of the strata in this district seem to be fairly inferrible from the position of these vegetable remains:-1. The oolitic limestone, or Portland stone, a marine formation beneath the dirt-bed, was deposited at the bottom of the ocean. 2. This formation rose, either gradually or violently, till it reached the surface of the sea, and became dry land for a time long enough to allow of the accumulation of the black mould, and the growth of the trees. 3. The surface was afterwards submerged beneath the waters of a river or a fresh-water lake, as the superjacent strata are of fresh-water formation. 4. The whole has subsequently been elevated into the position now occupied by the strata in the hills of Dorset. However at variance with the present comparatively quiescent state of the earth these great geological changes may seem, we are compelled to have recourse to them to explain the phenomena; but supposing them to have gradually transpired, the discordance vanishes, for precisely parallel examples of elevation and subsidence have marked the operations of nature during the brief history of mankind.

In stating the range of the oolitic system in England, including the lias, it has been described as extending in an almost uninterrupted band from the coast of Dorsetshire, through the midland and eastern districts of the kingdom, to the sea-coast of Yorkshire above Whitby; and though the subordinate divisions of the oolite are identified by local names chiefly with southern districts, they must not be supposed to be confined to them. Thus the great oolite, or Bath stone, is a formation prominent about Northampton and Stamford, where it is quarried, and extends continuously into Yorkshire, though there it is covered by the chalk. The coralline oolite is exposed between Scarborough and Malton, and at the latter place it becomes likewise concealed by the chalk. The Oxford clay also is met with to the north of Lincoln; the Portland stone appears in the Vale of Aylesbury, and the Kimmeridge clay fills the Vale of Pickering, watered by the Yorkshire Derwent. An intelligent observer of the oolitic formations of the north, Dr. Young of Whitby, remarks upon the numerous vertical fissures which occur in the strata serving as conduits for the waters which descend upon the superficies. Most of the rain that falls on the hills around the Vale of Pickering is immediately absorbed by the light soil that covers them, and sinking into the fissures, it runs through the hills in subterranean streams, which at length burst out at the foot of them in copious springs, sometimes in actual torrents. Hence these bills are remarkably dry. A spring is seldom found in any elevated situation, and wells there require to be dug to an immense depth to find water. Hence, also, as all the springs break out at the base of the hills, where they descend into the Vale of Pickering, a chain of towns and villages skirts their foot, built at these springs for the sake of their copious waters. Another common phenomenon of the district is also explained by these clefts in the rocks. The fissured hills not only absorb their own waters, but swallow up the rivers and streams which pass through their intervals from the country beyond them; for these currents sink into the fissures, and flow under ground, till they disembogue in the low Pickering Valley, where they burst up again as new springs. Yet still a channel remains above ground also, to convey the surplus waters, which the subterranean course, in some parts of the year, is incapable of admitting. Dr. Young notices several examples of this subsidence and reappearance of streams in the neighbourhood. 
Wealden Group. - The deposits under this name, generally associated witl oolitic strata by British geologists, occur principally in the wealds or wolds of Kent and Sussex, a tract covered with extensive forests in former times, and hence so denominated from the Saxon wald, a wood. Caxton, the first English printer, in the first book ever printed in the native language, remarks, that he was "born and learned mine English in Kent in the weald," a district now rich corn land and pasture, traversed by a railroad, which he describes as then "a desert and waste wilderness, stored and stuffed with herds of deer and droves of hogs." The country in question is bounded by the chalk hills of the North and South Downs, with the green sand of that formation at their base, and by the sea for some miles on each side of Hastings. Its greatest extent is nearly sixty miles from east to west, and about twenty miles from north to south; but analogous accumulations to those of the weald appear on the opposite coast of France, near Boulogne and Beauvais, and detached portions occur as outliers in the peninsulas of Purbeck and Portland, and in the Isle of Wight.

The Wealden formation consists of ferruginous sands and sandstones, which extend from Hastings to Tonbridge on the north, and to Horsham on the west. Beyond this area a zone of blue or brown tenacious clay appears at the surface, sometimes indurated and slaty. This zone is the most important member of the group, for it not only circles round the central deposit, but underlies it, and crops out in the lofty cliffs on the coast. The central region, or nucleus of the weald, is elevated, Crowborough beacon attaining the height of more than 800 feet, but the surrounding clay constitutes a flat track, having an average breadth of about fire miles. Thin beds of limestone occur in the clay, separated by argillaceous seams, almost wholly composed of paludina, the shells of a species of snail, held together by crystallised carbonate of lime. This limestone, when polished, forms the well-known Sussex marble so extensively employed by the architects of the middle ages for decorative purposes. The columns, parements, and monuments in our cathedrals and ancient churches are often composed of it, or of the Purbeck marble, a limestone of the same age and group, but an aggregation of a smaller species of the same shells. A row of columns in Chichester cathedral, and those of the Temple church in London, the tomb of Queen Eleanor in Westminster Abbey, and the throne of the Archbishop in Canterbury Cathedral, are constructed of this material; - the fragile shells of humble snails; once familiar with slime and and ; which have been petrified and agglutinated into an enduring limestone by the mysterious chemistry of nature, and subsequently converted into polished marble by the art of man! But its use in architecture appears to go back to the era of Roman domination in Britain. In the year 1723 a slab of grey Sussex marble was dug up at Chichester, bearing an inscription recording the dedication of a temple:- "The college, or company of artificers, and they who preside over sacred rites, or hold offices there, by the authority of King Cogidubnus, the legate of Tiberius Claudius Angustus, in Britain, dedicated this temple to Neptune and Minerva, for the welfare of the imperial family; Pudens, the son of Pudentinus, having given the site." This interesting relic of the olden time is now in the grounds of the Duke of Richmond at Goodwood.

There are no deposits of greater interest than those of the weald, on account of the striking forms of organic life unfolded by them, and the remarkable changes they proclaim to have occurred in this locality. The chalk in the hills of the North and South Downs has been mentioned as forming its general boundary, except where it is open to the sea; and as the wealden beds emerge from beneath the surrounding chalk, the probability is, that it was once continuous over them, and has been swept away from the enclosed area by some great denudation. However this may be, it is certain that while the chalk, under which the wealden strata dip, and the upper beds of oolite upon which 
they rest, are marine formations, the limestone, sandstone, and clay of the weald itself are of fresh-water origin. This interesting fact was first established by the indefatigable researches of Dr. Mantell in the district, and is clearly demonstrated by the character of the organic remains. There are no zoophyta, no cephalopoda, but an abundance of freshwater shells, various land-plants, and relics of terrestrial animals. The paludinæ of the Sussex and Purbeck marbles are the shells of river snails. The fact that none of the usual treasures of the deep appear in the wealden, which proclaim the marine origin of the chalk and other formations, but that its fossils belong to the river or to the land, is decisive against its being an oceanic deposit; and from the appearance presented by its animal and vegetable remains of having been drifted from a considerable distance, Dr. Mantell arrived at the conclusion, that in this locality some departed Orinoco once rolled its waters, laden with the spoils of the lands it had traversed, like the tropical rivers of the present epoch, and that here its course terminated at the sea in an estuary, at the bottom of which the wealden beds were deposited. This conclusion, the evidence of which has been carefully examined, is universally received, and it points to the following cycle of change, expressed by Mr. Bakewell :- " The marine beds (upper oolite) on which the Wealden rest, must, at a remote period, have been raised a considerable height above the ocean, and become dry land, having extensive rivers, lakes, or estuaries, filled with fresh-water, in which the Wealden beds were deposited. Again, at a subsequent period, the whole must have sunk deep beneath the surface of the sea, and been covered with a deposition of chalk, a thousand feet or more in thickness. At a more recent epoch, the chalk, with the subjacent beds of Wealden, were raised to their present elevation above the neighbouring sea."

The vegetable remains found imbedded in this district consist of petrified trunks allied to the palms, arborescent ferns, and gigantic reeds of tropical climates. Among the animal relics, there are those of birds, turtles, crocodiles resembling the existing gavial,

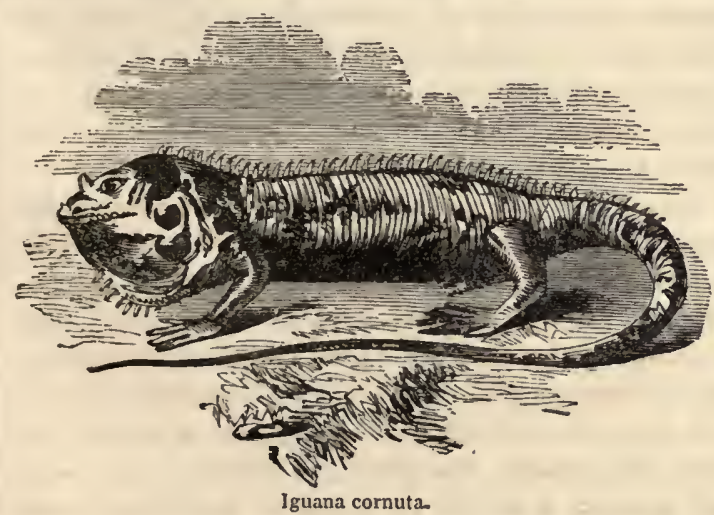
the plesiosaurus, pterodactyle, and megalosaurus, which have been already noticed, the iguanadon and hylæosaurus, new and gigantic species of the lizard family.

Iguanadon.-This animal, the largest of the reptiles of a former world, has received its name from its structure approaching to that of the living iguana, especially as it respects the teeth. The existing iguana, of which the cut is a representation of one species, is an inhabitant of Mexico, the Antilles, and South America, feeding on vegetables, living principally in trees, but taking to the water and swirnming with facility. A fringe of cartilaginous spines extends along the back from the neck to the tail, and a small conical horn appears on the head. The size of the animal seldom exceeds the length of five feet, and lideous as is its appearance, some of the species are considered very delicate food. The fossil prototype of this reptile resembled it in the construction of the teeth, in possessing a nasal horn, and in being herbivorous, but its dimensions were enormous, realising all that has ever been reported respecting the dragons of fable. The thigh-bone exceeded in bulk that of the largest elephant, and upon good grounds has been estimated at from four to five feet in length. Carefully comparing the bones of the iguanadon with those of the iguana, and taking an average 
from eight separate parts of the respective skeletons, Dr. Mantell gave the following as the dimensions of the former:-

Length from the snout to the extremity of the tail -
Length of the tail
Circumference of the body

Though these proportions have been much reduced by Professor Owen, we may still pronounce this reptile, with Cuvier, one of the most extraordinary animals yet discovered. A considerable portion of a skeleton found in 1834 in the quarries of Kentish Rag, near Maidstone, shows the animal to have flourished in the dawn of the chalk formation.

Hylcosaurus.- The first relic of this animal, termed the forest-lizard, was discovered by Dr. Mantell in the summer of 1832, in a quarry of Tilgate Forest, a part of the weald. Other specimens were met with in the same district in 1837, consisting of a series of twenty-six vertebræ, having a total length of six feet, with dermal bones, or thick scales and spines. This lizard is computed to have been about twenty-five feet long, and resembled the living iguana in the fringe of spines along the back.

It has often been said that truth is stranger than fiction, and we have a forcible illustration of the statement in the facts disclosed by the wealds of Kent and Sussex, a district through which the steam-engine now rushes with its train of passengers, by ancient towns, and quiet villages, and grazing flocks, but in by-gone ages the estuary of a river proceeding from a country occupied by giant reptiles, and clothed with a vegetation answering to the luxuriance of our tropics. The estuary, the river, and the country have vanished, but we have the memorials of their existence in the strata occupying the site, in the organic remains collected from them laid up in the cabinet of the natural philosopher, and in the fresh-water shelly limestone columns of our cathedrals; and some idea may be formed of the probable condition of the country through which the waters flowed, which deposited the wealden group, and of its animal and regetable productions. "Whether," says Dr. Mantell, in his "Illustrations of the Geology of Susscx," " it were a continent or an island, may not be determined; but that it was diversified by hill and valley, and enjoyed a climate of a higher temperature than any part of modern Lurope, is more than probable. Several kinds of ferns appear to have constituted the immediate vegetable clothing of the soil: the elegant Iymenopteris psilotoides, which probably never attained a greater height than three or four feet, and the beautiful Secopteris reticulata, of still lesser growth, being abundant every where. It is easy to conceive what would be the appearance of the valleys and plains covered with these plants, from that presented by modern tracts, where the common ferns so generally prevail. But the loftier vegetables were so entirely distinct from any that are now known to exist in European countries, that we seek in vain for any thing at all analogous without the tropics. The forests of Clathrarice and Endogenita (the plants of which, like some of the recent arborescent ferns, probably attained a height of thirty or forty feet,) must have borne a much greater resemblance to those of tropical regions, than to any that now occur in temperate climates;-if we attempt to portray the animals of this ancient country, our description will possess more of the character of a romance, than of a legitimate deduction from established facts. Turtles of various kinds must have been seen on the banks of its rivers or lakes, and groups of cnormous crocodiles basking in the fens and shallows. The gigantic megalosaurus, and yet more gigantic iguanadon, to whom the groves of palms and arborescent ferns would be mere beds of reeds, must have been of such prodigious magnitude, that the existing animal creation presents us with no fit objects of comparison. Imagine an animal of the lizard tribe, three or four times as large as the largest crocodile, having jaws, with teeth equal in size to the incisors of the 
rhinoceros, and crested with horns, - such a creature must have been the Iguanadon! Nor were the inhabitants of the waters much less wonderful; witness the Plesiosaurus, which only required wings to be a flying dragon." The name of Mantell will ever be associated with the Wealden beds, as that of Cuvier is with the Paris basin, Murchison with Silurian strata, and Lyell with the Tertiary deposits.

\section{CHAPTER IX.}

\section{CRETACEOUS SYSTEM.}

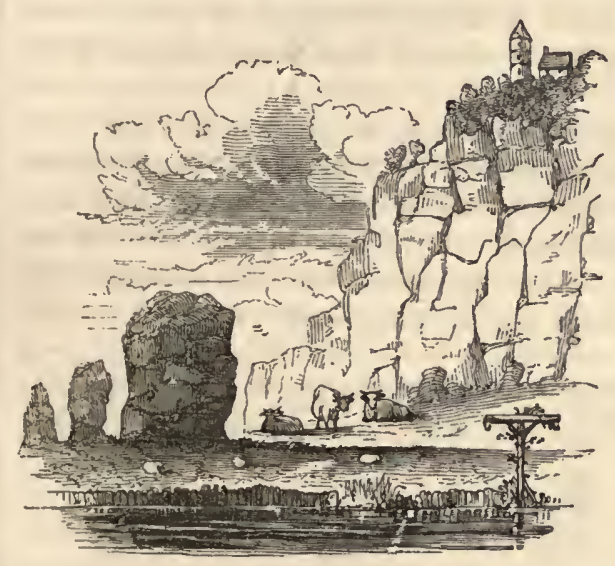

$\mathrm{HE}$ scheme of deposits included in this system, ranging from a thousand to twelve hundred feet in thickness, receives its name from the eommon mineral, chalk (creta), the most prominent member of the group. This is one of the best known and clearly defined formations of the globe, resting upon wealden strata in Kent and Sussex, upon oolitic rocks in other places, and, where these are wanting, upon the lias. In England, the cretaceous system extends over a considerable part of the south-eastern and eastern counties, overlooks the waters of the Channel at Brighton, and the German Ocean at Flamborough Head in Yorkshire, though it is not continuous through the interval between these two points. From the latter headland, it travels inland in a large curve to the Humber, reappears on the Lincolnshire side of the river, and proceeds in a straight broad band to Spilsby, where its course is interrupted. South of the estuary of the Wash, it occurs in a detached curved tract in Norfolk. At Thetford, in that county, the chalk becomes continuous, from thence ranging southward through the counties of Cambridge, Bedford, Oxford, and Wilts, to the sea in Dorset, and, proceeding eastward from Wiltshire through the south-eastern counties, it extends to the coast of Kent at Dover. The cretaceous system makes no appearance in Wales or Scotland, but it occurs in the north of Ireland. On the continent, it is largely developed in Franee, bordering the Channel from Boulogne to Havre, and surrounding in a broad ring the tertiary basin of Paris. The members of the formation appear in various parts of Germany, in the Alps, the Carpathians, and Pyrenees. In North America, it is supposed to occur abundantly on the Missouri to the foot of the Rocky Mountains. But in Ireland, the chalk occurs under circumstances which nowhere belong to it in England, for there, in the county of Antrim, it has been broken through and overlain, by that magnificent outburst of basalt which built up the Giants' Causeway. Here, the metamorphic change induced by the action of intense heat is manifest, in the conversion of the chalk into a crystalline marble, while the lias has been changed into a kind of flinty slate, and the coal shales and red sandstone have been variously hardened. In some foreign localities cretaceous strata have likewise been 
invaded by igneous rocks, at Weinbohla on the Danube, and in the Pyrenees, by granitic varieties.

The members of the cretaceous system, and the order of succession in the strata, are as follows :-

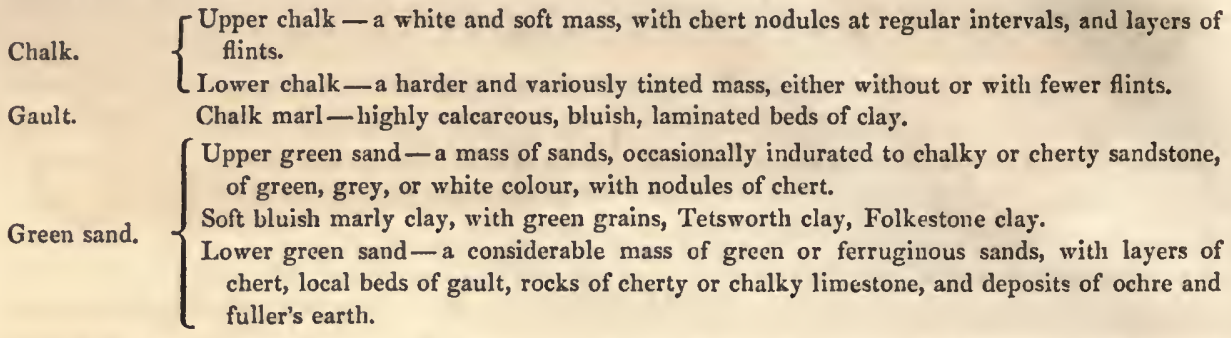

This is a detail of the system as it occurs in the south of England. In other cretaceous localities some of the preceding beds are wanting. The north of England has no upper green sand, Yorkshire none of the lower, which is largely developed in Lincolnshire. The Carpathian Mountains liave no chalk, but green sand in abundance; and this is the case also with the Alps.

Green sand.-This deposit, the base of the cretaceous system, divided into upper and lower beds, separated by a seam of soft blue clay, derives its name from its arenaceous composition and green hues, though yellow tints are frequently exhibited. The sand presents various degrees of fineness, and is employed as a manure in some parts of the United States with considerable success. The colouring matter has been analysed with much care by several distinguished chemists, with the following results :-

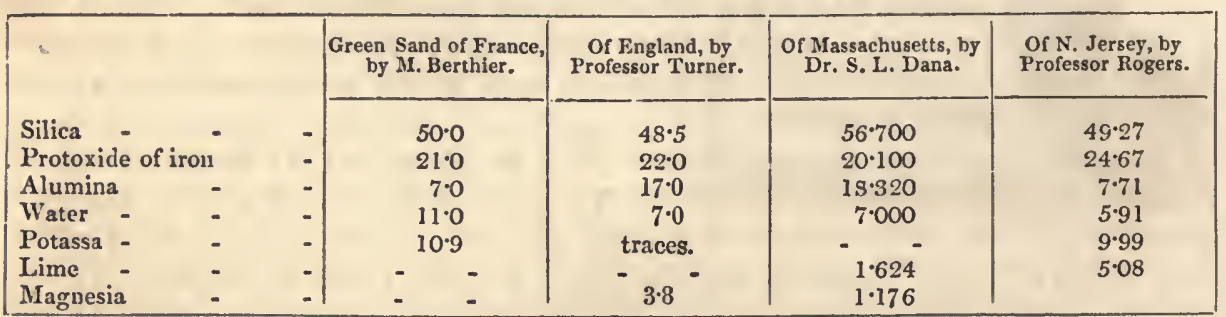

If the fertilising power of the sand depended alone upon the potassa, the English and Massachusetts deposits would obviously be of no value, but to its virtue as a manure the oxide of iron and the other ingredients may contribute. The green sand contains numerous fossils, zoophytes, sponges, echinites, and shells, which appear in the terrain néoco. mien of the French geologists, a deposit appertaining to the same formation. It has thus been styled from the site where it is largely developed, in the neighbourhood of Neuf-
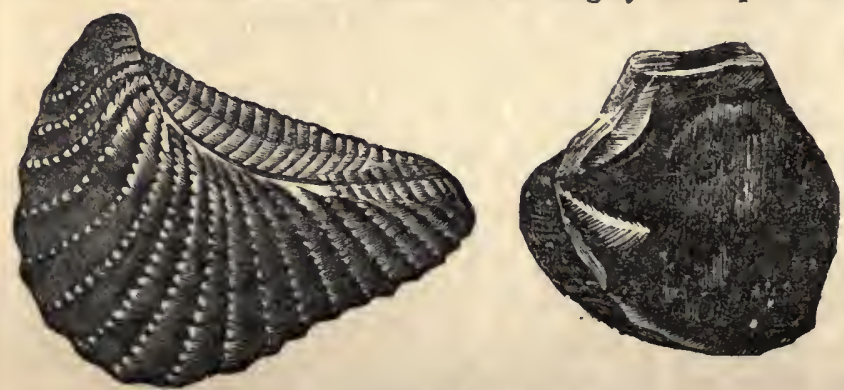
châtel in Switzerland, anciently called Neocomium, occurring also in the north of France, in the southwest within the range of the Pyrenees, and in Dauphiny and Provence. The more remarkable shells are, several species of Trigonia, three-cornered, Trigonla alæformis. alluding to the shape, 


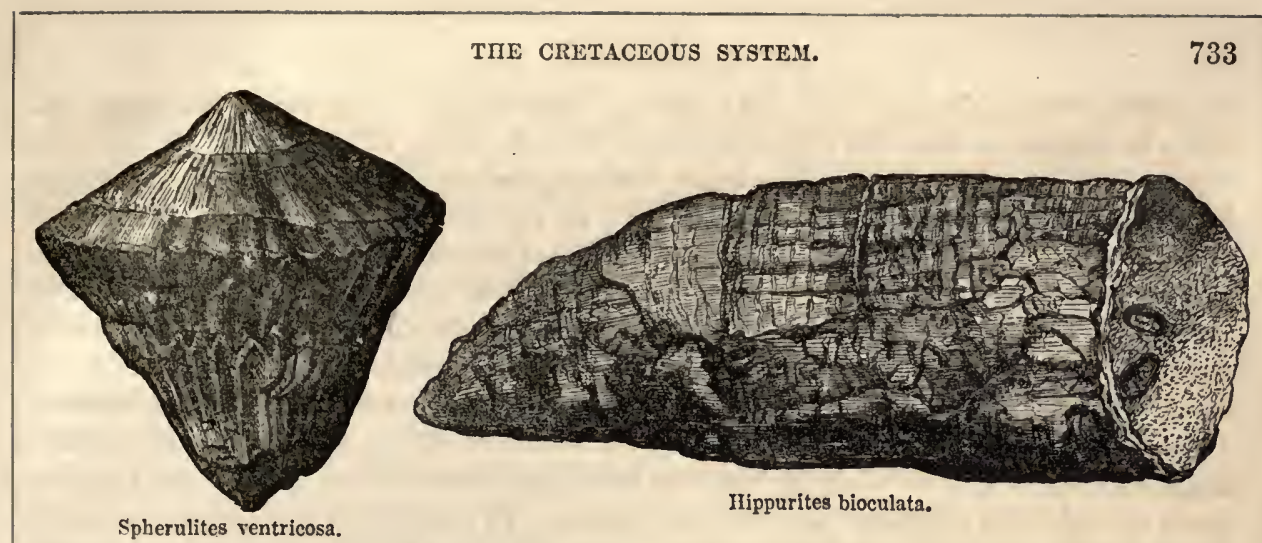

Hippurites, a name derived from that of the common herb hippuris, the mare's tail, the stem of which the shells are supposed to resemble, and Spherulites, shells of a globular form, as the title indicates. In the cretaceous system of England, as it appears in the midland counties, the green sand occupies comparatively low tracts; but in Wilts it constitutes a secondary range of hills, presents high insulated masses on the confines of Dorset, forms the summit of the extensive table land of Blackdown in Devon, and appears at the elevation of nearly a thousand feet in Leith Hill in Surrey, thus rivalling in height the chalk hills of the North and South Downs. The formation is variously a loose sand, and formed into sandstone by a calcareous cement.

Gault. - This is a provincial name for beds of chalky clay overlying the green sand, varying in colour from a light grey to a dark blue, holding irregular balls of argillaceous ironstone and iron pyrites. The craie tufeau of the continent corresponds with

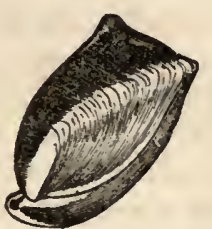
our English gault, but no where are the strata very persistent in their occurrence, or of much importance. Marine shells are abundant, generally distinguished by their brilliant pearly lustre, of which the engraving shows an example.

Chalk. - This mineral, occupying the upper part of the system, so useful in the arts and in agriculture, is a carbonate of lime, composed Terebratula digona. of nearly 44 parts of carbonic acid, and 56 of lime. It seldom, however, occurs pure, but has earthy admixtures. Some of the foreign chalks contain as much as from eight to ten per cent. of carbonate of magnesia, and are characterised by minute black spots, like gunpowder grains, imbedded in them. The two divisions of the chalk formation, the upper and lower, differ to some extent in their character. The upper is in general friable and soft, so as to be readily scratched with the nail; the lower is harder, and is sometimes used as a building-stone. The colour of the upper chalk is often a clear snowy white, while that of the lower passes into a dusky grey, and even a red. The upper beds contain numerous nodules of siliceous or flinty matter, arranged in layers, which are either entirely absent, or not so common in the lower. In general, the appearance of stratification in the chalk is not distinct, arising from the soft yielding nature of the mass, admitting of the beds passing indiscriminately into each other. The red colour of the lower part of the Yorkshire chalk is clearly seen in the cliffs of the coast between Flamborough and Filey; and this hue characterises the scaglia in the neighbourhood of Genoa, considered to be a mode of chalk.

Chalk with numerous fiints, that with few flints, and that without them, may be seen well exposed in the range of rocks reaching from Shakespeare's Cliff, near Dover, along the coast to the South Foreland, and round that point to St. Margaret's Bay. The occurrence of these siliceous aggregations, so different from the surrounding mass, is 
the most remarkable feature of the deposit. They exhibit every variety of shape, and differ in magnitude from the circumference of an inch to that of a yard. They are commonly separated from each other, being entirely enclosed by the chalk, and occur in layers horizontally disposed in the rock; but in one instance a continuous stratum of flint rises from the beach near St. Margaret's Bay, about an inch and a half thick, and may be readily traced from thence for a distance of two miles. But this is an exception to a rule which very generally obtains. The flints in chalk are almost universally detached nodules, with rugged edges, arranged in horizontal strata. These strata are separated from each other by varying distances, and differ also in their own breadth. Upon examination, the flints are frequently found to be siliceous accumulations around organic substances, parts of shells, sponges, and other marine forms, into the most minute pores of which the siliceous matter has penetrated. In many cases the organic structure has bcen admirably preserved; but where it has perished, its place has either been left vacant, or filled up with a sparry incrustation. Mr. Brande makes a remark, with a view to throw light upon the enigmatical appearance of the flints, that if finely powdered silica be mixed with other earthy bodies, and the whole diffused through water, the grains of silica have, under certain circumstances, a tendency to aggregate into small nodules. Now grains of quartz are discoverable in chalk, and some conceive it to be a probable explanation of the case, that silex, which occurs in a state of solution in the hot springs of Iceland, was largely present in the waters which deposited the upper chalk, and was aggregated by the elective affinity of its own particles, forming, under control of some peculiar attraction, upon the now enclosed organic substances as so many central nuclei. We may be tempted to inquire respecting the prevalence of silica in the seas of the period; but such inquiries are endless, and would be equally pertinent and unanswerable, concerning the material of the chalk and the magnesia so largely prevalent during the deposition of the magnesian limestone.

Large masses of limestone are evidently owing to the organic efforts of secreting animals, being entirely composed of comminuted shells and corallines; and a similar organic origin is now generally ascribed to the chalk, for, upon being submitted to microscopical examination, its particles exhibit those appearances of structure which identify them either as excessively minute shells and corals, or portions of them. But if we admit the rital origin of chalk, and of all the enormous masses of carbonate of lime which compose nearly one-eighth part of the superficial crust of the globe, this is obviously no solution of the problem, for we have every reason to suppose that the inhabitants of the ocean secreted the material of their structures from the waters of the deep. The question, therefore, remains to be answered, whence the sea obtained its immense amount of calcareous matter, which appears to have more remarkably characterised it at certain eras than at others. The chief difficulty in the case is, as Dr. Buckland states, that it could not have resulted, like sand and clay, from the mechanical detritus of rocks of the granitic series, because the quantity of lime these rocks contain bears no proportion to its large amount among the derivative strata. Perhaps the true theory may be, that, as lime appears to some extent in lava, basalt, and various kinds of trap-rocks, the ocean obtained its carbonate of lime from springs charged with carbonic acid gas percolating through those igneous masses, and received, at some periods, a preponderating supply from the prevalence of igneous discharges.

Chalk, with an abundance of flints, presents itself in the cliffs of this formation in the north, and there, on the Yorkshire coast, exposed to the full violence of the German Ocean, the rocks bear witness to the excavating power of the waves, the abrading influence of the stormy wind and rain, and their own comparative fragility. The general contour of the chalk developed in this district has been noticed, that of a 
curve or bow, having one end at Flamborough Head, and the other on the Humber, the middle part bending inland. The breadth of the extremities of the bow, both at the ocean and the river, is comparatively small; but that of the central region amounts to about 15 miles, and the length from end to end to about sixty, without including the sinuosities of the outline. The chalk first appears on the coast, above the level of the sea, a little to the north of Bridlington Quay. From thence it gradually rises towards Flamborough and Speeton, forming the cliffs, which rise precipitously 300 feet, but reaching a greater elevation away from the shore. Proceeding westward towards the wolds, the chalk becomes still more lofty, and attains its highest elevation in Wilton beacon, ascertained to be 809 feet above the level of the sea. From thence, towards the Humber, the hills diminish; yet at Hunsley beacon, six miles from the river, the elevation is still 531 feet. The most striking part of the district is the Flamborough headland, and its neighbourhood. The chalk here shows a tendency to split in a perpendicular direction, and the cliffs in consequence exhibit in various places somewhat of a columnar aspect. The rough waves of the ocean beating into the lower part of the perpendicular fissures have hollowed out niches, grottoes, and large caves, some of them highly romantic, harder or more protected masses of chalk remaining as pillars to support the undermined rock. In the loftier Speeton cliffs, a few miles further on the coast, an analogous effect appears at their summit, produced by the beating of the rains, to that caused by the dashing of the waves at the base of those at Flamborough. Deep sinuosities and breaks have been worn by the rains in the upper part of these rocks, the firmer chalk remaining between them, presenting to a spectator from the beach the appearance of the walls of some stupendous castle, surmounted by a range of pinnacles. A less boisterous sea, and a sloping mound, keep the base comparatively uninjured. The Speeton cliffs are interesting, for here the lower coloured chalk is exposed beneath the upper, the former exhibiting a brick-red or chocolate colour, with green, blue, and grey tinges, which strikingly contrast with the milk-white aspect of the latter, brilliant when lighted up by the beams of the rising or the setting sun.

The fossils of the chalk, and of the cretaceous system in general, are eminently the remains of oceanic life, very few examples of land organisms occurring in any of its formations. Plants are rare, and are nearly all referable to marine types, fuci, and other sea-weeds, a circumstance which is understood as indicating that the sea was very little disturbed by inundations from the land during the deposition of the strata, otherwise the remains of ferns and other forms of terrestrial vegetation would have been im-

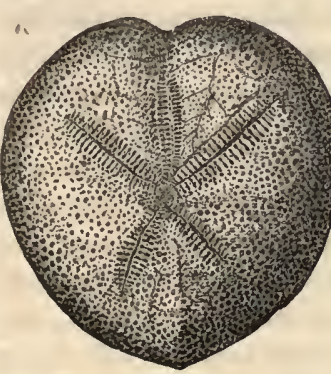

Spatangus cor-anguinum. bedded. Among the spoils of the ocean we are presented with sponges, zoophytes, star-fishes, many shells, and echinites. Of the latter, a most abundant family, a representation of the most common species, Spatangus cor-anguinum, or the heart-shaped echinite, is given in the annexed cut. Remains of vertebrated fishes have been exhumed by Dr. Mantell, but no mammalia have been discovered. "There appears," says Professor Phillips, "no sufficient evidence in the fossils of this system to justify any positive inference as to the character of the climate then prevailing in the northern zones."

An addition to the cretaceous system, its uppermost member, entirely wanting in the British series, occurs on the continent, remarkable for bringing to light a marine reptile, the remains of which have since been found in the chalk of England. This is a friable, shelly, and sandy limestone, containing layers of flints, of which St. Peter's Mountain, in the neighbourhood of Maestricht, is composed. Here the celebrated Hoffman, in the 
year 1780 , found the nearly perfect head of an animal, which greatly attracted public curiosity, and long baffled the attempts of naturalists to ascertain its true place in the animal kingdom, at a period when comparative anatomy was yet in its dawn. The discoverer was soon afterwards compelled to abandon his prize, upon the ecclesiastics of the city claiming the possession of it, on the ground that it had been taken from a domain belonging to the cathedral. Its further history is curious, and has been detailed in a French work specially devoted to the object. Upon the commencement of the wars of the Revolution, a number of savans from Paris accompanied the French army to the gates of Maestricht, for the express purpose of obtaining this animal remain. The garrison were invited to hoist a flag on the town hall, where it was known to be kept, in order that the besiegers might avoid destroying that building with their shells. Upon the capture of the city, the relic was transported to Paris, where it now remains. Cuvier confirmed a previous suggestion concerning it, that it belonged to a gigantic marine animal, nearly allied to the monitor, the remains of which have since been discovered in the upper chalk near Lewes by Dr. Mantell, and in the green sand of the United States. This reptile received the name of the Mososaurus, or the lizard of the Meuse, from the place of its first discovery. It is supposed to have been from twenty to thirty feet in length, the oar-like construction of the tail indicating a capacity to move rapidly in the ocean after the large and powerful fishes, upon which, from the great size of the jaws and teeth, it is conceived to have preyed. The era when this creature first appeared in the seas of the ancient earth was immediately subsequent to the age when the ichthyosaurus governed the inhabitants of the deep, and it doubtless performed the same office-that of checking an excessive multiplication of the occupants of the ocean during the period of its reign, which appears to have been exclusively confined to the cretaceous epoch.

The physiognomy of chalk districts is not unprepossessing in general, and it is often very attractive, presenting a series of bold hills, with valleys intersecting them in every direction, remarkable for their smooth and flowing outline, affording a scant though sufficient herbage for numerous flocks of sheep. The economic value of the deposits is of high importance, the flints supplying a material used in the manufacture of glass and porcelain, and the chalk itself being eminently serviceable in agriculture. A soil, to be fertile, must contain a certain proportion of argillaceous, siliceous, and calcareous earth, and where the latter is deficient, the land may be improved by the addition of a few loads of chalk, more than by any quantity of animal or vegetable manure used alone. Still, Cuvier and Brongniart represent sterility as one of the most prominent features of a chalk deposit, and refer to Champagne as an instance of its soil being almost uninhabitable. Mr. Conybeare also remarks, that in this country the population of the chalk district is less than that of any other secondary rock, in proportion to its size, and large portions of it are unenclosed commons, only used as sheep-walks. 'This arises from the mineral being in excess, and from the dryness of the strata. Many of the valleys of Kent and Sussex are, however, extremely fertile, and upon a chalk soil, well manured, some of the cereal grasses flourish luxuriantly. The beech also thrives well, and now, when a member of parliament vacates his seat by accepting office under the crown, the stewardship of the Chiltern Hundreds, he takes in hand a task no longer required-that of watching over a chalk domain in Oxfordshire, once famous for the harbour afforded to banditti by its woods and thickets of beech.

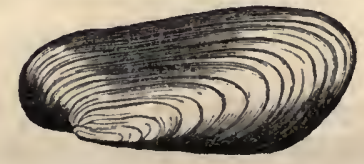




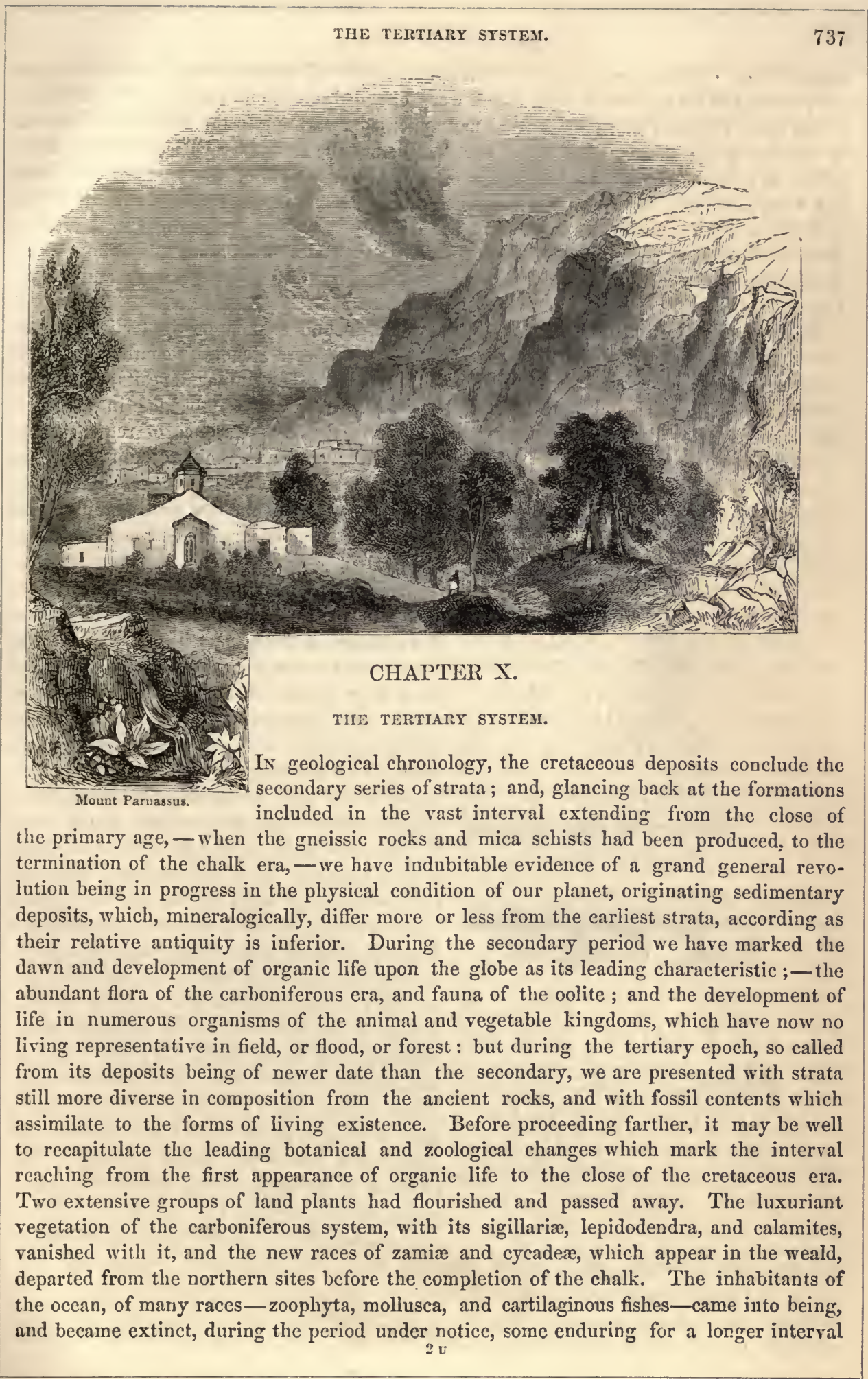


than others. Of the numerous and remarkable family of crustaceans, the trilobites, with which the seas of the silurian epoch were crowded,-not one survived the carboniferous era. Tribes of enormous reptiles had appeared, swarming in the waters of estuaries, or occupying the shores, all of which perished before the secondary period closed. Yet, before it terminated, the highest form of animal organisation, the mammalian class had been produced, though upon a very insignificant scale, the only vestiges of it being a few minute jaws in some of the oolitic beds, chiefly belonging to the marsupial order. But, as we advance through the tertiary system, we shall meet with numerous examples of mammalia, of extinct species and genera in the older tertiaries, becoming more and more identical with the living types in those of newer date.

Before the publication by Cuvier and Brongniart of their memoir on the tertiary strata around the city of Paris, in the year 1810, these beds were generally confounded with recent superficial accumulations; but, since that period, other similar deposits have been studied with diligence and success, and the remains of animals imbedded in them of genera and species distiuct from the existing races, with the appearance of regular stra-

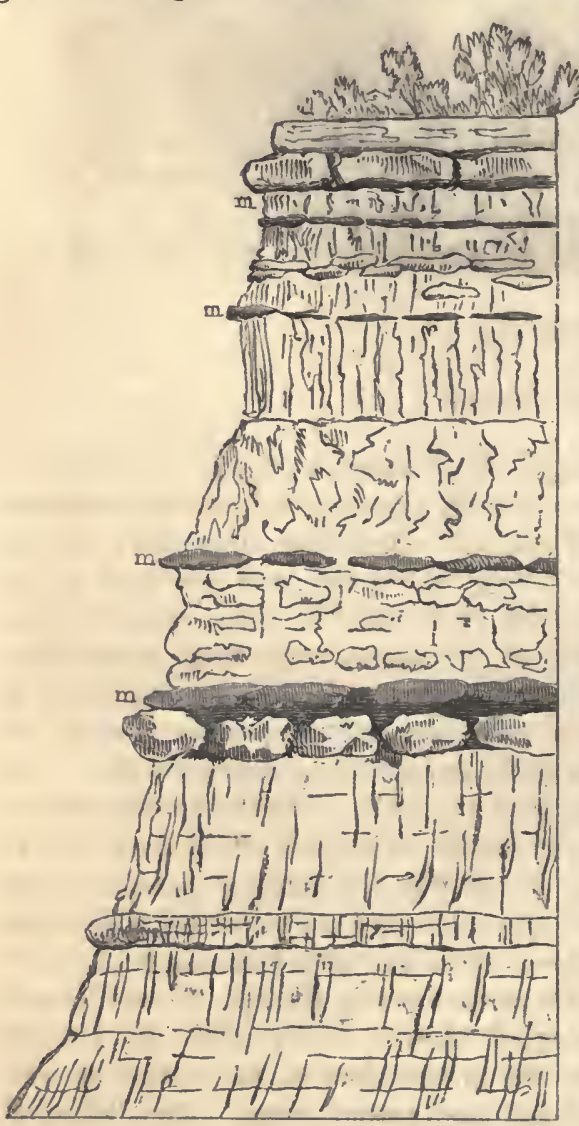

Maris with magnesite, $m$, near Coulommiers. tification, have led to their recognition as an independent scheme of formations. The prevailing materials of the system are arenaceous, argillaceous, and calcareous, in general loosely aggregated. They occupy great hollows of the chalk, and occasionally of older strata; and owing to the tertiary beds having undergone less pressure from their position at the surface than more ancient deposits, their fossil shells have been preserved with remarkable perfection. The arenaceous members are either pebbly conglomerates, or sands, seldom indurated so as to form sandstone; in some districts white and colourless, in others of a general green tinge, derived from the silicate of iron; while at Alum Bay, in the Isle of Wight, the sand is of various hues, imparted by the oxide of iron, giving to the rock a fantastic, beautiful, and fairy-like appearance. The argillaceous beds likewise exlibit great diversity, being laminated clays almost pure, or clays without lamination scarcely distinguishable but by their fossils from the alluvium of existing rivers, or clays with a sandy admixture, or marls more or less calcareous. Their colour varies from a dull blue or brown tint to a light green; but at Alum Bay the hues of the associated clays are as diversified as those of the sands, being almost black, and again almost entirely red, or richly mottled with red and white. The calcareous formations are also very dissimilar, being rough coralline rocks, or coarse sandy limestones, soft, marly, and full of shells, easily distinguishable from the limestones of the preceding systems by their inferior degree of induration. The tertiary system includes subordinate formations of lignite, or carbonised wood, forming an imperfect coal, which holds an intermediate place 
between that mineral and peat. Lignitic beds occur in tertiary strata at Bovey Heathfield in Devonshire, and at the interesting locality of Alum Bay, in connection with amber. They indicate the submergence of woods and forests, the amber, unquestionably a mineral substance, derived from the vegetable kingdom, being a gum or gum-resin exuded by the associated trees. Plastic clay, yielding the common pipe and potter's clay, and gypsum, are extensively obtained from the London and Paris tertiaries, the latter forming, when calcined and combined with water, the well-known plaster of Paris, so largely employed in the arts. Magnesite, a stone essentially composed of magnesia, silex, and water, the material of the meerschaum, occurs at various points around Paris, particularly in a hill near Coulommiers, which has been cut to form a canal, exposing the interior structure. The strata here consist of siliceous and calcareous marls, in which the magnesite shows itself distinctly, as at $m$, in the section.

Two of the largest cities in the world, and three of the most ancient capitals of Europe, London, Paris, and Vienna, are situated upon tertiary strata. In England the geographical range of the system includes the north of the Isle of Wight, parts of Hampshire and Dorset, the north of Kent and the Isle of Sheppey, a considerable area around and west of the metropolis, with the eastern coast from the Thames into Holderness in Yorkshire. No similar deposits have been recognised in Ireland; in Scotland also they scarcely can be said to exist; but on the continent of Europe they are very extensively developed. This appears from the following classification, which shows the relation of the European tertiaries to existing seas :-

Connected with the North Sea, $\{$ The basin of London, Suffolk, Norfolk, Lincoln, and Yorkshire. The or German Ocean. $\quad$ north-east of France Belgium, Westphalia, Holstein, and Jutland.

Connected with the English $\{$ The basin of Hampshire, including parts of Dorset and the Isle of Channel.

Wight. The basin of Paris.

Between the Baltic and Black Sea. The extensive sandy deposits of Prussia, Poland, Volhynia, and Wallachia. Connected with the Atlantic. The basin of the Garonne.

Connected with the Mediterra- $\left\{\begin{array}{r}\text { Tertiaries of Catalonia. } \\ \text { of the south coast of France and the valley of the Rhone. } \\ \text { of the northern sub-apennine regions, and of Sicily. } \\ \text { of the northern parts of Africa. }\end{array}\right.$
Secluded tracts.
\[ \begin{array}{r}\text { The valley of the Rhine from Basle to Bingen. } \\ \text { The interior basin of Bohemia. } \\ \text { The great hollow of the northern Swiss lakes, and the valley of the } \\ \text { Danube, with the Moravian, Hungarian, and Transylvanian strata. }\end{array} \]

The tertiaries occupy more than half the surface of Europe. They have likewise been recognised along the southern roots of the Himalaya, while in America they embrace nearly all the level region in the eastern part of the middle and southern United States. In no English locality are they in association with igneous rocks; but in Auvergne, in Hungary, and Transylvania, in Tuscany and Campagna di Roma, and in Sicily, they are found in connection with volcanic products. The external aspect of tertiary districts, excepting those where disturbance from igneous action has taken place, is generally monotonous, as in the great plains bordering on the Garonne, and the vast levels between the Baltic and the Black Seas, but around London and Paris the scenery is varied, the strata undulating with the subjacent chalk.

The fossil contents of tertiary deposits, their most interesting feature, are of marine, freshwater, and terrestrial origin. The beds containing them are frequently alternated and mingled with each other in a confused and irregular manner. Rivers, lakes, landfloods, and the sea, have contributed, therefore, to their formation, and we may conclude generally that, during the tertiary era, the relations of land and sea were repeatedly altered; that the land was successively raised above the level of the ocean, and sunk 
below it; and that large European tracts were the sites of lakes, rivalling in size those of the American continent, into which rivers disembogued. Supposing the Niagara Falls to be removed to Lake Erie, by the gradual gnawing away of the rock by the river; the waters of the lake being consequently drained off, a vast plain would be opened to examination, consisting of a base of ancient limestone covered with fresh-water formations. The latter are now slowly accumulating from the sediment brought into the lake by its feeders, or being more rapidly created as the effect of the streams oecasionally rushing into it in flood, and in these strata organic remains are deposited of the existing tenants of the lake, of animals also and vegetables peculiar to the land, which are drifted into it. 'The case imagined is preciscly parallel to that of some of the fresh-water tertiaries, whose fossil contents proclaim their fluviatile or lacustrine origin. The organisms of the entire system constitute an immense assemblage, generally characterised by being widely different from those of the secondary rocks, and exhibiting a marked analogy to the existing forms of life. They consist of plants, a few marine, but others terrestrial, presenting the true dicotyledonous structure; molluses in great abnndance, many belonging to living species; fishes, mostly of extinct species, though some are referable to gencra common in tropical regions; reptiles, among which are the remains of genuine crocodiles, with prototypes of the frog tribe; and mammalia, of which between fifty and sixty species have been determined, of rarions orders, but chiefly belonging to the pachydermata or thick-skinned division of the animal kingdom, having their nearest representative in the existing tapir. M. Deshayes, in 1830, compared the living and tertiary molluscs with the following results; but since that date, large additions have been made to both classes.

Number of living species examined _ - _ - $\quad-\quad 4780$

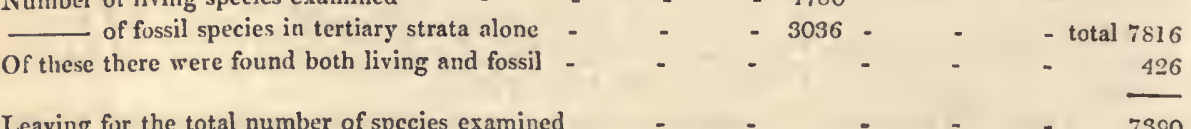

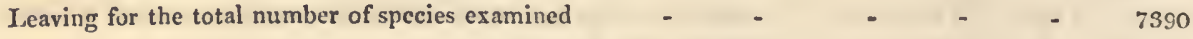

The ratio of the species which are both living and fossil to the whole number is 5.7 to 1000 .

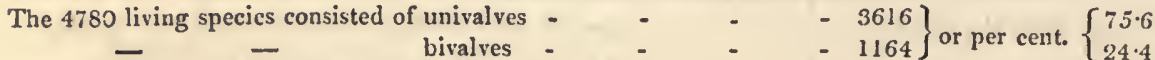

The 3036 tertiary species consisted of univalves $\quad-\quad-\quad-2098\}$ or per cent. $\left\{\begin{array}{l}60 \cdot 1 \\ 39 \cdot 9\end{array}\right.$

Proceeding upon the warrantable assumption that the tertiary beds which contain the greatest proportion of living species are the most recent, M. Deshayes thus classified the system :-

Upper or most recent group. $\left\{\begin{array}{l}\text { Localities, - Sicily; the Italian sub-apennine beds, with whose fossils } \\ \text { those of the Morea and Perpignan in the south of France agree; the } \\ \text { crag of Norfolk and Suffolk. } \\ \text { General proportion of living species, } 49 \text { per cent. }\end{array}\right.$
Middle group. $\left\{\begin{array}{c}\text { Bourdeaux; Dax; Turin; Touraine; Baden; Vienna; Angers; Rouen. } \\ \text { The fossils of Baden and Vienna are a general type for those of Moravia, } \\ \text { Hungary, Cracovia, Volhynia, Podolia, and Transylvania. } \\ \text { General proportion of living species, } 18 \text { per cent. }\end{array}\right.$
Lower group.
$\left\{\begin{array}{c}\text { Paris; London; Hampshire; Valognes; Belgium. The fossils of Castel- } \\ \text { gomberto and Pauliac are the same nearly as those of the Paris basin. } \\ \text { General proportion of living species, } 3 \frac{1}{2} \text { per cent. }\end{array}\right.$

Sir C. Lyell, adopting the same principle of classification, proposed a division of the system similar to the above, except that he gave an independent rank to the Sicilian deposits, separated them from the upper group of M. Deshayes, and thus made four terms of the whole mass of tertiary strata, employing a Greek nomenclature to distinguish them.

Newer Pliocene.-Sicilian deposits, with 95 per cent. of recent species.

Elder Pliocene.-Italian and crag deposits, with 41 per cent. of recent species. 
Miocene. - Vienna, Bordeaux, Turin, \&zc, with 18 per cent. of recent species.

Eocene.-Paris, London, Belgium, with $3 \frac{1}{2}$ per cent. of recent species.

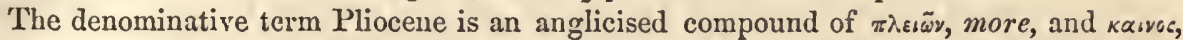
recent, denoting the greater preponderance among its fossils of recent species. Miocene

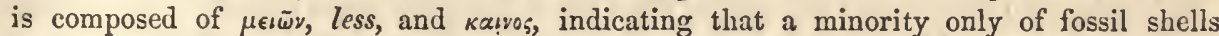
imbedded in formations of this period are of recent species. Eocene consists of $\dot{\eta} \omega \xi$, the

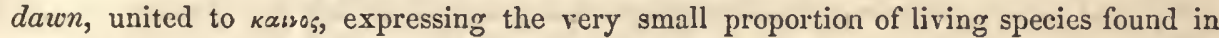
strata of this description, therefore regarded as furnishing the dawn of the existing day with reference to the animate creation. These terms may be familiarly taken to signify ancient tertiary, middle tertiary, and modern tertiary, two divisions being made of the deposits denoted by the latter term, the one more modern than the other.

1. Eocene period, the dawn of recent, or ancient tertiary era. The strata of this division, with which we are principally acquainted, are in England and France; and form the London, Hampshire, and Paris basins. The series of beds in these districts differ in number, composition, and order of succession; but so far agree in their general features, and in their organic remains, as to evidence their aggregation during the same geological epoch. It is common, in the present day, for rivers at no great distance from each other to be depositing at the same time different materials, and for marine formations to be proceeding together, of a varying character, at several points of the same gulf.

The London basin, of which a section is given, is a series of marine deposits, which

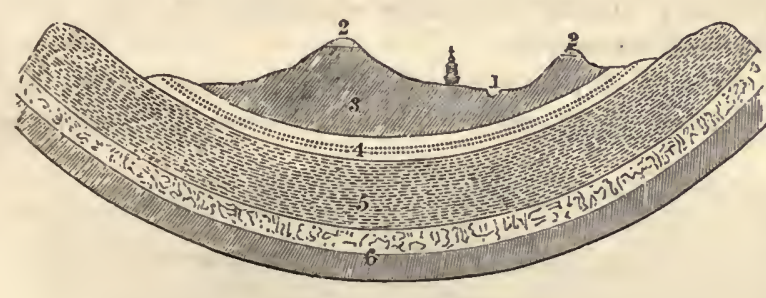

LONDON BASIN.

1. River Thames ; 2. Marine sands; 3 . London clay; 4. Plastic clay and sards ; 5. Chalk with fints; 6 . Green-sand and Gault-clay. occupy an extensive hollow or depression in the chalk. The chalk appears surrounding the basin in the hills of the North Downs; Wiltshire, Oxfordshire, Berkshire, and Hertfordshire, on the south, south-east, west, and north-west; the other directions from the metropolis to the sea being occupied by continuous tertiary strata, and the channel of the Thames. That the chalk actually underlies the basin is not a geological inference, but a fact proved by the sinking of wells through the superjacent beds to it. Immediately above the chalk we have the Plastic Clay formation, so called from the use made of that material for pottery; but it is merely a subordinate stratum, connected with extensive depositions of sand and shingle. The tunnel under the Thames, from Rotherhithe to Wapping, traverses this formation, and the main difficulties of its construction arose from the loose sandy strata. The next member above this is the firm London clay, varying considerably in thickness, but sometimes attaining that of five hundred feet, and presenting various shades of colour. 'This is the general substratum of the metropolis and its vicinity, occurring immediately beneath the surface soil. It has not hitherto presented the remains of any terrestrial mammalia; but a great number of marine shells occur in it, and the skeletons of crocodiles and turtles have been met with in it, at Highgate and Islington, a proof, as Mr. Conybeare remarks, that the shores of some dry land must have existed at the period of its deposition, within a distance easily accessible, to which these animals resorted, according to their present habits. Pieces, and even masses, of fossil wood have also been often found, exhibiting the perforations, and even the casts of an animal, allied to the teredo navalis, the ship-worm, or borer, which now infests the seas surrounding the West Indian islands, and proves so destructive to our vessels. Sir C. Lyell thus speaks of one of these fragments: - "It must have once been buoyant and floating 
in the sea, when the teredince lived upon it, perforating it in all directions. But before they settled on the wood the branch of a tree must have been floated down to the sea by a river, uprooted perhaps by a flood, or torn off and cast into the waves by the winds; and thus our thoughts are carried back to a period when the tree grew for years on dry land, enjoying a fit soil and climate." The Isle of Sheppey, at the mouth of the Thames, is an outlier of the London clay, being composed of it, and one of the most interesting of geological sites, on account of the abundance and nature of its fossils. Besides the usual shells, there are here to be found the remains of fishes; of crustaceans; of birds, serpents, and turtles; of plants allied to the cucumber, bean, cypress, and laburnum; of the fruits of palms, and specimens resembling the spices of the East. So numerous are the vegetable relics, that they have been estimated as indicating many hundreds of species, mostly of a tropical nature. The imagination may be pardoned, arising from the occurrence of these vegetable forms, that when they were imbedded in their present site the elevated parts of England formed a number of spice islands like the Moluccas, enjoying an equatorial warmth, whose products, committed by natural agencies to the waves, were drifted hither by an oceanic current, and laid up in their present resting-place. A more sober conclusion is, that the climate of our northern zone still possessed a tropical temperature, and that here was the estuary of a river which brought down these specimens of the flora of the neighbouring land. The third and uppermost group of the London basin consists of arenaceous deposits, the sands of Highgate, Hampstead, Finchley, and Bagshot Heaths, with very few organic remains, forming the wastes abandoned to their native furze, which mark the neighbourhood of the capital.

The Hampshire basin includes an area of the mainland beyond that county, east and west, and the northern part of the Isle of Wight, which is, in fact, a disrupted mass from

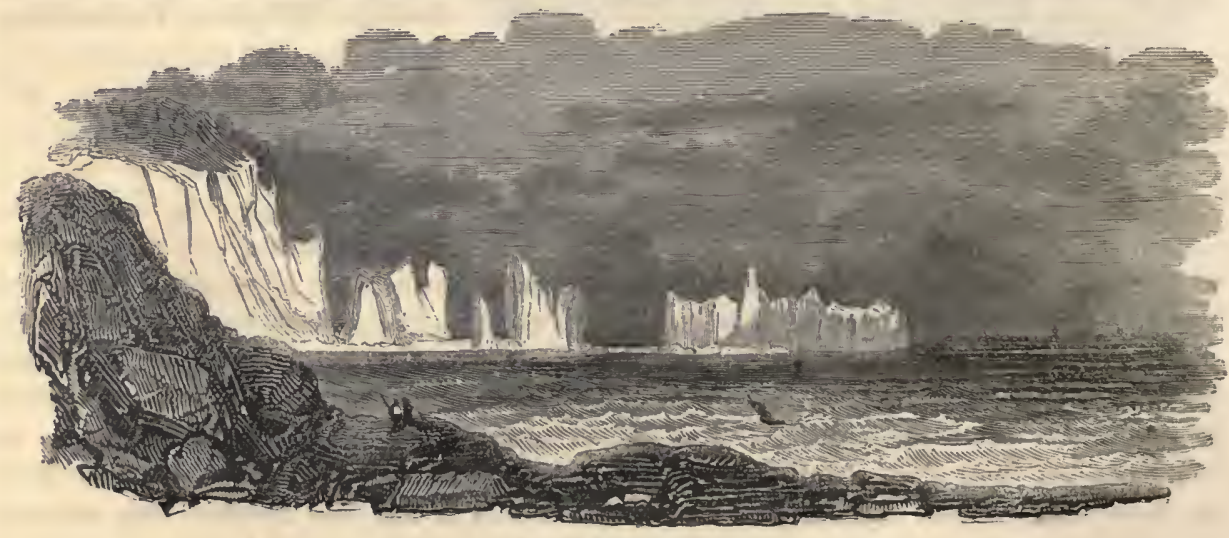

Alum Bay, Isle of Wight.

the south coast of England. Strata here alternate of marine and fresh-water origin, and so far this tertiary district of the eocene era differs from that just noticed. This fact indicates alternations in the level of the land with reference to the sea; and the existence of an estuary into which a river poured its waters during the elevation of the land, bearing along specimens of the organisms of an interior country, which were deposited in its bed, the whole being subsequently submerged and re-elevated. The fresh-water strata contain very perfect remains of tortoises and crocodiles, with the bones of mammalia, belonging to land animals identical with those which we shall have to notice as occurring in the Paris basin, a formation of the same epoch. By far the most remarkable locality in this district is Alum Bay, whose vertical and variously-coloured strata at once arrest the eye of the spectator, the tints of the cliffs being so bright and varied that they have 
not the appearance of anything natural. Deep purplish red, dusky blue, bright ochreous yellow, grey nearly approaching to white, and absolute black, succeed each other, as sharply defined as the stripes in silk; and after rain, the sun shining upon the cliffs gives a brilliancy to some of these colours, rivalling the resplendence of real silk when high lights are thrown upon it.

The Paris basin is larger than either of the preceding, and more remarkable on account of the abundance of its organic contents, which, examined by the genius of Cuvier, gave birth to true philosophical geology. It includes an area of more than seven thousand square miles around the capital, and forms an irregular polygon, elongated from north to south, the Loire flowing through its southern confine, and the Seine pursuing a winding course through the middle, nearly dividing it into two equal parts. The greatest extent of the basin, from north to south, is about 180 miles, and 100 miles from east to west. The site of Paris is nearly centrical. The sides of the polygon pass in the vicinity of the towns of Laon, Clermont, Chartres, Vendome, Blois, Orleans, Epernay, and Rheims. Everywhere, within these limits, the strata rest upon chalk, which is visible at the surface beyond them, and forms a great belt around the tertiary deposits. The Paris basin comprises a quintuple series of formations, two of marine, and three of fresh-water origin, which alternate with each other in the following order:-

Upper fresh-water group. $\begin{aligned} & \text { Marls interstratified with layers of flints, one series of layers without shells, } \\ & \text { and the other replete with them. }\end{aligned}$
Upper marine group. $\left\{\begin{array}{r}\text { Beds of micaceous sand and sandstone, loosely aggregated, except at Fontaine- } \\ \text { bleau, and commonly white, but sometimes slightly red or yellow. }\end{array}\right.$
Second fresh-water group. $\left\{\begin{array}{r}\text { Calcaire silicieux, a siliceous limestone resembling a precipitate from the } \\ \text { waters of mineral springs; marls; gypsum, with abundant bones in the } \\ \text { hill of Montmartre, near Paris. }\end{array}\right.$
Second marine group. $\left\{\begin{array}{r}\text { Culcaire grossier, a coarse limestone, and green-sands, containing the greater } \\ \text { proportion of the shells of the Paris basin. }\end{array}\right.$
Third fresh-water group. $\left\{\begin{array}{r}\text { Plastic clay and sands; beds of lignite, and pebbly beds, of partial extent } \\ \text { and irregular occurrence. }\end{array}\right.$

It is clear, that to account for the phenomena of these formations, we must have recourse to the hypothesis that the sea once occupied that depression in the chalk which is now filled up with tertiary strata; that the ocean probably flowed into it from the north, as into a bay or gulf, while a river or rivers charged with argillaceous sediment, drifting down, also, fresh-water shells and terrestrial plants, entered it from the south ; and that this aspect of the district was repeatedly modified through a long series of ages, the relations of land and sea being changed, and extensive vicissitudes occurring, till the final elevation of the deposits to their present position transpired. But passing by the mutations of inanimate nature indicated in this district, we have a large assemblage of organic remains in the Paris basin unfolding new and interesting forms of life. The coarse limestone, calcaire grossier, is remarkable for containing shells belonging to an immense number of species, upwards of 400 distinct species having been collected from it in one locality; but it is also remarkable for its great abundance of species belonging to the genus Cerithium which occur, measuring from ten to fourteen inches in length. M. Deshayes states the number of species in the Paris basin at 137, almost all of them found in the calcaire grossier. The living specimens of this genus are met with in the Mediterranean, along the shores of Australia, and the west coast of Africa; and Sir C. Lyell makes the remark, that they inhabit the sea near the mouths of rivers, where the water is brackish, so that their abundance in the marine strata of the Paris basin is an interesting corroboration of the hypothesis advanced respecting it.

But what has conferred special celebrity upon the locality we are noticing, are the remains exhumed from the fresh-water formation of gypsum and gypseous marls, which 
have long been quarried in the hill of Montmartre. They consist of land and river shells, fragments of dicotyledonous wood, bones of fresh-water fish and crocodiles, with other land and river reptiles, and the skeletons of manmalia. Cuvier, who first developed these fossil quadrupeds, has an interesting passage respecting his course of discovery :-

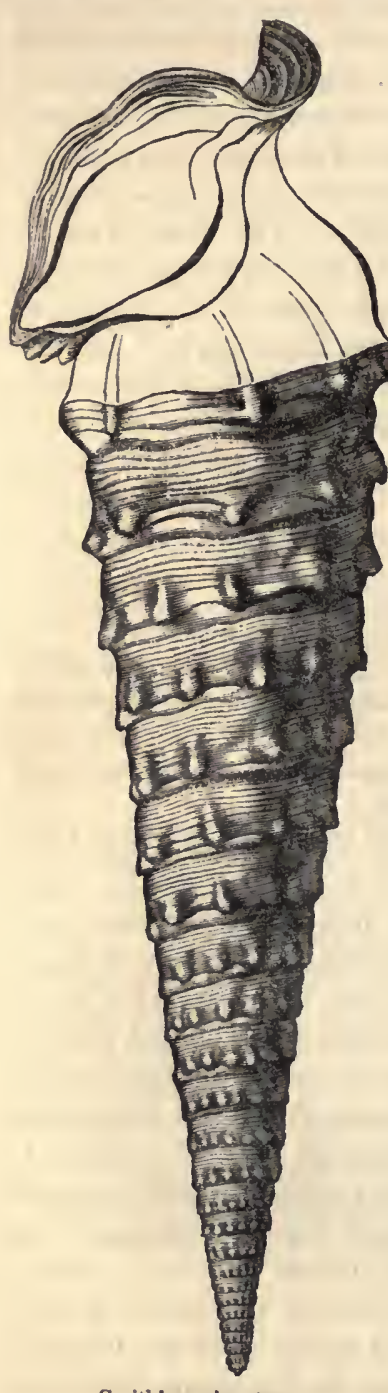

Cerithlum giganteum

"When," says he, "the sight of some bones of the bear and elephant, twelve years ago, inspired me with the idea of applying the general laws of comparative anatomy to the re-construction of fossil species; when I began to perceive that these species were not perfectly represented by those of our day which resembled them the most; I did not suspect that I was every day treading upon a soil filled with remains more extraordinary than any that $I$ had yet seen ; nor that I was destined to bring to light whole genera of animals unknown to the present world, and buried for incalculable ages at vast depths under the earth." He proceeds to describe his first acquaintance with the ossiferous gypsum quarries at Montmartre:- "I was in the situation of a man who had given to him the mutilated and incomplete fragments of a hundred skeletons, belonging to twenty sorts of animals, and it was required that each bone should be joined to that which it belonged to. It was a resurrection in miniature; but the immutable laws prescribed to living beings were my directors. At the voice of comparative anatomy each bone, each fragment, regained its place. I have no expression to describe the pleasure experienced in perceiving that, as I discovered one character, all the consequences, more or less foreseen, of this character, were successively developed. The feet were conformable to what the teeth had announced, and the teeth to the feet; the bones of the legs and the thighs, and every thing that ought to reunite these two extreme parts, were conformable to each other. In one word, each of the species sprung up from one of its own elements. Those who will have the patience to follow me in these memoirs may form some idea of the sensations which I experienced in thus restoring by degrees these ancient monuments of mighty revolutions." Among the remains found in the ossiferous gypsum are those of -

Pachydermata. - Palæotherium and anoplotherium of many species, all extinct, and all belonging to that division of the order which is now represented by only four living species, namely, by three tapirs and the daman of the Cape.

Carnivora. - Several species allied to the fox and gennet.

Rodentia.-Dormouse, two species; squirrel.

Marsupialia. - Opossum.

Birds. - Nine or ten species, all extinct, but referable to the following genera;-buzzard; owl; quail; woodcock; sea lark; curlew ; pelican.

Reptiles. - Crocodiles and tortoises of extinct species.

Fishes. - Seven extinct species of extinct genera.

The annexed view represents the restored outline of some of these ancient inhabitants 
of the globe. The Palcotherium magnum - the former term signifying an ancient wild beast, and the latter denoting the species to be of the largest class - resembled the tapirs in the form of the head and short proboscis or trunk, but approached to the rhinoceros in the cliaracter of the molar teeth. Unlike the tapirs also, the feet of the animal had only three toes instead of four. It was about the size of the horse, but much more clumsy; the head massive, the legs short and thick, and is supposed to have inhabited marshy ground, feeding on the roots and stems of juicy vegetables. "Probably," says Cuvier, "it was a timid animal, with large moveable ears like those of the deer, which could apprise it of the least danger. Doubtless its skin was covered with short hair ; and we only want

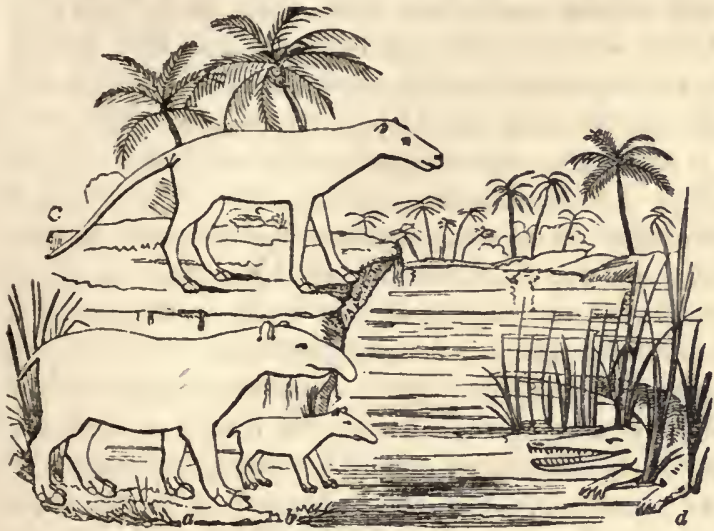

ANIMALS OP THE PARIS BASIN.

$a$, Palæotherium magnum ; $b$, Palæotherium minus ; $c$, Anoplotherium commune; $d$, Crocodile.

to know its colour in order to paint it as it formerly lived in the country where, after so many ages, its bones have been dug up." Eleven species have been determined, of which one, the Palcootherium minus, was considerably less than the preceding, had somewhat of the light and agile figure of the antelope, resembled it in size, and is supposed to have browsed on aromatic plants, or the buds of young trees. Cuvier remarks, that could this animal be re-animated as easily as its bones have been collected, we should behold a tapir smaller than the roebuck, with slender limbs, for such undoubtedly was its figure. Another species, Palcotherium minimum, was considerably less; not larger than the hare, with very small and slight feet. The Anoplotherium commune, or unarmed wild beast, having no defensive teeth, appears to have been about the height of the wild bonr; but much more elongated in form. In addition to the above, the remains of several genera of closely related animals occur, as the lophiodon, crested-tooth, of which twelve species have been determined ; and the anthracotherium, a genus approximating to the size and character of the hog, and so named from having been first discovered in a tertiary bed of anthracite or lignite. In England no entire skeleton of any of these remarkable animals has been found, so abundant in the tertiaries of France of a corresponding era, and no remains whatever had been discovered until a few years ago, when some portions of two species of anoplotlerium, and of four species of palæotherium, were met with at Seafield, and near Ryde, in the Isle of Wight.

Towards the centre of France, south of the confluence of the Allier and the Loire, some detached tracks of tertiary strata occur referable to the eocene era, all of freshwater origin, evidently the sites of a series of lakes, whose waters have been drained off and their beds elevated, in the course of those physical re̊volutions which the terrestrial superficies has undergone. The largest of these tracks occupies a considerable part of the valley plain of the Allier, and contains, besides vegetable remains, land and freshwater shells, with bones of the palæotherium, anoplotherium, and the other quadrupeds of the Paris basin. The most remarkable deposit is an indusial limestone, so called from the Latin indusium, a case, because essentially composed of the cases of a species of insect in its larva state, encrusted with travertin, and cemented into a rock. The reader has no doubt often observed, when by the side of a clear and shallow pool of water, little oblong masses moving along the bottom, resembling pieces of straw, wood, or even 
stones. These are the straw, or caddis-worms, employed by the fisherman as a bait, really the larvæ of a tribe of four-winged insects, of which nothing is seen in the water but the head and legs, by means of which they move, and drag along the case in which the rest of the body is enclosed, and into which, on any alarm, they wholly retire. "The construction of these habitations," says Kirby and Spence, "is very various. Some select four or five pieces of the leaves of grass, which they glue together into a shapely polygonal case; others employ portions of the stems of rushes, placed side by side so as to form an elegant fluted cylinder; some arrange round them pieces of leaves like a spirally-rolled riband; others enclose themselves in a mass of the leaves of any aquatic plants, united without regularity ; and others, agrain, form their abode of minute pieces of wood, either fresh or decayed. Other species construct houses which may be called alive, forming them of the shells of various aquatic snails, of different kinds and sizes, even while inhabited, all of which are immoveably fixed to it, and dragged about at its pleasure - a covering as singular as if a savage, instead of clothing himself with squirrels' skins, should sew together into a coat the animals themselves. Even those that are most careless about the nature of the materials of their houses, are solicitously attentive to one circumstance respecting them, namely, their specific gravity. Not having the power of swimming, but only of walking at the bottom of the water, by the aid of the six legs attached to the fore part of the body, which is usually protruded out of the case, and the insect itself being heavier than water, it is of great importance that its house should be of a specific gravity so nearly that of the element in which it resides as, while walking, neither to incommode it by its weight, nor by too great buoyancy; and it is as essential that it should be so equally ballasted in every part as to be readily moveable in every position. Under these circumstances our caddis-worms evince their proficiency in hydrostatics, selecting the most suitable substances, and, if the cell be too heavy, glueing to it a bit of leaf or straw ; or, if too light, a piece of shell or gravel." In a precisely similar way the cases which compose the indusial limestone we are noticing are composed. Around the larva dwelling the shells of a small spiral univalve belonging to the genus paludina, a tribe of fresh-water snails, are aggregated, and both the insects and molluses must have existed in countless swarms in the ancient lakes of central France, since ten or twelve cases may be packed within the space of a cubic inch, and some single strata of the indusial limestone are six feet in thickness, and may be traced over an area of several miles.

The district where these singular beds occur is the ancient Auvergne, so remarkable for its long dormant volcanoes, the principal of which range in a chain from north to south by the town of Clermont, partially shown in the annexed view. We have before

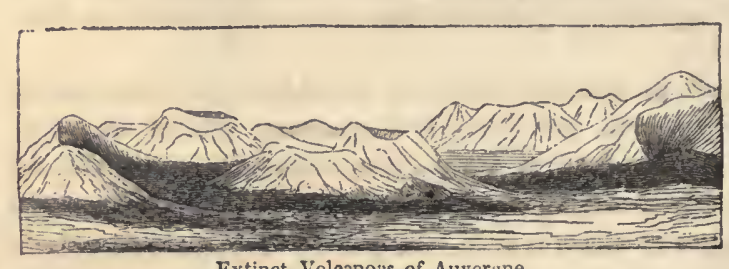

Extinct Volcanoes of Auvergne. remarked upon the abundant igneous products of this region, immense quantities of scoriæ and lava occupying the surface, and the fact has been referred to, that no notice of volcanic activity lias been preserved by history or tradition, but that evidence appears, in the cutting of deep channels by streams and rivers through the lava masses, of the vast remoteness of the era when the crateriform hills poured them forth. An examination of the fresh-water strata in the immediate vicinity of the voleanic rocks corroborates the conclusion. When the ancient lakes first began to deposit their sediment, it may be inferred that the igneous eruptions had not commenced. The absence of volcanic matter in the older tertiaries warrants this assumption, for, had it then been scattered over the surface of the sur- 
rounding country, it would inevitably have been transported into the lakes, and deposited at their bottom, with the other detritus of the adjoining land. But long before the depositions from the lakes were completed, and their waters ceased to distinguish the physical geography of Auvergne, the subterranean forces came into action, and masses of lava and tufa were erupted, whose material intermingles with some of the newer subdivisions of the lacustrine deposits. Sir C. Lyell remarks that, in the gravelly and sandy beds of Lake Superior, no pebbles of modern volcanic rocks can be included, since there are none of these at present in the district; but, if igneous action should break out in that country, and produce masses of lava and scorix, the deposition of gravel and sand might still continue as before, but, in addition, there would be an intermixture of the volcanic ejections carried down into the bed of the lake by the numerous rivers and torrents that pour into it. We may conclude, therefore, that though we know not the era when the craters of Auvergne ceased their eruptions, the period of their activity goes back to an interval ages before the present epoch, when central France was a region of lakes, the site of Paris an arm of the sea, and the palæotherium inhabited the contiguous lands. To alterations produced in the general level of the country by the long-continued play of the subterranean fires, we are probably to attribute the drainage of the lakes.

2. Miocene period, or Median Tertiary Strata. - The deposits included in this division are characterised by their fossil contents presenting a greater admixture of extant with extinct species than the eocene beds, and, by their overlying position when the latter are present, denoting their later accumulation. They are far more extensive, likewise, occupying an immense space of the area of Europe. In the ancient province of Touraine, what are provincially called the "Faluns," or marls of the Loire, are miocene tertiaries. They occur in the basin of that river, and consist of an extensive formation of marl beds, a series of marine strata, resting upon the upper fresh-water group of the Paris basin. Nearly four hundred species of shells found in this district have been compared with those common to the deposits around the capital, and scarcely more than twenty are identical, a sufficient evidence of the entire distinctness of the two tertiary groups. The Touraine marls contain terrestrial and river shells, as well as marine, with the remains of land quadrupeds, and vertebrated inhabitants of the ocean, intimating that here anciently, the waters of a river encountered the sea in an estuary, the one drifting down the fluviatile and land organisms, and the other washing up the oceanic forms, to be entombed in the strata deposited by the estuary, which passed away with the elevation of its bed. The bones of the mastodon, an extinct genus, the hippopotamus, rhinoceros, tapir, and horse of extinct species, intermingle with those of whales, and other cetaceous animals. The former evince considerable fracture, and rolling, as if by a long drift along a river course, and in connection with the latter are coated with marine polypi, from which it may be inferred that, for a lengthened interval, they were covered with a tranquil and stationary sea. A notice of the above fossil mammalia will be more appropriate on a subsequent page.

Tertiary deposits containing shells analogous to or identical with those of Touraine, - referable, therefore, to the same age, - are much more extensive in the south of France, in the basin of the Garonne, and in the country intervening between that river and the Pyrenees. They occur, also, in the neighbourhood of 'Turin, in the low country of Switzerland, along the course of the Rhine, and occupy a large part of the basins of Vienna and Styria, the plains of Bohemia and Hungary, with the plateaus of Volhynia, and Podolia.

Besides an immense number of shells, belonging to 1418 species, according to the catalogues of M. Deshayes, by far the greater portion of which are extinct, the strata of the miocene period present many vegetable remains, the silicified stems, fruits, and leaves of palms, often of great beauty, and very perfectly preserved. A shell, and 
a palm stem with the leaves, appear in the succeeding cut. Professor Kaup gives the following list of remains of quadrupeds found in miveene strata of sand at Epplesheim, to the south of Mayence, and now preserved in the museum at Darmstadt : -

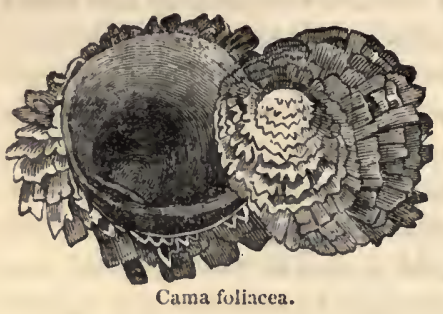

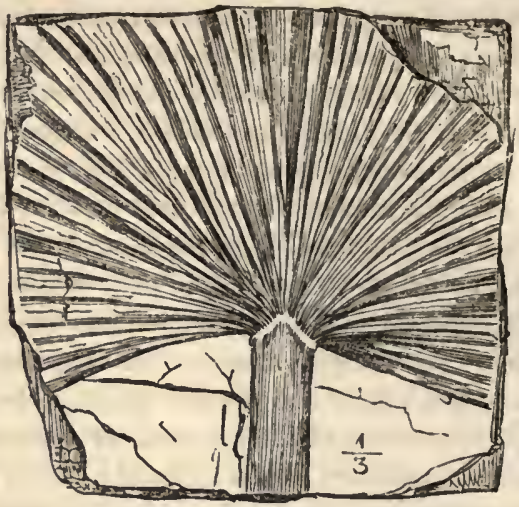

Palmacites Lamanonis.

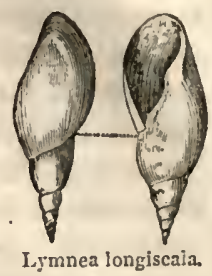

Ly̧mea longiscala.

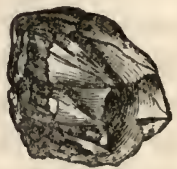

Bulanus crassus.

$$
\begin{aligned}
& \text { Dinotherium - - } \quad 2 \text { species - } \\
& \text { 'Tapirs - - - } \quad 2^{-} \quad- \\
& \text { Chalicotheriun - } \quad-2- \\
& \text { Rhinoceros - - - } \\
& \text { Tetracaulodon - } \quad-\quad \text { - } \quad \text { - _ - - } \quad \text { - Allied to the mastodon. } \\
& \text { Hippotherium - - - } 1 \text { - - - - Allied to the horse. } \\
& \text { Sus - - - - - } 3 \text { - - - - Hog. } \\
& \text { Felis - - - } \quad-4 \quad-\quad-\quad \text { - } \quad \text { - Large cats, some as large as the lion. } \\
& \text { Machairodus - - - } 1 \text { - _ - - Allied to the bear-Ursus cultridens. } \\
& \text { Gulo - } \quad \text { - } \quad-1 \quad-\quad \text { - } \quad \text { - } \quad \text { - Glutton. } \\
& \text { Agnotherium - - - } 1 \text { - - - Allied to the dog, as large as the lion. }
\end{aligned}
$$

The most remarkable of these quadrupeds is the Dinotherium, of which the annexed

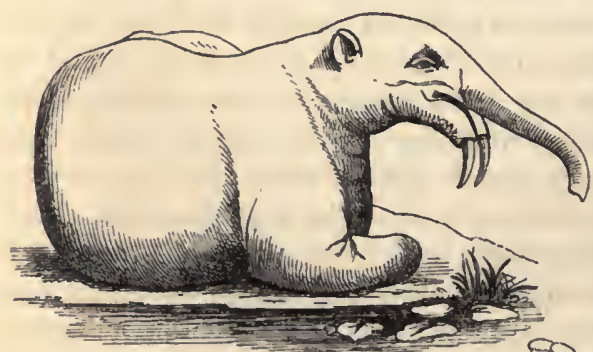
view is a restoration, perhaps the largest of all the terrestrial mammalia that ever inhabited the earth. The teetl, first discovered at Grenoble in France, and afterwards in Bavaria and Austria, led Cuvier to describe it as an extinct colossal tapir; but the jaws, skull, and other remains, found at Epplesheim, have enabled Professor Kaup to establish an entirely new genus, bearing an affinity to the mastodon and tapir, and apparently adapted to that lacustrine condition of the earth which scems to have been its marked feature during the deposition of the tertiary strata. The animal had a trunk like the elephant, with two large tusks at the anterior extremity of the lower jaw, which curved downwards like those of the walrus. Supposing it to have been an inhabitant of the land, Dr. Buckland remarks upon the meehanieal impossibility of a lower jaw nearly four fect long, loaded with heavy tusks at its extremity, being otherwise than excessively 
cumbrous and inconvenient; but such a structure would be no disadvantage to a creature destined to live principally in fresh-water lakes and rivers like the hippopotamus. It is conceived, therefore, to have been an aquatic, employing its tusks for the purpose of tearing up the roots of vegetables at the bottom of the water, which, as the teeth show, constituted its food. 'They may also have served for defence, and likewise to assist in dragging the huge body of the animal out of the water as occasion required, by being hooked on the bank-a purpose to which the walrus applies the same implements.

The remains of organic existence, found in the median and other tertiaries, conduct us from the colossal and imposing to the minute and microscopic; for beds occur entirely composed of the fossil relics of animalculites - those infinitesimal forms now present in our lakes, rivers, and streams, invisible to the unassisted sight, whose perfect organisation places them among the wonders of the creation. They were formerly supposed to be little more than mere particles of matter endowed with vitality; but Ehrenberg has discovered in them an apparatus of muscles, intestines, teetb, different kinds of glands, eyes, nerves, and organs of reproduction. Yet some of the smallest are not more than the 24,000th of an inch in diameter, the thickness of the skin of their stomachs not more than the $50,000,000$ th part of an incl, a single drop of water having been estimated sometimes actually to contain $500,000,000$ individuals. Not less astonishing is their power of multiplication, an individual of one species increasing in ten days to $1,000,000$, on the elerenth day to $4,000,000$, and on the twelfth day to $16,000,000$; while, of another kind, Ehrenberg states that one individual is capable of becoming, in four days, 170,000,000,000: To this distinguished naturalist we are indebted for the development of the fact, that ages ago our world was rife with these minute organisms, belonging to a great number of species, whose mineralised skeletons actually constitute nearly the whole mass of some tertiary soils and rocks several feet in thickness, and extending over areas of many acres. Such is the Polirschiefer, or polishing slate of Bilin in Bohemia, which occupies a surface of great extent, probably the site of an ancient lake, and forms slaty strata of fourteen feet in thickness, almost wholly composed of the silicified shields of animalcules. The size of a single one, forming the polishing slate, "amounts upon an average, and in the greatest part, to $\frac{1}{288}$ of a line, which equals $\frac{1}{6}$ of the thickness of a human hair, reckoning its average sizc at $\frac{1}{48}$ of a line. The globule of the human blood, considered at $\frac{1}{300}$, is not much smaller. The blood globules of a frog are twice as large as one of these animalcules. As the Polirschiefer of Bilin is slaty, but without cavities, these animalcules lie closely compressed. In round numbers, about 23 millions would make up a cubic line, and would in fact be contained in it. There are 1728 cubic lines in a cubic inch; and therefore a cubic inch would contain, on an average, about 41,000 millions of these animals. On weighing a cubic inch of this mass, $I$ found it to be about 220 grains. Of the 41,000 millions of animals, 187 millions go to a grain; or the siliceous shield of each animalcule weighs about $\frac{1}{187}$ millionth part of a grain." Such is the statement of Elhrenberg, which naturally suggests the reflection of the French philosopher, that if the Almighty is great in great things, he is still more so in those which are minute; and furnishes additional data for the well-known moral argument of the theologian, derived from a comparison of the telescope and the microscope:- "The one led me to see a system in every star; the other leads me to see a world in every atom. The one taught me that this mighty globe, with the whole burden of its people and of its countries, is but a grain of sand on the high field of immensity. The other teaches me, that every grain of sand may liarbour within it the tribes and the families of a busy population. The one told me of the insignificance of the world I tread upon. The other redeems it from all insignificance; for it tells me that in the leaves of every forest, and in the flowers of every garden, and in the waters of every rivulet, there are worlds teeming witl life, and 
numberless as are the glories of the firmament." The composition of the polishing slate of Bilin is far from being unique; for in several other European localities, and very largely in America, strata consisting mainly of fossil animalcules have been observed. This is the case with some siliceous marls belonging either to the ancient or to the median tertiary era, which have a total thickness of twenty feet, and spread out to a considerable distance, upon which the town of Richmond, in the state of Virginia, is built.

3. Pliocene period, or Modern Tertiary Strata. - Deposits are included in this division, in which the fossil shells are largely identical with living species; but this much more strongly applies to some members of the group than to others, and lence the subdivision of pliocene strata into older and newer. A great part of the sub-appenine range in Italy belongs to the older, whose shells were observed by Lamarck to differ from those of the Paris basin, and to have a considerable proportion agreeing with species now living in the Mediterranean or in the seas of tropical climates. The sub-apennine hills rise to the

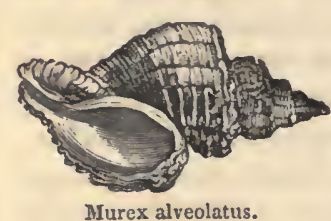
height of from one to two thousand feet, and extend along the main chain of the Apennines, which are composed of secondary rocks, both on the Mediterranean and Adriatic sides. They consist of marls, sands, clays, and calcareous tufa, generally of marine origin. By dredging the bed of the Adriatic, it has been ascertained that depositions are now forming there, whose lithological character closely resembles that of the sub-apennine tertiaries. There can be no doubt of the formation of the latter from the waste of the central mountains of the peninsula, when the sea flowed up to their base, depositing their detritus in its bed through a long course of ages, subterranean forces raising the strata at various intervals to their present elevation. Testaceous fishes and marine plants, now found imbedded in the hills, indicate their oceanic origin; but another class of deposits, containing fluviatile and lacustrine remains, intimate that, after tlee ocean had retired, rivers and lakes held possession of parts of the vacated territory for a time sufficient to produce the fresh-water beds, which alternate with marine, near the town of Sienna, the sea re-entering its ancient haunt, and again retreating, in the course of those various alterations of the level of the land from volcanic action, the monuments of which are so striking in the Campagna di Roma. With the sub-appenines, in point of age, some tertiaries in the Morea are classed, with patches in Spain, and the largely developed provincial "crag" of Norfolk, Suffolk, and Essex, which overlies the London clay in the latter county. The crag is a heterogeneous group of strata, in part lacustrine, but chiefly marine, presenting among its fossils mammalian relics, teeth and bones of a species of shark, an abundance of corals, and shells, among which, out of 111 species examined by M. Deshayes, 66 were found to be extinct and 45 living, the latter, with one exception, now the inhabitants of the German Ocean.

4. A much greater approximation to the present state of things appears in Sicily, where Sir C. Lyell found that, amid vast accumulations of marine shells, entering into the conposition of mountains of no inconsiderable altitude, nearly all were specifically identical with those now inhabiting the contiguous sea. These formations are therefore regarded as part of the most modern tertiaries, the Newer Pliocene, otherwise called Pleistocene, or most recent. The south of Etna is occupied by an extensive tract of limestone, marl, and sandstone, connected with volcanic rocks, called the Val di Noto, in which the hills rise to the height of from one to two thousand feet, composed of sedimentary strata and igneous products. These are associated in such a manner as to show, by the stratified rocks overlying lava, that during their deposition submarine igneous eruptions occurred at intervals in that now active focus of volcanic action. Probably the formation of the fresh-water strata, through which the beautiful Rhine passes in its course from Constance to Schaffhausen, 
belongs to the same era, the quarries of which abound with innumerable remains of land and river organisms, proclaiming the existence of an ancient lake in this locality in whose bed they were deposited. The volcanic masses of the Rhine, consisting of the Roderberg, the Eifel, and the "castled crag of Drachenfels," with its associates, forming the Siebengebirge, or group of Seven Mountains, and almost all the vine-clad hills from Bonn to Mayence, on each side of the river, which have been erupted through secondary rocks during the tertiary era, are enduring memorials of some of the great physical changes which have transpired in this attractive region since the general contour of the continent was formed.

\section{CHAPTER XI.}

DRIFT AND ERRATIC BLOCKS.

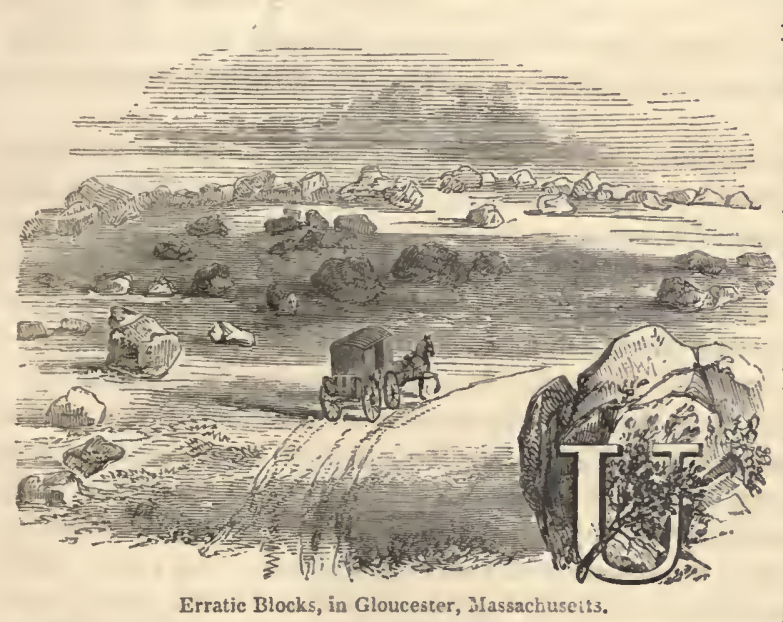

NDER a variety of designaticns, as the "drift," "boulder-clay," and "erratic-block group"-the diluvium of the early geologistsdiversified deposits are embraced, widely spread over the surface of many countries, but entirely wanting in others; occurring in valleys, on plains, on plateaux, and at high elevations; distributed over formations of all ages, either constituting the visible superficies, or thinly covered with the turf and cultivable soil. The Drift-a term which is sufficiently accurate for a general view of the subject - is composed of, First, a tenacious and compact clay, of blue or red colour, and containing boulders of various sizes distributed throughout its mass; Second, lying over this, a series of beds of gravel, sand, and plastic or brick-clay. The former appears generally a tumultuous accumulation, the result of some species of violent action; the latter usually bear the marks of a quiet deposition from water. In the tenacious or boulder-clay, there are occasionally found small beds of water-laid gravel and sand, as indications of times of quiet occurring throughout its deposition. Sometimes the sand and gravel have been consolidated into sandstone and conglomerate by the infiltration of iron or carbonate of lime. The drift belongs to the Newer Pliocene or Pleistocene era. It is distinguishable from the older tertiary deposits by its confused aggregation and general unstratified character; and from accumulations proceeding at the present period, by its occurring at every altitude attainable by mountains in situations where no agency as now acting could have placed it. In many instances its materials have been originated locally; that is, been derived from rocks within a few miles of the spot where they are now found, as appears from the accordance of their 
mineral character; but in eases equally numerous, they have been transperted fiom a considerable distance, and even from the mountains of remote lands, from which they are now separated by seas, which are thus proved not to have existed at the period of the passage. The preceding remarks must not be understood as applying to every case of drift, which is often a mere bed of gravel or pebbles. The surface of the drift frequently

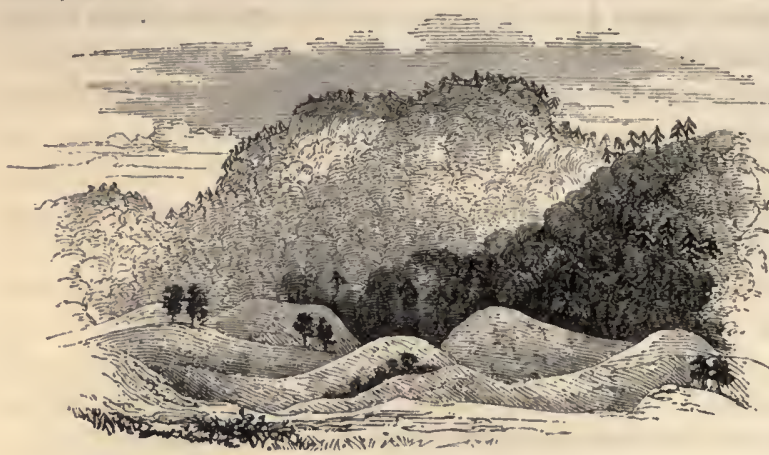

Monument Micultain. appears scooped out into deep basin-shaped depressions, and raised into corresponding elevations, the difference of level amounting to from one to two hundred fect, the external aspect presenting a series of tortuous conical heaps with intervening cavities, as if excavatcd by the hands of 'Titans. 'These roundtopped tumuli are very common in the northern part of the western continent, as in the

annexed view, taken from the neighbourliood of Monument Mountain, in the United States; and in some instances they have been mistaken for artificial mounds, the sepulchres of a departed race!

Along the eastern side of England from the Thames to the Treed, extensire and thick beds of gravel or loam are distributed, not only mantling lowland districts, but elevated table lands, and capping insulated hills, covering the chalk of the Yorkshire wolds and the crag of Forfolk and Suffolk. In the midland counties these accumulations are abundant. "From Houghton on the Hill," says Mr. Conybeare, "near Leicester, to Braunston, near Daventry, proceeding by Market Harborough and Lutterworth, the traveller passes over a continuous bed of gravel for about forty miles ;" and througlout the red marl, lias, and oolite districts similar masses occur, the pebbly constituents consisting of the wrecks of rocks of the most distant ages, and derived from remote localities. In the gravel deposits of South Derbyshire there are fragments of almost all the English formations from granite upwards to the chalk; and it would not be difficult, according to the authority just cited, to form almost a complete geological series of English rocks from many single gravel beds. In Earl Spencer's park at Althorp, Northamptonshire, in the gravel used for the roads, brought from an adjoining parish, there is a large proportion of chalk flints, though at such a distance from the present limits of the chalk; and on the oolite formation near Northampton, there are fields as thickly strewed over with fragments of pure white chalk, as the superficial soil is generally witl the substance of the subjacent rock. Sir Joseph Banks observed pebbles of porphyry in the gravel near the town of Dunstable, in Bedfordshire, porphyritic rocks occurring at no nearer point than the Charnwood Forest hills of Lcicestershire. In various places the transported matter is highly metalliferous, yielding lead, tin, platinum, and gold, with many of the more valuable of the precious stones, as the diamond, sapphire, ruby, and topaz. The native sites of these products have been broken down and reduced to grarel, and their mineral wealth removed with the débris. Lead is obtained from drift between lake Superior and the Mississippi ; tin occurs in the gravel of Mexico and Cornwall; and pebbles of lead are found under similar circumstances in the vale of Clywdd in a sufficient quantity to be worth working. 'The drift is also highly fossiliferous, containing abundant remains of quadrupeds, mostly of extinct species, but belonging to extant genera, which are now however confincd to regions far distant from the sites where the fossil species are met with. 
Among the organic remains of the drifted clays or gravels, the skeletons of colossal herbivorous mammalia occur in great profusion, and are the most remarkable, consisting of the elephant and mastodon - animals belonging to the proboscidian tribe, being furnished with a flexible trunk; the rhinoceros, the hippopotamus, the megatherium and megalonyx, the sivatherium, the horse, and the gigantic horned elk.

Elephant-Elephas primigenius of Blumenbach, Elephas fossile of Cuvier; and mammoth of the Russians. - There are two species of the living elephant; the Indian, inhabiting the warm countries of Asia, below $30^{\circ}$ of north latitude, but flourishing the most, near to the equator; and the African, ranging from Senegal to the Cape of Good.Hope. 'The fossil elephant is a distinct species, but agrees more nearly with its Asiatic than with its African congener, its remains being very widely distributed, and found in very ligh northern latitudes. Several species have been indicated from differences of form in the molar teeth; but the living animal will suffice for a general description of the extinct race, only supposing more colossal dimensions, a mane, and clothing of long hair. Teeth, tusks, and bones of prodigious size have been met with in different parts of our own island, in the county of Northampton, at Gloucester, at Trenton, near Stafford, and Harwich, in the valleys of the Thames and Medway, in Salisbury Plain, and in Holderness, never occurring in the regular strata, but in the overlying drift. They were noticed in the early periods of British history, and occupy a place in the old chronicles. By antiquaries they were once supposed to be the remains of elephants brought over by the armies of Rome-an idea which comparative anatomy refuted, by showing their discordance with the living species of the genus, and which was seen to be untenable by bones of hippopotami being found in connection with them - animals which never could have travelled in the train of the Roman legions. Fossil elephantine remains have been dug up in Ireland and Scotland, in Iceland and Sweden; and with probability Cuvier conjectured that the bones of supposed giants, mentioned by Pontoppidan as having been found in Norway, were relics of these ancient animals. They have been repeatedly exhumed in North and South America, from the plain of Quito, from Mexico, and the United States; and throughout Europe they are very generally distributed, appearing in abundance in some localities. Those particular spots, rich in elephantine remains, are at Seilberg, near Cronstadt, on the Necker; at the village of Theide, near Brunswick; in the valley of the Arno, near Florence; and at Bielbecks, near Market Weighton in Yorkshire, in a gravel bed of very limited extent, occupying a hollow of the new red sandstone. Blumenbach states, writing in 1803 , that within his knowledge more than two hundred elephants had been found in Germany. It is, however, particularly in the severer latitudes of Asiatic Russia that the fossil elephant is common; and there the ivory of the tusks is so far uninjured as to be used for ornamental purposes, and sought as an article of profit. To the natives of Siberia the animal is known as the mammoth, signifying an animal of the earth, from the presumption that it was unable to endure the light of day, and actually lived beneath the surface of the soil, like the existing mole. According to Pallas, from the river Don to the promontory of Tchutskoinoss - the most ensterly point of Asia - there is scarcely a stream the banks of which do not afford remains of the mammoth; and one remarkable case in which the animal was found preserved - both the entire skeleton and fleshy parts - and inspected by Mr. Adams, an academician of Petersburg, has attracted great attention.

In the year 1799 a Tungusian fisherman named Schumachoff, who generally went to hunt and fish at the peninsula of Tamut, after the fishing season of the Lena was over, had constructed for his wife some cabins on the banks of the lake Oncoul, and had embarked to seek along the coast for mammoth tusks. During this expedition he one day observed a strange shapeless mass projecting from a bank, the nature of which he did 
not understand, and which was at such an elevation as to be beyond his reach. The bank consisted of frozen earth covered with ice partially thawing in the summer season. Returning to the same spot the succeeding year, 1800, he observed the object rather more disengaged, but still could not determine what it was; but towards the end of the summer of 1801 , he could distinctly see that it was the frozen carcase of an enormous animal, the entire flank of which, and one of the tusks, had become exposed. The summer of 1802 was cold, and the animal remained in much the same state: but that of 1803 was warmer than usual; and, the ice melting largely, the carcase became entirely disengaged, and fell down from the crag on a sand-bank forming part of the coast of the Arctic Ocean. In March 1804, Schumachoff came to the mammoth, carried off the tusks, which he sold to a merchant for the value of fifty rubles. In 1806 - the seventh year from the discovery - Mr. Adams, travelling in that distant and desert region, on an embassy to China with Count Golovkin, examined the animal, which still remained on the sand-bank where it had fallen, but in a greatly mutilated condition. The wandering fishermen had taken away large quantities of the flesh to feed their dogs; the wild animals, white bears, wolves, wolverines, and foxes had also feasted on the carcase; but the skeleton remained quite entire, with the exception of one of the fore-legs. The entire spine, the pelvis, one shoulder blade, and three legs were still held together by their ligaments, and by some remains of the skin; the pupils of the eyes were still distinguishable; the brain remained within the skuil, but a good deal shrunk and dried; and one of the ears was in excellent preservation, still retaining a tuft of strong bristly hair. The animal was a male, and had a long mane on the neck, but was not one of the largest sizc. The skin was extremely thick and heavy, and as much was undestroyed as required the exertions of ten men to remove, which they accomplished with difficulty. Mr. Adams had the good fortune to re-purchase the tusks from the merchant to whom they had been sold, and finally transported the whole skeleton to Petersburg, where it now is, in the museum of the Academy, exhibiting the following dimensions, -9 feet 4 inches higl, 16 feet 4 inches long, exclusive of the tusks, which are 9 feet 6 inches, measuring along the curve. The hair of the mammoth appears to have consisted of strong bristles, a foot or more in length, with another kind, more flexible, and a third, a reddish brown wool, growing among the roots of the long hair. Cuvier remarks upon this fact, as an undeniable proof that the animal belonged to a race of elephants with which we are now unacquainted, by no means adapted to dwell in the torrid zone, but adapted to a temperature which would soon be fatal to the existing Asiatic and African races from its cold. We shall, subsequently, notice this consideration of climate, merely remarking, that the ligh latitudes now abounding with the "thick-ribbed ice" appear to have sustained an immense number of these colossal quadrupeds. There are islands in the Aretic Ocean, where the bones of the mammoth occur in prodigious abundance, which show no marks of detrition by a far transportation, and prove the exuberance of the race in the localities where their remains are found.

Mastodon. - The animals of this proboscidian tribe constitute a distinct genus, of which

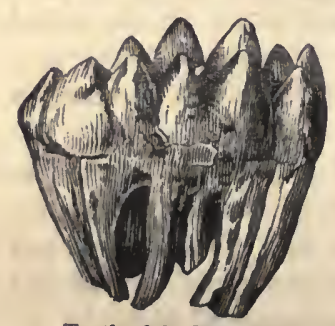
there are no living species, but they are more nearly allied to the elephant than to any other existing race. The name is a compound of two Greek words, signifying mamillary teeth, referring to the principal character of the mastodon as distinct from its elephantine contemporary. The teeth are covered with a thick and brilliant enamel, and with sharp points, which caused the animal for a long time to be regarded as camivorous. The remains of thirteen species have been discovered, six in Europe, four in India, two in South America, and one in North America. 
The latter is the Mastodon maximus of Cuvier, a colossal creature, armed with gigantic tusks. Parts of the skeleton found at Albany, on the Hudson river, were described by Dr. Mather in the year 1712, who deemed them the bones of giants, and regarded the diseovery as confirming the sacred record, "There were giants in the earth in those days." Afterwards similar remains were found abundantly along the course of the Ohio; and the "animal of the Ohio" became the name of the unknown creature, till Cuvier originated its scientific denomination. Myriads of its bones oceur along the river of the Osages, and indeed are commonly met with all over North America between the parallels of $33^{\circ}$ and $43^{\circ}$ north latitude, or in the country between Charlestown and Lake Erie, from near the coast of the Atlantic to the Rocky Mountains. Within these limits the principal locality is the Big Bone Lick in Kentueky, one of those marshy valleys containing brackish water, locally termed "licks," on account of the deer and other animals resorting to them. Here a vast number of bones of various extinct animals, accompanied with remains of plants, have been found imbedded in darkcoloured mud and gravel, the broken appearance of which seems to indicate a long drift and the violent action of water. It has been estimated that the bones of one hundred mastodons, two hundred elephants, twenty buffaloes, two oxen, and two deer, have been carried from this marsh. The native Indians have long been aequainted with the gigantic quadrupeds entombed in their territory. Aceording to an old tradition, they occupied it till, attacking the deer and buffalo created for their own use, the "Mighty One above" seized his thunder and killed them all, with the solitary exception of one of the largest males. He shook off the thunderbolts as they fell upon his massive head; but, being wounded in the side, fled at length to the great lakes, where he has continued to the present period. Mr. Darwin mentions a similar idea current among the native inhabitants of South America respecting the mastodon, to that which the northern Asiatics entertain of the mammoth. Sailing down the river Parana, he found two immense skeletons near each other, projecting in bold relief from a perpendicular cliff, and was told by the men in the canoe that they had often observed them, had wondered how they got there, and coneeived, as the most probable theory, that they were the remains of huge burrowing animals. The great mastodon probably haunted marshy places, feeding upon the roots of the vegetables common to such sites. It was probably lower in stature than the Indian elephant, but more elongated. The largest and most perfect specimen, hitherto discovered, was exlumed in the town of Newburg, New York, the length of the skeleton being 25 feet, and its height 12 feet, while the tusks were 10 feet long.

Rhinoceros. - The range of this animal is now comparatively limited and exclusively tropical, being chiefly located in Southern Africa, the Asiatic islands, and India beyond the Ganges, the one-horned rhinoceros occupying the two latter districts, and the twohorned the former. 'The remains of five extinet species are noticed by Cuvier, three of large size, and all two-horned; but altogether ten species are enumerated. They are very widely spread, and occur abundantly in the cold regions of the globe, towards the severe latitudes of the polar circle, as well as in all the temperate parts of Europe. In short, wherever the bones of the fossil elephant are found, they are generally in connection with those of the now associate animal, the rhinoceros. Germany has furnished them in great profusion; and Italy likewise in immense quantities, but of a different species; while the clay and gravel beds of our own country have been seareely less prolific. Their first discovery with us was in 1668, upon digging a well at a village near Canterbury. As in the case of the mammoth, we have an instance of an entire rhinoceros found buried in the sand on the banks of one of the tributaries of the Lena, in $64^{\circ}$ north latitude, the head and feet of which are now preserved at Petersburg. The discovery was made in December 1771, and is described by Pallas. The animal was 
clothed with long thick hair, as if adapted to sustain a Siberian temperature. The hair was particularly abundant on the limbs, while the existing species are totally deficient of it in these parts. Both with reference to the fossil elephants and rhinoceroses, no doubt can be entertained, that in the time of their living existence they were the inhabitants of the eountries where their bones are found imbedded; but it is extremely difficult to come to any satisfactory conclusion respecting the climate of the northern latitudes coincident with their era of life. On the one hand, the ice-entombed carcases, and their hair clothing, indicate a temperature as rigorous in those regions as at the present period. On the other hand, the adaptation of the extant genera to tropical warmth - the occurrence of fossil crocodilians, tortoises, shells, and vegetables in the far north, allied in structure to those that are now peculiar to hot climates - and the difficulty of large animals finding subsistence - these are considerations which seem to require the hypothesis of a milder contemporaneous physical climate. It is true that the larger herbivorous quadrupeds are not now located where a luxuriant vegetation exists, the elephants and rhinoceroses of South Africa inhabiting a barren country; but their present territory cannot be compared with the coasts of the Arctic Ocean, which are productive of little more than moss and lichens, and are annually covered for months with impenetrable ice and snow. Some have supposed, that as many modern animals migrate - for instance, the musk ox and reindeer of Melville Island - so the Siberian mammoths and rhinoceroses may have periodically departed southward at the approach of winter, to avoid the inclemency of the season and to obtain food; but such huge and unwieldy quadrupeds seem evidently unfitted for extensive locomotion, while to their conteniporary crocodiles and tortoises long migrations were next to impossible. But if we embrace the idea of a warmer climate prevailing in the northern regions when these animals tenanted them, it is necessary to suppose an immediate reduction of the temperature to have been coincident with their destruction - one of the physical events accompanying the great inundation which annihilated their races; for had not the mammoth been at once frozen and enclosed in its icy sepulchre, the carcase must have perished from the decomposing action of the elements. The subject is beset with difficulties, whatever view is taken of it, which defy intelligence to remove.

Hippopotamus. - The living river-horse, occasionally found not less than seventeen feet long, fifteen in circumference, and seven in height, was formerly known in the lower regions of the Nile, and now inhabits the Ethiopic and Abyssinian lakes, with many of the great African rivers, to which it appears to be exclusively confined. If not the Behemoth of sacred literature, it is eertain that no existing ereature answer's so well to the description :-

" Come behold Behemoth, whom I have created as well as thyself I

He feedeth on grass like the ox.

Bars of brass are his bones;

His joints like masses of iron :

He is the chief of the ways of God.

Under the shady trees he reposeth;

In the covert of the reeds and the ooze :

While they overshadow him, the shady trees tremble;

The willows of the river, while they surround him.

If the stream rage, he recoileth not;

He is unmoved, though Jordan rush against his mouth."

The fossil bones of hippopotami of several species, repeatedly met with in England, France, Germany, and especially Italy, show that these animals were formerly tenants of the northern hemisphere, and had a much wider geographical range than at present. In the years 1809 and 1810 Cuvier found in the museum of Florence, and in the 
Academy of the vale of the Arno, such an abundance of the remains of the hippopotamus that he had little difficulty in recomposing a skeleton. They had been obtained from the sand hills at the base of the mountains which nearly shut in that beautiful valley, where also the elephantine remains are so common, with relics of several other departed animal races. He removed a considerable quantity to Paris, purchased from the peasants ; and in 1816 an almost entire skeleton was found, now in the cabinet of the Grand Duke. The Hippopotamus major of Cuvier resembles the present African species so much that an attentive comparison is required to distinguish them.

Megatherium.-This leviathan of the vast plains of South America, which were once occupied by immense numbers of the race now entirely extinct, partakes of the general character of the existing diminutive sloths. It rivalled in size the largest rhinoceros, was armed with claws of enormous length and power, its whole frame possessing an extreme degree of solidity. With a head and neck like those of the sloth, its legs and feet exhibit the character of the armadillo and the ant-eater. Some specimens of the animal give the measurement of five feet across the haunches, and the thigh bone was nearly three times as thick as that of the elephant. The spinal marrow nnust have been a foot in diameter, and the tail, at the part nearest the body, twice as large, or six feet in circumference. The girth of the body was fourteen feet and a half, and the length eighteen feet. The teeth were admirably adapted for cutting vegetable substances, and the general structure and strength of the frame for tearing up the ground in search of roots, wrenching off the branches of trees, and uprooting their trunks, on which it principally fed. "Heavily constructed, and ponderously accoutred," says Dr. Buckland, in his eloquent description of the megatherium, "it could neither run, nor leap, nor climb, nor burrow under the ground; and all its movements must have been necessarily slow. But what need of rapid locomotion to an animal whose occupation, of digging roots for food, was almost stationary? And what need of speed, for flight from foes, to a creature whose giant carcase was encased in an impenetrable cuirass, and who, by a single pat of his paw, or lash of his tail, could in an instant lave demolished the couguar or the crocodile? Secure within the panoply of his strong armour, where was the enemy that would dare encounter this leviathan of the Pampas? or in what more powerful creature can we find the cause that has effected the extirpation of his race? His entire frame was an apparatus of colossal mechanism, adapted exactly to the work it had to do. Strong and ponderous in proportion as this work was heavy, and calculated to be the vehicle of life and enjoyment to a gigantic race of quadrupeds, which, though they have ceased to be counted among the living inhabitants of our planet, have in their fossil bones left behind them imperishable monuments of the consummate skill with which they were constructed." Since this passage was written, it has been shown by Professor Owen that the megatherium was not encased with a bony armour, like the armadillo; as is here assumed, and that the tessellated shell or case, found in one instance with some remains, which led to the surmise, belonged to another contemporaneous extinct animal, nearly as colossal, which he has called the Glyptodon, discovered near Monte Video, by Sir Woodbine Parish.

The megatherium is peculiar to America, and has been chiefly found in the southern part of the continent, though bones of the animal have been obtained from the island of Skiddaway on the coast of Georgia. The first skeleton, almost entire, was discovered in excavations made on the banks of the river Luxan, not far from Buenos Ayres, at the depth of a hundred feet. It was sent to Spain by the viceroy, the Marquis of Loreto, in the year 1785, and placed in the royal cabinet at Madrid. A second arrived from Lima in 1795, and a third was found in Paraguay, from which locality it obtained the name of "the animal of Paraguay." More recently Sir Woodbine Parish pro- 
cured some remains discovered in the river Solado, which runs through the Pampas of Buenos Ayres. After several unusually dry seasons the waters were lowered to an extraordinary degree, and a skeleton was exposed standing upright in the bed of the river. Two more were subsequently secured by the same party, and in 1839 the interesting discovery was made of a nearly perfect adult megatherium, on the banks of the Rio de la Matanza. There were all the vertebræ of the body, the ribs, the teeth, the head, the legs, and every part excepting the tail and one foot, with a perfect young one, so small that the epoch of destruction must have transpired almost immediately after its birth. Mr. Darwin met with remains extensively in various parts of the great Pampean formation; and particularly, in one spot on the coast, near to Bahia Blanca, he found imbedded in gravel and reddish mud, within the space of about two hundred yards square, many bones of the megatherium, and the allied animals, the megalonyx, mylodon and scelidotherium, all gigantic quadrupeds. The megalonyx had longer and sharper claws, was somewhat smaller, but of the size of the ox. It was first described by President Jefferson, from relics found in the nitre caverns of Virginia, who entirely mistook its character, supposing it a carnivorous animal, an error which prevailed till Cuvier established its analogies with the sloths. Of the mylodon, a closely related animal of little inferior size, a skeleton, nearly perfeet, obtained from the neighbourhood of Buenos Ayres, measures eleven feet in length, and nine feet nine inches for the eircumference of the trunk. The scelidotherium, a creature of the same order, was as large as the rhinoceros, and resembled in its structure the Cape ant-eater and the armadilloes. What is most remarkable in these ancient inhabitants of the American continent, and without a parallel, is the immense proportions of the extinct megatheridx, and the diminutive size of the existing related animals.

Sivatherium.-From the drift of the Sivalik hills, a sub-range of the Himalaya on the southern side, Dr. Falconer and Captain Cautley have brought to light this extinct animal, styled after the locality, which appears to form a link intermediate between the ruminants and the pachydermata. The living creature probably resembled an immense antelope or gnu, had two pairs of persistent horns eresting a short thick head, the structure of the snout indicating that it was furnished with a trunk. From the Sivalik hills the remains of all the preceding animals noticed have been obtained, with the exception of the megatheridæ, with many specimens of large ruminants allied to the giraffe, camel, elk, and deer. Collocated with them are the bones of a large species of monkey, differing from those found in England or France; and of two or more species of the horse, resembling the animal of the present day, but inferior in size, the largest not exceeding the zebra, and the smallest being about equal to a Shetland pony. The fossil horse is widely distributed through Europe and Asia. It is common also in North America, and was discovered by Mr. Darwin in several Pampean deposits in the South. Yet the native horse of the Western World vanished entirely from it, and remained utterly unknown there for ages after the epoch of Man commenced. "Certainly," remarks the naturalist just named, "it is a marvellous fact in the history of the mammalia, that in South America a native horse should have lived and disappeared, to be succeeded in after ages by the countless herds descended from the few introduced by the Spanish colonists." 'The history of the Old World, as far as it has been developed, presents nothing analogous to this.

Gigantic horned Elk. - Of all the fossil ruminants, the stag with enormous antlers is the most celebrated, belonging to a species now lost, which appears to have bcen more common in Ireland than any where else, though found in England, Germany, France, on the Rhine, in Silesia, and in Lombardy. A magnificent and almost entire skeleton has been obtained from a bed of marl in the Isle of Man, at the depth of eighteen feet, and is now preserved in the museum at Edinburgh. The dimensions are six feet high, nine 
feet long, and the whole height, to the tip of the right horn, rather more than nine feet and a half. The antlers dug out of a bed of marl near Drogheda, in Ireland, had the under-mentioned gigantic proportions: from the extreme tip of each horn, 10 feet 10 inches; from the tip of the right horn to its root, 5 feet 2 inches; and from the nearest tip of one horn to the nearest tip of the other, 3 feet $7 \frac{1}{2}$ inches.

The remains of deer of unknown species, but allied to the red deer, reindeer, fallow deer, and musk deer, are very numerous, often associated with those of the horse, bear, dog, wolf, beaver, and ox, generally discordant with the existing races. The oxen differ from the present varieties in being larger, with the horns relatively more massive, and separated from each other at the tips by a wider expansion.

We are no doubt justified in ranking as contemporaneous formations with the drift containing the remains of the animals noticed, the osseous breccias and the ossiferous deposits of ancient caverns, which have exercised so much the ingenuity of geologists. The former are fissures of certain rocks filled up, or partially so, with a conglomerate consisting of the bones of ruminants, pebbles, mud, and parts of shells, cemented into a hard rock by a reddish calcareous concretion, the principal of which at present known are those of Gibraltar, of Antibes, and Nice. The latter have been described in the chapter

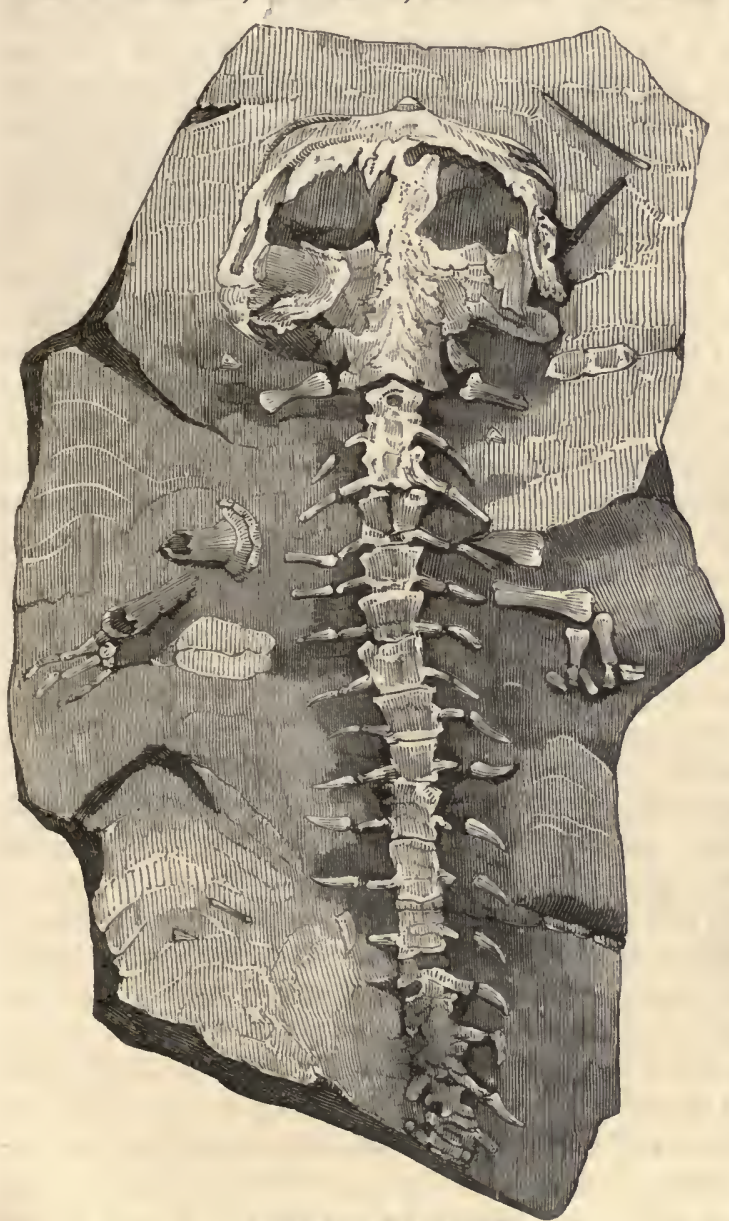

Remains of a Salamander. on Caverns as having a floor of drifted sand and gravel, with bones, consolidated into a hard pavement. The wrecks of the mighty herbivorous animals noticed are chiefly imbedded in the superficial drift, the bones of the caves consisting mainly of carnivora, extinct species of bears, wolves, weasels, foxes, hyænas, and tigers. The conclusions indicated by these ossiferous caves are, that some of them were the dens of wild beasts, perhaps for a long period before the epoch of their destruction, which here devoured their prey, leaving the bones to accumulate; or that here several animals fled to escape from the inundation which effected their extinction; or that their remains were subsequently drifted hither with the sand and mud during the prevalence of the catastrophe which submerged the country they had inlabited. Probably the ossiferous caverns are the result of all these causes.

No trace of Man, or of any of his works, has been discovered in any formation so antique as those deposits of drift which are the tombs of the quadrupeds we have noticed. At a former period, when the drift was regarded as the pro- 
duct of the Noachian deluge, and hence received the name of diluvium, the absence of liuman bones in connection with the abundant remains of the animal races was viewed with surprise; and, eager to detect the presence of the antediluvian man in accumulations which were believed to be the work of the Noachian flood, several inquirers fell into gross mistakes in interpreting some fossil relics. Thus Scheuchzer, a physician in the ycar 1726, described a schistus rock from Enningen on the Rhine as containing the impression of a man, and wrote a dissertation upon the object, entitled Homo Diluvii testis, remarking in another of his works, "that it is indubitable, and that it contains a moiety, or nearly so, of the skeleton of a man; that the substance even of the bones, nay more, of the flesh, and of parts still softer than the flesh, are there incorporated in the stone; in a word, that it is one of the rarest relies which we possess of that cursed race which was overwhelmed by the waters." This rare object was ultimately dispossessed of its interest by being shown to be the remains of a salamander. Some human skeletons, along with articles of human fabrication, have indeed been found imbedded in a rock in the island of Guadaloupe; but the rock is comparatively of very recent date-one of those coralline formations common in that archipelago, now in process of construction and augmentation from the fragments of corals detached by the wares. The skeletons were first discovered in 1805 by an officer of the colony, in which year the governor caused one to be extracted, in order to be transmitted to Paris, when the island surrendered to the English arms. Admiral Cochrane therefore forwarded it to England, where it is now deposited in the British Museum, conceived to be the skeleton of a Carib, its native bed being unquestionably of very modern date, composed of coralline débris. 'The remains of man have also been found in several ossiferous caverns, but under circumstances which show their recent accumulation. His bones are met with in turf-bogs and alluvial beds, in burying grounds and battle ficlds; but no well-authenticated case exists to establish a conviction that he had come into existence when the extinct species of elephants and rhinoceroses, of mastodons and megatheridx, in vast herds occupied the earth, roamed the jungles, and browsed the herbs; or when those great catastrophes took place which annihilated these tribes, aggregated the drift, the osseous breccias, and the ossiferous deposits of the caves. Cuvier remarks, that human bones preserve equally well with those of animals, when placed in the same circumstances; that there is no observable difference in this respect in Egypt betwcen the mummies of men and those of quadrupeds; that we do not find, in ancient fields of battle, that the skeletons of men are more wasted than those of horses, except in so far as they may be influenced by size; and that the bones of animals as small as rats have been perfectly well preserved as long as those of the gigantic mammoth. We may infer, therefore, from the absence of human remains in the drift, and from the presence there of animals of extinct species, and, in several instances, of extinct genera, that its aggregation belongs to an epoch anterior to the appearance of man; and various circumstances conspire to prove, that it is not only more ancient than the era of the Noachian flood, but that it has been accumulated at distinct periods, and by the action of different causes.

Scattered through the gravel, clay, and sand of the drift, and frequently occurring in an independent manner, there are masses of rock denominated erratic, from being found at a distance from the place of their origin. Owing to alluvial agency having removed the light accompanying débris from these blocks, they appear insulated upon the surface, sometimes forming rocking-stones, being so poised that a small force will make them oscillate. The size of some of these erratic blocks is enormous. That out of which the pedestal of the statue of Peter the Great at Petersburg was hewn, weighed fifteen hundred tons, and was an insulated drifted mass of granite, that lay on a marshy plain near the city, from whence it was removed on rollers and cannon-balls, while the ground of the 
marsh was hard frozen. The Needle mountain in Dauphiny, described as erratic, is a thousand paces in circumference at the top, and two thousand at the base. Near Neufchâtel a mass of grinite occurs, forty feet high, fifty long, and twenty broad, estimated to weigh 3,800,000 pounds. On the Jura limestone mountains, at an elevation of 2000 feet above the Lake of Geneva, there are granitic blocks, the solid contents of which anount to 1200 cubic feet upon the Salere, to 2250 on the Côteau de Boissy; and the block called Pierre à Martin is mentioned by Mr. Greenough as containing even 10,296 cubic feet. The rock in Horeb, from which, according to monkish tradition, the leader of Israel miraculously drew water, is a mass of sienitic granite, six yards square, containing 5823 cubic feet, lying insulated upon a plain near Mount Sinai. Professor Hitchcock remarks of the United States:- "In this country boulders occur of equal dimensions. Thus, on Cape Ann and its vicinity, I have not unfrequently met with blocks of sienite not less than thirty feet in diameter; and, in the south-east of Bradford county, I noticed one thirty feet square, which contains 27,000 cubic feet, and weighs not less than 2310 tons. In the west part of Sandwich, on Cape Cod, I have seen many boulders of granitic

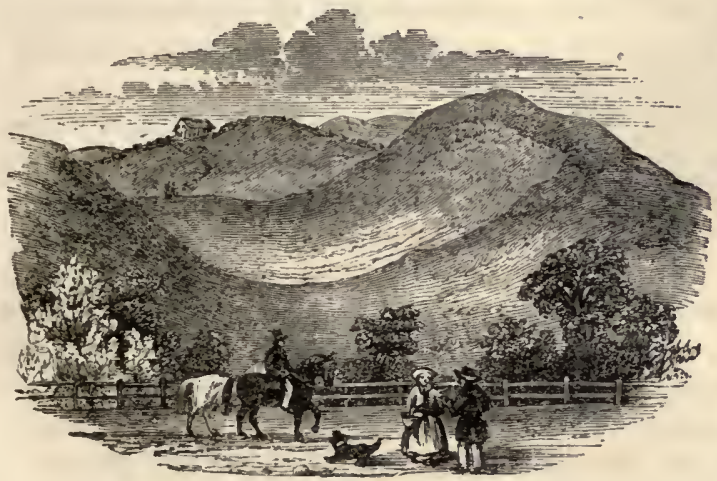

Drift near Cape Cod. gnciss, twenty feet in diameter, which contain 8000 cubic feet, and weigh as much as 680 tons. Two greywacke boulders of the same size lie a few rods distant from the meeting-house in Norton, in Dr. Bates's garden. A granite boulder of equal dimensions lies about half a milc south-east of the meetinghouse in Warwick; and one of similar dimensions lies on the western slope of Hosac mountain, at least 1000 feet above the valley over which it must have been transported. One of granite lies at the foot of the cliffs at Gay Head, on Martha's Vineyard, which is ninety feet in circumference, and weighs 1447 tons. At Fall river there is a boulder of conglomerate which originally weighed 5400 tons." But the in-

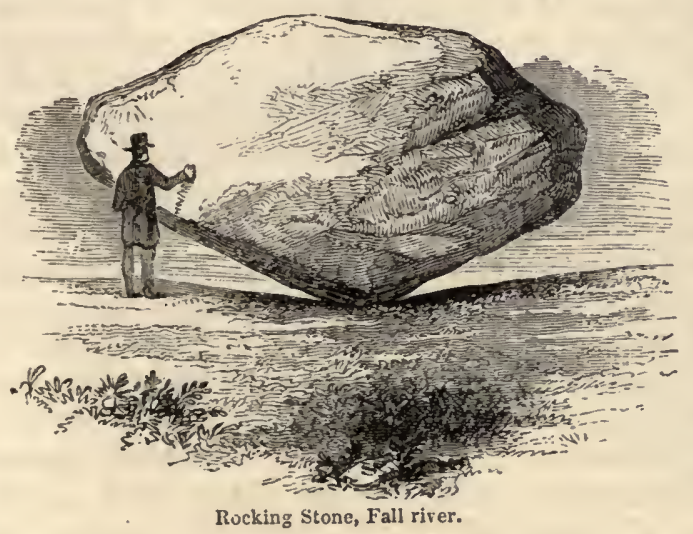

Rocking Stone, Fall river.

stances are endless that might be given of similar large and insulated masses, now lying at a remote distance from the parent rocks from which they have been abstracted. Wandering in the southern extremity of America, Mrr. Darwin speaks of his course being obstructed by well-rounded pebbles of porphyry, mingled with immense angular fragments of basalt and of primary rocks, nearly seventy miles apart from the nearest analogous mountain; while in Europe the vast plains of Prussia, Poland, and Russia, comprelıending a zone of country near 2000 miles long and from 400 to 800 miles wide, are strewed with loose detritus and crystalline blocks of colossal size, all of which have been transported from the mountain masses of Scandinavia. 
The facts ascertained respecting the dispersion of drift and of erratic blocks, comprise the following phenomena:

1. Evidence appears of the drift, using the term comprehensively, having been carried outward from the summits and axes of particular mountains, and spread over the plains and valleys in their neighbourhood. The best example of this occurs in the Alps, where boulders have been usually carried down the valleys, and exist in the greatest abundance opposite the lower openings of those valleys. Similar instances have been pointed out

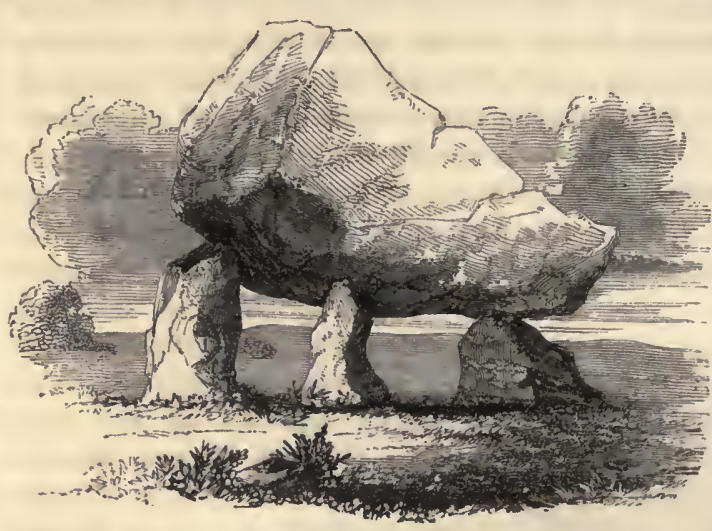

Block in Cornwall. among the mountains of Scotland and those of the north of England. The plain of Metidja, on the south of Algiers, is described by Rozet, as covered in its northern parts by boulders derived from a long chain of hills running along its northern border, while its southern region is strewed with blocks from the Atlas chain which stretclies along its southern limits.

2. Viewed upon a larger scale, the drift affords evidence of liaving been dispersed in a general southerly direction over all the northern hemisphere, often to a great distance, variously modified, however, by local obstructions. Dr. Buckland mentions pebbles and blocks of granite and sienite, of a very peculiar character, drifted from the Crifle mountain in Galloway, across the Solway Firth, and scattered over the plain of Carlisle; while pebbles, and large blocks of another kind of granite, have been drifted in still greater numbers from Ravenglass, on the west of Cumberland, over the plains of Lancashire, Cheshire, and Staffordshire, upon which they lie in masses of several tons weight. Professor Sedgwick states that the blocks of Shap granite, near Penrith, which cannot be confounded with other rocks in the north of England, are not only drifted over the lills near Appleby, but have been scattered over the plains of the new red sandstone, rolled over the great central chain of England, into the plains of Yorkshire, imbedded in the transported detritus of the Tees, and even carried to the eastern coast, a direction from the parent bed south by east. Another current of drift, found in the east of England, consisting of varieties of primitive and transition rocks which do not occur in this country, the origin of which must be referred to Norway, has pursued a course south by west. On the Continent the evidence of a southerly direction is very apparent, the blocks and pebbles that are strewed over the plains of North Germany, Poland, and Russia, having their parent rocks in Sweden, Lapland, and Finland. Across the Atlantic the boulders spread over the southern part of Nova Scotia have been derived from the ledges in the northern part of the province; and throughout Maine and Massachusetts the direction taken by the drift, as shown by a multitude of examples, is from north to south, varying a few points towards soutl-east or south-west. In many parts of the states south of the western lakes, the surface is bestrewed with an immense number of fragments of primitive rocks, significantly called "lost rocks," which may be traced to the north side of the lakes in Upper Canada. The great valley of the Missouri and Mississippi, from the Yellow-stone river almost to the Gulf of Mexico, is represented by $\mathrm{Mr}$. Catlin as covered with vast quantities of blocks of primary rocks, which have been drifted thither from the north-west. He describes five remarkable 
blocks of granite, from 15 to 25 feet in diameter, on the Côteau des Prairies, to the west of Lake Superior, several hundred miles from the nearest rock of that kind in place, which lies northward.

3. Mr. Darwin affirms, that in the intertropical parts of America, Africa, and Asia, erratic blocks have never been observed, nor at the Cape of Good Hope, nor in Australia. Though this complete limitation of them to the colder regions of the globe may be deemed an unsettled point, it is certain that such phenomena are far less frequent and extensive in equatorial countries. Beyond $41^{\circ}$ of south latitude in South America, the appearance of drift is common, upon the vast plains of Patagonia and Chili.

4. Rocks in situ, or in place, very frequently exhibit a marking with fine linear striæe or scratches, larger grooves, and even furrows, with a smooth and polished aspect of the surface, like that which the rapid passage of heavy masses over them would produce. Transatlantic facts of this description have been carefully collected by Professors Hitchcock and Rogers, from whom a few particulars may be introduced. In various parts of Massachusetts the striæ are very obvious and distinct, frequent on the hard sienitic rocks, though often these are merely smoothed, and sometimes polished. They are visible on the gneiss at the top of the Wachusett mountain, the lighest in the eastern part of the state, 2000 feet above the ocean. The precipitous hills and the lower grounds of the Connecticut river valley are covered with them, their direction being north and south, inclining a few points east of south, and west of north. Mount Everett, 2600 feet above the sea level, has been worn over its whole surface, and the strix are very visible in many places, though so long exposed naked to atmospheric and decomposing agencies. Mount Monadnoc, 3250 feet high, little else than a naked mass of mica-slate, of peculiar character, and almost destitute of stratification, has been from top to bottom scarified and scratched, the striæ running about north-west and soutl-east. Similar markings appear on the summits of all the Appallachian chain in Pennsylvania, which observe the same direction, and particularly, around the Wyoming valley the tops of the mountains are covered with parallel striæ. It is impossible, says one of the authorities named, to stand upon these lofty and precipitous ridges, and witness this phenomenon, without being struck with the great power and extent of the agency that has thus left its traces upon some of the most elevated spots in New England. The cut

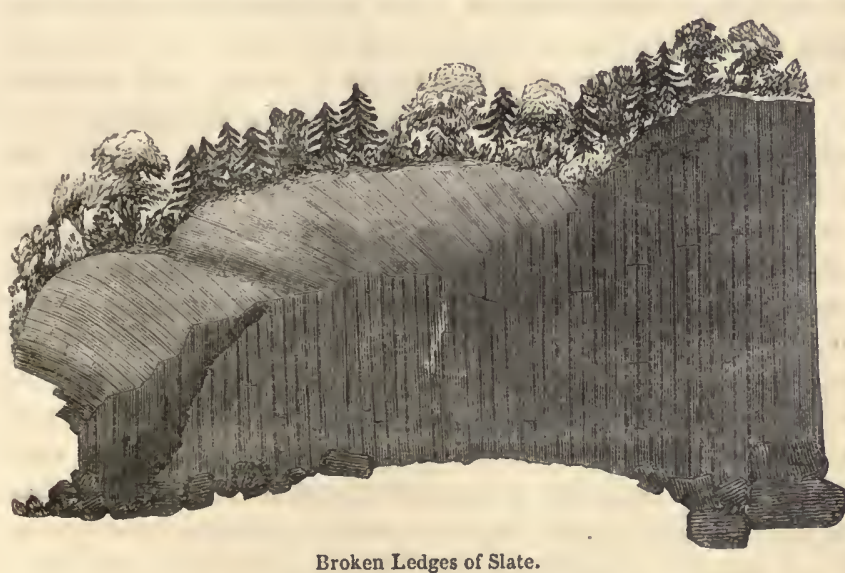

Broken Ledges of Slate. on the next page will convey an idea of the effect in quiestion, a surface of rock smoothed and striated. The same appearances have been noticed in North Wales, on Corstorphine hill near Edinburgh, and other parts of Scotland, in Sweden and North Russia. In some instances the tops of ledges of rock appear to have been crushed, and bent obliquely by the pressure upon them of an enormous load in movement.

In the annexed view, taken from a quarry of clay-slate in the state of Vermont, the perpendicular strata appear broken, and partially overturned, towards the summit.

The occurrence of drift, and of erratic blocks, constitutes one of the most complicated 
and difficult probleins of geology; nor has any theory yet been proposed offering a solution of it which is perfectly satisfactory. Some reasons have already been assigned for rejecting the long prevalent opinion that these phenomena resulted from the deluge

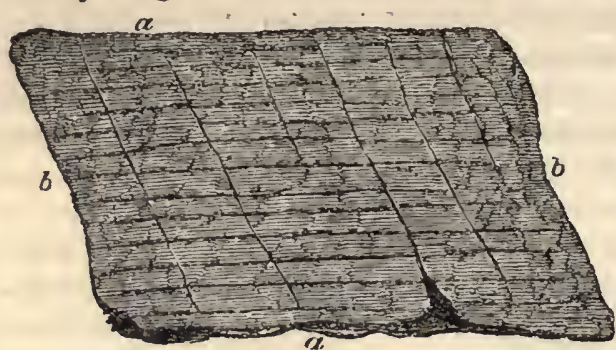

a a Divisions of the Strata. a $b$ Stria. of Noah; namely, the presence of animals of extinct species, and some of extinct genera in the drift, with the absence of the remains of human beings, and of all vestiges of the arts and operations of man: and, in addition, it may be remarked, that if that event was local, confined to a part of southwestern Asia, as we have previously argued, it is further inadmissible as an explanation of effects certainly common to the whole northern hemisphere, and to the southern extremities of America. But the single consideration that the vast masses of gravel and blocks strewed over such extensive areas, do not belong to one violent and transitory period, but have been aggregated at different epochs, by causes sometimes operating feebly and slowly, and at other times violently and powerfully - the evidence of which is irresistible to those who have studied the subject-is amply sufficient by itself to disprove the idea of these accumulations being the consequence of the transient flood recorded in the sacred history.

It would require a volume to detail and discuss the various views of scientific inquirers respecting the drift deposits. An outline of the principal theories will suffice. 1. The sudden elevation of chains of mountains, while yet wholly or in part beneath the water's, which, rushing away from the axis of elevation, would transport detritus and blocks in various directions, has been suggested to account for the phenomena. The Alps have been referred to, as supplying some evidence in favour of this view. They appear to lave been upheaved, if not from the occan, yet to a considerable height, after the deposition of the tertiary strata, for patches of these strata are found capping their summits, and lying in their mountain valleys, while the drift is scattered in all directions from the central axis, on the Jura range, and on the plains of Lombardy. It is very likely that this has been influential in the production of drift; but thougl the paroxysmal elevation of a mountain chain from submergence would cause the waters to rush away violently from it, sweeping along a vast amount of detritus, yet a sudden and transient rush is inadequate to the effect, which in many instances evinces the action of a disturbing cause for a considerable length of time. 2. Strong currents, waves, and tides of the ocean, bearing icebergs upon their bosom, while the districts covered with far-borne detritus and blocks were beneath the sea, have been proposed to explain their accumulation upon them, the districts being subsequently elevated. This theory has evidence in its favour, for in a former section we have noticed the transporting power of icebergs with reference to the solid materials of the land; and it admits not of a doulut, that if the floor of the north Atlantic were now laid bare, we should sec its surface covered with erratic blocks borne thither by the icy masses which annually melt away in its waters, derived from the shores of Greenland and Spitzbergen. But this can only be admitted as explaining part of the case, for it can scarcely apply to the drift containing the bones of the elephant and mastodon, with the other terrestrial quadrupeds. 3. It has been conceived that a powerful and extensive subaqueous elevation took place in the aretic regions, driving the northern ocean southward, over Great Britain, the north of Furope and America, bearing along masses of ice, blocks, and detritus; and that this vertical movement of the bed of the polar deep transpired repeatedly, producing 
successive waves of translation, which inraded the existing dry land, destroyed its organic life, and spread over it the various boulders and foreign débris that now appear upon its surface. This hypothesis receives support from several considerations. It is in harmony with the positive events of bygone ages, and of the present epoch, as in the formation of new islands, and the tremendous ware that shattered the coast of Portugal during the earthquake of Lisbon. It is mathematically demonstrable that sudden vertical elevations, each not exceeding 58 feet in the case of an ocean of 300 or 400 feet in depth, would produce waves having the power of hurling on enormous blocks, sand, and gravel to vast distances, and over considerable inequalities, while it accounts for the southerly direction of the drift, and the frequent presence of sea-shells in the same sepulchre with the remains of land quadrupeds. 4. Agassiz, struck with the transporting force of glaciers, which advance by their own gravitation upon inclined surfaces, and break off masses of rock from the sides of the valleys, bearing them away to a distant locality in the course of years, has endeavoured to show that the drift around the flanks of the Alps has been abstracted from the mountains, and carried thither by ancient and more extensive glaciers, which once covered, in fact, the whole of Switzerland. Starting from this point, he has attempted to establish a general glacial theory, according to which a sudden reduction took place in the temperature of the surface of the globe, at the close of the tertiary pcriod, whereby all organic life was destroyed, and the northern regions were converted into one vast mer de glace, which sent out enormous glaciers in a southerly direction. These he conceives to have smoothed, furrowed, and striated the rock-surfaces over which they passed, and to have carried along with them masses of entangled blocks and detritus, which were distributed far and wide, by the violent torrents occasioned through a raising of the temperature melting the glaciers. The development alone of this theory is due to Agassiz, for it was first suggested by $M$. Venetz, a Swiss engineer, and afterwards advocated by M. Charpentier. The reader will anticipate the chief difficulty in its way, the marked temporary alteration of the temperature, which could only have transpired through some transient derangement in the planetary relations of our globe. These are the chief theories proposed respecting the deposits under consideration, and probably a variety of agencies, to which each hypothesis contributes, has operated in their production.

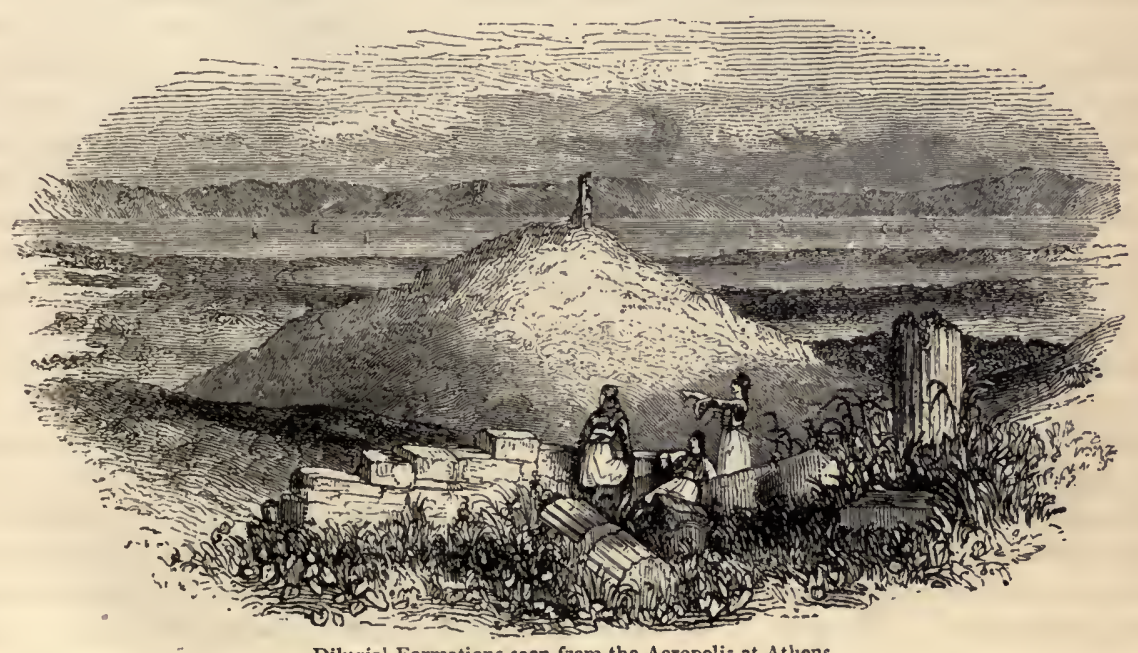

Dilurial Formations seen from the Acropolis at Athens. 


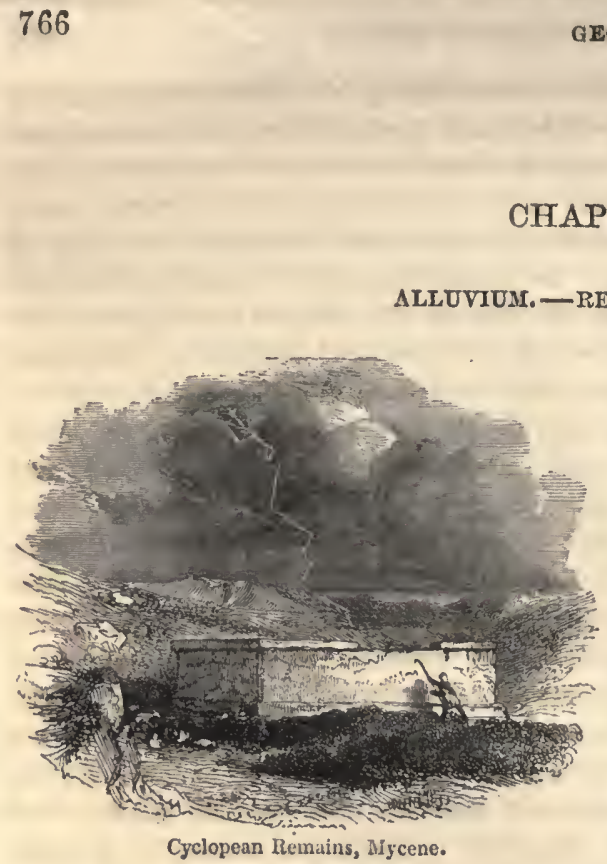

GEOLOGY.

CHAPTER XII.

ECENT FORMATIONS.

The term diluvium, applied to the great collections of gravel and detached blocks, from the idea that they originated with the historic deluge, is still retained in such a connection, because those accumulations indicate the extraordinary action of water, either in the form of strong oceanic currents, while the localities were in a state of submergence, or of waves of translation overspreading the land, produced by submarine disturbance, or torrents proceeding from rapidly-melting glaciers. On the other hand, the term alluvium is used to denote those formations of the modern and current epoch which result from the ordinary action of water; and, etymologically, it can only be properly employed in relation to aqueous products. But its more comprehensive application is sanctioned by usage,

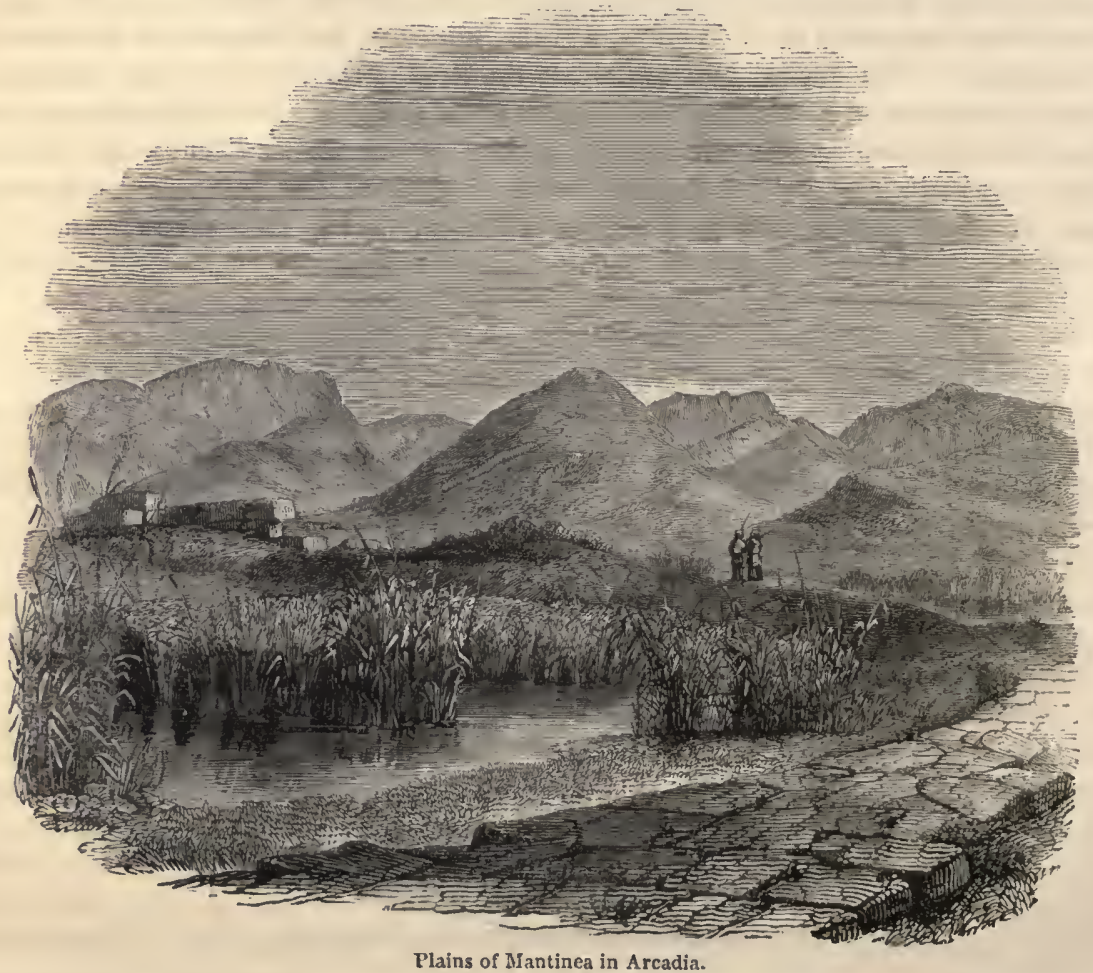

Plains of Mantinea in Arcadia. 
and may be granted in this place as a matter of convenience. It occurs therefore at the head of this chapter as a general title for those superficial formations which appear to lave transpired since our planet received its present configuration of land and sea, and Man became its occupant and master, which are now in course of production, whether due to aqueous, igneous, atmospheric, organic, or human agency, the effects of one or of several of these causes combined. In some of these recent aggregations we meet with the remains of man and contemporaneous animals and plants, with human utensils and ornaments also, characteristic of the ancient British age in our own country, the Etruscan in Italy, the Pelasgic in Greece, and the era of the Pliaraohs along the banks of the Nile. But we discover no bones that can be specifically identified as those of the great quadrupeds of the drift, which probably mostly perished in those physical changes under which it accumulated, subsequent to which the present state of things commenced, and man, with the existing animal races, was created. Some have supposed, indeed, that America had its droves of mastodons and megatheridæ browsing upon its savannahs down to a comparatively modern period; and good evidence supports the idea, that the gigantic horned elk continued to be an inhabitant of Europe coexistent with the human race. Such conclusions, supposing them to be established, are in harmony with the views already expressed respecting the first appearance of the present animal races as produced around several centres of creation, not contemporaneously, our sacred history dealing merely with one of those districts, the most recent, that in which the primitive man was placed. There is no difficulty in conceiving of the extinction of some tribes of animals as the consequence of current events; such as one of those unusually long droughts to which South America is occasionally subject, when, as during the gran seco, which lasted three successive years, it was calculated that from a million and a half to two millions of animals died exhausted by hunger, the borders of all the lakes and streamlets in the province of Buenos Ayres being long afterwards white with their bones. The case of the dodo, a large and remarkable bird existing in the Mauritius during the early voyages to the East, appears to be a well-authenticated instance of the death of a species in comparatively recent times; and now of several races dangerous to man, or useful to him for their skins, it may be predicated that the period of their extinction is not very distant.

Of formations contemporaneous with the present era, an arrangement may be adopted which classifies them according to the agency immediately operating in their production.

1. Organic - coral reefs; peat-mosses or bogs; subterranean forests.

Formations of coral-the agglutinated skeletons of departed races of coral zoophytes, composed of carbonate of lime secreted from the ocean, with broken shells, echinites, and sand, all cemented together into hard calcareous rock - are among the most interesting organic constructions of modern as of ancient times, now in course of augmentation from the living swarms. Detail here will be unnecessary, having previously referred at large to the islands which owe their origin to these marvellous creatures; and also to the submerged reefs advancing surely towards the surface of the waters, though at an excessively slow rate to us, which a slight submarine eruption might elevate into clains and clusters of islets, the agency undoubtedly which has uplifted some of the coralline formations of the Pacific thousands of feet above the deep. The island of Tahiti, composed almost cntirely of volcanic rocks, has on the summit of its highest mountain a coralline stratum; a similar bed occurs in the Isle of France, between two lava currents; and all voyagers of modern date-Beechey, Quoy and Gaimard, Stutchberry, and Darwin-concur in the opinion that the coral reefs and islands proceeding in the Pacific do not go down many hundred feet below the surface of the waves, but rest upon submarine volcanic ridges and rocks. The cut in the next page represents species of three common genera of corals : Caryophyllia, the external character of the polyparium or stony skeleton of 
a group of the zoophytes, being cylindrical, either simple or branched; Madrepora, character arborescent or frondescent; and Meandrina, character either turbinated or globular, the surface more or less confluent, but marked with sinuous ridges and valleys. We have had occasion repeatedly to notice corals in the more ancient strata of the globe, especially in the Silurian rocks, evidencing the existence, in far remote ages, of kindred forms of vitality to those that now inhabit the ocean; but their geographical range was then more extended than at present. Now it is tropical; but then it reached to high latitudes, intimating the higher temperature of the northern seas, and the general prevalence of a warm climate, in the earlier stages of our planet's history.

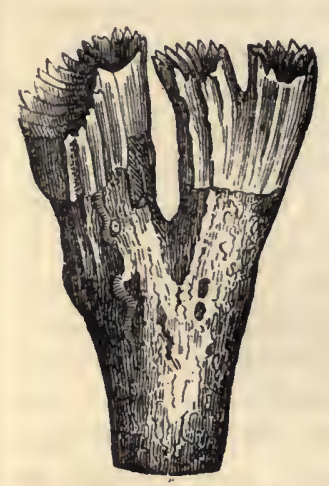

Caryophyllia fastigiata.

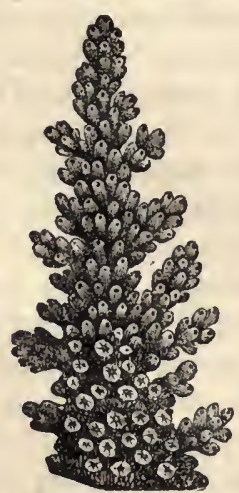

Madrepora muricata.

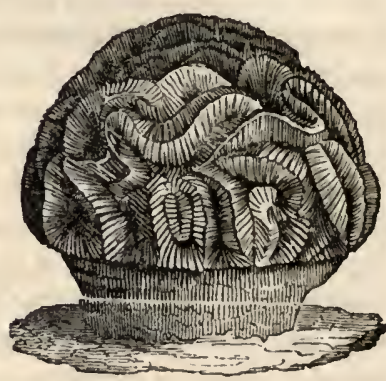

Meandrina labyrinthica.

Peat-mosses or bogs are organic products, consisting of vegetable matter spread over extensive areas in northern latitudes; for in tropical climates, except on high lands, the decomposition of vegetable substances proceeds so rapidly, that they are resolved into their ultimate elements before peat can be produced, or they are removed by insects. Accordingly, formations of this kind are limited chiefly to the colder regions of the globe. They are usually found in level situations, or on declivities abounding with springs, where varieties of plants are nourished, the decay of which produces a spongy vegetable mould, to which fresh contributions are annually made from the annual decay of new races. A morass, yielding and quivering to the tread, is the first product. This often becomes a firm deposit, as the accumulation increases, or when, from accidental causes, the mass is drained, or the supply of water ceases; but frequently the upper part is hard, yet trembling, arising from the slight consistency of the substratum. These are called moving-bogs in Ireland, and quaking-mosses in Scotland, and are frequently perilous to travellers and cattle. Gilpin describes the Solway moss - a flat area, about seven miles in circumference, on the confines of England and Scotland-as covered with grass and rushes, presenting a dry crust and fair appearance, but shaking under the least pressure, the bottom being unsound and semi-fluid. He states that the adventurous passenger, who sometimes in dry seasons passes this perilous waste to save a few miles, picks his cautious way over the rushy tussocks as they appear before him, for here the soil is firmest; but if his foot slip, or if he venture to desert this mark of security, it is possible he may never more be heard of. "At the battle of Solway, in the time of Henry VIII. (1542), when the Scotch army, commanded by Oliver Sinclair, was routed, an unfortunate troop of horse, driven by their fears, plunged into this morass, which instantly closed upon them. The tale was traditional, but it is now authenticated, a man and horse in complete armour having been found by peat-diggers in the place where it was always supposed the affair had happened. The skeleton of each was well preserved, and the different parts of the armour easily distinguished." 
The composition of peat, according to Sir H. Davy's analysis, consists of from sixty to ninety-nine parts of vegetable matter in the hundred, with a residuum of carths analogous to the subjacent strata, and oxide of iron. Three specimens obtained from different parts of the United States, upon analysis, yielded -

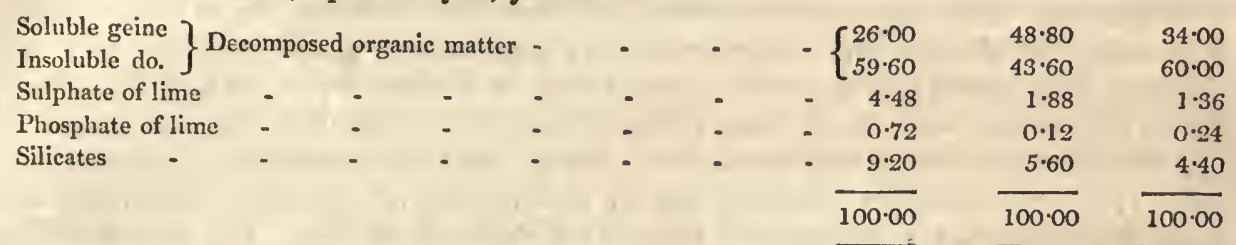

Lichens, moss, reeds, grasses, heaths, and shrubs of several kinds may commonly be traced in peat; but one particular species of moss, the Sphagnum palustre, enters into it most abundantly, the upper portion of which continues to flourish vigorously, while the lower portion decays and forms a soil. This contemporaneous vegetation and decay, proceeding for a series of years under favourable circumstances, rapidly forms a thick and extensive accumulation, embedding the trees that may have been growing in the locality, previously prostrated by the winds through the roots rotting. George, carl of Cromartie, relates a remarkable case of the rapid formation of a peat district, in about half a century, between the years 1651 and 1699, near Loch Broaw, on the west of Ross-shire. In 1651, when nineteen years of age, he noticed the spot as a plain covered with standing wood, the trees being entirely leafless and stripped of their bark, evidently a pine forest in one of its last stages. Some years afterwards, when again in the neighbourhood, he found the plain completely denuded of its trees, and presenting the aspect of a flat green ground spread over with moss. Upon inquiring what had become of the trees, and who had carried them away, he was informed that they had been all uprooted by the winds, and lay underneath the green moss; and before the year 1699, he states that the country people came there to dig turf and peat. It appears that the fallen timber, upon being soaked by the rains, first became coated with several species of fungi. An a'dhesive matter formed by the decay of these parasites, and washed off, rendered the soil with which it intermixed capable of retaining moisture, while the trunks of the trees prevented the rains from running off, thus giving rise to a marsh - a condition of the surface favouring the growth of mosses, which speedily took possession of it, and ultimately produced the peat.

Vast peat districts occur abundantly in France, the Netherlands, Germany, Russia, the Canadas, Scotland, and Ireland, and are found in insulated situations in Iceland, the Shetlands, and the Falkland Islands. Ireland has such extensive formations, owing to the prevailing humidity and low temperature of the climate. They occupy nearly onetentl of the surface; or, excluding some small mountainous and detached patches, the total quantity of bog has been estimated at 2,831,000 acres, of which 1,576,000 acres are flat red bog, capable of being reclaimed, and 1,255,000 are mountain bog, mostly convertible into pasture land. A single bog on the Shannon-that of Allen-extends fifty miles in length, by from two to three in breadth; while the great peat marsh of Montoire, near the mouth of the Loire, has a circumference of fifty leagues. The beds, in some instances, have been dug into to the depth of twenty feet, and even to twice that thickness; but such in general is their spongy nature, that a mass may usually be reduced by compression to about one-fifth of its original thickness. The rate at which a peat bog or moss advances varies so much under different circumstances, that we are precluded from forming any certain estimate of the antiquity of a formation, otherwise than from data supplied by imbedded animal and human relics. The coins of Gordian found in the peat at Groningen, and the Roman axes discovered in the peat of Yorkshire, throw light 
upon the date of those deposits. In the Irish bogs it is very common to find the remains of animals of which no living specimens now exist in that country, nor have existed within the era of authentic history-horns and skulls of the elk and deer-so that their age goes back to a remote period.

Peat-mosses have long been remarked for their antiseptic properties, or the power of preserving animal substances from putrefaction; some striking instances of which are on record. Two human bodies, buried in moist peat, in Derbyshire, in 1674, about a yard below the surface, were found, nearly twenty-nine years afterwards, with the colour of the skin fair and natural, and the flesh as soft as that of persons newly deceased. In June 1747, a Lincolnshire labourer, digging peat on one of the moors, discovered the body of a woman, a lady of the olden time, at the depth of six feet. The head and feet were nearly bent together, and the skin, nails, and hair were in a high state of preservation. She wore leathern shoes or sandals, each cut out of a single piece of tanned oxhide, folding about the foot and heel, and piked with iron. Chaucer mentions these piked shoes as part of the costume in his time; and in the reign of Edward IV. they had so increased in length, that all who wore them beyond a certain length were to be mulcted, or have them cut shorter, in passing in or out of the city gates of London. For several centuries, therefore, the body had certainly lain in the peat.

We have mentioned the semi-fluid condition of many peat-mosses below the surface crust, giving them a motion like that of a boat in water when subject to pressure. Hence, when overcharged in consequence of excessive rains, these swollen mosses have not unfrequently burst; and when occupying a high situation or declivity, their contents have been discharged with great violence upon a lower level, like a current of lava streaming from a volcano. Several cases of these inundations have occurred in recent times, the most remarkable of which transpired on the 16th of December 1772, in the instance of the Solway moss. This moss, already noticed as having entombed a troop of horse, occupied an area of 1300 acres, stretching along an eminence elevated from fifty to eighty feet above the fertile plain between it and the river Esk. The surface, of some consistency, vibrated to the tread, and might be easily pushed through with a pole, which descended without difficulty from fifteen to twenty feet, showing the soft and watery state of the subjacent matter. After greater rains than had happened for nearly two centuries, the surface of the moss rose, owing to the waters accumulated in it not being able to find a vent, and at length broke, discharging itself upon the liapless valley of the Esk, an entirely new phenomenon in the life of its simple shepherds. What added to their terror and danger was the hour of the eruption, about eleven on the night of the 15 th, when the inhabitants of the farms and hamlets of Eskdale had retired to their beds. Some were awakened by the strange noise of the eruption; others by the cry of alarm which speedily rang through the valley; and all awoke from their sleep to encounter in their cottages, or immediately upon opening their doors, a slowly rolling, resistless, and inexplicable deluge of black mud. The members of thirty-five families saved their lives with diffculty, but lost their agricultural produce, with many of their cattle; and when the morning shed light upon the scene, instead of fields, hedge-rows, and cottage gardens, there was a dark slimy torrent of half-consolidated peat earth, almost wholly covering some of the houses, and reaching up to the thatch of others. About four hundred acres were buried; and but for the crawling motion of the semi-solid mass, and the occurrence of an intervening "gap" or broad gully, which diverted into an opposite direction a large quantity of the invading matter, but few of the Eskdale shepherds would have survived the calamity. Though these sudden inroads are few and far between, yet the peat-mosses steadily advance in extent and thickness by natural increase, where the conditions essential to their growth remain unaltered; and in a series of years great changes are effected 
in particular localities. This is observable in the neighbourhood of lakes, upon which the peat gains, altering their limits - a process which may be remarked at the upper end of Derwentwater, and around all the small mountain lakes of Wales, the completion of which appears in many of the Irish bogs, which were once lakes, in process of time conquered by the regetable formations, and supplanted by spongy carbonaceous masses.

Subterranean forests, consisting of branches of trees, trunks uprooted or broken off, the roots retaining their natural position - a proof that the trees grew upon the spotare almost universally associated with peat wherever they occur, the soil of which now forms their sepulchre, though peat itself is found abundantly apart altogether from fallen timber. Upon the drainage of a low-lying forest being interrupted, the conversion of the site into a swamp would speedily follow, destroying the trees; and upon their prostration by the winds through the process of natural decay, or the hold of the trunks upon the soil being loosened, the entombment of the whole beneath peaty matter produced by vegetable accumulations would commence. In this way we may explain the occurrence of many of those subterranean forests that are found; though in several parts of northern Europe, and especially in Great Britain, man appears to have been the agent in felling these forests, whose prostration acting as a dam to the surface waters, prevented their running off, produced morasses, the growth and decay of aquatic plants finally covering up the timber. Unable to contend with the arms and discipline of the Roman legions in pitched battles or in the open country, the ancient Britons took shelter in their woods, from which they annoyed the invaders by frequent incursions. It was the policy therefore of the Roman generals to deprive the native inhabitants of these places of retreat by cutting down the forests, in which they not only employed their own troops, but the tribes previously subjugated. Hence Galgacus, in his speech before the battle with Agricola, warned his countrymen that these servile labours awaited them amid stripes and indignities should they be conquered. Such difficulties attended this plan of subjugation, with the building of his celebrated wall, and the construction of other works, that the emperor Severus is said to have lost fifty thousand men, though his army never met the Britons in the field. In particular the low level country of south Yorkshire and north Lincoln, is mentioned as an ancient primeval forest, which the invaders, taking advantage of a strong south-west wind, are supposed to have set on fire in various places, the pines readily burning, the unconsumed trees being felled with the axe. Hence in this locality, which continued for centuries an extensive swamp, a subterranean forest was discovered upon the draining of Hatfield Chase. From a valuable description of this operation and its singular revelations, drawn up by the Rev. A. de la Pryme, in the year 1701, the annexed particulars are gleaned :-

The famous levels of Hatfield Chase in Yorkshire constituted the largest chase of red deer in England belonging to Charles I., containing in all above 180,000 acres of land, about half of which was yearly drowned by vast quantities of water. This being sold to Sir Cornelius Vermuiden, a Dutchman, he at length effectually dischased, drained, and reduced it to arable and pasture ground, at the immense cost of $400,000 l$. The soil of most of this marsh land, all round to the highlands of Lincolnshire and Yorkshire, has yielded vast multitudes of the roots and trunks of trees of all sizes, and of most of the sorts that our island either formerly produced, or does at present-pines, oaks, birch, beech, yew, thorn, willow, and ash - the roots of the greater part standing in the soil in their natural position, and the trunks lying by their proper roots. The smaller trees are found in all directions, but the larger ones commonly north-east. A third part of the trees were of the fir tribe, some thirty yards long and more, and in such condition as to be sold for the masts and keels of ships. Oaks, black as ebony, abounded, capable of being used; and ash trees were the only ones found decayed. Many of the trees, espe- 
cially the pines, bore marks of having been burnt; others of having been chopped and split, with large wooden wedges in them, and broken axe-heads, somewhat like sacrificingaxes in shape, and this under circumstances and at depths excluding all supposition that the site lad been touched from the destruction of the forest to the time of the drainage. Near a large root in the parish of Hatficld several coins of the Roman emperors were discovered, much corroded and defaced by time; and, in other places, coins of Vespasian, axes, and links of chains. Hazel nuts, acorns, and bushels of fir-cones were commonly met with. Some of the trees were very large. An oak was four yards across at the base, three and a half yards in the middle, and two yards across the top, which was broken off, the length of the trunk remaining being forty yards. A fir tree also was thirty-six yards long, and estimated to be deficient at least fifteen yards, making in the whole fiftyone yards or 153 feet. Mr. Phillips states, that the highest tree of this kind that ever fell under his notice, was a spruce fir growing near Fountain's $\Lambda$ bbey, calculated to be 118 feet above the grass. Mr. Pryme concludes upon Hatfield Chase being the site of an ancient forest which the Romans destroyed, partly with the axe and partly by fire, during the prevalence of a south-west wind, the strongest that blows in our island; and hence the general direction of the larger trees being towards the north-east. De Luc remarks upon the aboriginal forests of Germany and Gaul, that they were largely destroyed by the Romans, in the same manner, and for a similar purpose, to those of Hercynia, Semana, and Ardennes, the remains of which would no doubt be found in equal abundance upon a removal of the soil that has since accumulated on their sites.

2. Marine - shore silt; sand drift; submarine deposits; submarine forests; raised beaches.

The agency of the ocean in producing geological changes, wearing away the land by its waves, tides, and currents, and conveying the detritus along with that received from the rivers to new sites; the consequent washing up of silt along the existing shores from which new land is occasionally gained, with the drifts of the sand inland encroaching upon fertile territories when exposed to the action of winds prevailing in that direction; these are incidents of physical geography which have been treated of in their place; and, though concealed from observation, it is plain that along the bed of the sea itself formations must be in constant process, which, if elevated into dry land, would be analogous to the systems of strata which compose our continents. Our knowledge of the bottom of the sea, with little exception, depends upon the simple apparatus of the mariner - a line and plummet-to ascertain the depth of water, with the addition of a little grease attached to the lower extremity of the plummet, to which particles adhere when it strikes against the bottom, from which we learn the quality of the soil. From a vast number of observations of the bed of the German Ocean, notoriously encumbered with sandbanks or great accumulations of débris, Mr. Stevenson calculated their aggregate superficial extent to amount to no less than 27,443 square miles, or an area equal to about $5 \frac{3}{4}$ of the whole surface of that sea. To render these dimensions more familiar by comparison, it may be stated that Great Britain contains about 77,224 square milcs, so that the area of the sand-banks bear a proportion equal to about one third of the whole terra firma of England and Scotland. Taking an average of the height of the banks, and the depth around each respectively, with their superficial area, the aggregate cubical contents of the whole of these immense collections of débris was estimated at no less than 2,241,248,568,110 of cubic yards, cqual to twenty-eight feet of the firm ground of Great Britain in perpendicular height or depth, supposing the surface to be a levcl plane.

Submarine forests, traceable at low water, have been observed at various points along the coasts of the United States and France, those of Great Britain with its adjacent 
islands, and the shores of the Baltic. They serve to show that the sea has gained upon the land, either by the actual depression of the latter, or, more probably, by the vegetation having grown upon low flat sites originally separated from the sea by mounds, througl which the waters have gradually worn themselves a passage, or suddenly broken in the hour of storm and tempest, and submerged the territory. Raised beaches present us with phenomena which call for more extended remark.

Beaches are composed of shingle or perfectly water-worn pebbles, and of sand, with shells, sea-weed, and other marine exuviæ cast up by the waves, and they mark the line of junction between the land and the sea. But such beaches, lying boyond the present reach of the ocean, and forming terraces more or less parallel with the existing coast-line, are observed in various parts of the world. On the margin of Lubec Bay, in the state of Maine, there is a deposit of recent shells with sand and shingle, elevated twenty-six feet above the present high-water mark; and at Plymouth and its neighbourhood, in our own island, the remains of an ancient beach are visible, of which the maximum elevation is

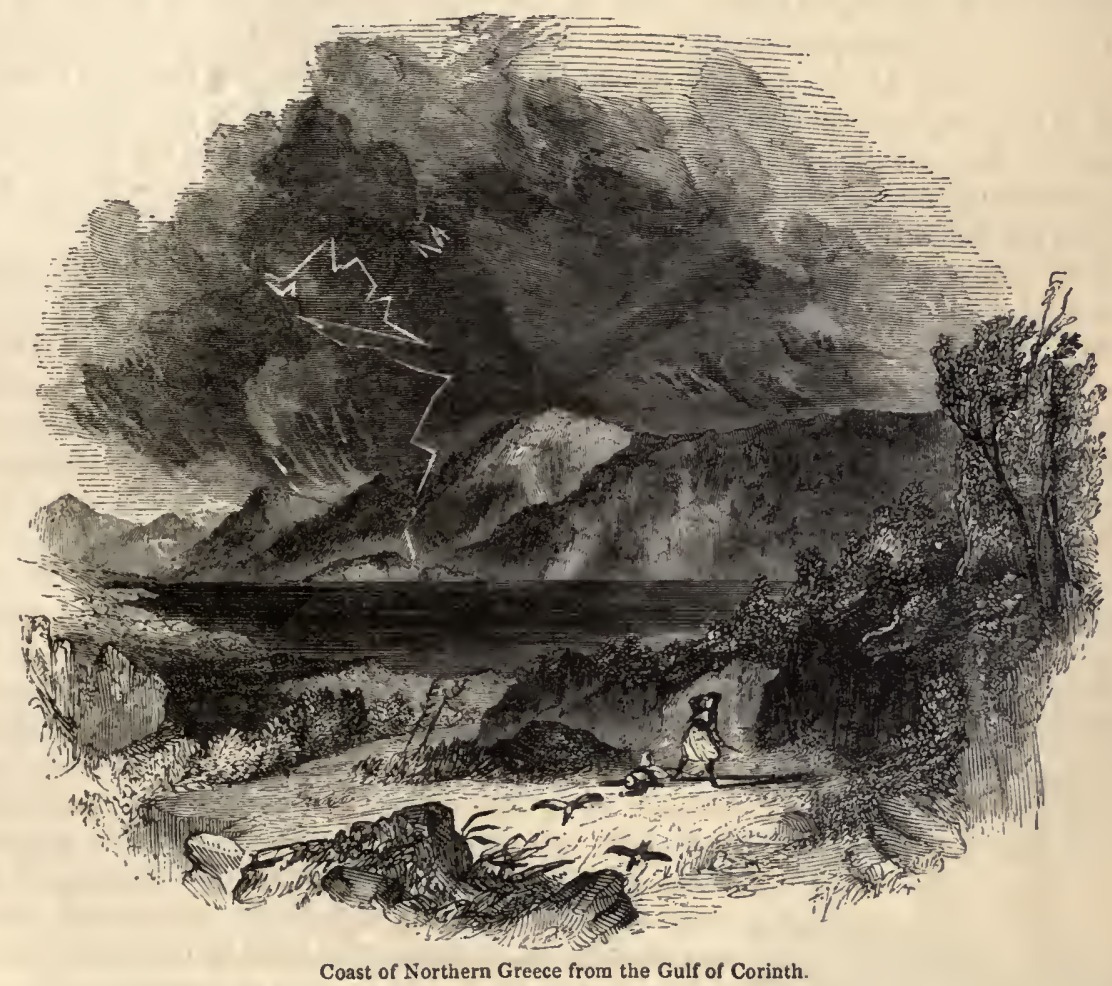

about thirty feet, sloping gradually to the sea. Similar raised terraces of marine detritus, containing shells of existing species, occur along the coasts of Yorkshire, Lancashire, and Durham, at various points of the Scottish shores, and on those of Norway, France, Portugal, Sicily, Italy, Greece, the Cape of Good Hope, and the West Indies, the elevation above the present high-water line varying from 20 to 200 feet. It cannot be doubted that these beaches mark the former reach of the waves; and in several instances the alteration in the level of the land appears to have taken place at different and distant intervals, for in the same locality a succession of terraces, rising one above another, may be observed. Six or seven lines of beach appear on the isle of Jura, one of the Hebrides, 
the lowest on a level with high water, the highest about forty feet above it. The rise of the land, in general gradual, and not by paroxysmal effort, is indicated by most of the phenomena in question, of which it is impossible certainly to assign the date, though referable to the modern epoch. It seems, indeed, a well-established fact, that various parts of our present continents are subject to vertical movements, either of elevation or depression, or of both alternately, and that in districts not known to have been visited in the historic period by the action of earthquakes, or of volcanic agency in any form.

The oscillation of Norway and Sweden, rising in the northern and sinking in the southern parts, some points of the coast showing no vertical movement, was first affirmed by Celsius upwards of two centuries ago, and has been investigated with great ability by Von Bûch and Sir C. Lyell, the latter a sceptic as to the fact, till a personal examination of the country satisfied him of its correctness. From Grottenburg to Tornea, and from thence to the North Cape - a distance of more than a thousand geographical miles - the country appears to have been raised up from 100 to 200 feet above the level of the sea. The breadth of the region thus elevated is not known, and the rate at which the land rises varies in different places. In some sites it has been estimated at four feet in a century. The evidence that such a movement is taking place, is derived from the measurement of the height of landmarks above the sea at various intervals, and from immense deposits of marine silt, containing the shells of mollusca now living in the Baltic, being found at the elevations named, with the barnacles attached to the rocks. One of these beaches, six miles from the present shore, and in some parts four or five hundred feet above the sea, may be traced for a great distance along the Trondheim fiord; while a large stone near Trelleborg, marked by Linnæus in 1749, is now a hundred feet nearer the shore than in his time. Points of elevation occur distinctly on the coast of Sweden between Calmar and Gefle, while the coast of Schonen is gradually subsiding. No traces of volcanic action are known to exist in these countries, nor have they ever been the seat of earthquakes during the historio era, nor would such paroxysmal events explain the phenomena of gradual elevation and subsidence. The oscillation of the coast of the bay of Baix, near Naples, as attested by the pillars of the temple of Jupiter Serapis, of which a view is here given, sufficiently illustrated by a preceding description, is more explicable in that region by the earthquakes of which it has been the focus, and by the gradual

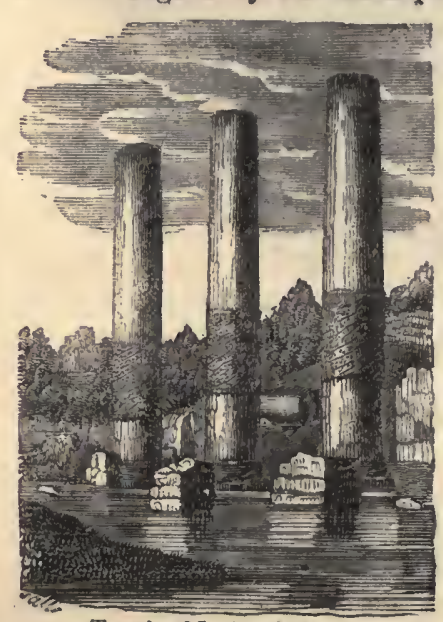

Temple of Jupiter Serapis. shrinking and expansion of the strata in periods of volcanic repose and activity. Some accurate experiments made by Colonel Totten on the expansion of rocks by heat, show that a block of granite five feet long, by a change of temperature of $96^{\circ}$ Fahrenheit, expanded 0.027792 inch, crystalline marble 0.03264 inch, and sandstone 0.054914 inch. The temple of Serapis, built of course originally above high-water mark, sunk down a considerable depth below the level of the sea, was again re-elevated by the terrible events of September 1538, and is now gradually subsiding - the latter, probably, an effect due to the shrinking of the strata by the radiation of heat. Mr. Smith, in March, 1819, found its floor elevated about six inches above the level of the sea; but, in May, 1845, he found it covered to the depth of 18 inches at low water, and $28 \frac{1}{2}$ at high tide, the sea being perfectly calm at the time. The custode of the building informed him that this change was progressive, amounting to about $1 \frac{1}{4}$ English inch per annum; and that in thirty years he knew of a difference of at least 3 feet 6 inches in the height of the 
sea upon the piers of the bridge of Caligula, giving the same amount of subsidence yearly.

Vertical movements, of elevation and subsidence, appear to be physical events of modern date in the history of the Isle of Wight. In the reign of James I., during an attempt to drain Brading Haven, a well was discovered near the middle, cased with stone, proving that the site had once been dry land, upon which man had planted his foot, and probably reared his habitation. This may be explained without recurring to an actual subsidence, by supposing the Haven to have been a low-lying level, protected from the ocean by a mound, through which the sea broke and took possession of the soil. But Sir Richard Worsley, in his history of the island, mentions the following particulars:“Looking eastward from the elevated spot (St. Catherine's Hill) where the tower stands, two other hills are to be seen; the nearest, which is about three miles distant, is called Week Down, over which, about a mile and a half farther, appears that called Shanklin Down, or Dunnose Head. Concerning these downs a singular circumstance is remarked by the inhabitants of Chale, of which the evidence seems unobjectionable. Shanklin Down may now be guessed to stand about a hundred feet higher than the summit of Week Down; yet old persons, still living, affirm that within their remembrance Shanklin Down was hardly visible from St. Catherine's : they declare, moreover, that in their youth old men have told them they knew the time when Shanklin Down could not be seen from Chale Down, but only from the top of the beacon, the old post of which stands near the chapel. This testimony, if allowed, argues either a sinking of the intermediate down, or a rising of one of the other hills." However dubious we may be as to the foundation of this record, the evidence of such physical changes having occurred in recent times appears in every quarter of the globe, the raised beaches proving the instability of the level of land and sea, and the change of level to have been occasioned by a real displacement of land. On the banks of the Frith of Forth, near Borrowstowness, there is a bed of marine shells several feet in thickness, extending about three miles in length, now situated many feet above the level of the waters of the Forth. Elevated beaches appear along the west coast of South America, showing successive uprisings of the land - the effect of the earthquakes that have so frequently acted upon that part of the continent. By the catastrophe of Feb. 20, 1835, the land round the bay of Conception was permanently upraised two or three feet; and the elevation was much greater in other places; for Captain Fitzroy, about thirty miles distant, found beds of putrid muscle-shells still adhering to the rocks, ten feet above high-water mark, where the inhabitants had formerly dived at low-water spring tides for these shells.

3. Lacustrine - shore silt ; marls, calcareous, siliceous, and aluminous.

Lakes, receiving a considerable river or many small runlets, act as settling pools to the dissolved or suspended matters conveyed into them from the adjacent districts, the waters running off through their natural outlets in a filtered condition. The débris brought into them consists ordinarily of fine particles; but heavier sediments are introduced when the streams are in flood, and the transported material will be deposited in the bed of a lake at a greater or less distance from the point of entrance, according to the force with which the waters from the land rush into it. Where a lake has a considerable expansion, so that the winds act powerfully upon it, producing strong waves, a portion of the foreign matter is washed up upon the shores, forming beaches of silt and shingle, as in the bays of Lake Superior. The immense reservoirs of fresh water in North America present several instances of the phenomenon of raised beaches, appearing one above another, like the seats of an amphitheatre, at some distance from their present shores. Seven of these have been remarked near Cabot's Head on lake Huron; the highest overgrown with spruce firs, the next covered with trees and bushes of a smaller kind, the third with shrubs and 
flowers, the fourth with moss and lichens, and the rest being destitute of vegetation. It is not the subsidence of the lake, but the elevation of the land, that is here indicated; for, owing to the constant additions of detritus made to their bed, the natural tendeney of the water of lakes is towards a rise of level. This effect transpires when no counteracting agencies operate, and appears in several of the Caledonian lochs. Mr. Stevenson mentions, in the ease of Loch Lomond, the site of a house in the village of Luss as being permanently under the summer water mark, while the gable of another house became in danger of being washed down by the rise of the waters of the loch.

Lacustrine deposits proceed most rapidly at the points of junction with the in-flowing rivers and streams, of which we have an example in the extensive alluvial formation produced sinee the time of the Romans, in the lake of Geneva, where the Rlione pours its turbid and diseoloured waters into it, bringing down a large amount of Alpine débris. At such points the disintegrated material is laid down, and the layer is gradually thickened and advanced forward by fresh aceumulations, aquatic plants growing upon it forming peat by their annual decay, the shells of fresh-water molluses and other organic exuviæ becoming imbedded in the strata. It is casy to coneeive of the entire obliteration of a lake by this process of shoaling up, first being converted into a swamp, and afterwards aequiring consistency so as to become a traet of firm cultivable soil, lying along the banks of the river from which it has sprung, or otherwise deserted by it, the parent river having been diverted into another direetion. Such, in fact, has been the origin of many of the richest districts which are arable and pasture lands, of which we have the evidenee in the presence of laeustrine shells, and the character of the beds in which they are deposited. Marls of various composition-calcareous, siliceous, and aluminous - are the most abundant and important formations of lacustrine origin. Calcareous marl is produced partiy by the deposition of the carbonate of lime from solution in the water, supplied to the lakes by means of springs, and partly by the decay of the shells of molluscous animals inhabiting their waters, an abundance of which, either entire or but little broken, likewise enter into it, with traces of clay and earthy matter. On this account it is fre. quently called shell-marl, and is of a soft friable nature; but, when solidified, it receives the title of rock-marl. 'This product, so valuable in agriculture, may readily be detected when no trace of organic structure presents itself, by testing it with an acid-the oil of vitriol, aquafortis, muriatic acid, or strong vinegar-when, if the substance effervesce upon the acid being applied, it is proved to be genuine calcareous marl. In the United States, beds occur, several feet thick, and covering many hundred acres; and, for the agriculturist of a future age, there appears from the following statement to be a sufficient supply in course of preparation:- "At Milk Pond, in New Jersey, countless myriads of bleached shells of the families of Limnaana and Peristomiana, analogous to species now living in the adjoining waters, line and form the shores of the whole circumference of the lake to the length and depth of many fathoms. Thousands of tons of these small species, in a state of perfect whiteness, might be used for agricultural purposes. In one case a perforation was made ten or twelve feet deep, and did not pass through the mass. It forms the whole basin of the lake, and may at some future time become a tufaceous lacustrine deposit."

In the aluminous marl, clay predominates; and, in the siliceous, silica, with little or no calcareous matter. The siliceous marl has been found to consist almost entirely of the indestructible siliceous shields or frustules of minute microscopic plants, called diatoms, which have lived and died in countless numbers in the pools at the bottom of which this substance has been deposited. The Berg-mehl, or mountain-meal of Germany (resembling flour, and mixed with it in food in seasons of scarcity), is chiefly composed of them; and likewise the Bog Iron Ore, a paste of fine earthy matter, strongly tinged with peroxide of iron, 
resenbling the mud of our common chalybente springs, observable in ponds, ditches, and stagnant pools. Professor Bailey, of West Point in the United States, speaks of the elegant fragile organisms of the bog iron ore, as occurring in immense quantities in the pools of that neighbourhood, "the bottoms of which," he states, "are literally covered in the first warm days of spring with a ferruginous-coloured mucous matter about a quarter of an inch thick, which, on examination by the microscope, proves to be filled with millions and millions of these exquisitely beautiful siliceous bodies. Every submerged stone, twig, and spear of grass is enveloped by them; and the waving plume-like appearance of a filamentous body, covered in this manner, is often extremely elegant. Alcohol completely dissolves the endochrome (soft colouring matter) of this species; and the frustules (siliceous shields) are left as colourless as glass, and resist the action of fire." Many of the shields are only $\frac{x}{21}$ of the thickness of a human hair, one cubic inch of the iron ore containing $1,000,000,000,000$ of the skeletons of these living beings !

4. Fluviatile-estuary deposits; deltas; marginal sediments; terraces in valleys.

Where rivers enter the sea with great force, the pebbly, sandy, argillaceous, and calcareous sediments in their waters, with drift wood and organic exuvix, may be carried far out into the heart of the ocean, and laid down upon its bed; but generally speaking, owing to a gentler flow, or to tidal action periodically arresting their current, deposition proceeds rapidly at their mouths, giving rise to bars and shoals in estuaries, and to new land in the form of gradually increasing deltas. The quantity of water discharged by the Merrimac river, running by Lowell in Massachusetts, in 1838, was estimated by Dr. Dana at $219,598,840,800$ cubic feet. The quantity of matter chemically and mechanically suspended in the water, he rated, after many experiments, at $1,678,343,810$ pounds avoirdupois. In the Merrimac Print Works at Lowell, the annual amount of anthracite coal used is about 5000 tons; and Dana calculated, that if the above mass of sediment brought down by the river had been coal, it would have sufficed to supply the works witli fuel for the period of 167 years! The nature of the sediment transported by rivers depends of course upon the countries through which they flow. After leaving the lake of Geneva, the waters of the Rhone become chiefly charged with calcareous matter, the deposits from which along the shore of the Mediterranean, at the mouth of the river, are formed into solid beds of limestone. The mud of the Nile has been ascertained to consist of $\frac{1}{2}$ of argillaceous earth, about $\frac{1}{4}$ of carbonate of lime, and $\frac{1}{10}$ of carbon, besides silica, oxide of iron, and carbonate of magnesia. Mr. Phillips remarks that materials of this description may be deposited together; but that, in the process of solidification, the arrangement of the particles may be so influenced by peculiar attractions, as to become rocks of the same character as the limestones, sandstones, and siliceous concretions of the ancient formations. But rivers all along their course originate deposits which largely modify their own channel; and those that are periodically in flood contribute to a general rise of the adjacent land, by annually spreading over it fresh layers of soil.

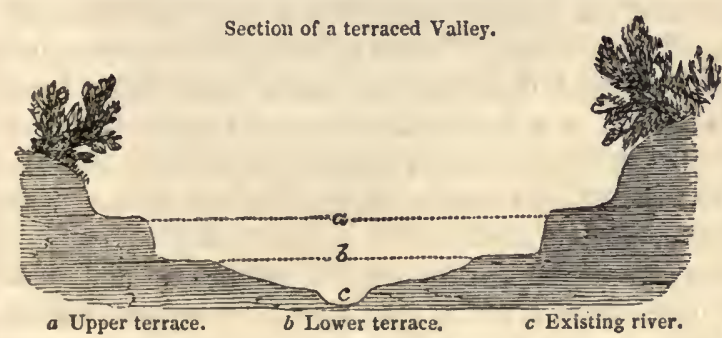

The appearance of terraces or shelves of no great breadth, but level and distinct, covered with sand and pebbles, is a very common feature of river valleys. 'On this account they are here noticed, though it is quite as probable that they are the monuments of lacustrine, and in some instances of marine, as of fluviatile action. Sometimes two or three occur in succession above each other, as in the diagram, and unquestionably they indicate levels 
successively occupied by water; but whether that of lakes which have vanished through the bursting of some barrier, or of rivers which hare cut their way down to a lower site through diluvial sediments, and lost part of their volume; or whether there has been a displacement of the land by elevation, and no actual subsidence of water, are points which remain open to discussion. The most striking example of these terrace constructions is known as the "parallel roads of Glen Roy," so called from their perfect regularity, and resemblance to artificial embankments. Glen Roy is a highland valley in the district of Lochaber, divided into upper and lower, the upper division being about four miles in length by one or more in breadth, bounded on the opposite sides by high mountains, from which two streams descend, and join their currents towards the centre. The united water forming the Roy then flows gradually to a rocky pass, through which it proceeds in a troubled course, and emerges into the wide, long, and sinuous valley of lower Glen Roy, where the terraces or parallel roads occur. Sir T. D. Lauder and Dr. Macculloch ascribe the terraces to the operations of a lake whose waters were successively lowered by the removal of obstructions from time to time, now represented by the stream that flows through the glen.

5. Chemical and Mineral-rock-salt; calcareous tufa or travertine; siliceous sinter; bitumen.

Chloride of sodium, or rock-salt, is deposited from solution in the waters of the ocean, of lakes, and springs; but the formation is rarely visible from the circumstances under which it transpires, though at the bottom of such seas as the Mediterranean the deposition is supposed to be proceeding extenșively, and in some of the cavities of the rocks along the shores it accumulates in such quantities as to be collected by the inhabitants. The beds of the great salt lakes of Persia and Asia Minor are also composed of saline incrustations, with which the shores appear coated during the annual reduction of the water to a lower level in the summer season; and table salt is largely obtained from saline springs in various countries by the artificial evaporation of the water. These springs usually contain a greater proportion of salt than the waters of the ocean, those of Cheshire yielding 25 per cent., and of the United States from 10 to 20 per cent., whereas sea water rarely contains more than 4 per cent. In the year 1829 the quantity of salt made from the springs in the United States amounted to $3,804,229$ bushels ; but in 1835, from the Onondago springs in New York alone, 2,222,694 bushels were obtained, and $3,000,000$ bushels from the Kenhaira springs in Virginia, the borings in some places extending to the depth of a thousand feet.

Calcareous tufa or travertin, a deposit of carbonate of lime from springs and rivers holding the substance in solution, is a light, porous, vesicular mass when first produced, as the word tufa implies, but forms a solid limestone, sometimes even crystalline, upon exposure to the atmosphere, so as to be used for architectural purposes. The thermal waters of Central France, Hungary, Tuscany, and Campagna di Roma, yield it abundantly; but it is also deposited by springs of the ordinary temperature, and is precipitated by the Tuscan rivers as well as those of Asia Minor. In the vicinity of Rome some of the calcareous tufa cannot easily be distinguished from statuary marble; and that which is constantly forming near Tabreez, in Persia, is a beautiful variety of semi-transparent marble or alabaster. The concretionary calcareous deposits formed in caverns, the stalactites depending from the roof, and the stalagmites resting on the floor, are similar productions. Siliceous sinter is an aggregation of successive films or scales of silica (sinter, a scale), formed from the waters of thermal or hot springs, which sometimes hold that earth in solution. The chief sites of its production are at the Geysers in Iceland, where a siliceous deposit, nearly a mile in diameter and twelve feet thick, occurs; and in the Azores, where elevations of siliceous matter are found thirty feet high. In these dis- 
tricts the stems and leaves of the frailest plants, exposed to the action of the waters, become incrusted with silex, and may be seen in various stages of petrification, slightly covered with the deposit, or completely permeated by it, and hardened into stone.

Bituminous matters, in the form of naphtha, the most limpid of the bitumens; of petroleum, or rock oil, a thicker liquid; of mineral pitch, which shows consolidation; and of asphalte, in which the substance is so far solidified as to become brittle, are plentifully exuded from the surface of the earth in various countries, in the Birman Empire, around the Caspian Sea, in Palestine, Greece, Italy, and the United States, either in an insulated state, or impregnating springs and pools. The various bitumens are supposed to be produced from vegetable matter buried in the earth, by the processes by which vegetable substances are ultimately converted into coal, the force of internal heat driving the product to the surface, which it reaches through chinks and fissures in the strata. The great abundance of bituminous matter now in course of production, and the manner in which it becomes incorporated with layers of soil, are highly interesting points to the geologist, because they enable him to explain the bituminous character of many of the older rocks in which no appearance of vegetable structure can be detected.

6. Volcanic-lava; obsidian; pumice; mud, scoriæ, and ashes, with gaseous products.

The points of volcanic eruption at present in action, or of which we have any record

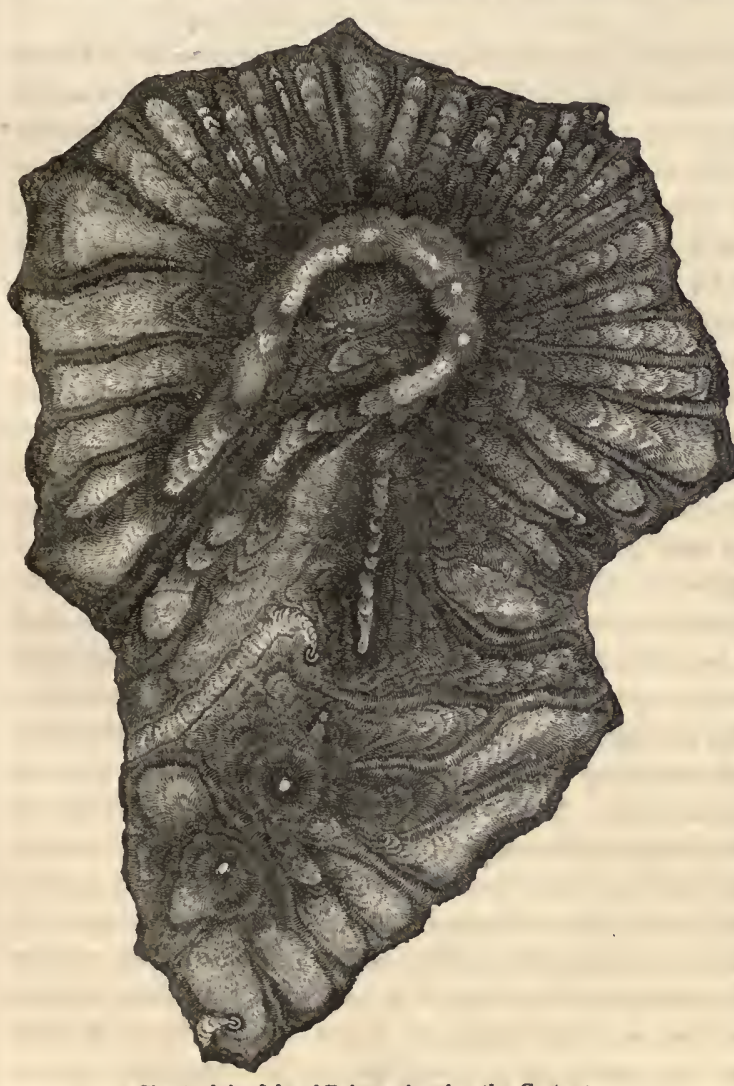

Chart of the Isle of Palma, showing the Crater: of action during the historic period, are few in number when compared with those conical masses whose crateriform summits and composition proclaim their igneous origin and former office. The annexed chart represents one of these ancient causes of geological change, an extinct volcano in the isle of Palma, one of the Canaries, a group of islands all of which are of volcanic formation. It is impossible to define the period that has elapsed since the era of repose commenced in relation to these ancient furnaces; but some may be supposed to have been active during the age of man; while in the case of Etna we have an example of one of unimpaired energy, whose fires were burning long before he appeared upon the earth, or during the tertiary epoch. There are a few volcanic vents which have been constantly erupting since their phenomena have been chronicled, always containing lava in a state of ebullition, and emitting gaseous exhalations. Stromboli, in the Lipari Isles, is one of this class, of which we have accounts which go back two thousand years; 
and during that space of time its operations have been unceasing, though very rarely violent. Lava never flows over the top of the crater, but it is occasionally discliarged through fissures into the sea, killing the fish; and Stromboli has been observed to be

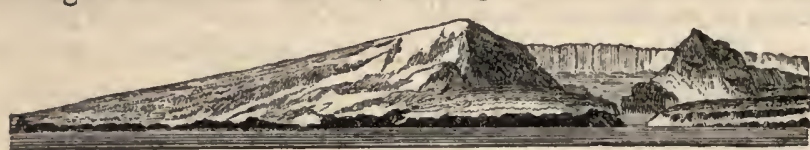

Isle of Palma. more active in stormy than in fair weather, likewise in winter than in summer a fact explained by the different degrees of pressure

exerted by the atmosphere upon the lava at different times. The internal force predominates when the atmospheric pressure is lessened. In most cases, however, the operation of active volcanoes is paroxysmal, an interval of repose following any marked display of energy, the time of dormancy varying from a few months to many centuries. With a very slight interruption, Vesuvius slumbered from the year 1306 to 1631, or for three and a quarter centuries; but, in the island of Ischia, seventeen centuries have been known to intervene between two eruptions. Hence it follows, that as the civilised world has only been acquainted with the western continent for a comparatively brief period, while a knowledge of its phenomena is still more recent, some of those Andean peaks, Chimboraço in Quito, Tacoza in Peru, and Nerado de Toluco in Mexico, which are regarded as extinct volcanoes, may yet break forth, and show themselves to belong to the intermittent class.

Volcanic formations consist principally of lava, or melted rock-matter, which is either upheaved by immense mechanical pressure through the hollow interior, so as to flow from the top of the volcano in eruption; or, as is usually the case, it makes for itself lateral passages on the flanks of the mountain, and overspreads the adjacent districts, sometimes to a considerable distance, filling up valleys, dividing streams and diverting their course, and elevating plains by adding broad and thick expanses of material to them. Lava is chiefly composed of the two mincrals, felspar and augite, with titaniferous iron. When the felspar predominates, light-coloured lavas are the result, called felspathic or trachytic; but when the augite is in excess, dark varieties, augitic or basaltic lavas are produced. Other simple minerals occur, upwards of a hundred species having been noticed in the single instance of Vesuvius, but entering in very inconsiderable proportions into its products. Besides varying in chemical composition, the character of lava is greatly modified by the circumstances under which it is cooled down, compact rock resulting from cooling under pressure, but a porous, fibrous, and light material being produced when cooled with the sole weight of the atmosphere upon it. If we suppose a current of matter of the consistency of honey, we shall have a tolerably correct picture of a stream of lava, which, as it moves over a district, is not thinned but walled at the sides, and, a crust soon forming upon the surface, tends still more to prevent it spreading out laterally. Hence it is sometimes possible, when the ground favours the attempt, to deflect one of these fiery floods from its course by attacking the sides and removing the crust, which has succeeded in turning it away from towns that were threatened by it. In one instance the inhabitants of Catania assailed a lava current in this way to divert it from their city, when the people of another locality, who were placed in jeopardy, took up arms to resist the operation. Lava rapidly cools externally; but the crust formed being a very bad conductor of heat, the interior of the mass remains lot, semi-fluid, and moves on after the surface has solidified. The stream thrown out of Etna in 1819 was in motion at the rate of a yard per day, nine months after the eruption; and another from the same mountain is stated not to lave become completely consolidated and at rest ten years after its emission. Dr. Daubeny states, speaking of temperature, that some days after ejection lava has raised the thermometer from $59^{\circ}$ to $95^{\circ}$ at the distance of twelve feet, while, three feet off, the heat greatly 
exceeded that of boiling water; that it has rendered a mass of lead fluid in four minutes, when the same mass, placed on red-hot iron, would have required double that time to enter into fusion; and that even stones have been melted when thrown into the lavas of Etna and Vesuvius.

Obsidian, another volcanic product, is a black glassy lava, containing a large proportion of silica, named, according to Pliny, after its first observer, Obsidius. Scorix, cinders, ashes, and stones are identical in mineral composition with the lava currents, and are portions of them, abstracted while yet in the fiery funnel, and shot upwards by the explosive energies in operation. Vesuvius - of which a view of the crater is annexed as

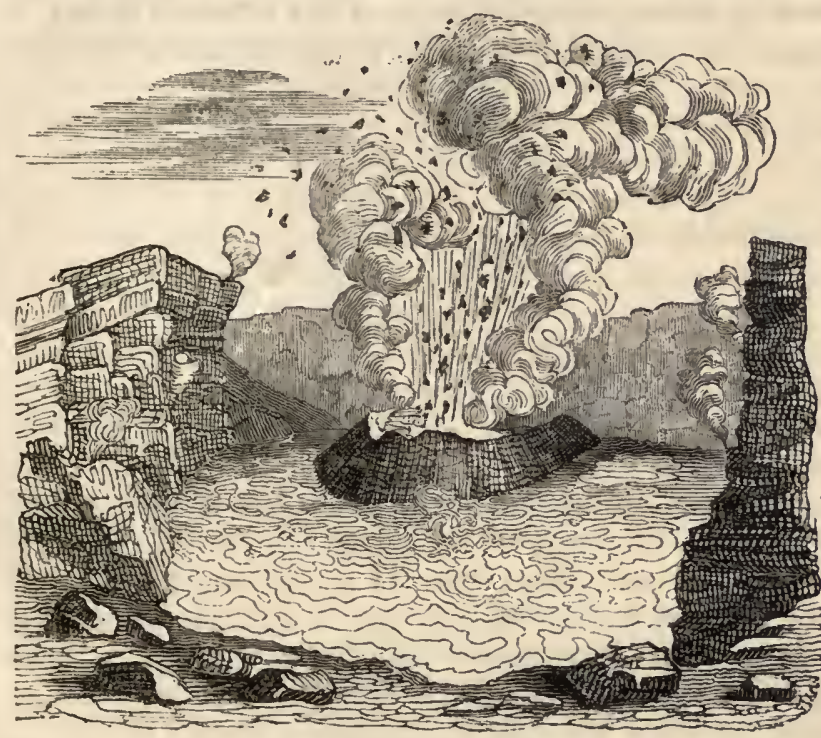

The Crater of Vesuvius in 1829. it appeared in 1829, - at its first recorded eruption, in A. D. 79 , ejected scorix and ashes vastly exceeding its own bulk, which buried for ages Herculaneum and Pompeii ; and its eruptions continued to be of the same nature for more than a thousand years, the first observed flow of lava occurring in the year 1066. Ashes from its summit have repeatedly fallen at Constantinople, in Egypt, and in Syria; and among its peculiarities the emission of boiling water from its flanks has : been often remarked. This is not uncommon with reference to transatlantic volcanoes, together with torrents of mud-a compost of water and ashes - forming a fetid clay. The power exerted by volcanic agency may be estimated by the amount of matter protruded, by the distance to which masses of rock have been projected, and by calculating the force requisite to raise lava to the tops of existing craters from their base. Vesuvius hurled stones eight pounds in weight to Pompeii, a distance of six miles, and has cast similar masses 2000 feet above its own summit; while Cotopaxi has projected a block of 109 cubic yards in volume to the distance of nine miles. The annexed table gives the height of the respective volcanoes named abore the sea, with the force requisite to cause lava to flow over their tops, and the initial velocity which such a force would produce:-

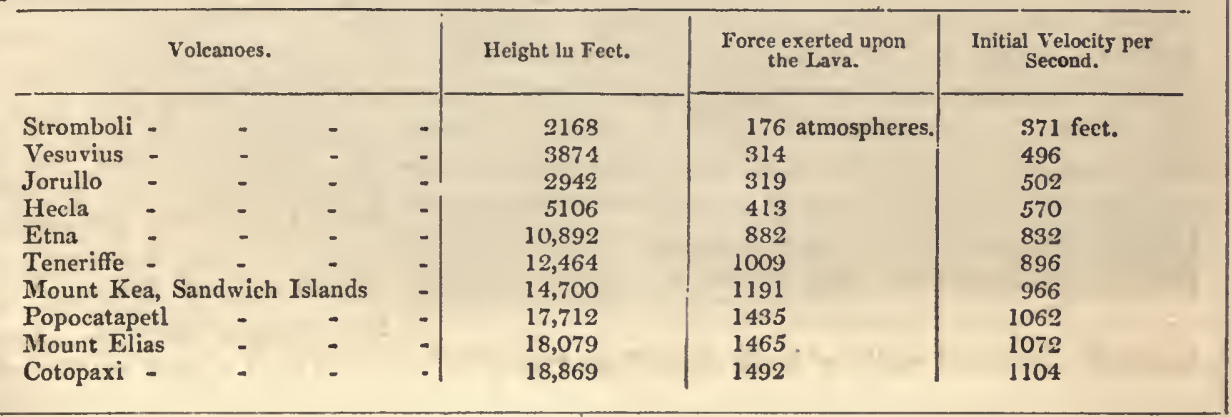


It must be borne in mind as almost certain, that the volcanic chimneys descend much further below the level of the sea than they rise above it-perhaps fifty times as much; so that the actual force pressing upon the lava in its reservoir, and the initial velocity, are much greater than represented in the preceding table. It is obvious that the matter ejected by volcanic action must be brought up from an immense depth, or a single volcano would soon become exhausted, as the lava of one eruption frequently exceeds in ámount what the whole mountain melted down could supply. The lava of Ftna in 1669 covered eighty-four square miles; and in 1660 the amount disgorged by the mountain was equal to twenty times its entire mass. The most prodigious masses accumulated by volcanic action have, however, transpired in Iceland, of which we have the following record of eruptions, since its first colonisation by the Norwegians at the commencement of the tenth century :-

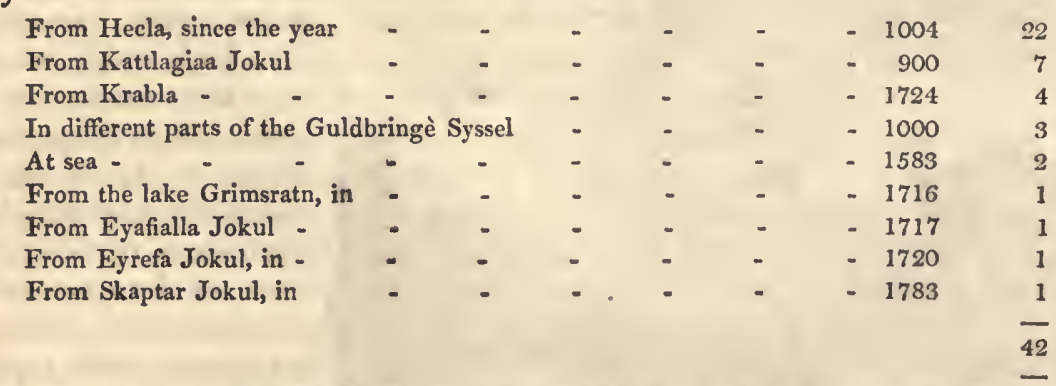

To the above list must be added the eruption of Hecla that took place in 1845 , which rivalled any of its former displays. On the night of $2 d$ September, during a violent storm, the largest of the Orkney islands was covered with fine ashes, resembling ground pumice stones. It was at once supposed that Hecla had been in eruption, though 400 miles distant, as the wind blew from that quarter, and the ashes were volcanic. The surmise was afterwards confirmed by the statement, that the mountain, after reposing between sixty and seventy years, had again resumed its explosions, bursting asunder in two places at mid-day on September $2 \mathrm{nd}$, and vomiting masses of molten matter. On the night of September 15th, the volcano resumed its activity, with loud subterranean detonations, heard over the whole island, and lava was projected to a distance of from twenty to thirty miles, killing numbers of cattle, and destroying a large extent of the finest pasturage. At the distance of two miles from the mountain, the fiery torrent was a mile in width, and from forty to fifty feet in depth. But though great geolo-

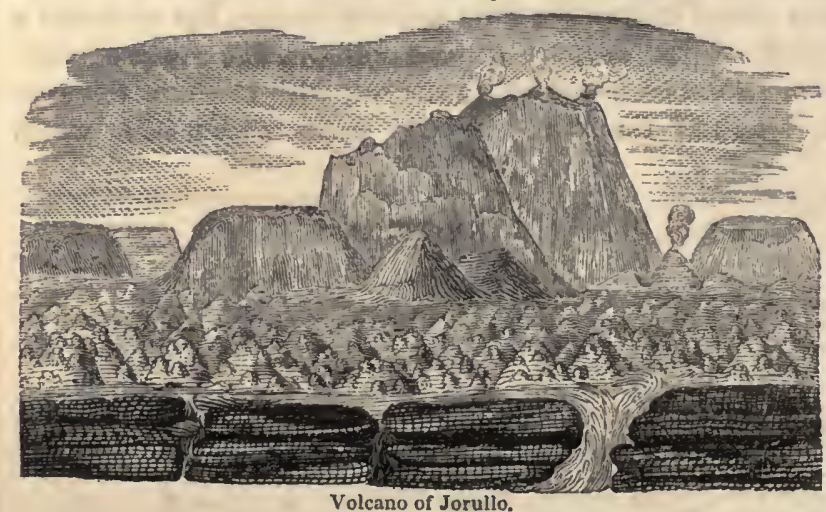
gical changes are at present wrought by volcanic action, they are confined comparatively to very limited areas; and it has been estimated, that while volcanic eruptions tend to increase the diameter of the earth by adding to the superficies at the expense of the interior, yet the mass of active and extinct mountains cannot be supposed to have augmented its diameter to the extent of two feet. Undoubtedly, however, striking local alterations transpire, as when such a mass as that of 
Jorullo in Mexico, at a single bound, starts up from a level plain to the height of 1600 feet above the adjoining surface.

To the preceding causes of geological change at present in action the agency of man must be added, who, during the brief period of the existence of his race, has contributed variously to modify his habitation, both involuntarily and by design. The human population finally mingle their remains with the superficial formations, while large draughts are continually made upon the strata to subserve the purposes of life, the material of our cities, temples, dwellings, and bridges, with the metallic products and carbonaceous matter in daily use, having been abstracted from the bowels of the earth. In many localities man has reclaimed land from the dominion of the ocean by artificial embankments, and now sows his corn where there was a periodical inroad of the tidal waters; and the degradation or elevation of the surface transpire in the prosecution of his industrial designs. But it is especially upon the occupation of a new country by the human race that a cycle of change commences in its physical character, which becomes most marked upon an extensive multiplication of the species. Forests are cleared away, producing a permanent effect upon the climate; swamps are drained, and become pasture ground; the wild animals are supplanted by the domestic varieties; and the introduction of a new flora ensues, consisting of the leguminous plants and cereal grasses that accompany man in his migrations. How different Britain at present from the island upon which Casar landed, when extensive forests and vast morasses occupied the chief part of its area, and the bear, the wolf, and the beaver were its tenants; and within a far more limited period, a precisely parallel alteration has transpired across the Atlantic, as the effect of colonisation by the civilised races.

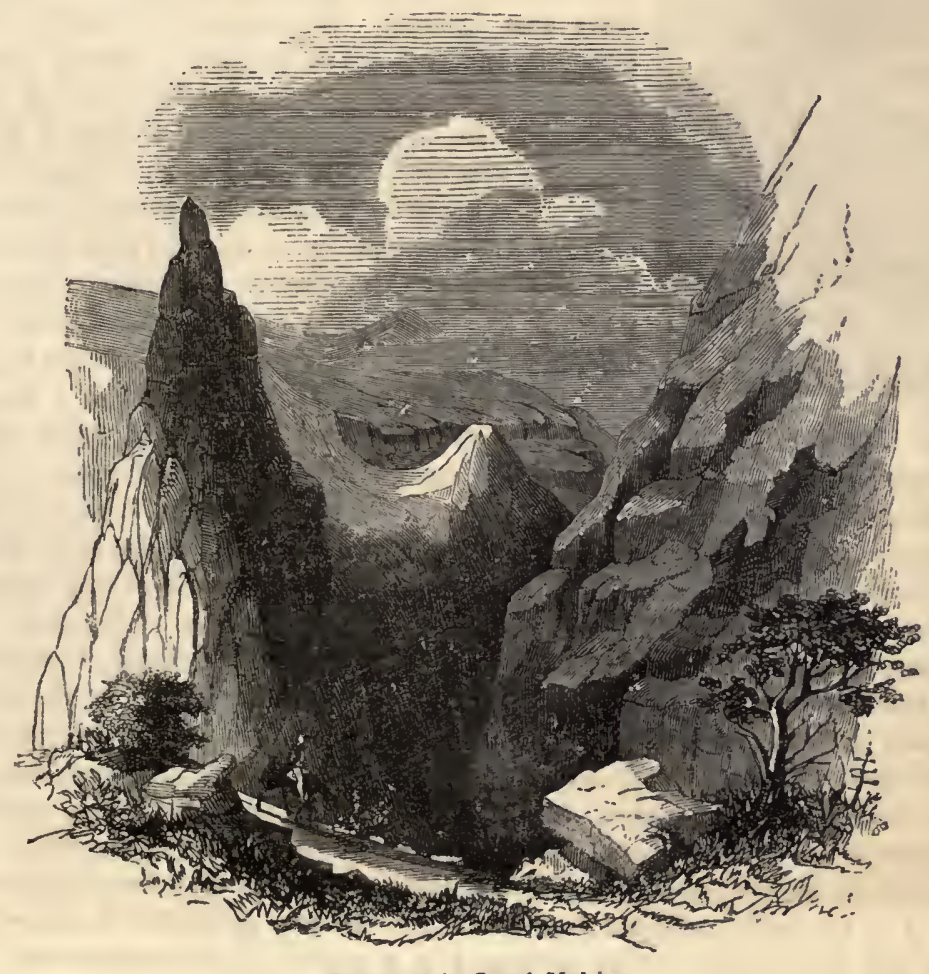

Descent of the Curral, Madeira. 


\title{
CHAPTER XIII.
}

\author{
GENERAL INDICATIONS.
}

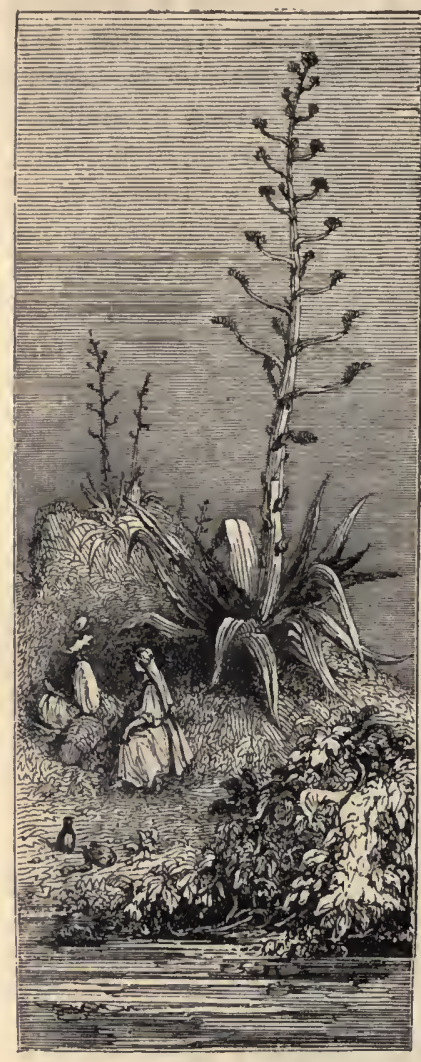

nat our globe existed through cycles of long duration before man trod upon its surface, so that the time of its intellectual occupation is but a handbreadth in comparison with its whole length of days, is a point of which the evidence derived from the study of the tcrrestrial crust is irresistible. It is difficult to convey an adequate conception of the strength of that evidence to those who are not practical observers, but some parts of it are very striking and intelligible. Let us imagine a person conversant with the history and details of architecture to go into an old manorhouse, and he will be able approximately to estimate its antiquity, by observing its style to be Elizabethan, or to belong to the early Tudor period. But if, upon a more minute examination, he should discover a part diverse from the rest, a crypt, a doorway, or a keep, of a Norman or Saxon character, then his thoughts will go back to a more remote era than the date when the edifice in its present state was formed. A process of recurrence from one period to another more ancient is forced upon us by an actual inspection of existing rocks. Let us consider, for example, the old red sandstone, plainly a deposition in water of fine sand, clay, and gravel, tinged with oxide of iron. We know by what a slow process a mass of matter is formed by aqueous deposition, the aggregation and hardening of a very thin stratum requiring a longer interval than our threescore years and ten. Macculloch states, that a Scottish lake does not shoal, or deposit mud and marl to remain at the bottom, at the rate of half a foot in a century, yet Scotland presents a vertical depth of far more than 3000 feet of this single formation, the aggregation of which, according to the ratio, involves a cycle equal to a hundred times the former presumed age of the earth. But in the lower range of the sandstone we meet with conglomerate, bearing similar relation to the mass in which it is imbedded, which a Saxon arch incorporated in an Elizabethan building would have to the edifice. The conglomerate consists of water-worn pebbles of granite, quartz, and other material, having no analogous character to that of the overlying formation. Here, then, we are constrained to go on to a still more remote antiquity, for the pebbles must have existed in their parent rocks, been detached from them, and eroded by long rolling on a solid bottom under water, before the deposition of the superjacent sandstone commenced. Now, let us remember, that the tertiary, cretaceous, oolitic, saliferous, and carboniferous series of strata, have been successively produced subsequent to the old red sandstone, while the silurian rocks, the clay slates, mica-schists, and gneisses, were formed anterior to it by similar aqueous deposition, and we are compelled to extend the chronology of the earth's adamantine pavement to a period in comparison with which the 
duration of human society upon it dwindles into an unit, and to which the lapse of time since man was made in the image of God bears a less proportion, than the life of one cut off on the day of birth to that of the species.

The opening verse of the Scriptures announces the fact of a dependant universe being created by the Almighty, but assigns no date to the mighty operation. Geology demands nothing beyond what this indefinite enunciation of the Creator's work as to time supplies; and theology, in the passage, requires only an acknowledgment of the will, power, and wisdom of the one God, in originating and superintending the terrestrial constitution. At a precise point of time, the earth, in its primordial elements, as we are left quite at liberty to conceive, was called into being, but the question is completely undetermined when that time was. An interval as long as the imagination can entertain may be placed between the first operation of Divine power and the subsequent arrangement of the globe for the habitation of man. 'The record allows room enough for all those wonderful changes and transformations to transpire, the indubitable memorials of which are discovered in the deep and dark places of the earth, which, after ages of entombment, have been commanded to show themselves; but yet, as if to prevent man from becoming proud amid the triumphs of his genius, he is checked at once in the cndeavour to measure the interval, the vastiess of which he can discern, which will ever remain to us in the present state, invested with the obscurity that marks the number of the ocean's sands. 'There has been, however, no little flippancy and contraction of mind evinced by many who have carped at the demands of geological time, for time is long or short according to the particular standard we employ in its measurement. The man of four-score years appears venerable when compared with the nestling infant in its mother's arms, but becomes a mere sapling by the side of Methusaleh ; and thus, the immense periods which terrestrial phenomena intimate, shrink into a span, in contrast with His duration at whose will they originated, and with the immortality for which we ourselves are destined.

That our globe also was the seat of animal and vegetable life, through a countless serics of ages, before its occupation by the human species - that successive races flourished, decayed, and altogether vanished, long anterior to the appearance of man upon the stage of life - is a conclusion of which irrefragable evidence is afforded in the myriad forms of once animated existence, whose remains have been disinterred from their graves in the lias, gypsum-quarries, and chalk, and which enter almost exclusively into the composition of vast masses of mountain limestone. The earth is in truth a charnel-house, full of bones, sinews, shells, leaves, and prostrate trunks, and with consummate skill the botanist and comparative anatomist have traced the animal and vegetable forms indicated by the fragments gathered from the wreck of life. Ancient conditions of our planet have thus been restored, when stately ferns and graceful palms threw their shadows upon its surface, and herbivorous and carnivorous quadrupeds roamed in its forests; when animate objects of uncouth shape swarmed in its rivers, and sported on its plains; all, however, swept away antecedent to the human creation, and whose skeletons, after being washed in the ocean, were laid up in the solid masonry of the globe's present superstructure. The current of popular opinion has run violently against statements of this kind; for no sentiment has stronger hold of the common mind, than that all the alarming phenomena of nature, with the existence of death in the animal kingdom, are the penal consequences of human transgression. Poetry has helped to extend and perpetuate this idea, which observation contradicts, and which a rational exegesis of the Scripture testimony bas shown to be unsupported by the record from which it was primarily derived.

"Thus began

Outrage from lifeless things; but Discord first,

Daughter of Sin, among the irrational, 
Death introduced, through fierce antipathy ;

Beast now with beast 'gan war, and fowl with fowl,

And fish with fish; to graze the herb all leaving,

Devour'd each other; nor stood much in awe

Of man, but fled him; or with countenance grim

Glared on him passing."

It may be well to glance at the difficulties necessarily connected with the hypothesis, that the subjection of the animal creation to the law of death is an accident that befell it in consequence of the sin of man, and formed no part of the Creator's original design. Examining the anatomical construction of the carnivorous races, the demonstration is complete, that they are organically adapted to prey upon each other, or subsist upon animal food. The lion has his canine teeth, claws and juices for digesting the fleshy material upon which he feeds, with instincts to direct him to it; and are we to suppose that this apparatus was originally given him without an office to perform? or that it was an alteration subsequently introduced? in fact, that he never became in reality a lion until some time after his formation? The microscope has enabled us to detect animalcules, invisible to the naked eye, existing in myriad swarms upon leaves, grasses, and in drops of water; and were these created before the event of human delinquency, or not till afterwards? The supposition that death came into the animal kingdom at that era," necessarily involves the fact, that the numerous families of invisible animalcules were parts of a subsequent creation, for beforehand the herbivorous quadrupeds must have destroyed them by wholesale, in walking the earth, or feeding on its plants. But it would be easy to show, that the law of death in the animal creation is a necessary adjunct of the law of reproduction, for without the regular removal of one generation of the species after another, the universal ruin of the whole would ensue, through failing nutrition. Revelation is not opposed to geology upon the point in question, for those passages of the former which treat of the sentence of death involve no other doctrine than that of its application to man, and it has been very justly remarked, that man being threatened with death as the penalty of disobedience, seems very clearly to imply a knowledge on his part of the nature of the event, or the means of acquiring it by observation.

Another general conclusion established by the ancient flora and fauna of the earth, is the former prevalence of a high temperature in northern latitudes, perhaps amounting to an ultra-tropical climate, or one warmer than at present exists upon the globe. The bones of the mammoth occurring in such profusion along the shores of the arctic ocean, and the banks of adjacent rivers, the Obi, Yenesi, and Lena; the remains of extinct species of the elephant, rhinoceros, hippopotamus, lion, tiger, and liyæna, scattered through the diluvium of almost every part of Europe, the existing genera being confined almost exclusively to regions within the tropics; the abundance of shells in the tertiaries of northern countries, the analogues of which are now found in tropical seas; the extraordinary development both of the animals and plants of the secondary rocks, compared with that of living organic beings of a similar kind; the tropical character of the flora of the coal formation, distributed around Baffin's Bay, and even as far north as Melville island; these are the leading facts for which it is impossible to account, but upon the assumption, that in early times the climate of the temperate and arctic zones possessed a temperature as elevated as that of equatorial latitudes in the present day, and probably more elevated, since the arborescent ferns, palms, equiseta, and lycopodiaceæ of the carboniferous era are much larger than their existing tropical analogues. When we consider that all the unstratified rocks, the oldest granites, have evidently been in a melted state, and that the primary stratified formations have either been entirely fused, or so highly heated as to be able to assume a crystalline arrangement, the hypothesis of a globe cooling down gradually from a condition of igneous fluidity commends itself to attention; and if this be admitted, we 
may reasonably impute to internal heat the high temperature of the climate of far remote ages, reduced to its present statical condition in the refrigeration of the surface by radiation. Whatever be the true theory of volcanic action, whether the mechanical of Cordier, or the chemical of Daubeny, or both combined, each involves the existence of heated fluid masses in the earth which the phenomena display, while thermal springs occurring in regions far apart from any modern volcanoes, and the raising of the temperature as we descend below the surface, point to a generally heated interior, if not to an "ocean of molten rock," not far below the external shell.

It may be justly inferred also, that those causes which in former ages operated to modify the aspect of the earth, and those that are now in action, are identical in their nature - atmospheric, aqueous, and igneous agencies. But this conclusion leaves it an open question, whether their intensity was not much greater in ancient than in modern eras. Sir C. Lyell has answered here in the negative, contending that the causes of geological change now acting upon the globe, and with no more energy than at present, are amply sufficient to explain the revolutions which the crust of the earth has undergone, all its fractures, elevations, and subsidences. No catastrophes are admitted into his creed greater than what norr take place, and all effects which transcend any single effect of existing causes are resolved into the result of an agency repeating its play through an indefinite series. Still, though an authority so eminent demands all respect, there are various considerations which favour the hypothesis, that while the geological processes of the current epoch are in all cases the antitypes of those which operated in remote eras, they are less intense than formerly. Thus vertical movements of the strata gradually transpiring to the amount of a few feet in a century, or suddenly occurring through paroxysmal excitement, are among the events of the present era; but if the elevatory force has exerted its maximum energy during the historic period, it is difficult to conceive of a succession of such movements uplifting vast chains of mountains and continents, several thousand feet, as we know to have taken place in early times. It may also be observed, that in passing through the series of secondary rocks, we have noticed sudden and remarkable changes in the organic remains of successive systems of strata, which seem to intimate a long period of repose, followed by destructive catastrophes, and succeeded by restored tranquillity ; for the supposition that races of plants and animals became gradually extinct during periods of repose, new species gradually replacing them by a law of nature, is not sustained by the facts that are common to modern times. Though we have an example of the extinction of a species, as in the case of the dodo, and perhaps the Aptery $x$ australis of New Zealand, no instance of the creation of a new species has been discovered during the history of the human race. Nor have we any specimen of the more important of the older rocks, stratified and unstratified, mica-schist, gneiss, granite, and syenite, having been produced during the present cycle of geological change. Granitic varieties indeed may still be elaborating in the bowels of the earth, where the deep rolcanoes strike their roots, but their abundant obtrusion at the surface in by-gone ages at least proves a fiery activity operating then upon the superficies more powerful than the igneous agencies now brought to bear upon it. Upon the whole, the conclusion is most probable that while instruments of change have been incessantly modifying and altering the condition of our globe, their intensity has varied, and was far greater in ancient than in modern times, though the causalities themselves, mediate as well as primary, have been of the same kind.

But decisively is the sublime truth unfolded by geological examinations, that the present terrestrial constitution is not a chance condition;-that its memorials of decay and change, which everywhere present themselves, are not instances of defective arrangement, as the untutored mind is apt to conceive;-that its very instability is an essential 
element of its permanence as a fit residence for a human population ; and that our planet, so preyed upon, rent and shattered by various agencies, has been steadily advanced by its vicissitudes to an improved estate, developing a plan, the result of forethought and design, grand in its outlines, beautiful in its cxecution, and benign in its results, reaching far back into past eternity and anticipating the wants of future ages, by which the globe las become an appropriate home for moral and intellectual beings, and now takes its place in the universe among the performances of which it may be said

"These are thy glorious works ! Parent of good!"

While yet unfit for man, its intended lord, the earth was occupied with animals whose natures were adapted to its condition, and with a gigantic regetation, subsequently submerged, then entombed, and by chemical processes converted gradually into the beds of coal, now in course of disinterment, contributing so largely to human improvement and happiness, while formations of rock-salt, marble, limestone, and gypsum were aggregated, to minister to the comfort and pleasure of foreseen nations of men, furnishing materials for their dwellings, manure for their pastures, ornaments for their temples, and savour to their food. Wild was the chaos, and confused the scene, which the strata, elevated, disrupted, broken, and overturned, once presented to the eye: but system is now seen in the disorder, and benevolent intention in the derangement. The tilting up of the coal measures in troughs and basins has brought that mineral within reach of human industry, which would have been inaccessible had it remained horizontally disposed. By impervious alternating with pervious strata, the superficial rains are received as into natural reservoirs, in the bosom of the earth, and are returned by hydrostatic pressure in various directions to the surface, often pursuing a far wandering course, percolating through chinks and fissures created by dislocation, ultimately appearing in the form of springs, a machinery, of the action of which in the same localities we have records extending back to the Homeric age. But too for the play of elevating and disrupting forces, shaping mountains and scooping out valleys, the land redeemed from the ocean would have remained a dismal swamp, capable of supporting only the lowest forms of life, like the great floridan morasses, instead of presenting that diversity of hill and dale, glen, plain, and highland, essential to the economy of human life, and grateful alike to rustic simplicity and cultivated taste. These are indications, only a few of the number which might be named, yet sufficiently significant, which serve to establish the conclusion, that our present habitation has been framed under the direction of Divine Intelligence and Power.

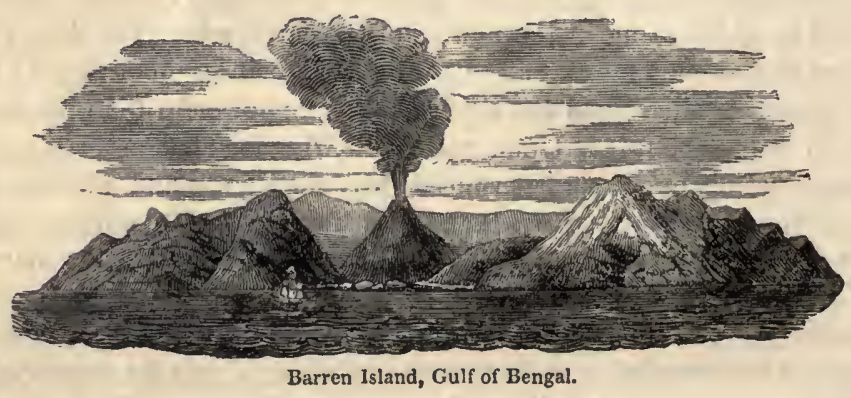




\section{N D E X.}

Aberdeenshire, granite of, 647,649 . Aberration of the stars, 43 .

Abyssinia, wild oat found by Bruce in, 567; climate of, 601 .

Achray, view of Loch, 465; citation from Walter Scott regarding, 465 .

Acotyledones, 551.

Actynolite, the mineral, 623, 644, 603. Adaptation of external nature to man's wants, 570 .

Adelsberg Cave, description and view of, 243,247

Adige, the river, its rapid descent, 284, 490; view of the valley of the, 413 . Adour, the river, 402, 549.

Adria, ancient city of, 400 .

Adriatic Sea, changes about the, 399.

Adventurers, mining, their ignorance of geology, 620 .

Egina and Agean Sea, vicw of, 340 port of, 857 .

Aêrolites, 130-143; derivation of the word, 131; table of, by M. Izarn, 132; fall of, at Ensisheim on the Gassendi, at Nice, 133; several fell at $\mathrm{L}_{3}$ Grange-de-Juillac, in France, 133,$134 ;$ a remarkable one fell in Yorkshire, 134; several fell near Benares, in India, 134; an immense fall of, in Normandy, 134 ; nature and composition of ärrolites, 135 recent instance at the Cape of Good Hope, 135 ; many fall which are never observed, 136 ; metallic masses supposed to be meteoric, 136 ; a remarkable fragment in the British Museum able fragment in the British Museum, the Punjaub, 136; probable origin of aërolites, 136 ; Laplace's theory, 137 ; Chladni's, 137; Sir H. Davy's, 137 ; Arago's and Olmstead's idleas on meteoric showers, 142; the subject involved in great uncertainty, 142.

Africa, eastern and western, floras of, 562 ; animals of, 590 ; population of, 596 ; granite mountains of, 645 .

Agalysian rocks, 657 .

Agassiz, Professor, 670, 679, 684-658, 713,765 .

Aged persons, account of various, 607 . Agriculture improved by geology, 620 . Aiguilles, the Swiss, 647.

Air, its nature and uses, 435 (see Atmosphere); effects of vitiated, 459 ; its composition, 461.

Aix, in Provence, hot springs of, 270.

Alban Mount rolcanic, 427

Albinos, 599.

Aleutian islands, $375,558,588$.

Alexandria, city of, its foundation, 8 its celebrated library, 8 ; the seat of extended astronomical science 8; Alexandrians early constructed various instruments, incluciing astrolabes, or armillary spheres, 16 ; bay of, 397.

Algr, or sea-weeds, 558

Algol, the star, its position, 170. Ali Pasha, 323.
Alleghany Mountalns, land-slip in the, 420; view of the, 494.

Allen, Bog of, 769 .

Alligators, 580 .

Alluvium, chapter on recent formation of, $766-783$; organic, $767-772$ marine, $772-775$; lacustrine, $775-$ 777 ; fluviatile, 386,777 ; chemical and mineral, 778 ; volcanic, $778-783$. Almagest, or Great Collection of Ptolemy, contents of the, 11 ; contained 48 constellations, 147.

Alphonsine tables, their invention and uses, 18.

Alphonso of Castile, his irreverent remark, 19.

Alpine flora of south of Europe, 560

Alps, the, 207, 236, 408-415; cretins of the, 459 ; Tyrolese, characteristic and view of, 490 ; fossiliferous remain of the, 635; granite mountains of, $645,649$.

Altai mountains, 645, 649 .

Alterations of coast-line, chapter on, 386-406; encroachments by the ocean, 386-397; accretions to the land, 397-400; accumulations shore sands, $400-402$; volcanic eic vations of shores, $402-406$.

Altitudes of various localities in the globe, 205.

Alum Bay, Isle of Wight, 628; fossil at, 738,742 ; view of, 742 .

Amazon, river of, 232; descent of it waters and junction with the Atlantic, $281,294,302,304$; east winds of the, 439 ; wooded banks of the, 555 valley of the, 584 ; jaguars near the, 586; raft-islands at the mouth of the 593.

America, lakes of, 312 ; transparent water of the, 322 ; climate of the continents of, 402-496; population of 596 ; races of men, 603,605 ; granit mountains of, 645; coal districts of 702 ; fossil elephants of, 753; mas todon of, 754 ; megatherium of, 757 sivatherium of, 758 ; fossil horses of sivatic.

Ammonite shells found at Whitby 617 ; catena, vicw of the, 640 ; a Hornsey, 641; varieties of, 719 .

Amygdaloids, 655 .

Anacreon, citation from, 482.

Analogy between the vegetable and animal world, 571.

Analysis of mineral water, 276 ; of seawatcr, 328-330.

Anaxagoras, 7,8 .

Anaximander, 7 .

Ancients, the, noticed all the celestial phenomena open to unaided visual observation except annular eclipses, 14 ; their instruments of observation simple and imperfect, 15 ; pyramids and obclisks with them served as measurers of hours, days, and years, 15 ; their clepsydræ or water-clocks, 15 ; the economy of the universe was a sealed book to the, 16 ; had but a circumscribed knowledge of the glolie, 194: carefully fortified mountainpasses, 218 : their limited knowledeo of physica inquiry, 433 ; used lightning conductors, 521 ; had glimpses of geological science, 615.

Andes, incidental notices of the, 219, et $a l ., 645,655$.

Andrews, castlo and coast of St, $\$ 93$.

Anemometer kept by the Royal Society, 459.

Angelucci, Father, his account of the Fata Morgana, 539.

Angitas, the river, sources of the, 299.

Anglo-Sax on Race, the, 608 .

Angular lamination in strata, 625 .

Animalculæ, fossil, 635 ; perfect preservation of, 641 ; tertlary, 749 .

Animals disseminate plant seeds, 506 ; chapter on the distribution of, 571 504 ; modern and ancient classificetions, 571 ; plant animals, 572 ; infusoria, 572 ; mollusca, 572 ; insects, 72 - 578; fishes, 574 , dc., 578 ; reptiles, 579 ; birds, $580-$ 584 ; quadrupeds, $584-591$; of the Old Worla superior to those of the New, $586,587,589,590$; localities of animals, 592 ; distribution of, by the Creator, E92; means of their dispersion, 592-594; lime in the bodies of, 623 ; bodies and traces of in strata, 631 , et al, the less complex tribes of appeared the first, 639 ; list of fossil of the several periods, 640

Anio, the, or Teverone, its cascade, 286 ; its ravages, 416.

Annelidans, fossil, described and illustrated, 666.

Anning, Miss Mary, 723

Anoplotherium, the, 745 ; skeleton of the, 641.

Antarctic continent, flora of, $5 \mathrm{c} 2$; has no indigenous human population, 596.

Anthracotherium, the, 745 .

Anthropophagists, 597

Antipodes Island, its situation, 196

Antiquity of the earth, 429,434

Antisana, Mount, 203, 645 .

Antrim, granitic mountains of, $C 50$.

Ants, white, or termites of India and

Africs, 573.

Apennines, the, 650

A pes, 590 ; class of, 592

Aphelia, 1 .

Appian, 575.

Apples, fabled, of the Dead Sea, 315.

Apricot, poisonous variety of the, 568 , 569.

Apteryx australis, the, 582,787 .

Aquarius, or constellation of the Waterbearer, 152.

Aquatic plants, 548 .

Aqueons atmospheric phenomena, chapter on, 461-483; atmospheric vapours, their amount and distribution, $461-463$; forms and nature of 
clouds, 463 ; cirrus and cumulus, 464 ; stratus, 464-467; cirrocumulus and cirotrotus, cumulostratus, 467; cirrostratus, 467 , curics nimbus, 408 , statistics of rain, 468 . 474 ; formation, nature, and localities of snow, $474-478$; of hail, $478-430$; of dew, $480-482$; of hoar frost, 483. Arabia, wells of, 262 ; is nearly rainless, 471 ; intense heats of, 495 ; flora of, 563 ; locust-eaters of, 597 .

Arabian Gulf, fishes of, 577 .

Arabs, the, improved and enlarged the astrolabe or armillary sphere, 16 ; began their career by dhe detion mental cultivation began with the mental cultivation began with the and geography adopted the system of Ptolemy, 18; their inventions and discoveries detalled, 18; Arabian cul tivation spread to various countries, 18; were acquainted with the rarefaction of the atmosphere, 25.

Arago, M., observations of, 116, 121 , $141,469,499,517,522$

Aral, lake or ses of, $\mathbf{8 2 4}, 423,578$.

Ararat, Mount, 203, 593; view of, 488 varying climate of, 489 ; vegetation of, 557 .

Aratus, quotations from, 144, 147

Arancaria, fossil, 708 .

Arbela, battle of, its date determined, 58 ; site of, 308.

Arcadia, view of limestone mountains on the coast of, 616 .

Arched forms of strata, 628 .

Archipelago, Greclan, 247, 347, 357, 374; Chonos, 568 .

Aretic region, flora of, 560 ; animals of, 588; intense cold in, 597 .

Arctophylax, the Bear-keeper. See Boütes.

Arcturus, the star, 2, 176

Area of land on the globe, 596.

Arethusa, fountain of, 259 .

Argall, the, 606 .

Argo, asterism of the ship, 155.

Aries, or constellation of the Ram, 149. Ariosto, a noted saying of, 619 .

Aristarchus, of Samos, his ingenuity, 9,10

Aristotle, 2; astronomical physies of, founded on false data, $13 ;$ is not answerable, however, for the vain inventions of all who called themselves Aristotelians, 14 ; mentions an occultation of Mars by the moon, 14: speaks of mirrors being used in his time for observing eclipses, 16 ; cited, $527,535,571$.

Armillary spheres early used by the Alexandrians, 16.

Aromatic plants grow best in the central lands of the tropics, 554 .

Arran, isle of, 647, 652, 653, 655.

Artesian wells, account of, 265 .

Ascension Island, 379

Asia, great levels of Sonth-western, were the birthplace of astronomical knowledge, 2 ; that district possessed many advantages for observationwhat they were, 2; Central, the cradle of the human race, 594 ; population of, 596 ; intense cold in the north-east of, 597 ; granite mountains of, 645 ; fossil elephant of, 753 ; mastodon of, 755 .

Asia Minor, view of the coast of, 398 ; electrical phenomena in, 517.

Ass, native country of the, 588 .

Asterias, fossll, 721 .

Asteroids. See Planetoids.

Asters, botanical region of the, 561 .

Astrolabes, or armillary spheres, early used at Alexandria, 16; were improved and enlarged by the Arabs, 16.

Astrology, judicial, origin of, 3

Astronomers-Royal, different, 36 .
Astronomical discovery, history of, 1 -32.

Astronomy the most perfect and ancient of all sciences, 1 .

Atchafulaya, great raft of the river, 593.

Athos, Mount, 326; promontory of 601.

Atlantic Ocean, the, 329, 337 ; coast of the, 345 ; basin of the, 346 ; ser weeds in the, 348 ; current of, 359 361 ; trade-winds of the, 438 ; wind of the, 473 .

Atlas, range of Mount, 203.

Atmosphere of the earth, 75 ; of the moon doubtful, 81 ; of the earth and its currents, chapter on the, 435 460 ; its height, 435 ; weight, 436 ; movement, how caused, 436 ; velocities, 437; trade-winds, 438-442 monsoons, 442-444; land and sea breezes, $444-446$; Etesian winds, 447: Khamsin, Samiel, Simoom, Harmattan, and Sirocco, 447-450; Mistral, Autun, Bise, 450; hurricanes, $451-456,458$; land - storms, 456 $451-456,458$; land - storms, 456 ; water-spouts, 457 ; winds of Great of oxygen and nitrogen, 622 .

Attica, ancient boast of its natives, 609.

Attraction, that between bodies mutua and proportioned to size and distance 40 ; causes perturbation, 40 ; its 40 ; causes perturbation, 40 ; its 183.

Augite, the mineral, $623,645,652$.

Augustine, St, 574 .

Aurora, do sounds accompany the ? 528 elevation of the, 529 .

Aurora Australis, 520 .

Aurora Borealis, $523-526$; views of, 524,526 ; phenomena of, $527-529$.

Aurora Island, 326

Australasia, plants of, $558,562-564$ animals of, 591,594 ; population of 596.

Australia, plants of, 562; contains peculiar forms of insects, 573 ; animals of, 591.

Author of the universe known only to man, 595 .

Antun, \& hot and unwholesome wind

Auvergne, extinct volcanoes of, 427429,656 ; geology of, 619 .

Avalanches, their formation and de

vastations, 206 ; their effects, 412.

Avernus, lake of, 403.

Avon river, at Bristol, tide of, 358 .

Aymestry limestone, 678,680 .

Azara, Senor, 600 .

Azoic period, 638 .

Azore islands, volcanic, 375.

Azov, sea of, or Palus Mrotis, 371

Back, Captain, 318, 322.

Bacon, Lord, 613.

Baden, grand duchy of, its hot springs, 270.

Bagnes, VaI de, inundation of, 413 415.

Bahamas, the, 333,348 .

Baire, territory of, with illustrative chart, 403 ; view at, 774

Bahr Assal, lake of 317 .

Baikal, Lake, Siberia, 811, 318, 320.

Bailey, Professor, 777

Baily, Mr, discovers letters of Flam stead, 37 .

Bakewell, iIr, 270, 412, 428, 647, 051 , 729

Bala limestone, 662, 664

Bala-pool, or Pimble-Mere, 325.

Baltic, waters of the, 328 ; has scarcely any tides, 357 ; climate near the

Banana, or plantain, the, 657.

Banda Oriental, the, $500,587$.
Banyan, or pagod tree, account and view of the, 554

Baobab, the gigantic tree, 550,562

Barbadoes, hurricanes in the island of, 454.

Bareges, 603.

Barren Island, 375 ; view of, 785.

Barrens of North America, 234.

Barrow, Mrr, 332.

Barrow's Strait, 589

Basalt, peculiarities of, $626,627,652-$ 654 ; illustrations of its forms, 626 653.

Bases of earths, alkalies, and alkaline earths, 623 .

Basin, the great European geological, 660 ; tertiary basins of Europe, 739 , et al.; flve grand basins in which the oceanic waters are divided, 196.

Bass Rock, view of the, 370 .

Bath, city of, its thermal waters, 269 ; stone of, 725,727 .

Bats, order of, 591 .

Bauman's Höhle, in the Hartz, 254.

Bayer, John, his Uranometria, 146.

Bayonne, port of, 402 .

Beachy Head, land-slip at, 392.

Beads, St Cuthbert's, 677.

Bear, constellation of the Great, or Ursa Major, is the most conspicuous in the northern hemisphere, 152 ; sometimes called Charles's Wain, 152; and Helice, 152; its place in the heavens, 153 . indicates the Pole-star by its Pointers, 153 ; is important in navigation, 153 ; diagram of its movement around the pole, 153.

Bear, the polar, 342,588 ; common, 589.

Bearings of strata, 627 .

Beaufort, Captain, 397.

Beaver, the, 589

Beccaria, 130

Beche, Sir H. de la, 657, 721.

Bed of the ocean, 326 ; upheavings of, $374-385$.

Beds, successive, of the New Red Sandstone system, 708.

Beech-trees, habitat of, 553 .

Beechey, Captain, his researches, 384, $525,529$.

Behemoth, the 756

Belemnites, 720 .

Beloochistan, plains of, 484 ; view of the, 485.

Belus, temple of, 2.

Ben Lair, 659.

Ben Lomond, atmospheric apparitions seen from, 541 ; view of, 646 ; outline of, 647 .

Ben Nevis, our highest mountain, 205 ; electrical observations made on, 517 . Benares, annual rain-falls at, 471 .

Bengal, annual rain-falls in, 471 ; bay of, 579 .

Bennachle, Mount, 648 .

Bennet and Tyerman, Messrs, 482.

Benzenberg, Professor, 131.

Berghaus, his theory of mountains, 201: his estimate of the human family, 596 .

Berg-mehl, 776

Bermard, hosplce of Great St, 206; its dogs, with an illustration, 477.

Bex, salt-mines of, 712 .

Bible, the, a book for general use, and therefore adapted to popular comprehension, 31 ; wrong conclusions have been drawn from it in past times and present, 32.

Bifurcation of the Orinoco, 298

Bimana, order of, 505

Biot, M., his account of the Fata Mor gana, 540 .

Birch-tree, regard of Linnzens for the, 552.

Birds, great dispersers of plant-seeds, 547 , 566 ; the class of, $580-584$; are 
naturally divided into the three orders of aèrial, terrestrial, and aquatio, $580 ;$ bird-rocks of the northern seas, 580 ; tameness of many ern seas, 580; tameness of many kinds, 581; singing-birds, 582; orders and species, 582 ; species in Britain, 582; locomotive powers of birds, migrations, 583; distribution of the varieties of, 592 ; fossil remains of during the several periods, 640 .

Birs Nimrool, view of, 1 ; ruins of, 2 .

Bise, a cold, piercing wind in France, 450 .

Bison, the, 589, 598.

Bituminous, or pitch springs, 275 ; fossils, 642 ; matter, 779.

Black Sea, 347 , 366 ; was once united to the inland Asian seas, 578.

Elanc, Mont, description of, and ascents to, 203, 205.

Blesson, Mr, his researches regarding the ignis-fatuus, 544

Dloomfield, Robert, quoted, 467.

Blue John Mine, description of, 248 . view of "Organ" stalactite in, 249. Blumenbach, Professor, 601, 604-606, 753.

Boa constrictor, the, 579 .

Bode, Professor, his observation of the planetary system, 46 ; his catalogue of the stars, 158 .

Bodies, the heavenly, were anciently objects of superstitious regard and fear, 3 ; animal and vegetable, contain carbonate of lime, 623 .

Body, the human, can bear great extremes of heat and cold, 484 ; diversities of the human, in different races, 605; its growth, decay, and diseases the same in all races, 608 . its bones and teeth contain much carbonate of lime, 623.

Bohemian coal-mines, 702

Boleslaw lake, in Bohemia, 320.

BoIton and Manchester Railway, fossil trees on the, 705 .

Bombay, annual rain-falls at, 470 .

Bone, how to petrify, 642 .

Bone Well, view of the, 667 .

Bones principally composed of carbonate of lime, 623.

Bonpland, Aimé, 518, 576.

Boötes, the herdsman, or bear-keeper, constellation of, 6,153 ; apparently pursues Ursa Major round the pole of the heavens, 154

Boothia, western coast of, 523 .

Borelli developed the inflnence of gram vity, 38.

Borrowdale, pure lumbago found in, 624.

Borrowstounness, fossil shells at, 775 .

Bory de St Vincent, M., 548.

Bosphorus, mouth of the, 199 ; view of 347 ; drains the Black Sea, 366 .

Botanical regions of plants, $560-564$.

Bothnia, gulf of, 328.

Bouguer, M., 533

Boulders, 342, 751,760 , et seq.

Bourbon, isle of, 581 .

Bovine race, the, 508, 598, 600, 601 . $605,606$.

Brachiopoda, fossil, illustrated, $\ell 65$.

Bradiey, Rev. James, was the third astronomer-royal, 42 ; discovered the cause of the aberration of the stars, 43 ; also the nutation of the earth's axis, 43 ; his great industry, 43 ; his death ignorantly interpreted as a divine judgment, 43,44 .

Brandes, Professor, 131.

Brazil, forests of, 556 .

Bread-fruit tree, the, 563.

Breakwater in Plymouth Sound, 850.

Breccia, its formation, 624.

Brecon, view of hills near, 667, 682.

Breeds, mired animal, 609 .
Breezes, alternate land and sea, 444446.

Breiddin gronp of hills, 680 .

Bremontier, MI, 549 .

Brescia, disastrous explosion in the city of, 521.

Bridge, natural, in Virginia, deseription and view of, 291; Ain el Leban, 301.

Bridlington bay, 394

Brighton, atmospherical spectra seen at, 540 .

Bristol Channel, tide in the, 356,358 .

Britain, climate of ancient, 507 ; the Romans in, 507; early surface of, 771,782 ; diagram of the suecession of strata in, 638 ; granitic rocks of, 645 ; coal strata of, 652 .

British Association, 350.

British Channel, the, prodnced by a disruption between France and England, 578.

British Museum, remarkable slab in the, 715 ; saurians in the, 721 .

Brittany, climate of, 493

Broaw, peat district of Ioch, 769.

Brocken, account of the spectre of the, with illustrative view, 541 .

Brockhill, view of trap-dyke at, 681 .

Brongniart, M., 643, 651, 657, 703, 704, 736, 738.

Brooke, Sir A. de Capell, 332.

Brown, Mr R., his botanical researches, 566.

Brnce, James, of Kinnaird, his imagined discovery of the source of the Nile, 279 ; his description of its localities, 295; of the simoom, 447; of a sand-storm, 456 ; of wild oats, 567.

Bruno, Jordano, maintains the proper motions of stars, 177.

Brydone, citations from his Tour in Sicily and Malta, 160, 369, 539; his account of a sirocco, 449 .

Bûch, Von, 619, 650, 711.

Buckland, Dr, 251-254, 619, 630, 672 $673,681,682,702,703,712,714,720$, $721,723,725,734,757,762$.

Buenos Ayres, drought at, 472 ; hailstorm in, 479 ; fatal thunder-storm in, 518 ; insects of, 574 ; estuary deposits near, 667.

Buffalo, 598, 606

Bnffon, the Count de, 497, 586, 587.

Bullers of Buchan, 648 .

Burdie-house, limestone, 604

Burnes, the late Sir Alexander, 422.

Buxton wells, 269.

Byron, Lord, quotations from the works of, $159,261,286,326,334,399,448$; swims across the Hellespont, 366.

Cabro di Capello, 579.

Cactus family of plants, indigenons only to America, 558; botanical region of the, 561 .

Caddis-worms, fossil, 745 .

Cader Idris, lake on, 324; porphyritic columnar trap of, 627 .

Caen Stone, 725.

Cainozoic period, 683.

Cairngorm, district of, 649 .

Calamites in carboniferons strata, view of, 700.

Calcutta, annual rain-falls at, 471 .

Calm at sea, illustration of $\mathrm{a}, 438$.

Cambrian system, 637, 662 .

Camel, the, 590 .

Campagna di Roma, is mainly voleanic, 427.

Canada, lakes of, 318 ; climate of, 497. Canary Islands, 362, 441.

Cancer, or constellation of the Crab, 150

Canis Major, and Canis Minor, constellations of, 154.

Canton, unwonted snow-fall at, 475.

Cape Cod, view of sand-drift at, 761 .
Cape Horn, view of, 348; Aurora Australis seen at, 527 .

Cape of Good Hope, observatory estab lished at, 156; coast and harbour, 603; thistle-butterfly found at the, 572

Capricornus, or constellation of the Goat, 151.

Caprifoliaceæ, region of the, 561 .

Caraccas, coast of, 362,364 ; earthquakes in, 431.

Caradoc sandstones, 668; group, 674 .

hill of Caer, 680 .

Carbonate of lime, enters into composition of organic and inorganic bodies, 623.

Carboniferous system, 638, 640, 642; coal often turned to coke in the, 658 ; chapter on the, $690-707$.

Cardona, salt-mines of, 711 . tility, 509.

Carex plant, of great use to the Iaplanders, 560 .

Carlsbad, granitic veins at, 650 .

Carnans, fall of the mountain, 408.

Carniola, caverns of, 571 .

Carnivorous races of men, 597.

Carrara marble, 624, 632 .

Caryophillw, botanical region of the, 560.

Caspian, the, 311, 314, 323, 824, 578.

Cassia plants, 563

Cassini discovered satellites of Saturn, 84, 45.

Cassiopeia, constellation of, new star appears in the, 167.

Cassiquiaire river, singularity of the, 280 ; its junction with the Orinoco, 299,500 .

Castalia, or Castaly, fountain of, 260 , 261 ; views of, 260,614

Castleton Dale cavern, description of, 244, 692.

Cat, notices of the, 588, 598 .

Catalogues of stars, $143,158,166$, et al.
Catania, city of, $\mathbf{4 1 0}$.

Cstaracts, how formed, 283; of the Nile, 284.

Catecucaumene, or burnt-up region of Asia Minor, 429 ; view in the, 430.

Catenipora escaroides, view of the, 640.

Catlin, Mr, 762.

Cattle, varieties of, 601, 606

Caucasian race of men, 601, 609

Cancasus, mountains of the, 218 ; road made in by Alexander of Russia, 219 ; great plain of the, 224 ; steppes of the, 225 ; snow-line of the, 488.

Caverns and subterranean passages, 238-258; temperature diverse in, $249-251$; fossils of, $251-255$; the Delphian in Greece, 239; Thor's, in Derbyshire, 239; of 'Sweden, Norway, \&c., 240 ; of Fingal, in Staffa, 241 ; of Iceland, 242; of Eldon Hole, 242 ; of Peveril of the Peak, 243; of Castleton Dale, 244, 692; of tho Guacharo, 245; stalactitic, such as Antiparos, 246; and Adelsberg, 247 ; of Blue John mine, 248; of Kirkdale 251. of Devonshire \&c 252. (5er) 255 255; Grotto del Cane, at Naples, 255 ; others similar to it, 256 ; of Dudley Castie, 257 ; of Odin's Mine,
258 ; of Carniola, 577 ; at Nottingham Castle, 707, 710.

Cayenne, humidity of, 471 .

Cayman, the, 579.

Cayster, the river, 398

Cedar-tree, respect of the Arabs for the, 559.

Celano, lake, the ancient Fucinus, 312.

Century, eighteenth, opened with the physical demonstrations of Newton, and closed with the telescopic discoveries of Herschel, 44; nineteenth, 
commenced with additions to the planetary system

Cephalespis, the, illustrated, $C S 6$.

Cerastes, the, or horned snake, 579 .

Cereals, the, or cultivated grains, 552 ;

tropical regions not favourable to the

growth of, $653,554,597$; origin of the, 567,594 .

Ceres, the planetoid, 91.

Cerithium giganteum, view of the, 744.

Ceylon, island of, 590 .

Chrtodon rostratus, or insect-shooting

Alsh, 575.

Chaldea, the plains of, the primal seat of astronomy, 4

Chaldeans, their priests noted the rising and setting of the stars, 2; eclipses, 3; wcre acquainted with cycle of days, 3 ; invented the zodiac, 3.

Chalk, notices of, 372, 635-637; of England, Ireland, and foreign countries, 731, et seq.; composition of, 733.

Challenger, loss of the frigate, 365 .

Chalmers, Mr, 520. Chalmers, Mr, 520.
Chamouni, valley of, 203, 208, 209,
$372,645,647$.

Champagne, poor soil of, 736

Chandler, Ur, his account of Castaly, dic., $261,398$.

Change common to man and universal nature, 370 .

Changes in oceanic regions, chapter on the, $370-385$; by denudation of the land, $370-372$; by accretions, 373 ; by elevations of the bed of the sea, as of volcanic islands, $374-380$; and coral islands and reefs, $380-385$.

Charles Island, 581.

Charnwood Forest, Ieicestershirc, 645 . granitic veins in, illustrated, 650 ; rocks of, 662,752

Charybdis and Scylla, 367-369. Chateaubriand, Mf., his adventure at
Nlagara Falls, 290.

Chellaston gypsum, 711

Chert, 677 .

Cheshire, rock-salt of, 712,778 .

Chiastolite slate, 663 .

Chichester, antique slab found at, 728 .

Chili, accounts of earthquakes in, 405 , 406,431 ; its climate, 486 ; its flora, 562, 564; Chonos archipelago, near, 568.

Chiltern Hundreds, the, 736 .

Chimboraço, Mount, 203, 205, 221, 645.

China, flora of, 563 ; people of, 602

Chinese claim the honour of first observing the celestial sphere, 4; their native histories of dubious credit, 4 .

Chinese porcelain, fclspar a component of, 648 .

Chinese seas, the, 371; boatmen, their complexions, 603 .

Chirotherium, view of fossil traces of the, 714.

Chlorite, its nature, and where found, 623,659 .

Chronology, geological, 621.

Cicero's villa, alleged remains of, 405 .

Cinchonæ, or medicinal barks, region of, 661 .

Cirknitz, lake of, 323.

Cirrocumulas, or sondercloud, 467 .

Cirrostratus, or waneclond, 467.

Cirrus, or curlcloud, 464.

Civilisation has arisen out of the wants and weakness of man, 596 ; is favonrable to longevity, 607 .

Classes of mankind, five grand, 601604.

Classes of plants, $548-550$; of animals, 671.

Classification of rocks, $622-642$.

Clathraria, fossil forests of, 730

Clay slate system, 638,662 , et al.
Claystone, a kind of basalt, 653 ; porphyry, 654

Clearness of the ocean waters, 331.

Cleavage planes in strata, 630 .

Clermont, valley of, its characteristics, 428.

Cleveland basaltic wall, 654 .

Climate, chapter on physical, 484-515: definition of the term, 484; determining causes of, 484 ; by geographcal position, 485 ; by land-levels, 486 492 ; by occanic proximity, $492-$ 495; from various other causes, 495 -504 ; in equatorial and hot regions, $504 ;$ in warm, tomperate, and cold regions, 505 ; in frozen, 506 ; changes of, inquiry into, 507-509; excessive winters, $509-513$; summers, $513-$
515 ; changes shewn by gcological researches, 515 ; extremes of heat and cold in opposite, 596 ; influences complexion, 602 ; of the tropics, fatal to Europeans, 608

Clinkstone, a felspathian basalt, 653

Clouds, 462-468; lightning, have been traversed with impunity, 517.

Clyde, river, and Severn, singularity of their courses, 280.

Cyywdd, vale of, 668,752 .

Coal, localities of, 620 ; zigzag stratum of, 625; "fault" in strata, 629; deceptive signs of, 629 ; fossil leaves in, 631 ; localities of, 639 ; strata of, 654 ; importance of, 690 ; unknown to the ancients, 691 ; earliest mention of in English history, 691 ; coalbearing system, $692-694$; measures, 694; beds of, in Britain, 696-099; mining of, 699 ; districts, 700-702; foreign localities of, 702 ; fossil ferns in, 703 ; sigillarix in, 704; stigmariæ, lepidodendra, and calamites in, 705 ; coniferro in, 706 .

Coasts, advance of, $397-406$.

Coccosteus, the, illustrated, 687.

Cocoa-palm, the, 557 .

Cod-fish, 577 .

Col du Midi, 646.

Cold regions, climate of, 505 .

Colebrook in Connecticut, gneiss at, 625

Coleridge, $\mathbf{S}$. T., citations from his hymn before sunrise in the valley of Chamouni, 209; from his Ancient Mariner, 328,450 .

Colours of water in lakes, 322,331 ; in the ocean, 330 ; of the various races of men, 599-601; of animals, 600 .

Columbia, gold found in, 634 .

Columbia 1iver, springs of the, 279 ;

bisons of the, 589 ; trap rocks of the, 627.

Columbus, his great discovery, 194, $359,360,439$; flrst obscrved the trade-winds, 439 ; incident in his second royage, 520 .

Columnar structure of rocks, 626.

Comets, general observations on, opinions of the ancients respecting origin of the word, their characteristics and diversities, 108; differences between them and plancts, 109 ; opinions regarding, of Aristotle, Seneca, Tycho Brahe, 109 ; researches relative to, of Hevelius, Newton, and Hallcy, 109; diagram of the path of one, 110 ; statistics of, 110 ; general characteristics of, 110 ; comet of the year 1680 , speculations and calculations regarding the, 111 ; comet of 1682, commonly called Halley's, 112 ; predictions of that astronomer, 113 ; verifled by its return in the years 1758 and 1835 , 113 ; appearances of, and speculations regarding, in former times, 114 ; illustrations of cometary phenomena, 116 ; details of various other comets, 117-119; comet of 1811, 119-121; Arago's table of comets, 121; Enclie's and Bicla's comets, 122 ; comet of 1843,123 127 ; transformations of, 127 ; gene ral reflections on comots, 127 ; irrationality of the fears indulged regard ing them, 128-130; periodical, 192. ing them, $128-130$; periodical, 192.
Commerce, the pursuits of, first stimuCommerce, the pursuits of, first stimu-
lated the knowledge of geography 193; extended, arose first in Egypt 194 ; thence spread to Westerm Europe, 194.

Como, lake of, intermitting spring near the, 260 ; mica-schist of the, 601 .

Complexion of the different races of men, $599-601$

Compositæe, arborescent, 562

Composition of rocks, 622 .

Compound stars, 172-179. See Stars.

Comrie, atmospheric phenomenon secn near the village of, 542

Conception, bay of, 775 .

Condamine, 11 de $7 \mathrm{n}, 239$

Conductors, lightning, their use and importance, 520 ; used by the ancients, $52 \%$

Conglomerate rocks, 624 .

Conglomerates, 662, et al.

Coniferse, view of fossil, 706, 709 .

Conjunction of the planets Saturm, Jupiter, and Mars, 167.

Connecticut river, the, 714 ; valley, 715.

Constantine, the emperor, 33

Constellations, reneral list of, 148: the zodiac, 149-152; of the northern hemispherc, 152-154; of the southern, 155.

Conto, Mont, in the Val Bregaglia, 410

Contorted lamination in strata, 625 .

Conybeare, Mr, 619, 657, 682, 708, 721, $722,736,741,752$

Cook, Captain James, his second royago and its results, 196, 504, 527, 563 .

Copernicus, 8 ; revolutionised for ever astronomical science, 19 ; particular of his life, 19; his scheme of the universe, 20-22; anticipated the discovery, seventy years after his death, of the phases of Venus by Galileo, 30.

Copper and zinc conjoined in tlio Cormish mines, $\mathrm{C33}, 634$.

Coprolites, 694

Cor Caroli, constellation of, 147.

Coral islands and reefs, $326,380-385$ blocks, view of, 380 ; how formed, 382; those of Australia, 383-385 of the Pacifie ocean, 384; ustually inhabited, 596.

Coral ragstone, 726

Corals, formation of, 767 ; illustrations of, 768 .

Cordilleras, the, 221, et al., 492, 591 insect swarms of, 574 ; aged Indians of the, 607 .

Corinth, limestone rocks in the gulf of 612

Cornbrash limestone, 724

Cornwall, rich in felspar, 623; mines of, 633 ; tin of, 649 ; erratic block in, 762 .

Corrao, volcanic island of, 376. Seo Hotham Island.

Corstorphine Hill, 652, 763 .

Cortes, a servant of, first sowed wheat in America, 567.

Cotopaxi, description and riew of, 211 , $221,781$.

Cotton quoted, 242

Cotyledonous plants, 550

Coulommiers, section of a hill at, 738 . Coup de soleil, 505.

Cowper quoted, 452.

Crab, the land, its migrations, 578 .

Craigleith quarry, fossil tree in, 706 .

Crampton, Mr, on the Mare Imbrium,

Creator, original design of the, 785 , et al. 
Cretaceous system, 639, 641: chapter on the, $731-736$; members of the 732.

Crétins, cagots, or goîtred icliots of the Alps and Pyrenees, 459.

Crich-hill, Derbyshire, view of, 628 .

Crinoildeans, 676 .

Crocodile, the, 579, 590, 741.

Cronburg Castle, and entrance to the Sound, view of, 363.

Crop out, the mining term, 629.

Cross, constellation of the, its composition, beauty, and utility, 155; Von Spix and Martins's description of 155; lines on, by Mirs Hemans,

Cruciferous plants, botanical region of the, 560 .

Crust of the earth, composition of the 611 , et seq.; stratified, 619 ; its mate rials, 622 ; carbonate of lime supposed to form one-seventh part of it, 624 disturbances of, beneficial, 629 .

Crustacea, fossil, 640 .

Cryptogamic plants, 550, 563, 565, 569 570.

Crystallization of rocks, 031 .

Crystals of snow, various forms of, 174 , 475 .

Cubs, island of, 606, 608; fresh springs in the ocean near 259 .

Culture, its ameliorating elfects on plants, 568

Cumana, electrical action manifested at, 518; double halo round the moon seen at, 530.

Cumbrian group, 663, et seq.

Cumulo-stratus, or twaincloud, 467 .

Cumulus, or stackencloud, 464.

Cunningham, Mr, 715.

Currents of rivers, 281, 283, 372 ; of the ocean, $359-369$; of the atmosphere 437.

Curved strata in rocks illustrated $625-630$.

Cuthbert, St, beads of, 677

Cuvier, olsservations of, 252, 254, 380 $397,400,571,590,505,603,619,713$ 721 - 760 .

Cycadex, 706 ; view of fossil, 709.

Cygnus, the swan, constellation of, 163 . temporary star in, 168.

Dalton, $\mathrm{Dr}$, his insensibility to colour, 170 ; on height of clouds, 463 ; estimates deposit of dew, 480 ; his accoun of the aurora borealis, 526,529 .

Dampier, Captain, his account of the tropical winds, 445, 446.

Daniell, Professor, his analysis of seawater, 390 ; his account of prerailin water, 329 ; his account of prevailing winds, 460

Danube, the river, 466 ; account of its shores, by Virgil, 508 .

Dardanelles, the.' See Bosphorus and Hellespont.

Darial, defile of the, $218-220$.

Dartmouth hills, thunder-storm in the, 519.

Darwin, observations of $\mathrm{Mr}, 471,472$ $504,555,556,564,568,509,574,581$, $582,585,593,650,668,755,758,761$

Date-palm, the, 556 .

Daubeny, Dr, 433, 787 .

D'Aubuisson, M., 617, 620, 649

Davy, Sir Humphry, philosophical ro fiection of, 399 ; his theory of earthquakes and rolcanic eruptions, 433 ; of mists, 465 ; on peat, 760

Dead fish in the ocean, 690.

Dead Sea, the, $314-316$; view of, 314 ; fabled fruits of the, 315 ; analysis of its waters, 316.

De Candolle, botanical notices of M., $331,547-550,560,569,598$.

Deccan, the, 652.

Dee, the river, 324 .
Deerfield in Massachusetts, remarkable stratum at, 625 .

Delaware Bay, 396.

De Luc, M., 648, 772 .

Delugc, the great, was partial only, 594 .

Dembia, lake of, 311 .

Denderah, sculptured planisphere of, 5 . Denon, M., 421.

Denudation of the land by rivcrs, $370-373$; valleys of, 629 .

Deposits, sedimentary, the origin of stratified rocks, 627, ct al.; were all originally horizontal, 631

Dcpths of lakes, table of, 322 ; of the ocean, 326, 327.

Derbyshire, toadstone of, 655 ; leadmines of, 692 ; peat-moss of, 770 .

Deserts, great, 223 ; of Europe, 223; of Asia, 225, 228; Africa, 225; of Sahara, 226-228; of the north, 229 ; of America, 230-232, 234; of France, 237 ; of the Cast, $421-423$

Deshayes, $\mathrm{M}_{\text {., }} \mathbf{7 4 0}, \mathbf{7 4 3}, \mathbf{7 4 7}, \mathbf{7 5 0}$.

Desmarest, MI., 578.

Devonshire, mild climate of, 492 ; geology of, 682 .

Dew, formation of, 430 ; depositions of, 480 ; in hot climates, 481.

Diablerets mountains, fall of one of the, 411.

Diallage, 650 .

Dicotyledonous plants, 550,563 .

Diluvium, fossil animals found in, $753-760$; boulders of, $763-765$

Dinornis of New Zealand, 715 .

Dinotherium, view of the, 748 .

Diodorus Siculus, 144, 423, 535 .

Diorite or greenstone, 645 .

Dip of strata, 614,627 .

Dipterous fossil fish, 689

Discordant, or unconformable strata 628.

Discorery, astronomical, history of, $1-32$

Disintegrated granite, view of, 648 .

Dislocation of strata illustrated, 629 .

Disruption of rocks by igneous action 632, et al.

Dissemination of plant-seeds, $505-567$. Distances, relative, of the planets from the sun, 46,189 ; of the stars, 162164.

Distribution of plants, $546-571$; of animals, $571-594$; of fossils, 635 .

Districts, the various coal, 700 , et seq.

Disturbances, ancient, of the earth's crust have been beneficial to mankind, 629.

Divination, founded on the appcarance of the heavens, 3

Division of plants, $548-550$.

Dobrizhoffer, 470 .

Docility of fish 575 .

Dodo, the, 767, 786 .

Dodona, inflammable fountain of, 275 . Dog, notices of the, 587, 595, 601, 606 . Dome, chain of Mont de, 746 .

Dorsetshire, land-slip on the corst of 392 ; cosst of abundant in ichthyo sauri, 722 ; strata of, 727 .

Dovedale, valley of, description and view, 221 .

Dover, straits of, 390 ; chalk-cliff of, 391 ; present state and ancient condition of, 396.

Downs or dunes, how formed, 400 localities of, 401 .

Dranse, the river, its source, 413; its irruption, 414.

Drayton quoted, 79

Drift and erratic blocks, 751-765, et al.

Drift timber in the arctic seas, 361 .

Dripping well at Knaresborough, 277.

Dromedary, the, 590 .

Drought, details of a great, in Sonth America, 471,472 ; in India, 472 .

Dru, Alguille de, view of, 647 .

Druids, tradition of the, 648 .
Drummond, Sir W., assigns a knowledge of the telescope to the Greeks, Chaldeans, and Hindoos, 16.

Ducie's Island, corals of, 384.

Duddon, source of the river, 279.

Dudley basalt, notices of the, 627,654 ; Silurian rocks of, 680 .

Dudley Castle caverns, description and view of, 257.

Dufrénoy, M., 650.

Dugong, the, 591.

Dumont d'Urvill

Dundry Hill, 725 .

Dunwich, changes at, 395 .
Durdham-down, fossil remains at, 713 .

Durham, magnesian limestone in, 639 .

Durrenstein, on the Danube, vicw of 466.

Dykes, in strata, 633 ; volcanic, 656.

Earth, transmission of light from the sun to the 35 ; its distance from the sun, 53,73 ; revolution of round the san, 64; general observations on, 70 . its spherical figure proved, 71 ; its diamcter at the pole and equator, 71 ita rotation proved, 72 ; its transla tion and velocity in space, 72 ; the seasons caused by its double more ments, 73; prccession of the equinoxes, 73 ; stmosphere of the $75^{\circ}$; risible to some of the planetarians, visible to some of the planetarians, a moiety of the lunarians, 80 ; density of the, 106; great natural divisity of the, 106; great natural divisions of the surface of the, 193-199; antiquity of the, 429,434; supposed causes of volcanic action and earthquakes in the, 433; importanee of rain to the, 462 ; benefits of diverse climates in the, 484 ; soils of, influence climate, 495; climate of, has undergone changes, $515 ;$ zoological undergone changes, 515 ; zoological provinces of the, 583-591; population of the, 598 ; true shape of, 613 ; composition of the crust of the, 022 , by upheavings, 629 .

Earthquakes, 386; at Iishon, 380 ; in Pern, 386; Jamaica, 386; Chili, 405 ; action of, 430; Creoles of Americs distinguish two kinds of, 430 . extencire influence of 431 ; cas, 131 ; in Calabria, 432 ; causes cas, 431 ; in

East, the, astronomical inquiry had its origin in, 2 ; in its deserts travellers early found the stars indispensable guides, 144.

Easter Island, 593

Easton, Mr, his table of longevities, 607.

Ebel, M., his account of glaciers, 208.

Ebullient springs, $271-275$.

Echinites, fossil, 721

Eclipses, annular, unobserved by the ancients, 14 ; of the sun, 57 ; cause of, and description, 58 ; annular, 59 , 81 ; description of a total, 60 ; anecdote, 61 ; eclipses of the moon, 79.

Ecliptic, obliquity of the, determined, 18,74 .

Edentes, the, of Cuvier, 590

Eel, the, its wanderings, 578 .

Figg, Scuir of, 653 .

Egypt, once the chief seat of astronomicsl science, 8 ; ancient and present condition of its land, 397, 421; hot winds of, 447, 448; granitic monuments of, 648 .

Egyptian system, the, explained and examined, 14 ; was the prototype of the Tychonic, 14.

Egyptians claim the honour of first observing the celestial sphere, 4 ; learned from the Greeks to measure the pyramids by their shadows, 4.

Egmont, Mount, in New Zealand, view and description of, 201. 
Ehrenberg, Herr, 635, 749.

Eldon Hole, in the Peak, description of, 242.

Electricity, manifestations of during hurricanes, 452 ; an agent in evaporation, 461 ; identical with lightning, 517; derivation of the word, 17 ; equator, 517; its operation in equaequator, 517; its operation in equatorial latitudes, nected with magnetism, 522 ;

Elements, the four, an exploded error, 613 ; of the solar system, 189-192. Elephant, the, 590,695 ; fossil, 753 .
Elevation, valleys of, illustrated, 630 . Filk, gigantic horned, 758, 759 .

Ellore, drought at, 472

Elmo, fire of St, 520 .

Encrinal limestone, jllustrated, 693.

Encrinites, illustrated, 676 .

Encrinitis moniliformis, view of the 640.

Encroachments of the sea, 386-388; chronological list of, $383-390$; in Holland, France, and Britain, 390396 ; in America, 396.

Endogenit $\approx$, fossil, 730

Engineer, geological knowledge useful to the, 620 .

England, flora of, 564 ; geological maps of, 619 ; east coast of, its alluvium and drift, 642 ; igneous formations of, 656; abundance of the New Red Sandstone strata in, 709; oolitic formation in, 718; chalk atrata of, 731 , et seq.

Ensisheim on the Rhine, fall of meteoric stones at, 132

Eocene tertiary period, 638, 741-747. "Eöthen," citation froin, 228.

Epacrides, botanical region of the, 562 . Epicycles, Ptolemy' a theory of, 13 .

Epoch, the human, in geology, 636.

Equatorial and hot regions, climate of the, 504 .

Equinoxes, precession of the, 73,74 ; has caused zodiacal changes, 149 .

Era (astronomical) of the Greek and Alexandrian schools, 1-16; of Copernicus, Tycho Brahé, Keppler, and Galileo, 17-32; of, Newton, Halley, and Herschel, 33-48.

Erebus, Mount, 210.

Erethrina, or coral-tree, 555 .

Erica, the genus, 558.

Erie, lake, depositions of, 740 .

Erratic rock8, 760 .

Escalonias, botanical region of the, 561 . Escape, providential, of a Swiss shepherd, 411

Escher, M., his account of the inundation from the Val de Bagnes, 414.

Escobar, Marie de, carries grains to Lima, 567.

Eskdale, peat-mosses of, 770

Esquimaux drift to the Orkneys, 363 ; shelter of the, 477,597 ; food of the, 597 ; skulls of, 605 ; stature of, 605 ; hair of, 606 .

Etesian winds, 447.

Ethiopian division of the human race, 603.

Etna, Mount, 210, 212, 410 ; view of, 213 ; changes in, 425,427 ; variety of climates on, 491; Ovid's remark on, 616 ; fissures in, 654 ; eruptions of, 780.

Euboea, earthquake at, 433

Eucalyptre, botanical region of the, 562.

Eudoxus of Cnidus described the face of the heavena, 147 .

Euomphali, fossil, illustrated, 675 .

Euphrates, the river, 294

Europe, computed population of, 596

diversities of the human flgure in,

605 ; granitic mountains of, 645 .

Euxine Sea. See Black Sea.
Evaporation, its causes and effects, 461 . takes place from terrene 8,8 well as aqueous surfaces, 461 ; its natural limits, 461

Everest, Mount, the culminating point of the world, 204.

Everett, Mr, quoted, 679.

External structure of rocks, 625 .

Eyes, immense number of, in some animals, 672 .

Fable, Arab, a beautiful, 616 .

Fahrenheit, thermometer of, 507.

Fair-head, Ireland, basaltic promontory of, 653 .

Falkland Islands, the, 502, 581, 596, 668.

Fall River, view of rocking-stone at, 761.

Falls of Trollhetta, 285; of Terni, 286 . of Leeambye or Zambesi, 286 ; of Tequendama, 286 ; of Niagara, $287-$ 290.

Fata Morgana, 535, 540; view of the, 538 ; causes of it, 538,540 .

Fault in strata, illustrated, 620,698 .

Fayal, marine meadows near, 348 .

Feejee island, hot spring in, 269.

Feline race, the, 598 .

Felspar, its compounds, and where found, 623 ; a component of granite, 644 ; its crumbling nature, 648 ; forms a moiety of greenstone, 652 ; porplyyry, 654 ; glassy, 655 .

Fennel, its prolific nature, 569 .

Ferguson, James, 158

Fern plants, 551 ; fossil, 706.

Fibrous structure of rocks, 624 .

Field plants, $E 49$.

Fifeshire, coal of, 639.

Findhorn, loss of land at the river, 401, $416-420$; basin of the river, 683 .

Fiords of Norway, description and view of, 332.

Fir-trees, various species of, 552 ; extraordinary, 772

Fire-balls, 131, 519. See Stars, falling.

Fires of the interior of the earth, 656 .

First cause, necessity for $\mathrm{a}, 40,107$, 164,$183 ;$ is not suspended by the adoption of the nebular hypothesis, 188.

Fishes, class of, 574-579; longevity of, 575 ; aword-fish, 575 ; phosphorescence of fish, 575 ; numbing power of aeveral kinds, 575 ; climatic differences in the varieties of, 577 ; the cod, 577; tunny, pilchard, and herring, 577; migrations of severa kinds, 578; species having analog to land mammalia, 678 ; fossil, list of successive, 640 .

Fissures at Polistena, 432; in rocks, 625,632 ; volcanic, 644,656

Fitzroy, Captain, 451, 775 .

Fixed stars. See Stars.

Flamborough Head, cliffs of, $731,735$.

Flamstead, the first sstronomer-royal, 36 ; is highly esteemed, 37 ; was of humble origin, yet attained the summit of practical astronomy, 37; his labours much assisted Newton, 37 his letters discovered by $\mathrm{Mr}$ Baily, 37; was injuriously treated by Newton and others, 37 ; observed the northern hemisphere, 41; cited, 358.

Fleabane, wide dissemination of the plant, 565.

Flinders, Captain, his researches, 383.

Flints, found in chalk, 733

Floating islands, $318-320,593$.

Floods, great, at Martigny, 413-415 in Morayshire, 416,592

Flora, ancient, of the earth, 707 .

Flowers, their beauty and uses, 546 .

Fluviatile deposits, 777 .

Flying-fish, the, 575 .
Folkstone, land-slip at, 392

Coot-marks and other traces of anims? in strata, 631,716 .

Forbes, Professor, his alpine experiences, 203, 207, 208, 341.

Forest plants, 549 ; marble, 724.

Forests of equinoctial America, description of, by Humboldt and Darwin, 655 .

Formations, geological, 636, et al.

Forster, Mr W. M., Newcastle colliery tables, 696 .

Forth, river, its tortuous course, 282.

Fossil organic remains found in caverns, $251-255$; their true nature and origin unknown till recent times, 617; definitely distributed in the earth's strata, 619 ; ferns in coal strata, 631 ; remains, 662 ; of the Silurian system, 670 ; in the Carboniferous system, 690, et seq.; fossil trees, vielvs of, 705,706

Fossiliferous rocks, division of, 635, et seq.; thickness of, in Britain, 637 .

Fox, the, 588, 592; polar, 588 .

Foyers, falls of, 280.

France, coast of, 402 ; extinct voleanocs in central, 427,429 ; retion of winds in, 450 ; varying climates of, 493 ; flora of, 564 ; New Red Sandstone of, 708 ; oolites of, 724, 725; clays of, 726 ; chalk of, 731 , et al.; tertimry strata of, 745,747 .

Franklin, Dr Benjamin, observes the effect of oil in stilling waves, 351 ; his celebrated kite experiment, 517 .

Franklin, Sir John, 525, 528.

Freiberg, mines of, 501 ; school at, 61 ; masses of ailver found there, 634

Fresnel, M., 463

Frost, its operation on rocks, 408

Frozen regions, climate of, 506 .

Frugivorous races of men, 597 .

Fruits and cultivated vegetables, notices of the introduction of various, 567 569.

Fuci, 558.

Funchal, great floods at, 415 .

Fuller's earth, 725

Fungi, 550, 551.

Gailenreuth Cave, 254 ; section of, 255. Galapagos islands, the, 582.

Galaxy, the. See Milky Way.

Galileo, his birth and carcer, 29; advances the systen of Copernicus, 29 ; discovers the four satellites of Jupiter, 29 ; discovers, though imperfectly, the peculiar atructure of Saturn, and the phases of Venus, 30; demonstrates the earth's rotation, 30 ; persecuted for his doctrines, 30 ; and persecuted for his dis in in his latter years, but dies at an advanced age, 31 ; candid apology for, in the mistaken conduct of his persecutors, 31; observes a nebulosity, 185.

Ganges, the river, 280, 281, 294, 370; mouth of the, 302 ; contrasted with the Jumna, 325; gavial of the, 579 , $590,723,729$; raft-islands at the mouth of the, 593

Garonne, the river, 280,540

Garnet, 659

Gas, irrespirable, formed in caverns 255 ; at the Grotto del Cane, 255; at St Leger, in Dunsthohle, and in Java, 256.

Gases, the five elementary, 622 .

Gassendi, the celebratcd, 133.

Gault, 732, et al.

Gavial of the Ganges, the, 579 , 590, $723,729$.

Gay-Lussac, M., 242, 463 .

Geant, mountain of the, 648 .

Gemini, or constellation of the Twins, 150.

Gemma, Cornelius, 527. 
Geneva, or Leman Iake, 320; lateral mirage on the, 543 ; alluvium of, 776 . Gensanne, M., 501

Genus, definition of the word, 598.

Geography, science of, its origin, 193 ; definition of the word, 195; and of the snbordinate terms of, 197.

Geological Society of London, its labours, 620 .

Geology, what it is, 611 ; Its origin as a science, 611 ; obstacles it had to encounter, 612; its study exalis humanity and glorifles the Creator, $614,786,787$; the ancients had some glimpses of the truths of, 615 ; ers of modern, 617; Werner'a theory of 617, 618; Dr Hutton's, 618; William Smith's labours in, 619; use of, in the arts, 620 ; tells the early history the arts, 620 ; te

Geophagists, or earth-eaters, 597.

Gerard, Captain A., his description of the Darial Pass, 219.

Gerdau, lake, floating islands in, 319 .

German Ocean, tides of the, their operation on the British coasts, 372 : sands of the, 772 .

Germany, surface of, 236; New Red Sandstone system of, 708,713 ; oolitic fossils of, 721 .

Germination of plants, after long immersions in the ocean, 566 .

Geysers of Iceland, description and view of the, $271-273,778$.

Giants' Causeway, the, 626 ; notices of the, $653,731$.

Gibraltar, Straits of, 329,337 ; view of 360; Dutch ship sunk in the, 366 .

Giggleswick spring, Yorkshire, 268.

Gilpin, $\mathbf{M r}, 768$.

Giraffe, the, $587,590,594$.

Glaciers, their nature and movements, 207 , 341; their disastrous action $412-415$.

Glairine, a fossil animal substance, 277.

Glamour of the Highlanders, 535 .

Glance at the stars, $143-158$.

Glen Roy, 778 .

Glen Tilt, geological character of, illustrated, 632, 659, 663 .

Glencroe, 659

Globe, area of the, 195; presents the two grand natural divisions of land and water, 195; tides at various points of the, $355-357$; denudation of its lands by river action, $370-373$; geological reasoning respecting the 425 ; changes in the, 434 ; botanical regions of the, $560-564$; crust of the, 611, et seq.; fossils in the strata of the, 635 , et seq.

Glogau, a powder-magazine saved from explosion at, 521 .

Gmelin, M., 529, 602, 603 .

Gnciss system, 638, 657-659.

Goat, the, 588, 606 .

Goatfell in Arran, 655 .

Gold ore, where found, 631.

Goldau, vale of, 409.

Good, Dr Mason, 169.

Goodwin Sands, the, when and how formed, 387.

Gorbitz, valley of, ignis-fatuus in the, 544.

Graba, his account of the Vogel-berg, 580 .

Graham, Mrs, her account of an earthquake in Chili, 405.

Graham, Professor, 570.

Grampians, the, 659, 681

Gran Seco, the, 767 .

Granite, 638, 642; its composition, 624 ; interminglings of, in strata, 631 ; underlying masses of, 632 ; croppings ont of, in Glen Tilt, 632 ; forms the skeleton of the earth, 645 ; general localities of, 645 ; area in Britain 656.
Granitic rocks, 644-651; reins in grauwacke and gmeiss, 649 ; igneous character of, 057 .

Granular structure of rocks, 624

Graphic granite, illustrated, 644

Grass plants, 551.

Gravity, or gravitation, the great law of, 39. See Attraction.

Great Britain, the surface of, nearly all stratifled, 635 .

Great Slave Iake, 318, 323.

Greeks, their attainments in astronomical geience, 6,12

Green, Mr, the aêronant, 69, 205.

Green sand, 732, et al.; shells found in, 732,733

Greenland, east coast of, 342,507 animalculs in the seas of, 348 ; insect scourges of, 573 ; white hare of, 580 ; brown fox in, 592

Greenough, Mr, 619, 761 .

Greenstone rock, is often columnar, 626 ; or diorite, 645 ; or whinstone, 652 ; porphyry, 654 .

Greenwich Observatory, 664 - its origin, 35; Its successive superintendents, 36 ; its arrangements and importance, 36 .

Grenier, fall of Mont, 411

Greywacke, 662

Grindelwald, valley of, 208.

Grinsill, fossil animal remains found at, 713.

Groningen, peat of, 769

Grotte des Fromages, view of the, 053

Grotto del Cane, description and view of, $255,256$.

Gryllus migratorius, or locust, ravages of, 573 .

Guacharo, cavern of the, description of, 245 ; subterranean vegetation in the, 547 .

Guadiana, the river, 292.

Guadaloupe, island of, 860 ; limestone, human skeleton found in the, 636 , 760.

Gulf Stream, 360, 362, 364, 372, 494, 592.

Guiana, spider of, 573; opossum of, 589.

Gurtshellir cavern in Iceland 242.

Guwo-Upas, or Poisoned Valley of Java, its noxions gas, 256 .

Gny's Cliff, fossil batrachians found in, 713.

Gwennap, consolidated mines of, 634

Gymnotus electricus, the, 576; Humboldt' a account of the numbing power of the, 576 .

Gypsum found in red sandstone, 711; its nature, 739 .

Hæmatite, or bloodstone, 634.

Hail, formation and theory of, 478 ; operations of, $478-180$.

Hair, divers colours of the human, $599-601$.

Halfway Island, coral formations of, 383.

Hall, Sir James, 649

Hall, Captain Basil, an expert navigator, 144 ; observationa by, 329 , 365; his Alpine experiences, 208 . his account of Niagara Falls, 288 289 ; of 8ea-water, 329 ; of troplcal storms, 334; of the Yellow Sea, 371 . of the coral insects, 382 ; of Italian remains, 405; of an inundation, 415 .

Halley, 3; his birth, carcer, and labours, 41 ; his voyages, 41 ; becomes second astronomer-royal 41 ; observes the comet of 1680 , which since took his name 41 . tince took his cine, death, 42 ; notice of death, 42 ; notice of an eclipse, 60
his opinions on meteors, 131; his courtliness, 147; proceeds to St Helena, 156; his observations on variable gtar in the Swan, 171 ; observations by, 181, 182, 527.

Halos, 530 ; view of, 531 .

Hamilton, Sir Willlam, 404, 432.

Hammer, M. von, the Orientalist, $1 \mathrm{~s}$.

Hammerfest, island of, 552

Hampshire geological basin, 742 .

Hand, the, its importance to man, 595.

Hannibal, his passage into Italy, 217.

Harding, discovered a planetoid, 158.

Harmattan, or desert hot wind, 448.

Hartside Mountain, 451.

Hastings, aingular atmospheric phenomena seen at, 537.

Hatfield Chase, account of, 771 .

Hatteras, Cape, 364.

Hawaii, or Owhyhee, prodigious volcano in, 210.

Hawkshaw, memoir by $\mathrm{Mr}, 704$.

Hayti, negroes of, 609.

Head, Sir Francis, 569; his description of the Pampas, 233.

Heads, shape and illustrations of the varieties of human, $001-605$.

Heat, rarefaction of air by, famillarly

illustrated, 436 ; is a grand agent in evaporation, 161 ; a high degree of, supportable by man, 484 ; intense, in various places, 495 ; increases as we descend into the earth, 501 ; has caused the upheavings of rocks, 631 , et al.; supposed focus of, in the centre of the earth, 643; intense action of, 643.

Heath plants rare in Asia, and almost unknown to America, 558 .

Heavens, appearance of the, 63 scenery of the, 49-192; optical illusion regarding the, 146 ; guide to the constellations in the, 157,158 .

Heber, Bishop, observation of, 599 .

Heberden, Dr, 469.

Hebriđes, the, 363 ; geology of the, 660 ,

Hecla, ermptions of Mount, 781, 782 .

Hedge or thicket plants, 550 .

Helena, St, observatory established at, 157 ; island of, 320,356 ; peculiarity of ita plants, 558,563 ; had no indigenous population, 596 .

Heliacal rising and setting, the, 5 ,

Heligoland, islands of, 393.

Heliopolis, obelisk at, 15.

ellespont, movement of its waters,

366 ; Byron swam across, 366.

Helm-wind in Cumberland, account of the, 451.

Hemans, Mrs, quoted, 156.

Hemispheres of the globe, diversities of the old and new, 198; temperatures of northern and southern, 502 .

Henderson, Mr, 528.

Henderson's Island, corals of, 384.

Henslow, Professor, 568.

Herbivorous fish, 578 .

Herculanenm, city of, $212,423$.

Hercules, the constellation, 178, 188.

Herefordshire has no coal, 639; sandstone of, 682 .

Herodotus cited, $7,275,308,397$.

Herring, the, its rapid movement, 575 .

Herschel, Sir William, his birth and history, 44: his great telescope 44 mneh extended onr lnowledpe molar with its satellites, 45; also the sixth and seventh satellites of Saturn, 45 ; resolved the Mfilky-Way Into an infinite number of stars, 46 ; time of his death, 46; view of his great telescope at Slongh, 160; suggests the proper motion of stars, 178 ; his cata logue of nebulæ, 181' his observa tions on 181,185 , his estimations of their distances, 184

Herschel, Caroline, sister of the preceding, and the constant partner in 
INDEX.

his labours, 46, 181; survived her brother, 46.

Herschel, Sir J., nephew of the latter, erschel, sir son former, 45,46 ; his and son of the former, 45 , 46 ; hical discourse before the 1 stronomithern society, 143; remarks on southern stars, 157; his catalogue of nebnlæ, citations from his disquisitions, 183, et al.

Hesiod, 5,6 .

Hesseburg, fossil footmarks at, 714 .

Hevelius of Dantzic, his labours, 34 specially observed the northern hemisphere, 41; Hounds of, 154, 155; discovers a temporary star, 168; searches for the Stella Mira, 170

High-water at various places, time of 350

Highlands, the Scotch, $658,659,662$. 681 , et al.

Himalaya mountains, 204, 487, 546 . geology of the, 645,681 , et al.

Hindoo tables," 4

Hindoos, complexions of the, 599,600 . Hinds, Mr, 548, 560, 569 .

Hipparchus, 11 ; the greatest astronomical name in antiquity, 10 ; made a catalogue of the fixed stars, 10 ; also an artificial globe, 11; his system illustrated and examined, 12

Hippopotamus, the, 590,594 ; the fossil, 756.

History of astronomical discovery, 148.

Hitchcock, Professor, 633, 702, 714716,761 .

Hoar-frost, 453.

Hob-hole, Whitby, view and description of, 393.

Hoff, M., 388, 398 .

Hog, notices of the, $588,592,593,605$, 606.

Hogg, the Ettrick Shepherd, quoted,

Holland, tides of, 358 ; coasts of, 401 .

Holland, Dr, 712 .

Hollows, circular, at Polistena, 433.

Holoptychius, the, 688.

Home, Sir Everard, 721.

Homer cited, $5,6,76,130,154,259$ $269,207,600$

Homo, the genus, 595 .

Honfleur, fossil bones found near, 723 , 726.

Inooke, Dr, developed the influence of gravity, 38

Hooker, Sir William Jackson, 517.

Horizontal stratification illustrated, 625 .

Hornblende, a component of granite 644 ; and of greenstone, 652 ; of trachytic rock, 655 ; of slate, 659 .

Horrock and Crabtree observe transit of Venus, 68.

Horsburgh, Captain, 384, 439.

Horse, the wild, of South America, 587,600 ; other animals of the equine 587,600 ; other animals of the equin
kind, 598 ; diversities of the, 605 .

kind, 598 ; diversities

Hot spring plants, 550 .
Hot wells. See Thermal Springs.

Hot winds, $447-450$.

Hotham volcanic island, visit to, description and view of, $377-379$.

Howard, Mr Luke, 463 , $480,483$.

Hndson, the river, 620 ; Palisadoes, or basaltic rocks of the, 627 .

Human race, cliapter on the distribution of the, 595-610; its numbers, 593 ; food, 597; varieties, 598 ; colour of skin, and complexion, 599 ; shape of the head, $601-605$; bodily proportions, 605 ; odours, 605 ; other diver sities, 606; longevity, 607 ; general analogies, 608 ; pretensions and usurpations of races, 609 ; original unity, 609; and accidental dispersions, 610 ; and accldental disper-

Humboldt, Von, 211; his account of

IIygrometer, the, 462. the Cordilleras, 221 ; of the Sahara and other deserts, 226, 229; of the llanos, 230 ; of cavities in the earth, 240,242 ; of Guacharo, 245 ; of the climate of tropical America 296299 : his conjecture regarding the Caspian, 317 ; notice of ocean springs, 328; light and colour of ocesnic water, 330,333 ; his observations on the Mediterranean, 347 ; on the Atlantic sea-weeds, 345 ; currents, 362 ; of the earthquake at Caraccas, 431 ; of the tropics, 441; his observations on Teneriffe, 441, 491; his table of climates, 493; his theory of American climates, 495; his account of climates in general, $496-503$; of a thunder-storm at Cumana, 518; and of a halo seen there, 530 ; of subterranean plants near, 547 ; gigantic trees measured by, 549 ; his account of the forests of equinoctial America. 555 ; and its trees, 557 ; declares the native conntry of the potato to be nnknown, 567. describes the setion of the electrical eel on man and animals, 570 ; his account of a cayman 580 ; of the jaguar, 586 ; of the wild horses of South America, 587; of the earth-eating Indians, 598: of the acute scent of Indians, 606 ; of the longevity of Indians, 607; was a pupil of Werner, 617 ; his observations on the Peruvian rocks, 645 ; on the the Peruvian rock

Hungary, mountains of, 656 .

Hunter, Mr John, 609.

Hurricanes, $451-456$; illustration of tropical, 451; in South America, 451 ; in the East and West Indies, $452-455$; their whirlwind character 453 , 456: their action on desert sands, 456 ; on dusty plains, 457 ; on the ocean, 457; their uses in the economy of nature, 458,565 .

Hutton, Dr James, propounded the Vulcanian or igneous hypothesis of geology, 618; his exploration of Glen Tilt, 632 .

Hutton, $\mathrm{Mr}, 702$

Huygens discovered a satellite of Satur and the great nebula in Orion, 34 , 185 ; is invited to, but afterward banished from, France, 34 ; a remark of his, 164

Hyades, constellation of the, 159 .

Hydrogen, with oxygen, forms water, 622 .

Hylæosaurus, the, 730

Hypersthene, a component of granite, 644,645 .

Hypogenous rocks, 643 .

Hypothesis of Linnæeus regarding the original habitat of plants, difliculties attending the, 564 .

Ice-fields in the ocean, description and view of, 337 ; icebergs, origin and character, with an illustration, 338345 ; perils to navigators from, $339-$ $341,342-345$; animals drifted on, 592

Iceland, 361; Yokuls of, 207 ; rolcanic isle near, 375; calamities in, 376 ; boiling mud of, 515 ; lightning in, bolling mad of, 615 ; lightning in, spherical isothermal phenomens of, 542 ; rein-deer and white bear of, 588

Ichnolites, or foot-prints in stone, 714 Ichthyolites, 684-686, 689, 694 .

Ichthyophagous races of men, 597 . Ichthyosaurus, the, $610,721,724$.

Igneous action, force of, 631,643 ; past, in Britain, 656, 698 .

Ignis-fatuus, the, 543-545; localities of, $543-545$; view of an, 544 ; arises from inflammable gas, 545 .
Iguana, the, 729

Iguanodon, the, 728

llusions, aërial, 535-543.

Inclined stratification, illustration of $627-630$.

India, flora of, 562,563.

Indications, concluding chapter on general geological, 784-7S8.

Indus, the river, $294,357$.

Inequalities of the ocean-bed, 320 .

Inflammable springs, 275 .

Infusoria, 572,614 .

Inglis, Mr, his mountain experiences, 214, 217; traced rivers to their sources, 278 ; his opinion of the Shannon rapid, 284 ; his estimation of divers European rivers, 299: account of the Tyrolese Alps, 490.

Ingredients, the various, found in granite, 644.

Inquiry into the origin of the varions races of men, $599-610$.

Insect tribes, the, 572 ; in equatoric and polar regions, 573 ; fossil, list of successive, 640

Intermittent springs, 265 ; diagram of the action of one, 265 .

Internal structure of rocks, illustrated, 624.

Intertropical regions of animals, 589 .

Irby and Mangles, Captains, 315, 421.

Ireland, lakes of, 310,311 ; climate of, 492 ; has no serpents or toads, 579 ; has no tertiary strata, 739; granite of, 649,650 ; pitchstone of, $65:$; geological districts of, 659,668 ; bogs of, 769 .

rone localities of, 095 .

rving, Washington, his description of the prairies, 234.

Ischia, island of, 780 .

Islay, isle of, 601 .

Jaguar, the, or American tiger, 586, 589.

Jameson, Professor, 401, 421, 617, 619.

Jarrow colliery, fossil lepicodendra found in, 705.

Java, isle of, 591

Jefferson, President, 758

Jericho, rose of, a remarkable plant, 548

Jerome, St, passage in his commentaries, 267.

Jerusalem, temple of, 522

Jews, various complexions of the, 600 .

Joannina, description and view of, 323

$\mathrm{Job}, \mathrm{Book}$ of, gives indications of the heavenly bodies, 2 . Joints of strats 630 .

Jordan, the river, 300,315 .

Jorullo mountain in Mexico, description and views of, 239,782 ; it origin, 426.

Josephus, citations from, 315,522 .

Judea, rains of, 469,470 ; hail-storms in, 479 ; dews of, 482

Jungfrau, the, or Virgin Mountain 203.

Juno, the planetoid, 91

Jupiter, the pianet, 93 ; his brightnes -distance from the sun-path and rate of movement-dimensions, 93 his density-form, 94 ; has no seasons like the terrestrin-reasons therefor, 94: zones or bands, otherwise belts, ; of, 94 ; their supposed nse, 95 satellites of, four in number, 95,191 eclipses of the, 96; are of great usc in astronomical calculations, 96 ; the Jovian system a miniature of the solar, 97 ; area and solid contents of 102; inclination of, to the earth, 104 density of, 106.

Jura district of the 408. section of and a d a stone of the, 718,761 ; Oolitic system of the, 724 . Jura, isle of, 601 . 
Jussieu, M., 551.

Kaaterskill Falls, description and view of the, 234

Kadu, a native of Ulea, his enforced voyage, 610 .

Kalofaro, the ancient Charybdis, 368

Kamenis, volcanic isles of the, 374 .

Kamtschatka, 588 .

Kandal Steig Lake, view of, 310.

Kangaroo, the, $591,594$.

Kaup, Professor, 714, 748.

Keith, $\mathrm{Nr}$, on the dissemination of plants, 565.

Kelloway rock, the, 726 .

Kentish ragstone, 730 ; chalk, 731.

Keppler, John, is invited to Prague by

Tycho Brahé, 26; his birth, education, and discoveries, 27 ; his three great laws, 27 ; becomes a zealous Copernican, and was the harbinger of Newton, 28; his observations on the comet of 1604 , and others, 28 ; falls into distress in his latter years, 28 his death, 29 ; was the discorerer of the general laws of the universe, 33 surmiscd those of gravitation, 38 ; also the existence of other planets, 46; was a zealous watcher of the stars, 158; his familiar refutation of the Epicurean atheism, 107; his graphic account of a new star, 168

Kerguelen's Land, flora of, 565 ; has no indigenous population, 596 .

Keswick, rainfall at, 459, 474.

Khamsin wind, 447 .

Killarney, lakes of, 310 .

Killicrankie, 659

Killingworth coal-mine, 502 .

Kimmeridge clay, the, 726,727 .

Kinderscout, eminence of, 694

Kingsclere, valley of, illustrated, 630 .

Kirby, Rev. Mr, 543 .

Kirby and Spence's Entomology quoted, 746.

Kirkcudbright, illustration of rocks at, 655

Kirkdale Cavern, fossil bones found in, 251 ; view of opening to, 252.

Knight, Mr T. A., 678.

Koferstein's estimate of fossils, 635 .

Konig, $\mathrm{Mr}, 721$.

Konigsberg in Norway, huge mass of silver found at, 634 .

Koran, mentions the stars as used in navigation, 144 .

Iabiatæ, botanical region of the, 560 . Laborde, Count A., 712.

Labyrinthodon, the, 713 .

Lacépede, $\mathbf{6 7 5}, \mathbf{5 7 8}$.

Lacustrine deposits, 775 .

Ladoga, Lake, 318.

Lagoons, what they are, 308 ; common in coral isles, 394 .

Lakes, chapter on, 308-325; their characteristics, and origin, 308 ; those of primary regions, 309 ; of secondary regions, 310 ; of Britain, 310 ; of Ire land, 311: of .Europe, \&c. lakes without affluents or ontlets, those with outlets and no affluents, those with outlets and no affuents, ontlets, and those with both affluents ontlets, and those with both affluents and outlets, $312-318$; characterisin, $318-320,593$; fluctuations and changes in, 320 ; the American, 321 ; depth of various, 322 ; periodical, 322 ; decrease in, 323 ; of Wales, 324.

Lalande, M., ancedote of, 158; his cata. logue of the stars, 158 .

Lamarck, M., 750 .

Lamartine, M. de, 559.

Laminar structure of rocks, 624 ; formations, hypothesis of, 658 .

Lammermuir hills, the, 662 .

Lancaster Sound, 450 .
Land changes, interior, chanter on $407-435$; in mountainous regions, 407 ; in sandy regions, $421-423$; in active volcanic districts, 423 ; in inactive volcanic regions, 427 ; after earthquakes, 430 ; conclnding reflections on, 434 ; land-slips and mountain-slips, their causes, 408; of Mount Carnans, 408; of the Rosenberg, 408; of MIont Conto, 410; of Les Diablercts, 411 ; of Mont Grenier, 411 ; in the Alleghanies, 419,420 ; at Seminaria, 433 ; view of $\mathrm{a}, 613$; of Marley Hill and Kynaston, 679 .

Landes of Bordeaux, 237, 402 .

Languedoc, extinct volcanocs of, 417 .

Laplace, MI., 3,436 ; solved the problem left by Newton and Keppler, 34; enlogises Flamstead, 37 ; his estimate of Newton's Principia, 38 ; and of Bradley's merits, 42; his opinlons of temporary stars, 163

Lapland, swarms of insects in, 573 ; white fox of, 588

Latham, Mr W., his account of some remarkable atmospheric phenomena, 536.

Latitude of a country much determines its climates, 485.

Lauder, Sir Thomas Dick, his account of the Morayshire floods, 292,416 420 ; of Glen Roy, 778

Lauren, hill of, 649 .

Laurentine Chapel, Florence, 650.

Lava, streams of, 428,434 ; recent and ancient, has the columnar form, 626 . Lavoisier, $M$. de, 130, 501.

Lawrence, $\mathrm{Mr}$, his hypothesis of races, 609.

Lawrence, St, river, islands of the, 280 ; rapids of the, 284,294 ; elevation of the waters of the, 292 .

Lay Well, near Torbay, 268.

Lead, where found, 634 ; black, or plumbago, is a carburet of iron, 624 . Leaves, fossil, 631

Lebanon, cedars of, with an illustration 559.

Leeambye, or Zambesi river, falls of 286.

Leeuwenhoek, 577.

Lehman, his classification of rocks, 637 Leibnitz, first classified rocks, 635 . Lemur, 591.

Lepidodendræ, view of fossil, 704 .

Leschenault, M., 563.

Leslie, Sir John, observations of, 463 $468,478,506,507,509,514$.

Lesson, M., 591.

"Letters from the Baltic" quoted, 506.

Lencous or albinous variety of humankind, 599.

Level of the sea, height of lakes above the, 317.

ewis, curved strata in the isle of, 627 , 628.

Lias, oolitic group of, 718; of Whitby and Lyme Regis, 720, 724 .

ibra, or constellation of the Balance, 151 .

Library, Alexandrian, the, 8, 11; destruction of, 17

Librations of the moon, 80 .

Lichens, 551, 563

light, its transmission through space 35 ; action of, 50 ; zodiacal, 62 stellar, tremulous omission or twinkling of, accounted for, 145, 146; its relative intensity, 146

Lightning, 516; electrical origin of, 517.

Llgnite, 738.

Lima, city of, its inhabitants characterised, 410 ; corn grains first taken to,

Lime, carbonate of, 614, 623 .

Limestone, mountains of, 612 ; in Arcadis, 616 ; mountain' limeston used in building the now houses of parliament, 620,711 ; intermingling of, with granite, 631 ; metallic veins in, 634; human skeleton found in, 636 ; strata, 654.

Lincolnshire, peat-mosses of, 770

Lindley, Dr, 548, 706 .

Link, M., 714.

innæus, observations of, $551,552,557$, $564-566,590,591,593,595,598,774$ Lion, the, 589,590 .

Lisbon, earthquake of, 386 ; its remote influence, $270,431$.

Liverpool, prevailing winds at, 450 .

Lizard class, animals of the, 579 ; leth

argy they are occasionally subject to,

580 ; general tribes of, 592 .

clama, the, 589, 594 .

clampeter, fossil remains at, 666 .

Llandeilo rocks, 669 , et al.

Llanos of Sonth America, account of the, $230,576,587$.

Loch Dee granite, 649

Loch Earn, 65:

Loch Katrine, 311, 659 ; vicw of, 309.

Loch Leven, view of, 524 .

Loch Lomond, 320, 542, 776.

Loch Sunart, 658.

Loch Tay, 659 .

Locke, Professor, 672

Locomotive powers of birds, 582 .

Locust, particulars of, and its ravages,

573 ; serves as food in the East, 597.

Logan-stone, the celebrated, 648 .

Loire, descent of the river, 281.

Lombardy, plain of, 553 .

Lomonosov, a Russian poet, his verses on the northern lights, 524 .

London, anemometer of, 459 ; climate of, 492 ; winters and summers of, 498 ; built on tertiary strats, 739 .

London basin, strata of, illustrated, 741.

Longevity of mankind, 607 .

Lonsdale, $\mathrm{Mr}, 670$.

Lophiodon, 745 .

Lowerz, lake of, 409, 410.

owland, or ground-level of Europe, defined, 223.

Lucretius, citations from, $271,275,295$, $457,571,615$.

Lucrine Lake, 403, 405.

Lucullus introduced the cherry-tree,

Ludlow rocks, 669 , et al.; site of town of, 678 .

unar observations of Flamstead, 37 ; influences examined, 86, 482.

Lunardi, the aëronaut, 437.

Lyell, Sir Charles, 687; his theory of

thermal springs, with an illustrative

diagram, 273 ; his account of the

force of river-currents, 283 ; his summary of losses at sea, 373 ; observations at Sheringham, 395 ; at Dunwich, 395 ; on the Rhone, 398; on the temple of Serapis, 405 ; on earthquakes in Chili, 406; on the absence of heath-plants in America, 558 ; on the dissemination of plant-seeds, 566,567 ; on fish of inland seas, 578 ; on stray birds, 583 ; his Principles of Geology, 615,616 ; his geological researches, $643,657,661,684,731,740$, $741,743,750,774,787$.

Lyon, Captain, 528.

Lyons, Gulf of, 450 .

Lyra, constellation of, 163.

Macculloch, Dr, his geological observations, $619,628,633,635,643,654,655$, $658,659,661,702,774,784$.

Madras, surf at, 350 ; descriptlon of a monsoon at, $442-444$

Irander, river of, 232, 398 .

Maelstrom of Norway, 367 .

Maestricht, mososaurus found near, 735,736 .

Magellan's voyage, incident of, 520 . 
Magnesian limestone, composition and localities of, 711 .

Macalite or meerschnum, 739

Mingnetic needle, dip of the, 522 ; variation of the, 523 .

Magnetism is intimately connected with electricity, 522 .

Magnitude of the stars, 164

Magnolias, region of the, 561 .

Mairan, MI., lis observations on the aurora borealis, 528, 529 .

Malay islands, 591, 592; race, the 603,604 .

Malpais, a rolcanic district in Mexico Malpais,

Malte Brun, M., 221, 579, 610.

Ialvern Hills, the, $628,645,680$; fatal storm in the, 520 .

Mam Tor Hill, 407 .

Mammalia, 584-591 ; marine, 578 came after reptiles, 639 ; list of fossil, 640 .

Mammifers, fiying, 591 .

Mammoth, the, 753 .

Man, reflections on his humble and yet exalted nature, 165 ; heedless natur of, 410 ; unreasonable selfishness of, 434 ; his position in nature, 595 ; animal inferiority and belplessness, 595 : numerical distribution of, 596 ; adaptability of, to climate, 596 ; classed by nature of food, 597 ; varieties of 598-606; longevity, 607 ; comparison of tribes of, 608 ; migrations of 610 ; remains of, 759 ; recent creation of, $784-786$.

Manatus Americanus, the, 578 .

Mandia Lake, description and view of, 226.

Mantell, Dr, his Geology of Sussex 388 . his list of strata and their animal remains, 636; his observation on the perfect preservation of fossil animals, 641, 642; his geological observations, $677,729-731,735,736$.

Marble, its composition, 677 ; statuary, 660,661 .

Marcet, Dr, his analysis of sea-water. 329.

Mareotis, lake of, 397.

Marine plants, 548,658 ; allaviam, 772. Mariners' lights, 520

Maritime or saline plants, 548 .

Mark, tower of St, in Venice, view and particulars of, 521.

Marley Hill, 679 .

Marmorice Bay, storm at, 479.

Marriotte, M., his experiments, 263

Mars, the planet, 64,75 ; his distance

from the sun, 90 ; once an object of fear, 89; varying distance of, from the earth, 80 ; revolution of, round the sun, 90 ; dlameter, form, and volume of, 90 ; physical constitution of, 90 ; superficial appearances of, 91; analogies of, with our earth, 91 ; inclination of, to the earth, 104 ; inclinution of, to the

relative density of, 106.
Marsh or swamp plants, $548,558$.

Marshes and bogs, carburetted hydrogen exhaled from, 545 .

Marsupial animals, family of, 589, 591, 725.

Martial, cpigram of, on Vesuvius, 423. Martigny, on the Upper Rhone, 413415.

Martineau, Miss, her visit to Niagara Falls, 290.

Massachusetts, surface of the State of, has one quarter unstratiffed, 635: view of erratic blocks in, 751

Mastodon, the fossil 747,754 .

Matapan, Cape, with Leuctra, view of, 198.

Mather, Dr, 755

Matlock, 692, 694 ; waters of, 269.

the Skaptar Yokul, and Hecla, esti- mated amount of the, 425 ; in the earth's centre, probably in a state of fuslon, 643 .

Maundrell, 482.

Mauritius, the, 452, 453, 502 .

Mauvoisin, Mont, 414

Mayer's lunar tables, 44

Meadow or pasture plants, 549

Mechanical structure of rocks, 62

Mediterranean Sea, its colour, 331 ; it extent, depths, and peculiarities, 336 , $346-348$; is almost without tides, 357,404 ; hot winds in the, 449; water-spouts in the, 458 ; flora of the isles of, 560 ; flsh of the, 577 .

Meerschaum, or magnesite, 739

Megalonyx, the, 758 .

Megalosaurus, 725 .

Megatherium, the, 614, 757 ; skeleton of the, 641 .

Melanic, or dark-haired races of mankind, 599.

Melville Island, register of cold experienced at, 506 ; carboniferous formation in, 515 ; plants of, 547,780 . mation in, 515 ; plant
Memnon, head of, 645 .

Mendip Hills, the, 692,697 ; section of the, 098.

Mer de Glace at Montanvert, 341 ; view of the, 647,648 .

Mercury, the planet, 64 ; its distance from the sun, 64,65 ; is the smallest yet swiftest planet in our solar system, 64; its extreme density, 64 ; length of its days and nights, 64 ; its probable light and heat, 65 shews phases like the moon, 65; transits the solar disk, 65,66 ; Inclination of, to the earth, 104 ; density of, 106 .

Meredith, Mrs, her account of a sirocco at Sydney, 450 ; of columns of dust in the air, 457 .

Merrimac River, 776 .

Mesembryanthema, botanical region of the, 562 .

Mesozolc period, 638.

Messier, M., the "comet-ferret" 118;

his list of nebnlw, 182.

Messina, earthquake of, 433; fata morgana between, and Reggio, 538540.

Metalilic bases, 623 .

Metals, the various simple, 623,624 : localities and extent of the veins of. 633 ; localities of, in various rocks, 634 ; but origin of obscure, although probably igneous, 635; almost all found in gneiss, 658 ; found in the Carboniferous system, 690

Meteor, a remarkable, in 1718, 131.

Meteora, view of the granitic rocks of, 621.

Meteoric showers. See Stars, fal. ling.

Mexico, varying climates of, 489,492 : atmospheric phenomena seen by Humboldt in, 530; wheat first sown in, 567; abundant crops of, in, 570 ; gold found in, 634 ; Gulf of, 302,591 , 593.

Meyendorff, Baron, 324.

Mica, 644 , 659 ; its nature, and where found, 623; used in Russia for glazing, 625 .

Mica-schist system, 638, 642, 659-662 ; illustrated, 658 .

Michaelis, cited by Salverte, 522

Michael's Mount, St, 388 .

Michael's, Island of St, boiling foun-

tains in, 271; its orange-trees, 570.

Micrometer, its discovery, loss, and rediscovery, 32.

Microscopic fossil animals, perfect preservation of, 641

Middle ages, in Europe, a time of astro logical delusion, 4

Middleton Moor quarries, 677 .

Migrations of fish, 577 ; of tortoises,
579 ; of saurians, 579 ; of birds, 583 ; of man, 594, 596 .

Mfilan, Duomo of, 661 .

Milk Pond, New Jersey, 776.

Milky-Way, the, resolved by the elder

Herschel into an infinite number stars, 46; of which 50,000 occupied but two degrees, 159 ; called by the Greeks Galaxy, by the Romans Via Lactea, 159 ; its position and aspects, 159 ; its superior brilliancy in the southern heavens, 159 ; was thought by some ancients to be $a$ disused path of the sun, 160 ; its true compo sition conjectured by modern istronomers, but first made manifest by Herschel, 160; apparently the outward boundary of the solar systcm, 180.

Miller, $\mathrm{Mr}$, his geological observations, $681,683,684$.

Millstone grit, 691 ; projection of, illus trated, 695.

Milton, the Ptolemaic theory supposed to be impugned by, 19 ; his lines on Galileo's discoveries, 30 ; on the Milky-Way, 159: on the heaven generally, 189; cited, 267, 278, 291 $532,536,722,723,785$.

Mimosas, their beauty, 555 ; localitics of, 563 .

Minasi, Signor, 540

Mineral springs, various, 270 .

Minerals, the various simple, 623

Mines, high temperature in different deep, 501 ; of Cornwall, 633; of France, 634; of silver, gold, and copper, 634 ; of Peru, 634 .

Mining operations, importance of geological science in, 620 .

Miocene tertiary period, 638, 747750.

Miqué, village of, noar Poitlers, apparition of a cross seen at, 541 .

Mirage, the, 227, 535; view of a, 536 .

Misenum, port of, 423 .

Mississippi, sources of the river, 282 ;

varying colour of its waters, 283 ; its

periodical risings, 294; its width, 302 : course of the, 305 ; its tributaries, 306; floating island-rafts in 319 ; soll in its waters, 372 ; winds in valley of the, 450 .

Missouri, springs of the, 279, 280 prairies of the, 589

Mistral, a violent wind in the south east of France, 450

Mocesamus concentricus, shell of the 641.

Mole, legend regarding the river, 291.

Molucca Isles, dispersion of nutmeg seeds through the, 567 .

Mollnsca, class of, 572 ; composition of shells of, 624 ; fossil, $639,665,666$ living and extinct, 740 .

Monge, M., his account of a mirage in Egypt, 536 .

Mongolian race of men, 602 .

Monkeys, 590, 595.

Monocotyledonous plants, 563.

Monotreme animals peculiar to Aus tralia, 591.

Monsoons, 442; illustration of their commencement, 443; causes of, not well understood, 444.

Mont Blanc, granite of, 644,645 .

Iontanari, 131

Monte Nuovo, near Napies, 403.

Monte Rossi, its origin, 425, 420.

Monte Rotondo Lake, 312.

Monteith, Colonel, 324 .

Montmartre, spring at, 203; quarries of, 743,744 .

Montoire, bog of, 769 . U.S., view of Monu.

752.
Moon, the, 191 ; causes of her acceleration, 3 ; peculiar eclipse of, 3 savages worship the, 3 ; lunar 
phenomena, 76; has served as a measurer of time, 76 ; diagram of her phases, 77 ; is evidently not selfIuminous, 77 ; its ashy light, or earth-shlne, 78; her distance from the earth, diameter, motions, and tour round the earth, 78 ; luni-solar period of Meton, 79; how her eclipses are caused, 79 ; remarkable eclipse of, as seen in Africa, 79; turns always the same face to the earth, 80 ; librations of the, 80 ; earth is 80 ; librations of the, 80 ; earth is ants of the, 80 ; equality of day and ants of the, 80 ; equality of day and night on the. 81 ; uncertainty as to there being any atmosphere around the, 81 ; superffcial appearances of the, 81-83; phenomena attending the occultation of, 81 ; maps of the, 83 ; supposed mountains and seas in the, 83-85; imagined rolcanoes in the, 84; delusions as to the appearances of the, 85 ; occultations of the, 86 ; tides are caused by the, 86,352 , 353 ; imputed lumar infiuences examined, 86, 482; light of the, its peculiarities, ntility, and amount of, light with the, 88 .

Moonbeams, supposed malign effect of, 87,482 .

Moore, Thomas, his Canadian Boatsong, 284: his account of the Bahar mas, 333 ; lines on the acacia, 563.

Miorasses, 768 .

Morat, lake of, 331.

Morayshire floods, 292, 416-420, 592,

Moselle, course of the river, 282 ; colour of its waters, 283.

Moskwa, Prince of the, his ascent of the Pyrenees, 161

Mososaurus, the, 730 .

Moss plants, 551 ; botanical region of, 560.

Mountain limestone in the coal formation, 691

Mountain-slips. See Land-slips.

Mountains, definition of the term, 200; length of the principal chains of, 201; heights of the chief, in Europe, Asia, Africa, America, and the Antarctic continent, 203-205; land changes among, $407-421$; unstratified, 408 ; stratified, 409 ; plants of, 650 ; rich flora of, 557; table of the vegetation on, 557 ; some wholly composed of organic matter, 635

Mourne, mountains of, 649 .

Moutiers, springs of, 270 .

MIowna Roa volcano, in the Sandwich islands, 206, 210.

Mudstone, 668

Multiple or compound stars. See Stars.

Muncaster Fell, Cumberland, 644.

MIurad IV., Sultan, 312.

Murchison, Sir $\mathbf{R}, \mathbf{I}$, observations of

$627,628,666,670,678,680,681,684$

$687,689,694,699,731$.

$687,689,694,699,731$.
Muschelkalk of Germany, $708,713$.

Myans, Abymes de, 412

Mycene, view of cyclopean remains at, 766.

Mysore, sheep of the, 600 .

Naphtha springs at Baku, 275.

Napier, his invention of logarithms, 33.

Naples, bay of, 403

Naseby, battle-field of, 279

Nativities, calculation of, 4.

Nature always is changing, though man is slow to perceive it, 370 .

Nautical Almanac, its uses, 144

Nebulæ, the, examined by Sir William Herschel, 46; appearances and probable nature of, 180 ; chapter on the, 180-189; their immense distanco from us, 180 : catalogue of, by Sir J. Herschel, 181 their aspects, $182-$ 188; nebula in Hercules, 182; in Doradus, Pollux, and Sobieski's Shield, 183; planetary and double nebulæ, 184; nebula in Orion, 185 ; dumb-bell and halo nebulx, 187 ; what are the nebula? 188.

Needle Rocks, the, Isle of Wight, 503 ; views of, 394,656 .

xegroes, complexions of, 599: herds of, 603 ; skulls of, 604,605 ; longevity of, 607 ; natural equality of the race , 600 .

Neocomium, 732.

Neptune, planet, 102-106; satellites of, 191.

Neptunists, the disciples of Werner, 618.

Nereidina, the, 666

Nettle, the English, now rife in North America, 569.

Neva, the river, 292

New, variable, and compound stars, 166-179.

New Zealand, flora of, 562.

Newcastle coal-fields, $696-698$.

Newioundland, 339

Newton, Sir Isaac, 10, 34; was much indebted to Flamstead's labours, 37 ; his birthplace, 38; was the architect of physical astronomy, though his of physical astronomy, though his till long after his death, 38 ; popular tradition concerning the manifestation of gravitation, 38 ; rationale of that great law, 39 ; Newton left a more thorough investigation of the subject to his successors, 40 ; his house at Woolsthorpe, descriptlon of, 40 ; was associated with Halley in his labours, 41; was the founder of physical astronomy, 41; his tidal theory, 352 .

Ngami, the lake, 312

Niagara, falls of, $287-290$; river of, 324.

Nichol, Dr, his illustration of donble motions, 13; his reasoning on the multiple stars, 174, on nebul 186. Niebuhr, 266.

Nile, source of the river, $278,279,283$. its inundations, 294 - 296, 307 ; its inundations, 294-296, 307 ; condition of, $397,400,421$; crocodiles of the, 579 ; alluvium of the, 777.

Nimbus, or rainclond, 468 .

Nitrogen, with oxygen, forms air, 622. Noah, ark of, 593 .

Non-fossiliferous rocks, division of 635 , et $a l$.

North Cape, 650, 773 ; sun at midnight at the, 51 .

Northampton, Marquis of, 721 .

Northern lights. See Aurora Borealis,

Northwich, brine springs at, 712 .

Norway, transparency of water in the

lakes of, 322 ; flords of, 332 ; pines

of, 552 ; diallage of, 650 ; shores of, 773

Norwich, altered position of the eity of, 396 .

Nottingham Castle, views of, 707,710 .

Nova Zembla, 588, 596 .

Numa, said to have brought fire from heaven, 521.

Number, distance, and magnitude of the stars, 158-165.

Nyöe, or New Island, near Iceland, its rolcanic appearance and disappearance, 376.

Oak-trees, boundary of the growth of, 552.

Oases of Egypt, 226.

Obsidian, or volcanic glass, 653,781 .

Observatories, list of public and private,

192; Tycho Brahes at Uraniberg, 25,
26; at Greenwich (see Greenwich Observatory): at Paramatta maintained by government, 157 ; of Paris, rain-gange kept at the, 469 ; temperature in the substructions of the latter, 501 .

Occultations of the stars and planets, 14; of Mars and Saturn, 14; of Jupiter and Saturn, 81 ; explanation of the term, 86 ; occultations of fired stars, 164.

ccesn, the, is continuous, but divided into flve grand divisions, 196; Arctic, Atlantic, Pacific, Indian, and Antarctic Oceans, their several limits, 197; influences, by its temperature, the climates of the earth, 492; general chapter on the, $325-348$; its extent and influences, 325 ; our knowledge of its boundaries, 325 ; its unequal depths, 326 ; composition, $327-330$; specific gravity, 328 ; bitterness, 329 ; colour, 330 ; transparency, 331-333; phosphorescence, 333,575 ; calms and storms, 334 ; temperature, $335-337$; ice, $337-$ 345 ; coast-line of Atlantic and Pacilc, 345; the the ffe; w muriate of lime in the waters of the, 624

Oceania. See Australasia.

Oceanic highways. See Tides.

Ochill Hills, 683.

Odin's Mine, Derbyshire, description and view of entrance to, 258 .

Odours of human races, 605 . winds in the valley of the, 450 . mastodon in the 755

Oil, effect of, in stilling waves, 351. Olafsen, 592.

Olbers, Professor, 47, 137.

Olive-tree, the, 568 .

Olivine, 652.

Olmstead, Professor, 141, 142.

Oolitic system, 620, 638, 640,642 : chapter on the, 717-731; development of, in England, 718; shells of the, $719-721$; saurians in, 721-724 729,730 ; lithic and other materials of, 724-727; distribution of, in England, 727-729; speculations on the, 730 .

Opossum, the, 589,591

ptical phenomena, chapter on, 516545; lightning, 516, 517 ; electricity in southern latitudes, 518; different kinds of lightning, 519; meteoric lights, 520 ; lightning strokes, $520-$ 522 - magnetism and electricity congeneric, 522; aurora borealis and aurora australis, 523-529; halos, 530 ; parhelia, $530 \_532$; paraselena, 532; rainbows, solar and lunar, 532 -535 ; aèrial illusions, 535; the mirage, 536 ; illusions by refraction, $536 \rightarrow 538$; the fata morgana, 538540 ; illusions by reflection, $540-$ 542: by reflection and refraction combined, 542; ignis-fatuus, 543-

Oran-outang, the, 505 .

Orange-trees, prolific, 570 .

Orbits of the planets, 64 ; orbit of the earth, 161.

Order of successive strate fixed and universal, 639

Organic alluvium, $76{ }^{\circ}$

Origin of springs, inquiry into the, 262 ; of lakes, 308 ; of plants, 563 , et seq.; of animals, 571, et seq.; of man, 595 , et seq.

Orinoco River, $230,280,292,297,439$; climate of plains of the, 492 ; wooded banks of the, 655 ; confluents of the, 576. Manatus Americanus of the, 578 ; floods of the, 584 ; wild horses 
on the plains of the, 587 ; raft-islands at mouth of the, 593 ; Otomacs of, 597

Orion, constellation of, a ; is visible all over the habitable globe, 154 ; its all over the habitable globe, 154 ; position in the has known to and dreaded in the trapezium $154 ;$ num

Ornithichnites, or stony bird-tracks,

714 . Spitz Mountain, ascent of the, 203 ; view of, 547.

osteolepis, the, 659

Otomacs, an earth-eating tribe of South America, 507.

Ovid quoted, $271,615,616$; his Epistles from Pontus, 508.

Owen, Captain, his surveying voyage, 472 .

Owen, Professor, 713, 722, 726, 730, 757.

Ox, the , 587, $598,600,601,605,606$.

Oxford stone, the, 620,726 ; clay, 726 , 727.

Oxidation, hypothesis of subterranean, 433.

oxide of iron, found in basalt, 652 .

Oxus, the river, 423.

Oxygen, with nitrogen, composes the principal part of the atmosphere, 622 ; with hydrogen composes water, 622 ; combines largely with earth and metals, 622 .

Pachydermata, tribes of the, 592, 744. Pacific ocean, 355, 361; gale in the, illustration of $a, 335$; winds in the, 439 ; isles of the, 592 , 593 .

Paderborn, spring at, 268 .

Paleosaurus, the, 713 .

Palreotherium, the, 744, 745.

Palæozoic period, 638.

Palestine. See Juder.

Paley, Archdeacon, his question regarding the laws of nature, 182

Palitzch, George, a landowner and astronomer, 114, 170 .

Pallas, the planetoid, 92, 190

Pallas, Professor, 136, 605, 753, 755.

Palma, volcanic isle of, illustrated, 779 , 780.

Palmæ, or palm tribe, the, 556, view of a forest of, 556 ; description of a palm-grove, 557 ; luxuriance and fertility of different species, 557 .

Palmer's Cairns, view of, 680

Palmir, or "Roof of the World," table land of, 216.

Palmyra, or Tadmor in the desert, 228. Paludina, 746.

Pampas of South America, account of the, 233 ; pamperos, or hurricanes in the, 451 ; of Buenos Ayres, 451. bones in the, 472 .

Panama, Isthmus of, 440.

Paraguay, animals of, 600

Paraguay, river, descent of the, 281.

Paraliax, 1, 9, 10 ; what it is, defined, with a diagram, 161 ; annual, of the fixed stars long a desideratum, 162 ; now ascertained by Professor Bessel, 162

Parallelism of strata, 630.

Paramatta, observatory erected at, 157; nebula sketched at, by Mr Dunlop, 183.

Paraselenæ, or mock-moons, 532.

Parasitic and pseudo-parasitic plants, 550.

Parhelia, or mock-suns, 530-532; vlew of, 531 .

Paris, climate of, 492 ; temperature in the substructions of its observatory, 501 ; built on tertiary strata, 739 ; basin, 743 ; animals of the, illustrated, 745 .

Paris, Matthew, citation from his history, 531 .
Parish, Sir Woodbine, 472, 757. Parkinson, Mr, observation on fossils by, 642 .

Parliament, stone of the new houses of, $620,711$.

Parmassus, Mount, 260 ; view of, 737.

Parrot, Professor, the Russian traveller, 204, 239, 488.

Parry, researches of Captain, 341, 344, $361,450,506,525,528,529,531,532$, $534,547,588$.

Patagonians, stature of the, 605 .

Peach, introduction of the, 568 .

Peat, formation of, 768, 769 .

Pendulum, the, of clocks, an importan acquisition to practical astronomy,

Pennant, Mr, 593, 606, 661, 664, 605 .

Pennsylvania, State of, rich in coal 620,702

Pentacrinites, 676 ; Caput-Medusæ, 678. Pentland Hills principally felspar, 623 . Perca scandens, the climbing-fish, 578 .

Perfection, gradual, of the and vegetable species, an illusivo theory, 639 .

Periods of appearance, the successive, of past and present animal and vegetable races, 640, 641 .

Peripatetics held the earth to be the centre of the universe, 7 . See Aristotle.

Permian and Triassic systems, 638 ; chaptcr on, 707-716.

Peroul, ebullient spring at, 274.

Perturbations of the planets, 40 .

Peru, mountain districts of 645 .

Petcheres, miserable race of the, 507.

Peter Botte Mountain, in the Mauri-

tius, view and description of, 202.

Petersburg, city of St, its perilous site, 293 ; falls of rain at, 470 ; snow of, 474

Petrifactions, how formed, 277, 399.

Petroleum springs, 275

Peveril of the Peak's castle and cavern, view of, 243 .

Peyronncl, M. de, his researches on corals, 380.

Phænogamic plants, 550 .

Phascolotherium, the, 726 .

Philippine Islands, 610 .

Phillips, Professor, his table of British fossiliferous rocks, 637 ; notices by, $658,660,665,681,719,735,772,777$. Philolaus, 7,8

Phlegroean fields, the, 403, 404.

Phocæ, the, or seal tribe, 517,578

Phonicians, the, 348; the reputed in ventors of nautical astronomy, 144.

Phormium tenax, or New Zealand flax. 562.

Phosphorescence of the sea, its cause, $333,575$.

Physical nature, general analogies of, 103 ; diversitics of, 104 .

Piazzi's catalogue of the stars, Sir $J$. Herschel's observations on, 143 .

Pichincha, Morunt, 645.

Pickering, Vale of, 727 .

Pigeons, enormous flock of passenger. 584.

Pike, longevity of the, 575 .

Pillars of Hercules, 347 . See Gibraltar. Pindar mentions the eruptions of Etna, 212.

Pine tribe, the, 552

Pinna marina, the, 572

Pisees, or constellation of the Fishes, 152.

Pitchstone, a bituminous basalt, 653 . porphyry, 654.

Pits of coal, British and foreign, 690 et seq.

Plains, great, of Europe, 223-225, 235 -238 ; of the Caucasus, 224,225 ; of Peru, 225; of South America, including the llanos, selvas, and pampas, 230, 233; of North America, 233-
235 ; of Thebes, vicw of, 422 ; of the Himalayas, 487 ; of Africa, 590 .

Planetoids, the, 91; their anomalous movements, 02 ; lists of, $92,03,190$ 192; their frasmentary appearance, 93.

Planets, 189 ; what they are, 03 ; are primary and secondary, 63 ; thei courses, 63 ; are superior and inferior, 63 ; their symbols, 64 ; their paths are elliptical, 64; their distance from the sun, 64; orbits of the different, 64; those technieally called "smperior" (properly exterior), the phenomena they present, $89^{\circ}$ contents and area of the Earth, Jupiter, Saturn, and Uranus, 102; extent of combined surface of, 102,103 ; orbits of, 103; analogies between the plancts, 104; relative distances from the sun, and size of, 105 ; leugth of day and year of each, 105; form and magnitudes of, 105, 106; density of the various, 106 ; general observations on the, 107.

Plantain, or banana, the, 557

Plants, chapter on the geos phical distribution of, $546-571$; their wide dispersion, 546; their aggregate numbers and general division, 548 550 ; their relative numbers and respective localities, 550,551 ; in northern latitudes, 551 ; in temperate remions, 552; in torrid 553 rate regions, 52 , in torri, tion of places of growth, 557 ; marino plants, 558 ; local species, $558-560$; plants, 558 ; local species, $558-560$; sources whence all varieties sprang also their means of dispersion and reproduction, $564-571$; fossil, list of successive, 640,641; sometimes perfect in form, and sometimes bituminised, 642

Plastic-clay formation, 739,741

Plata, La, or Plate River, $230,518,588$ 601.

Plateaus, or table-land, 214-216.

Plato, 6, 8.

Playfair, Professor, 650

Pleiades, the, or starry group in the neck of the Bull, 2,5 ; supposed derivation of the term, 144; ancient fable concerning, 150 ; constituents of the group of, 159 .

Plesiosaurus, the, $723,724,729,731$.

Plica polonica, the disease of, 609 .

Plinlimmon, 639, 662.

Pliny the elder, his account of a river in Judea, 267; on tides, 352; his death, 423.

Pliny the younger, $11 ;$ his description of the Caucasian defiles, 215 ; of tho Grotto del Cane, 258; of the Lariau spring, 266 ; fount of Ammon, 271; strange omission of, 273 ; his notices of Dodona fountain, 275 ; his relation regarding Claudius, 313 ; his letter to Gallus, 318 ; observation of oil stilling waves, 351 ; on the Anio floods, 416; of the eruption of Vesuvius, 423,424 ; his assertion regarding Tullus Hostilius, 521, 522; and aerrial illusions in Scythia, 535 ; of the introduction of clierries, 568; on obsidian, 781.

Pliocene tertiary period, $638,750,751$.

Plot, Dr, his History of Oxford, 535 .

Plurnbero, or craphite, a carburet of iron, 624.

Plutonic or igneous rocks, chapter on the, 643-656; their nature and how classiffed, 643; granitic, 644-649; foreign bodies found in granite, 640 651 ; trappean rocks, $651-655$; volcanic rocks, $655,656$.

Po, the river, 400 .

Poikilitic system, 708

Pole, the, magnetic, 523 
Polirschiefer, composition of, 749

Polistena, effects of volcanic action at 432 ; view of fissures at, 432 ; view of circular hollows at, 433 .

Polynesia, population of, 596 .

Polypi, tribes of, 572.

Pompeii, city, 212, 423-425, 781 .

Pompey's pillar, 644.

Ponponius Mela, 535.

Pont-Royal at Paris, quantity of water passing throngh the, 263 .

Pools, wherein they differ from lak's, 308.

Population of the five regions of the globe, 596

Porphyry, 651; composition of the porphyries, 654.

Portici, city of, 410 .

Portland, stone of the Isle of, $726-$ 728.

Port Royal in Jamaica, earthquake at, and its effects, 336.

Portsoy, Banfishire, 644, 649, 651.

Post-tertiary system, 638, 641 .

Potato, the, imported from the New World to the old, 567 ; not found wild by Humboldt, 567 ; but discovered by later authorities, 568 .

Potosi, silver-mine of, 634 .

Pottery-ware, felspar used in compounding, 623 .

Powis Castle rock illustrated, 627.

Pozzuoli, view of, 404 ; earthquakes at, 404

Prairies of North America, 234, 589.

Presepe, constellation of, 159

President steamer, presumed cause of its loss, 340

Prichard, Dr, his hypothesis of the distribution of plants, 564, 569, 572, 592; of the varieties of man, 599 , et sen.

Priestley, Dr, 519.

Primary limestone, 660

Primitive man, place of the creation of, 609.

Principia, the, of Newton, 37 ; its estimation by Laplace, 38 .

Produce, abundant, of the cocoa-palm, the date-palm, the sago-palm, and the banana, or plantain, 557 ; of the orange, potato, wheat, dc., 570 .

Proteus anguineus, the, 571

Prout, Mr, his felicitous remark on rainbows, 533 ; on tropical animals, 584.

Pryme, Mr, 771.

Pterichthys, the, illustrated, 688,689

Pterodactyle, the, $723,724,729$.

Ptolemies, the, 10.

Ptolemy, the geographer, $3,4,11$; was a learned man, and made the Great Collection, or Almagest, 11 ; diagram of the Ptolemean system, 12 ; theory of epicycles, 13 ; his later followers tried to amend his scheme, 14 ; was a practical astronomer, 14; speaks of vessels of oil being used to observe eclipses, 16; mentions the refraction of the atmosphere in his treatise on optics, 25.

Pumice-stone, its porousness, 624.

Pny de Dome, 428; de Pariou, 428.

Pyrenees, valleys of the, 221; hot springs of the, 270 ; line of snow on the, 488 ; survey of the, 5

Pythagoras, 7 ; his disciples had just notions of the solar scheme, 7 .

Pytbon, the eriental, 579.

\section{Quadrumana, order of, 595 .}

Quadrupeds, class of, 584; notices of several individuals, $584-588$; topographical distribution of, 588; the Arctic region, 588 ; north temperate region, 589 ; region of intertropical and South America, 589; region of intertropical and Southern Africa,
590 ; region of India, 590 ; region of Australia, 591 ; fiying, 591 ; animals which have strayed out of bounds, 592 ; of the isles of the Prciflc, 593. Quarry, view of OId Lincoin, 675.

Quartz, what it is, and where found $623 ;$ a component of granite, 644.

Quito, genial climate of the city of

492; European corn first taken to 567 ;

Races, mixed hnman, of America, 604 Raffles, Sir Stamford, his account of the volcano of Sumbawa, 210.

Rafts of wood originate floating islands, 593.

Rain, is the probable source of springs, 263; is all-important in fertilisin the earth, 462 ; amount of rain, 468 . distribution of, 469 ; in the tropics, distribution of, 469 ; in the tropics, 470 ; regions unvisited by, 471 ; or
overwhelmed with, 471,472 ; annual overwhelmed with, 471,472 ; annual
falls of in various countries, 473 ; in Britain, 473, 474 .

Rainbow, the solar, how formed, 533; view and description of the lunar, 534.

Ramsgate, singular phenomena seen at,

Rapids, how produced, 283 ; of St Anne, on the river Ottawa, 284; Richelieu, on the St Lawrence, 294. Raratonga Island, hurricane in, 455. Rats, 592

Rattlesnake, the, 579 .

Ravenspur, port of, 395.

Ray, the naturalist, 367 .

Reciprocating springs, 266-268.

Red men, or copper-coloured races, 599 603.

Red Sea, 317; its colour, 331; pre valent winds in the 450 .

Redfield, Mr, 455 .

Refraction of the atmosphere, 52 ; in the Polar Sea, view of the effects of 543.

Regions of the globe, climates of the various, 504-509, 597, 598; had special races of animals and plants assigned to them, 598 ; botanical, of plants, $560-564$.

Reid, Colonel, 453-455.

Reindeer, the, all-important to the Lap landers, 552 ; native region of the, 588,594 .

Relugas, torrential ravages at, 417 420.

Remains, organic, of South America, 590 ; regular distribution of, 619 found in unstratifled layers, 635 , e the ; prodigious masses of animal, is 637,642 .

Rennell, Major, $360,370$.

Reptiles, varieties of, 579 ; preceded mammalia, 639 ; list of successive fossil, 640,641 .

Resina, city of, 410 .

Rhamni, region of the, 561

Rhine, descent of the river, 281 ; colour of its waters, 283 ; basin of the, 750 .

Phinoceros, the, 590 ; fossil, 755.

Rhone, glacier of the river, description and view, 220 ; source of the, 278 ; nnderground course of the, 291 passes through Iake Leman, 320 . colour of its water, 331 ; its embouchure, 308; rise in the valley of the, 450 ; alluvium of, 776 .

Rhynchosaurus, the, 713 .

Rice-plant, locality of the, 553 .

Pichard, Abbé, 517.

Richardson, Dr, 528, 559, 580.

Richman, Professor, his desth, 522.

Righi, Mont, 409 ; Pass, view of the 409

Rio Negro, or Black River, its course and colour, 280, 283, 298, 299.
Ripplemarks in strata, $625,631,683$, 716.

Rivers, chapter on, 278-308; sources of various, 278 ; of the Nile, 279 courses of, 279 ; islands in, 280 ; cur rents of, 281 ; nature and colour of waters of 282 . cateracts and 283; of the St , awrence 283 ; of the St lawrence, 284 ; of the Ottaws, 284; of the Kaaterskill, 284 ; of Trolhetta, 285; of Foyers, 286; of Schaffhausen, 286 ; of Terni, 286 ; of the Jeeambye, 286; of Tequendama, 286 ; of Niagara, 287-290; erosive action of, $290-292$; rivers change their levels, 292 ; many rise periodic ally, 293-297; annual overflow of cal floods in America, 296; of the Orinoco, 297-299; classiflcation of Orinoco, 297-299; classiflcation of the Jordan, \&c., 300 ; mouths of the Jordan, \& C., 300 ; mouths of rivers, $302,303,593$; tables of the
great streams of the globe, 303,304 ; courses of the Amazon, 304; of the Mississippi, 305-307; of the Nile, 307; denudation of the land by rivers, $370-373$; rivers disseminate plant-seeds, 565 ; raft-islands formed at the months of, 593 ; hold petrifying matter in solution, 642.

Robinson, Dr, his researches in the Erst, 262, 267, 274, 300, 315 .

Rochefort, aspect and topography of, 238.

Rochet d'Hericourt, M., on the BahrAssal, 317.

Rock or wall plants, 549

Rockall, the remarkable island of, 199.

Rocks torn asunder by frozen water, 408; unstratifled, 408; chapter on the structure and classification of, 622-642; true nature of rocks, 622 ; component parts of 623,624 ; structure of, 624 ; stratified and unstratified, 625 ; basaits, 626 ; stratifled are of aqneous origin, 627 ; varieties of, 627-630 ; peculiarities of structure, 630-032; Glen Tilt strata, 632; metallic veins, $633-635$; fossiliferous and non-fossiliferous rocks, 635 ; list of strata, by Dr Mantell, 636; table of, by Professor Phillips, 637; table of, by Profssor Phillips, maniarrangement by Lehman, 637 ; manirocks, $639-641$; order of fossil remains in strata, 640,641 ; granitic, 644-651; trappean, $651-655$; volcanic, 655, 650 ; Silurian, 669.

Rock-salt, 711; mines of, 712 .

Rocky Mountains, 201, 552, 558, 589, 627.

Roëmer, inventor of the transit instrnment, 32,35 .

Romans, the ancient, adverse to the cultivation of the physical sciences, 17; their partiality for Baiæ, 403; received the vine from the Greeks, 568.

Rome, city of, its volcanic site, 427 .

Rosa, Mont, 650 .

Rosiano, volcanic chasm in the district of, 433.

Rosenberg, or Mount Ruffi, fall of the, $408-410$.

Rose-tree, the, unknown in South America, 558 .

Ross, Captains, their discoveries and observations, 101, 196, 327, 331, 337, $339,341,523$.

Rosse, Earl of, his great telescope, 45 , 186.

Royal Academy of Sciences at Paris, its foundation and first members,

Royal Society of London, its founda-

tion and early members, 34 .

Rubbish, plants found on, 549 .

Russegger and Bertou, Messrs, 316. 
Sars, valley of, 650 .

Sabine, Colonel, $360,525,56 \overrightarrow{6}$.

Sabrina island, Its appearance and disappearance, 375 .

Saddleback mountain, 663.

Sagittarius, or constellation of the Archer, 151.

Sahara, desert of, 220 ; traversed by caravans, 226; snbject to sand-storms and the mirage, 227; limits and description of, $22 \mathrm{~s}$; passage regarding from "Eüthen," 228 ; is rainless, 471 ; dromedary of, 590 .

Salem in Massachusetts, rock of sienitlc greenstone at, 633 .

Salisbury Crags greenstone rocks, 626 , 652.

Salt, Jir, 295.

Salt from saline springs, 778 .

Saltuess of the ocean, $327-329$.

Salverte, M., 521, 522 .

Samiel wind, or simoom, 447-449.

Sand plants, their growth and uses, 549.

Sandstone, period of the red, 640 ; its composition and where found, 710 ; imprints in, 716 ; systems, old and new, 638, 639; chapter on the old red, 681-690; general composition of, 681-684 ; vegetable remains in, 684 ; fossil fishes of, $684-689$; chapter on the new red, $707-716$; series of its beds, 708. illustration of fossil remains in, 709; localities, 709 . sil remains in, 709; localities, sum, rock-salt, $710-712$; saliferous strata, 712; organic fossils, 713716.

Santorin, Gulf of, 374

Saratoga, lake, description and view of,

Satellites of Jupiter and Saturm conceived by some to have been known to the ancients, 1C; Jupiter's discovered by Galileo, 29, 30 ; the number allotted to the various known planets, $89,101$.

Saturn, the planet, his satellites discovered by Huygens, Cassini, Herschel, and Lassel and Bond, 34, 45, 47, 191; mean distance of this planet from the sun, 87 ; time occl97; length of his day, 97 ; diameter of, 97 ; form and rings of, 98 ; belts of, 99 ; days and seasons of, 99 ; satellites of, 99,191 ; general system, his, 99; orbital positions of, 100 ; his satellites, the various phases of, 101 ; area and solid contents of, 102 ; inclination of, to the earth, 104 . density of, 106; is nearly $900,000,000$ miles distant from the earth, 164 .

Saurians, the great fossil tribes of, 592 ; where found, 721

Sauroidichnites, 714

Saussure, M. de, his observations on the Alps, 208, 331, 517; on the Pyrenees, 450 ; on crétinism, 459 ; his geological creed, 619; his ascent of Mont Blanc, 045, 646.

Savages worship sun and moon, 3.

Savannah la Mar destroyed by an earthquake, 38 Savoy, Alps of, their geological charac-
teristics, 645 .

Saxifrages, botanical region of the, 560.

Saxon Chronicle, the $60,387$.

Saxony, schorl and tin of, 649; Weinbohla in, 650 .

Scales of fishes important in classifica tion, 684 ; illustrated, 685 . Scamander, the river, 269 ; its source,

Scelidotherium, the, 758

Scenery of the heavens, 40-192

Schenchzer, Dr, 760 .

Schouw, Professor, 560.
Scliroeter of Lilienthal, 69 ; his exclamation on viewlng the MillkyWay, 160

Schubert, Professor, 310.

Scilly Islands, the, 387.

Scitaminer, botanical region of the 562

Scoresby, Captains, 327, 330, 340-345, $348,474,542,588$.

Scorpio, or constellation of thescorpion, 151.

Scotland, lakes of, 311,318 ; severe winters in, 477 : granitic rocks of, 648 ; igneons formations of, 658 ; predominance of gneiss formationa in, 658; sandstone of, illustrated, CS4.

Scott, Sir Walter, citations from his Lake" 485" " "L1; "Lady of the atrel," 614 ; "Marmion," 617, 077.

Scripture, rightly interpreted, not incompatible with science, 593, 598, compatible

Scrope, Mr, 643,714

Scylla and Charybdis, 367-369.

Sea, the, beneficlal to mankind, 325 ; aaltnesa of, 327 ; tides of, 352 ; atruggles between it and the land, 386. See Ocean.

Sea-beaches, 773 .

Sea-cow, the, 578

Sea-urchin, shell of the, 572

Sea-weeds in the Atlantic, 348, 558.

Seams of coal, 696, et seg.

Sedgeley rocks, 678 .

Sedgwick, Professor, geologicalobservations of, 619, 621, 630,633,662, 689, 762.

Sedimentary formations, the, 657,661 . Seeds of plants, various nieans of dispersing the, 565 .

eine, the river, amount of its waters, 263 ; descent of the, 281

Seitzen, his account of the Dead Sea, 316

Selinga, the river, 318 .

Selvas, or central levels of South America, 232.

Seminaria, singular land-slip at, 433 .

Seneca, the Roman philosopher, men-

tions smoked glass as being used to observe eclipses, 16 ; prophetical passage from his tragedy of Medea, 16.

Senegal, heat on the banks of the river, 597

Serapis, antique pillars of the temple of, 405,774 .

Séron and Leseur, Messrs, 577.

Serpentine is similar to hornblende, 623 ; rocks, illustrated, 651 .

Severn, the river, 283, 668; and Clyde, how differing from other British streams, 280.

Shakspeare quoted, 7 ; his account of Clarence's dream, 373; of Dover Cliff, 391.

Shannon, source of the river, 278 ; Its descent, 281, 283.

Shap, in Westmoreland, its porphyritic granite, 644 .

Sheep, the, 588, 605

Shells, masses of, found at the summits of the Pyrenees and Andes, 380; fossil, 640,641

Sheppey, Isle of, 742

Sheringham, coast changes at, 395 .

Shetland Islea, action of the sea on the, 392.

Shipping at sea, annual loss of, 373 .

Shooting-stars, 130.

Siberia, fossil mammoths of, 753

Sicily, geology of, 750 .

Sickler, his account of cultivated vegetables, 568

Sienitic granite, 644 .

Sierra Leone, 330 .

Sigillarix, fossil 704

Silesia, mountains of, 648 .
Silius Italicus, 416.

Stliman, Professor, 424

Siloam, pool and spring of, 267.

Silures, region of the ancient, 667

Silurian aystem, $620,636-638,542,640$,

612 ; chapter on the, $667-680$; geological boundaries of the, 668; genera scheme of the, 669 , et seq.

Siluridan family, the, 578 .

Silurus electricus, the, 670 .

Silver ore, where located, 634 ; masses of, fonnd, 634

Silver-mine, view of the interior of $a_{\text {, }}$ 634; of Potosl, 634.

Simeto, the river, in Sicily, 290.

Simoom wind, or Samiel, $447-449$

Simple and compound rocks, 624 .

Simplicity, one of the Creator's laws, 022

Sinai, Monnt, 644

Singing-birds, local to the temperate zones, 582.

Sinkings of the earth, at Malpais, in Sicily, at Marseille, \&c., 240.

Sinope, view of, 365 .

Sirius, the star, 6 ; the brightest in the heavens, 146, 164 ; is larger than the sun, 165.

Sirocco, account of the, 449 .

Sivatherium, the, 758 .

Skaptar volcano in Iceland, 376.

Skeletons, fossil, perfect preservation of. 641 .

Skiddaw mountain, atmosphere of, 463 ; illustrated, 663 .

Skin, varieties of the human, $599-601$ 605 .

Skull, shapes of the human, $601-605$.

Skye, Isle of, trap-rocks in, illustrated, 652; limestone of, 661 .

Slate, 659 , et seq.; view of broken lediges of, 763 ; rocks of Devon, 629 of Wales, illustrated, 630 .

Slikensides, an explosive mineral, 258. Sloane, Sir Hans, 131

Sloth, peculiarities of the, 590 .

Slough, view of Herschel'a great telescope at, 160.

mith, Dr WVilliam, on volcanoes, 429 his geological researches, 618,620 .

Smyth, Professor C. Piazzi, observe the radiated heat of the moon, 88 .

Smoke of Vesuvius, an indicator of daily air-currents, 444 .

Snakes, varietles of, 579,580 ; English 579 ; none in Ireland, 579 ; orienta and occidental, 579, 580; genera species of, 692.

Snow, red, 331 ; origin and beanty of snow, 474 ; its crystals, various forms of, 475 ; localities of, 475 ; unwonted fall of, at Canton, 475 ; Alpine, 476 individuals buried under, 477 ; in Scotland, 477 ; view of a snow-storm, 478.

Snow-line, is variable on mountains, $586,487$.

Snowdon, ascent of, by Pennant, 664 665; observations on its geology, by Phillips, 665, 666

Snowdonia, geological region of, 663 666.

Sobieski's Shield, constellation of, 183. Social plants, localities of the, 551 .

Soil of the land, removal by the sca of 371.

Soils influence climate, 495

Solar system included eighteen bodies only before the elder Herschel's time, but he increased the number to twenty-seven, 45 ; remarks on the 102: stupendons area of the, 103 yet insignificant compared with that of the unlverse, 103; familiar illustra tion of the relation of the sun and its attendants, 105 ; composition and density of the solar and planetary orbs, 106 ; elements of the, 189-192. Solfatara, lake of, 899. 
Solidagos, botanical region of the, 561 . Solway Firth, 359 ; sands, view of, 359 ; floods of the river Esk, 477.

Solway Moss, accounts of, $768,770$.

Somerville, Mrs, 333.

Sorgues, source of the river, 279

South Georgia, island of, 504 .

South Sea Islands, plants of the, 563 .

Southey, Robert, citation from, 554.

Spain, central elevated plain of, 347 .

Spaniards, the, first introduced grain to America, 507 .

Spar, calcareous, or green earth, 655; white, 677.

Spatangus cor-anguinum, shell of the fossil, 721,735

Species, definition of the word, 598; of plants, ascertained and presnmed numbers of the different, 548 ; of numbers of the different, animals, fossiliferous, their analogous distribution with the existent, 635; number of organic
Speedwell mine, 245 .

Speedwell mine, 245 . Spey river, rise of the, 292 ; floods in, Spezzia, Gulf of, jet of fresh water in, 259.

Sphænopteris Hæninghausi, the fossil

plant, 640 .
Spitzbergen, notices of, $342,345,301$, $588,596$.

Springs, chapter on, 259-278; oceanic, 259,328 ; of Árethusa, 259 ; of Castaly, 260; of the deserts, 261; Eastern, 262; origin of, 262-264; perennial, 264; intermittent, 265 ; Artesian, 265 ; reciprocating, 266 ; of Siloam and others, 267, 268; thermal, 268-271; ebullient, 271 ; of the Iceland Geysers, 271-273; origin of ebullient, 273 ; bot, of Turbaco, 274 ; inflammable, 275 ; mineralized, list of prinmable, 275; mineralized, list of principal, and their quahities, dripping, at Knaresborough, 277; uses of springs and the regard they have
been held in, 277 ; hot, at Mont d'Or and Vichy, 429; petrifying quality of, 640 .

Squirrel, reference to the habits of the, 567 ; flying nocturnal, 591.

Stabiæ, city of, 424.

Stack Balloch-nan-fey, shining mountain of, 661 .

Staffa, description and view of the basaltic cave of, 241,626 .

Staffordshire coal district, $701,702$.

Stalactites, how formed, 246 ; how coloured, 248.

Stars, glance at the, 143-158; fixed, are of immense use in science by their apparent immobility, 143 ; yet which attribute is not real, 177; position, \&c., of the, 157 ; number, distance and magnitude of the, 158distance and magnitude of the, 15s165 ; the fixed, are suns, 165; new, variable, and compound, 166-179; many have disappeared, 166 ; some are but recently visible, 166 ; others appear and disappear, 166 ; remarkable instances of this, 167 ; speculations regarding, and illustrative diagram, 169; examples and list of rariable stars, 170,171 ; speculations regarding these, 172 ; multiple or regarding these, 172; multiple or compound stars, $172-177$; their

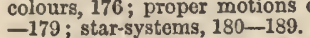

Stars, falling, or meteoric showers, some notices of, 137-143; as seen during the middle ages, 137 ; in modern times in Greenland by the Moravian missionaries, 138 ; by Humboldt, Bonpland, and Fillicott, in America, 138; observed in other regions, 139 ; remarkable one at the falls of Niagara, \&c., 140,141 ; obserfations of M. Arago regarding, 141. 142; Professor Olmstead and Arago' a 142; Professor O
theories on, 142.
Statue of Peter the Great, 760 .

Staunton, Slr George, 871.

Staurolite, 659 .

Stella Mira, account of, with a diagram, 170.

Sternberg, Count, 707.

Stephens, Mr, the American traveller, his account of the steppes of Russia, 224 ; of the Dead Sea, 315.

Stephenson, Mr, 558, 772

Stewart, Jugald, his insensibility to colour, 176.

Stigmaria, view of fossil, 705 .

Stiper Stones, 674 ; view of the, 673 .

Stirlingshire, vitality of plant-seeds disinterred in, 570 .

Stocke, Dr, on dew, 481.

Stone, crumbling, of Bath and Oxford, 620 ; for building, importance of a judicious choice of, 620 .

Stonesfleld slate, 725,720 .

Storeton hill quarries, 714,715 .

Storm, great, in England, of 1703, par ticulars of, by Derham, 452

Stow's Annals, citations from, 527.

Strabo, 226, 368, 397, 423, 429; was a geologist, 615 .

Strata, list of, and their animal remains, 636 ; of the New Red Sandstone system, in England, France, and Germany, 708; its prevalence in Eng land, 709 ; scanty in Scotland, 710 .

Stratificd rocks, 625 ; era of aqueous

formation, 627 ; views of inclined 627 ; composes nearly all the surface of Great Britain, 635; but only threefourths of Massachusetts, 635 .

Stratus, or fallcloud, 464.

Stromboli, volcano of, 210.

Strontian, lead vein at, 658

Structure of rocks, 622, et seq. See Rocks.

Struggles between the sea and land, 386.

Struve's catalogue of the stars, 158

Submarine forests, 772 .

Substances, elementary, their paucity, 622.

Subterranean plants, 550 .

Sumatra, Island of, 590

Sumbawa, awful volcanic eruption at, 210.

Summer, hot, in England, 498; in France, 499; excessive, chronological list of, 513,514 .

Sun, savages prostrate themselves before the rising, 3 ; worship of the, plausible reasons for, 3 ; transmission of light and heat from the, to the earth, 35 ; action of the upon the earth, 49,53 ; rising of the, 50 ; is constantly above the horizon for sir months at the north pole 51; seom months at the morth pole, larger at setting, why, 52 ; apparent the earth, 53 ; direct light, amount of, 53 ; caloriflc power of, 53,57 ; of, 53 ; calorific power of, 53,57 ; diameter of, 53 ; density of, 53 ;
spots on the disc of, $53-57$; rotation of, 54 ; setting of the, 63 ; density of, 106 ; supposed to have a movement of translation in the universe, 178; its diameter and composition, 189 aids in causing tides, 353

Suns, mock, or parhelia, 52, 530-532 ; view of, 531

Superflcial accumulations over strata, 688

Superior, Lake, 318, 321.

Susianic atreams, the, 308 .

Susquehanna River, description and view of the, 280,281 .

Sussex marble, 728 ; chalk, 731

Sutherlandshire, limestone of, 661.

Swarthfell in Cumberland 658 .

Sweden, aurora borealis in, 527 ; shores

of, 774 .

Swine, varietics of, $601,605,606$.
Switzerland, characteristies of the lakes of, 320 ; variety of climates in, 489; geological characteristics of the Alps of, 645.

Sword-fish, the, 575 .

Syene in Upper Kgypt, 9, 71, 644.

Symonds, Lieutenant, 316 .

Systems, gneiss, mica-schist, and clay-

slate, $657-666$; Silurian, $667-690$

Old Red Sandstone, 681-690; Car

boniferous, $690-707$; Permian and Triassic, 707-716; Oolitic, 717-731; Cretaceous, 781-736; Tertiary, 737751.

Table-land, 223.

Tacitus, 600.

Tagua-cagua, lake of, Its floating islands, 593 .

Tahiti, Island of, 610 .

Talc, its qualities, 623 ; a component of granite, 044 ; intermixed with schist, 659 .

Tameness of terrestrial birds, 581.

Tapir, the, 590 .

Taurus, Mlount, 312; view of cascade in, 313

Telescope, the, a knowledge of, as algned by Sir W. Drummond to the Greeks, Chaldeans, and Hindoos, 16 . that of Galileo imperfectly discovered Saturn, 30; was in use before his death for measuring angular distances, 32 ; and first applied to the quadrant by Gascoyne, 32 ; is the chief glory of the 17th century in mechanical constructions, though at first very rude, 32 ; Herschel's great, 44, 160; greater, of Lord Rosse, 45 186.

Temperate regions, climate of, 505

Temperature of the ocean, 335-338

of the earth, causes and operation of

the various, 485-515; mean, how ascertained, 496 ; uniformity in, 499 . relative, of 8outhern hemisphere, 502

Teneriffe, Peak of, 206, 213; strand of the island of, 362 ; variety of climat in the Peak of, 491 .

Tequendama, Falls of the Funza at, 286.

Terebratula, fossil, 674

Teredinæ, 742.

Teredo navalis, the, 572,741

Terni, description and view of the Fall of, 286.

Tertiary system, 638, 641, 656 ; reigns around London, 642 ; chapter on the 737-751; order and classification of, 738 ; fossil shells of, 740 ; Eocene period, 741-747; Miocene period, account of the Pontus Euxinus, 508 .

Tererone, or Anio, water-fall of the river, near Tivoli, 286 ; ravages, past and present, of its waters, 416 .

Texture of rocks, 624 .

Thales the founder of astronomy among the Greeks, 6.

Thames, the river, 283,493 ; view of a fair on the ice of, in 1716, 512 .

Thecodontosaurus, the, 713 .

Theodomer marches his army across the Danube, 509.

Theophrastus, number of plants known to, 548 .

Thermal aprings, or bot-wells, 268271 ; abound most in volcanic districts, 268 ; their probable sources, 209 ; those of Buxton, \&c., 269 ; in a Feejee island, 269; at Aix, in Provence, 270: at Baden-Baden, \&c., 270 some change their temperature, 270 271 ; at Mont d'Or and Vichy, 429.

Thessaly, flood of, 387.

Thistle-seed, how disseminated, 565 . 
Thoresby, Mr, 535.

Thucydides, 433.

Thunder-storm, phenomena of $\mathrm{a}$, and its influences on the animal creation,

516.
Tiber, mouth of the river, 899 ; scrved as a drainer, 427.

Tidal action on the British coasts, 372 . Tides and oceanic highways, chapter on the, 349-369; distinction of waves, tides, and currents, 349 ; tides, operation of, 352 ; causes of, surmised before Newton, but first demonstrated by him, 352 ; explanation of, with diagrams and chart, 353-357; various phenomens of, 257-359; currents, their operation, 359; Gulf Stream, 360, 362; arctic current, 360 ; stream-currents, 361 ; equatorial, 362-364; effects of oceancurrents on navigation, 364 ; undercurrents, 365-367; shore-currents, tides and currents, 369 .

Tierra del Fuego, notlces of, 211, 556, $596,597$.

Tiger, the, 584, 590.

Tigris, subterranean course of the river, 201; its periodical risings, 204. Tilestone strata, 682, 683 .

Tilgate forest, bones of fossil reptiles in, 642,730 .

Timber trees, varieties and ages of, 549.

Titan's Piazza, view of, 626 .

Titicaca, lake of, 312

Tivoli, ravages of the Anio at, 416.

Toadstone, 655 .

Tooth of the mastodon, 754

Torpedo, the, 575 .

Torrid zone, vegetation of the, 553557.

Tortoises, 579 .

Totten, Colonel, 774.

Tournefort attempts to ascend Ararat,

203 ; his description of the grotto of

Antiparos, 247; of the vegetation of Ararat, 557.

Touraine, geology of, 747 .

Tonrmaline, 649 .

Towy, vale of the, 668 ; view of, 671 .

Trachytic rock, 655,650 ; lava, 656 .

Trade-winds, 438-442.

Transit instrument, invention of the 32 ; Roëmer's observations with it,

Trappean rocks, $651-655$.

Trees, their importance to man, 546 size and age of, 549; beauty and luxuriance of the tropical, 553-557 fossil, 703

Trent, the river, 283 ; red marly banks of, 711 .

Trenil coal-mine, vcin of fossil trees in, 704 .

Triassic and Permian systcms, 038 ; chapter on the, 707-716.

Tribbioch, valleys of, 653 .

Trilobites, description and illustrations of, $671,672,674$.

Trinidad, bituminous springs around and in the island of, 275 .

Tripergoli, ancient site of, 403 .

Tristan d'A cunha, island of, 581.

Trolhetta, description and view of the great falls of, 285 .

Tropics, hurricanes in the, 451 ; alternations of rain and drought in the 470 ; beautiful plumage of the birds of the, 582 ; qualities of animals in the, 584 ; colours of animals in the, 601 ; climate of the, always deadly to Europeans, 608.

Trosachs, the, 659 .

Tufa, or travertin, 778.

Tulloch, Major, his statistics, 608.

Tunnel, Thames, 741.

Turner' 8 Falls, Massachusetts, slab
found at, 715 .
Tuzla, lake of, 312.

Twilight, duration of, 50

Tyrolese Alps, characteristics and view of the, 490 .

Tycho Brahe, his birth and education, 22; rejects the Ptolemean and Copernican systems, and forms one of his own, 22; explanation of his views, 23; a better practical than theoretical astronomer, 24 ; his observations and labours detailed, 24 ; his castle of Uraniberg, in the island of Hoëne, 25, 26; becomes an exile, and settles at Prague, where he dies, 26 ; laid the basis of the discovery of the universe's laws, 33.

Ulloa, Don Antonio, 527, 533.

Ulugh Beigh, a Tartar prince and astronomer, 18; his catalogue of the stars, 158 .

Umbelliferous plants, botanical region of the, 580 .

Undercliff, Isle of Wight, view and characteristics of, 391,392 .

Under-currents, 365-367.

Undulation, valleya of, illustrated, 630 . Unclulatory movement of the Swiss and

Italian lakes, 320 .

United States, climate of the, 494,496 497 ; tertiary deposits of the, 739 , 751 , 752 ; boulders of the, 761 , et al. springs of, 777,778 .

Unities, various, of the solar system, 104.

Unity of the human race, $605,807,609$. Universe, the physical, has no limits known to man, 48.

Unstratiffed rocks, 408 ; are of igneous origin, 625 ; compose the bulk of the earth's interior, 635 .

Upheavings of the ancient world, 629, et al.; of unstratified through. stratified rocks, illustrated, 631 .

Ural river, 317; mountains, 645, 649 : gold found in the, 634 .

Uranus, or Herschel, the planet, its distance from the sun, 101; when first observed, 101. length of its day and year, 101; has six satellites, their anomalous movements, 101 , 191 ; amount of light and heat received by, 102 ; area and solid con-
tents of, 102 ; inclination of, to the earth, 104 ; density of, 106.

Urumiah, great lake of, 313.

Vadimon lake, now Lago di Bassaniello, 318.

Valais, canton of the, adventure of one of its shepherds, 411; crétins of the Lower, 459 ; climate of, 489,490 .

Valleys and great levels of the earth, $217-238$; valleys, divers, 221, 222 ; how formed, $6290^{\circ}$ of elevation and undulation, illustrated, 630 .

Yalparaiso, elevation of the coast at, 406 ; the wild potato indigenous in,

Van, Lake, 314.

Variable stars. See stars.

Varieties of the human species accounted for, 598 , et sea.

Vegetable tribes, $540-571$; cultivated, and fruits, account of the introduction of various, 567,569 ; carbonate of lime enters into the composition of, 624 ; matter, fossiliferous, 637 ; illustration of, 640 .

Vegetation, luxuriant, of the tropics, 553 ; of equinoctial America, 555557,586 ; not indispensable for the gubsistence of large animals, 585, 586 .

Veins in strata, 632, 649 ; illustration of granitic, 633, 649 ; metallic, 633 .

Velocity, mean, of the planets in their orbits, 64

Venetz, M., 765.
Venus, the planet, 64; her distance from the sun, 64, 66; is a mornin and evening star, 66; was once called Hesperus and Vesper, also Phosphorus and Lucifer, 66 ; her periodical revolution, 67; her size, 07 ; is sometimes crescent and decrescent to the view, 67; diagram of her phase 67 . trapits the futuransits the future transits indicated, 68,09 ; her supposed physical constitution, 69 ; superflcial appearances, 69 ; inclination

106.
Vesta, the planetoid, $91,190$.

Vesuvius, Mlount, 212, 213, 410, 423430,444 ; view of, from St Elmo, 445. snow on, 475. plants in the crater of, 547 ; eruption of, in 1794, 654 ; eruptions of 780,781 .

Via Lactea. See Milky-Way.

Via Lactea. See Millky- Way.

Vienna built on tcrtiary strata, 739.
Vince, Professor, 169; atmospheric phenomena seen by, 537.

Vincent, St, volcanic eruption in that island, 441 ; Scotch skipper's adventurous voyage to, 441 ; huge serpent drifted to, 580 ; negroes in, 608 .

Vincs, region of, 491,505 ; original countries of, 568 .

Virgil mentions shooting-stars, 130 ; and Orion, 154 ; cited, 464, 467, 408, $508,509,690$

Vitality, tenacious, of plant-seeds, 569 . Vögel-bergs, or bird-rocks, $5 \$ 0$.

Volant, view of basaltic rocks on the river, 626.

Volcanic rocks, 655 .

Volcano, origin of the term, 200, 433 ; peculiarities of a 209; list of volcanoes, 210 ; account of a huge volcano in Hawaii, 210 ; and of another in Sumbawa, 210; volcanoes in Sonth America, 211 ; Cotopaxi, 211 ; various chains of volcanoes, 212 ; Italian and other volcanoes, 212 ; refiections, 213 ; volcanoes of Jorullo,

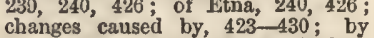
changes caused by, $423-430$; by
Vesuvius, 423-425; Skaptar Yokul, 425: Roman, 427; in Auvergne, 427 425; Roman, 427 ; in Auvergne, 427
-429 ; at Catecucaumene, 429,430 ; origin of, 433 ; phenomena of, 654 ; erupted inatter of volcanoes, 779783.

Volga, the seventy mouths of the river, 302 ; its source, 312 .

Volney, M., his account of the simoom in Egypt, 447.

Vosges mountain, situation and geology of the, 708.

Volta, M., his theory of hail, 478 .

Vulcanists, the followers of Hutton, 618.

Wacke, a species of basalt, 653

Wales, slate-rocks of, illustrated, 630 geology of, 662, et al.

Wallis, Dr, surmised the true cause of tides, 352 .

Ward, Dr, 713 .

Warm regions, climate of, 505

Washington, crumbling stone of the Capitol at, 620 .

Water, the five great basins of, 197; its different states, 259; amount of discharged by the principal rivers in the world, 303; colour of lake, 322 331 ; of oceanic, $330-332 ;$ move-
ment of sea, 349 ; action of frozen, 408 ; amount of, annually evaporated in Britain, 462 ; 19 formed of oxygen and hydrogen, 622 .

Waterloo Bridge, its two granites, 644

Watersponts, account of, with an illus. tration, 457,458 .

Watson, Rev. J., 451.

Watt, Mr Gregory, 627 . 


\section{INDEX.}

Waves, livw formcd, 349 ; their characteristics, 349, 350 ; height of, 369 .

Wealden clays, perfect fossil shells found in, 639; oolitic group, 718,724 $728,729$.

Weaver, salt-rocks near the river, 712 .

Weeding well, Derbyshire, 268.

Weight of various quadrupeds, 584.

Wells, Dr, his theory of dews, 480 ,

W clsh lakes, characteristics of the, 324 Wenlock group of Silurians, 675 ; corals, 678.

Werner of Freiberg, the illustrious founder of modern geology, 617; his Neptunian theory, 618

West Indies, hurricanes in the, 453455.

Westmannshavn in the Farüe Islands, extraordinary bird colony at, 580 , 581.

Westminster Hall, stone of, 711.

Westphal and Hoffmann, their account of the site of Rome, 427 .

Wetter, Lake, 320 .

Weymouth, burning bill at, 719 .

Whale fishery, losses and perils of the $340,344,345$; tribes, 578.

Wheat grown from grains found in Exyptian sepulchres, 570

Whichwood Forest, 724 .

Whinstones, 652 .

Whitby Abbey, view of, 386; its foundation and position, 394 ; ammonites found near, 617,720 ; burning cliff at, 719 ; lias of, 720 ; strat near, 727.

White Mountain in the Alleghanies, view of the, 419 .
Wight, geology of the Isle of, 738,742 , 775 , et al.

Wildness of birds instinctive, 582

Wilkes, Captain Charles, an American explorer, his 'researches, 190,269 $380,381$.

Wilkinson, Sir Gardner, 307.

IVill-0'-the-wisp. Sce Ignis-fatuus.

Willeys, family of the, killed by a landslip, 420 .

Villiams, $\mathrm{Dr}, 495$.

Villiams, Rev. John, 455

Willoughby and Ray, their theory of the ignis-fatuus, 543 .

Wilson, Sir Robert, 479

Winandermere, and other English lakes, 310.

Winch, Mr N. J., his coal statistics, 697.

Winds, influence tides, 357 ; table of the velocity of the, 437 ; are of three kinds, permanent, periodical, and variable (see Atmosphere), 437 ; of Great Britain, tables of prevailing, 459,460 ; influence evaporation 462 ; affect temperature, 496 ; also distribution of animals, 592.

winifred, well of St, account and view of, 264.

Winters, severe, in England, 498 ; chronological list of, in various regions, $509-513$.

Witham, Mr, 706 .

Wolf, the, 592

Wollaston, $\mathrm{Dr}, 543$.

Women, complexions of, 599,601 .

World, one of the smallest provinces in the great empire of nature, 2 ; chart of the 195 .
Wrath, Cape, 658, 681.

Wrekin, hill of the, 680 .

Wye, contorted strata of the river, 627 , 628 ; gorge of the, 630 .

Xanthous, or fair-haired races of men, 590.

Yellow, Sea, the, 329, 371.

Yokuls of Iceland, 207.

York minster, stone of, 711

Yorkshire, chalk of, 734 ; peat of, 769 ; sea-beach of, 773 .

Younz, Dr, 727.

Zamang del Guarre, a famous tree, 550 . Zambesi, Falls of the, 286

Tante, batuminising ante, bituminising springs in the island of, 275

Zigzag lamination in strata, 625.

Zimmerman, 588.

Zodiac, the, an imaginary zone or girdle in the heavens, origin of the signs of the, 5,143 ; list of constellations in the, $148,149$. 150. Taures Gemini Cancer 150 , Ieo, Virgo Leo, irgo, Libra, Scorpio, Sagit tarius, Capricornus, 151, 152 ; Aquarius and Pisces, 15

Zones of the globe, amount and relative proportion of land in the several, 190 ; tables of plants found in the various, 551 ; torrid zone, vegetation in the, 553; insect life in, 573 ; human food in the various, 597.

Zoophytes, or plant-animals, 572 ; fossil, 639.

Zug Lake of, 408

Zuider Zee, the, 390 .

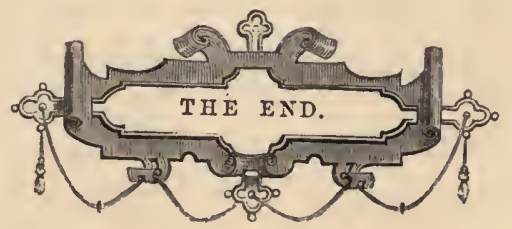

Edinkurgh :

Triated by W. \& R. Clambers. 


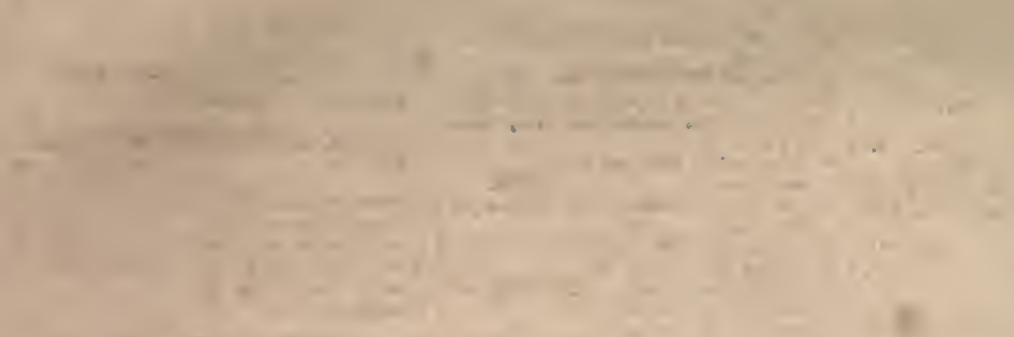

$$
\text { S. }
$$

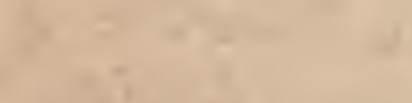

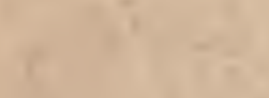

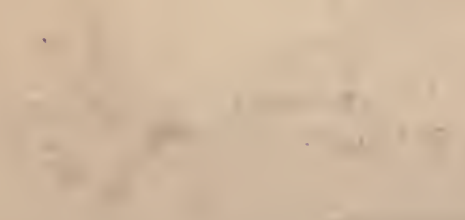




3 


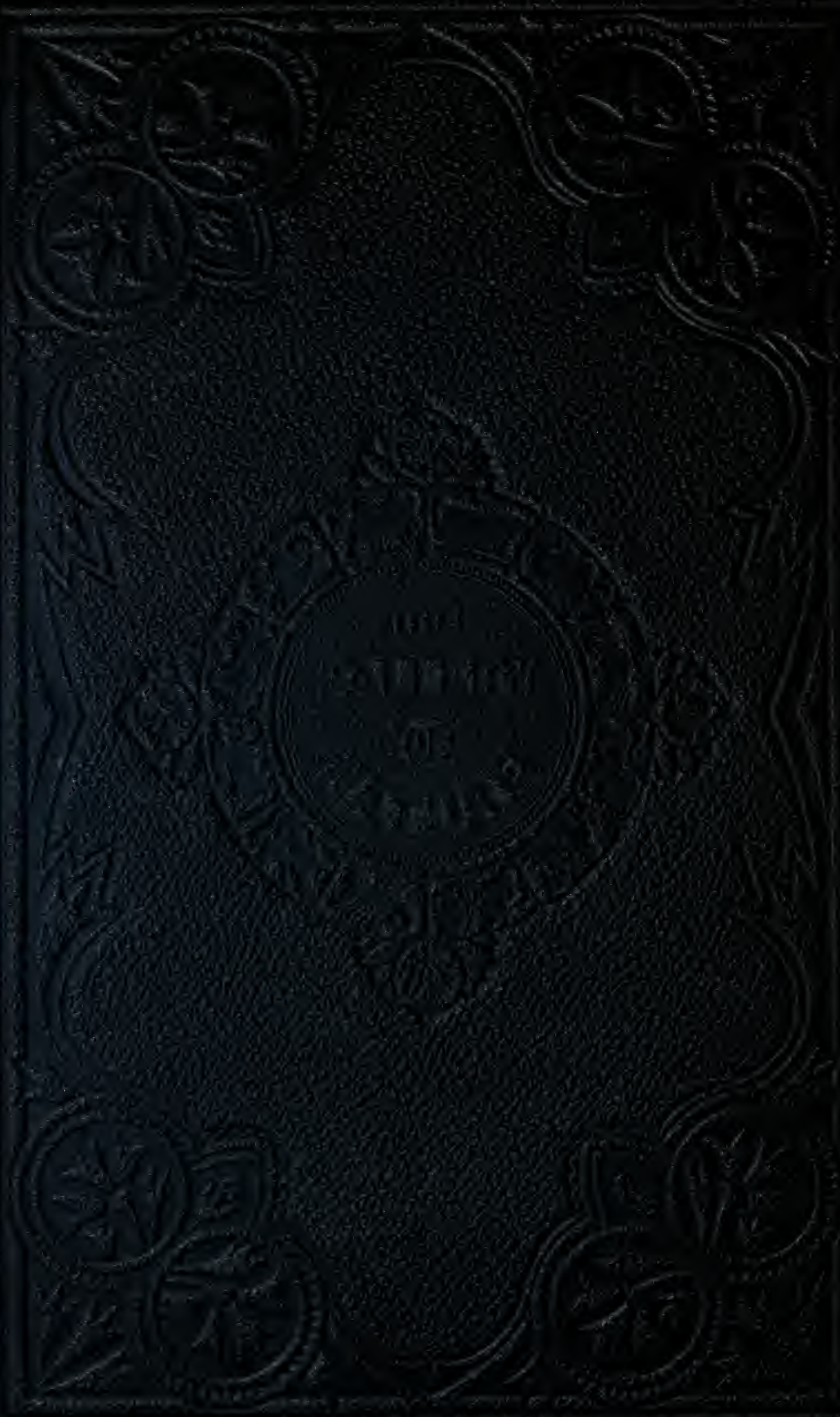

